\title{
Les dieux olympiens et la mer
}

\author{
AnNick Fenet
}




\section{Les dieux olympiens et la mer}

\section{Annick Fenet}

DOI : 10.4000/books.efr. 5550

Éditeur: Publications de l'École française de Rome Année d'édition : 2016

Date de mise en ligne : 8 juillet 2019

Collection : Collection de l'École française de Rome

ISBN électronique : 9782728310661

\section{Sbooks}

http://books.openedition.org

\section{Édition imprimée}

ISBN : 9782728310654

Nombre de pages : 728

\section{Référence électronique}

FENET, Annick. Les dieux olympiens et la mer. Nouvelle édition [en ligne]. Rome : Publications de l'École française de Rome, 2016 (généré le 08 février 2021). Disponible sur Internet : <http://

books.openedition.org/efr/5550>. ISBN : 9782728310661. DOI : https://doi.org/10.4000/books.efr. 5550

(c) Publications de l'École française de Rome, 2016

Conditions d'utilisation:

http://www.openedition.org/6540 
Cet ouvrage est diffusé en accès ouvert dans le cadre du projet OpenEdition Books Select.

Ce programme de financement participatif, coordonné par OpenEdition en partenariat avec Knowledge Unlatched et le consortium Couperin, permet aux bibliothèques de contribuer à la libération de contenus provenant d'éditeurs majeurs dans le domaine des sciences humaines et sociales.

La liste des bibliothèques ayant contribué financièrement à la libération de cet ouvrage se trouve ici :

https://www.openedition.org/22515.

This book is published open access as part of the OpenEdition Books Select project.

This crowdfunding program is coordinated by OpenEdition in partnership with Knowledge Unlatched and the French library consortium Couperin. Thanks to the initiative, libraries can contribute to unlatch content from key publishers in the Humanities and Social Sciences.

Discover all the libraries that helped to make this book available open access: https: / $/$ www.openedition.org/22515?lang $=e n$.

\section{IIIJ Qopenedition couperinore}




LES DIEUX OLYMPIENS ET LA MER 

COLLECTION DE L'ÉCOLE FRANÇAISE DE ROME 509

ANNICK FENET

\title{
LES DIEUX OLYMPIENS ET LA MER
}

ESPACES ET PRATIQUES CULTUELLES

\author{
Préface de Madeleine JosT
}

ÉCOLE FRANÇAISE DE ROME

2016 
Cet ouvrage a été publié avec le soutien du laboratoire d'excellence TransferS (programme Investissements d'avenir ANR-10-IDEX-0001-02 PSL* et ANR-10-LABX-0099) et du laboratoire AOROC (CRNS-ENS).
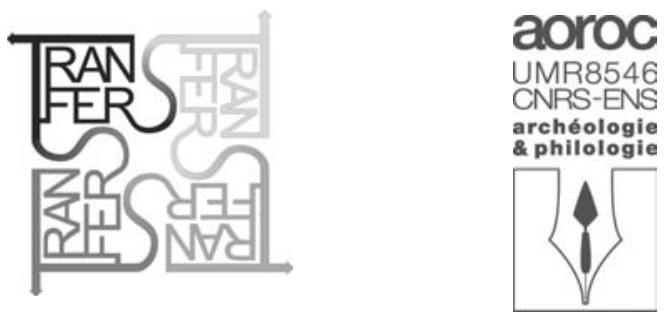

Fenet, Annick, 1968-

Les dieux olympiens et la mer : espaces et pratiques cultuelles Rome : École française de Rome, 2016

(Collection de l'École française de Rome, 0223-5099; 509)

ISBN 978-2-7283-1065-4 (br.)

1. Religion grecque -- Grèce -- Antiquité 2. Ex-voto -- Grèce 3. Navigation -- Aspect religieux -- Grèce -- Antiquité 4. Dieux de la mer -- Grèce -- Antiquité 5. Mer -- Aspect religieux -- Antiquité

CIP - Bibliothèque de l'École française de Rome 

À l'extrémité de la cave, qui était oblongue, sous une archivolte cyclopéenne d'une coupe singulièrement correcte, dans un creux presque indistinct, espèce d'antre dans l'antre et de tabernacle dans le sanctuaire, derrière une nappe de clarté verte interposée comme un voile de temple, on apercevait hors du flot une pierre à pans carrés ayant une ressemblance d'autel. L'eau entourait cette pierre de toutes parts. Il semblait qu'une déesse vint d'en descendre. On ne pouvait s'empêcher de rêver sous cette crypte, sur cet autel, quelque nudité céleste éternellement pensive, et que l'entrée d'un homme faisait éclipser. (...) Il était invraisemblable qu'il n'y eût point là un fantôme. Une femme toute nue, ayant en elle un astre, était probablement sur cet autel tout à l'heure. Sur ce piédestal d'où émanait une indicible extase, on imaginait une blancheur, vivante et debout. L'esprit se représentait, au milieu de l'adoration muette de cette caverne, une Amphitrite, une Téthys, quelque Diane pouvant aimer, statue de l'idéal formée d'un rayonnement et regardant l'ombre avec douceur. C'était elle qui, en s'en allant, avait laissé dans la caverne cette clarté, espèce de parfum lumière sorti de ce corps étoile. L'éblouissement de ce fantôme n'était plus là; on n'apercevait pas cette figure, faite pour être vue seulement par l'invisible, mais on la sentait; on avait ce tremblement, qui est une volupté. La déesse était absente, mais la divinité était présente.

Victor Hugo, Les travailleurs de la mer II, i, 13.

\author{
À Papa Louis, \\ ce livre de mer et de voyages
}




\section{REMERCIEMENTS}

Ulysse en a fait l'expérience : la route droite n'est pas la plus directe pour arriver au terme du périple. Avant de pouvoir finaliser ce volume, il m'a fallu tirer des bords et même - qui l'eût cru? opérer un détour par l'Afghanistan.

Ce travail n'aurait donc pu aboutir sans l'aide de divinités tutélaires pour lesquelles le lecteur pourra s'amuser au jeu de l'interpretatio antiqua.

$\mathrm{M}^{\mathrm{me}}$ Catherine Virlouvet, Directrice de l'École française de Rome, m'a fait l'honneur d'accepter la publication dans la Collection de l'École et m'a accordé la faveur d'un séjour de 2 mois à Rome pour finaliser le manuscrit. Au Palais Farnèse et à la place Navone, M. Stéphane Bourdin, Directeur des études pour l'Antiquité, et le responsable des publications M. Richard Figuier m'ont accueillie avec affabilité et dispensé des conseils avisés; M. Bertrand Grandsagne a accompagné avec patience et efficacité la publication de ce mémoire.

Ce séjour a également bénéficié d'une subvention de la fondation Debrousse de l'Institut de France, sur décision de l'Académie des inscriptions et belles-lettres. Je ne saurais exprimer ma reconnaissance à cette honorable institution et à M. Henri Lavagne, véritable deus ex machina.

J'ai trouvé en AOROC (UMR 8546) un laboratoire où il fait bon travailler, sous la dynamique direction de Stéphane Verger. Je sais gré à ce dernier et à Laurianne Sève, qui pilote avec art notre équipe «Hellénismes d'Asie et civilisations orientales», de leur l'intérêt amical pour mes recherches et leur soutien constant, sans oublier le concours fidèle du Labex TransferS, dirigé par M. Michel Espagne.

En remontant l'horloge du temps, je salue M. Pierre Chuvin qui sut guider mes premiers pas dans cette enquête et me détermina à suivre les précieux cours de M. Paul Bernard, à l'EPHE, M. Pierre Cabanes qui fut un directeur de thèse bienveillant durant ces années d'études, ainsi que M. Roland Étienne, qui m'a ouvert les portes de la Grèce et rendu accessibles les inestimables richesses de la bibliothèque de l'École française d'Athènes. À la faveur de bourses de l'EFA, de l'EFR, du gouvernement grec et du Centre Jean Bérard, j'ai 
pu découvrir les réalités du terrain parfois bien différentes de celles des livres et profiter in situ des visites des meilleurs archéologues, tel feu Dinu Adamesteanu à Métaponte.

La soutenance reste un excellent souvenir, grâce aux qualités scientifiques et humaines du jury composé de MM. Pierre Chuvin, Piero Gianfrotta et Patrice Pomey. Sa Présidente, Mme Madeleine Jost, a été la première à m'inciter à publier : son appui n'a jamais faibli et s'est manifesté jusque dans des relectures du texte final et l'écriture de la préface. À M. Pomey, je dois également ma participation au colloque Tropis à Pylos en 1999 avec la rencontre de savants hors normes en affaires maritimes, la regrettée Miss Honor Frost et M. Lucien Basch. La transformation du manuscrit a ensuite bénéficié des conseils de $\mathrm{M}$. François Lissarrague et de $\mathrm{M}^{\mathrm{me}}$ Pauline Schmitt-Pantel, ainsi que de ceux de M. Antoine Hermary qui, en m'attribuant la rédaction d'un chapitre du ThesCRA, m'a fait me replonger dans la religion marine.

Les heures passées en bibliothèques ne sauraient faire oublier l'indispensable : l'affection de la famille et des proches. Merci à mes amis historiens qui m'encouragent depuis des années, en particulier Osmund Bopearachchi, Bruno Cabanes et Natacha Lubtchansky; à Anne Coulié et sa chaleureuse générosité; à mon bon génie Odile Cavalier, dont l'optimisme est si réconfortant. Mille et une pensées pour ma sœur Joëlle qui m'a toujours précédée ou suivie avec enthousiasme sur les chemins de la Méditerranée, et pour Alain, mon compagnon de toutes ces années postdoctorales, qui a partagé les joies de la découverte (de Rochefort au cap Malée et au musée de Palerme) comme les vents contraires. E la nave va! 


\section{PRÉFACE}

$\mathrm{Au}$ fil des activités riches et multiples d'Annick Fenet, on retrouve son amour de la vie marine grecque et de ses dieux, vers lesquels l'avait orientée Pierre Chuvin pour sa thèse. Appelée à en parler à Nantes, Boulogne-sur-Mer ou en Grèce à Pylos, elle a été aussi pour un temps Chargée de mission au Centre international de la mer (Corderie Royale-CIM) et membre du Comité scientifique de l'exposition «Peurs bleues. Prendre la mer à la Renaissance» à Rochefort.

C'est à la mesure de la place occupée par les activités maritimes dans la vie des Grecs qu'elle nous offre aujourd'hui un ouvrage d'importance sur "Les dieux olympiens et la mer : espace et pratiques cultuelles». Les dieux et les hommes sont traités en deux volets, offrant ainsi un tableau judicieux d'une "religion marine grecque» dont aucun ouvrage ne donne l'équivalent à ce jour. Le lecteur y trouvera, dans une large fourchette chronologique et sans limites géographiques, une somme considérable de documents de tous ordres, présentés et analysés avec rigueur. Annick Fenet utilise les textes littéraires jusqu'aux plus basses périodes, en tenant toujours compte de leur chronologie et sans amalgames entre eux. L'épigraphie a sa place tant pour le culte des divinités que pour des objets inscrits comme les ancres. Les données de l'archéologie concernent les sanctuaires où se marque une orientation marine des divinités; elle est à la base de la seconde partie sur les pratiques cultuelles en relation avec la mer. Cette pluridisciplinarité constitue un des intérêts de l'ouvrage et en fait la richesse.

La composition du volume est simple et logique. La première partie étudie les divinités olympiennes dans leur rapport avec la mer; celle-ci ne sont pas désignées par une appellation abstraite, mais bien en temps que "personnes» divines, notion récemment réhabilitée par R. Parker dans ses réflexions critiques sur le structuralisme (On Greek Religion 2011, p. 95). Quatre chapitres aux titres nuancés organisent la matière : "À la conquête de la mer» (Athéna, Héra), «La maitrise des éléments» (Zeus, Aphrodite), "La domination de la mer» (Apollon, Poséidon), «Les frontières de la mer, ou la mer domestiquée» (Artémis, Dionysos, Hermès). Ce classement très subtil engendre des recoupements de détail entre les divinités, tant il 
est vrai que chacune d'elles est «multiple». Comme le note Annick Fenet, toutes ces «personnalités» ont des points en commun : leur action, par exemple, s'exerce en grande majorité au moyen des vents et elles partagent certaines épiclèses comme Apobatèrios («du Débarquement»), qui peut s'appliquer à Apollon, Aphrodite, Artémis ou Zeus. Au total, il y a dans les aspects marins des personnalités divines un certain manque de spécialité qui rend les frontières poreuses.

Les chapitres étudient successivement les légendes de chaque divinité, ses lieux de culte, ses épiclèses en rapport avec la mer (celles-ci ayant souvent des implications plus larges, comme Sôter («Sauveur»). Il en ressort un tableau neuf et intéressant des pouvoirs marins des divinités grecques. On est frappé au premier abord par le nombre important des dieux et des déesses qui peuvent revêtir un caractère marin, en dehors de leur domaine d'action dominant; elles sont concernées avant, pendant et après la navigation; il est clair que, comme dans les autres domaines, les Grecs cherchent à multiplier les protections, sans hésiter à ajouter l'une à l'autre. La multiplicité de toutes ces divinités est en relation avec le paysage grec où abondent rivages, îles et promontoires.

Poséidon et Hermès occupent une place tout à fait secondaire par rapport à ce qu'on pouvait attendre. C'est pour Poséidon, un éclairage nouveau et un des apports d'Annick Fenet : il est plus le dieu des tremblements de terre qu'un protecteur marin. C'est une puissance qui s'affirme souvent de manière négative, dans un déchaînement de violence des éléments, si bien qu'on le craint plus qu'on ne l'honore. Le rôle principal est tenu par Zeus, avec plusieurs épiclèses comme Ourios ("dieu des vents favorables»), et Aphrodite, qui assure le calme des eaux et de la traversée en tant qu'Euploia ( ¿De la navigation heureuse»). À côté, Artémis, qui protège les rivages et les expéditions de colonisation, ainsi que les déesses poliades Athéna et Héra, toutes deux associées au mythe des Argonautes, sont bien représentées. Apollon bénéficie de son statut de dieu d'un sanctuaire panhellénique : c'est lui qui reçoit le plus d'offrandes navales. Dionysos est associé à une mer calme. Déméter et Koré ne sont que rarement attestées.

La seconde partie s'attache aux pratiques cultuelles en relation avec la mer, que ce soit à bord des navires ou sous forme d'ex-voto à terre. Nous sommes ici en contact avec les realia et cet aspect concret donne vie au tableau des pratiques religieuses des marins. La construction est analytique. Sur mer, on découvre le décor naval et religieux de la proue et de la poupe, comme ces parasèmes en bronze ou appliques s'adaptant à la coque de part et d'autre à l'avant du bateau, avec la représentation de Dionysos et Ariane, provenant de l'épave de Mahdia. La poupe est l'élément religieux essentiel : on peut y trouver, sur la stylis, le nom de la divinité tutélaire du navire, 
sans que cette pratique des noms théophores de bateaux soit majoritaire. Les divinités concernées sont surtout Athéna et Aphrodite. Les ancres en plomb, que révèle l'archéologie sous-marine, sont à bord l'objet qui incarne le mieux la recherche de protection divine. Annick Fenet leur consacre de longues pages riches de données et de mises au point, en particulier pour les concepts d'ancre sacrée et d'ancre «de miséricorde». Pour le rôle «magico-religieux» et apotropaïque du décor, on retiendra, entre autres, de savants raisonnements sur la combinaison des faces des osselets qui apparaissent parfois sur les jas et la valeur religieuse de ces objets.

Viennent ensuite les ex-voto à terre. Durant toute l'Antiquité grecque, les dieux olympiens se voient consacrer des bateaux sous des formes diverses, en remerciement d'une traversée réussie ou d'une victoire navale. Il s'agit de dons de bateaux réels, de modèles réduits, d'images de bateaux dont Annick Fenet donne des analyses détaillées. Le cas des bateaux sacrés et des chars-bateaux retient particulièrement l'attention. Une collecte méthodique et exhaustive des sources littéraires et épigraphiques relatives au char des Panathénées et au péplos d'Athéna conduisent à une analyse serrée de la chronologie d'apparition des différents éléments - bateau, péplos, voile - à partir de la fin du $\mathrm{V}^{\mathrm{e}}$ siècle et du début du $\mathrm{IV}^{\mathrm{e}}$, avec un changement à l'époque d'Hérode Atticus dans le mode de traction du navire, auparavant tiré par des bêtes, puis muni de "machineries secrètes»(Philostrate) difficiles à restituer.

Mais ce sont les ancres en pierre découvertes en lien avec des sanctuaires comme ex-voto à terre qui sont l'objet de prédilection de l'auteur. Le don d'ancres est une pratique attestée par les sources littéraires, les inscriptions déliennes et l'archéologie qui fournit un matériel relativement nombreux. Annick Fenet dresse un catalogue raisonné des ancres inscrites, puis des ancres anépigraphes. Son talent est d'allier des descriptions précises à des discussions critiques toujours prudentes sur les données et les problèmes qu'elles posent. L'ancre de Gravisca, dont le propriétaire, Sostratos, serait connu par ailleurs ou l'ancre de Métaponte donnent lieu à de réelles monographies. Ces études ont en commun une problématique : l'inscription est-elle contemporaine de la fabrication de l'ancre ou gravée dans un second temps? Elles donnent lieu à d'utiles remarques sur des matériels voisins dans la forme, comme les cippes ou les argoi lithoi ("pierres brutes») : même intégrées à un ensemble d'argoi lithoi les ancres gardent leur valeur d'ex-voto.

Des cartes, de nombreuses et précieuses annexes et un index accompagnent le volume : elles donnent, sous forme de corpus ou de tableaux faciles à consulter, les sources utilisées. Ajoutons que la plupart des illustrations qui jalonnent le texte sont des clichés de l'auteur, ce qui témoigne de son implication totale dans le sujet. 
Le lecteur s'apprête ainsi à lire une étude foisonnante mais ordonnée, qui lui apportera des connaissances nouvelles et l'incitera à réfléchir sur le polythéisme grec et sur la vie religieuse des marins.

Madeleine Jost 


\section{SOMMAIRE}

Remerciements $\ldots \ldots \ldots \ldots \ldots \ldots \ldots \ldots \ldots \ldots \ldots \ldots \ldots \ldots \ldots$ IX

Préface de Madeleine Jost $\ldots \ldots \ldots \ldots \ldots \ldots \ldots \ldots \ldots$ XI

Introduction $\ldots \ldots \ldots \ldots \ldots \ldots \ldots \ldots \ldots \ldots \ldots \ldots \ldots$

PREMIÈRE PARTIE

LES DIVINITÉS OLYMPIENNES ET LA MER

Chapitre I - À LA CONQUÊTE DE LA MER ............ 21

Athéna ............................ 21

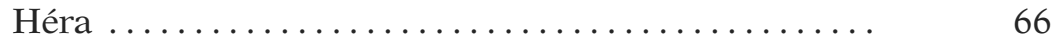

Chapitre II - LA MAÎTRISE DES ÉLÉMENTS . . . . . . . . . . . 83

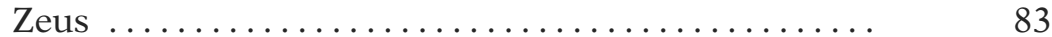

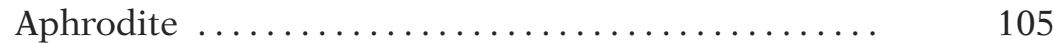

Déméter et Koré $\ldots \ldots \ldots \ldots \ldots \ldots \ldots \ldots \ldots \ldots$

Chapitre III - LA DOMINATION DE LA MER ........... 139

Apollon .................................... 139

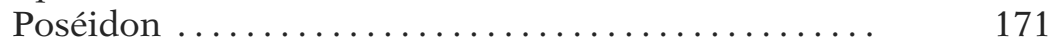

Chapitre IV - LES FRONTIÈRES DE LA MER, OU LA MER

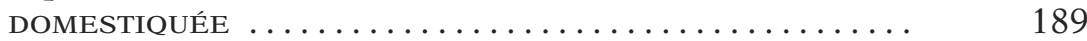

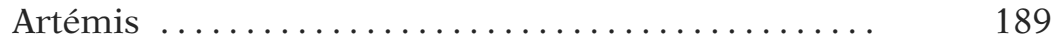

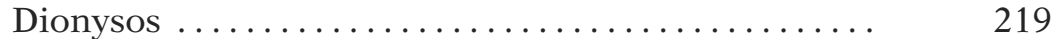

Hermès .............................. 235 
DEUXIÈME PARTIE

\section{PRATIQUES CULTUELLES MARINES}

Chapitre V - PrÉSEnCE des diEUX SUR LE BATEAU ..... . 245

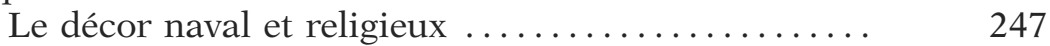

Les noms théophores de bateaux ............ 272

Les ancres à bord ..................... 290

Chapitre VI - LES EX-Voto À TERRE ... . . . . . . . . . . . 349

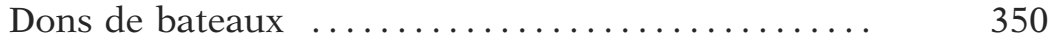

L'offrande à terre : le cas des ancres ........... 456

Autres offrandes marines .................. 501

CONCLUSION $\ldots \ldots \ldots \ldots \ldots \ldots \ldots \ldots \ldots \ldots \ldots \ldots$

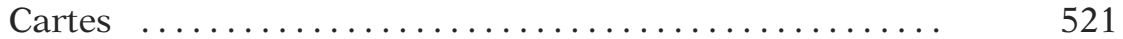

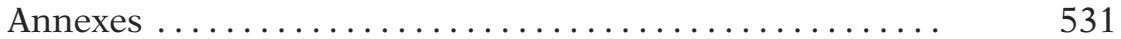

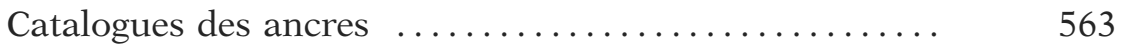

Bibliographie générale ..................... 615

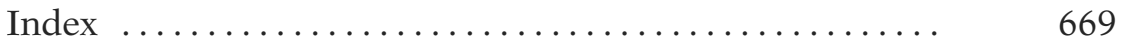

Table des illustrations ................... 697

Table des matières $\ldots \ldots \ldots \ldots \ldots \ldots \ldots \ldots \ldots \ldots \ldots$ 


\section{INTRODUCTION}

La mer, en tant qu'espace mouvant, changeant, barrière avec l'inconnu, a frappé les imaginations antiques : sentiments d'admiration, de peur, des deux à la fois nourrissent l'imaginaire collectif 1 . Pour les Grecs, que la tradition a longtemps considérés comme un peuple de marins ${ }^{2}$, vient s'ajouter à ces émotions mêlées l'angoisse essentielle de la mort sans sépulture qui rend la fréquentation de la mer encore plus effrayante ${ }^{3}$. Celle-ci, au contact de laquelle la géographie de l'Égée soumet les hommes, ne peut être conciliée qu'avec des puissances surnaturelles : "personne ne prend la mer, sans avoir auparavant sacrifié et invoqué l'aide les dieux» (Épictète, Entretiens III, 21, 12). Les activités maritimes sont ainsi ponctuées d'actes de dévotion, censés attirer la protection divine et éloigner les périls d'un espace considéré comme étranger.

"Le monde des navigateurs forme une véritable société close et, de même qu'il a ses coutumes juridiques, il a sa religion. Cela d'autant plus que le navigateur, homme des contrastes, est tout à la fois le plus immoral des hommes, tout au moins d'après la tradition, et le plus religieux. Cette religiosité s'explique par les dangers auxquels il doit faire constamment face, dangers pour lesquels il n'a souvent d'autre recours que la divinité. C'est pourquoi l'on dit aussi qu'il est le plus superstitieux des hommes» écrit Jean Rougé en dernières pages d'un ouvrage sur la marine antique ${ }^{4}$. Religion et superstition : il est en effet souvent difficile, dans un contexte maritime et de surcroît antique, de discerner la frontière entre les deux

${ }^{1}$ Séchan 1955, p. 4 s. La perception de la mer par les Romains a inspiré la belle étude de Saint-Denis 1935.

${ }^{2}$ Augustin Cartault ouvrait ainsi en 1881 son ouvrage d'architecture navale avec un chapitre intitulé «Les Hellènes et entre les Hellènes les Athéniens sont avant tout un peuple de navigateurs et de marins». Les études régionales de ces soixante dernières années ont fortement nuancé ce jugement.

${ }^{3}$ Radermacher 1949 , p. 307-315. Sur les stèles et les épigrammes de noyés, voir Georgoudi 1988; Cavalier 1990; Cavalier 1997, p. 133-134; Di Stefano Manzella 1997 (naufrages).

${ }^{4}$ Rougé 1974 b, p. 206. 
notions ${ }^{5}$. Cette évocation pose en principe l'existence d'une religion spécifique au monde de la mer, dont Dietrich Wachsmuth s'est attaché il y a presque un demi-siècle à définir les rites dans l'étude

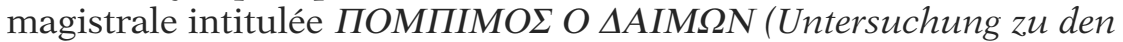
Antiken Sakhralhandlungen bei Seereisen) ${ }^{6}$.

\section{Historique de la recherche}

En 1967, dans son introduction aux tonalités parfois amères, le chercheur allemand déplorait le manque d'attention accordé dans la recherche historique et religieuse à l'étude des croyances relatives à la navigation, ou de manière plus large au monde maritime, pour la période de l'Antiquité. Détaillant longuement les articles ou ouvrages qui ont pu approcher le sujet mais sans l'aborder vraiment - dont un certain nombre sur ce que l'on pourrait appeler les aspects «symboliques» de la mer en tant qu'élément liquide, variations autour des notions d'eau primordiale, d'ordalie et de principe purificateur $^{7}$-, il aboutit à cette conclusion que l'étude de celui-ci préoccupe davantage, mais pour une période contemporaine, les ethnologues ou les savants en traditions populaires.

Trente ans plus tard, au moment de l'achèvement de la thèse dont est tirée la présente publication, le constat était à peine à moduler d'un bémol ${ }^{8}$. Certes, comme le ressentait déjà Wachsmuth, la connaissance des techniques navales et du monde maritime progressait, entre autre grâce au développement de l'archéologie sous-marine qui reçoit du grand public un intérêt certain. De grands noms comme ceux de Lucien Basch, Lionel Casson, John S. Morrison, Patrice Pomey ont amplement contribué à faire avancer ces recherches. Mais dans le domaine religieux, personne ne semblait avoir suivi les traces de D. Wachsmuth, malgré les nombreuses ouvertures que celui-ci proposait dans son introduction et tout au long des quatre cents pages suivantes... Si quelques études

${ }^{5}$ Ayala 1985 met en évidence, à partir de quelques exemples concrets actuels, la difficulté de démêler tous les éléments qui déterminent les tabous et les rites à bord d'un bateau : il n'existe pas une explication, mais souvent un ensemble d'éléments qui ne sont plus compris comme tels.

${ }^{6}$ Dissertation allemande : Wachsmuth 1967.

${ }^{7}$ Par ex. Glotz 1904; Rudhardt 1971; López Monteagudo 1998.

${ }^{8}$ Thèse : Fenet 1998. Depuis Wachsmuth 1967, deux articles trop généraux n'avaient rien apporté de neuf sur la question : Bloch 1985a; Goyens-Slezakowa 1990-1991. En revanche, la thématique a davantage été développée - avec bonheur - pour ce qui concerne la religion phénicienne (Fantar 1977; Baslez 1986; Bonnet 1988; Brody 1998) ou isiaque (Bricault 2006). 
ont porté sur la survivance de cultes ou de fêtes antiques ${ }^{9}$, de nombreux articles ou ouvrages, conscients de l'existence d'une thématique intéressante ${ }^{10}$, l'abordent pour tout aussitôt l'éluder par la référence au fameux ouvrage de $\mathrm{D}$. Wachsmuth - dans la majorité des cas sans renvoi à des passages précis, ce qui laisse douter de sa connaissance effective. Seules quelques publications de deux savants, également de langue allemande, témoignent d'un certain intérêt pour une religion maritime antique. Le premier, Arvid Göttlicher, après s'être surtout penché sur les représentations antiques de bateaux, a ensuite proposé, avec un bel intitulé, une étude plus précise sur leur usage religieux lors de cérémonies ${ }^{11}$; toujours dans une optique iconographique, mais seulement pour le monde romain, il a tenté de déterminer les attributs divins en relation avec le monde de la navigation ${ }^{12}$. Le second, Gerhard Kapitän, spécialiste d'archéologie sous-marine, a proposé quelques interprétations religieuses de récentes trouvailles d'objets en relation avec la mer ancres, objets céramiques ${ }^{13}$. Dans ces dernières années du $\mathrm{XX}^{\mathrm{e}}$ siècle, l'aspect maritime a cependant commencé à être pris

${ }^{9}$ Citons en particulier Manni 1963; Neutsch 1965b; Chevallier 1968; ainsi que plusieurs contributions des actes du colloque L'Homme méditerranéen et la mer (Homme médit. 1985), qui propose d'intéressantes directions de recherche.

${ }^{10}$ Par exemple, un essai sur la religion grecque comme celui de Burkert 2011, dans le chapitre intitulé "Crisis management / Dépasser la crise», évoque le thème en une vingtaine de lignes (p. 354-355). Les ouvrages sur la navigation ou la pratique de la mer dans l'Antiquité se montrent davantage sensibles à la question, sans la développer : ainsi l'ouvrage d'Höckmann comporte bien un chapitre concernant la religion maritime ( VII. Seefahrt und Religion»), par ailleurs assez riche, mais il se réduit à trois pages (Höckmann 1985, p. 157-160); même constat pour Gianfrotta \& alii 1997 (p. 111 à 113) et Parker 2005, p. 409-411; Vélissaropoulos 1980 aborde le thème dans un chapitre intitulé «les dieux des nauclères et des navires» de cinq pages (p. 86-90); tandis que Janni 1996 en développe dix (p. 387-396) sur les «devozione e supertizione», dont deux phrases aux divinités invoquées.... L'exposition «Greece and the Sea» organisée à Amsterdam en 1987 a présenté de nombreux documents ayant trait à la religion maritime, mais la question n'est abordée qu'en trois pages sous l'intitulé «Greece and the Sea : the mythical Aspect» (Delivorrias 1987, p. 58-60 sous la plume de P. Themelis). Le précieux guide Mentor sur la religion grecque (Motte \& alii 1992) ne présente aucune entrée "mer», "bateau», "religion marine», ou terme approchant; le compte-rendu (p. 716) du livre de D. Wachsmuth y tient en trois lignes.

${ }^{11}$ Göttlicher 1978; Göttlicher 1992.

${ }^{12}$ Göttlicher 1981. La seconde partie, qui opère l'inventaire par divinité, est malheureusement rapide et succincte; on attendrait, suivant l'intitulé, une recherche plus approfondie, surtout en matière religieuse au sens strict.

${ }^{13}$ Kapitän 1979 : rituels de sortie de port; Kapitän 1986 : dépôt d'ancre dans une tombe; Kapitän 1989 : article, qui reprend d'ailleurs certaines conclusions déjà publiées antérieurement, sur des rites observés à bord du bateau. 
davantage en considération dans les études historiques et archéologiques sur le monde grec, avec l'attention portée aux processus de colonisations et d'échanges à travers la Méditerranée et aux travaux sur la Grande Grèce ${ }^{14}$. Depuis le tournant du siècle, l'histoire religieuse s'est beaucoup attachée à suivre la diffusion d'un culte d'une divinité ou d'une épiclèse à travers la Méditerranée et/ou de définir des phénomènes de "syncrétisme ${ }^{15}$, à réfléchir sur les rapports du religieux avec la politique ${ }^{16}$ et à analyser individuellement certains dieux (dans leur complexité ou selon un aspect de leur culte) ${ }^{17}$. Dans le même temps, se sont multipliées les publications sur les conditions de la navigation: surtout géographiques et techniques, mais aussi humaines ${ }^{18}$; parmi elles, plusieurs études portent sur les cultes maritimes ${ }^{19}$.

Néanmoins, le thème reste largement ouvert à de nombreuses et longues perspectives, aussi bien de synthèse que d'analyses particulières. Car l'irremplaçable ouvrage de D. Wachsmuth reste un ouvrage d'érudition : la réunion de toutes les sources littéraires est impressionnante, mais le texte s'avère essentiellement descriptif. Ceci se justifie tout à fait pour une première vaste synthèse réalisée sur le sujet ${ }^{20}$. Outre les nombreuses découvertes et références biblio-

${ }^{14}$ Malkin 1987 (religion et colonisation); catalogues et mises au point sur la Grande Grèce publiés dans le cadre des expositions de 1996 (par ex. Prontera 1996 ou Santuari Calabria 1996), ou les colloques de Tarente sur la Magna Grecia. Dans une veine davantage économique et commerciale, citons également l'ouvrage de F. Arata consacré aux œuvres d'art trouvées en mer : Arata 2005.

${ }^{15}$ En témoignent des colloques sur Héra, sur Aphrodite Érycine ou sur les syncrétismes religieux : Colloque Héra 1997; Bonnet \& Motte 1999; Costa \& Fernández 2000; Acquaro \& alii 2010. 2008.

${ }^{16}$ Parker 1996; Shear 2001; Parker 2005; Dasen \& Piérart 2005; Chankowski

${ }^{17}$ Bonnet 1996; Detienne 1998; Mylonopoulos 2003; Pironti 2007; Graf 2009; Grotta 2011.

${ }^{18}$ Citons Janni 1996; Morton 2001; Arnaud 2005; Gianfrotta 2005; Göttlicher 2006; Kowalski 2012; Duchêne \& Fraisse 2001 (approche littorale). Sur la vie à bord : Beltrame 2002.

${ }^{19}$ Romero Recio 2000 (d'après p. iv-v : thèse de l'Université Complutense de Madrid débutée en 1995 et achevée semble-t-il en 1999 ou 2000); Fenet 2002 (étude régionale); Alvar \& Romero Recio 2005 (sauf l'introduction, résumé de Romero Recio 2000); Fenet 2005 (étude régionale); Marangou 2006 (étude régionale); Fenet 2010 (chapitre de synthèse pour le ThesCRA); Acquaro \& alii 2010 (étude régionale, de l'Antiquité à nos jours); Romero Recio 2010 (fêtes).

${ }^{20} \mathrm{Ce}$ que reconnaît volontiers l'auteur son Introduction (p. 43-62). Malheureusement, cet aspect «inventaire systématique»- souvent dénué de descriptions et de mise en contexte des sources -, la langue et la disgracieuse typographie ont dû rebuter bon nombre de lecteurs. 
graphiques postérieures qu'il convient d'ajouter, celle-ci demande des approfondissements sur bon nombre de points, ainsi que des angles d'approche diversifiés.

\section{Orientation du sujet}

C'est sur ce dernier terrain que la présente étude voudrait s'insérer. Loin de nous la prétention de vouloir donner un travail équivalent à celui du savant allemand : ce dernier reste pour nous la référence par excellence, et notre but n'est pas d'imiter sa démarche ni de répéter d'une autre manière le contenu de sa dissertation. Nous souhaiterions plutôt nous inscrire dans sa continuité : le dernier chapitre du livre, intitulé «Die im Euploia-Gebet anrufbaren Gottheiten ${ }^{21}$, aborde de manière très succincte une énumération des divinités concernées par le rituel maritime. Et c'est cette problématique qui nous a d'emblée intéressée, celle d'envisager la religion des gens de mer non plus par le biais des Sakhralhandlungen optique développée par l'ouvrage de 1967 -, mais par celui des divinités concernées. L'expression "divinités marines» ou «dieux des marins» représente en effet dans la littérature spécialisée une manière commode de désigner les figures objets de la dévotion des gens de mer. Ces expressions demandent à être définies : à qui s'adressent réellement les Grecs lorsqu'ils invoquent la puissance divine dans un contexte maritime? À lire les textes antiques, nombreux sont les daimones intervenant dans le monde de la navigation $^{22}$. Contrairement à l'image commune d'un Poséidon souverain de la mer à qui s'adressent les prières en rapport avec ce milieu $^{23}$, la mythologie fourmille d'ö $\lambda$ ıo $\theta \varepsilon o i ́$. Or, à y regarder de près, outre les figures attendues des Néréides, Vieillards de la mer ou des divinités locales, un certain nombre de sources indiquent la présence d'autres dieux qu'a priori rien ne semble rattacher à la mer : l'éventail des divinités recevant un culte marin s'avère beaucoup plus large et diversifié que ce que nous apprennent les manuels et l'historiographie traditionnelle ${ }^{24}$.

${ }^{21}$ Wachsmuth, p. 476-479.

${ }^{22}$ Höckmann 1985, p. 157-160, fait état de cette diversité, malheureusement de manière très rapide, en évoquant les différentes familles divines (olympiens et non olympiens). Bien avant lui, Rouse 1902, p. 228-233 énumérait succinctement un certain nombre de divinités concernées par les ex-voto marins.

${ }^{23}$ Le dieu, sur les différents aspects duquel on a beaucoup écrit depuis deux siècles, mériterait pourtant une étude approfondie et actualisée (avec les découvertes archéologiques et épigraphiques, et l'apport des synthèses régionales des cinquante dernières années) en ce qui concerne son culte marin.

${ }^{24}$ Dans ce domaine, la tradition conserve le classement mythologique du 
Dès lors, la restriction du champ d'investigation à un groupe précisément limité s'impose d'elle-même. Le constat est le suivant : le tableau d'ensemble de la religion marine que nous révèlent les sources montre deux grandes catégories de dieux : d'une part les divinités que nous pourrions qualifier de folkloriques - regroupant les divinités marines secondaires -, images poétiques ou idéalisées personnifiant la mer, sujets de légendes centrées sur la mer et parfois secourables; de l'autre, des dieux plus polyvalents pour lesquels apparaissent de véritables manifestations d'un culte marin. Le choix d'étudier cette seconde catégorie s'inscrit également dans une certaine communauté de vue avec de récentes recherches menées surtout en Italie du Sud, mettant en lumière les relations ici plus précisément religieuses - des colonies avec leurs citésmères : les divinités olympiennes ${ }^{25}$. Ces dieux de la troisième génération représentent un groupe cohérent, omniprésent dans la vie des Grecs.

L'objectif de cette étude est ainsi de voir de quelle manière ces dieux Olympiens participent également à la vie maritime des Anciens, comment leur emprise a pu s'étendre sur un domaine particulier, celui de la mer, parfois éloigné de leur personnalité première; d'étudier les rites et les pratiques religieuses qui leur étaient voués dans ce contexte précis. Il s'agit donc, en observant un groupe de dieux, de questionner le polythéisme autour de la $\operatorname{mer}^{26}:$ d'examiner

$\mathrm{XIX}^{\mathrm{e}} \mathrm{s}$. à l'image de celui de M. Collignon qui considère, parmi les «divinités des eaux», les «divinités de la mer» suivantes : Nérée, Néréides, Poséidon, Amphitrite (Collignon 1883, p. 197-216).

${ }^{25}$ L'intérêt de ce thème a été perçu dans le bref chapitre de Höckmann 1985 (loc. cit.), qui donne ainsi cette rapide esquisse des divinités des marins : «Es liegt nahe, dass der frühe Mensch das fremde Element mit Göttern und Damönen bevölkert, die Namen haben und sich durch Gebet und Opfer beeinflussen lassen. In den Ras-Samra-Texten steht Yamm als Meeresgott obenan. Bei den Griechen entspricht ihm Poseidon. Hinzu kommt eine Fülle niederer, ursprünglich vielleicht vorhellenischer Gottheiten, wie der heilige Meeresgreis Nereus mit seinen Töchtern, oder Proteus, dessen Wandlungsfähigkeit das Verhalten des Meeres selbst widerspiegelt. Aber auch olympische Gottheiten wie Apollon und Artemis, Hera und Athena, Asklepios und andere erscheinen in maritimer Sonderform als Meeres- oder Hafengottheiten».

${ }^{26}$ À l'heure où j'achevais la thèse, M. Detienne - avec lequel je n'ai jamais eu l'honneur de communiquer - écrivait en conclusion de son étude sur Apollon, à propos de ses diverses facettes : «certains ajoutent, en effet, le dieu marin : ne voit-on pas un Apollon des bords de mer? Il embarque, débarque, on le voit même sauver un navire en perdition. Voilà bien un champ d'activité ou, sans nuire aucunement aux enquêtes généalogiques, l'expérimentateur en polythéismes interrogera les gestes, les objets et les situations qui font se croiser Apollon et quatre ou cinq autres puissances divines» (Detienne 1998, p. 237). 
comment, dans les traditions, une telle intervention de ces différents dieux dans l'univers maritime a pu être justifiée et expliquée. La multiplicité de ces pratiques religieuses doit ainsi exprimer la manière nuancée et diversifiée dont les Grecs appréhendaient cet espace, à travers les représentations des dieux, leurs qualificatifs, leurs fonctions propres...

\section{Culte marin}

Il convient dès lors de définir et délimiter la notion de «culte marin». Cette expression renvoie tout d'abord à un espace bien défini : la mer en tant qu'étendue d'eau salée. Les fleuves sont ainsi strictement écartés de notre étude ${ }^{27}$. Cet espace marin est lui même multiple, entre surface et profondeur de l'eau, pleine mer et littoral, où l'Égée a dessiné des côtes très découpées et des myriades d'îles. Multiple aussi par l'étendue : le monde des Grecs comprend cette mer, mais s'étend en réalité sur toute la Méditerranée et même au delà par le biais de la colonisation et des périples commerciaux ou de découverte; il comprend ainsi également le Pont-Euxin, la façade atlantique de la péninsule Ibérique et le golfe Persique. En tant que marin, nous entendons tout ce qui se rapporte à cette double diversité géographique à la fois physique et spatiale.

Par ailleurs la notion de culte engage la présence des hommes qui en sont les acteurs; dès lors, l'adjectif évoque par extension les hommes qui vivent au contact de la mer et leurs activités. De façon générale, nous appliquons l'expression de culte marin à toute manifestation cultuelle établissant un rapport entre une divinité et la mer, entendue au niveau géographique et à celui des activités humaines maritimes. On peut bien sûr différencier des sous-groupes dans cet ensemble, comme l'ont déjà fait certaines études en distinguant des sanctuaires ou des cultes des promontoires, de la navigation ou de la pêche ${ }^{28}$.

Nos critères de repérage d'un culte marin rendu à une divinité sont de trois types : tout d'abord topographiques, en considérant les lieux à fort caractère maritime consacrés à un dieu, dans la mesure où les sources insistent sur cette caractéristique. Ainsi, un temple

${ }^{27}$ Voir également Fenet 2010, p. 405-406. Nous avons par ailleurs bien conscience que pour les Grecs, l'oikouméné était entourée d'un grand fleuve, l'Océan : la Méditerranée constitue pour eux la mer.

${ }^{28}$ Edith Semple (Semple 1927 et Semple 1932) et D. Wachsmuth ont abordé ce thème, sans toujours aller au bout de leurs analyses. Dieux de la pêche : Mazaubert 1937; Icard \& alii 2011; des promontoires : par ex. Robertson 1996. 
situé sur un port ou sur un promontoire, dont la situation géographique maritime est mise en avant par les Anciens, constitue pour nous l'indice d'un culte en rapport avec la mer. Le deuxième critère est nominal, d'après l'attestation d'épiclèses ou d'épithètes poétiques évoquant un lien entre la divinité et la mer. Le troisième comprend les manières dont le fidèle invoque la divinité dans un contexte marin : des sacrifices ou des prières - parlées ou écrites - demandant par exemple une bonne navigation, ainsi que des offrandes et ex-voto appartenant à l'univers marin comme les bateaux et les ancres.

Nous voulons insister sur deux points qui nous paraissent essentiels pour la compréhension de notre étude. Lorsque nous parlons de culte marin rendu à une divinité dans un sanctuaire ou sous une épiclèse, ceci ne doit pas s'entendre dans un sens exclusif : cela signifie qu'à tel endroit ou sous tel nom la divinité est mise en relation avec l'univers marin, mais que par ailleurs l'essentiel de son culte peut relever d'un domaine différent - initiation, fécondité, etc. Par ailleurs dans cette étude sont privilégiés les realia de la religion grecque : ce qui nous intéresse est d'observer les croyances et les pratiques cultuelles des Grecs envers leurs dieux, dans leur quotidienneté. Il ne s'agit absolument pas pour nous d'essayer d'expliquer ou de déterminer l'origine de ces faits religieux : les recherches portant par exemple sur la provenance d'Apollon ou le symbolisme de Dionysos, ou cherchant à prouver, par une multiplicité de références mythologiques, une ancienneté présumée de culte, représentent à nos yeux une approche détachée des réalités concrètes de la religion relative au milieu marin que nous souhaitons au contraire définir ${ }^{29}$. Nous éviterons donc de rentrer dans des débats trop théoriques ou généalogiques; c'est pour cette raison que la mise en valeur du matériel archéologique et des sources descriptives constitue la base essentielle de notre travail. Les critères de délimitation exposés ci-dessus écartent certes un certain nombre de cas, mais ont la vertu d'éviter l'écueil de voir des cultes maritimes partout $^{30}$ ou d'entraîner leur examen vers des digressions sans fin. Notre démarche ne s'inscrit donc pas dans le pur courant structuraliste des études anciennes - même si nous retenons dans une certaine mesure le principe de «mode d'activité» des dieux en l'appliquant à la "sphère d'activité» maritime $-{ }^{31}$, mais plutôt dans

${ }^{29}$ C'est en partie en cela que notre approche se différencie de celle adoptée par Romero Recio 2000, qui accorde une grande importance aux traditions mythologiques au détriment parfois de l'examen des realia et du terrain.

${ }^{30}$ Par ex. critique de Parker 2005, p. 410 note 93.

${ }^{31}$ Nous avons donc eu plaisir à lire les doutes de Parker 2002, p. 152 sur la 
une position positiviste; le lecteur constatera d'ailleurs, en parcourant la bibliographie, que les publications du $\mathrm{XIX}^{\mathrm{e}} \mathrm{s}$. et du début du $\mathrm{XX}^{\mathrm{e}}$ s. ont volontiers été consultées et utilisées, au même titre que les travaux plus récents. De ce côté, notre approche a été fortement influencée à la fois par la méthode rigoureuse d'analyse pratiquée par deux éminents hellénistes ${ }^{32}$, et par des historiens contemporanéistes : notamment par l'étude d'Alain Cabantous sur la religion dans le milieu maritime européen des XVI ${ }^{\mathrm{e}}-\mathrm{XIX}^{\mathrm{e}} \mathrm{s}$., qui a apporté à cet égard des perspectives nouvelles sur la manière d'aborder historiquement un sujet religieux, en l'ancrant sur les petites choses de la vie quotidienne des populations ${ }^{33}$. En recensant les cultes marins dans leurs réalités pratiques, géographiques et topographiques, c'est l'aspect vivant de la relation des Anciens avec la mer que nous espérons mettre en évidence et ainsi contribuer à la connaissance de la "culture maritime», telle qu'elle a été bien définie par C. Virlouvet en tant que «rapport que le monde gréco-romain entretint avec la mer, cet élément essentiel de son paysage, de son économie, de son imaginaire ${ }^{34}$.

\section{Les divinités olympiennes}

Quels sont donc les dieux retenus dans le cadre de notre étude? Par «divinités olympiennes» nous entendons les dieux censés appartenir au panthéon de l’Olympe, désignés parfois sous l'expression de

pertinence de telles analyses en religion maritime. L'auteur a ensuite de façon très claire montré les incontestables apports de l'analyse structuraliste, mais aussi ses limites : présupposé d'un immense savoir théologique et mythologique dans l'esprit de chaque Grec; description platonicienne des dieux plutôt qu'incarnée dans des pratiques cultuelles avec des variantes locales; faiblesses en terme de prise en compte des nouveaux dieux et de l'évolution du panthéon grec depuis Hésiode et les Hymnes homériques (Parker 2011, p. 84-98).

${ }^{32}$ Mme Madeleine Jost en religion grecque et M. Paul Bernard en archéologie grecque.

${ }^{33}$ Cabantous 1990. L'auteur s'est attaché dans ce livre - clair et très bien écrit - à déterminer la place réelle du christianisme dans les populations maritimes, conformément à un temps qui leur est propre, rythmé entre le retour à terre et le temps passé en mer. Il y analyse également la place des femmes restées à terre qui vivent selon ce même rythme binaire et leur influence sur le développement du christianisme et sur la religion à bord. Cette dernière, particulièrement bien décrite, met en évidence les peurs et les croyances d'une communauté tout en reflétant l'existence de groupes sociaux bien distincts. Une telle étude n'est pas applicable à l'Antiquité : l'historien moderniste a à sa disposition une masse de documents d'archives que ne possède pas l'historien de la Grèce ou de Rome. Néanmoins elle définit des méthodes et surtout la notion de culture maritime.

${ }^{34}$ Virlouvet 1998. Les contributions aux séminaires où a été développé ce thème ont été publiées dans les volumes MEFR CX à CXII, 1998-2000. 
Douze Dieux ${ }^{35}$. Les deux seules sources qui témoignent que ces divinités pouvaient être évoquées de façon collective en matière de navigation donnent l'une et l'autre formulation. Apollon lui-même, après avoir guidé le bateau des Crétois jusqu'à Delphes, leur donne pour instruction d'offrir des libations sur le rivage auprès de leur

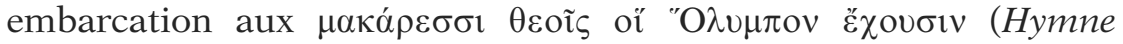
homérique à Apollon Délien, v. 388-512), tandis que les Argonautes bloqués par les vents érigent un autel aux Douze Bienheureux dans le Bosphore (Apollonios de Rhodes, Argonautiques II, v. 528-533; Polybe, Histoires IV, 39, 4-6) ${ }^{36}$. Une scholie (à Arg. II, v. 531-532) indique les douze divinités honorées à cet endroit ${ }^{37}$ : Zeus, Poséidon, Hadès, Hermès, Héphaistos, Apollon, Déméter, Héra, Hestia, Artémis, Aphodite et Athéna.

Par ailleurs, on connait à travers le monde grec des listes légèrement différentes des Douze Dieux : sur la frise orientale des Panathénées sur le Parthénon, le groupe est constitué par Zeus, Héra, Poséidon, Athéna, Apollon, Artémis, Aphrodite, Hermès, Déméter, Dionysos, Héphaistos et Arès. Sur cette frise, Dionysos remplace Hestia qui devait appartenir également au canon dit «original» figurant sur l'autel des Douze Dieux érigé par les Pisistratides sur l'Agora, tandis qu'Arès s'y substitue à Hadès. C'est donc sur ces quatorze noms que l'étude a porté 38 .

\section{La période chronologique et les sources}

Examiner des manifestations de cultes marins dans le monde grec imposait une période chronologique très large - huit siècles d'histoire - et ce pour deux raisons essentielles.

Tout d'abord, il est un présupposé admis par tous que le milieu maritime se caractérise précisément par ses permanences et son caractère conservateur ${ }^{39}$. Des textes, des traditions et légendes orales

${ }^{35}$ Sur l'opposition entre «olympiens» et «chtoniens», voir notamment Parker 2011, p. 80-84 qui montre sa non-pertinence, une divinité (par ex. Zeus) pouvant être honoré, selon ses épiclèses, pour des aspects célestes ou eschatologiques.

${ }^{36}$ Wachsmuth 1967, p. 402 et 404; Semple 1927, p. 362.

${ }^{37}$ Sur ce hiéron de Chalcédoine, voir Vian 1974, p. 91 et 95-99; Cook 1914-40, III p. 147-148; infra, p. 92-93.

${ }^{38}$ Long 1987, p. 333 s., conclut à la non-fixité de cette liste des Douze Dieux. Ceux honorés au Dôdékathéon de Délos ne nous sont pas connus : Bruneau \& Ducat 2005, p. 216-217 ( $\mathrm{n}^{\circ}$ 51). Nous avons exclu Héraclès de cette liste, suivant en cela le jugement de Georgoudi 1998, p. 73-74.

${ }^{39}$ Par exemple Cabantous 1990, p. 368 : «L'espace marin façonne et provoque nécessairement, pour celui qui le fréquente, un ensemble de croyances, 
qui se perpétuent marquent durablement les manières de considérer la $\operatorname{mer}^{40}$ : on ne peut évoquer de culte marin sans évoquer les textes homériques. Traiter une période bien délimitée de l'Antiquité grecque - laquelle? aucune ne le justifierait plus qu'une autre n'aurait fourni qu'une vision réductrice, tandis qu'une étude d'ensemble permet au contraire de percevoir les évolutions des représentations et pratiques cultuelles. Par ailleurs les sources dont nous disposons ne pourraient pas permettre une étude partielle. Celles-ci sont très disparates au niveau chronologique et obligent à étendre le plus possible la période d'investigation ${ }^{41}$.

Les sources littéraires se rapportant au sujet sont en effet très diversifiées, non seulement dans le temps mais aussi dans le champ thématique. La poésie et la tragédie fournissent de nombreuses indications sur la manière dont sont perçus les dieux. Une attention particulière a été portée sur les descriptions géographiques. L'intérêt des ouvrages de Strabon ou Pausanias pour l'histoire religieuse est unanimement reconnu; à leurs noms s'ajoutent entre autres ceux de Pomponius Mela, Skylax, Denys de Byzance, Aviénus qui ont établi des itinéraires côtiers ou, comme Arrien, ont détaillé le déroulement du voyage de la flotte d'Alexandre vers l'Inde ${ }^{42}$. Leurs témoignages nous sont particulièrement précieux; l'utilisation de ces sources reste cependant limitée par manque de références directes au texte

de prières de rites, bref une culture religieuse qui, depuis les thalassocraties archaïques aux villes portuaires de la modernité, ne manquent pas d'analogies. Rappelons le rapprochement hardi et révélateur d'Érasme entre le culte de Vénus et celui de Marie! Le fonds antique entretenu par la mer elle-même, ses dangers, ses rêves, s'est trouvé cependant intégré avec plus ou moins de vigueur au christianisme dominant»; Vélissaropoulos 1980, p. 6: «De fait, ni les conditions naturelles de la navigation ni les croyances des gens de mer n'ont beaucoup évolué au cours de l'Antiquité. Aussi les usages maritimes sont-ils restés à peu près stables». Ceci n'exclut pas, bien sûr, des évolutions en terme de navigation (techniques, connaissances géographiques, aspects juridiques, etc.).

${ }^{40}$ L'étude de V. Bérard sur les navigations d'Ulysse (Bérard 1927-29) montre bien la persistance de certaines traditions littéraires; ainsi les Voyages de Simbad le marin ne manquent pas d'analogies avec les aventures du fils de Laërte ou celles des Argonautes. Dans un autre registre, A. Cabantous (1990, p. 19-51) a finement analysé l'image de la mer au travers des récits bibliques et l'évolution de la manière dont elle fut perçue depuis l'Antiquité tardive jusqu'à l'époque moderne. Cette approche, dans la lignée des travaux d'Alain Corbin sur la perception des rivages (Corbin 1988), a donné lieu à deux expositions diachroniques sur les peurs maritimes, depuis Homère : Augeron \& alii 2004 et Corbin \& Richard 2004; voir également Alvar \& Romero Recio 2005, p. 167-172.

${ }^{41}$ Wachsmuth 1967, en introduction, insiste sur ce problème des sources et celui, inhérent, de déterminer une chronologie précise pour les pratiques qu'elles attestent.

${ }^{42}$ À ce sujet, voir l'excellent livre de Nicolet 1988, plus spécialement les chapitres III et IV; Jacob 1991. 
et par l'absence d'éditions précisément commentées ${ }^{43}$. Ces sources géographiques sont d'autant plus intéressantes qu'elles considèrent le plus souvent l'espace depuis la mer ${ }^{44}$ et constituent ainsi un contrepoint à une vision trop «terrienne» de la religion grecque. Un dernier groupe non négligeable est constitué par les écrits des commentateurs tardifs. De nombreux textes de l'époque romaine impériale - notamment les textes poétiques latins - transmettent, sciemment ou inconsciemment, des traditions grecques ${ }^{45}$. Des auteurs tardifs de la fin de l'Antiquité nous communiquent, de façon négative la plupart du temps pour des raisons de propagande, des informations concernant les cultes du monde grec, pour certains inconnus par ailleurs ${ }^{46}$. Enfin, les scholiastes byzantins éclairent de leur érudition certains mots ou certains passages; ceux-ci constituent également des témoignages non négligeables. L'index des sources littéraires (voir infra p. 541-556) permet de rendre compte du nombre et de la diversité de toutes ces traditions; parmi elles, le lecteur trouvera disponibles en annexe (p. 533-540) quelques textes difficiles d'accès ou importants pour la démonstration ${ }^{47}$.

Outre les sources littéraires, le sujet nécessite le recours à d'autres types de documents : à l'épigraphie, la numismatique et l'archéologie traditionnelle, et tout particulièrement à l'archéologie navale. Les inscriptions et les monnaies n'ont pas fait l'objet d'un dépouillement systématique, mais ont été intégrées autant que possible dans ce travail ${ }^{48}$. Une attention particulière a été portée sur les découvertes archéologiques, qui pour certaines ont été exami-

${ }^{43}$ Le commentaire de certains livres de Strabon reste à faire; la plupart des périples nautiques réunis par Müller 1855-1861, nécessiterait également un commentaire détaillé et réactualisé. Des publications récentes marquent cependant un intérêt nouveau pour ce type de sources: Counillon 2004 (PseudoSkylax); Arnaud 2005, p. 232-236 (utile liste récapitulative); Medas 2008 (Stadiasmus).

${ }^{44}$ Kowalski 2012, p. 173-176. L'Odyssée peut également être incluse dans cette description du monde depuis la mer (ibid.; Cuisenier 2003, p. 381-386).

${ }^{45}$ Sur la littérature grecque depuis l'époque hellénistique jusque la fin de l'Empire romain, voir Sirinelli 1993.

${ }^{46}$ Chuvin 1981, p. 326.

${ }^{47}$ Sur les problèmes d'accès et d'établissement des sources en matière de mythologie, voir Chuvin 1992, p. 10-13. Le corpus complet figure dans Fenet 1998 (textes latins ou grecs avec une traduction française, précédés d'une situation de chaque passage dans son contexte) : se nourrir des textes permet de s'imprégner d'un état d'esprit qu'une lecture rapide d'une citation ne permet pas toujours de saisir.

${ }^{48}$ De façon générale, les inscriptions les plus importantes sont retranscrites en notes; en annexe p. 557-561 figurent les inscriptions déliennes mentionnant un ex-voto naval. 
nées sur le terrain. Dans le domaine nautique, comme l'exposait déjà D. Wachsmuth en 1967, la documentation, très vaste, est disséminée un peu partout. Les travaux récents sur ce thème sont souvent difficiles à trouver dans les bibliothèques: des revues spécialisées, comme Das Logbuch, Mariner's Mirror, CRIS..., en histoire (diachronique) des techniques et traditions navales, sont peu ou nullement diffusées dans les instituts; de même, les publications relatives à l'archéologie sous-marine qui se multiplient ces dernières années restent souvent à tirage limité ${ }^{49}$. Au total, la documentation se révèle très riche et il convient de l'organiser de manière méthodique.

\section{Plan et limites du volume}

Pour répondre au mieux à l'analyse des realia et à la diversité des sources, l'étude a été partagée en deux parties. La première tente de définir les spécificités et les cultes marins de chacune des divinités tour à tour. Pour cela il sera fait appel à toutes les sources sans exception, afin d'attribuer à chaque dieu l'ensemble des témoignages le concernant. La seconde s'attache à décrire et recenser les pratiques religieuses concernant ces divinités dans le cadre d'un contexte marin, en respectant la dualité géographique et temporelle des populations maritimes : d'une part la présence du sacré à bord du bateau, à travers le décor et l'onomastique navals, d'autre part les ex-voto à terre. Les deux parties sont ainsi complémentaires : les éléments développés en seconde partie sont simplement mentionnés dans la première ${ }^{50}$.

En annexes figurent le corpus thématique des sources littéraires (par divinité ou notion), la bibliographie et l'index, ainsi que deux catalogues concernant un matériel dispersé dans les publications : le premier recense les ancres de plomb avec inscriptions théophores et décors trouvées en mer, le second les jas d'ancre de pierre votifs. Les illustrations, quant à elles, apparaissent au fil du texte.

${ }^{49}$ Le dépouillement systématique de toutes ces revues et l'établissement d'une bibliographie très variée a nécessité des années d'incursions dans de très nombreuses bibliothèques, tant à Paris (y compris Musée de la Marine ou celle des archives navales du château de Vincennes), qu'en Grèce et en Italie. Aujourd'hui, avec le développement du numérique et des catalogues en ligne, le repérage et l'accès aux sources secondaires prendraient moins de temps.

${ }^{50}$ C'est également en cela que notre étude diffère de celle de Romero Recio 2000, qui traite ainsi, par exemple, en même temps des ancres trouvées en mer et de celles mises au jour dans des sanctuaires, et inclut dans le cadre de son sujet les pratiques funéraires. Les sanctuaires y sont abordés dans un second temps (p. 113-137). Les liens avec les divinités sont discutés au cas par cas (à propos d'un ou plusieurs ex-voto ou sanctuaires); l'absence d'un index détaillé ne permet pas de s'y retrouver aisément. 
Comme le lecteur l'aura compris, cette monographie constitue donc une version remaniée de la thèse - soutenue il y a une quinzaine d'années - dont la publication a été sans cesse retardée par d'autres travaux qui ont accaparé l'essentiel de notre temps ${ }^{51}$. Une mise à jour de la bibliographie a été opérée : les nouveaux titres ont été soit simplement ajoutés en notes de bas de page, soit ont fait l'objet de modifications ou d'ajouts de paragraphes lorsque leur contenu imposait une révision du texte primitif. Un certain nombre de sources utilisées sont communes avec celles de deux ouvrages déjà cités parus entretemps sur des thématiques très voisines (cultes maritimes et vie à bord à l'époque romaine ${ }^{52}$ ), mais qui diffèrent de notre étude par leur chronologie et/ou angle d'approche, par les choix de développements ainsi que par certaines conclusions. Les pages qui suivent tiennent compte de ces deux titres, mais en limitant aux points les plus importants les renvois bibliographiques.

Enfin, pour ce qui est de la profondeur des analyses, l'auteur a pleinement conscience que de nombreuses questions, liées à l'histoire des religions, à la colonisation et à la navigation, n'ont été qu'effleurées dans cette étude : il reviendra à d'autres, plus compétents en la matière, d'apporter des développements dans ces directions.

\section{Conventions}

Pour les datations, nous avons utilisé un système de notation unique : a.C. et p.C.

Les principales références littéraires sont citées à l'intérieur du texte entre parenthèses et figurent dans les listes établies en annexe; celles citées en notes de bas de pages, pour ainsi dire secondaires, ne sont pas reprises en fin de volume.

Les renvois internes apparaissent également dans le corps du texte.

${ }^{51}$ Fenet 1998. Quelques articles sur des sujets maritimes ont cependant été publiés entretemps : voir supra note 19; Augeron \& alii 2004; article et comptes rendus dans des revues généralistes (L'Histoire; Notre histoire).

${ }^{52}$ Romero Recio 2000; Beltrame 2002. 
PREMIÈRE PARTIE

LES DIVINITÉS OLYMPIENNES ET LA MER 

L'étude des cultes d'un ensemble de divinités en rapport avec un thème spécifique soulève deux problèmes méthodologiques majeurs : celui de l'approche et du traitement des sources pour chacune d'entre elles, puis dans un second temps celui de l'organisation générale de ces études individuelles ${ }^{1}$.

En ce qui concerne le premier point, nous avons tenu à privilégier les sources de tous types afin de présenter la masse de la documentation disponible pour chacun des dieux, avant de proposer une analyse d'ensemble. Pour chaque divinité, notre étude débute donc par l'inventaire de ces informations, en distinguant dans un premier temps les traditions mythiques liées aux cycles épiques, puis les attestations cultuelles. Celles-ci sont inventoriées de manière géographique : par site, par région ou par littoral de la Méditerranée. Sauf cas particulier, la description géographique part de l'Attique pour s'achever aux confins du monde grec ${ }^{2}$. Pour éviter des répétitions inutiles et ne pas alourdir cette présentation des sources, les documents liés aux rites nautiques faisant l'objet de la seconde partie de l'ouvrage sont simplement recensés; des renvois facilitent les correspondances entre les deux parties. Ainsi les offrandes navales, les noms ou décors religieux de bateaux sont rattachées à la divinité et au site auxquels ils appartiennent afin d'offrir un tableau complet des données cultuelles divinité par divinité.

Une fois cet inventaire terminé, alors seulement est proposée une analyse dirigée dans deux directions. Dans un premier temps, l'attention est portée, dans la lignée des travaux d'Edith Semple³, sur

\footnotetext{
${ }^{1}$ Une présentation synthétique regroupant l'ensemble des attestations par domaine d'activité s'avère impossible et ingérable devant la quantité de documents, leur caractère lacunaire ou complexe. Des études de ce type sont possibles à une petite échelle : à l'intérieur d'une œuvre (par exemple Mazaubert 1937 pour un livre de l'Anthologie Palatine), ou à l'intérieur d'une zone bien définie (Vian 1974 pour le Bosphore).

${ }^{2}$ L'ordre suit dans ses grandes lignes celui des notices de la $R E$.

${ }^{3}$ Semple 1927; Semple 1932. L'auteur a recensé à travers le bassin méditerranéen tous les sanctuaires placés de façon à être visibles depuis la mer, cherchant à percevoir une relation entre les conditions de navigation et la géographie religieuse. Ce travail comptabilise ainsi plus de 175 sites; on peut lui reprocher
} 
l'aspect géographique des cultes marins de chaque divinité : sont-ils répartis par zones bien définies? Peut-on distinguer une logique d'implantation? Les lieux de culte présentent-ils ainsi des points communs pouvant aider à la compréhension de la nature du culte maritime qui y est rendu? Ensuite, il convient de cerner la personnalité marine du dieu : la manière dont il est perçu dans son rapport à la mer, son/ses domaine(s) d'activité.

Ce principe posé, restait le problème de la détermination d'un critère de classement de ces études individuelles, une présentation alphabétique n'offrant aucun intérêt. Une répartition par domaine d'activité au sens strict s'avérait malaisée car une même divinité peut en posséder plusieurs. Finalement, c'est le caractère général du culte marin de chacune d'elles qui permet le mieux de cerner une cohérence parmi l'ensemble de ces cultes ${ }^{4}$. Une étude comme celle de Marcel Detienne sur Athéna ${ }^{5}$ a montré que ce qui constituait la base des relations d'Athéna avec la navigation était sa métis. Sans vouloir reproduire à l'identique ce genre d'analyse, il nous a paru intéressant de l'enraciner dans un contexte historique et dans une réalité cultuelle.

Par ailleurs A. Lesky ${ }^{6}$, dans le cadre d'une recherche sur les relations entre les Grecs et la mer, a étudié l'évolution de leurs comportements et de leur usage de cet espace : apprentissage, découverte, maîtrise. Dans cet esprit, une classification suivant la nature du rapport à la mer qu'exprimait le culte de telle ou telle divinité s'est imposée comme la plus satisfaisante, d'autant plus qu'elle respectait globalement une certaine chronologie cultuelle. Ainsi nous étudierons tout d'abord la conquête de la mer (Athéna et Héra), puis la maîtrise des éléments (Zeus, Aphrodite, Déméter et Koré), dans un troisième chapitre la domination de la mer (Apollon, Poséidon) pour ensuite achever sur sa domestication (Artémis, Dionysos et Hermès).

parfois une lecture rapide des sources qui conduit à des erreurs ou attributions hâtives ou erronées. À signaler également l'usage comme sources de nombreuses gravures anciennes, qui permettent de mieux reconstituer la configuration antique des lieux littoraux.

${ }^{4}$ Jost 1992, p. 33-34 montre la complexité de la notion de «fonction» divine : une même sphère d'activité fait intervenir plusieurs divinités en même temps que chacune d'elles possède une certaine polyvalence; «il est clair néanmoins que chaque divinité a une personnalité qui s'exprime dans une multitude de préoccupations». analyse.

${ }^{5}$ Detienne 1970; aux p. 134-135, l'auteur explique le fondement de son

${ }^{6}$ Lesky 1973. 
Dans une perspective de présentation synthétique, l'insistance est mise sur le culte marin, mais les éléments bien connus ne sont pas développés inutilement. Ainsi pour des divinités comme Aphrodite ou Apollon pour lesquelles les sources sont nombreuses et parfois répétitives, nous n'avons fait que peu appel à des sources tardives qui renvoyaient souvent l'image du culte ou de la déesse telle qu'elle s'est fortement imposée à l'époque impériale. De même, la bibliographie générale des grands sanctuaires et divinités se limite volontairement à quelques titres, de façon à ne pas alourdir les notes. 



\section{CHAPITRE I}

\section{À LA CONQUÊTE DE LA MER}

Le désir et le mouvement de découvrir la mer et, au-delà, de nouveaux espaces s'affirment au travers d'Athéna et d'Héra. La première, par la construction du premier bateau et par sa science nautique, marque le début de la navigation des Grecs qu'Héra accompagne et protège dans leurs périples nautiques. Ces deux déesses se trouvent ainsi veiller à l'expédition des Argonautes, qui évoque l'exploration de l'espace maritime grec vers le septentrion.

\section{ATHÉNA}

Athéna a été rapprochée de la mer par M. Detienne dans un article paru en 1970 intitulé «Le navire d'Athéna ${ }^{1}$. Comme l'indique cette formulation, l'étude a porté sur les liens unissant la déesse au monde de la navigation. Il n'est pas dans notre intention de répéter ce brillant travail, mais de reprendre les sources anciennes afin de définir la spécificité d'Athéna par rapport aux autres divinités en matière de culte maritime et d'en voir l'évolution historique, tant littéraire que cultuelle. Dans cette optique, nous insisterons davantage sur les realia et sur le matériel archéologique qui n'avait alors pas été pris en compte.

${ }^{1}$ Detienne 1970. Il a été précédé de trois articles abordant le thème des relations d'Athéna avec la mer. Le premier, un article allemand de la fin du $\mathrm{XIX}^{\mathrm{e}}$ siècle (Hildebrandt 1888) présente un tableau général de la plupart des sources; le second, écrit dans l'entre-deux-guerres, tente de définir à travers des copies de statue d'époque romaine un type iconographique d'Athéna marine que l'auteur rattache au type de l'A. ailée et de la Nikè. Cet article présente des remarques intéressantes, mais le ton général est forcé et trop subjectif, conduisant à des interprétations et conclusions excessives et erronées (Anti 1920). Une démarche similaire avait été quelques années plus tôt menée par Kiock 1915. Nous ne renverrons pas systématiquement en notes à ces articles, qui tous les quatre exposent plus ou moins brièvement un certain nombre des sources développées ci-après. 


\section{LES SOURCES}

Les sources littéraires sont relativement nombreuses et à peu près équilibrées entre les traditions mythiques et les témoignages cultuels. Si les premières constituent un ensemble relativement cohérent, les seconds composent - nous le verrons - un tableau plutôt décousu.

\section{Mythologie et épopée}

Dans les récits mythologiques, la personnalité d'Athéna s'affirme notamment par la protection qu'elle accorde à certains héros. Ulysse et Héraclès bénéficient constamment de l'aide de la déesse, mais ils ne sont pas les seuls. Cette dimension tutélaire est interprétée par les historiens des religions comme la raison, notion qu'incarne la déesse, venant s'adjoindre aux qualités physiques et morales des héros ${ }^{2}$. Ainsi se montre-t-elle apte à veiller sur le personnage pur, qui a toujours respecté les dieux. C'est ce qui est à plusieurs reprises affirmé dans l'Odyssée à propos d'Athéna et de son protégé Télémaque ${ }^{3}$. En ce qui nous concerne, il convient de considérer si cette aide de la déesse s'étend également au domaine maritime.

\section{a) L'épopée homérique}

Athéna est mise très tôt en relation avec la mer dans la littérature : elle joue un rôle maritime dès la tradition homérique. Cependant, il est notable que la déesse, pourtant bien présente durant la guerre de Troie du côté des Achéens, n’intervient ni durant le voyage de ces derniers vers Ilion ni dans un quelconque rapport avec les vaisseaux gardés sur la grève du camp grec. En réalité, elle n'intervient sous cet angle que dans l'Odyssée, et ce de manière spécifique puisqu'elle le fait uniquement sur la personne de Télémaque à la recherche de son père. Ulysse en revanche, sous la protection constante d'Athéna, ne semble pas - à première vue en tous cas bénéficier de son intervention dans le domaine maritime.

Athéna apporte donc un soutien directement lié à la mer dans ce qui constitue un épisode à part de l'épopée homérique : la Télé-

${ }^{2}$ Dümmler 1896, col. 1942-1947; Séchan \& Lévêque 1966, p. 327-331; Grimal 1951, p. 57-58.

${ }^{3}$ Athéna l'assure à Pénélope dans un songe (Odyssée IV, v. 806 ss), et Zeus à Athéna (V, v. 25 ss); c'est ce que Wachsmuth 1967, p. 272, appelle «l'euploia par

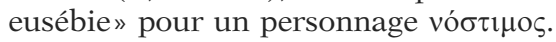


machie ${ }^{4}$. Le fils d'Ulysse parvenu à l'âge de raison décide, sur les conseils d'Athéna travestie en Mentès ou Mentor, d'aller en quête d'informations concernant son père parti d'Ithaque depuis tant d'années ${ }^{5}$. La déesse ne se contente pas d'exhorter le jeune homme à armer un bateau, elle intervient également dans les préparatifs et la navigation. Tout d'abord (Odyssée II, v. 382-433), elle réunit l'équipage, équipe le navire et l'installe au mouillage aproprié; lorsque tout est prêt, c'est elle qui donne les ordres de navigation : disposition et recommandations à l'équipage, ordre de départ, et comme véritable commandant, elle occupe la partie arrière du bateau (غ่ $\pi$ ì $\pi \rho v \mu v \tilde{n})$ avec Télémaque qui donne les prescriptions de manœuvre. De surcroît, elle envoie un vent favorable, autant en force qu'en

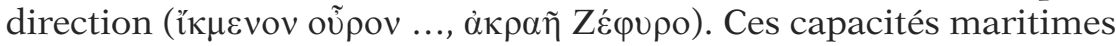
se répètent plus loin dans la Télémachie, lorsque le fils d'Ulysse est pressé par les événements de revenir au plus vite à Ithaque $(O d$. IV (Télémachie), XV, v. 33-35) : Athéna indique la meilleure route à suivre et assure à Télémaque un vent apte à le pousser dans la bonne direction (oũpov ö $\pi 1 \sigma \theta \varepsilon v$ ). Ainsi, Athéna affirme par ses actes une maîtrise certaine des affaires maritimes.

Cette prérogative de la divinité est gardée dans la tradition littéraire fidèle aux textes homériques. Ainsi au $\mathrm{III}^{\mathrm{e}}$ siècle de notre ère, Quintus de Smyrne, dans le récit des événements postérieurs à ceux relatés dans l'Iliade, attribue à la déesse (La suite d'Homère, IX, v. 436-437) la même faculté d'aider à la propulsion du bateau grâce au vent arrière $(\dot{\varepsilon} \xi$ ó $\pi \imath \theta \varepsilon v \ldots$ oṽpov). Cependant, cette fois c'est le camp grec qui bénéficie de ce soutien - plus précisément les occupants du bateau parti à la recherche de Philoctète et de ses précieuses armes - et non plus la personne de Télémaque. Ce dernier n'est plus le seul à bénéficier des qualités d'aide à la navigation d'Athéna : conformément à ce que l'on attend d'elle, il s'agit du groupe des Achéens sous le commandement partiel d'Ulysse.

Une tradition augustéenne la fait également intervenir lors du retour des Achéens vers leurs contrées respectives. Selon Ovide (Métamorphoses XIV, v. 466-476), parmi les Grecs poursuivis par la colère des dieux, ballotés et violentés par les flots, Diomède est personnellement sauvé grâce à l'intervention de la déesse; cependant les modalités du sauvetage ne sont pas détaillées précisément par le poète. Cette attention tardive, unique, est cependant à signaler; il faudra essayer dans un second temps de la rapprocher d'autres épisodes littéraires.

${ }^{4}$ Voir Wachsmuth 1967, p. 72-74.

${ }^{5}$ Odyssée I, v. 267-295. Dans le livre I de l'Odyssée, Athéna prend les traits de Mentès de Taphos fils d'Anchialos, puis au livre II ceux de Mentor ami d'Ulysse. 
Enfin, pour en terminer avec la tradition homérique, l'Hymne I à la déesse (v. 9-16) montre la puissance d'Athéna qui se manifeste, dès la naissance de celle-ci, sur tous les éléments y compris l'élément marin. Le soleil suspend sa course, la terre tremble et la mer se déforme en gros creux avant de s'apaiser brusquement. Le pouvoir d'Athéna impose donc sa marque à l'ensemble de l'univers. Dans cette optique, il n'est pas étonnant de voir par ailleurs la déesse guider ses protégés à travers ce même milieu.

\section{b) L'épopée argonautique}

Athéna est surtout connue, dans un contexte maritime, pour ses multiples actions dans la conquête de la Toison d'or en faveur de Jason et de ses compagnons. L'épopée hellénistique des Argonautiques rédigée par Apollonios de Rhodes s'en fait largement l'écho ${ }^{6}$, ainsi que les réécritures tardives du mythe directement inspirées du précédent ouvrage : celle de Valerius Flaccus au dernier quart du $\mathrm{I}^{\mathrm{er}}$ s. p.C. et celle désignée sous le titre des Argonautiques orphiques composée quelques siècles plus tard. La lecture commune des trois poèmes permet de connaître la variété des traditions concernant ce mythe et leur évolution.

Athéna n'est pas l'unique protectrice du chef de l'expédition; celui-ci est également favorisé par Héra (voir infra, p. 67-68) et Apollon (voir infra, p. 144-145). Comme les autres dieux, la déesse aux yeux pers intervient dans le processus de la navigation. C'est elle qui est à l'origine de la construction de la nef Argô : ceci est affirmé dès le début du poème (Arg. I, v. 18-19; suivi par Valerius Flaccus I, v. 91-99 et 121-126), et selon une longue tradition si l'on en croît l'écrivain. Mais le bateau n'est pas un bateau comme les autres : non seulement pour certains il constituerait le premier du genre (Arg. Orph., v. 59-69), mais surtout il est doué de vie, grâce à une poutre située au milieu de l'étrave, tirée d'un chêne de Dodone (Arg. I, v. 519-535; ibid., II, v. 611-614; ibid., IV, v. 580-583; repris par le Pseudo-Apollodore, Bibliothèque I, ix, 16, et Arg. Orph., v. 266-271 et v. 1155-1157 ${ }^{7}$. La déesse l'a ainsi intégrée à la coque de l'embarcation afin d'attirer la protection de Zeus, dieu du sanctuaire

${ }^{6}$ Les légendes concernant les Argonautes sont antérieures à Apollonios de Rhodes; la date relativement tardive de l'épopée d'Apollonios ne doit pas en imposer. Dès Pindare, la littérature célèbre les actions des héros; à l'époque classique, un certain nombre de tragédies disparues s'en inspiraient directement (Vian, in Apollonios de Rhodes, éd. Budé, t. I p. xxvi-xxxi). Sur le voyage initiatique de Thésée chez Apollonios, voir Duchêne 1992.

${ }^{7}$ Wachsmuth 1967, p. 357-360; Göttlicher 1992, p. 129. Trippé 2008 y voit une sorte de stylis qui se trouverait à la proue. 
oraculaire, sur les héros, mais aussi comme élément de bon augure. Le morceau de bois, devenu ainsi l'interprète d'Athéna, les presse au départ car les conditions de vent et de mer sont bonnes (Arg. I,

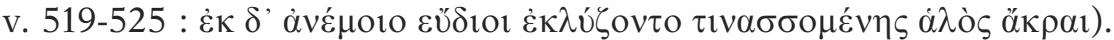
La poutre parlante ( $\alpha$ $\delta \tilde{\eta} \varepsilon v \delta$ ó $\rho v)$ intervient encore (Arg. IV, v. 576595; Arg. Orph., v. 1155-1170) pour leur porter secours en leur communiquant la nouvelle de la colère de Zeus et le moyen de l'apaiser, et ainsi d'éviter le naufrage à venir du navire. Tout au long du périple, Argô se montre ainsi une embarcation fidèle, bonne navigatrice, douée de sens nautique ${ }^{8}$.

Un texte augustéen (Hygin, Astronomie II, 37) évoque, à propos de la constellation portant le nom du vaisseau des Argonautes, les différentes traditions se rapportant à sa construction, notamment les écrits d'Homère, de Pindare, d'Eschyle et Callimaque ${ }^{9}$. La majorité d'entre elles (complures) le considèrent bien comme le premier bateau qui ait jamais pris la mer. Une seule allusion en revanche est faite à Athéna, à propos du lieu de l'élaboration d'Argô appelé Pagases, situé selon les uns en Magnésie selon les autres en Thessalie. C'est là, "d'après Eschyle et quelques uns", que le bois parlant fut assemblé par la déesse. Cette brève mention montre l'ancienneté, déjà affirmée par Apollonios de Rhodes (I, v. 18-19 : oi $\pi \rho$ ó $\sigma \theta \varepsilon v$ Ě $\tau$ 1 $\kappa \lambda \varepsilon i ́ o v \sigma \imath v$ åoıoì) et remontant donc au moins à Eschyle, de la légende attribuant à Athéna une place essentielle dans la construction du bateau, voire même du premier bateau digne de ce nom.

Cette fonction d'Athéna comme architecte naval est célébrée dans une épigramme du ${ }^{\mathrm{er}}$ s. p.C. d'Antiphilos (Anthologie Palatine IX, 306). La référence à Argô y est encore explicite, tandis que le poème célèbre de nouvelles techniques de fabrication de navires. La déesse joue un rôle primordial dans les deux cas, car c'est elle qui est à l'origine de ses différentes réalisations navales comme le marque

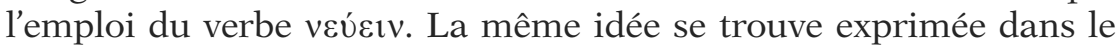
résumé de la légende des Argonautes donné par le pseudo-Apollodore (Bibliothèque I, ix, 16), mais avec un verbe différent vi $\operatorname{lo}_{\imath \imath} \theta \dot{\varepsilon} v \alpha 1$. Une nuance est apportée à cette unanimité par les Argonautiques orphiques (v. 59-69), qui indiquent que c'est sur ordre d'Héra qu'Athéna assuma ce rôle : si cette dernière assure la partie tech-

${ }^{8}$ C'est sans doute pour ses caractéristiques si particulières que la nef est nommée sacrée par les auteurs latins lorsqu'ils font allusion à des épisodes de sa navigation: Ovide, Pontiques I, 3, v. 76 (trabs sacra); Silius Italicus, XI, v. 471 (carina sacra).

${ }^{9}$ Il nous en reste quelques bribes dont le sens est ainsi explicité : cf. Eschyle, Argô, Fgt 36; Antimaque Fgt 58; Callimaque Fgt 16 Pfeiffer. 
nique de l'ouvrage, l'idée en revient à l'épouse de Zeus. Enfin quelques sources iconographiques d'époque romaine montrent la déesse participant à la construction de la nef. Deux reliefs de terre cuite du milieu du $\mathrm{I}^{\mathrm{er}}$ s. p.C. figurent Athéna assise, occupée semble-t-il aux voiles du bateau tandis qu'Argos travaille au ciseau le bois de la poupe $^{10}$. Une peinture d'Herculanum montrait quant à elle la déesse surveillant la fabrication de l'embarcation ${ }^{11}$. Ces images témoignent

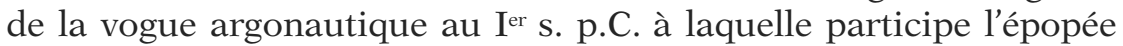
de Valérius Flaccus, mais aussi de la tradition solidement ancrée d'une Athéna architecte du bateau mythique.

Athéna ne se contente pas de doter Argô des meilleures qualités, elle suit et protège le voyage. Cette aide à la navigation est célébrée explicitement par un long discours du pilote d'Argô ${ }^{12}$ destiné à rassurer ses compagnons dans la version de Valerius Flaccus (II, v. 47-68) : la déesse cursus erudiit, saepe ipsa manu dignata carinam est. C'est elle également qui permet la navigation de nuit, en enseignant la science des étoiles et en sauvegardant le vaisseau durant les tempêtes nocturnes. De façon générale, le poète latin (III, v. 487491) présente Athéna comme consortem curis cursusque regentem envers les héros. Lors du périlleux passage des Symplégades (ou Kyanées : carte 1), elle intervient physiquement pour éviter que le bateau ne soit fracassé contre les roches (Arg. II, 593-606). Après que les Argonautes, sur les conseils de Phinée, aient lâché une colombe afin d'obtenir le présage du franchissement des deux îlots, le bateau qui s'est alors élancé derrière l'oiseau est pris dans les tourbillons. À ce moment la déesse, placée sur un rocher et y prenant appui, donne l'impulsion nécessaire au vaisseau pour qu'il franchisse cette passe dangereuse $^{13}$. Celui-ci sort indemne de l'épreuve - seul l'aplustre souffre légèrement du choc des Symplégades - et Athéna peut alors rejoindre sa demeure de l'Olympe. La version de Valerius Flaccus (IV, v. 670-693) diffère en cela que c'est Athéna qui envoie elle-

${ }^{10}$ British Museum inv. D603 et Louvre inv. Cp 4144. Göttlicher 1992, p. 128 et fig. 69; Blatter 1984, 1 p. $601 \mathrm{n}^{\circ} 13$ \& 15 et 2, p. 433-434. À ces deux décors s'ajoutent une monnaie romaine du milieu du $\mathrm{II}^{\mathrm{e}}$ s. sur laquelle Athéna donne des ordres à l'architecte d'Argô : ibid., n ${ }^{\circ} 17$.

${ }^{11}$ Musée de Naples. Canciani 1984, 1 p. 1099 no 361; Helbig 1868, p. 268-269 et p. $460 \mathrm{n}^{\circ} 1259$. Une monnaie de Commode figure une scène identique : Imhoof-Blumer 1910, p. 28 no 10 et pl. II, 7.

${ }^{12}$ Tiphys, doté lui aussi de nombreuses qualités : Detienne 1970, p. 172-174.

${ }^{13}$ Conseils de Phinée : Arg. II, v. 317-344; lâcher de l'oiseau : II, v. 549-573. Cf. Vian in Apollonios de Rhodes, éd. Budé, t. I p. 128 ss., 150 ss. et 275 note 599. 
même un fulmineam facem afin de séparer les roches, et qu'ensuite elle retient l'une des deux - Héra s'occupant de l'autre - afin de permettre le passage du bateau. L'action physique des deux déesses est de manière surprenante comparée à celle du paysan forçant le taureau à rentrer sous le joug. La prédominance d'Athéna dans la tradition hellénistique est ici amoindrie par la présence d'Héra au même instant critique. La lueur envoyée par Athéna pour indiquer la route à suivre figure également chez Apollonios de Rhodes (Arg. IV, v. 294-297), mais lors du trajet de retour. La déesse - dont le nom n'est pas mentionné, mais qui est identifiable comme telle au vu de ses interventions au voyage d'aller - confirme ainsi la direction proposée par Argos.

Les Argonautiques orphiques (v. 680-711) racontent ce même épisode du terrible passage des Roches Kyanées ${ }^{14}$. Athéna n'agit cependant pas directement dans cette version: elle envoie un oiseau, en l'occurrence un héron ( $\dot{\varepsilon} \rho \omega \delta$ ióv) pour servir de guide. Comme il a déjà été précédemment noté, le rôle d'Athéna est minimisé dans les Argonautiques orphiques en faveur de celui d'Héra, qui est encore ici l'instigatrice de l'aide octroyée par Athéna (v. 694696). Le héron vient se percher au point le plus haut du bateau puis se glisse entre les roches, de façon à montrer aux navigateurs la manière de passer avec le moins de dommage possible; ensuite, le pouvoir d'Orphée exerce son effet. L'action d'Athéna apparaît donc réduite dans cet extrait : la déesse ne se manifeste pas en personne et c'est à Héra que revient le mérite du péril évité, ainsi qu'au charisme orphique qui triomphe des courants et des écueils. La colombe d'Apollonios de Rhodes s'est transformée en héron, un don divin attribué directement par Athéna. La nature de l'intervention de la déesse est donc totalement différente dans ces deux versions : dans la seconde, plus tardive, Athéna a perdu de ses prérogatives et de sa puissance en matière maritime.

Malgré l'aide considérable que leur apporte Athéna, les héros eux-mêmes ne lui vouent qu'un sanctuaire. Après leur rencontre avec Triton dans le lac homonyme, les navigateurs rejoignent la Crète où grâce à Médée, ils viennent à bout du terrible Talos. Le lendemain, aux premières heures du jour, ils consacrent un hiéron à Athéna Mivwís, avant de faire provision d'eau et de reprendre la mer (Apollonios de Rhodes IV, v. 1691-1694). La scène est située sur la pointe Salmônis, c'est-à-dire sur le long promontoire nord-est de l'île compris dans le territoire d'Itanos (voir infra p. 45) ${ }^{15}$. L'épithète de

${ }^{14}$ Vian 1983, p. 451-463.

${ }^{15}$ Aujourd'hui appelé cap Sidéros : Delage 1930, p. 271-272; Bürchner, «S.v. 
Minoenne renvoie sans nul doute au roi mythique crétois. Le passage indique ainsi comment un lieu devient sacré, sans pour autant comporter de construction particulière : le «finistère» oriental de l'île porte la marque de la déesse et doit probablement être salué de cette manière par les navigateurs qui le doublent, en l'occurrence ici par les Argonautes qui doivent tant à Athéna.

\section{c) Autres héros}

Trois épisodes héroïques mettent encore en scène une Athéna dans un contexte maritime, veillant ainsi sur Thésée, Héraclès et Oreste.

De façon générale, la protection de la déesse sur le héros athénien ne concerne nullement le domaine maritime, à une seule exception près. Lors du voyage vers la Crète emmenant le groupe de jeunes filles et jeunes gens destiné au Minotaure, survient l'épisode bien connu de la visite du héros à Poséidon et Amphitrite ${ }^{16}$. Or, ce n'est pas lors de ce plongeon dans les flots qu'intervient Athéna, mais sur la bonne marche du bateau tout au long de cet épisode. D’après la poésie de Bachhylide (Dithyrambe III), datée de la première moitié du $\mathrm{V}^{\mathrm{e}}$ s. a.C., la déesse se manifeste par le vent favorable qui permet au navire d'avancer promptement: les vers 5-8, repris en 90-91, indiquent que les souffles réguliers de Borée sont dus à Athéna porteuse d'égide $(\pi \varepsilon \lambda \varepsilon \mu \alpha i ́ \gamma ı \varsigma)$.

Dans un autre de ses poèmes, Bacchylide (Dithyrambe II, v. 13-18) évoque un sacrifice offert par Héraclès en Eubée après la destruction de la cité d'Echalie. Pour ce faire, le héros se rend sur le promontoire situé au nord-ouest de l'île, sur lequel il sacrifie des bovidés à trois divinités précises et selon un ordre d'importance. Après Zeus Kènaios auquel est voué le promontoire (voir infra p. 86-87) et Poséidon, Athéna vient en troisième position avec une offrande moindre, une génisse. Il convient de comprendre pourquoi

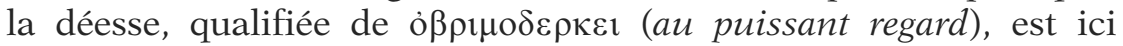

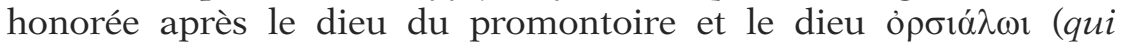
soulève la mer). Sans doute, Athéna en tant que protectrice constante d'Héraclès n'est pas omise par celui-ci dans ses actes de

$\Sigma \alpha \lambda \mu \omega ́ v \eta », R E$ I A, 2, Stuttgart, 1920, col. 1986-1989. F. Vian, in Apollonios de Rhodes, éd. Budé, t. III p. 66, rapproche cette brève mention du sanctuaire du cap Salmônis avec un cratère de Ruvo qui montre Athéna couronnant les Dioscures vainqueurs de Talos.

${ }^{16}$ La tradition la plus complète est donnée par le poème de Bachylide, Dithyrambe III; voir aussi la célèbre coupe d'Euphronios du Musée du Louvre, inv. G104, daté d'environ 500 a.C. 
dévotion. Cependant il est intéressant de noter la référence à Athéna dans un tel contexte de religion à forte connotation maritime.

La déesse intervient encore dans un tel domaine au travers d'une version classique du mythe d'Iphigénie. Euripide, dans sa tragédie consacrée aux retrouvailles par Oreste de sa sœur sauvée par Artémis du sacrifice paternel, fait intervenir Athéna alors que tout semble perdu pour nos héros. Celle-ci persuade le roi de la Tauride, Thoas, de les laisser partir tandis qu'elle-même assure la bonne traversée du bateau qui les ramène à Athènes (Iphigénie en Tauride, v. 1486-1489) : non seulement la déesse commande aux vents de favoriser la course du vaisseau, mais de surcroit elle l'accompagne ( $\sigma \nu \mu \pi \circ \rho \varepsilon v ́ \sigma \varepsilon \tau \alpha \imath)$ afin de veiller sur la statue d'Artémis qu'emmène Iphigénie. Ainsi, Athéna favorise de manière générale le voyage des frère et sœur par voie de mer, depuis le départ en éliminant les obstacles possibles et durant la traversée par l'assurance d'un vent propice et d'une protection constante.

Les sources littéraires montrent l'existence de liens privilégiés entre Athéna et la mer de façon continue depuis Homère jusqu'à l'époque romaine. Cette relation remonte à l'Odyssée qui la fait intervenir dans un épisode en marge de l'aventure d'Ulysse. Les autres interventions de la déesse dans l'univers homérique sont dues à des poètes tardifs qui doivent s'inspirer pour une part de traditions déjà existantes. Le caractère maritime d'Athéna s'affirme essentiellement à travers l'épopée hellénistique des Argonautes, mais s'affaiblit dans les versions plus tardives du mythe. L'époque classique évoque de façon sporadique une aide d'Athéna envers des héros au cours de leurs voyages maritimes, élargissant le cercle jusqu'ici réduit de ses bénéficiaires.

\section{Témoignages cultuels}

À ces rôles mythiques répondent un certain nombre d'attestations cultuelles. Celles-ci concernent l'Attique, comme l'on peut s'y attendre, mais également l'ensemble du monde grec ${ }^{17}$ (voir cartes 1 et 12 ).

${ }^{17}$ Deux cas ne sont pas traités ici, mais à propos d'Artémis à laquelle ils sont plutôt rattachables : le témoignage d'Hérodote (Enquête III, 59) évoquant le sanctuaire de la déesse à Égine alors qu'il s'agit plutôt du grand hiéron d'Aphaia, ainsi que le temple du port d'Eniadae en Acarnanie pour lequel nous n'avons aucune source écrite (voir infra, p. 196-198 et 203-204). 
a) Attique

\section{- Athènes}

Plusieurs témoignages littéraires nous indiquent de façon indirecte qu'Athéna, souveraine d'Athènes, était invoquée aussi pour des problèmes maritimes. Le texte le plus ancien à ce propos, du VI ${ }^{\mathrm{e}} \mathrm{s}$. a.C., est extrait d'une fable d'Ésope intitulée Le naufragé (Fable LIII). Celle-ci met en scène un Athénien, en bien mauvaise posture, invoquant désespérément l'aide d'Athéna en échange d'offrandes variées. Certes, en tant que divinité poliade, elle est la divinité priée de façon prioritaire par les habitants d'Athènes, cependant il est bon de noter qu'à l'époque archaïque elle est sollicitée également lors de dangers encourus en mer $^{18}$. Plusieurs siècles plus tard, au II ${ }^{\text {e }}$ s. p.C., un autre texte ironique nous donne un renseignement du même type. Dans un dialogue satirique, Lucien (Piscator 47) place ses personnages sur l'Acropole d'Athènes, plus précisément dans le sanctuaire d'Athéna Poliade (ibid. 21), et leur fait emprunter à la prêtresse des lieux des ex-voto qui s'y trouvent. Or, les objets en question se trouvent consti-

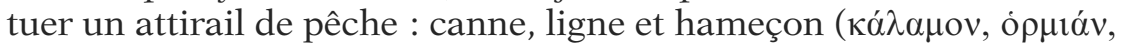

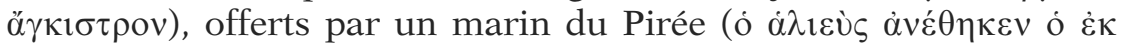

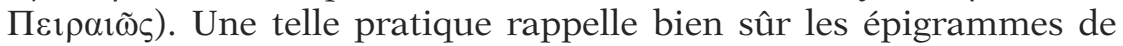
l'Anthologie Palatine, qui s'adressent à Hermès (voir infra p. 237) et à $\operatorname{Pan}^{19}$. En tous cas, cette fantaisie de Lucien nous atteste qu'à une date certes avancée, des populations du Pirée vouées à la pêche dédiaient, sur l'Acropole et dans des bâtiments consacrés à Athéna, leurs outils de travail.

Cette présence d'ex-voto à caractère maritime à l'intérieur du sanctuaire de la déesse sur le rocher sacré est confirmée par au moins une trouvaille archéologique. À l'intérieur de l'Érechthéion, fut découverte une lampe de bronze en forme de bateau explicitement dédiée à Athéna: elle porte l'inscription IEPON TH $\mathrm{A} \Theta \mathrm{HNA} \mathrm{\Sigma}$. Ce témoignage, en revanche, porte sur une époque antérieure à celle de Lucien puisque l'objet est daté au plus tard des $\mathrm{IV}^{\mathrm{e}}$-IIII ${ }^{\mathrm{e}} \mathrm{s}$. D'autres représentations de bateaux retrouvés sur l'Acropole sont peut-être de la même manière à mettre en relation avec le culte d'Athéna: tout d'abord le relief dit Lenormant (voir infra p. 395 ss.), objet de nombreuses études d'architecture navale, qui représente un bateau vu de profil propulsé par des rameurs, ainsi qu'un autre fragment sculpté d'une trière (voir infra p. 396). Tous

${ }^{18}$ Wachsmuth 1967, p. 477.

${ }^{19}$ Mazaubert 1937. 
deux sont datés de l'époque classique ${ }^{20}$. De manière toujours hypothétique, une statuette de bronze représentant un jeune homme sur un dauphin est à joindre aux documents précédents. Il a été trouvé à l'est du Parthénon, avec du matériel archaïque; l'œuvre est datée du début $\mathrm{du} \mathrm{V}^{\mathrm{e}} \mathrm{s} .^{21}$

Les fêtes athéniennes ${ }^{22}$ vouées à Athéna présentent plusieurs liens avec la mer. Lors des Panathénées au mois d'Hekatombaion, la procession qui conduisait le péplos à la déesse sur l'Acropole comprenait un char d'un type tout à fait particulier : un bateau monté sur roues (voir infra p. 437 ss.). Pausanias (I, xxix, 1) nous en mentionne un lors de sa description de l'Aréopage et des ses alen-

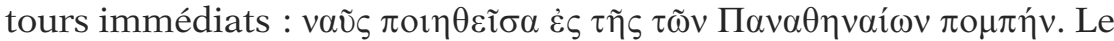
fait est principalement connu par Flavius Philostrate (Vie des Sophistes II, 1, $550=$ voir corpus p. 536) et par Himerius (Orationes XLVII, 12-16 = voir corpus p. 537-538) qui évoque la déesse admirant le spectacle, ainsi que par d'autres brèves mentions et un basrelief. Les festivités des Panathénées comportent par ailleurs des courses de bateaux qui ont lieu au Pirée. Elles sont supposées se dérouler entre le grand port et Mounichie ${ }^{23}$.

Une autre fête, celle des Plyntéria, verrait le xoanon d'Athéna Polias transporté jusqu'au Phalère et plongé dans la mer ${ }^{24}$. Cette cérémonie se déroule au mois de Thargélion durant une journée, à la fin du printemps ${ }^{25}$. Deux sources littéraires la mentionnent, en inv. 1339

${ }^{20}$ Musée archéologique national d'Athènes, inv. 7038; Musée de l'Acropole,

${ }^{21}$ Delivorrias 1987, p. $184 \mathrm{n}^{\circ}$ 85; Harrison 1888; Ridder 1896, p. 278-280 $\mathrm{n}^{\circ}$ 755. Le type s'apparente à celui de Taras, d'Arion ou de Mélicerte; pour cette raison peut-être est-il davantage attribuable à Poséidon qu'à Athéna.

${ }^{22}$ Pour ces fêtes et leur calendrier, voir le synthétique appendice de Parker 2005, p. 456-487.

${ }_{23}^{23}$ Garland 1987, p. 103-104; Gardner 1881, p. 93; Parke 1977, p. 37. Ainsi des inscriptions attestent, pour le $\mathrm{I}^{\mathrm{er}} \mathrm{s}$. a.C. et le $\mathrm{I}^{\mathrm{er}}$ p.C., l'existence d'équipages rhodiens ayant participé à ces festivités et y ayant remporté des victoires : Blinkenberg 1938, p. 49-50. S'il est raisonnable de penser, comme M. Romero Recio (Romero Recio 2000, p. 144 et id. 2010, p. 106-110), que ces régates confirment le lien des Panathénées avec la mer, il semble tout à fait excessif d'y associer la procession aux flambeaux qui «en passant par le Céramique pouvaient rappeler aux aristoi qu'ils s'étaient fait enterrer dans des tombes marquées par des grands vases décorés avec les bateaux dans lesquels ils avaient développé leur activité de piraterie avec l'aide d'Athéna» (id. 2010, loc. cit.).

${ }^{24}$ Jost 1985, p. 119; Kahil 1994, p. 217-223; Parke 1977, p. 152-155; Ginouvès

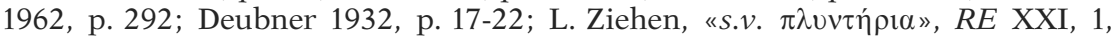
Stuttgart, 1951, col. 1060-1065.

${ }^{25}$ Sur les problèmes de date et de situation par rapport à la fête de Kallynteria, voir Deuner, 1932, p. 17-18 qui discute le témoignage de Photius, s.v.

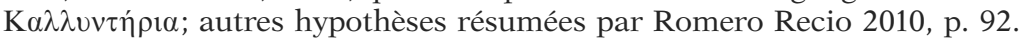


évoquant un déshabillage de la statue et sa couverture par un simple voile ${ }^{26}$. Par ailleurs, deux inscriptions indiquent que celle-ci était conduite au Phalère jusqu'à la mer puis ramenée à Athènes semblet-il, mais on ne nous précise pas à l'occasion de quelle cérémonie ${ }^{27}$. En réalité, aucune source n'évoque explicitement de bain de la statue pour les Plyntéries: les commentateurs ont rapproché ce nom d'un commentaire de Photius sur des jeunes filles appelées $\lambda$ ov $\rho^{\prime} \delta \varepsilon \varepsilon^{28}$. Or, même si la désignation de celles-ci évoque le bain, rien ne permet non plus de mettre ces loutrides en rapport avec cette fête d'Athéna. Les Plyntéria sont attestées durant les époques classiques et hellénistiques, mais on ne peut assurer avec certitude l'existence, durant son déroulement, d'un bain de la statue dans la mer $^{29}$. Le rituel du bain, s'il a existé, joue sans conteste un rôle purificateur et régénérateur envers la personnalité magique incarnée dans la statue ${ }^{30}$. Pour toutes ces raisons, il n'est pas possible d'intégrer les Plyntéria parmi les actes religieux voués à Athéna liés à la mer ou à la navigation ${ }^{31}$. Notons simplement que le fait que la déesse se rende une fois l'an au bord de la mer - à quelque occasion que ce

${ }^{26}$ Xénophon, Helléniques I, 4, 12; Plutarque, Alcibiade 34, 1 qui tous deux font mentionnent ce rite à propos d'Alcibiade : son retour à Athènes coïncidant avec la célébration de cette fête, les Athéniens y virent un mauvais présage puisque la déesse se couvrait d'un voile pour ne pas le regarder (Xénophon : toṽ

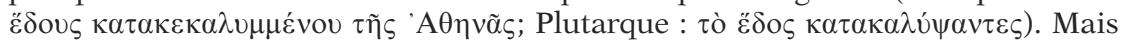
il n'est fait aucune allusion à un bain ni à un déplacement au Phalère.

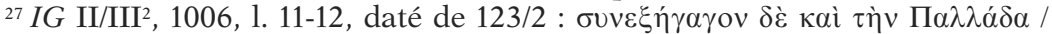

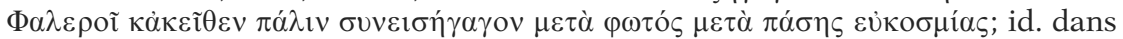
$I G \mathrm{II} / \mathrm{III}^{2}, 1008,1.9-10$ daté de 119/8. Ces deux textes énumèrent alors des actes religieux effectués par des éphèbes. En faveur du bain de mer est aussi invoquée une source tardive (Philochoros F64ß, éd. Costa) sur des nomophylakes (s.v. oi

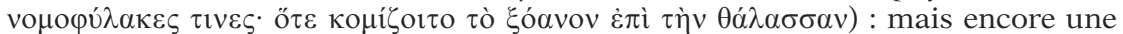
fois rien ne permet d'affirmer que ceux-ci intervenaient lors des Plyntéria et présentaient un lien avec les éphèbes des inscriptions. Nagy 1991 a ainsi proposé de voir dans la procession des éphèbes l'un des rites mémoriels des guerres Médiques, ayant lieu en dehors des Plyntéries et évoquant le retour de la statue d'Athéna dans sa ville; mais l'auteur n'évoque aucun bain.

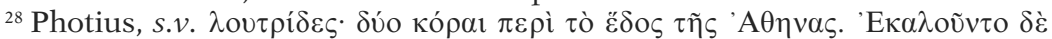

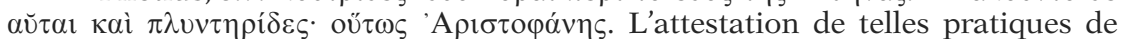
bains de statues d'Héra, Artémis ou même d'Athéna a également joué dans la démonstration. Les lexicographes byzantins ne disent rien de précis : Harpokra-

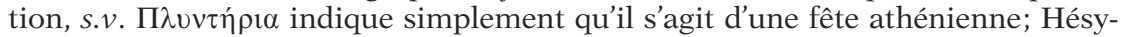

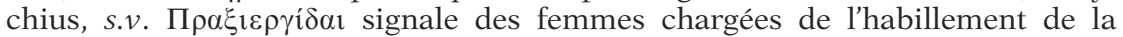
déesse. Brulé 1987, p. 110-113, qui met les Plyntéries en parallèle avec une fête romaine, conclut qu'un bain constitue bien le rite essentiel de la cérémonie mais place celui-ci à Athènes sur l'Acropole, en aucun cas à la mer.

${ }^{29}$ Seul Duchêne 1992 émet des doutes quant à la restitution de ce bain.

${ }^{30}$ Kahil 1994 met ce bain d'Athéna attique en parallèle avec celui d'Argos chanté par Callimaque, Pour le bain de Callas, qui avait lieu au bord de l'Inopos.

${ }^{31}$ Contra : Romero Recio 2000, p. 143-144 et id. 2010, p. $92-95$ et 110 qui voit 
soit - ne rendait pas impossible par ailleurs un quelconque caractère ou culte maritime d'Athéna : celle-ci ne restait pas confinée à l'intérieur d'Athènes.

- Pirée

$\mathrm{Au} \mathrm{IV}^{\mathrm{e}}$ s. a.C., un discours d'accusation (Lycurgue, Contre Léocrate, 17) nous informe de l'existence au Pirée d'un temple commun de Zeus et d'Athéna portant la même épiclèse Sôter et Sôteira ${ }^{32}$. La scène se passe en 338, au lendemain de la bataille de Chéronée; un Athénien quitte la cité de nuit au moyen d'un navire qui l'attend mouillant au large du port. Le fuyard aperçoit depuis son embarcation l'Acropole et ce hiéron du port. La mention de ces deux sites n'est pas anodine : l'Acropole symbolise la cité-mère que Léocrate déserte, tandis que le temple de Zeus Sôter et d'Athéna Sôteira est sans doute réellement le plus visible depuis le large et le plus significatif pour les voyageurs par mer, qui lui adressent leurs espoirs de bonne traversée. Le sanctuaire - attribué à Athéna et à Zeus sans épiclèse - est situé par Pausanias (I, i, 3) près du port du Kantharos ${ }^{33}$; il se trouvait sans doute au nord-est de celui-ci, mais il n'a pu être encore localisé précisément ${ }^{34}$.

Un autre épisode de départ en bateau pourrait se rattacher à ce culte du Pirée. Le texte épigraphique connu sous l'appellation de pseudo-décret de Thémistocle ${ }^{35}$ comporte un paragraphe concernant des obligations religieuses à remplir avant de prendre la mer. Il convient de sacrifier à Zeus, Athéna, Niké et Poséidon ${ }^{36}$. Les déci-

dans les Plyntéries, comprenant le bain rituel au Phalère, une fête très ancienne qui pouvait «rénover les pouvoirs d'Athéna sur la mer».

${ }^{32}$ Le temple est à nouveau signalé dans le même discours (§ 136-137), mais avec la seule mention de Zeus Sôter, à propos d'un vol de statue.

${ }^{33}$ D'autres sources très disparates complètent notre connaissance : TiteLive XXXI, 30, 9 ne fait que mentionner un sanctuaire aux deux divinités Zeus et Athéna (sans épiclèse) au Pirée. Pline, H.N. XXXIV, 74 complète le commentaire artistique de Pausanias en attribuant l'une des deux statues de culte au sculpteur Céphisodote du IV e s. a.C. Strabon (IX, 1, 15) y signale des portiques avec œuvres d'art. Enfin l'inscription $I G \mathrm{II} / \mathrm{III}^{2}, 5063$ nous informe que le prêtre commun aux deux divinités était honoré d'un siège au théâtre de Dionysos. Deux inscriptions signalent le culte commun des deux divinités au Pirée : $I G \mathrm{II} / \mathrm{III}^{2}$, 783; $I G \mathrm{II} / \mathrm{III}^{2}$, 1035. Sur la statue d'Athéna, Imhoof-Blumer \& Gardner 1964, p. lii-liii.

${ }^{34}$ Certains le situent près de l'actuelle église d'Haghia Triada; de façon plus large, vraisemblablement près de la colline qui domine à l'ouest le port de Munychie : cf. Baladié in Strabon IX, éd. Budé, p. 193; Garland 1987, p. 152.

35 Jameson 196; SEG XVIII, 1962, no 153 (nouvelle lecture); Morrison \& Williams 1968, p. 122-127.

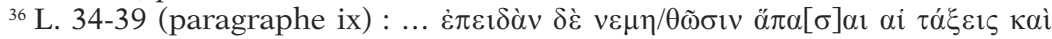

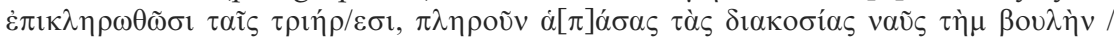


sions concernent la flotte athénienne quelques jours avant l'arrivée des Perses en Attique en 480, même si l'inscription est plus tardive au moins d'un siècle et demi ${ }^{37}$. L'ordre dans lequel sont énoncées les divinités à honorer pourrait suggérer que la flotte adressait ses dévotions à Zeus Sôter et Athéna Sôteira dont le sanctuaire se trouvait tout proche. L'urgence de la situation et la localisation des forces navales, ainsi que le moment choisi pour accomplir le sacrifice alors que les équipages ont embarqué, tout cela laisse soupçonner un culte rendu aux deux divinités du port. La scène dut être similaire à celle narrée par Thucydide pour le départ de la flotte de l'expédition de Sicile (La guerre du Péloponnèse VI, 32, 1-2).

Le caractère marin du culte commun est indéniable. Des régates avaient lieu en l'honneur des deux divinités lors des fêtes de Diisôteria au mois de Skirophoriôn ${ }^{38}$. Le fait n'est pas attesté avant 122/1; il semblerait que ces épreuves ne vinrent s'adjoindre que tardivement aux fêtes dont le succès et la richesse étaient vantés ${ }^{39}$. Le trajet de la course nautique partait du Kantharos pour atteindre Mounichie $^{40}$. Il n'est pas sûr en revanche que tout bateau accostant au port devait acquitter la taxe d'une drachme au sanctuaire ${ }^{41}$.

Ce dernier paraît le plus important du Pirée ${ }^{42}$, mais aussi un des plus anciens peut-être contemporain de la fondation du port ${ }^{43}$. Les

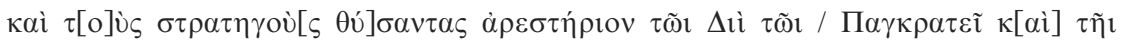

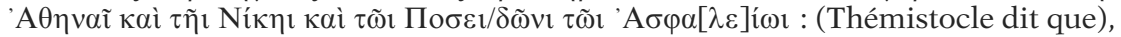
quand toutes les troupes auront été réparties et assignées dans les trières, la Boulè remplisse tous les 200 bateaux et les stratèges accomplissent un sacrifice propitiatoire à Zeus Tout-puissant, à Athéna, à Nikè et à Poséidon Asphaleios.

${ }^{37}$ Selon les épigraphistes, la datation oscille entre 330-322, 280 ou 250; mais tous considèrent que le texte constitue une réécriture «littéraire» d'un décret archaïque : Morrison \& Williams 1968, p. 122-127.

${ }^{38}$ Sur ces fêtes, voir Deubner 1932, p. 174-176; Farnell 1896, I p. 47; résumé dans Romero Recio 2000, p. 149; Parker 2005, p. 466-467. La date de celles-ci correspond aux derniers jours de l'année du calendrier attique.

${ }^{39}$ Garland 1987, p. 138.

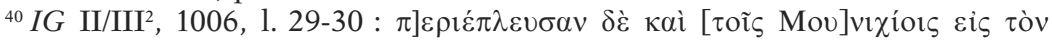

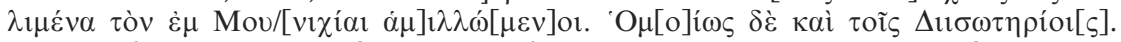
Pour Parke 1977, p. 139, les régates n'ont rien à voir avec un éventuel caractère marin des dieux, mais correspondraient à une période de l'année favorable aux exercices sportifs de ce genre...

${ }^{41}$ Vélissaropoulos 1980, p. 229 l'affirme catégoriquement; id. dans Garland 1987, p. 137. Or le texte de l'inscription auquel ils renvoient $\left(I G \mathrm{I}^{2}, 128\right.$, décret daté de 428/7) n'est pas assuré : il s'agit d'une restitution proposée par R. Schlaifer (voir SEG XXI, 37, commentaire de la p. 30).

${ }^{42}$ Garland 1987, p. 104; voir notamment allusions d'Aristophane, Ploutos, v. 1174 ss.

${ }^{43}$ Certains chercheurs (notamment Parke 1977, p. 168) supposent plutôt la fondation du temple et du culte liée à la victoire de la Seconde Guerre médique et à la récupération du port par les Athéniens; si l'hypothèse concernant le pseudo- 
sources témoignent d'un culte dès les Guerres médiques, particulièrement actif au $\mathrm{IV}^{\mathrm{e}} \mathrm{s}$. - époque à laquelle des travaux importants ont été réalisés - et qui s'est poursuivi jusqu'à l'époque romaine $^{44}$. Si la personnalité de Zeus y est à peu près discernable (voir infra p. 86 et 103-104), les informations sur celle d'Athéna font défaut. Elle semble jouer un rôle mineur dans cette association cultuelle, mais est néanmoins liée à la navigation et au départ de la flotte de guerre athénienne.

\section{- Sounion}

Le sanctuaire d'Athéna à Sounion fut longtemps confondu avec celui de Poséidon à cause de la méprise de Pausanias (I, i, 1). Le Périégète, qui arrive en Attique par bateau, navigue devant le cap Sounion où on lui montre un mouillage et un temple qui surplombe

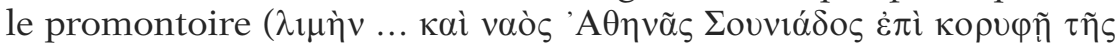

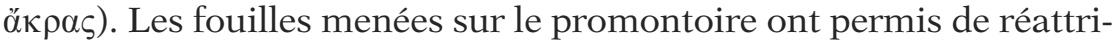
buer le temple du sommet encore visible à Poséidon ${ }^{45}$, tandis que le sanctuaire d'Athéna fut découvert en contrebas du précédent, au nord-est en dehors de la forteresse du Sounion. Bien qu'erroné, le témoignage de Pausanias transmet le souvenir d'un hiéron voué à Athéna à l'extrémité de l'Attique.

De façon générale, les sources littéraires à mentionner le sanctuaire d'Athéna à Sounion sont rares contrairement à celui, plus important il est vrai, de Poséidon (voir infra p. 176-178). L'Odyssée

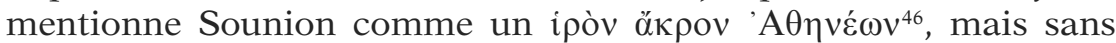
l'attribuer à une divinité particulière. Outre Pausanias, Euripide est le seul à y faire allusion, dans un passage concernant d'ailleurs le culte de l'Ébranleur du sol (Cyclope, v. 290-295): dans cette comédie, Ulysse, prisonnier du géant fils de Poséidon l'implore de lui laisser la vie sauve en arguant du fait que les Achéens ont préservé les temples consacrés à son père. Parmi ceux-ci, Ulysse cite Sounion en le précisant dédié à la divine Athéna; cette mention englobe de façon raccourcie les mines d'argent du Laurion, précisant ainsi de façon implicite qu'Athéna est la divinité maîtresse de toute l'Attique ${ }^{47}$.

décret de Thémistocle se vérifiait, cette datation ne serait plus envisageable et serait à reculer jusqu'à celle de la création du port.

${ }^{44} I G \mathrm{II} / \mathrm{III}^{2}$, 1669; Garland 1987, p. 137-138 avec références.

${ }^{45}$ Les inscriptions trouvées in situ $\left(I G \mathrm{I}^{2} 310\right.$, 324; II/III $\left.{ }^{2} 1270,1300\right)$ ont confirmé les mentions d'Aristophane (Oiseaux, v. 868; Cavaliers, v. 559) qui attribuaient ce temple au dieu au trident.

${ }^{46}$ Odyssée III, v. 278.

${ }^{47}$ Sinn 1992, p. 177-178 utilise cette source pour étayer sa thèse d'un culte commun à Poséidon et Athéna au sanctuaire de l'extrémité du promontoire. 
Le sanctuaire de Sounias a fait l'objet de fouilles et ses vestiges sont encore aujourd'hui visibles sur une butte ${ }^{48}$ (fig. 1 et 8 ).

$\mathrm{Au}$ sud de celui-ci un dépôt a livré des offrandes des $\mathrm{IX}^{\mathrm{e}}$ et $\mathrm{VIII}^{\mathrm{e}}$ s., ce qui semble montrer que cette partie du promontoire avait vocation cultuelle depuis une date antérieure à celle du sanctuaire de Poséidon. Le téménos est délimité par un mur d'enceinte à peu près rectangulaire, sans doute très ancien. Au nord, un autre mur circulaire est supposé avoir abrité un culte également ancien car l'aire qu'il délimite est dépourvue de construction $^{49}$. L'historique du sanctuaire, établi lors des fouilles
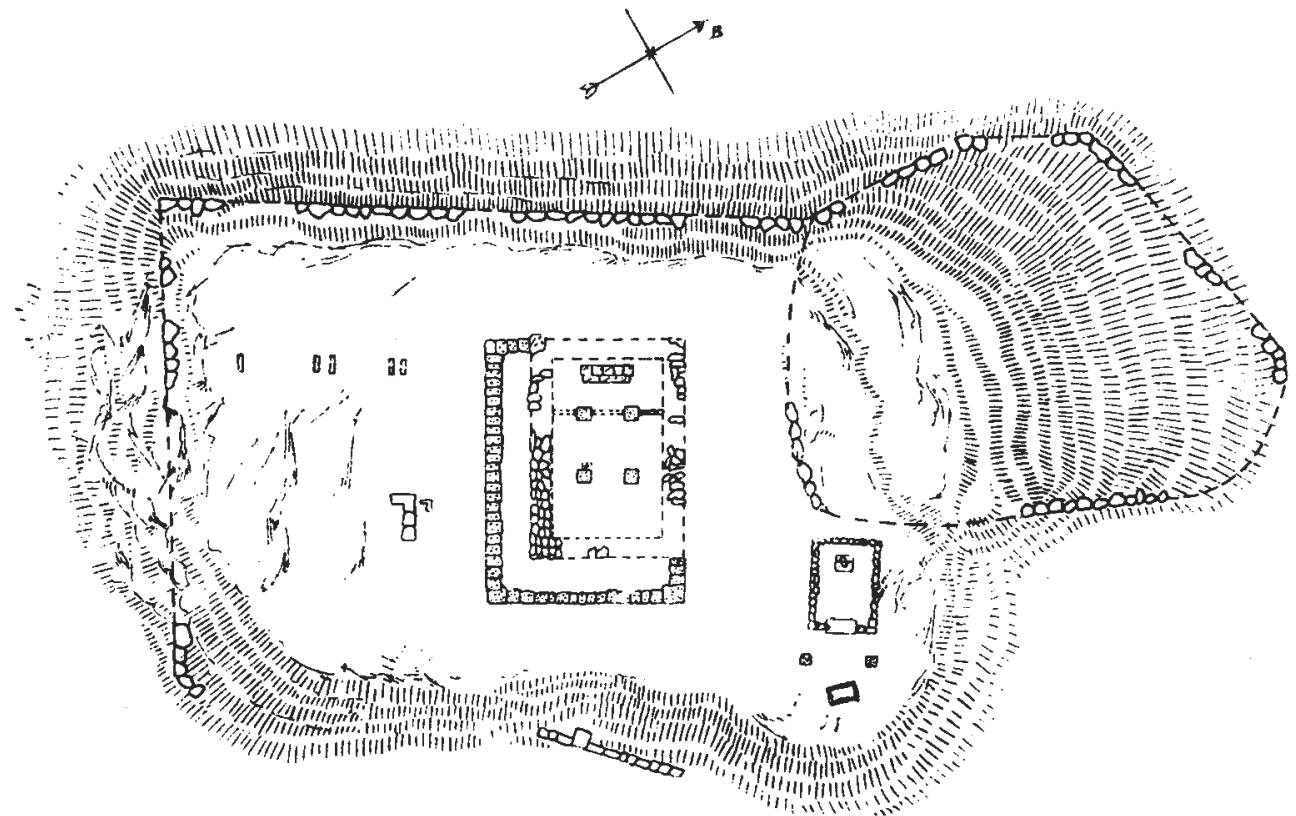

8

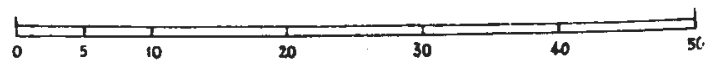

Fig. 1 - Temple Athéna à Sounion (d'après Davaras 1979, fig. 23).

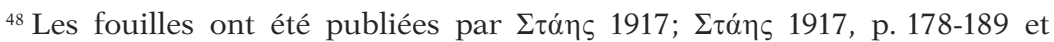
p. 201-213. Voir également Davaras 1979; Thémélis 1974. Pour des ouvrages généraux concernant Sounion, voir chapitre "Poséidon».

${ }^{49}$ Certains l'ont interprété comme la tombe du pilote de Ménélas, Phrontis, dont les funérailles sont décrites dans Odyssée III, v. 278 ss. Sur l'hérôon de 
du début du siècle, a été récemment remis en cause. Il convient de considérer les deux chronologies.

L'interprétation "traditionnelle» du site considère qu'un premier temple a été érigé dès le $\mathrm{VI}^{\mathrm{e}} \mathrm{s}$. a.C., c'est-à-dire à une période antérieure à celle du sanctuaire de Poséidon. Il est constitué d'un simple naos de dimensions modestes - environ $5 \mathrm{~m} \times 6,8 \mathrm{~m}$ d'où sa désignation sous le nom de petit temple contenant une base de statue, devant lequel se trouve un autel. Il aurait été détruit par les Perses lors de l'invasion de l'Attique, ce qui aurait entraîné la construction rapide du second temple. Celui-ci fut placé au sud du premier suivant la même orientation. Plusieurs publications plus récentes contestent cette chronologie, mais sans l'étayer d'une argumentation. Selon elles, le petit et le grand temple seraient contemporains, tous deux datés de la seconde moitié du Ve s. a.C. ${ }^{50}$ Sans preuves à l'appui, il est difficile de prendre en considération cette nouvelle interprétation du site; quoiqu'il en soit le matériel archéologique atteste un culte important à l'époque archaïque.

Le grand temple présente un plan particulier que décrit par ailleurs Vitruve (De l'architecture IV, 8, 4). Le Palladis Minervae aedes était entouré d'une colonnade sur le côté sud et la façade; dans le naos subsiste la base de la statue de culte ${ }^{51}$. Autre originalité : la position supposée de l'autel au sud ${ }^{52}$. Des socles d'offrandes ont été dégagés également dans la partie méridionale du sanctuaire. La question de la raison de cette organisation des structures ne semble jamais avoir été véritablement soulevée ${ }^{53}$. Vitruve évoque parmi les plans originaux similaires celui de l'Érechthéion. En ce lieu, c'est bien connu, des raisons topogra-

Phrontis, voir Picard 1940 et Abramson 1979, p. 1-19 qui estiment le petit temple du sanctuaire d'Athéna comme dédié au héros; Sinn 1992, p. 176-177 considère que tout le sanctuaire avec ses deux bâtiments lui est consacré : mais c'est contredire le matériel du site et l'appellation donnée par Vitruve au sanctuaire. Présentation confuse du culte de Phrontis par Detienne 1970 (lié à Athéna ou Poséidon?).

${ }^{50}$ C'est Dinsmoor 1971, p. 50-51 qui a affirmé cette nouvelle chronologie,

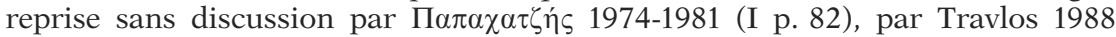
(p. 404-407 et fig. 528-535) et par Sinn 1992 (p. 176). W.B. Dinsmoor suppose alors l'existence d'un bâtiment plus ancien situé à l'emplacement du petit temple; N. $\Delta$. П $\alpha \pi \alpha \chi \alpha \tau \zeta$ ńৎ interprète ce petit temple comme consacré à Artémis.

${ }^{51}$ Sur ce plan, voir Gruben 1966, p. 209.

${ }^{52}$ Aucune trace d'autel n'a été repérée à l'est du temple; de ce fait, on le place au sud où sont encore visibles quelques blocs.

${ }^{53}$ Seul Dinsmoor 1971, p. 50 évoque une recherche d'économie (!) et le désir d'une stoa orientée vers le sud. 
phiques et religieuses expliquent le choix d'un tel plan, ce qui ne paraît pas être le cas de Sounion. Si l'on prend en compte l'orientation générale des structures d'Athéna Sounias, il nous semble qu'elle ne peut se comprendre que dans l'optique de visiteurs venant du sud, c'est-à-dire par voie maritime. Le temple est conçu pour des fidèles qui l'appréhendent depuis la mer. De fait, il reste des vestiges d'une rampe d'accès permettant de rejoindre le port de l'est, où se trouvaient des cales couvertes ${ }^{54}$. Par ailleurs les fouilles n'ont révélé aucune trace de propylées ou de quelconque entrée pour le sanctuaire ${ }^{55}$.

Parmi ce qui est considéré comme les débris du premier état du sanctuaire détruit par les Perses, a été découvert un fragment de tablette céramique représentant un bateau et son équipage; daté vers 700 a.C. (voir infra p. 401) ${ }^{56}$, il témoigne d'un culte maritime à cet endroit. Un certain nombre d'objets des niveaux archaïques sont d'origine étrangère - notamment des scarabées égyptiens de la XXVI ${ }^{\mathrm{e}}$ dynastie -, attestant la fréquentation du temple par des étrangers ou de voyageurs grecs en contact avec d'autres pays en particulier orientaux. Se trouvaient également parmi les offrandes des kouroi et reliefs de marbre ${ }^{57}$. Ainsi à l'époque archaïque, Athéna semble prédominante par rapport à Poséidon à Sounion, tant par la chronologie que pour le culte maritime (voir aussi infra p. 356 s.). Poséidon finit par s'imposer, comme si les rôles étaient inversés par rapport à la cité d'Athènes. Néanmoins, l'Athénaion continue à coexister avec le grand sanctuaire voisin jusqu'à l'époque hellénistique. Sous le règne de l'empereur Auguste, des blocs et des sculptures architectoniques sont transportées sur l'Agora athénienne ${ }^{58}$; lors du voyage de Pausanias au $\mathrm{II}^{\mathrm{e}} \mathrm{s}$. il ne devait pas rester grand vestige du hiéron.

En Attique, Athéna reçoit donc un culte maritime sur l'Acropole d'Athènes ainsi que dans les deux lieux majeurs de la navigation attique : sur le grand port du Pirée et au finistère sud du territoire ${ }^{59}$.

${ }^{54}$ Davaras 1979, p. 52. Voir la carte et la reconstitution de П $\alpha \alpha \alpha \chi \alpha \tau \zeta \dot{n} \varsigma 1974-$ 1981, I fig. 9 et 17 qui montrent bien la position et l'orientation du sanctuaire par rapport à la mer.

${ }^{55}$ Dinsmoor 1971, p. 39; l'entrée est supposée alors se trouver au nord du sanctuaire.

${ }^{56}$ Athènes, Musée National inv. 3588.

${ }^{57}$ On estime à cinq le nombre de ces kouroi. Le célèbre relief de «l'athlète se couronnant» conservé au Musée national d'Athènes provient de là.

${ }^{58}$ Travlos 1988, p. 404, avec références.

${ }^{59}$ Semple 1927, p. 368-369. 
b) Mégaride

En suivant le littoral à l'ouest, on la trouve ensuite à Mégare, où

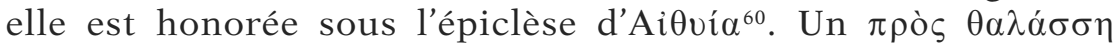
$\sigma \kappa о \pi \varepsilon ́ \lambda$ os lui est consacré d'après Pausanias (I, v, 3), où se trouve le tombeau de Pandion, roi de Mégare chassé de son trône. Le Périégète évoque à nouveau (en I, xli, 6) celui-ci brièvement, cette fois lors de son passage dans la ville, selon les mêmes termes. Le promontoire devait se trouver en dehors de la cité, car Pandion y possède un hérôon distinct de sa tombe. Un lexicographe tardif enrichit ces pauvres informations. Hésychius (s. $v . \dot{\varepsilon} v \delta^{\prime}$ A $\left.i^{\prime} \theta v i \alpha\right)$ rapporte une tradition selon laquelle ce culte mégarien serait dû à une métamorphose d'Athéna en oiseau de mer afin de protéger et emmener Kékrops dans la cité. L'épiclèse correspond au nom de cet

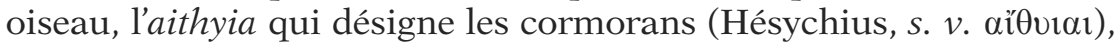
et ce dès les poèmes homériques ${ }^{61}$.

Les deux témoignages sont contradictoires dans le sens où ils ne se rattachent pas au même personnage, mais attestent tous deux une tradition selon laquelle la déesse, sous la forme d'un oiseau, le transporte peut-on supposer au-dessus des flots. Ce double lien héroïque tend à faire considérer le culte mégarien comme bien antérieur à Pausanias $^{62}$.

\section{c) Péloponnèse}

\section{- Achaïe}

Le littoral de l'Achaïe à l'est de Patras comporte selon Pausanias (VII, xxii, 10) un lieu-dit Teichos d'Athéna. Cet endroit est signalé au fil d'une description générale de la côte avec les distances d'un point à l'autre - promontoires ou ports -, ce qui ne laisse aucun doute sur son caractère maritime. Il se situe entre les ports de Panormos et d'Érinéos, vraisemblablement dans la partie de l'Achaïe qui s'avance le plus dans le golfe face au golfe de Naupacte, appelée cap Drépanon $^{63}$; peut-être faut-il y voir un espace qui marque la frontière entre le territoire des deux cités. Le nom de Teichos peut renvoyer alors à la présence d'une fortification à cet endroit stratégique, ou de ruines d'un bâtiment à vocation inconnue - religieuse,

${ }^{60}$ L'article de la R.E., «S.v. Aithyia» sous la plume de G. Wentzel (tome I', col. 1111) se réduit à 6 lignes et renvoie simplement aux sources; Wachsmuth 1967, note 1840; Glotz 1904, p. 43.

${ }^{61}$ Par exemple Odyssée XII, 418; XIV, 308. Sur l'identification de l'aithyia avec le cormoran, voir Detienne 1970, p. 139-140.

62 "Débris d'un mythe royal» pour ibidem.

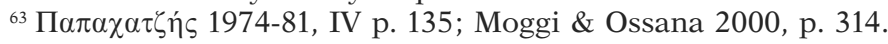


militaire ou privée. Quoi qu'il en soit, le Teichos et le sol sur lequel il repose sont consacrés à Athéna, en particulier pour les navigateurs du golfe de Corinthe.

\section{- Laconie}

En Laconie et en Messénie, les descriptions de Pausanias signalent le long de ces littoraux un certain nombre de marques de dévotions envers la déesse en relation avec la mer.

Tout d'abord entre les cités laconiennes d'Asopos et de Boiae, à deux cents stades de cette dernière, le Périégète (III, xxii, 10) mentionne l'existence, sur un promontoire appelé curieusement

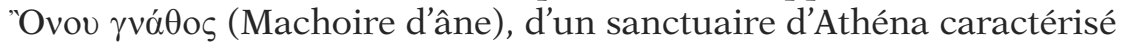
par son absence de toit et de statue cultuelle ${ }^{64}$. Son attribution à Ménélas témoigne de l'ancienneté de ce lieu de culte à ciel ouvert. La tradition situe par ailleurs sur ce cap le tombeau du pilote du héros achéen, Kinados. Le lien entre la divinité du promontoire et l'hérôon situé à proximité est ainsi justifié par la légende troyenne. Sur le promontoire qui devait marquer la limite entre le territoire des deux cités $^{65}$, le voyageur anglais Leake a cru reconnaître les restes du temple sur une butte, à $500 \mathrm{~m}$ de la ligne du rivage ${ }^{66}$.

Beaucoup plus au nord de la Laconie, non loin de la frontière avec l'Argolide, le petit promontoire de Brasiae - aujourd'hui Plaka - était marqué de quatre statues de bronze (Pausanias, III xxiv, 5) ${ }^{67}$. Trois d'entre elles portaient un pilos sur la tête, ce pourquoi Pausanias y reconnaît des Dioscures ou des Corybantes; la dernière est en revanche catégoriquement identifiée comme une Athéna. Il faut sans doute voir dans ce groupe les Cabires et la déesse, ce qui confirme la valeur maritime à accorder à ces sculptures ${ }^{68}$.

\section{- Messénie}

En Messénie, le visage maritime d'Athéna se précise. Sur la côte ouest du Péloponnèse, elle est appelée à Mothone sous l'épiclèse

${ }^{64}$ Wide 1893 , p. $51-52$ et $57-58$.

${ }^{65}$ Il séparait les deux golfes antiques; aujourd'hui, il est devenu île, nommée

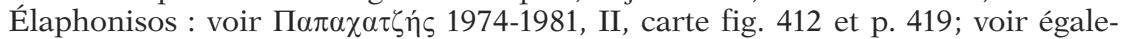
ment Baladié 1980, p. 245.

${ }^{66}$ Leake 1830, p. 508; Musti \& Torelli 1986-1991, III p. 270.

${ }^{67}$ Wide 1893 , p. 52 et $57-58$.

${ }^{68}$ Le chiffre trois correspond en effet aux Cabires : Hemberg 1950, p. 38 note 6 et p. 61 ss. Un groupe statuaire identique est mentionné par Pausanias (III, xxvi, 1) à Pephnos sur un îlot, mais cette fois sans Athéna. Musti \& Torelli 19861991, III p. 275, jugent les statues de Brasiae «difficilement antérieures à l'époque hellénistique». 
d'Anémôtis, selon une tradition attribuée à Diomède (Pausanias IV, xxxv, 8). Celui-ci, alors que la contrée était ravagée par des vents violents, invoqua la déesse qui ramena le calme ${ }^{69}$. En remerciement, le héros lui consacra une statue, déposée dans un temple (vaós) visité par Pausanias au $\mathrm{II}^{\mathrm{e}} \mathrm{s}$. L'agalma devait présenter un aspect ancien pour être ainsi daté de l'époque du héros fondateur de la cité $^{70}$; il figure par ailleurs peut-être sur des monnaies romaines ${ }^{71}$. Le culte d'Athéna Anémôtis est révélateur de la vocation maritime de la cité dont il ne reste aucun témoignage archéologique antique ${ }^{72}$.

Plus au nord, le promontoire Koryphasion de Pylos comporte un hiéron de la déesse, désignée de manière toponymique Kopvpacía (Pausanias IV, xxxvi, 2) ${ }^{73}$. Le Périégète ne fournit pas plus de détail, hormis la présence dans la même zone d'un sanctuaire de Nestor. L'endroit nous est plus connu sous les noms de Navarin et de Sphactérie; le cap en question se situe précisément au nord de cette dernière, à l'entrée de la baie ${ }^{74}$. Il correspond probablement à l'Acropole de la cité historique ${ }^{75}$. La statue de culte de la divinité poliade fait partie des types monétaires de la cité ${ }^{76}$.

Le Péloponnèse, principalement dans sa moitié sud, est ainsi marqué par la personnalité d'Athéna à qui sont consacrés plusieurs promontoires. Ce caractère maritime de la déesse semble remonter à une époque ancienne et est souvent mis en relation avec des héros troyens : Nestor, Diomède, Agamemnon et Kinados.

Si nous continuons l'enquête en mer Égée, quatre îles (1 des Sporades, 1 des Cyclades, 1 du Dodécanèse et la Crète) montrent également des liens entre Athéna et l'environnement maritime.

${ }^{69}$ Sandberg 1954, p. 23-24.

${ }^{70}$ Sur Diomène et Mothone, Pausanias IV, xxxv, 1.

${ }^{71}$ Imhoof-Blumer \& Gardner 1964, p. 68 et pl. P8 no 11-12. La représentation d'Athéna sur ces monnaies ne présente rien de particulier : la déesse casquée tient d'une main une lance et de l'autre semble faire une libation.

${ }^{72} \mathrm{La}$ ville est aujourd'hui connue pour ses vestiges vénitiens, qui témoignent de l'importance maritime qu'a gardée Mothone après l'Antiquité : voir les photos

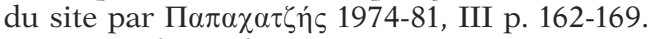

${ }^{73}$ Wachsmuth 1967, note 1840.

${ }^{74}$ À cet endroit s'élèvent aujourd'hui les ruines de Paléokastro (ou Paléo-

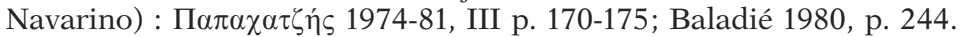

${ }^{75}$ Musti \& Torelli, 1986-1991, IV p. 270.

${ }^{76}$ Imhoof-Blumer \& Gardner 1964, p. 69 et pl. P15, GG24. La représentation d'Athéna s'apparente beaucoup à celle des monnaies de Mothone : la déesse casquée, une lance à la main, semble faire une libation. 
d) Îles de la mer Égée

- Skyros

Quelques vers de Stace (Achilléide I, v. 695-698), quoique figurant au sein d'une épopée héroïque, sont dignes d'attention. Ulysse, parti à la recherche d'Achille dans le but de l'entraîner dans la guerre de Troie, parvient à Skyros, près de la côte escarpée de l'île (se scopulosa levavit / Skyros); au moment d'accoster, l'auteur nous donne cette indication curieuse des sentiments religieux qui occupent l'esprit des voyageurs : magis indubitata magisque / Skyros erat placidique super Tritonia custos / litoris. Non seulement ces quelques mots indiquent la nature d'un pouvoir attribué à la déesse, celui de protéger un littoral et de lui assurer un aspect tranquille, mais encore l'adverbe super peut laisser supposer l'existence d'un temple de la déesse surplombant le rivage de l'île. La phrase suivante nous indique d'ailleurs qu'après leur débarquement les héros rendent grâce à Athéna, peut-être dans ce sanctuaire tout proche, comme on se doit de remercier les dieux après toute traversée réussie ${ }^{77}$. Même si le témoignage de Stace, daté de la fin du ${ }^{\text {er }} \mathbf{s}$. p.C., doit être considéré avec grande prudence en ce qui concerne Skyros - vu l'aspect imaginaire du genre littéraire et de l'itinéraire parcouru par Ulysse à la recherche d'Achille -, il doit néanmoins référer à des situations et pratiques similaires dans l'archipel égéen : un sanctuaire ou une statue d'Athéna surplombant une côte que l'on suppose alors placée sous la protection de la déesse.

- Délos

Athéna est peu présente dans le sanctuaire délien ${ }^{78}$. On la trouve cependant sur le Cynthe, où en tant que Kynthia elle est associée à Zeus. Les inventaires déliens mentionnent, pour ce sanctuaire du mont, au milieu du $\mathrm{II}^{\mathrm{e}}$ s. a.C., plusieurs tridents ${ }^{79}$. Sans doute ces petits objets témoignent-ils d'un culte commun de la part de simples pêcheurs.

Une deuxième source, hypothétique, peut renvoyer à une offrande plus monumentale à la déesse en relation avec le monde maritime. À l'intérieur du Néôrion de Délos, identifié avec le Monu-

${ }^{77}$ Sur le sacrifice après une traversée, voir Wachsmuth 1967, p. 115-126.

${ }^{78}$ Dans l'île, elle ne semble pas avoir eu de lieu de culte important; elle est souvent associée à d'autres divinités. Sa présence à Délos est attestée dès l'époque archaïque, sous plusieurs épiclèses : Bruneau 1970a, p. 248.

${ }^{79}$ Le Kynthion, réaménagé au III ${ }^{\text {e }}$ s. a.C. avec terrasse et oikoi servant aux banquets, faisait l'objet d'un règlement cultuel très strict (Bruneau \& Ducat 2005, p. 285-28 no 105). On a de là une vue splendide sur l'île et la mer qui l'entoure. 
ment des Taureaux (voir infra p. 359 s.), dans la partie nord appelée thalamos, se trouvaient déposés un certain nombre d'objets, inventoriés par les administrateurs du sanctuaire. Un compte daté de 166 a.C. ${ }^{80}$, malheureusement incomplet, mentionne la présence, dans ce local abritant un bateau en guise d'ex-voto, de deux statues de bronze d'Apollon, une de Poséidon et d'une troisième divinité : Athéna, affublée de deux Nikés de bronze. La suite du texte manque,

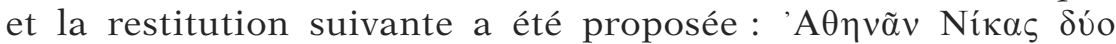

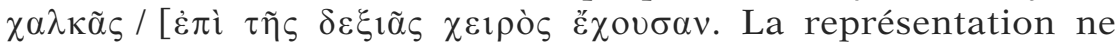
manque pas de surprendre, car on ne lui connaît aucun parallèle ${ }^{81}$. La déesse doit faire référence à la victoire navale, célébrée par ailleurs par le bateau et son écrin ${ }^{82}$.

Enfin signalons encore pour Délos des listes de pompostoles de Zeus Polieus Sôter et d'Athéna Polias Sôteira qui seraient à rattacher à un autel commun des deux divinités, identifié de manière très incertaine avec l'autel hellénistique situé à l'angle sud-est du Monument des Taureaux ${ }^{83}$. Cette association des deux divinités rappelle celle du Pirée (voir supra, p. 33 s.) et l'on serait tenté d'y reconnaître un culte maritime; mais ceci ne reste qu'une hypothèse.

\section{- Rhodes}

En revanche, que la divinité poliade lindienne ${ }^{84}$ présente un caractère maritime indéniable, diverses sources nous l'indiquent.

La position de son sanctuaire tout d'abord, qui surplombe la cité et la mer : le temple de la déesse, visible depuis le large, affirme la protection d'Athéna sur les eaux rhodiennes ${ }^{85}$. Par ailleurs, sa statue à Lindos, d'après le Pseudo-Apollodore (Bibliothèque II, i, 4) est à mettre directement en relation avec ses qualités nautiques. Le

${ }^{80}$ ID 1403; la dernière édition critique du texte est donnée par Roux 1989.

${ }^{81}$ Tréheux 1987, p. 176-177. Bruneau 1970a, p. 124, met en doute la validité de la restitution.

${ }^{82}$ L'interprétation proposée par Tréheux 1987, p. 176-177 et p. 183, selon laquelle la statue de Poséidon et celle d'Athéna portant deux Nikès renverraient à la célébration d'une double victoire, à la fois sur terre et sur mer, ne repose sur rien et n'est pas selon nous recevable. En fait, c'est un argument utilisé par l'auteur pour justifier son hypothèse d'attribution du Monument à Démétrios en commémoration de sa double victoire à Salamine de Chypre.

${ }^{83}$ Sur cet autel et les interprétations, voir Bruneau \& Ducat 2005, p. 191 et 193-194 (n 25); Bruneau 1970a, p. 233-238. Pour L. Basch, la présence de cet autel à proximité du Néôrion ne serait pas anodine : elle s'inscrirait dans un contexte religieux maritime (Basch 1995).

${ }^{84}$ Morelli 1959 , p. $80-89$, souligne son caractère très ancien, préhellénique. L'auteur ne s'attache pas à définir le caractère de la déesse, insistant plutôt sur l'histoire du sanctuaire et de son clergé.

${ }^{85}$ Semple 1927, p. 357. 
mythographe rapporte comment Danaos, entré en rivalité avec son frère Égyptos, fut le premier $(\pi \rho \tilde{\omega} \tau \sigma \varsigma)$, suivant les ordres d'Athéna ( $\dot{\pi} 0 \theta \varepsilon \mu \varepsilon \varepsilon^{\prime} \nu \varsigma^{\prime} A \theta \eta v \tilde{\alpha} \varsigma$ ), à construire un bateau et à prendre la mer. Lorsqu'il accosta à Rhodes, il remercia la déesse en lui élevant une statue. Cette offrande mythique suite à une navigation réussie est suivie d'autres attestations similaires. Dans la fameuse Chronique lindienne, Timachidas de Rhodes (Fgt $12=$ Chron. lind. B XII, 1. 73-77) recense, vers 100 a.C., parmi les ex-voto anciens du temple, des gouvernails voués à Athéna et Poséidon attribués au pilote de Ménélas, Kanopos (voir infra p. 411). Selon le même texte, un certain Amphinomos et ses fils de Sybaris ont dédié à la déesse une vache et veau en bois après le sauvetage de leur bateau (Chron. lind. C, XXVI, 1. 15-20), en guise de dîme; la même part d'un profit maritime crétois a également été consacré par Arétos et ses fils (ibid. B, XVI, 1. 101$108)^{86}$. Au milieu du $\mathrm{III}^{\mathrm{e}}$ s. a.C., la flotte de l'île consacre à la déesse lindienne une base en forme de proue de bateau sur l'agora de la ville suite à un succès naval (voir infra p. 386 s.). Parmi les petits objets, figurent également des coquillages et du corail (voir infra, p. 504).

L'importance maritime de la cité apparaît à travers le culte rendu à la divinité poliade ${ }^{87}$. La tradition s'attache à renforcer cette image d'une Athéna, protectrice de la navigation et tout particulièrement des bateaux. Il est à souligner à ce propos que les Argonautiques hellénistiques composées par un enfant de l'île accordent, on l'a vu, un rôle essentiel à Athéna dans le déroulement du périple. Son culte semble s'être diffusé également dans un contexte très maritime ${ }^{88}$.

\section{e) Crète}

Un itinéraire maritime anonyme tardif 89 (Stadiasmus, sive Periplus Maris Magni, 318) indique la présence, sur le promontoire le plus au nord de la Crète appelé Sa(1)mônion, l'existence d'un sanc-

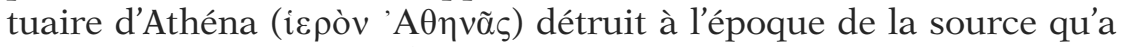
utilisée l'auteur du Périple. Seuls subsistent le mouillage et un point d'eau douce. Le site est dit se trouver à 300 stades de l'île Kasos,

${ }^{86}$ Principales éditions de la Chronique : Blinkenberg 1912; Higbie 2003.

${ }^{87}$ Wachsmuth 1967, p. 477.

${ }^{88}$ Bianchi, 1957, p. 10-24 signale notamment l'existence d'un hiéron d'Athéna Lindia à Potidaion dans l'île de Carpathos et d'un culte dans plusieurs colonies rhodiennes (à Géla et de là à Agrigente et Camarina; à Soloi en Cilicie).

${ }^{89}$ L'auteur de ce traité géographique est tardif, mais il a compilé des informations qui pour certaines s'avèrent antérieures à Strabon : Letronne 1829 considère la composition de l'ouvrage postérieure au IVe s. p.C.; Jacob 1990, p. 19, la date quant à lui du $\mathrm{III}^{\mathrm{e}}$ s. p.C. Medas 2008, pour qui l'œuvre est le plus ancien portulan connu digne de ce nom, la place à la moitié du $\mathrm{I}^{\mathrm{er}} \mathrm{s}$. p.C. et considère que ses sources sont de l'époque républicaine et du tout début de l'Empire. 
située au sud-ouest de Karpathos. Nous avons déjà évoqué ce sanctuaire pour la tradition qui le faisait remonter aux Argonautes (Apollonios de Rhodes, Argonautiques IV, v. 1691-1694 : voir supra p. 27). D'autres informations viennent compléter notre connaissance à son sujet $^{90}$.

Jusqu'à nos jours, la sainteté du lieu a été maintenue par une chapelle dédiée à saint Isidore. Deux inscriptions attestent également l'existence et la localisation de l'ancien culte : elles mentionnent le nom d'une Athéna Samônia ${ }^{91}$; cependant toutes deux ont été trouvées sur d'autres sites crétois. La première ${ }^{92}$, provenant de Sulia, est une dédicace de parents en faveur de leurs enfants à Athéna Samônia; elle est datée du II ${ }^{\text {e }}$ s. a.C. ${ }^{93}$ La seconde inscription ${ }^{94}$, datée de la même époque, était gravée sur un fragment de colonne aujourd'hui perdu de la cité de Hierapytna. Elle comporte une énumération de dieux invoqués, parmi lesquels figure encore une 'A $\theta \alpha v \alpha i ́ \alpha \Sigma \alpha \mu \omega v i ́ \alpha$.

Outre ces inscriptions, des graffiti ont été relevés sur les roches avoisinantes du site, de dates très variées semble-t-il ${ }^{95}$. L'un d'entre eux $^{96}$ montre dans la partie supérieure une main et en-dessous de celle-ci un phallus (?); au-dessous de ces dessins, figure une inscription boustrophedon comportant le nom d'Athéna. D'après les caractères, le texte serait daté de l'époque archaïque ${ }^{97}$. Les autres

${ }^{90}$ Cf. notamment A. Nawrath, «S.v. Salmonia», RE I A, 2, Stuttgart, 1920, col. 1990 : résumé un peu ancien à corriger; Willetts 1962, p. 281-282.

${ }^{91}$ Voir Guarducci 1942, p. 156-163. L'épigraphiste signale des vestiges d'un temple («peut-être du VI ${ }^{e}$ a.C.»), en l'occurrence des blocs de pierre, visibles sous l'eau. Didier Viviers, qui dirige les recherches sur le territoire d'Itanos, avoue très mal connaître le promontoire car il est classé zone militaire : lors de son unique visite, il n'a pas eu loisir de vérifier même si ces inscriptions étaient toujours visibles. Nous le remercions pour ces informations et son amicale visite de l'ensemble du site d'Itanos.

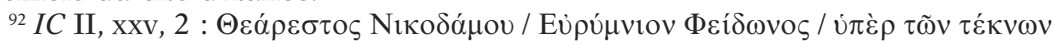

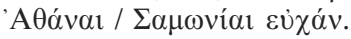

${ }^{93}$ Les commentateurs de l'inscription sont tous d'avis que la pierre a été transportée par mer depuis le promontoire de Salmonion jusqu'au littoral de Sulia : cf. Guarducci 1942, p. 280.

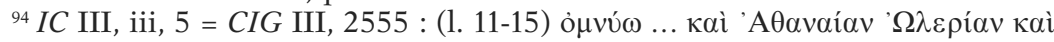

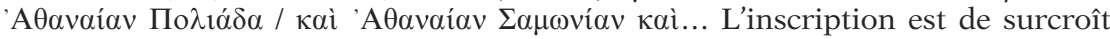
fragmentaire : il manque le début du texte.

${ }^{95}$ Willetts 1962, p. 281-282, les place cependant sous l'Empire à une date tardive. Certes, beaucoup sont de cette époque, mais ce n'est pas le cas de tous.

${ }^{96}$ IC III, vii, 3.

${ }^{97}$ Les dessins n'ont peut-être rien à voir avec l'inscription : ils ont pu être gravés plus tard. Le commentaire des IC III, p. 162 est très pauvre et propose des restitutions plus que douteuses. Le texte est très lacunaire, et la disposition boustrophedon lue de bas et haut paraît surprenante. La forme du $\mathrm{H}$ semble indiquer une origine non crétoise de l'auteur de l'inscription. Voir les quelques remarques de Jeffery 1990, p. 310-311. 
graffiti relevés dans cette zone présentent un dauphin, des pieds ou encore un bateau ${ }^{98}$ : dessins renvoyant peut-être au souhait de bon voyage, d' $\varepsilon{ }^{\prime} \pi \lambda{ }^{\circ} \alpha^{99}$. Même si les inscriptions ne s'adressent pas directement à Athéna Samônia ${ }^{100}$, elles témoignent en tous cas du caractère profondément maritime de la zone où se situe le sanctuaire de la déesse. L'ensemble des informations renvoie l'image d'un culte ancien, sur un finistère connu des navigateurs, qui connaît une vie religieuse perdurant durant toute l'Antiquité et même bien au-delà. L'attestation du nom de la déesse en dehors de cette extrémité nord-est montre que ce culte était reconnu dans toute la Crète.

\section{f) Ionie}

En Ionie, Athéna reçoit un culte lié à la navigation à Cyzique ${ }^{101}$. Les Argonautes y auraient laissé des traces de leur navigation. Ainsi, peu après leur départ, lors de leur arrivée à cet endroit, les voyageurs changent d'ancre de pierre (Ev่vaíns ò $\lambda i$ íov $\lambda i \dot{\theta}$ ov) pour une autre mieux adaptée à leur bateau. La pierre abandonnée est plus tard consacrée par les Grecs de la région, suivant un oracle d'Apollon, dans un temple dédiée à la déesse, alors appelée Jasonienne (Argonautiques I, v. 953-960; voir infra p. 460). L'indication est d'importance, car elle signifie qu'à l'époque d'Apollonios (III ${ }^{\mathrm{e}}$ s. a.C.) est connu un sanctuaire consacré à Athéna à Cyzique, dans lequel on montre des objets remontant selon la tradition aux Argonautes et renvoyant à son rôle d'auxiliaire de la navigation. Un résumé de la fin

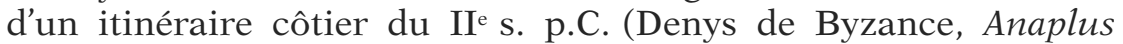
Bospori 87) nous apprend de surcroît que le lieu où l'on supposait que l'ancre avait été abandonnée était identifié avec un promontoire, portant le nom de circonstance Ancyreum. Le caractère maritime de la déesse dans cette zone est clairement défini par ses habitants qui

${ }^{98}$ IC III, vii, 2 : dauphin; IC III, vii, 4, 18-19, 22 (?) : pieds; IC III, vii, 27 : bateau. D'autres dessins représentent deux labyrinthes (IC III, vii, 21 et 27), une tête de bœuf et une mouche (?) (IC III, vii, 27).

${ }^{99}$ L'inscription IC III, vii, $1 \mathrm{du} \mathrm{II}{ }^{\mathrm{e}}$ ou $\mathrm{I}^{\mathrm{er}} \mathrm{s}$. a.C. qui se présente sous la forme [Noms de personnes $+\chi \alpha \rho \imath \sigma \tau \varepsilon \tau i o v]$ renforce l'impression d'un sanctuaire où l'on remercie la déesse d'un voyage bien déroulé; cf. Guarducci 1942, p. 157-158. Sur les inscriptions d'euploia, voir infra, p. 274 ss.

${ }^{100}$ IC III, vii, 19 donne trois fois le nom d'Apollon : deux au génitif, une au datif. Les formes différentes de l'oméga pousseraient à distinguer plusieurs inscriptions plutôt qu'une seule. Quoi qu'il en soit, la graphie des trois noms est tardive.

${ }^{101}$ Nous n'avons pas retenu le concours nautique de Sidè en l'honneur d'Apollon et Athéna mentionné par L. Robert : il est attesté seulement pour le III ${ }^{\mathrm{e}}$ s. p.C. (Robert 1948). 
ont jugé bon de lui dédier la pierre et le promontoire en souvenir de son action en faveur des héros navigateurs.

Une épigramme votive de l'Anthologie Palatine (VI, 342) présente un autre rapport privilégié entre Athéna et la ville de Cyzique en ce qui concerne la navigation. En effet la déesse, considérée comme l'inventrice d'un art ancien ( $\pi \rho \omega ́ \tau \alpha \nu \pi \mathrm{o} \tau$ ' $\dot{\varepsilon} \mu \eta ́ \sigma \alpha \tau$ o s.e. $\tau \dot{\varepsilon} \chi v \alpha \nu)$ qui est celui de la fabrication du premier bateau, honora les habitants de la cité - selon leurs propres termes - de cette science, en remerciement de leur dévotion à son égard; cette distinction est rappelée par la présence d'un ex-voto maritime, une petite stylis, sous un portique appelé portique des Grâces. Les commentateurs discutent le fait que ce portique et cet objet aient été situés à Cyzique ou en trésor à Delphes $^{102}$. Quoi qu'il en soit, le petit poème atteste bien l'existence d'un culte à Athéna par les Cyziquéens pour des motifs maritimes, dont ils font remonter l'origine aux débuts de la navigation : ils en seraient en quelque sorte les pionniers après le Argonautes.

Un autre fragment du même itinéraire nautique du Bosphore (Anaplus Bospori, Fgt 8) indique par ailleurs que dans cette zone on honorait une Athéna sous l'épiclèse d'Ekbasia (du Débarquement). Le culte est attribué aux fondateurs de la colonie qui mirent pour la première fois pied à terre à l'endroit où est érigé l'autel de la déesse. L'auteur reproduit ici une source plus ancienne (Dionysos), malheureusement non datée. L'épiclèse et l'explication qui en est donnée semblent indiquer un culte archaïque ${ }^{103}$.

\section{g) Grande Grèce et Sicile}

Les sites du monde grec occidental ne sont pas en reste en ce qui concerne le culte rendu à Athéna. Pour deux d'entre eux, le caractère maritime de cette divinité est fortement prononcé (cartes 12 et 14).

\section{- Cap Iapygie}

À l'extrémité du territoire des Salentins se trouve un sanctuaire d'Athéna mentionné par un certain nombre de sources. D'après Denys d'Halicarnasse (Antiquités romaines I, 51, 3), le site est connu pour être un lieu important de la géographie virgilienne : c'est là

\footnotetext{
${ }_{102}$ Waltz, in Anth. Pal., éd. Budé, t. III p. 164, note 4, penche pour la seconde hypothèse; Trippé 2008 , p. 387-393 pour la première.

${ }^{103}$ Cette citation de Denys de Byzance est controversée : pour Vian 1974, p. 94, il s'agirait d'une confusion, l'autel en question étant connu par une autre source dédié à Artémis. Voir également le commentaire de Müller 1855-1861, II au dit passage; Jessen 1905 l'enregistre comme une Athéna et Anti 1920, p. 279 la met en relation avec l'Athéna Aithyia de Mégare, métropole de Byzance.
} 
qu'Énée aurait mis pour la première fois le pied en Italie. L'Athénaion ne serait pas situé au cap d'Iapygie proprement dit mais à proximité, puisque les deux endroits constituent deux points de

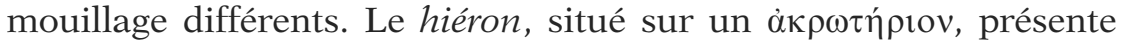
l'avantage d'un point d'ancrage en saison estivale ( $\theta \varepsilon \rho$ plvò ö $\rho \mu о \varsigma)$ qui

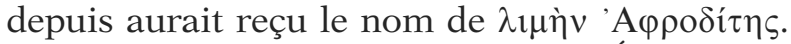

La version virgilienne (Virgile, Énéide III, v. 525-553) est loin d'être aussi précise. Le poème nous décrit l'Italie telle qu'elle est apparue à Énée et ses compagnons après leur départ de Bouthrotos. Alors qu'ils s'approchent de celle-ci, après une libation aux dieux pour une bonne navigation, un port s'offre à eux en arc de cercle que surplombe sur un arx le temple de Minerve, échappant ainsi aux humeurs des flots. Les Troyens se rendent au temple pour y rendre grâces à la déesse, ainsi qu'à Junon argienne. Il est à noter la qualification de graiugenum donnée à la contrée : le sanctuaire est considéré, dans la culture augustéenne, comme un lieu ancien appartenant à une tradition grecque. Ceci explique peut-être pourquoi Énée et ses compagnons ne sacrifient pas à Athéna seule tandis que le port a ensuite été attribué à Aphrodite. Le sanctuaire est de surcroît lié à deux traditions hérö̈ques : celle d'Ulysse et celle d'Énée.

Le lieu est mentionné également par Strabon (Géographie VI, 3, 5) qui répète à peu près les mêmes informations. Le sanctuaire d'Athéna, situé non loin du cap Iapygien, appartient aux anciens colons grecs que sont les Salentins. Le géographe précise cependant que l'Athénaion était autrefois ( $\pi$ o $\tau \dot{\varepsilon})$ connu pour sa richesse. On peut supposer, en réunissant toutes ces informations, qu'il s'agissait d'un sanctuaire important dès l'époque archaïque et dont la fondation coïncide avec les mouvements de colonisation de la région. À la fin de l'époque hellénistique, le sanctuaire garde un certain prestige dû à son passé glorieux, mais semble avoir diminué d'importance.

La localisation de l'Athénaion a été sujet à controverse : l'hypothèse la plus vraisemblable et généralement admise aujourd'hui le situe à l'extrémité du Salento à Santa Maria di Leuca, à l'emplacement de la cathédrale actuelle, en surplomb sur le canal d'Otrante ${ }^{104}$.

\section{- Sorrente}

Strabon, dans sa description du sud de la Campanie, évoque à

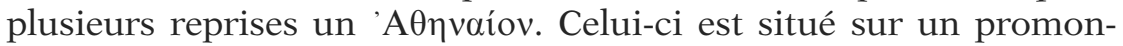

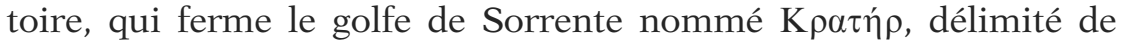
l'autre côté par le cap de Misène (Géographie V, 4, 3). Le temple est visible de loin, grâce à son implantation sur un promontoire orienté

${ }^{104}$ Fenet 2005, p. 42-43, avec références. 


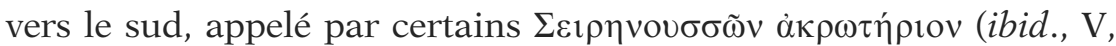
$4,8)$. Ce point de la côte italienne s'avance ostensiblement dans la mer vers l'île de Capri, délimitant au nord le golfe de Naples/Poseidonia (ibid. I, 2, 12). Le nom du promontoire est à mettre en relation avec un sanctuaire voisin consacré aux Sirènes et à des îlots rocheux du même nom dans la baie, ce que Pline l'Ancien (Histoire naturelle III, 62) expose lui aussi brièvement ${ }^{105}$. Strabon nous apprend par ailleurs que la tradition fait remonter la fondation du temple d'Athéna à Ulysse, et que le promontoire était aussi désigné simplement du nom de la déesse. Ceci témoigne de l'ancienneté du culte et du sanctuaire ainsi que d'une lecture locale de l'Odyssée qui devait localiser à cet endroit l'épisode du retour du héros, selon lequel il sort vainqueur de sa confrontation avec les femmes-oiseaux ${ }^{106}$. L'attribution à Ulysse de ce temple légitime également pourquoi c'est Athéna qui est honorée à cet endroit.

Le site est connu par des sources postérieures. Dans la seconde moitié du $\mathrm{I}^{\mathrm{er}}$ s. p.C., Stace évoque à plusieurs reprises le temple d'une Minerva Tyrrhena : tout d'abord dans la description de la villa de Pollius Felix (Silves II, 2, v. 1-3), puis dans un poème de vœux de bon voyage par voie de mer adressé à Mecius Celer (III, 2, v. 1-55). Dans les deux cas, le poète qui s'adresse à des personnes de sa connaissance évoque pour eux des points culturels communs. Le contexte dans lequel apparaît la déesse est assurément maritime. La villa du bord de mer, à Sorente, est voisine des saxa sur lesquels se trouve le temple. Le poète imagine Mecius Celer offrant une libation depuis le navire à Minerve Tyrrhénienne, lorsque le bateau passe à proximité de Capri au large de son sanctuaire. Dans un troisième poème, Stace $(\mathrm{V}, 3,162-166)$ représente la déesse dominant les eaux de la cité de Sorrente. Il est indéniable qu'Athéna-Minerve possédait sur le littoral sorrentin, sur un point élevé, un sanctuaire et qu'on lui rendait un culte maritime ${ }^{107}$ notamment à bord des bateaux quittant le port ou naviguant au large. La déesse veillait, de par sa position stratégique, sur la navigation dans la zone. Le sanctuaire a été localisé à la pointe Campanella, où a été découverte une inscription rupestre en osque relative à des meddices Minervii, datée après la fin $\mathrm{du} \mathrm{IV}^{\mathrm{e}}$ et avant le $\mathrm{II}^{\mathrm{e}} \mathrm{s}$. a.C. ${ }^{108}$. Les vestiges archéologiques mis au

${ }^{105}$ La source de Strabon et de Pline serait la même, en l'occurrence Artémidore, ce qui reculerait d'autant la datation de ces informations : cf. commentaire de l'éditeur du texte de Strabon dans la collection Budé. Les îlots des Sirènes sont identifiés avec Li Galli, à $8 \mathrm{~km}$ à l'est de la Punta della Campanella : Caro \& Greco 1993, p. 105-108.

${ }^{106}$ Odyssée, XII, v. 1-200. Bérard 1957, p. 309 et 316-317.

${ }^{107}$ Wachsmuth 1967 , note 1840 et p. 403.

${ }^{108}$ Morel 1982, p. 149-153 et III pl. xxix-xxxiii; Russo \& alii 1990. 
jour montrent un culte actif dès l'époque archaïque, avec un accès direct au sanctuaire depuis la mer, par une grotte naturelle et un escalier aménagé par ces meddices ${ }^{109}$. L'épithète donnée par Stace à la déesse est relayée, dans la troisième mention, par le nom donné à la mer elle-même : il est ainsi difficile de savoir si la désignation de Minerva Tyrrhéna correspond à une épiclèse ou s'il s'agit d'un raccourci du poète.

Un épisode historique rapporté par Tite-Live (Histoire romaine XLII, 20, 3-4) a peut-être eu pour cadre l'Athénaion sorrentin. En 172 a.C., un orage renverse la colonne des rostres du Capitole romain, à la suite de quoi des mesures religieuses sont préconisées. Un sacrifice doit être réalisé à la fois au Capitole et au promontoire de Minerve en Campanie : ce dernier vraisemblablement ne fait qu'un avec le sanctuaire face à Capri. Le fait que ce soit celui-là et pas un autre qui fasse l'objet de ces précautions rituelles est à interroger. Le contexte est nautique, les rostres de la colonne provenant de bateaux pris sur l'ennemi. S'il convient d'apaiser Minerve par un sacrifice, ce peut être ou bien parce que les rostres provenaient de la zone en question et étaient à l'origine consacrés à la déesse, ou parce que celle-ci était considérée comme ayant un rôle particulièrement important dans l'issue des batailles navales menées par les Romains. L'épisode livien renforce l'impression d'un culte maritime rendu à Athéna, encore important à l'époque hellénistique ${ }^{110}$.

\section{- Pouzzoles}

Un peu plus au nord, à Pouzzoles, dans un même contexte littoral, est attestée la présence d'Athéna, probablement sous la forme d'une statue sinon d'un temple sur un promontoire dominant la mer. C'est une citation de Sénèque (Lettres à Lucilius 77, 2) décrivant l'animation que provoque, au premier siècle de notre ère, l'arrivée des navires alexandrins dans le port, qui nous l'apprend. L'expression utilisée alta procelloso speculatur vertice Pallas n'est pas du philosophe, sans que l'on connaisse l'identité de son véritable auteur ${ }^{111}$. Elle permet de supposer cependant l'existence d'une consécration de ce lieu à Athéna, au moins pour l'époque hellénistique.

${ }^{109}$ Russo \& alii 1990; Guzzo \& alii 1992; Caro \& Greco 1993, p. 105-108.

${ }^{110}$ L'éditeur de l'inscription pense que celle-ci n'est pas étrangère à cet événement : ce serait un moyen pour Rome de faire sentir sa présence sur un territoire sorrentin encore très samnite (Guzzo \& alii 1990, p. 213).

${ }^{111}$ Sénèque, Lettres à Lucilius, éd. Budé, p. 66. 
- Syracuse

En ce qui concerne la Sicile, un passage de Polémon le Périégète (Fgt 75, éd. Preller = Athénée, Deipnosophistes XI, 462b-c) daté de la fin du $\mathrm{III}^{\mathrm{e}}$ ou du début du $\mathrm{II}^{\mathrm{e}} \mathrm{s}$. décrit un rituel effectué à bord en rapport avec Athéna à Syracuse. Le texte est ainsi interprété ${ }^{112}$ : les équipages des bateaux qui quittent le port sicilien, au moment où le bouclier de la statue de la déesse devient invisible, consacrent à la déesse une coupe ainsi que son contenu en la jetant à l'eau. Ce geste serait confirmé archéologiquement par le nombre important de coupes trouvées dans le port de Syracuse mais aussi dans d'autres. Cette lecture très séduisante au premier abord est contestable par une étude plus attentive du texte grec. La description laisse supposer deux vases différents : celui mis en relation avec une eschara, et puis celui contenant des libations utilisé à bord. En effet, le premier est

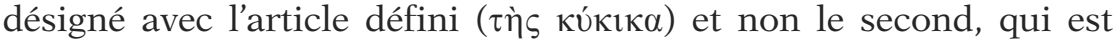
qualifié de surcroît $\kappa \varepsilon \rho \alpha \mu \varepsilon ́ \alpha \nu$. Le passage pourrait donc correspondre à une mauvaise retranscription par Athénée, qui a peut-être coupé le texte original. L'accent est mis dans le rite sur le contenu de la coupe : fleurs, miel, aromates divers. Il n'est pas assuré en revanche que la coupe soit jetée avec son contenu : le verbe $\alpha \dot{\varphi} i ́ \eta \mu$ signifie «laisser aller» et peut désigner le geste de tendre le vase vers

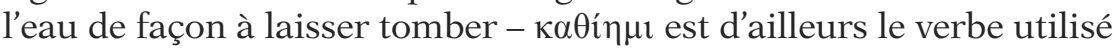
pour le mélange offert en libation - ce dont il est rempli. Ceci correspond aux nombreux exemples de libations qui apparaissent dans la littérature ${ }^{113}$ selon lesquels le récipient est conservé à bord une fois l'acte accompli. L'amas de céramiques à l'entrée du port peut tout aussi bien correspondre à un chargement de vases noyé à cet endroit ou simplement aux ordures des usagers du port durant plusieurs siècles ${ }^{114}$; en tous cas, le texte de Polémon ne peut constituer en aucun cas une preuve décisive d'un tel rituel. En ce qui concerne la déesse, l'écrivain désigne par ailleurs comme point de repère le bouclier du temple d'Athéna et non pas sa statue, ce qui semblerait plus naturel. Le naos d'Athéna à Syracuse est situé sur l'île d'Ortygie,

112 Wachsmuth 1967, p. 407. Kapitän, 1967-68, p. 167-180; Kapitän 1989, p. 147-148 et fig. 2-3.

${ }^{113}$ Nombreuses références dans Wachsmuth 1967, p. 116-118; voir également infra, passim.

${ }^{114}$ Pour une telle présence de céramiques dans le port Marseille, c'est l'avis de A. Hesnard, que je remercie de m'avoir communiqué. De plus, Kapitän 1989, p. 147-148 et fig. 2-3, présente des exemplaires de $65 \mathrm{~cm}$ de diamètre : il ne s'agit plus de kulikes mais de plats! L'hypothèse de Kapitän semble cependant être couramment suivie : voir par ex. Romero Recio 2000, p. 89-91; ou Beltrame 2002, p. 75-76 qui rattache ainsi les beaux objets ouvragés de l'épave d'Ilovik à la pratique de telles libations. 
sur le point le plus élevé115. Le témoignage de Polémon doit ainsi être intégré parmi les mentions de libation à bord au moment du départ, au large du sanctuaire d'Athéna. Il rejoint ainsi les sources concernant Sorrente et le rituel des marins devant un hiéron de la même divinité.

h) Aux confins du monde grec

Deux dernières attestations de géographes complètent cet inventaire des cultes maritimes d'Athéna.

- Ibérie

La première est rapportée par Strabon (Géog. III, 4, 3), qui répète le témoignage d'un de ses prédécesseurs, Asclépiade de Myrléa, à propos d'un sanctuaire ibérique d'Athéna. Selon lui, dans l'arrière-pays d'Abdèra, se trouve un endroit nommé Odysséia ${ }^{116}$ d'après le célèbre navigateur, où l'on trouve un hiéron de la déesse sur les murs duquel on montrait des boucliers et des éperons de navire ( $\dot{\alpha} \kappa \rho о \sigma \tau o ́ \lambda ı \alpha)$ lui ayant appartenu (voir infra p. 419). Que des boucliers attribués au héros homérique soient présentés dans un sanctuaire de Pallas n'a rien d'étonnant, quand on considère son rôle de protectrice d'Ulysse tout au long de l'Odyssée. En revanche, la présence d'éperons ne renvoie à aucun épisode connu où la déesse aurait apporté une aide maritime au héros. De plus l'emplacement de ce sanctuaire à l'intérieur de la montagne, et non directement sur le littoral, ne manque pas de surprendre ${ }^{117}$ (carte 11).

- Éthiopie

Enfin, selon Claude Ptolémée (Géographie IV, 7, 11), au large de

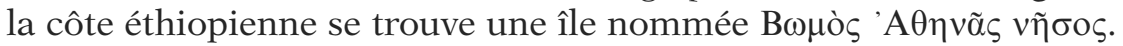
Cette description géographique du $\mathrm{II}^{\mathrm{e}}$ s. p.C., qui enregistre des

${ }^{115}$ Coarelli \& Torelli 1984, p. 232-234 et plans de situation p. 221, 225. Aujourd'hui le Duomo occupe l'emplacement du temple dont il a conservé quelques restes. Les fouilles ont mis au jour un temple dorique daté du $\mathrm{VI}^{\mathrm{e}} \mathrm{s}$. a.C., auquel a succédé un temple d'époque classique. La décoration de la porte d'entrée est connue par la description de Cicéron, Seconde action contre Verrès II, 4, 124-125.

${ }^{116}$ F. Lasserre, in Strabon III, éd. Budé, p. 61 note 3, renvoie sans trancher à deux identifications du lieu : une cité d'Oducia située dans la vallée du Guadalquivir, et celle d'Ulisi repérée dans la sierra au nord de Malaga.

${ }^{117}$ En ce qui concerne les traditions homériques de la région, Strabon opère ensuite une digression sur les récits populaires répétés par les géographes qui l'ont précédé et sur ce qu'il est à son avis juste de retenir de l'ensemble de ces propos. 
renseignements de datations diverses, montre ainsi qu'une île peut être consacrée à Athéna, vraisemblablement à cause de la présence sur son rivage d'un autel qui lui a été consacré par des Grecs ${ }^{118}$. Ceci n'est pas sans évoquer les sacrifices littoraux de la flotte d'Alexandre dans son périple indien ${ }^{119}$. En raison de ce parallèle et de la localisation en Éthiopie, il n'est sans doute pas inconsidéré d'y reconnaître une appellation hellénistique.

En comparant les sources mythologiques et les sources cultuelles, une constatation s'impose : de façon générale, il faut souligner que les attestations de cultes d'Athéna liés à la mer renvoient elles aussi à des personnages hérö̈ques. Cette aide accordée aux héros dans la tradition poétique se retrouve ou dans l'attribution à ceux-ci de l'origine du culte, ou dans un lieu qui comporte également un hérôon.

\section{Iconographie isolée: Athéna et l'univers maritime}

À ces divers indices mythologiques et culturels viennent s'ajouter pour ce dossier un certain nombre de documents iconographiques, non rattachables aux sources précédemment étudiées, montrant un lien privilégié entre Athéna et la mer. Ils ne constituent pas pour autant des preuves d'une personnalité marine de la déesse : ils peuvent servir à comprendre dans quel contexte ou quel état d'esprit celle-ci a pu être invoquée pour des motifs maritimes.

\section{a) Le bouclier d'Athéna}

Athéna est identifiable, iconographiquement, grâce à certains attributs : le casque, l'égide, la lance et le bouclier - tous n'étant pas systématiquement représentés - constituant un répertoire répétitif. Un motif cependant varie d'une représentation à l'autre : l'épisèmon du bouclier. Peu d'études se sont intéressées à la valeur à accorder à celui-ci, notamment sur les amphores panathénaïques ${ }^{120}$. Un passage de Plutarque peut nous inviter à penser que le décor choisi pour orner un bouclier n'était pas dû au hasard. Le moraliste

${ }_{118}$ Wachsmuth 1967, p. 410, qui y voit un lieu propre à ce qu'il appelle «le sacrifice intermédiaire» : réalisé en cours d'un trajet lors d'une escale.

${ }^{119}$ Voir dans le corpus les références à l'Indica d'Arrien.

${ }^{120}$ Tiverios 1996 les interprète non pas comme des marques distinctives de peintres, mais comme des repères pour les tamiai responsables de l'huile sacrée d'Athéna (cf. Aristote, Constitution des Athéniens 60, 2-3) afin de différencier les répartitions. Voir aussi Lacroix 1955-56. 
raconte en effet qu'Ulysse choisit un dauphin comme épisème en souvenir de ce qu'un tel animal ait sauvé Télémaque de la noyade ${ }^{121}$. De la même manière, on peut penser que les peintres qui réalisaient l'ornement du bouclier d'Athéna évoquaient - peut-être à leur insu une qualité, un trait de personnalité qu'ils prêtaient à la divinité ou indirectement à la cité d'Athènes. Sans vouloir accorder une importance inconsidérée à ces éléments décoratifs, il convient cependant de noter l'attestation de plusieurs épisèmes marins appartenant à la déesse.

L'ancre apparaît sur deux amphores panathénaïques attribuées au peintre d'Antiménès, datées entre 520 et 510 , l'une conservée au

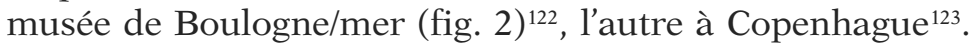

La figuration de ce motif est d'autant plus remarquable qu'elle est rare dans la peinture grecque ${ }^{124}$. Une Athéna d'une amphore datée des mêmes années porte un bouclier orné de deux dauphins ${ }^{125}$, tandis qu'un exemplaire du Louvre n'en présente qu'un seul ${ }^{126}$. Il est à noter la concordance chonologique de la plupart de ces différents documents, sans qu'on puisse pour le moment les expliquer de manière satisfaisante ${ }^{127}$.

${ }^{121}$ Plutarque, De sollertia animalium 985B.

${ }^{122}$ Inv. 441; Bentz 1998, no 6.070 (p. 129) et pl. 22. D'après la fiche d'inventaire du vase, celui-ci, provenant de Vulci, est entré au musée par achat d'une collection privée.

${ }^{123}$ Glyptothèque, inv. 2653. Boardman \& alii 1990, 1 p. 146 n $^{\circ} 3124$ et 2 p. 138; Bentz 1998. Apparemment, les deux vases sont apparentés : dus au même peintre ou au même groupe; cependant, les ancres ne sont pas similaires.

${ }^{124}$ Seul l'ouvrage de F. Moll aborde le thème de la représentation de l'ancre dans l'Antiquité (Moll 1929a, ch. XXI p. 36-38, pl. E II a et b et légendes p. 6972); un exemple d'une ancre sur une amphore attique à figures noires du British Museum figure dans Gianfrotta \& alii 1997, p. 301. Le motif de l'ancre apparaissant sur monnaies, cas le plus fréquent sans doute, ne doit en revanche révéler que le caractère maritime des cités qui les ont émises (Anson 1910-16, V p. 87-91 et pl. XIV; voir Moll 1929, ch. XXI p. 36-38, pl. E II a 1-48 : il s'agit surtout de monnaies hellénistiques de la zone orientale). Il sert aussi de marque sur les timbres amphoriques : par exemple Delivorrias 1987, n $120 \mathrm{~b}$ : sur une amphore cnidienne du $\mathrm{II}^{\mathrm{e}}$ s. a.C., trouvée à Délos.

${ }^{125}$ British Museum B 237. Boardman \& alii, 1 p. 146 n 3121 et 2, p. 138. L'amphore, datée 520-510 a.C., est attribuée au «Eye-siren group». Bentz 1998, p. 204-207, recense également une amphore d'Exékias, datée 540-530.

${ }^{126}$ Louvre inv. F274; le vase, provenant d'Étrurie, est daté vers 530-520 a.C. Bentz 1998, p. 204-207, inventorie pour sa part deux amphores portant ce motif : l'une de 566-560, l'autre de 520-510 (celle du Louvre), ainsi qu'une troisième avec un poisson, datée 530-520.

${ }^{127}$ Aucun fait maritime marquant ne semble être survenu à Athènes durant les années 520/510 qui ont vu la fin du règne de Pisistrate. Bentz 1998, p. 48-50, estime que ces motifs marins, plutôt que de renvoyer à la déesse poliade, renvoient à la cité et à sa puissance. Par ailleurs, selon une enquête menée auprès de spécialistes de céramique et d'histoire de l'art, aucune relation n'a pu être 


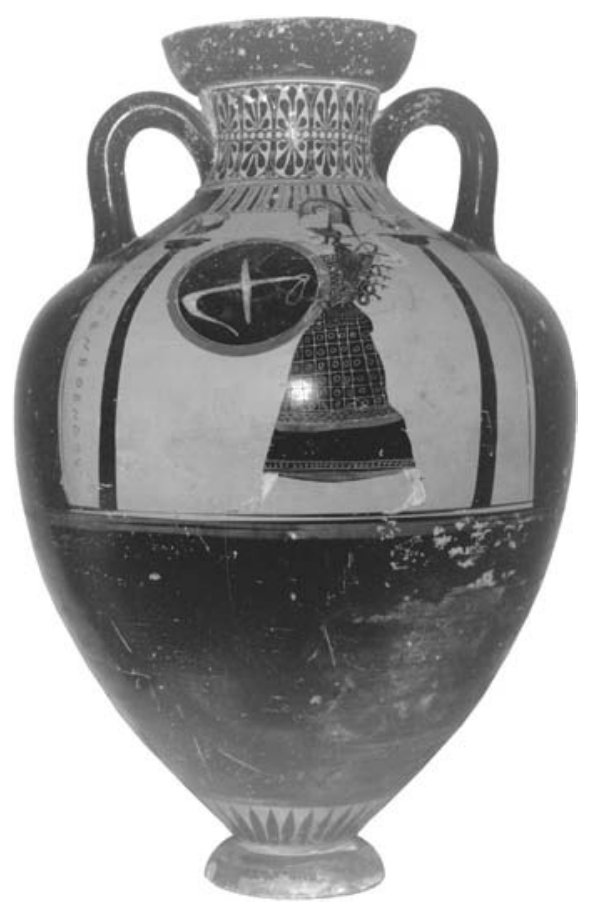

Fig. 2 - Amphore panathénaïque

(musée de Boulogne/Mer, inv. 441. Photo F. Lissarrague).

\section{b) Athéna à l'aphlaston}

Une amphore de Nola du peintre de Nikon montre une Athéna reconnaissable à son égide tenant de la main droite la lance et brandissant de la gauche un aphlaston ${ }^{128}$. Devant elle court une jeune femme, que l'on interprète comme une personnification de l'Asie. L'image constituerait une allusion directe à la victoire de la Seconde Guerre Médique, ce qui correspondrait tout à fait à la datation du vase entre 480 et $460^{129}$. Sur un lécythe attique à figures rouges

établie entre un atelier et ce type de motif : peut-être ce dernier est-il la marque personnelle du commanditaire du vase; c'est une piste qu'il faudrait sans doute explorer.

${ }^{128}$ Lenormant \&Witte 1894, p. 245-249 et pl. LXXV; Demargne 1984, 1 p. $1012 \mathrm{n}^{\circ}$ 599. Sur le terme d'aphlaston, voir infra p. 251 et fig. 12.

${ }^{129}$ Wade-Gery 1933, p. 99-101 et fig. 4. Le savant américain rapproche ce vase de trois fragments contemporains trouvés sur l'Acropole d'Athènes figurant des personnages féminins brandissant un aphlaston: le manque d'attributs empêche toute affirmation pour deux de ces fragments, tandis que pour le troi- 
attribué au peintre Brygos, daté entre 480-470, figure également une Athéna à l'aphlaston à laquelle a été prêtée la même signification ${ }^{130}$. Des variantes montrent une Nikè tenant à la main la même partie de bateau. Dans les années qui ont suivi le succès de Salamine, les peintres athéniens à travers l'iconographie ont glorifié l'action de leur cité et ont naturellement associé à la victoire leur divinité poliade ${ }^{131}$.

Le motif apparaît également en dehors de l'Attique. Une gemme en cornaline, d'origine probablement chypriote, figure une Athéna promachos tenant de la main gauche un aphlaston; à ses côtés se dresse un serpent interprété comme une allusion à Érichthonios ${ }^{132}$. L'objet est daté de la fin du Ve s. a.C. Un tel travail provient, comme c'est le cas pour d'autres objets de l'île, d'artistes puisant largement dans le répertoire iconographique attique. Il n'est donc pas rattachable à un événement ou un culte particulier de Chypre ${ }^{133}$.

\section{c) Athéna sur un bateau}

La représentation iconographique d'Athéna sur un bateau relève des types monétaires. Plusieurs cités ont frappé des monnaies présentant ce motif, qui ont pour point commun d'être toutes hellénistiques ${ }^{134}$.

Phasèlis en Lycie a émis dans les années 190-168 des statères d'argent présentant au revers une proue de navire de guerre portant face au stolos ce qui ressemblerait à une Athéna debout stylisée ${ }^{135}$. La silhouette du personnage rappelant fortement un

sième il est certain qu'il ne peut s'agir d'Athéna. Ces fragments sont enregistrés par Demargne 1984, sous le no 597 (p. 1012).

${ }^{130}$ Richter 1936, p. 69-70 no 48 et pl. 46; Gauer 1968, p. 72; Demargne 1984, 1 p. $1012 \mathrm{n}^{\circ} 598$ et 2, p. 762. Un autre lécythe (Musée de Berlin, inv. 2211) signalé comme troisième attestation du type Athéna à l'aphlaston par Richter 1936, loc. cit., paraît plutôt représenter une Nikè : voir Lenormant \& Witte 1894, pl. XCVI.

${ }^{131}$ Demargne 1984, 1 p. 1037; Deubner 1927, p. 181 et fig. 14 montre une Athéna tenant ce qui semble être une stylis figurant sur une amphore panathénaïque. L'absence totale de référence, de datation empêche de prendre en compte l'information, faute de pouvoir la vérifier.

${ }^{132}$ British Museum inv. 89.II-II.I. Demargne 1984, 1 p. 1013 no 514 et 2, p. 763; Walters 1926, p. 63 n' 515 pl. 9; J. Boardman 1970, p. 288 et fig. 486.

${ }_{133} \mathrm{Je}$ remercie Anne Destrooper, numismate spécialisée sur les émissions chypriotes, pour ce commentaire.

${ }^{134}$ Nous ne tenons pas compte ici des types trop tardifs telle l'émission de Corcyre sous Plautilla qui comporte au revers un navire à voile, sur la proue duquel se trouve une Athéna Promachos: Anson 1910-16, V p. 100, n 714 (= Gardner 1883, p. 165, n 693). pl. XIX.

${ }^{135}$ Hill 1897, p. $81 \mathrm{n}^{\circ} 14$ et pl. XVI, 12; Anson 1910-16, V p. 119 n 933, 
épouvantail laisse supposer une ornementation de type phénicien attestée également sur des monnaies et par un passage d'Hérodote (Enquête III, 37), plutôt qu'une représentation réelle de divinité ${ }^{136}$. Cependant la comparaison de ces statères avec des monnaies contemporaines offrant au droit une proue surmontée d'une chouette et au revers Athéna confirme le lien d'Athéna avec la navigation dans la numismatique phasélienne de la première moitié du $\mathrm{II}^{\mathrm{e}}$ s. a.C. Ceci est à rapprocher d'une inscription du $\mathrm{IV}^{\mathrm{e}}$ s. a.C. qui indique l'offrande à la divinité Poliade de Phasèlis,

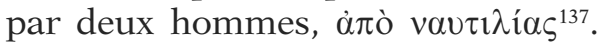

Le monnayage chypriote comporte une série de représentations apparentées au type monétaire connu de la divinité assise sur un bateau. Athéna, cette fois bien dessinée et reconnaissable à son casque, se tient assise à l'avant - ou sur le pont $(\mathrm{P})$ ou sur le côté de la stolos (S) - d'un navire de guerre, un aphlaston à la main (fig. 3) ${ }^{138}$.

L'iconographie d'Athéna paraît regrouper deux modèles en un : celui hellénistique de la divinité assise sur une embarcation, ainsi que celui déjà évoquée plus haut d'Athéna à l'aphlaston créé suite à la Seconde Guerre médique. Ce dernier avait déjà été copié par un artiste chypriote pour une gemme à la fin du $\mathrm{V}^{\mathrm{e}} \mathrm{s} .{ }^{139}$; il semble bien qu'il ait également inspiré les types monétaires de l'île, sans que l'on puisse lui accorder une valeur religieuse particulière à Chypre ${ }^{140}$.

L'iconographie marine d'Athéna s'avère donc presque exclusivement attique et concentrée sur les dernières décennies du VI ${ }^{\mathrm{e}} \mathrm{s}$. et les premières du Ve S. a.C. ${ }^{141}$

${ }^{136}$ Sur ces monnaies, l'ornementation des bateaux en relation avec des figures divines et cette tradition phénicienne, voir infra $2^{\mathrm{e}}$ partie p. $251 \mathrm{ss}$. De la même manière, le personnage armé debout sur une proue du monnayage de Lébédos (Ionie), daté après 190 a.C., ne nous semble pas devoir être identifié avec une Athéna: Head 1892, p. $155 \mathrm{n}^{\circ} 12$ et pl. XVII, 11

${ }^{137}$ Hill 1897, p. 81 n $^{\circ} 15$ et pl. XVI, 13; Anson 1910-16, V p. 121 no 949 et pl. XX. Des émissions attiques du règne d'Hadrien montrent également une chouette au-dessus d'une proue : Anson 1910-16, V, p. 121 n $^{\circ} 948$ et pl. XX; Head 1977 p. 109 no 792. Inscription : Tituli Asiae Minoris II, 3, no 1184.

${ }_{138}$ Basch 1987, p. 272-274; Hill 1904, p. xliii et pl. XXV, 6-8.

${ }^{139}$ Voir supra, p. 56.

${ }^{140}$ Ces monnaies ne sont pas attribuées à une cité de façon sûre ni datées précisément.

${ }^{141}$ Signalons encore, pour l'écarter, un tétradrachme de Lysimaque, frappé à Byzance en 195 a.C. (donc bien après la mort du roi), qui présente au revers une Athéna assise, tenant une Nikè sur sa main; en-dessous de la déesse apparaît un trident : Ringel 1984, p. 34, n 28 . Il doit s'agir en effet d'une marque monétaire indiquant une information purement pratique (superviseur?), ou d'un symbole référant à la cité, sans lien direct avec la divinité. 


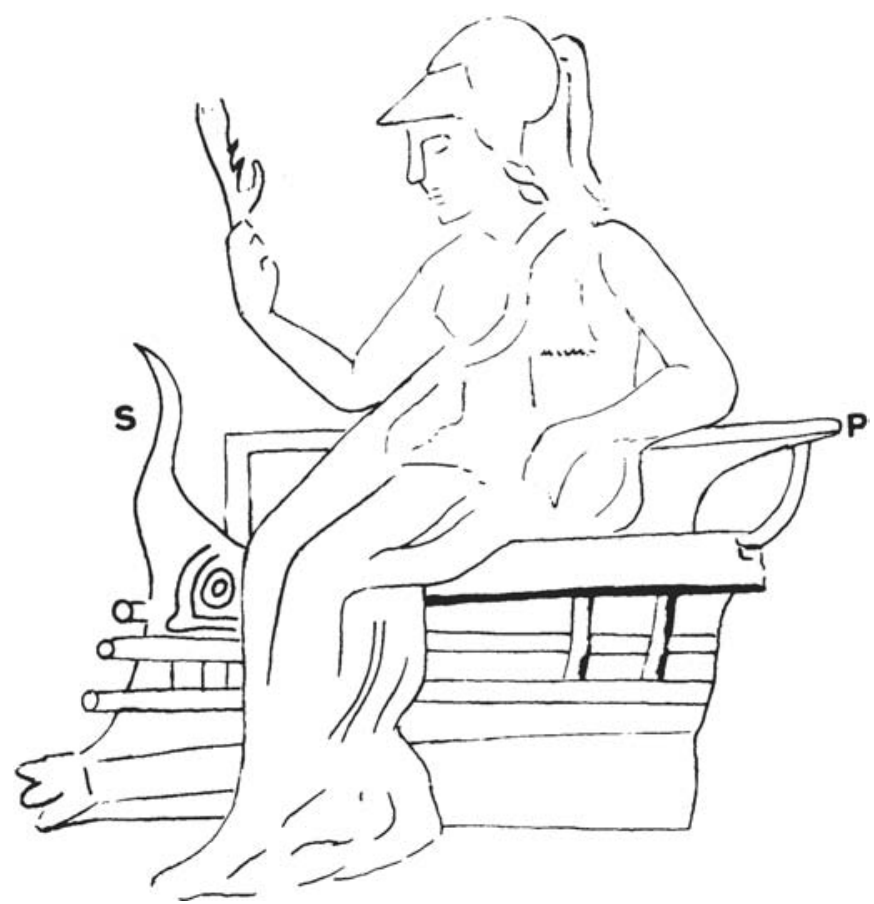

Fig. 3 - Athéna assise à la proue d'un navire de guerre. Monnaie chypriote de la fin du Ve s. a.C. (d'après Basch 1987, fig. 582).

\section{ANALYSE}

Géographie du culte

Athéna est ainsi mise en relation avec la mer tant dans l'épopée mythologique que dans l'iconographie, sous des registres différents, en rapport avec les cultes rendus à travers le monde grec. La répartition de ces derniers montre qu'ils se concentrent essentiellement en deux pôles : l'un au sud de la latitude du golfe de Corinthe et l'autre en Grande Grèce. Rien n'apparaît pour la Grèce centrale et du nord, si ce n'est à Skyros. Sur le littoral oriental, Cyzique et Lindos semblent présenter deux cas isolés. Sur ces vingt lieux consacrés à la déesse, neuf sont présentés par les sources comme des promontoires, auxquels s'ajoutent quatre sites insulaires et deux portuaires. Le caractère dominant de la plupart de ces sites est frappant, sur une hauteur que distinguent de loin les navigateurs. Les auteurs insistent beaucoup sur ce point en ce qui concerne la Grande Grèce; ce caractère s'applique également aux sanctuaires délien et rhodien 
d'Athéna. La majorité de ses épiclèses connues renvoie à des toponymes littoraux: Sounias, Koryphasia, Samônia et dans une moindre mesure Kynthia et Lindia. Trois épiclèses s'avèrent porteuses d'un sens plus connoté : Aithyia, Anémôtis et Sôteira. Aucune dénomination particulière ne désigne les sites et cultes de Grande Grèce : la simple désignation d'Athénaion ou d'Athéna semble suffire à leur évocation. Les sites consacrés ne comportent pas tous des constructions : Athéna peut simplement se voir vouer un promontoire ou un lieu marin, orné parfois d'une statue, d'un autel; la présence d'un temple ne s'avère pas systématique.

Tous les témoignages cultuels renvoient à une haute Antiquité. Lorsqu'ils sont datables, ils remontent à une tradition archaïque ou au plus tard classique. Dans le cas contraire, leur mise en relation avec un personnage ou un ex-voto héroïque leur confère un caractère d'ancienneté. Il faut noter également la continuité de fréquentation d'un certain nombre de lieux de cultes jusqu'à l'époque hellénistique. Ceci se manifeste notamment dans les sanctuaires de Grande Grèce pour lesquels le caractère maritime du culte s'impose de manière flagrante encore à cette époque.

\section{Personnalité marine d'Athéna}

a) Athéna et l'art nautique

Son rôle d'architecte naval est bien affirmé par les sources littéraires et déjà bien connu ${ }^{142}$ : nous ne nous y attarderons donc pas. Argô s'impose comme le premier modèle de bateau jamais réalisé, conçu entièrement par Athéna. Les habitants de Cyzique se donnent la primauté de l'art nautique qu'elle leur aurait enseigné. Les Lindiens quant à eux affirment que la navigation fut inaugurée par Danaos. Même si les bénéficiaires de ce savoir nautique d'Athéna diffèrent selon les lieux, celui-ci est unanimement mis sur le compte de l'intelligence de la divinité. La conquête des mers commence par ce don qu'Athéna accorda aux héros puis aux hommes : le bateau et l'art de la navigation. Ceci est à mettre en liaison, comme l'a bien

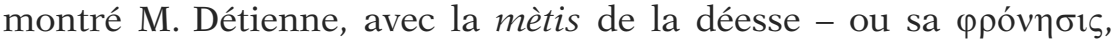
selon le scholiaste de Lycophron (ad Alexandram v. $359=$ voir corpus p. 539) ${ }^{143}$.

Car elle ne se contente pas de la conception technique de l'embarcation, elle conseille également sur la route à suivre et la manière de diriger un bateau. Outre les traditions argonautiques où

${ }_{142}$ Detienne 1970; Basch 1978.

${ }^{143}$ Detienne 1970, spécialement p. 153-154, 157-163, 176-177. 
son intervention se manifeste parfois par la voix de la poutre vivante, il est à souligner le lien établi entre Athéna et deux pilotes mythiques : à Sounion avec Phrontis le kubernétès d'Agamemnon et à Lindos avec Kanopos celui de Ménélas ${ }^{144}$.

Athéna accompagne également le bateau et le guide à travers l'élément liquide. Ovide (Tristes I, 10, v. 1-44) explique ainsi que la déesse écarte du vaisseau les dangers et le mène à bon port. Sa présence est marquée à bord par son nom donné à l'embarcation et la représentation d'un de ses attributs sur la coque. Cette protection du bateau en mer remonte à la tradition homérique où son heureux bénéficiaire est Télémaque, et transparaît à travers les différentes versions de l'épopée argonautique. Ce caractère explique l'importance d'Athéna dans la décoration et l'onomastique navales (voir infra p. 277 ss.). La première, attestée par des sources littéraires (Euripide, Iphigénie à Aulis v. 235-257; Aristophane, Acharniens v. 544-551 et scholie au v. $547=$ voir corpus p. 533; Valerius Flaccus, Argonautiques VIII, v. 202-203) semble renvoyer à une présence de la déesse à bord, à l'image de la scène homérique du départ de Télémaque ou plus indirectement à celle de la poutre d'Argô. Le passage d'Euripide est explicite sur l'influence positive d'Athéna dans les affaires maritimes : sa représentation est un

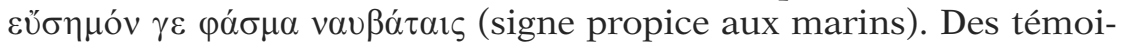
gnages iconographiques montrent des images d'Athéna figurant sur des bateaux - ou à défaut son nom sur une stylis d'après une monnaie d'Eubée - auxquels on peut éventuellement rattacher le motif dit de la tête de Gorgone sur des ancres emmenées à bord.

Par ailleurs, le pouvoir de la déesse peut s'exercer de façon négative et servir à assouvir sa colère. Lycophron (Alexandra, v. 348-386) dépeint une Athéna rancunière, avide de vengeance envers les Grecs suite à leur comportement outrancier lors de leur victoire à Troie, qui s'acharne sur eux et leurs bateaux au cours de leur navigation. Cependant Euripide (Troyennes, v. 75-94), la montre désarmée, sans réels moyens d'action. Elle ne peut œuvrer sur les éléments et contrecarrer le retour des Grecs qu'avec l'aide des autres dieux : Zeus provoque, pour elle, tourmentes et ouragans et lui prête son foudre, tandis que Poséidon bouleverse et renverse les flots de la mer Égée à sa demande. Athéna peut ainsi intervenir sur mer, mais en faisant appel aux attributions de dieux "spécialisés» dans le déchaînement ou la maîtrise des éléments naturels. Il est à noter que cette restriction du pouvoir d'Athéna se fait dans un cadre précis : celui d'une action négative, vengeresse, destructrice ${ }^{145}$. Peut-être la

${ }^{144}$ Detienne 1970, p. 169-170.

${ }^{145}$ Wachsmuth 1967, p. 268 évoque également le naufrage d'Ajax, consé- 
divinité ne peut qu'agir de façon bénéfique sur la mer, en donnant des vents favorables, des conseils de navigation ou sa protection au sens large, mais qu'inversement ses pouvoirs sont nuls en matière de démesure, de déraison des éléments marins.

\section{b) Athéna-oiseau et le sauvetage d'homme en péril}

Les deux mentions du culte mégarien d'Athéna font référence à une légende selon laquelle elle apparaitrait sous la forme d'un cormoran, emportant sous ses ailes ou Pandion ou Kékrops. À cette tradition sont tout d'abord rattachables plusieurs mentions littéraires concernant une Aithyia.

La transformation d'Athéna en oiseau est attestée par un certain nombre de sources - et ce dès Homère - notamment en chouette. Il est ainsi un passage de l'Odyssée qui évoque une métamorphose de la déesse qui pourrait présenter des similitudes avec celle de Mégare. Lors de sa première intervention auprès de Télémaque, Athéna s'est présentée sous les traits d'un mortel avant de disparaître à la fin de l'entrevue (Odyssée I, v. 319-323) sous l'apparence

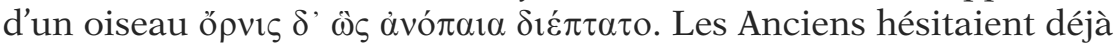
au sens à donner au terme d'àvó $\pi \alpha 1 \alpha$. La scholie au vers 320 nous apprend ainsi que pour les uns anopaia en un seul mot était une sorte d'oiseau, ou encore un adverbe signifiant "de manière invisible», tandis que pour d'autres il s'agissait d'une expression en deux mots (une préposition suivie d'un nom) «par la lanterne du toit» ${ }^{146}$. Le mot - ou l'expression - n'étant pas exprimé ailleurs, il est difficile de trancher entre ces différentes interprétations. V. Bérard, dans sa traduction de l'Odyssée ${ }^{147}$, choisit la première solution par rapprochement avec d'autres interventions d'Athéna qui s'achèvent de manière identique ${ }^{148}$. En revanche, l'identification du type de

quence de la violence portée contre Cassandre arrachée à la statue d'Athéna; ceci relève de la catégorie que le savant allemand nomme «naufrage par asébie». Voir également Mc Cartney 1932, p. 214.

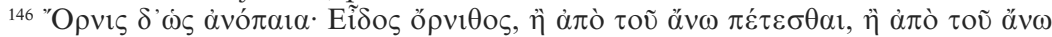

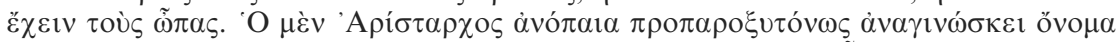

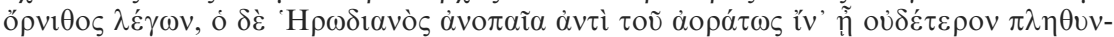

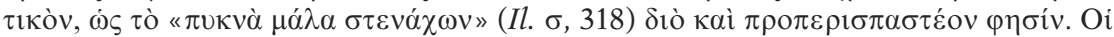

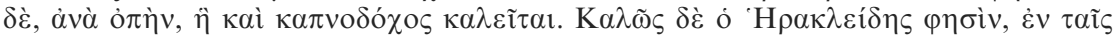

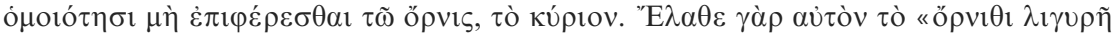

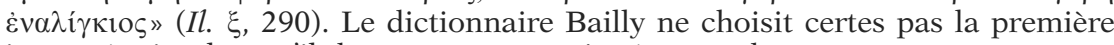
interprétation lorsqu'il donne pour anopaia «à perte de vue».

${ }^{147}$ Éd. Budé, t. I, p. 20.

${ }^{148}$ Par exemple Odyssée III, 372, où Athéna prend l'apparence d'une orfraie. La scholie à $O d$. V, v. 337 rapproche ainsi plusieurs vers homériques dans lesquels une divinité, notamment Athéna, est assimilée à un oiseau; le scholiaste interprète d'ailleurs ces attestations comme des comparaisons et non des méta- 
l'oiseau n'est pas aussi assurée quand il prétend qu'il s'agit d' «un oiseau de mer, mouette, corneille, goéland», les scholies n'évoquant rien de tel ${ }^{149}$. Rien ne permet de confirmer cette hypothèse, bien séduisante il est vrai, mais qu'il nous faut à regret abandonner.

L'épopée homérique comporte par ailleurs un épisode connu explicitement placé sous le signe d'une Aithyia. Ulysse, qui a quitté l'île de Calypso au moyen d'un radeau qu'il a confectionné de ses propres mains, se voit encore en butte à l'hostilité de Poséidon qui déchaîne la mer en ondées déferlantes. Son frêle esquif se renverse et le héros, à bout de force, ne doit d'échapper à la noyade qu'à l'intervention d'Aithyia qui lui délivre un voile (Odyssée V, v. 282462). Or ce n'est pas Athéna qui prend cette apparence, mais Leucothéa-Ino dont le mythe est évoqué en quelques vers ${ }^{150}$. Les éditeurs du texte homérique reconnaissent dans ce passage des rajouts ou modifications postérieurs à l'ensemble du texte, mais les différents manuscrits ne permettent pas de comprendre l'épisode autrement ${ }^{151}$. Il est donc difficile de faire remonter la tradition d'une Athéna Aithyia à l'Odyssée.

Par ailleurs, il faut prendre en compte deux vers des Argonautiques d'Apollonios de Rhodes (IV, 594-595) qui concluent la scène du passage des Planctes par Argô réussi grâce à l'intervention d'Héra et des Néréides. Celles-ci, après avoir accompli leur devoir d'accompagner la navigation du bateau, retournent dans leur demeure marine sous la forme d'aithyiai. Cette tradition hellénistique montre que l'oiseau n'est pas associé à une seule divinité mais à plusieurs : à Ino, aux Néréides et Athéna. Il semblerait que cette faculté de transformation en cormoran ne soit pas l'apanage d'une seule déesse, mais applicable à plusieurs dans un contexte de secours en mer.

Il convient dès lors de définir la nature des interventions d'Athéna Aithyia. Le qualificatif donné à Athéna apparaît au travers d'une source hellénistique. Le poème volontairement énigmatique

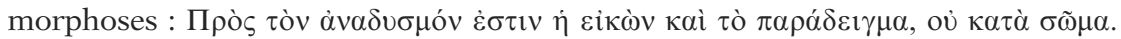

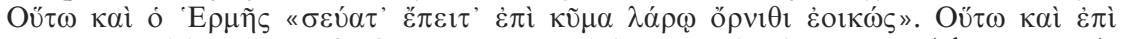

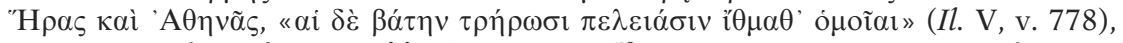

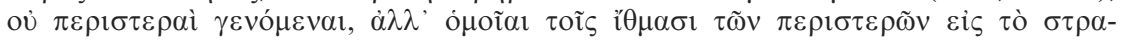

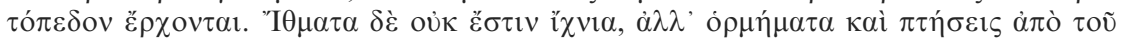

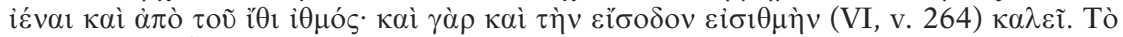

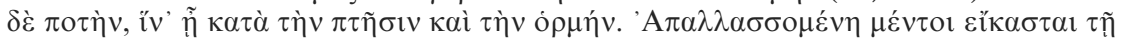

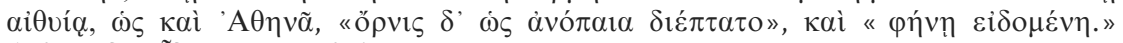

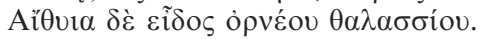

${ }^{149}$ Le dictionnaire Liddell-Scott qui évoque les trois interprétations penche quant à lui pour une sorte d'aigle, par rapprochement avec l'hébreu anapha.

${ }^{150}$ Sur Ino, voir notamment Bonnet 1986; Farnell 1916; Krauskopf 1981.

${ }^{151}$ La position de Detienne 1970, p. 141-142 et 176 n'est pas très explicite; il semble néanmoins ne pas considérer Leucothéa comme une Athéna Aithyia. 
de Lycophron place dans la bouche de Cassandre la prophétie des malheurs à venir aux Achéens suite à l'outrage qu'ils auront fait subir en sa personne à la déesse (Lycophron, Alexandra v. 348-386). $\mathrm{La}$ jeune troyenne crie vengeance et invoque Athéna au moyen

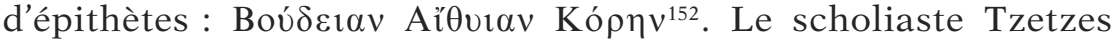
(Scholie à Alexandra, v. 359 = voir corpus p. 539) commente celle d'Aithyia en la rattachant à la science nautique d'Athéna qu'elle a transmise $(\dot{\varepsilon} \delta i \delta \alpha \xi \varepsilon)$ aux hommes. Elle n'est alors nullement rattachée à un lieu ou à quelque héros.

Par ailleurs, deux sources évoquent une intervention d'Athéna envers un homme au bord de la noyade : dans la continuité de l'histoire du retour mouvementé des Grecs après la prise d'Ilion, quelques vers d'Ovide (Métamorphoses XIV, v. 466-476) attribuent le sauvetage de Diomède à Athéna, tandis que la fable d'Ésope, $L e$ naufragé, met en scène un Athénien qui invoque son aide divine dans un moment critique analogue. Le culte de Mégare ne paraît donc pas isolé, mais se rattacher à un ensemble de traditions remontant au moins à l'époque classique.

Quels sont les caractères de cette identification animale? ${ }^{153}$ Un grammairien tardif, Diomédès, souligne le genre féminin du nom en grec contrairement au latin ${ }^{154}$, ce qui a dû faciliter l'assimilation de l'oiseau avec Athéna et Ino. La façon de se déplacer d'Athéna décrite par Apollonios de Rhodes ${ }^{155}$, qui parcourt les étendues marines par les airs sur un nuage au-dessus de la mer pour ensuite se tenir sur une roche, s'apparente au vol des oiseaux de mer. Mais c'est essentiellement une information naturaliste d'Élien (De la nature des animaux VII, 7) qui permet de comprendre l'assimilation. Selon un phénomène déjà observé par Aristote, l'examen du comportement des oiseaux permet de prévoir le temps à venir. Plus précisément, les aithyiai peuvent annoncer un vent violent, et les oiseaux marins de

${ }^{152}$ Kiock 1915, p. 129 et Anti 1920, p. 282 rapprochent cette scène d'une coupe à figures noires (British Museum B379, datée entre 575 et 550) représentant Ajax et Cassandre près de la statue d'Athéna, à droite de laquelle se trouve un oiseau à tête humaine. Ce dernier est identifié comme une sirène par O. Touchefeu («s.v. Aias II», LIMC I, Bern, 1981, 1 p. 339 n 16 et 2 p. 253) qui ne donne cependant aucun commentaire explicatif.

${ }^{153}$ Pour Detienne 1970, p. 140, l'oiseau aithyia possède «la position de médiateur au cœur d'un triangle d'éléments - la terre, l'eau et l'air -», ce qui en fait un «homologue du navigateur» ainsi que du «bâtiment de course».

${ }^{154}$ Grammatici Latini, éd. Keil 1857 : I, 552, 12; l'équivalent latin est mergus.

${ }^{155}$ Argonautiques II, v. 535 ss. Ce déplacement d'Athéna se situe au moment où les Argonautes s'approchent du redoutable passage des Roches Symplégades. 
façon générale une tempête ${ }^{156}$. Cette faculté s'apparente à l'épiclèse d'Athéna à Mothone en relation directe avec les vents ${ }^{157}$. Cela peut aussi évoquer indirectement la science de la navigation qui comprenait sans doute ce genre de connaissances, de même que l'utilisation d'oiseaux à bord afin de se repérer par rapport à la terre ${ }^{158}$.

Si les sources littéraires permettent de se faire une idée de la personnalité d'Athéna Aithyia, aucune représentation iconographique n'est rattachable de façon assurée à celle-ci. Une olpé attique $^{159}$ datée vers 520-500 av. figure un personnage féminin ailé, muni d'une lance et la tête coiffée d'un casque, transportant un homme nu inanimé au-dessus de la mer. La scène a été interprétée par C. Anti ${ }^{160}$ comme Athéna ailée transportant le corps de Pandion, ce que conteste P. Demargne, arguant de l'absence totale de parallèle iconographique ${ }^{161}$. Quoi qu'il en soit, le casque et la lance définissent une Athéna et non Éos comme il a été également proposé $^{162}$.

La fameuse coupe attique à figures noires de Nicosthénès conservée au Musée du Louvre est également évoquée à propos d'Aithyia. Deux scènes se déroulent de part et d'autre du vase, figurant des bateaux naviguant de concert que regarde un oiseau à tête de femme ${ }^{163}$. Celui-ci est interprété généralement comme une Sirène, mais aussi par certains comme une Athéna Aithyia ${ }^{164}$. En effet, l'atmosphère de la scène plutôt sereine ne témoignant d'aucune tension dramatique, rien n'autoriserait à y reconnaître une

${ }^{156}$ Sur les animaux annonciateurs du temps, voir Mc Cartney 1921, notamment p. 91-92.

${ }^{157}$ Mc Cartney 1933, p. 3.

${ }^{158}$ Luzón Nogué \& Coín Cuenca 1986, p. 65-85 ont par ailleurs mis en évidence l'utilisation de l'oiseau dans la navigation antique, ce dont l'épisode argonautique du passage des Symplégades avec la colombe constituerait une illustration. Selon eux, l'épiclèse d'Aithyia renverrait à cette pratique, de même que ses liens avec le corbeau et la corneille ainsi que la faculté de la déesse de voir dans le noir. Cf. également Detienne 1970, p. 145 et note 3.

${ }^{159}$ Paris, Cabinet des médailles inv. 260. Anti 1920, p. 270-318; Demargne 1084, 1 p. 964 n $^{\circ} 61$ (avec une erreur concernant les sources : le v. II, 600 d'Apollonios de Rhodes est cité à tort comme mentionnant une Athéna ailée, alors que l'adjectif qualifie Argô) et p. 1019; 2 p. 710.

${ }^{160}$ Anti 1920, p. $287-288$ et fig. 9.

${ }^{161}$ L'auteur reconnaît l'existence d'un type d'Athéna ailé qu'il conclut archaïque et originaire de la Grèce de l'Est, mais lui refuse tout lien avec une tradition maritime.

162 Demargne 1984, loc. cit.

${ }^{163}$ Musée du Louvre inv. F123. Morrison \& Williams 1968, Arch. 57 p. 98 et pl. 15 a-b; Casson 1991, pl. 5c.

${ }^{164}$ Reddé 1986, p. 124; Anti 1920, p. 285 et fig. 6. 
représentation de l'épisode d'Ulysse. Pour les deux vases, il faut admettre l'impossibilité de trancher entre les différentes lectures ${ }^{165}$.

c) Athéna et la victoire sur mer : la déesse athénienne

Ce double caractère d'Athéna-oiseau et de protectrice du voyage en mer s'enrichit dans des circonstances particulières des qualités guerrières de la déesse ${ }^{166}$. À Athènes, où la déesse occupe la première place en tant que divinité poliade, elle devient l'égérie de la victoire obtenue en mer. L'heureuse issue de la Seconde Guerre médique est ainsi attribuée à la puissance d'Athéna. Une tradition rapportée par Plutarque (Thémistocle 12,1) explique qu'une chouette apparue aux Grecs avant Salamine, se posant sur le mât de la trière de Thémistocle, leur avait donné bon espoir dans le plan proposé par celui-ci ${ }^{167}$. Cette anecdote fabriquée a posteriori synthétise en quelque sorte les traditions existant à l'époque classique concernant les liens d'Athéna avec la mer. Le motif de l'Athéna à l'aphlaston commémore donc la victoire de Salamine due, selon les Athéniens, à la protection sans faille de leur divinité. Une autre anecdote rapportée par Plutarque (Cimon 5, 2) montre comment celle-ci a su évoluer et s'adapter aux usages athéniens. La figure politique de Cimon, au moment le plus critique de la Seconde Guerre médique alors que les Athéniens hésitent à quitter leur ville pour s'engager dans la flotte créée par Thémistocle, montre l'exemple à suivre. Pour ce faire, il choisit la manière symbolique et religieuse : il se rend sur l'Acropole pour consacrer à la déesse un mors de cheval signifiant ainsi que l'avenir serait naval ou ne serait pas. Cet épisode est significatif : le culte et la personnalité d'Athéna suit la vie politique et les grandes orientations de ses dirigeants. Lorsqu'Athènes devient une puissance maritime, son Athéna Poliade le devient aussi et naturellement protège les activités militaires de sa flotte. Aristophane (Cavaliers, v. 1181-1186) se fait l'écho de cette croyance; en témoignent sans doute également les représentations de trières retrouvées sur l'Acropole (voir infra p. 395) ainsi que les noms référant à la déesse dans l'onomastique navale athénienne du IV e s. (voir infra p. 277 s.).

${ }^{165}$ Nous n'avons retenu ici que les deux cas les plus vraisemblables. Anti 1920 présente un certain nombre d'autres vases et statues qu'on ne peut sans parti pris excessif accepter comme des représentations possibles d'Athéna marine.

${ }^{166}$ Sur Athéna guerrière, voir Vian 1968, p. 57-58 et 64-66.

${ }^{167}$ L'anecdote est reprise de façon très allusive par Aristophane, Guèpes,

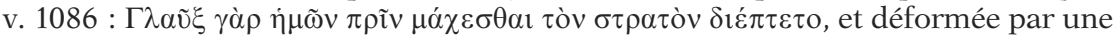

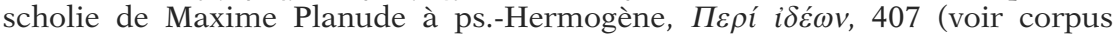
p.539), qui cantonne le vol de la chouette au dessus de la flotte athénienne et voit plutôt une colombe se poser sur la trière du stratège (voir infra, p. 115). 
Cette tutelle d'Athéna sur la flotte de guerre n'est pas exclusive à Athènes. D'autres cités lui attribuent une puissance analogue : c'est le cas de Lindos, ainsi que peut-être de Milet et Smyrne, mais c'est à Athènes qu'elle est le plus affirmée.

La toute puissance d'Athéna incluant le domaine maritime est célébrée dès l'époque archaïque (Hymne homérique à Athéna, v. 9-16). On la retrouve beaucoup plus tard affirmée par Apulée (Métamorphoses XI, 3-XI, 17) en ce qui concerne le culte athénien. Isis apparue à Lucius énumère les noms et formes sous lesquels elle est honorée à travers l'oikoumène oriental; parmi ceux-ci, elle cite l'Athéna Kékropienne des Athéniens autochtones. Le rapprochement n'est pas fortuit et renvoie à une dimension marine du culte de la fille de Zeus - quoique bien sûr bien moindre en importance que celui de la déesse égyptienne.

\section{HÉRA}

Depuis les années 1990, de nombreux travaux ont porté sur le caractère du culte d'Héra à l'époque archaïque, axés essentiellement sur la comparaison entre les différents Héraia du monde grec occidental et oriental ${ }^{168}$. Ces études ainsi que les découvertes archéologiques des quarante dernières années ont mis en évidence le lien privilégié existant entre cette déesse et la mer. Il ne s'agit pas ici de répéter ce qui a déjà été (bien) écrit sur ce sujet, mais d'examiner cette relation et ses manifestations cultuelles, depuis l'époque archaïque jusqu'à l'époque hellénistique. Les sources littéraires, peu nombreuses, sont complétées par des témoignages archéologiques importants, pour la plupart développés dans la seconde partie puisqu'il s'agit d'ex-voto navals ${ }^{169}$.

\section{LES SOURCES}

Mythologie et épopée

Les interventions maritimes d'Héra dans l'épopée se limitent à l'épopée de Jason, ainsi que peut-être à la légende d'Agamemnon.

${ }^{168}$ Citons en particulier : le très riche Colloque Héra 1997; Parisi Presicce 1985 (un article essentiel sur Héra et la navigation).

${ }^{169}$ Dans notre étude, les offrandes de bateaux provenant des sanctuaires d'Héra sont d'abord considérées comme des offrandes liées au monde de la navigation, même si elles ont pu en même temps revêtir d'autres aspects symboliques : voir à ce sujet Polignac 1997, et son résumé par Parker 2011, p. 90-91. 
a) L'épopée homérique

Héra se voit attribuer un rôle dans la navigation héroïque dès Homère. Deux vers de l'Odyssée (IV, v. 512-513) semblent lui prêter la survie d'Agamemnon lors de son retour de Troie par mer. Ce passage qui narre le destin des chefs grecs par le biais du discours de Protée à Ménélas est peu clair. Il est difficile de déterminer si cette aide divine s'est manifestée par le fait même que le père d'Égisthe ait pu quitter Troie sain et sauf sur son bateau, ou si Héra lui a permis d'échapper au courroux de Poséidon qui a frappé les Achéens - tel Ajax, dont le funeste destin est raconté par le Vieillard de la mer dans les vers qui précèdent -, en évitant la mort dans les parages du cap Malée évoqué aux vers suivants ${ }^{170}$.

En dehors de cette allusion, l'intervention maritime majeure de la déesse dans le texte homérique consiste déjà en ce qui sera développé plus tard avec le succès que l'on sait. La légende des Argonautes est en effet évoquée dès l'Odyssée (XII, 55-100), à travers la scène du passage difficile des roches Planctes qu'Héra

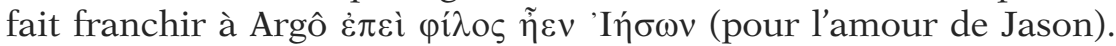
Comme dans le passage précédent relatif à Mélénas, l'épisode ne fait pas l'objet d'une description, mais est mentionné rapidement à travers des discours narratifs. Tous deux paraissent donc appartenir à une tradition bien établie à l'époque de la fixation de l'Odyssée.

b) Épopée argonautique

Le pouvoir maritime d'Héra donne sa pleine mesure dans le périple argonautique ${ }^{171}$. Nous avons déjà évoqué (p. 24 ss.) l'évolution croissante de sa participation dans le mythe par rapport à celle d'Athéna. Elle intervient à deux reprises lors de moments particulièrement critiques du retour des héros depuis la Colchide. Un premier danger les menace lorsque Zeus veut les punir du meurtre d'Apsyrtos et les mener à leur perte (Apollonios de Rhodes IV, v. 576-595). Héra contrecarre les projets de son époux en suscitant

${ }^{170}$ Les vers $514-520$ semblent douteux : ils constitueraient un rajout pour tenter de concilier deux traditions concernant la mort d'Agamemnon, la seconde ayant pour cadre les environs du cap Malée - où Agamemnon n'avait rien à faire dans un itinéraire joignant la Troade à l'Argolide. Voir Bérard dans Odyssée, éd. Budé, t. I p. 104-105.

${ }^{171}$ Mc Cartney 1933, p. 5-6. 
des vents qui contraignent le bateau à revenir sur sa route, parce

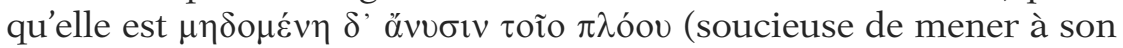
terme cette navigation). Peu après (IV, v. 640-653), elle évite aux héros de s'engouffrer dans l'Océan sans retour en retenant Argô, puis les préserve de l'attaque des Celtes et Ligures grâce à la diffusion d'une brume qui les cache à la vue. Apollonios de Rhodes attribue l'issue heureuse de cette partie du périple de la quête de Circé à Héra ainsi qu'aux Dioscures, qui ont servi d'intermédiaires avec les dieux et guidé le bateau. Après la rencontre avec la magicienne, les Argonautes entreprennent le trajet du retour et survient le fameux passage des Planctes (ibid. IV, v. 576-967, résumé très brièvement par le Pseudo-Apollodore (Bibliothèque I, ix, 25). Héra permet de franchir cette passe difficile, non pas en agissant directement mais en faisant intervenir un certain nombre d'acteurs divins. Tout d'abord, par l'intermédiaire d'Iris, elle transmet des ordres à Héphaistos et Éole pour qu'ils retiennent l'un le feu de ses forges, l'autre ses vents à l'exception d'un doux Zéphyr. Ensuite, ayant fait venir Thétis du fond de la mer, elle l'entretient longuement pour l'inviter à protéger Argô avec l'aide de ses sœurs les Néréides. Héra déclare alors qu'elle est apte à sauver Jason et ses compagnons dans ce passage des Planctes, notamment par les ordres donnés aux dieux du feu et des vents. L'action simultanée des uns et des autres permet en effet à Argô de poursuivre son chemin sans dommage. Il est à noter qu'Héra n'intervient pas physiquement dans l'épisode ni n'est présente sur les lieux: elle contemple la scène depuis les hauteurs célestes. C'est aux filles de Nérée que revient le rôle magnifiquement décrit de faire danser le bateau sur les vagues en évitant les écueils.

Dans les versions postérieures, Héra assume dès le début du projet un autre rôle: elle se charge d'affirmer la renommée de l'expédition et de lui assurer un équipage (Valerius Flaccus, Argonautiques I, v. 91-99), ou d'ordonner à Athéna la construction de la nef (Argonautiques orphiques, v. 59-69); c'est encore elle qui envoie un vent favorable lors du départ (ibid., v. 361-362). Elle intercède en outre dans le passage difficile des roches Kyanées (carte 10) : en incitant Athéna d'envoyer un héron pour guide selon les Argonautiques orphiques (v. 680-711), tandis que Valerius Flaccus (IV, v. 670693) la fait intervenir en personne dans le franchissement des écueils. Junon retient l'un des deux tandis qu'Athéna exerce sa force sur l'autre; l'action conjointe des deux déesses permet à Argô de ne pas être écrasée.

L'aide d'Héra apparaît ainsi plus concrète à travers les épopées tardives. Cependant, l'ensemble de l'épopée argonautique montre un visage autoritaire de la déesse qui, par ses directives, facilite la bonne marche du périple. 
Témoignages cultuels

Un certain nombre de sources littéraires mentionne de manière inégale une poignée de sanctuaires où l'on honore une Héra marine ${ }^{172}$. Ceux-ci sont davantage connus par l'exploration archéologique et le matériel mis au jour ${ }^{173}$.

\section{a) Pérachora}

En Grèce continentale, Héra possède, semble-t-il, un seul sanctuaire lié au monde maritime. À Pérachora, sur le territoire de la ville de Corinthe, à l'extrémité nord-ouest, s'élance une pointe rocheuse dans le golfe du même nom. Le site est particulièrement évocateur : une anse naturelle au bout d'un finistère faisant face au sud au port du Léchaion (fig. 4) ${ }^{174}$.

Le sanctuaire d'Héra entoure ce mouillage de plusieurs édifices. Il apparaît dans deux sources littéraires tardives mais contemporaines. Strabon (Géographie VIII, 6, 22) mentionne au passé «entre Léchaion et Pagai» un manteion d'Héra Akraia. Le lieu, qui s'avère donc à l'abandon au tout début de notre ère, est difficile à situer par rapport au parcours du géographe. L'information de Tite-Live (Histoire romaine XXXII, 23, 10) est plus précise à cet égard quand il évoque un promontoire face à Sicyone consacré à Junon Acraea.

L'endroit a été fouillé par l’École américaine sous la direction de H. Payne dans les années $1930^{175}$. Le sanctuaire se compose d'un temple et de nombreux bâtiments annexes répartis sur plusieurs niveaux de la colline; en ce qui concerne le bord de mer, sur le petit port lui-même se trouvent le temple et son autel encadrés de deux espaces de réunions - stoas et cours ouvertes - tournés vers le port. On a notablement insisté sur les aménagements d'eau douce à

172 Wachsmuth 1967, note 1830.

${ }^{173}$ Respectant le principe exposé dans l'introduction, ne sont pas traités ici systématiquement tous les sites pour lesquels on a pu supposer un culte d'Héra plus ou moins lié avec la mer, ou certains sanctuaires dont la divinité n'est pas identifiée et qu'on lui attribue. L'article Loicq-Berger \& Renard 1982 recèle ainsi de nombreux sites présupposés en Occident dont nous n'avons pas tenu compte.

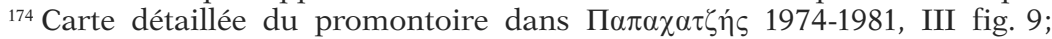
Semple 1927, p. 374. Bonne présentation des atouts nautiques dans NavaroLefèvre 2000, p. 42-44 et 55.

${ }^{175}$ La publication des fouilles est parue en 1940 (Payne 1940), celle du matériel en 1962 (Dunbabin 1962); résumé des remises en cause à propos des datations et hypothèses dans Novaro-Lefèvre 2000, p. 45 ss. 


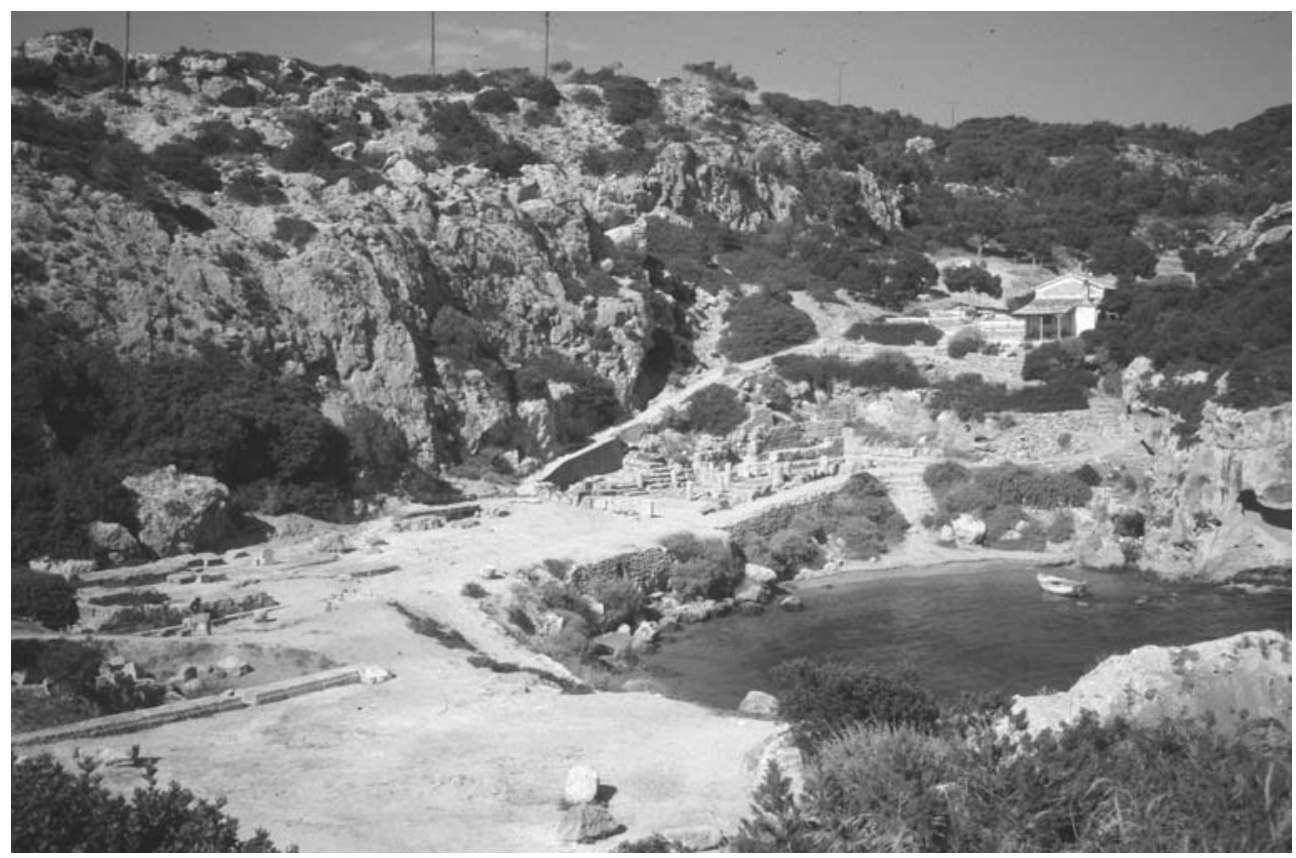

Fig. 4 - L’Héraion de Pérachora, partie ouest (Photo de l'auteur).

l'intérieur du sanctuaire qu'on met en relation avec l'oracle mentionné par Strabon ${ }^{176}$. D'autres rites y étaient sans doute pratiqués : d'initiation, de protection de la fécondité et peut-être chtoniens ${ }^{177}$. Parmi le matériel du sanctuaire est à signaler la présence d'un modèle réduit de bateau de terre cuite (voir infra p. 375) et de deux harpons en bronze, ainsi que du corail (voir infra p. 505) et de nombreux objets d'origine orientale déposés entre la fin du VIII ${ }^{\mathrm{e}} \mathrm{s}$. et le VII ${ }^{\mathrm{e}}$ s. a.C. ${ }^{178}$.

L'épiclèse d'Akraia (des Cimes ou des Promontoires), connue par les sources littéraires et des inscriptions d'époque classique, ainsi que celle de Liménia que renseignent des inscriptions du

${ }^{176}$ Sur l'aspect oraculaire du sanctuaire lié à un bassin sacré au fond duquel on a retrouvé quelque 200 phiales de bronze et à un passage d'Hérodote $(\mathrm{V}, 92)$ : Tomlinson 1992; Will 1953, p. 145-169. Wachsmuth 1967, note 188 reprend l'hypothèse de Dunbabin 1951 qui considérait le geste de jeter une phiale dans un bassin comme un rituel effectué en l'espoir de bonne navigation.

${ }^{177}$ Synthèse dans Novaro-Lefèvre 2000, p. 59-68.

${ }^{178}$ Harpons : Payne 1940, p. 73 et 182 , avec pl. 17 ( $\left.n^{\circ} 9\right)$ et 80 ( $\left.n^{\circ} 6\right)$. NovaroLefèvre 2000, p. 65-66. 
$\mathrm{VI}^{\mathrm{e}} \mathrm{s}$. renvoient manifestement au caractère maritime du sanctuaire (promontoire et port), même s'il n'est pas clairement affirmé par tous ${ }^{179}$. Deux inscriptions attestent une troisième épiclèse, plus ancienne: Leukôlenos (Aux bras blancs): terme récurrent pour désigner l'épouse de Zeus et de belles jeunes femmes dans les poèmes homériques ${ }^{180}$. Les nombreuses études consacrées au sanctuaire discutent du culte qui y était pratiqué : oraculaire, garant de la fécondité, et de son origine (Mégare, ou Corinthe et Argos - en liaison avec le grand Héraion de la cité181). Le site de Pérachora et son avancée dans le golfe de Corinthe, outre ses atouts forestiers et d'avant-poste d'observation, devait particulièrement être fréquenté par les caboteurs et marins modestes de cette partie du golfe ${ }^{182}$.

\section{b) Îles de la mer Égée}

Le culte d'Héra apparaît rattaché avec le monde maritime dans trois îles : à Thasos, à Délos et bien évidemment à Samos.

- Thasos

À l'entrée du sanctuaire de Poséidon à Thasos, situé au voisinage du port militaire et non loin du port de commerce, a été trouvé un autel d'Héra Épiliménia (Littorale) ${ }^{183}$. Cet autel monumental en marbre, placé à l'extérieur au sud de la grande entrée du téménos (soit juste à droite des portes pour celui qui arrive depuis la place), présente en caractères archaïsants une loi sacrée interdisant le sacrifice de chèvres à la déesse. Dans la zone portuaire thasienne était donc honorée une Héra marine que l'on devait remercier d'être arrivé à bon port.

${ }^{179}$ Parmi les partisans d'un sanctuaire maritime : Höckmann 1985, p. 157 en évoquant simplement le cadre d'un «Hafenbucht» et Novaro-Lefèvre 2000 (jugement nuancé); Tomlinson 1992, pour sa part, occulte totalement cet aspect.

${ }^{180}$ Novaro-Lefèvre 2000, p. 45-52; les inscriptions sont datables entre le milieu du VIII ${ }^{e}$ s. et le milieu du VI ${ }^{\mathrm{e}}$ s. a.C. Pour l'auteur, le blanc, commun à plusieurs divinités aquatiques, présente un lien avec la mer, mais aussi l'initiation, le passage et la mort. Cette thématique du blanc est reprise également par Romero Recio 2010, p. 113 à propos d'Athéna à Skyros.

${ }^{181}$ Will 1955, p. 81 ss. voyant une influence du sanctuaire de Pérachora sur le culte corinthien de Médée.

${ }^{182}$ Ibid., p. 36-38.

${ }^{183}$ BCH LI, 1927, p. 488-489; Bon \& Seyrig 1929, p. 345-347; Grandjean \& Salviat 2000, p. $52-57$ (ports), 97, 230 et fig. 12. L'inscription figure dans les IG XII, suppl., 409. 
- Délos

Un inventaire délien de l'Héraion ${ }^{184}$ mentionne une Héra $\dot{\varepsilon} v$ $\lambda \mu \mu \varepsilon v i ́$. Le texte, daté vers le milieu du $\mathrm{II}^{\mathrm{e}} \mathrm{s}$. a.C., énumère pour le prodomos du temple les objets qui y sont conservés; parmi eux figure ce qui semblerait être un tableau votif appartenant à la déesse ${ }^{185}$. Cette mention unique pour Délos d'une Héra mise en relation avec la mer est loin d'être explicite : faut-il supposer une Héra honorée sur le port par une quelconque construction, ou le culte dans l'île d'une Héra avec l'épiclèse de Liménia ou d'Épiliménia? Et s'il s'agit bien d'un tableau votif, que représentait-il : la déesse, une scène en relation avec le monde maritime? ${ }^{186}$ Mise à part la présence de fragments de corail parmi le matériel du sanctuaire ${ }^{187}$, l'absence d'autres témoignages ne permet pas aujourd'hui de définir l'importance et la portée, privée ou collective, du culte d'une Héra marine délienne.

\section{- Samos}

De nombreuses sources concernent le sanctuaire et le culte de l'île désignée par Xénophon d'Éphèse (Éphésiaques I, xi, 2) ทं $\tau \tilde{\eta} \varsigma$

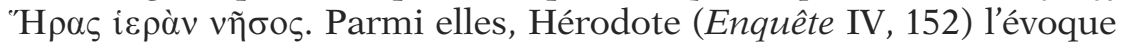
en premier lieu à propos d'un épisode des navigations hasardeuses archaïques. Des Samiens sous la conduite de Kolaios se rendant en Égypte furent détournés de leur route - l'expression est faible! - par un fort vent d'est au-delà des Colonnes d'Hercule. Ils bénéficièrent

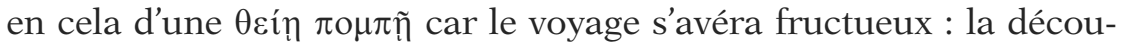
verte de Tartassos leur permit de revenir chez eux en ayant réalisé un bénéfice considérable, le deuxième en taille jamais obtenu par un Grec, selon Hérodote. Ils consacrèrent alors la dîme s'élevant à six

${ }^{184}$ Sur l'Héraion de Délos, qui se trouve presqu'au pied de l'escalier N.-O. du Cynthe, sur la terrasse des dite des dieux étrangers, et dont le premier état remonte à la fin de l'époque géométrique, voir Bruneau \& Ducat 2005, p. 279-281 $\left(n^{\circ} 101\right)$.

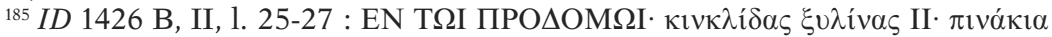

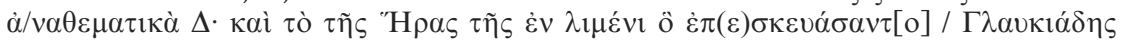

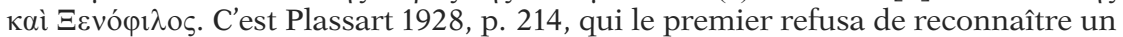
agalma de la déesse, mais plutôt un pinax; son interprétation fut ensuite reprise par tous. Synthèse du dossier : Duchêne \& Fraisse 2001, p. 159.

${ }^{186}$ Vallois 1944, p. 66 semble reconstituer une chapelle sur le port à l'emplacement futur de la salle nord du Portique de Philippe, avec un tableau votif la représentant - elle ou la déesse - dans le prodomos de l'Héraion; avant lui, Roussel 1987, p. 245, supposait l'existence d'une chapelle désaffectée sur le port, dont on aurait ramené la statue à l'Héraion; enfin Bruneau 1970a, p. 245, suppose l'existence d'une statue d'une Héra Liménia ou Épiliménia sur le port, par rapprochement avec Pérachora et Thasos (voir supra et infra).

${ }^{187}$ Tassignon 2005, p. 295 et 301. 
talents en un trépied de bronze dans l,Héraion ${ }^{188}$. Ce don remercie vraisemblablement la déesse de cette navigation heureuse dont elle est reconnue comme l,instigatrice : la pompè qui les guida devait sans nul doute être la sienne.

Les fouilles du sanctuaire situé à $6 \mathrm{~km}$ de la ville ont mis en évidence son importance à l,époque archaïque ${ }^{189}$. Un nombre appréciable d,,ex-voto permet d,,esquisser les facettes de la personnalité de l,Héra samienne $\mathrm{e}^{90}$. Entre autres offrandes, on compte une vingtaine de modèles réduits $\mathrm{d}$,, esquifs en bois datés du VII e $\mathrm{s}$., tandis qu,,une inscription du $\mathrm{VI}^{\mathrm{e}} \mathrm{s}$. marque la consécration de sept embarcations à Héra et Poséidon (voir infra p. 372). Le long de la voie processionnelle ont été dégagé, en outre, deux bases effilées ayant supporté deux bateaux grandeur nature (voir infra p. 354 s.). Ÿ ces documents, il faut rajouter la présence parmi le matériel du site d,un graffite naval et d, une base ornée d,,une proue (voir infra p. 408 et 413), ainsi que le tableau votif de Mandroclès figurant le pont de bateaux de Darius connu par des sources littéraires (Hérodote, Enquête IV, 87-89; Anthologie Palatine VI, 341; voir infra p. 402) ${ }^{191}$.

Des fêtes de la déesse dénommées Tonia sont attestées pour le III s. a.C. par Ménodotos ( Fgt 1, éd. Jacoby = Athénée, Deipnosophistes XV, 672 a-e) qui rapporte à ce sujet la tradition suivante. La procession escorte la statue d,Héra jusqu,,au bord de la mer ${ }^{192}$ au

${ }^{188}$ Vélissaropoulos 1980, p. 27; Bürchner, 's.v. Samos', RE XXIV, Stuttgart, 1920, col. 2203.

${ }^{189}$ Sur 1,Héraion, voir la synthèse de Walter 1990; Furtwängler 1997; Zapheiropoulou 1997. Les fouilles, commencées par Cavvadias dans les années 1890 et menées par les Allemands depuis les années 1910, ont fait l,objet d,,un certain nombre de publications archéologiques par le Deutsches archäologisches Institut sous le simple titre générique de Samos.

190 Ÿ travers Brize 1997, se dessinent pour Héra les rôles de protectrice du mariage, de la maison et de kourotrophe... L,auteur (p.137) rattache cette pluralité de fonctions à la divinité carienne Hékaté, célébrée dans les vers 411-452 de la Théogonie hésiodique.

${ }_{191}$ Tassignon 2005, p. 295 et 303 signale également deux fragments de corail, offrande archaïque qu,,elle considère comme l,équivalent contemporain des modèles de bateaux ou de maisons.

${ }^{192}$ Brize 1997, p. 136, affirme qu,à cette occasion la statue aurait été lavée dans la mer. Le texte de Ménodotos rapporté par Athénée évoque d,un côté la purification de la statue suite à l,épisode du rapt des pirates avant qu,,elle ne soit replacée sur son socle, et de l,autre le fait de $\dot{\alpha} \varphi \alpha \gamma v i ́ \zeta \varepsilon \sigma \theta \alpha$ c celle-ci lors des fêtes. Le bain d,\#Héra dans la mer est énoncé au conditionnel par Ginouvès1962, p. 289 et p. 383 : si le mot signifie bien laver, rien n,,assure que cette opération n,,ait pas été réalisée dans le sanctuaire (cf. Zapheiropoulou 1997, p. 153). Romero Recio (2000, p. 138-139 et 2010 , p. 95-100) restitue au contraire une procession avec bain purificateur dans la mer, à la manière de celle réalisée pour une statue de la Vierge ou d, un saint. 


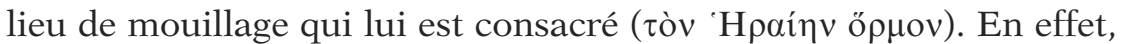
c'est là que l'auraient laissée des pirates tyrrhéniens venus pour la voler, mais qui n'auraient pu quitter le rivage avec l'objet du délit malgré force coups de rames ${ }^{193}$. Les autochtones, ayant cru d'abord en un départ volontaire de la statue puis l'ayant retrouvée et rétablie sur sa base, pensent ainsi l'honorer en la ramenant au port tous les ans. Cette tradition montre le lien qui unit Héra à la mer, plus précisé-

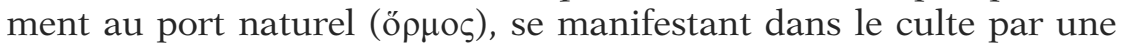
procession. L'anecdote étiologique souligne de plus le pouvoir de la divinité en manière de navigation qui peut aussi bien entraver la marche d'un navire. Pausanias (VII, iv, 4) propose deux versions pour l'origine de la statue et la fondation du sanctuaire : une locale et une argienne, la seconde remontant aux Argonautes ${ }^{194}$.

Toutes ces sources diverses attribuent sans conteste un rôle maritime important à l'Héra samienne pour les VII e-VIe $\mathbf{s} .{ }^{195}$ que beaucoup mettent en relation avec la puissance navale de la cité à l'époque archaïque ${ }^{196}$.

\section{c) Grande Grèce}

C'est en Grande Grèce que le culte marin d'Héra se montre le mieux représenté : quatre sanctuaires maritimes lui sont consacrés (carte 12).

\section{- Crotone}

L'Héraion de Crotone est bien attesté au travers des sources littéraires. Lycophron est le premier en date à évoquer (Alexandra, v. 856-858) un Lacinion à propos des errances d'Agamemnon sur mer après la guerre de Troie : le sanctuaire situé non loin du fleuve

${ }^{193}$ Wachsmuth 1997, p. 268 range ce témoignage parmi les cas de «naufrage par asébie».

${ }^{194}$ En outre, le trône de l'agalma serait une offrande d'un certain Aeakès prise sur la sylè (droit de saisie) : Syll. ${ }^{3}, 10$. La sylè peut être ou terrestre ou maritime; Vélissaropoulos 1980, p. 27 opte pour la seconde possibilité. Le passage de Ménodotos, comme celui de Pausanias (voir commentaire de П $\alpha \pi \alpha \chi \tau \zeta \zeta ́$ 1974-1981, IV p. 37-38), établit également un lien ancien entre l'Héra samienne, Argos et l'osier.

195 Johnston 1985, p. 50-51; Höckmann 1985, p. 157-160; Parisi Presicce 1985, p. 66-67; Polignac 1997, p. 116. Certains cependant refusent tout culte maritime et lient les présences de bateaux dans le sanctuaire à un rite de fertilité selon lequel on les porte en procession - à la manière de la fête contemporaine se déroulant près de l'Héraion du Sele (voir infra) : par exemple Kyrieleis 1980, p. 92-94, ou encore P. Lévêque concluant Colloque Héra 1997, p. 267-270.

${ }^{196}$ Par exemple Kyrieleis 1980, p. 92-94; Basch 1987, p. 242 ss. Romero Recio 2010, p. 99, considère en outre qu'avant l'aménagement de la voie sacrée, l'accès principal au sanctuaire se faisait par mer. 


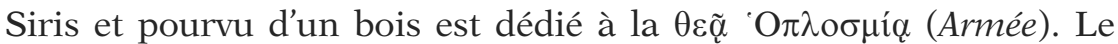
scholiaste Tzetzès éclaire l'allusion en précisant la localisation sur le promontoire crotoniate par quelques vers du poète du III ${ }^{e}$ s. a.C., Théocrite, qui cite également, dans une autre Idylle (IV, v. 33), à propos d'un sacrifice, le lieu consacré. Celui-ci se trouve sur la route de la flotte athénienne faisant voile contre la Sicile, au-delà de la cité de Crotone; il est alors mentionné comme un hiéron d'Héra Lacinia (Diodore, Bibliothèque historique XIII, 3, 1-4). De même, l'épopée virgilienne (Énéide III, v. 551-553) compte le site de la diva Lacinia du golfe de Tarente parmi ceux qui se révèlent aux yeux émerveillés des Troyens fugitifs qui remontent le littoral italien.

Strabon (Géographie VI, 1,11) se fait plus précis en définissant le Lacinion du littoral de Crotone comme un hiéron d'Héra dont il rappelle la richesse passée. Tite-Live (Histoire romaine XXIV, 3, 3-7) s'attarde sur ce sujet en décrivant notamment le caractère bucolique du lieu, avec ses troupeaux paissant librement. Il insiste sur sa célébrité et sa popularité, et la particularité de son autel situé dans le vestibulo du temple dont la cendre n'était remuée par aucun souffle. Ce prodige est également rapporté par Pline l'Ancien (Histoire naturelle II, 240) qui le représente, pour sa part, en plein air (sub diu sita) et exposé à des bourrasques. Enfin, on sait depuis Aristote (De mirabilibus auscultationibus, 96 = Deipnosophistes XII, 541 a-b) que la fête du Lacinion rassemblait tous les Grecs d'Italie.

Le site est notable encore aujourd'hui par l'unique colonne dorique restante du temple se dressant au bord de la mer ${ }^{197}$, qui a donné son nom actuel au promontoire Capo Colonna. Celui-ci s'avance fortement dans les eaux, fermant le golfe de Crotone : le sanctuaire extra-urbain devait constituer ainsi une limite du territoire crotoniate au sud. Les fouilles ont révélé la grande superficie de l'Héraion, les nombreux bâtiments qui le composaient et les phases d'occupation. Il semblerait que le temple encore visible aujourd'hui, daté du Ve s. a.C., ait été précédé d'un autre situé au même endroit, peut-être daté du milieu du $\mathrm{VI}^{\mathrm{e}} \mathrm{s}$. Au nord, a été dégagé un bâtiment sacré nommé $B$, antérieur au temple classique. Les archéologues considèrent que l'édifice B et la plupart des offrandes qu'il contenait constituent les premiers témoignages d'un culte sur le promontoire ${ }^{198}$.

${ }^{197}$ La variation du niveau de la mer et d'autres modifications géologiques font que les vestiges du temple se trouvent aujourd'hui en partie effondrés sur le rivage. Les recherches archéologiques sous-marines effectuées le long du promontoire n'ont rien relevé qui puisse avoir appartenu au temple (Roghi 1971, p. 310-315).

${ }^{198}$ Principaux résultats dans Crotone 1984; Spadea 1997; Mezzetti 2009. Au début des années 2000, dans la zone d'habitat romain, ont été découverts des 
Deux consécrations d'importance concernant le monde maritime sont à noter dans cette zone. Un bateau de bronze de type sarde fait partie des ex-voto de valeur consacrés à Héra (voir infra p. 376377). Par ailleurs le célèbre jas de pierre portant une dédicace à Zeus Meilichios de la part de l'athlète Phayllos de Crotone, retrouvé à proximité, pourrait se rattacher au sanctuaire (voir infra p. 464 ss.). Les deux objets datent de l'époque archaïque.

\section{- Poseidonia}

Sur la façade tyrrhénienne, près de la cité de Poseidonia, à l'embouchure du fleuve Siris se tient un Héraion appelé communément Héraion du Sele. Strabon (Géographie VI, 1, 1) signale l'existence à cet endroit d'un sanctuaire d'Héra Argienne dont il attribue la fondation à Jason ${ }^{199}$. Le site a été fouillé par les Italiens dans les années 1940; les travaux ont repris dans les années 1990200. Parmi le matériel du temple figure un certain nombre d'hameçons; une hypothèse bien répandue y reconstitue par ailleurs un rituel de fête avec procession de bateaux (voir infra p. 74 et 454-455). L'emplacement du sanctuaire est remarquable : le fleuve permet l'accès jusqu'aux massifs Apennins voire au-delà; de plus il constituait une frontière naturelle avec l'Étrurie. Il a dû être très tôt fréquenté par des marchands venus de Grèce ${ }^{201}$.

\section{- Pythécusses et Cumes}

Un peu plus au nord, à Ischia, un dépôt archaïque voué à Héra a livré des objets en terre cuite, dont des modèles de bateaux (voir infra p. 372-373). Les Eubéens, colons de l'île de Pythécusses, auraient ensuite rejoint le continent voisin de pour y fonder Cumes : dès leur implantation sur le littoral, ils auraient consacré un temple et un xoanon à la déesse ${ }^{202}$. Le culte d'Héra y est en effet attesté archéologiquement pour l'époque archaïque, dès le VIII ${ }^{\mathrm{e}}$ s. a.C., dans un sanctuaire situé au sud-ouest de la cité, sur un promontoire, près du port grec supposé; le matériel recueilli à cet endroit couvre une large période, du $\mathrm{VII}^{\mathrm{e}}$ s. a.C au $\mathrm{V}^{\mathrm{e}}-\mathrm{VI} \mathrm{I}^{\mathrm{e}}$ s. p.C. ${ }^{203}$. Ces divers

éléments architectoniques en terre archaïques formant un dépôt votif, qui constituent un toit : ce «Tetto B» est peut-être celui du temple archaïque.

${ }^{199}$ Le lien du sanctuaire avec Jason apparaît également dans Pline (Histoire naturelle LXX).

${ }^{200}$ Publication des premières fouilles : Zancani Montuoro \& Zanotti-Bianco 1951-1954. Nouvelles recherches : Colloque Héra 1997 présente quatre articles sur l'Héraion du Sele (p. 173-210).

${ }^{201}$ Bosi 1980, p. 72-75.

${ }^{202}$ Tite-Live VIII, 22, 5-6; Phlégon de Tralles, De mirabilibus, 495-510.

${ }^{203} \mathrm{Au}$ lieu-dit Fondo Valentino : La Rocca \& alii 1995. Valenza Mele 1977, 
éléments indiquent, à Pithécusses comme à Cumes, une Héra très probablement honorée, parmi ses multiples prérogatives, en relation avec ces voyages de fondation.

- Gravisca

Le sanctuaire de l'emporion de Gravisca, où étaient principalement célébrées Aphrodite et Héra, a livré un certain nombre d'offrandes liées au monde maritime : plusieurs jas de pierre, dont un inscrit portant la fameuse dédicace de Sostratos d'Égine à Apollon (voir infra p. 470-477). Un bateau de plomb de type sarde, qui figure également parmi le matériel archaïque du temple, semble appartenir aux ex-voto consacrés à Héra (voir infra p. 376).

\section{d) Confins occidentaux}

- Malte

Cicéron (2nde action contre Verrès IV, 103-104), lors de sa confrontation avec Verrès, lui reproche, outre les pillages commis en Sicile, celui du sanctuaire d'Héra à Malte. Ce dernier, situé sur un promontoire, est respecté par les marins de telle sorte que ni les troupes des flottes des guerres civiles ni les pirates ne l'ont jamais menacé. L'orateur insiste particulièrement sur ce point afin de mettre en relief la scélératesse et l'impiété de l'accusé. Parmi les offrandes déposées dans l'Héraion se distinguaient un grand nombre d'ivoires, spécialement des défenses que le roi Massinissa lui-même tint à restituer lorsqu'il prit connaissance de leur vol et des Nikès du même matériau. Le sanctuaire est également mentionné dans la Géographie de Ptolémée (IV, 3, 13) comme un point de repère important à Malte.

Le sanctuaire et le culte maltais sont sans conteste d'origine punique, comme l'indiquent l'alphabet de la dédicace des défenses de Massinissa et les fouilles du sanctuaire qui ont livré notamment de nombreuses inscriptions à Astarté, datées depuis le $\mathrm{V}^{\mathrm{e}}$-IV $\mathrm{e}$. jusqu'au $\mathrm{II}^{\mathrm{e}} \mathrm{s}$. a.C. et peut-être même au $\mathrm{I}^{\mathrm{er}} \mathrm{s}$. a.C. Il est cependant manifeste que la divinité du lieu Astarté a été identifiée avec HéraJunon $^{204}$. L'accent est mis sur la vénération et la fréquentation du

p. 498-504 et Breglia 2009, p. 256-262 comparent le sanctuaire de Cumes avec celui de Pérachora; Valenza Mele 1991-92, p. 9-17; Polignac 1998, p. 23 et 28; Pasqualini 2000. La plupart de ces articles supposent également l'existence d'un sanctuaire d'Héra à Naxos (Sicile), au bord de la mer et au sud-ouest de la cité, entre le $\mathrm{VII}^{\mathrm{e}}$ et la fin du $\mathrm{V}^{\mathrm{e}} \mathrm{s}$. a.C. : le caractère hypothétique de cette attribution et surtout le manque d'indications concernant le contexte de fondation du sanctuaire et le culte de la divinité empêchent d'intégrer Naxos dans ce chapitre.

${ }^{204}$ Loicq-Berger \& Renard 1982, p. 101; Parisi Presicce 1985, p. 72; Bonnet 1986, p. 244-249; Bonnet 1996, p. 112-114. Le site est identifié avec Tas Silg, près 
lieu par des marins; de la même manière, les Victoires peuvent renvoyer à des batailles navales.

- Ibérie

L'extrémité sud de l'Ibérie, au niveau où la terre européenne s'avance le plus dans la mer vers la côte africaine, est consacrée selon les descriptions des géographes à Héra (carte 9). La topographie du lieu varie selon les traités, mais il faut noter son caractère maritime : pour Pomponius Mela (Chorographie II, 6, 96), il s'agit du promontoire lui-même appelé aujourd'hui Trafalgar ${ }^{205}$; pour Strabon (Géographie III, 5, 3; 5, 5) qui s'appuie sur des sources antérieures, c'est une île située face aux Colonnes d'Hercule sur laquelle se trouve d'ailleurs un temple de la déesse. Mela (Chorographie III, 1, 4) signale par ailleurs un temple et un autel d'Héra sur le rivage de l'Atlantique, au nord de Gadès. Dans la péninsule Ibérique, Héra est donc associée par les Grecs à des lieux à forte connotation maritime qui marquent comme des points extrêmes de navigation.

\section{ANALYSE}

\section{Géographie du culte}

La géographie de l'Héra maritime, bien que concernant un petit nombre de sites, est tout à fait caractéristique ${ }^{206}$. Presque tous ceux-ci sont situés sur des promontoires (Pérachora, Crotone, Cumes, Gravisca) ou sur une île en position de dominer la mer (Pithecusses, Samos, Malte, en Ibérie) ou encore sur un port bien exposé (Thasos, Gravisca et peut-être Délos). Deux épiclèses s'avèrent plus particulièrement connotées dans ces sens : Héra Épiliménia à Thasos ${ }^{207}$ / Liménia à Pérachora et celle d'Akraia au même endroit ${ }^{208}$. La plupart du temps, ils se trouvent en dehors de la ville,

de la baie de Marsaxlokk au sud-est de l'île, où un culte rendu depuis le III millénaire a vu se succéder aux époques historiques Astarté, Héra puis Junon (Debergh 1976). Sur la capacité d'Astarté de se greffer sur Aphrodite, Héra ou Artémis, voir Bonnet \& Pirenne-Delforge 1999, p. 264-268. Offrandre de corail : Tassignon 2005, p. 294-296 et 303.

${ }^{205}$ C'est le jugum sacrum d'Aviénus 322, de Skylax 112 : Wachsmuth 1967, note 1830 .

${ }^{206}$ Comparer avec les remarques de Polignac 1997, p. 115.

${ }^{207}$ Wachsmuth 1967, p. 262.

${ }^{208}$ La notice de Stéphane de Byzance (s.v. Héraia) ne parle pas d'une Héra Akraia, contrairement à ce qu'on peut lire dans certaines études : voir infra p. 81 . 
constituant des sanctuaires extra-urbains à Pérachora ou Crotone ${ }^{209}$. Deux sites sont implantés à l'embouchure d'une rivière et de la mer, l'Héraion samien sur l'Imbrasos et l'Héraion de Poseidonia sur le Sele.

La Grande Grèce s'affirme comme la zone de développement la plus forte du culte ${ }^{210}$. Quatre sanctuaires, placés à des endroits stratégiques, de la navigation autour de la botte italienne, montrent les étapes successives d'avancée vers le nord des Grecs en Italie jusqu'en Étrurie. De cette manière, la majorité des sites apparaissent comme des finistères, des points de repères extrêmes pour les navigateurs : à Pérachora, Crotone et davantage encore à Malte et en Ibérie. Sans nul doute ces lieux constituent autant d'amers, d'escales, et le développement privilégié des points d'eau douce à l'intérieur ou aux abords de ces sanctuaires n'y est pas étranger. La manière dont Denys d'Halicarnasse présente le cabotage d'Énée le long de la mer Ionienne montre comment ces arrêts réguliers rendent le voyage par voie de mer aisé et agréable; le sanctuaire constitue alors une étape que l'on marque par quelque offrande de circonstance ${ }^{211}$.

Le caractère commun de tous ces sites consiste en leur importance à l'époque archaïque. Ils s'affirment comme appartenant aux plus anciens sanctuaires grecs, parfois implantés sur des lieux de culte plus anciens ${ }^{212}$, dont la notoriété fut immédiate. En témoignent à cet égard la richesse des offrandes qui y étaient déposées ainsi que l'hétérogénéité des origines géographiques mais aussi sociales des fidèles. Ces derniers sont d'autant plus variés que ces hiéra sont à vocations multiples et suscitent l'intérêt cultuel de gens très diversifiés. Autre caractéristique des Héraia : leur limitation dans le temps. Si leur développement est rapide et précoce, en revanche leur prestige décroît très fortement à l'époque classique - ce qui tend encore plus à les mettre en relation avec les courants de navigation et de colonisation archaïques ${ }^{213}$.

${ }^{209}$ Polignac 1997 les définit comme des sanctuaires «du milieu».

${ }^{210}$ Torelli 1971, p. 63 insiste également sur le caractère maritime des sanctuaires d'Héra en Italie.

${ }^{211}$ Fenet 2005, p. 42 et 46.

${ }^{212}$ Ceci a été particulièrement souligné dans les différents articles de Colloque Héra 1997, notamment p. 115-116.

${ }^{213}$ Sur ce point voir la démonstration brillante de Parisi Presicce 1985, p. $58 \mathrm{ss}$. 
Personnalité marine d'Héra

Un fait essentiel sur lequel il faut bien insister est le caractère marin non exclusif d'Héra. Aucun sanctuaire, aucune épiclèse ne la définit exclusivement ou principalement comme marine. Ce sont les ex-voto et l'emplacement des sanctuaires qui permettent de reconnaître ses liens avec la mer, mais dans ces lieux de culte la déesse présente toujours un culte matrimonial ou de fécondité très marquant ${ }^{214}$.

Les sources littéraires ne donnent qu'un aperçu discret de ses prérogatives marines. La mythologie limite son intervention au périple argonautique, et là encore il faut avouer ses modes particuliers d'action. En fait, elle y est constamment liée aux divinités secondaires, les Dioscures ${ }^{215}$ et Néréides ou encore Éole. Elle ne peut opérer des aides maritimes sans l'aide d'autres divinités à qui elle donne des ordres pour favoriser une navigation sans embuches. Elle apparaît comme la puissance positive qui influe sur les éléments marins par l'intermédiaire d'autres daimones. Elle se montre ainsi spécialement attentive aux vents, qu'elle maîtrise à plusieurs reprises lors du voyage d'Argô, ces mêmes vents qui permirent la découverte de Tartessos aux vaisseaux samiens. C'est par ce moyen aussi qu'Héra s'acharne sur les Troyens en quête d'une terre d'après quelques vers de l'Énéide (V, v. 789-795). L'action d'Héra en faveur de la navigation semble s'exercer de manière globale mais indirecte, et porter particulièrement sur les vents et courants qui permettent d'arriver à une bonne destination - comme elle évite aux Argonautes la dérive vers l'Océan et les fait arriver là où il convient d'aller. Elle détermine ainsi les bonnes routes maritimes et l'arrivée en un endroit favorable. Sans doute est-ce ce qui explique l'importance d'Héra dans le processus colonial à l'époque archaïque, la localisation des lieux qui lui sont consacrés, puis l'abandon progressif de son culte maritime lorsque la géographie du monde grec était fixée

${ }^{214}$ Le lien est souvent fait avec une statuette de l'Argolide, représentant Héra portant sur l'épaule droite une sorte de panier en forme de barque contenant des fleurs, publiée par Frickenhaus 1912b, p. 63 no 9 pl. III8 et p. 124-125 fig. 47-48. Dans la bibliographie relative à Héra, cette iconographie sert souvent de parallèle pour évoquer une continuité avec la fête contemporaine se déroulant près de l'Héraion du Sele. Mais ce qui se dégage de ces deux cas, c'est davantage une signification de fertilité que de protection de la navigation. Voir à ce sujet également Payne 1940, p. 196, 244 n 245 fig.110; Polignac 1997.

${ }^{215}$ Héra ne figure pas parmi les déesses mises en relation avec les Dioscures dans Chapouthier 1935a. 
dans ses grands traits. On comprend dès lors les ex-voto d'ancres ou de bateaux, ces derniers nombreux à Samos ou parmi les plus anciens objets du sanctuaire de Crotone. Les deux bateaux sardes, les temples d'Ibérie ou de Malte témoignent aussi des liens entretenus avec le sud-ouest de la Méditerranée mis sous la protection de l'épouse de Zeus.

Ces liens d'Héra avec la navigation archaïque peuvent peut-être expliquer, a contrario, deux sources problématiques. Tout d'abord, la notice de Stéphane de Byzance (s.v. "H $\rho \alpha 1 \alpha)$ : celle-ci s'annonce en effet $a$ priori contradictoire, puisqu'elle désigne un promontoire face à Chalkédon nommé Héraia où le mouillage s'avère particulièrement dangereux. S'il ne s'agit pas d'une erreur du lexicographe, il faut supposer que la pointe reçut ce nom car elle présentait l'apparence - démentie ensuite par la pratique - d'un endroit favorable. Par ailleurs, Héra semble absente de l'onomastique navale grecque (voir infra p. 286). Or, l'importance nautique d'Héra se développant à l'époque archaïque en Occident et en dehors de la sphère attique, il paraît logique qu'aucun bateau ne soit appelé de la sorte à l'époque classique dans la flotte de guerre athénienne ou à l'époque hellénistique. Un document montre cependant que cet aspect du culte d'Héra n'avait pas complètement disparu à la fin de l'époque hellénistique : un jas de plomb trouvé au sud de l'Italie porte le nom de la déesse (voir infra p. 315). En Occident, la protection d'Héra sur mer était encore sollicitée au début de notre ère.

Athéna et Héra sont mises en relation avec le monde maritime par l'assistance qu'elles apportent aux héros dans leurs explorations maritimes. Ce caractère commun doit expliquer les différentes versions des légendes argonautiques. Ces traditions constituent pour les Grecs l'origine du culte qui leur est rendu à l'époque archaïque, particulièrement en Grande Grèce. Elles s'affirment ainsi toutes deux comme des divinités de la colonisation vers l'Occident, mais aussi de puissances navales comme Samos et Lindos. 



\section{LA MAÎTRISE DES ÉLÉMENTS}

Athéna et Héra ont motivé le départ des Grecs sur la mer, leur ont indiqué les moyens et les chemins à prendre à travers cet espace vierge. Mais les instants passés sur les flots recèlent des dangers que l'homme ne peut maîtriser. La navigation requiert un certain nombre de facteurs liés aux éléments naturels : l'euploia n'est pas seulement le fait de bons marins, elle nécessite une protection divine qui assure au bateau de bonnes conditions de voyage et lui évite les périls maritimes. C'est dans ce domaine qu'interviennent Zeus et Aphrodite, qui sont parfois associés dans des sources navales : des inscriptions sur ancres.

\section{ZEUS}

La figure de Zeus a été bien étudiée au début du $\mathrm{XX}^{\mathrm{e}}$ siècle par A.B. Cook dans son magistral ouvrage; plus récemment c'est à ses cultes de sommet que s'est intéressé François de Polignac'. Des documents nouveaux permettent d'étoffer aujourd'hui ce qui concerne son culte marin, très peu évoqué dans la monographie anglaise ${ }^{2}$.

Les relations du maître de l'Olympe avec la mer sont riches et variées, comme on peut s'y attendre de la part du dieu qui a prise sur

\footnotetext{
${ }^{1}$ Polignac 2002. Ces cultes archaïques seraient liés à la sécheresse / pluie; leur déclin, à l'intégration du monde rural.

${ }^{2}$ Cook 1914-40. Le premier volume concerne Zeus en tant que «god of the bright sky», tandis que les deux suivants développent "the god of the dark sky». Le volume II s'occupe des «tremblements de terre, nuages, vents, rosée, pluie, météorites» et le troisième des «tonnerre et foudre». Un dernier volume contient des d'appendices traitant d'épiclèses ou de thématiques précises, et un index. L'optique choisie pour l'étude du dieu fait que les mentions d'un culte maritime apparaissent en notes et de façon très anecdotique. Pour une vision d'ensemble des sources sur Zeus, voir les notices de Schwabl 1972-78; ses liens avec la navigation, Romero Recio 2000, p. 46-49.
} 
tout l'univers et en particulier sur l'état du ciel ${ }^{3}$. D'après les sources, la place que celui-ci occupe parmi les dieux intervenant dans la navigation s'avère très importante. La littérature, l'épigraphie et l'archéologie convergent pour nous montrer un culte marin ou nautique de Zeus bien présent durant toute l'Antiquité grecque.

\section{SOURCES}

Mythologie et épopée

a) Nature du dieu

Le rôle de Zeus dans le déroulement de la navigation est clairement affirmé dès les Hymnes homériques. Lors de la pérégrination du bateau emmenant les Crétois destinés à fonder le sanctuaire d'Apollon à Delphes (Hymne à Apollon Délien, v. 388-512), c'est Zeus qui dirige jusqu'à Krisa l'embarcation $\dot{\alpha} \gamma \alpha \lambda \lambda o \mu \varepsilon \dot{v} v \eta \Delta \iota \grave{s}$ oü $\rho \omega$ (joyeuse du bon vent de Zeus). Quand elle approche de son but, il envoie alors le Zéphyr pour accélérer la course nautique par l'octroi de vents favorables qui poussent le bateau vers sa destination avec célérité. Ce rôle dévolu à Zeus se perpétue, nous allons le constater, à travers les traditions et les cultes jusqu'à une date tardive.

Quelques siècles plus tard, Callimaque, pour sa part, conclut son Hymne I à Zeus (v. 70-75) par une esquisse des domaines et des humains bénéficiaires de sa protection divine. Le poète évoque alors les marins, mais pour préciser que le maître des dieux ne pouvait, dans cette activité comme dans les autres, que se préoccuper des maîtres des hommes : des chefs, des meneurs. Protecteur des navigateurs assurément, Zeus n'étend cependant pas sa puissance sur tous.

b) L'épopée homérique

Dans les traditions liées à la geste homérique, Zeus n'intervient pas toujours de manière favorable, bien au contraire. En matière de navigation, son rôle apparaît même presque entièrement négatif ${ }^{4}$. Il

${ }^{3}$ Mc Cartney 1925, notamment p. 154 et 156; id. 1929, p. 6; Séchan \& Lévêque 1966, p. 81.

${ }^{4}$ Dans l'Iliade VIII, v. 238-241, Agamemnon harangue les Achéens découragés et demande à Zeus une aide en invoquant les sacrifices qu'il n'a jamais manqué de lui faire depuis qu'il navigue. Ce passage ne peut, comme le pense Wachsmuth 1967, p. 402, faire référence à un culte marin au dieu, car Agamemnon précise bien que c'est uniquement dans l'optique de la victoire sur les Troyens qu'il agit ainsi, et ce seulement depuis son départ de Grèce. 
est ainsi responsable du naufrage d'Ulysse et de ses compagnons peu après leur départ de l'île du Soleil (Odyssée XII, v. 407-419), naufrage dont Ulysse s'inspire pour raconter un malheur analogue lorsqu'il se présente à Ithaque sous l'allure d'un mendiant (ibid. XIV, v. 303313). La première scène montre le dieu déchaînant d'abord un Zéphyr violent qui met à mal la mâture du bateau, puis le tonnerre et la foudre qui règle le sort de l'esquif. Dans la seconde, Zeus utilise une nuée $(v \varepsilon \varphi \varepsilon ́ \lambda \eta v)$ pour ensuite foudroyer l'embarcation, mais permet au narrateur d'être sauvé du désastre. Le fils de Laërte l'accuse encore d'être responsable des mauvaises conditions de navigation après avoir quitté l'île de Calypso sur un radeau : Zeus couvre

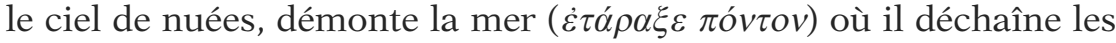
vents (Odyssée V, v. 299-305).

Euripide dans les Troyennes (v. 75-94) se fait l'écho d'une telle opposition. Lorsqu'Athéna cherche à venger l'affront qu'elle a subi de la part des Achéens, elle requiert l'aide de Zeus qui doit déchaîner les vents, les pluies, la grêle et la foudre pour entraver le retour des guerriers et détruire leurs embarcations. Le pouvoir de Zeus est double : il possède les moyens d'aider le voyage maritime comme ceux d'y faire obstacle de manière violente et mortelle. C'est ce qu'affirme par ailleurs Iphigénie sous le calame du même tragique (Iphigénie à Aulis v. 1319-1329) : Zeus retarde par des vents contraires les bateaux à Aulis, contraignant les navigateurs à l'attente alors qu'il sait si bien par ailleurs gonfler leurs voiles. Seul Stace (Achilléide I, v. 679-688), à la fin du I $\mathrm{I}^{\mathrm{r}} \mathrm{s}$. p.C., montre a contrario une action positive du dieu lorsque celui-ci empêche Thétis de déchaîner la mer pour contrecarrer le voyage d'Ulysse parti à la recherche du fils de celle-ci, Achille.

\section{c) L'Énéide}

Dans l'épopée virgilienne, Zeus intervient pour sauvegarder la flotte d'Énée à la demande de Cybèle (Enéide IX, v. 69-122). Au moment de la construction des navires, la Grande Mère des dieux avait prié le maître de l'Olympe de les protéger de toute tempête et de toute destruction. Zeus agréa cette requête en promettant, une fois la course du héros achevée, de transformer le bois de ces bateaux en divinités marines. L'incendie qu'allume Turnus sur le rivage latin parmi la flotte troyenne marque la réalisation de ce terme fixé par Zeus : les navires prennent apparence humaine. Cette métamorphose accomplie grâce à Cybèle et au Kronide ne doit pas occulter la protection que ce dernier a implicitement procuré à la navigation d'Enée. Le texte de Virgile s'inspire d'une double tradition : le pouvoir de Zeus sur le bon déroulement d'un périple en écartant particulièrement les tempêtes (turbine venti), et le bois 
naval humanisé comme l'était la poutre maîtresse d'Argô, originaire de Dodone, sanctuaire de Zeus ${ }^{5}$. Les prérogatives de Zeus en ce qui concerne la navigation sont ainsi affirmées dans la tradition poétique grecque et latine.

\section{Témoignages cultuels}

Les mentions de cultes rendus à Zeus dans un contexte maritime sont relativement nombreuses et surtout présentent une grande diversité de formes (carte 3).

\section{a) Attique}

Il a déjà été question plus haut du culte commun de Zeus Sôter et d'Athéna Sôteira au Pirée ${ }^{6}$ (Lycurgue, Contre Léocrate 17; Pausanias I, 1, 3; supra p. 33-35); il reste cependant à définir plus précisément la place et les caractéristiques de Zeus dans ce duo. Il est cité en premier dans cette association divine et certaines sources - ainsi Strabon, Géographie IX, 1, 15 - référant au sanctuaire du port d'Athènes ne mentionnent même que lui. Il paraît donc y occuper une position prédominante par rapport à Athéna. Par ailleurs, le fait que sa statue, d'après la description de Pausanias, tienne un sceptre et une victoire et que les éphèbes et stratèges honorent particulièrement le $\mathrm{dieu}^{7}$, tend à lui accorder une valeur militaire, plus précisément des liens avec la victoire ${ }^{8}$.

Au cap Sounion, il recevait peut-être également un culte. Une dédicace du VI ${ }^{e}$ s. a.C. semble mentionner un Zeus Sounieus tandis qu'un relief encadré de deux serpents est rattaché à un Zeus Meilichios $^{9}$.

b) Eubée

En Eubée, le maître de l'Olympe possédait un promontoire, comme l'attestent plusieurs sources. La tradition rattache le lieu au sacrifice ultime d'Héraclès, se consumant après avoir revêtu la

${ }^{5}$ Comme la poutre d'Argô, les bateaux d'Énée transformés en jeunes femmes viennent l'avertir du danger qui guette les héros (Énéide X, v. 156-255). La scène est reprise par Ovide, Métamorphoses XIV, v. 527-567.

${ }^{6}$ Une dédicace phénicienne à Baal Sochen trouvée dans le sanctuaire montre que le dieu était également honoré par des étrangers (Amit 1965, p. 87).

${ }^{7}$ Voir Garland 1987, p. 44, 102-104, 137-139 et inscriptions numérotées no 130-133, 137-138 p. 239-240; comme le souligne Deubner 1932, p. 174, le corps des éphèbes participait à la procession de la fête des Diisôteria.

${ }^{8}$ Garland 1987, p. 137 la met en relation avec la victoire de Salamine.

${ }^{9}$ Thémélis 1974, p. 15; Jameson \& alii 1993, p. 83; Davaras 1979, p. 18; Dins- 
tunique fatale transmise par Déjanire ${ }^{10}$. Bacchylide (Dithyrambe II, v. 13-18) et Sophocle (Trachiniennes, v. 237-238 et 750-805) décrivent ainsi le héros consacrant à Zeus $K \eta v \alpha i ̃ o s$, selon le poète ${ }^{11}$ un sacrifice animal et pour le tragique un autel et des fruits. Le cap Kènaion se trouve au nord-ouest de l'île; Eschyle (Fgt 30, éd. Smyth, 1926 = Strabon, Géographie X, 1, 9) - y situe la tombe de Lichas, serviteur d'Héraclès. Le culte de Zeus Kènaios (Kènéen) s'avère donc bien connu au $\mathrm{V}^{\mathrm{e}} \mathrm{s}$. et lié directement à la geste héracléenne. La scène décrite par Sophocle ne laisse aucun doute sur le caractère maritime de la scène, avec le héraut projeté sur un écueil (v. 780) en geste de vengeance et le départ du héros agonisant en bateau (v. 803). Des fouilles menées à cet endroit n'ont rien révélé qui puisse ressembler à un sanctuaire ${ }^{12}$. Aucune source ne mentionnant un téménos - au mieux un autel - et Strabon restant muet sur le site, il faut considérer le Kènaion comme un cap voué au dieu, sur lequel on a pu éventuellement effectuer des sacrifices ${ }^{13}$.

\section{c) Laconie}

La cité d'Épidaure Liméra est bâtie sur une hauteur non loin de la mer. En contre-bas, sur le port, Pausanias (III, xxiii, 10) mentionne un naos de Zeus Sôter. De ce port, également cité indépendamment de la ville par Ptolémée qui le désigne sous le nom du dieu (Géographie III, 14, 32), on devait apercevoir le rocher de Monemvasia, le cap Minoa antique ${ }^{14}$. Aux XVII ${ }^{e}$ et XVIII ${ }^{e}$ s. p.C., le

moor 1971, p. 37. L'inscription (SEG XVI, 18) est très fragmentaire; on y lit seule-

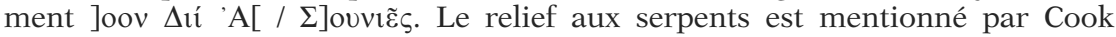
1914-40, op. cit. III, 1184.

${ }^{10}$ Chuvin 1992, p. $358-360$.

${ }^{11}$ Bacchylide ajoute par ailleurs qu'Héraclès s'apprêtait à sacrifier également à Poséidon et à Athéna (voir supra, p. 28).

${ }_{12}$ Malgré ce que croit y reconnaître le fouilleur. Les recherches ont en effet révélé la présence d'un péribole pentagonal entouré d'un mur, garni de tours aux angles, dont les blocs ont été récupérés dès l'époque byzantine, mais aucune trace de temple ou d'autel; la céramique ne remonte pas au delà du IV ${ }^{\mathrm{e}}$ s. a.C. (Chronique Kinaion 1924-26).

${ }^{13}$ Le cap est mentionné dans une loi d'Érétrie du VI ${ }^{\text {s }}$ s. a.C. fixant des règles de navigation. Le promontoire sert pour délimiter une zone maritime et les tarifs de la solde des matelots distincts de ceux d'une navigation en haute mer : Vélissaropoulos 1980, p. 138.

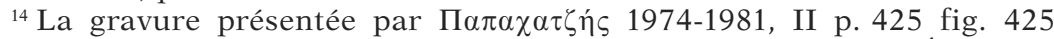
(= Castellan 1808, I. pl. 7) donne une idée de la configuration du port d'ÉpidaureLiméra et de la vue qu'on avait depuis cet endroit. Aujourd'hui sont encore visibles les murs et les terrasses impressionnants de la cité; en revanche rien n'est discernable du côté de la mer dont le niveau s'est modifié depuis l'Antiquité. 
port appelé Saint-Paul était réputé pour ses bons fonds et présentait les ruines d'une église ayant probablement succédé au temple ${ }^{15}$. Il semble ainsi que l'anse portuaire d'Épidaure Liméra était placée sous la protection de Zeus Sôter qui possédait un temple à cet endroit ${ }^{16}$. Il est impossible en revanche de dater l'origine du culte.

\section{d) Dodone}

À Dodone, Zeus Naios se serait vu consacrer rien moins qu'une poupe sur laquelle le dédicant échappa au naufrage (Lexeis rhetorikai, s. v. Nó́os Zev́s = voir corpus p. 540, et infra p. 423 s.). Ce type d'offrande est à rapprocher des petits textes des lamelles oraculaires formulant des questions de la part de fidèles venus consulter le dieu : un certain nombre d'entre eux, en effet, concernent la navigation ${ }^{17}$ ou la pêche. Ainsi Phainylos, au IV ${ }^{\text {e }}$ s. a.C., s'inquiète de savoir s'il doit, comme ses ancêtres, se consacrer à cette seconde activité18, et pas moins de 13 demandes des $\mathrm{IV}^{\mathrm{e}}-\mathrm{III} \mathrm{I}^{\mathrm{e}} \mathrm{s}$. portent sur des voyages ou le commerce par mer ${ }^{19}$.

${ }^{15}$ Wace \& Hasluck 1907-08, p. 179-182 (avec références). Le voyageur français A. L. Castellan (Castellan 1808, I p. 53 et pl. 7 bis) a laissé un dessin de la rade d'Épidaure-Liméra avec l'emplacement du port.

${ }^{16}$ C'est également l'avis de Pirenne-Delforge 1994, p. 215 qui met l'accent sur la proximité du cap Malée.

${ }^{17}$ Salviat 1993; Prestianni Giallombardo 2002, p. 123-130; Fenet 2005, p. 46. Les lamelles sont attestées depuis le milieu du VI ${ }^{\text {e }}$. a.C.; leur pratique cesse après le premier tiers du II ${ }^{e}$ s. a.C., sans doute après les destructions des troupes de Paul-Émile dans la région. Lhôte 2006, qui en a publié 167, classe celles qui concernent la navigation dans la catégorie "grand commerce maritime» (p. 11-17 et 24-25).

${ }^{18}$ Lhôte 2006 , no 83 p. 179-180.

${ }^{19}$ Lhôte 2006, $\mathrm{n}^{\circ}$ 6B p. 39-44 (pertinence de l'installation d'un privé avec les Pariens à Pharos dans l'Adriatique; datée 385/4; à noter : autre texte similaire du IVe s., le no 130 p. 271-273); no 90 p. 191 (du commerce sur mer; IVe s.); no 91 p. 192-193 (de travailler sur la mer; fin $I^{\text {e }}$ s.); $n^{\circ} 92$ p. 193-196 (de prendre la mer, avec réponse négative; IV ${ }^{\text {e }}$.); $\mathrm{n}^{\circ} 93$ p. 196-198 (pertinence d'armer un navire; IV e-III ${ }^{\mathrm{e}}$ s.); no 94 p. 198-201 (sauvetage - financier? - d'un bateau et de son propriétaire; $1^{\text {ère }}$ moitié du IV ${ }^{\text {e }}$ s.) : voir également infra p. 150 note $32 ; \mathrm{n}^{\circ} 95$ p. 201-205 (commerce sur mer et sur terre, avec réponse nuancée; $1^{\text {ère }}$ décennie du IV ${ }^{\text {e }}$.); $n^{\circ}$ 96A p. 205-208 (travail en relation avec la mer et investissement dans un navire; $c a .375-\mathrm{III}^{\mathrm{e}}$ s.); $\mathrm{n}^{\circ} 97$ p. 208-211 (navigation vers Apollonia [d'Illyrie] sans pirates; IV ${ }^{\mathrm{e}} \mathrm{s}$ ); $\mathrm{n}^{\circ} 100$ p. 214-216 (pertinence d'une navigation vers Adria en Vénétie; $1^{\text {er }}$ quart du IV ${ }^{\mathrm{e}} \mathrm{s}$.); $\mathrm{n}^{\circ} 102$ p. 217-219 (idem, vers la Sicile; $I^{\text {e }}$ s.); no 103 p. 219-221 (idem, vers Syracuse puis "vers la colonie»; $1^{\text {er }}$ quart du IV ${ }^{\text {e }}$ s.); no 106 A p. 225-226 (idem, vers Messine; IV ${ }^{\text {e }}$ s); + 2 indéterminés : no 98-99 p. 211-214 (commerce maritime ou terrestre (?), emploi de mots de la famille d'emporia). 
L'épiclèse du dieu de Dodone a fait l'objet de nombreuses propositions étymologiques et d'interprétations : aujourd'hui, l'on considère que le terme, de la même famille que le verbe voí (habiter), doit être compris comme Résidant ou Habitant ${ }^{20}$. Les sources indiquent donc que ce Zeus oraculaire offrait, comme dans d'autres domaines, des réponses aux inquiétudes concernant le milieu maritime, ce qui pourrait justifier la présence dans le sanctuaire épirote d'ex-voto navals. La situation de ce dernier bien à l'intérieur des terres n'est pas contradictoire avec des préoccupations nautiques, notamment si l'on considère les liens privilégiés de Dodone avec Corcyre, colonie corinthienne et cité maritime s'il en est ${ }^{21}$.

\section{e) Kassiopè}

$\mathrm{Au}$ nord de l'île de Corcyre, sur le territoire de Kassiopè, se trouve un bateau de pierre attribué à Ulysse et voué à Zeus Kasios (Procope, De Bello Gothico IV, 22, 23-29) (voir infra p. 390-391). Par ailleurs, le culte du dieu est bien attesté dans la cité par des sources romaines: par un texte de Pline (Histoire naturelle IV, 52) qui mentionne son temple, deux dédicaces latines et des monnaies datées entre la deuxième moitié du I ${ }^{\mathrm{er}} \mathrm{s}$. a.C. et la première moitié du $\mathrm{II}^{\mathrm{e}}$ s. p.C. le représentant trônant ${ }^{22}$. Zeus Kasios possédait donc un temple au moins à la fin de l'époque hellénistique dans la cité dont le nom, selon Procope, aurait été inspiré précisément par celui du dieu.

\section{f) Messapie}

De l'autre côté de l'Adriatique, le littoral messapien est caractérisé par deux sanctuaires maritimes présentant de nombreuses similitudes qui semblent consacrés au dieu (carte 12).

Dans le détroit d'Otrante, au nord de la ville, dans la partie sud de la baie de Torre dell'Orso, se trouve une grotte dénommée aujourd'hui San Cristoforo, creusée dans la falaise de manière artificielle. L'entrée comporte des restes d'une ancienne terrasse et l'intérieur

${ }^{20}$ Lhôte 2006, p. 407-420; Quantin 2008, p. 29-33.

${ }^{21}$ «Tout se passe comme si Dodone était une sorte de sanctuaire officiel de Corcyre, et il est extrêmement probable qu'une proportion considérable de consultations privées doive aussi être assignée à des Corcyréens» (Lhôte 2006, p. 21-22).

${ }^{22}$ CIL III 576 et 577; Salač 1922, p. 161-162; Fenet 2005, p. 44. La visite de Néron à l'autel de Zeus Kasios rapporté par Suétone, Néron 22, 9 peut être interprétée comme une action de grâces envers le dieu après une traversée (Chuvin \& Yoyotte 1986, p. 62). 
témoigne d'un culte chrétien de la part de marins au Moyen Âge, comme l'indique un graffito de bateau marchand du XII ${ }^{\text {e }}$ s. p.C., qui s'inscrit dans la continuité de pratiques païennes remontant jusqu'au VIe s. a.C. ${ }^{23}$ Les fouilles ont livré pour l'Antiquité de nombreux fragments de céramique, une banquette aménagée au $\mathrm{IV}^{\mathrm{e}} \mathrm{s}$. a.C. et ce qui apparaît être un autel sur la terrasse extérieure. Des inscriptions d'époques républicaine et impériale encore lisibles sur les parois invoquent une divinité masculine nommée Anichetos, Épèkoos, Hypsistos. L'une d'elles, en latin, exprime le vœu d'une traversée directe du détroit; une autre, détachée au XIX ${ }^{\mathrm{e}} \mathrm{s}$. et conservée au musée de Lecce, donne en grec un souhait d'euploia de la part d'un affranchi de la gens des Anicii et de ses patrons ${ }^{24}$.

De l'autre côté de la baie, du côté nord, la roche porte également des traces d'inscriptions latines et grecques, pour certaines aujourd'hui sous le niveau de la mer; on a pu y lire le nom de Iuppiter Optimus Maximus ainsi que celui d'un dédicant, membre d'équipage d'une liburne nommée Hamon ${ }^{25}$.

Plus au sud, à la pointe de l'Iapygie, à Santa Maria di Leuca, se trouve une autre grotte cultuelle : la fameuse grotte Porcinara, elle aussi dotée d'inscriptions liées à la bonne navigation et précédée d'une terrasse où l'on a trouvé un jas d'ancre antique (fig. 5) ${ }^{26}$. D'après les dédicaces rupestres et des graffites sur céramique, était honoré là depuis le $\mathrm{VI}^{\mathrm{e}} \mathrm{s}$. a.C un Zis Batas messapien reconnu comme un Zeus Batios par les Grecs, désigné aussi plus tard comme Iuppiter Optimus Maximus ${ }^{27}$.

L'ensemble de ces éléments définit sans conteste une série de cultes maritimes sur la côte messapienne, au niveau de cette zone intense d'échanges qu'est le canal d'Otrante. Des grottes y sont principalement consacrées à Zeus, quoique sous des épiclèses différentes ${ }^{28}$. Zeus Batios est une divinité locale de la foudre et des éléments, identifiée avec le maître de l'Olympe grec et latin; l'épi-

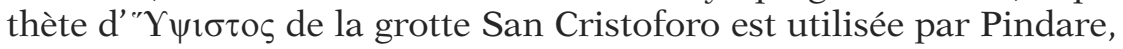
Eschyle et Sophocle pour désigner le Kronide ${ }^{29}$. Ces lieux de cultes

${ }^{23}$ Pagliara 1991, Lamboley 1996, p. 196-197; Fenet 2005, p. 43-44.

${ }^{24}$ Pagliara 1994.

${ }^{25}$ Lamboley 1996, p. 445, 515-516 et pl. XXVI-XXVII.

${ }^{26}$ Van Compernolle \& alii 1978 (en particulier l'introduction de Van Compernolle p. 1-6; la présentation archéologique par F. d'Andria p. 47-49 et 86-87; les inscriptions par C. Pagliara p. 177-221); Fenet 2005, p. 39-42 et infra, p. 487 s.

${ }^{27}$ Lamboley 1996, p. 432-433 (sur Zis Batas); Pagliara, loc. cit. $\mathrm{n}^{\circ} 14$ et 17 (inscriptions latines).

${ }^{28}$ Fenet 2005. Gianfrotta 2005, p. 28 les intègre parmi toute une série de ce qu'il désigne comme des "grottes-refuges».

${ }^{29}$ Pindare, Néméennes I, v. 90; XI, v. 2; Eschyle, Euménides, v. 28; Sophocle, Philoctète, v. 1289. Pausanias II, 2, 8 signale une statue de Zeus Hypsistos dans 


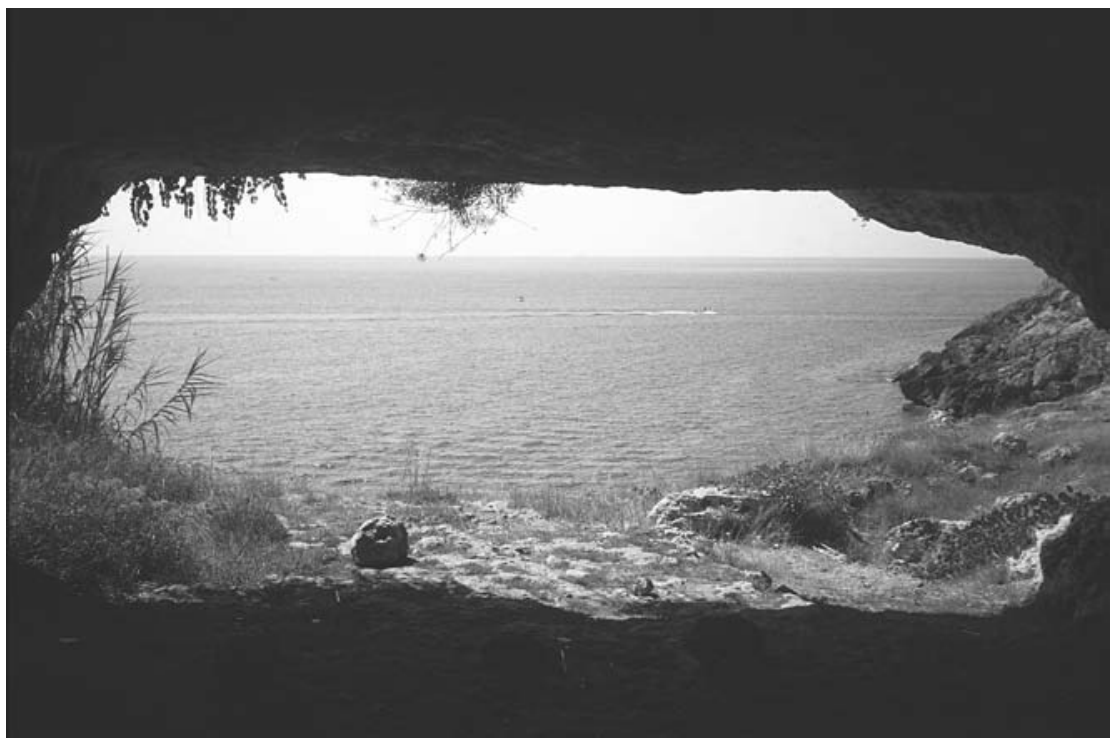

Fig. 5 - Vue depuis l'intérieur de la grotte Porcinara (Santa Maria di Leuca) (Photo de l'auteur).

messapiens, remontant pour certains au $\mathrm{VII}^{\mathrm{e}}$ s., ont été de bonne heure fréquentés par les marins grecs qui se les sont en quelque sorte appropriés ${ }^{30}$.

\section{g) Délos}

Sept dédicaces hellénistiques attestent le culte de Zeus Ourios à Délos $^{31}$; deux d'entre elles s'avèrent particulièrement significatives. L'une commémore le don d'un autel au dieu et à Astarté Palaistiné Aphrodite Ourania d'Ascalon de la part de Daimon «sauvé des

l'agora de Corinthe. L'épiclèse 'E $\pi$ ńкoos, évoquant un dieu à l'écoute des fidèles, qui exauce leurs vœux, est appliquée à bon nombre de divinités (cf. O. Weinreich, in $\operatorname{MDAI}(A)$ XXXVII, 1912, p. 1-68). Le terme d'Anichetos reste inconnu à ce jour.

${ }^{30}$ Nous n'avons pas retenu le cas de la grotte Poesia, située sur le littoral de Roca et vouée par les Messapiens à Taotor Andirahas, transformé en un Tutor Andraios : à cause de l'absence de tout graffito de caractère maritime, et du lien seulement supposé avec Zeus (Fenet 2005, p. 46).

${ }^{31}$ ID $1754 ; 2305 ; 2128 ; 2179 ; 1561 ; 2415 ; 2416$; sur ces inscriptions et le culte de Zeus Ourios à Délos, voir Bruneau 1970a, p. 245-246. Deux des inscriptions sont datées autour des années 105 a.C.; les autres ne le sont pas précisément. Selon Roussel 1915-16, p. 95 ss., le culte du dieu aurait été introduit dans l'île par des marchands du Pont-Euxin. 
pirates ${ }^{32}$. La circonstance de l'ex-voto ainsi que le caractère marin de la divinité féminine invoquée attribuent sans conteste également un rôle maritime à Zeus. Dans la seconde inscription, Eutychos et son fils honorent Zeus Ourios associé à Sérapis, Isis, Anubis, Harpo-

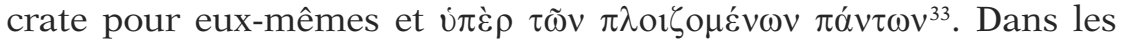
deux cas, l'association du dieu grec avec des divinités orientales laisse supposer des marques de vénération émanant d'étrangers venus de l'Est de la Méditerranée. À cet égard, une scholie d'Hésychius (s.v. $\Theta \alpha \lambda \alpha \dot{\sigma} \sigma \sigma 10 \varsigma$ Zev́s) indique qu'à Sidon était vénéré un Zeus Thalassios.

Zeus reçoit peut-être également dans l'île un culte en rapport avec la mer en association avec Athéna (voir supra p. 42) : comme Kynthios dans son sanctuaire du Cynthe et, en tant que Sôter, à l'autel situé à l'angle sud-est du téménos d'Apollon, près du Néôrion $^{34}$. L'ensemble de ces documents évoque des cultes actifs à l'époque hellénistique, mais peut-être d'origine plus ancienne.

\section{h) Bosphore}

Arrien, lors de son Périple du Pont-Euxin (12, 2-3) effectué en vue d'inspecter la région dans les années 130 p. C., décrit attentivement le littoral. Il signale la présence, sur le côté est de l'embouchure du Pont, à 120 stades de Byzance, d'un hiéron de Zeus Ourios $^{35}$. Pomponius Mela (Chorographie I, 19, 101), pour sa part, y place un temple consacré à Jupiter - sans épiclèse - dont il attribue la fondation à Jason. Un autre itinéraire géographique, daté vers 400 p.C. et faisant référence à un géographe du ${ }^{\text {er }}$ s. p.C., cite encore le temple comme point de repère pour la navigation (Marcien d'Héraclée, Epitome Peripli Menippei 7) ${ }^{36}$. Ce sanctuaire-amer fréquenté par les navigateurs se situe à environ $7 \mathrm{~km}$ de l'entrée du Pont, sur la rive orientale, au niveau du dernier resserrement du

${ }^{32}$ ID 2305. La double dénomination de Palaistiné et d'Ourania souligne le caractère sémitique et oriental d'Astarté (Bonnet 1996, p. 88).

${ }^{33}$ ID 2128.

${ }^{34}$ Zeus Sôter - sans Athéna - est également associé dans une inscription hellénistique (ID 2109) aux dieux égyptiens dans le Sérapeion C. Bruneau 1970 (p. 238) ne croit pas à un culte marin du dieu à Délos, contrairement à l'opinion de Roussel 1987, p. 229.

${ }^{35}$ Detienne 1970, p. 149-150.

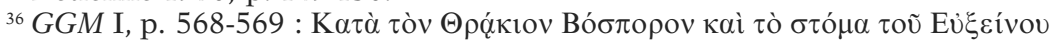

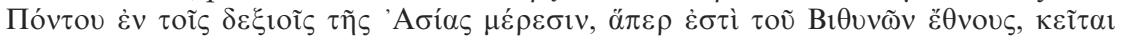

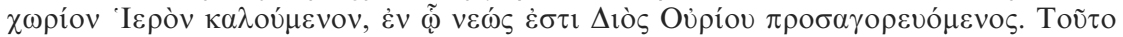

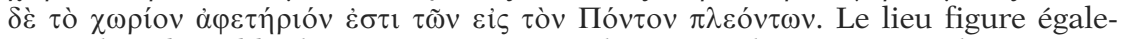
ment dans la Table de Peutinger et a été décrit par des voyageurs des époques moderne et contemporaine (Cook 1914-40, III p. 142-143). 
détroit avant le débouché sur la mer Noire (carte 10) ${ }^{37}$. Un siècle avant Arrien, la statue du dieu est déjà mentionnée par Cicéron dans sa Seconde action contre Verrès (IV, 128-129) comme un chef-d'œuvre de sculpture ${ }^{38}$. L'orateur souligne qu'elle n'a subi aucun dommage ni outrage malgré le passage de nombreuses flottes de guerre : ceci s'accorde avec l'agalma d'un dieu prié par les marins traversant le détroit.

De la même zone provient une base inscrite qui, comme l'indique la dédicace versifiée, portait une statue du dieu. Selon cette épigramme, dans laquelle Poséidon représente les flots sombres, c'est à Zeus que l'on s'adresse pour un vent favorable et une euploia. Le nom du personnage et la graphie tendent à dater l'inscription de la fin du $\mathrm{I}^{\mathrm{er}}$ s. a.C. ou du début du $\mathrm{I}^{\mathrm{er}}$ s. p.C. ${ }^{39}$.

Toutes ces sources attestent un culte au dieu en cet endroit pour la fin de l'époque hellénistique. De fait, il semble bien que le temple de Zeus Ourios s'est substitué ou est venu s'agréger à un lieu consacré aux Douze Dieux que des sources des $\mathrm{III} / \mathrm{II}{ }^{\mathrm{e}}$ s. a.C. placent de la même manière au dernier resserrement du détroit (pour le voyageur venant de la Méditerranée et de la Propontide) avant le Pont-Euxin ${ }^{40}$.

Apollonios de Rhodes (Argonautiques II, v. 528-533) représente

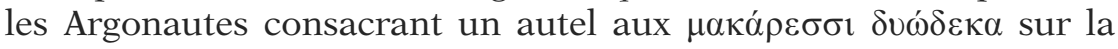
côte ( $\dot{\alpha} \lambda \grave{o} \varsigma \dot{\rho} \eta \gamma \mu \tau \tilde{v})$ orientale du Bosphore lors de leur premier passage. La scholie de ce passage (Scholie Arg. II, v. 531-532) qui rapporte diverses traditions contradictoires à cet égard - sur la rive concernée et les fondateurs de l'autel - conclut à un hiéron de diapleusantes et donne la liste de ces douze dieux. Pour sa part Polybe (Histoires IV, 39, 4-6), qui situe précisément cet autel, le prétend consacré par Jason au retour de Colchide. Le contexte de l'épisode argonautique tourne autour du problème des vents : les héros bâtissent l'autel au terme d'une période durant laquelle les vents contraires les bloquent dans le Bosphore, tandis que les vers

${ }^{37}$ Vian 1974, p. 91-93; Kowalski 2012, p. 110. Le sanctuaire est désigné sous le nom de Hiéron de Chalcédoine. p. 707.

${ }^{38}$ Wachsmuth 1967, p. 404-405. Sur le type de la statue, voir Cook 1914-40,

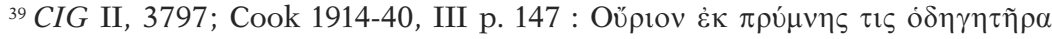

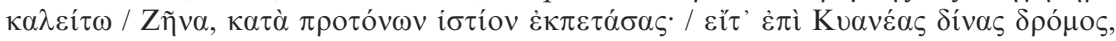

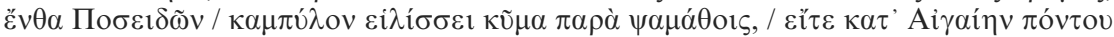

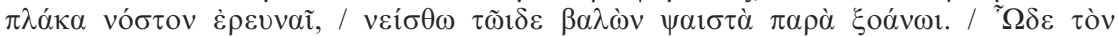

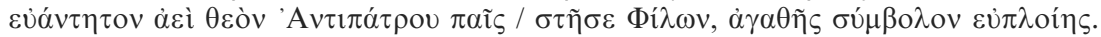

${ }^{40}$ Cette conclusion apparaît dans Cook 1914-40, III p. 147-148 et est développée dans Vian 1974. Voir également Long 1987, p. 55-57, 153-154, 217-218; Georgoudi 1998, p. 74-76. 
précédents narrent la légende des vents étésiens envoyés par Zeus ${ }^{41}$. Le culte de Zeus Ourios à cet endroit - même s'il n'apparaît comme tel que tardivement - appartient à des traditions anciennes honorant les vents et leur origine divine dans un contexte entièrement maritime ${ }^{42}$.

\section{i) Ancyre}

La fondation de la ville d'Ankyra, au sud de la mer Noire, remonterait au roi Midas et tirerait son nom de l'instrument nautique. Zeus est fortement lié à cette légende étiologique : son temple renferme l'ancre royale que Pausanias (I, iv, 5) semble avoir vue et le dieu est représenté sur des monnaies d'époque impériale avec cet attribut. La position géographique d'Ancyre, dont le territoire s'étendait jusqu'au littoral de la mer Noire, et le type du Zeus à l'ancre laisse supposer un culte maritime rendu à Zeus dans la cité (voir infra p. 461-462).

\section{Ex-voto et invocations maritimes}

\section{a) Ex-voto}

Outre ces quelques lieux pour lesquels un témoignage explicite ou plusieurs sources convergentes permettent de définir l'existence d'un culte marin à Zeus, il existe un certain nombre d'ex-voto et de dédicaces isolés qu'il convient de ne pas omettre. Les premiers étant développés en détail dans la seconde partie, ils font ici l'objet d'un simple regroupement.

À Mégare, le temple de Zeus Olympien renferme selon Pausanias ( $\mathrm{I}, \mathrm{xl}, 5)$ un éperon d'une trière athénienne en guise de trophée de l'un des épisodes archaïques de la lutte des deux cités pour la possession de Salamine (voir infra p. 413). De même, le sanctuaire d'Olympie reçut l'offrande d'une statue en bronze du dieu sur le butin des batailles navales de la Seconde Guerre Médique (Pausanias $\mathrm{X}$, xiv, 5). Une inscription hellénistique de Butrint promet à Zeus Kasios un bateau plus beau que les deux que lui a déjà offerts le pauvre dédicant (voir infra p. 383).

${ }^{41}$ Apollonios de Rhodes, Argonautiques II, v. 498-528 : légende de Kyréné et de son fils Aristée, et culte de Zeus Ikmaios (Pluvieux) à Kéos. Les vents étésiens soufflant vers le sud empêchent dans l'Antiquité toute remontée du Bosphore; ils soufflent régulièrement en juillet et en août : Labaree 1957, p. 29-33.

${ }^{42}$ Le lieu consacré aux Douze dieux puis à Zeus Ourios est également appelé simplement Hiéron ou hiéron to Chalcèdoniôn par plusieurs auteurs à commencer par Hérodote, Enquête IV, 87. 
Par ailleurs provient du rivage de Crotone le fameux jas d'ancre de Phayllos, l'athlète de la fin du VI/début $\mathrm{V}^{\mathrm{e}} \mathrm{s}$. portant la dédicace à Zeus Meilichios (voir infra p. 464 ss.). En Sicile à Sélinonte, le sanctuaire de la Malophoros comportant un téménos de Zeus Meilichios a livré deux ancres de pierre fichées en terre (voir infra p. 489 ss.).

\section{b) Invocations}

Les invocations à Zeus ou les appels à sa protection dans un contexte maritime sont bien représentés : l'épigraphie mais aussi la littérature en ont gardé le souvenir.

Quelques vers du comique Diphile (Fgt 43 = Athénée, Banquet des sophistes, VII, 296a-297c), qui écrit à la fin du IVédébut III ${ }^{\mathrm{e}} \mathrm{s}$., montrent un capitaine de bateau arrivant au port après une traversée sans problème, invité par un cuisinier à sacrifier à Zeus Sôter. La scène, qui met en parallèle le bon et le mauvais navigateur, montre l'aspect systématique de l'acte religieux accompli au terme du voyage. À travers une Idylle (XXVIII, v. 5-6), le poète hellénistique Théocrite qui se rend par mer à Milet prie, pour lui et ses compagnons de voyage, Zeus de leur accorder une navigation dotée

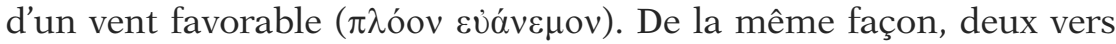
attribués à son contemporain Callimaque (Fgt 400, éd. Pfeiffer) implorent Zeus Liménoscopos en faveur d'un bateau. Une épigramme du I ${ }^{\text {er }}$ s. a.C. (Anthologie Palatine IX, 9) remercie le dieu

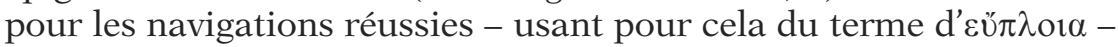
et le prie pour la dernière à venir. Le fameux poème de Poseidippos de Pella sur le phare d'Alexandrie (Poseidippos XI, éd. Gow \& Page) fait supposer à certains hellénistes que le Zeus Sôter nommé dans la pièce, protecteur du marin dans la nuit, était l'un des deux dieux Sauveurs à qui était dédié le monument ${ }^{43}$.

Navigation historique, le périple de la flotte d'Alexandre sous le commandement de Néarque des bouches de l'Indus jusqu'à Suse est ainsi placé sous la protection de Zeus Sôter. Même si d'autres dieux

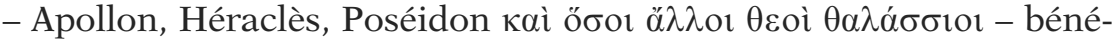
ficient également des marques de dévotion des navigateurs, Zeus Sôter occupe parmi eux une place privilégiée. Avant le départ, Néarque lui offre un sacrifice accompagné de jeux (Arrien, Indica

${ }^{43}$ Épigramme de Poseidippos : voir la lecture et la traduction de Chamoux 1976, avec bibliographie. La dédicace de Sostratos transmise par Strabon (XVII,

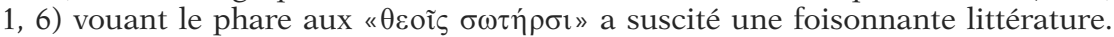
Parmi elle, si Picard 1952, p. 68 identifiait ceux-ci avec Ptolémée I ${ }^{\text {er }}$ Sôter et son épouse, F. Chamoux restitue sur l'édifice les statues de Zeus Sôter et de Protée, tandis que Bernand 1996 pense que le célèbre monument était surmonté de celles de Zeus et de Poséidon. 
XXI, 2). Lorsque l'expédition parvient enfin à rejoindre les troupes d'Alexandre en Carmanie, les retrouvailles sont célébrées par des sacrifices avec procession et concours en l'honneur de ce dieu, cité en premier lieu, et des autres (ibid. XXXVI, 3). Plus loin encore vers l'ouest, lorsque les bateaux regagnent la côte après s'en être dangereusement éloignés, le commandant offre à Zeus Sôter un sacrifice et des jeux (ibid., XXXVI, 9). Alexandre avait donné l'exemple lors du départ de l'expédition en Asie en 334 par un autel consacré à Zeus 'A $\mathrm{so \beta} \alpha \tau$ ๆ́pıos - du Débarquement - (Arrien, Anabase I, 11, 6-7) à l'endroit où il avait mis le pied en $\mathrm{Asie}^{44}$.

Une inscription grecque trouvée dans le golfe Persique pourrait être rattachable à la navigation de Néarque. Il s'agit d'une dédicace, provenant de l'île de Failaka, l'antique Ikaros (voir infra p. 212 s.), consacrée à trois divinités : respectivement Zeus Sôter, Poséidon et Artémis Sôteira. Le lieu d'origine de la pierre, la graphie irrégulière, qui semble celle d'un amateur, ainsi que les trois dieux invoqués renvoient à un ex-voto de navigateurs. Comme dans le texte d'Arrien, Zeus Sôter y est cité en premier, ce qui autorise le rapprochement avec le périple de la flotte d'Alexandre ${ }^{45}$. Une autre inscription hellénistique, reproduisant une lettre d'Ikadion à Anaxarchos, trouvée dans l'île confirme le culte d'un Sôter ${ }^{46}$.

Les dédicaces de navigateurs à Zeus se poursuivent à la fin de l'époque hellénistique et sous le Haut-Empire avec des épiclèses diverses. Celle d'Apobatèrios ${ }^{47}$ est parfois associée au culte impérial;

${ }_{44}^{4}$ Pugliese Carratelli 1965.

${ }^{45}$ La pierre, publiée pour la première fois par Tod 1943, a fait l'objet de nombreuses discussions, dont Picard 1961: voir synthèse par Salles 1986, p. 107-296, spéc. p. 107, 128-129-135. Le texte de l'inscription est le suivant:

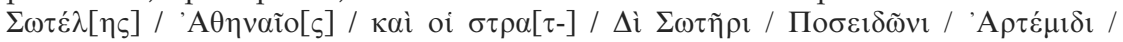
$\Sigma \omega \tau \varepsilon i ́ p \alpha$. Outre les découvertes du bord de mer (voir infra, p. 212 et 383), les fouilles menées depuis dans l'île ont mis au jour un peu plus à l'intérieur (environ 500 m), à Tell Khazneh, d'où provient la triple dédicace, un sanctuaire construit vers 300 a.C. contenant, entre autre matériel, un trésor monétaire et une plaquette céramique avec une dédicace fragmentaire. L'ensemble des structures hellénistiques de Failaka paraît avoir été abandonné circa 150-100 a.C., i. e. avec l'effondrement de la puissance séleucide (Salles 1986, p. 119).

${ }^{46}$ Voir infra à Artémis, p. 212. L'épiclèse de $\Sigma \omega \tau \eta \tilde{\rho o s ~ a p p a r a i ̂ t ~ a ̀ ~ l a ~ 1 . ~ 23, ~}$ précédée d'une lacune, que certains éditeurs du texte restituent en [B $\omega \eta]$ oṽ et d'autres en $[\theta] \varepsilon$ oṽ; ils attribuent également à ce même Sôter le hiéron mentionné aux 1. 43-44.

${ }^{47}$ Une inscription impériale de l'Argolide, IG IV, 1575 donne $\Delta$ iò ${ }^{\prime}$ 'A $\pi$ o $\beta \alpha$ -

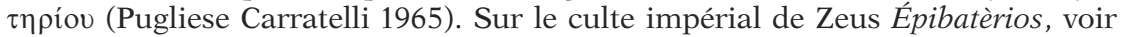
essentiellement Robert 1969 (le contenu est résumé dans d'autres notices sans éléments nouveaux). Le dieu fut particulièrement honoré par Hadrien, à Alexandrie et Phasèlis, et l'empereur put être assimilé au dieu : Richard 1981, p. 37-45. 
des nautai remercient Zeus Ornéos, le Zeus d'Ornoi en Proconnèse, pour une traversée réussie. Quelques inscriptions latines s'adressent encore à Juppiter Serenus ou à la Tempête de Jupiter ${ }^{48}$. En 12 a.C., un affranchi navigator consacre à Capoue un relief orné d'une embarcation à Iuppiter Optimus Magnus ${ }^{49}$.

Par ailleurs, huit ancres de plomb retrouvées en mer portent une inscription référant au dieu, établissant un lien incontestable entre celui-ci et la navigation (voir infra p. 302 ss. et cat. I1-I8). Les noms de [sic] Zeus Hypatos, Zeus Kasios, Zeus Kasios Sozôn associé avec Aphrodite Sôzousa sur une ancre pêchée près du cap de Palos près de Carthagène - auquel on peut rattacher un Sozôn, un Casius (?) et un Kase (?), apparaissent sur ces jas ainsi que deux fois celui de Jupiter - dont un également associé à Vénus. Plusieurs noms de trières athéniennes du $\mathrm{IV}^{\mathrm{e}} \mathrm{s}$. peuvent se rapporter au dieu (voir infra p. 284). Dans le même esprit, des nauclères et commerçants s'associent à la fin du $\mathrm{II}^{\mathrm{e}} \mathrm{s}$. a.C. sous le patronage de Zeus Xénios. L'inscription qui mentionne ce synode ne permet pas de définir le statut de ses différents membres ni de situer précisément son siège. Le fait qu'il possède un proxène au Pirée qui est par ailleurs l'épimélète du port peut laisser soupçonner que le centre de l'association se trouvait à Délos ${ }^{50}$. Cette référence au dieu des étrangers se couple vraisemblablement d'une protection espérée de sa part dans les affaires maritimes.

L'accumulation de ces attestations révèle un Zeus bien présent dans le milieu maritime, en tous lieux et toutes époques.

ANALYse

Géographie du culte

Le culte de Zeus de la part de navigateurs est très disséminé : à la fois en mer Noire, dans le golfe Persique, en mer Égée et en mer Ionienne. Un pôle majeur se dessine autour de cette dernière : Kassiopè, Butrint, Dodone, Otrante, Leuca - soit dans le détroit

${ }^{48}$ CIL XI, 6312, de Pisaro : Iovi S[e]reno; CIL XI, 6823-6824 : Tempestas Iovis. Susini 1960, p. 43-45; Susini 1971; Susini 1975, no 1 et 47. L'épigraphiste y voit la survivance du culte de Zeus Ourios en Italie dans les premiers siècles de notre ère. Sur la dédicace à Zeus Ornéos : Robert 1989.

${ }^{49}$ CIL X, 3804 (cymba); Di Stefano Manzella 1997, p. 229.

${ }^{50} I G \mathrm{II} / \mathrm{III}^{2}, 1012$ (= Syll. $\left.{ }^{3}, 706\right)$, daté de 112/1. Garland 1987, p. 138; Vélissaropoulos 1980, p. 104. 
d'Otrante ${ }^{51}$-, Crotone auxquels on peut ajouter Olympie et Sélinonte. Par ailleurs la zone du Bosphore comporte trois lieux consacrés au dieu. En revanche des vides s'imposent sur la carte de répartition, sur la façade occidentale de l'Italie et dans les terres qui lui sont occidentales ainsi que sur le littoral d'Asie Mineure.

Les lieux de culte de Zeus marin s'avèrent très significatifs. Si deux ex-voto proviennent isolément de deux sanctuaires panhelléniques - Olympie et Dodone -, les sources révèlent des sanctuaires de petite taille et situés en dehors de la cité : deux grottes à l'extérieur de Leuca et d'Otrante, un promontoire avec un autel (?) à Kènaion; à Délos, un ou deux autels ainsi qu'un petit hiéron en haut du Cynthe. De véritables temples, Zeus en possède deux sur un port - au Pirée qu'il partage avec Athéna et à Épidaure Liméra -, un isolé à l'embouchure du Bosphore et un à Sélinonte intégré dans le sanctuaire de la Malophoros. Deux sanctuaires, ceux de Kassiopè et d'Ancyre, semblent devoir se rattacher à un culte citadin d'importance.

Un bon nombre des sources montrent le caractère spontané et indépendant des invocations. Le dieu est invoqué très souvent à l'air libre, sur le bateau ou une fois à terre; nul besoin pour cela de la présence ou d'une référence à un sanctuaire particulier. Des dédicaces, des ex-voto de bateaux et d'ancres qui lui sont consacrés témoignent d'une vitalité certaine du culte durant toute l'Antiquité grecque, malgré son caractère souvent ancien. En Messapie et en Sicile notamment, Zeus est honoré par les marins depuis l'époque archaïque. Les traditions se rapportant à Ancyre et Kassiopè indiquent également une vieille origine. Le dynamisme du culte se décèle aussi par la multiplicité des épiclèses attribuées au dieu - pas moins d'une douzaine - : Apobatèrios, Batios, Kasios, Kènaios, Liménoscopos, Meilichios, Naios, Olympios, Ourios, Sôter, Thalassios, Hypatos, Hypsistos. Parmi celles-ci, deux seulement renvoient à des toponymes, l'un de montagne l'autre de promontoire. Le Zeus des marins n'est pas fortement lié à une géographie cultuelle, mais leur ressemble par son caractère voyageur.

\section{Personnalité marine de Zeus}

Le culte de Zeus est centré sur la navigation : la météorologie ${ }^{52}$, le bateau, les escales et par conséquent le parcours qui permet d'aller de l'une à l'autre constituent les domaines d'intervention du

\footnotetext{
${ }^{51}$ Fenet 2005, p. 8-9.

${ }_{52}$ Mc Cartney 1933, p. 3; Farnell 1896, I p. 47.
} 
dieu. Trois épiclèses sont à cet égard significatives : Thalassios (Marin), Liménoscopos (Gardien du port) et Apobatèrios (du Débarquement) renvoient explicitement à un rapport avec la mer. Une scène du périple argonautique dans la version ancienne de Pindare (IVe Pythique, v. 191-209) célèbre ainsi la puissance de Zeus en matière de navigation. La libation de départ d'Argô est accomplie par Jason à la poupe qui invoque alors le $\pi \alpha \tau \varepsilon^{\prime} \rho$ ' Oủ $\alpha \alpha v i \delta \tilde{\alpha} \nu \dot{\varepsilon} \gamma \chi \varepsilon 1 \kappa \dot{\varepsilon}-$ pavvov Z̃̃v $\alpha$, auquel il associe ensuite un certain nombre de notions liées à la navigation : les flots et les vents, les nuits, les jours, le chemin maritime et le retour. À cette prière Zeus répond favorablement par le tonnerre et la foudre. L'ensemble du voyage des héros est ainsi placé, pour Pindare, sous la protection du dieu auquel Jason s'est adressé selon les termes qui convenaient à l'étendue de sa puissance. À y regarder de près, les vers de Pindare correspondent à une bonne définition du domaine d'activité de la divinité.

À la violence de son action dans l'épopée homérique, s'oppose à travers le culte une image positive du dieu. Dans l'Odyssée, Zeus possède le pouvoir de déchaîner les éléments marins alors qu'on invoque sa faculté à les maîtriser ou les apaiser. Sa figure paraît perdre de sa violence et de sa sauvagerie dès les écrits posthomériques pour revêtir un rôle bienfaisant. Par ailleurs, en dehors des invocations multiples du périple d'Alexandre, Zeus n'est que rarement associé avec une autre divinité : avec Athéna au Pirée et peut-être à Délos; avec Aphrodite sur deux ancres.

Parmi toutes les épiclèses du dieu ${ }^{53}$, la plupart ne sont attestées qu'une seule fois; il est alors difficile de déterminer s'il s'agit d'une dénomination purement locale - voire même d'une épithète poétique - ou d'un culte plus largement diffusé. Trois d'entre elles renvoient au pouvoir immense du maître des dieux : Olympien ${ }^{54}$,

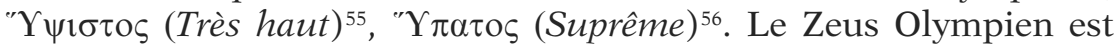
directement associé à la victoire s'étendant aux conflits maritimes : l'offrande navale de Mégare témoigne de cet aspect particulier du culte de la cité ${ }^{57}$. Pour ce qui est des autres dénominations, il

${ }^{53}$ Wachsmuth 1967, p. 478.

${ }^{54}$ Cette épliclèse est sans doute la plus répandue à travers le monde grec : voir Kruse \& Schwabl 1942-1972.

${ }^{55}$ Sur Zeus Hypsistos, Cook 1914-40, II p. 876-890. Le dieu est honoré dans toutes les régions du monde grec, mais plus particulièrement dans sa partie orientale : Lydie, Mysie, Cappadoce, Syrie... À l'époque hellénistique, le nom s'applique à des divinités orientales tels Baal ou Jehovah.

${ }^{56}$ Sur l'épiclèse du dieu, E. Fehrle, «s.v. Zeus», RE, Stuttgart, 1924, col. 570; voir Guarducci 1970, à propos d'un cippe du Ve s. a.C. provenant de Vélia portant

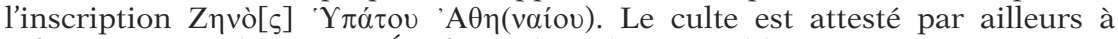
Athènes, Sparte (?), Paros, Érythrées (Ionie), Priène (?).

${ }^{57}$ Des monnaies romaines de la cité figurent un Zeus tenant une Victoire 
convient en revanche de s'attarder sur les quatre attribuées à plusieurs reprises au maître de l'Olympe : Ourios, Kasios, Sôter et Meilichios ${ }^{58}$.

\section{a) Zeus Ourios}

L'épiclèse d'Ourios possède, par son étymologie, un rapport aux vents, plus précisément à ceux propices à la navigation ${ }^{59}$. Une épigramme du $\mathrm{II}^{\mathrm{e}}$ s. a.C. (Anthologie Palatine XII, 53, de Méléagre) montre même le dieu gonflant les voiles des bateaux. Cette manifestation de Zeus Ourios apparaît dans ce poème d'espoir amoureux comme la grâce rendue aux bateaux qui ont servi de messagers à la belle. L'épithète s'avère dans ce contexte entièrement positive : sans nul doute Zeus Ourios est le dieu du vent favorable, loin de l'image homérique.

L'épiclèse est ancienne: elle se trouve déjà chez Eschyle (Suppliantes, v. 594) mais non pas dans un contexte moins explicite $^{60}$. En effet l'adjectif revêt également un sens plus général de «favorable», ce que M. Detienne analyse comme caractérisant le moment où l'«occasion est offerte aux navigateurs de s'élancer vers la mer» sur la base d'inscriptions de Vélia ${ }^{61}$, dont deux cippes portant le nom du dieu ${ }^{62}$. Il semblerait donc que le culte de Zeus au vent favorable remonte au moins à l'époque classique. À Délos et au Bosphore, il est connu pour l'époque hellénistique, ce qui correspond davantage à l'analyse de A.B. Cook, pour qui la figure de Zeus

(Imhoof-Blumer \& Gardner 1964, p. 4-5) : le Zeus Olympien, victorieux, reçoit comme de juste un trophée d'une victoire maritime remportée par la cité.

${ }^{58}$ Baslez 1986, p. 298 souligne comment ces différentes épiclèses de Zeus correspondent à des cultes rendus par des Phéniciens à Zeus assimilé à Baal; Bonnet 1988, p. 378-379 (Baal et Z. Sôter). Zeus apparaît donc aux yeux des Phéniciens comme un «patron des marins», bien plus que Poséidon.

${ }^{59}$ Wachsmuth 1967, p. 365; Cook 1914-40, III p. 140-157.

${ }^{60}$ Cook 1914-40, III p. 142 cite également des vers de l'Iliade et de l'Odyssée où Zeus, sans épiclèse d'Ourios, est mis en relation avec un ouros.

${ }^{61}$ Detienne 1970, p. 150.

${ }^{62}$ L'inscription qui donne le nom du dieu au génitif est datée du Ve s. a.C. : Guarducci 1966a, p. 282-284; Guarducci 1970, p. 253-255. L'épigraphiste

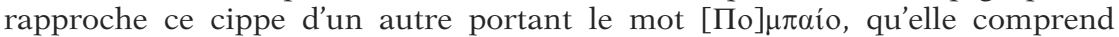
comme Zeus Pompaios qui donne le bon vent à l'instar de Zeus Ourios. Un troi-

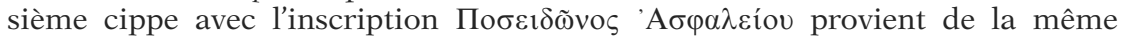
terrasse appuyée au mur nord de la cité sur laquelle se trouve un petit téménos. M. Detienne interprète l'inscription d'un quatrième cippe portant le nom de Kairos Olympios comme une puissance divinisée, fils de Zeus qui accompagne Zeus Ourios dans l'opportunité d'un départ en mer, et comme le fait de la saisir (Detienne 1970, p. 149-151). Le culte de Zeus Ourios dans la cité fut confirmé par la présence à un autre endroit d'un deuxième cippe inscrit mais trouvé seul cette fois : Guarducci 1970, p. 253-255. 
évolue de plus en plus comme manifestant une action météorologique $^{63}$. Le fait que Zeus Ourios supplante les Douze Dieux à l'embouchure du Pont est révélateur de l'importance que prend cet aspect de la personnalité de Zeus et de son rôle grandissant dans la religion des navigateurs.

\section{b) Zeus Kasios}

Les analyses portant sur Zeus Kasios et ses origines orientales sont nombreuses ${ }^{64}$. Le dieu originaire de Péluse a été transporté d'une rive à l'autre de la Méditerranée, comme le montrent les témoignages de son culte. En ce qui nous concerne, son culte marin est attesté à Kassiopè (Corfou) et peut-être sur le rivage opposé à Butrint; les ancres portant son nom le véhiculent ainsi jusqu'à Carthagène près des Colonnes d'Hercule. Les sources ne remontent cependant pas au-delà du $\mathrm{II}^{\mathrm{e}}$ s. a.C., date attribuée à l'inscription de Bouthrotos et à une ancre trouvée à Syracuse. Zeus Kasios pourrait donc avoir été introduit parmi les divinités grecques seulement à partir de l'époque hellénistique. Son culte à Kassiopè aurait alors été favorisé par la ressemblance des noms entre la ville et le dieu ${ }^{65}$.

Le mont Kasion à Péluse a donné son épiclèse au dieu qui est honoré, par un temple dans la ville-même ${ }^{66}$, d'un culte de type solaire et mantique ${ }^{67}$. Cependant, des liens avec la navigation apparaissent au travers d'une tradition théologique phénicienne qui voit les descendants des Dioscures parvenir en radeau jusque là et fonder un sanctuaire (Eusèbe de Césarée, Préparation évangélique I, 10,

${ }^{63}$ Cook 1914-40, I p. 1-4.

${ }^{64}$ Notamment à propos des jas de plomb portant son nom (voir infra p. 302 ss.). Les deux articles essentiels pour l'étude du dieu sont dus à Chuvin \& Yoyotte 1986, ainsi qu'à Salač 1922. Des rapprochements intéressants ont été proposés pour la première fois par Fíta 1906; voir également Wachsmuth 1967, p. 396; Turcan $1992^{2}$, p. $168-169$.

${ }_{65}$ García y Bellido 1967, p. 100, note 2.

${ }^{66}$ En premier lieu Paris 1906, se basant sur Stéphane de Byzance, s. v. Kasion et l'inscription CIG 7044B. Sur Zeus et le mont de Péluse, voir Cook 1914-40, II p. 984-987; description de la zone et de ses difficultés nautiques dans Chuvin \& Yoyotte 1986, p. 41 et carte fig. 1. Le temple du dieu, identifié grâce à une dédicace d'Hadrien, a été fouillé au début du siècle : Clédat 1914. Les sources sont nombreuses concernant le sanctuaire et le culte à l'époque romaine : voir en particulier Salač 1922, p. 166 ss.; Chuvin \& Yoyotte 1986, p. $42-48$ qui poursuivent leur article en présentant des objets liés au culte : une marque appartenant au temple servant à imprimer des bouchons de jarre (p. 52-58), des amulettes (p. 58-59).

${ }^{67}$ García y Bellido 1967, p. 101. 
20) ${ }^{68}$; une autre fait du dieu un nauclère dont le tombeau serait vénéré par les habitants de Péluse ${ }^{69}$.

De façon générale, Zeus Kasios semble ainsi associé à un certain nombre de monts, depuis la Syrie jusqu'en Scythie ${ }^{70}$. Selon Aviénus (Ora maritima, v. 255-261), le même nom est attribué à un mont situé en Ibérie ${ }^{71}$, dans la région de Tartessos, qui explique ainsi l'origine du mot désignant l'étain : le cassiterus. La présence de l'ancre au cap Palos s'ajoute comme un argument supplémentaire à l'hypothèse d'un culte du dieu dans cette région ${ }^{72}$. Celui-ci lierait alors l'exploitation de mines - à Carthagène on extrait et on traite le plomb - à la navigation servant à l'exportation. Il s'avère impossible d'établir les origines des noms donnés au mont et au métal : à quelle époque, par qui ces désignations ont été fixées, et surtout si le lien avec le dieu n'est apparu qu'a posteriori comme à Kassiopè ou dès l'instauration de liens commerciaux avec cette région.

Le culte de Zeus Kasios doit également figurer en Sicile ${ }^{73}$. Au total quatre ancres de plomb proviennent des eaux de l'île, dont trois portant cette épiclèse du dieu. Cette concentration, notable parmi l'ensemble des jas inscrits, ne peut pas résulter du simple hasard. Elle laisse soupçonner la présence de Zeus Kasios dans l'île, même si aucun autre témoignage n'en a laissé trace. Le contexte géographique s'y avère cependant favorable : non seulement Zeus en tant que Meilichios est vénéré à Sélinonte ${ }^{74}$ et sous d'autres épiclèses en Messapie, mais encore la Sicile se situe sur la route pour le détroit de Gibraltar.

Les ancres apportent également un éclairage supplémentaire sur le caractère marin du dieu. L'une d'entre elles le nomme Zeus Kasios Sozôn [sic], lui attribuant ainsi un rôle salvateur, actif dans

${ }^{68}$ Eusèbe répète les écrits d'Herennius Philon de Byblos (vers 60-140 p.C.) dans son histoire mythique de la Phénicie : voir $F G H$ IIIC, n ${ }^{\circ} 790$, p. 802 ss.

${ }^{69}$ Epiphanius, Ancoratus 109 (dans Patrologiae graecae XLIII, Paris, 1864, éd. Migne, col. 209-210). Le passage traite de morts dont la tombe devient lieu de culte et qu'on vénère $(\tau \uparrow \tilde{\omega} v \tau \alpha \iota)$ : ainsi Antinoous, Timagénès, Canobos à Alexan-

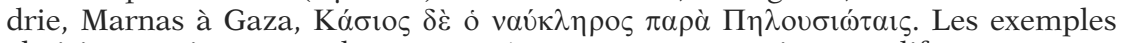
choisis renvoient cependant encore à un contexte romain et tardif.

${ }^{70}$ Benoît 1951, p. 227.

${ }^{71}$ Le mont en question se situe près de Faro (ou Ossonoba). De fait, la région renferme des mines (Fíta 1906, p. 159, notes 3-4); une inscription à Zeus a été trouvée dans la ville qui possède par ailleurs des types monétaires maritimes bateaux, poissons - : ces différents éléments correspondent aux aspects divers de la personnalité de Zeus Kasios.

72 Benoît 1951, p. 228.

${ }^{73}$ Manganaro 1977, p. 159.

${ }^{74}$ Cook 1914-40 établit par ailleurs une relation très forte entre Zeus Sôter et Zeus Meilichios : cf. nombreuses notes II p. 1121 ss. et conclusions p. 1159. 
les périls de la navigation. Cette épithète se retrouve seule sur un autre jas, renvoyant très probablement au même dieu. La première ancre atteste également une association entre le dieu et Aphrodite Sôzousa. Une autre ancre portant la double inscription latine Iovi / Veneri prouve que cette association en matière de navigation n'était pas occasionnelle. Une tradition rapportée dans l'œuvre astrologique de Claude Ptolémée assurait les voyages plus sûrs et plaisants lorsqu'ils étaient placés sous l'union de Jupiter et Vénus ${ }^{75}$. Cependant, le caractère purement "planétaire» du commentaire de Ptolémée ne permet pas de conclure à une semblable croyance au niveau des dieux; de plus, les voyages en question ne sont pas réservés au milieu maritime, et les bienfaits espérés ne concernent plus directement ce domaine que sur un seul point, celui des conditions atmosphériques. Nous évoquerons plutôt le caractère salvateur des deux divinités, ainsi que leur origine orientale, qui ont dû faciliter leur rapprochement dans l'esprit des marins.

\section{c) Zeus Sôter}

Zeus Sôter reçoit un culte important dans tout le monde grec durant toute l'Antiquité ${ }^{76}$. Les références au dieu dans un contexte marin sont également nombreuses - et ce dès l'époque classique -, paraissant s'intensifier à l'époque hellénistique ${ }^{77}$.

Le sens de l'épiclèse est clair et l'on comprend facilement pourquoi Zeus Sôter a pu être particulièrement invoqué par les marins. Les passages d'Arrien montrent bien à quel moment ils font appel à lui. En effet, si le premier sacrifice inaugure le départ de la flotte de Néarque, les suivants lui rendent grâces après des situations difficiles : lorsque les troupes navales et terrestres se rejoignent alors

${ }^{75}$ Rapprochement proposé par Gianfrotta 1994, p. 601. Claude Ptolémée,

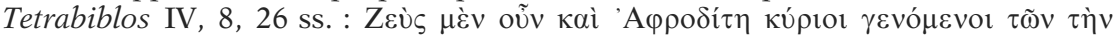

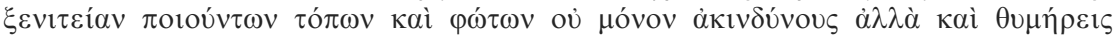

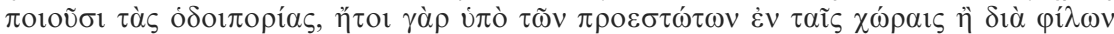

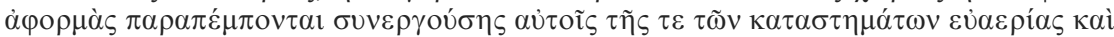

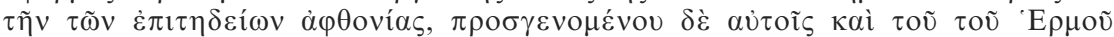

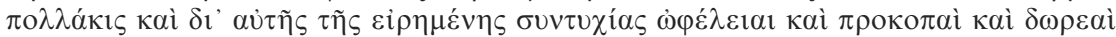

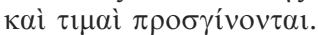

${ }^{76}$ Schwabl 1972-78, col. 362-364 et 1212 ss. Cook 1914-40, qui insiste (II, p. 1123-1125) sur le caractère chtonien du dieu, ne lui consacre pas une étude spécifique : des références au dieu apparaissent de manière épisodique tout au long de l'ouvrage.

${ }^{77}$ Bonnet 1996, p. 87. Baslez 1986, p. 292-293 montre par ailleurs le culte que reçut Zeus Sôter de la part des Phéniciens qui l'assimilaient à Baal. Ce rapprochement de la part des Phéniciens dans des sites portuaires (au Pirée, à Lindos, à Kos) souligne le caractère marin de l'une et de l'autre divinité. 
que les seconds croyaient les premiers perdus, puis après des moments d'angoisse endurés par les navigateurs qui s'étaient trop éloignés des côtes. L'épigramme de Julius Polyen (Anthologie Palatine IX, 9) qui loue l'euploia de Zeus l'implore de le sauver une dernière fois, c'est-à-dire de le mener à bon port dans son ultime course. Ainsi, l'action du dieu s'opère lors de situations difficiles ${ }^{78}$ ou, de manière plus large, préserve lors du voyage par bateau de tout dommage ou accident. Cette fonction de protection en mer est affirmée par ailleurs par la présence, sur un vase, d'une stylis marquée Zeus Sôter à la poupe d'un navire (voir infra p. 269 et fig. 19); ceci rappelle, dans une moindre mesure, l'ancre de plomb marquée Zeus Kasios Sozôn (voir supra p. 102-103).

\section{d) Zeus Meilichios}

Le nom de Zeus Meilichios (Qui apaise) est uniquement lié dans nos sources à des ancres de pierre : l'une, crotoniate, portant une dédicace explicite et deux anépigraphes retrouvées dans son sanctuaire à Sélinonte (voir infra p. 464 ss. et 489 ss.). Par ailleurs, la divinité est bien connue pour le caractère chtonien de son culte ${ }^{79}$, à tel point que A.B. Cook le compare aux Lares latin, le considérant davantage comme un daimôn qu'un véritable dieu ${ }^{80}$. Il convient donc de s'interroger sur ces offrandes de jas à Zeus Meilichios.

Une seule source littéraire le met en relation avec la mer ${ }^{81}$. Dans

${ }^{78}$ Le caractère sauveur de Zeus apparaît sous d'autres épiclèses : ainsi le pseudo-Apollodore, Bibliothèque I, 7, 2 raconte que Décalion, échappant au déluge enfermé dans un coffre en bois, sacrifie à Zeus Phyxos une fois qu'il a touché terre. Sur Zeus Phyxos, voir Cook 1914-40, I p. 415-417; Mc Cartney 1933, p. 18.

${ }^{79}$ Jameson \& alii 1993, p. 81-91; Cook 1914-40 y a consacré l'appendice M du vol. II, p. 1091-1160 et met l'accent sur le caractère pacificateur du dieu; Iacopi 1952 recense les différentes interprétations du dieu et attestations de son culte, en insistant sur le caractère chtonien du dieu. Celui-ci est par exemple bien présent au Pirée (Garland 1987, p. 135). Grotta 2010, p. 137-175 conclut, pour sa part, aux aspects sociaux du culte du dieu et à son caractère bienveillant et purificateur.

${ }^{80}$ Cook 1914-40, loc. cit., p. 1159.

${ }^{81}$ Lazzarini 1996, p. 242-243 mentionne une anecdote de Xénophon (Anabase VII, 8, 4-5) qui pour lui signifie que le dieu protège les voyageurs. Dans ce passage, le stratège accoste à Lampsaque où le devin Euclide lui conseille de sacrifier à Zeus Meilichios qu'il a négligé; Xénophon s'exécute à la suite de quoi il récupère son cheval et poursuit son voyage. On peut opposer au rapprochement avec ce passage le contexte non-maritime de l'incident, voire même nier tout rapport avec le voyage proprement dit. Il semble plutôt en effet que la nécessité d'honorer Zeus Meilichios vient du fait que la fête athénienne consacrée au dieu à laquelle Xénophon avait l'habitude de participer venait d'avoir lieu; même au loin, il se devait de la respecter. 
les traditions phéniciennes rapportées par Philon de Byblos (Eusèbe, Préparation évangélique I, 10, 11), le Zeus Meilichios est assimilé à Chousor. Celui-ci non seulement inventa avec son frère le fer et l'art de le travailler - ce pourquoi on l'identifie parfois à Héphaistos -, mais aussi la pêche à la ligne, le bateau ( $\sigma \chi \varepsilon \delta i ́ \alpha v)$ et la navigation, ce qui lui valut d'être vénéré après sa mort ${ }^{82}$. Si le Zeus Meilichios grec a pu être assimilé à ce demi-dieu phénicien à la fin du I ${ }^{\mathrm{er}} /$ début $\mathrm{II}^{\mathrm{e}} \mathrm{s}$., c'est qu'il présentait des caractéristiques similaires dans le domaine maritime. Par ailleurs, on a pu proposer une étymologie phénicienne de l'épiclèse en rapprochement avec le dieu Melqart : l'origine commune des noms remonterait à un mot sémitique signifiant $" \operatorname{marin}{ }^{83}$.

Il convient de noter la proximité géographique de ces jas de Zeus Meilichios. Le "champ de stèles» du dieu a dû favoriser la consécration de ce type d'offrande, ainsi que certaines influences orientales. Le culte de Zeus paraît particulièrement important et ancien autour de la mer ionienne; quelle que soit son épiclèse, il semble qu'on lui ait attribué un rôle non négligeable dans la navigation. Il se pourrait dès lors qu'on consacre des ancres au dieu dans le sanctuaire qui se présente: à Zeus Meilichios à Sélinonte et à Crotone, ou à Santa Maria di Leuca à Zeus Batos. La diversité des épiclèses du dieu fait que probablement leurs cultes respectifs ne possédaient pas de limites réelles, mais permettaient de passer de l'un à l'autre.

Zeus qui régit les éléments du ciel est ainsi associé dans le cadre de la navigation à Aphrodite. Selon toute logique, celle-ci devrait maîtriser les flots sur lesquels se meuvent les bateaux : leur action conjointe permettrait ainsi une traversée sans encombre.

\section{APHRODITE}

Malgré la grande diffusion et la grande popularité du culte d'Aphrodite, le caractère marin de la divinité - en dehors du contexte de sa naissance - n'est pas aussi affirmé ou généralisé qu'on pourrait s'y attendre. En effet, lorsque l'on dresse un constat de ses épithètes, de ses attributions ou de ses cultes marins, le tout

${ }^{82}$ Lipinski 1995, p. 108-112.

${ }^{83}$ Iacopi 1952, p. 174 qui hésite entre les interprétations d'un culte crotoniate chtonien ou maritime. 
ne constitue qu'une partie seulement de sa personnalité. En fait, l'iconographie d'Aphrodite développée à l'époque romaine peut donner une image du caractère marin de la déesse exagérée voire stéréotypée; en ce qui concerne l'Antiquité grecque, le portrait est à nuancer.

L'étude de synthèse due à V. Pirenne-Delforge sur le culte et la personnalité d'Aphrodite aux époques archaïques et classiques a permis une bonne mise au point sur les sources et les différents courants d'interprétations concernant la divinité. Dans cet ouvrage capital, le culte maritime d'Aphrodite est cependant très peu développé tant dans son analyse que dans la présentation du matériel archéologique $^{84}$. Surtout, le cadre géographique de l'étude est limité aux frontières les plus strictes de la Grèce : ceci exclut un nombre important de sanctuaires marins d'Aphrodite et cet aspect de son histoire religieuse. Quelques article parus depuis ont éclairé les liens de la déesse avec la mer selon des optiques diverses : dans ses «interactions» avec Astarté, dans ses cultes hellénistiques, et dans le rapprochement souvent opéré avec la prostitution et le sexe ${ }^{85}$. Les pages qui suivent s'efforcent de compléter les sources de ces travaux, tant dans ses limites géographiques que chronologiques, afin de mieux mettre en évidence les pratiques cultuelles rendues à l'Aphrodite marine grecque.

\section{LES SOURCES}

\section{Mythologie et épopée}

Contrairement à la majorité des divinités olympiennes, Aphrodite est mise en relation avec la mer dès sa naissance. Cette tradition relevant des récits théogoniques remonte aux textes homériques et se trouve durablement évoquée à travers toute la littérature antique.

${ }^{84}$ Pirenne-Delforge 1994. Le culte maritime est abordé dans le paragraphe intitulé «la mer et le ciel», p. 433-437, l'historiographie d'Aphrodite clairement exposée p. 1-9. Parmi les offrandes (p. 375 ss.), aucun ex-voto marin n'est mentionné. L'article «s. v. Aphrodite» de la RE I, 2, München, 1894, col. 27292787 est dû à Dümmler; deux compléments par divers auteurs ont suivi, déjà anciens : dans $R E$ suppl. I, Stuttgart, 1903, col. 102-106 et $R E$ suppl. III, Stuttgart, 1918, col. 132-133. Quelques idées rapides sur le culte d'Aphrodite marine ont été exprimées par Queyrel 1990 ou encore par Séchan 1955, p. 43-46; Séchan \& Lévêque 1966, p. 371-372. La monographie de Pironti 2007 a pour sa part insisté sur les rapports d'Aphrodite avec la guerre.

${ }^{85}$ Bonnet \& Pirenne-Delforge 1999; Parker 2002; Barbantani 2005; Demetriou 2010. 
a) La naissance d'Aphrodite

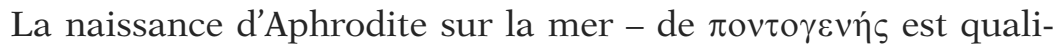
fiée la déesse dans l'Hymne orphique qui lui est consacré (LV, v. 3) apparaît de façon allusive pour la première fois dans l'Hymne homérique à Aphrodite (II, v. 1-5). Dès ce poème, le nom de la divinité est rapproché du mot aphros signifiant l'écume ${ }^{86}$. À vrai dire il n'y est pas à proprement parler question de naissance, mais de transport de la déesse, poussée par le Zéphyr à la surface des eaux, vers Chypre. Les deux éléments - l'écume et Chypre - constituent en réalité les termes du mythe. Le récit hésiodique (Théogonie, v. 187-197), en revanche, en donne une relation plus précise. Il fait intervenir la naissance d'Aphrodite suite à la castration d'Ouranos par son fils Kronos. Les bourses du dieu mutilé tombent à la mer et leur

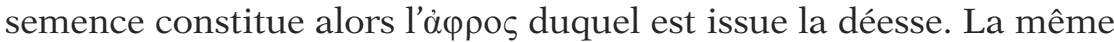
version figure chez Nonnos (Dionysiaques XIII, v. 432-443) où un dauphin recueille alors la nouvelle venue ${ }^{87}$. L'iconographie la montre d'ailleurs chevauchant un dauphin dès l'époque classique ${ }^{88}$.

La tradition inspire particulièrement les écrivains de l'époque impériale. Ovide notamment (Métamorphoses IV, v. 523-540) fait dire à la déesse qu'elle provient de l'écume qui lui a donné son nom grec, ce que le poète réaffirme par ailleurs (Fastes IV, 61-62). Plutarque (Propos de table V, 685e) explique cette naissance et l'épithète d'A $A \imath \imath \varepsilon \dot{\varepsilon} v \eta \varsigma$ attribuée selon lui à Aphrodite par une symbolique rationnelle : le sel qui a pouvoir générateur fut ainsi imaginé avoir généré la divinité ${ }^{89}$. Nonnos (Dionysiaques IV, v. 236-246) précise

${ }^{86}$ La question de l'étymologie du nom d'Aphrodite n'est toujours pas résolue; quoi qu'il en soit, celle donnée par les auteurs antiques en relation avec le nom de l'écume n'est pas fondée: Dugand 1974, p. 73-98; Pirenne-Delforge 1994, p. 9 note 53. Cette lecture antique du nom est à mettre en relation avec la vision d'une déesse «du bouillonnement» (Pironti 2007, p. 153-208).

${ }^{87}$ Dans l'Iliade (XX, v. 105-107), Aphrodite est dite fille de Zeus. Cette autre version est explicitée par Proclus, Commentaire sur le Cratyle de Platon 406c-d : il y aurait deux Aphrodite, la première née d'Ouranos, la seconde née de la semence de Zeus tombée elle aussi dans la mer. Cette double naissance permet à Platon (Banquet, 180d-181c) de faire de l'une des deux déesses le symbole de l'amour intellectuel et de l'autre de l'amour sensuel. Sur la naissance d'Aphrodite, voir Séchan 1955, p. 44-46; Simon 1959; Pirenne-Delforge 1994, p. 312-318; Pironti 2007, p. 24-73.

${ }_{88}$ Delivorrias 1984,1 p. $100-101$ et 2 p. 95-96.

${ }^{89}$ Le grain de sel est de surcroît cité dans des sources tardives (chrétiennes) comme une offrande symbolique servant lors des mystères célébrés en l'honneur d'Aphrodite : Pirenne-Delforge 1994, p. 342-343. Parmi les nombreuses sources tardives reprenant le mythe de la légende de la naissance d'Aphrodite, signalons l'Hymne Orphique XXII ou Achille Tatios, Les aventures de Leucippé et Clitophon $\mathrm{V}, 16,3-5$ qui célèbrent Thalassa comme mère de la déesse. Cette tradition existe déjà à l'époque de Pausanias (II, i, 7-ii, 1) qui décrit dans le temple de Poséidon à 
pour sa part que la naissance d'Aphrodite eut lieu par mer calme, à l'image de la tranquillité des flots que peut procurer la déesse.

L'iconographie antique illustre avec bonheur ce thème. Pausanias $(\mathrm{V}, \mathrm{xi}, 8)$ qui décrit à Olympie le socle de la statue phidienne de Zeus reconnait Aphrodite sortant de la mer accueillie par Éros ${ }^{90}$. L'Aphrodite hors des eaux devient un sujet de plus en plus prisé et sans rapport avec la légende de la naissance ${ }^{91}$. On se plait à imaginer la déesse dans un contexte marin, avec son cortège devenant thiase à l'époque romaine comme Apulée (Métarmophoses IV, 32) ou l'Hymne orphique (LV, v. 21-22) en donnent une bonne illustration.

\section{b) Descendance marine d'Aphrodite}

La descendance d'Aphrodite, peu nombreuse, compte une figure digne d'être relevée car elle appartient aux divinités marines: Aphrodite a en effet pour petite-fille Ino-Leucothée - et pour arrièrepetit-fils Palaimon-Mélicerte ${ }^{92}$. Cette filiation est établie dès Hésiode et mentionnée lors des récits de la légende d'Ino ${ }^{93}$. Dans certaines versions du mythe, Aphrodite peut elle-même intervenir en faveur de cette dernière, précisément en faisant valoir ses propres qualités marines (Ovide, Métamorphoses IV, v. 523-540).

Le lien établi entre les deux divinités explique aussi que leurs mythes aient pu parfois se confondre. Ovide (Fastes II, v. 459-474) dans son récit de la légende d'Aphrodite-Atargatis, l'Aphrodite syrienne ${ }^{94}$, en donne une version proche de l'histoire d'Ino. Poursuivie, Aphrodite se trouve avec son fils au bord de l'eau; saisie de peur, elle saute avec l'enfant dans les bras... pour être recueillie sur le dos d'un poisson. Ce syncrétisme montre qu'Ino et Aphrodite présentaient des caractères communs, ce que laissait déjà soupçonner leur lien de parenté ${ }^{95}$.

l'Isthme un groupe statuaire consacré depuis peu; sur la base du char de cette sculpture figure une représentation de Thalassa soulevant Aphrodite enfant.

${ }^{90}$ Séchan 1955, p. 45. Cette représentation est rapprochée du dossier du trône Ludovisi (Museo Nazionale Romano, inv. 8570) : Pugliese Carratelli 1996, p. 392-393.

${ }^{91}$ Delivorrias 1984, 1 p. 113-117 et 2 p. 115-119. Voir les exemples présentés in id. 1987, no 109 à 112, 119, 129-132 (A. Anadyomène - d'après la peinture d'Apelle exposée à Kos (Athénée XIII, 590f) - et types dérivés du $\mathrm{IV}^{\mathrm{e}} \mathrm{s}$. au $\mathrm{II}^{\mathrm{e}} \mathrm{s}$. a.C.).

${ }_{92}^{92}$ Sur Mélicerte-Palaimon, voir notamment Witte 1879; Hawthorne 1958.

${ }^{93}$ Théogonie, v. 975-976. Glotz 1904, p. 34-37; Farnell 1916; Krauskopf 1981, p. 137-151; Bonnet 1986.

${ }^{94}$ Sur l'assimilation Atargatis-Aphrodite : Lambrechts \& Noyen 1954; Morin 1960; Glueck 1965, chap. XI : Atargatis-Aphrodite, p. 359 ss.; Turcan 1992, p. 134-135 expose l'avancée du culte d'Atargatis en Grèce et le développement de ses assimilations; Pirenne-Delforge 1994, p. 249.

${ }_{95}$ Will 1955, p. 228-231 propose l'hypothèse d'un culte d'Aphrodite fortement 
Une version légèrement différente de la légende d,AphroditeAtargatis voit la déesse se transformer elle-même en poisson, ce qui explique l,interdiction alimentaire des Syriens pour les poissons (Hygin, Astronomie II, 30) ${ }^{96}$.

\section{c) Récits hérö̈ques}

Si le mythe de sa naissance fournit matière à littérature, Aphrodite marine n,,intervient que rarement dans les récits héroïques. Elle est associée au voyage de Thésée en Crète, selon une tradition rapportée par Plutarque ( Thésée 18, 1-3) ${ }^{97}$. Avant le départ, Thésée reçoit d,,Apollon l,oracle de prier Aphrodite afin de l,avoir pour guide $(\kappa \alpha \theta \eta \gamma \varepsilon \mu o ́ v \alpha)$ et compagne de voyage ( $\sigma v v \varepsilon ́ \mu \pi \circ \rho o v)$. Obéissant à ce conseil, le fils d,Égée se rend au bord de la mer où il sacrifie à la déesse une chèvre qui se métamorphose alors en bouc. Plutarque

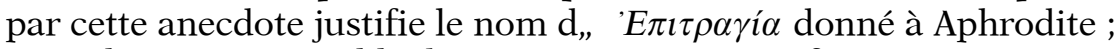
mais il est aussi possible $\mathrm{d}$,interpréter cette transformation comme un signe de l,assentiment de cette dernière pour veiller sur la navigation des jeunes Athéniens. Pareillement, lors de son retour, le héros

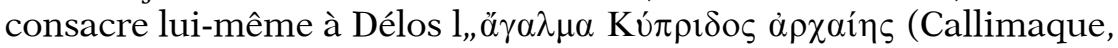
Hymne IV, v. 307-326), en remerciement doit-on supposer de sa protection durant le voyage ${ }^{98}$.

Une tradition tardive la fait intervenir une fois dans le trajet de retour des Argonautes, lorsqu,,elle sauve Boutès de la noyade alors qu,,il s,était précipité dans l,onde pour rejoindre les Sirènes (PseudoApollodore, Bibliothèque I, ix, 25). La présence d,,Aphrodite dans les périples maritimes des héros est donc quasiment nulle : la déesse paraît effacée devant les personnalités plus fortes d,„Athéna ou d,Héra.

influencé par celui de divinités locales plus anciennes, en particulier Ino en ce qui concerne Corinthe : le caractère marin d,Aphrodite serait davantage dû à des éléments locaux qu,,à des origines orientales. Ÿ 1,,inverse, Farnell 1896, II p. 637-638 pense que Leucothée représente une variante de la déesse orientale dont Aphrodite constitue 1,autre aboutissement.

${ }^{96} \mathrm{~L}$,interdiction syrienne de manger du poisson en rapport avec le culte d,,Atargatis est connue par d,,autres sources notamment ibid. II, 41; Athénée VIII, 346 c-e.

${ }^{97}$ Pirenne-Delforge 1994, p. 35-39, pense que Épitragia correspond à une épiclèse fi et non à un type iconographique fi de la déesse, sans doute honorée au Phalère : un siège du théâtre de Dionysos est en effet réservé à son prêtre $\left(I G \mathrm{II} / \mathrm{III}^{2}, 5115,5148\right)$. Elle met son culte en relation avec le passage de 1,adolescence à la sexualité adulte.

${ }_{98}$ Plutarque, Thésée 21 raconte que la statue était un cadeau d,,Ariane à Thésée; Pausanias IX, 40, 3-4 donne une description de la statue. 


\section{Témoignages cultuels}

Il est malaisé de percevoir parmi les si nombreux lieux de culte à Aphrodite ceux qui possèdent réellement une signification maritime ${ }^{99}$. Naturellement, l'inventaire qui suit ne prétend à pas l'exhaustivité (cartes 4, 11-13); il doit cependant permettre d'esquisser les grands traits de la place d'Aphrodite dans la religion des marins grecs. Devant la variété des lieux de culte et leur chronologie, le classement géographique utilisé jusqu'ici a été légèrement modifié. Nous avons en effet choisi de commencer l'étude de ces sites en commençant par les îles pour lesquelles les sanctuaires de la déesse remontant à une haute Antiquité sont liés à ses origines mythiques.

Pausanias constitue la source essentielle pour l'établissement de cette liste, mais son témoignage est rarement conforté par d'autres documents. Il est donc difficile de dater les cultes de la Corinthie ou du Péloponnèse; certains relèvent sans doute de l'époque impériale, sans que nous puissions le déterminer pour le moment.

a) Les îles. Aux origines du culte marin d'Aphrodite

- Chypre

Chypre constitue le haut-lieu du culte de la déesse ${ }^{100}$. Le pseudonyme de Kypris en témoigne - pour ce qui est d'un contexte marin depuis Sappho (Fgts 192; 194; 241) ${ }^{101}$. Les sources littéraires sont unanimes pour reconnaître la primauté de l'île en ce qui concerne l'ancienneté et l'importance de ses sanctuaires. C'est en effet à Chypre qu'Aphrodite sortit de l'eau de manière définitive selon Hésiode (Théogonie, v. 187-197) ou Pomponius Mela (Chorographie II, 7, 102). L'événement se serait produit à Paphos, où téménos, naos et bômos sont attestés dès les hymnes homériques (Hymne homérique à Aphrodite I, v. 58-59). L'épiclèse de Paphienne donnée à la divinité s'inspire directement du toponyme (Apulée, Métamorphoses

${ }^{99}$ Un exemple suffira à montrer l'ambiguïté de l'enquête. À Eantheia en Locride, Pausanias $(X, 38,9)$ signale l'existence d'un sanctuaire sans fournir de détail supplémentaire; la localisation de la cité sur le littoral du Golfe de Corinthe et les compétences marines d'Aphrodite tendraient à expliquer selon PirenneDelforge 1994 (p. 306) le culte d'Aphrodite à cet endroit. Mais le Périégète ne précisant pas l'emplacement du sanctuaire dans la ville et en l'absence de sources complémentaires, nous ne pouvons pas, en ce qui nous concerne, retenir cette attestation parmi les cultes marins de la déesse.

${ }^{100}$ Pirenne-Delforge 1994, p. 309-370 : différents sites connus à ce jour; Karageorghis 1977 : origines du culte dans l'île jusqu'au Ve s. a.C.

${ }^{101}$ Sur la connotation particulière que prennent les occurrences de Kypris dans l'Iliade, voir Pirenne-Delforge 1994, p. 310-311. 
XI, 3-17). Le lien entre Chypre, la mer et Aphrodite est tel que la mention du lieu suffit à évoquer la déesse. Ainsi Horace (Odes I, iii, v. 1-8), qui compose un propemptikos pour Virgile embarquant pour la Grèce, invoque en premier lieu la diva potens Cypri pour que le bateau mène le poète à bon port. Chypre, lieu de la première apparition de la déesse reste son domaine privilégié, voire sa résidence préférée (Hymne orphique LV, v. 16 et 25-27).

La description que donne Strabon (Géographie XIV, 6, 3) énumère plusieurs sanctuaires placés en bordure de mer, sur des promontoires de façon à dominer les flots. Un premier temple situé sur une montagne surplombant un promontoire et des îles voisines l'honore sous le nom d'Akraia; cet endroit est interdit aux femmes. Un deuxième hiéron est juché sur une colline au-dessus d'un cap nommé Pèdalion ${ }^{102}$. À Paleapaphos se trouve un troisième sanctuaire - ancien précise Strabon -, dominant le port et consacré à Aphrodite Paphienne. Ce dernier, à présent connu suite à des fouilles allemandes, abritait une statue aniconique de la déesse ${ }^{103}$. Le géographe évoque un quatrième lieu de culte à Soloi en association avec Isis. La mention de la divinité égyptienne et d'un port à cet endroit permettent d'y reconnaître un sanctuaire fréquenté par les navigateurs ${ }^{104}$. À Amathonte, des bateaux en terre cuite sont déposés dans celui d'Aphrodite (voir infra p. 375).

- Cythère

L'épithète de Cythérée apparaît dès la Théogonie d'Hésiode (v. 187-197) ${ }^{105}$. Elle est donnée à la déesse car c'est la première terre qu'elle rencontra $(\pi \rho \circ \sigma \varepsilon ́ \kappa v \rho \sigma \varepsilon)$ après sa naissance dans la mer mais, semble-t-il, sans s'y arréter - avant même d'arriver à Chypre. Pausanias (III, xxiii, 1) souligne l'antiquité du sanctuaire, le premier en Grèce selon lui. Il indique par ailleurs le type de la statue représentant la déesse en armes ainsi que son épiclèse d'Ouranienne, qui

${ }_{102}$ Pirenne-Delforge 1994, p. 362-363. Une inscription (SEG XX, 316) confirme l'existence du premier sanctuaire, au moins pour l'époque impériale.

${ }_{103}$ Tacite, Histoires II, 3, 1-2. Récapitulatif in Pirenne-Delforge 1994, p. 334-347 avec bibliographie. Deux grandes phases de construction ont marqué la vie du sanctuaire : vers 1200 a.C., puis l'époque romaine.

${ }^{104}$ L'aniconisme de la déesse laisse supposer une origine sémitique du culte, qui remonte au $\mathrm{II}^{\mathrm{e}}$ millénaire; les mouvements autour du sanctuaire ont sans doute accentué le caractère maritime de la divinité au fil du temps (Bonnet \& Pirenne-Delforge 1999, p. 261-263). Le triple port mentionné avec le sanctuaire d'Aphrodite - on ne précise pas lequel - dans Stadiasmus 297 souligne le lien entre celle-ci et la navigation (Medas 2008, p. 158-160).

${ }^{105}$ Pirenne-Delforge 1994, p. 217-226 et 434, qui signale deux occurrences de l'épithète dans l'Odyssée (VIII, 288; XVIII, 193-194). 
renvoie à ses origines mythiques. Denys d'Halicarnasse (Antiquités romaines $\mathrm{I}, 50,1)$ attribue la fondation du sanctuaire à Énée, lors de son voyage vers l'Italie. Mais il s'avère plutôt que le culte d'Aphrodite à Cythère relève d'une tradition phénicienne; il est notamment lié au commerce de la pourpre de l'île ${ }^{106}$. Le sanctuaire se trouvait près de la cité homonyme de l'île, Cythère (aujourd'hui Paleokastro), sur une terrasse d'où l'on surplombe le littoral et le large (fig. 6).

Le site, qui devait comprendre un édifice dorique de la fin du VIe s. a.C., n'a jamais été fouillé. Il convient d'insister sur le caractère ancien du culte à Cythère, affirmé par les Grecs eux-mêmes, qui doit être mis en relation avec l'importance géographique de l'île servant d'escale aux navigateurs minoens puis phéniciens depuis le III $^{\mathrm{e}}$ millénaire ${ }^{107}$. Les marins de passage dans l'île, avant ou après le

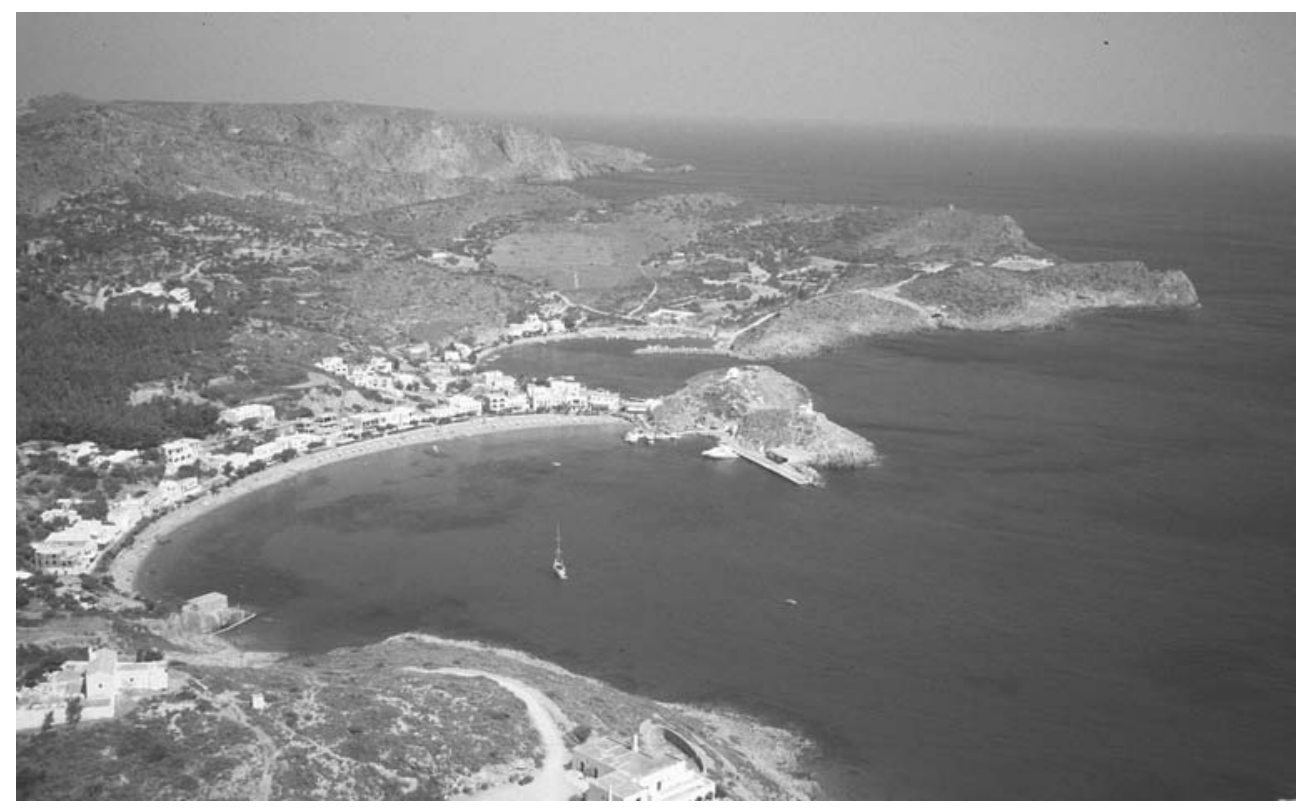

Fig. 6 - Vue depuis le sanctuaire d'Aphrodite à Cythère (Photo de l'auteur).

106 Pour une localisation précise, voir Wace \& Hasluck 1907-08, p. 175 ss. et Coldstream \& Huxley 1972, p. 35, 311-313; П $\alpha \pi \alpha \chi \alpha \tau \zeta \eta ́ \varsigma ~ 1974-1981$, p. 421-422. Le hiéron est mentionné par Hérodote I, 105; sur la pourpre Pline, Histoire naturelle IV, 56; Stéphane de Byzance, s.v. Kú $\eta \eta \rho \alpha$.

${ }^{107}$ Pirenne-Delforge 1994, loc. cit. L'emplacement de la ville de Cythère - et du sanctuaire d'Aphrodite - se trouve en arrière d'une baie facilement accessible aux embarcations, sur la côte orientale de l'île. 
franchissement du cap Malée, se devaient de présenter leurs dévotions à la déesse ${ }^{108}$; par ailleurs un poisson, la dorade, lui était ici tout spécialement consacré (Athénée, Deipnosophistes VII, 328a) ${ }^{109}$.

- Sicile

Après Chypre et Cythère, l'un des sanctuaires les plus vénérables d'Aphrodite se trouve en Sicile. Le temple, comme le décrit Polybe (Histoires I, 55, 5-10), se situe sur un plateau au sommet du Mont Éryx ${ }^{110}$, dominant la mer Ionienne au nord-ouest de l'île. Le lieu, précise l'historien, est connu pour sa richesse et sa magnificence, ce qui paraît particulièrement vrai pour la période républicaine ${ }^{111}$. Le culte consacré à Aphrodite-Astarté comprenait notamment la pratique de la prostitution sacrée et un rituel de vol de colombes ${ }^{112}$. La position topographique du site, servant à l'occasion à des fins militaires, devait constituer un amer précieux pour les bateaux doublant la Sicile ${ }^{113}$. L'origine phénicienne de la déesse, avant son hellénisation datable du $\mathrm{V}^{\mathrm{e}} \mathrm{s}$. a.C., laisse également supposer un culte actif de la part des navigateurs ${ }^{114}$.

Dans l'île, Aphrodite marine était, semble-t-il, honorée par ailleurs à Camarina d'où provient un ex-voto tout à fait particulier : un galet avec des lettres grecques en relief. Sur une face est inscrit le nom de la déesse, sur l'autre celui de la dédicante Aristocleia avec un dauphin dans le registre inférieur. L'objet a été trouvé sur le territoire de la commune, sans localisation précise ${ }^{115}$. La forme de l'alpha avec la barre brisée date l'offrande au plus tôt de l'époque hellénistique. L'animal et le type de pierre, ainsi que la localisation de

${ }^{108}$ Baladié 1980, p. 245.

${ }^{109}$ Callimaque, Fgt 378; Plutarque, De sollertia anima 32. Bodson 1978, p. 52.

${ }^{110}$ Descriptions dans Acquaro \& alii 2010, p. 25-47. Sur le lien avec Éryx en Arcadie et le culte qui y est rendu à Aphrodite Érycine, voir Jost 1985, p. 513-514; Pirenne-Delforge 1994, p. 256 ss.

${ }^{111}$ Coarelli \& Torelli 1997, p. 56-57, s'appuyant sur Diodore IV, 83. Le sanctuaire déclina à la fin de l'époque hellénistique. Les fouilles du site dans les années 1930 et les prospections récentes n'ont mis au jour que de pauvres vestiges : Barresi 2010. Strabon, Géographie VI, 2, 6 évoque un temple entouré d'un portique, tandis qu'une monnaie de 57 a.C. figure un temple sur un sommet entouré d'une muraille.

${ }^{112} \mathrm{Ibid}$. Selon Élien (Nature des animaux IV, 2), le vol de ces colombes était interprété comme une visite au sanctuaire d'Astarté à Sicca Veneria sur la côte africaine.

${ }^{113}$ Semple 1927, p. 356; Manni 1963, p. $79-88$ insiste sur la position dominante du sanctuaire - et de sa déesse.

${ }^{114}$ Bonnet 1996, p. 115-120; Acquaro \& alii 2010.

${ }^{115}$ Coll. privée. Manganaro 1977, p. 150 et pl. XLVIII, 5; Kron 1992, p. 68. Aucune autre trace archéologique référant à un culte d'Aphrodite à Camarina n'est apparue pour le moment. 
Camarina en bord de mer, au sud de la Sicile centrale, renvoient à l'image de la déesse en relation avec la mer.

Signalons enfin à Messine une inscription ${ }^{116}$ dédiée à Aphrodite, constituant peut-être une dédicace de la part d'un groupe de nauclères.

Aphrodite marine est donc bien présente en Sicile; la fin du roman de Chariton d'Aphrodise (Les aventures de Chairéas et de Callirhoé VIII, 4, 10) montre d'ailleurs l'héroïne enfin prête à regagner l'île par mer, priant la divinité de lui accorder une traversée paisible. L'invocation se justifie d'autant mieux que les eaux siciliennes sont placées sous sa protection.

\section{- Délos}

Parmi les îles, il convient encore de s'arrêter sur Délos, où l'ancienneté du culte d'Aphrodite est affirmée par les sources et rattachée à l'aventure crétoise de Thésée. Si cette légende peut renvoyer à une offrande pour une navigation réussie, dans l'état actuel de nos connaissances, rien dans le culte officiel d'Aphrodite dans l'île n'indique clairement quelque rapport avec la mer ${ }^{117}$. En revanche, à l'époque hellénistique, les marques de dévotion privée l'assimilent à plusieurs divinités orientales. Aphrodite Astarté se voit ainsi consacrer des coquillages dans l'Établissement des Poseidoniastes (voir infra p. 504), et l'une des dédicaces du Sanctuaire des dieux syriens célèbre Isis Sôteira Astarté Aphrodite Euploia ${ }^{118}$. Ce triple syncrétisme souligne la valeur marine de l'Aphrodite honorée sous l'épiclèse d'Euploia ${ }^{119}$.

${ }^{116} I G$ XIV, 401; Vélissaropoulos 1980, p. 87 note 216. La dédicace, fragmentaire, consiste en une liste de noms au nominatif et à la dernière ligne le nom de la déesse au datif. Cette liste est surmontée d'une sorte de titre NAYPOI; lue

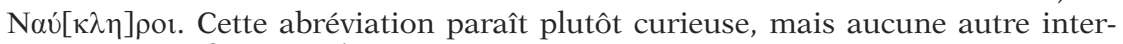
prétation satisfaisante n'a été proposée.

${ }^{117}$ Voir supra, p. 91-92. Aucun temple ni statue ancienne n'ont été retrouvés dans le sanctuaire d'Apollon, et l'on sait peu de choses des fêtes des Aphrodisia qui avaient lieu en Hékatombaion (juillet-août). En revanche, les fouilles déliennes ont mis au jour, au nord-est du quartier du théâtre, le temple consacré à Aphrodite par Stéliséos à la fin du IVe s. a.C. : Bruneau 1970a, p. 333-348; Bruneau \& Ducat 2005, p. 261 (no 88).

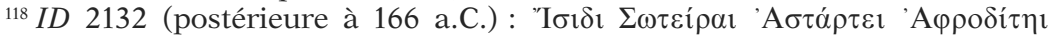

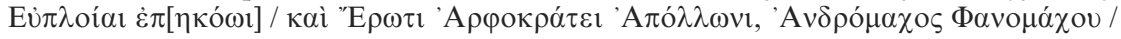

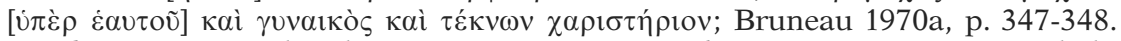
Sur le Sanctuaire des dieux syriens, où étaient honorés Atargatis et Hadad: Bruneau \& Ducat 2005, p. 274-275 (n 98); Bonnet 1996, p. 88.

${ }_{119}$ Bonnet \& Pirenne-Delforge 1999, p. 271-272. Bérard 1985 propose de reconnaître dans le thème iconographique d'Isis à la voile un modèle plus ancien d'Aphrodite à la voile, repris notamment à Délos lors du syncrétisme opéré entre les deux divinités. 
À Délos, le culte de la déesse en rapport avec la navigation semble donc n'apparaître qu'assez tard et être fortement influencé par les étrangers qui fréquentaient l'île ${ }^{120}$.

b) Attique

En Grèce continentale, Aphrodite marine est d'abord attestée sur le littoral attique. À Sounion, des dédicaces s'adressent à Aphrodite Pontia (Marine) ${ }^{121}$. Au Pirée, c'est Aphrodite Euploia qui est l'objet d'un culte de la part des marins (Pausanias I, i, 3) ${ }^{122}$. La fondation du sanctuaire est attribuée au stratège Conon, après qu'il eut détruit devant Cnide la flotte spartiate en 394 a.C. ${ }^{123}$ Le hiéron qui se trouve au bord de la mer correspond bien à un ex-voto offert à une divinité marine pour une victoire navale. Selon l'itinéraire suivi par le Périégète, le temple devait se situer près du Kantharos et du marché, non loin du rivage ${ }^{124}$. Une inscription du début du $\mathrm{I}^{\mathrm{er}}$ s. a.C. due à un stratège athénien confirme l'épithète d'Euploia donnée à la déesse ${ }^{125}$. Le geste de Conon fait peut-être écho à un autre sanctuaire d'Aphrodite, plus ancien, installé dans la presqu'île d'Éétonie : celui-ci aurait été voué par Thémistocle après Salamine, parce que l'oiseau sacré d'Aphrodite se serait posé sur sa trière

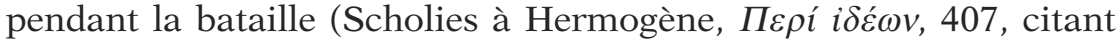
Ammonios, Sur les autels = voir corpus p. 539) ${ }^{126}$. Ce supposé précédent pose cependant un problème de contradiction entre les sources : selon Plutarque (Plutarque (Thémistocle 12,1), seule une chouette serait venue distinguer le bateau du général athénien (voir supra p. 65). On peut donc aussi interpréter l'épisode relatif à Conon comme une variante et surenchère de celui de Salamine : en écho à l'oiseau d'Athéna annonciateur de la victoire de Thémistocle, la victoire de 394 a repris la tradition en y ajoutant l'intervention d'une autre divinité : Aphrodite.

Au sud de l'autre port du Phalère se trouve le cap Kolias, célèbre par les épaves mèdes venues s'y échouer ${ }^{127}$; Strabon (Géographie IX,

${ }^{120}$ Baslez 1999.

${ }^{121}$ Bases de statues avec dédicaces : SEG 50, n 206; Thémélis 1974, p. 15; Davaras 1979, p. 18; Kovpivou 2004-2009.

122 Pirenne-Delforge 1994, p. 33 et 433.

${ }^{123}$ Will \& alii 1975 , p. $20-21$ et 29.

${ }^{124}$ Sur la localisation : Garland 1987, p. 109 et 112; Musti \& Torelli 1986-1991,

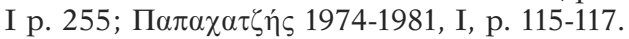

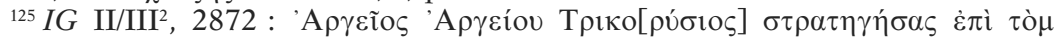
$\Pi \varepsilon \imath \rho \alpha[1 \tilde{\alpha}]$ 'A

${ }^{126}$ Pironti 2007, p. 245-247. Inscription d'Éétionie avec mention d'un Aphrodision : IG II/III'2, 1657 (datée de 394).

${ }^{127}$ Hérodote, Enquête VIII, 96. 
I, 21) y situe un hiéron d'Aphrodite Koliade tandis que Pausanias (I, i, 5) y signale une statue de cette même divinité et la présence de divinités nommées Génétyllides. L'épiclèse toponymique de la déesse, qui est par ailleurs porté par une trière de guerre athénienne (voir infra p. 280), peut laisser supposer que le promontoire est consacré à une Aphrodite marine. Ce culte du cap semble antérieur à l'épisode des guerres Médiques, et non pas consécutif à celles-ci ${ }^{128}$.

À Athènes même, notons que deux bateaux de terre cuite archaïques, retrouvés sur le flanc nord de l'Acropole, proviennent d'une zone où fut dégagé un sanctuaire rupestre d'Aphrodite et d'Éros (voir infra p. 375), et que la flotte athénienne du IV e s. baptise plusieurs bâtiments de noms évoquant la déesse : Aphrodisia, Aphrodisias ou Kythéria (voir infra p. 280).

\section{c) Corinthe}

Dans l'Isthme, Aphrodite possède un sanctuaire à Cenchrées, le

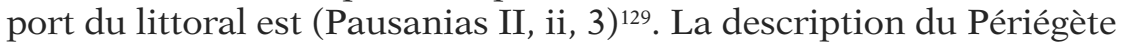
laisse supposer que le naos se trouvait d'un côté du port, tandis qu'à l'autre extrémité lui faisaient face des sanctuaires d'Isis et Asclépios. Une monnaie impériale figure en effet le port encadré par deux temples. Une autre, qui représente la tête de la déesse sous laquelle est placé un navire portant le nom du port, doit probablement correspondre à la statue mentionnée par Pausanias ${ }^{130}$.

Le port opposé du Léchaion, sis au bord du golfe, comportait peut-être également un lieu de culte d'Aphrodite. Plutarque mentionne en effet un sanctuaire dédié à celle-ci à cet endroit; mais il est tout aussi difficile de dater l'établissement de ce culte que de déterminer si le moraliste n'a pas opéré une confusion entre les deux ports corinthiens ${ }^{131}$.

${ }^{128}$ Aujourd'hui, le promontoire est désigné sous le nom de pointe d'Haghios

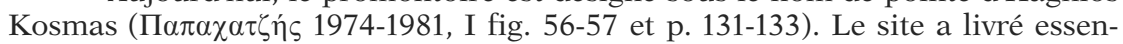
tiellement des vestiges préhistoriques. Les Génétyllides sont liées à la maternité (Musti \& Beschi 1982, p. 257-258); Pirenne-Delforge 1994, p. 76-78, insiste sur le caractère féminin du sanctuaire et du culte.

${ }^{129}$ Pirenne-Delforge 1994, p. $94-95$ et 434.

${ }^{130}$ Imhoof-Blumer \& Gardner 1964, p. 17 et pl. D, lx et lxv; Roux 1957, p. 104. Les fouilles menées au port de Kenchreai n'ont rien donné de concluant concernant le temple d'Aphrodite (Scranton \& alii 1978, p. 79-90); reconstitution de la configuration du port dans П $\alpha \pi \alpha \chi \tau \zeta \zeta$ ń 1974-81, II fig. 27. Le culte d'Aphrodite à Corinthe prend énormément d'importance à l'époque romaine: Pausanias énumère au cours de sa visite dans l'Isthme un certain nombre de statues de la déesse auxquelles correspondent par ailleurs plusieurs types monétaires.

${ }^{131}$ Pirenne-Delforge 1994, p. 95-96 et 434, citant Plutarque, Banquet des sept sages $146 \mathrm{~d}$ et SEG XXIII, 170. 
De façon plus assurée, la fouille du quartier des potiers à Corinthe a livré, à l'extérieur d'une chapelle archaïque, un dépôt votif dans lequel se trouvait une inscription à Aphrodite ainsi qu'un bateau de terre cuite. Ainsi, le culte marin de la déesse à Corinthe, bien attesté à l'époque romaine notamment dans la nouvelle cité ${ }^{132}$, trouve néanmoins quelque antécédent à l'époque archaïque.

\section{d) Péloponnèse}

\section{- Argolide}

À Égine, sa présence est assurée par diverses sources. Pausanias (II, xxix, 6) mentionne son temple sur le port le plus fréquenté de l'île ${ }^{133}$. Un jas d'ancre de pierre, trouvé à proximité de celui-ci et portant le nom d'Aphrodite Épiliménia (voir infra p. 466 ss. et cat. V2), nous renseigne sur l'épiclèse éginète. Le culte d'une Aphrodite protectrice des navigateurs à Égine ${ }^{134}$ s'explique d'autant plus que Pausanias insiste sur les difficultés qu'ils rencontrent pour accoster l'île. La ville moderne empêche toute localisation antique du temple; celui-ci nous est peut-être cependant connu par des monnaies romaines représentant le bassin du port et un bâtiment à colonnade ${ }^{135}$.

Sur le continent, à l'extrémité de l'Argolide, on vénère Aphrodite à Hermione indifféremment sous les noms de Pontia et Liménia (Pausanias II, xxxiv, 11). Le temple se trouve dans la cité récente, construite dans la première moitié du Ier s. a.C., où se situe également un autre sanctuaire de la déesse dans lequel lui sont rendus des $\ddot{\alpha} \lambda \lambda \alpha \imath \tau \mu \alpha \iota^{136}$. Le Périégète conseille la visite du temple d'Aphrodite marine à cause de la qualité de sa statue ${ }^{137}$. Le problème se pose

${ }^{132}$ Williams 1986, nuancé par Pirenne-Delforge 1994, p. 126-127, qui montre qu'avant l'époque romaine le culte d'Aphrodite n'occupe pas à Corinthe une place aussi considérable qu'on a bien voulu le dire.

133 À l'époque de Pausanias, il s'agit du port marchand : Musti \& Torelli 19861991 II, p. 310. Ce port marchand serait situé au sud de la ville actuelle : carte

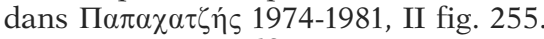

${ }^{134}$ Pirenne-Delforge 1994 , p. $176-178$ et 434 , cite en particulier un passage de Plutarque, Quaest. gr. 44, qui explique l'origine de fêtes rendues à Poséidon et à Aphrodite par la joie des guerriers éginètes rescapés de Troie rentrant chez eux dans l'île, obligés de célébrer leur retour en cachette.

${ }^{135}$ Imhoof-Blumer \& Gardner 1964, p. 45 et pl. L, 1.

${ }^{136}$ Pausanias II, xxxiv, 12; en revanche, il ne mentionne pas de sanctuaire d'Aphrodite dans l'ancienne cité d'Hermione présentée dans le paragraphe $10 \mathrm{du}$ même chapitre.

${ }^{137}$ La statue figure peut-être sur des monnaies (Imhoof-Blumer \& Gardner 1964, p. 50), mais rien ne permet d'y reconnaître l'Aphrodite Pontia plutôt que celle de l'autre temple. 
de déterminer l'ancienneté du culte marin de la divinité. V. PirenneDelforge avance l'hypothèse d'activités navales mais aussi commerciales, telles que l'exploitation du pourpre, pour expliquer cette double épiclèse dans un seul sanctuaire : la déesse serait ainsi honorée depuis l'époque archaïque ${ }^{138}$.

\section{- Laconie}

Au nord-ouest du cap Ténare, la cité de Kainèpolis possédait un temple d'Aphrodite au bord de la mer (Pausanias III, xxv, 9) ${ }^{139}$. La position du sanctuaire sur le rivage et dans le golfe précédant l'extrémité réputée périlleuse de la Laconie, laisse supposer un culte de type maritime. Il est impossible cependant de le dater, et ainsi de définir s'il est antérieur ou non à la cité qui constituerait une création de l'époque romaine ${ }^{140}$.

\section{- Achaïe}

Au nord du Péloponnèse, le culte d'Aphrodite marine apparaît sur le port de Patras (Pausanias VII, xxi, 10-11). Le Périégète semble évoquer deux sanctuaires ${ }^{141}$ distincts dans la zone du port, dont l'un voisin de celui de Poséidon, ce qui permet de reconstituer un culte lié aux activités portuaires. Ce hiéron possède d'ailleurs une statue qui aurait été sortie de l'eau par des pêcheurs une génération avant Pausanias. La déesse est honorée en outre d'un troisième lieu de culte dans un bois au bord de la mer en association avec Apollon. L'importance maritime de la cité doit expliquer en grande partie cet engouement pour Aphrodite. La multiplication de ses sanctuaires dans la zone du port montre que les populations marines étaient particulièrement attachées à son culte, ce peut-on supposer depuis une époque bien antérieure à celle de Pausanias.

Plus à l'est en suivant le littoral du golfe de Corinthe, le voyageur (VII, xxiv, 2) signale encore à Aigion un sanctuaire maritime d'Aphrodite, voisin d'un autre consacré à Poséidon. Les deux divinités figurent d'ailleurs sur les monnaies de la ville, Aphrodite étant accompagnée d'un dauphin ${ }^{142}$.

${ }^{138}$ Pirenne-Delforge 1994, p. 186-187 et 434, base son argumentation sur l'expression d'Haliéens utilisée par Strabon, Géographie VIII, 6, 12 pour désigner la population locale; cf. Baladié 1980, p. 216-220.

${ }_{139}$ Wide 1893, p. 139.

${ }^{140}$ La cité est localisée sur une colline près du bourg moderne de Kyparissos : Woodward 1906-07; Pirenne-Delforge 1994, p. 215-216 et 434.

${ }^{141}$ Pirenne-Delforge 1994, p. 240-242 et 434 pense même qu'en réalité Pausanias en évoque trois.

${ }^{142}$ Imhoof-Blumer \& Gardner 1964, p. 87 et pl. R, xxiii; Moggi \& Musti 2000, 
Ainsi, dans l'ensemble du Péloponnèse, le culte d'Aphrodite marine ne se manifeste que de manière sporadique autour de quelques points stratégiques; il donne la sensation en revanche se développer au fur et à mesure qu'on s'en éloigne.

\section{e) Mer Ionienne}

En mer Ionienne, plusieurs sanctuaires de bord de mer consacrés à Aphrodite sont attribués, selon la tradition rapportée par Denys d'Halicarnasse, au passage d'Énée naviguant vers l'Italie ${ }^{143}$. L'île de Zakynthos retient quelque temps les héros en raison de conditions défavorables à la navigation (aploia) : ils y offrent un hiéron à la déesse et instituent un sacrifice et des jeux (Denys d'Halicarnasse, Antiquités romaines I, 50, 3-4). L'escale suivante, à Leucade, voit encore l'établissement d'un sanctuaire à Aphrodite Aeneias, cette fois sur un îlot localisé entre Dioryktos et la ville proprement dite de Leucade. La divinité est sans doute reconnaissable dans le type de la déesse à l'aplustre figurant sur des monnaies hellénistiques ${ }^{144}$.

De Leucade, la course des Troyens continue toujours vers le nord jusqu'à Actium où les héros fondent un autre sanctuaire d'Aphrodite Aeneias et un autre consacré aux Grands Dieux ${ }^{145}$. Puis, une fois débarqués à Ambracie, les navigateurs reproduisent cet acte de dévotion envers la déesse, pour le répéter à nouveau à Butrint avant de traverser le détroit d'Ionie (ibid., I, 51, 2). C'est pour cette raison que le mouillage naturel situé en contre-bas de l'Athénaion à l'extrémité de la Iapygie est nommé - du moins à la fin de l'époque hellénistique - Port d'Aphrodite (ibid. I, 51, 3) ${ }^{146}$. Tous ces sanctuaires, placés le long d'un littoral non loin les uns des autres, semblent liés au cabotage des bateaux remontant le long de la cote occidentale de la Grèce avant de passer en Italie. À Actium le rapprochement, à la fois dans l'espace et dans la tradition, avec un sanctuaire consacré aux Grands Dieux renforce l'impression d'une Aphrodite marine. Un poème de l'Anthologie Palatine (V, 16 de Gétu-

p. 321-322, les suppose situés près du port moderne qui a gardé l'emplacement du port antique.

${ }^{143}$ Chapouthier 1935a, p. 267. Le problème de la crédibilité du témoignage de Denys d'Halicarnasse ne se pose pas ici, sa source directe étant Varron qui a voyagé dans cette partie de la Grèce (Perret 1942, p. 57-61).

${ }_{144}$ Texier 1934; Gardner 1883, p. 179-182 et pl. xxviii-xxix y voit une Artémis.

${ }^{145}$ Fenet 2005, p. 42.

${ }^{146}$ Voir supra p. 47-48 (Athénaion); Van Compernolle \& alii 1978, p. 6 (PortAphrodite). 
licus) formule ainsi, dans la seconde moitié du Irr s. p.C., un vœu de bonne traversée à Aphrodite de la part d'un homme qui s'apprête à traverser la mer Ionienne. Le culte de la divinité qui protège ces navigations doit remonter à une date plus haute que celle de la seconde moitié de l'époque hellénistique : l'épiclèse d'Aineias, malgré son empreinte romaine, montre en tous cas qu'au dernier siècle avant notre ère, ces sanctuaires étaient considérés comme anciens $^{147}$.

\section{f) Grande Grèce}

Outre le Port d'Aphrodite que nous venons d'évoquer, le culte de la déesse est bien présent sur la péninsule de l'Adriatique à la mer Tyrrhénienne (carte 12).

À l'est de la péninsule du Gargano, de l'autre côté de la baie de Shkodra, dans la rade formée par les caps S. Francesco et S. Croce, un îlot nommé aujourd'hui Vieste (l'antique Uria) porte un phare utile aux navigateurs. À cet endroit, se trouve une grotte dont les parois sont gravées de nombreuses inscriptions médiévales et modernes, incisées directement sur la roche. Les dédicaces antiques, en grec et en latin, s'échelonnent entre le III $^{e}$ a.C. et l'époque romaine tardive. Au moins cinq dédicaces témoignent du culte de Venus Sôsandra. Certaines d'entre elles indiquent le nom du marin et du bateau. L'épiclèse $\Sigma \omega ́ \sigma \alpha v \delta \rho \alpha$ est attestée à Athènes, pour une statue fameuse due à Calamis ${ }^{148}$.

Sur la façade occidentale, depuis la villa sorrentine du bord de mer de Pollius Felix, chantée par Stace (Silves II, 2, v. 76-80) ${ }^{149}$, on aperçoit Euploia, «heureux présage pour les navires». Le détail ne relève pas seulement de l'art poétique, mais il doit évoquer une réalité géographique: un lieu littoral voire même un sanctuaire, visible depuis Sorrente, était vraisemblablement consacré à la déesse sous cette épiclèse ${ }^{150}$.

${ }^{147}$ Texier 1934; Farnell 1896, II, p. 638-639; Fenet 2005, p. 46. Signalons encore, en continuant la navigation vers le septentrion, une crique située au nord d'Orikos dans les monts Acrocérauniens, portant sur le rocher une inscription d'époque romaine surmontée de deux niches ornées l'une d'un portrait féminin, l'autre d'Aphrodite nue et Éros. Malgré le contexte maritime du lieu, le caractère érotique de l'offrande, l'absence de mention de navigation et le sexe supposé de la dédicante (portrait?) empêchent cependant d'y reconnaître catégoriquement une inscription d'euploia (Fenet 2005, p. 44-45).

${ }_{148}$ Russi 1989; Medas 2000, p. 47. Statue : Pausanias I, 23, 2; Lucien, Imag. 4 et 6; Lucien, Dialogues marins 3, 2.

${ }^{149}$ La même expression est reprise dans Silves III, 1, v. 149.

${ }^{150}$ Hülsen 1909; Bérard 1957, p. 83 l'identifie avec le promontoire de Pizzo Falcone; Giangiulio 1988, p. 103 ss. rapproche ce culte maritime de ceux de 
Un sanctuaire d'Aphrodite Pontia est ensuite cité pour Minturne, par un scholiaste de Virgile (Servius, Comm. in Eneid. VII, 47) qui évoque le culte d'une Nymphe locale, Marica, dont le sacellum serait voisin de celui de la déesse. L’emploi du passé et la

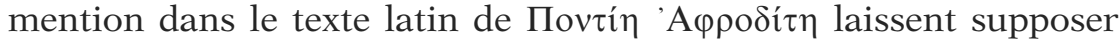
un sanctuaire ancien, dédié à la divinité grecque ${ }^{151}$.

Encore plus au nord, sur le promontoire de Circeo, Aphrodite devait recevoir un culte maritime comme l'atteste une inscription marquant les limites du téménos ${ }^{152}$. Le temple, constituant un amer pour les navigateurs doublant le cap, n'a pas été fouillé, mais a livré quelques découvertes architectoniques ${ }^{153}$. Enfin, la déesse était aussi vénérée dans le site de Gravisca, sans que l'on puisse préciser actuellement si elle l'était sous des aspects maritimes (voir infra, p. 376).

\section{g) Gaule et Ibérie}

Les Grecs ont associé Aphrodite en plusieurs lieux du littoral de la péninsule Ibérique (carte 11).

Sur la façade méditerranéenne, au sud-ouest de la Gaule, un sanctuaire d'Aphrodite Pyrénaia marque à l'époque de Strabon la frontière entre la Narbonnaise et l'Ibérie (Strabon, Géographie IV, 1, 3). Topographiquement, l'Aphrodision ferme le golfe du Lion situé au sud de Marseille tout en marquant le dernier contrefort des Pyrénées (ibid., 6). Pomponius Mela (Chorographie II, 6, 84) évoque quant à lui un Portus Veneris - le Port-Vendres d'aujourd'hui. Ces différentes informations renvoient l'image d'un endroit à la jonction de plusieurs mondes naturels et culturels, où les bateaux peuvent venir mouiller avant de doubler la barre des Pyrénées ${ }^{154}$.

Plus au sud, en Ibérie, Aphrodite se voit encore consacrer des lieux marins. Aviénus (Ora maritima, v. 158-60; 425-448) mentionne

Leucothéa et d'Athéna rendus sur le même littoral. Miranda 1989, p. 123-144, refusant de reconnaître dans ce nom l'épiclèse de la déesse, l'a interprété comme le toponyme d'un mouillage, interprétation contre laquelle s'est opposé Pugliese Carratelli 1992, p. 58-61.

${ }^{151}$ Le sanctuaire de Marica se situait à l'embouchure du Liris, aujourd'hui Garigliano. Giangiulio 1988, p. 107; sur Minturne, voir Ruegg 1983.

${ }^{152}$ CIL X, $6430: \mathrm{ad} /$ promuntur / Veneris / public. circeiens / usq. ad marem / a termi no LXXX / long. ped. L T pe CCXXV.

${ }^{153}$ Gianfrotta 1989, p. 43-53; Boetto 1997.

${ }^{154}$ Ruiz de Arbulo 2000, p. 42-43. La traduction de Pomponius Mela dans l'édition Budé donne "Portus Veneris dépourvu de mouillage», ce qui semble pour le moins contradictoire; sans doute vaut-il mieux comprendre le terme de salum comme "agitation de la mer». Baladié 1980, p. 235 ss. donne de bonnes définitions des ports, mouillages, etc. antiques au travers du vocabulaire utilisé par Strabon. 
deux promontoires de Vénus: le premier au nord-ouest dans la région dite d'Ophiussa, ce qui correspond à la zone du cap finistère espagnol ${ }^{155}$, et le second sur le littoral de Tartessos, identifiable avec le cap de Gata ${ }^{156}$. S'y ajoute une île nommée Érythia, à l'ouest du détroit de Gibraltar (ibid., v. 308-321) - i. e. sur la façade atlantique, l'île de Léon au large de Gadès -, qui comporte un sanctuaire d'Aphrodite creusé dans la roche, avec un oracle que le géographe fait remonter à la présence phénicienne ${ }^{157}$. Aviénus précise bien la position du sanctuaire dans la partie occidentale de l'île : c'est donc du côté océan et vers le large que la déesse était vénérée.

\section{h) Asie mineure}

- Ionie

Les cultes ioniens d'Aphrodite marine ne sont connus qu'à travers des sources épigraphiques. À la fin du III ${ }^{e}$ s. a.C. à Téos, la reine attalide Apollonis de Pergame, épouse d'Attale I ${ }^{\text {er }}$, divinisée sous le nom d'Apollonis Eusébès est honorée comme Apobatèria (du Débarquement). Sous cette épiclèse, elle reçoit un culte, desservi par le même prêtre que celui d'Aphrodite, et selon L. Robert sur un autel qu'on lui a érigé sur l'agora du port ${ }^{158}$. L'assimilation avec Aphrodite d'une souveraine hellénistique s'accompagne ici d'un culte directement lié à la navigation. Il convient de souligner le rapprochement avec l'épiclèse Apobatèrios ${ }^{159}$ plutôt connue pour Apollon, dieu à qui le nom de la reine Apollonis fait déjà référence.

Par ailleurs à Érythrées, une dédicace datée du I Ir s. a.C. s'adresse à Aphrodite Pontia ${ }^{160}$. En face de la péninsule, dans l'île de Chios, une autre du $\mathrm{II}^{\mathrm{e}}$ ou $\mathrm{I}^{\mathrm{er}}$ S. a.C. est vouée à Aphrodite Euploia par un polémarque nommé Gnôsis; l'inscription provient du Kastro, tout près de la mer ${ }^{161}$.

${ }^{155}$ Berthelot 1934, p. 66-67.

156 Ibid., p. 96 et 87 note 4.

${ }^{157}$ Ibid., p. 87.

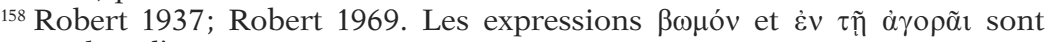
restituées dans l'inscription.

${ }^{159}$ Sur cette épiclèse, voir Pugliese Carratelli 1965; infra p. 168 (Apollon) et 99 (Zeus).

${ }^{160}$ Pirenne-Delforge 1994, p. 434; Inschriften griechischer Städte aus Kleina-

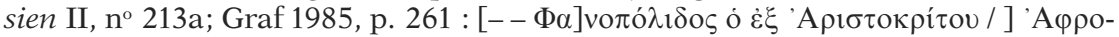

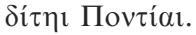

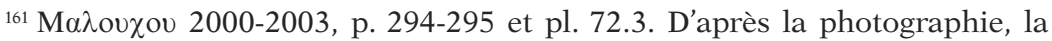
graphie semble irrégulière et ne pas présenter de caractère officiel. 
- Carie - Cilicie

La Carie montre un attachement particulier pour Aphrodite et ses prérogatives maritimes. Le célèbre culte de la déesse à Cnide est décrit par un passage de Pausanias (I, i, 3), déjà évoqué à propos d'Aphrodite Euploia au Pirée ${ }^{162}$. Selon le Périégète, l'importance accordée par la cité à la divinité se signale en particulier par l'existence de trois sanctuaires, auxquels correspondent trois épiclèses : respectivement Dôritis, Akraia et Euploia ${ }^{163}$. Les deux dernières - les plus récentes - relèvent comme leur nom l'indique d'un culte maritime, l'épiclèse d'Akraia devant renvoyer sans doute à l'emplacement $\mathrm{du}$ hiéron sur une pointe littorale ${ }^{164}$. Quant au temple cnidien d'Euploia, il abritait la célèbre statue de Praxitèle ${ }^{165}$. D'autres sources rattachent Aphrodite à Cnide et la mer: Horace (Odes III, xxviii) célébre la déesse comme régnant sur Cnide et les Cyclades; Pline l'Ancien (Histoire naturelle IX, 80) évoque de son côté un type de murex «honoré» à Cnide en relation avec Aphrodite. Ce coquillage de grande taille a pour particularité de freiner la marche des navires; les exemplaires de Cnide consistent peut-être en des ex-voto consacrés à la déesse, ou du moins des objets considérés comme tels. Pline raconte en effet à leur sujet l'histoire du navire de Périandre, emmenant des enfants de nobles familles pour les châtrer et stoppé en pleine course par ces coquillages. Hérodote fait état d'un tel envoi de jeunes gens depuis Corcyre vers Sardes, mais sans aucune allusion à un incident de ce genre ${ }^{166}$. L'aspect curieux du

${ }_{162}$ Miranda 1989; Pirenne-Delforge 1994, p. 434; Laumonier 1958, p 658.

${ }^{163}$ Miranda 1989 a interprété le texte de Pausanias comme l'énumération de trois épiclèses s'étant succédé dans le temps, ce que contredit Pugliese Carratelli 1992.

${ }^{164}$ Semple 1927, p. 368 et p. 383.

${ }^{165}$ Le type de la statue représentant la déesse debout, à demi dévêtue, parfois accompagnée d'un dauphin, est commodément appelé «d'Aphrodite Euploia»: Delivorrias 1984, 1 p. $69-70$ et 2 p. 59-60; il est proche de celui dit «Vénus marina» : ibid. 1 p. $65-66$ et 2 p. 55 . La forme iconographique montre les limites floues existant entre Aphrodite et d'autres divinités marines secondaires telles Ino ou les Néréides (Becatti 1971). Les fouilles du sanctuaire d'Aphrodite Euploia ont mis au jour un bâtiment monoptère et d'un autel (Love 1972-73) et des statuettes de terre cuite de la déesse remontant à la première phase du site, avant 390-380 a.C. (Sahin 2005).

${ }^{166}$ L'épisode est daté vers 585 a.C. Selon Hérodote (Enquête III, 48), le bateau corinthien emmenant les jeunes gens fait escale à Samos, où les habitants, prenant fait et cause pour eux, les placent comme suppliants dans le sanctuaire d'Artémis; les Corinthiens essaient alors d'affamer les jeunes Corcyréens que les Samiens ravitaillent de nuit. Lassés, les hommes de Périandre repartent sans leurs captifs qui sont ramenés dans leur île. Hérodote ne fait aucune allusion à Cnide; Plutarque, évoquant la même histoire (De Herodoti malignitate 22), affirme que ce sont des Cnidiens qui ont ramené les Corcyréens chez eux. 
coquillage et l'iconographie d'Aphrodite expliquent la consécration de celui-ci à la divinité marine; dans le même temps, la présence de tels objets, dans le sanctuaire de Cnide, confirme le caractère maritime de ce culte.

Aphrodite marine est honorée en d'autres sites de la région : à Mylasa, où une inscription fragmentaire donne les noms de deux prêtres d'Aphrodite Euploia ${ }^{167}$; à Caunos, où au $\mathrm{I}^{\mathrm{er}}$ s. p.C. la cité peut imposer aux bateaux accostant au port des offrandes à Aphrodite en guise de taxe ${ }^{168}$. Entre Caunos et Halicarnasse, Pomponius Mela (Chorographie I, 16, 84) mentionne un promontoire nommé Aphrodisium ${ }^{169}$. Son culte est à présent bien attesté à Kos, tout d'abord par une inscription bilingue gréco-phénicienne du roi de Sidon Abdalonim, datée du dernier quart du $\mathrm{IV}^{\mathrm{e}}$ s. a.C. consacrant quelque

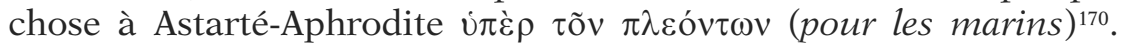
Pour l'époque hellénistique, deux lois sacrées datées autour de 200 a.C. mettent en scène une Aphrodite Euploia et une Aphrodite Pandamos. Les deux textes énumèrent notamment diverses catégories de personnes qui doivent sacrifier à la déesse ou lui donner un écot : parmi elles, des commerçants et des marins ${ }^{171}$. La première inscription, datée vers 200 a.C., stipule ainsi que les marins de la flotte doivent, à leur retour, sacrifier à Aphrodite Pontia ou bien payer 15 drachmes à la prêtresse et 1 drachme au trésor, et que les pêcheurs qui opèrent en dehors de la cité et les nauclères qui naviguent autour de la chôra doivent verser une dîme de 5 drachmes ${ }^{172}$. La seconde rappelle l'obligation de sacrifier à Aphrodite Pandamos pour les marchants et nauclères qui font voile depuis

${ }^{167}$ Pirenne-Delforge 1994, p. 434; Hauvette-Besnault \& Dubois, 1881, p. 108 $\mathrm{n}^{\circ} 11 \mathrm{~A}, 1.1-2$ et 1. 5. Le texte n'est pas daté.

${ }_{168}$ SEG XIV, 639 C.; J. et L. Robert, Bulletin épigraphique LXXII, 1959, p. 229-230 no 325; Vélissaropoulos 1980, p. 223-229; Pirenne-Delforge 1994, p. 402 note 161. Franco 1996 relie le culte de Caunos à celui d'Euploia à Cnide, et de là à Chypre.

${ }^{169}$ Le cap est identifié avec l'actuel promontoire Karaburun. Laumonier 1958, p. 625 suppose également un culte à une Aphrodite marine à Halicarnasse, d'après Vitruve II, 8 qui mentionne un temple commun d'Hermès et d'Aphrodite sur le côté droit de la corne que forme la ville. Mais la localisation vague Vitruve ne parle pas de bord de mer ou bord de port - empêche d'adhérer sans réserve à cette hypothèse.

${ }^{170}$ Bonnet 1996, p. 87-88 et 159-160; Parker 2002, p. 147-150.

${ }^{171}$ Parker 2002; Paul 2013, p. 90-91 et 305.

${ }_{172}$ SEG L, 2000, no 766. Miranda 1989; Pirenne-Delforge 1994, p. 434; Parker

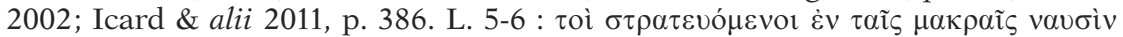

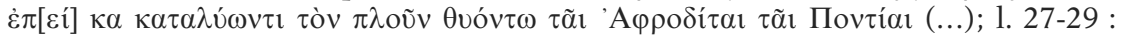

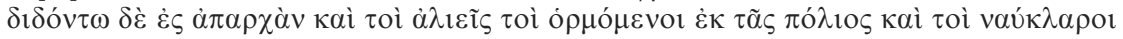

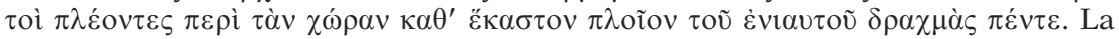
pierre, réemployée, provient de l'Asklépeion. 
la ville, et met en relation Aphrodite Pontia avec des cales et la construction de bateaux ${ }^{173}$. Le culte de ces deux Aphrodite était abrité dans un complexe construit sur le port dans la seconde moitié du III ${ }^{\mathrm{e}}$ s., comprenant une paire de temples orientés vers la mer ${ }^{174}$.

Pour ce qui est de la Cilicie, une seule dédicace de la fin du $\mathrm{I}^{\mathrm{er}}$ s. a.C. s'adresse à la fois à Théos Sébastos, Poséidon Asphaleios et Aphrodite Euploia. L'inscription provient du site antique d'Aigai, situé sur le golfe d'Issos et dont Strabon signale la qualité des mouillages ${ }^{175}$.

\section{i) Autour du Pont-Euxin}

En Troade, le golfe d'Adramyttion est fermé d'un côté par le cap de Pyrrha sur lequel se trouve un sanctuaire de la déesse (Strabon, Géographie XIII, 1, 51) ${ }^{176}$. En remontant vers le Bosphore, une inscription hellénistique concernant Cyzique donne le nom d'Aphrodite Pontia. Il s'agit d'une dédicace réalisée par un groupe s'occupant de pêche du thon, importante source de revenus pour la cité. Aphrodite n'est pas la seule divinité invoquée, elle est ici associée à Poséidon, en remerciement ( $\chi \alpha \rho \iota \tau$ ń de bonnes prises. Sur la stèle sont représentés en outre Cybèle et Apollon ${ }^{177}$.

De l'autre côté de la Propontide, le sanctuaire thrace d'Aphrodite établi sur un promontoire de la péninsule de Pallène, remonterait selon Denys d'Halicarnasse (Antiquités romaines I, 49, 3-4) au passage d'Énée le long du littoral ${ }^{178}$. Le cap relève de ces lieux où les héros, contraints d'attendre la saison favorable de navigation, font une escale prolongée.

L'itinéraire pontique d'Arrien (Périple du Pont-Euxin 12, 2-3) indique pour sa part un sanctuaire d'Aphrodite sur la côte, à l'est du

${ }^{173}$ Segre 1993, no ED178 p. 120-123 et pl. 49-51; Fgt a, face A, 1. $22-24$ : (...)

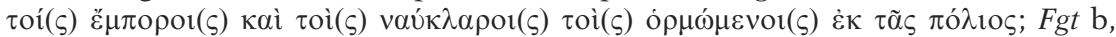

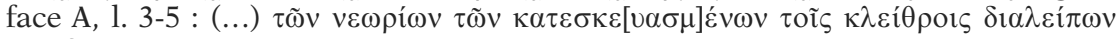

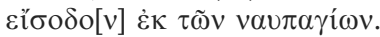

${ }_{174}$ Parker 2002; Rocco 2009, avec plans et restitutions; Paul 2013, p. 79-83.

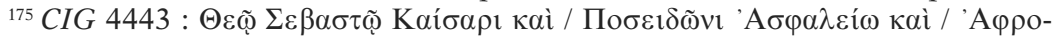

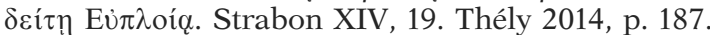

${ }^{176}$ Ce promontoire est généralement identifié avec celui de Kara-tepe : W. Leaf, Strabo on the Troad, book XIII, cap. 1, Cambridge, 1923, p. 260-261.

${ }_{177}$ Robert 1950, p. 94-97; Pirenne-Delforge 1994, p. 434; Icard \& alii 2011, p. 387. Voir aussi Thély 2014, p. 187.

${ }^{178}$ En réalité, Denys d'Halicarnasse a opéré une confusion entre Aineia où il place le sanctuaire d'Aphrodite et Ainos où celui-ci se trouvait réellement. Le site correspond aujourd'hui à la ville turque d'Enez, près du golfe de Saros (Denys d'Halicarnasse, Antiq. rom., éd. Budé, I p. 149. 
débouché thrace du Pont, à 390 stades de celui de Zeus Ourios. Le temple se trouve à l'embouchure de la rivière Artanè et marque l'emplacement d'un bon mouillage pour des bateaux de petite taille ${ }^{179}$.

Un autre itinéraire côtier du Bosphore (Denys de Byzance, Anaplus Bospori 35-36) mentionne quant à lui à Bolos, un lieu réputé pour la pêche, un sanctuaire d'Aphrodite appelée Praeia (la Douce) à qui les Byzantins rendent un sacrifice annuel. Elle y est associée avec une Artémis Phôsphoros. Le géographe explique l'épiclèse par l'action de la première déesse qui apaise, dans cette zone, les vents en faveur de la navigation. Les habitants ont en effet profité jusqu'à une date récente des qualités maritimes et halieutiques de ce rivage ${ }^{180}$.

En Thrace, sur le site de l'ancienne Teiristasis, une inscription remercie Aphrodite Pontia ${ }^{181}$. En remontant le littoral vers le nord, Aphrodite apparaît ensuite à Istros, au moins à partir de l'époque hellénistique ${ }^{182}$. Une base de statue en marbre ${ }^{183}$ datée du $\mathrm{II}^{\mathrm{e}} \mathrm{s}$. a.C. nous indique qu'elle y était honorée sous la même épiclèse. Le culte remonte peut-être à une date plus ancienne, car un naos d'époque classique retrouvé à proximité du temple de Zeus Polieus a livré une autre dédicace à la déesse, mais sans épithète ${ }^{184}$.

Dans la cité d'Olbia, c'est cette fois à une Euploia que rend grâces une inscription hellénistique ${ }^{185}$.

Le culte de la déesse est encore attesté de part et d'autre du Bosphore cimmérien : en Chersonèse Taurique, à Pantikapaion, en tant que Navarchis (Amirale) ${ }^{186}$, et sur le littoral opposé, à Nymphaion, où un sanctuaire est dédié à Apollon et Aphrodite

${ }^{179}$ Arrien est seul à mentionner un temple d'Aphrodite à cet endroit; la rivière est reconnue comme le Kuzgun (Arrien, Pér. P.-E., éd. Budé, p. 39).

${ }^{180}$ Identifié avec Kursumlumagsen, au rivage de Mumhane: Dallegio d'Alessio 1946, p. 219-220, 226-228.

${ }^{181}$ H. G. Lolling, «Inschriften aus den Küstenstädten des Hellespontos und

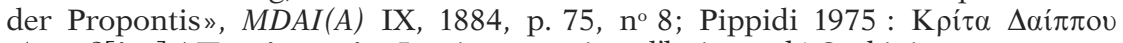

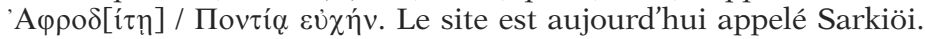

${ }_{182}$ Pippidi 1975; J. et L. Robert, Bulletin épigraphique 1963, n 170; PirenneDelforge 1994, p. 434. Un fragment de stèle en marbre (Musée d'Histria, inv. 304) témoigne du culte de la déesse pour le $\mathrm{III}^{\mathrm{e}} \mathrm{s}$.

${ }^{183}$ Musée d'Histria, inv. 112.

${ }^{184}$ Bordenache 1967, p. 143-147.

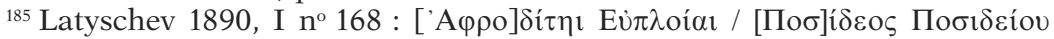

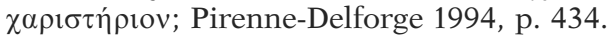

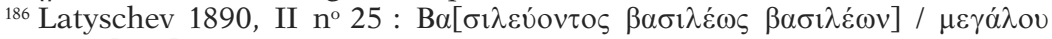

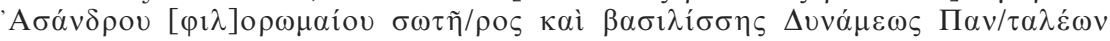

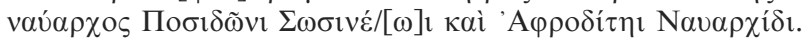


comme protecteurs des marins, comme en témoigne la grande représentation hellénistique du bateau appelé Isis (?), recouvrant tout un mur d'une des pièces (voir infra p. 404 ss.).

j) Égypte et Arabie

- Égypte

L'épigramme V de Callimaque localise un culte d'AphroditeArsinoè à Alexandrie, plus précisément à l'est de la cité, au promontoire du Zéphyrion. Le poème raconte, à la première personne, l'histoire d'un coquillage jadis parcourant les mers puis sa consécration dans le sanctuaire d'une divinité désignée sous les noms variés de Zéphyritis, Kypris et Arsinoè. Celui-ci, fondé par le navarque Kallicratès dans le deuxième quart du $\mathrm{III}^{\mathrm{e}} \mathrm{s}$., est connu par d'autres épigrammes de Poseidippos qui soulignent la visibilité du temple et la qualité de son mouillage ${ }^{187}$. Strabon (XVII, 1, 16) mentionne pour sa part sur l'akra un naiskos d'Arsinoè-Aphrodite. Le site, le type d'offrande et l'insistance portée sur le caractère marin de ce dernier indiquent qu'on honorait là une Aphrodite marine, assimilée à Arsinoé Philadelphe ${ }^{188}$.

Polycharme de Naucratis (rapporté par Athénée, Deipnosophistes XV, 675f-676c) témoigne, au moins pour l'époque hellénistique, d'une tradition se rapportant à un culte de marins envers Aphrodite à Naucratis ${ }^{189}$. Il rapporte en effet qu'à la $23^{\text {e }}$ olympiade (689-686 a.C.) ${ }^{190}$, un marchand de la ville, Hérostratos, revenant de Paphos avec une statue de la déesse, subit une tempête. Les occupants du navire, pris de peur et du mal de mer, se réfugient auprès de la statue. La déesse intervient alors, répandant du myrte sur le bateau ${ }^{191}$ et provoquant la réapparition du soleil. Arrivé à bon port, le voyageur célèbre Aphrodite par des sacrifices et des

${ }^{187}$ Robert 1966, p. 198-202; Barbantani 2005, p. 148-149; Demetriou 2010,

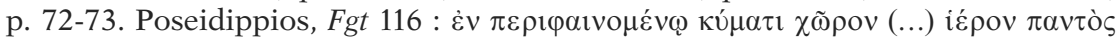

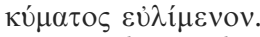

${ }^{188}$ Chapouthier 1935, p. 266; Tondriau 1948, p. 172-175; Miranda 1989 juge ce culte directement influencé par le culte cnidien; Mattingly 1950, p. 126-128 établit d'après l'épiclèse un lien entre Arsinoè Zéphyritis et Locri Epizephyrii; Picard 1952, p. 61-62 reconstitue un petit temple «avec l'effigie de la reine». Un nouveau poème célébrant Arsinoé-Aphrodite, provenant d'un papyrus du $\mathrm{II}^{e} s$. a.C. (P. Li. Goodspeed 2, I-IV), la désigne comme maîtresse de la mer (Barbantani 2005).

${ }^{189}$ Mc Cartney 1933, p. 10; Wachsmuth 1967, p. 97 note 91; Pirenne-Delforge 1994, p. 436.

190 À cette date, Naucratis n'existait pas encore, mais la référence chronologique de l'épisode doit souligner le caractère ancien du culte (Franco 1996).

${ }^{191}$ L'histoire n'est pas sans rappeler l'épisode de Dionysos et des pirates 
offrandes, à la fois de la statue et du myrte. Cette histoire, censée expliquer l'origine de la couronne dite «naucratique», est intéressante à plus d'un titre. Elle montre que l'Aphrodite chypriote était honorée par les marins, qui pouvaient prendre à leur bord son image sous forme de statue(tte). Elle établit un lien entre les cultes de deux contrées, le culte paphien étant transporté jusqu'à Naucratis et communiqué à tous : l'offrande de la statue et le repas collectif auquel invite Hérostratos supposent une transmission du culte et des traditions s'y rapportant. L'existence du sanctuaire a été confirmée par des trouvailles épigraphiques ${ }^{192}$.

\section{- Mers orientales}

En Arabie, Strabon (Géographie XVI, 4, 5) signale un port surnommé Port d'Aphrodite. Le bassin, appelé Myos, se distingue par ses grandes dimensions et une entrée sinueuse. Toute cette région est marquée dans la description qu'en donne Strabon par des fondations et des noms hellénistiques : l'appellation du port correspond à une consécration du lieu par les Grecs fréquentant les eaux de la mer Rouge ${ }^{193}$.

Enfin, dans le golfe Persique, l'expédition de Néarque double, à

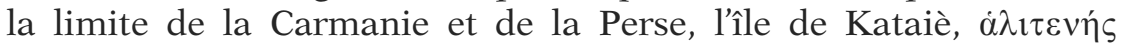
(basse) $)^{194}$, consacrée à Hermès et Aphrodite (Arrien, Indica, XXXVII, 10-XXXVIII, 2). Cette «île sacrée» est seulement peuplée de moutons et de chèvres apportés par les habitants du littoral voisin. Un culte commun des deux mêmes divinités, mais sans aucune mention de lieu, figure dans un poème de l'Anthologie Palatine (VI, 299 = Phanias, Épigramme V). Un voyageur s'engage à leur sacrifier sur le bord de la mer un chevreau : à Hermès parce qu'il protège les routes, à Aphrodite sans doute parce qu'elle veille sur les voies maritimes. Cette prérogative explique peut-être, ainsi que la topographie de l'île, cette identification avec Aphrodite plutôt qu'à une Artémis ${ }^{195}$.

tyrrhéniens telle qu'elle apparaît dans l'Hymne homérique à Dionysos (voir infra p. 220 s.) : par la pousse spontanée de végétaux et l'odeur qui emplit le navire.

${ }^{192}$ Gardner 1888, p. 11ss., 33ss; Bernand 1970, II p. 829-837; Boardman 1980, p. $119-120$.

${ }^{193}$ Myos est plusieurs fois cité comme un port important dans le Périple de la mer Érythrée; il a été identifié, sur la rive occidentale, avec Quseir al-Qadim (Casson 1989, p. 13-14, 51-52, 96-97).

${ }^{194}$ Pline l'Ancien, Histoire naturelle VI, 111 la nomme Aphrodisias et la dit habitée. Elle est identifiée avec l'île de Kish.

${ }^{195}$ Arrien décrit par ailleurs (Anabase VII, 20, 3-4) une île qui présente certaines similitudes est considérée comme consacrée à Artémis : voir infra p. 212. 
AnAlyse

\section{Géographie du culte}

La répartition du culte d'Aphrodite marine s'avère très éclatée : elle semble se répartir en cercles concentriques depuis la Grèce continentale, où la déesse se trouve peu présente. Elle privilégie en revanche tous les littoraux de la Méditerranée, depuis les Colonnes d'Hercule jusqu'au golfe Persique. Quelques zones concentrent plusieurs de ses sanctuaires : le littoral oriental de la mer Ionienne, depuis Leucade jusqu'à Bouthrotos et peut-être Orikos; le long de la côte sud du golfe de Corinthe entre peut-être le Léchaion, Aigion et Patras; dans le golfe de Minturne; aux trois extrémités du Péloponnèse (Ténare, Cythère, Hermione); sur toute la façade de l'Asie Mineure depuis Cnide jusqu'au Bosphore de Thrace; sur le pourtour occidental de la mer Noire; le littoral égyptien et le golfe Persique, et enfin autour du littoral de la péninsule Ibérique. La carte de répartition met en évidence des vides apparents : tout le sud de la botte italienne, toute la côte orientale de la Grèce depuis l'Attique jusque la Thrace, les Cyclades, le littoral occidental du Péloponnèse et la Grèce centrale. Le tout dessine une géographie cultuelle d'Aphrodite marine pourrait-on dire presque organisée. La plupart des sites constituent des points stratégiques de la navigation, ou s'échelonnent le long du littoral comme pour poser les balises d'un parcours nautique déterminé.

Quelques sources littéraires, évoquant des lieux consacrés à la déesse mais non rattachés à une site géographique précis, fournissent des éléments de réponse concernant les choix cultuels des sanctuaires d'Aphrodite marine. Trois épigrammes hellénistiques de l'Anthologie Palatine (IX, 144 d'Anytè; IX, 333 de Mnasalces; IX, 143 d'Antipater de Thessalonique) vantent ainsi la position privilégiée d'un de ses sanctuaires. Le lieu est censé lui plaire, du fait de sa vue sur la mer, ce qui lui permet de protéger la navigation des marins. Ces poèmes de genre définissent en quelque sorte un critère topographique des sanctuaires d'Aphrodite marine: sur le rivage, tournés vers les flots.

De fait, l'ensemble des sites présente des points communs. Le culte d'Aphrodite marine privilégie les promontoires ${ }^{196}$ : Kôlias, Sorrente, Pallène, Cnide, Port-Vendres, Zéphyrion... Pour les sites les plus anciens il s'agirait plutôt d'un point dominant le littoral ${ }^{197}$ :

${ }^{196}$ Observation déjà notée par Fíta 1906, p. 159; Farnell 1896, p. 636-637; Wachsmuth 1967, p. 398.

${ }^{197}$ Séchan \& Lévêque 1966, p. 371. 
ainsi à Chypre, en Sicile. Un plus grand nombre encore de sanctuaires sont implantés en relation avec un port ${ }^{198}$ : à Corinthe, au Pirée, Égine, Hermione, Patras, le long de la côte ionienne, en mer Rouge... L'endroit où débarque Énée, rebaptisé à l'époque hellénistique Port-Aphrodite, marque bien le caractère portuaire d'Aphrodite, déesse des bons mouillages.

Par ailleurs, d'après ce que transmettent les sources, les lieux consacrés à la divinité présentent tous des bâtiments, des constructions : le culte se rend dans des structures prévues à cet effet qui marquent le paysage côtier d'autant de points de repère. Aphrodite marine possède ainsi très peu d'épiclèses toponymiques Paphienne, Pyrénaia et Koliade - comme si finalement le caractère particulier du lieu importait peu. De la même manière, les deux bateaux géants de Hiéron de Syracuse et de Ptolémée Philopator dont la description nous est parvenue grâce à Athénée (Callixène, Fgt 627 et Moschion, Fgt 575, éd. Jacoby = Deipnosophistes V, 205d et 207e), comportaient tous deux une pièce richement décorée consacrée à Aphrodite, ainsi honorée à bord d'un véritable sanctuaire.

Ces différents éléments témoignent d'un culte actif, dynamique, propagé d'un port à l'autre de la Méditerranée. L'anecdote du marchand de Naucratis de retour de Paphos, des échanges bien attestés entre Naucratis et Égine à l'époque archaïque grâce au matériel du sanctuaire égyptien d'Aphrodite ${ }^{199}$, permettent de reconstituer quelques lignes de transmission du culte de la divinité à travers les réseaux commerciaux. L'exemple de l'Aphrodite cnidienne du Pirée rend compte de la souplesse de la déesse s'adaptant également au contexte militaire, mais surtout la désigne comme une divinité "voyageuse», dont le culte est véhiculé de rivage en rivage. En cela, elle se rapproche assez de la figure de Zeus; il n'est dès lors pas étonnant de les voir associés dans un contexte naval.

\section{Personnalité marine d'Aphrodite}

Le caractère marin d'Aphrodite possède un lien étiologique avec la naissance de la déesse ${ }^{200}$, bien que celui-ci ne suffise pas à tout expliquer. Néanmoins il est certain que cet élément a joué un certain

${ }^{198}$ Pirenne-Delforge 1994, p. 433.

${ }_{199}$ Torelli 1982, p. 317 ss. explique que le plus généreux donateur du sanctuaire d'Aphrodite à Naucratis est d'un génos Sostratos, nom que nous connaissons bien. Ses réflexions concernant les liens Naucratis-Égine suivent l'observation d'un certain nombre de dédicaces sur vase, formulées en alphabet éginète, retrouvées dans le sanctuaire d'Aphrodite-Turan à Gravisca.

${ }^{200}$ Pirenne-Delforge 1994, p. 437. 
rôle : Aphrodite revêt à cet égard un aspect très différent des autres divinités olympiennes puisqu'elle est la seule à être liée à la mer dans sa conception même. Ainsi, chez Euripide, Aphrodite est qualifiée de Despoina Pontia (Hippolyte, v. 415; v. 522) et chez les auteurs tardifs de $\theta \alpha \lambda \alpha \sigma \sigma \alpha i \eta^{201}$. Pour cette raison sans doute, tous les animaux marins lui sont consacrés (Plutarque, De Sollertia animalium 983e-984c). Le caractère maritime des autres dieux, comme nous l'avons vu jusqu'ici, s'affirme par des traditions héroïques; Aphrodite, elle, échappe à ce schéma ${ }^{202}$.

Les épiclèses doivent en revanche nous éclairer sur ses qualités marines. Elle est invoquée le plus souvent sous le nom de Pontia ${ }^{203}$ ou Euploia ${ }^{204}$, et à travers des cultes locaux de Liménia, Épiliménia ${ }^{205}$, Akraia, Apobatèria, Praeia, Aeneias, Zéphyritis et Navarchis; à celles-ci s'ajoute l'épiclèse d'Épipontia, attestée par Hésychius (s.v. $\dot{\varepsilon} \pi \imath \pi$ ovtía) qui l'applique sans autre commentaire à la déesse. La presque totalité de ces épiclèses ramène à une action bénéfique d'Aphrodite sur la navigation et le terme de celle-ci, c'est-à-dire les ports.

Deux extraits de romans montrent la dévotion que les marins, de manière générale, rendaient à Aphrodite. Dans Les aventures de Chairéas et de Callirhoé (Chariton d'Aphrodise III, 2, 14), l'héroïne embarque sur une plage; l'équipage saisi à sa vue et la prenant pour la déesse, se jette à ses pieds et fait diligence. Un épisode similaire apparaît chez Nonnos (Dionysiaques IV, v. 236-246) lorsqu'Harmonie navigue sur le bateau de Cadmos. Il est sûr que ce topos littéraire permet de mettre l'accent sur la beauté des personnages féminins, mais il renvoie aussi aux marques de dévotion des marins selon une tradition hellénistique. En effet, la scène ressemble curieusement à l'arrivée de Cléopâtre VII, parée en Aphrodite et entourée de pseudo-Néréides à Tarse en 41 a.C., telle qu'elle est rapportée par Plutarque (Antoine 26, 1-5) ${ }^{206}$.

Par ailleurs, la déesse paraît recevoir des marques de dévotion

${ }^{201}$ Notamment chez Nonnos; cf. Pirenne-Delforge 1994, p. 434 note 178.

${ }^{202} \mathrm{Il}$ est notable par ailleurs qu'en dehors du lien avec le mythe de sa naissance ou avec la tradition virgilienne, les sanctuaires d'Aphrodite marine ne font pas l'objet de légendes étiologiques : le besoin ne s'en fait pas sentir.

${ }^{203}$ Kruse 1953 énumère les différentes divinités qui prennent cette épiclèse : outre Aphrodite, Poséidon, Glaucos, Thétis, Leucothéa. Le terme de Pontia s'applique doublement à Aphrodite : par sa naissance et par son domaine d'activité.

${ }^{204}$ Jessen 1909.

${ }^{205}$ Wachsmuth 1967, p. 262.

${ }^{206}$ Tondriau 1948, p. 175. 
féminines, comme le galet de Catamarina ou l'inscription voisine d'Orikos. Même s'il est difficile d'y reconnaître exclusivement un culte maritime, on peut imaginer qu'Aphrodite recueille les vœux de bonne navigation de la part de femmes, elles-mêmes en voyage ou en l'attente d'un proche. Les xoana de la déesse à Thèbes, attribués selon la tradition à Harmonie qui aurait ainsi réutilisé les akrostolia des bateaux de Cadmos (Pausanias IX, xvi, 3-4), témoignent là encore d'un culte féminin rendu à Aphrodite présentant un lien avec la navigation (voir infra p. 420) ${ }^{207}$. Ceci est d'autant plus notable que ces attestations constituent les seuls éléments de la présence féminine dans cette religion marine. Le culte de la déesse, du moins à l'époque hellénistique, semble très populaire : touchant les différents groupes de populations, hommes, femmes, marchands, marins de la flotte et stratèges, Grecs et étrangers par le jeu des syncrétismes ${ }^{208}$.

La chronologie du culte marin d'Aphrodite s'avère difficile à établir : très important à l'époque hellénistique, qu'en est-il auparavant? Un certain nombre d'éléments permet de penser qu'il existe à des périodes plus anciennes, mais sans doute de manière moins prononcée ${ }^{209}$. Ceci pourrait notamment expliquer pourquoi les ex-voto navals à Aphrodite ne constituent qu'une part minime de ce type de matériel à l'époque archaïque (voir infra p. 427 s.).

Pour définir plus précisément les prérogatives d'Aphrodite en ce qui concerne la navigation, il convient de s'attarder sur les deux épiclèses, explicites à cet égard, d'Euploia et de Sôzousa.

\section{a) Euploia}

Selon les termes de Stace, qui écrit au I ${ }^{\mathrm{er}} \mathrm{s}$. de notre ère, Euploia constitue un heureux présage (omen felix) pour les bateaux. Littéralement, le terme signifie une navigation heureuse, se déroulant dans des conditions favorables sans que rien ne vienne entraver la marche du bateau et le bien-être de ses occupants. Dans une tragédie euripidéenne (Hélène, v. 1022-1027), Hélène qui vient de

${ }^{207}$ Pour le reste, la description des statues par Pausanias renvoie plutôt à un culte politique et civique (Moggi \& Ossana 2010, p. 303-305).

${ }^{208}$ Telle est la caractéristique des cultes d'Aphrodite à Kos, mis en évidence par Parker 2002.

${ }^{209}$ Miranda 1989 avance l'hypothèse d'un culte marin d'Aphrodite apparaissant sporadiquement à l'époque archaïque et de la formation de l'épiclèse d'Euploia entre la fin du VI ${ }^{\text {e }}$ s. et le début du IVe à Cnide; la diffusion de celle-ci ne serait pas antérieure à l'époque hellénistique. Demetriou 2010, p. 80-81, le fait remonter à l'époque archaïque sur la base d'un fragment de Solon (Fgt 19, éd. West). 
retrouver Ménélas en Égypte prie Aphrodite de favoriser son retour dans sa patrie: il faut comprendre cette invocation comme un souhait de bonne navigation, puisque c'est le moyen de locomotion qui sera utilisé par le couple. De même, un fragment de Sappho (Fgt 193) implore peut-être la déesse et les Néréides de ramener le frère sain et sauf - d'un voyage maritime - vers Lesbos. Aphrodite Euploia possède ainsi le pouvoir de favoriser le voyage par mer, en exerçant une action positive sur les vagues et sur les bateaux ${ }^{210}$.

Par ailleurs, à la fin de l'époque hellénistique, Aphrodite est fortement liée à la reprise de la navigation. Ovide (Fastes IV, v. 131132) explique ainsi indirectement l'étymologie du mois d'avril : le printemps et la déesse invitent les bateaux à faire voile sur les ondes. Cette même spécificité apparait dans l'énumération que donne Denys d'Halicarnasse des sanctuaires d'Aphrodite fondés par Énée : la plupart d'entre eux marquent en effet des périodes d'aploia qui contraignent les navigateurs à attendre le moment favorable pour reprendre la mer. Ce thème est repris chez Nonnos (Dionysiaques IV, 114-118) à propos de la navigation de Cadmos et d'Harmonie favorisée et par la saison et par Aphrodite. L'Idylle VII (v. 52-62) de Théocrite, qui invoque le nom de la divinité en faveur des amours d'Agénax, lui adresse en réalité un souhait d'euploia pour la traversée de celui-ci vers Mytilène. Le passage qui s'achève par l'évocation de l'ẅpı et de navigation heureuse laisse supposer que ce lien entre Aphrodite et l'époque propice à prendre la mer est déjà établi au III ${ }^{\mathrm{e}}$ s. a.C.

Quelques documents épigraphiques confirment la confiance en Aphrodite dans le domaine nautique. Deux autres ancres portent en latin le nom seul de la déesse : l'une Venus et l'autre Veneri associé à Iovi (voir infra, p. 310); elle semble également être figurée sur un relief funéraire de Pompéi représentant un bateau avec une divinité féminine à bord (voir infra, p. 265). Dès l'époque classique, des bateaux sont baptisés d'après elle (voir infra, p. 280); cette pratique se poursuit à l'époque hellénistique à Corcyre ${ }^{211}$ et avec un grand succès sous l'Empire. Sur les jas de plomb, le motif des osselets est rattaché au dit «coup de Vénus», signe de bonne fortune (voir infra, p. 329 s.).

${ }^{210}$ Chapouthier 1935a, p. 266 (Kypri restitué). Dans une épigramme hellénis-

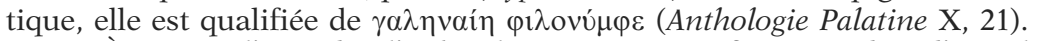

${ }^{211}$ À propos d'un culte d'Aphrodite marine à Corfou, rappelons l'anecdote du bateau de Périandre, chargé d'enfants corcyréens, arrêté par les murex de la déesse. 
b) Sôzousa

Aphrodite assure le calme des eaux et de la traversée, mais elle sauve également ceux qui se trouvent en mer : c'est du moins ce qu'affirme une courte épigramme de l'Anthologie Palatine (V, 10). Deux récits se rapportent à cette faculté : ceux de Boutès et du commerçant de Naucratis déjà évoqués précédemment, auxquels vient s'ajouter une histoire rapportée par Plutarque (Moralia $303 c-d)$. Un jour, Aphrodite conseilla à un nauclère samien d'embarquer beaucoup d'eau douce, ce dont il tira grand profit lors du voyage. En effet, les passagers mourant de soif lui achetèrent l'eau à prix d'or, alors que le bateau était immobilisé en mer par une accalmie $^{212}$. Tout en se montrant favorable aux bénéfices commerciaux, Aphrodite intervient surtout comme une puissance providentielle, dans la mesure où elle permet aux occupants du navire de survivre à l'aploia qui les frappent. C'est ce qu'affirme d'ailleurs la phrase de conclusion qui clôt l'anecdote dans le traité de Plutarque.

Une autre épiclèse, seulement livrée par des sources archéologiques, permet de confirmer ce caractère salvateur de la divinité. Deux documents navals désignent en effet Aphrodite avec l'épiclèse de Sôzousa: l'ancre de plomb du cap Palos portant la double inscription Zeus Kasios Sozon et Aphrodite Sozousa [sic], ainsi qu'une peinture pompéienne représentant un bateau en-dessous duquel se trouve le nom 'A $\varphi \rho o \delta \varepsilon i ́ \tau \eta \Sigma \omega ́ \zeta o v \sigma \alpha$ et à l'intérieur duquel la déesse est assise (voir infra p. 304 ss. et cat. I7; 265) ${ }^{213}$. La reine Bérénice II, épouse de Ptolémée III, fut vénérée au bord de la mer avec la même épiclèse, avatar du culte rendu à une reine hellénistique assimilée à Aphrodite ${ }^{214}$.

À la fois Euploia et Sôzousa, Aphrodite ne peut qu'attirer voyageurs et marins de toute la Méditerranée. De fait, une épigramme anonyme (Anthologie Palatine IX, 601), malheureusement non datable, définit Aphrodite comme la protectrice de la marine $(\tau \tilde{\eta} \varsigma$ $\pi \alpha ́ \sigma \eta \zeta v \alpha v \tau i \lambda i \eta\rceil \zeta v \lambda \alpha \kappa \tilde{\alpha})$. Les quelques récits de sauvetage montrent d'ailleurs que les deux aspects ne sont jamais réellement séparés. Plus qu'une réelle intervention providentielle, Aphrodite permet

${ }^{212}=F G H$ IIIB, $\mathrm{n}^{\circ} 545$, fgt 4 . Velissaropoulos 1980, p. 77 et 87; PirenneDelforge 1994, p. 436 y voit un épisode caractéristique de l'action d'Aphrodite : celle de son pouvoir apaisant.

${ }^{213}$ Pour Romero Recio 1999, p. 544-545, Sôzousa établit un lien entre Aphrodite et les Moires, à la fois chtoniennes et personnifications du destin.

${ }^{214}$ Tondriau 1948, p. 173; Richard 1981, p. 37-45. 
d'influer en faveur de conditions plus supportables de vie en mer : ainsi permet-elle à Hérostratos de Naucratis d'apercevoir le port n'est-elle pas également Liménia? -, mais ce sont les hommes qui se chargent d'amener le bateau jusqu'à sa destination.

\section{c) Aphrodite et les autres dieux}

Le fait est bien connu : le phénomène de syncrétisme joue un rôle très important dans le culte de l'Aphrodite marine à l'époque hellénistique. L'assimilation est favorisée avec l'Astarté phénicienne qui possède - comme le montre par exemple le début du roman d'Achille Tatios (Les aventures de Leucippé et Clitophon I, 1, 2) - un caractère marin marqué dans les grands ports de la Méditerranée : au Pirée, à Délos, à Kos ${ }^{215}$. Elle fonctionne également avec bonheur tant avec Atargatis qu'avec Isis ${ }^{216}$. Le rapprochement établi par Apulée entre la déesse égyptienne et Aphrodite dans ses Métamorphoses (XI, 3-7) se justifie d'autant mieux qu'elles sont toutes deux liées à la saison de navigation. À ces grandes divinités orientales, viennent de surcroît s'adjoindre les cultes royaux hellénistiques ou encore Tychè ${ }^{217}$. Aphrodite se manifeste ainsi comme une déesse universelle, ouverte à toutes les mers de l'oikouménè.

Une comparaison est parfois établie entre Aphrodite et les Néréides, bien sûr à l'avantage de la première comme si elles appartenaient à une même catégorie. Mais il est notable que c'est la naissance qui lui accorde cette primauté et non ses qualités marines ${ }^{218}$. Par ailleurs, la figure d'Ino-Leucothée, nous l'avons vu, s'apparente fortement à celle d'Aphrodite. Or, il est frappant de constater combien le Péloponnèse ou la Béotie sont si peu marqués par l'empreinte d'Aphrodite, alors que s'y trouve particulièrement déve-

${ }^{215}$ Baslez 1986, p. 300-303. Cependant Wilamowitz 1931-32, I, p. 98, expliquait pour sa part la présence de culte d'Aphrodite marine dans les ports par l'origine étrangère de la déesse, qui aurait donc provoqué une première implantation de son culte dans ces lieux précis. En mer Tyrrhénienne, l'accent est mis sur l'origine chypriote par l'intermédiaire de Cnide du culte maritime rendu à Aphrodite (Giangiulio 1988, p. 110 ss.).

${ }^{216}$ Isis et son culte dans le monde grec font l'objet d'une dense bibliographie. Une série d'articles a porté sur la définition de l'Isis Euploia en tant que type iconographique : Bruneau 1961-74; Picard 1962; Pucci 1976; Bérard 1985, p. 163-171 et pl. h-texte. Sur Isis et la mer : Bricault 2006. Sur le syncrétisme d'Isis à l'époque hellénistique : Dunand 1977; Turcan 1992, p. 77-127.

${ }^{217}$ Daszewski 1986, p. 299-309; Turcan 1992, p. 31-32 et 87.

${ }^{218}$ De l'Iliade (XX, v. 105-107), il ressort qu'elle est supérieure à Thétis car elle est fille de Zeus. Stace (Silves I, 2, v. 114-116) reprend la comparaison en plaçant Aphrodite au-dessus des Néréides. Sur la beauté «active» de la déesse, PirenneDelforge 1994, p. 463-464. 
loppé le culte d'Ino ou celui de Thétis ${ }^{219}$. La faiblesse du culte corinthien d'Aphrodite marine à date ancienne s'explique peut-être également ainsi : la déesse est absente des lieux où sont rendus des cultes à d'autres divinités marines qui possèdent avec elle de nombreux points communs.

Enfin, si elle est associée à Zeus dans son action bénéfique sur la navigation ou à Hermès sur les voyages, son opposition avec Poséidon mérite d'être notée : ils partagent en effet des mêmes sites littoraux, mais sans être associés l'un à l'autre dans le culte. V. Pirenne-Delforge explique cela par le caractère antithétique des deux divinités, l'une apaisant et l'autre déchaînant les éléments ${ }^{220}$.

Aphrodite et Zeus favorisent ainsi, quoique de façon différente, le déroulement de la navigation. Ils accompagnent de leurs présences bénéfiques les bateaux lors de leurs traversées.

\section{DÉMÉTER ET KORÉ}

Les Deux Déesses sont par de rares attestations mises en relation avec la mer dans des contextes critiques de conflits. Il convient de considérer en quelles circonstances et de quelles manières.

Le culte éleusinien ${ }^{221}$ comporte une cérémonie qui se déroule dans la mer. Les mystes, avant leur initiation, le deuxième jour, doivent se purifier en prenant un bain au rivage du Phalère ${ }^{222}$. Ils s'y rendent accompagnés d'un porcelet et rentrent dans l'eau au cri bien connu de «À la mer les mystes!» (halade mustai) ${ }^{223}$. Le flot marin est censé ainsi laver les baigneurs - ainsi que la victime qu'ils vont sacrifier - de leurs souillures et les rendre aptes à recevoir les révélations des Mystères. On rapporte qu'un incident survint à cette occasion en $322^{224}$ : l'animal d'un des participants fut dévoré à moitié par un monstre marin; l'événement fut interprété comme un signe de l'occupation partielle d'Athènes et du Pirée par des troupes macédoniennes d'Antipater ${ }^{225}$. Par ailleurs, les mystes considèrent le poisson

\footnotetext{
${ }^{219}$ Sur Thétis, voir notamment Bader 1986b et Vernant 1970.

${ }^{220}$ Pirenne-Delforge 1994, p. 435-436.

${ }^{221}$ Pour une présentation rapide, voir Séchan \& Lévêque 1966, p. 135-173.

222 Pausanias I, 1, 4 signale au Phalère un sanctuaire de Déméter.

${ }^{223}$ Duchêne 1992, p. 124 et 128-129; Garland 1987, p. 103-104.

${ }^{224}$ Sur la situation politique à Athènes en 322, voir Cabanes 1995, p. 18.

${ }^{225}$ Plutarque, Phocion 28, 5-6 qui situe le bain dans le Kantharos.
} 
$\tau \rho i ́ \gamma \lambda \alpha$ consacré à la déesse (Plutarque, De Sollertia animalium 983e-984c). Entre Athènes et Éleusis se trouvent également des sortes de rias que les Anciens dénommaient Rheitoi. Dans ces courants d'eau salés consacrés aux deux divinités, seuls les prêtres de celles-ci ont le droit de pêcher (Pausanias I, xxxviii, 1) ${ }^{226}$.

À travers les sources n'est rapporté qu'un unique prodige de Déméter et Koré survenu dans une circonstance maritime réelle. Elles sont intervenues selon la tradition lors de la navigation de Timoléon vers la Sicile en 340 a.C.227 (Diodore, Bibliothèque historique XVI, 66, 3-5). Après l'avoir annoncé à leurs prêtresses, elles accompagnèrent en effet les bateaux dans leur traversée, en contrepartie de quoi Timoléon leur consacra son navire. Leur action se manifesta par la lueur d'une torche qui guida les hommes dans la nuit. Le miracle fut expliqué par les contemporains par le lien qui unit l'île aux déesses ${ }^{228}$. Cette lampas rappelle évidemment l'attribut de Déméter et la cérémonie éleusienne (Plutarque, Timoléon 8, 1-9,1). Cette anecdote est à rapprocher d'un relief votif éleusinien qui représente une scène de navigation (voir infra p. 397).

Quelques sources disparates mettent encore Déméter en relation avec la mer. Sur un skyphos de Makron, peintre daté vers 490 a.C., la divinité porte un tissu orné de dauphins (fig. 12) ${ }^{229}$. Une trière athénienne porte un nom renvoyant au culte éleusinien et des bateaux plus tardifs sont baptisés Déméter ou Céres (voir infra p. 282); deux modèles de bateaux en terre cuite ont été trouvés dans des sanctuaires siciliens (voir infra) et une ou deux ancres de plomb portent également inscrit son nom (voir infra p. 316 et cat. I21-22).

L'intervention des Deux Déesses dans le domaine maritime se justifie de la part de divinités dont le culte a la prétention d'universalité. Le chœur euripidien évoquant le culte éleusinien y fait participer les éléments : l'éther, les étoiles, la lune; la mer est alors personnifiée par les danses des Néréides évoluant en l'honneur de Déméter et de sa fille ${ }^{230}$. La situation du sanctuaire en bord de mer et certaines de ses pratiques cultuelles ${ }^{231}$ pouvaient entraîner de la part

${ }^{226}$ Duchêne 1992.

${ }^{227}$ Will \& alii 1975, p. 164; Wachsmuth 1967, p. 276-277 inclut cet épisode parmi les exemples d'oniromancie liée à la navigation.

${ }^{228}$ Le culte de Perséphone est particulièrement développé en Grande Grèce et Sicile : Le Dinahet 1984; une abondante documentation a été réunie dans Lambrechts 1952; Wachsmuth 1967, p. 371, met quant à lui le culte syracusain de Déméter en relation avec la mer.

${ }^{229}$ Ridgway 1970, fig. p. 89; Somville 1984, p. 9.

${ }^{230}$ Euripide, Ion, v. 1074-1089.

${ }^{231}$ Duchêne 1992, p. 132-133 reconnaît plusieurs références à l'univers marin 
de ses initiés des dévotions liées à des circonstances maritimes, et ceci durant toute l'Antiquité grecque tant pour les Athéniens détenteurs du site éleusinien que pour des hommes extérieurs à l'Attique comme le corinthien Timoléon. Les deux merveilles «historiques» renvoient aussi au caractère politique du sanctuaire dépendant de la ville d'Athènes ${ }^{232}$.

dans le rite éleusinien, notamment par les origines prêtées à ses ministres du culte.

${ }^{232}$ Jost 1992, p. 237. 


\section{LA DOMINATION DE LA MER}

La découverte d'un espace inconnu et sa fréquentation régulière n'en font pas pour autant un domaine appartenant à tous. La mer constitue une sorte de territoire sur lequel il faut apposer sa marque ou, mieux, primer. Cette domination ou supériorité sur l'espace maritime s'affirme de différentes façons que l'on peut deviner au travers des figures d'Apollon et de Poséidon. Le fils de Léto incarne en effet le mouvement vers de nouvelles terres, une dynamique de fondation et de colonisation ${ }^{1}$.

\section{APOLLON}

Les relations d'Apollon ${ }^{2}$ avec la mer ont fait l'objet d'études partielles. En effet, on s'est davantage penché sur le problème des origines du dieu ou sur ses grands sanctuaires Delphes et Délos. Les rapports entre la divinité et le milieu maritime n'ont été abordés que dans le sens où ils permettaient d'éclairer ou de justifier des hypothèses concernant ces thèmes en question. C'est ainsi qu'Apollon Delphinios a fait l'objet de plusieurs articles axés en fait sur le dauphin animal du dieu. L'approche la plus riche a été fournie par P. P. Bourboulis qui a rassemblé les sources concernant cette

${ }^{1}$ «Un dieu de la voirie, une puissance qui trace elle-même sa voie en direction du lieu où s'établir et où instituer ses autels», un dieu "du faire du territoire» et un dieu «archégète» (Detienne 1998, p. 15 et 85-104).

${ }^{2}$ Pour une vision globale des sources concernant Apollon, la référence reste Wernicke 1894-95b. L'image du dieu a été fortement marquée par les conceptions modernes au travers par exemple de la vision de Goethe, comme l'a bien montré Bömer 1963. L'Apollon romain semble avoir été davantage étudié que le grec : ainsi Gagé 1955 en présente-t-il une bonne synthèse, clairement exprimée. Un ouvrage à ne pas omettre, bien que n'abordant que très rarement notre sujet, est celui de C. Picard sur Éphèse et Claros, (Picard 1922), très riche d'érudition. Les aspects maritimes d'Apollon ne sont pas toujours reconnus : ils ne figurent par exemple pas dans Burkert 2011, p. 202-209, ni dans Graf 2009. 
épiclèse; cependant cette analyse reste concentrée sur des questions de genèse religieuse ${ }^{3}$.

En dehors de ces cadres, la figure d'Apollon reste encore à étudier, notamment en ce qui concerne la majorité des sanctuaires. Ainsi notre tour d'horizon de ses sanctuaires à caractère maritime s'avère-t-il dans l'ensemble décevant, par manque d'informations sur les sites: fouilles inexistantes ou mal publiées, absence d'études locales, impliquant souvent des méconnaissances chronologiques. Par ailleurs, pour ces raisons et en fonction des critères de sélection que nous nous sommes imposés, il est certain que ne sont pas répertoriés ici des sanctuaires qui mériteraient sans doute de l'être : ainsi ni Cumes ${ }^{4}$ ni Didyme ni Circeo $^{5}$, pas plus que ceux de la sicilienne Naxos $^{6}$ ou certaines Apollonia ${ }^{7}$, bien que placés de façon à être vus de loin depuis la mer et sur des circuits maritimes bien fréquentés,

${ }^{3}$ Bourboulis 1949 conclut son étude par l'hypothèse d'un Delphinios dieu ionien assimilé avec Apollon dorien, ce que critique J. Défradas, dans REG LXIV, 1951, p. 337-338; Dumont 1975 aboutit à la même conclusion d'un Delphinios "génie marin prophétique et protéiforme» assimilé à Apollon, tout en affirmant que «jamais Apollon n'est célébré en tant que dieu de la mer»; Graf 1979 conteste le lien exclusif entre l'épiclèse de Delphinios et le dauphin ou la mer : le culte d'Apollon Delphinios serait davantage lié aux cultes civiques et à des confréries d'hommes; Somville 1984. Cependant, les prérogatives marines n'apparaissent nullement dans le chapitre "Apollon» de Séchan \& Lévêque 1966, p. 201-225; en revanche A. Bouché-Leclercq constatait sans le développer combien «dans tous les Delphinia de la Grèce, Apollon a l'air d'un dieu marin » (Bouché-Leclercq 1882, III, 57 note 5). Sur le dauphin, voir encore Bodson 1978, p. 53-57.

${ }^{4}$ Sur l'Apollon de Cumes, voir particulièrement G. Pugliese Carratelli 1979; Breglia 2009, p. 238-248. En revanche, Cumes figure dans le chapitre consacré à Héra : voir supra p. 76.

${ }^{5}$ À quelque distance du promontoire Circaeum, se situait un petit naos d'Apollon surplombant la mer, connu par l'anecdote suivante. Lorsque Cicéron en fuite se réfugia par voie de mer dans sa villa de Formianum, une nuée de corbeaux se serait en effet envolée du temple voisin vers le bateau, dont ils auraient investi la vergue et becqueté les cordages : un bien mauvais présage aux yeux des compagnons de l'homme politique et de Plutarque (Plutarque, Cicéron 47,8 ). Mais l'absence de précision sur le culte et le fait que les oiseaux sont liés à Cicéron (qu'ils poursuivent chez lui) et non au bateau nous empêchent de retenir cette attestation.

${ }^{6}$ Doté d'un autel du débarquement et de l'embarquement pour Detienne 1998, p. 99.

${ }^{7}$ Parmi le nombre de villes portant le nom d'Apollonia à cause du rôle colonisateur du dieu, plusieurs d'entre elles se situent en bord de mer et en tirent leur prospérité : ainsi Apollonia de Mysie a-t-elle pu émettre des monnaies portant au droit une représentation d'Apollon et au revers une ancre : Anson 1910-1916, V p. 90 et pl. XIV, no 605-611; elles sont datées entre 450 et 350 pour les premières ( $\mathrm{n}^{\circ}$ 605-608), du IV ${ }^{\mathrm{e}} \mathrm{s}$. av. n.è. pour les suivantes. Peut-on pour autant en tirer des conclusions concernant le caractère du dieu de la cité? 
ne figurent parmi notre inventaire. Parmi toutes les divinités que nous avons à traiter, Apollon présente la personnalité la plus difficile à saisir car les limites de ses attributions et ses cultes s'avèrent le plus souvent floues ou ambiguës ${ }^{8}$.

C'est pourquoi, pour d'une part éviter la répétition du contenu des articles concernant Apollon Delphinios et d'autre part tenter de sortir de leur cadre restrictif, notre analyse a porté sur l'ensemble des testimonia et épiclèses à caractère marin d'Apollon pour en esquisser les grands traits.

\section{LES SOURCES}

Mythologie et épopée

Les traditions mythologiques concernant Apollon, particulièrement riches, interviennent pour beaucoup dans la vie de ses deux sanctuaires panhelléniques ou du moins dans les justifications qu'on veut en donner. Ainsi les frontières entre mythe et culte ont-elles tendance ici à s'effacer. De la même manière, la présence effective du dieu dans les épopées renvoie à l'existence de sanctuaires apolliniens bien plus qu'à des actions retentissantes.

\section{a) Naissance d'Apollon}

L'accouchement de Léto à Délos est raconté pour la première fois dans l'Hymne homérique à Apollon'. L'île accepte d'accueillir la future mère à la condition d'être au centre d'une vénération particulière. Ainsi la légende de la naissance d'Apollon à Délos marque-telle le lien indestructible qui rattache le dieu à l'île et dans une moindre mesure à l'insularité. L'Hymne homérique à Apollon Délien (v. 70-88) exprime la force de cet attachement par le serment que prononce Léto à l'île de Délos : Apollon fera de l'̂̂le son domaine, il l'honorera plus qu'aucun autre lieu.

Par ailleurs une variante rapporte que c'est Apollon lui-même qui fixa l'île, alors qu'avant la naissance du dieu elle errait sur les eaux, et la chargea alors d'accueillir les hommes et de défier les vents (Virgile, Enéide III, v. 73-79).

${ }^{8}$ Complexité bien mise en évidence par Detienne 1998.

${ }^{9}$ Sur ce thème, voir particulièrement l'article de la RE; Bruneau 1970a, p. 16-19. Sur le problème de la date de l'Hymne, Gallet de Santerre 1958, p. $240-242$. 
b) Apollon $\delta \varepsilon \lambda \varphi i s$

Une légende, racontée elle aussi dès l'Hymne à Apollon Délien (v. 388-512) ${ }^{10}$, décrit la transformation d'Apollon en dauphin. Le jeune dieu, sous cette forme, escorte un bateau de Crétois vers le sanctuaire qu'il a décidé de s'attribuer à Delphes. Les commerçants crétois se rendaient par mer à Pylos, lorsqu'il les aperçut et décida d'en faire les desservants de son culte delphien. Pour mener à bien son projet, il se métamorphose en dauphin ( $\delta \varepsilon \lambda \pi i ̃ v ı ~ \dot{\varepsilon o \iota \kappa \omega ́ \varsigma) ~ e t ~ s e ~ j e t t e ~}$ sous cette apparence sur le pont du navire. Les occupants stupéfaits ne songent plus aux manœuvres du bateau, dont Apollon peut alors infléchir la course avec l'aide du Notos (v. 408 et v. 420). Lorsqu'ils reprennent quelque peu leurs esprits près du cap Ténare, le gouvernail refuse de leur obéir : le dieu empêchant la nef d'accoster, celle-ci longe la côte du Péloponnèse à tribord jusqu'au niveau du golfe de Corinthe. À ce niveau, Zeus envoie un vent d'ouest, le Zéphyr, qui permet de conduire l'embarcation à Krisa où elle s'échoue sur le sable. Alors seulement Apollon change d'apparence pour prendre

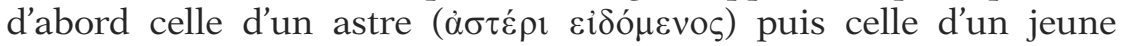
homme aux cheveux longs. Le dieu impose aux Crétois ses volontés : qu'ils tirent leur navire au sec, aménagent un autel sur le rivage ( $\dot{\varepsilon} \pi \mathrm{i}$ $\dot{\rho} \eta \gamma \mu \tilde{v} v \mathbf{\theta} \theta \alpha \lambda \dot{\alpha} \sigma \sigma \eta \varsigma)$ où sacrifier des blanches farines et prier le dieu sous le nom de Delphinios ${ }^{11}$. Après ces actes de piété, Apollon les emmène à l'emplacement de son sanctuaire delphien.

Trois points sont intéressants à relever dans cette légende. Tout d'abord, l'action d'Apollon sur le navire se manifeste par le vent qu'il suscite et le trajet qu'il impose. Ensuite, le dieu n'accompagne pas le bateau en nageant dans la mer, mais en prenant place à bord sous la forme d'un animal marin; ceci n'est pas sans rappeler la légende de la métamorphose de Dionysos sur le bateau tyrrhénien. Cette apparence du dauphin semble alors seulement servir à justifier l'épiclèse du dieu ${ }^{12}$. Enfin, une des formes du culte rendu à Apollon doit s'exercer sur le rivage, à l'aide d'un autel, juste après le débarquement, par un sacrifice non sanglant; cette pratique rituelle - nous le verrons - est attestée par ailleurs.

Plutarque (De Sollertia animalium 983e-984c) donnant une

${ }^{10}$ Sur les origines mythiques d'Apollon à Delphes, voir Defradas 1954, p. $55-110$.

${ }^{11}$ Bouché-Leclercq 1882, III p. 54-59, interprète cette légende de la façon suivante : Apollon Delphinios est un dieu crétois qui aurait supplanté Poséidon à Delphes.

${ }^{12}$ Somville 1984, p. 11-12 met en évidence le rapprochement entre le nom de l'animal et celui du sanctuaire; en revanche, nous ne suivons pas son raisonnement en ce qui concerne un «dédoublement» du féminin/masculin... 
version qui se veut plus rationnelle de l'histoire montre que celle-ci évolua au cours des siècles ${ }^{13}$. Le moraliste refuse de reconnaître le dieu dans le dauphin qui guide le bateau en nageant en avant - ce qui constitue déjà une déformation du mythe - : il reconnaît seulement dans l'animal un envoyé d'Apollon. Toujours d'après Plutarque, cette navigation sous la conduite d'un dauphin connut un parallèle à l'époque hellénistique avec un bateau mandaté par Ptolémée Sôter. L'embarcation en route vers Sinope ${ }^{14}$ fut détournée vers le Malée puis vers Kirrha, où les voyageurs finissent par débarquer et offrir immédiatement un sacrifice au dieu. La récupération de la légende dans un contexte politique témoigne indirectement de l'intérêt que portaient les rois hellénistiques aux sanctuaires panhelléniques et de leur prétention à leur revendication.

La tradition relative au dieu delphien rapporte par ailleurs que le dieu se rend une fois l'an chez les Hyperboréens ${ }^{15}$. Ce voyage à l'extrémité de l'oikouménè semble être représenté sur deux vases figurant Apollon assis sur un trépied au-dessus de la mer ${ }^{16}$. Dans les deux cas, le dieu est muni de la cithare et accompagné de deux dauphins; sur le second objet, le trépied est doté de grandes ailes. Cette iconographie d'Apollon sur la mer n'est attestée que sur une courte période, dans la seconde moitié du $\mathrm{VI}^{\mathrm{e}}$ et le début du V $\mathrm{V}^{\mathrm{e}} \mathrm{s}$. a.C.

\section{c) L'épopée homérique}

Dès le premier chant de l'Iliade (I, 477-479), Apollon est mis en relation avec la navigation. Lorsque l'ambassade chargée de ramener Chrysèis à son père a achevé sa mission, elle s'en retourne

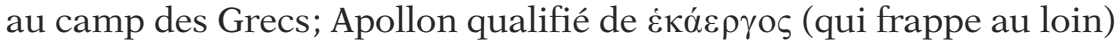
fournit le vent propice à la navigation. Son action se manifeste comme un apaisement du dieu grâce à l'hécatombe offerte la veille par les Achéens à son temple. En effet le fils de Léto, imploré par son prêtre Chrysès repoussé par les Grecs, avait envoyé la peste sur

${ }^{13}$ Servius, Ad Aen. III, 332 raconte quant à lui l'histoire d'Eikadios, fils d'Apollon et de la Nymphe Lykeia, faisant naufrage et recueilli sur le dos d'un dauphin qui le conduit jusqu'à Delphes où il fonde un sanctuaire en l'honneur de son père.

${ }^{14}$ Pour y chercher une statue de Sérapis : cf. Will 1979-82, I p. 149 et p. 204-207 sur les aspects religieux de la politique extérieure des Lagides.

${ }^{15}$ Pindare, Pythiques X, 30; Callimaque, Hymne IV, v. 281-282; Hérodote, Enquête IV, 32. Selon d'autres traditions, le dieu peut se rendre à Patara en Lycie : scholie à Virgile, Enéide IV, 143. Séchan \& Lévêque 1966, p. 201-202.

${ }^{16}$ Louvre, inv. C10619 : amphorette à figures noires, datée du troisième quart du VI ${ }^{\text {e }}$ s. a.C.; Vatican, musée Gregoriano inv. 16568 : hydrie à figures rouges datée vers 480 a.C. Lambrinudakis \& alii, 1984, 1 p. 233 et 2 p. 213; Ridgway 1970, p. 89. 
eux et seul un sacrifice et la restitution de Chrysèis devaient permettre de l'adoucir. Strabon (XIII, 1, 62-63) qui, menant une exégèse homérique en Troade, discute l'emplacement du sanctuaire du dieu à Chrysa, le situe avec raison près du rivage.

Dans la veine homérique, Stace (Achilléide I, v. 679-688) représente Ulysse se rendant à Skyros afin de chercher Achille pour le décider à guerroyer à Troie. Lorsque son navire double Délos, ses occupants, depuis la poupe, offrent des libations; en échange, Apollon, depuis le Cynthe, envoie le Zéphyr gonfler leur voile. Cette intervention, que le poète interprète comme un bon présage pour leur ambassade, renvoie à la scène homérique précédemment évoquée.

\section{d) L'épopée argonautique}

Apollon fait partie intégrante de l'expédition argonautique ${ }^{17}$. Sa présence est affirmée avant même le départ à travers les premiers ordres de Jason à peine désigné comme chef (Apollonios de Rhodes, Argonautiques I, v. 351-362). Ce dernier commande à ses compagnons, après avoir mis Argô à l'eau, d'ériger un autel et de sacrifier à Apollon Embasios (de l'Embarquement). C'est le dieu lui-même qui a donné ces directives, en échange de sa compagnie lors du voyage

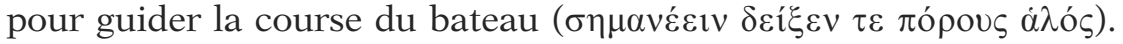
Les héros s'exécutent donc, réalisant un autel improvisé à l'aide de pierres sur la plage et priant le dieu de favoriser leur entreprise (ibid., I, v. 402-438). L'invoquant non seulement sous le nom d'Embasios mais aussi d'Aktios (du Rivage), ils lui sacrifient deux

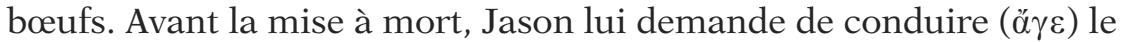
bateau comme il l'avait annoncé et qu'un vent favorable les porte, en contrepartie de quoi il promet moult offrandes tant à Delphes qu'à Délos. Durant la prière, il jette des grains d'orge sur l'autel, ce qui n'est pas sans rappeler les farines sur l'autel de l'Hymne homérique. Hygin (Astronomie II, 37), qui rapporte la version de Callimaque du même sacrifice de départ, le situe en Magnésie dans la ville Démétriade au lieu-dit Pagases; il ajoute que les Argonautes fondèrent un temple à cet endroit en l'honneur d'Apollon Aktios. Cette localisation en Magnésie respecte semble-t-il la version de Pindare.

Dans le récit du Pseudo-Apollodore, durant la totalité de leur navigation, les héros exécutent des actes de dévotion similaire envers le dieu; en revanche les Argonautiques orphiques (v. 12981299) ne mentionnent qu'un seul sacrifice à Apollon Épaktios (du

${ }^{17}$ Mc Cartney 1933, p. 4; Detienne 1998, p. 136-142, 147-149. 
Rivage) à Corcyre. Dans la version hellénistique donc, à Cyzique les Argonautes lui élèvent sur le sable en tant qu'Ekbasios un autel, sur lequel ils accomplissent un sacrifice avec les habitants de la ville (Apollonios de Rhodes, I, v. 953-971). Plus loin en Mysie, au terme d'une journée de navigation, ils sacrifient encore à Apollon Ekbasios (ibid., I, v. 1185-1186). Plus à l'est sur le rivage de la mer Noire, ils font escale au tombeau de Sthénélos, compagnon d'Héraclès mort des suites d'une blessure reçue lors de la guerre contre les Amazones. Sur le promontoire où se trouve la tombe, ils accomplissent des libations et sacrifices destinés à l'âme du défunt mais vénèrent également Apollon Nèossoos (Sauveur des navires) par la construction d'un autel sur lequel ils grillent des morceaux de viande (ibid. II, v. 927-929). L'épiclèse différente du dieu doit sans doute correspondre à une tradition situant une tempête subie par Argô dans les parages ${ }^{18}$. Enfin les héros érigent un autre autel de pierres sur un îlot des Sporades à Apollon Aiglètès (Éblouissant) lors de leur retour après leur passage en Crète (ibid., IV, v. 1691-1731). En effet, alors que naviguant de nuit ils furent saisis de frayeur par la nuit noire qui régnait, Jason invoqua l'aide du dieu. Celui-ci descendit du ciel pour se jucher sur un écueil et éclaira l'obscurité de son arc, laissant apparaître aux yeux des navigateurs une île déserte où accoster. Dans le résumé qu'en donne le Pseudo-Apollodore (Bibliothèque I, ix, 26), c'est une tempête qui provoque l'intervention d'Apollon. Celle-ci - la seule dans le récit d'Apollonios explique le nom qu'on lui donne ainsi que celui de la terre en question : Anaphè ou île de l'Apparition.

La présence du dieu est bien affirmée dans la version hellénistique du périple ${ }^{19}$, mais davantage au niveau du culte qu'au niveau de l'action. Plus exactement, le dieu reçoit des marques de dévotion lorsque la navigation se déroule sans encombre : en tant qu'Embasios, Ekbasios, Aktios, Épaktios, il reste dans l'ombre d'un voyage sans problème, prêt à intervenir comme Nèossoos ou Aiglètès en cas de nécessité.

\section{e) La tragédie}

Chez les tragiques, Apollon est évoqué une fois dans un contexte maritime. Le chœur euripidéen, qui chante le retour d'Iphigénie vers Athènes depuis la Tauride, le place sous la protection d'Apollon

${ }^{18}$ F. Vian, édition du texte en Budé, p. 220 note 2. L'épiclèse de Nèossoos est attribuée à Artémis au vers 570 du chant I de ces mêmes Argonautiques.

${ }^{19}$ Vian 1974, p. 100-103 présente également deux traditions indirectes se rapportant à Apollon et aux Argonautes sur le Bosphore. 
(Euripide, Iphigénie en Tauride, v. 1123-1136). Celui-ci, accompagnant la course du bateau de sa lyre et de ses chants, conduira la jeune fille à bon port ( $\left.\varepsilon \tilde{v} \sigma^{\prime} \alpha^{\prime} \xi \varepsilon 1\right)$. L'évocation d'Apollon suit celle de Pan, associé aux mouvements des rames; à cette double référence font écho les vers suivants qui décrivent l'avancée du bateau d'abord à l'aviron puis sous l'action des voiles gonflées par le vent.

L'ensemble de ces traditions mythologiques montre un Apollon associé à la navigation, favorisant la course du bateau, auquel en retour on adresse un acte religieux précis.

\section{Témoignages cultuels}

L'inventaire des témoignages cultuels à Apollon se doit de commencer par les deux grands sanctuaires panhelléniques qui lui sont consacrés et dont les cultes sont relativement bien connus. Pour ce qui est des autres attestations, l'archéologie fait souvent défaut et les sources restent essentiellement littéraires ou parfois épigraphiques (cartes 4 et 10).

\section{a) Délos}

Plusieurs pratiques cultuelles déliennes renvoient à la navigation de Thésée et à son bon déroulement. Au retour de Crète, les jeunes Athéniens auraient ainsi manifesté leur joie et remercié le dieu en dansant autour d'un autel une danse dite «de la grue» (Callimaque, Hymne $I V$, v. 307-326) ${ }^{20}$. Cette marque de dévotion renvoie à celle réalisée avant leur départ au Delphinion athénien en tant que suppliants (Plutarque, Thésée 18, 1) ${ }^{21}$. Le poète hellénistique explique en outre qu'aucun marin naviguant au large ne manque de s'arrêter pour remplir ses devoirs religieux envers le dieu, en l'occurrence faire le tour du grand autel et mordre l'olivier sacré22. Cette attention toute particulière des marins pour le dieu délien rappelle la scène de libation décrite par Stace (Achilléide I, v. 679-688), effectuée lorsque

${ }^{20}$ L'analyse de Bruneau 1970a, p. 19-52 est la plus détaillée qui soit sur les traditions déliennes. L'autel en question est le fameux autel de cornes (kératon), et la danse censée imiter les méandres du labyrinthe. Friis Johansen 1945 propose la théorie suivante : les liens de Thésée avec Délos auraient été créés tardivement au dernier quart du VIe s. a.C., mais la danse de Délos serait plus ancienne, sans rapport à l'origine avec le retour de Crète du héros athénien.

${ }^{21}$ Salviat 1989, p. 229-240; Bourboulis 1949, p. 63-64.

${ }^{22}$ Sur cet olivier, Bruneau 1970a, p. 26. 
le bateau double l'île. Le texte de Callimaque, bien qu'ambigu en ce qui concerne la compréhension des rites déliens, met cependant en évidence le lien entre le culte d'Apollon et la navigation dans les eaux cycladiques.

Athènes envoie quant à elle chaque année un pèlerinage à Délos en souvenir de Thésée, à l'aide d'un bateau dont le départ et le retour délimitent une période durant laquelle la cité attique se préserve de toute souillure (Platon, Phédon 58a-c; Callimaque, Hymne IV, v. 307326) (voir infra p. 431) 23. Apollon se trouve ainsi honoré tant dans son sanctuaire de Délos qu'à Athènes, où son prêtre purifie le navire au port.

Le sanctuaire (fig. 7) reçoit à partir du $\mathrm{IV}^{\mathrm{e}} \mathrm{s}$. un certain nombre d'offrandes navales : des bateaux en argent ou plomb, des cratères en forme de bateaux, des éperons, des proues et surtout un bateau grandeur nature (voir infra p. 359 ss., 380 ss., 418, 421).

Par ailleurs une dédicace de navigateurs italiens de la première moitié du $\mathrm{I}^{\mathrm{er}} \mathrm{s}$. a.C. remercie le dieu de les avoir sauvés du naufrage ${ }^{24}$. Dans le premier quart du $\mathrm{II}^{\mathrm{e}}$ s. a.C., une corporation de marins de Bérytos consacre à Apollon une statue de leur bienfaiteur Héliodoros, geste qui signifie que ce groupement de marine marchande est placé sous le patronage de la divinité25. Les textes et toutes ces offrandes révèlent la variété des fidèles : hommes d'état, commerçants, simples marins, tous d'horizon divers, honorent Apollon Délien.

Mais lorsqu'on lui fait affront, le dieu semble aussi pouvoir se servir de la mer comme d'une arme, d'après une histoire racontée par Cicéron à propos de Verrès (Seconde action contre Verrès I, xviixviii, 46 ${ }^{26}$. Alors légat de $\mathrm{Cn}$. Cornelius Dolabella, Verrès de passage à Délos dérobe de nuit les statues d'Apollon; le lendemain, une tempête se déchaîne, empêchant les hommes de partir et fracassant le bateau où étaient cachées les idoles. Dolabella ayant ordonné de restituer ces dernières au sanctuaire, la mer redevient alors navigable.

${ }^{23}$ Servius, Comm. in Aen. III, 332, évoque une escale de cette trière à Salamine pour effectuer un sacrifice à Apollon.

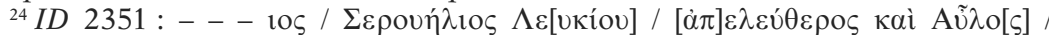

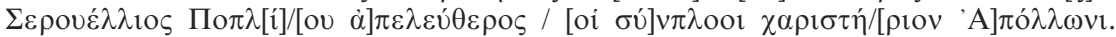
Bruneau 1970a, p. 169 juge sans intérêt, devant l'importance d'Apollon en Italie, de chercher à savoir si le dieu honoré est italien ou délien.

${ }^{25}$ IG XI, 4, 1114; OGIS 247. Vélissaropoulos 1980, p. 107-108.

${ }^{26}$ Wachsmuth 1967, p. 268-269. Un peu plus loin dans son discours (ibid., xviii, 48), Cicéron utilise le topos qui nous est à présent bien connu du sanctuaire marin si vénéré que même les Barbares - en l'occurrence les Mèdes - n'avaient osé y porter la main. 





b) Delphes

Apollon Pythien reçoit à Delphes, parmi les nombreux ex-voto qu'on lui consacre, un certain nombre de dons liés à des victoires navales ou à la mer.

Ainsi dès le VI ${ }^{\text {e }}$ s. a.C., Lipari aménage dans le sanctuaire une vingtaine de statues de bronze, autant que de navires étrusques capturés (Pausanias X, xvi, 7) ${ }^{27}$. Les Grecs le remercient ensuite à la victoire de Salamine ${ }^{28}$ : les prémices du butin servent alors à la réalisation d'une statue masculine de douze coudées - représentant Apollon d'après Pausanias (X, xiv, 5) - tenant un akrôtèrion, cadeau de tous les Grecs, tandis que les Éginètes se trouvent contraints d'offrir à part un mât de bronze doté de trois étoiles d'or (Hérodote, Enquête VIII, 121-122 : voir infra p. 414).

Peut-être dans les mêmes années qui suivirent les guerres Médiques, les Athéniens auraient commémoré une victoire navale par l'érection du Portique des Athéniens abritant des proues de navires (Pausanias X, xi, 6), pour lequel l'archéologie a conservé au moins l'édifice et la dédicace à défaut des offrandes déposées (voir infra, p. 415 ss.).

La victoire navale spartiate de la fin de la guerre du Péloponnèse a été de même commémorée à Delphes par diverses offrandes : statues, bateau et étoiles d'or (voir infra, p. 377 et 415).

Par ailleurs les Tarentins, sur la dîme du butin obtenu sur les Peucétiens, consacrent notamment au dieu de Delphes un groupe statuaire, réalisé par Onatas d'Égine et de Calynthos, bronziers de la première moitié du Ve s. a.C. (Pausanias X, xiii, 10) ${ }^{29}$. Dans cette œuvre figurent entre autre les deux héros locaux - respectivement éponyme et fondateur -, Taras et Phalantos à côté d'un dauphin; en effet ils doivent tous deux à un tel animal d'avoir été ramenés sain et sauf sur le rivage, l'un à Tarente l'autre dans le golfe de Krisa ${ }^{30}$.

${ }^{27}$ Spigo 1991, p. 72.

${ }^{28}$ Liste in Jacquemin 1999, p. 84.

${ }^{29}$ Guide Delphes 1991a, p. 163-164; Amandry 1949, p. 447-463; Daux 1936, p. 151-154. La base se situe juste en face de la façade du temple d'Apollon, derrière l'autel. Une première dédicace rétrograde est gravée sur la plinthe, répétée de gauche à droite sur l'assise inférieure un siècle plus tard.

${ }^{30}$ Pausanias X, x, 6-8 considère Phalantos comme le fondateur de la cité de Tarente et Taras comme un héros local, fils de Poséidon et d'une nymphe; Wuilleumier 1939, p. 33-39 et 517-518; Dumont 1975, p. 70-71. Sur Taras, H. Philipp, «S.v. Taras», RE 2e série VII, Stuttgart, 1931, col. 2286-2287 qui distingue la rivière de Tarente du héros homonyme; sur les monnaies de Tarente : Ringel 1984, no 38, $42-44$ et 48; sur Phalantos de Lacédémone, V. Ehrenberg, RE XXXVII, Stuttgart, 1937, col. 1623-1624; Lambrinudakis \& alii, 1984, 1 p. 232 hésite quant à l'identification sur une amphore du début du Ve s. a.C. du personnage assis sur un dauphin : Apollon ou Phalantos, ou encore Arion? 
L'allusion s'adresse à Apollon Delphinios qui doit se trouver derrière ces deux interventions providentielles d'un dauphin en faveur d'un homme au bord de la noyade. L'histoire des deux héros de Tarente et cette offrande témoignent du culte rendu à Tarente à un Apollon Delphinios.

La représentation de la nef Argô sur des métopes archaïques dites du Trésor des Sicyoniens (voir infra p. 393-395) renvoie quant à elle à la reconnaissance du dieu comme protecteur de l'expédition des Argonautes.

Une statue de bronze exposée à Delphes constitue la copie d'un xoanon pêché dans la mer par des habitants de Méthymna dans l'île de Lesbos (Pausanias X, xix, 3) ${ }^{31}$. Ces derniers demandèrent en effet au dieu ce qu'il convenait de faire, et l'oracle leur répondit d'honorer le morceau de bois sous le nom de Dionysos Phallène. Un double en métal de la statue remercie ainsi Apollon de son bon conseil et de sa connaissance des choses divines parfois transportées par la mer. Enfin une épigramme de l'Anthologie Palatine (VI, 342), d'un auteur anonyme, mentionne une offrande envoyée au sanctuaire delphien par les habitants de Cyzique en liaison avec le culte d'Athéna et la naissance de la navigation. Le don consiste en une "charge de briques dorées».

À l'origine sans doute d'autres offrandes inconnues, l'agrément donné par le dieu à certaines entreprises maritimes. Ainsi Plutarque (Timoléon 8, 1-9, 1) raconte que Timoléon, s'étant rendu à Delphes avant de faire voile vers l'Italie, reçut un signe favorable d'Apollon dans le sanctuaire : une bandelette ornée de couronnes et victoires brodées tomba sur la tête du stratège. Cette anecdote signifie en outre que la flotte, avant de quitter la Grèce, a fait escale à Itéa pour consulter le dieu - chose tout à fait compréhensible avant une action militaire de cette importance.

Placés dans le contexte du sanctuaire panhellénique, cette démarche et tous ces présents revêtent un caractère officiel et émanent de cités; ils semblent par ailleurs concerner essentiellement le $\mathrm{V}^{\mathrm{e}}$ s. a.C. ${ }^{32}$

\section{c) Attique}

Un certain nombre de sources décousues attestent l'existence en Attique de plusieurs lieux de culte où l'on honorait Apollon en rapport avec la mer.

${ }^{31}$ Sur l'emplacement présumé de la statue à Delphes, Daux 1936, p. 158.

${ }^{32}$ Une lamelle de Dodone de la première moitié du $\mathrm{IV}^{\mathrm{e}} \mathrm{s}$. pourrait témoigner d'une consultation d'un particulier à Apollon pour une affaire maritime : un 
Tout d'abord, à propos du tribunal athénien du Delphinion, on rapporte qu'il s'agit d'un ancien sanctuaire d'Apollon Delphinios fondé par des Crétois (Etymologicum Magnum, s.v. 'E $\pi$ ì $\Delta \varepsilon \lambda \varphi \imath v i ́()$. Ils auraient ainsi remercié la divinité venue les sauver sous l'apparence d'un dauphin de les avoir menés en Attique. Ce récit, très proche de la légende des Crétois de Delphes ${ }^{33}$, montre que le lieu honorait le dieu de Delphes qui protégeait ici les jugements d'homicide. L'ancienneté du lieu ressort de la tradition selon laquelle Thésée aurait dû s'y défendre des meurtres de deux brigands notoires ${ }^{34}$. Ce lien établi entre la défense de la vérité et le dauphin est à rapprocher de la mort d'Hésiode telle qu'elle est racontée par Plutarque (Banquet des sept sages 160e-162e): Hésiode, assassiné injustement, voit son cadavre jeté à la mer et recueilli par des dauphins qui l'amènent au rivage; les Locriens qui découvrent ainsi le corps peuvent au terme d'une enquête punir les coupables en les jetant à la mer ${ }^{35}$. D'autres attribuent en revanche la fondation du lieu à Égée en l'honneur d'Apollon Delphinios et d'Artémis Delphinia (Pollux, Onomasticon VIII, 119). C'est là que Thésée aurait sacrifié à Apollon avant de partir pour le Pirée puis pour la Crète (Plutarque, Thésée 18,1). La cité d'Athènes célèbre en son honneur la fête des Delphinia, le 7 du mois de Mounichiôn considéré comme le jour de sa naissance ${ }^{36}$. Plusieurs noms de trières athéniennes du $\mathrm{IV}^{\mathrm{e}} \mathrm{s}$. a.C. sont également à mettre en relation avec le culte du dieu.

En dehors d'Athènes, deux sanctuaires d'Apollon conservaient des offrandes navales. Tout d'abord Plutarque (Thémistocle 15, 3) rapporte que lors de la Seconde Guerre médique, au début des engagements entre Grecs et Perses à Salamine, la première prise navale réalisée par le triérarque athénien Lycomédès fut consacrée à Apollon. Le Grec prit les parasèma du bateau perse pour les offrir au dieu Daphnèphoros dans son sanctuaire de Phlyées (voir infra p. 417 et 614).

certain Arcéphon interroge Zeus à propos d'un «bateau qu'il a fait construire sur

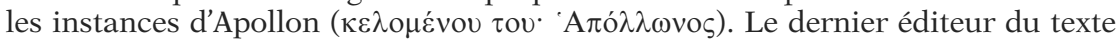
pense que cette formule renvoie à un oracle delphique (Lhôte 2006, n 94 et voir supra p. 88).

${ }^{33}$ Wide 1893 , p. $87-88$, considère ainsi que l'Apollon Delphinios attique est équivalent à l'Apollon Pythien.

${ }^{34}$ Sur le tribunal de type archaïque et mal connu du Delphinion, Will 1972, p. 456; sur le sanctuaire de l'Ilissos : C. Wachsmuth, «s.v. Delphinion 3», RE IV, Stuttgart, 1901, col. 2512-2513; Travlos 1971, p. 83 ss.; Calame 1990.

${ }_{35}$ Glotz 1904, p. 29-30; Somville 1984, p. 21.

${ }^{36}$ Wachsmuth 1987, p. 477-478; Bourboulis 1949, p. 62-69 met la célébration de ces fêtes en relation avec l'ouverture de la saison de navigation, d'après l'observation de la date de celle-ci dans la tradition néo-hellénique; Deubner 1932, p. 201; Parke 1977, p. 137. 
D'autre part à Vouliagméni, un sanctuaire d'Apollon Zôstèr a été découvert au bord de la mer sur le promontoire du même nom, ou plus exactement sur l'isthme sableux qui permet d'y accéder ${ }^{37}$. Cette partie de la côte, particulièrement découpée, surprit les Mèdes d'après Hérodote ${ }^{38}$. Le temple remonte à la fin du VI ${ }^{\text {e }}$ s. a.C., puis fut agrandi dans la seconde moitié du IV ${ }^{\text {e }}$ s.; un bâtiment annexe a été ensuite dégagé au nord, suivant la même évolution chronologique que celle du temple. L'identification du dieu ressort de plusieurs inscriptions trouvées in situ pour la plupart dédiées par les 'A $\lambda \alpha 1 \varepsilon i \tilde{\zeta}$, c'est-à-dire les habitants du dème d'Hales ${ }^{39}$. Un graffiti naval (voir infra p.408-409 et 613) et un certain nombre d'hameçons pourraient constituer des ex-voto de la part de marins habitant dans cette partie sud-ouest de l'Attique.

Deux attestations litigieuses se rapportent encore au culte d'Apollon en Attique : il semblerait qu'il ait reçu une dédicace au sanctuaire de Sounion ${ }^{40}$, mais rien de solide ne permet d'appuyer l'existence d'un culte d'Apollon Délien au Pirée ${ }^{41}$.

\section{d) Nord du Péloponnèse}

Des ex-voto navals isolés sont signalés pour deux sanctuaires d'Apollon du nord du Péloponnèse. À Corinthe, dans son sanctuaire

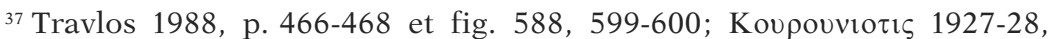

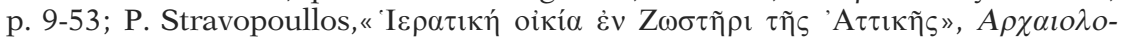

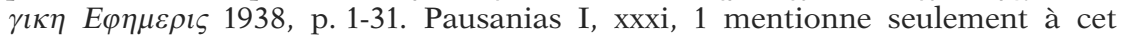
endroit un autel d'Athéna, d'Apollon, d'Artémis et de Léto. Le Périégète explique le nom du promontoire par la tradition selon laquelle Léto aurait à cet endroit dénoué sa ceinture (zôstèr); or, le mot s'applique à une ceinture d'homme et non de femme. Cette étymologie a dû être élaborée a posteriori pour expliquer le nom du lieu et la présence d'Apollon à cet endroit.

${ }^{38}$ Enquête VIII, 107 : «En arrivant dans les parages du cap Zôstèr, comme en ce lieu d'étroits promontoires rocheux avancent en mer, les Barbares crurent voir des navires et s'enfuirent en désordre; ils reconnurent enfin que c'étaient des rochers et non des navires, se raillèrent et continuèrent leur route». Pausanias IX, 1, 21 le qualifie de $\mu \alpha \kappa \rho \grave{\alpha}$ öк $\rho \alpha$.

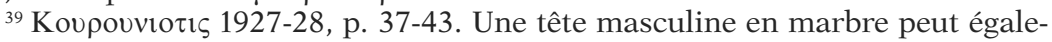
ment être reconnue comme une représentation du dieu. Sur la répartition des dèmes en Attique, voir la carte de Will 1972, p. 70.

${ }^{40}$ Thémélis 1974, p. 15 et Davaras 1979, p. 18 qui ne citent pas la source épigraphique.

${ }^{41}$ Vélissaropoulos 1980, p. 229 et Garland 1987, p. 104, affirment sur la base d'une inscription datée vers 430 a.C. (SEG XXI, $37=I G \mathrm{I}^{2}, 128$ ) que les nauclères du Phalère devaient financer la réfection du sanctuaire d'Apollon Délien en versant une taxe d'une drachme par navire. Or, le texte est pour moitié restitué en ce qui concerne le nom du dieu, le lieu et le montant; il faut donc se montrer très prudent vis-à-vis de cette source. Sur une restitution identique concernant Zeus Sôter au Pirée, voir supra. 
archaïque, on lui consacre un bateau de terre cuite ${ }^{42}$. À Sicyone d'Achaïe, le sanctuaire d'Apollon possède sous l'Empire un certain nombre de reliques considérées comme authentiques, parmi lesquelles figurent les rames et gouvernails des Argonautes (Ampelius, Aide-mémoire 8, 4-5; cf. infra p. 420). Lorsque l'on considère que la représentation archaïque d'Argô à Delphes est originaire de cette même cité ${ }^{43}$, il semble bien que le dieu sycionien soit honoré en relation avec le périple argonautique bien avant la période romaine.

En Argolide, le culte d'Apollon marin se laisse davantage cerner. À Trézène, Apollon est vénéré en tant qu'Épibatèrios (de l'Embarquement) (Pausanias II, xxxii, 2) ${ }^{44}$. Son temple qui se trouve à l'intérieur du péribole d'Hippolyte ${ }^{45}$ correspond selon la tradition à une fondation de Diomède pour avoir échappé à la tempête lors du retour de Troie. Des concours pythiques y sont par ailleurs rattachés. Le culte marin d'Apollon présente à Trézène deux particularités : son lieu de culte est intégré à l'intérieur d'un sanctuaire voué à une autre divinité, de surcroît éloigné de la mer ${ }^{46}$.

Plusieurs témoignages concourent à faire d'Apollon à Égine un dieu lié à la navigation ${ }^{47}$. Une ancre de pierre retrouvée à Gravisca, le port de Tarquinia, porte une dédicace de la part de Sostratos à Apollon Éginète (voir infra p. 470 ss.). Le temple, mentionné par des sources littéraires, est encore visible sur un promontoire appelé cap Kolona se détachant à l'entrée d'Égine ${ }^{48}$. Le sanctuaire surplombe le

42 Johnston 1985, Arch. 31. Une provenance plus détaillée de l'objet, inédit, n'est pas donnée dans ce catalogue. Voir infra p. 374 et 611.

${ }^{43}$ Voir supra, sur Apollon à Delphes.

${ }^{44}$ Mc Cartney 1933, p. 3.

${ }^{45}$ Le téménos d'Hippolyte a été fouillé par les Français : Legrand 1897-1905, puis en partie par Welter 1941, p. 25 ss. Le temple d'Apollon a été identifié avec un sacellum de 6 × 9 m situé au sud-ouest du sanctuaire, qui lui-même se trouve au NO de la ville actuelle de Trézène à plusieurs kilomètres du littoral. L'attribution à Diomède reflète vraisemblablement l'ancienne dépendance de Trézène par

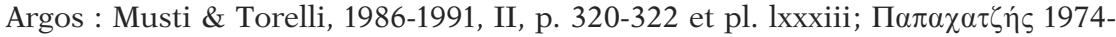
1981, II, p. 249 ss. et fig. 282-283. Imhoof-Blumer \& Gardner 1964, p. 48 signalent une série monétaire romaine avec un type d'Apollon au tripode, pouvant renvoyer à ce culte d'Apollon autant qu'à celui honoré dans la cité même de Trézène.

${ }^{46}$ L'épiclèse d'Épibatèrios a pu, à partir de l'époque augustéenne, être appliquée à l'empereur lui-même : Levy 1982-83 explique ainsi le culte alexandrin d'Auguste sous cette épiclèse par la victoire d'Actium et les actions contre les pirates.

${ }^{47}$ Sur le culte d'Apollon à Égine, Bourboulis 1949, p. 70-77; des fêtes étaient semble-t-il célébrées en l'honneur du dieu : scholies à Pindare, Pythiques VIII, v. 113 et à Néméennes V, v. 81.

${ }^{48}$ Pausanias II, xxx, 1 le mentionne dans sa description du quartier du port Kryptos; selon lui, la statue de culte est en bois, rustique. Le temple se trouve 
rivage où aujourd'hui subsistent semi-immergés des vestiges d'aménagements portuaires antiques. Un pinax naval trouvé dans cette zone constitue peut-être un ex-voto marin au dieu (voir infra p. 401). Le tout dessine un culte d'Apollon particulièrement actif à l'époque archaïque, à l'époque où l'Égine indépendante prospère grâce à sa flotte.

e) Laconie et Messénie

- Laconie

Apollon marin est particulièrement présent sur les deux pointes sud de la Laconie.

À Zarax, c'est-à-dire sur la côte est de l'avancée orientale du Péloponnèse, Pausanias (III, xxiv, 1) ne signale rien de notable si ce n'est un temple d'Apollon à l'extrémité du port où le dieu est représenté avec une lyre ${ }^{49}$. L'emplacement du sanctuaire, au bord d'un magnifique port naturel ${ }^{50}$, ne laisse aucun doute sur la nature du culte rendu à Apollon.

Plus au sud sur cette même côte laconienne, à cent stades du cap Malée sur le territoire de Boiae, se trouve une localité littorale nommée Épidèlion ${ }^{51}$, consacrée à Apollon (Pausanias III, xxiii, 1-4). En effet, les habitants des lieux racontent que leur xoanon provient de Délos et qu'il est arrivé jusqu'à leur rivage porté par les flots, après que les soldats de Mithridate pillant l'île l'aient jeté par impiété à la mer. Ces informations laissent supposer un culte d'Apollon Délien dont la statue en bois aurait été repêchée un jour sur la côte. La référence à Mithridate ne renvoie pas à un culte antérieur au ${ }^{\text {er }}$ s. a.C. ${ }^{52}$ Le sanctuaire semble être mentionné égale-

situé au cœur de vestiges plus anciens datant de l'âge du bronze; il a été construit

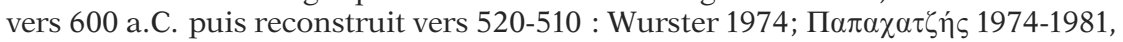
II p. 236-237 et fig. 255-259. Apollon apparaît parmi les types monétaires éginètes : Imhoof-Blumer \& Gardner 1964, p. 45 et pl. L2.

${ }^{49}$ Wide 1893 , p. 71.

${ }^{50}$ Le site est identifié avec l'actuel Limani Geraki; voir la configuration du lieu dans П $\alpha \pi \alpha \chi \alpha \zeta \eta_{\text {ń }}$ 1974-1981, II p. 427 et fig. 426-427.

${ }^{51}$ Wide 1893, p. 71 et 93. Le site recouvert par les eaux, se trouve à environ $2 \mathrm{~km}$ au nord du village moderne de Vutama : Hasluck \& Wace 1907-1908, p. 175 ss.

${ }^{52}$ Musti \& Torelli 1986-1991, III, p. 271-272 discute l'identification des acteurs et de la date de l'épisode historique du sac de Délos évoqué dans ces lignes. Bruneau 1970a, p. 62 l'identifie avec le xoanon délien consacré par Érysichthon (Plutarque, De daedalis plataeensibus, fgt 10). 
ment par Strabon (Géographie VIII, 6, 1) qui signale un sanctuaire d'Apollon nommé Délion en Laconie, qu'il rapproche de son homonyme béotien.

Au cap Malée ${ }^{53}$ même, Apollon était peut-être vénéré sous l'épi-

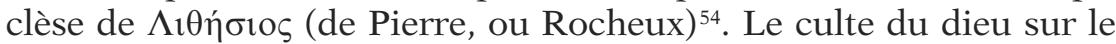
fameux cap paraît par ailleurs confirmé par son culte spartiate sous les épiclèses de Maléatès ou Akritas (Pausanias III, xii, 8) ${ }^{55}$. Il ne serait guère surprenant qu'Apollon soit honoré à la pointe autour de laquelle la légende l'imagine entraîner des navires. L'épiclèse de Lithèsios, si elle se vérifiait, renverrait à un culte ancien.

À l'ouest sur l'autre finistère laconien, le cap Ténare conserve la mémoire de l'aventure d'Arion, le citharède, sauvé par un dauphin (Servius, Comm. in Buc. VIII, 55) ${ }^{56}$ De retour de tournée, le musicien se rendait par mer à Corinthe lorsque les hommes du bateau convoitèrent ses richesses. Averti par un songe suscité par Apollon, Arion, au moment critique, obtint un sursis pour jouer une dernière fois de son instrument. C'est à ce moment que survinrent des dauphins et l'un d'entre eux emporta le musicien qui s'était jeté à la mer. Il regagna la terre ferme à Ténare, où il remercia le dieu par une statue le représentant assis sur le dauphin, sa cithare à la main. La version de Servius attribue à Apollon le rôle de sauveur, ce qui n'apparaît pas explicitement dans le récit donné par Plutarque (Banquet des sept sages 160e-162e). Ce dernier explique la conscience que possède Arion de la situation non par un songe divin, mais par la dénonciation du pilote. Deux allusions peuvent cependant évoquer l'intervention du fils de Léto : l'idée de se vêtir en citharède lui vient de $\tau \imath v \imath \delta \alpha \mu o v i ́ \omega$, et c'est le nome pithyque qu'il choisit de jouer. La version d'Hygin (Astronomie II, 17) quant à elle mentionne seulement le "pouvoir des dieux immortels» qu'Arion invoque avant de sauter.

Par ailleurs, Servius place un temple d'Apollon au cap Ténare où Arion dépose son ex-voto. Pausanias pour sa part n'y signale que la statue seule et les fouilles du site n'ont mis à jour aucun sanctuaire du dieu ${ }^{57}$. La légende situe l'épisode sous le règne du roi corinthien

${ }^{53}$ Sur le cap Malée et la route maritime de Strabon, Baladié 1980, p. 262-264 exprime bien le contraste ressenti par les navigateurs quand ils doublaient le cap.

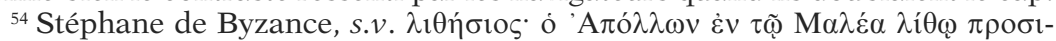

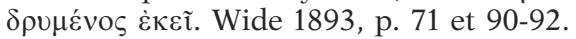

${ }_{55}^{5}$ Wide 1893 , p. 63.

${ }^{56}$ Ibid., p. 72 et 88-89. Sur Arion : Ridgway 1980, p. 90.

${ }^{57}$ Pausanias III, xxv, 7; sur les vestiges du cap Ténare, voir П $\alpha \pi \alpha \chi \alpha \tau \zeta \dot{\eta} \varsigma$ 19741981, II p. 440-447. 
Périandre, c'est-à-dire au début $\mathrm{du} \mathrm{VI}^{\mathrm{e}} \mathrm{s}$. a.C. ${ }^{58}$ Le premier récit transmis par Hérodote, qui ne comporte absolument aucune allusion divine, signale au Ténare une statue de petite taille représentant un homme sur un dauphin ${ }^{59}$. La tradition se rapportant à Arion remonte ainsi à l'époque archaïque, mais le rapprochement avec Apollon semble relever d'une évolution tardive qu'on ne peut pour le moment pas situer avant les premiers siècles de notre ère.

\section{- Messénie}

Encore plus à l'ouest, à l'extrémité de la Messénie, à Coronè, sur le littoral à 80 stades de la cité, se trouve un sanctuaire d'Apollon Korynthos dont Pausanias (IV, xxxiv, 7) signale le caractère vénérable. Les Messéniens, qui le disent ancien, y vénèrent un dieu guérisseur. Le Périégète signale une statue de bois et une autre de bronze, considérée comme une offrande des Argonautes. Les fouilles du site ont confirmé l'ancienneté du lieu de culte remontant à l'époque géométrique ${ }^{60}$. Si le caractère médical du sanctuaire est indéniable, sa position et le lien avec les Argonautes indiquent cependant un rapport privilégié avec la mer. Parmi le matériel votif archaïque, signalons la présence de nombreux petits objets de bronze dont un certain nombre d'hameçons ou outils de pêche ${ }^{61}$.

\section{f) Golfe de l’Eubée}

Au nord-est de l'Attique et sur le littoral de l'Eubée, trois sanctuaires d'Apollon marquent des lieux portuaires de passage entre les deux rives de la partie sud du golfe de l'Eubée ${ }^{62}$.

${ }^{58}$ Sur Périandre, voir C. Mossé, La tyrannie dans la Grèce antique, Paris, 1969, p. 32-37; Murray 1995, p. 147-164.

${ }_{59}$ Enquête I, 23-24; dans cette version, le poète joue l'hymne orthien. Une statuette de bronze datée entre 490 et 480 trouvée sur l'Acropole, qui représente un homme à califourchon s'apparentant à l'ex-voto d'Arion, montre que ce type iconographique existait au tout début du Ve s. : Ridder 1896, p. 278 no 755 et fig. 263; Delivorrias 1987, p. 184.

${ }^{60}$ Le sanctuaire, comprenant divers bâtiments, se situe près de la plage de Haghios Andreas voisine de Longa, à $20 \mathrm{~km}$ au sud de la ville actuelle de KoronèPétalidi (attention à la confusion avec la ville actuelle de Koronè); il a connu une continuité de culte jusqu'à l'Antiquité tardive où fut construite une basilique

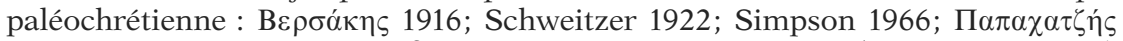
1974-1981, III, p. 154-155 et fig. 105-106. Trois inscriptions (SEG XI, 993-995) confirment l'épiclèse du dieu.

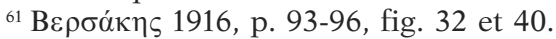

${ }^{62}$ Sur les cartes actuelles, cette zone est divisée en deux golfes distincts : le golfe sud de l'Eubée - c'est-à-dire au sud du détroit de Chalkis jusqu'au niveau de Marathon - et le golfe Pétalion qui en constitue le prolongement. 
Tout d'abord le port correspondant au sanctuaire d'Oropos, face à l'ancienne cité d'Erétrie, porte le nom de Delphinion (Strabon IX, $2,6)^{63}$. En face sur l'île d'Eubée, près d'Erétrie, la cité de Tamynae consacrée à Apollon possède un temple ancien, attribué à Admète, près du détroit (Strabon $\mathrm{X}, 1,10)^{64}$. Enfin au sud de l'île à Marmarion, un sanctuaire d'Apollon Marmarios lié à l'exploitation des carrières de marbre voisines marque le point d'embarquement pour franchir le détroit jusque l'Attique (Strabon X, 1, 6) ${ }^{65}$.

\section{g) Golfe de Corinthe}

La rive nord du golfe de Corinthe comporte deux sanctuaires littoraux consacrés à la divinité. La proximité de Delphes doit expliquer en grande partie cette implantation du dieu.

Ainsi, la cité de Chaléion (Locride) à l'ouest d'Itéa honore un Apollon Nasiotas. Le culte est attesté pour la fin du III e s. a.C. par plusieurs inscriptions ${ }^{66}$. L'épiclèse renvoie à l'emplacement du sanctuaire sur un îlot situé face à la citée ${ }^{67}$. Le culte d'Apollon à Chaléion était marqué par des fêtes nommées Poitropia qui se déroulaient au printemps $^{68}$.

Plus à l'ouest sur la même rive du golfe de Corinthe, à Naupacte, le temple d'Apollon se situe tout près du rivage. En effet, le récit que donne Thucydide (Guerre du Péloponnèse II, 91) de la bataille de Naupacte montre les trières athéniennes les proues face à son temple. Celui-ci devait marquer le port de la cité et accueillir les marins du golfe.

Mentionnons encore au large du golfe de Corinthe l'île de Céphallénie, dont le port de Panormos situé face à Ithaque était protégé par le dieu d'après quelques vers du début du $\mathrm{I}^{\text {er }} \mathrm{s}$. p.C. (Antipater de Thessalonique, Épigramme XL = Anthologie grecque $\mathrm{X}, 25)$.

${ }^{63}$ Aujourd'hui port de Kamaraki.

${ }^{64}$ Sur Admète à qui Apollon aurait loué ses services, voir G. Wentzel, «S.v. Admetos», RE I, Stuttgart, 1894, col. 1623-1624. D'après l'édition Budé, p. 169, le sanctuaire a été localisé à Itéa où l'on aurait retrouvé des vestiges d'un temple archaïque.

${ }^{65}$ D'après l'édition Budé, l'information provient d'Artémidore donc antérieure à l'époque romaine.

${ }^{66} \mathrm{FD}$ III, 3, 145, 1. 37; IG IX, 12, 721c, 1. 4.

${ }^{67}$ Lerat 1952, I p. 159 ss. et 198-205. L'îlot correspond vraisemblablement à Apsiphia, au large de Galaxidi.

${ }^{68} F D$ III, 3, 145, 1. 17-18; des fêtes du même nom étaient célébrées à Delphes : Nilsson 1906, p. 470. 
h) Leucade et Actium

- Leucade

Le sanctuaire d'Apollon à Leucade est mentionné dès l'époque classique $^{69}$, mais il est surtout connu au travers de sources du I $^{\text {er }} \mathrm{s}$. p.C. ${ }^{70}$ Virgile évoque un mont Leucate consacré à Apollon formidatus nautis (Énéide III, v. 274-275). Strabon (X, 2, 8-9) explique ainsi le nom du lieu: il correspond au promontoire de roche blanche de l'extrémité sud-ouest de l'île sur lequel se trouve le temple d'Apollon. Le géographe rapporte alors la tradition du saut, prétendu guérir des peines d'amour, tout en lui accordant une autre origine et signification. Selon certains, les Leucadiens choisissaient une fois l'an un homme sur lequel pesait une accusation, lui attachaient des plumes d'oiseaux sur le corps et le précipitaient du haut de la falaise. Des barques mouillaient en contrebas, prêts à recueillir l'homme et l'emmener hors des frontières du pays. G. Glotz a expliqué la véritable signification du rite, dans un ouvrage riche d'enseignements divers ${ }^{71}$ : le saut dans la mer constitue une ordalie, c'est-à-dire un jugement divin. L'accusé subit une épreuve qui doit aux yeux des hommes ou l'innocenter s'il en sort vivant ou le punir s'il n'en réchappe pas. Cette sentence par l'eau de mer purificatrice perdit son sens et fut comprise comme un remède aux tourments amoureux et pratiquée sous forme de cérémonie religieuse ${ }^{72}$. Il est frappant cependant de constater dans cette forme de justice la ressemblance avec les traditions se rapportant au Delphinion d'Athènes.

Au point de vue topographique, l'emplacement du sanctuaire d'Apollon renvoie clairement à un sanctuaire de type maritime ${ }^{73}$. La falaise, à l'extrémité sud de l'île et tournée vers le large de la mer Ionienne, constitue un amer de premier choix pour les marins croisant dans la zone. La vision d'un temple à son sommet devait rassurer tous ceux qui l'apercevaient depuis le large, comme l'affirme une épigramme du $\mathrm{I}^{\mathrm{er}}$ p.C. (Philippe de Thessalonique,

${ }^{69}$ Thucydide, La guerre du Péloponnèse III, 94 le situant comme la cité «en deçà de l'isthme»; il figure parmi les sanctuaires littoraux pillés par les pirates avant l'action de Pompée (Plutarque, Pompée 24, 6).

${ }^{70}$ Gagé 1936, p. 47-51; Oberhummer 1887, p. 223-226.

${ }^{71}$ Glotz 1904, spécialement p. 34-50. Le chapitre II (p. 11-68) est consacré à «l'ordalie par la mer». Voir également Radermacher, p. 307-315; Borzsák 1951, p. 207; Lesky 1947, p. 142 ss.

${ }_{72}$ Glotz 1904, p. 60-61, énumère les différents cas connus de personnes volontaires pour le saut, l'issue de celui-ci, et surtout les subterfuges utilisés pour donner les meilleures chances de s'en sortir au plongeur...

${ }^{73}$ Semple 1927, p. 384-385 et fig. 6. 
Épigramme VII = Anthologie grecque VI, 251 ${ }^{74}$. C'est cette impression que dégagent les derniers vers de l'Élégie (III, xi, v. 69-72) de Properce s'adressant au marin fréquentant la mer Ionienne: l'Apollon de Leucade, présence qui lui est familière, doit désormais lui évoquer également la défaite d'Antoine. Ovide (Tristes $\mathrm{V}, 2 \mathrm{~b}$, v. 29-34), évoquant le saut de Leucade parmi les plus terribles châtiments, définit ses eaux comme la propriété du dieu. Le poème de Philippe de Thessalonique (ibid.) exprime la prière d'un navigateur espérant un vent favorable de la part d'Apollon de Leucade jusqu'à Actium : l'action de la divinité semble s'étendre jusqu'à son prochain sanctuaire où l'on invoquera alors l'aide d'Apollon Aktios. Ces vers, témoignant de pauvres offrandes, montrent que le dieu était honoré par des populations de modestes marins effectuant de petits trajets maritimes sur ce littoral.

\section{- Actium}

Plus au nord sur le continent, à l'embouchure du golfe d'Ambracie, se trouve le fameux sanctuaire d'Actium. Malgré sa notoriété augustéenne, Apollon reçoit un culte à Actium bien avant la victoire d'Octave et sert alors de patron au koinon des Acarnaniens, comme l'indique une inscription datée de 216 a.C. ${ }^{75}$. Le temple fut restauré par le vainqueur romain ${ }^{76}$, ce qui montre bien la continuité - ou la récupération - d'un culte plus ancien. La fondation du culte et l'épiclèse d'Aktios remontent selon certains au départ des Argonautes (voir supra); le matériel laisse plutôt deviner un établissement religieux archaïque par les habitants de la ville voisine d'Anaktorion ${ }^{77}$. Les fêtes des Aktia ${ }^{78}$ étaient célébrées en l'honneur du dieu que l'on voit représenté sur des monnaies de 229-168 a.C.79; mais rien ne ressort de la nature du culte rendu à Apollon au travers de ses informations. Le lieu décrit par Strabon (Géographie VII, 7, 6) montre un sommet sur lequel le temple surplombe au sud le golfe

${ }^{74}$ Wachsmuth 1967, p. 409; Mazaubert 1937, p. 320.

${ }^{75}$ IG IX, 122, 583; J. et L. Robert, Bulletin épigraphique 1958, n 270; J. Pouilloux, Choix d'inscriptions grecques, Paris, 1960, p. 108-114; Gagé 1955, p. 508.

${ }^{76}$ Servius, ad Aen. III, 280. Le sanctuaire est également mentionné par Plutarque, Pompée 24, 6, parmi ceux pillés par les pirates hellénistiques.

${ }^{77}$ En 1867 deux kouroi archaïques ont été mis à jour, déposés ensuite au Louvre par les bons soins de Champoiseau, consul de France à Ioanina: Collignon 1886.

${ }^{78}$ Ces fêtes sont attestées depuis le IV ${ }^{e}$ s. a.C.; elles comprenaient une

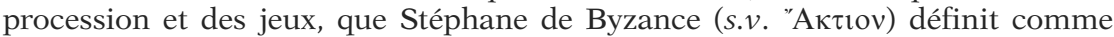
hippiques, gymniques et nautiques, mais qui doivent sous cette forme appartenir aux jeux romains conçus par Auguste; sur ces régates, Gardner 1881, p. 93.

${ }_{79}$ Sur les monnaies, le dieu couronné est représenté assis sur un trône, un arc à la main : Gardner 1883, p. 168-169 et pl. XXVII, 2-3. 
d'Ambracie; ailleurs le géographe distingue le sanctuaire du promontoire qui ferme le goulet (ibid. X, 2, 7) ${ }^{80}$. Dion Cassius (Histoire romaine $\mathrm{L}, 12,7$ ) vante la longueur de ce bras de mer qui permet un bon mouillage. Peut-être ce port porte-t-il le nom du fils de Léto comme paraît l'indiquer Properce (Élégie IV, vi, v. 11-68).

Lors de l'affrontement d'Actium, la tradition augustéenne a propagé l'histoire d'un prodige en faveur d'Octave : Phoibos serait apparu comme une lumière à la poupe du navire du Romain, l'aurait assuré de la victoire à venir en lui promettant son aide (Properce, ibid.). L'action du dieu consiste non seulement dans ses jets de flèche ${ }^{81}$ mais aussi, comme il l'affirme lui-même, dans sa conduite des bateaux. Cette légende renvoie à des croyances plus anciennes : elle rappelle l'apparition d'Apollon aux Argonautes et le rôle de guide nautique qu'on lui attribue. Suite à la victoire d'Actium, Auguste dota la zone de différentes offrandes navales : dix vaisseaux pris à la flotte d'Antoine et des éperons qui ornèrent la terrasse d'un autel monumental (Strabon, Géographie VII, 7, 6; Dion Cassius, Histoire romaine LI, 1, 2-3) (voir infra p. 422 s.).

Le culte d'Apollon Aktios à l'entrée du golfe d'Ambracie semble donc essentiellement axé sur la navigation opérée dans cette zone, la divinité étendant sa protection jusqu'aux eaux du sanctuaire de Leucade (Philippe de Thessalonique, Épigramme VII). Remontant à l'époque archaïque, il connaît un développement particulier en jouant le rôle politique de sanctuaire fédéral à l'époque hellénistique; la victoire d'Actium lui confère une aura plus large, mais aussi une réorientation de la personnalité divine d'Apollon Aktios.

\section{i) Sicile et Grande Grèce}

Deux sanctuaires occidentaux d'Apollon présentent des caractères marins indéniables; sans doute ne sont-ils pas les seuls, mais les sources ne suffisent pas pour le moment à l'établir (carte 10).

En Sicile, Apollon possède un sanctuaire sur le promontoire Pachynum sous l'épiclèse de Libystinus (Macrobe, Saturnales I, 17, 24). La tradition rapporte à ce propos que le dieu décima de la peste

${ }^{80}$ Rien ne subsiste du temple, mais la morphologie du terrain a bien dû changer depuis l'Antiquité. La description donnée par Mythographi Vaticani II, 231 (Leucada mons est altissimus promontorio Epyrrhi juxta Ambrachiam civitatem quam Augustus Nicopolim appellavit victis illic Antonio et Cleopatra, ubi et templum Actiaco Apollini constituit et ludos Actiacos nominavit) est contradictoire avec celle de Strabon. Comme cette source tardive attribue également de façon erronée la fondation du temple à Auguste, nous ne pouvons pas la considérer comme fiable.

${ }^{81}$ Également dans le récit virgilien du livre VIII de l'Énéide, v. 704-705. 
la flotte des Libyens venus envahir l'île. Le cap Пóxvvo $\varsigma^{82}$, situé à l'extrémité sud-est de l'île, constitue un finistère et un amer important pour les navigateurs qui doublent la Sicile à l'ouest pour se diriger vers la péninsule Ibérique. L'épiclèse doit renvoyer aux Carthaginois et à leurs nombreuses tentatives pour prendre pied en Sicile, mais aussi à l'assimilation d'un ancien culte phénicien à cet endroit pour lequel aurait été créée une tradition étiologique ${ }^{83}$.

À Métaponte, le hiéron d'Apollon Lykeios, connu par quelques attestations littéraires ${ }^{84}$, a été fouillé et identifié par des inscriptions trouvées in situ. L'étymologie de l'épiclèse, discutée par les spécialistes, est souvent interprétée comme faisant référence au $\lambda$ ókos (loup). Le site a livré plusieurs jas de pierre archaïques considérés comme votifs (voir infra p. 477 ss., cat. V4 et V17-22), ce qui en fait un sanctuaire fréquenté à cette période par des navigateurs.

\section{j) Asie Mineure}

Le culte apollinien est particulièrement présent dans les cités grecques d'Asie Mineure, à tel point que certains y placent l'origine du dieu ${ }^{85}$. En ce qui nous concerne, il s'agit d'examiner s'il présente un caractère marin prononcé de ce côté de la Méditerranée. Les sources s'avèrent décevantes à cet égard : des témoignages éclatés permettent de repérer quelques cultes marins d'Apollon mais difficilement reliables entre eux.

\section{- Propontide et Bithynie}

Ainsi en Propontide dans la région de Cyzique, le dieu est vénéré

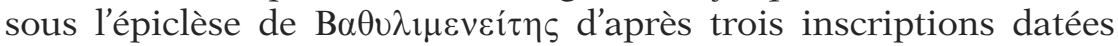

${ }^{82}$ Il est nommé à deux reprises dans l'Alexandra de Lycophron comme théâtre d'un épisode lié à la geste homérique : v. 1029 ss. Ulysse y débarque; v. 1181 ss. cénotaphe d'Hécube.

${ }^{83}$ Sordi 1985, qui rapproche cette tradition sicilienne avec celle en 212 a.C. qui est à l'origine à Rome des ludi Apollinares (Tite-Live XXV, 12, 8-15). Pausanias $(\mathrm{V}, 25,5)$ décrit à Olympie l'offrande des Agrigentins sur les Libyes kai Phoinikes stationnés en Sicile dans une zone proche de celle du promontoire. Sur les tentatives carthaginoises en Sicile et Grande Grèce, voir Will 1972, p. 219-255, qui établit de surcroît la différence entre Carthaginois et Phéniciens : ces derniers avaient en effet établi quelques établissements en Sicile sur la route des métaux; l'emplacement du promontoire permet d'envisager qu'il en faisait partie.

${ }^{84}$ Hérodote, Enquête IV, 15; Théopompe, Fgt 248, cité par Athénée, Deipnosophistes XIII, 83; Plutarque, De l'oracle de la Pythie, 8. Présentation par Manni Piraino 1968, p. 426-427 et Giacometti 2005, p. 28-51.

${ }^{85}$ Cette thèse a été particulièrement défendue par Wilamowitz 1931-32, I p. 324-326 et Nilsson 1955, p. 527 ss. 
vraisemblablement du $\mathrm{I}^{\text {er }}$ s. a.C. ${ }^{86}$. Littéralement, l'épiclèse signifie «du Port profond», que L. Robert comprend comme le nom même d'un port. Sur ces stèles votives, Apollon est représenté en citharède. Une scholie discute de l'épiclèse sous laquelle il reçoit un culte marin à Kyzique: Ekbasios, Iasonios ou simplement Kyzikènos (Scholie à Apollonios de Rhodes, I v. 966). Sur le littoral voisin de la Bithynie, un Apollon Akreitas reçoit des offrandes de la part de pêcheurs comme l'indique une épigramme non datée de l'Anthologie Palatine (VI, 230).

\section{- De la Troade à la Cilicie}

Plus au sud, sur la côte troade, le sanctuaire apollinien de Chrysa occupe un emplacement privilégié (Strabon XIII, 1, 47-48). Il est bâti sur une hauteur rocheuse surplombant la mer; à proximité les habitants exploitent des salines formées naturellement par les vents étésiens. Strabon nous expose les différentes traditions se rapportant à l'épiclèse du dieu Smintheus, dérivée du mot sminthos : le rat. La statue de culte, œuvre de Scopas, représente en effet Apollon avec l'animal à ses pieds. L'histoire la mieux admise renvoie à l'établissement de Troyens venus de Crète à la suite d'un de ses oracles, qui leur aurait conseillé de s'établir là où s'attaqueraient à eux des «enfants de la terre» ( $\gamma \eta \gamma \varepsilon v \varepsilon i \tilde{s})$; ceux-ci s'avérèrent être des rats qui rongèrent tout le cuir de l'équipement des émigrants. Le culte est ainsi mis en relation avec Apollon delphien et surtout avec le processus de colonisation. Strabon reprend dans un autre passage (XIII, 1, 62-63) son commentaire sur ce temple de Chrysa. Il distingue deux villes de ce nom : la nouvelle, bâtie à l'intérieur des terres et voisine de celle d'Hamixos, de l'ancienne littorale et proche de Thèbè. C'est la seconde, munie d'un port, qui possédait le sanctuaire du dieu mentionné dans l'Iliade. Abandonnée à l'époque de Strabon, elle ne présente que des vestiges tandis que le culte a été transporté dans la nouvelle cité homonyme. Le commentaire du géographe insiste sur le caractère maritime du lieu en liaison avec la navigation de l'ambassade conduite par Ulysse. Son témoignage atteste un culte ancien remontant au moins à l'époque archaïque, lié à la vie d'une ville portuaire et situé sur une hauteur surplombant la mer. Le développement du culte sous cette épiclèse - pour preuve l'énumération des sanctuaires d'Apollon Smintheus donnée par Strabon - fut particulièrement important et les autres prérogatives du dieu expliquent son implantation dans la nouvelle cité, non mari-

${ }^{86}$ Musée d'Istanbul, inv. 4407 et 4737; Robert 1955; Wachsmuth 1967, p. 262. E. Schwetheim, dans EA I, 1983, p. 109-110; Schlosser 2014, p. 267-268. 
time, de Crysa. Le tout donne l'impression d'un culte marin rendu à Apollon à haute époque s'évanouissant peu à peu au profit du caractère essentiel de la divinité : l'épiclèse de Smintheus et l'association avec le rat, renvoyant à la peste que le dieu envoie aux Grecs dans l'Iliade. Parmi les anciens hiéra du dieu, il convient de signaler encore l'île de Ténédos qui, d'après Strabon (XIII, 1, 46), possède deux ports et un sanctuaire d'Apollon Smintheus, déjà mentionné chez Homère ${ }^{87}$.

De Ténédos jusqu'à Lesbos, Strabon (XIII, 2, 5) montre le culte d'Apollon omniprésent sous des épiclèses diverses. La multitude d'îles appelées Hékatonnèses - en raison de leur grand nombre faut-il comprendre - sont aussi désignées sous le terme d'Apollononnèses car le dieu y règne en maître et qu'il est parfois appelé Hékatos, épiclèse qui signifie "Qui frappe au loin» 88 . La tradition a ainsi probablement rapproché les deux noms quoique se rapportant à des étymologies différentes. Dans l'île voisine de l'archipel nommée Pordosélènè, abandonnée à l'époque de Strabon, se trouvait également un temple d'Apollon.

Plus au sud en Carie, à Cnide, Apollon possède un sanctuaire sur la pointe du promontoire appelée Triopion (Thucydide, Guerre du Péloponnèse VIII, 35, 2) ${ }^{89}$.

Une dédicace du I ${ }^{\mathrm{er}} \mathrm{s}$. a.C. trouvée à Athènes exprime les remerciements pour une bonne traversée à Apollon de Tarse de Cilicie de la part de l'équipage d'un bateau ${ }^{90}$. Un texte plus tardif ${ }^{91}$ mentionne le culte dans la ville d'un Apollon au trident, type qui n'est pas attesté sur les monnaies impériales de la ville. En revanche, une monnaie de la fin du $\mathrm{V}^{\mathrm{e}} \mathrm{s}$. a.C. de la cité sous domination perse figurant un personnage au trident doit représenter le dieu local, assimilé ensuite à Apollon ${ }^{92}$. Le culte marin d'Apollon à Tarse est le résultat

${ }^{87}$ Iliade I, v. 38.

${ }^{88}$ L'adjectif qualifie Apollon dès l'Iliade VII, v. 83; O. Jessen, "s.v. Hekatos», $R E$ VII, 1912, col. 2799-2800. Les îles se situent au nord-est de Lesbos, dans le golfe d'Adramyttion.

${ }^{89}$ Sur la topographie générale de Cnide, voir Texier 1839-49, III p. 171-176; Cook 1957, p. 85-87. Les fouilles américaines ont porté sur le sanctuaire d'Aphrodite.

${ }^{90}$ IG II/III, 3, 1, no 3003; Chuvin 1981, p. 309-310.

${ }^{91}$ Dion de Pruse, Discours 33, 1.

${ }^{92}$ Chuvin 1881, p. 305-311 et 325-326. 
d'un syncrétisme, pour lequel il est intéressant de noter le rapprochement opéré avec Apollon alors que le type iconographique aurait plutôt penché en faveur d'un Poséidon, signe que le fils de Léto présentait par ailleurs des caractéristiques analogues.

\section{k) Îles du sud de la mer Égée}

À l'est de Santorin, l'île d'Anaphè connue par le périple argonautique possède bien un sanctuaire d'Apollon Aiglètès, comme le confirme Strabon $(\mathrm{X}, 5,1)$ ainsi que des inscriptions ${ }^{93}$. Les Argonautes remercièrent le dieu à la mesure de leurs ressources qui se résument à peu de choses : de l'eau, pas de viande. Ce simulacre de sacrifice est à l'origine, d'après Apollonios de Rhodes (Argonautiques, IV, v. 1691-1731), des quolibets que se lancent hommes et femmes lors des sacrifices donnés dans l'île en son honneur. L'emplacement du temple, sur l'isthme oriental de lîle, renforce l'image d'un culte rendu à un Apollon marin ${ }^{94}$.

En ce qui concerne le territoire crétois, un règlement de Gortyne daté du II ${ }^{\mathrm{e}}$ s. a.C. fixant le statut de l'île de Gaudos située au sud de la Crète attribue une dîme à Apollon Pythien, prise sur l'ensemble des biens recueillis échoués sur le rivage de l'île ${ }^{95}$. Il est difficile de déterminer si cette somme était destinée à un sanctuaire d'Apollon Pythien à Gortyne ${ }^{96}$ ou au sanctuaire delphien. Quel qu'il soit, le dieu recueille les fruits des naufrages qui parviennent jusque là - qui ne devaient pas constituer des événements rares, pour qu'une telle clause soit envisagée et réglementée.

À l'ouest de Rhodes, la petite île de Chalcia comporte un ville, un temple d'Apollon et un port (Strabon X, 5, 15). Cette seule mention laisse envisager un caractère insulaire de la divinité. À Chypre, Strabon (XIV, 6, 3) mentionne un promontoire d'où l'on jette ceux qui ont touché l'autel d'Apollon. Le cap se trouve près de Kourion, au sud-ouest de l'île. Ce saut dans la mer évoque un rite identique à celui de Leucade.

${ }^{93}$ L'île possède encore aujourd'hui le même nom; des inscriptions mentionnent le culte d'Apollon Aiglatas ou Asgelatas : IG XII, 3, 248, 1. 47; 249, 1. $25 ; 259 ; 260$.

${ }^{94}$ Des vestiges du sanctuaire seraient visibles autour du couvent de la Panaghia Kalamiotissa, d'après l'édition Budé de Strabon.

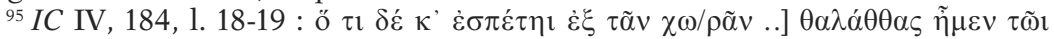

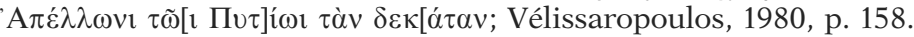

${ }^{96}$ Le culte d'Apollon est attesté depuis l'époque archaïque jusqu'à la fin de l'époque hellénistique à Gortyne par deux inscriptions et des monnaies : Willetts 1962, p. 258. 


\section{1) Confins}

Quelques sources signalent encore des sanctuaires d'Apollon marin situés aux limites du monde grec : sur la côte africaine et au nord de la mer Noire.

À Cyrène, une dédicace néronienne s'adresse à Apollon Apobatèrios (du Débarquement $)^{97}$. Cette épiclèse peut s'éclairer par d'autres liens attestés dans la cité entre Apollon et la navigation. Le port de Cyrène, à quatre-vingts stades de la ville, porte le nom d'Apollonia (Strabon XVII, 3, 30); cette zone littorale constitue une plaine, de telle sorte qu'il est possible de voir Cyrène depuis la mer. Le nom du port renvoie au rôle primordial du dieu de Delphes dans la fondation de cette colonie théréenne, avec l'aide il faut le souligner d'un pêcheur ${ }^{98}$. Les habitants de Cyrène vénèrent ainsi la divinité à qui ils doivent la naissance de leur cité également pour ses prérogatives navales.

Bien plus à l'ouest sur la côte africaine, dans l'ancien territoire carthaginois, plusieurs descriptions géographiques (Strabon XVII, 3, 13; Pomponius Mela, Chorographie I, 7, 34) situent un cap d'Apollon près d'Ityque, définissant deux grands golfes ${ }^{99}$. Sans connaître l'origine de cette attribution, la topographie des lieux doit l'expliquer en grande partie.

Enfin rappelons l'existence en Crimée, à Nymphaion, du sanctuaire d'Aphrodite et d'Apollon (?) abritant une grande représentation d'un bateau ptolémaïque (voir infra p. 404 ss.).

\footnotetext{
${ }^{97}$ Robert 1969 qui explique l'attribution «occasionnelle» de cette épiclèse à Apollon par les prétentions artistiques de Néron et son identification avec le dieu; ce jugement réducteur occulte tout aspect maritime du dieu. Sur Apollon à Cyrène, voir La Vitali 1932, p. 127 et Pugliese Carratelli 1965. Nous n'avons pas retenu le concours nautique de Sidè en l'honneur d'Apollon nommé également Apobatèrios et d'Athéna mentionné par L. Robert : ils sont connus seulement pour le III ${ }^{\text {e }}$ s. p.C. (Robert 1948).

${ }^{98} \mathrm{Cf}$. le long récit non dénué d'humour de la fondation de Cyrène dû à Hérodote IV, 150-158. L'épisode des Argonautes en Libye et de leur rencontre avec Triton est peut-être à mettre en relation avec les qualités de guide d'Apollon : dans la version d'Hérodote, Jason embarque un trépied dans l'intention de se rendre à Delphes, mais à la hauteur du cap Malée un vent l'emporte en Lybie. Le vent, la destination prévue et l'offrande emmenée à bord peuvent indiquer une intervention du dieu. Pour Apollonios de Rhodes (Argonautiques IV, v. 15371764), la rencontre des Argonautes et de Triton, réalisée grâce à l'offrande à ce dernier du trépied apollinien lorsque les héros sont perdus dans le lac, permet à long terme la fondation de la ville. Sur la fondation de Cyrène, voir Defradas 1954, p. 242-257 et Malkin 1987, p. 60-69. L'expédition des Théréens aurait eu lieu en 644; sur les bateaux de l'expédition, Salviat 1989, p. 236 ss.

${ }^{99}$ Situé non loin du Cap Bon, il s'agit aujourd'hui du Ras-el-Mekki; Pline (XVI, 216) signale un culte d'Apollon dans la région : A. Silberman, commentaire de Méla en l'édition Budé p. 122.
} 
ANALYSE

\section{Géographie du culte}

Les lieux de culte à Apollon marin se répartissent essentiellement sur la partie orientale de la Méditerranée, à l'est environ du 20 e degré de longitude situé à la hauteur de l'île de Leucade. À l'ouest de cette ligne, trois sites seulement lui sont consacrés : dans le golfe de Métaponte et sur deux promontoires, l'un à la pointe de Sicile et l'autre sur la côte africaine. Ces deux caps dessinent l'esquisse d'une route vers l'Ibérie et ses métaux où cependant le dieu n'est pas attesté, ou peut-être vers Massalia sur laquelle Apollon Delphinios règne avec Artémis (Strabon IV, 1, 4) ${ }^{100}$. À l'est de cette ligne donc, les lieux recensés se répartissent tout d'abord en Grèce centrale depuis le golfe d'Ambracie jusqu'à Leucade et Céphallonie puis sur la rive nord du golfe de Corinthe : Naupacte, Chaléion, Delphes. Un deuxième groupe suit le littoral de la moitié sud du Péloponnèse : Messénie et surtout Laconie; deux autres se définissent autour du golfe Saronique - Trézène, Égine, Vouliagmeni, Sounion - et autour du sud du golfe de l'Eubée. En dehors de cet ensemble de la Grèce continentale, un grand nombre d'îles honore le dieu : Délos, Gaudos, Ténédos, les Hékatonnèses et Pordosélènè, Chypre. Sur le littoral d'Asie Mineure n'apparaissent que quelques cités: Cyzique, Chrysa, Cnide, Tarse. Enfin Nymphaion au nord de la mer Noire semble représenter le seul lieu de culte pontique à un Apollon marin, tandis que Cyrène marque la limite sud de son monde maritime.

Cette disposition dément la vision d'un culte d'Apollon essentiellement concentré dans la partie orientale de la mer Égée ${ }^{101}$. Sa présence en Grèce continentale, loin d'être marginale, est implantée avec cohérence le long de plusieurs lignes de côtes.

La topographie des lieux de culte s'avère remarquable : Apollon est le dieu des promontoires ${ }^{102}$, mais aussi des îles et des rivages ${ }^{103}$.

${ }^{100}$ L'emplacement de la cité, l'épiclèse du dieu ainsi que la consécration d'akrothinia de batailles navales de la part des Massaliotes (Strabon IV, 1, 5) laissent soupçonner un culte d'Apollon marin à Marseille qu'aucun élément ne peut confirmer pour le moment; pour cette raison la cité massaliote ne figure pas dans l'inventaire des testimonia. Sur le culte d'Apollon à Marseille, voir Properzio 1989, p. 295-299.

${ }^{101}$ Gallet de Santerre 1958, p. 135-136.

${ }_{102}$ Wachsmuth 1967, p. 399.

${ }^{103}$ Gallet de Santerre 1958, loc. cit. 
L'Hymne à Apollon Délien (v. 144-145) l'affirme : Apollon privilégie les lieux élevés, plus précisément les skopiai, les akroi, ainsi que les embouchures des fleuves.

Il occupe des avancées sur la mer à Leucade, Actium, Chrysa, Zôstèr, Malée, Ténare, Anaphè, Égine. Aimant particulièrement les îles, il s'implante de préférence dans celles-ci sur un promontoire : ainsi par exemple à Leucade, Pachynum ou Anaphè. De façon générale, il privilégie les ports: dans le golfe de l'Eubée, à Zarax, Cyzique, c'est lui qui préside aux activités portuaires. Qu'il se tienne au sommet d'une hauteur - à Leucade, à Delphes, à Actium -, à l'extrémité d'un finistère, sur le rivage au centre d'un golfe ou sur une île, il paraît toujours dominer l'espace maritime et le surveiller du regard. Ceci n'empêche cependant pas Apollon de recevoir un culte ou des ex-voto navals dans des sanctuaires situés à l'intérieur des terres : à Phlyées, Trézène, au Delphinion athénien. Mais de manière générale, le dieu est tourné vers le large, placé à des endroits d'où il peut sur une large étendue observer le pontos. Chypre, la Sicile, Rhodes, Leucade honorent Apollon sur le point de l'île le plus ouvert vers l'extérieur et la haute mer. À Nymphaion, Cyrène, Métaponte ou Marseille qui marquent les limites ce monde apollinien, il domine encore un large horizon marin ${ }^{104}$.

Dans tous ces endroits, il possède le plus souvent de véritables hiéra avec temples. De plus il n'est désigné semble-t-il sous aucune épiclèse toponymique; au contraire, c'est lui qui semble donner leur nom à plusieurs promontoires ou localités : Zôstèr, Actium, (Épi)dèlion.

\section{Personnalité marine d'Apollon}

Par cette géographie cultuelle Apollon s'impose comme un maître vigilant des espaces marins : tourné vers eux, il peut à la fois observer le large et les rivages du littoral et les hommes qui s'y activent.

Il apparaît en rapport avec la mer sous de nombreuses épiclèses : Aiglètès, Akreitas, Aktios, Apobatèrios, Bathylimeneitès, Délien, Delphinios, Ekbasios, Embasios, Épaktios, Épibatèrios, Hékatos, Korynthos, Lithèsios, Lykeios, Nasiotas, Nèossoos, Smintheus, auxquelles s'ajoute peut-être celle d'Opsophagos ${ }^{105}$. La plupart d'entre elles désignent un type d'endroit maritime sur lequel la divi-

${ }^{104}$ Notons que ces caractéristiques peuvent également s'appliquer au sanctuaire thasien d'Aliki, supposé consacré à Apollon (voir infra, p. 276).

${ }^{105}$ En Élide, Apollon reçoit un culte sous cette épiclèse d'après une source hellénistique (Polémon, Fgt 7070, éd. Preller = Athénée, Deipnosophistes VIII, 
nité doit étendre sa protection - localement à l'emplacement du sanctuaire en question ou de façon générale sur tous lieux répondant à cette définition. Les unes concernent des points élevés ou

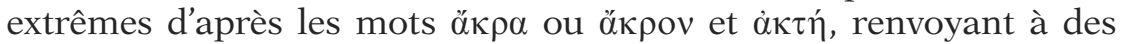
côtes escarpées ou des promontoires. D'autres évoquent un port ou une île: Bathylimeneitès, Nasiotas. Quelques épiclèses définissent plus précisément des domaines sur lesquels s'applique le pouvoir du dieu : l'embarquement et le débarquement d'après les composés du verbe ßaív - Ekbasios, Embasios, Épibatèrios et Apobatèrios -, ou encore la sauvegarde des bateaux : Nèossoos.

Ainsi Apollon se définit-il comme le dieu du large et des côtes, protégeant les hommes et les bateaux qui les fréquentent. Et c'est bien ainsi qu'une épigramme du $\mathrm{I}^{\mathrm{er}} \mathrm{s}$. p.C. l'invoque (Antiphilos, Épigramme XI = Anthologie grecque X, 17).

Il s'attache ainsi particulièrement tant au départ qu'à l'arrivée des embarcations, sans négliger cependant l'espace intermédiaire ${ }^{106}$. Dans les récits mythiques il accompagne en effet la navigation: ouvertement celle des marins crétois, plus discrètement celle des Argonautes. Par ailleurs le poème de Bacchylide racontant l'épisode de Thésée et d'Amphitrite (Dithyrambe III) s'achève par une invocation à Apollon en tant que théopompe. Le contexte du récit qui se conclut par le péan entonné par les occupants du bateau devant le prodige dont ils viennent d'être témoins peut laisser supposer une allusion à Apollon dieu propice à la bonne route du bateau.

Le plus souvent, son action dans le domaine de la navigation s'avère positive et tout en douceur : responsable des voyages réussis, lorsqu'il manifeste cependant sa présence ce n'est pas par une action violente. De façon significative, il ne calme pas les eaux ni ne fait disparaitre réellement la difficulté, mais pallie les embuches et obstacles. Ainsi il éclaire la nuit angoissante des Argonautes ou envoie un dauphin pour conduire le bateau ou l'homme vers des eaux plus calmes. De même la flotte de Néarque lors de son périple indien, rejoignant enfin les troupes terrestres en Carmanie après des moments d'angoisse et célébrant ces retrouvailles par des sacrifices et des jeux, honore-t-elle Zeus Sôter, Héraclès, Apollon Alexikakos (Qui écarte les maux) ${ }^{107}$, Poséidon et de nombreux autres dieux

346b). Le terme renvoie à l'amour de la bonne chère et particulièrement du poisson, de sorte que le mot désigne également une sorte de cet animal.

${ }^{106}$ Detienne 1998, p. 139.

${ }^{107}$ Sur l'emploi de ce mot (plutôt dans un sens médical), voir Dumont 1975, p. 64; Nilsson 1927, p. 505. 
marins. Apollon est célébré pour sa propension à résoudre les problèmes et aplanir les difficultés d'un voyage maritime en association avec d'autres divinités.

C'est lui aussi qui conduit vers de nouvelles terres; son rôle primordial dans plusieurs légendes de fondation - avec ou sans l'intermédiaire de l'oracle pythien - le prouve assez: à Théra, à Lycos (Plutarque, Mulierum Virtutes, 247d-f)... ${ }^{108}$. Ainsi les sources

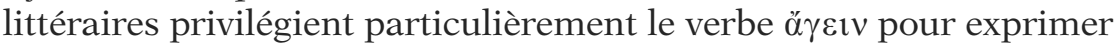
son action. Apollon représente le guide de ces étendues marines, un guide omniscient et tranquille qui permet de comprendre et de tirer profit de la mer en tant qu'espace d'échanges. Cela explique également pourquoi à deux reprises on le met en relation avec des xoana transportés par les flots : ce qui est véhiculé à la surface des flots d'un rivage à l'autre n'est pas étranger au dieu.

Cette sorte de souveraineté sur les routes et mouvements marins le mène naturellement à se voir attribuer cette même suprématie à échelle humaine : il reçoit ainsi les offrandes consécutives à plusieurs batailles navales. Dans cette perspective, s'avère particulièrement notable l'importance des traditions et sanctuaires marins d'Apollon pour les souverains hellénistiques: Ptolémée Sôter, Antigone Gonatas, puis Octave. Le culte rendu à cette divinité en particulier est une façon pour eux de marquer leur puissance en Méditerranée; celle-ci a pu être représentée sur des monnaies par le type d'Apollon assis sur un bateau ${ }^{109}$. On comprend dès lors la place qu'occupe Apollon à bord du navire: des bateaux et une ancre portent des noms en rapport avec Delphinios et Smintheus; des jas de pierre sont consacrés au dieu; Virgile place un Apollon d'or à la poupe du bateau d'Abas (Énéide X, 156-255) ${ }^{110}$.

${ }^{108}$ Stadler 1901, col. 2515, insiste sur la place élevée du dieu dans la navigation liée à la colonisation; Defradas 1954, p. 232-258 et Malkin 1987, p. 1-113 sur celle d'Apollon delphien dans la colonisation archaïque. Pausanias (I, xxxvii, 6-xxxviii, 1) évoque la fondation d'un sanctuaire par des descendants de Képhallos, originaire de l'île de Céphallénie, suite à un oracle d'Apollon delphien leur enjoignant de sacrifier à Apollon là où ils auraient vu une trière courir sur la terre - ce qui s'avéra être un serpent. Difficile d'interpréter ce texte en rapport avec le culte apollonien; au mieux peut-on dire qu'il devait s'agir d'un Pythion, situé sur la voie conduisant d'Athènes à Delphes. Le sanctuaire se situe sous le monastère de Daphni qui a récupéré un certain nombre de blocs antiques : Musti \& Beschi 1982, p. 408.

${ }^{109}$ Anson 1910-16, V p. 108, no 793, pl. XVII (tétradrachme d'argent; au droit tête de Poséidon); Göttlicher 1978, n 361c. Sur la datation et l'attribution de ces monnaies, voir infra sur le bateau d'Antigone à Délos.

110 À l'époque impériale, le bétyle d'Apollon Agyieus figure au-dessus d'une proue de navire sur des monnaies romaines impériales : Lambrinudakis \& alii 1984, 1 p. 329 et 2 p. 281. 
Dernière prérogative apollinienne : un pouvoir particulier, du moins aux époques archaïque et classique, sur les vents ${ }^{111}$. Dans le chant I de l'Iliade, Apollon Smintheus envoie la brise au bateau d'Ulysse; son sanctuaire de Chrysa est par ailleurs lié à des salines formées par les vents étésiens. Il génère également les vents favorables dans l'Hymne homérique et chez Euripide. À la manière dont les scènes sont décrites, on peut se demander si les aèdes n'ont pas voulu jouer avec l'image poétique de cordes vibrantes de la lyre évoquant le bruit du vent dans les étais et les voiles ${ }^{112}$. Les derniers vers de l'Hymne orphique consacré au dieu (XXXIV, v. v. 16-27) le rapprochent de Pan à cause des sifflements des vents. Dans plusieurs sanctuaires marins - par exemple à Zarax, à Actium Apollon est représenté en citharède.

Chronologiquement, les sources montrent une continuité de culte depuis l'époque archaïque jusque la fin de l'époque hellénistique. La plupart des sanctuaires marins du dieu remontent à une fondation ancienne. L'évolution notable durant ces siècles est le déclin du sanctuaire delphique en faveur du sanctuaire délien : à partir du $\mathrm{IV}^{\mathrm{e}} \mathrm{s}$. a.C. les offrandes réalisées dans un contexte marin s'adressent au second ${ }^{113}$. Si le culte d'Apollon marin connait un regain de vigueur à l'époque hellénistique, il ne faut pas pour autant minimiser son existence à l'époque classique, attestée à plusieurs reprises au travers des sources.

La divinité est honorée par différents groupes de fidèles. Elle reçoit souvent un culte de type collectif, officiel, pour avoir guidé un groupe de colons ou avoir fait remporter la victoire à un camp au détriment d'un autre. Mais les vers concernant Actium ou Leucade, des hameçons retrouvés dans certains sanctuaires renvoient également à des cultes privés, individuels, de la part d'humbles marins pêcheurs. Apollon présente d'ailleurs certains liens avec des poissons ${ }^{114}$; il se voit par exemple tout naturellement vouer celui nommé

${ }^{111}$ Mc Cartney, 1933, p. 4.

112 À rapprocher de la description du char-bateau des Panathénées décrit par Himerius (voir infra).

${ }^{113}$ Ceci correspond à l'historique des deux sanctuaires et à leur «vogue» successive : cf. Guide de Delphes 1991a, p. 21-22.

${ }^{114}$ Le sanctuaire littoral d'Apollon à Soura en Lycie pratique la mantique à l'aide de poissons vivant dans le creux taillé par les vagues au pied du temple d'apollon : Athénée, Deipnosophistes VIII, 333d-334e; Élien, De la nature des

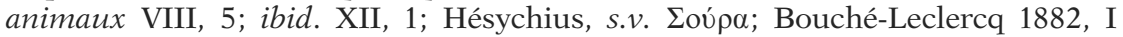
p. 152; Bodson 1978, p. 45. Signalons encore, cette fois dans le milieu étrusque, une plaque peinte archaïque du sanctuaire d'Apollon à Veio, représentant peutêtre une scène de pêche, du moins figurant un personnage entouré d'animaux 


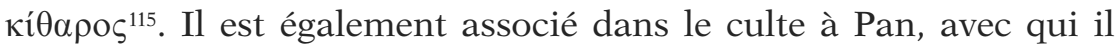
partage spécifiquement la même épiclèse Aktios ${ }^{116}$.

Mais c'est avec Poséidon qu'Apollon apparaît le plus souvent en relation, particulièrement à cause du dauphin qu'ils chérissent tous deux particulièrement ${ }^{117}$. Ce rapprochement s'explique, comme nous allons le voir, par l'affirmation d'une puissance - quoique de nature différente - portant sur une topographie similaire.

\section{POSÉIDON}

Apollon domine la mer de façon effective par la position de ses sanctuaires et par la force guerrière qu'il incarne à travers les victoires navales. Poséidon, qui sur terre est parfois associé à son neveu $^{118}$, personnifie quant à lui la domination sourde sur la mer en tant qu'élément liquide, une domination négative qu'il faut craindre et ménager.

Le cadre de ce travail ne permet pas une étude de la personnalité et du culte de Poséidon en liaison avec la mer identique à celle des autres divinités olympiennes. Outre qu'elle nécessiterait une monographie à elle seule et déséquilibrerait l'orientation de notre problématique, le culte du dieu s'avère souvent difficile à déterminer ou définir avec certitude. Très souvent dans les publications, la localisation d'un sanctuaire de Poséidon non loin de la mer, une inscription le mentionnant ou une monnaie le figurant provenant d'une cité littorale suffit à lui attribuer un culte marin. Dessiner une géogra-

marins (une raie, un dauphin, quatre poissons) : Stefani 1951, p. 138-146 et pl. XXX; Stefani 1953, p. 79 et fig. 54a-b); Lubtchansky 1998, p. 139-141 et fig. 17.

${ }^{115}$ Bodson 1978, p. 52; Athénée VIII, 306a.

${ }^{116}$ Aktios est une épiclèse qui s'adresse aussi à Pan : Théocrite, Idylle V,

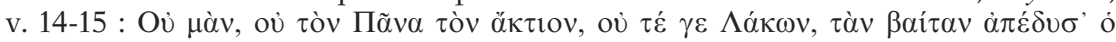

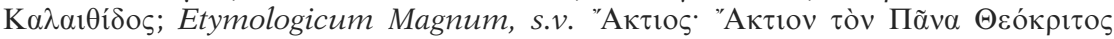

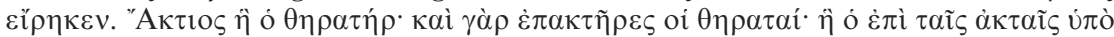

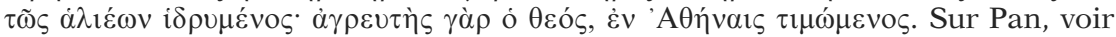
Borgeaud 1979; Cabanes 1988; Mazaubert 1937, p. 313-324.

${ }^{117}$ Apollon et Poséidon sont honorés dans des mêmes lieux de culte : ainsi par exemple à Ténare, Sounion, c'est Poséidon qui règne en maître et Apollon est l'objet d'un culte secondaire; à Calaurie on rapporte que Poséidon échangea avec Apollon la primauté sur ce lieu en échange de Delphes (Strabon VIII, 6, 14; Pausanias II, 32, 2). Sur substitution de Poséidon par Apollon, voir supra, notes concernant Apollon Delphinios.

${ }^{118}$ Detienne 1998, p. 24, 92 et 166-169. 
phie de ce culte devient dès lors très malaisé. Par ailleurs, la vogue hellénistique des scènes de genre, des cortèges de dieux, puis le rapprochement avec le Nethuns romain ${ }^{119}$ ont fait évoluer la figure du dieu au tournant de notre ère; les sources tardives se trouvent de ce fait d'un usage ambigu, car elles ne renvoient la plupart du temps qu'à un culte différent de celui de l'Antiquité grecque.

Pour ces raisons, notre approche de Poséidon se veut synthétique et surtout utile pour mesurer l'importance des différentes divinités olympiennes dans les cultes maritimes. Il ne s'agit pas tant de définir ce qu'il est, que de déceler les carences des marques de dévotion qu'on peut lui rendre et d'esquisser les grands traits du culte marin du dieu comparativement à celui des autres. Plus précisément, il s'agit de nuancer cette image lisse d'un maître de la mer vers qui s'adresse la dévotion des marins. C'est pourquoi, dans un premier temps, seront abordées les traditions référant à Poséidon tout en mettant en évidence, après d'autres, le caractère non exclusivement marin de celles-ci. Dans un second temps, seront examinés plusieurs sanctuaires à caractère marin du dieu, puis nous nous pencherons sur quelques pratiques cultuelles le concernant. Pour ces approches, seules quelques sources littéraires significatives seront évoquées, de façon à distinguer quelques éléments de définition du dieu marin ${ }^{120}$.

\section{Mythologie ET ÉPOPÉE}

\section{Théogonie}

Dès les poèmes homériques, Poséidon est présenté comme le souverain de la mer. On l'imagine alors vivant dans l'élément salé, dans une grotte marine en compagnie de son épouse Amphitrite. Il a choisi celle-ci parmi les filles de Nérée, habitant elles aussi en compagnie de leur père au fond des ondes ${ }^{121}$. De ce mariage est né

${ }^{119}$ Bloch 1985b.

${ }^{120}$ Sur Poséidon, il existe quelques études de synthèse - principalement en allemand - ainsi que des articles sur différents aspects du dieu : ils seront mentionnés au travers de notre propos. De façon générale, on consultera plus particulièrement Wüst 1953 : spécialement col. 490-491 (dieu de la tempête, de la mer et de l'eau) et col. 492-493 (dieu de la pêche); Séchan \& Lévêque 1966, p. 99116; Simon 1998, p. 58-79; Romero Recio 2000, p. 116-118.

${ }^{121}$ Hésiode, Théogonie v. 930; Ps.-Apollodore, Bibliothèque I, iv, 5. Selon certaines traditions, Poséidon aurait préféré sa sœur Thétis au sujet de laquelle il serait rentré en compétition avec Zeus, mais l'oracle prophétisant un fils de la Néréide supérieur au père les découragea tous deux : Pindare, Isthmiques VIII, 32. La demeure sous-marine de Poséidon, qui est évoquée dans l'Iliade XIII, 
Triton, autre divinité marine appartenant à ce qu'on appelle les Vieillards de la mer ${ }^{122}$ qui possède deux particularités : mi-homme mi-poisson, il détient la connaissance de l'avenir. La mer s'entrouvre pour leur donner passage et Poséidon comme les Néréides ne sont pas mouillées au contact de l'eau ${ }^{123}$.

Cette maîtrise de Poséidon sur la mer est due, selon la tradition, à un partage du monde qu'ont réalisé les trois frères Hadès, Zeus et lui-même : au premier les ténèbres, au deuxième le ciel, au troisième la mer ${ }^{124}$; ou, pour les Crétois, il l'avait reçu de Kronos luimême (Diodore V, 69, 4). Des érudits antiques voyaient par conséquent dans le trident le symbole de cette troisième partie de l'univers (Plutarque, Isis et Osiris, 381e) et rattachaient à cette étymologie les noms de l'épouse et du fils du dieu.

Conformément à ces légendes, Poséidon est représenté dans l'iconographie avec son attribut, le trident ${ }^{125}$, et souvent dans un cortège marin accompagné d'Amphitrite et autres divinités ou démons marins (ainsi dans l'Énéide V, 816-826) ${ }^{126}$. Il est également souvent figuré avec un dauphin au pied ou à la main, ce que les Anciens expliquaient par l'affection qu'il porte à cet animal (Hygin, Astronomie II, 17) ${ }^{127}$. Comme Aphrodite, le dieu est perçu comme évoluant dans une sphère marine : son entourage, ses lieux de vie, ses représentations figurées renvoient à l'univers maritime ${ }^{128}$.

v. 10 ss. et dans Euripide, Troyennes, v. 1-3, est située non loin de Samothrace (Séchan 1955, p. 32-34).

${ }^{122}$ Sous cette dénomination sont désignés Triton, Nérée, Phorcys, Protée et Glaucos. Sur leurs spécificités, voir Briquel 1985, p. 141-158; M. Detienne 1967. Dès Homère, ces Vieillards de la mer sont mis en liaison avec Poséidon : d'après l'Odyssée I, v. 68 ss., Poséidon s'unit à la fille de Phorcys, la nymphe Thoossa et en naquit le Cyclope Polyphème; dans l'Odyssée IV, v. 380 ss., Protée est présenté comme un vassal de Poséidon.

${ }^{123}$ Iliade, loc. cit. La faculté de ne pas être mouillé apparaît à plusieurs reprises dans la littérature à propos des divinités marines secondaires : voir Iliade VIII, 65; Euripide, Andromaque, v. 1259. Sur les phénomènes d'immersion et de sortie de l'eau, voir Bader 1986a.

${ }^{124}$ Iliade XV, v. 185-199. Dans ces vers, Poséidon revendique cependant son importance vis-à-vis de son frère sur la mer comme sur la terre.

${ }_{125}$ Moreno 1976; Mylonopoulos 2003, p. 361-364.

${ }^{126}$ Simon 1994; Schefold 1981, p. 248-258.

${ }^{127}$ Le Poséidon posant le pied sur un dauphin correspond au type créé par Lysippe au IVe s. a.C., tandis que Scopas réalisa un groupe réunissant Poséidon, Amphitrite et les Néréides (Collignon 1883, p. 203 ss.).

${ }^{128}$ Burkert 2011, p. 194, qui insiste sur le caractère marin du dieu, souligne qu'il est ainsi représenté dans le chant XIII de l'Iliade (v. 17-31) comme rejoignant depuis l'Olympe son élément marin. 


\section{Interventions marines}

Poséidon comme dieu marin intervient cependant très peu dans les récits héroïques, si ce n'est dans l'Odyssée où il constitue le rouage essentiel de l'épopée : c'est lui qui empêche Ulysse de rentrer paisiblement chez lui à Ithaque. Dans l'Iliade, il agit comme «ébranleur de la terre», mais dans un contexte uniquement terrestre ${ }^{129}$. Lors du retour du héros, il déchaîne vagues et rafales afin de provoquer naufrages et mort d'hommes (Odyssée V, v. 282 ss.). En revanche, la navigation de Télémaque ne le voit pas apparaître, ni dans un sens positif ni dans un sens négatif. Le dieu semble uniquement concentré sur celle d'Ulysse dont il fait une affaire personnelle. Chez Euripide (Troyennes, v. 75-94), Poséidon, à la demande d'Athéna, bouleverse les eaux afin de contrarier le chemin de tous les Achéens en Méditerranée, notamment dans l'archipel des Cyclades. Loin d'être un auxiliaire de la navigation, il entrave de manière violente les traversées des héros.

En tant que dieu de la mer, il peut agir comme celui qui a le pouvoir de transformer un humain en divinité marine : ainsi pour Castor et Pollux (Hygin, Astronomie II, 22), pour Ino et Mélicerte (Ovide, Métamorphoses IV, v. 523-540). Il intervient également indirectement en faveur de l'un de ses fils, Thésée, quand celui-ci demanda à son père de prouver ses origines divines lors du voyage vers la Crète (Bacchylide, Dithyrambe III). L'histoire est connue : il est cependant notable que Thésée, que l'on décrit emmené par des dauphins jusqu'à la demeure sous-marine de Poséidon, y soit reçu et honoré par Amphitrite ${ }^{130}$. Le dieu, absent de la tradition poétique et de son illustration iconographique, apparaît seulement sur les vases pour symboliser la reconnaissance filiale de Thésée ${ }^{131}$.

Dans ces traditions mythologiques, Poséidon est affirmé comme une force marine : il détient la puissance de la mer et peut ainsi en contrôler l'espace. C'est lui qui accepte ou non le passage des hommes ou demi-dieux dans son univers : ainsi pour Ulysse, Thésée ou Ino.

${ }^{129}$ Par exemple Iliade XX, v. 57 ss.

${ }^{130}$ Dans le périple des Argonautiques, la légende du lac Triton et l'apparition du char de Poséidon est elle aussi uniquement imputée à Amphitrite : Apollonios de Rhodes, Argonautiques IV, v. 1325-1392.

${ }^{131}$ Ce mythe de Thésée est évoqué également par Pausanias I, xvii, 3. La célèbre coupe d'Euphronios (Louvre inv. G104) ignore ainsi Poséidon. En revanche, une série de vases montre Thésée et le fils de Kronos se serrant la main : signe d'accord entre le dieu et le héros (Nadal 2007, p. 162-166). 


\section{Complexité du dieu}

À cette représentation cohérente du dieu dans un univers marin, s'opposent de nombreux récits ou traditions locales qui attribuent à Poséidon d'autres prérogatives - maître des mouvements telluriques, des torrents et du cheval -, d'autres lieux de prédilection spécifiquement terrestres ${ }^{132}$, et la paternité de nombreux bâtards ${ }^{133}$. À ce sujet, F. Vian a mis en évidence les liens qui le rattachent avec tous les génies des passes et des défilés : soit par filiation soit par culte commun, ou encore par leur meurtre ${ }^{134}$. Cette double personnalité du dieu est affirmée dès l'Hymne homérique à Poséidon (v. 5 et

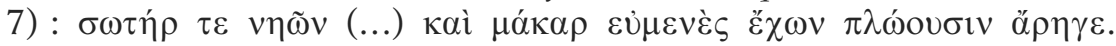
L'ébranleur de la terre et de la mer, dompteur de chevaux et sauveur de navires possède ainsi un double privilège. Dans le théâtre attique de l'époque classique, on le célèbre à la fois pour les chevaux et la puissance de la mer (Sophocle, Edipe à Colone, v. 707-719) ${ }^{135}$.

L'origine de cette complexité est expliquée de la façon suivante : Poséidon ne s'est intéressé à la mer que tardivement ${ }^{136}$. Son nom apparaît sur des tablettes mycéniennes et serait à mettre en relation avec un culte uniquement chtonien; ce n'est qu'au contact du monde ionien qu'il aurait pris des prérogatives marines. C'est ainsi que l'on explique en particulier sa paternité de plusieurs géants. En Attique, il se serait adapté à l'histoire de la cité, passant dans l'iconographie des chevaux et cavaliers à la marine ${ }^{137}$.

Néanmoins, à l'époque homérique, le caractère maritime du dieu est déjà bien affirmé même s'il n'est pas exclusif, de même que la légende lui attribuant la suprématie sur les eaux.

${ }_{132}$ Par ex. Burkert 2011, p. 192-197. Voir notamment l'importance du culte de Poséidon en Arcadie, non lié à des préoccupations maritimes : Jost 1985, p. 279-296 le rattache finalement aux «forces essentielles de la nature».

${ }^{133}$ Beschaouch 1985, p. 419-424 met également en évidence un Poséidon lié à la fertilité, ce qu'il rattache à la personnalité d'un dieu de l'eau au sens large : la mer mais aussi les sources.

${ }_{134}$ Vian 1952, p. 153-154.

${ }^{135}$ Le même thème est repris par Aristophane, Cavaliers, v. 551 ss. Séchan \& Lévêque 1966, p. 105; Parker 2011, p. 94.

${ }^{136}$ Cette thèse a été développée par Schachermeyr 1950 et acceptée par de nombreux savants : ainsi Séchan \& Léveque 1966, p. 105-106 et 109-110; Dumont 1975, p. 75; Bloch 1985a; Bloch 1985b.

${ }^{137}$ Nadal 2007, s'appuyant sur le nombre de vases attiques le représentant comme dieu hippique et marin. 
QUELQUES SANCTUAIRES MARINS

\section{Attique}

Le culte de Poséidon sur l'Acropole est mis en relation avec le souvenir de sa lutte avec Athéna pour la domination de l'Attique et un point d'eau sur le rocher qu'on appelle thalass $a^{138}$. Des fêtes de Poseidea à Athènes célèbrent le dieu durant le mois de Poseideôn c'est-à-dire en décembre ${ }^{139}$. Hormis le nom de la thalassa, rien ne permet de croire que Poséidon recevait sur l'Acropole un culte marin. En réalité, les prérogatives de la divinité dans ce domaine semblent se concentrer pour l'Attique dans le sanctuaire de Sounion, où il surpasse cette fois en importance celui voisin d'Athèna (fig. 8) ${ }^{140}$.

Le hiéron de Poséidon au cap Sounion ${ }^{141}$ est sans conteste le plus connu des sanctuaires marins. Le temple qui surplombe le promontoire, se dressant en figure de proue de l'Attique, sert encore aujourd'hui d'amer pour la navigation dans cette zone ${ }^{142}$. Peu de sources antiques le mentionnent (Aristophane, Cavaliers, v. 560; id., Oiseaux, v. 869; Skylax in GGM I p. $46 \mathrm{n}^{\circ}$ 57), mais son attribution est assurée par des inscriptions ${ }^{143}$ trouvées in situ. Les fouilles archéologiques conduites au début du siècle permettent de reconstituer l'histoire du sanctuaire.

L'occupation du promontoire est ancien - il recèle des tombes de l'époque préhistorique -, mais l'existence d'un culte n'est attestée que depuis le VII ${ }^{\mathrm{e}}$ s. a.C. Pour l'époque archaïque, sont dressées en plein air des offrandes prestigieuses comme les fameux kouroi de marbre ${ }^{144}$, dont l'effet devait être saisissant pour les navigateurs

${ }^{138} I G \mathrm{II} / \mathrm{III}^{2}, 1146$; $\mathrm{III}^{2}$, 5058; Pausanias I, xxvi, 5.

${ }^{139}$ Deubner 1932, p. 215; Parke 1977, p. 97-103.

${ }^{140}$ Garland 1987, p. 104 et 132 note à juste titre l'absence de Poséidon parmi les cultes du Pirée et l'explique par l'abondance de divinités protectrices de la navigation dans la cité. Seule une stèle paraît lui être consacrée (SEG XXVI, 72, 1. 46-47 datée de 375/4, trouvée sur l'Agora d'Athènes).

${ }^{141}$ Cette présentation rapide du sanctuaire de Poséidon est faite d'après plusieurs petites monographies qui se répètent les unes les autres : Stais 1900; Stais \& Orlandos 1917; Dinsmoor 1971; Thémélis 1974; Davaras 1979; Travlos 1988 , p. 404-407 et fig. 508-527. Voir par ailleurs supra p. 35 ss. à propos du sanctuaire d'Athéna à Sounion.

${ }^{142}$ Semple 1927, p. 356.

${ }^{143}$ IG II/III'2, 1270; 1300; Peek 1934, p. 35-39. Sinn 1992 attribue le sanctuaire à la fois à Poséidon et Athéna, considérant que l'ensemble des sources littéraires est ambigu.

${ }^{144}$ D'après les fragments, on estime à 17 le nombre de ces kouroi, datés des années 615-590 a.C.; aujourd'hui, ils sont conservés au Musée national d'Athènes. 


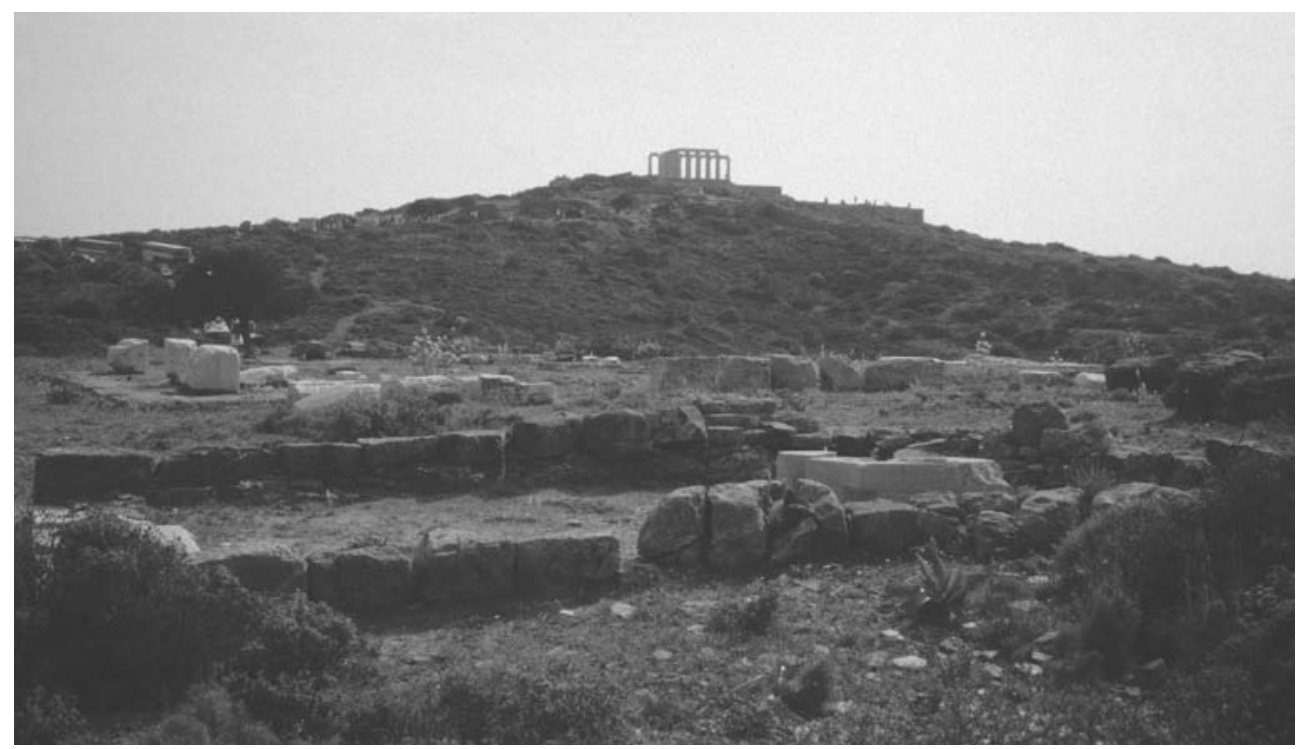

Fig. 8 - Sanctuaires d'Athéna (au $1^{\text {er }}$ plan) et de Poséidon à Sounion (Photo de l'auteur).

passant au large. Au tout début du Ve s., est construit un temple en tuf que les Perses détruisent encore inachevé lors de la Deuxième Guerre médique; il est alors temporairement remplacé par un naiskos. Puis le sanctuaire se développe à nouveau à partir du $\mathrm{V}^{\mathrm{e}} \mathrm{s}$. a.C., où il prend définitivement le pas sur celui voisin d'Athéna. Le téménos est englobé à l'intérieur d'une enceinte munie d'une dizaine de tours qui couvre une surface de trois hectares et demi. En effet, durant la guerre du Péloponnèse, le lieu revêt un rôle militaire de premier plan : ces remparts construits en 412 a.C. sont renforcés à deux reprises au cours du $\mathrm{III}^{\mathrm{e}}$ a.C. Le temple, daté des années $444 / 440$, se situe au sud, sur l'emplacement du premier édifice, à l'extrémité de la pointe à $60 \mathrm{~m}$ environ au-dessus de la mer. Il est de bonne taille: environ $31 \mathrm{~m}$ sur 13,50 m. Lui furent adjoints des propylées flanquées de deux portiques. À l'intérieur de la forteresse, se trouvent des bâtiments d'habitation privés et militaires, des puits et citernes, ainsi que deux loges à bateaux de l'époque hellénistique. Le sanctuaire semble être tombé en désuétude au tournant du millénaire. Au II ${ }^{e}$ s. p.C., Pausanias (I, i, 1) ne fait que le signaler de façon erronée.

Des fêtes en l'honneur du dieu étaient célébrées à Sounion, comme en témoigne une inscription qui impose une taxe aux 
bateaux mouillant dans la zone durant cette période ${ }^{145}$. Par ailleurs, selon Lysias (Discours XXI, 5), des régates ont lieu à Sounion à l'époque classique, tandis qu'Hérodote (Enquête VI, 87) mentionne au promontoire une fête quinquennale à laquelle les aristoi des Athéniens se rendaient à bord d'un bateau de théorie ${ }^{146}$. Mais aucun des deux auteurs n'explicite en l'honneur de quel dieu celle-ci avait lieu et il n'est pas assuré que les deux témoignages correspondent à une même réalité; pourtant la plupart des commentateurs les considèrent l'une et l'autre dédiées à Poséidon ${ }^{147}$. De la même manière, lorsque les Grecs après Salamine consacrèrent un des bateaux pris sur l'ennemi à Sounion (Hérodote, Enquête VIII, 121-122), celui-ci a peut-être (voir infra p. 356 s.) été consacré au sanctuaire du dieu au trident.

Sounion s'affirme comme un sanctuaire de grande importance, tant par le culte qui y est rendu que par son rôle dans la vie militaire de l'Attique. Sa situation privilégiée en fait un avant-poste précieux pour surveiller et dominer cette partie de la mer Égée. L'épiclèse de la divinité ne nous est pas connue. Une scholie à Aristophane (Acharniens, v. 682 = voir corpus p. 533) affirme que les Athéniens honoraient Poséidon Asphaleios pour une navigation sûre ${ }^{148}$. Même si l'on ne peut sans d'autres sources attribuer ce nom au Poséidon de Sounion, ce témoignage montre cependant la place du dieu dans la religion des marins athéniens. Il est plusieurs fois mentionné dans le théâtre classique en liaison avec la ville d'Athènes et sa flotte ${ }^{149}$. Il est également associé à la victoire comme le montre une peinture attique. Parallèlement à l'iconographie d'Athéna, un cratère à colonnettes du peintre de Pan montre Poséidon brandissant un aphlaston : l'image doit constituer une allusion directe à la victoire de la Seconde Guerre médique, ce qui correspondrait tout à fait à la datation du vase entre 480 et 460 a.C. ${ }^{150}$.

\section{Ténare}

Le cap Ténare, finistère du Péloponnèse au sud et promontoire redouté par les navigateurs ${ }^{151}$, est consacré à Poséidon. Il est égale-

${ }^{145}$ SEG X, 1949, p. 156, 1. 15-24. Vélissaropoulos 1980, p. 220-221.

${ }^{146}$ Dinsmoor 1971, p. 6. Le passage d'Hérodote évoque un épisode de la rivalité entre Athènes et Égine à la fin du $\mathrm{VI}^{\mathrm{e}} \mathrm{s}$. et au début du V $\mathrm{V}^{\mathrm{e}} \mathrm{s}$.

${ }^{147}$ Par exemple Deubner 1932, p. 214-215.

${ }_{148}$ Vélissaropoulos 1980, p. 89.

${ }^{149}$ Par ex. Aristophane, Thesmophories, v. 312-330: associé avec les Néréides.

${ }_{150}$ Wade-Gery 1933; Beazley 1931, nº 4.

${ }^{151}$ Semple 1927, p. 356. 
ment considéré comme possédant une entrée pour les Enfers : c'est là qu'Héraclès aurait ramené Cerbère. Peu avant l'extrémité de la pointe, à l'est, une petite crique marque l'emplacement du sanctuaire. Le hiéron consiste en une grotte devant laquelle se trouve la statue de culte (Pausanias III, xxv, 4) ${ }^{152}$. C'est à cet endroit également qu'Arion déposa la statue rappelant son sauvetage par un dauphin (voir supra p. 155 s.); seule une source tardive l'évoque comme une offrande à Poséidon ${ }^{153}$. Les fouilles ont confirmé le témoignage du Périégète. À l'origine, existaient trois lieux distincts : un naos, une grotte et un psychopompeion; mais à l'époque de Pausanias, le sanctuaire est en déclin ${ }^{154}$. Ces aménagements et le travail d'Héraclès mettent en évidence le caractère chtonien du dieu à Ténare ${ }^{155}$. Comme l'indiquent ses trois épiclèses de Tainarios, Pontios (Eupolis, Fgt 140) et Asphaleios, le souverain de la mer n'était pas seulement honoré sur un tel promontoire pour ses prérogatives maritimes.

\section{Corinthe}

Poséidon occupe une place essentielle parmi les cultes de Corinthe, mais les sources font défaut pour en appréhender les spécificités. La description tardive du sanctuaire de l'Isthme ${ }^{156}$ par Pausanias (II, i, 7-9) n'est précédée d'aucune autre. À cette date, la présence d'autres divinités marines dans le sanctuaire est frap-

${ }^{152}$ Strabon (VIII, 5, 1) rapporte des informations analogues : le promontoire, un sanctuaire de Poséidon et la caverne d'entrée des Enfers. Pausanias évoque par ailleurs (IX, xxiv, 5-6) que le dieu de Ténare, irrité parce que des suppliants lacédémoniens avaient été arrachés de son autel et mis à mort, dévasta la ville de Ténare de fond en comble. Autres sources : voir Mylonopoulos 2003, p. 228-229 et 282. Gianfrotta 2005, p. 28 range le sanctuaire parmi les sanctuaires maritimes "grottes-refuges».

${ }^{153}$ Élien, De la nature des animaux XII, 45 rapporte ainsi le texte de la dédicace attribuée à Arion lui-même; Wachsmuth 1967 note 247.

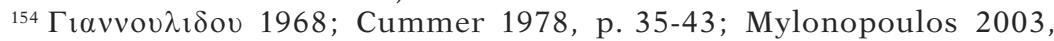
p. $230-237$.

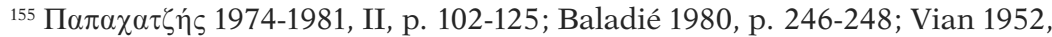
p. 13; Schumacher 1993; Mylonopoulos 2003, p. 238-239. La crique qui se trouve devant le sanctuaire du dieu - dont il ne reste presque rien - constitue un très beau mouillage naturel; par ailleurs toute la pointe est très rocailleuse et déserte. L'extrémité de celle-ci, difficilement accessible depuis la terre - au moins une heure de marche depuis le sanctuaire sur un sol malaisé - et aux allures de bout du monde, ne pouvait recevoir un hiéron : c'est de ce côté que se trouvait l'entrée des Enfers, non loin du phare actuel. On comprend dès lors le choix de l'emplacement du sanctuaire, non sur la pointe même, mais dans un endroit protégé, accessible par mer et aussi par une voie terrestre.

${ }^{156}$ Les fouilles du sanctuaire de l'Isthme par les Américains ont fait l'objet d'une double publication: Broneer 1971-73. Pour un compte-rendu rapide des fouilles du sanctuaire : Gebhard 1993; Broneer 1976; Roux 1957, p. 91 ss.; Mylonopoulos 2003, p. 160-198. Le premier état du temple remonte au début du VII ${ }^{\mathrm{e}}$ s. a.C. 
pante : Amphitrite, Néréides, Ino, Mélicerte ${ }^{157}$, Triton. Quelques vers de Pindare (Isthmiques VI, v. 1-6) montrent cependant que les filles de Nérée étaient associées à son culte corinthien dès le $\mathrm{V}^{\mathrm{e}} \mathrm{s}$. a.C. Toujours d'après le Périégète (II, ii, 3), le dieu est présent dans les ports de Corinthe, avec un sanctuaire au Léchaion - avec l'épiclèse toponymique de Léchaion (Callimaque, Hymne IV, v. 271) - et une statue sur le môle de Cenchrées ${ }^{158}$.

Quelques offrandes anciennes montrent que Poséidon était vénéré à l'époque archaïque en rapport avec la navigation. La nef Argô lui fut consacrée dans son sanctuaire de l'Isthme (voir infra, p. 353 s. $)^{159}$; un grand nombre de pinakes archaïques retrouvés à Penteskouphia le figurent dans la plupart des exemplaires avec trident et poisson à la main ${ }^{160}$, mais offrent aussi des représentations de bateaux (voir infra, p. 398 s.). Par ailleurs, Plutarque (Propos de table V, 675d-676d) explique la consécration du pin à Poséidon dans l'isthme car c'est le bois dont on fait les bateaux. Le matériel archaïque du sanctuaire comprend également des coquillages et du corail (voir infra p. 504).

\section{Îles de la mer Égée}

Le culte de Poséidon en relation avec la mer semble particulièrement actif dans ce bel espace insulaire. À Mykonos, il est vénéré comme Phykios d'après le nom des algues; ce sont alors les pêcheurs qui financent son culte par une taxe sur la pêche ${ }^{161}$. À Thasos, le dieu possède un sanctuaire très proche du port de commerce et du port fermé militaire, d'un accès facile pour les marins débarquant sur le rivage de l'île ${ }^{162}$. À Tinos, un sanctuaire honorait le frère de Zeus en association avec Amphitrite sur le bord de mer $^{163}$. Les Rhodiens expliquent le culte marin de Poséidon dans

${ }^{157}$ Mélicerte-Palaimon recevait un culte chtonien dans le sanctuaire de l'Isthme, dans un bâtiment circulaire : voir notamment Robert 1939. Mais il est difficile de dater l'origine de ce culte, attesté pour l'époque romaine.

${ }^{158}$ Mylonopoulos 2003, p. 198-201 et 145-148.

${ }_{159}$ Broneer 1958, p. 84-85 en tire l'hypothèse que les jeux Isthmiques ont pu comporter des régates.

${ }^{160}$ Corinthe, Inv. F452, F460, F471, F477, F479, F485, F755, F765, F906. Simon 1994,1 p. $456-458$ et 2 p. 359-361. Un deuxième groupe de pinakes le représente en char accompagné d'Amphitrite. Forsén 2004, p. 293-295.

${ }^{161}$ Sokolowski 1969, n' 96 ; Bodson 1978, p. 50; Icard \& alii, p. 386.

${ }^{162}$ Bon \& H. Seyrig 1929; Grandjean \& Salviat 2000, p. 52-57 (ports), 96-98 (n 58 : sanctuaire), 230 et fig. 12,52 . Le sanctuaire ne doit pas remonter au-delà du $\mathrm{IV}^{\mathrm{e}} \mathrm{s}$. a.C. Des hameçons trouvés durant la fouille du sanctuaire pourraient correspondre à des offrandes au dieu.

${ }^{163}$ Étienne \& Braun 1986. 
leur île par ses amours avec Halia, dont Rhodes serait le fruit (Diodore de Sicile V, 55); son sanctuaire aurait été fondé par Cadmos, comme ex-voto après une navigation difficile (Diodore de Sicile $\mathrm{V}, 58)^{164}$. À Lesbos, c'est un rocher consacré à la divinité qui est rattaché selon la tradition à l'origine même de la ville (Plutarque, Banquet des sept sages, 163b-d). En effet, les colons reçurent comme oracle de sacrifier, une fois arrivés, un taureau à Poséidon et une jeune fille aux Néréides. La vierge désignée fut sauvée grâce à l'intervention d'un jeune homme nommé Enalos, épris d'elle. Celui-ci justifia ses dires par un prodige : alors qu'une vague gigantesque menaçait l'île, Enalos l'affronta, suivi de poulpes dont l'un apporta au sanctuaire du dieu cette grosse pierre. Cette légende, qui n'est pas sans présenter des similitudes avec le saut de Thésée - saut dans l'eau, dauphins qui accompagnent les héros, preuve à fournir de ses liens avec la mer -, montre un Poséidon honoré communément avec les Néréides et un culte associé à des éléments négatifs: sacrifice d'un taureau associé à celui d'une jeune fille, vague déferlante.

À Délos, le dieu est vénéré sous l'épiclèse de Nauklarios dans une inscription du I ${ }^{\text {er }}$ S. a.C. ${ }^{165}$ Mais il n'occupait qu'un rôle secondaire dans la religion de l'île, même s'il y était honoré sous six épiclèses différentes ${ }^{166}$. Il possédait un téménos proche de la mer, de petite taille, dont l'existence n'est pas attestée avant le III ${ }^{\mathrm{e}}$ s. a.C. et n'est plus mentionnée après le milieu du $\mathrm{II}^{\mathrm{e}} \mathrm{s}$. a.C. ${ }^{167}$. Des fêtes étaient célébrées en son honneur dans le mois qui portait son nom, ce qui laisse supposer cependant un culte plus ancien ${ }^{168}$. En revanche, son

${ }^{164}$ Sur le culte de Poséidon à Rhodes, voir Morelli 1959, p. 167 ss.; Vélissaropoulos 1980, p. 89; Bonnet 1988, p. 375-376 (signe de présence phénicienne).

${ }^{165}$ Roussel \& Hatzfeld 1909; Vélissaropoulos 1980, p. 89; Duchêne \& Fraisse 2001, p. 159.

${ }_{166}$ Bruneau 1970a, p. 257-267, qui critique par ailleurs un certain nombre de conclusions de Gallet de Santerre 1958, p. 160 ss. Les cinq autres épiclèses sont les suivantes : Asphaleios, Orthosios, Théméliouchos, Aisios, Hippègétès; elles ne paraissent présenter que peu de rapport avec la mer - sauf à rattacher la première au culte athénien cité supra (voir note 36 p. 33 et p. 178).

${ }^{167}$ Duchêne \& Fraisse 2001 estiment qu' «un autel devait suffire à célébrer le dieu».

${ }^{168}$ Ces fêtes célébrées en décembre comprenaient des sacrifices de taureaux ainsi que des jeux dotés de prix; Durrbach 1905, p. 524-531 (n 179) supposait qu'il s'agissait de régates, ce que Bruneau 1970a, p. 262 refuse de croire étant donné l'état de la mer à Délos en cette saison. Selon ce dernier, le culte de Poséidon à Délos reposerait essentiellement sur l'attribution au dieu de la fixation de l'île (Hygin, Fabulae 140; Virgile, Énéide III, v. 73-77; Stace, Thébaïde III, v. 439; Anthologie grecque IX, 100, v. 2; Nonnos, Dionysiaques XXXIII, v. 337 ss.) : il serait la divinité de la stabilité de la terre et des assisses de l'île. Robertson 1984 qui analyse l'ensemble des fêtes de Poséidon se déroulant à la 
culte marin est bien affirmé de la part des étrangers : les Phéniciens de Tyr, Bérytos et Ascalon l'honoraient parfois en association avec Aphrodite-Astarté ${ }^{169}$.

\section{SACRIFICES ET OFFRANDES MARINES}

\section{Sacrifices de taureaux}

La littérature mentionne de nombreux sacrifices taurins à Poséidon effectués dans le cadre d'une navigation ${ }^{170}$. Le premier apparaît dans l'Odyssée (III, v. 5-12) l71 $^{17}$ les habitants de Pylos lui offrent sur la plage de noirs taureaux lorsque survient le bateau de Télémaque. Jason opère une même action, lors de sa traversée du Bosphore, sur un autel déjà existant (Pindare, Pythiques IV, v. 360371) : sans doute celui des Douze Dieux ${ }^{172}$. Dans une épopée de la fin du I ${ }^{\text {er }}$ s. p.C., Achille offre un tel animal en sacrifice au bord du rivage avant de s'embarquer (Stace, Achilléide II, v. 12-22). Alexandre, lors de ses expéditions maritimes prend garde de ne pas oublier le dieu (Arrien, Anabase I, 11, 6-7, d'après les témoignages de contemporains) ${ }^{173}$. Ainsi, au départ de son expédition, lors de la traversée de l'Hellespont, il réalise à bord un sacrifice taurin à Poséidon et aux Néréides. Plus tard, avant l'embarquement de la flotte sous le commandement de Néarque, le frère de Zeus figure

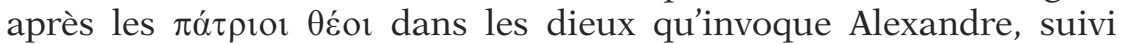
d'Amphitrite et des Néréides (Arrien, Indica XVIII, 11-12); lorsque la jonction entre l'armée de terre et la flotte s'effectue après des moments difficiles, Poséidon, bien qu'appelé avec d'autres divinités marines, n'est cité qu'après elles (Arrien, Indica XXXVI, 3).

Euripide décrit avec force détails un sacrifice de ce type réalisé en mer (Hélène, v. 1581 ss.). La bête est soulevée et portée à bord, puis égorgée de façon à ce que son sang tombe dans la mer. Il

même période dans le monde grec - particulièrement à Délos et Athènes conclut sur un culte de la fertilité dans lequel Poséidon est souvent associé à Déméter; contra : Romero Recio 2010, p. 113-114.

${ }^{169}$ Bruneau 1970a, p. 266.

${ }^{170}$ Simon 1998 , p. 58-79 les analyse comme des sacrifices expiatoires aux puissances naturelles que représente le dieu.

${ }^{171}$ Un autre est évoqué dans le même chant v. 178 ss. au sud de l'Eubée à Géraistos (sur ce culte, voir Schumacher 1993 et Paul 2013, p. 138).

${ }^{172}$ Vian 1974, p. 95-96; sur le Hiéron des Douze Dieux, voir également supra p. $92 \mathrm{~s}$.

${ }^{173}$ Vélissaropoulos 1980, p. 89. 
semble que le dieu au trident soit le seul en l'honneur de qui aient été réalisés des sacrifices sanglants de cette sorte ${ }^{174}$.

\section{Offrandes marines}

Quelques offrandes marines sont attestées pour lui aux époques archaïques et classiques. Outre Argô et les pinakes de Corinthe, deux bateaux grandeur nature lui sont consacrés dans le contexte de la guerre du Péloponnèse (Thucydide, Guerre du Péloponnèse II, 84, 4; 92, 5; Diodore, Bibliothèque historique XII, 48, 1) (voir infra, respectivement p. 353 s., 398 s. et 358). À Lindos, c'est un gouvernail qu'il se voit offrir en association avec Athéna.

Le dieu reçoit des offrandes en rapport avec la pêche ${ }^{175}$. À Halai, le

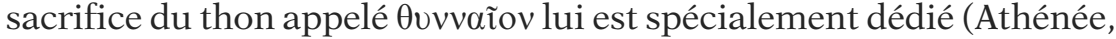
Deipnosophistes VII, 297e) ${ }^{176}$. De nombreuses épigrammes du livre VI de l'Anthologie Palatine (VI, 4 de Léonidas de Tarente; 30 et 69-70 de Macédonios; 38 de Philippe de Thessalonique; 164; 349 de Philodème) indiquent différents présents de la part de marins et pêcheurs qui l'honorent, souvent avec des divinités mineures ${ }^{177}$. À Delphes, les Corcyréens consacrent un taureau à Poséidon et Apollon en remerciement d'une pêche prodigue (Pausanias X, 9, 3-4)178. À Cyzique, il est célébré avec Aphrodite par un groupe s'occupant du fermage de la pêche (voir supra p. 125). Un poisson votif archaïque en bronze, avec une dédicace au dieu POHOIDANOS, figure parmi le matériel trouvé dans la zone du sanctuaire de Poséidon Amyklaios à Sparte ${ }^{179}$.

\section{ANALyse}

La violence de la mer

Le culte marin de Poséidon s'exerce le plus souvent sur des promontoires ${ }^{180}$ ou sur des îles. Cela renvoie effectivement à sa

${ }^{174}$ Glotz 1904, p. 13-14; Wachsmuth 1967, p. 66 ss. et 127 ss.

175 Romero Recio 2000, p. 74-76; Icard \& alii 2011, p. 379-382.

${ }^{176}$ Ailleurs, Athénée (VIII, 346c) indique que le thon est un attribut du dieu. Mazaubert 1937, p. 321 et 324; Schlosser 2014, p. 275.

${ }^{177}$ Ajoutons également un poème de Théocrite, Les pêcheurs (v. 54-55), qui associe Poséidon et Amphitrite à ce secteur d'activité.

${ }^{178}$ Daux 1936, p. 77-78; Bodson 1978, p. 52-53; Somville 1984, p. 20 voit dans cette consécration une allusion à la double nature du dieu, à la fois tellurique et marin.

${ }^{179}$ Sparte, Mus. 16678. Mylonopoulos 2003, p. 227 et 371; Olmos \& MorenoConde 2012, p. 423 n $^{\circ} 116$ a et pl. 50.

${ }^{180}$ Wachsmuth 1967, p. 398; Detienne 1985, p. 145-147 considère l'implantation des sanctuaires de Poséidon sur les promontoires comme une manifestation 
toute-puissance sur la mer, telle qu'elle est admise par tous. Platon (Critias 116c-117a), dans sa description de la cité idéale d'Atlantide, imagine son sanctuaire poliade consacré à Poséidon et en fait un lieu de glorification du pouvoir des gouvernants. Cependant, cette puissance s'affirme de manière le plus souvent négative, dans la violence des éléments. Le dieu se caractérise principalement par sa faculté de déchaîner les flots de la mer, de déclencher les tempêtes ${ }^{181}$.

Dans cette optique, on le craint beaucoup plus qu'on ne le vénère $^{182}$ : les sacrifices qu'on lui adresse sont réalisés dans l'intention de se le concilier, de ne pas provoquer son ressentiment qui pourrait avoir de funestes conséquences. Il est ainsi souvent associé aux catastrophes, à la mort, aux noyades ${ }^{183}$, au raz-de-marée ${ }^{184}$ et aux monstres marins ${ }^{185}$.

Ainsi, les Perses restés en Grèce après le désastre de Salamine auraient subi à une autre reprise le courroux de Poséidon. Près de Potidée, la mer se retira à tel point que les Barbares décidèrent de se rendre à pied par cet espace découvert dans la presqu'île de Pallène. Alors qu'ils se trouvaient en route, la mer remonta plus haut que son niveau précédent et les soldats périrent noyés ou tués par les habitants du pays venus en barque (Hérodote, Enquête VIII, 129). Le prodige est attribué à Poséidon, courroucé de la profanation de son sanctuaire potidéate.

C'est sans doute pour cette raison que son nom est le plus souvent associé à celui d'autres divinités plus bénéfiques ${ }^{186}$. La majorité de ses attestations cultuelles l'invoque en compagnie d'Amphi-

de sa nature sauvage et turbulente (notion reprise par Parker 2011, p. 90, pour définir le mode d'activité du dieu).

${ }^{181}$ Ceci a été bien mis en évidence par Detienne 1970, p. 153-154, 156, 164-167, et par Detienne \& Vernant 1974, p. 201-215, 221-222, 235-241. Voir également Mc Cartney 1933, p. 3; Pirenne-Delforge 1994, p. 435-436; Bouché-Leclercq 1882, p. 363-365.

${ }_{182}$ Séchan \& Lévêque 1966, p. 103. Pour Burkert 2007, p. 197, Poséidon, dieu grave, appartient à l'ancienne génération et reste "une force incarnée de la nature».

${ }^{183}$ Par exemple Strabon (VIII, vii, 1-2) raconte que, suite à une victime noyée, dit-on, par Poséidon, on offre des dons au dieu pour apaiser son courroux; Pausanias VIII, vii, 1-2; Appien, Mithridate 70; Plutarque, Conviv. VII, 20; Souda, s.v. $\pi \varepsilon \rho i ́ \psi \eta \mu \alpha$.

${ }^{184}$ Bloch 1984, p. 115-117. Cf. le culte de P. Asphaleios à Cyzique : Thély 2014.

${ }^{185}$ Pseudo-Apollodore, Bibliothèque II, v, 9; Valerius Flaccus, Argonautiques II, v. 470; Achille Tatios, Les aventures de Leucippé et Clitophon III, 6 qui raconte la légende d'Andromède affirme que le monstre fut envoyé par Poséidon; cf. son intervention dans la légende de la mort d'Hippolyte.

${ }^{186}$ Wüst 1953, col. 457-478 recense les divinités marines mineures mises en relation avec Poséidon, ainsi que de manière générale ses amours et ses enfants. 
trite $^{187}$, des Néréides ${ }^{188}$, d'Aphrodite. La dédicace hellénistique de Failaka dans le golfe Persique l'associe à Zeus Sôter et Artémis (voir supra p. 96 et infra p. 212 ${ }^{189}$, et dans le Bosphore, au niveau du Hiéron de Chalcédoine de la rive asiatique, son culte semble se juxtaposer à celui des Douze Dieux et à celui de Zeus (voir supra p. 10 et 93). Des synthèses régionales sur le culte du dieu dans le Péloponnèse ou en Épire et Illyrie méridionale montre que ses prérogatives maritimes sont finalement mineures ou absentes par rapport à ses autres fonctions, et plutôt assumées par d'autres divinités ${ }^{190}$. Hérodote (Histoires II, 50-51), associe même Poséidon et les Néréides dans leur origine : ce sont les seules divinités que ne connaissent pas les Égyptiens.

De ses nombreuses épithètes en relation avec la mer ${ }^{191}$, aucune ne lui confère véritablement une action maritime et aucune ne lui donne un caractère salvateur; Pindare (Pythiques IV, v. 368) est le

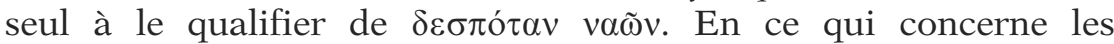
épiclèses ${ }^{192}$, la même constatation s'impose : certaines davantage connotées sont citées dans des sources tardives ${ }^{193}$. On l'invoque ainsi sous les noms d'Aigaios (Anthologie Palatine VII, 256), Akraios ${ }^{194}$, Einalios ${ }^{195}$, Épilimnios (Hésychius, s.v. Epilimnios), Isthmios (Pindare, Olympiques XIII, 4), Pélagaios (Pausanias VII, 21, 7) ou Pélagios ${ }^{196}$, Pontios (Sophocle, Edipe à Colone v. 1071) ${ }^{197}$, Pontomédôn (Pindare, Olympiques VI, 103) ${ }^{198}$, Porthmios ${ }^{199}$, Thalassios

${ }^{187}$ Pausanias qui décrit des chefs d'œuvre antiques signale la présence de Poséidon et Amphitrite sur le piédestal du Zeus d'Olympie (Pausanias V, xi, 8), de même que sur le socle de la statue d'Apollon à Amyclée (Pausanias III, xix, 3).

${ }^{188}$ Dans la comédie attique également : Euripide, Cyclope, v. 262-269.

${ }^{189}$ Une autre inscription trouvée dans l'île montrerait qu'il y portait l'épiclèse d'Asphalaios: Salles 1986, p. 266 (aucune mention dans Piejko 1988).

${ }^{190}$ Péloponnèse : Mylonopoulos 2003, p. 395-396 et 437-440; Épire : Quantin 1999, p. 68, 85; Quantin 2004.

${ }^{191}$ Énumérées dans Wüst 1953, col. 490.

192 Wüst 1953, col. 493-504

${ }^{193}$ Ainsi Poséidon Agreus envoyant la pêche n'est attesté que chez Lucien, Piscator 47.

${ }^{194}$ Wüst 1953, à Mytilène: avec Zeus et Hadès.

${ }^{195}$ IG IV, 797, 1. 2 à Troizène.

${ }^{196}$ Syll. ${ }^{3}$ 289, 17 (à Athènes). IG XII, 3, 1347 (à Théra); triple dédicace à Zeus Olympios, P. Pélagios et Apollon Stéphanophoros, chacun symbolisés par l'aigle, le dauphin et le lion (Olmos \& Moreno-Conde 2012, p. 396 et 418, no 64 .

${ }^{197}$ Également $C I G$ II, 130 à Élatée. Cf. G. Kruse, «s.v. Pontios», RE XXII, 1, Stuttgart, 1953, col. 28-29.

${ }^{198}$ Eschyle, Sept contre Thèbes v. 131; IG I², 706.

${ }^{199}$ IG XII 1, 1031, 1. 12; 1032, 1. 34; 1033, 1. 23; 1035, 1. 11; 1036, 1. 12 : Porthmos de l'île de Carpathos. 
(Aristophane, Oiseaux, v. 1519). Le Poséidon Prosbèterios / Potbatèrios connu à Éleusis en 20/19 a.C. et à Delphes n'est pas à mettre en relation avec la navigation ou la mer, mais avec l'accès par degrès ${ }^{200}$. Hérodote (VII, 192) constitue la rare source évoquant un Poséidon Sôter ${ }^{201}$. Mais le contexte particulier explique cette épiclèse : suite à la terrible tempête qu'ont subie les Perses et qui a détruit leurs flottes, les Grecs ne peuvent que rendre grâces à la divinité qui en est responsable. La violence et la mort qu'il provoque et qui dans cette occasion leur est favorable, méritent leur dévotion. C'est sans doute dans cette perspective qu'il faut comprendre la consécration des deux bateaux qui lui est faite durant la guerre du Péloponnèse.

\section{Évolution du culte}

De façon générale, le dieu paraît revêtir pour la navigation une certaine importance à l'époque $\operatorname{archaïque~}^{202}$, ce dont témoignent les offrandes navales uniquement attestées pour cette période. Sa présence à bord des bateaux de l'Antiquité classique et hellénistique ne se manifeste sous aucune forme : aucun nom, aucun décor naval ne renvoie à lui. Ce dernier semble alors relayé à ces époques par Apollon $^{203}$ ou par Zeus. La manière dont le perçoivent certains étrangers est significative à cet égard.

Poséidon est en effet honoré par les Phéniciens dans le monde grec, mais de façon particulière. Si sa représentation iconographique le rapproche de leur dieu de la mer, en revanche ses fonctions et sa personnalité présentent peu de points communs avec le culte phénicien. C'est pourquoi il cède la place dans les marques phéniciennes de vénération liées à la navigation à son frère, qui bénéficie d'un succès plus grand dans ce domaine ${ }^{204}$. Cette différence de perception des deux divinités de la part d'étrangers montrent bien leur caractère distinct au sein même de la religion grecque.

Les sources montrent par ailleurs que Poséidon est honoré à l'époque classique et hellénistique, non pas en rapport avec la navi-

${ }^{200}$ Jacquemin 2002.

${ }^{201}$ Le renvoi à un Poséidon Sôter à Sounion d'après l'inscription $I G \mathrm{II} / \mathrm{III}^{2}$, 1300 (Wüst 1953) repose sur un texte très fragmentaire reconstitué : seul le mot

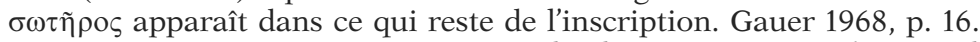

${ }^{202}$ Simon 1998, p. 58-79 insiste sur la place conséquente de son culte marin à haute époque.

${ }^{203}$ Bouché-Leclercq 1882, p. 364-364 met cette évolution sur le caractère trop inhumain du dieu, «trop craint pour être adoré».

${ }^{204}$ Baslez 1986, p. 297-299. 
gation mais avec la pêche ${ }^{205}$. Dans ce domaine, le dieu se montre alors bienfaisant. Il provoque de bonnes prises et la prospérité pour des cités entières. L'iconographie, le figurant avec son trident mais surtout avec des animaux marins, reflète cette évolution du culte. Dès lors, dans l'Anthologie Palatine, il est invoqué par des populations littorales de la même manière qu'une des autres divinités protectrices de la pêche, telle Artémis.

${ }^{205}$ Burkert 2011, p. 194. 



\section{LES FRONTIÈRES DE LA MER, OU LA MER DOMESTIQUÉE}

La mer se définit souvent pour les Anciens comme un espace autre, dans lequel l'homme se sent toujours étranger : elle ne lui est pas naturelle. Elle incarne ainsi un monde extérieur, différent, dont il faut fixer les limites. Si Artémis personnifie la frontière entre ces deux univers, Dionysos s'amuse pour sa part à les brouiller. En effet, ces zones de séparation sont aussi des zones de rencontre. À cet égard, l'homme peut également les exploiter depuis la terre ou en restant dans sa proximité par la pêche, à laquelle renvoie encore la figure de la déesse mais aussi celle d'Hermès ${ }^{1}$.

\section{ARTÉMIS}

Artémis est une figure divine bien étudiée ${ }^{2}$; l'attention de nombreux chercheurs s'est portée notamment sur son culte attique à travers le sanctuaire de Brauron ${ }^{3}$ ou sur ses liens avec la potnia thèrôn ${ }^{4}$. En ce qui nous concerne plus particulièrement, depuis une

${ }^{1}$ Sur Artémis, Hermès et la pêche : Icard \& alii 2011, p. 380-381.

${ }^{2}$ Parmi les études, citons I. Chirassi, Miti e culti arcaici di Artemis nel Peloponneso e Grecia Centrale (Università degli studi di Trieste. Istituto di storia antica III), Trieste, 1964; M. B. Hollinshead, Legend, cult, and architecture at three sanctuaries of Artemis, Thèse Lett. (Bryn Maur College), 1980; L. Kahil, "La déesse Artémis : mythologie et iconographie», Greece and Italy in the classical world. Acta of the XI international Congress of classical archaeology (London, 3-9 sept. 1978), Londres, 1979, p. 73-87. L'article de K. Wernicke 1895 est toujours indispensable pour les références qu'il réunit.

${ }^{3}$ L. Kahil, «Autour de l'Artémis attique», Antike Kunst VIII, 1965, p. 20-33; Id., «L'Artémis de Brauron. Rites et mystère», Antike Kunst XX, 1977, p. 86-98; id., "Le cratérisque d'Artémis et le Brauronion de l'Acropole», Hesperia L, 1981, p. 253-263; J. Papadimitriou, «The sanctuary of Artemis at Brauron», Scientific American, juin 1963, p. 111-120; C. Montepaone, "L'akteia a Brauron», Studi storico-religiosi III, p. 343-364.

${ }^{4}$ C. Chryssanthos, Пó $\theta \mu 1 \alpha$ $\theta \eta \rho \tilde{v}$. Eine Untersuchung über Ursprung, 
trentaine années, l'accent a été mis sur l'espace d'Artémis - et par conséquent sur ses relations avec la mer ${ }^{5}$. Les conclusions de ces excellents articles concourent à mettre en évidence ses liens avec les rivages et les zones de confins.

Par ailleurs, examiner les liens d'Artémis avec la mer oblige à réunir non seulement les sources référant à elle, mais aussi à d'autres divinités auxquelles on l'a parfois assimilée, afin d'essayer de comprendre quand et pourquoi se sont opérés de tels rapprochements. Ainsi, à travers les attestations de cultes seront traitées également Diktynna, Britomartis et quelques divinités locales.

\section{LES SOURCES}

Mythologie et épopée

a) L'espace d'Artémis

Le caractère d'Artémis apparaît bien défini dans la littérature ancienne en dehors même de tout sanctuaire. Selon la tradition, elle est associée aux espaces naturels ${ }^{6}$ : elle court, libre, à travers les étendues, préférant la compagnie des animaux à celle des hommes. L'Hymne homérique à Artémis (II, v. 1-10) célèbre sa personnalité et sa puissance sur la nature. Même la mer poissonneuse (

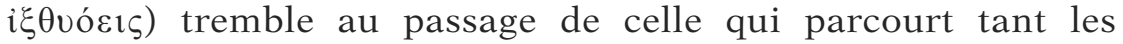

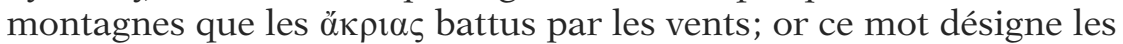
hauteurs comme les promontoires. Callimaque définit aussi l'espace d'Artémis dans l'Hymne qui lui est consacré (III, v. 31-40) : outre les villes que son père lui octroie, elle reçoit de lui le privilège d'être

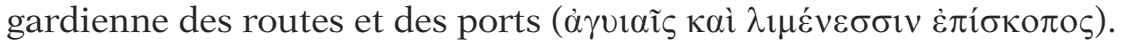

Cet espace recouvre ainsi non seulement bois et montagnes, mais de façon générale elle est également liée par essence aux bords de mer: rivages, promontoires, ports.

Erscheinungsformen und Wandlungen der Gestalt einer Gottheit, Thessalonique, 1968.

${ }^{5}$ Piccirilli 1981, p. 223-252; Ellinger 1984, p. 51-67; Brulé 1993, p. 57-65; Cole 1999-2000; enfin l'article de Kahil 1984 comporte un petit paragraphe sur Artémis et la navigation : 1 p. 677 et 2 p. 504. Voir également Kowalzig 2013, sur Artémis Tauropole.

${ }^{6}$ Séchan \& Lévêque 1966, p. 354-356. 
b) Artémis à Aulis

L'histoire des Grecs retenus à Aulis apparaît pour la première fois dans le récit qu'en donne le chœur de l'Agamemnon d'Eschyle; en tout état de cause elle est postérieure aux textes homériques ${ }^{7}$. Dans cette version, Artémis empêche le départ des bateaux pour

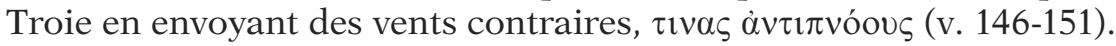
Ces vents du Strymon entraînent l'arrêt forcé des Achéens, le mauvais état de la mer et le dommage des embarcations ainsi que la faim et la discorde parmi les équipages; à tous ces maux, la divinité exige un seul remède, le sacrifice d'Iphigénie ${ }^{8}$.

Cette légende a beaucoup inspiré Euripide qui y consacra deux tragédies: Iphigénie à Aulis et Iphigénie en Tauride. Dans cette dernière, le tragique qui imagine la suite des aventures d'Iphigénie, sauvée in extremis grâce à Artémis et emmenée chez les Taures, fait exprimer à l'héroïne tous ses sentiments concernant les événements passés. La flotte fut ainsi retenue à Aulis par des vents d'aploia, empêchant toute navigation (Iph. Aul., v. 87-93; Iph. Taur. v. 4-30). La raison invoquée pour expliquer le courroux d'Artémis consiste dans le non-respect par Agamemnon d'une promesse faite à la déesse de lui vouer le plus beau produit de l'année; or, ce fut cette année-là que naquit Iphigénie (ibid.). Après bien des hésitations et des subterfuges, le sacrifice de la jeune fille peut avoir lieu (Iph. Aul. v. 1563-1603). Avant que soit porté le coup fatal, Achille prononce une prière adressée à Artémis, lui demandant en échange de la victime une navigation sans malheurs ( $\pi \lambda$ oṽ $\nu \dot{\alpha} \pi \eta ́ \mu o v \alpha)$ et la prise de Troie. La substitution d'Iphigénie par une biche est ensuite accueillie par tous avec joie et interprétée par le devin Calchas

${ }^{7}$ Le deuxième chant de l'Iliade (v. 303 ss.) montre en effet les Grecs sacrifiant à Aulis avant leur départ, mais le sacrifice est adressé collectivement aux dieux olympiens sans que ne soit mentionnée particulièrement Artémis ou Iphigénie. L'événement qui marque l'arrêt à Aulis est l'apparition d'un serpent qui avale des oisillons et leur mère, indiquant par là le nombre d'années de guerre à venir. Ailleurs (Iliade, IX, v. 145), Agamemnon nomme Iphigénie parmi les filles qu'il a à marier, ce qui signifie qu'elle n'est pas morte à Aulis mais qu'elle grandit dans le palais de son père.

${ }^{8}$ Glotz 1904, p. 13-14 le rapproche des sacrifices de taureaux ou de chevaux vivants à Poséidon, ou des rites analogues carthaginois : il s'agit selon lui de rites très anciens par lesquels on espère apaiser la mer par le prix du sang. Il met ainsi le sacrifice d'Iphigénie en parallèle avec celui de Polyxène sacrifié à Achille avant le retour des Grecs vers leur patrie dans l'espoir d'une bonne navigation (Euripide, Hécube, v. 534 ss.). En revanche, P. Brulé réfute tout lien de la légende d'Artémis et d'Iphigénie avec la mer (Brulé 1987, p. 191-192). Bonnechère 1994, met en relation le meurtre de la jeune fille avec les rites d'initiation et de passage (étude des traditions p. 38 ss.). Des sacrifices humains à Artémis Triklaria étaient célébrés à Patras (Pausanias VII, xix, 6-10) : voir infra Dionysos. 
comme un signe de l'envoi à venir par la divinité d'un vent favorable à la navigation (oüprov $\pi \lambda$ oṽv). La version d'Ovide (Métamorphoses XII, v. 8-38) suit celle du tragique : des vents furieux retiennent les navires à Aulis mais avec le sacrifice, les flots retombent comme la colère de la déesse qui envoie aux Grecs le vent en poupe.

Diverses traditions affirment qu'Agamemnon continua par diverses offrandes d'assurer la bonne marche de la flotte achéenne vers Troie 9 . Au sud de l'île, à Géraistos, un bateau de pierres dédié à Artémis d'Eubée est considéré comme un ex-voto du chef achéen pour la navigation de sa flotte (Procope, De bello Gothico IV, 22, 23-29). La dédicace, formulée en deux vers en hexamètres, rapporte l'offrande, son motif et son dédicant; un autre fragment donne le nom du sculpteur, Tynnichos, et la divinité honorée Artémis Bolosia. Procope assimile la divinité à Eileithyia, car il rapproche l'épiclèse

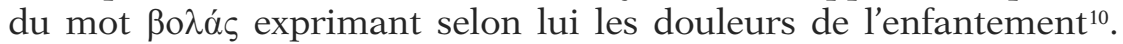
Hors de l'Eubée, Agamemnon consacra à la fille de Léto dans son temple samien du promontoire Chésion un gouvernail contre l'aploia qu'elle lui imposait - cette fois semble-t-il par l'absence de vent - (Callimaque, Hymme III, v. 225-232) ${ }^{11}$.

Le rôle d'Artémis dans la navigation des Grecs vers Troie apparaît ainsi comme une création relativement tardive, de l'époque classique, dont la tragédie fixa définitivement les traits.

\section{c) L'épopée argonautique}

Dans les Argonautiques, elle ne joue pas de rôle actif mais elle intervient de manière indirecte dans le déroulement du voyage à deux reprises ${ }^{12}$. Le jour du départ des héros, une fois la voile hissée et le bateau filant dans de bonnes conditions de navigation, Orphée se met à chanter Artémis comme v et qui veille sur les skopias halos, c'est-à-dire les hauteurs d'où l'on peut observer la mer ${ }^{13}$. À ce chant, les poissons, comme un troupeau devant son berger, suivent le bateau en sautillant (Apollonios de Rhodes, Argonautiques I v. 569-579).

Au retour les Argonautes trouvent refuge, alors qu'ils sont poursuivis par les troupes du frère de Médée $^{14}$, dans l'une des deux îles

\footnotetext{
${ }^{9}$ Wachsmuth 1967, p. 402.

${ }^{10}$ Cette association Artémis-Eileithyia est attestée à Sparte : dans le sanctuaire d'Artémis Orthia, Eileithuia recevait un culte (Kilian 1978, p. 219-222).

${ }^{11}$ Sur ces deux offrandes, voir infra p. 390 s. et 411.

${ }_{12}$ Mc Cartney 1933, p. 4.

${ }^{13}$ Wachsmuth 1967, p. 406.

${ }^{14}$ Sur cette tradition, voir F. Vian, édition Budé, p. 20-21. Les îles correspondent aux Apsyrtides en Adriatique.
} 
Brygéides, près de l'embouchure de l'Istros, consacrées à la déesse (Apollonios de Rhodes, Argonautiques IV, v. 329-335). Son hiéron, situé sur l'autre, est le théâtre du meurtre fratricide. Il est à noter ici la consécration supposée à Artémis de deux îles apparemment peu habitées voire désertes.

Dans les récits de navigations mythologiques, la divinité est rattachée à deux meurtres et non des moindres : un père envers sa fille et une sœur envers son frère; pour le reste elle est évoquée dans le cadre de certains lieux auxquels elle est directement associée.

\section{d) Artémis-Britomartis - Diktynna}

On ne peut aborder la mythologie et le culte d'Artémis sans étudier l'assimilation avec ces deux autres divinités. En effet, Artémis est honorée sous l'un ou l'autre nom ou même les deux; il est donc nécessaire d'exposer les différentes traditions concernant l'une et l'autre en respectant leur chronologie afin de saisir leur évolution. L'approche la plus complète sur ce sujet a été réalisée par M. Guarducci qui a bien mis en évidence la chronologie et l'origine du syncrétisme ${ }^{15}$.

Callimaque rapporte, dans un poème consacré à Artémis (Hymne III, v. 183-203) que Britomartis était une nymphe de Gortyne, chère à la fille de Léto en raison de leur habileté commune à la chasse. Minos, épris d'elle, la poursuivit longtemps jusqu'à ce que, sur le point d'être saisie par lui, elle se jeta du haut d'un rocher dans la mer pour être récupérée dans sa chute par des filets de pêcheurs. Depuis lors, elle est vénérée sous le nom de Diktynna. Le récit de Callimaque comporte deux points notables. Tout d'abord, il explique le nom donné à la Nymphe par celui du mont Dicté d'où elle se serait précipitée; or, ce mont est situé à l'intérieur des terres, comme l'explique clairement Strabon (X, 4, 12-13) qui place le Diktynnéon sur le flanc du mont Tityros. Par ailleurs, le myrte n'est pas utilisé pour les couronnes de sa fête parce que c'est à ce feuillage que se prit son péplos dans sa fuite. Ces deux détails laissent plutôt envisager deux versions du mythe de Britomartis-Diktynna: l'une

${ }^{15}$ Guarducci 1935, p. 187-203; voir également Willetts 1962, p. 179-193; O. Jessen, «s.v. Diktynna», RE X, Stuttgart, 1905, col. 584-588; K. Tümpel, «s.v. Britomartis », RE III, Stuttgart, 1899, col. 880-881; Glotz 1904, p. 40-42; Borzsák 1951, p. 208; C. Boulotis, «s.v. Diktynna», LIMC II, Bern, 1986, 1 p. 391-394 et 2 p. 282 montre à quel point les types iconographiques de Diktynna s'apparentent à ceux d'Artémis. 
avec Minos, le saut dans la mer et les pêcheurs, l'autre avec le mont Dicté et une chute causée par une branche de myrte ${ }^{16}$.

Une version plus tardive d'au moins cinq siècles fait de Diktynna une fille de Zeus et de Carmé, née sous le nom de Britomartis en Phénicie (Antoninus Liberalis, Métamorphoses XL). Arrivée en Crète et poursuivie par les assiduités de Minos, elle trouve refuge auprès des pêcheurs qui la cachent sous des filets, à la suite de quoi ils la vénèrent comme Diktynna. Diodore (Bibliothèque historique $\mathrm{V}, 76$, 3-4) qui lui attribue la même filiation, affirme non seulement catégoriquement qu'elle représente une divinité distincte d'Artémis, mais aussi que la légende concernant Minos et les pêcheurs n'est que mensonge de la part de gens non respectueux des dieux. Selon lui, la déesse est vénérée pour avoir inventé les filets de chasse, le reste n'étant qu'inventions impies. Cette identification évoquée par Diodore est également affirmée au travers de plusieurs sources. L'Hymne Orphique à Artémis l'invoque comme Kydonienne aux formes changeantes, Kydonia étant le lieu de culte de Diktynna ${ }^{17}$. Isis lors de son apparition à Lucius affirme qu'elle est vénérée chez les Crétois sous le nom de Diane Diktynna (Apulée, Métamorphoses XI, 3-5). Hésychius (s.v. Britomartis) définit Britomartis comme une Artémis crétoise $^{18}$, tandis que Britomartis est assimilée à la LuneDiktynna selon un poème latin d'époque augustéenne (PseudoVirgile, Ciris, v. 301-305), ce qui renvoie encore à Artémis.

Une dernière tradition explique encore le culte de Diktynna d'une manière différente (Mythographi vaticani II, 36). Une jeune femme nommée Britè, fille de Mars, s'était vouée à Diane de Crète : autrement dit, avait fait vœu de chasteté. Face au roi Minos qui tenta de la violenter, elle se jeta dans la mer où son corps fut récupéré dans des filets de pêcheurs. Après cet événement, une peste s'abattit sur l'île; suite à un oracle, les habitants érigèrent un temple à Diane qu'ils appelèrent Diktynna. Ce récit fait d'Artémis l'objet du culte des Crétois - et non plus une divinité distincte - puisque le mot de Diktynna apparaît alors comme une épiclèse attribuée à la déesse.

Un point commun cependant relie ces traditions : pour les Grecs, l'étymologie du nom Diktynna est apparentée à celui de $\delta$ fícuov: le filet ${ }^{19}$. L'assimilation entre Artémis et les Britomartis-

${ }^{16}$ Selon Guarducci 1935, l'étymologie donnée par Callimaque est la bonne et

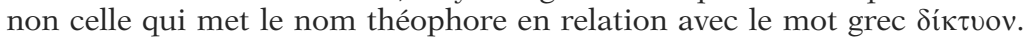

${ }^{17}$ Hymne orphique XXXVI, v. 12.

${ }^{18}$ La scholie à Euripide, Hippolyte, v. 146 raconte encore de façon brève la légende de Britomartis-Diktynna.

${ }^{19}$ Sur le rôle du filet dans la religion grecque, Glotz 1904, p. 51-54. 
Diktynna ne se réalise qu'à une époque tardive, pas antérieure à l'époque hellénistique : Diodore, le premier à l'évoquer, la discute, ce qui montre qu'elle n'était pas encore solidement établie à son époque. Britomartis et Diktynna constituent de surcroît à l'origine deux entités divines distinctes : la première originaire du centre de la Crète, la seconde de sa partie orientale ${ }^{20}$ et à caractère marin.

\section{Témoignages cultuels}

Les attestations de culte d'Artémis en relation avec la mer s'avèrent nombreuses, d'autant plus si on y ajoute celles concernant des divinités locales qui lui ont été assimilées (cartes 6, 7, 9).

\section{a) Attique}

À Mounichie, l'un des ports d'Athènes, Artémis recevait un culte sous l'épiclèse de Mounychia (Pausanias I, i, 4). Ce sanctuaire permet à l'oracle delphien de désigner l'endroit sous le nom de hiéron aktèn dans la prophétie annonçant la victoire de Salamine grâce à un pont de bateaux (Hérodote VIII, 77). Le contexte exclusivement maritime et guerrier de l'événement associe ainsi implicitement la déesse à la mer et au succès de l'entreprise. Callimaque (Hymne III, v. 259) la qualifie par ailleurs à Mounichie de gardienne du port $(\lambda \iota \mu \varepsilon v o \sigma \kappa o ́ \pi o \varsigma)$. Le sanctuaire fut le théâtre du renversement des Trente par les partisans de Thrasybule qui occupèrent la route qui menait depuis l'agora dessinée par Hippodamos jusqu'au hiéron (Xénophon, Helléniques II, 4, 11)21. Plusieurs mentions précisent son emplacement sur un promontoire (akrôtèrion) ${ }^{22}$; de fait, le temple a été identifié avec un bâtiment situé sur le promontoire sud-ouest de Mounichie, qui a livré du matériel votif remontant à l'époque géométrique ${ }^{23}$. Des fêtes appelées Mounichia étaient célébrées le 16

${ }^{20}$ Guarducci 1935.

${ }^{21}$ Ellinger 1984, p. 60; Will 1972, p. 398.

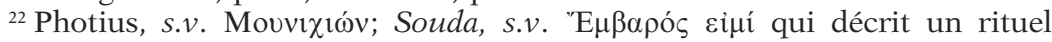
transformant une fille en ourse renvoie à un culte brauronien : Garland 1987, p. 113-114. Plutarque, Phocion 28 transmet l'oracle de Dodone concernant

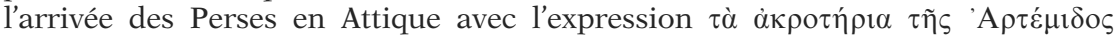
$\varphi v \lambda \alpha ́ \sigma \sigma \varepsilon 1 v$ désignant le sanctuaire. Wade-Gery 1933, p. 99-101 comprend akrôtèrion dans le sens d'aphlaston et y voit des offrandes à la déesse déposées dans son temple. Lysias, Contre Agoratos 24-26 décrit son client réfugié près de l'autel de Mounichie et refusant de fuir dans les bateaux prêts à appareiller sur le rivage.

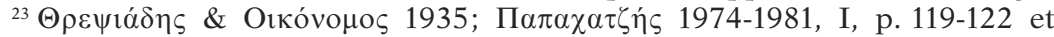
fig. 25-26. Le matériel votif est daté depuis la période géométrique jusqu’à l'Antiquité tardive; des dédicaces ont fourni le nom d'Artémis et celui du héros éponyme Mounichos. 
du mois de Mounichiôn au Pirée avec pompe et régates; celles-ci, concourues par des éphèbes, ne sont pas attestées avant le dernier quart du $\mathrm{II}^{\mathrm{e}}$ s. a.C. ${ }^{24}$. Le nom donné au mois indique l'importance de ce culte d'Artémis. Ces festivités revêtaient d'autant plus de faste que ce jour constituait la date anniversaire de la bataille de Salamine. Certains n'hésitaient d'ailleurs pas à attribuer cette victoire à la bonne lune que la déesse avait montrée à cet instant critique ${ }^{25}$.

Dès lors, il n'est pas surprenant de trouver à Salamine un sanctuaire d'Artémis signalé par Pausanias (I, xxxvi, 1), auquel semble associé le trophée des Grecs consécutif au succés de 480 a.C. ${ }^{26}$

\section{b) Argolide}

En Argolide, le littoral de Trézène est consacré à Artémis, d'après un vers d'Euripide (Hippolyte, v. 227) ${ }^{27}$. Mais la présence de la déesse en contexte marin dans cette région n'est guère connue par ailleurs, si ce n'est à Égine.

Le temple d'Aphaia se trouve au nord-est de l'île, au sommet d'un mont surplomblant tout le territoire et les eaux d'Égine (fig. 9) ${ }^{28}$. L'étymologie du nom de la divinité divise encore les spécialistes ${ }^{29}$. Hésychius (s.v. Aphaia) établit une parfaite correspondance entre Aphaia, Diktynna et Artémis. Il convient donc de s'interroger sur la nature de ce culte.

${ }^{24} I G \mathrm{II} / \mathrm{III}^{2}, 1006,1011,1028$; Photius, s.v. Movvıนı́́v; une bataille navale est même avérée à la fin du $\mathrm{II}^{\mathrm{e}}$ s. p.C. (IG II/III' 2 2130). Deubner 1932, p. 204-205; Parke 1977, p. 138-139, pour qui ces régates n'ont rien à voir avec la mer, avec laquelle Artémis n'a aucun rapport, et correspondent seulement à une époque propice aux exercices physiques de ce genre; Dumont 1975, p. 65; Garland 1987, p. 104 et 114.

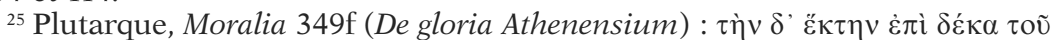

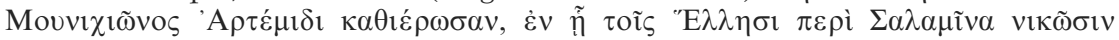
$\dot{\varepsilon} \pi \varepsilon \dot{\varepsilon} \lambda \alpha \mu \psi \varepsilon v \dot{\eta} \theta \varepsilon \dot{\jmath} \varsigma \pi \alpha \nu \sigma \varepsilon ́ \lambda \eta v o \varsigma$.

${ }^{26}$ On situe l'un et l'autre à l'est de l'île : Ellinger 1984, p. 61; F. Chamoux, édition Budé, p. 246.

${ }^{27}$ En effet, Pausanias II, 30, 7 appelle cette côte Фoıßaía $\lambda i ́ \mu v \eta$ d'après le culte d'Artémis; c'est là qu'Hippolyte doit chasser : L. Méridier, édition Budé p. 38; Somville 1984 , p. 8.

${ }^{28}$ Semple 1927, fig. 368. Sur Aphaia, voir Furtwängler 1906; G. Welter, "Aeginetica XXXI», AA LXIX, 1954, p. 37-39; D. Olhy, "Aegina, Aphaia-Tempel»,

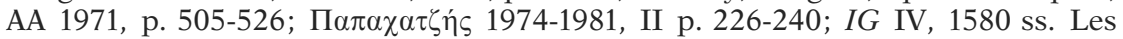
traces cultuelles à cet endroit remontent à l'époque mycénienne. Trois édifices se sont succédé : le premier est daté de la fin du VII ${ }^{\mathrm{e}}$ s. a.C., le deuxième de 570 a.C., le troisième vers 500 a.C. p. 164 .

${ }^{29}$ M. Papathomopoulos, Antoninus Liberalis, Métamorphoses, Paris, 1968, 


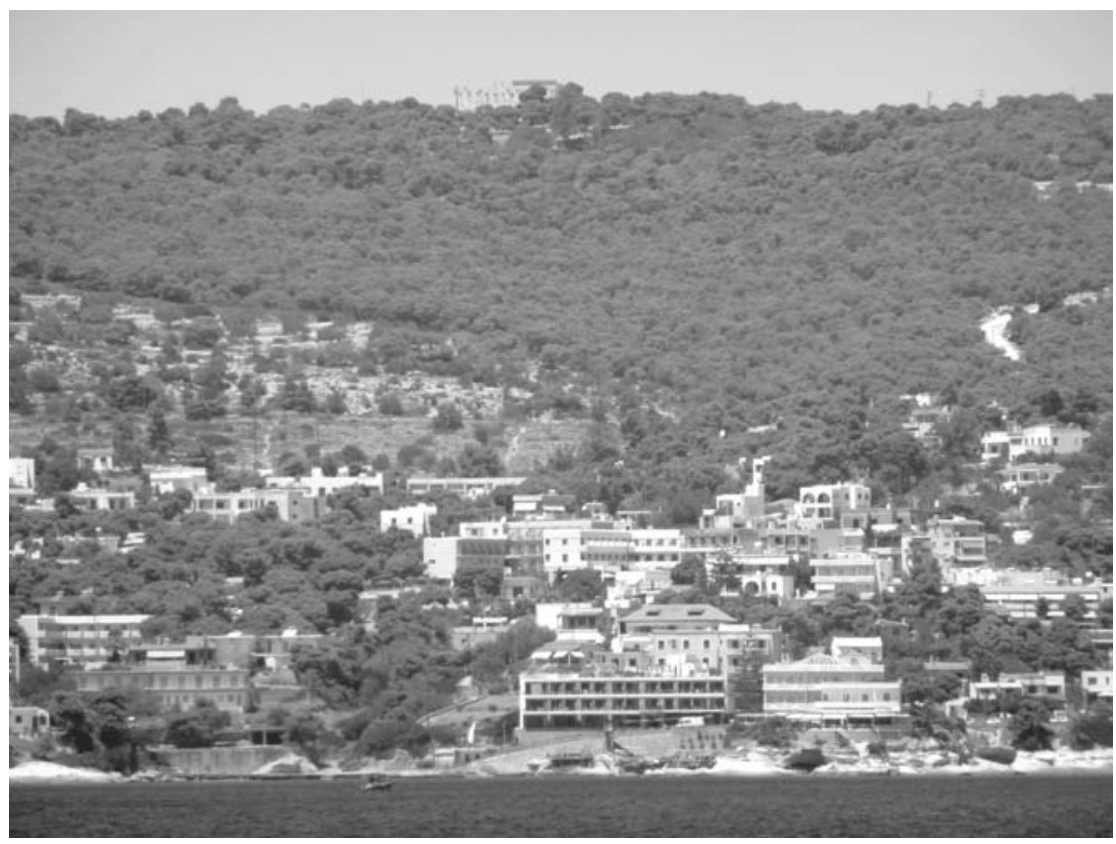

Fig. 9 - Le temple d'Aphaia à Égine depuis la mer (Photo de l'auteur).

Une tradition l'assimile à la crétoise Diktynna, qui part pour Égine sur la barque d'un pêcheur qui lui aussi prétend à ses faveurs; sautant alors dans l'eau, elle gagne l'île et va se cacher dans un bois où on lui éleva un temple sous le nom d'Aphaia (Antoninus Liberalis, Métamorphoses XL) ${ }^{30}$. Cette version dissocie un temple d'Artémis et un autre d'Aphaia ${ }^{31}$. Quelques vers d'un poème augustéen (Pseudo-Virgile, Ciris, v. 301-305) rapportent par ailleurs la

${ }^{30}$ À ce sujet, les spécialistes s'opposent : Furtwängler 1906, p. 473 ss., soutenait la thèse de la divinité venue de Crète avec une colonie crétoise, tandis que Harland 1925, p. 92-100 voyait dans Aphaia une déesse hellénique; selon lui, ce sont au contraire les Éginètes qui, s'emparant de Kydonia en 519, auraient reconnu en Diktynna leur propre divinité Aphaia. Enfin Guarducci 1935, p. 197 pense que l'association entre Diktynna et Aphaia, purement artificielle, remonte à un poète érudit - peut-être Callimaque.

${ }^{31}$ Furtwängler, 1906, p. 473 ss. Par ailleurs, Pausanias (II, xxx, 1) mentionne un sanctuaire d'Artémis près du port, voisin de celui d'Apollon, que Welter 1962, p. 50 pense avoir identifié dans les restes de l'un des deux petits temples dégagés à l'ouest de celui d'Apollon; voir également П $\alpha \pi \alpha \chi \alpha \tau \zeta$ ńs 1974-1981, II p. 236-237 et fig. 255. 
croyance selon laquelle Britomartis, ayant survécu au saut crétois, serait la même jeune femme honorée à Égine sous le nom d'Aphaia.

Pausanias (II, xxx, 3), sans donner ces détails en ce qui concerne les mésaventures survenues dans l'île, affirme que les deux divinités crétoise et éginète sont les mêmes, dotées simplement d'épiclèses différentes; mais pour les uns et les autres, il s'agit à l'origine d'une Britomartis née des amours de Zeus avec une mortelle. Artémis intervient dans le récit de Pausanias en tant que celle qui est à l'origine de la déification de la jeune femme. Le Périégète insiste sur l'origine crétoise de la légende, reprise selon lui par les Éginètes; enfin il signale un chant que Pindare aurait composé en son honneur à la demande de ces derniers. Ces différentes traditions convergent vers un aspect maritime du culte qu'on devait lui rendre, ce que paraissent confirmer les ex-voto du sanctuaire (voir infra resp. p. 412 s. et 373). C'est là sans doute que les Éginètes consacrèrent les proues de vaisseaux samiens battus en Crète dont parle Hérodote (III, 59); la mention dans ce passage du sanctuaire d'Athéna à Égine doit vraisemblablement constituer une erreur de la part de l'historien ${ }^{32}$. Par ailleurs, neuf bateaux de terre cuite archaïques ont été mis au jour parmi le matériel dégagé en fouilles.

De toutes ces informations, il ressort qu'Aphaia était une divinité locale éginète, d'origine ancienne, que l'on rapprocha, pour certains aspects de son culte ou de sa personnalité, à BritomartisDiktynna et sans doute dans un second temps, tardivement, à Artémis. Il est à noter le caractère hybride de la déesse qui put ainsi être considérée par les uns comme une Britomartis-Diktynna(Artémis), par les autres comme une Athéna et dont le culte archaïque présente des ressemblances avec celui d'Héra ${ }^{33}$.

c) Corinthie et Laconie

À Corinthe, entre le sanctuaire de l'Isthme et le port de Kenchreai, Pausanias signale un naos d'Artémis et un xoanon dont il souligne le caractère ancien. Seule cette ancienneté et la position du culte pourraient laisser supposer un lien étroit avec la mer et le port proche ${ }^{34}$.

${ }^{32}$ Musti \& Torelli 1986-1991, II p. 312 soulignent avec raison l'affinité entre les représentations iconographiques d'Aphaia et celles d'Athéna; pour nous, cela suffirait à expliquer la confusion d'Hérodote. Voir infra p. $412 \mathrm{~s}$.

${ }_{33}$ Polignac 1997, p. 113-122.

${ }^{34}$ Des monnaies corinthiennes représentent la déesse munie d'une torche et d'un carquois : Imhoof-Blumer \& Gardner 1964, p. 18 et pl. D lxvi-lxix. Le temple correspond peut-être aux vestiges trouvés à environ $1 \mathrm{~km}$ du port : Scranton \& Ramage 1964, p. 145. 
En Laconie, à Sparte, le culte d'Artémis s'avère prépondérant et complexe aux vues des différents sanctuaires qui lui sont consacrés $^{35}$. Parmi eux, il s'en trouvent deux voisins l'un de l'autre (Pausanias III, xiv, 2). Dans le premier elle est invoquée sous le nom d'Aiginaia $^{36}$ et dans le second sous celui d'Issôria ou Limnaia. Le périégète précise alors que pour lui, le second hiéron n'est pas consacré à une Artémis mais à une Diktynna pour laquelle il renvoie à son commentaire éginète. Le culte d'Artémis Issôria devait alors présenter de nombreuses similitudes avec celui d'Aphaia. D'autres témoignages portant sur ce sanctuaire le situent sur un point élevé appelé Issôrion ${ }^{37}$. Le Périégète mentionne également un autre sanctuaire de Diktynna, au bout de la rue nommée Aphétaïde, où se trouvent également des tombes royales (Pausanias III, xii, 8).

Par ailleurs à Sparte, plusieurs ex-voto navals ont été consacrés à Artémis: une plaque d'ivoire ciselée montrant le départ d'un bateau ainsi que deux reliefs de plaques de calcaire; mentionnons encore deux petits poissons de plomb. Ils proviennent tous du même sanctuaire d'Artémis Orthia et sont tous datés du VII s. a.C. (voir infra p. 392 s. et 505).

À Boiae, la fondation de la cité est due selon la tradition à Artémis Sôteira (Pausanias III, xxii, 12) ${ }^{38}$. Suivant un oracle, celle-ci devait indiquer aux exilés d'Étis, Aphrodisias et Sidé39 l'endroit où s'établir; à peine débarqués en Laconie, ils voient un lièvre qu'ils prennent pour guide et fondent la ville à l'endroit où il disparaît à leur yeux dans du myrte. Depuis ce temps, l'arbre est vénéré sous le nom de la déesse. Son culte est donc lié à l'établissement d'une nouvelle cité mais aussi au myrte, élément qui rappelle le culte

${ }^{35}$ Wide 1893 , p. $97-117$.

${ }^{36}$ Wide 1893, p. 109 hésite à la rapprocher d'une Artémis Brauronia ou d'une Agrotera.

${ }^{37}$ Plutarque, Agésilas 32; Polyen II, Stratagema 1, 4; Cornelius Nepos,

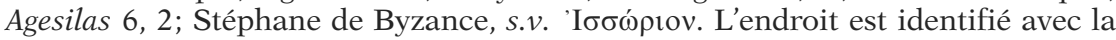
colline de Vamvakia située au nord de Sparte : Musti \& Torelli 1986-1991, III, p. 212 et carte L. Des jeux étaient célébrés en son honneur: Hésychius, s.v.

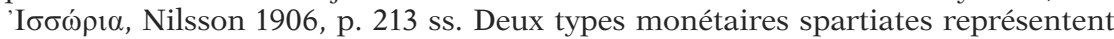
une Artémis, mais il est difficile de les rattacher à une épiclèse particulière : Imhoof-Blumer \& Gardner, p. 54-55 et pl. N1-2. Wide 1893, p. 109-110 suivant le parallèle crétois considère Issôria comme une vieille divinité locale identifiée avec Artémis.

${ }^{38}$ Wide 1893 , p. 121-22, considérant que le myrte étant traditionnellement associé avec Aphrodite, que celle-ci était vénérée dans l'île voisine de Cythère et que l'une des origines des colons était Aphrodisias, conclut à un culte ancien d'Aphrodite à Boiae transformé ensuite en celui d'Artémis.

${ }^{39}$ Ce synœcisme regroupe des habitants de cités du sud du Péloponnèse :

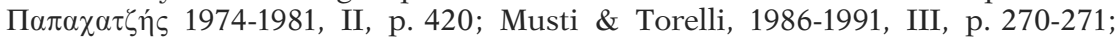
M. Moggi, I sinecismi interstatali greci, Pisa, 1976, p. 11-16. 
crétois de Diktynna. La ville de Boiae se trouve au centre du golfe situé au nord-ouest du cap Malée, face à l'île de Cythère et d'Élapho$\operatorname{nisos}^{40}$ : sa position maritime stratégique pour les bateaux contournant le Péloponnèse à l'est doit être pour beaucoup dans le choix de cet endroit pour la fondation d'une ville, et celle-ci est rattachée à une Artémis Sôteira.

Sur l'autre façade littorale de cette extrémité sud-est du Péloponnèse, sur le territoire d'Epidaure Liméra au bord de la route maritime qui lie Boiae à cette ville, se trouve un sanctuaire d'Artémis Limnatis (Pausanias III, xxiii, 10) ${ }^{41}$. L'épiclèse évoque un culte similaire à celui d'Artémis Limnaia de Sparte décrit auparavant par Pausanias ${ }^{42}$.

Sur la péninsule occidentale de la Laconie, le territoire de Las inclut sur une pointe un temple d'Artémis Diktynna où a lieu une fête annuelle (Pausanias III, xxiv, 9). Des monnaies de la cité représentent la divinité avec arc et carquois accompagnée d'un chien ${ }^{43}$. Plus au sud, à cent cinquante stades du cap Ténare, la cité maritime de Teuthrone honore principalement le culte d'Artémis Issôria (Pausanias III, xxv, 4) ${ }^{44}$. L'épiclèse renvoie encore une fois au culte spartiate.

\section{d) Arcadie}

Près de Phigalie, Pausanias (VIII, xli, 4-6) décrit le sanctuaire d'Eurynomé que les habitants identifient à Artémis ${ }^{45}$. Le sanctuaire n'est ouvert qu'un jour par an, permettant d'apercevoir la statue de culte. Celle-ci représente la déesse mi-femme mi-poisson, entourée de chaînes d'or. Le Périégète préfère reconnaître en cette épiclèse la fille d'Océan, mentionnée dans l'Iliade pour avoir recueilli Dionysos avec Thétis, refusant le rapprochement entre cette femme à corps de poisson et Artémis. M. Jost reconnaît dans ce culte «une divinité des eaux courantes», Okéanos représentant un fleuve pour les Grecs. Il

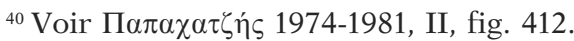

${ }^{41} \mathrm{Ibid}$., p. 426 qui reconstitue le tracé antique de la route de Boiae à Épidaure Liméra. Le sanctuaire d'Artémis a été localisé sous l'église d'Haghios Théclas dans le village au nom évocateur de Limnes : Wace \& Hasluck 1907-1908, p. 176.

${ }^{42}$ Wide 1893, p. 116.

${ }^{43}$ Imhoof-Blumer \& Gardner 1964, p. 65 et pl. O21. Le site doit se trouver aujourd'hui sur le territoire de Vathy : Woodward 1906-07, p. 233-234.

${ }^{44}$ La cité se trouve sur la péninsule de Scopa, près du village moderne de Kotronas, où l'on a trouvé un relief d'Artémis et un autel inscrit : Woodward

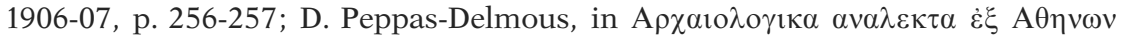
VI, 1973, p. 482-491; П $\alpha \pi \alpha \chi \alpha \zeta \eta ́ \varsigma ~ 1974-1981$, II, p. 439-440.

${ }^{45}$ Jost 1985, p. 89 et 411-414; Nilsson 1906, p. 228-230. 
est à noter cependant l'assimilation d'Artémis avec une divinité locale aquatique au centre du Péloponnèse, qui confirme ses liens avec les poissons et l'eau - qu'ils soient marins ou non.

e) Aulis et Eubée

- Aulis

La tradition de l'épisode homérique d'Aulis trouve sa confirmation dans l'existence à cet endroit d'un sanctuaire d'Artémis. Aulis se trouve face à Chalcis, formant une rade profonde, et la déesse règne

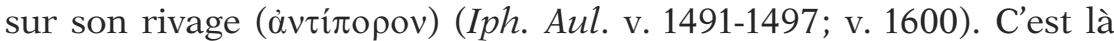
que se rend la flotte spartiate sous le commandement d'Agésilas en 396 a.C. avant de se rendre en Asie, afin de sacrifier à l'endroit où le firent les Grecs au moment de s'embarquer pour Troie (Xénophon, Helléniques III, 4, 3-4) ${ }^{46}$. Le geste se veut symbolique : répéter les gestes des Achéens, présage d'une victoire contre les Perses. Mais il renvoie aussi à un sacrifice réalisé avant une traversée en vue d'une bonne navigation ${ }^{47}$. L'anecdote, telle qu'elle est racontée par Xénophon, montre la mer toute proche du sanctuaire. Plutarque (Agésilas, 6, 6-11) fournit un récit plus romancé des faits : la déesse d'Aulis elle-même apparut en rêve à Agésilas, le comparant à Agamemnon et lui conseillant de réaliser le même sacrifice de départ. L'acte religieux est cependant interrompu par des envoyés des béotarques pour des raisons de vice de forme, et Agésilas s'embarque le cœur lourd, inquiet de ce qu'il prend pour un mauvais présage $^{48}$. La troisième source littéraire concernant Aulis n'indique rien de plus : les quelques vers de Stace (Achilléide I, v. 447-451), qui prétendent décrire par ailleurs les litora d'Aulis chers à la déesse, ne donnent qu'une image déformée et confuse des lieux qui prouvent que l'auteur ne les a pas vus lui-même.

Le sanctuaire, fouillé à la fin des années cinquante, comporte un temple classique et de nombreuses structures annexes. Le culte ne semble pas antérieur au $\mathrm{V}^{\mathrm{e}}$ s. a.C. ${ }^{49}$, ce qui correspondrait à la naissance de la légende d'Iphigénie.

${ }^{46}$ Sur cette expédition, Will \& alii 1975, p. 19.

${ }^{47}$ Semple 1927, p. 376-377.

${ }^{48}$ Glotz 1904, p. 14.

${ }^{49}$ Daux 1956-61; Travlos 1988, p. 200. Une inscription trouvée in situ a permis de confirmer l'identification du sanctuaire. Aujourd'hui, la physionomie des lieux est décevante : le sanctuaire, situé non loin d'une cimenterie et derrière la voie de chemin de fer reliant Athènes à Eubée, donne l'impression d'être perdu dans son environnement, d'autant plus que la ligne du rivage a reculé depuis 
- Eubée

Au nord-est de l'Eubée se trouve l'Artémision, célèbre pour la bataille de la Seconde Guerre médique qui s'est déroulée non loin de là ${ }^{50}$. La configuration géographique des lieux décrite par Hérodote (VII, 176) met en valeur le détroit que domine cette langue de terre : le site contrôle l'accès aux golfes du Pélion, Maliaque et de l'Eubée. Le sanctuaire d'Artémis proprement dit se situe sur une plage ( $\alpha i \gamma 1 \alpha \lambda$ ós). Les opérations navales menées à cet endroit - également suite au désastre perse du cap Sèpias (Hérodote VII, 188-192) montrent qu'il constitue un point stratégique pour contrôler les eaux de la mer de Thrace. De même le dernier paragraphe conservé du pseudo-décret de Thémistocle - texte déjà évoqué à propos d'Athéna et de Zeus ${ }^{51}$ - donne l'ordre à la moitié de la flotte, c'est-à-dire cent trières, de se rendre en Eubée au temple d'Artémis ${ }^{52}$. Cette mention indique que ce dernier se trouvait bien sur le littoral de l'île, à un point stratégique, favorable au mouillage d'un nombre important de bateaux.

Plutarque (Thémistocle 8, 3-6) décrit le sanctuaire d'Artémis

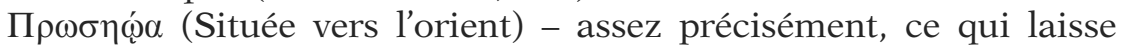
supposer qu'il l'a lui-même visité ${ }^{53}$ - : un temple autour duquel se dressent des arbres ainsi que des stèles de marbre blanc dégageant l'odeur du safran. L'une de celles-ci porte quelques vers commémorant la victoire sur mer des Grecs face aux Mèdes et la consécration qui a suivi de ces offrandes à la divinité ${ }^{54}$; plus loin on montre l'endroit du bûcher des épaves et des cadavres ${ }^{55}$. Le culte de la déesse sur ce rivage est antérieur au $\mathrm{V}^{\mathrm{e}}$ s. a.C.; en revanche l'épiclèse

l'Antiquité. En revanche, dès que l'on a rejoint celle-ci, le point de vue est saisissant sur toute la rade et le golfe de l'Eubée.

${ }^{50}$ Wachsmuth 1967, p. 398.

${ }^{51}$ Morrison Williams 1968, p. 122-127. Sur commentaire général du texte, voir supra p. 33-34.

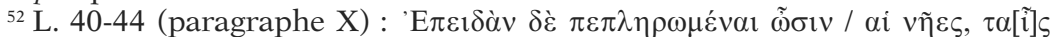

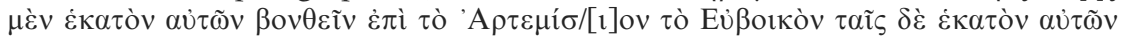

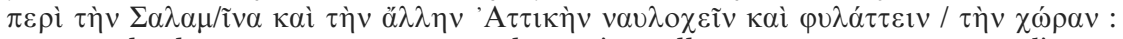
Lorsque les bateaux seront au complet, qu'on aille au secours pour cent d'entre eux à l'Artémision d'Eubée et pour les cent autres, qu'on établisse une station autour de Salamine et du reste de l'Attique et qu'on garde la région.

${ }^{53}$ Commentaire du texte de Plutarque dans l'édition Budé, p. 220.

${ }^{54}$ Gauer 1968, p. 117-120.

${ }^{55}$ Les découvertes faites à cet endroit ont été publiées par Lolling 1883. La carte donnée ibidem p. 13 rend compte de l'emplacement du sanctuaire par rapport à la mer. Notre recherche sur le terrain n'a rien donné : tout vestige a disparu; d'après les dires d'un vieux monsieur du village, il semblerait que le site antique se trouve à présent sous la petite église de Saint-Georges, de construction récente, dans le village de Pevki. La petite butte sur laquelle elle repose donne une belle perspective sur la mer. 
de celle-ci, confirmée par une inscription ${ }^{56}$, a dû lui être appliquée après les guerres Médiques car la position géographique du sanctuaire ne répond pas exactement à cette définition; cette épiclèse ne figure d'ailleurs pas dans le texte d'Hérodote ni dans le pseudodécret de Thémistocle.

Un autre témoignage atteste un culte marin d'Artémis à Eubée : le bateau de pierre de Géraistos au sud de lîle (voir infra p. 391); mais il n'est pas certain que les monnaies représentant une femme assise sur une proue, émises par Histiée entre 315 et 146 a.C., évoquent la fille de Léto $^{57}$.

\section{f) Grèce centrale}

En Phocide à Anticyra, Artémis est vénérée sous le nom de Diktynna dans un sanctuaire situé à l'extérieur de la ville, près de la route qui mène à Ambryssos, sur une hauteur (Pausanias $\mathrm{X}$, xxxvi, $5)^{58}$. La statue de culte, d'après le Périégète, est une œuvre éginète réalisée en pierre noire. La situation du sanctuaire sur une butte face à la mer évoque bien un culte marin.

La cité étolienne de Kalydon possède un temple d'Artémis Laphria, connu par les fouilles menées à cet endroit ${ }^{59}$. Parmi les milliers d'offrandes mises à jour, figurent de petites ancres en bronze $^{60}$. La divinité des lieux était ainsi honorée, entre autres domaines, en relation avec la mer.

En revanche l'existence d'un culte maritime d'Artémis à Eniadae d'Acarnanie est sujet à controverses. La cité possède un petit temple, bâti sur un promontoire face au port et relié à la mer. Une partie inférieure d'une statue cultuelle trouvée lors des fouilles montre que le sanctuaire était consacré à une divinité féminine, sans qu'il soit possible de déterminer précisément laquelle. Par rapprochement avec celui du Pirée d'Athéna Sôteira, l'hypothèse a été formulée d'attribuer le temple d'Eniadae à la même déesse ${ }^{61}$. L'argument est faible - d'autant plus qu'au Pirée elle n'est pas honorée seule et apparaît dans l'association avec Zeus occuper un rôle

${ }^{56}$ Lolling 1883 , p. 18-20, 1. 5-6.

${ }^{57}$ Kahil, 1984, 1, no 725 (Artémis); BMC Central Greece p. 127-135 et pl. xxiv (nynphe Histaia).

${ }^{58} \mathrm{La}$ statue doit figurer sur les monnaies de la ville : Imhoof-Blumer \& Gardner, p. 124-125.

${ }^{59}$ Les fouilles ont été publiées par Dyggve \& Poulsen 1948. L'apogée du sanctuaire se situe entre le $\mathrm{VI}^{\mathrm{e}}$ et le $\mathrm{IV}^{\mathrm{e}} \mathrm{s}$. a.C. et connaît la prospérité jusqu'au règne d'Auguste. La statue de culte est transportée à Patras à cette époque, où elle se trouve encore lors du voyage de Pausanias (VII, xviii, 8-10).

${ }^{60}$ Dyggve \& Poulsen 1948, p. 335 ss.; Antonetti 1990, p. 235-256.

${ }^{61}$ Powell 1904, p. 203-206. 
mineur -, et d'autres divinités peuvent tout aussi bien remplir le rôle de protectrice du port: Artémis ${ }^{62}$ tout particulièrement.

\section{g) Délos}

Le culte d'Artémis à Délos remonte à une haute Antiquité et a succédé à un culte plus ancien d'une divinité de la nature ${ }^{63}$. À l'époque historique et en ce qui concerne un éventuel culte marin, Artémis possède un sanctuaire " $\dot{\varepsilon} v$ Ní $\sigma \omega$ " où elle est vénérée autant sous le nom d'Artémis que sous celui d'Hécate ${ }^{64}$. On lui aurait consacré à cet endroit des gouvernails ${ }^{65}$; ce type d'offrande et l'emplacement du sanctuaire laissent supposer qu'on l'honorait en tant que divinité protectrice de la navigation. Une inscription délienne qui qualifie Hécate de Sôteira renvoie elle aussi peut-être à son culte marin ${ }^{66}$.

Dans l'île de Délos on connaît par ailleurs une Britomartis dont le culte est distinct de celui d'Artémis ${ }^{67}$. Elle a été parfois rattachée à une divinité délienne, une certaine Brizô connue par quelques commentateurs tardifs répétant tous semble-t-il les propos d'un auteur de la fin du III s. a.C. (Sémos de Délos, Fgt 4 = Athénée, Deipnosophistes VIII, 335 a-b; repris par Hésychius, s.v. B Eustathe, Ad Odyss. M, v. 252; Etymologicum magnum, s.v. B $\rho 1 \zeta \omega ́){ }^{68}$. Le culte de cette divinité est rendu par les femmes de Délos qui lui offrent des skaphai remplies de bonnes choses, à l'exception de poissons. On explique ces deux exigences par le fait qu'elle préserve les bateaux. Le nom de la déesse proviendrait d'un verbe signifiant «dormir» parce qu'elle rend des oracles durant le sommeil ${ }^{69}$.

${ }^{62}$ C'est l'hypothèse opposée par E. Kirsten, «s.v. Eniadae», RE XVII, 2, Stuttgart, 1937, col. 2221.

${ }^{63}$ Gallet de Santerre 1958, p. 129-131 signale notamment, parmi le dépôt d'offrandes mycéniennes retrouvé sous le temple d'Artémis situé à l'intérieur du sanctuaire d'Apollon, la présence de nombreuses coquilles de mollusques.

${ }^{64}$ Bruneau 1970a, p. 202 et 206; Gallet de Santerre 1958, p. 155-156.

${ }^{65}$ Voir infra, ex-voto navals, p. 422.

${ }^{66}$ ID 2448; Bruneau 1970a, p. 203.

${ }^{67}$ Bruneau 1970a, p. 203; Gallet de Santerre 1958, p. 154-155. Deux fêtes distinctes sont célébrées en l'honneur de l'une et de l'autre à quelques jours d'intervalle.

${ }^{68}$ Bruneau 1970a, p. 477-478 écarte le rapprochement entre cette divinité et Britomartis opéré par Wernicke 1895, col. 1371 sur la base du nom donné par Hésychius; Nilsson 1906, p. 209-210.

${ }^{69}$ Bouché-Leclercq 1882, II p. 27 ss. Wachsmuth 1967, p. 276-277 réunit les différentes prérogatives de Brizô : les rêves servaient d'indicateurs pour les navi- 
À Délos coexistent donc plusieurs Artémis, une Britomartis, une divinité locale qui pourrait présenter des points communs avec elles sans que leurs cultes aient l'air de se mêler.

\section{h) Crète}

La légende de fondation d'une cité crétoise, Lyktos $^{70}$, intéressante à plus d'un titre, met directement Artémis en relation avec le voyage de colonisation. Plutarque (Mulierum Virtutes, 247d-f) explique la double origine dont se réclament les habitants de la ville : ils descendent des Athéniens par leurs mères que leurs pères ont enlevées alors qu'ils vivaient à Lemnos. Ces couples chassés trouvèrent refuge à Sparte où on les accusa de complot; ils parvinrent néanmoins à obtenir les moyens d'aller fonder une colonie reconnue comme lacédémonienne. Les colons reçurent d'Apollon pythien l'oracle suivant : ils devaient fonder leur ville à l'endroit où ils perdraient à la fois leur ancre et leur divinité. Celle-ci consistait en un xoanon d'Artémis provenant de Brauron, hérité des ancêtres et qui les accompagna partout depuis Lemnos. La prophétie se réalisa alors qu'ils mouillaient en Crète au lieu-dit Cherronèsos : une peur panique les prit qui les poussa à prendre la mer en oubliant la statue à terre et en rendant l'ancre inutilisable. Cette anecdote montre comment une divinité est transportée par des colons vers de nouvelles terres : le culte est respecté, mais surtout il est concrètement représenté par la statue que l'on emmène avec soi. Les aléas qui peuvent survenir la concernant durant le voyage ont une répercussion sur les décisions des hommes ainsi que sur la façon de percevoir la divinité. Transportée au gré des pérégrinations de ces migrants, de Brauron à Lemnos puis au cap Ténare, à Milos jusqu'à Cherronnèsos - tel est le parcours que Plutarque reconstitue - Artémis finit par signifier l'endroit où ils doivent s'implanter : l'epouvante qui les saisit et le fait de rester à terre expriment les volontés de la divinité. La perte de l'ancre se révèle tout aussi symbolique : elle montre le lieu où les colons doivent enfin s'ancrer définitivement. L'histoire établit ainsi une relation très forte entre Artémis et la navigation, entre Artémis et le mouillage des bateaux sur le rivage.

Par ailleurs Strabon (X, 4, 14) mentionne un sanctuaire de

gations à venir; en témoignent les nombreuses notices concernant ce domaine dans le recueil d'Artémidore.

${ }^{70}$ La cité, plus communément désignée sous le nom de Lyttos (Strabon X, 4, 7), se trouve à environ $25 \mathrm{~km}$ au sud d'Héraklion. Willetts 1962, p. 122; le nom de la ville figure parmi le catalogue des vaisseaux de l'Iliade (II, 647). Les sources concernant cette ville sont réunies dans IC I, p. 179-230. 
Britomartis à Cherronèsos ${ }^{71}$, épineion de la cité de Lyttos, culte confirmé par une inscription du II ${ }^{\text {e }}$ s. a.C. et des monnaies datées du $\mathrm{IV}^{\mathrm{e}}$ s. a.C. ${ }^{72}$; une autre inscription de Cherronèsos livre le nom d'Artémis $^{73}$ tandis qu'à Lyttos même on honore une Artémis Sôteira ${ }^{74}$. À Lyttos et son antenne littorale Britomartis et Artémis sont l'objet de cultes distincts, celui de la seconde étant relié à l'arrivée des colons en Crète.

Plus à l'est, Pausanias (IX, 40, 3) mentionne également une statue de Britomartis attribuée à Dédale conservée à Olonthe ${ }^{75}$, où sont célébrés des jeux en son honneur ${ }^{76}$.

Au nord-ouest de l'île, à Kydonia, se trouve un sanctuaire de Diktynna où la tradition situe son saut (Callimaque, Hymne III, v. 183-203). Le caractère maritime du sanctuaire est indéniable: placé dans une baie, à l'extrémité d'une pointe, face à la mer $^{77}$. Selon Hérodote (Enquête III, 59), ce sont des Samiens opposants au tyran Polycrate qui vécurent durant cinq ans à Kydônia qui établirent ce culte. Des monnaies de la cité la représentent à l'époque hellénistique sous des traits proches de ceux d'Artémis ${ }^{78}$. Un relief hellénistique trouvé dans le sanctuaire représente une proue de navire à la droite de laquelle deux personnages féminins se serrent la main. Dans celui de droite, vêtu d'un vêtement court, un carquois sur le dos, on doit reconnaître la divinité des lieux ${ }^{79}$. La scène surmonte un décret d'entente passé entre Polyrrhénia et Phalasserne contre Kléonymos et les Lacédémoniens ${ }^{80}$, ce qui renvoie au contexte de

${ }^{71}$ Le site doit correspondre au cap appelé aujourd'hui Chersonisos, à quelques kilomètres de la ville homonyme (cf. Strabon éd. Budé, p. 154).

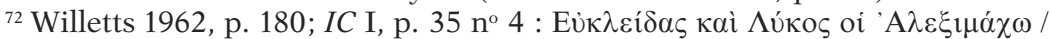
B

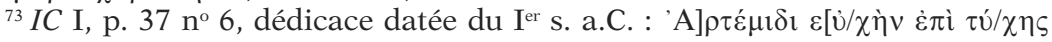
$\Theta \varepsilon о \delta \omega ́ \rho \omega$. déesse.

${ }^{74}$ IC I, p. $191 \mathrm{n}^{\circ} 12$ (non daté) : un bienfaiteur a restauré le temple de la

${ }^{75}$ Pausanias IX, 40, 3. La statue semble représentée sur des monnaies du III s. a.C. : Willetts 1962, p. 180; Head 1911, nº 472.

${ }^{76}$ IC I, p. 243-244.

${ }^{77}$ Le temple se trouve à l'extrémité de la longue presqu'île de Rodopos, surplombant une baie formant un magnifique port naturel. Matz 1951, pl. 76; Andreadaki-Blasaki 1997, p. 63-64, fig. 72-73. Kydonia, située non loin de l'actuelle Chania, possédait ce sanctuaire de confins.

${ }^{78}$ Suivie d'un chien, avec une torche à la main : Willetts 1962, p. 191-192; Head 1911, n 464.

${ }^{79}$ Musée de Chania, inv. 1. C. Boulotis, op. cit. LIMC, 1 p. 392 et 2 p. 282; IC II, p. 130-133 no 1 . Qu'il s'agisse bien de deux divinités est confirmée par le mot @EOI gravé sur la pierre.

${ }^{80}$ Le texte fragmentaire ne dit rien de plus; la référence historique renvoie au premier quart du III ${ }^{\mathrm{e}}$ s. a.C. Sur le personnage de Cléonyme, Will 1979-1982², I 
l'alliance entre Cléonyme et Pyrrhos visant tout deux Sparte. Diktynna se porte alors garante de l'engagement des Polyrrhéniens voisins de son sanctuaire (Strabon $\mathrm{X}, 4,13$ ), ce à quoi l'autorise tout particulièrement son caractère marin ${ }^{81}$.

L'ensemble de ces attestations montre que les Crétois honoraient ainsi distinctement Artémis et Britomartis-Diktynna : l'assimilation de ces divinités ne vint pas d'eux mais s'avère extérieure ${ }^{82}$. Ces différents cultes coexistent dans l'île et parfois même dans une même ville. Le culte d'Artémis, bien que développé en Crète ${ }^{83}$, n'a pas absorbé les cultes locaux même s'ils présentaient quelques similitudes avec le sien.

\section{i) Gaule et Ibérie}

Massalia, fondation phocéenne, honore particulièrement deux

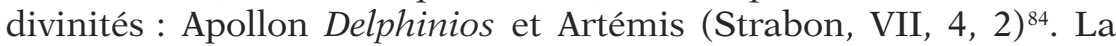
cité s'étale sur un terrain de choix : le port de grande taille est protégé naturellement par une falaise en amphithéâtre. La déesse occupe quant à elle un sanctuaire sur l'Acropole de la ville où on l'honore comme Éphésia; elle surplombe alors la ville et le port ${ }^{85}$. La tradition rapporte qu'au moment de leur départ, les colons entendirent une voix leur conseiller de prendre pour hègémôn l'homme reçu de l'Artémis d'Éphèse ${ }^{86}$. Contrairement à toute attente, c'est une femme, Aristarché, qui se présenta, suite à un songe dans lequel la déesse lui enjoignait de partir avec eux en emportant un modèle

p. 214; T. Lenschau, «s.v. Kleonymos 3», RE XI, Stuttgart, 1922, col. 730-732; Diodore de Sicile, Bibliothèque historique XX, 104 ss.

${ }^{81} \mathrm{Il}$ faut comprendre en effet que le sanctuaire, autrefois sur le territoire de Kydonia, est passé sous le contrôle de Polyrrhénia; de cette acropole, on a d'ailleurs un très bon point de vue sur le golfe occidental de la presqu'île où se trouve le sanctuaire. L'autre divinité représentant Phalasserne n'a pas été identifiée : on a proposé en rapport avec la navigation une Aphrodite (Euploia?), ce que le manque de sources concernant les cultes de Phalasserne ne permet pas de confirmer; Guarducci 1935-50, III p. 220) y reconnaît plutôt une Nymphe locale. Mais que la cité ait vénéré elle aussi une divinité marine ne fait aucun doute lorsque l'on visite l'emplacement absolument extraordinaire de Phalasserne : un promontoire rocheux formant acropole donnant au sud sur un port naturel.

${ }^{82}$ Guarducci 1935 (et dans IC II, p. 130-131) la considère comme une invention attique.

${ }^{83}$ Willetts 1962, p. 272-277.

${ }^{84}$ Properzio 1989, p. 295-299; Salviat 1992, p. 142-143.

${ }^{85}$ Semple 1927, p. 370-371.

${ }^{86}$ Sur le sanctuaire d'Artémis et son culte, Picard 1922, particulièrement p. 375 ss. sur fondation de Marseille; sur la statue R. Fleischer, Artemis von Ephesos und verwandte Kultstatuen aus Anatolien und Syrien, (Études préliminaires aux religions orientales dans l'empire romain XXXV), Leiden, 1973. 
réduit du sanctuaire. Une fois fixés à Massalia, les Phocéens bâtirent un temple à Artémis d'Éphèse et firent d'Aristarché sa prêtresse. L'importance du culte qui lui est rendu se traduit par la conservation, dans les colonies massaliotes, du type de la statue cultuelle ${ }^{87}$ et des rites. Ceci apparaît dans la description que donne Strabon de l'Ibérie ${ }^{88}$ (carte 9).

Au sud-est de la péninsule Ibérique, sur le littoral méditerranéen, le promontoire d'Hèméroskopeion possède un sanctuaire d'Artémis d'Éphèse (Strabon III, 4, 6) ${ }^{89}$. Réputé très ancien, il a donné son nom au promontoire: Artémision, devenu en langue latine Dianion. Sa fondation est liée à celle de la cité, colonie de Massalia; la proximité de mines de fer doit être à l'origine de cette implantation grecque. La description du site par le géographe insiste sur sa position stratégique en façade maritime : visible de loin pour les navigateurs et naturellement fortifié, ce qui en fait un lieu propice à la piraterie que Sertorius avait su exploiter. Le promontoire constitue en effet une avancée dans la mer en direction des îles Pityussae; plus au sud se trouvent des îlots et à l'intérieur des terres une lagune.

D'autres fondations massaliotes sur ce littoral, plus au nord, présentent un sanctuaire d'Artémis d'Éphèse lié à la mer (Strabon III, 4, 8). Ainsi la cité d'Emporion qui se trouvait à l'origine sur une île ${ }^{90}$, puis dont les habitants s'installèrent en face sur le continent; non loin, la cité de Rhodos, habitée par des Emporites, qui revendique d'après son nom une origine rhodienne ${ }^{91}$. Strabon insiste dans sa description de cette partie de la côte ibérique sur le nombre de ports et leur qualité : elle offre des conditions favorables à la navigation. En revanche, sur la façade atlantique, la déesse appelée Phôsphoros (Porte-lumière) par Strabon, qui possède un sanctuaire littoral à Ebura au nord de Gadès, peut être interprétée comme une Artémis-Hécate d'origine phénicienne ${ }^{92}$.

${ }^{87}$ Sur la statue de culte qui figurerait sur une monnaie datée de 48 a.C., voir C. Ampolo, "L'Artemide di Marsiglia e la Diana dell'Aventino», PP XXV, 1970,

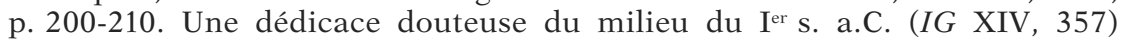
mentionne une théa Dictya, comprise comme une Diktynna : Properzio 1989.

${ }^{88}$ García y Bellido 1967, p. 18-20.

${ }^{89}$ García y Bellido 1967, p. 18-20 : aujourd'hui Denia, à $80 \mathrm{~km}$ au sud de Valence.

${ }^{90} \mathrm{Il}$ s'agit bien sûr de la cité d'Ampurias; l'île en question appelée de San Martín est aujourd'hui devenue une presqu'île.

${ }^{91}$ Le nom a été rapproché de celui de Rosas, petite station proche de Barcelone. Sur la présence de céramique rhodienne dans cette zone, voir F. Villard, $\mathrm{La}$ céramique grecque de Marseille, $V I^{e}-I V^{e}$ s., Paris, 1960, p. 72-76.

${ }_{92}$ Strabon III, 1, 9. F. Lasserre, édition Budé p. 187, rapproche le nom de Phôsphoros de celui de Lux divina attestée par plusieurs inscriptions (CIL II, 
Le culte d'Artémis le long des rivages ibériques, bien que procédant ainsi de diverses origines, marque la consécration de la part des Grecs d'un certain nombre de ports à la divinité.

\section{j) Chersonèse et Pont}

L'extrémité sud-est de la Chersonèse taurique est marquée par un promontoire appelé Parthénion (Strabon VII, 4, 2). Au nord, dans la baie abritée que forme ainsi le cap, se trouve la cité de Cherchonésos $^{93}$ pourvue d'un sanctuaire de cette Parthénos, avec un temple et un xoanon. Dans cette divinité poliade, il faut probablement reconnaître la divinité locale des Taures, assimilée à Artémis. Le culte de celle-ci s'apparente à celui d'Iphigénie chez les Taures tel qu'il est décrit par Hérodote (IV, 103, résumé par Pausanias I, xliii, 1) qui insiste sur sa barbarie. L'historien raconte en effet que cette population ferait subir aux Grecs capturés en mer une série d'outrages : après avoir consacré leur prisonnier, ils l'assommeraient puis le précipiteraient du haut du temple situé sur un rocher escarpé ou l'enfouiraient dans le sol, pour finalement fixer sa tête sur une croix. L'identification de cette divinité taure avec Iphigénie par les Grecs tend à rapprocher le culte des Taures avec celui d'Artémis que connaît la légende troyenne ${ }^{94}$, d'autant plus que la position du temple et la chute d'un homme depuis une hauteur peuvent également renvoyer à la figure de Diktynna.

Un téménos est consacrée à Artémis Phôsphoros - associée à Aphrodite Praeia qui dispense les bons vents - sur le littoral du Bosphore (voir supra p. 126). Le lieu en question est appelé Bolos, ce qui signifie «filet», constituant un bon lieu de pêche en hiver (Denys de Byzance, Anaplus Bospori 35-36) : c'est pour cette raison qu'Artémis s'y voit honorée et le géographe ne juge pas utile de le préciser.

Artémis Diktynna possède également un sanctuaire un peu plus loin sur le littoral, à propos de laquelle on raconte une histoire curieuse (Denys de Byzance, Anaplus Bospori 56-57). Les habitants de Cyzique connurent des jours sans que leur pêche soit fructueuse.

676-677, 2407) : il s'agirait d'un culte rendu à une divinité de caractère astral par des navigateurs. Sans chercher aussi loin, Strabon cite à proximité l'existence d'un phare : Phôsphoros peut tout simplement renvoyer à la divinité à laquelle est consacrée le feu qui guide les bateaux dans ces zones de confins.

${ }^{93} \mathrm{Le}$ site, à $2 \mathrm{~km}$ de Sébastopol, inoccupé aujourd'hui, portait encore au $\mathrm{XV}^{\mathrm{e}} \mathrm{s}$. le nom de Cherson. D'après les fouilles soviétiques menées à cet endroit, il ressort que la ville fut fondée vers 420 par Héraclée du Pont. Le port de cette ville occupait une position privilégiée, à l'abri des vents (Strabon VII, édition Budé, p. 201-202 et 272).

${ }^{94}$ Sur l'Artémis Taurique, F. Graf, "Das Götterbild aus dem Taurerland», Antike Welt IV, 1979, p. 33-41. 
Le dieu - vraisemblablement Apollon par l'intermédiaire d'un oracle - leur ayant ordonné d'honorer la déesse, ils vinrent en cachette s'emparer de la statue du sanctuaire. Or non seulement leurs affaires ne s'arrangèrent pas, mais la statue retourna chez elle. Les habitants de Cyzique revinrent chercher, cette fois ouvertement, la statue qu'ils attachèrent chez eux avec des chaînes dorées, ce dont elle leur tint rigueur... Malheureusement, la fin du texte manque et nous ignorons le dénouement de l'histoire ${ }^{95}$. Il faut cependant considérer que la statue reprit sa place initiale, puisque le début du passage la montre recevant des offrandes de poissons; en effet, explique le géographe, elle favorise tant la chasse que la pêche. Les chaînes d'or ne sont pas sans rappeler celles dont est entourée la statue arcadienne d'Eurynomè.

\section{k) Asie Mineure}

À Érythrées, le culte d'une Artémis Apobatèria est attesté par une inscription de la première moitié du $\mathrm{II}^{\mathrm{e}}$ s. a.C. ${ }^{96}$. Son nom apparaît parmi ceux des dieux pour lesquels la cité opère des dépenses publiques.

Plus au sud, Artémis possédait un sanctuaire dans l'île de Samos que Callimaque (Hymne III, v. 225-232) situe sur un promontoire nommé Chesion et près du fleuve Imbrasos. Le cap n'apparaissant ni dans d'autres sources ni dans la toponymie moderne, la localisation du téménos n'est donc pas permise en l'absence d'informations nouvelles. On a proposé cependant de l'identifier avec une église de Chora nommée Megali Panaghia, en supposant que la précision concernant le promontoire est une erreur du poète ${ }^{97}$. L'existence d'un sanctuaire d'Artémis à Samos est confirmée par deux autres sources : Hérodote ${ }^{98}$ et Stéphane de Byzance ${ }^{99}$, qui définissent la déesse comme Tauropole. La tradition rapportée par Callimaque d'une consécration dans le temple par Agamemnon d'un gouvernail pour conjurer l'absence de vents lors du voyage des Achéens vers

\footnotetext{
${ }^{95}$ Quelques mots d'un résumé en latin du texte de Denys de Byzance laissent supposer que la déesse manifesta son courroux en déchaînant les flots de la mer.

${ }_{96}^{96}$ Sokolowski 1955, no 26 A, 1. 17; Pugliese Carratelli 1965; Robert 1969.

${ }^{97}$ Von Geisau, «S.v. Samos», RE I, 2, 2e série, Stuttgart, 1920, col. 2199.

${ }^{98}$ Hérodote, Enquête III, 48. On a retrouvé à Samos les restes d'un sanctuaire

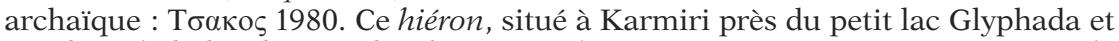
non loin de la basilique paléochrétienne de Panayitsa, constituerait une sorte de dépendance de l'autre sanctuaire. De toute façon, la chronologie du site s'avérait trop haute par rapport au témoignage de Callimaque, le sanctuaire ayant été détruit vers 524. Il faut donc encore chercher le sanctuaire hellénistique, sans doute sur le littoral de l'île.

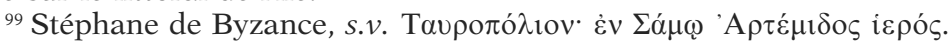


Troie (cf. infra p. 411) conforte la vraisemblance d'une telle épiclèse. Le parallèle entre l'épisode d'Aulis et l'anecdote samienne laisse supposer que la déesse honorée à Samos l'était sous la même forme qu'à Aulis. Artémis était invoquée dans l'île à une époque ancienne pour favoriser la navigation. Les sources montrent que, même si ce caractère ne s'est pas maintenu durant toute l'Antiquité grecque, le sanctuaire a perduré de l'époque archaïque jusqu'à l'époque hellénistique où l'on a gardé souvenir de cet aspect du culte ${ }^{100}$.

Dans l'île d'Icarie, à l'ouest de Samos, Strabon (XIV, 1, 19) signale également un Tauropolion. Celle-ci se caractérise par son manque de ports; elle possède cependant quelques mouillages, dont le meilleur consiste en un promontoire situé à l'ouest. Le géographe recense deux agglomérations sur l'île, abandonnées à son époque : Icarie n'est désormais habitée que par les troupeaux des Samiens. La topographie renvoie aux lieux chers à Artémis : sauvages, bucoliques, battus par les vents, au bord de l'eau mais avec cependant de bons mouillages. Il est difficile en revanche de dater le culte et le sanctuaire: anciens, correspondent-ils à l'époque où l'île était habitée, et si oui, sont-ils encore actifs à la date des sources de Strabon? Ou bien sont-ils postérieurs à l'abandon de l'île?

Sur le continent, peu avant Éphèse, la cité de Pygela abrite sur le littoral un sanctuaire d'Artémis Mounichia qui remonte selon la tradition à Agamemnon (Strabon XIX, 1, 20). Le port voisin de Panormos comporte quant à lui un hiéron d'Artémis d'Éphèse. Entre Colophon et Lébédos, Strabon (XIV, 1, 29) signale encore une petite île vouée à Artémis : déserte semble-t-il, elle constitue l'endroit où les biches viendraient mettre bas en nageant depuis le continent.

Selon Callimaque (Hymne III, v. 225-232), Nélée prit la mer depuis Athènes sous la conduite d'Artémis quand il partit fonder Milet ${ }^{101}$; depuis lors cette ville honore la déesse sous le nom de Chitônè, épiclèse sous laquelle elle est honorée à Athènes ${ }^{102}$.

Plus au sud en Carie, à l'ouest de Daidala après le golfe appelé Glaukos, une description du littoral vu depuis la mer mentionne un promontoire nommé Artémision doté d'un sanctuaire (Strabon XIV, $2,2)$. Cette avancée dans la mer fermant le golfe à l'ouest devait à la fois protéger les eaux de la baie et servir d'amer aux navigateurs ${ }^{103}$.

${ }^{100}$ D'ailleurs le fait qu'il s'agisse d'un Hymne à Artémis, à prétention «universelle» pourrait-on dire et non seulement locale, permet de penser que les allusions de Callimaque étaient comprises implicitement par tous les Grecs et que le sanctuaire possédait une certaine importance.

${ }^{101}$ Nélée fils de Codros; Milet est considérée comme une colonie athénienne.

102 Wernicke 1895, col. 1401; cette épiclèse renvoie au culte brauronien.

${ }^{103}$ Le golfe de Glaukos se situe au sud de Caunos; son promontoire ouest est tourné vers Rhodes. 
Le culte d'Artémis dans un contexte marin est donc bien attesté en Asie Mineure, particulièrement autour d'Éphèse; quant au sanctuaire carien, il occupe une position privilégiée pour la navigation depuis Chypre vers Rhodes et vers tout le littoral de l'Ionie.

\section{1) Confins orientaux}

À l'embouchure de l'Euphrate, Arrien (Anabase VII, 20, 3-4) décrit deux îles. Sur l'une d'entre elles, où se trouve un sanctuaire d'Artémis, vivent en liberté des chèvres et des biches qu'il est interdit de chasser : les animaux, consacrés à la déesse, ne sont tués qu'en vue d'un sacrifice à la divinité de l'île. Il faut sans doute reconnaître là un lieu de culte anciennement voué à une divinité orientale assimilée par les Grecs à Artémis. La description rappelle par ailleurs l'île mentionnée par Strabon au large de Lébédos ${ }^{104}$.

Une inscription grecque trouvée fortuitement dans l'île de Failaka, située à environ $25 \mathrm{~km}$ à l'est de la ville moderne de Koweit dans le golfe Persique, porte une dédicace peinte à Artémis Sôteira, associée à Zeus Sôter et à Poseidon (voir supra p. 185) ${ }^{105}$. Les fouilles menées par les Danois, puis les Français depuis 1983 ont permis la découverte, près de la mer, d'une forteresse contenant des habitations et deux temples, ainsi qu'un autre sanctuaire hellénistique situé en bord de plage ${ }^{106}$ qu'un petit autel avec une inscription peinte en rouge retrouvé in situ permet d'attribuer à Artémis ${ }^{107}$. Cet autel, provenant de la seconde phase du bâtiment, serait à dater du $\mathrm{II}^{\mathrm{e}} \mathrm{s}$. a.C. L'épiclèse, sans nom de divinité, apparaît également dans une inscription hellénistique fragmentaire trouvée devant le plus grand temple de la forteresse, reproduisant deux lettres relatives à un ordre royal de déplacement d'un hiéron de Sôteira ${ }^{108}$. L'île de

${ }^{104}$ Voir supra. Pour Salles 1986, p. 130-131, le lien est évident entre Amphipolis, où était honorée Artémis Tauropole et d'où provenaient plusieurs membres de l'expédition de Néarque, et l'attribution de l'île de Failaka par les Grecs.

${ }^{105}$ Publiée pour la première fois par Tod, 1943; voir supra p. 96.

106 Jepesen 1965; Salles 1984, p. 9-19 avec plan.

${ }^{107}$ Salles 1984, p. 73-156. L'autel, enregistré sous le numéro 201 p. 96 et fig. 44, est commenté aux notes 41 et 41bis, p. 136-137; le texte est le suivant : Y $\pi \dot{\varepsilon} \rho$ /

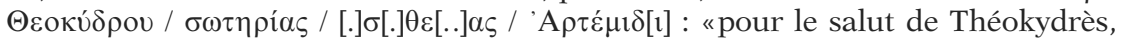
[...] as à Artémis». L'emplacement du sanctuaire au bord de mer ne fait pas de doute, même s'il faut supposer la ligne du rivage plus éloignée de ses murs qu'elle ne l'est aujourd'hui : Salles 1984, p. 73.

${ }_{108}$ Principales publications : Jeppesen 1960, p. 195-196; SEG XX, 1964, $\mathrm{n}^{\circ}$ 411; Altheim \& Stiehl 1965; Cohen 1978, p. 42-44; Piejko 1988; Quantin \&

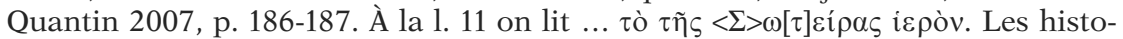
riens ont surtout discuté l'identification du roi, la datation du texte (à l'intérieur $\mathrm{du} \mathrm{III}^{\mathrm{e}} \mathrm{s}$.) et les restitutions des lacunes, sans s'attarder véritablement sur le contenu religieux du document. 
Failaka, située en face du delta de l'Euphrate supra et du Tigre, correspond à l'île d'Arrien et à l'Ikaros décrite par Strabon (XVI, 3, 2), qui y situe un temple d'Apollon et un manteion d'Artémis Tauropolos $^{109}$. Le nom donné à l'île rappelle sans conteste l'île homonyme d'Asie Mineure (voir supra) qui présente ainsi d'autres points communs avec son homologue persique. Le matériel trouvé dans le temple au petit autel, nombreux et d'une grande diversité d'inspiration, a livré également des bateaux de terre cuite (voir infra p. 383 s.), des poids - ou pesons? - ${ }^{110}$ ainsi que des naturalia marins (voir infra p. 504). Même si rien ne permet de relier ce temple avec celui de la stèle royale, ces offrandes de caractère marin incitent à l'attribuer à une Sôteira; l'archéologie ne semble pour le moment pas confirmer la Tauropolos de Strabon ${ }^{111}$. Il ne fait nul doute qu'une divinité féminine locale fut identifiée très tôt par les Grecs par une Artémis, et que son culte hellénisé donna lieu à la construction d'un sanctuaire extra muros au bord de mer fin $\mathrm{III}^{\mathrm{e}}$ s.-début $\mathrm{II}^{\mathrm{e}}$ s. a.C., abandonné au cours de la seconde moitié du $\mathrm{II}^{\mathrm{e}}$ s. a.C. ${ }^{112}$.

Ces différentes sources sont révélatrices de la complexité du culte rendu à l'époque hellénistique à Artémis dans les territoires sur lesquels les Grecs veulent imposer leurs marques, et de l'importance accordée au lieu d'implantation d'un de ses sanctuaires. Les espaces et les fidèles sont fortement marqués par le contexte maritime et insulaire.

\section{ANALYSE}

Géographie du culte

L'ensemble de ces attestations confirme les propos des Hymnes à Artémis. En effet, les lieux consacrés à la déesse pour leur grande majorité peuvent se classer en trois catégories : les îles, les promontoires et les rivages. Les implantations insulaires concernent particulièrement les îlots déserts, non habités, peuplés d'animaux, qui ne

${ }^{109}$ Également par Élien, Sur les animaux XI, 9, auquel il faut ajouter toute une série de sources tardives : voir Y. Calvet dans Salles 1984, p. 21-29, avec textes et traductions.

${ }^{110}$ Salles 1984, $\mathrm{n}^{\circ} 225,231,269-270,344-351$, avec commentaire p. 129-131. Ces objets correspondent à la phase 2 du sanctuaire, datée du II ${ }^{\mathrm{e}} \mathrm{s}$. a.C.

${ }^{111}$ Salles 1984, p. 182. Rien ne permet de relier le temple fouillé avec celui mentionné par l'inscription SEG XX, 411.

${ }_{112}$ Salles 1984, p. 125, 179-184; Piejko 1988, p. 91-92. Pour ce qui est de la divinité locale, on peut hésiter entre une Atargatis ou la déesse lunaire Nanai, toutes deux assimilées à Artémis : Teixidor 1979, p. 71-76 et 111-113. 
nécessitent dès lors pas forcément une construction cultuelle : la nature de ces lieux suffit en elle-même. Cette localisation paraît particulièrement assurée à l'époque hellénistique aux vues des auteurs qui décrivent de tels endroits : Callimaque, Arrien, Strabon. Cependant le culte d'Artémis à Délos et à Salamine, quoique moins marqué, montre qu'aux époques archaïque et classique de petites îles étaient déjà consacrées à la déesse. Notons que toutes se trouvent à proximité d'un lieu de vie : aucune n'est perdue en mer mais au contraire toutes se révèlent proches d'un rivage fréquenté ainsi à Délos, à Icarie ou Ikaros ${ }^{113}$.

La majorité des sanctuaires d'Artémis sont implantés sur un promontoire, le plus souvent en relation avec un golfe ou une anse : au Pirée, à Boiae, Las, Cherronèsos de Crète, Samos, en Carie, Massalia et dans les colonies ibériques, en Chersonèse taurique; ou encore sur un rivage ouvert : au nord de l'Eubée, à Aulis, au centre d'un golfe à Boiae, près d'Épidaure Liméra, dans le Bosphore.

Tous ces lieux présentent comme point commun leur situation limitrophe ${ }^{114}$ : liés à des mouillages et ouverts sur la mer et le littoral, ils permettent d'embrasser du regard un large espace maritime. Souvent, ils se trouvent à l'extérieur de la cité, formant ainsi la frontière entre deux territoires terrestres.

Par ailleurs, les sanctuaires de Britomartis-Diktynna et d'Aphaia se ressemblent au niveau topographique : des akrai, des positions dominantes permettant de voir à travers une grande étendue comprenant la mer. Cette position privilégiée est un des éléments qui a dû faciliter le rapprochement de ces divinités avec Artémis.

La déesse particulièrement présente à Sparte y reçoit également un culte marin. Le fait est notable, car plusieurs sanctuaires de l'intérieur des terres lui sont ainsi consacrés. On comprend mieux dès lors qu'on puisse lui assimiler une divinité comme Eurynomé ou Britomartis : le clivage littoral / intérieur des terres n'existe pas pour Artémis qui, libre et courant sans cesse, se trouve partout à la fois. En Arcadie comme à Sparte, régions peu tournées vers le milieu maritime, c'est à Artémis qu'on attribue finalement les prérogatives de ce type.

Pour ce qui est de sa répartition géographique, le culte d'Artémis se concentre en quelques zones : en Asie Mineure autour d'Éphèse, dans le sud du Péloponnèse dans la sphère spartiate, en Grèce centrale jusqu'en Eubée, sur le littoral occidental de la Méditerranée en liaison avec Massalia, auxquelles s'ajoutent quelques sites isolés. La Grande Grèce n'apparaît pas concernée par le culte

${ }^{113}$ Ellinger 1984, p. 61 place ainsi Artémis à la limite du sauvage et du civilisé.

${ }^{114}$ Cole 1999-2000, p. 472, 475, 477 : "where the land met the sea». 
d'Artémis marine, du moins pas de façon directe ${ }^{115}$. Aux extrémités de ce monde méditerranéen, là où des cultes barbares sont rendus à une divinité féminine, les Grecs substituent l'image d'Artémis : en Chersonèse taurique, à Gadès ou dans le golfe Persique.

\section{Personnalité marine d'Artémis}

Les épiclèses sous lesquelles on rend un culte marin à Artémis sont nombreuses: Apobatèria, Chitonè, Diktynna, Éphésia, Issôria, Laphria, Limnaia et Limnatis, Mounichia, Orthia, Phôsphoros, Prosèoa, Sôteira, Tauropolos. Trois d'entre elles renvoient à un toponyme : le promontoire attique devenu port a donné son nom à la divinité de Pygela ${ }^{116}$, de même que la colline spartiate a baptisé deux sanctuaires laconiens d'Artémis; enfin le souvenir d'Éphèse est resté vivace dans les pratiques cultuelles de ses colons et de leurs descendants.

Les sources révèlent également des liens, réels ou imaginaires, entre les différents cultes et épiclèses. Le culte d'Artémis Mounichia au Pirée relève sans consteste d'une Artémis de Brauron ${ }^{117}$ et c'est de là que provient le xoanon des colons de Lyktos. Par ailleurs une équivalence peut être établie entre Artémis Sôteira et Artémis Tauropole, et entre Artémis Issôria et Artémis Limnaia - qui présentent quant à elles des ressemblances avec Diktynna et Aphaia. Tout ceci révèle qu'en substance, les épiclèses de la déesse ne revêtaient qu'une valeur locale mais que sa personnalité était ressentie de manière assez identique pour l'ensemble des Grecs; seule l'Artémis d'Éphèse, à l'iconographie si reconnaissable, échappe à ces variations.

Au travers de ses différentes appellations, les sources mettent Artémis en rapport avec la mer à travers trois domaines différents : la navigation, la colonisation et la pêche.

${ }^{115}$ Lamboley 1996, p. 445-446 signale la présence de statuettes retrouvés en plusieurs points du littoral messapien côté ionien, correspondant à des lieux d'échanges commerciaux entre Grecs et indigènes, interprétées comme des objets de culte maritime lié au cabotage. Ces figurines représentant le type de l'ArtémisBendis tarentine apparaissent à partir du $\mathrm{IV}^{\mathrm{e}} \mathrm{s}$. a.C.; elle aurait été alors associée à la divinité locale Thana (Lamboley 1996, p. 432).

116 À Sicyone, Artémis était peut-être honorée sous la même épiclèse à moins qu'il ne s'agisse d'une confusion avec le sanctuaire du Pirée : Clément d'Alexandrie, Protreptique IV, 47, 8 énumérant des statues de dieux païens cite le xoanon d'Artémis Mounichia à Sicyone, œuvre de deux sculpteurs crétois Skyllis et Dipoinos; nous n'avons pas pu trouver la scholie à ce passage évoquée par plusieurs commentateurs.

${ }^{117}$ Cette parenté est à la base des travaux de P. Brulé (Brulé 1993, p. 57) et de P. Bonnechère (Bonnechère 1994, p. 26 ss.). 
a) Artémis et la navigation

Artémis est liée aux eaux et à la navigation ${ }^{118}$. Certaines épiclèses à sens topographique : Apobatèria, Limnaia et Limnatis - d'après $\lambda i ́ \mu v \eta$, qui désigne aussi bien le marais qu'un bras de mer - ou descriptif Apobatèria, Sôteira ${ }^{119}$ renvoient à un culte marin. Cela correspond par ailleurs à certaines épithètes poétiques hellénistiques : néossoos, liménoscopos ${ }^{120}$. Par la position de ses sanctuaires, Artémis peut ainsi protéger les côtes, les ports et les embouchures.

Un certain nombre de sources non littéraires confirme ce rôle. En dehors des monnaies controversées d'Eubée, d'autres types figurent une Artémis sur une proue : un arc à la main sur des émissions thessaliennes de la première moitié du $\mathrm{II}^{\mathrm{e}}$ s. a.C. ${ }^{121}$ et même un aplustre à la main sur des exemplaires de Leucade à partir de 167 a.C. ${ }^{122}$. Une ancre de plomb trouvée en mer porte le nom Artemidos et un bateau appelé Artémis apparaît dans une inscription thasienne (voir infra p. 315 et cat. I18, et p. 283). Toutes ces sources hellénistiques montrent l'importance que prend Artémis dans le monde maritime - peut-être parallèlement à la place grandissante d'Apollon dans ce domaine. Mais ce trait existe dès l'époque archaïque : la fondation de plusieurs sanctuaires marins comme celui de Mounichie, les ex-voto navals de Sparte attestent un tel culte dès cette période. À l'époque classique, plusieurs trières athéniennes portent des noms référant à Artémis. Cependant, aux époques archaïque et classique, la déesse peut se montrer hostile et doit être évitée pour sa mauvaise humeur et sa violence. L'Hymne homérique, la légende d'Iphigénie montrent une personnalité redoutable en ce qui concerne l'état de la mer, qui se manifeste notamment par des vents forts ${ }^{123}$. En tant que Tauropolos, elle peut recourir au prix du sang par l'intermédiaire de sacrifices humains. Elle se montre bénéfique aux Grecs dans un contexte général qui n'est pas moins fait de violence : les guerres Médiques. Les batailles de Salamine et de l'Artémision ont vu Artémis participer à la

${ }^{118}$ Wilamowitz 1931-32, I p. 183; Piccirilli 1981.

${ }^{119}$ Wachsmuth 1967, p. 478.

${ }^{120}$ Wachsmuth 1967, p. 262.

${ }^{121}$ Kahil 1984 avec fig.; Basch 1987, p. 300; Anson 1910-1916, V p. 109, $\mathrm{n}^{\circ}$ 794-795, pl. XVII-XVIII. La déesse tient un arc à la main.

${ }^{122}$ Kahil 1984; Anson 1910-16, V p. 112-113, no 849-852, pl. XVIII; Robert 1969 , p. 1510 note 5. On a autrefois identifié la divinité comme une Aphrodite dont le culte est connu à Leucade.

${ }^{123}$ Wachsmuth 1967, p. 365; Mc Cartney 1933, p. 2-3. 
défense des Grecs, mais elle n'y intervient pas de façon décisive. Le culte d'Artémis à l'époque classique est tourné vers l'Orient, c'est-àdire prêt à passer à l'offensive d'un conflit oriental pour lequel la mer devient frontière. Aulis et la légende d'Iphigénie, le culte eubéen et toutes les traditions se rapportant à Agamemnon - parallèle d'Agésilas, l'origine attribuée au sanctuaire de Pygela témoignent d'un culte maritime indirect d'Artémis, orienté vers la mer Égée considérée comme l'espace qui sépare de l'ennemi.

\section{b) Artémis et la colonisation}

La déesse intervient dans des légendes de fondations de cités liées à des déplacements en mer. Le cas le plus manifeste est la place que tient la déesse d'Éphèse dans l'établissement de Massalia puis des colonies de celle-ci. C'est elle qui par l'intermédiaire d'une femme devenue sa prêtresse choisit le site de la nouvelle ville, tournée ainsi que les autres colonies ostensiblement vers la mer. C'est elle qui désigne aux Péloponnésiens le site de Boiae par l'intermédiaire d'un lièvre, comme elle indique par sa statue aux hommes venus de Sparte l'endroit en Crète où suspendre leur course.

Dans la colonisation, elle privilégie le littoral : son action ne s'exerce pas pendant la traversée mais à l'arrivée, sur la côte tout de suite après le débarquement. Les fondations qu'elle détermine

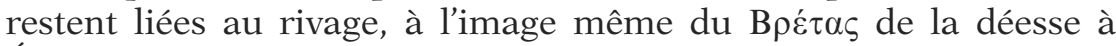
Éphèse dressé par les Amazones sur le bord de mer et qui fut à l'origine du sanctuaire (Callimaque, Hymne III, v. 237-239) ${ }^{124}$.

L'histoire de Lyktos amène deux remarques. Artémis est ainsi particulièrement rattachée aux liens que peuvent entretenir les Spartiates avec la mer : en témoignent les seuls ex-voto navals de la cité et l'expédition d'Agésilas qui semble placée sous sa protection, ce qui n'a rien d'étonnant pour une divinité majeure du panthéon spartiate. En retour, le culte crétois de Diktynna est attesté dans la cité laconienne.

${ }^{124}$ Picard 1922, p. 12, restitue l'existence d'un lieu de culte primitif près du Port-sacré adressé à un arbre; plus tard on le déplaça en construisant ailleurs le premier temple vers 700 a. C. Notons qu'un arbre marque également à Boiae l'emplacement choisi par la déesse. Picard 1922 (p. 312-320) interprète par ailleurs la procession éphésienne dite de Daitis comme un bain d'Artémis dans la mer, renvoyant à ses prérogatives marines remontant à la grande déesse égéenne. 


\section{c) Artémis et la pêche}

Le domaine réservé d'Artémis Diktynna est la pêche comme celui d'Artémis Agrotéra la chasse, c'est du moins ce qu'affirme Plutarque (De sollertia animalium 965c-d), et à ce titre on lui consacre les prémices du gibier des eaux. La déesse aime en effet la faune aquatique de façon générale (ibid., 983e-984c). Une épigramme datée des règnes d'Auguste-Tibère exprime l'ex-voto d'un surmulet de la part d'un pauvre pêcheur à Artémis Liménitis (du Port), maîtresse de tous les filets (Apollonidès, Epigramme 1). Le poisson est même emmené en procession lors d'une fête de la déesse $^{125}$. Ces différents types d'offrandes montrent les liens qu'entretient cette dernière avec la pêche et faune marine ${ }^{126}$. Il faudrait opérer la restriction suivante : toutes ces sources renvoient à une vision hellénistique. Dès lors, la faveur que semble accorder Artémis à la pêche se rapporte à l'assimilation opérée entre elle et Diktynna ou d'autres divinités locales protectrices de cette activité, assimilation favorisée on l'a vu par des similitudes topographiques. De la même façon elle a pu être associée à Atargatis. Dans l'Anthologie Palatine (VI, 24), une épigramme adressée à la déesse syrienne Atargatis faut-il comprendre - lui consacre de la part d'un pêcheur un filet. La similitude de ce poème et de l'offrande avec d'autres pièces de l'Anthologie dédiées à Artémis, la nature même de l'ex-voto soulignent la ressemblance entre le culte des deux déesses. Le filet, cher à Artémis-Diktynna, pourrait éclairer l'épiclèse de Bolas qui figure dans la dédicace du bateau de pierre de Géraistos. Une étymologie plus satisfaisante renvoyant à $\beta o ́ \lambda o s$ (le filet) évoquerait plutôt Artémis-Diktynna qu'Eileithyia comme le proposait Procope (Procope, De bello Gothico IV, 22, 23-29). Dès lors, il serait raisonnable de ne pas faire remonter l'offrande au-delà de l'époque hellénistique.

Le culte marin d'Artémis s'avère conforme à sa personnalité : déesse des frontières, de l'eschatia, des frontières entre la mer et la terre, entre le sauvage et le civilisé ${ }^{127}$. Dans ce sens elle humanise des divinités ou des rites barbares; elle autorise le passage d'un univers à l'autre. Dans ce domaine elle reste très proche des divinités anciennes, astucieuses, à qui elle est souvent assimilée ${ }^{128}$.

${ }^{125}$ Bodson 1978, p. 52; Athénée VII, 325a-d (citant divers auteurs).

${ }^{126}$ Bodson 1978, p. 49; Piccirilli 1981.

${ }^{127}$ Ellinger 1984. Cole 1999-2000 lie cet aspect à la notion de danger, dont la déesse protège.

${ }^{128}$ Piccirilli 1981; Chirassi 1964. 


\section{DIONYSOS}

La figure de Dionysos a donné lieu à une abondante bibliographie, et plus spécialement ces dernières décennies selon différentes approches se réclamant de l'anthropologie historique ou philosophique, du structuralisme et autres courants ${ }^{129}$. Ses liens avec l'eau et la mer ont fait l'objet de plusieurs études de qualité que nous ne prétendons pas remettre en cause et qui ont fait le tour de la question $^{130}$. Il s'agit ici d'appliquer la même grille d'analyse utilisée pour les autres dieux olympiens afin de comparer leurs spécificités.

\section{LES SOURCES}

Dans sa mythologie personnelle, Dionysos apparaît à plusieurs reprises en relation avec la mer; en revanche, il n'intervient pas dans les récits héroïques.

\section{Mythologie}

a) L'enfance de Dionysos

Durant son enfance, le dieu est mis en contact physique avec la mer, et ce dès sa naissance ${ }^{131}$. En effet sa mère Sémélé, rejetée par son propre père Cadmos, est enfermée avec l'enfant dans un coffre livré à la mer. Lorsque celui-ci finit par s'échouer sur une plage, les hommes découvrent à l'intérieur l'enfant vivant et la jeune femme morte, à qui ils rendent alors les honneurs funèbres (Pausanias III, xxiv, 3-4) ${ }^{132}$.

Son enfance ne fut guère plus paisible car Dionysos fut longtemps en butte à l'hostilité d'Héra. Le bébé fut confié à sa tante, la sœur de Sémélè, Ino, qui l'éleva avec son propre fils Mélicerte. C'est pour cette raison, dit-on, qu'Héra frappa de folie Athamas, l'époux d'Ino, ou Ino elle-même, ce qui devait provoquer le saut de celle-ci avec son enfant dans la mer. Dionysos est ainsi lié aux divinités

${ }^{129}$ Les études de référence sont celles de Jeanmaire 1951; Otto 1969; ajoutons-y les riches actes du colloque Dionysos 1991.

${ }_{130}$ Maass 1888; Glotz 1904, surtout p. 53-54; Nilsson 1968; Daraki 1982, p. 3-22 (attention cependant à un certain nombre de références erronnées en notes); Somville 1984, 1984, p. 14ss.; Lissarrague 1987 (chap. p. 104-118 «La mer vineuse»); Kossatz \& Kossatz-Deissmann 1992. En ce qui concerne les Anthestéries et le char bateau, voir seconde partie avec bibliographie.

131 Borzsák 1951, p. 204-205.

${ }^{132}$ Glotz 1904, p. 19. 
marines que sont devenus Ino et Mélicerte sous les noms de Leucothéa et Palaimon ${ }^{133}$.

Dionysos subit également la folie de Lycurgue qui poursuivit les nourrices du jeune dieu. Pour y échapper, il trouva refuge dans la mer et ce fut Thétis la déesse marine fille de Nérée qui le recueillit. Cette tradition apparaît dans la littérature dès l'Iliade (VI, v. 132-137) qui montre le dieu plongeant dans les flots. De même le Pseudo-Apollodore (Bibliothèque III, v, 1) évoque l'asile que lui procura Thétis dans la mer ${ }^{134}$. Une tradition «mixte» imagine les nourrices de Dionysos, les Hyades, allant confier Dionysos à Ino suite à la folie de Lycurgue (Hygin, Astronomie II, 21, 1); or le nom d'Hyades signifie Humides ${ }^{135}$. Nonnos (Dionysiaques XXI, v. 170-184) se plaît à dépeindre le séjour enchanteur de Dionysos dans la mer, choyé à la fois par Thétis, ses sœurs ainsi qu'Ino et son fils. De son passage dans la demeure marine de Thétis, Dionysos a acquis une connaissance de cet élément dans lequel il peut, adulte, à l'occasion plonger à nouveau pour s'y battre à son aise (Nonnos, Dionysiaques XXIII, v. 18-26) ${ }^{136}$.

Le fils de Sémélè doit ainsi la vie aux flots marins qui l'ont porté à sa naissance et l'ont ensuite recueilli en leur sein. En une autre occasion, le dieu montre qu'il n'a rien à craindre des dangers venus de la mer.

b) Dionysos et les pirates

L'Hymne homérique à Dionysos est uniquement centré sur l'épisode de Dionysos et des pirates tyrrhéniens. Au début du poème, le dieu, sous une apparence juvénile et avenante, paré d'un manteau éclatant, apparaît sur un promontoire. Surgit un navire de pirates

${ }^{133}$ Les mentions littéraires sont nombreuses et en ce qui concerne la mise en nourrice de Dionysos répètent les mêmes éléments : scholie à Odyssée V, v. 334; scholie à Euripide, Médée, v. 1284; Tzetzès, Ad Alexandram, v. 229; PseudoApollodore, Bibliothèque III, iv, 2-3; Lucien, Dialogues marins 6, 1-2; Hymnes orphiques LXXIV et LXXV; Nonnos de Panopolis, Dionysiaques V, v. 556-561; ibid. IX, v. 49-138. Plutarque, De l'amour fraternel, 492d et Camille, 5, 1-2 explique ainsi le culte rendu par les matrones romaines à Mater Matuta, identifiée avec Ino. Sur un rapprochement avec Thésée : Somville 1984, p. 15-16.

${ }^{134}$ Devant Lycurgue, Dionysos plonge à plusieurs reprises dans la mer, selon l'œuvre de Nonnos: Dionysiaques I, v. 26-30; ibid. XX, v. 343-395; ibid. XXI, v. 287-298.

${ }^{135}$ Chez le Pseudo-Apollodore, Bibliothèque III, iv, 2-3, l'ordre est inversé : après la mort d'Ino, Zeus confie Dionysos aux nymphes Hyades à Nysa.

${ }^{136}$ Dans le poème de Nonnos (Dionysiaques XXXIX, v. 93-122), Dionysos qui harangue ses troupes avant la bataille navale affirme haut et fort qu'il peut bénéficier de l'aide des divinités marines qu'il connaît bien et dont il est l'ami : Poséidon, Nérée, Thétis, Ino, Mélicerte, Glaucos, Phorcys ainsi qu'Éole et tous les vents. 
qui à sa vue accostent et l'enlèvent, le prenant pour un prince. Ils essaient de l'attacher mais aucun lien ne tient sur lui. Le pilote tente de plaider sa cause, reconnaissant en Dionysos un dieu ${ }^{137}$, en vain; le capitaine n'en a cure et commande de mettre à la voile. Le bateau est bientôt le théâtre de prodiges : du vin se répand sur le pont, emplissant l'embarcation d'une forte odeur; autour des voiles pousse le pampre et autour du mât un lierre portant fleurs et fruits. Ensuite le dieu lui-même se métamorphose en lion, tandis qu'un ours fait son apparition. Le lion bondit sur la seule personne à garder son sang-froid, le capitaine du vaisseau, tandis que le reste de l'équipage épouvanté se jette à l'eau. Ces hommes, tombant dans la mer divine ( $\varepsilon i \varsigma \alpha \ddot{\lambda} \lambda \alpha \delta \tilde{i} \alpha v$ ) se transforment en dauphins. Seul le pilote est épargné, retenu à bord par le dieu qui lui révèle son identité.

Cette légende n'est pas sans susciter quelques interrogations : pourquoi, quand et où le dieu se tenait-il ainsi sur un promontoire? Aucun élément ne permet de rattacher cet épisode à un moment ou à un autre de la biographie de Dionysos. Il se présente sous l'aspect d'un jeune homme, mais rien ne permet de comprendre s'il s'agit de sa réelle apparence extérieure ou d'une illusion. La fin de l'histoire reste en suspens : que deviennent le capitaine, le pilote du bateau? L'Hymne homérique à Dionysos diffère des autres Hymnes homériques dans le sens où le dieu n'est pas célébré par une avalanche de qualificatifs ou de lieux de culte; la légende ne sert pas non plus à expliquer un culte comme c'est le cas pour l'Hymne à Apollon Délien. En fait, ce poème ressemble davantage à la description d'un tableau, à la manière de celui décrit bien des siècles plus tard par Philostrate (Imagines I, 19) représentant le même sujet ${ }^{138}$.

La légende telle qu'elle est racontée par Philostrate se distingue en plusieurs points de la version originale. Dionysos apparaît non plus à terre, mais à bord d'un bateau dont il semble le maître, accompagné de Bacchantes qui célèbrent des hiéra; la terre lydienne n'est cependant pas loin. Une musique emplit l'atmosphère et la mer se fait lac pour le dieu. Des pirates tyrrhéniens sur un vaisseau de guerre se sont lancés à la poursuite de celui de Dionysos, appâtés par tous les bruits colportés à son sujet. Le navire dionysiaque se présente avec la proue ornée d'une panthère, animal que le dieu chérit entre

${ }^{137}$ Notons au passage que dans ce contexte marin, le pilote hésite à identifier Dionysos entre Zeus, Apollon ou Poséidon, et il craint que le dieu n'envoie contre le bateau des vents terribles et un ouragan (Hymne homérique à Dionysos, v. 19-25).

${ }^{138}$ Le commentaire de cette peinture par Bougot 1881, bien que daté, reste très riche de remarques diverses et d'érudition. 
tous et dont un exemplaire vivant se trouve à ses côtés, bondissant en direction des pirates. Un thyrse y fait office de mât soutenant des voiles de pourpre que couronnent du lierre et de la vigne d'où pendent des grappes; du vin coule comme d'une source depuis l'intérieur du bateau. Dionysos se tient à la proue, riant à la vue des Tyrrhéniens se transformant en dauphins après avoir perdu la raison. Philostrate achève le conte en l'expliquant comme la métamorphose d'hommes méchants en animaux secourables par la puissance du dieu.

On voit comme l'histoire a évolué, modifiant les circonstances, les acteurs et les actions. L'image qui ressort du dieu et ses rapports avec la mer sont très différents d'un récit à l'autre; il convient d'essayer d'en saisir la teneur pour les périodes qui nous occupent.

Hygin, écrivain de la fin du $\mathrm{I}^{\mathrm{er}}$ s. p.C. et du début du suivant, résume l'histoire telle que l'a écrite Aglaosthène ${ }^{139}$ selon une tradition naxienne (Hygin, Astronomie II, 17). Le dieu, alors enfant, embarque sur un bateau tyrrhénien afin d'être conduit avec des camarades à Naxos auprès des Nymphes qui doivent lui servir de nourrices. Lorsqu'il réalise les mauvaises intentions de l'équipage, il ordonne à ses compagnons de chanter. La musique charme les Tyrrhéniens qui se mettent à danser et dans leur entrain se jettent à l'eau sans même en avoir conscience; c'est alors que s'opère leur métamorphose, que Dionysos tient à commémorer en plaçant l'animal parmi les étoiles. Cette version naxienne valorise la musique du dieu et la douce folie qu'elle engendre.

Le Pseudo-Apollodore (Bibliothèque III, v, 3) met également la navigation du dieu en relation avec Naxos. Ici c'est lui qui loue les services d'une trière dont l'équipage tyrrhénien pousse vers l'Asie. Dionysos transforme alors le mât et les rames en serpents, fait surgir du lierre et de la musique sur le bateau; les marins pris de folie se précipitent à l'eau et se transforment en dauphins. Ce serait par cet épisode qu'il convainquit les hommes de sa nature divine.

Ovide ne pouvait que reprendre la légende dans ses Métamorphoses (III, v. 600-691) ${ }^{140}$. Le dieu embarque sur le bateau à Chios, alors que celui-ci fait escale sur la route de Délos. Dionysos, sous les traits d'un adolescent, est emmené de force par l'équipage qui l'a découvert endormi par l'ivresse. Hébété, le jeune homme demande qu'on le conduise à Naxos; les marins s'empressent alors de prendre la direction opposée. Le dieu, feignant de découvrir la supercherie, proteste. C'est alors que le bateau s'immobilise sur les eaux malgré les

${ }^{139}$ M. Wellmann, «Aglaosthenes», RE I, Stuttgart, 1894, col. 825 : l'auteur, cité pour la première fois par Diodore, doit être hellénistique.

${ }^{140}$ Somville 1984, p. 17-19. 
coups de rames, qui sont de même que les voiles entourées de lierre. Dionysos se montre alors ceint d'une couronne de vigne, une lance à la main, entouré de bêtes fauves. Les hommes apeurés se jettent à l'eau et se transforment en dauphins. Le seul épargné est le pilote qui avait pris la défense du jeune homme, suspectant un dieu sous une apparence humaine; c'est lui qui rapporte l'événement qui a déterminé sa vie : voué depuis lors à Dionysos, il accompagne son cortège. Hormis les détails précieux qu'affectionne Ovide, l'action de la divinité se manifeste encore par la croissance du végétal sur le bateau, empêchant toute manœuvre. Les animaux - panthères, lynx et tigres - constituent des apparitions, des illusions et non une réalité. Il est à noter particulièrement l'immobilité du bateau provoquée par le dieu; elle rappelle les eaux calmes de la mer de Philostrate.

La folie des pirates n'apparaît donc que tardivement dans la légende : l'Hymne homérique et Ovide ne l'évoquent pas. Tous deux montrent également un Dionysos jeune que l'on fait monter de force dans le bateau, quoiqu'il semble l'avoir provoqué. L'impression qui se dégage de ces deux récits est celle d'une épreuve que le dieu fait passer aux pirates; lorsque sont manifestes les pensées et actes des uns et des autres, il punit ou épargne. La transformation de Dionysos en bête fauve - en lion - n'est donnée que par le texte le plus ancien; dans les écrits postérieurs, il est accompagné d'une panthère et éventuellement d'autres animaux sauvages. Le lion et l'ours de l'Hymne homérique sont à rapprocher des métamorphoses successives de Thétis ${ }^{141}$ ou de Protée ${ }^{142}$; mais dans le cas de Dionysos, l'ours ne constitue pas une transformation de celui-ci. Au vin qui coule dans le bateau paraît dans les versions «naxiennes» se substituer la musique, les deux produisant le même effet sur les occupants du navire.

$\mathrm{Au}$ travers de tous ces récits mis à part celui d'Aglosthène, la puissance du dieu se manifeste doublement : par la pousse spontanée ${ }^{143}$, particulièrement autour des voiles, de plantes grimpantes : lierre, vigne, pampre, qui entravent l'avancée du bateau, et la transformation des hommes en dauphins qui devient effective une fois qu'ils touchent l'eau de la mer.

Trois documents iconographiques se rattachent à la légende ${ }^{144}$.

${ }^{141}$ Pindare, Néméennes IV, v. 62-64 : feu et lions; Pseudo-Apollodore, Bibliothèque III, 4-8 : feu, eau, thèrion.

${ }^{142}$ Odyssée IV, v. 450 ss. : lion, dragon, panthère, porc géant, eau, arbre.

${ }^{143}$ Pour Detienne 1985, p. 143-150, ceci est l'expression du «dieu du jaillissement».

${ }^{144}$ Nous avons écarté l'hydrie étrusque attribuée au Peintre du Vatican 238 (Toledo, Museum of art, inv. 82134) qui représente des hommes mi-hommes 
La célèbre coupe attique d'Exekias ${ }^{145}$ datée vers 530 a.C. représente le dieu barbu et couronné, seul, à demi allongé sur un bateau qu'entourent sept dauphins. À côté du mât s'élève un double cep, se ramifiant au-dessus de la voile en deux branches de part et d'autre de l'axe du navire; celles-ci portent des feuilles et sept grappes au total ${ }^{146}$. Sur la coque figurent également deux dauphins. Cette peinture s'apparente au texte homérique sans le reproduire : le fils de Zeus serait représenté après la transformation des pirates, ayant repris son apparence normale anthropomorphe, non plus sous des traits juvéniles mais sous ceux d'un homme d'âge mûr ${ }^{147}$.

Une amphore attique de la fin du $\mathrm{VI}^{e}$ s. a.C. ${ }^{148}$ figure quant à elle Dionysos assis le tyrse à la main dans un bateau, entouré de silènes dansant ou jouant de la musique; d'autres servent de rameurs. Une femme se tient à la poupe soufflant dans un aulète double. Du lierre entoure le navire dont on ne distingue aucune voile ni aucun mât. Aucun dauphin n'apparaît non plus dans cette scène, tandis que la mer est figurée par des ondes. Cette représentation s'avère bien distincte de la précédente et ne peut pas être rattachée à la légende de l'Hymne homérique. En revanche elle se rapproche de la version de Philostrate plaçant le dieu sur son propre bateau entouré de son cortège habituel. Le rapprochement de ces deux peintures contemporaines semble montrer l'existence simultanée de deux traditions se rapportant à sa présence sur une embarcation : l'une pourrait-on dire générique, et l'autre anecdotique évoquant directement la légende des pirates transformés en dauphins. Une anecdote historique montre par ailleurs que les Athéniens connaissaient et identifiaient immédiatement le type de Dionysos sur un bateau.

mi-dauphins tombant dans la mer. Seule une branche de lierre à gauche du cadre permet de rattacher la scène avec la légende dionysiaque. Dans le cadre supérieur défini par le peintre sur l'épaule du vase, figure un homme barbu avec la partie inférieure du corps en forme de poisson, nageant et tenant dans chaque main une sorte de thon. Ce personnage ne doit pas représenter Dionysos mais plutôt Triton ou une divinité équivalente. N'ont pas été retenus non plus d'autres vases avec dauphins, mais sans Dionysos (voir recensement iconographique de De' Spagnolis 2004, p. 54-60 et pl. XXXIII-XXXVI).

${ }^{145}$ Munich, inv. 2044; Gasparri 1986, 1 p. 489 no 788 et 2 p. 392. Delivorrias $1987, \mathrm{n}^{\circ} 75$.

${ }^{146}$ Daraki 1982, p. 5 insiste sur le parallélisme établi entre les sept dauphins et les sept grappes, ainsi que sur l'absence de délimitation de la mer - l'eau n'est pas représentée et les dauphins paraissent se répartir à la fois dans et au-dessus de la mer -; pour l'auteur, le peintre a voulu montrer «l'interpénétration des deux espaces». Somville 1984, p. 16-17.

${ }^{147}$ Lissarrague 1987, p. 94-96 : le vase représente plutôt une "épiphanie triomphale» du dieu, dans un espace sans limites.

${ }^{148}$ Frickenhaus 1912, p. 76-77; Gasparri 1986, 1 p. 489 no 790 et 2, p. 392. 
Lorsqu'Alcibiade revient de Byzance en 408 a.C. ${ }^{149}$, il organise une mise en scène pour son arrivée en Attique : le bateau amiral muni d'une voile de pourpre, avec des musiciens en robe dont un joueur d'aulète, fait son entrée dans le port à la manière d'un cortège dionysiaque $^{150}$.

La frise du monument de Lysicrate (fig. 10) ${ }^{151}$, chorège athénien en 335/334, divisée en deux séquences représente d'un côté la trans-

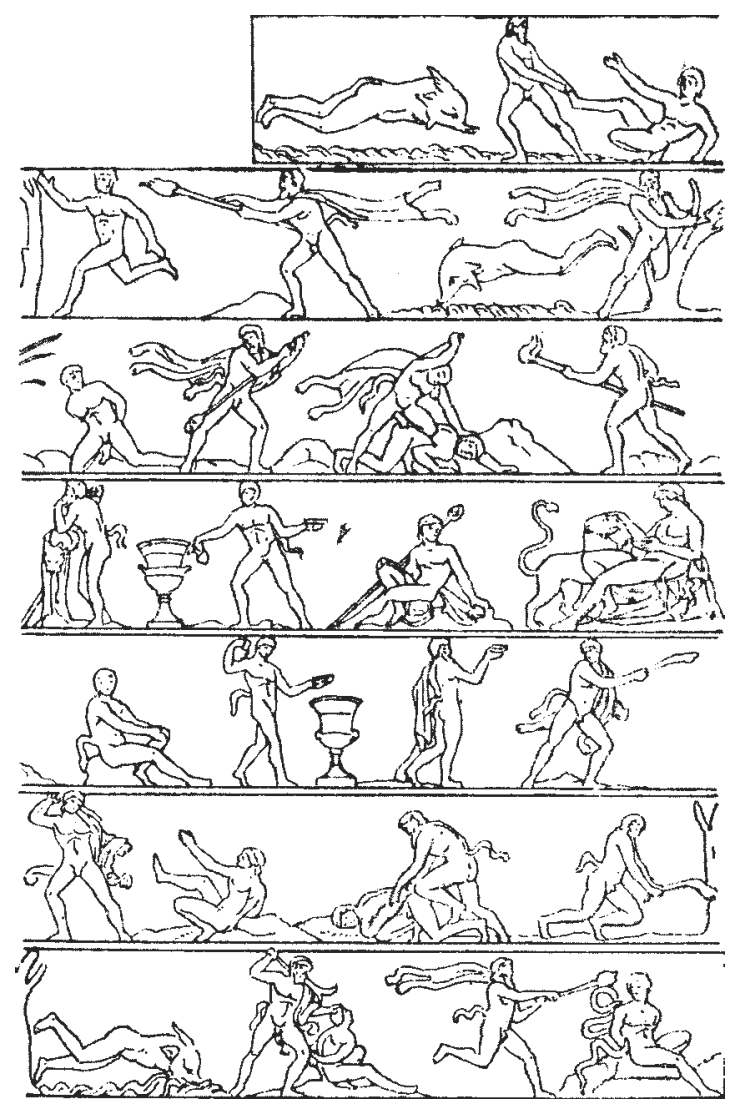

Fig. 10 - Frise du monument chorégique de Lysicrate (d'après De' Spagnolis 2004).

${ }^{149}$ Will 1972, p. 378-383.

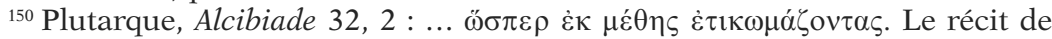
Diodore, Bibliothèque historique XIII, 69 n'évoque rien de tel.

${ }^{151}$ Kossatz \& Kossatz-Deissmann 1992, particulièrement la planche 107; Schefold 1967, p. 210-211; Gasparri 1986, 1 p. 489 no 792 et 2 p. 393; Ridgway 1970, p. 88-89. 
formation d'hommes en dauphins, de l'autre le dieu assis sur un rocher caressant un animal - un léopard? - encadré par deux silènes qui lui tournent le dos. Pas de bateau ni de plante grimpante dans cette scène : l'histoire est évoquée de façon minimale. Le dieu paraît extérieur à l'action : il en est seulement spectateur. Celle-ci est rendue par les hommes que poursuivent des Satyres sur la terre ferme. En effet, la scène semble se dérouler sur le rivage, et seul un personnage en cours de transformation, mi-dauphin mi-homme, se trouve au-dessus de vagues stylisées. Un tronc d'arbre figure à la limite de la terre et de la mer. La légende telle qu'elle est représentée sur un monument voué indirectement à Dionysos consiste en une adaptation très libre de l'Hymne homérique.

Les sources iconographiques témoignent du succès du motif à Athènes depuis la fin du $\mathrm{V}^{\mathrm{e}} \mathrm{s}$. jusqu'au milieu du $\mathrm{IV}^{\mathrm{e}} \mathrm{s}$. a.C. tout en révélant deux scènes différentes : Dionysos sur un bateau et la transformation des pirates. Ces scènes participent également au thème plus répandu de l'analogie entre le vin et la mer qui font de la navigation un motif courant de la vaisselle du banquet ${ }^{152}$.

Le mythe pourrait cependant être attesté également en Grande Grèce, à l'époque hellénistique, dans un contexte funéraire. Dans la province de Salerne, la nécropole de l'antique Nuceria Alfaterna a livré, lors d'une fouille de sauvetage, trois tombes du II ${ }^{e}$ s. a.C., dont une très richement ornée. La majorité de son matériel est réalisé en céramique plaquée d'or : une centaine de pièces décoratives de joaillerie (rosettes, perles, feuilles...), deux Erotes d'une dizaine de centimètres ainsi que huit dauphins anthropomorphes (long. max. $8 \mathrm{~cm}$ ); deux figurines de têtes de taureaux, portant traces de couleurs et de dorure, les accompagnaient ${ }^{153}$. M. De' Spagnolis restitue une couronne funéraire, composée des éléments dorés, y compris les «hommes-dauphins» qui renvoient à la légende dionysiaque. Selon son interprétation, le bijou serait porteur d'une signification eschatologique et l'adjonction de ces personnages d'une valeur politique, évoquant les Tyrrhéniens-Étrusques à un moment où Rome affirme son pouvoir sur le monde hellénisé ${ }^{154}$. Quoi qu'il en soit, la présence de ces images de transformation physique dans une tombe doit symboliser le voyage vers l'au-delà - avec la mer comme espace frontière.

${ }^{152}$ Lissarrague 1987; Bacci \& Lentini 1994, p. 175-178.

${ }^{153}$ De' Spagnolis 2004, p. 1-40 et pl. I-XXXII, XLI-LI.

${ }^{154}$ De' Spagnolis 2004, p. 40-77. 
c) Exégèses antiques

Les Anciens s'interrogeaient déjà sur la signification de ces mythes et de la figure dionysiaques. Leurs réflexions reflètent la manière dont les cultes ont pu être perçus par des érudits, ayant une approche plus riche d'informations mais aussi plus proche dans le temps et l'esprit que la nôtre.

Le passage de Dionysos dans la mer a ainsi pu être interprété comme la métaphore d'une manière ancienne de fabriquer le vin. En effet, l'eau de mer était censée posséder la faculté d'adoucir le vin (Athénée, Deipnosophistes I, 26b). Pour Héraclite (Allégories d'Homère 35, 6-8), cette opération permettait une meilleure conservation du vin. Le commentateur file la métaphore en comparant le frémissement de Dionysos effrayé avec le bouillonnement du vin nouvellement pressé ${ }^{155}$.

De façon générale, Plutarque (Isis et Osiris, 364d et 365a) définit

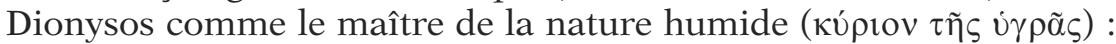
c'est pour cette raison qu'il est parfois appelé Hyès ${ }^{156}$. Cette humidité, qui apparaît comme une substance fécondante, s'insère dans une vision religieuse égyptienne de Plutarque qui veut ainsi rapprocher Osiris du dieu grec. Le moraliste insiste, par une citation de Pindare, sur l'aspect productif de Dionysos. L'argument est répété par ailleurs (Propos de table, 675d-676d) : le dieu possède ceci de commun avec Poséidon qu'ils sont «maîtres du principe humide et

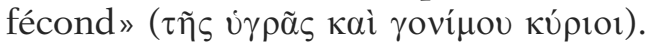

Ces commentaires montrent qu'à une époque tardive, si l'on concevait bien le lien entre Dionysos et les eaux douces et stagnantes, en revanche ses rapports avec la mer nécessitaient le recours à des explications renvoyant à des traits connus du dieu.

\section{Témoignages cultuels}

Selon l'épisode des Tyrrhéniens, la puissance de Dionysos s'opère également sur la mer, en partie peut-être à cause des expériences de son enfance. Certaines manifestations cultuelles montrent de surcroît qu'on pouvait l'honorer pour cette raison.

\footnotetext{
Dionysos.

${ }^{155}$ Detienne 1985, p. 149-150 reprend l'image pour définir la dynamis de ${ }^{156}$ Aristophane, Fragment 478.
} 
a) Attique

Plusieurs sources attiques - outre celles iconographiques de la légende des pirates - témoignent d'un culte rendu à un Dionysos marin.

Dans une comédie du Ve s., le commerce sur mer et l'importation de denrées diverses de toute la Méditerranée sont rattachés à Dionysos. La mer qui sert de scène à ces transferts de marchandises est alors qualifiée d'oinops pontos: la mer couleur de vin (Hermippos, Fragment 63 = Athénée, Deipnosophistes I, 27e-28a) ${ }^{157}$. Pour le III ${ }^{\mathrm{e}}$ s. a.C., une satire de Théophraste (Caractères III, 3) nous apprend que les fêtes des Dionysies athéniennes marquaient le début de la navigation ${ }^{158}$. Celles-ci sont célébrées au mois d'Élaphéboliôn, c'est-à-dire en mars-avril. Il est difficile de percevoir dans quel sens s'est opéré ce rapprochement : est-ce que les Dionysies ont été célébrées à cet instant de l'année car on attribuait un caractère maritime à la divinité, ou lui a-t-on donné a posteriori cette nature après s'être rendu compte de la coïncidence des dates? Par ailleurs deux trières athéniennes du $\mathrm{IV}^{\mathrm{e}} \mathrm{s}$. a.C. portent des noms évoquant sans nul doute possible le dieu. À une autre fête célébrée en son honneur, les Anthestéries, sont rattachées quelques représentations iconographiques montrant un Dionysos à l'intérieur d'un charbateau (voir infra p. 449 ss.).

L'ensemble de ces sources comprises entre la fin du VI ${ }^{\mathrm{e}}$ s. et le $\mathrm{III}^{\mathrm{e}}$ s. a.C. concourent à l'existence d'un culte marin à Dionysos en Attique au moins pour toute l'époque classique ${ }^{159}$. Il faut signaler cependant, pour le dernier quart du $\mathrm{II}^{\mathrm{e}}$ s. a.C., la réalisation dans un atelier attique de parasèmes d'un bateau représentant d'un côté le fils de Sémélè et de l'autre Ariane (voir infra p. 257 s. et fig. 13).

\section{b) Péloponnèse}

- Argolide

À Argos, Pausanias (II, xxiii, 1) signale un temple de Dionysos que la tradition fait remonter aux Argiens de retour de Troie. En effet, ceux-ci subirent leur lot de tempête au niveau de l'Eubée. Les hommes qui purent joindre la terre ferme au cap Kaphèreus situé à l'extrémité sud-est de l'île furent accablés par la faim et le froid.

${ }^{157}$ Davies 1978, p. 74.

158 Otto 1969, p. 155.

${ }^{159}$ Ceci explique le comique des vers 203-205 des Grenouilles d'Aristophane, dans lesquels Dionysos est présenté comme un incompétent en matière de navigation: Davies 1978, p. 74. 
Priant alors quelque divinité d'intervenir en leur faveur, une grotte leur apparut où s'étaient réfugiées des chèvres sauvages : celles-ci leur fournirent viandes et peaux. Or, cette grotte était consacrée à Dionysos et abritait une statue du dieu. Les Argiens, lorsqu'ils réembarquèrent enfin vers leur patrie, emmenèrent le xoanon et lui établirent un culte dans leur cité. Le sanctuaire se trouve à l'extérieur de la ville, au-delà de la porte sud-est Cilarabis, le long d'une voie. Le récit de Pausanias met en avant l'ancienneté du culte par le récit étiologique et par la mention d'un xoanon. Celui-ci figure peutêtre sur des monnaies impériales ${ }^{160}$. L'action du dieu se manifeste en marge de la navigation : il est le dieu $\sigma \omega \tau \eta ́ \rho$ qui pallie les difficultés dues au naufrage. Originellement il était situé dans un lieu extrême, un promontoire ${ }^{161}$, vide d'hommes et d'habitations, régnant depuis une grotte sur des chèvres sauvages. Le fond de l'histoire atteste le transfert d'une statue éginète rapportée à Argos, fait couramment pratiqué dans l'Antiquité.

À Hermione, le dieu est vénéré sous l'épiclèse de Mélanaigis, en l'honneur duquel on célébre tant des jeux musicaux que sportifs (Pausanias II, xxxv, 1) ${ }^{162}$. Ces derniers consistent en concours nautiques : régates, mais aussi de natation ou de plongée ${ }^{163}$. L'épiclèse «à la peau de chèvre noire» doit renvoyer à la statue de culte, peut-être représentée sur des monnaies ${ }^{164}$. La situation topographique d'Hermione, bâtie sur un promontoire séparant deux ports naturels est tout à fait adaptée à ce genre d'activités. Il est difficile en revanche de dater le culte et les jeux nautiques, Pausanias décrivant alors le site de la nouvelle Hermione ${ }^{165}$.

Un fragment hellénistique (Philochoros, Fragment 194) semble mentionner le culte d'un Dionysos Halieus à Haliées, située à l'ouest d'Hermione ${ }^{166}$. L'épiclèse renvoie au nom de la ville mais aussi à la mer conçue en tant qu'öis, l'élément salé.

${ }^{160}$ Imhoof-Blumer \& Gardner 1964, p. 40 et pl. K xlvi souligne le caractère atypique de cette représentation de Dionysos, à son avis très ancienne.

${ }^{161} \mathrm{Le}$ site est connu pour ses nombreux naufrages: Geyer 1903, p. 6-7; Semple 1932, p. 618-619 et 634 .

${ }_{162}$ Will 1955, p. 222; Eitrem 1935, p. 54.

${ }^{163}$ Il est difficile de choisir entre les deux sens du mot кó $\lambda \cup \mu \beta o \varsigma$ : étymologiquement, il se rapporte au saut dans l'eau; de façon générale, il s'applique à toute immersion y compris la natation. Daraki 1982, p. 8 insiste sur le fait que ce sont les seuls concours connus de ce type.

${ }^{164}$ Imhoof-Blumer \& Gardner 1964, p. 50 et pl. M1 : le dieu est représenté un canthare à la main.

165 À ce sujet, voir supra p. 117.

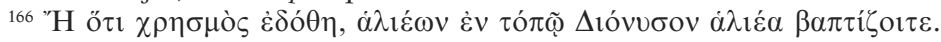


- Achaïe

Les habitants de Patras rapportent à propos de leur Artémis Triklaria une légende dans laquelle Dionysos intervient (Pausanias VII, xix, 6-10). Courroucée par les rencontres amoureuses qu'un jeune couple contrarié opérait dans son temple, Artémis imposa à la cité un sacrifice annuel d'un jeune garçon et d'une jeune fille qui ne prendrait fin, selon un oracle, qu'avec l'arrivée d'un roi inconnu apportant avec lui une divinité étrangère. Par ailleurs, lors du partage du butin qui suivit la guerre de Troie, le roi thessalien Eurypyle se vit octroyer un coffre contenant une statue œuvre d'Héphaistos lui-même. Eurypyle ouvrit la boîte et fut pris d'une folie entrecoupée de quelques instants de conscience. Dans cet état, il fit voile non vers son pays, mais vers Kirrha où il débarqua pour consulter l'oracle. On lui répondit d'établir son coffre et lui-même à l'endroit où il serait témoin d'un sacrifice inhabituel. La suite se laisse deviner: Eurypyle arrive à Patras avec son coffre et les affaires s'arrangent pour tout le monde. La statue en question est celle de Dionysos, ce qui explique dans l'histoire la folie du Thessalien et l'origine étrangère du dieu ${ }^{167}$. L'introduction du culte dionysiaque à Patras est ainsi, selon la tradition, rattachée aux errances d'une statue qui dirige le bateau là où elle veut se rendre. Le récit précise que des vents poussèrent les navires d'Eurypyle jusqu'à leur destination; ceux-ci doivent résulter selon toute logique de l'action divine. Les fêtes des Dionysies honorent à la fois le dieu et le roi ${ }^{168}$.

\section{- Laconie}

La cité de Brasiae vénère particulièrement Dionysos (Pausanias III, xxiv, 3-4). Les habitants racontent en effet que c'est chez eux qu'échoua le coffre dans lequel il était enfermé avec sa mère. Ils montrent de surcroît la grotte où Ino aurait recueilli son neveu. Ces traditions servent aux Brasiates pour expliquer le nom de leur cité : ekbebrasthai signifie en effet «être rejeté par les flots» ${ }^{169}$.

${ }^{167}$ Héphaistos possède également un lien avec Dionysos: lui aussi fut recueilli par Thétis dans son enfance : Iliade XVIII, v. 393-408; Pseudo-Apollodore, Bibliothèque I, iii, 5.

${ }^{168}$ Dionysos figure parmi les types monétaires de la cité : Imhoof-Blumer \& Gardner 1964, p. 76 et pl. Qv.

${ }^{169}$ Pausanias est le seul à expliquer ainsi le nom; de nombreuses autres sources le rattachent à Prasiai ou Prasia : Musti \& Torelli 1986-1991, III p. 276. 


\section{c) Béotie}

À Tanagra, le temple de Dionysos renferme deux statues : l'une de Dionysos attribuée à Calamis sculpteur du Ve s. a.C. et l'autre d'un Triton acéphale (Pausanias IX, xx, 4-5). Les habitants racontent à son sujet plusieurs histoires. Selon la première, les femmes de la ville ont coutume de se purifier dans la mer avant les fêtes dionysiaques. Il leur arriva à cette occasion d'être attaquées par un Triton que Dionysos tua en un combat singulier, suite à leurs prières. Une deuxième tradition, à laquelle adhère Pausanias, veut qu'un monstre marin s'attaquait aux bêtes et petites embarcations du littoral. Les habitants n'en vinrent à bout qu'à l'aide d'un stratagème : ils l'enivrèrent et lui coupèrent la tête une fois endormi. Ce passage indique que les Dionysies de Tanagra comportaient un rituel de purification qui avait lieu dans la mer ${ }^{170}$. La présence d'une statue d'un Triton sans tête dans le sanctuaire met le dieu en relation avec le milieu maritime, lien auquel les deux récits tentent de donner une explication. Les monnaies reflètent le rapprochement entre Dionysos et Triton : sous un toit supporté par deux atlantes, le premier se tient debout tenant un canthare et le thyrse; en dessous-de lui figure un Triton nageant ${ }^{171}$.

d) Thessalie

À Pagasae ${ }^{172}$, à l'époque classique, Dionysos était vénéré sous l'épiclèse de Pélagios. Le dieu intervint en faveur de l'un de ses fidèles, mort noyé : il apparut en rêve à un pêcheur, lui ordonnant de restituer les os du mort à sa famille afin qu'elle pût lui rendre les honneurs funèbres (Théopompe de Chios, Fragment 352, éd. Jacoby $=$ Schol. Iliade XXIV, 428) ${ }^{173}$. Pagasae se trouve en Thessalie; il s'agit du port de la cité de Phères où habitait le défunt. Le tout laisse supposer que ce dernier était lui aussi pêcheur et que tout particulièrement dans le cadre de ses activités, il vouait un culte à Dionysos Pélagios. Par ailleurs, la presqu'île du Pélion qui ferme à

\footnotetext{
${ }^{170}$ Moggi \& Ossana 2010, p. 332-334 proposent de situer le bain rituel au Délion, port de Tanagra cité en IX, xx, 1.

${ }^{171}$ Imhoof-Blumer \& Gardner 1964, op. cit., p. 114 et pl. xvii-viii. Le numismate considère que le type de la statue de Dionysos représentée sur ces monnaies ne peut correspondre à celle mentionnée par Pausanias, mais doit être de date plus récente. Le Triton constituerait alors une contremarque monétaire de la cité de Tanagra. En revanche, il pense reconnaître la statue de Calamis dans une monnaie augustéenne : le dieu debout tient un sceptre d'une main et de l'autre une grappe : ibid. et pl. xix.

${ }^{172}$ Le site se trouve tout à proximité de la ville moderne de Volos, dans le Pélion.

${ }^{173}$ La lecture de ce passage a été établie par Maass 1888, p. 70-80.
} 
l'est le golfe de Pagasae était consacrée aux Néréides et à Thétis ${ }^{174}$ (Hérodote, Enquête VII, 188-192). Un culte de Dionysos en relation avec la mer s'explique tout particulièrement à cet endroit, puisqu'il aurait passé son enfance non loin de là.

\section{e) Asie Mineure}

\section{- Ténédos}

Pour l'île de Ténédos, située au large de la Troade, Élien nous rapporte une coutume étrange concernant le culte de Dionysos Anthroporrhaistès (Fléau des hommes). Les habitants prennent soin d'une vache pleine en l'honneur du dieu et l'accouchent comme une femme. Le veau nouveau-né lui est alors sacrifié; pour cela on le chausse de cothurnes. L'homme qui a porté le coup fatal est poursuivi par la foule à coups de pierres jusque la mer. En l'absence d'autres sources ou commentaires, il faut tenter de rapprocher cette pratique d'autres faits connus. Le veau représente un enfant nouveau-né : son sacrifice ressemble à un sacrifice de substitution. Un enfant en bas âge, une course jusque la mer: ces éléments rappellent la légende d'Ino et Mélicerte se précipitant dans les flots. Dionysos dans la mythologie est rapproché de Mélicerte par des liens de parenté : cousin de celui-ci, il est également son frère de lait; de plus le saut de Dionysos auprès de Thétis rend leur enfance similaire, marquée par une plongée marine. À Ténédos, les deux figures divines ne font qu'une ${ }^{175}$. Par ailleurs, la course du sacrificateur jusque dans la mer peut s'expliquer comme une purification de celui-ci après le meurtre qu'il vient de commettre. L'épiclèse du dieu s'avère en revanche plus difficile à expliquer.

\section{- Lesbos}

$\mathrm{Au}$ nord de Lesbos, à Méthymna, les habitants vénèrent Dionysos Phallène (Pausanias X, xix, 3). Le culte a pour origine une statue en bois d'aspect étranger que des pêcheurs ont retirée de la

${ }^{174}$ Maass 1888, p. 71-72.

${ }^{175}$ La scholie due à Tzetzès de Lycophron, Alexandra, v. 229 évoque un culte

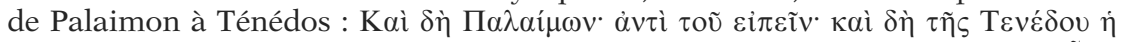

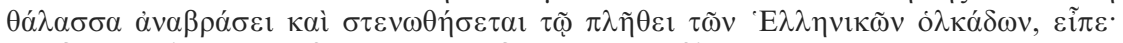

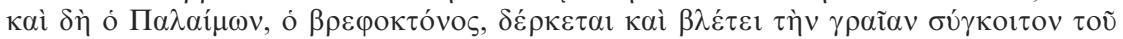

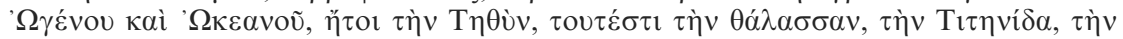

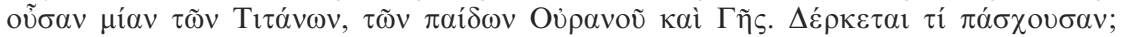

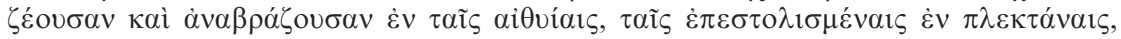

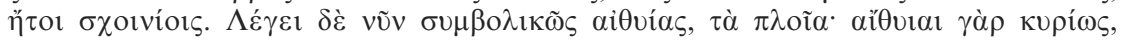

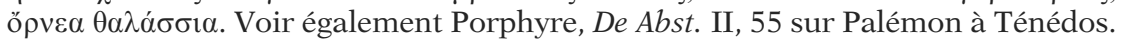


mer dans leurs filets. Consultée, la Pythie leur enjoignit d'honorer le xoanon comme un Dionysos avec l'épiclèse qu'elle leur enseigna. Le fait est confirmé par Eusèbe de Césarée qui s'insurge contre l'adoration d'un malheureux bout de bois préconisée par l'oracle delphien ${ }^{176}$. L'étymologie de celle-ci, du mot phallos, indique un culte lié à la fécondité ${ }^{177}$. Dionysos figure par ailleurs sur des monnaies de Mytilène, associé à une proue ou une stylis ${ }^{178}$.

\section{- Smyrne}

Les Smyrniotes célèbrent leurs Dionysies au printemps avec la promenade d'un bateau monté sur roues autour de l'agora, cérémonie qu'ils expliquent par une attaque surprise des Chiotes venus débarquer sur leur rivage (Aelius Aristide, Prosphonétique de Smyrne 473474; Politique de Smyrne 402-403; Philostrate, Vie des sophistes I, 25, 530-531 = voir corpus p. 534 et 536). Ces sources tardives constituent pour le moment nos seules informations sur le culte de Dionysos à Smyrne qu'il est ainsi difficile de dater (voir infra p. 447 s.).

\section{ANALYse}

Géographie du culte

Ces quelques attestations ne permettent de dessiner une géographie cultuelle que dans ses grands traits ${ }^{179}$. Présent sur la côte d'Asie Mineure et en particulier sur deux îles, en Grèce continentale, le culte marin de Dionysos apparaît lié à des golfes : à Patras, Argos, Hermione, Pagasae, Tanagra.

Il occupe une place notable en Thessalie : non seulement il est honoré à Pégasai, mais encore le culte de Patras est rattaché à cette région par l'intermédiaire d'Eurypyle. Par ailleurs la statue que ce dernier transporte est considérée comme troyenne, c'est-à-dire de la même région que Ténédos et Lesbos.

${ }^{176}$ Eusèbe de Césarée, Préparation évangélique V, 36.

${ }^{177}$ Le texte de Pausanias pose problème : dans les manuscrits l'épiclèse se lit

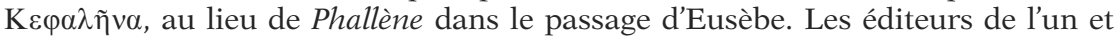
l'autre auteur ont longtemps hésité entre les deux substantifs. Finalement la seconde leçon est adoptée par tous, pour des raisons philologiques de formation des substantifs et par rapprochement avec le culte phallique de Dionysos. Svoronos 1914 garde en revanche la première leçon, ce qui lui permet de reconnaître dans le xoanon la figure de proue d'une épave.

178 Svoronos 1914, p. 103; Wroth 1894, p. 195-196 n 126-139, pl. xxxviii, $\mathrm{n}^{\circ} 16-19\left(\mathrm{II}^{\mathrm{e}}-\mathrm{I}^{\mathrm{er}}\right.$ s. a.C. $)$.

${ }^{179}$ L'article de Mass 1888, p. 79 aboutissait aux mêmes conclusions de répartition géographique. 
À Athènes, le culte de Dionysos s'avère particulièrement important à la fin de l'époque archaïque et durant toute l'époque classique. Après cette période, il semble s'affaiblir; s'il subsiste ailleurs - en Asie mineure particulièrement -, il ne paraît plus très bien compris mais justifié par la tradition. Signalons cependant deux bateaux du début de l'époque romaine portant le nom du dieu : Dionysos en grec et Liber Pater en latin.

\section{Personnalité marine de Dionysos}

À travers ses mythes et ses cultes, le fils de Sémélè est mis en relation avec la mer, surtout dans un contact intime avec l'eau. Il a plongé et vécu dans la mer; on célèbre en son honneur des concours de natation. Par ailleurs son mythe et certains de ses rites attribuent une fonction cathartique à la mer : elle sert à purifier, à transformer le négatif en positif. Le plongeon dans la mer apparaît aussi comme un voyage vers l'au-delà ${ }^{180}$. Comme l'a bien montré J.-M. Pailler, Dionysos se révèle comme une "divinité de passage(s)» notamment par la mer qui unit et sépare à la fois ${ }^{181}$.

Il apparaît aussi comme un dieu navigateur à travers l'iconographie, lors de processions mais aussi à travers les traditions se rapportant à des statues de culte. Plusieurs noms de vase à boire sont empruntés au vocabulaire nautique ${ }^{182}$. À deux fois il arrive par mer : à Lesbos, à Patras, sous la forme d'une statue à l'air étranger. Tout ceci pourrait indiquer un caractère maritime de Dionysos peutêtre lié à l'arrivée du dieu par bateau ${ }^{183}$.

De manière générale, il est associé à une mer calme : les navires qui naviguent en sa présence ne connaissent pas de déchaînement des éléments. Lors de la seule tempête mise en rapport avec lui, celle des Argiens, il intervient pour aider les naufragés à terre. Le commerce maritime évoqué par Hermippos, prospère et ne connaissant apparemment aucun obstacle, se déroule sur l'oinops pontos : une mer obscure, profonde mais propice à la navigation, très doucement agitée ${ }^{184}$. Une histoire de beuverie racontée par un auteur de la première moitié du $\mathrm{III}^{\mathrm{e}} \mathrm{s}$. a.C. est à cet égard significative. Elle met

${ }^{180}$ Daraki 1982, p. 8 et 20.

${ }^{181}$ Pailler 1995.

${ }^{182}$ Vélissaropoulos 1980, p. 90; Athénée, Deipnosophistes XI, 473d, 475b, 497b, XI, 481f, 482d-e, 496, 500f, 782. Sur des vases en forme de bateau, voir infra p. 381-382.

${ }_{183}$ Parke 1977, p. 109.

${ }^{184}$ Daraki 1982, p. 17 évoque les vases à boire sur lesquels figurent des embarcations : une fois remplis de vin, elles ont l'air de naviguer sur le liquide. Sur le rapprochement entre la mer et le vin, voir également Davies 1978, p. 72 ss. 
en scène des hommes dans un état si avancé d'ébriété que, s'imaginant se trouver dans un bateau au bord du naufrage, ils jettent pour l'alléger tout le mobilier par les fenêtres (Timée de Tauromenium, Fragment 149 = Athénée, Deipnosophistes II, 37b-e). Le doux roulis de l'ivresse peut ainsi rapprocher la mer de Dionysos comme l'indique le nom de «Trière» donné à l'endroit; mais lorsque les creux se font plus gros, c'est la panique et il n'est plus question de Dionysos, mais de "dieux sauveurs».

Divinité de la navigation tranquille, voire de la légère ivresse qu'elle peut procurer, Dionysos n'est cependant pas étranger à la profondeur mystérieuse des eaux qui peuvent s'avérer accueillantes et positives.

\section{HERMÈS}

La protection d'Hermès sur les voyageurs est bien connue : dieux des carrefours et des routes, il est souvent invoqué et honoré lors des déplacements terrestres. Il convient dès lors de considérer dans quelles mesures ce rôle du fils de Zeus et de Maia s'étend également sur les routes maritimes. Les sources s'avèrent peu nombreuses à ce sujet : aucun récit mythologique ne met en scène le dieu dans un contexte marin. Mais à quelques attestations de lieux maritimes qui lui sont consacrés, s'ajoutent plusieurs documents évoquant des pratiques cultuelles le mettant en relation avec la mer.

\section{SOURCES}

\section{Lieux consacrés}

a) Eubée

Une inscription d'Érétrie témoigne de la dédicace d'un Hermès par les aeinautai datée du Ve s. a.C. ${ }^{185}$. Ces hommes sont définis comme des marins réunis en association, plus certainement des administrateurs d'affaires maritimes au sens large ${ }^{186}$. Il est difficile

qui signale entre autres choses le mot pitylos désignant le clapotis de la mer comme celui du vin.

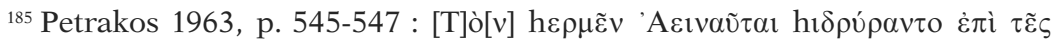

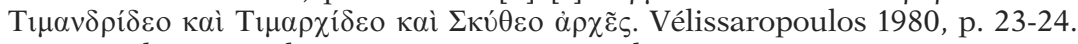

${ }^{186}$ Vélissaropoulos 1980, p. 23-24; Kontoleon 1963. 
cependant de définir la nature de ce groupement et surtout de considérer si l'offrande n'est pas le fait de notables locaux qui financent des travaux d'aménagement sur le territoire d'Érétrie. L'érection d'un Hermès peut simplement renvoyer à l'établissement d'une borne à un carrefour de la cité.

\section{b) Thrace}

Hermès est vénéré à Ainos, sur le littoral thrace à l'embouchure de l'Hèbre. Un poème mutilé de Callimaque (Iambe III) fait parler la statue du dieu qui raconte son histoire. Emportée par une crue du Scamandre jusqu'à la mer, elle semble pêchée une première fois et manque alors d'être brûlée sur un bûcher - ce qui laisse supposer qu'il s'agit d'un xoanon ${ }^{187}$. Par quelque prodige, la statue est rejetée à la mer et repêchée à nouveau. On sait par ailleurs que la statue, reconnue alors comme divine, reçut différentes marques d'honneurs : un sanctuaire sur le rivage, offrandes de poissons de la part des pêcheurs puis, sur l'ordre d'Apollon, une place dans la cité188.

c) Ionie

Le promontoire sud de la péninsule d'Érythrées était consacré à Hermès (Hymne orphique XXVIII, v. 8-20). Ce cap appelé Kôrykos, tourné au sud vers Samos, ferme le golfe de Téos. Le dieu est alors

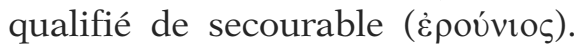

\section{d) Carmanie}

La flotte de Néarque double lors de son périple indien l'île de Kataiè, consacrée à Hermès et Aphrodite (Arrien, Indica XXXVII, 10-11). Déserte, sans relief, elle n'est fréquentée que par des chèvres, offrandes des habitants du littoral, redevenues sauvages. L'assimilation du dieu local à qui est vouée Kanaiè est due au caractère du lieu : un endroit inhabité, où les animaux vivent en liberté.

e) Afrique

À l'est de Carthage, le promontoire qui s'avance le plus dans la

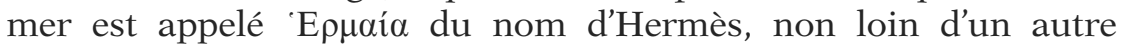
consacré à Apollon (Strabon XVI, 3, 13) ${ }^{189}$. Le géographe précise par

${ }^{187}$ L'histoire est connue également par une «diégèse» : la statue fut seulement blessée à l'épaule et le feu ne put la brûler; après ces vaines tentatives, les hommes la rejetèrent à la mer. Voir commentaire de l'édition Budé, p. 172.

${ }^{188}$ Ibid.

${ }^{189}$ Il s'agit du cap Bon : Vélissaropoulos 1980, p. 137; Rougé 1966, III p. 1477. 
ailleurs que le site est rocheux (Strabon XVI, 3, 16). Ce cap est bien connu par un certain nombre de périples qui ne manquent pas de le signaler (par ex. Pomponius Mela, Chorographie I, 7, 34) pour le golfe qu'il ferme.

\section{Consécrations marines}

Le culte marin d'Hermès apparaît à travers plusieurs poèmes de l'Anthologie Palatine $^{190}$. Une épigramme du ${ }^{\text {er }}$ s. p.C. (Philippe de Thessalonique, Épigramme VIII = Anthologie grecque VI, 5) exprime l'offrande d'un pêcheur au dieu. L'homme qui met un terme à ses activités après une vie de labeur lui consacre tout son attirail. Le thème est repris dans deux compositions tardives (Anthologie Palatine VI, 28-29) où Hermès est invoqué sous l'épiclèse d'Ériounios (bienfaisant) ${ }^{191}$. Ces poèmes sont à rapprocher d'un autre, de la première moitié du $\mathrm{III}^{\mathrm{e}}$ s. a.C., qui marque également le don d'un pêcheur, à l'heure de la retraite, de ses instruments de travail (Léonidas de Tarente, Epigramme LII) ${ }^{192}$. Un autre poème anonyme dédie une panoplie de pêche bien fatiguée au sanctuaire d'Hermès (Anthologie Palatine VI, 23). Celui-ci consiste en une grotte battue par les flots dans laquelle se trouve le dieu sur un rocher - peut-on supposer sous forme de statue - et qui sert de refuge aux mouettes. Hermès semble ainsi recevoir particulièrement des marques de vénération de la part des pêcheurs, et ce depuis l'époque hellénistique jusque dans l'Antiquité tardive.

Une pièce hellénistique marque encore la consécration à cette divinité de diverses denrées comestibles : raisin, galette, fromages, farine et vin (Phanias, Épigramme V = Anthologie Palatine VI, 299). Ces cadeaux s'adressent à Hermès Enodios (protecteur des routes) associé à Aphrodite; le dédicant promet également de leur sacrifier sur la grève un chevreau. Le lieu du sacrifice promis ainsi que le culte commun avec Aphrodite laissent supposer que ces offrandes correspondent à un voyage maritime ou littoral.

Quelques sources navales évoquent implicitement le dieu. Le caducée figure sur l'éperon hellénistique d'Athlit retrouvé au large

${ }^{190}$ Mazaubert 1937, p. 313-324.

${ }^{191}$ Cette épiclèse est appliquée à Hermès dès l'Iliade (XX, v. 72).

${ }^{192} \mathrm{Il}$ pourrait s'agir également de Pan, à qui s'adresse également ce type d'offrandes dans l'Anthologie Palatine. En revanche, nous ne suivons pas l'interprétation de Mazaubert 1937, p. 313-315 qui reconnaît Poséidon à cause de la présence, parmi les objets cités, d'un trident précisément défini comme l'arme d'un dieu : si l'ensemble était consacré à celui-ci, son nom ne serait pas rattaché à

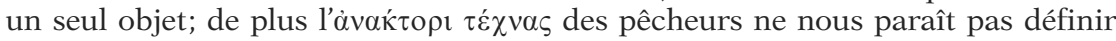
précisément sa personnalité. 
d'Israël (voir infra p. 262 s. et fig. 16). Ce motif est aussi représenté sur quatre ancres de plomb trouvées en Méditerranée (voir infra p. 343). Le nom de Mercuri apparaît associé à celui d'Isis également sur un jas de plomb (voir infra p. 317, cat. I23).

Un parasèmon daté apparemment du $\mathrm{I}^{\mathrm{er}} \mathrm{s}$. p.C. porte en relief l'image du dieu (voir infra p. 257). Par ailleurs, un relief fragmentaire du British Museum représente Hermès et Cybèle opérant des libations à côté d'une proue de navire (fig. 11). Entre eux, figure un troisième dieu qui pourrait être Sérapis (?); à l'arrière-plan sont représentés deux guerriers brandissant leurs armes, tandis que sur la proue est assis un personnage dont il ne subsiste que les jambes ${ }^{193}$. L'auteur de l'article suppose une origine d'Asie Mineure du relief, peut-être Cyzique (?).

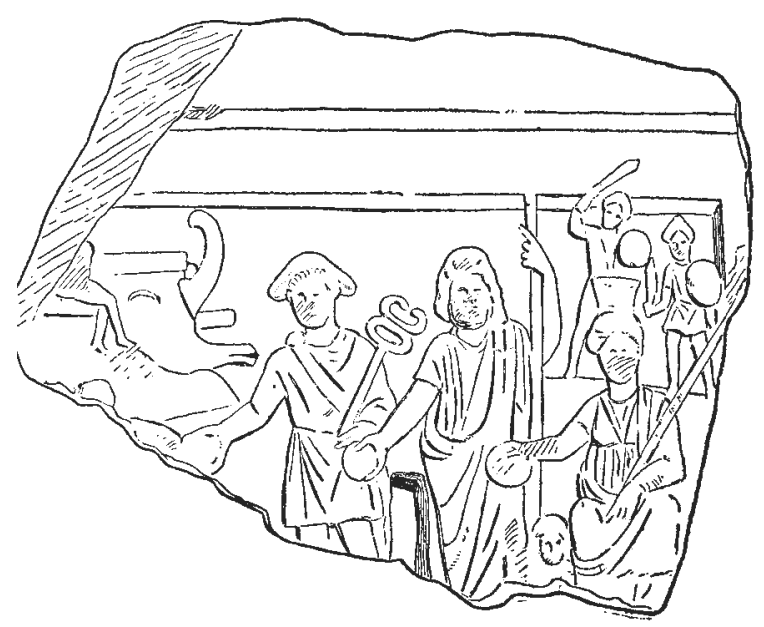

Fig. 11 - Relief de marbre figurant Hermès dans un contexte naval (British Museum, inv. 80. 5-4. 1; d'après Conze 1891).

Enfin un poisson est particulièrement voué à Hermès : le bogue $(\beta \text { ó } \alpha \xi)^{194}$.

${ }^{193}$ Inv. 80. 5-4. 1. Le document a seulement été publié par une brève notice (Conze 1891).

${ }^{194}$ Athénée VII, 287a; 325b. Bodson 1978, p. 52. 
ANALyse

Les sources peu nombreuses évoquent un culte marin d'Hermès peu développé ou du moins pas de façon ostentatoire. Quelques lieux isolés lui sont attribués : île déserte, promontoire rocheux, grotte marine. Ces endroits ne semblent pas marqués par une construction cultuelle - temple ou autel - : au mieux une statue l'y représente ${ }^{195}$.

Mis en rapport avec la navigation, il est honoré par les humbles pêcheurs ${ }^{196}$ qui lui consacrent de simples ex-voto ou l'animal qu'il privilégie : le chevreau. Il est à deux reprises associé à Aphrodite lors de l'évocation de caprins.

De façon générale, toutes les sources indiquent un culte d'Hermès en relation avec la mer pour l'époque hellénistique se poursuivant sous le Haut-Empire : dans les classes impériales, pas moins de cinq bateaux portent le nom du dieu (voir infra p. 286) ${ }^{197}$. Pour les périodes antérieures, rien ne laisse deviner une vénération particulière à Hermès en matière de navigation, comme si les routes maritimes n'étaient pas de son domaine.

${ }^{195}$ Voir par ex. le pilier hermaïque et les pêcheurs d'une péliké attique du Ve s. a.C. : Icard \& alii, p. 380 et pl. 114,3 (avec réf.).

${ }^{196}$ Icard \& alii 2011 : divinité de la "petite pêche traditionnelle».

${ }^{197}$ Voir aussi infra p. 248, note 16 le cas discuté de la statuette de Mercure de l'épave de Camarina. 



\section{CONCLUSION}

Les divinités olympiennes reçoivent indéniablement des spécificités ou des marques de dévotion maritimes. Légendes, sanctuaires, épiclèses, ex-voto rattachent ces dieux au monde de la mer, à travers tout le bassin méditerranéen et durant toute l'Antiquité grecque.

Le fait le plus notable est l'absence dans ce tableau de quatre membres du panthéon ${ }^{1}$ : Arès, Hadès, Héphaistos, Hestia et Hadès. On comprend sans peine les raisons d'exclure toute allusion au seigneur des Enfers dans un contexte maritime déjà suffisamment périlleux et mortel. En ce qui concerne la seconde divinité, absolument aucune source ne la met en relation avec la mer, si ce n'est une île d'Arès, située sur la côte pontique de la Turquie, où auraient accosté les Argonautes (Pseudo-Skylax, Périple 36) et qui représente un site facilement défendable ${ }^{2}$. Ceci est d'autant plus surprenant que l'on aurait pu s'attendre au moins à une reconnaissance envers le dieu de la force guerrière à l'issue des batailles navales. Avant Actium et les consécrations d'Auguste consécutives à sa victoire (voir infra p. 367 et 422 s.), Arès n'est même pas évoqué dans de telles circonstances. La violence aveugle, forcenée que représente le dieu n'a sans doute que faire avec un élément qu'on souhaite au contraire le plus paisible possible; d'ailleurs, en matière de violence dans un contexte marin, Poséidon suffit à cet égard ${ }^{3}$. De plus, le combat naval requiert davantage de stratégie et de maîtrises techniques que de force. Ces deux raisons doivent expliquer en grande partie l'absence d'Arès dans la religion marine des Grecs. L'absence d'Héphaistos se comprend davantage : objet d'un culte mineur et très spécialisé, il est difficile de l'honorer en rapport avec le monde

'Sur la liste des quatorze définie supra p. 9-10.

${ }^{2}$ Dotée de sources et d'un port naturel, l'île située à l'ouest de Trapézonte est connue pour avoir pu résister à un long blocus à l'époque byzantine (Counillon 2004, p. 99-103 et 108-110). Le Périple donne l'image du littoral tel qu'il était connu à Athènes vers le milieu du IV $\mathrm{s}$.

${ }^{3}$ Vian 1968, p. 55-57, considérant «qu'Arès représente une conception primitive et barbare de la guerre», note également que celui-ci et Poséidon sont deux divinités très proches l'une de l'autre. 
de la mer, même s'il n'est pas tout à fait étranger à cet univers"4; une trière athénienne est cependant baptisée d'après son nom.

En ce qui concerne Hestia, son absence de la religion maritime est manifeste durant l'époque grecque. Des bateaux sont dénommés Hestia ou Vesta mais seulement à l'époque romaine, de même pour une ancre de plomb qui présente le nom latin Vesta (voir infra p. 286; 317 et cat. I24). La déesse ne semble ainsi avoir été mise en relation avec la navigation qu'à une époque tardive ${ }^{5}$.

En revanche, si l'on compare les cartes de répartition, la divinité olympienne la plus attestée est sans nul doute Aphrodite, dont la présence est affirmée dans tout le monde grec, y compris dans le Pont-Euxin, en mer Rouge et dans le golfe Persique. Artémis et Apollon sont également bien représentés, mais sur des zones géographiques plus spécifiques, ainsi que Zeus et Athéna, à une échelle inférieure. Le domaine d'Héra se situe majoritairement dans la partie occidentale de la Méditerranée.

Les mêmes endroits peuvent abriter des marques de dévotion marines à plusieurs divinités : à Corinthe ou Délos, comme on peut l'imaginer sans peine, mais aussi par exemple à Érythrées sur le littoral d'Asie Mineure, ou à l'extrémité de la Laconie à Boiae, ou dans l'île persique d'Ikaros.

L'échantillon des divinités à invoquer pour des questions maritimes s'avère donc très large : le fidèle peut s'adresser à des dieux qu'il affectionne particulièrement ou qu'il invoque en d'autres circonstances. Si les destinataires restent finalement du domaine habituel et connu, il convient à présent de s'interroger sur les manières ou les moyens d'attirer leur bienveillance pour les activités maritimes. Le sacrifice, comme les textes en témoignent, restent le moyen privilégié d'invoquer les dieux. Celui-ci s'accomplit alors de préférence sur le rivage, sur un promontoire avant et/ ou après la navigation, ou sur le bateau lui-même ${ }^{6}$. Dès lors, c'est l'endroit ou la circonstance qui fait du sacrifice un acte cultuel marin. Cependant, parmi l'ensemble des sources évoquées pour ces divinités, apparaissent plusieurs pratiques cultuelles tout à fait spécifiques au monde maritime.

${ }^{4}$ Héphaistos, recueilli par Thétis, a passé plusieurs années au fond des eaux où il a appris son art : Iliade XVIII, v. 393 ss.; Apollodore, Bibliothèque I, iii, 5.

${ }^{5}$ Une scholie aux Guèpes d'Aristophane, v. 846, rapporte un vers de Sophocle

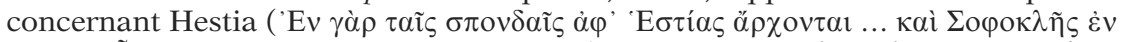

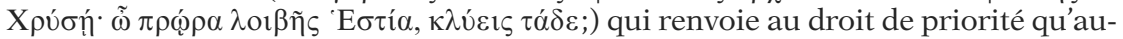
rait Vesta dans les libations. Certains ont pu y voir une allusion à la proue comme un symbole de la déesse : ainsi Bulard 1926, p. 474-475 a émis cette hypothèse à propos de la proue visible sur certaines monnaies des gentes Eppia et Rubria.

${ }^{6}$ Voir Wachsmuth 1967, essentiellement axé sur ces questions. 
DEUXIÈME PARTIE

\section{PRATIQUES CULTUELLES MARINES}





\section{PRÉSENCE DES DIEUX SUR LE BATEAU}

\section{INTRODUCTION}

L'ensemble des pratiques cultuelles relevées jusqu'ici par divinité se distingue par le double lieu géographique de leur réalisation. En effet, toutes ces sources témoignent d'appels à la présence des dieux lancés en mer mais aussi à terre ${ }^{1}$. C'est pourquoi il paraît pertinent de dissocier les rituels en fonction de ces deux contextes, afin d'apprécier leurs spécificités mais aussi peut-être leurs points communs. Pour cela, il convient de faire appel à un matériel plus diversifié, à une bibliographie beaucoup plus large que ceux du domaine religieux au sens strict. Ces cinquante dernières années ont été riches en découvertes archéologiques liées au monde maritime, notamment grâce aux progrès de l'archéologie sous-marine et à des études nouvelles portant sur le monde de la navigation. Sans prétendre apporter des solutions ou appuyer des hypothèses douteuses, nous nous efforcerons ici de faire un tour d'horizon de toutes les données connues à ce jour - des nombreux problèmes encore non résolus ou nouvellement posés.

S'il est nécessaire d'invoquer les dieux avant le départ ou de les remercier à l'arrivée, leur présence est tout aussi espérée et sollicitée à bord. Le pompimos o daimôn accompagne le navigateur tout au long du voyage et protège l'embarcation. Le fait de prendre la mer constitue une action périlleuse et considérée comme une entreprise dépassant les prérogatives humaines ${ }^{2}$. Pour cette raison l'embarcation toute entière paraît dotée d'une valeur religieuse par la présence plusieurs fois attestée d'une pièce de monnaie sous le

${ }^{1}$ Cabantous 1990 a mis en évidence - quoique pour une autre période historique - le rythme et le monde binaires des marins, et leurs répercussions sur la vie religieuse de ces dernières.

${ }^{2}$ Wachsmuth 1967 et Lesky 1947 insistent tous deux dans les premiers chapitres de leur ouvrage sur la notion de "sacrilège" appliquée à tout homme qui prend la mer; cf. le fameux passage d'Hésiode, Les travaux et les jours, v. 618 ss. sur la folie de la navigation; Goyens-Slezakowa 1990-1991. 
pied du mât de bateaux antiques ${ }^{3}$. Cette pratique rappelle curieusement le rite de fondation de certains édifices religieux ${ }^{4}$.

Mais pour contrer le sacrilège que représente la navigation et surtout ne pas s'attirer le courroux ou le désintérêt des dieux, il faut avant tout les honorer même à bord et susciter ainsi leur bienveillance par différents procédés. Hormis les sacrifices ${ }^{5}$, les sources permettent de déterminer ainsi trois registres dans lesquels figurent les divinités. L'ornementation de l'embarcation permet d'insérer une image d'un dieu à bord, censée apporter sa force bienfaisante sur l'embarcation et les hommes qu'elle transporte. Par ailleurs l'onomastique du bateau, qui permet de l'individualiser, fait usage de noms en relation directe avec des puissances divines. Ces appellations sont à confronter dans un troisième temps avec celles, relativement nombreuses, figurant sur les ancres. Or ces dernières comportent également des figures qui semblent faire allusion à quelque divinité. Il conviendra alors de s'interroger sur les liens éventuels entre les éléments décoratifs et ces noms de bateaux et les noms qui figurent sur ces ancres. Comme l'a écrit J. Vélissaropoulos, "Le nom du navire, ses emblèmes, ses divinités tutélaires (...) font du navire une entité qui se différencie des autres biens patrimoniaux ${ }^{6} »$. Cette individualité du bateau, nous allons le voir, est parfois marquée par des invocations indirectes adressées souvent, pour ce qui est du monde grec, aux divinités olympiennes.

Trois ouvrages nous ont été précieux pour déterminer le matériel concerné. Ceux-ci néanmoins abordent un thème bien différent, celui de l'architecture navale. En effet, depuis le début du XX $\mathrm{XX}^{\mathrm{e}}$ siècle, quelques savants se sont appliqués à établir des catalogues commentés des représentations d'embarcations antiques afin d'aider l'étude de la construction, de la forme, des caractéristiques des outils anciens de navigation. Le premier, publié à Bonn en 1929, est l'œuvre de l'Allemand F. Moll : Das Schiff in der bildenden Kunst

\footnotetext{
${ }^{3}$ Basch 1981, p. 37 et 54-55, qui les considère comme des «cas-limites» d'exvoto; citons en exemple l'épave de Plane 1, dont le naufrage au large de Marseille est daté du milieu du I ${ }^{\text {er }}$ s. a.C., qui conservait dans la cavité d'emplanture du mât une monnaie datée de la seconde moitié du $\mathrm{II}^{\mathrm{e}}$ s. av. J-C. : cf. Lequement \& Liou 1976.

${ }^{4}$ Rudhardt $1992^{2}$, p. $230-231$. 113 ss.

${ }^{5}$ Les sacrifices à bord ont été étudiés par Wachsmuth 1967, p. 66 ss. et

${ }^{6}$ Vélissaropoulos 1980 , p. 57. L'auteur a conçu dans son ouvrage un paragraphe (p. 67-71) concernant «l'individualité du navire», considérant que le navire porte un nom, une ethnique, des divinités protectrices, des signes et emblèmes.
} 
vom Altertum bis zum Ausgang des Mittelalters ${ }^{7}$. L'ouvrage est loin d'être exhaustif, mais il a ouvert une nouvelle voie de recherche dans le domaine nautique et archéologique. Les planches sont nombreuses, bien que trop dépouillées parfois : l'auteur ne fait que reproduire le détail qui l'intéresse et ne montre pas toujours l'ensemble du document, de même que les légendes des figures ne donnent qu'une information minimum concernant ce dernier (lieu de conservation, datation). L'ouvrage reste donc aujourd'hui un outil de travail essentiel, mais insuffisant. Il est à compléter par ceux plus récents de A. Göttlicher, Materialen für ein Corpus der Schiffsmodele im Altertum ${ }^{8}$ et de L. Basch, Le musée imaginaire de la marine antique ${ }^{9}$. Le premier, d'un auteur qui s'affirme comme le spécialiste de ce type de matériel et sur l'œuvre duquel nous reviendrons, complète, en ce qui concerne les modèles réduits, les maquettes, le catalogue de son prédécesseur avec des notices plus conséquentes: formats, provenance, bibliographie, commentaire des objets ${ }^{10}$. Quant au second, bien que parfois boudé par les antiquisants, il s'agit d'un ouvrage essentiel. Il constitue un corpus unique, une somme considérable de documentations et de recherches, de surcroît remarquablement illustrée. Même si certaines conclusions techniques ont été contestées par d'autres spécialistes tel J. S. Morrison ${ }^{11}$, le Musée reste pour nous un ouvrage indispensable, primordial, une malle aux trésors de documents antiques.

\section{LE DÉCOR NAVAL ET RELIGIEUX}

Le sacré est donc présent sous des formes diverses à bord car il faut le plus possible multiplier les chances d'échapper à toutes les catastrophes qui peuvent survenir en mer. À travers ce que nous ont

${ }^{7}$ Moll 1929a.

${ }^{8}$ Göttlicher 1978.

${ }^{9}$ Bach 1987.

${ }^{10}$ Néanmoins ce premier ouvrage du savant allemand témoigne des mêmes lacunes et insuffisances que celles signalées infra (p. 351-352) pour une autre de ses publications. On y retrouve mêlés des objets de tous les continents ainsi que des exemples de date récente. Le lieu de découverte précis de l'objet est rarement signalé, ce qui ne permet pas de repérer sa vocation (funéraire, religieuse, ou profane) de même que sa description parfois sommaire (dire qu'il présente "beaucoup de détails» laisse le lecteur sur sa faim).

${ }^{11}$ Par exemple sur la disposition des rameurs sur les trières : cf. Morrison \& Coates 1990. 
transmis les sources tant littéraires qu'épigraphiques, la référence à une ou des divinités à l'intérieur du bateau se fait à trois niveaux : l'ornementation de l'embarcation, le nom de celle-ci et les ancres embarquées. Ces trois médiateurs concrets doivent ainsi explicitement attirer la protection de la divinité, ou par la mention de son nom ou d'un décor s'y rapportant. En ce qui concerne le premier domaine, les sources s'avèrent peu nombreuses ou plus difficiles à interpréter. On aborde par là l'étude du bateau lui-même, de sa constitution, de ses aménagements extérieurs et intérieurs. Et ces derniers particulièrement restent encore insufisamment documentés ${ }^{12}$.

En effet, les textes littéraires sont pauvres en ce qui concerne la décoration des bateaux : à part la description détaillée de deux navires qui semblent avoir marqué l'esprit des contemporains ${ }^{13}$, l'architecture et surtout l'ornementation navale nous sont assez mal connues. Les découvertes archéologiques sous-marines ont permis depuis une cinquantaine d'années ${ }^{14}$ de progresser dans la compréhension de l'élaboration d'ensemble des embarcations, mais pas sur les accessoires. Il est donc particulièrement difficile à ce jour de percevoir les éléments religieux qui pouvaient être présents sur le bateau de volonté délibérée ${ }^{15}$. Les sculptures figurées gisant sur les fonds marins posent particulièrement problème. Prenons pour exemple une petite tête féminine d'ivoire de type hellénistique trouvée à Fos, dans un dépôt alluvionnaire : tenue pour une Aphrodite ou une Artémis, elle fut définie comme une applique, puis comme un élément de décoration navale; ou la statuette en bronze de Zeus de l'épave Cavallo I, au sud de la Corse, datée du milieu du $\mathrm{I}^{\mathrm{er}}$ s. p.C., considérée par certains comme statue de culte à bord ${ }^{16}$. En

${ }^{12}$ À ce sujet, voir les remarques de Rougé 1974b, p. 47-49.

${ }^{13}$ Les deux textes sont bien connus: Lucien, Le bateau décrit un gros tonnage chargé de transporter le blé annonaire; Athénée, Deipnosophistes V, 208 ss. dépeint le gigantesque bateau de Hiéron II de Syracuse.

${ }^{14}$ Voir le recensement des décors retrouvés dans les épaves par Arata 2005, p. 16-17.

${ }^{15}$ Par ex.: Benoît 1952, p. 288 et fig. 47; Benoît 1953, p. 111-112 et fig. 14; Benoît 1971, p. 409.

${ }^{16}$ Corsi-Sciallano \& Liou 1985, p. 127-129; Parker 1992, p. 134-135 et 197; Arata 2005, p. $16-18$ et cat. 21 , p. 156 . Autres cas pour l'époque romaine: statuette de bronze de Neptune de l'épave italienne de Grado, datée de la première moitié du II ${ }^{\text {e }}$ s. p.C. (ibid., fig. 15 et cat. 34 p. 164; Saporiti 2005, avec démonstration très forcée); petit groupe en marbre d'Esculape et Télesphore de l'épave de Spargi, dans les eaux sardes, transportant une cargaison des années 120-100 a.C. (Arata 2005, cat. 80 p. 196); Mercure de l'épave de Camarina de la fin du $\mathrm{I}^{\mathrm{er}}$ s. ou du début du $\mathrm{II}^{\mathrm{e}}$ s. p.C. (Di Stefano 2003); Priape (?) en bois de l'épave de Planier A du début du I ${ }^{\text {er }}$ s. p.C. à Marseille (L'Hour 1984, p. 65-73; Parker 1992, p. 315; Neilson 2002). 
l'absence de tout contexte précis, il est impossible de déterminer quelle était la place réelle de ces objets : appartenaient-ils au décor ou à l'aménagement d'un bateau, ou à une cargaison, ou encore s'agissait-il d'objets personnels appartenant à un membre de l'équipage ou à un passager? S'ils avaient une réelle valeur religieuse, était-elle en relation avec le bateau ou le voyage? Les principales sources pour juger du décor naval restent ainsi majoritairement les documents iconographiques, même si ce champ d'investigation reste encore limité car restreint le plus souvent à une figuration extérieure du bateau.

À cette insuffisance numérique des sources s'ajoutent de surcroît des problèmes d'interprétation. Pour ce qui est des images figurées, il convient d'identifier le décor - personnage, monstre ou animal reproduit -, mais aussi de distinguer la partie du bateau dont il s'agit, et aussi de relativiser la représentation par rapport aux intentions de son auteur. Pour ce qui est des descriptions écrites, savoir quelle partie du bateau est concernée s'avère délicat puisqu'il n'est pas toujours aisé de comprendre la réalité du vocabulaire technique antique ${ }^{17}$, mais aussi parce que l'écrivain, s'il n'est pas connaisseur des questions navales, peut ne pas employer forcément le terme dans son sens technique précis ou au contraire utiliser un terme vague. C'est notamment le cas des textes à dimension épique ou héroïque impliquant imagination, emphase imaginative de son auteur qui accumule ainsi des données pas toujours compatibles entre elles et pas toujours conformes à la réalité ${ }^{18}$.

Pour toutes ces raisons, ce chapitre ne peut être développé à outrance, sous peine de trop nombreuses supputations ou de lectures forcées. N'y sera répertorié que ce qui concerne les divinités olympiennes (en effet, contrairement aux ancres à bord qui se rapportent à elles uniquement, des éléments de décor du bateau renvoient aux divinités marines secondaires telles les Néréides ${ }^{19}$ ). Un article majeur pour la question des symboles religieux à bord est celui de J. N. Svoronos, «Stylides, ancres hierae, aphlasta, stoloi, ackrostolia, embola, proembola et totems marins», Journal international d'archéologie numismatique XVI, 1914, Athènes, p. 81-152. Cette étude s'attache à démontrer l'importance de l'arrière du bateau en ce qui

${ }^{17}$ Par exemple Rougé 1974b, p. 64 à propos de la terminologie gréco-latine de la voile.

${ }^{18}$ À ce sujet, voir Reddé 1986, p. 121-130 qui s'appuie pour illustrer son propos sur des exemples pris à Silius Italicus et autres poètes latins.

${ }^{19}$ Par exemple voir Wachsmuth 1967, notes 78-79. 
concerne le sacré. Quoique vieilli et parfois excessif dans ses conclusions, l'article reste riche d'enseignements et l'approche du sujet tout à fait intéressante. L'ensemble trop catégorique a été corrigé par D. Wachsmuth ${ }^{20}$ qui, sans contester la valeur de la poupe pour le domaine religieux, réfute son exclusivité en montrant comment le sacré se trouve également présent à l'avant du bateau.

Mais avant de considérer ce décor naval et ses liens avec la religion, commençons par en préciser le vocabulaire technique, afin de bien estimer la place de la divinité dans l'architecture navale et dans le champ visuel des marins ou voyageurs; les dessins qui suivent (fig. 12) éclaireront ces définitions ${ }^{21}$.

L'extrémité avant du bateau désignée de manière générale sous le nom de proue $(\pi \rho \tilde{\varphi} \rho \alpha)$ se compose de différentes parties dont la présence varie aussi selon les types de bateaux. On y distingue tout d'abord le $\sigma \tau o ́ \lambda o s(S)$, la partie qui s'élève de manière verticale à l'étrave qui, lorsqu'elle prend la forme d'une corne, est désignée sous le nom de $\kappa \varepsilon ́ p a \varsigma^{22}$. L'akrostolion constitue une partie du stolos, son extrémité supérieure ${ }^{23}$.
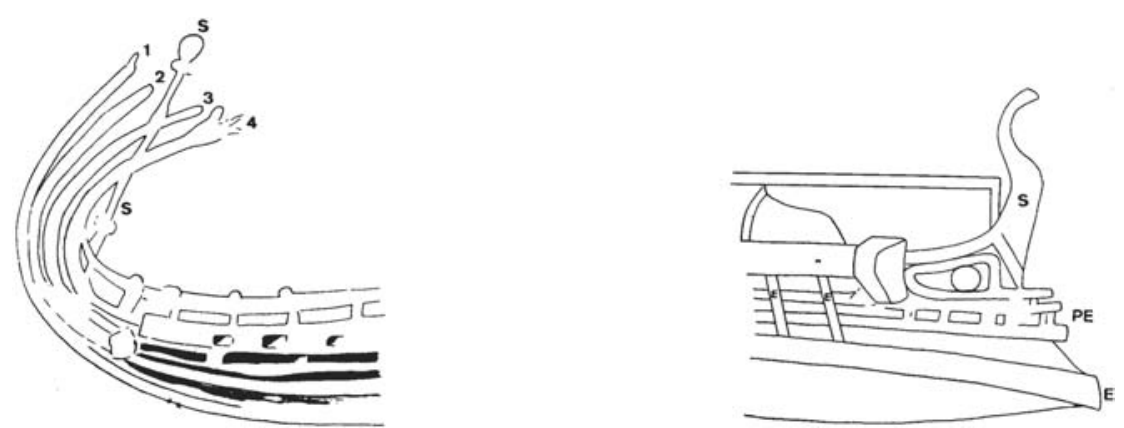

Fig. 12 - Poupe et proue de navire type trière (d'après Basch 1987).

${ }^{20}$ Le point est développé dans un long chapitre qui couvre les pages 342-393. Signalons encore, pour la marine romaine, des remarques pertinentes dues à Duval 1949, Paris, p. 338-351.

${ }^{21}$ Ces définitions rapides ont été réalisées pour l'essentiel grace à celles données par Vélissaropoulos 1980; Casson 1971. Pour des termes techniques courants utilisés aujourd'hui, voir Jal 1848 et plus récemment P Gianfrotta \& alii 1997, p. 194-195.

${ }^{22}$ Sur ces cornes, voir en dernier lieu Beltrame 2002, p. 71.

${ }^{23}$ Wachsmuth 1967, note 83, met particulièrement en évidence les confusions d'emploi de ce mot dans la littérature ancienne et moderne : la bonne définition est celle donnée par Svoronos 1914, p. 130, suivant en cela celle de Didyme 
Le parasèmon - nous y reviendrons - consisterait en des emblèmes placés de part et d'autre de l'avant de l'embarcation. L'épisèmon est un terme imprécis qui peut désigner tout aussi bien le stolos que le parasèmon ${ }^{24}$. L'éperon ( $\left.\varepsilon \mu \beta o \lambda o v / o \varsigma\right)$ métallique, de bronze, est placé de manière proéminente sur l'étrave au niveau de la ligne de flottaison du navire (E); il semble le plus souvent être divisé en trois, à l'image d'un trident. Le proembolon (PE) peut être considéré comme une sorte d'éperon supérieur à l'éperon proprement dit.

À l'extrémité arrière du bateau, la poupe $(\pi \rho v ́ \mu v \alpha)$, sont disposés un certain nombre d'éléments pas toujours clairement identifiables ni même reconnus avec certitude comme tels; ceux qui nous intéressent sont dénommés la stylis et l'à $\varphi \lambda \alpha \sigma \tau o v^{25}$. Ce dernier est la partie courbée s'élevant à l'arrière, divisée en plusieurs branches correspondant à la partie terminale d'autant d'élements de la coque $^{26}$. La stylis (S) consiste en une espèce de hampe plantée à l'intérieur du bateau avant l'aphlaston ${ }^{27}$.

\section{LA PROUE}

La proue, comme partie du bateau qui la première se présente à la vue et surtout s'avance à travers l'élément liquide, mérite une attention particulière. Ainsi, sur la coque, à bâbord et à tribord, sont représentés de façon courante des yeux apotropaïques ${ }^{28}$; y est peutêtre inscrit également le nom du bateau ${ }^{29}$. Mais la proue est l'endroit

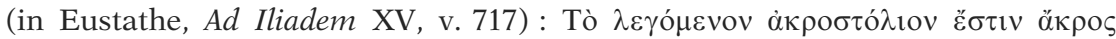

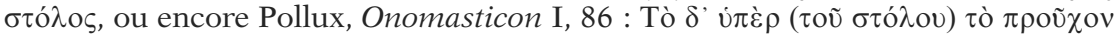

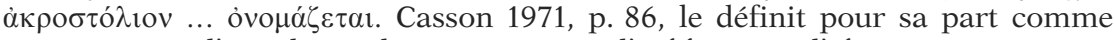
appartenant à l'étambot et le regroupe avec l'aphlaston et l'akrôtèrion.

${ }^{24}$ Définitions différentes établies par Reddé 1986 , p. 123 à propos de la marine romaine : pour lui parasèmon s'applique aux décorations latérales du stolos, et l'épisèmon désigne la partie supérieure décorée du stolos.

${ }^{25} \mathrm{Cf}$. la définition donnée par Pollux, Onomasticon I, 90 : Tà $\delta \dot{\varepsilon} ~ \alpha \ddot{\kappa} \rho \alpha \tau \tilde{\eta} \varsigma$

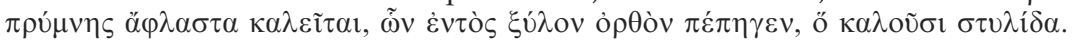

${ }^{26}$ Voir également Wachsmuth 1967, note 79 . Le nom latin correspondant est aplustre; sur l'aplustre romain, voir Duval 1949, p. 347-350.

${ }^{27}$ Ibid., note 81; Trippé 2008, p. 396-400. Différentes formes de stylis relevées sur des monnaies ont été regroupées en tableaux par Svoronos 1914; ne pas retenir cependant leur interprétation individuelle.

${ }^{28}$ Rougé 1974a, p. 47; Reddé 1986, p. 123; Wachsmuth 1967, note 82 et p. 256-257; Svoronos 1914, p. 131-132; Medas 2010. Le matériel archéologique aujourd'hui bien étudié prouve que ces yeux pouvaient consister en éléments

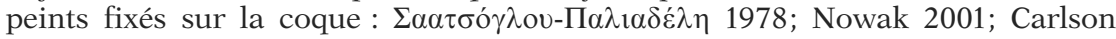
2009.

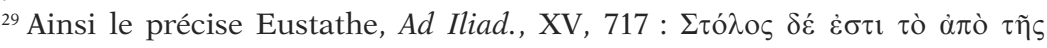


où l'on peut pratiquer des libations et prières en vue d'une navigation favorable ${ }^{30}$. On y trouve aussi sur des représentations iconographiques une divinité assise ${ }^{31}$. Dès lors, l'on peut se demander si l'avant du bateau offre également à travers le décor une consécration ou une forme d'invocation à une divinité.

\section{La "figure de proue»}

En liaison directe supposée avec le nom du bateau, la première réaction est de porter l'enquête du côté de la proue du navire, plus précisément de ce qui s'impose au regard lorsque le bateau se présente de face. L'image qui vient immédiatement à l'esprit est celle de la figure de proue, du type des galères européennes des XVI$\mathrm{XVIII}^{\mathrm{e}} \mathrm{s}$. En ce qui concerne l'Antiquité, le thème n'a été abordé qu'à une date très récente ${ }^{32}$. Comme on l'a ainsi noté, l'existence d'une figure de proue est attestée pour la marine romaine par de nombreux témoignages $^{33}$. Il convient cependant d'ajouter une restriction à cette constatation : de façon générale, aucune figure de proue antique n’a été à ce jour retrouvée par l'archéologie et les sources iconographiques donnent à voir presque exclusivement des bateaux de profil. Il est donc difficile de s'en faire une idée réelle.

Qu'en est-il pour la marine grecque antique? Les sources littéraires ${ }^{34}$ et surtout iconographiques montrent des proues, ou plutôt des proembola en forme d'animaux : sanglier, taureau ${ }^{35}$. Un écrivain tardif du III e s. p.C., Philostrate l'Ancien (Imagines I, 19) évoque également une panthère, l'animal de Dionysos. Mais la date de ce témoignage et surtout le type d'écrit dans lequel il apparaît - l'auteur

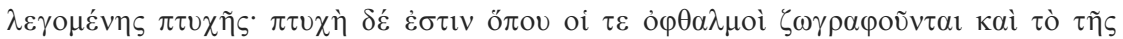

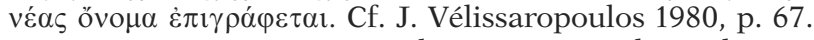

${ }^{30}$ Les témoignages sont donnés par Wachsmuth 1967, p. 342-343, 369 ainsi qu'aux notes 181 et 1603 .

${ }^{31}$ Wachsmuth 1967, note 1628 . Voir détail dans la première partie. C'est également une partie de la proue qu'une divinité envoie aux héros d'Achille Tatios (III, 5, 1) pour les sauver d'un naufrage.

${ }^{32}$ Sur la valeur symbolique à accorder à ces figures : Reddé 1986 (époque romaine); Williams 1989, p. 293-297 (gréco-romain); Brody 1998, p. 63-72 (phénicien).

${ }^{33}$ Par exemple voir Virgile, Énéide X, v. 156-255 et les parallèles établis par Reddé 1986.

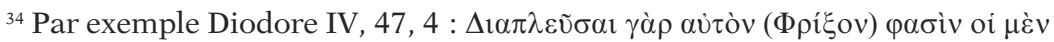

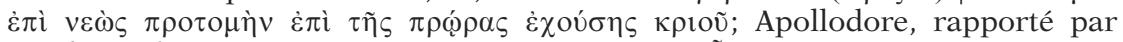

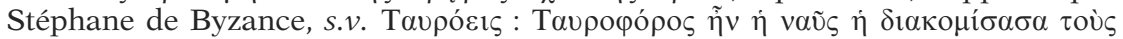

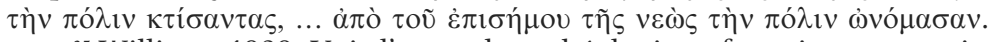

${ }^{35}$ Williams 1989. Voir l'exemple archéologique fourni par un petit navire de combat dans le golfe de Fos qui comportait une tête de sanglier en bronze : Benoît 1971, p. 409-410; Gianfrotta \& alii 1997, p. 75. 
décrit une peinture figurant elle-même un épisode mythologique et plus précisément le bateau du dieu lui-même - nuancent fortement le crédit à donner à une telle information ${ }^{36}$. Apparemment dans l'Antiquité grecque, les protomés d'animaux comme figures de proue ne sont pas à mettre un relation avec un dieu particulier.

La question se pose donc de savoir s'il existe des figures de proues à l'effigie d'une divinité comme il y en a à l'époque romaine ${ }^{37}$.

Les sources littéraires ne nous disent rien de catégorique à ce sujet. Cependant quelques mentions sont avancées pour soutenir cette hypothèse. Il s'agit tout d'abord d'un passage d'une comédie d'Aristophane, qui décrit l'effervescence qui saisit les Athéniens quand il s'agit d'armer leur flotte; parmi les préparatifs effectués, sont mentionnées des $\pi \alpha \lambda \lambda \alpha ́ \delta 1 \alpha \chi \rho v \sigma o v \mu \varepsilon ́ v \alpha$. Un scholiaste explicite l'expression (Acharniens, scholie au v. 547 : corpus p. 533) en affir-

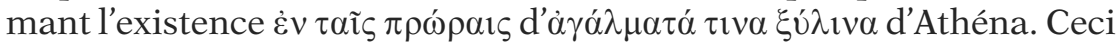
ne constitue pas un argument définitif : le commentaire est tardif et peut correspondre à un usage bien connu pour le monde romain. À l'époque d'Aristophane, il doit en effet y avoir des représentations d'Athéna sur les trières athéniennes, mais ces palladia peuvent être placés à un autre endroit du bateau : à la proue mais pas en position centrale comme une figure de proue, ou encore à la poupe.

Comme confirmation de la scholie d'Aristophane est citée une inscription de $\operatorname{Kos}^{38}$, datée du III ${ }^{\mathrm{e}}$ s. a.C., signalant quant à elle un agalma d'Asclépios à la proue; or, cette mention est due à une restitution du texte, le décret étant fragmentaire ${ }^{39}$. Si l'on admet la justesse de la restitution, le terme d'agalma, déjà utilisé dans la scholie d'Aristophane, peut être entendu de différentes façons, sans qu'il s'agisse à proprement parler d'une statue : une simple image, peinte, constitue un ö $\gamma \alpha \lambda \mu \alpha$. Enfin on rapproche ces deux textes d'un passage de Diodore de Sicile (Bibliothèque historique XIII, 3, 1-4) concernant la description de la flotte de l'expédition de Sicile au départ du Pirée ${ }^{40}$. À ce moment, la foule émue se presse auprès des

${ }^{36}$ Il faut rapprocher cette représentation du bateau de Dionysos de celui d'Enée décrit par Virgile, Énéide X, v. 156-158.

${ }^{37}$ Signalons par exemple le cas du relief funéraire de Naevoleia Tychè (Pompéi), évoqué par ailleurs (infra p. 265). La tête d'Athéna reconnaissable à son casque figure en relief sur une surface à peu près rectangulaire à l'avant, se détachant au-dessus de la proue du navire marchand. Cette projection de l'extrémité de l'étrave, appelée commodément par L. Basch ferro, est caractéristique des navires marchands romains : Basch 1987, p. 457 et fig. 1021.

${ }^{38}$ Segre 1933; Vélissaropoulos 1980, p. 69-70.

${ }^{39}$ Le doute sur cette restitution est d'ailleurs exprimé par un point d'interrogation dans le rapport fait par J. et L. Robert, Bulletin épigraphique 1956, no 3 .

${ }^{40}$ Thucydide (La guerre du Péloponnèse VI, 31-32) qui décrit le même épisode 
navires qui resplendissent du fait des armes et des épisèma placés aux proues. Cette image raccourcie laisse reconstituer des décors rutilants, de métal noble comme le bronze ou couverts de dorures comme l'évoquait déjà Aristophane. Dans toutes ces mentions littéraires, l'imprécision est de mise : aucune localisation détaillée n'est indiquée si ce n'est la proue, aucun terme commun (palladia, agalma, épisèma) ni même précisément définissable ${ }^{41}$.

Par ailleurs, les sources iconographiques, et notamment les monnaies, ne nous présentent aucunement ce genre d'ornement à l'avant d'un bateau grec. Ceci est d'autant plus troublant que de nombreuses pièces phéniciennes reproduisent cette caractéristique pour l'époque archaïque et l'époque classique. Des monnaies de Sidon, Arados et Carnè, émises à partir des années 385 a.C. montrent indifféremment au droit comme au revers des parties avant de navires avec une figure de proue sous la forme d'un personnage armé d'un casque, d'un bouclier et parfois même d'une épée, en position immobile ou en mouvement vers l'avant ${ }^{42}$. Pour certaines séries, les numismates y reconnaissent simplement un guerrier et pour d'autres, une Athéna, sans qu'il soit véritablement possible d'établir une différence. Cette figure de proue est à mettre en parallèle avec une d'un autre genre, encore uniquement sur les monnaies phéniciennes ${ }^{43}$. On la désigne sous le nom de pataikos, d'après la description qu'en a faite Hérodote (Enquête III, 37) qui la compare à un pygmée, c'est-à-dire pour un Grec à un être grotesque et de petite taille $^{44}$. La manière dont l'historien expose l'anecdote est à relever : il n'utilise aucun terme précis pour désigner ce qu'est un pataikos par

souligne seulement les dépenses effectuées pour l'armement de la flotte, par les

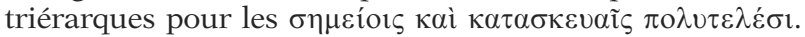

${ }^{41}$ De son côté, Plutarque (Nicias, 21,1$)$ utilise le terme de parasèma comme éléments de décor notables pour des trières envoyées en renfort en Sicile. Deux explications sont possibles : ou il utilise le terme précis qui convient à ces ornements, ou il reproduit avec un vocabulaire impropre les informations lues chez d'autres.

${ }^{42}$ Hill 1910 : p. 144, $\mathrm{n}^{\circ}$ 20-27 et pl. XIX, 1-3 (monnaies de Sidon entre 384 et 370); p. 145-149, n 29-62 et pl. XIX, 5-21 (Sidon, 370-358); p. 150 n $^{\circ} 63-64$ et pl. XX, 1-2 (Sidon, 354-348); p. 154, no 81-84 et pl. XXI, 1-3 (Sidon, règne de Darius III); p. 13-20, no 86-145 et pl. III (Arados, 260-171; parfois avec Poséidon assis sur la proue); p. 35-38, n ${ }^{\circ}$ 292-317 et p. 43 n $^{\circ} 346$, pl. V (Arados, 137-110 et 86-52); p. $111 \mathrm{n}^{\circ} 1-2$ et pl. XIII, 11-12 (Carnè, vers 225 av.). Voir également Anson 1910-16, V p. 120 n $934-937$ et pl. XX; Svoronos 1914, p. 135.

${ }^{43}$ Hill 1910, p. 9-11, no 56-69 et pl. II, 11-20; p. 12, no 83-85 et pl. II, 30-31 (monnaies d'Aratos, entre 350 et 332). P. Demargne, "s.v. Athéna», LIMC II, Bern, 1984, 1 p. 1013 n 615 et 2 p. 764 les recense à tort comme des représentations d'Athéna.

${ }^{44}$ Sur ces pataikoi, voir Cook 1914-40, III p. 158-160. 
rapport au bateau, mais une périphrase ( $\dot{\varepsilon} \nu \tau \tilde{\eta} \sigma 1 \pi \rho \varphi ́ \rho \eta \sigma 1 \tau \tilde{\omega} \nu \tau \rho ı \eta-$ $\rho \varepsilon ́ \omega \nu \pi \varepsilon \rho 1 \alpha ́ \gamma \sigma v \sigma l)$ comme s'il n'existait pas d'équivalent grec. Les attestations monétaires exclusives de ces figures de proue et le passage d'Hérodote tendent à faire de celles-ci une caractéristique purement phénicienne et non grecque.

Un second élément est à ajouter au dossier iconographique. Des monnaies d'Athènes montrent un buste d'Athéna surmontant le stolos d'un navire dominé par un Thémistocle, mais seulement au $\mathrm{II}^{\mathrm{e}}$ s. p.C. sous le règne d'Hadrien ${ }^{45}$. Il est surprenant, s'il existait de telles figures de proue depuis les Guerres médiques, qu'un tel type iconographique n'ait pas été exploité suite à Salamine ou durant la suprématie maritime d'Athènes. Ce buste de Pallas en figure de proue, même s'il correspond à une réalité de l'architecture navale et pas seulement à une référence mythologico-historique, ne peut renvoyer qu'à un modèle du monde des Antonins.

L'ensemble des éléments concourt à une même évidence. L'existence de figures de proue à figures divines dans le monde grec pour les périodes antérieures à la domination romaine est encore à prouver. L'usage de la figure de proue «anthropomorphe» existe dans la marine phénicienne - sous la forme de pataikos ou de personnage armé - ainsi que de manière non systématique dans la marine romaine. En ce qui concerne la marine grecque, malgré les influences et emprunts aux Phéniciens, l'usage de la figure de proue ne paraît pas avoir été pratiqué.

Il convient à présent de tenter de définir les éléments décoratifs qui ornent réellement la proue.

\section{Le parasèmon}

Un des lieux communs souvent mentionnés à propos du divin à bord des navires de l'Antiquité raconte l'anecdote du voyage de saint Paul depuis Alexandrie dans une embarcation où figuraient les Dioscures $^{46}$; le terme utilisé est alors celui de parasèmon. Une merveil-

${ }^{45}$ Anson 1910-16, V p. 100 et pl. XVI, no $718-719$. Svoronos 1914, p. 136 rappelle à ce propos l'anecdote de la chouette apparue en faveur de Thémistocle avant Salamine (cf. Plutarque, Thémistocle 12,1) : en effet, une variante de ce monnayage présente une chouette à la place de la tête d'Athéna (Imhoof-Blumer 1910, p. 27 n 6 6-7 et pl. II, 5-6). D'autres séries, émises sous les Sévères, montrent un bateau sur lequel se déroule un combat militaire avec un buste d'Athéna en figure de proue : ibid., p. 30-31 no 22-23, pl. II, 19-20. Toutes ces monnaies sont également réunies dans Svoronos 1923-1926, pl. 97.

${ }^{46}$ Actes des Apôtres XXVIII, 11. Comparer avec Isis représentée des deux côtés de la proue du bateau décrit par Lucien, Le navire, 5. 
leuse illustration nous est parvenue d'une telle effigie à travers le décor mural d'un sanctuaire hellénistique de Nymphaion représentant un bateau peut-être nommé Isis (voir infra p. 404 ss. avec fig.). ${ }^{47}$. Pour le navire de guerre, le parasèmon semble consister alors en une sorte de plaque fixée sur la caisse de rames ${ }^{48}$ à l'intérieur de laquelle figure un buste; le Dioscure est reconnaissable à son pileus et à une tête de cheval qui l'accompagne.

Une fois le terme défini et la notion visuellement identifiable ${ }^{49}$, il s'agit à présent de voir s'il existe d'autres attestations de parasèma de type religieux ${ }^{50}$. Un texte égyptien du $\mathrm{III}^{\mathrm{e}}$ s. p.C. l'affirme sans doute en signalant que les parasèma des bateaux correspondent aux dieux des cités dont sont originaires ces derniers. Cependant, ce témoignage comme toutes les sources littéraires ou épigraphiques mentionnant des parasèma à figure divine ${ }^{51}$ sont tardives. Les sources iconographiques - monnaies, vases - ne présentent pas ce détail. Il est donc difficile de réaliser l'importance qu'avaient ces parasèma en matière religieuse, quels dieux pouvaient être représentés et à partir de quelle période cette pratique est apparue ${ }^{52}$.

${ }^{47}$ Basch 1985, p. 356, qui rapproche le motif avec ceux de l'éperon d'Athlit (voir infra p. 262 et fig. 16).

${ }^{48}$ Les représentations iconographiques des caisses de rames sont, pour des raisons de perspective, très souvent représentées ainsi, rabattues de face sur la coque du bateau. Voir pour comparaison le monument funéraire de Cartilius Poplicola à Ostie (infra, fig. 15) : Basch 1987, p. 436-437.

${ }^{49}$ Nous n'avons pas retenu la définition donnée par Casson 1971, p. 344 ss. et reprise par Vélissaropoulos 1980, p. 69, qui voit dans le parasèmon une apposition du nom du bateau de chaque côté de la coque. Ceci peut convenir pour la marine romaine, mais pas pour la marine grecque. Le bateau hellénistique de Nymphaion montre bien que le nom et le décor de la coque avant sont distincts, faisant référence de surcroît à des divinités différentes. Les exemples d'emploi de [parasèmon suivi au génitif de ce qui doit être un nom de bateau] sont tous tardifs, notamment ceux fournis par le Papyrus Oxyrhynchos 2415 (cf. Lobel \& alii 1957, p. 176-179); rien ne prouve de surcroît qu'il s'agisse du nom du bateau, et non pas une ornementation. En outre, plusieurs inscriptions grecques de l'époque hellénistique précisant le nom du bateau n'utilisent jamais le terme de parasèmon : les inscriptions d'équipages de Milet et de Smyrne à Délos en 69 a.C.

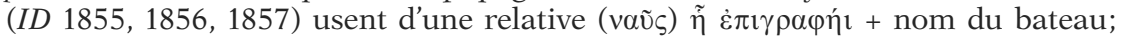
des inscriptions rhodiennes de la seconde moitié du $\mathrm{I}^{\text {er }}$ s. a.C. (Blinkenberg 1938, p. 17-18 n $\left.{ }^{\circ} 36-37\right)$ se servent du terme óvo $\mu \alpha$; la nef à huit rangs de rames de

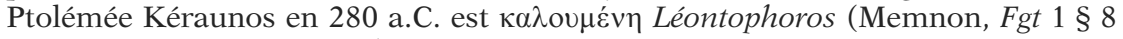
in FGH IIIB, p. $334 \mathrm{n}^{\circ} 434$ ).

${ }^{50} \mathrm{La}$ mention la plus ancienne semble-t-il de ce type de décor naval, mais figurant un animal fantastique, se trouve dans Aristophane, Grenouilles, v. 931-

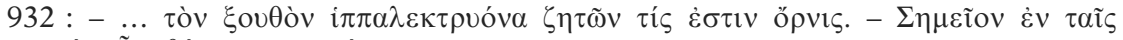

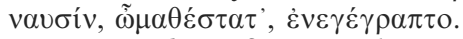

${ }^{51}$ Voir les références données en notes par Casson 1971, p. 344 ss.

${ }^{52}$ Notons l'offrande de parasèma à Apollon au moment des Guerres 
Deux documents d'époque romaine sont à évoquer cependant car ils concernent nos divinités.

Le premier, une inscription en latin du $\mathrm{I}^{\mathrm{er}} \mathrm{s}$. de n. è. ${ }^{53}$, désigne Jupiter et Junon comme motifs de parasèma. Elle figure sur la panse d'une petite amphore découverte à Pompéi dans l'insula VIII de la regio $\mathrm{I}^{54}$.

Le second document a été mis au jour dans les années 1970 lors d'une plongée sous-marine. Est sortie ainsi des eaux de l'Île-Rousse (Corse) une plaque décorative de bronze qui peut être identifiée comme un parasèmon d'un navire de commerce. En effet elle épouse la forme d'une étrave, avec une extrémité étroite et deux faces latérales - dont une seule a subsisté - convexes. Celle-ci comporte en relief sur l'extrémité un Hermès à tête barbue, et sur la face restante un dauphin ${ }^{55}$. Le matériel gisant autour de l'épave dont provient cet objet est daté du I ${ }^{\text {er }}$ s. p.C.

Pour une date antérieure, l'épave de Mahdia naufragée vers 80-75 a.C. a livré elle aussi, parmi toutes les œuvres d'art qu'elle contenait en cargaison, deux appliques de bronze devant s'adapter à une coque de bateau. Elles montrent, sculptés, les bustes de Dionysos et d'Ariane tournant la tête de façon opposée, placés ainsi en vis-à-vis par rapport à l'axe du navire (fig. 13) ${ }^{56}$. Les œuvres de grande qualité et finesse sont datées de l'époque hellénistique, plus précisément sorties d'un atelier attique vers 120 a.C. Des travaux récents ont montré qu'elles devaient appartenir à un monument naviforme, du type du socle de la victoire de Samothrace. Ces plaques, selon leurs contours, étaient fixées aux caisses de rames d'un bateau hellénistique ${ }^{57}$. Même si le navire auquel elles apparte-

médiques (Plutarque, Thémistocle 15, 2) : voir infra p. 417. Mais aucune indication n'est donnée sur ce qu'ils représentaient.

${ }^{53}$ In n(ave)... Iovis et Iuno(nis) parasemi... (Année épigraphique 1951, $\left.\mathrm{n}^{\circ} 165 \mathrm{~b}\right)$. Il est à relever dans cette inscription latine l'usage du mot grec : Casson 1971, p. 345 note 2.

${ }_{54}$ Corte 1946, p. 110-111 n ${ }^{\circ}$ 232b. Dans la publication, l'épigraphiste italien avait rattaché le mot d'épisème au mot suivant qui est Victoria. Mais la construction et le sens général de l'inscription réfutent cette lecture.

${ }^{55}$ Liou 1973, p. 607; Gianfrotta \& Pomey 1980, p. 285; Gianfrotta \& alii 1997, p. 17, 40. Le pilier hermaïque bifrons provenant d'un des navires de Nemi (Gianfrotta \& Pomey 1980, p. 291; Ucelli 1950) ne peut pas être rapproché de la plaque corse car il représente des visages de satyres.

${ }^{56}$ Inv. F 108. Fuchs 1963, p. 15; Reddé 1986, p. 126; Horn 1994; Gianfrotta, \& alii 1997, p. 184; Arata, p. 174-176 cat. 51. L'ensemble de la cargaison contient des œuvres d'art attiques, probablement «acquises» à Athènes et destinées à de riches Romains amateurs d'art.

${ }^{57}$ Horn 1994, avec fig. 

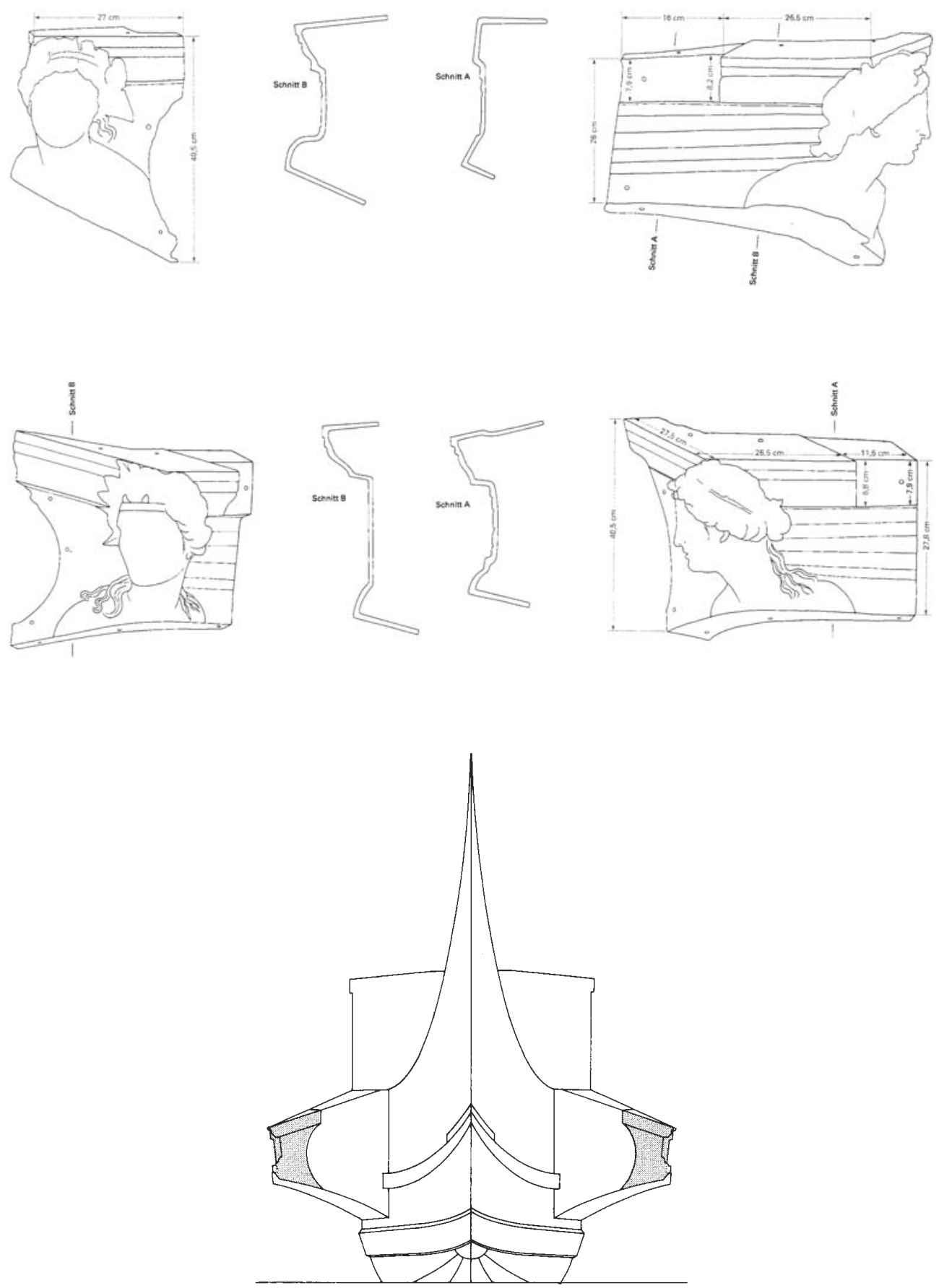

Fig. 13 - Parasèmes de Dionysos et d'Ariane, Mahdia (d'après Horn 1994, p. 459). 
naient ne constituait pas une embarcation réelle, il en était cependant une reproduction et en présentait les caractéristiques et détails.

Des eaux d'Actium aurait été repêché un objet de bronze qui semble avoir eu la même fonction ${ }^{58}$. La forme générale indique qu'il épousait la forme de l'étrave. À l'extrémité, en haut-relief, se détache comme d'un bouclier le buste d'une Athéna casquée (fig. 14). Lors de la trouvaille, on a daté cet élément décoratif vers 50 a.C. en le supposant appartenir à un bateau des deux flottes qui se sont rencontrées en ce lieu. Properce dans sa $I V^{e}$ Élégie (vi, v. 23-24) décrit le navire d'Octave à Actium voguant sous le Iovis omine; il ne serait donc pas surprenant que les autres bateaux de l'une ou l'autre flotte soient ainsi placés sous la protection d'autres divinités.

Le parasèmon à figure divine est donc attesté pour les flottes hellénistiques mais, dans la limite des sources actuelles, pas pour les périodes antérieures. Les dieux choisis pour figurer à cette place sont variés.

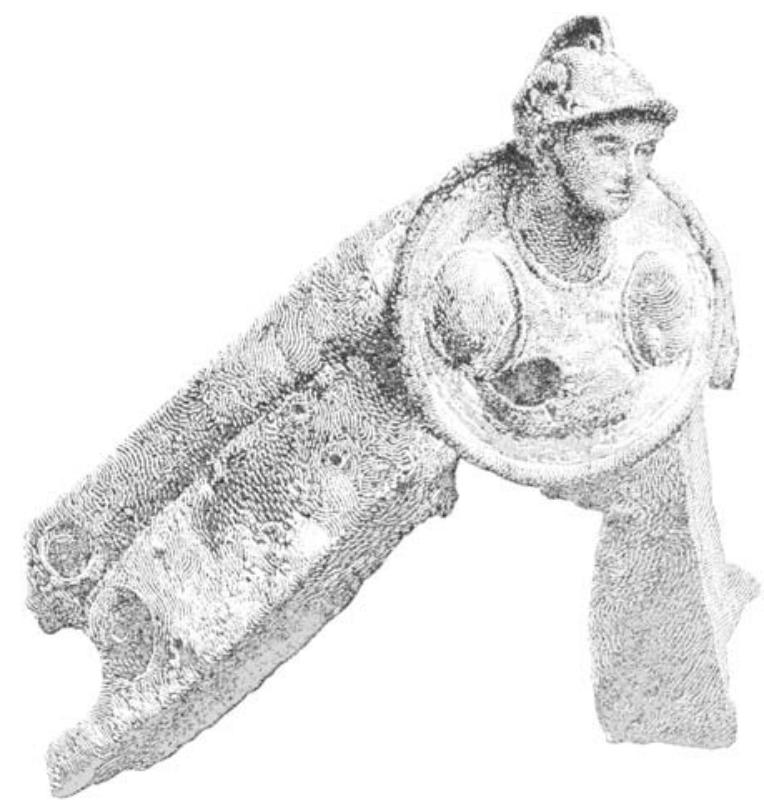

Fig. 14 - Parasèmon d'Athéna trouvé dans les eaux d'Actium (d'après Torr 1894, p. 41).

${ }^{58}$ Publié par Torr 1894, p. 66, pl. 8 fig. 41, l'objet est dit être déposé au British Museum. 
Le stolos

En revanche, ce qui paraît plus assuré est l'existence de stoloi figurés à valeur religieuse. Ceux-ci sont attestés pour l'époque hellénistique et les exemples connus appartiennent plutôt au monde romain qu'au monde grec $^{59}$.

Cependant, la représentation incisée du navire de Nymphaion daté communément du III e s. a.C. (voir infra p. 404 ss. et fig. 35) possède également une tête vue de profil dans l'akrostolion, la partie supérieure du stolos. Elle est interprétée, en relation avec le nom supposé du bateau Isis, comme une représentation de la déesse égyptienne ${ }^{60}$. Le modèle du genre le plus connu est fourni par le monument d'Ostie de la seconde moitié du I ${ }^{\text {er }}$ s. a.C. consacré à Cartilius Poplicola. Un bas-relief fragmentaire y figure un navire dont la volute du stolos est ornée d'une tête d'Athéna casquée (fig. 15) ${ }^{61}$.

En ce qui concerne les sources littéraires, un témoignage de l'ère augustéenne est à prendre en considération. Ovide, dans les Tristes, évoque les périls encourus durant le voyage qui l'emmena en exil loin de Rome. Il a parfois aussi (Tristes I, 10, v. 1-14) chanté les périodes de bonne navigation, voyant en elles les signes de la protection de Minerve. En effet, la déesse qui a donné son nom au bateau est symbolisée sur celui-ci par son casque qui y est pictus. Ovide ayant embarqué dans le navire en question à Cenchrées, cette mention indique d'abord qu'au tout début de l'époque impériale, des bateaux grecs portent des représentations de dieux ou du moins de leurs attributs. De plus cette décoration est ici non seulement en relation directe avec la tutela, la divinité protectrice de l'embarcation, mais aussi avec le nom de cette dernière. Ovide ne précise pas sur quelle partie du bateau se trouve ce décor, mais deux éléments

${ }^{59}$ Plutarque, Alcibiade 32 décrivant le retour triomphant d'Alcibiade à Athènes, le montre ramenant à Athènes les akrostolia des navires vaincus; rien ne précise s'ils sont ornés et surtout rien n'affirme que Plutarque écrivant au II ${ }^{\text {e }}$ s. p.C. ait utilisé le terme juste pour des bateaux du Ve $\mathrm{V}^{\mathrm{e}}$. a.C. Le petit inventaire établi par Pekáry 1983 recense principalement des attestations romaines.

${ }^{60}$ Cette interprétation pose cependant quelques problèmes : si Basch 1985, p. 138-140, y voit une représentation de la déesse égyptienne avec les cheveux courts, d'autres y voient une tête masculine barbue (Nowicka 1999).

${ }^{61}$ Williams 1989 , p. 294, qui le rapproche de bateaux représentés sur l'arc d'Orange et de Poitiers et sur une monnaie de Q. Lutatius Cerco frappée en 109-108, ainsi que plus tardivement sur des monnaies d'Abydos émises entre 193 et 236. Ibid. p. 296 signale des monnaies du règne d'Hadrien figurant une Athéna en proue. Basch 1987, p. 435-438; Fenet 2011, p. 410 et pl. 119, 3. 


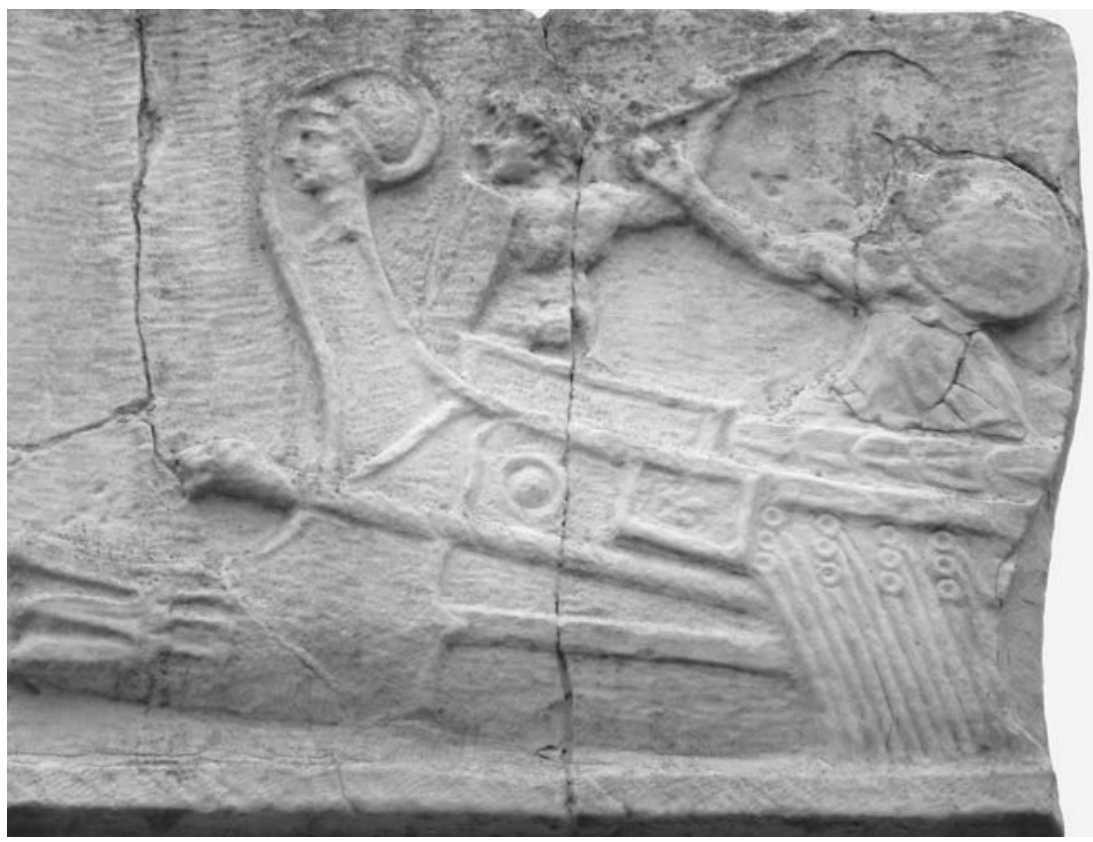

Fig. 15 - Le bateau du monument funéraire de C. Cartilius Poplicola (détail) (Photo de l'auteur).

peuvent faire penser qu'il s'agit du stolos. Tout d'abord, le poète présente une allusion similaire dans une autre pièce du même recueil (Tristes I, 4, V. 7-8) dans laquelle il décrit une tempête qu'il a essuyée entre les côtes italiennes et illyriennes, avec les vagues s'élançant à l'assaut du bateau jusqu'aux deos pictos. Étant donné le contexte, il semble plausible de situer ces derniers à un endroit du bateau où ils ne sont habituellement pas mouillés par l'écume. Assimiler ces pictos deos à des parasèmes paraît insuffisant : il convient de les placer plus en hauteur ${ }^{62}$. Il est à noter dans les deux cas l'usage du verbe pingere qui indique de quelle manière la décoration peut être réalisée. Le second argument, iconographique, renvoie à la représentation d'Athéna sur le monument funéraire d'Ostie et autres parallèles ${ }^{63}$.

${ }^{62} \mathrm{La}$ traduction de l'édition Budé commente l'expression par des «images des dieux placés à la poupe», en renvoyant à Ovide, Tristes I, 10 : cela nous paraît injustifiable.

${ }^{63}$ Parallèle établi également par Reddé 1986, p. 125. 


\section{Éperon}

Les sources concernant l'existence de décoration sur éperon sont uniquement iconographiques. Le caractère tripartite de l'éperon a fait qu'on l'a parfois représenté sous la forme d'un trident, pouvant évoquer alors Poséidon ${ }^{64}$.

Mais surtout, la mer a livré un magnifique spécimen orné à Athlit en Israël. Celui-ci a été étudié sous toutes ses faces ${ }^{65}$, mais l'examen du décor a été limité à la détermination de l'origine et de la date de l'objet. Il appartient sans conteste, selon des critères d'architecture navale, à l'époque hellénistique ${ }^{66}$. En relief, issus du moulage, figurent un caducée sur la tranche de l'éperon prolongeant l'étrave, ainsi que sur une face latérale un bonnet surmonté d'une étoile (fig. 16). Ces motifs font clairement référence à Hermès et aux Dioscures.

Le rôle de protecteurs de la navigation des seconds a été souligné; la référence au premier a été moins évoquée ${ }^{67}$. On ne peut en effet expliquer la référence à Hermès comme une invitation à de bons profits commerciaux puisque l'éperon appartient à un navire de guerre. Il faut alors bien supposer un lien direct entre Hermès et la mer. Mais surtout, l'éperon d'Athlit montre que cette partie du bateau pouvait elle aussi être décorée, personnalisée et placée sous la protection de forces divines éventuellement multiples ${ }^{68}$. Il est tentant d'établir un parallèle avec les ancres présentes à bord, d'autant plus que le caducée est un motif connu pour celles-ci.

Nous soumettons de surcroît un parallèle inédit. Il s'agit d'une monnaie ${ }^{69}$ de Tabae $(\text { Carie })^{70}$, portant au revers un caducée entre les bonnets à étoiles des Dioscures. Elle est datée vraisemblablement du

${ }^{64}$ Basch 1987, p. 390-391.

${ }^{65}$ Steffy 1983, p. 229-250, suivi de la monographie Casson \& Steffy 1991.

${ }^{66}$ Des analyses faites sur des petits morceaux de bois encore accrochés à l'éperon indiqueraient la première moitié du $\mathrm{II}^{\mathrm{e}}$ s. a.C. La présence de deux petites têtes d'aigle-griffon dans deux angles de l'éperon incite les deux savants à attribuer le bateau aux flottes chypriotes des Ptolémées V ou VI.

${ }^{67}$ Dans la dernière étude, le caducée est présenté comme un kérukeion, sans relation particulière avec quelque divinité, qu'on met en parallèle avec des types monétaires du début du $\mathrm{II}^{\mathrm{e}}$ s. a.C. : ibid., p. 61 et fig. 4-24. L'identification comme caducée/kérukeion et l'éventuel rapport avec Hermès ont été seulement abordés par H. Frost in Steffy 1983, p. 249-250 et Fenet 2011, p. 410 et pl. 120, 1.

${ }^{68}$ Un rapprochement a été proposé avec l'éperon d'un navire romain daté de la fin du I ${ }^{e r}$ ou début $\mathrm{II}^{\mathrm{e}} \mathrm{s}$., trouvé dans le Rhin près de Cologne-Deutz, qui porte un croissant de lune et un phallus : peut-être une évocation des Dioscures et de Priape (Neilson 2002).

${ }^{69}$ Anson 1910-1916, IV p. 121 n 203 et pl. IV; Head 1897, p. 160 n 2, pl. XXV, 2.

${ }^{70}$ Sur Tabae, voir Robert \& Robert 1954, p. 80-152. La monnaie y figure parmi les monnaies autonomes p. 129 sous la lettre X et pl. XXI, 13. 


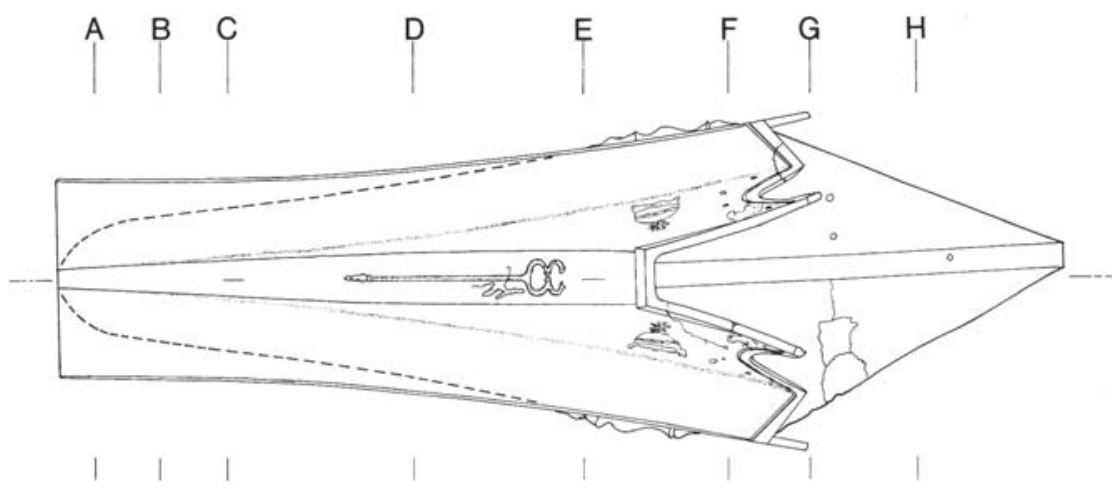

Fuc. 2-8. Top view of the ram (Drawing by J. R. Steffy)

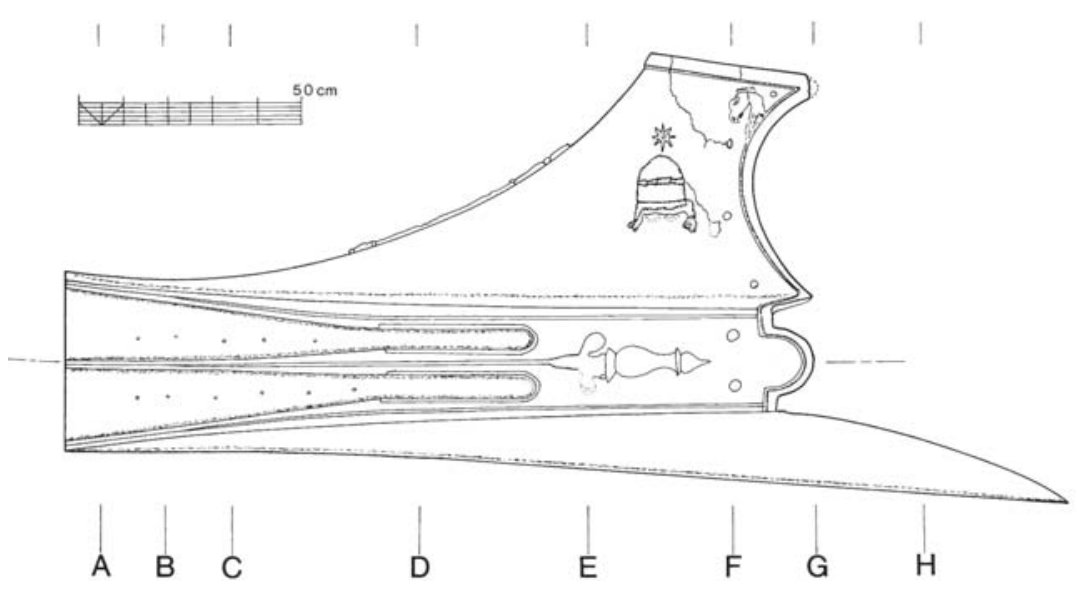

Fig. 16 - Éperon d'Athlit (d'après Casson \& Steffy 1991, p. 13).

$\mathrm{II}^{\mathrm{e}}$ s. a.C. ${ }^{71}$ Ainsi le rapprochement de ces attributs divins est également attesté durant l'époque hellénistique. À partir de là, il est possible de supposer un lien direct entre les divinités honorées dans la cité et celles sous la protection desquelles cette cité place le bateau.

À considérer l'ensemble des sources, la représentation d'une divinité à l'avant du bateau n'apparaît pas avant l'époque hellénistique. Pour cette période le stolos, les parasèma, l'éperon se placent clairement sous le signe d'un ou plusieurs dieux comme le montre l'embolos d'Athlit.

${ }^{71} \mathrm{La}$ datation du $\mathrm{I}^{\text {er }} \mathrm{s}$. de B.V. Head, reprise par des publications postérieures, a été contestée et reculée par Robert \& Robert 1954, p. 131-132 et 134. 


\section{Lieu du sacré}

Un certain nombre d'éléments conduisent à penser que la partie arrière du bateau était particulièrement considérée comme détentrice de sacré ${ }^{72}$.

Clément d'Alexandrie (Protreptique II, 35), dans une diatribe contre les croyances païennes, mentionne parmi les daimones un $\kappa \alpha \tau \alpha ̀ ~ \pi \rho u ́ \mu v \alpha v$ ท̃ $\rho \omega \varsigma$ adoré au Phalère ${ }^{73}$. Ce culte tend à attribuer une valeur religieuse à la poupe ${ }^{74}$. De même, le fait que l'ache du navire d'Antigone (Plutarque, Propos de table V, 675d-677b) ait selon la tradition poussé à cet endroit du bateau n'est pas dû au hasard ${ }^{75}$. C'est également l'endroit où peuvent avoir lieu les libations faites en mer ou au moment du départ comme le précisent certains écrivains de Pindare (IVe Pythique, v. 191-198) à Stace (Achilléide I, v. 679$688)^{76}$. De nombreuses représentations montrent une divinité assise à la poupe d'un navire ${ }^{77}$, parfois même tenant la barre et dirigeant ainsi la route de l'embarcation. La lecture immédiate de ces images est de nature symbolique: le bateau et ses occupants sont ainsi

${ }^{72}$ C'est la thèse de Svoronos 1914, nuancée par Wachsmuth 1914 : voir supra p. 249-250. Des indices forcés ont parfois été avancés pour étayer cette thèse : ainsi Couchoud \& Svoronos 1921, p. 281, énoncent également comme argument de la sacralité de la poupe la position de la poutre parlante insérée par Athéna sur Argô. Or le texte d'Apollonios de Rhodes (Argonautiques I, v. 526) la situe au milieu de l'étrave : $\mu \varepsilon ́ \sigma \sigma \eta \nu \sigma \tau \varepsilon \tilde{\imath} \rho \alpha \nu$, tandis que le résumé d'Apollodore $(\mathrm{I}, 9,16)$ la situe à la proue. Nous évoquerons également au conditionnel l'hypothèse de L. Bach (notamment Basch 1987, p. 434-435) qui voit dans certaines représentations de bateaux grecs la présence d'une draperie au niveau de la poupe à laquelle il accorde une valeur sacrée. Cf. aussi la poupe de l'inscription CIG II, 3797 (supra note 39 p. 93).

${ }^{73}$ Il a été rapproché de Pausanias, Description de la Grèce I, 1, 4, signalant au Phalère un culte à Androgée. Sur ce culte et ses mentions plus anciennes, voir Wachsmuth 1967, p. 384 ss.; Deubner 1932, p. 225.

${ }^{74}$ Vélissaropoulos 1980, p. 70.

${ }^{75}$ On peut rapprocher cette présence de feuillage «naturel» à la poupe de l'épisode du Satyricon, 108, dans lequel la femme qui doit servir de médiateur à bord entre les passagers qui se sont pris de querelle prend au préalable un rameau d'olivier à la tutela navigii.

${ }^{76}$ L'exemple iconographique qui sert de référence en la matière est le fameux relief Torlonia (voir infra, note 96). Kapitän 1979, qui a étudié l'ensemble des louteria trouvés en mer, conclut par ailleurs à l'existence à bord de ce type d'objet servant à des fins religieuses (contra : Beltrame 2002, p. 75); son argumentation repose sur la présence, bien attestée selon lui, d'un seul louterion par épave dont il restitue la place à la poupe, d'après l'emplacement du sacrifice représenté sur le relief Torlonia.

${ }^{77}$ Wachsmuth 1967, note 1628. Voir détail dans la première partie. 
protégés directement par la divinité qui veille au bon déroulement du voyage. L'allégorie est ancienne : lors du départ de Télémaque raconté dans l'Odyssée (II, v. 382-433), c'est là que vient s'asseoir Athéna pour guider l'expédition.

Bien qu'extérieures au cadre chronologique établi, les peintures et décors pompéiens s'avèrent dignes d'enseignement à ces sujet. Ils nous transmettent en effet des croyances du $I^{\text {er }} s$. de notre ère, romaines certes, mais héritées d'une culture hellénistique méditerranéenne. Ainsi, les murs de la maison dite de Lesbianus sont marqués par des inscriptions grecques et latines, et par un grand panneau peint représentant un navire ${ }^{78}$. Sous cette peinture est inscrit en grec le nom 'A $\varphi \rho о \delta \varepsilon i ́ \tau \eta ~ \sigma \omega ́ \zeta o v \sigma \alpha^{79}$. Or, à la poupe est assise une figure féminine, de grande taille comparée au reste de l'équipage et tenant un sceptre d'une main. En considérant l'inscription accompagnant le décor, il est tout à fait légitime d'y reconnaître une image de la déesse, présente à l'intérieur du navire. Un autre exemple orne la tombe de la famille de Naevoleia Tychè dans la Via delle Tombe, en deçà de la porte Ercolano ${ }^{80}$; l'onomastique de cette femme indique par ailleurs très vraisemblablement une origine grecque. Ce bas-relief représente un navire, dont l'équipage est occupé à mettre à la voile, barré par un personnage féminin de taille plus grande que celle des autres occupants. Ce dernier dirige le gouvernail de la main gauche et paraît de la main gauche faire un signe d'encouragement ou de commandement. Le réalisme de la scène et le nom de la commanditaire du tombeau, ainsi que le rapprochement avec la peinture précédente, amènent à penser que la scène est en liaison directe avec la profession des morts et que la divinité représentée à l'arrière renvoie à une Vénus-Aphrodite Euploia ${ }^{81}$.

Cependant, il faut peut-être aussi considérer une autre interprétation, ou du moins une autre arrière-pensée guidant la place de la divinité à l'arrière du bateau. Cet endroit est la zone la plus sensible de la nef au point de vue religieux, là où se trouvent les objets religieux primordiaux lors du voyage. Sur le dessin hellénistique du navire dit Isis de Nymphaion, c'est à cette place que se trouve une

${ }^{78}$ Maiuri 1958, p. 15-18 et fig. IV. La maison appartient à la Regio I, 13, 10 de Pompéi; le panneau (environ $1 \mathrm{~m}$ de hauteur sur $60 \mathrm{~cm}$ de largeur) figure sur le mur extérieur de la maison, à gauche de la porte d'entrée.

${ }^{79}$ Rien n'autorise à considérer le nom figurant en dessous de la peinture comme le nom du bateau comme l'affirme Maiuri 1958, p. 15-18 et les autres commentateurs après lui.

${ }^{80}$ Sur cette tombe, voir Overbeck \& Mau 1884, p. 413-415 et fig. 211-214.

${ }^{81}$ Maiuri 1958, p. 13-14 et fig. IIIa; représentation dans Moll 1929a, BIV, $\mathrm{n}^{\circ}$ 96. Le même bas-relief présente une tête d'Athéna à la proue : voir supra 
sorte de temple miniature ${ }^{82}$. Ainsi la représentation d'une divinité à l'arrière du bateau peut également renvoyer à la présence d'une statue, statuette ou d'une amulette visible dans cet espace précis. Un vers de Virgile (Énéide X, 171), qui dans sa poésie décrit des bateaux de son temps ${ }^{83}$, évoque un Apollon doré à la poupe d'un navire. La position d'images de divinités à cet endroit est attestée depuis le $\mathrm{V}^{\mathrm{e}} \mathrm{s}$. par des vers d'Euripide (Iphigénie à Aulis, v. 235-257) qui imaginent

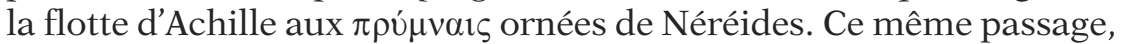
qui reproduit une sorte de rapide catalogue des vaisseaux achéens en

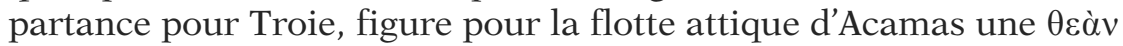

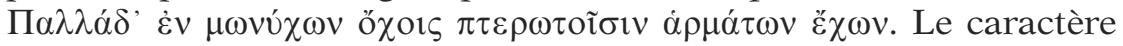
répétitif de l'ensemble, énonçant la composition, le chef et les sèmeia de chaque escadre, laisse penser que cette représentation d'Athéna sur un char ailé se trouvait à la poupe ${ }^{84}$. Le poète précise que ce décor est particulièrement propice aux marins. Selon ce témoignage, la décoration de la poupe à l'époque classique n'est pas anodine et se révèle porteuse d'un sens religieux important, compris comme tel pour les équipages. Elle personnalise certes la flotte et la rattache à l'histoire et aux traditions de sa cité d'origine comme le montrent les différents exemples donnés par Euripide, mais elle a aussi pour certains d'entre eux une valeur sacrée et protectrice considérable. De la même manière, dans la version des Argonautiques de Valerius Flaccus (VIII, v. 202-203), la divinité protectrice de Jason est symbolisée à l'extrémité de la poupe (puppe summa) par une aurata Minerva aux genoux desquelles se tient Médée. Une histoire de tempête en mer rapportée par Athénée (Deipnosophistes XV, 675f-676c) montre les occupants du bateau se réfugiant auprès d'une statue d'Aphrodite au

${ }^{82}$ Nowicka 1999; Grač 1987, pl. XXXVIII. Il ne faut cependant pas attribuer cette même fonction aux six temples miniatures en argent à suspendre, découverts dans l'épave de Comacchio (au nord de l'Italie) ayant fait naufrage vers 12 a.C., dont quatre exemplaires comportent dans la cella une statue de Vénus et un cinquième est voué à Hermès (Berti 1990, p. 71-72, 205-207; Berti 1992; Janni 1996, p. 390 fig. 71). Car au vu de leur nombre et concentration, ces modèles devaient faire partie de la cargaison du navire et ne doivent pas être considérés comme des objets religieux dépendants de l'équipage ou de l'embarcation.

${ }^{83}$ Ceci a été démontré par Saint-Denis 1935. Sa conclusion est admise depuis lors par tous les spécialistes.

${ }^{84}$ La succession donnée par Euripide est la suivante : la flotte des Myrmidons avec Néréides aux proues; celle des Argiens sans décor précisé; celle des Athéniens, avec Athéna sur un char ailé; celle des Béotiens avec sèmeia de Cadmos au dragon; trois groupes sans décor précisé; celle de Pylos avec un taureau symbolisant le fleuve Alphée comme $\pi \rho u ́ \mu v \alpha \varsigma \sigma \tilde{\eta} \mu \alpha$. Il est à noter l'erreur de traduction commise dans l'édition Budé, qui traduit cette dernière expression comme «emblème de proue». Voir aussi Lacroix 1955-1956, p. 93. 
plus fort du danger. L'anecdote ne précise pas cependant où se trouvait la statue à l'intérieur du navire, ni si elle appartenait à la cargaison du marchand qui l'avait achetée pour la revendre ou s'il l'avait acquise en vue de la protection de son bateau. Ces différentes mentions montrent globalement que la pratique est constante, depuis au moins l'époque classique jusqu'à l'époque romaine ${ }^{85}$, de placer une représentation d'une divinité à la poupe. Elle était peinte ou plutôt, semble-t-il, dorée, mais on ignore tout de sa taille, de son style (ronde-bosse, relief, buste...) et de son emplacement exact.

Un document iconographique en donne peut-être un témoignage plus précis ${ }^{86}$. Le site de Lindos est connu par les spécialistes de l'architecture navale antique pour une sculpture réalisée à même le rocher, en contrebas des escaliers qui menaient à l'acropole, représentant une poupe de bateau (fig. 17).

Le bas-relief de Lindos ${ }^{87}$ consiste en un socle naviforme conçu pour une statue de bronze qu'une inscription ${ }^{88}$ attribue au sculpteur Pythocritos. Cet hommage, offert par les Lindiens à l'un des nommés Agésandros rhodiens, est daté du début du $\mathrm{II}^{\mathrm{e}} \mathrm{s}$. a.C. selon des critères épigraphiques ${ }^{89}$. Voici la description connue pour ce décor naval : "Il y a, à la façade postérieure du siège bizarre en forme de trône, installé à la proue (sic), un relief sûrement jamais reproduit auparavant qui représente une femme debout vêtue du chiton et du péplos, coiffée du calathos. Le bras gauche est plié en sorte que la main repose sur la poitrine, le bras droit pend le long du corps. Les vêtements tombent jusqu'aux pieds. Une natte de cheveux tombe sur l'épaule droite, peut-être aussi sur l'épaule gauche ${ }^{90}$ ». Le

${ }^{85}$ Peut-être est-ce la tutela ebore caelata de Sénèque, Lettres à Lucilius LXXVI, 13 qui n'en précise pas l'emplacement. Les vers d'Aristophane (Acharniens, v. 544-551) évoqués supra pourrait dès lors évoquer la même réalité, le scholiaste ayant opéré une confusion entre proue et poupe due aux usages des bateaux romains; la dorure des Palladia rappelle en effet étonnamment celle des figures de poupe.

${ }^{86}$ Un pinax fragmentaire représentant le rap d'Hélène, conservé au musée P. Orsi de Syracuse (inv. 85661) et daté 470-460 a.C., figure un personnage féminin sur le pont du navire au niveau de la poupe. Spigo 1991 (p. 74-76 et fig. 2-3) y reconnaît Aphrodite accompagnant les amants; mais la taille de ce personnage pourrait plutôt faire penser à une statue qu'à la divinité elle-même.

${ }^{87}$ Descriptions dans Basch 1987, p. 364-365; Blinkenberg 1938, p. 22-30.

${ }^{88}$ Blinkenberg 1941, col. 431-346, $\mathrm{n}^{\circ} 169$.

${ }^{89}$ Dyggve 1960, p. 56-57 et fig. III, 27-28. Lors de cette publication, la partie du bateau fut présentée comme une proue, alors que C. Blinkenberg l'avait auparavant dans ses deux travaux bien présentée comme une poupe, ainsi que le prouve indiscutablement la présence de l'aphlaston. La légende de la photo III, 27 («figure de proue féminine») est doublement injustifiée.

${ }^{90}$ Dyggve 1960, p. 56-57, note 54. 


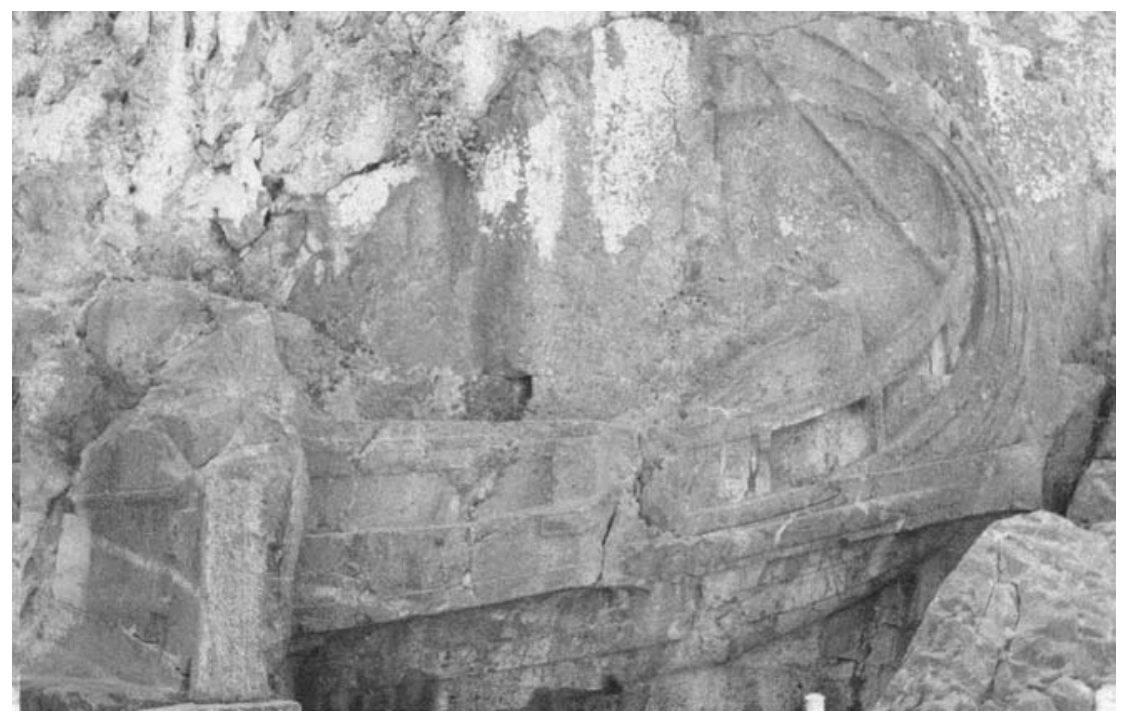

Fig. 17 - Relief de Lindos (d'après Blinkenberg 1941, p. 431).

trône en question doit être le siège d'une personne importante du bateau, peut-être le kubernetès. Mais vu de dos, il constitue une sorte de niche, à l'intérieur de laquelle se trouve cette silhouette féminine. On pourrait alors concevoir la présence d'une statuette de divinité, gardée dans un endroit spécial du bateau. Malheureusement le relief, érodé, ne laisse pas voir davantage de détails; ceux donnés par E. Dyggve concernant l'apparence de cette femme sont à peine identifiables $^{91}$.

\section{La stylis}

Une série monétaire d'Histiée (Eubée) montre au type une poupe de navire reconnaissable à l'aphlaston sur laquelle est assis un personnage féminin (fig. 18) ${ }^{92}$. Ce dernier s'appuie de la main gauche sur la stylis comportant une sorte de plaquette sur laquelle on peut lire sur une des monnaies ces caractères : A $\Theta A$ que l'on restitue sans hésitation 'A $\theta \alpha ́ v \alpha$. Or, la jeune femme n’est pas la

${ }^{91}$ Höckmann 1985, p. 159. Blinkenberg 1941, loc. cit., rapproche cette figure féminine d'une statuette de terre cuite trouvée à Lindos et représentant une porteuse de torche. Mais la statuette présente une attitude générale différente et la femme de la poupe ne tient pas de torche à la main.

${ }^{92}$ Basch 1987, p. 276-278; Newell 1921. 


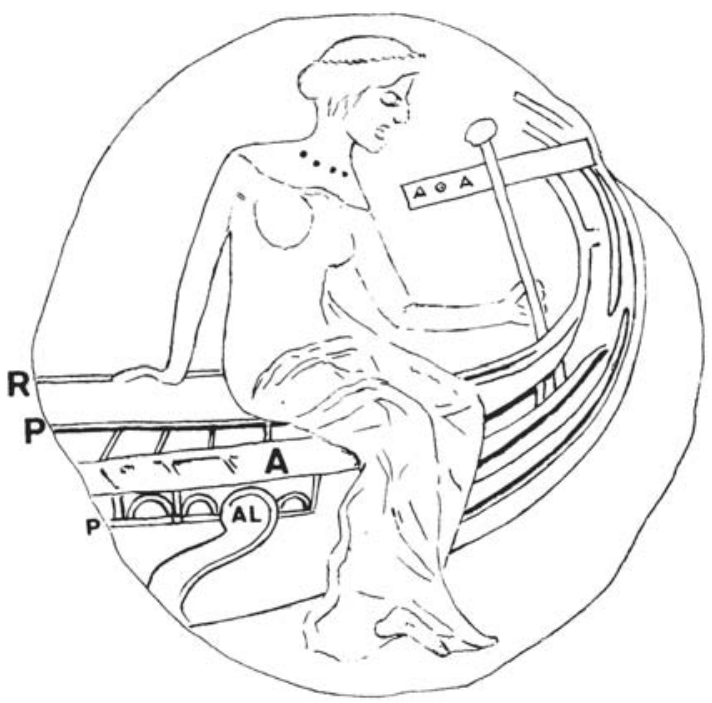

Fig. 18 - Stylis d'Athéna (d'après Basch 1987, fig. 587).

déesse - aucun de ses attributs habituels n'est représenté -, mais la Nymphe protectrice et homonyme de la ville. Sur ces octoboles datées du début de 340 a.C., la présence de cette stylis inscrite met ainsi l'embarcation sous la protection directe de la divinité olympienne.

Une autre attestation d'un nom de dieu sur une stylis nous est donnée par une hydrie campanienne. Le vase, malheureusement disparu, a été publié en 1889; il provenait de Santa Maria di Capua et était daté du IV ${ }^{\text {e }}$ s. a.C. ${ }^{93}$ Le vase montre l'arrière d'un navire au départ : l'échelle est en place du côté de la poupe et un personnage masculin prêt à embarquer semble faire ses adieux à une femme tenant une couronne à la main (fig. 19). La poupe est bien détaillée, avec l'aphlaston à cinq branches, le gouvernail et une stylis. Cette dernière porte inscrit sur une plaquette Zeus Sôter.

Ces stylides avec inscriptions sont toutes les deux datées de la même époque. Elles peuvent également être doublement interprétées : où elles évoquent le nom du navire, où elles nomment la divinité tutélaire du bateau - voire peut-être les deux.

La question se pose également de savoir s'il y a concomitance de

${ }_{93}$ Duhn 1888; Diels 1915; Blinkenberg 1938, p. 8 et fig. 1.; Basch 1987, p. 412. Le vase appartenait au Musée de Karslruhe; il est connu uniquement par le dessin donné par F. von Duhn. 


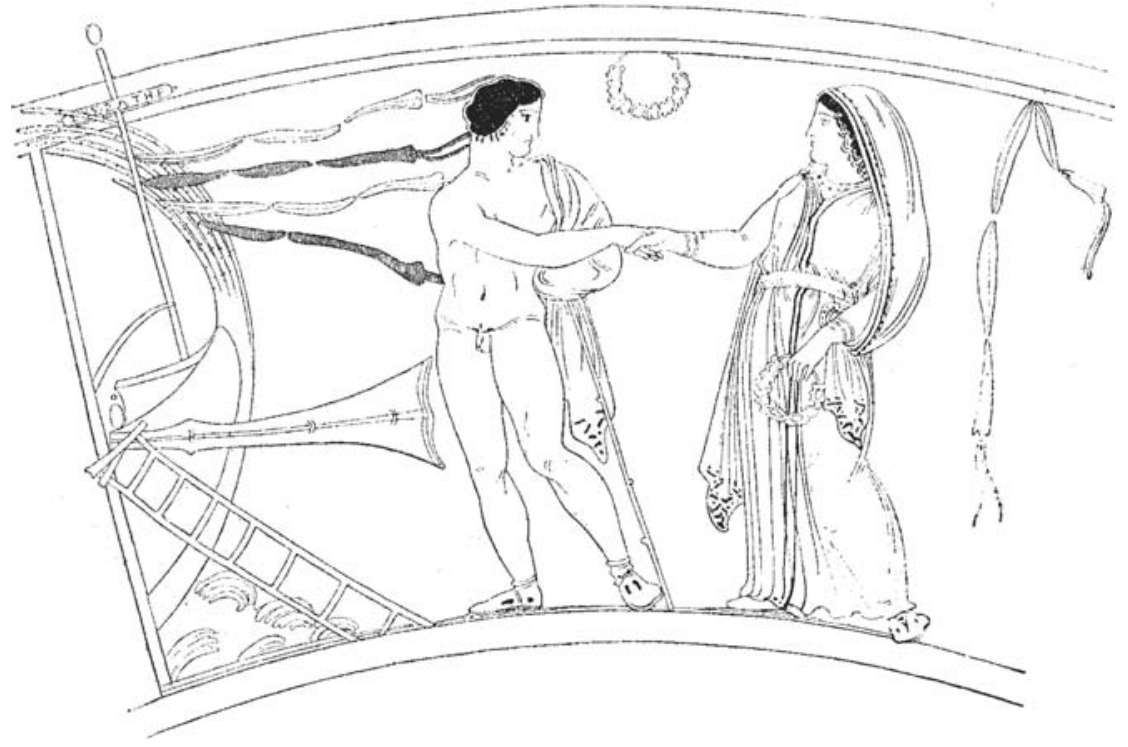

Fig. 19 - Stylis de Zeus Sôter (d'après Duhn 1888, p. 229).

stylides et de représentations de dieux à la poupe. L'une remplace-telle l'autre, la stylis avec inscription est-elle une version simplifiée de la représentation du dieu à bord ou figurent-ils tous les deux à l'arrière du bateau? ${ }^{94}$

\section{Alia}

En dehors de la proue et de la poupe, il convient d'ajouter pour terminer des mentions particulières. Deux exemples, marginaux il est vrai par leur démesure, montrent la place accordée à la divinité dans le bateau. Les deux géants décrits dans les Deipnosophistes d'Athénée (V, 205d et V, 207e = Callixène, Fgt 627 et Moschion, Fgt 575 , éd. Jacoby), le navire de Hiéron de Syracuse et celui de Ptolémée Philopator, nommés respectivement la Syracusia et le Thalamègue, comportaient tous deux une pièce consacrée à Aphrodite. Dans le cas du bateau ptoléméen, elle est même qualifiée de hiéron. Dans les deux installations, la décoration est somptueuse. Même si l'on peut mettre en doute les détails fournis dans ces

${ }^{94}$ Svoronos 1914 paraît tout amalgamer et considérer les représentations de dieux comme des versions élaborées des stylides. 
descriptions et trouver troublants les points communs aux deux textes, il est notable qu'il y ait eu volonté d'agencer, en proportion avec la taille des embarcations, un lieu où la divinité pouvait trouver sa place ${ }^{95}$. Cela pourrait renvoyer, à une autre échelle, à l'éventuelle présence d'un autel - portatif ou modèle réduit - ou sacellum à bord, attestée pour l'époque romaine, à défaut d'être assurée pour l'Antiquité grecque, par le fameux relief Torlonia, daté de l'époque sévérienne, qui montre un groupe de personnes réunies à bord autour d'un autel ${ }^{96}$. Comme pour les statues citées au début de ce chapitre, il n'existe cependant pas encore de preuves archéologiques de tels aménagements navals.

\section{CONCLUSION}

Dans l'Antiquité grecque, la divinité a sa place à bord. Si on ne peut rien affirmer sur l'existence éventuelle d'une statue monumentale à la poupe, néanmoins des représentations de divinités sont réalisées sur la coque (parasèma) parfois même sculptées de façon à se détacher à l'avant du bateau; la stolos porte aussi des images de divinités ou des symboles de celles-ci. À l'arrière la divinité est supposée être présente, sous la forme de son nom inscrit sur une stylis et/ou sous la forme d'une représentation figurée. Tous ces décors sont soignés et témoignent d'une certaine richesse ou recherche : bronze, peintures, dorures.

Il est difficile en revanche d'établir une chronologie de ces ornements. Ainsi pour l'époque archaïque nous ne possédons aucune information et peu pour la période classique. La plupart des décors navals représentant des dieux sont connus uniquement pour l'époque hellénistique. De façon générale, nous voulons insister sur la différence du nombre des sources entre le monde grec et le monde romain, et ne pas céder à la tentation de prêter au premier tout ce qui appartient au second.

En matière de sujets iconographiques, la religion n'est pas le

${ }^{95}$ Cette pratique pourrait avoir été copiée par les souverains ptolémaïques sur le modèle des bateaux transportant les images de cultes lors des processions égyptiennes (Palladino 2013).

${ }^{96}$ Relief Torlonia : Guglielmotti 1866; Wachsmuth 1967, p. 143-150; Basch 1987, p. 463-467. Sur les autels à bord : Maetzke 1965 (non convaincant); Wachsmuth 1967 note 259; Beltrame 2002, p. 73-74; Fenet 2011, p. 409. On évoque souvent à cet égard les quatre petits autels en terre cuite de l'épave archaïque de Gela (Panvini 2001, p. 33-35 et 60). Comme pour les six temples miniatures en argent à suspendre, découverts dans l'épave de Comacchio (voir supra note 82 p. 266), ces modèles devaient faire partie de la cargaison du navire. 
seul thème abordé. Et parmi celle-ci, l'exclusivité ne revient pas aux divinités olympiennes. Des divinités secondaires comme les Dioscures, les Néréides, des personnifications, des figures mythologiques font partie du répertoire des motifs utilisés dans le domaine nautique. Parmi les divinités olympiennes notons la considération accordée à Athéna puis, dans une moindre mesure, à Zeus, Aphrodite et Apollon. Poséidon ne semble pas dans ce contexte revêtir une grande importance.

\title{
LES NOMS THÉOPHORES DE BATEAUX
}

\author{
INTRODUCTION
}

\section{Problématique}

Il est admis depuis longtemps que parmi les noms de bateaux connus par les textes littéraires ou les inscriptions figurent des noms de divinités ou renvoyant à certaines d'entre elles. Depuis plus d'un siècle, des savants ont établi des listes d'onomastique navale et distingué des grandes lignes concernant les usages des Anciens dans l'attribution de ces noms ${ }^{97}$. L'ouvrage de K. Schmidt établissant la composition de la flotte athénienne au $\mathrm{IV}^{\mathrm{e}} \mathrm{s}$. a.C. constitue à cet effet un outil essentiel. Cet inventaire fut publié à la même période que l'article «Seewesen» de la $R E$ dans lequel F. Miltner donna une liste de noms portant sur l'ensemble de la marine antique : grecque et romaine, bateaux de commerce ou de guerre. Lionel Casson a complété et corrigé la totalité de ces données en s'aidant notamment de l'article de N. Sandberg paru entre temps.

Si l'on regarde donc ces listes, on remarque cependant que cette pratique de noms théophores est loin d'être majoritaire. On baptise plutôt les embarcations de noms géographiques, d'adjectifs évoquant une qualité présupposée du bateau. Finalement, les noms théophores ne représentent qu'une petite partie des noms connus pour les flottes de l'Antiquité. Cependant il est indispensable de les traiter dans la mesure où ils peuvent s'avérer révélateurs de certaines croyances religieuses ${ }^{98}$ entretenues par les

${ }^{97}$ Cartault 1881, p. 164, 176; Miltner 1931, col. 946-956; Schmidt 1931; Sandberg 1954; Casson 1971, p. 350-360 et liste p. 439-441. Le rappel des grandes lignes et de la bibliographie est donné par Vélissaropoulos 1980, p. 67-69.

${ }^{98}$ Wachsmuth 1967, p. 98-100 évoque très rapidement cette thématique. 
hommes gravitant autour du bateau : ceux qui le commandent ou le possèdent, ceux qui y travaillent ou ceux qui y voyagent. Comme pour les noms de personnes, le choix d'une référence divine n'est pas anodin, même s'il répond à des variantes géographiques ou chronologiques et témoigne d'une vitalité et popularité des cultes ${ }^{99}$. Ces différentes attestations sont alors à mettre en relation avec la présence à bord d'autres moyens usités pour évoquer une personnalité divine.

Dans l'Antiquité grecque, il apparaîtrait que les noms donnés au bateau soient essentiellement de genre féminin, à cause du genre attribué au nom générique vaṽ $\mathcal{G}^{100}$. D'autre part, L. Casson discerne pour sa part des «modes» concernant le choix des noms donnés au bateau tout au long de l'Antiquité : si les Égyptiens privilégient les noms de dieux-rois et de divinités, les trières athéniennes du $\mathrm{IV}^{\mathrm{e}} \mathrm{s}$. ne suivent pas cette pratique hormis à travers l'emploi de quelques adjectifs dérivés ou épithètes; quant aux flottes hellénistiques - même si au ${ }^{\mathrm{er}}$ s. a.C. l'aversion de nommer des bateaux d'après des divinités majeures a disparu ${ }^{101}-$, la vogue est de les affubler de noms inspirés de ceux des souverains du moment, tandis que les Romains préfèrent jouer d'allusions mythologiques. C'est finalement parmi les bateaux de commerce que le savant anglais reconnait le plus de noms faisant référence à des divinités ${ }^{102}$. Sans contester les grandes lignes de ce tableau, il conviendra cependant de nuancer ce jugement en examinant dans le détail toutes les mentions possibles des grandes divinités du panthéon grec.

Les critères de détermination d'un nom théophore sont loin d'être toujours assurés. Il est des cas où l'origine du substantif donné au bateau ne suscite pas d'interrogation; malheureusement pour le monde grec, ceci n'est pas le plus courant. Sans être catégorique sur l'orientation à donner aux différents noms, nous soumettons tous

${ }^{99}$ Parker 2000

${ }^{100}$ Svoronos 1914, p. 107, note 4; Vélissaropoulos 1980, p. 68. Sur le genre du mot «bateau» dans les langues indo-européennes, voir Ayala 1985, p. 370-378.

${ }^{101}$ L. Casson reprend ici les remarques exprimées par Robert 1936 (p. $2 \mathrm{n}^{\circ} 1$ ) qui corrigeait ainsi de manière chronologique la distinction de Miltner 1931, loc. cit., entre pratique grecque et pratique romaine.

${ }^{102}$ Loc. cit. Il conclut ainsi que pour les Athéniens du IV s. a.C., cependant, des «divinités plus petites ou des figures mythologiques sont une source riche pour environ 1 pour 4 noms retenus, jamais au hasard: nymphes de la mer (Néréides, Thétis, Amphitrite)» - ce que nous serions tentés de désigner comme divinités secondaires, issues du folklore -, tandis que les Romains de l'époque impériale «adoptent des noms de divinités majeures d'après l'usage hellénistique, pour environ 1 bateau sur $5 »$. 
ceux qui ont un rapport de près ou de loin avec les divinités olympiennes. Les plus litigieux sont les adjectifs toponymiques, à propos desquels nos prédécesseurs ont eu parfois une attitude également ambiguë. K. Schmidt, tout au long de son analyse, hésite entre l'interprétation purement géographique et l'allusion religieuse ${ }^{103}$. L. Casson quant à lui penche pour la première solution, tout en nuançant son jugement pour quelques cas : il invoque alors une valeur religieuse lorsqu'il s'agit de sanctuaires comme Délos, Delphes ou le mont Ida. Cependant, des noms comme ceux d'Éleusis ou Sounias sont intégrés parmi les noms toponymiques faisant référence à un district d'Athènes ${ }^{104}$. Ces incohérences montrent bien la difficulté d'interpréter ces désignations et de les ranger dans des catégories strictes.

\section{Limites des sources; les inscriptions d'euploia}

Les sources sont essentiellement épigraphiques, mais également dans quelques cas littéraires et numismatiques. Cependant, elles demeurent restrictives dans le sens où les bateaux dont nous avons conservé les noms sont en très grande majorité des bâtiments appartenant aux flottes de guerre ${ }^{105}$ : athénienne au $\mathrm{IV}^{\mathrm{e}}$ S. a.C. ${ }^{106}$ et romaine impériale, ou servant au grand commerce : il s'agit surtout de navires "publics». En ce qui concerne le monde grec, aucune attestation de nom de bateau ne semble exister pour l'époque archaïque $^{107}$, et peu de choses sont connues pour l'époque hellénistique et de façon générale en dehors d'Athènes. Il est encore plus difficile de saisir les noms donnés par les particuliers à des petites embarcations - si elles en possédaient -, et ainsi de dresser un portrait plus quotidien des marines grecques.

Les seuls témoignages que nous pouvons envisager de noms donnés à des embarcations privées, de taille et tonnage là encore indéterminés, proviennent des inscriptions d'euploia gravées sur des falaises comme celles de Prôtè, Thasos, Santa Maria di Leuca. Il

${ }^{103}$ Schmidt 1931, p. 63-92.

${ }^{104}$ Casson 1971, p. 353.

${ }^{105}$ Il existe également de grandes inégalités à l'intérieur même de ces listes : Casson 1971 indique ainsi un rapport d'environ 300 noms pour les trières athéniennes du $\mathrm{IV}^{\mathrm{e}} \mathrm{s}$. contre deux douzaines de noms de bateaux de guerre hellénistiques et 80 de la flotte impériale romaine, principalement de Misène et Ravenne.

${ }^{106}$ Sur les inscriptions navales d'Athènes, voir la présentation générale de Basch 1987 p. 266-267. rapide».

${ }^{107}$ Le seul nom grec ancien de bateau s'avère être Argô, littéralement «le 
convient, avant d'étudier des rites maritimes, d'évoquer globalement ces sources et leur contexte.

Un certain nombre de sites à ciel ouvert à travers le bassin méditerranéen manifestent la religiosité des marins. Ce sont des lieux fréquentés par des équipages qui y laissent des marques de leur dévotion, de leurs craintes et de leurs espoirs devant les dangers de la mer directement sur la roche par l'intermédiaire d'inscriptions. Celles-ci sont de deux types : les vœux avant départ, et le remerciement après une traversée réussie ${ }^{108}$. Le vœu d'euploia proprement dit renvoie à la première alternative ${ }^{109}$, sans omettre cependant la seconde ${ }^{110}$. Ces inscriptions indiquent parfois le nom du bateau auquel appartient le dédicant, ce qui nous intéresse ici de prime abord ${ }^{111}$.

Ces lieux privilégiés sont des endroits pourrait-on dire stratégiques au niveau de la navigation : sur des routes maritimes fréquentées, refuges en des passes sans doute dangereuses du fait de courants ou de vents brusques comme en connaît la Méditerranée. Il s'agit le plus souvent de falaises, de grottes surplombant la mer ou de rochers dans des criques - quoique la physionomie des lieux ait changé depuis l'Antiquité, ce qui nous donne une vision déformée de ces sanctuaires naturels. Sont connues jusqu'à présent les inscriptions de l'île de Prôtè ${ }^{112}$, à l'ouest du Péloponnèse, celles de Grammata ${ }^{113}$ au nord de l'île de Syros ${ }^{114}$, celles du même nom au sud de l'Albanie actuelle ${ }^{115}$, ainsi que celles de la grotte Porcinara à Santa Maria di Leuca à l'extrémité des Pouilles ${ }^{116}$ et de la baie de Roca dans le détroit

${ }^{108}$ Wachsmuth 1967, p. 113-115.

${ }^{109}$ Ceci a été montré par Sandberg 1954, p. 10-11.

${ }^{110}$ Salviat 1962, p. 610 note 7.

${ }^{111}$ Les noms de bateaux figurant dans ces inscriptions n'ont pas toujours été reconnus comme tels : c'est à Sandberg 1954, p. 14 ss. qu'il revient d'avoir fixé l'interprétation de ces textes.

${ }^{112}$ Le premier relevé de ces inscriptions a été realisé par Stridj, 1904. Sur le nom et la position géographique privilégiée de l'île, premier amer ou première escale pour les navigateurs venant de l'ouest, voir Kowalski 2012, p. 90-91.

${ }^{113}$ Les inscriptions ont été publiées pour la première fois en grec par $\Sigma \tau \varepsilon \varphi \alpha v o \varsigma$ 1875, p. 3-32; voir également les croquis figurant dans $I G$ XII, 5, 1, p. 198. L'endroit est aujourd'hui difficilement accessible, si ce n'est par bateau.

${ }^{114}$ Les inscriptions des deux sites ont été réunies par Sandberg 1954 : Prôtè $\mathrm{n}^{\circ}$ 1-28, Syros $\mathrm{n}^{\circ}$ 29-38; un compte-rendu de cette étude a été publié par J. et L. Robert dans le Bulletin épigraphique 1956, no 3.

${ }^{115}$ Hadjari \& al. 2007, avec bibliographie. La pratique de graver des inscriptions sur ce site, qui offrait dans l'Antiquité un point d'abri sur une côte réputée dangereuse, s'est poursuivie au moins jusqu'au XIVe $\mathbf{s}$.

${ }^{116}$ Van Compernolle \& alii 1978 : voir particulièrement l'introduction de R. Van Compernolle p. 1-6, la présentation archéologique de la grotte par F. d'Andria p. 47-49 et 86-87, et les inscriptions par C. Pagliara p. 177-221. 
d'Otrante ${ }^{117}$; on peut également y rajouter celles de la presqu'île d'Aliki au sud de l'île de Thasos ${ }^{118}$ quoique gravées sur les degrés de façade d'un édifice cultuel ${ }^{119}$. Les divinités honorées par ces dédicaces sont diverses ou parfois inconnues. Les inscriptions grecques de Grammata (Épire) remontant au plus tôt au III ${ }^{\mathrm{e}}$ s. a.C. s'adressent principalement aux Dioscures, de même que vraisemblablement celles de l'île thasienne ${ }^{120}$. La divinité honorée à Prôtè n'est pas mentionnée, pas davantage que celle de Syros. Une seule divinité olympienne, à ce qu'il paraît, s'est vu consacrer des lieux de ce type ${ }^{121}$ : Zeus à Santa Maria di Leuca et dans la baie de Roca. Ces endroits accessibles par mer, désolés, sont plutôt associés aux divinités secondaires.

La plupart de ces lieux sacrés ont connu une continuité rituelle jusque parfois le $\mathrm{XX}^{e} \mathrm{~s}^{122}$. Ceci et le caractère aérien de ces sites battus par les vents et les embruns font que le plus souvent les inscriptions les plus anciennes ont disparu ou sont difficilement déchiffrables. Ainsi, malheureusement, les inscriptions les plus anciennes concernant précisément notre période chronologique sont souvent couvertes ou effacées par de plus récentes; les graffiti

${ }^{117}$ Pagliara 1991. Il n'y a pas de réelle publication de la zone à ce jour. Notons que la baie de Roca, située à l'ouest sur la côte italienne, fait face au site de Grammata à l'est sur la côte albanaise.

${ }^{118}$ Hicks 1887, p. 409-433; Bernard \& Salviat 1962, p. 609-611; Bernard \& Salviat 1967, p. 583-587; Grandjean \& Salviat 2000, p. 45, 48, 160-165, 180 (carrières) et fig. 10. Les inscriptions d'Aliki ont été réunies avec celles de Prôtè et de Syros par N. Sandberg 1954, n 39-44. Ce dit "édifice nord» est implanté sur une terrasse dominant la baie et appartient à un sanctuaire dont la fondation remonte au VII ${ }^{\mathrm{e}}$ s. a.C., peut-être voué à Apollon (kouros et dédicace de la fin du $\mathrm{IV}^{\mathrm{e}}$ ou du début du III ${ }^{\mathrm{e}}$ s. a.C. trouvée sur l'isthme); les huit inscriptions d'euploia connues à Aliki (dont une relative à un ou des polémarque(s)) sont postérieures au $\mathrm{II}^{\mathrm{e}}$ s. p.C. L'exportation du marbre des carrières voisines, bien exploitées jusque la fin de l'Empire romain, laisse supposer de nombreux mouvements maritimes dans la baie.

${ }^{119}$ Signalons en outre deux inscriptions accompagnées d'un dauphin gravées sur une falaise de l'îlot nommé Prasonisi situé dans le golfe de Mirabello au nord-est de la Crète: Chapouthier 1935, p. 376-381 et pl. XXV; IC III, ix, 1, p. 167-168. D'après le tracé des lettres, le tout est d'époque romaine.

${ }^{120}$ Bernard \& Salviat 1962. Une seule inscription d'euploia mentionne les

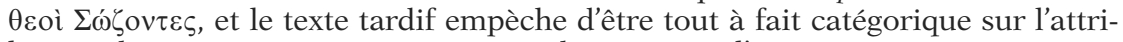
bution de ce sanctuaire aux Dioscures durant toute l'Antiquité.

${ }^{121}$ C'est donc les deux seuls que nous évoquerons dans cette étude : pour Santa Maria di Leuca, voir infra, chapitre ex-voto d'ancres; sur la baie de Roca, voir supra, chapitre Zeus. Nous avons tenu cependant à présenter d'emblée, une bonne fois pour toutes, ces sites d'euploia qui, sans concerner directement notre travail en ce qui concerne les ex-voto à terre, seront évoqués à plusieurs reprises tout au long de cette deuxième partie.

${ }^{122}$ C'est assurément le cas pour Grammata de Syros et Grammata d'Albanie. 
lisibles sont pour une grosse majorité postérieurs au I r $^{\text {S. a.C. }}{ }^{123}$. En l'absence de témoignages antérieurs et du fait du poids de la tradition dans les coutumes des populations orientales de l'Empire, ces inscriptions ont été rapprochées des autres. De la même manière, nous avons tenu à noter les noms de bateaux des classes impériales, afin de pouvoir, si possible, nuancer le jugement de L. Casson et L. Robert à propos de la distinction chronologique et percevoir les continuités ou ruptures éventuelles ${ }^{124}$.

\section{INVENTAIRE}

L'inventaire qui suit est basé sur les études de référence en la matière ${ }^{125}$, d'où son caractère parfois fastidieux. Dans le cadre de notre étude, nous avons adopté une approche différente de celles suivies dans les ouvrages concernant l'histoire de la navigation grecque : non plus strictement historique par période et zone géographique mais par divinité concernée, depuis la plus représentée, tout en respectant pour chacune d'elle l'ordre chronologique ${ }^{126}$. Pour une vision d'ensemble, le lectur trouvera en annexe, p. 607-609, un tableau récapitulatif.

\section{Athéna}

Athéna paraît bien avoir été à l'origine d'un nombre relativement important de noms de bateaux. Il est cependant difficile d'être catégorique car un certain nombre d'entre eux peuvent s'interpréter de différentes manières. Les occurrences d'époque classique étant presque exclusivement athéniennes, il n'est certes pas surprenant de trouver plusieurs termes référant à la fois au territoire de la cité et à des épiclèses de sa divinité poliade.

${ }^{123}$ Sur les datations de Prôtè, Syros et Thasos, voir Sandberg 1954, p. 19. Ces inscriptions ne sont pas datables précisément; on les place globalement aux premiers siècles de notre ère.

${ }^{124}$ En revanche, nous n'avons pas retenu les noms de bateaux fournis par le Papyrus Oxyrhynchos 2415 donnés par Casson 1971, p. 359-360, d'une part à cause de leur date avancée - il s'agit d'une liste de navires marchands de la fin du III s. p.C. - mais aussi car le document ne donne pas le nom des bateaux. Il en précise les propriétaires ou responsables, ainsi que parfois le parasèmon, ce qui n'est pas tout à fait la même chose : voir supra.

${ }^{125}$ Voir références données dans les notes antérieures.

${ }^{126}$ Pour ne pas surcharger le texte de chiffres, nous avons choisi de désigner les années par la date de leur début (ex. 342 pour 342/341) en gardant bien conscience que les deux semestres de l'année athénienne se répartissent sur deux années de notre calendrier. 
Ainsi, la flotte athénienne du IV $\mathrm{IV}^{\mathrm{e}}$ s. a.C. compte une trière Пoגıós en l'an $357^{127}$. Pour K. Schmidt, ce nom attribué à un bateau renvoie à l'aptitude guerrière d'Athéna, et par là-même du navire. Selon cette même thématique ${ }^{128}$, d'autres épithètes s'appliquant à la

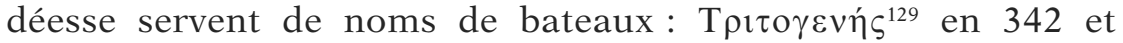

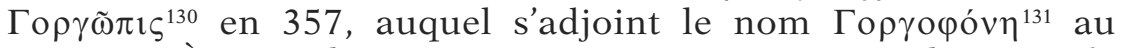
$\mathrm{V}^{\mathrm{e}}$ s. a.C. À cette liste on pourrait encore ajouter le nom de $\Pi \alpha \rho \theta \varepsilon \dot{\varepsilon} \varsigma^{132}$, recensé pour une trière en $348^{133}$.

Deux adjectifs toponymiques peuvent être compris dans un sens purement géographique ou à consonnance religieuse. La trière de 377 baptisée $\Sigma o u v i \alpha ́ \varsigma^{134}$ peut renvoyer au promontoire attique tout aussi bien qu'au sanctuaire d'Athéna (Pausanias, Description de la Grèce I, i, 1). Le nom de П $\alpha \lambda \lambda \eta v i \varsigma^{135}$ connu pour 323 peut faire référence à un sanctuaire d'Athéna situé à l'est d'Athènes ${ }^{136}$.

L'époque hellénistique n'est pas en reste en ce qui concerne l'hommage à la divinité. Le nom П $\alpha \lambda \lambda \alpha$ ás inscrit au-dessus d'une proue de navire 137 figure au droit d'une monnaie au-dessus d'une proue de galère, émise à Corcyre dans les trois premiers quarts du III s. a.C. Elle fait partie d'un ensemble d'émissions de bronze

${ }^{127}$ Casson 1971, p. 351; Miltner 1931, col. 951; Schmidt 1931, p. $28 \mathrm{n}^{\circ} 130 ;$;G II/III ${ }^{2} 1611,148$.

${ }^{128}$ Schmidt 1931, p. 57-58.

${ }^{129}$ Miltner 1931, col. 952; Schmidt 1931, p. 45 no 235; IG II/III ${ }^{2} 1622$, 189.

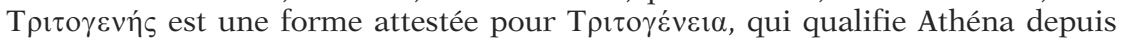
Homère.

${ }^{130}$ Miltner 1931, col. 948; Schmidt 1931 p. 27 n 113; IG II/III ${ }^{2} 1611$, 81. Le mot désigne Athéna dans Euripide, Hélène, v. 1316.

${ }^{131}$ Casson 1971, note 39 p. 350; Schmidt 1931, p. 7 n 5 ; IG II/III ${ }^{2} 1604 a$. Euripide, Ion, v. 1418, nomme Athéna de cette manière Gorgophona.

${ }^{132}$ Schmidt 1931, p. 65 et Casson 1971, p. 352 l'interprètent tous deux comme un qualificatif donné à l'embarcation d'après une comparaison faite par Aristophane, Cavaliers, v. 1302. Mais cette interjection comique est à replacer dans le contexte de la pièce : alors que les trières personnifiées tiennent conseil, la plus âgée d'entre elles prend la parole et s'adresse aux autres qu'elle considère forcément comme des parthenoi. La mention d'Aristophane ne signifie en rien que les trières étaient désignées de cette façon.

${ }^{133}$ Casson 1971, p. 352; Miltner 1931, col. 951; Schmidt 1931, p. no 221; IG II/III' $1621,67$.

${ }^{134}$ Casson 1971, p. 353; Miltner 1931, col. 951; Schmidt 1931, p. 9 n 24; $I G \mathrm{II} / \mathrm{III}^{2} 1604,24$.

${ }^{135}$ Casson 1971, p. 353; Miltner 1931, col. 951; Schmidt 1931, p. 50 n 269; IG II/III ${ }^{2}$ 1631, 475.

${ }^{136}$ Dans les deux cas, Schmidt 1931, p. 82 hésite entre le toponyme et l'épiclèse de la déesse, tandis que Casson 1971, p. 353 les entend au sens géographique. Le culte d'Athéna Pallènis est mentionné par Hérodote, Enquête I, 62 et par Euripide, Héraclides, v. 849 et 1031. Autre Pallènè : voir supra p. 125.

${ }^{137}$ Casson 1971, p. 355; Gardner, op. cit., p. 131 n 271-273. 
présentant des proues associées à un nom. Le numismate anglais $P$. Gardner a émis l'hypothèse que toutes ces séries monétaires figurant des navires avec leur onomastique renvoient à des régates, jouées à Corcyre ou à Actium, dans lesquels les dits-bateaux auraient remporté la victoire ${ }^{138}$. Pour le $\mathrm{I}^{\mathrm{er}}$ s. a.C., deux attestations contemporaines témoignent de l'existence de bateaux portant des noms de la déesse. En effet en 69 a.C., Délos qui a souffert des exactions d'un allié de Mithridate, Athénodoros, fut réparée et fortifiée en partie par les Romains, sous la houlette du légat de Lucullus, C. Valerius Triarius ${ }^{139}$. Trois inscriptions provenant de ce rempart lui sont dédiées par les équipages milésiens et smyrniotes de bateaux

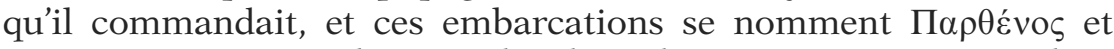
'A $\theta \eta v \tilde{a}^{140}$. Le rapprochement des deux désignations, correspondant à des équipages proches les uns des autres, ne doit pas être fortuit et paraît conforter l'allusion religieuse à Athéna que comporte le nom Parthénos.

Toujours au ${ }^{\text {er }}$ s. a.C., le poète Ovide (Tristes I, 10, v. 1-44) envoyé en exil en 8 p.C., emprunte depuis Corinthe un bateau qui porte le nom de la déesse : Minerva dit-il en latin dans ses vers, mais sans doute 'A $\theta \eta v \tilde{\alpha}$ vu l'origine du bateau.

Pour les premiers siècles de notre ère, cet usage se maintient. Des navires portent le nom d'A $\theta \eta v \tilde{\alpha}$, comme en témoignent deux inscriptions de l'île de Prôtè ${ }^{141}$. Une trièmiolia rhodienne du troisième quart du I ${ }^{\mathrm{er}} \mathrm{s}$. a.C. porte le nom de Пo $\lambda i^{\prime} \varsigma^{142}$, qui peut renvoyer à la grande déesse lindienne. Le fait est d'autant plus notable que la flotte rhodienne maintenue par Rome ne porte que des noms se rapportant à la gloire de l'empire et de l'empereur. Un certain nombre de navires de guerre romains sont baptisés Minerva ${ }^{143}$ : une quadrirème ${ }^{144}$, une trirème ${ }^{145}$, une liburne et un bateau de type non défini ${ }^{146}$ à Misène ${ }^{147}$ et

${ }^{138}$ Gardner 1881; Gardner 1883, p. xlix.

${ }^{139}$ Roussel 1987, p. 331.

${ }_{140}$ Casson 1971, p. 354 note 53; ID 1855, 1856 et 1857; une quatrième dédi-

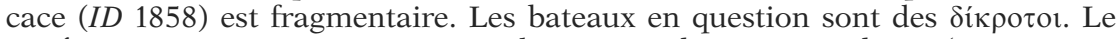
Parthénos est enregistré comme une dière par Miltner 1931, col. 951 (renvoyant à OGIS 447).

${ }^{141}$ Casson 1971, p. 359; IG V, 1, 1553 = Sandberg 1954 nº 16; SEG XIV $342=$ Sandberg $1954 \mathrm{n}^{\circ} 22$.

${ }_{142}$ Casson 1971, note 61 p. 358 avec datation inexacte; Miltner 1931, col. 951; X $\alpha \beta$ « $\rho \tilde{\alpha} \varsigma$ 1913, p. 9-10, n 9; Blinkenberg 1938, p. 17-18 no 37 avec commentaires annexes p. $52 \mathrm{n}^{\circ} 7$ et p. 47-48.

${ }^{143}$ Casson 1971, note 58 p. 357; Miltner 1931, col. 954.

${ }^{144}$ CIL VI, 3136; X, 3406; Ephemeris epigraphica VIII p. 116 no 444.

${ }^{145}$ CIL VI, 3129; X, 3453; 3520; 3619; 3626; Not. Sc. 1892, p. 119.

${ }^{146}$ CIL VI, 340.

${ }^{147}$ CIL X, 3607. 
une trirème de Ravenne ${ }^{148}$; auxquels L. Cassson a rajouté une quadrirème ${ }^{149}$ et un autre bateau indéterminé de Misène ${ }^{150}$.

\section{Aphrodite}

La déesse a inspiré plusieurs noms de bateaux, et ce dès l'époque classique. Une trière athénienne 'A $\varphi \rho o \delta ı \sigma^{\prime} \alpha^{151}$ apparaît dans trois inscriptions datées entre 377 et 356. Une autre dénommée 'A $\varphi$ $\rho$ бías est connue par deux inscriptions de 377 et vers $348^{152}$. La référence à Aphrodite est comprise par K. Schmidt comme un hommage à la jeunesse et à la beauté, point commun d'un certain nombre de noms de bateaux référant à des figures mythologiques féminines ${ }^{153}$. Une trière de 357 nommée $\mathrm{K} \omega \lambda$ ió $\varsigma^{154}$ peut éventuellement renvoyer à l'épiclèse de la divinité honorée sur ce promontoire de l'Attique (Pausanias, Description de la Grèce I, i, 5). De même c'est peut-être la déesse de Cythère ${ }^{155}$ que peuvent évoquer les deux trières

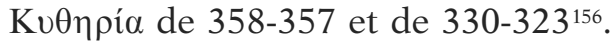

Pour l'époque hellénistique, on connaît une Kú $\pi \rho 1 \varsigma^{157}$ que donnent les monnaies de Corcyre du $\mathrm{III}^{\mathrm{e}}$ s. évoquées à propos d'Athéna.

Un navire portant le nom d'A 'A bateaux relevés dans les vœux d'euploia de l'île de Prôtè158. Une inscription presque identique se trouve dans la grotte de Santa Maria di Leuca, à la pointe de l'Iapygie ${ }^{159}$. Le nom apparaît également en latin, Venus, pour une quadrirème ${ }^{160}$ et une trirème de

${ }^{148}$ CIL XI, 35, 36, 72, 119.

${ }^{149}$ Casson 1971, note 57 p. 356; AE 1949, 206.

${ }^{150}$ Casson 1971, ibid., AE 1964, 103.

${ }^{151}$ Casson 1971, p. 351; Miltner 1931, col. 948; Schmidt 1931, nº 31; IG II/III ${ }^{2}$ 1604,$79 ; 1607,155 ; 1611,80$.

${ }^{152}$ Miltner 1931, col. 948; Schmidt 1931, no 64; IG II/III ${ }^{2}$ 1605, 48; 1621, 76.

${ }^{153}$ Schmidt 1931, p. 55-56.

${ }^{154}$ Miltner 1931, col. 950; Schmidt 1931, p. 27 n 122 ; IG II/III ${ }^{2} 1611,135$.

${ }^{155}$ Schmidt 1931, p. 82-83.

${ }^{156}$ Miltner 1931, col. 950; Schmidt 1931, p. 35 no 173; IG II/III ${ }^{2} 1611,126 ; 1611$, $139 ; 1611,169 ; 1627,206 ; 1627,225 ; 1631,623$.

${ }^{157}$ Casson 1971 p. 355; Gardner 1883, p. 131 n 264.

${ }^{158}$ Casson 1971, p. 359 et note 69; Sandberg 1954 p. 29-31, nº $27=$ SEG XIV

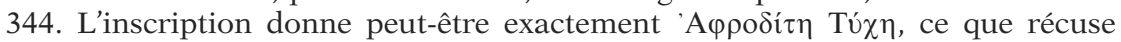
Sandberg 1954, critiqué à son tour par J. et L. Robert, Bulletin épigraphique 1956, p. $105 \mathrm{n}^{\circ} 3$.

${ }^{159}$ C. Pagliara in Van Compernolle \& alii 1978, p. 205-206 no 23 et p. 213,

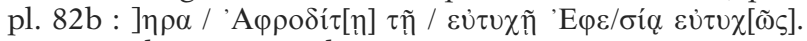

${ }_{160}$ Miltner 1931, col. 956; Casson 1971, p. 358; note 64 p. 314; note 57 p. 356. ILS 2845; CIL X, 3391, 3420, 3478, 3491, 3574, 3605; RA IV, 1904, p. 448 no 171. 
Misène ${ }^{161}$. Trois autres mentions sont à noter, qui ne concernent peut-être pas les deux navires : dans ce cas il s'agirait de deux attestations supplémentaires pour les flottes impériales d'embarcations portant le nom d'Aphrodite ${ }^{162}$.

\section{Apollon}

Les références à Apollon sont difficiles à déterminer avec certitude. Pour l'époque classique, un certain nombre de noms de bateaux renvoient à des lieux qui lui sont consacrés. Comme pour Athéna, les références géographiques se doublent vraisemblablement d'une intention religieuse ${ }^{163}$.

Dans la flotte athénienne du IV ${ }^{\mathrm{e}}$ s. a.C., sont recensées une trière $\Delta \varepsilon \lambda \varphi i^{164}$ et une autre $\Delta \varepsilon \lambda \varphi v v^{16} \alpha^{165}$. La première est connue pour les années 334-323, la seconde en 377. De même s'y trouve entre 377 et 323 une $\Delta \eta \lambda 1 \alpha \varsigma^{166}$ et entre 370 et 357 une $\Delta \tilde{\eta} \lambda \mathrm{o} \varsigma^{167}$.

La référence au dieu est en revanche explicite aux premiers siècles de notre ère. Parmi les inscriptions d'euploia de Thasos, s'en trouve une, malheureusement fragmentaire, mentionnant un bateau dénommé Z $\mu \mathrm{v} v$ [... Celui-ci est d'abord reconstitué - au datif -

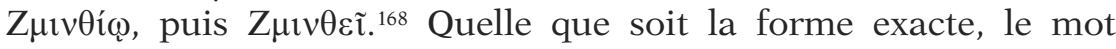
renvoie à une épithète connue, celle d'Apollon Smintheus ${ }^{169}$. Le nom latin Apollo est établi pour plusieurs trirèmes ${ }^{170}$ : une de Misène ${ }^{171}$, une de Ravenne ${ }^{172}$ et une au port d'attache indéterminée ${ }^{173}$.

${ }^{161}$ Miltner 1931, ibid.; Casson 1971, ibid.; AE 1965.145; CIL VI, 3110; X, 3382, 3458, 3460, 3461, 3468, 3472, 3539, 3596, 3598, 3635, 3652, 6800.

${ }_{162}$ Miltner 1931, ibid.; CIL V, 8819; X, 3509, 3618 p. 353.

${ }^{163}$ C'est l'opinion de Schmidt 1931, p. 83-84, partagée par Casson 1971,

${ }^{164}$ Casson 1971, p. 353; Miltner 1931, col. 948; Schmidt 1931, p. no 243;

IG II/III' ${ }^{2}$ 1623, 294; 1629, 588; 1629, 599; 1629, 838; 1631, 192.

${ }^{165}$ Milner, col. 948; Schmidt 1931, p. n $20 ; I G \mathrm{II} / \mathrm{III}^{2} 1604,91$.

${ }^{166}$ Casson 1971, p. 353; Miltner 1931, col. 948; Schmidt 1931, p. $11 \mathrm{n}^{\circ}$ 35; IG II/III' 1604 , 29; 1623, 124; 1628, 403; 1629, 923; 1631, 15.

${ }^{167}$ Miltner 1931, col. 948; Schmidt 1931, p. 24 n 97; IG II/III² 1609, 69; 1611, 223.

${ }^{168} I G$ XII, 8, 586 = Sandberg 1954, n 44; Bent 1887, p. 414, corrigé par Robert 1936, p. 2 n. 1.

${ }^{169}$ Première mention dans l'Iliade, I, v. 39.

${ }^{170}$ Casson 1971, p. 358 et note 57 p. 356; Miltner 1931, col. 952.

${ }_{171}$ CIL VI, 3139; X, 3383, 3471; RA IV, 1916, p. 478 n 109.

${ }_{172}$ CIL X, 3527; XI, 101, 109.

${ }^{173} C I L \mathrm{~V}, 2840$. 


\section{Déméter et Koré}

Une anecdote historique témoigne au IV e s. d'un nom théophore donné à un bateau. Diodore de Sicile (Bibl. Hist. XVI, 66, 3-5) ainsi que Plutarque (Vies (Timoléon), 8, 1-9, 1) rapportent qu'en 344, la flotte athénienne sous le commandement de Timoléon, fit voile vers la Sicile avec l'aide de Déméter et Koré. En effet, elles accompagnèrent sous la forme d'un flambeau la course des navires ayant pour but leur île de prédilection. Ce prodige avait été annoncé préalablement par des prêtresses au chef de l'expédition, qui remercia les deux déesses en leur consacrant son meilleur bateau rebaptisé ainsi

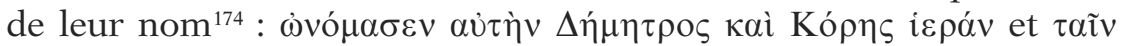

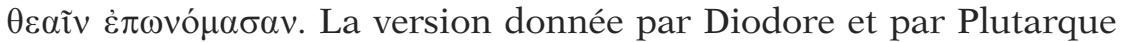
n'est pas identique. La première, hellénistique, voit l'attribution du nom divin à la suite du prodige, et sous-entend un changement d'appellation pour l'embarcation en question. L'anecdote de Plutarque lui donne ce nom dès le départ du navire, équipé par les Corinthiens, suite à la prophétie des prétresses. Cette petite histoire montre que d'une part nommer un bateau d'après le nom d'un dieu n'est pas pratique inconcevable au $\mathrm{IV}^{\mathrm{e}} \mathrm{s}$., mais que dès lors la nef est

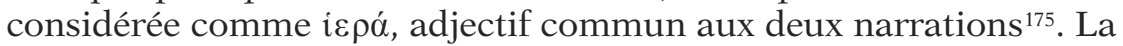
trière - comme la définit Plutarque - porte le nom des deux déesses car leur culte est commun; les Grecs n'ont pas jugé bon de consacrer un bateau à chacune des deux déesses. Cependant le nom exact de l'embarcation ne nous est pas parvenu.

Par ailleurs, la flotte athénienne des années 377-370 possédait

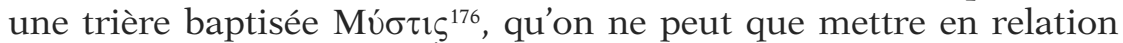
avec le culte éleusinien ${ }^{177}$. À l'époque romaine, sont attestés au moins deux bateaux désignés du nom de la mère seule ${ }^{178}$. La première

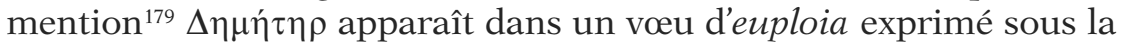
formulation la plus simple possible gravé dans l'île de Prôtè. Le second cas $^{180}$ est plus douteux : le nom qui figure parmi les inscriptions du temple d'Aliki à Thasos est en partie restitué. En revanche, une trirème de Ravenne porte de façon assurée le nom de Ceres $^{181}$.

${ }^{174}$ Casson 1971, p. 351, n. 43.

${ }^{175}$ Göttlicher 1992, p. 129 classe cet exemple dans une catégorie qu'il nomme de bateaux «semi-sacrés».

${ }^{176}$ Schmidt 1931, p. 13 no 45; Miltner 1931, col. 950; IG II/III² 1604, 72; 1609, 114.

${ }^{177}$ Schmidt 1931, p. 62.

${ }^{178}$ Casson 1971, p. 359.

${ }^{179}$ SEG XI 1012 = Sandberg 1954 n 23.

${ }^{180} I G$ XII, 8, 584 = Sandberg $1954 \mathrm{n}^{\circ} 42$.

${ }^{181}$ Casson 1971, p. 358; Miltner 1931, col. 953; Sandberg 1954, p. 29; CIL X, 3517, 3540, 3546, 3554, 3592. 
Artémis

Une trière 'A $\rho \tau \varepsilon \mu 1 \sigma i \alpha^{182}$ appartient à la flotte athénienne dans les années 377 à 353. Par ailleurs, deux trières athéniennes

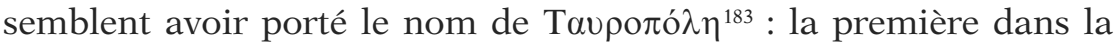
seconde moitié du Ve s., l'autre entre 377 et 356. Ces deux noms de bateaux renvoient sans conteste à la déesse Artémis ${ }^{184}$. Il en est certainement de même pour la trière 'O $\rho \tau u \gamma i \alpha^{185}$ connue pour l'année 342, qui peut s'entendre comme une épiclèse d'Artémis ${ }^{186}$.

À une époque plus tardive, parmi les inscriptions d'euploia relevées à Thasos au lieu-dit Aliki, mention est faite d'un bateau nommé "A $\rho \tau \varepsilon \mu 1 \varsigma^{187}$.

\section{Dionysos}

La flotte athénienne du IV e s. a.C. comprend une trière Bók $\chi$, plus précisément dans les années 377-370 188 , ainsi qu'une autre appelée Evía $\alpha^{189}$ dans les années 330. Dans les deux cas l'allusion dionysiaque est manifeste ${ }^{190}$. Beaucoup plus tard, le nom de Liber Pater est donné à une trirème de Misène ${ }^{191}$, ainsi que celui de $\Delta$ tóvvoos à un navire marchand qui a laissé sa marque parmi les inscriptions de l'île de Prôtè ${ }^{192}$.

${ }^{182}$ Casson 1971, p. 351; Miltner 1931, col. 948; Schmidt 1931, p. 16, n 63; IG II/III' 1605,$29 ; 1611,68 ; 1613,149$.

${ }^{183}$ Casson 1971, p. 351; Miltner 1931, col. 952; Schmidt 1931 p. 8-9, no 16; IG II/III ${ }^{2}$ 1604, 2; 1605, 20; 1611, 89; 155; 179; 1612, 25; EA 1901, 81, 2. C'est Schmidt 1931 seul qui distingue deux embarcations différentes.

${ }^{184}$ Schmidt 1931, p. 56-57, suivi par Casson 1971, p. 351. L'épiclèse Tauropole est attestée une première fois par Sophocle, Ajax, v. 172; voir ensuite notamment la tragédie d'Euripide, Iphigénie en Tauride.

${ }_{185}$ Miltner 1931, col. 951; Schmidt 1931, p. 45 n 232; IG II/III'² 1622, 769.

${ }^{186}$ Schmidt 1931, p. 84-85. L'épiclèse apparaît dans Sophocle, Trachiniennes, v. 214; le terme peut aussi être compris comme l'autre appellation de l'île de Délos, utilisée depuis l'Odyssée.

${ }^{187}$ Casson 1971, p. 359; Sandberg 1954, n 43; IG XII, 8, 585; Chapouthier 1935b, p. 379, note 9; Bent 1887, p. 417. 97.

${ }_{188}$ Miltner 1931, col. 948; Schmidt 1931, p. 10 no 32; IG II/III ${ }^{2} 1604,71 ; 1609$,

${ }_{189}$ Miltner 1931, col. 949; Schmidt 1931, p. 47 no 248; IG II/III ${ }^{2} 1624,61$.

${ }^{190}$ Schmidt 1931, p. 62.

${ }_{191}$ Casson 1971, p. 358 et note 57 p. 356; Miltner 1931, col. 954; CIL X, 3535, 3540, 3563, 3563, 3579, 3595; CPL 120 corrigé par IGLS III, 1168.

${ }^{192}$ Casson 1971, p. 359; SEG XIV 341 = Sandberg 1954, n 21. 
Zeus

Pour le $\mathrm{IV}^{\mathrm{e}}$ s. a.C., en 357 précisément, est connue une trière du nom de $\Delta \tilde{\imath} \alpha^{193}$. Il est difficile de déterminer si l'adjectif est à mettre étymologiquement en relation avec Zeus, ou s'il faut le prendre au sens général de divine ${ }^{194}$. À la même période, la flotte athénienne comprend entre 377 et 356 et en 323 deux 'O $\lambda \nu \mu \pi i \alpha \varsigma^{195}$, ainsi qu'entre 374 et 358, en 356 et en 334 trois $\mathrm{N} \varepsilon \mu \varepsilon \alpha \varsigma^{196}$ qui peuvent renvoyer aux sites et jeux consacrés à Zeus ${ }^{197}$.

À l'époque romaine, Jupiter comme nom de bateau est connu pour une trirème de Misène ${ }^{198}$ et une autre sans port d'attache déterminé ${ }^{199}$.

Arès

Une trière nommée 'A $\mathrm{e} \varepsilon \alpha^{200}$ est recensée pour la flotte athénienne entre 359 et 356 . Elle est mise en relation avec le dieu de la guerre $^{201}$, qui dans le monde romain a donné son nom, Mars, à plusieurs navires de guerre ${ }^{202}$ : une trirème de Ravenne ${ }^{203}$, une de Misène ${ }^{204}$, et un autre indéterminé ${ }^{205}$.

${ }^{193}$ Miltner 1931, col. 948; Schmidt 1931, p. $\mathrm{n}^{\circ} 114$; IG II/III ${ }^{2} 1611$, 410. Les deux occurences sont attestées dans la littérature.

${ }^{194}$ Schmidt 1931, p. 62 l'interprète de la seconde manière.

${ }^{195}$ Casson 1971, p. 353; Miltner 1931, col. 950; Schmidt 1931, p. $14 \mathrm{n}^{\circ} 48$; IG II/III ${ }^{2}$ 1604, 8; 1612, 291; 1631, 534.

${ }^{196}$ Casson 1971, p. 353; Miltner 1931, col. 950; Schmidt 1931, p. 18 n 68 ; IG II/III ${ }^{2} 1606,82 ; 1611$, 84; 1611, 265; 1612, 37; 1612, 167; 1615, 105; 1616, 131; 1623, 245.

${ }^{197}$ Schmidt 1931, p. 81, suivi par Casson 1971, p. 353.

${ }^{198}$ Casson 1971, p. 358; Miltner 1931, col. 954; CIL X, 3638, 3664; Ephemeris epigrafia VIII, p. $116 \mathrm{n}^{\circ} 444$. 1158 .

${ }^{199}$ Casson 1971, note 57 p. 356; Miltner 1931, col. 954; CIL XIV, 233; IGLS III

${ }^{200}$ Miltner 1931, col. 948; Schmidt 1931, p. 29 no 145; IG II/III ${ }^{2} 1611,120$; 1611,$135 ; 1611,165 ; 1612,42$.

${ }^{201}$ Schmidt 1931, p. 63.

${ }^{202}$ Casson 1971, p. 358; Miltner 1931, col. 954.

${ }^{203}$ CIL II, 4063; X, 3524; XI, 51, 52, 67.

${ }^{204}$ CIL X, 3584, 3627.

${ }^{205}$ CIL V, 1956. 
Héphaistos

Le dieu du travail du métal a prêté son nom ${ }^{206}$ à une trière athénienne ${ }^{2} \varphi \alpha \_\tau \tau i \alpha^{207}$ de 357 à 342. Aucun autre nom de bateau ne semble lui être rattaché.

\section{Poséidon}

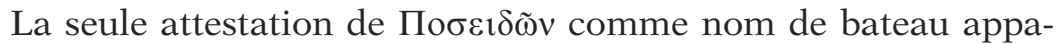
raît à l'époque romaine dans une inscription d'euploia d'Aliki à (Thasos) ${ }^{208}$. Neptunus en revanche connait un certain succès dans les flottes impériales ${ }^{209}$ : une quadrirème de Ravenne ${ }^{210}$, une trirème de Misène ${ }^{211}$, une de Ravenne ${ }^{212}$ et une de type indéterminé $^{213}$ ainsi qu'une liburne de Misène ${ }^{214}$ et une d'Alexandrie ${ }^{215}$ portent ce nom.

Il convient d'évoquer au conditionnel le bateau l'’'I $\sigma \theta \mu 1 \alpha^{216}$ d'Antigone Gonatas (276 à 239) ${ }^{217}$, signalé par Plutarque (Propos de table V, 675d-677b). Celui-ci met le nom en relation avec le feuillage dont on aurait couronné les vainqueurs des jeux de l'Isthme qui aurait poussé spontanément à bord. L'argumentation complexe de Plutarque doit signifier que celui-ci a fabriqué l'exemple pour étayer sa thèse générale sur l'origine des différentes sortes de feuillages utilisés pour la confection des couronnes, mais que le nom du bateau avait pour origine un autre motif ${ }^{218}$.

${ }^{206}$ Schmidt 1931, p. 63.

${ }^{207}$ Miltner 1931, col. 949; Schmidt 1931, p. 34 n 162; IG II/III ${ }^{2} 1611$, 351; 1622, 699.

${ }^{208}$ Casson 1971 p. 359; IG XII, 8, 582 = Sandberg 1954 n $^{\circ} 40$; Bent 1887, p. 416, corrigé par Robert 1936, p. 2 n. 1.

${ }^{209}$ Casson 1971, p. 358 et note 58 p. 357; Miltner 1931, col. 955.

${ }^{210}$ CIL XI, 45.

${ }^{211}$ CIL X, 3375, 3378, 3656.

${ }^{212}$ CIL VI, 3161, XI 94, 97.

${ }^{213}$ CIL VI, 3165.

${ }^{214}$ CIL X, 3412, 3475, 3647.

${ }^{215}$ Casson 1971, note 57 p. 356; CPL 250.

${ }^{216}$ Casson 1971, p. 355.

${ }^{217}$ Sur ce bateau et son offrande, voir infra.

${ }^{218}$ Tarn 1986, p. 218-220, pense plutôt que le nom est inspiré du lieu de sa construction, Corinthe. Cette hypothèse paraît plus plausible lorsque l'on considère que l'Isthmia se voulait la rivale d'un bateau contemporain, la Syracusia de Hiéron de Syracuse. Il faut sans doute mettre en parallèle les deux noms de bateaux, en relation avec leur port d'origine. 


\section{Hermès}

Dans le monde grec, Hermès semble absent de l'onomastique navale.

En revanche plusieurs navires de guerre romains, une trirème de Ravenne ${ }^{219}$ et une de Misène ${ }^{220}$, une quadrirème également dans chacun des deux ports ${ }^{221}$ et une liburne de la flotte d'Alexandrie ${ }^{222}$, portent le nom latin du dieu : Mercurius.

\section{Hestia}

Une Eotía de Kamiros est présente dans les noms de bateaux de l'île de Prôtè ${ }^{223}$. On trouve son équivalent latin Vesta dans la flotte impériale romaine ${ }^{224}$ : à Misène surtout - une quadrirème ${ }^{225}$, une trirème ${ }^{226}$ et un bateau indéterminé 227 - et à Ravenne pour une quadrirème 228 .

\section{Héra}

De la même manière, le nom d'Héra n'est pas mis en relation avec une onomastique de bateau avant l'époque romaine. Juno est attestée pour une trirème de Misène ${ }^{229}$.

\section{Épithètes féminines}

À cet inventaire il faut ajouter plusieurs adjectifs féminisés, employés comme noms de bateaux. Quoique le plus souvent considérés comme se rapportant au bateau et à ses qualités présupposées $^{230}$, ils peuvent cependant correspondre également à des

${ }^{219}$ Miltner 1931, col. 954; CIL XI, 122.

${ }^{220}$ Miltner 1931, col. 954; CIL X, 3338, 3401, 3452; XIV, 239.

${ }^{221}$ Miltner 1931, col. 954; respectivement CIL XI, 106; CIL VI, 3114.

${ }^{222}$ Casson 1971, p. 358 et note 57 p. 356; CPL 125.

${ }^{223}$ Casson 1971, p. 359; SEG XIV $342=$ Sandberg $1954 \mathrm{n}^{\circ} 22$; voir J. et

L. Robert, Bulletin épigraphique 1956, p. 105, 3.

${ }^{224}$ Casson 1971, p. 358; Miltner 1931, col. 956.

${ }^{225}$ IL X, 3365, 3372, 3404, 3454, 3481, 3489, 3495, 3531, 3534, 3566, 3653.

${ }^{226}$ IL X, 3483, 3572, 3585; VI, 3097; AE 1929, 146.

${ }^{227}$ IL X, 3464a.

${ }_{228}^{22}$ IL VI, 3158; XI, 62.

${ }^{229}$ Casson 1971, p. 358; Miltner 1931, col. 954; CIL X, 3374, 3482.

${ }^{230}$ C'est l'opinion de Casson 1971, p. 352, ainsi que celle de Schmidt 1931, p. 63-76. 
épiclèses. Ils sont notés à part à cause de leur interprétation incertaine, mais aussi parce que certaines de ces épiclèses sont connues pour plusieurs divinités.

\section{a) Phôsphoros}

C'est le cas de $\Phi \omega \sigma \varphi$ ópos. Quatre bateaux portent ce nom : trois à l'époque classique - une trière en 373 , la deuxième entre 373 et 356 et la troisième en $323-{ }^{231}$, une à l'époque hellénistique ${ }^{232}$. On peut hésiter à attribuer cette épiclèse à Artémis ${ }^{233}$, Déméter, Hécate ou même Aphrodite ${ }^{234}$. Il faut peut-être considérer dans une trirème de Misène Lucifer ${ }^{235}$ son équivalent latin.

\section{b) Euploia}

Ev̌ $\pi \lambda$ or $\alpha$ est le nom de trois trières athéniennes durant le $\mathrm{IV}^{\mathrm{e}} \mathrm{s}$. a.C. ${ }^{236}$. Plutarque (Compendium argumenti stoicos absurdoria poetis dicere, 1057e) atteste également cette désignation pour des bateaux, lorsqu'il le cite avec humour parmi d'autres noms à connotation optimiste quant à la destinée du voyage et du bateau. Le mot peut évoquer le souhait d'une bonne traversée ${ }^{237}$ comme il peut correspondre à l'épiclèse d'Aphrodite.

\section{c) Idée de Salut}

L'idée de secours qui est à la base de nombreux noms de bateaux est perçue dans une relation entre le navire et la citée 238 ; elle pourrait aussi évoquer une divinité salvatrice invoquée en mer ou d'une autre manière ce que $\mathrm{D}$. Wachsmuth appelle les nomina boni ominis $^{239}$. Ainsi on trouve dans la flotte athénienne classique deux trières $\Sigma \varphi_{\zeta} \zeta o v \sigma \alpha^{240}$ en 370 puis en 323 , substantif également cité par

${ }^{231}$ Miltner 1931, col. 952; Schmidt 1931, p. 21 no 85; IG II/III ${ }^{2} 1607,17 ; 1607$, $28 ; 1612,107 ; 1612,334 ; 1631,467 ; 1631,590$. $\mathrm{n}^{\circ} 279$.

${ }^{232}$ Sur une monnaie de Corcyre : Casson 1971, p. 355; Gardner 1883, p. 131,

${ }^{233}$ Schmidt 1931, p. 68.

${ }^{234}$ Casson 1971, p. 355.

${ }^{235}$ Casson 1971, p. 358; Miltner 1931, col. 954; CIL X, 3384, 3394, 3395, 3579.

${ }^{236}$ Casson 1971, p. 352; Miltner 1931, col. 949; Schmidt 1931, p. $17 \mathrm{n}^{\circ} 66$; IG II/III' ${ }^{2}$ 1606, 86; 1612, 202; 1632, 296.

${ }^{237}$ Schmidt 1931, p. 75, suivi par Casson 1971, p. 352.

${ }_{238}$ Schmidt 1931, p. 71; Casson 1971, p. 352 et 355.

${ }^{239}$ D. Wachsmuth, p. 99.

${ }^{240}$ Casson 1971, p. 352; Miltner 1931, col. 952; Schmidt 1931, p. $26 \mathrm{n}^{\circ} 106$; IG II/III' 1609, 83; 1631, 39; 1632, 20. 
Plutarque (ibid.); puis deux dénommées $\Sigma \omega \tau \eta \rho^{2} \alpha^{241}$ entre 373 et 357 et en 342, et une autre $\Sigma \dot{\omega} \tau \varepsilon 1 \rho \alpha^{242}$ en 357 . Ce dernier nom se retrouve également à l'époque hellénistique pour un bateau de Corcyre $^{243}$, qui figure dans les séries monétaires frappées entre 300-229 déjà évoquées plus haut (p. 278-279). Une quadrirème ${ }^{244}$ des soldats de César faisant route vers l'Afrique du nord en 46 a.C. porte également ce nom. Une trirème Salvia ${ }^{245}$ est également connue dans le monde romain; c'est aussi le nom donné à l'embarcation qui ramena la Magna Mater à Rome et que dégagea la vestale Claudia Quinta en 205-204 a. C. ${ }^{246}$. Signalons enfin l'existence d'un petit navire $(\lambda \dot{\varepsilon} \mu \beta \mathrm{o} \varsigma)$ $\Sigma \omega \tau \eta \dot{\rho \imath \chi о \varsigma} \varsigma^{247}$.

\section{CONCLUSION}

L'analyse historique de L. Robert et L. Casson se vérifie clairement. Il y a bien rupture entre la pratique grecque et la pratique romaine. Le nom du dieu en tant que tel n'apparaît réellement usité qu'à partir du premier siècle avant notre ère, sous forme grecque ou latine selon le lieu d'origine du bateau. L'attribution de noms de dieux pour des bateaux semble un fait courant, tant dans la flotte impériale que dans ce qui doit être la marine marchande.

Dans l'Antiquité grecque en revanche, la référence aux dieux est loin d'être marginale, sans pour autant être courante. Dans tous les cas, la divinité est évoquée d'une manière détournée : tout se passe comme si l'on n'osait pas donner le nom d'un dieu olympien à un bateau ${ }^{248}$. Des noms de divinités secondaires sont bien adoptés - des Néréides notamment ${ }^{249}$-, en revanche aucun substantif ne nomme directement un dieu olympien. Dans l'épisode de Timoléon, le seul

${ }^{241}$ Casson 1971, p. 352; Miltner 1931, col. 952; Schmidt 1931, p. $21 \mathrm{n}^{\circ} 84$; IG II/III' 1607,$22 ; 1611,101 ; 1615,11$ (?); 1622, 729.

${ }^{242}$ Miltner 1931, col. 952; Schmidt 1931, p. 28 n 135 ; IG II/III ${ }^{2} 1611,149$.

${ }^{243}$ Casson 1971, p. 355; Gardner 1883, 131, n 275-277.

${ }^{244}$ Casson 1971, note 54 p. 355; Miltner 1931, col. 952, qui la donne comme trière; Syll $^{3} 763,5$.

${ }^{245}$ Casson 1971, p. 357; Miltner 1931, col. 955; CIL XI, 3094; X, 3532; 3580; 3600. Il est sans doute excessif d'y voir, comme l'exprime L. Casson, une «beneficial qualitie of Roman rule»!

${ }^{246}$ Gianfrotta 1994, p. 607. Sur l'introduction de la Magna Mater à Rome, voir le récit donné par Tite-Live, Histoire romaine XXIX, 10, 4-14, 14 et par Ovide, Fastes IV, v. 297-328.

${ }^{247}$ Anthologie Palatine XI, 331 : épigramme de Nicarque qui écrit sous les Flaviens. Sur le lembos, voir Casson 1971, p. 395.

${ }^{248}$ Le même sentiment est exprimé par Sandberg 1954, p. 18.

${ }^{249}$ Pour s'en faire une idée, voir la liste récapitulative de Schmidt 1931, p. 93-94. 
cas où le nom d'un bateau est explicite, des circonstances particulières justifient cet usage. Quelques épiclèses ou surnoms sont alors utilisés : ainsi Pallas, Euploia, Phôsphoros. Plus souvent, le procédé consiste à faire allusion à la divinité grâce des adjectifs substantivés, par exemple Aphrodisia, Artémisia ${ }^{250}$. La forme de ceux-ci, au féminin, n'empêche pas de faire intervenir des dieux masculins. Il est à noter le grand nombre de références à un lieu qui peuvent, nous l'avons vu, être doublement interprétées.

Entre la pratique grecque et la pratique romaine, le peu d'exemples pour l'époque hellénistique empêche de distinguer si une évolution est déjà discernable à cette date. Les noms donnés par les monnaies de Corcyre consistent en des épiclèses : Kypris, Pallas, Sôteira, Phôsphoros, tandis que les équipages de Milet et Smyrne naviguent sur des bateaux nommés Parthénos et Athéna. Il est vrai que ceux-ci sont à ce moment déjà sous le joug de l'autorité romaine.

Parmi les dieux auxquels il est fait explicitement référence à l'époque classique, Aphrodite est l'une des plus aimées. Elle bénéficie d'un succès constant tout au long de l'Antiquité. Minerve, bien connue pour la marine romaine, paraît auparavant dans le monde grec également avoir beaucoup influencé l'onomastique des bateaux. Mais répétons-le, il faut nuancer ce jugement d'après les sources qui donnent un état de la marine officielle de la cité où Athéna règne en maître. Cependant, la plupart des noms divins hellénistiques font également référence à elle. Apollon semble lui aussi bien représenté dans les flottes de l'époque classique, par l'intermédiaire de ses cultes dans les deux sanctuaires panhelléniques que sont Délos et Delphes. Artémis quant à elle inspire directement des noms de bateaux : trois lui sont directement rattachés au $\mathrm{IV}^{\mathrm{e}}$ s. a.C. Déméter et Koré, ensemble, font l'objet d'attentions particulières, au moins dans des circonstances particulières. Un nom de bateau renvoie à une particularité de leur culte, ce que l'on observe aussi pour Dionysos. Deux divinités pourtant très rarement mises en relation avec la mer sont également attestées, Arès et Héphaistos : la présence du premier dans une flotte de guerre n'est pas étonnant.

Enfin il convient de noter quelques absents à ce tableau qui n'apparaissent pas avant l'époque romaine : Héra, Hermès et très certainement Poséidon. Il est notable qu'aucune allusion à celui-ci n'apparaisse parmi ces flottes, alors que son épouse Amphitrite baptise des trières athéniennes ${ }^{251}$.

${ }^{250}$ Schmidt 1931, p. 94-95; Davaras 1980, p. 55.

${ }^{251}$ Schmidt 1931, p. $45 \mathrm{n}^{\circ} 237$. 


\section{LES ANCRES À BORD}

\section{INTRODUCTION}

Le nom d'une divinité peut apparaître sur la stylis ou à travers l'onomastique navale. Une troisième catégorie rejoint celles-ci : les noms théophores figurant sur les ancres retrouvées en mer. La divinité peut être ainsi présente à bord également par l'intermédiaire de l'ancre du bateau. Or, certaines ancres portent par ailleurs un décor. C'est pourquoi il nous a paru bon non seulement d'étudier les inscriptions sur ancres mais aussi les motifs représentés, afin d'examiner leur valeur religieuse et d'examiner le lien éventuel avec les autres présences du sacré à bord. Cet examen des ancres s'avère d'autant plus essentiel à nos yeux que les noms de dieux qui y apparaissent correspondent quasi exclusivement aux dieux olympiens : aucune divinité secondaire telles les Néréides, Ino ou les Dioscures ne figure ici parmi les noms apparus sur jas ${ }^{252}$.

Devant l'abondance du matériel, la variété de la bibliographie et les confusions en tous genres, il nous a très vite paru indispensable d'établir un corpus de toutes les ancres recensables, afin si possible de dégager des grandes lignes de recherche et de classement: celui-ci figure en annexe (p. 563-594). Certes dresser un catalogue des ancres, ou plutôt des jas d'ancres avec décor et inscription n'est pas une idée nouvelle ${ }^{253}$. Des listes ont déjà été publiées, mais de manière souvent décousue, avec une bibliographie lacunaire dans la plupart des cas. Les descriptions manquent en outre de détails : il arrive ainsi par exemple qu'on présente une ancre avec inscription en omettant les décors qui y figurent également.

Le problème le plus important, pour établir ce catalogue, consiste en la connaissance de l'existence même de ces objets.

${ }^{252}$ Par souci d'exhaustivité, toutes les ancres avec noms théophores seront exposées ici : seules deux divinités, attestées une seule fois, sortent du cadre de cette étude (Héraclès, Isis).

${ }^{253}$ Par exemple Boon 1977a, p. 10-30, a constitué un tableau (p. 22) comprenant des exemplaires du motif des astragales sur jas d'ancres; Gianfrotta 1980 a donné une vision générale des différents motifs connus; Zemer 1981 a tenté également une synthèse des jas présentant un décor, mais son catalogue produit de fausses attributions et la conclusion de son article, constatant l'évolution de ces dernières années sur la recherche menée sur les jas de plomb, est plutôt décevante. Les regroupements opérés dans les autres articles sont également insuffisants et de surcroît recèlent une grande quantité d'erreurs, que nous signalerons quelquefois en note. 
P. A. Gianfrotta ${ }^{254}$ souligne, avec raison, le peu de publications de ce type d'artefact en comparaison du nombre existant. Lui-même avoue en avoir vu plus d'une centaine, mais il n'en donne pas de liste détaillée ${ }^{255}$. Ainsi seul le dépouillement systématique de certaines revues a permis de détecter la trace de certains jas. Malheureusement, il existe sans aucun doute d'autres objets de ce type, décrites dans des périodiques à diffusion limitée ou dans des catalogues de musée, qui ont échappé à notre attention. Quelques uns aussi nous sont apparus par l'effet du hasard, lors de la visite d'un site ou d'un musée. Sans prétention d'exhaustivité, ce catalogue se présente au moins comme une mise à jour d'une bibliographie décousue, et comme un répertoire d'inscriptions et de motifs que peut-être une vue d'ensemble permettra de mieux percevoir.

Le but de ce catalogue est donc d'essayer de comprendre et de saisir la présence réelle du religieux à travers cet objet, le plus maritime s'il en est ${ }^{256}$. C'est pourquoi en sont exclues les inscriptions purement onomastiques, c'est-à-dire donnant le nom d'un personnage lié étroitement au bateau - sûrement l'armateur ou le propriétaire - ${ }^{257}$, ou encore numérales, fournissant une indication de poids $^{258}$ ou encore de l'appartenance à une légion ${ }^{259}$. En revanche ces mêmes ancres sont retenues quand elles combinent l'inscription avec un décor, et sont alors classées pour ce dernier dans le corpus. Les motifs quels qu'ils soient sont enregistrés et feront ensuite l'objet d'une discussion au sujet de leur signification, en l'occurrence religieuse ou non.

Un deuxième problème explique la variété de ce corpus :

${ }^{254}$ Gianfrotta 1980, p. 103 et 108.

${ }^{255}$ Par ailleurs, le corpus - ne concernant de surcroît que le motif des astragales - «préparé par G. Kapitän» (mentionné par Queyrel 1987, p. 207 note 3) n'est à ma connaissance toujours pas paru, à moins qu'il ne s'agisse de l'article Kapitän 1989, qui ne donne que des tableaux de comptage et des conclusions brèves sur les motifs en général; y figure le nombre de 111 jas de plomb avec décor(s) en relief (tableau IV).

${ }^{256}$ L'épave de Commachio nous livre un témoignage de l'importance de l'objet pour les marins : une lampe de type Dressel présente une ancre en graffito, que l'on peut raisonnablement supposer appartenir à un membre de l'équipage : Berti 1992, fig. 5.

${ }^{257}$ Voir le corpus donné par Hesnard \& Gianfrotta 1989. L’interprétation de ces noms est unanime, et depuis un certain temps : voir entre autres Gianfrotta, 1980, p. 110 ss; Gianfrotta \& Pomey 1980, p. 309; Guarducci 1967-78, III, Rome, 1974, p. 362-363. Gianfrotta 1994, p. 591-608, évoque également le cas rare du nom du fabricant du jas ou de l'ancre.

${ }^{258}$ Citons pour exemple la fameuse ancre en fer trouvée dans le contexte des bateaux de Nemi : Ucelli 1950, p. 238-239.

${ }^{259}$ Voir les deux cas datés de la période julio-claudienne donnés par Gianfrotta, 1980, p. 110. 
l'absence de chronologie fine pour les jas. Si l'on peut à présent définir de grandes catégories ${ }^{260}$, trop peu nombreuses sont les ancres trouvées dans un contexte archéologiquement datable pour permettre une typologie détaillée ${ }^{261}$. Même pour les exemplaires associés à des épaves, il faut souligner que les datations proposées correspondent à celles de la dernière cargaison, qui n'est bien sûr pas forcément celle de l'ancre. La fourchette chronologique est ainsi très large, dépassant les cadres imposés pour cette étude. De même, si un certain nombre de ces jas sont bien romains, comme il est dit dans leurs publications, nous sortons dès lors de l'espace du «monde grec». Dans le doute cependant, il ne faut exclure aucun objet de ce corpus, d'autant que certains paraissent bien attestés pour l'époque hellénistique, sans que l'on puisse déterminer avec certitude si le jas provient d'un rivage ou l'autre de la Méditerranée. Sans compter

${ }^{260}$ Indices bibliographiques :

- Généralités : Luebeck, 1894, col. 2219-2220; Moll 1929a, p. 36-38, pl. E II et légendes p. 69-72: considérations générales et catalogue de représentations figurées. Sur le nom de l'ä $\gamma \kappa v \rho \alpha$, inspiré par son aspect courbe : Gianfrotta \& Pomey Milano, 1980, p. 301. Son invention est attribuée au philosophe scythe Anacharsis, ou à Eupalamos de Sycione, ou à Midas, roi de Phrygie.

- Sur la typologie des ancres, voir Gargallo 1961 (à travers la présentation des découvertes du port de Syracuse, l'auteur réportorie différentes ancres, y compris avec description du jas démontable, dit "ancre de l'amirauté"); résumé général (pierre, puis ancres...) par Davaras 1980, p. 49-53. Sur les jas de plomb, cf. Boon 1977a (typologie et datation); survol général de l'histoire de la recherche sur les ancres et des catégories de jas de plomb dans Zemer 1981. Sur l'approche économique et l'évolution des techniques (avantages du plomb, etc.), cf Gianfrotta 1980; Gianfrotta \& Pomey 1980, p. 297-309.

- Sur la distinction principale jas de type fixe / jas de type mobile : Gianfrotta 1980, p. 106; Gianfrotta \& Pomey, p. 305-306

- Sur les distinctions internes par fonction (ancres de jet, de bossoir), voir Carrazé 1973; Casson 1971, p. 250-258.

Les bateaux de taille relativement importante possédaient plusieurs ancres : Pindare (Olympiques VI) en témoigne dès cette époque.

${ }^{261}$ Le problème est bien exposé par Gianfrotta 1980, p. 103 ss. La principale étude portant sur ce point est l'ouvrage de Mercanti 1979, qui la première a tenté une synthèse en vue de constituer une amorce de chronologie et de typologie des ancres. Pour cela, elle a regroupé et classé toutes les ancres connues à cette date, trouvées dans un contexte datable sûr et moins sûr (à signaler en outre p. 11 un précieux petit tableau de correspondance du vocabulaire technique de l'ancre dans les cinq principales langues de publication). De nombreux articles ont depuis lors essayé d'apporter des compléments, notamment à l'aide des découvertes plus récentes; il serait trop long et hors de propos de tous les énumérer ici. Citons entre autres les articles de Gianfrotta 1980 et de Pallarés Salvador 1971. En ce qui concerne les ancres à jas de pierre, Gianfrotta \& Pomey 1980, p. 302, soulignent à ce propos que les meilleures possibilités de datation pourront en fait être données par les exemplaires trouvés dans les fouilles terrestres! 
bien sûr l'intérêt que présente la conservation pendant plusieurs siècles de telles pratiques et traditions.

\section{LE MATÉRIEL}

\section{Les ancres}

Les ancres sont des objets fonctionnels, qu'un accident lors de leur utilisation (naufrage, cable rompu...) nous a permis de conserver. Or, les ancres avec inscription ou décor retrouvées en mer sont toutes de plomb ${ }^{262}$. Ceci peut nous amener à penser que, ou les jas de pierre retrouvés en mer ont perdu toute trace d'inscription ou décor, ou alors ils n'en présentent pas pour la simple raison qu'ils n'en ont jamais eu. Une explication chronologique pourrait expliquer cette divergence de matériau : l'usage des ancres de pierre est en effet bien antérieur à celui des jas de plomb, même si l'ancre de pierre a continué à coexister avec celle de plomb ${ }^{263}$. Il n'est donc pas certain, a priori, de pouvoir considérer que la pratique de faire figurer des motifs et/ou des inscriptions ait existé également sur des modèles d'ancre en pierre archaïques.

Cependant, les décors sont connus sur des ancres de pierre, mais pour une période beaucoup plus ancienne ${ }^{264}$. Le critère d'absence n'est certes pas un argument persuasif, mais il paraît évident aussi qu'il est beaucoup plus facile de réaliser un relief sur un jas de plomb, grâce à la technique de l'estampage du moule, que sur un jas de pierre ${ }^{265}$. En revanche, aucune ancre de fer connue à ce jour ne présente quoi que ce soit qui puisse évoquer l'existence d'une ornementation $^{266}$.

${ }^{262}$ Y compris celle de l'épave archaïque de Mazarrón (prov. Murcie), figurant des monogrammes phéniciens (García Cardiel 2013, p. 54-55 et fig. 57-62).

${ }^{263}$ Voir par exemple les ancres de pierre de forme pyramidale, exposées au Pirée, au Musée nautique et au jardin du Musée archéologique, historiquement très intéressantes. Datées du $\mathrm{V}^{\mathrm{e}}$ au IV $\mathrm{IV}^{\mathrm{e}}$ s. a.C., elles proviennent du port de Zéa; elles seraient à mettre en rapport avec l'importation de bois depuis le Nord jusqu'à Athènes pour la construction des fameuses trières athéniennes. Cf. Frost 1989.

${ }^{264}$ Cf. par exemple l'ancre crétoise de Cnossos, décorée d'un poulpe : Frost 1973, n 6; Davaras 1980, outre celle-ci, signale également la présence de hiéroglyphes sur des ancres de pierre égyptiennes, ou encore d'inscriptions chyprominoennes sur des objets chypriotes; voir également infra sur les pratiques plus anciennes.

${ }^{265}$ Sur les différentes techniques : voir infra p. 300-302.

${ }^{266}$ Peu d'exemples sont, il est vrai, connu à ce jour. Le plus célèbre, et de taille (plus de 3,5 m!), est celui des galères de Nemi, publié dans Ucelli 1950. Sur 
Sur les jas de plomb, les combinaisons des décors et inscriptions sont multiples : inscription ou décor seuls, combinés entre eux, ou encore combinaisons d'inscriptions ou de décors. La répartition sur le jas n'est de même pas uniforme : les deux faces des deux bras peuvent porter des motifs - isolément ou à plusieurs ${ }^{267}$. Il est pour le moment impossible de déterminer si ces répartitions ont un sens ou si elles sont aléatoires, au gré de la fantaisie du fabricant ou de la personne qui commande l'objet. Nous avons donc divisé l'analyse en deux catégories : dans la première, les ancres de plomb à inscriptions théophores et celles avec un décor associé; dans un second temps, les ancres de plomb à motif simple puis à motifs combinés.

Une démarche originale a conduit A. Hesnard et P. A. Gianfrotta à comparer les inscriptions sur bouchons d'amphores et inscriptions sur ancres en plomb ${ }^{268}$. Cela en effet se justifie, comme les auteurs le développent parfaitement, sur des ancres romaines où apparaissent des onomastiques aptes à des études prosopographiques. En revanche, la comparaison rapide entre les décors toujours sur bouchons d'amphore et sur ancres en plomb, convainc moins. D'une part, les motifs communs sont peu nombreux (seulement trois : le trident, l'étoile ou rosette, le visage humain). De plus, c'est oublier que ces motifs apparaissent antérieurement aux onomastiques cataloguées et qu'il ne s'agit pas d'une pratique purement romaine. Comparer ces deux types de décor consiste en outre à nier implicitement une signification symbolique du décor sur ancre, ce qui est peut-être le cas à époque tardive, mais paraît peu probable à date plus ancienne ${ }^{269}$. Il est d'ailleurs sans doute significatif que les motifs communs aux bouchons d'amphores et aux ancres soient des motifs plus ou moins neutres, assez courants effectivement dans d'autres contextes, selon lesquels ils peuvent prendre différentes significations : par exemple le visage humain peut être compris de différentes manières, et pas seulement comme un signe apotropaïque. En revanche les motifs plus significatifs, comme par

les ancres de fer, voir entre autre Casson 1971, p. 253 et notes 113-114; Gianfrotta \& Pomey 1980, p. 306.

${ }^{267}$ Des cas plus rares montrent aussi des inscriptions ou décors sur l'épaisseur des bras (par exemple, une ancre de plomb de $170 \mathrm{~kg}$ du musée de Hvar en Croatie portant un même cartouche inversé sur dessus de bras : FL ANTONII FELIX ET CERD) ou un motif ovale sur le cadre central (jas d'Anzio, cat. D83).

${ }^{268}$ Hesnard \& Gianfrotta 1989, p. 393-441.

${ }^{269} C^{\prime}$ 'est peut-être ce que les auteurs ont voulu suggérer en passant en revue brièvement «les motifs sur ancres les plus apotropaïques, invoquant la protection divine ou faisant clairement allusion à la navigation et au commerce». Néanmoins l'ambiguïté subsiste. 
exemple les astragales, n'apparaissent pas sur les bouchons. Il ne semble donc pas exister d'association entre le nom et le motif, comme c'est le cas pour certains systèmes de timbres amphoriques ${ }^{270}$.

\section{L'ancre sacrée et l'ancre de miséricorde}

On ne peut aborder une étude des ancres antiques sans aborder un thème récurrent dans la littérature spécialisée : celui de «l'ancre sacrée». La première personne à l'avoir évoquée, J. N. Svoronos, la qualifie d'emblée de «relique», «d'ancre divine» ayant «la force, quand tout était désespéré, de calmer la tempête» ${ }^{271}$. Cette notion est reprise de façon catégorique par la quasi-totalité des savants qui ont ensuite publié des ancres. Il convient tout d'abord de la définir précisément.

L'expression de hiéra ankyra apparaît dans des textes tardifs, au plus tôt à la fin du I ${ }^{\mathrm{er}} \mathrm{s}$. p.C. Plutarque est le premier à l'évoquer, et ce à trois reprises (Préceptes politiques, $812 \mathrm{~b}$; ibid. $815 \mathrm{c}-\mathrm{d}$; Coriolan $32,1)$, dans le cadre d'une comparaison au long cours litteraire, celle de l'État et du bateau. D'autres références complètent notre connaissance, mais en nombre limité. Les passages de Plutarque évoquent bien un objet que l'on sort de quelque endroit ( $\dot{\alpha} \rho \alpha \dot{\mu} \mu \varepsilon v o v \dot{\varepsilon} \xi)$ en cas de difficultés extrêmes. Au II ${ }^{\mathrm{e}}$ s. p.C., Lucien (Fugitifs 13) utilise l'expression comme métaphore de la dernière extrémité à laquelle l'homme peut se trouver réduit, le recours à la dernière chance. Le verbe $\kappa \alpha \theta t \varepsilon ́ v \alpha \imath$ exprime le geste pratiqué à cette occasion. Dans un autre dialogue (Juppit. tragoedus 51-52), le philosophe reprend l'image tout en jouant à la fois sur la notion de "sacré» et sur le câble de l'ancre.

À la même période, Pollux (Onomasticon I, 93 = voir corpus p. 536), qui dresse un inventaire du vocabulaire nautique, distingue tout particulièrement l'ancre sacrée par son utilisation, des autres ancres caractérisées par leur configuration : celle-là n'intervient qu'en absolue nécessité. Un ou deux siècles plus tard, parmi les nombreuses péripéties du roman d'Héliodore (Éthiopiques VIII, 6, 9), se produit - non pas une tempête qui frappe le navire emportant les héros - mais une machination perverse qui vise à obtenir le résultat espéré après l'échec de toutes les tentatives précédentes. L'expression d'ancre sacrée, une fois de plus employée comme métaphore, renvoie à la solution extrême, du désespoir, celle à laquelle Thasos.

${ }^{270}$ Voir par exemple les études de Y. Garlan sur les timbres amphoriques de

${ }^{271}$ Svoronos 1914, Athènes, p. 105-110, précisément p. 106. 
on voudrait ne pas recourir mais que les circonstances obligent à

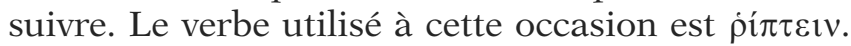

De la même manière au $\mathrm{IV}^{\mathrm{e}} \mathrm{s}$., Libanius (Epistula 230, 1) compare la confiance totale accordée aux mains d'un médecin à celle de l'ancre sacrée : l'idée récurrente reste la croyance forte en une aide extérieure, qui peut produire des miracles. Dans un autre passage (Progymnasmata - laudationes 2, 13), le rhéteur emploie l'expression pour désigner la statue d'Athéna gardienne des Troyens : ainsi l'ancre sacrée possède-t-elle une valeur religieuse, protectrice, une force magique.

L'ensemble des sources laisse donc deviner l'existence d'une ancre, bien distincte des autres sur le bateau, qui ne servait qu'en toute dernière extrémité272. La notion de "sacrée» réside dans le fait qu'on accorde à cette ancre un pouvoir salvateur in extremis, après que tous les moyens humainement possibles aient été mis en œuvre. Pour certains ${ }^{273}$, l'expression est postclassique, ce que paraissent montrer les attestations conservées; mais son succès perdura puisqu'on la retrouve dans un roman byzantin du XII ${ }^{e}$ s (Nicetas Eugenianos, Les amours de Drosilla et Chariclès VI, 349-352). Cependant, les commentaires byzantins, tels ceux de la Souda au $\mathrm{X}^{\mathrm{e}}$ s. (s. v.

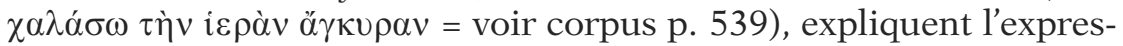
sion en renvoyant à deux tragédies classiques qui doivent évoquer cette ancre précisément mais sans la nommer de cette manière. C'est le cas pour la scholie à l'Hécube d'Euripide (voir corpus p. 533) ${ }^{274}$. Il semble donc que la hièra ankyra, même sous une autre désignation, est une réalité concrète au moins dès l'époque classique.

H. Frost pense avoir reconnu cette pratique sur un vase chypriote du VIII e s. a.C. ${ }^{275}$. Ce vase attribué au peintre Blanc IV² représente un bateau, dirigé vers la gauche, avec une poupe en cou de cygne tourné vers l'intérieur, un mât central et deux rames (fig. 20). Une ancre pend à l'arrière de l'embarcation, au bout d'un

${ }^{272}$ C'est ainsi que l'on a pu interpréter l'allusion faite par Synésios de Cyrène, dans sa Lettre IV à dater de 407 p.C. L'auteur y souligne la présence attendue de trois ancres pour le type de bateau sur lequel il a embarqué, au lieu de l'unique trouvée à bord (1. 174-177).

${ }^{273}$ Les éditeurs des Éthiopiques dans la collection Budé, tome III, note 1 p. 13-14.

${ }^{274}$ Svoronos 1914, loc. cit., indique également deux références probablement erronées : la première source (Actes des Apôtres XXVII, 17, 29, 30) mentionne en effet des ancres jetées lors d'une tempête, mais sans précision supplémentaire; la seconde (Diogen. 5, 29, ParGr 1, 256) reste pour nous énigmatique et inconnue.

${ }^{275}$ Frost 1982b; Basch 1987, fig. 563.

${ }^{276}$ Musée de Nicosie, inv. 1947/I - 16/1; cf. Karageorghis \& Gagniers 1974, $\mathrm{n}^{\circ} \mathrm{XI}, 2$, p. 122-123. 
câble en zigzag qui semble - mais peut-être s'agit-il de câbles différents - passer par le haut du mât et se prolonger de l'autre côté de la coque. Un être caricatural, de grande taille par rapport à celle du bateau, se penche sur celui-ci, un pied en équilibre (?) sur l'extrémité d'une des deux rames. H. Frost interprète cette scène, en comparaison avec l'autre représentation connue, également chypriote, d'une ancre de pierre ${ }^{277}$, comme un navire en situation difficile - ce que symboliserait une swastica figurée à gauche du bateau - ayant en dernier recours jeté l'ancre sacrée, qui seule parmi les ancres trouve sa place à l'arrière; le personnage difforme serait la divinité qui, répondant à cet appel, vient secourir l'embarcation ${ }^{278}$.

La question se pose alors de savoir, lorsqu'on est en présence

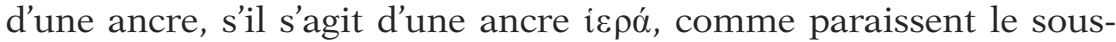
entendre un grand nombre de commentateurs modernes. Le fait de porter une inscription ou un décor constitue-t-il un trait distinctif de cette ancre? Ou encore plus précisément un nom de divinité279? L'identification comme ancre sacrée varie d'une publication à l'autre. Ainsi par exemple l'ancre du cap de Palos apparaît implicite-

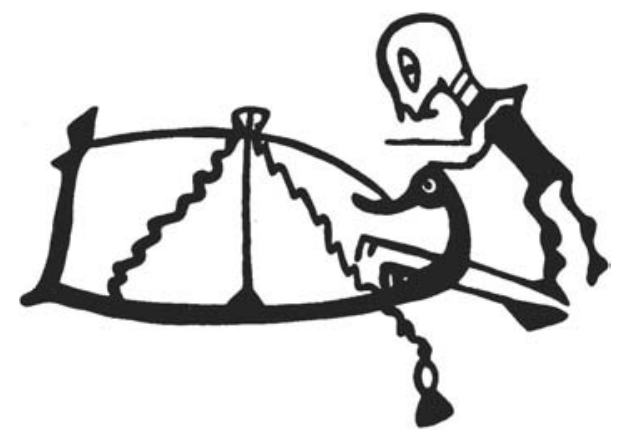

Fig. 20 - Vase chypriote avec représentation de l'«ancre sacrée» (?) (d'après Bach 1987, fig. 563).

${ }^{277}$ Frost 1982b, fig. 1; vase du Peintre Bichrome IV, aujourd'hui au British Museum, inv. 1926,6 - 28,9 : Kargeorghis \& Gagniers, n XI, 1.

${ }^{278}$ Kargeorghis \& Gagniers 1974, loc. cit., décrivent le personnage comme un homme qui avec "hâte (...) se prépare à monter à bord», et les lignes ondulées comme les «drisses» du bateau.

${ }^{279}$ C'est par exemple ce qu'affirme F. Benoît (Benoît 1951, p. 227 et presque dans les mêmes termes in Benoît 1952, p. 273) à propos de l'ancre portant le nom de Zeus Kasios seul : "La consécration de l'ancre à Zeus, dieu tutélaire des marins, dont le culte était répandu dans les ports, montre que celle-ci était le secours suprême en cas de tempête, pour apaiser les flots». 
ment sacrée lors de sa première publication, sans doute parce qu'elle porte deux noms de divinités ${ }^{280}$. Le motif des astragales dit «du coup de Vénus» est associé également implicitement au concept d'ancre sacrée ${ }^{281}$. Ou encore attribue-t-on de manière générale aux ancres "une signification sacrée en vertu de leur nature» ${ }^{282}$, c'est-à-dire à cause de leur importance pour la sauvegarde du bateau ${ }^{283}$. Une attitude moyenne consiste à voir certaines d'entre elles comme étant "sacrées», notamment celles portant un nom révélateur d'une aide surnaturelle ${ }^{284}$; celles-ci sont dès lors «dédiées à une divinité protectrice, soit offertes à son sanctuaire, où on les retrouve aujourd'hui dans les fouilles, (...) soit dédiées directement à la divinité, mais sans quitter le bateau; dans ce dernier cas, elles peuvent aujourd'hui se trouver partout, évidemment très souvent dans la mer ${ }^{285}$. Des doutes, timides certes, ont cependant déjà été formulés à cet égard ${ }^{286}$ : comment expliquer en effet la présence sur une même épave de deux ancres portant toutes deux des motifs considérés comme apotropaïques? ${ }^{287}$

Outre la notion d'ancre sacrée, est apparu par ailleurs dans les publications le concept $d$ ' «ancre de miséricorde», par parallèles effectués avec la marine du XVIII ${ }^{\mathrm{e}}$ s. En partant du principe qu'il existe différents types d'ancres, correspondant à des fonctions différentes de l'objet, et que les navires antiques d'une certaine taille en possédaient plusieurs $^{288}$, on en a déduit que l'ancre la plus lourde et la plus grande, utilisée en cas de vents forts et souvent en dernier

${ }^{280}$ Fíta 1906, p. 158. Sur cette ancre, voir infra p. 304 ss. et cat. I7.

${ }^{281}$ Voir infra.

${ }^{282}$ Davaras 1980 , p. $55-56$.

${ }^{283}$ Kapitän 1989, p. 152; c'est la même idée qui soutient l'interprétation du motif à l'époque chrétienne, selon laquelle l'ancre est devenue par sa fonction symbole de l'espérance et du salut : cf. Kirsch 1907.

${ }^{284}$ Moll 1929b, faisant référence précisément aux inscriptions de Zeus Hypatos, Sôtira et Aphrôdite Sôzousa; en ces quelques lignes il entend nuancer la théorie de Svoronos.

${ }^{285}$ Davaras 1980, p. 56, qui mélange ainsi plusieurs options d'interprétation,

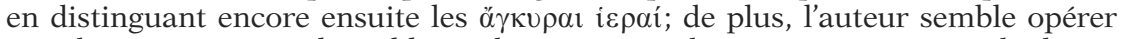
une division incompréhensible en deux groupes des ancres avec noms de dieux, selon le genre (féminin ou masculin) de celles-ci (p. 54-55 d'une part, p. 56 d'autre part).

${ }^{286}$ Boon 1977a, p. 20 : «Since the Greeks knew the heaviest, or sheet-ancor, as the sacred anchor, there is strong inducement to regard stocks as bearing divine names as cases in point; but mundane names scarcely appear, and considerable doubt attaches to such a view.»; Gianfrotta 1980, p. 109 admet l'hypothèse en ajoutant cependant qu'il est nécessaire «ne pas généraliser et de vérifier cas par cas».

${ }^{287}$ Boon 1977a, p. 20-21, faisant allusion précisément aux deux ancres de l'épave de la Jeaune-Garde B.

${ }^{288}$ Sur le nombre d'ancres emportées par les embarcations antiques, voir 
recours - en particulier pour maintenir le bateau surpris par la tempête au mouillage à l'entrée d'une rade -, était l'ancêtre de cette ancre dite de $"$ miséricorde ${ }^{289}$.

D'un usage pratique de cette ancre, les interprétations ont abouti ensuite à une vision plus symbolique dans laquelle la notion de «sacré» résidait dans le fait que l'objet en question, possesseur de vertus surnaturelles grâce à l'évocation d'un dieu, était par ailleurs détenteur des derniers espoirs des occupants du bateau ${ }^{290}$. Ne voyant dans cette ancre pas «autre chose que l'idole du dieu suprême des marins", J. N. Svoronos a rapproché cette pratique d'une coutume d'Italie du Sud, selon laquelle l'idole, resserrée habituellement dans un lieu bien clos, d'un saint local appelé Mamouotso - dont il ne faut jamais prononcer le nom sur un bateau et qui est représenté avec une ancre comme emblème -, est jetée à la mer en dernier recours lors de situations extrêmes, après force prières et injonctions; le saint est alors censé appliquer son pouvoir sur les éléments déchaînés ${ }^{291}$. Le numismate place alors cet objet à usage très particulier à un emplacement bien précis, à la poupe du bateau, et lui attribue, comme idole, une matière de préférence, le bois ${ }^{292}$.

L'explication, très séduisante dans les premiers temps d'étude de la navigation antique et en particulier des ancres, ne tient pas devant les nombreuses découvertes de ces quarante dernières

surtout Casson 1971, p. 255-256; Gianfrotta \& alii 1997, p. 15; le texte le plus souvent cité est celui des Actes des Apôtres, 27, 29-30.

${ }^{289}$ C'est à Carrazé 1973 qu'en revient la paternité, repris en premier lieu par Rougé 1974b, p. 74-75; en dernier lieu, discussion par Romero Recio 2000, p. $55-59$.

${ }^{290}$ Davaras 1980, p. 57 : «La nature sacrée de cette ancre ne consistait pas dans le fait qu'elle était le dernier espoir pour arrêter et fixer un navire qui courait, ingouvernable, conduit par les courants ou chassé par la tempête, vers la catastrophe, comme on pourrait penser aujourd'hui en réalistes, mais bien au contraire, par une transposition étiologique typique de l'esprit d'une société au fond primitive, l'ancre était sacrée parce qu'elle était douée de forces protectrices magiques - peut-être même calmantes de la tempête - liées invisiblement à une divinité pélagique; alors on se servait de ce moyen surnaturel seulement en dernier ressort dans le cas où tous les autres moyens naturels (y compris les autres ancres habituelles) avaient échoué. Cela ferait de cette dernière ancre un vrai objet sacré, et peut-être cultuel.» Pour Gianfrotta 1994, p. 608, l'objet en question devient sacré lorsqu'il est "placé sous la protection divine de manière à assumer des pouvoirs exceptionnels».

${ }^{291}$ Svoronos 1914, p. 106-108.

${ }^{292}$ Ibid., p. 107-110; c'est ainsi qu'il comprend les douze ancres (huit en fer, quatre en bois) du gigantesque bateau de Hiéron de Syracuse (Athénée, Deipn. V, 208e), en considérant que la taille du bateau devait sans doute requérir plus d'une seule idole! 
années ni devant le développement, à la fois des contextes archéologiques plus sûrs et des trouvailles groupées, grâce à l'archéologie sous-marine. Ainsi, pour donner une idée d'ordre très général, P. A. Gianfrotta évaluait en 1980 un pourcentage d'environ 10\% d'ancres présentant un décor ou une inscription, par rapport au nombre total d'ancres connues ${ }^{293}$. Ce chiffre est suffisamment élevé pour susciter davantage que quelque doute sur l'attribution restrictive de l'apparition du motif sur un jas à une fonction bien particulière. Si l'on ne peut donc considérer toutes les ancres avec inscription ou décor comme des ancres sacrées, cela signifie que l'ancre à bord, tout comme certaines parties de la poupe ou de la proue, peut être porteuse d'une marque religieuse destinée à attirer l'attention des dieux sur la navigation du bateau. En cela, l'ancre rejoint le décor naval et contribue à la présence quotidienne du sacré à bord.

\section{Technique sur jas de plomb}

En dernier lieu, avant de passer à l'inventaire des inscriptions et motifs apparaissant sur les ancres, il convient de rappeler et préciser la technique de fabrication de celles-ci, lorsqu'elles sont en plomb. Le métal est fondu dans un moule, qui peut s'effectuer de différentes manières ${ }^{294}$. Et ce moule est estampé, ce qui explique la quasigénérale apparition des décors ou inscriptions en relief.

Sur certains jas est très nettement visible la technique d'estampage $^{295}$ : par exemple, on peut reconnaître l'unique astragale qui a servi au total seize fois à estamper le moule du jas de Portinaixt, grâce aux dimensions uniques $(3 \mathrm{~cm} \times 2 \mathrm{~cm})$ de ces seize exemplaires ${ }^{296}$. De même la plupart des représentations très réalistes de coquillages témoigne d'une réalisation faite à partir d'un coquillage réel ${ }^{297}$. Sur de rares exemples, on identifie d'autre techniques, mais qui paraissent plutôt marginales : le jas est frappé à froid, après avoir été fondu, d'une matrice métallique ${ }^{298}$; ou encore le métal est

${ }^{293}$ Gianfrotta 1980, p. 108 indiquait alors les chiffres d'une centaine de jas avec décor ou inscription sur un millier d'exemplaires examinés.

${ }^{294}$ Cf. Gianfrotta \& Pomey 1980, p. 305.

${ }^{295}$ Carrazé 1973, p. 15, la rapproche à juste titre des techniques "sigillées».

${ }^{296}$ Almagro Gorbea 1969, p. 350-351 et pl. I, 2.

${ }^{297}$ Gianfrotta 1980, p. 108 et fig. 8.

${ }^{298}$ Ripoll Perelló 1962, p. 311-312, pour une ancre (non retenue dans notre catalogue) découverte à Blanes près de Barcelone, portant l'inscription latine SEPTV; malheureusement, aucune photo n'en a été publiée (sur ce jas, voir aussi Pascual Guasch 1959; Mercanti 1979, p. 56-58). Un autre exemple est documenté 
incisé - semble-t-il lorsque le métal est encore chaud ${ }^{299}$. La technique du martelage, selon toute vraisemblance, ne concerne que des ancres du monde romain: elle marque l'ancre de noms ou de chiffres romains; elle serait ainsi plus tardive que la technique de l'estampage, même si les deux coexistent à un même moment, et de surcroît concernerait des informations pratiques et/ou commerciales. En tous cas, la position quelquefois non symétrique d'un motif ou d'une inscription sur une face de jas ou d'une face à l'autre ne signifie donc pas que la technique de réalisation soit forcément différente, comme on le lit dans certaines publications. La technique de l'estampage explique en outre que certaines inscriptions se lisent de droite à gauche ${ }^{300}$, ou encore l'inversion de certains motifs ${ }^{301}$.

Le plomb ayant une température de fusion assez faible ${ }^{302}$, la technique de fabrication est plus simple que celle des objets de bronze. Par ailleurs, on a déjà remarqué l'existence de jas de dimensions et de formes identiques, présentant cependant des décors différents. De plus, en prenant en compte la taille des jas, la technique la plus facile doit être l'utilisation de moules de terre réfractaire, servant une seule

en Italie : Massa 1982-83 témoignant de la double technique d'estampage (osselets) et de martelage (inscriptions latines, et signes divers : cat. D84). Le même article signale une information de P. A. Gianfrotta sur un jas trouvé dans les eaux de Furbara portant un timbre réalisé de la même manière.

${ }^{299}$ Pratique attestée sur onze jas trouvés à la pointe Licosa, près de Paestum, et portant des nombres latins : Gianfrotta 1974, p. 77-86 et fig. 3-8. Sur dix d'entre eux apparaissent ensemble les deux techniques, puisqu'on y lit également un sigle en relief. Le onzième (répertorié par Gianfrotta sous le numéro 11) présente peut-être également une quatrième technique, de "graffito", car les lettres y sont beaucoup moins visibles : le métal aurait sans doute été travaillé à froid. Technique d'incision aussi sans doute pour les inscriptions de deux jas conservés du Musée de Palerme (cat. D87 ou 88 et D90) : Tusa 1971, p. 274-275 et Tusa 1973, p. 423-424; leurs motifs en revanche apparaissent en relief. L'ancre de Rosignano citée note précédente présenterait également l'inscription A. MVNIO incisée "sur le plomb non encore complètement refroidi». De même, l'ancre du musée de Reggio di Calabria portant deux rosettes et le nom Héra en relief (cat. I18) comporte trois lettres ligaturées incisées à chaud: Gianfrotta 1980, p. 109 et fig. 12-14. L'explication pratique de cette technique, en ce qui concerne la graphie de nombres, est donnée par ibid., note 39.

${ }^{300}$ Fait déjà signalé par Gianfrotta 1980, p. 109; pour l'anecdote, rappelons l'interprétation en 1914 de J. N. Svoronos (p. 108), pour qui l'«inscription boustrophedon» était une preuve du "caractère sacré et fort ancien de ces ancres».

${ }^{301}$ La remarque suivante de Kapitän 1989, p. 152, concernant la disposition du motif sur le jas, paraît à ce propos curieuse : «The reliefs were applied during casting and almost always set in such a way that they are legible or recognizable from the rope side; for it was the anchor rope that was in danger of being cut off, as ancient sailors believed, by evil spirits».

${ }^{302}$ Le paragraphe qui suit est dû aux observations de feu M. Claude Rolley, qui avait bien voulu très aimablement répondre à toutes mes questions sur cet aspect technique. 
fois, et détruits lors de l'extraction de l'objet. Ces moules seraient euxmêmes reproduits d'après un premier moule de bois, servant de standard. En revanche, si l'on avait utilisé un moule de terre réutilisable, on verrait la ligne de jonction entre les deux parties de ce moule, ce qui ne semble pas être le cas. Il s'en suit qu'alors chaque commanditaire peut à loisir personnaliser l'ancre selon ses désirs, puisque chaque moule de terre, estampé à la demande, est unique. Un exemple concret confirmerait cette hypothèse : le jas de plomb dit de l'épave Grand Ribaud A présente exactement les mêmes dimensions qu'un autre jas trouvé à la Capte, c'est-à-dire dans une même zone située autour de la presqu'île de Giens. Or, les deux jas présentent des décors tout à fait différents : un groupe de quatre astragales sur les quatre faces pour la première ancre, un motif indéterminé unique sur deux faces pour la seconde ${ }^{303}$.

Si les formes des jas peuvent être "standardisées», l'inscription ou le décor restent l'expression d'un choix personnel, suivant certaines motivations ou inclinaisons. À présent et dans un premier temps, nous allons considérer les inscriptions théophores qui y apparaissent afin de tenter de comprendre leur réelle signification et leur valeur religieuse. Pour cela, examinons de près le matériel concerné, les inscriptions dans le détail, et surtout en reprenant les documents depuis leur première publication en faisant table rase de toutes les erreurs accumulées pour certaines depuis plus d'un siècle.

\section{LES INSCRIPTIONS SUR JAS DE PLOMB}

\section{Les objets}

\section{a) Ancre de Zeus Hypatos}

Cette ancre (voir Annexe, cat. I1) appartient au groupe des premières découvertes du $\mathrm{XIX}^{\mathrm{e}} \mathrm{s}$. en ce domaine, qui sont maintes fois citées dans des études diverses ${ }^{304}$, mais que personne n'a apparemment eu la curiosité de revoir depuis lors. La première publication en est donnée par C. Torr, avec dessins ${ }^{305}$. Le jas, provenant de la côte de Cyrénaïque - sans autres précisions géographiques -, est conservé alors au British Museum, où il se trouve encore ${ }^{306}$. L'ins-

${ }^{303}$ Cette ressemblance entre les deux jas a été remarquée par Carrazé 1973, p. 15. Voir infra, cat. D4 et D65.

${ }^{304}$ Voir la liste des références dans le corpus ci-joint.

${ }^{305}$ Torr 1894, p. 71-72 et pl. VIII, 45-47.

${ }^{306}$ Aucun article ne mentionnait son existence après la publication de Torr, ni ne donnait de numéro d'inventaire éventuel; tous se contentaient de 


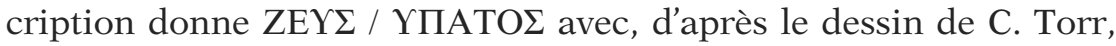
un zéta inversé; celle-ci est comprise par le savant anglais comme le nom d'un bateau. Mais une lecture plus rigoureuse du texte laisse place à des problèmes d'interprétation. Il s'agit en effet non pas d'une seule ancre cette fois, mais de trois pièces différentes, qui pour l'auteur de cette première publication, sont les éléments constitutifs d'un seul objet : "one piece seems to be the stock, and the other two the arms » ${ }^{307}$. Dès lors, on ne comprend pas très bien comment reconstituer l'ancre! Il nous faut donc considérer la trouvaille au même endroit de deux ou trois ancres distinctes, selon que les deux éléments identiques s'adaptent l'un à l'autre comme sur les dessins 46 et 47 proposés par C. Torr. L'inscription n'est alors plus assurée : en l'absence de certitude sur l'emplacement des deux mots sur la même pièce de métal, rien ne permet d'y voir plutôt une inscription unique que deux inscriptions distinctes. La lecture de la première publication nous laissa fortement soupçonner que l'inscription se répartissait sur les deux morceaux : la position des deux mots - à gauche - sur les dessins 46 et 47 le laissait supposer ${ }^{308}$, ainsi que de légères différences au niveau des deux éléments eux-mêmes. L'un est légèrement plus haut que l'autre à l'extrémité où est censé se faire le raccord, et également d'allure générale plus incurvé ${ }^{309}$. L'examen des pièces conservées au British Museum a confirmé ce doute : il existe bel et bien deux morceaux, chacun portant un mot de l'inscription. Néanmoins, l'information inexacte de l'existence d'une seule ancre découverte sur la côte de Cyrénaïque et portant l'inscription Zeus Hypatos se transmet d'un article ou d'un ouvrage à l'autre. Seul W. Froehner semble avoir bien lu C. Torr : il évoque «trois jas d'ancres» au lieu d'un exemplaire unique, et même deux avec inscriptions - un Zeus, l'autre Hypatos - ${ }^{310}$, mais sans plus ample

mentionner le nom du musée. Une recherche auprès de cette institution m'a permis de retrouver la trace de l'objet : il y est en effet conservé, sous le numéro d'inventaire GR 1893-11-13-1. Je remercie A. Meadows et B. Jackson du British Museum qui ont bien voulu répondre à toutes mes demandes, et surtout O. Bopearachchi qui s'est fait si gentiment mon ambassadeur à Londres.

${ }^{307}$ Torr 1894, p. 71; la première pièce correspond au jas représenté sur la figure 45 et pesant «372 lbs», et les deux autres placées l'une à côté de l'autre en vis-à-vis forment le jas unique représenté sur chacune des deux faces sur les dessins 46 et 47 . Ces deux dessins laissent d'ailleurs deviner le «recollage» des deux pièces.

${ }^{308}$ La description de Torr 1894 , p. 72 note 160 n'est pas très claire et peut prêter à confusion : «Zev́ৎ is on the right arm facing one way, and ü $\pi \alpha \tau o \varsigma$ on the right arm facing the other way» : à notre avis, elles confirment en fait l'hypothèse de la répartion des deux mots sur les deux objets et non sur le même.

${ }^{309}$ Ces deux bras, appartenant (ou non?) à une seule ancre, ont des poids sensiblement identiques : 472 et 473 livres.

${ }^{310}$ Froehner 1897, p. 4-5, no 17 . Impossible de savoir si l'auteur a vu ces 
commentaire que d'y voir néanmoins des noms de bateaux. Dans sa théorie sur les ancres sacrées, J. N. Svoronos l'identifie comme telle $\mathrm{au}$ «nom du dieu dont cette ancre même était l'idole» ${ }^{311}$. C. Torr datait en outre l'ancre considérée comme unique selon les caractères épigraphiques du $\mathrm{I}^{\text {er }}$ S. a.C. ${ }^{312}$, ce qu'il convient donc de reconsidérer aujourd'hui.

La forme Iovis, figurant sur un autre jas trouvé à Ostie (ancre I2), près de la secca de Tor Paterno, est rattachée, sans doute à cause du lieu de sa trouvaille, à un navire militaire ${ }^{313}$. Cependant, cela ne nous dit pas davantage si le nom du dieu correspond à celui du bateau ou à celui de sa force protectrice. Le cas utilisé, le génitif, n'est pas à négliger dans l'étude de l'objet ${ }^{314}$. Par les formes des lettres, l'objet est daté de l'époque républicaine tardive.

\section{b) Autour de l'ancre du cap Palos (Zeus et Aphrodite)}

Cette ancre (cat. I7), bien connue par de nombreuses mentions, est cependant l'objet de grandes confusions depuis plus de trois quarts de siècle. Car il s'agit d'un seul et unique jas présentant deux inscriptions, et non l'inverse comme on le lit presque partout; les trois premières publications ${ }^{315}$ l'attestent sans conteste. À dix ans d'intervalle, en 1977 et 1986, les deux articles rétablissant le double texte sont malheureusement passés inaperçus aux spécialistes des ancres $^{316}$. Inversement, le plus récent article publié sur ces découvertes méconnaît totalement la littérature relative aux ancres et à

pièces, ou s'il a seulement lu et regardé avec grande attention les pages de C. Torr; en tous cas, il déclare avec une franchise étonnante que ces jas ont été publiés (sic) «avec une explication assez bizarre». Malheureusement, le savant allemand ne développe pas ses impressions : le tout tient à peine en sept lignes!

${ }^{311}$ Svoronos 1914, p. 108 : curieuse idole qu'un tel morceau de plomb...

312 Torr 1894, loc. cit., qui par comparaison attribue la même datation à l'ancre d'Athènes inscrite Sôteira (voir infra, cat. I10); repris par Moll 1929a, pl. E II 86 et légende p. 70, qui étend également cette datation au jas d'Athènes, mais aussi aux deux autres ancres inscrites inventoriées dans son ouvrage.

${ }^{313}$ Gianfrotta 1980, p. 110. Le jas, qui présente sur l'autre bras le chiffre romain 4 , est conservé à la surintendance d'Ostie.

${ }^{314}$ Gianfrotta 1994, p. 600 propose également d'y voir un «nominatif archaïque».

${ }^{315}$ Laymond \& Jiménez 1906; Fíta 1906; Merlin 1912. Le dessin et la numérotation apparaissant dans l'article de F. Fíta, ainsi que la langue de la publication - l'espagnol -, sont sans doute à l'origine de cette confusion.

316 Manganaro 1977, p. 159. Chuvin \& Yoyotte 1986, avec quelques petites erreurs : grande confusion dans la mention d'une ancre avec l'inscription de Zeus Hypatos, qui effectivement se trouve à Londres (voir supra, cat. I1), mais ne provient pas du gisement du cap Palos; sur ce que les Anglais ont emporté de ce dernier qui, d'après les deux Espagnols, consiste en un lingot de plomb; omissions dans la bibliographie du début du siècle. 
leurs inscriptions et décors, la traitant comme un objet isolé et comme un ex-voto trouvé in situ ${ }^{317}$. De surcroît, l'ancre semble avoir disparu peu de temps après sa découverte; ou du moins peut-être sommeille-t-elle dans les réserves des musées de Carthagène ou d'ailleurs ${ }^{318} \ldots$ En tous cas, elle ne se trouve pas au musée archéologique de Madrid, et ne semble jamais y être allée ${ }^{319}$.

Le cap de Palos ${ }^{320}$ est situé au sud de l'Espagne, près de la ville de Carthagène. C'est à proximité de ce cap, dans une anse où viennent s'abriter les embarcations en cas de mauvais temps ${ }^{321}$, que fut trouvée l'ancre, parmi un prolifique matériel archéologique. Mais les recherches menées depuis pour identifier précisément cet endroit se sont avérées vaines ${ }^{322}$.

Le dépôt du cap de Palos livra donc en 1906, par l'intermédiaire de pêcheurs d'éponges, une trentaine d'ancres (dont quatre avec inscriptions), ainsi que des lingots de plomb; les deux correspondants espagnols de l'Académie affirment en outre avoir noté la présence d'une amphore, en parfait état de conservation. Sans doute les fonds marins recelaient-ils d'autres objets : c'est c'est ce que laisse sous-entendre l'allusion aux informations données par le propre directeur de la Sociedad Esponjera del Sur de España ${ }^{323}$. F. Fíta, P. Paris et A. Merlin rapportent plus précisément le chiffre avancé de la

${ }^{317}$ Perea Yébenes 2004.

${ }^{318}$ Les ancres furent dans un court premier temps, au moment de leur découverte, réunies à Carthagène; six ans après, A. Merlin les déclare, par ouïdire, "...dispersées (...); il y en a notamment au Musée de Madrid et à celui de Barcelone; plusieurs ont été détruites»(Merlin 1912, p. 394); le tableau de F. Moll, repris par toutes les publications postérieures, indique simplement à côté du dessin de l'ancre la mention «Madrid» (Moll 1929a). En 1946, l'objet ne se trouve pas au musée de Carthagène, d'après Jáuregui \& Beltrán Martínez 1947. Voir également Romero Recio 1999, p. 541.

319 Je remercie pour cette information la Señora M. del Carmen Pérez Die, Directrice du Museo Arqueológico Nacional de Madrid, qui a répondu si aimablement et si rapidement à ma lettre en 1996.

${ }^{320}$ On trouve les deux dénominations : cap Palos ou cap de Palos.

${ }^{321}$ Merlin 1912, p. 394; Fíta 1906, p. 163, déplore que la Sociedad Esponjera ne veuille indiquer avec précision le(s) lieu(x) de découverte. En tous cas, pas «à Carthagène et au cap de Palos», comme le présente Benoît 1951, 1, p. 227, et Benoît 1952, p. 272.

${ }^{322}$ Cf. Jáuregui \& Beltrán Martínez 1947, avec carte de la zone p. 338. Leur enquête poussée montre les contradictions des différents témoignages de l'époque; il est à noter que n'y est pas mentionnée la version de A. Merlin citée ci-dessus. Les Archivos de la Real Academia de la Historia, contenant quelques lettres et photos relatives aux trouvailles, ne permettent pas d'en préciser le lieu ni leur devenir après 1907 (Romero Recio 1999, p. 541-542 : archives «Legajo antiguedades de Murcía» 9-7063-57 à 59).

${ }^{323}$ Laymond \& Jiménez 1906. 
présence de quatre cents ancres à cet endroit ${ }^{324}$. Une telle concentration laisse supposer un mélange de chargements issus de plusieurs naufrages, ainsi que des ancres perdues dans ce point de mouillage difficile ${ }^{325}$.

L'ancre fut révélée au public par les deux correspondants espagnols de l'Académie qui ont vu l'objet, l'ont fait prendre en photo ${ }^{326}$ et ont fait des calques et deux dessins, correspondant aux deux faces de l'ancre. Les auteurs n'étaient malheureusement pas de grands spécialistes du grec, comme en témoigne leur description des caractères épigraphiques : ils y ont vu des inscriptions en latin, dès lors incompréhensibles pour eux. Ces deux dessins, retranscrivant leur lecture maladroite, et depuis lors reproduits dans toute la bibliographie postérieure, donnent SEYCKAC / I CCOSA et AФPOAITE / COSOYCA. Dans le même temps, un linguiste plus confirmé, F. Fíta, examine, sans voir l'ancre, les inscriptions à l'aide des calques et des photos, et reconnait leur texte grec; mais il les publie avec les dessins ne correspondant pas à sa propre lecture ${ }^{327}$. Celle-ci est la suivante : ZEYCKAC / IOCCOZON et sur l'autre face AФPO$\triangle \mathrm{ITH} / \mathrm{COZOYCA}$ (avec un delta retourné). Le texte, qui présente des sigmas lunaires, ainsi que l'emploi des o brefs pour des omégas, est daté alors du $\mathrm{III}^{\mathrm{e}} \mathrm{s}$. a.C. Il est vingt ans plus tard daté par F. Cumont ${ }^{328}$ de l'époque impériale, à cause des sigmas lunaires et de la présence au même endroit de trois ancres avec inscriptions

${ }^{324}$ Fíta 1906, p. 156; Paris 1906; Merlin 1912, p. 394; García Cardiel 2013, p. 48-49 et fig. 49-51.

325 Jáuregui \& Beltrán Martínez 1947 recense les différentes trouvailles effectuées par ailleurs dans le port de Carthagène et dont les archives ont gardé la trace; entre autre figure un bateau romain de l'époque de Septime Sévère. La zone semble donc avoir été le lieu de plusieurs drames maritimes. Chuvin \& Yoyotte 1986, p. 61.

${ }^{326}$ Selon le témoignage du photographe D. Bernardino Rolandi, cité par Jáuregui \& Beltrán Martínez 1947, p. 337-338, une des épreuves, propriété de la Real Sociedad Económica del País, est conservée en 1946 au Musée local.

${ }^{327}$ La graphie des dessins à côté de la lecture de Fíta sont reproduits sans aucun complexe dans la chronique publiée par P. Paris, in A. A. 1906. De plus, comme le font en effet remarquer Chuvin \& Yoyotte 1986 (note 79), le titre de l'article de Fíta a donné suite à une autre mauvaise transmission des informations: Salač 1922, p. 188, parle d'ancres portant des inscriptions latines et grecques, mais aussi hébraïques; néanmoins cela ne paraît pas avoir eu de conséquence sur son interprétation de l'inscription qui nous occupe. Cette erreur est présente également dans Adler 1919.

${ }^{328}$ Cumont 1927, p. 330, note 3; comme l'ont encore fait remarquer Chuvin \& Yoyotte 1986, note 79, l'auteur, après une lecture rapide de l'étude de Fíta, conteste la lecture de l'Espagnol qu'il prend pour une "correction (...) trop violente». De même Adler 1929 précise la restitution incertaine des dernières lettres. 
latines; celles-ci étaient cependant datées par F. Fíta de l'époque républicaine. De toute façon, la trouvaille simultanée d'ancres avec inscriptions latines n'est pas un argument décisif pour appuyer une datation, sauf dans le cas d'une seule et même épave, d'une seule et unique cargaison; ceci n'est pas assuré pour les trouvailles du cap de Palos, malgré l'hypothèse énoncée plus haut, qui n'exclut pas l'existence de plusieurs frets ${ }^{329}$.

C'est dans l'inventaire des ancres de plomb donné en 1929 par F. Moll qu'apparaît clairement pour la première fois l'attribution des deux inscriptions à deux ancres différentes ${ }^{330}$. Si le dessin regroupant les deux inscriptions peut encore évoquer un objet unique, les numéros attribués aux deux inscriptions, 12 et 14, en font deux objets distincts; et par cet article, ensuite repris comme référence majeure pour l'étude des ancres avec inscriptions, est perpétuée l'erreur dans les études postérieures ${ }^{331}$. La déformation de l'information et la lecture trop rapide conduisent même jusqu'à distinguer deux ancres, l'une portant l'inscription d'Aphrodite devenue alors un objet "consacré» dans un sanctuaire de "Grèce propre», l'autre portant l'inscription à Zeus «dédiée directement à la divinité, mais sans quitter le bateau» ${ }^{332} \ldots$

L'interprétation donnée à l'ancre et aux inscriptions - pour les mentions où le jas était encore unique - variait d'un article à l'autre, sans que le sujet soit véritablement développé avec clarté : F. Fíta parle très allusivement d'«ancre sacrée»; P. Paris définit les deux inscriptions comme des «invocations»; A. Salač et F. Cumont emploient le terme de "dédicaces ${ }^{333}$. Lors des plus anciennes publications, l'objet soulevait un problème que personne ne posa claire-

${ }^{329}$ Évoquons simplement à ce sujet l'exemple des fouilles sous-marines de l'épave dite du Grand Congloué, qui s'est avérée correspondre à deux épaves d'époques différentes.

${ }_{330}$ Moll 1929b; les deux articles précédents de A. Salač et de F. Cumont présentent encore une certaine ambiguïté dans la manière de décrire les faits, empêchant de trancher entre l'allusion à une ancre ou à deux.

${ }^{331} \mathrm{La}$ liste serait longue et fastidieuse : cf. bibliographie du catalogue. Citons entre autres l'article - qui lui même sert de référence majeure pour les études actuelles - de Gianfrotta 1980, p. 103-116. Autre répétition erronée apparaissant dans la bibliographie postérieure : la lecture «mixte» de F. Moll, qui mêle celle de Fíta au dessin de R. Laymond et D. Jiménez de Cisneros y Hervás, en donnant bien l'épithète $\Sigma \Omega Z \Omega N$, mais le nom d'Aphrodite terminé par un epsilon.

${ }^{332}$ Sic, in Davaras 1980, p. 55. Parmi l'inventaire des erreurs - sans aller cependant jusqu'à cet extrême -, signalons que même dans l'ouvrage remarquable de D. Wachsmuth, le texte de l'inscription de Zeus est reproduit incorrectement (Wachsmuth 1967, note 1825 avec précédemment en note 991, le renvoi à deux ancres au lieu d'une).

${ }^{333}$ Fíta 1906, p. 158; Paris 1906, col. 168; Salač 1922, p. 188; Cumont 1927, p. 334; les autres auteurs gardent un silence prudent. 
ment; finalement, la séparation des deux inscriptions résolvait naturellement la difficulté...

En l'absence de l'objet et à la suite de cette bibliographie défaillante, il est très difficile d'avancer une datation ${ }^{334}$. Celles proposées par F. Fíta et F. Cumont, respectivement le $\mathrm{III}^{\mathrm{e}}$ s. a.C. et l'époque impériale ${ }^{335}$, sont l'une et l'autre acceptables ${ }^{336}$. En effet, la chronologie connue actuellement pour les jas de plomb est plutôt large, allant de la fin du IV e s. a.C. au I ${ }^{\text {er }}$ s. p.C., en poussant éventuellement jusqu'au $\mathrm{II}^{\mathrm{e}} \mathrm{s}^{337}$. Par ailleurs, les critères épigraphiques avancés, les sigmas lunaires et l'usage de l'omicron à la place de l'oméga, sont attribuées à la période hellénistique et au début de l'époque romaine. Par manque de contexte archéologique sûr, l'ancre ne peut être datée plus précisément.

De la même façon, l'origine de l'objet ne peut être établie. D'après la graphie maladroite, l'hypothèse a été avancée d'une fabrication romaine d'Espagne "à l'usage de clients hellénophones»"338. C'est possible, mais rien ne permet d'affirmer que l'ancre provient d'Espagne. Le bateau pouvait se rendre dans la péninsule, ou y faire une escale; la localisation de la trouvaille près des côtes espagnoles ne prouve en rien l'origine de l'objet ${ }^{339}$. Par ailleurs, l'épithète de Zeus a donné lieu à différents rapprochements géographiques avec le Portugal, la Syrie ${ }^{340}$, l'Égypte, etc., et permet bon nombre de suppositions. Aucune hypothèse n'est donc à exclure, même s'il l'on

${ }^{334}$ Même, selon l'opinion de Jáuregui \& Beltrán Martínez 1947, p. 339, «ninguna de estas inscripciones es concluyente (...) para determinar la fecha aproximada de las anclas».

${ }^{335}$ Fíta 1906; Cumont 1927.

${ }^{336}$ Nous ne retenons pas la datation proposée, sans argumentation ni même renvoi à F. Cumont, par García y Bellido 1967, p. 100-102, d'une «date déjà avancée de l'époque impériale», ni celle du ${ }^{\text {er }}$ s. a.C. donnée par Moll 1929a, pl. E II 81-82 et légende p. 70, qui assigne de façon lapidaire une même datation pour les ancres $\mathrm{n}^{\circ} 81$ à 86 de son catalogue, selon sans doute la datation assignée par C. Torr aux jas d'Athènes et Londres inscrits respectivement Sôteira et Zeus Hypatos (voir infra et supra, cat. I10 et I1).

${ }^{337}$ Chuvin \& Yoyotte 1986, p. 60-61; voir supra p. 292 la bibliographie générale sur les ancres.

${ }^{338}$ Chuvin \& Yoyotte 1986. Il est en effet vrai aussi que l'un des noms latins qui apparaissent sur trois autres ancres provenant du même endroit est attesté par ailleurs en Espagne : cf. Fíta 1906, p. 160-161, et Chuvin \& Yoyotte 1986; mais l'argument est insuffisant et, au risque de nous répéter, rien ne prouve non plus que ces ancres proviennent de la même cargaison.

${ }^{339}$ C'est ce qu'admettent par ailleurs un peu plus loin Chuvin \& Yoyotte 1986, p. 61, mais à propos du bateau de transport seul, non de son contenu.

${ }^{340}$ Par exemple en 1967, A. García y Bellido, loc. cit., voyait en ces ancres au nombre de deux pour lui - des objets qui «appartinrent sans doute à des navires qui faisaient le commerce avec les côtes de la Syrie». 
peut aisément avouer qu'une origine espagnole est plus séduisante qu'une autre à cause de l'exploitation du métal dans cette zone. Carthagène est en effet réputée dans l'Antiquité ${ }^{341}$ pour ses mines d'argent et de plomb.

Dans ces conditions, les conclusions à tirer de cet objet se doivent de rester très prudentes. Avec un objet disparu depuis plus d'un siècle, une lecture et une description des inscriptions non précisément assurées, une datation floue et un éventail large d'origines possibles, il est difficile d'être catégorique, y compris sur la nature de l'objet, qui semble faire partie d'une cargaison, mais pourrait cependant tout aussi bien faire partie de l'accastillage du bateau de transport. Et si cette ancre faisait réellement partie d'une commande ${ }^{342}$, à qui était-elle destinée? Car dans ce cas, ce sont les commanditaires qui ont imposé l'ajout des inscriptions sur le jas; l'origine espagnole ou non de l'ancre n'a alors aucune incidence sur l'attribution du rite et des croyances en les deux divinités mentionnées à un groupe géographique différent. Il serait donc intéressant de connaître, ou bien l'origine du bateau si l'ancre était utilisée à son bord, ou bien, la destination du navire si l'objet s'apprêtait à être livré.

Une autre ancre avec inscription théophore (cat. I3) du musée de Carthagène est peut-être à rapprocher de la précédente. L'inscription qu'elle porte et son lieu de conservation peuvent laisser supposer qu'elle représente l'une trois autres ancres inscrites qui avaient été remontées en 1906 et dont on a depuis perdu trace ${ }^{343}$. Lors de sa première publication, l'inscription a été lue COSM, selon des caractères latins ${ }^{344}$; elle a été revue selon l'alphabet grec et corrigée en $\Sigma o ́ \zeta \omega(v)^{345}$. Il est difficile de trancher définitivement en faveur de la deuxième lecture. En effet, le nu restitué pose problème : il n'est guère courant d'élider une épiclèse de ce genre et la graphie du zêta est également curieuse, de même que l'omicron utilisé à la place de l'oméga. La prudence s'impose donc, même s'il est tentant d'y retrouver l'épithète de Zeus, ainsi qu'une variante masculine du groupe constitué d'adjectifs de bon augure au féminin (voir infra, p. 287).

À l'heure actuelle, un seul autre cas est connu d'une association divine sur ancre; et celui-ci porte les mêmes noms de dieux, sans

${ }^{341}$ Cf. notamment Strabon, Géographie III, 2, 10 et 4, 6.

${ }^{342}$ C'est l'hypothèse, déjà citée plus haut, de Chuvin \& Yoyotte 1986, p. 60.

${ }^{343}$ Perea Yébenes 2004.

${ }^{344}$ Mas García 1979, p. 126.

${ }^{345}$ Gianfrotta 1994, p. 602 et fig. 4. Même lecture par Perea Yébenes 2004, qui souligne la similitude entre la graphie de cette ancre et la transcription du début de «Sozousa» par Fita 1906. 
épithètes, et en langue latine : VENERI / IOVI. L'ancre en question (cat. I8) fut trouvée à proximité de l'île delle Femine, en Sicile occidentale. Les eaux de cette zone ont livré un grand nombre d'ancres, qui pour la plupart sont conservées au musée de Palerme. Deux publications détaillées en ont été faites par le conservateur du musée au début des années $1970^{346}$. Les inscriptions apparaissant sur ces ancres de plomb sont toutes, sauf une, en latin; des motifs, tels astragale, lampe, trident, dauphin, caducée, sont également attestés (voir catalogue infra). Pour lui, il est évident que les inscriptions de ce jas sont de type votif, comme le confirme l'emploi du datif. Il date par ailleurs l'objet, suivant les caractères épigraphiques, de l'époque augustéenne.

Hormis les deux jas présentant l'association de Vénus-Aphrodite avec Jupiter-Zeus, un seul cas nous donne le nom seul de la déesse, et ce en latin : parmi un ensemble d'ancres trouvé dans les eaux de Maratea (Basilicate), celui d'un jas de plomb (cat. I9), sur lequel apparaît l'inscription rétroverse VENUS au nominatif. La divinité n'est qualifiée par aucune épithète particulière. Le nom est interprété dans les publications comme celui du bateau auquel appartenait l'ancre ${ }^{347}$.

\section{c) Autres ancres de Zeus Kasios}

Cette mention de Zeus Kasios sur une ancre n'est pas unique. Une autre inscription donnant le nom grec apparaît sur un autre jas de plomb (cat. I4), découverte dans les eaux du port de Syracuse ${ }^{348}$. Celui-ci n'est à ce jour pas encore véritablement publié, après avoir seulement fait l'objet de quelques évocations rapides ${ }^{349}$. Seul un second article de G. Manganaro ${ }^{350}$, portant sur un sujet plus général

${ }^{346}$ Tusa 1971; Tusa 1973. L'auteur, méconnaissant l'existence de la double inscription du jas du cap de Palos, pense découvrir une association inédite de ces deux divinités sur une ancre.

${ }^{347}$ Bottini \& Fresci 1993, p. 32 et fig. p. 33, 66, 142; Bottini \& Freschi 1994, p. 33 et fig. 2; Gianfrotta 1994, p. 601-602 et fig. 3 .

${ }^{348} \mathrm{La}$ découverte de plusieurs jas, dont celui-ci, dans une recherche portant sur les ports antiques de Syracuse est mentionnée dans Gargallo 1970; l'article ne donne aucun détail sur ces ancres et celle de Zeus Kasios n'apparaît pas parmi celles prises en photographie.

${ }^{349}$ L'inscription est d'abord mentionnée en note dans une étude générale concernant la Sicile par Manganaro 1972, p. 452, n. 50. Puis le jas apparaît représenté pour la première fois, mais sans aucun commentaire, par un dessin servant à expliciter une restitution d'un type d'ancre proposé dans Kapitän 1973, p. 384, fig. 1. Ce même dessin est reproduit une nouvelle fois dans un autre article du même auteur (Kapitän 1980, p. 46, fig. 6), mais encore sans aucune indication supplémentaire.

${ }^{350}$ Manganaro 1977, p. 159 et pl. XLVII, 5. 
de religion, nous fournit quelques informations plus précises, ainsi qu'une photo. La lecture donnée y diffère d'ailleurs de celle lisible en illustration, qui doit être corrigée en $\triangle \mathrm{IOC} / \mathrm{KACIOY}{ }^{351}$. Mais nos connaissances restent trop imprécises sur cet objet ${ }^{352}$, qui ne peut guère pour le moment nous éclairer davantage sur l'ancre du cap de Palos : ainsi par exemple, il est daté sans aucun commentaire du $\mathrm{II}^{\mathrm{e}} \mathrm{s}$. a.C. ${ }^{353}$ Seules évidences à souligner : l'apparition du nom du dieu, mais seul cette fois, non associé à Aphrodite ou à toute autre divinité; l'inscription est formulée en langue grecque ici encore, mais au génitif. C'est l'usage de ce génitif qui permet de manière catégorique à P. Chuvin et J. Yoyotte d'attribuer ce nom au navire qui utilisait l'ancre ${ }^{354}$. L'objet avait auparavant déjà permis à G. Manganaro de souligner la grande activité commerciale et la richesse agricole de la Sicile, d'après l'inscription qui témoignerait d'une origine corcyréenne du bateau venu charger sa cargaison en Sicile ${ }^{355}$. Mais le culte de Zeus Kasios est loin d'être seulement honoré à Corfou, ce qui ne permet pas d'établir quelque port d'origine de l'embarcation.

Les deux autres attestations du nom du dieu sur jas sont sujettes à caution. Et ces deux exemplaires proviennent également des eaux siciliennes. La première ancre (cat. I5), conservée au Musée de Palerme ${ }^{356}$, porte l'inscription, latine cette fois, CASIVS. L'épithète apparaît seule, sans être précédée par le nom du dieu lui-même; ceci pourrait être à rapprocher des évocations sur ancres de celle de Sôteira (voir infra), également non précisées. L'inscription, bien publiée, est à présent souvent citée par les spécialistes. Deux d'entre eux, cependant, ont proposé de corriger la lecture adoptée par tous et par un des deux co-auteurs de l'article lui-même quelques années auparavant - en CASTVS, qui deviendrait dès lors le nom d'un négociateur en rapport avec le monde de la navigation, et non plus l'épithète du dieu ${ }^{357}$. Rien ne permet encore de trancher entre les deux propositions. Enfin, à propos de l'inscription $\Delta$ iòs Kaбíov,

\footnotetext{
de frappe.

${ }^{351} \mathrm{Au}$ lieu de KACIOV; sans doute faut-il imputer l'erreur à une simple faute

${ }_{352}$ Gianfrotta 1980 , p. 103-116 et pl. hors-texte, qui la cite comme «inédite» sans référer à Manganaro 1977, n'apporte malheureusement pas de développement. Son information est simplement reprise dans Chuvin \& Yoyotte 1986, p. 61.

${ }^{353}$ Manganaro 1977, p. 159.

${ }^{354}$ Loc. cit.

${ }^{355}$ Manganaro 1972, loc. cit., en présupposant un culte de Zeus Kasios à Corcyre (cf. supra, sur étude du dieu).

356 Tusa 1971; Tusa 1973, p. 432.

${ }^{357}$ Correction proposée par Hesnard \& Gianfrotta 1989, p. 434, sous le numéro A.11; auparavant, lecture CASIVS dans Gianfrotta 1980, p. 109.
} 
G. Manganaro ${ }^{358}$ a signalé l'existence d'une ancre inédite (cat. I6),

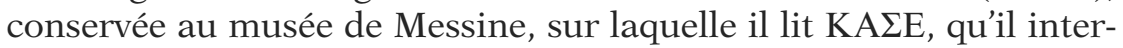
prète en $\mathrm{K} \alpha ́ \sigma(\sigma \iota) \varepsilon$. Si nous acceptons cette hypothèse - critiquable quant à la ligature éventuelle -, il faut alors considérer que le nom du dieu est mis au vocatif, chose inconnue par ailleurs sur les inscriptions sur ancres et qui paraît difficilement explicable dans un tel contexte.

\section{d) Ancres de Sôteira et assimilées}

Cinq ancres, plus une avec décor, portant cette même inscription sous des graphies différentes sont connues à ce jour (cat. I10I15). Le mot peut être considéré comme l'épithète, courante par ailleurs dans le vocabulaire religieux, d'un nom de genre féminin. Il semble dans les quatre occurrences présenter le cas du nominatif 359 . Le sens en est clair : «Salvatrice». Néanmoins plusieurs possibilités sont envisageables, selon ce à quoi se rapporte cet adjectif. Il peut

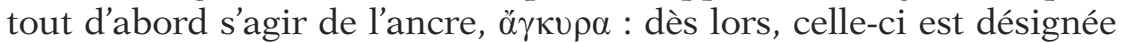
selon la fonction que l'on attend d'elle, d'aide et de secours; de là à y reconnaître l'ancre "de miséricorde», il n'y a qu'un pas ${ }^{360}$. Une seconde hypothèse est celle, qui fait à peu près l'unanimité, que ce mot reproduit le nom du bateau ${ }^{361}$.

Une troisième possibilité pourrait envisager d'y voir le nom, ou plutôt l'épithète d'une divinité, comme dans le cas de Zeus Kasios et Aphrodite Sozousa. Il conviendrait dès lors d'identifier la divinité à qui s'applique cette épiclèse. D'après les autres inscriptions sur ancres, le nom d'Aphrodite a souvent été avancé362. Mais on peut également penser à celui d'Artémis, qui non seulement revêt cette appellation et que l'on retrouve également dans les listes de noms de bateaux, mais encore apparaît en toutes lettres sur une ancre ${ }^{363}$. On

${ }^{358}$ Manganaro 1977, p. 159, pl. XLVII, 7. La lecture est sans doute à revoir : l'inscription est dite rétrograde, mais il suffirait de retourner le jas pour qu'elle ne le soit pas! Le jas est d'ailleurs photographié dans un sens inverse de celui sous lequel sont photographiés les autres jas présentés sur la même planche.

${ }^{359}$ Même si la forme n'exclut pas un datif, mais pour une époque tardive : le iota adscrit disparaît sur les inscriptions sur pierre à partir de l'époque impériale. Je remercie François Lefèvre pour cette précision.

${ }^{360}$ Hypothèse formulée sous forme d'interrogation par Liou 1973, p. 592 et fig. 24; de manière catégorique par Carrazé 1973 qui, sans aucune discussion, décrète que «cette épithète accompagne généralement le nom d'une divinité, mais ici c'est l'ancre elle-même qui est concernée par ce qualificatif».

${ }^{361}$ Notamment Gianfrotta 1980, p. 109.

${ }^{362}$ Tout particulièrement par Liou 1973, p. 592 et fig. 24.

${ }^{363}$ Voir supra, $1^{\text {ere }}$ partie. 
a même évoqué l'existence d'une déesse particulière, appelée simplement par ce nom ${ }^{364}$.

La première ancre de ce type (cat. I10) fut découverte, comme dans le cas du cap de Palos, par des pêcheurs d'éponges, vers le milieu du XIX ${ }^{\mathrm{e}}$ s. - sa première publication date de $1880^{365}$-, sur la côte de Carie; plus précisément sa provenance serait localisée près de l'île de Symè ${ }^{366}$. Elle aurait ensuite été transportée à Athènes pour le compte de la Société archéologique, comme l'affirment les mentions suivantes, où l'on perd ensuite sa trace ${ }^{367}$. L'objet a ceci de particulier qu'il ne se présente pas tout à fait sous la même forme que les autres jas d'ancre de plomb : il s'agirait plutôt à proprement parler d'un demi-jas ${ }^{368}$. Il est connu par le croquis réalisé par le directeur du Musée évangélique de Smyrne, qui l'a transmis à la Société des antiquaires de France pour communication : il est alors identifié comme "ancre à une seule patte, ou ancre borgne». Sur cette illustration, l'inscription $\Sigma \Omega$ TEIPA apparaît rétrograde; elle est datée par C. Torr - comme celle de Zeus Hypatos -, d'après la forme des lettres, des environs du début de notre ère, et lue comme le nom du bateau ${ }^{369}$ - interprétation combattue ensuite par J. N. Svoronos (voir supra). Un autre dessin simplifié, et reconstituant le jas en

${ }^{364}$ Svoronos 1914, p. 108-109 qui avance l'hypothèse d'un rapprochement avec la mystérieuse divinité connue sous le nom latin d'Angerona. Une ou deux dédicaces de la part de polémarques à une Sôteira sans nom de divinité sont également attestées à Thasos, désignant peut-être un sanctuaire hors les murs proche du port militaire (Martin 1944-45; Grandjean \& Salviat 2000, p. 58 et 231).

365 Schlumberger 1880 , p. 85-86. Cette communication paraît être inconnue pour la presque totalité des auteurs postérieurs; l'article de référence donné pour cette ancre est seulement le suivant, ou celui de F. Moll.

${ }^{366}$ En premier lieu Torr 1894, p. 71-72, notes 159-160; pour les suivants, qui répètent les informations contenues dans cet article, voir bibliographie du corpus.

${ }^{367}$ Torr 1894, loc. cit.; Svoronos 1914, p. 107, précise qu'elle se trouve «au Musée d'Athènes", mais il ne semble pas l'avoir vue lui-même. L'information est répétée ainsi durant tout le siècle; seul Gianfrotta 1980, p. 109, la signale, sans aucune autre indication, «au Pirée». Plus récemment, dans son article de 1994, p. 602, il publie une photo de l'inscription (fig. 5) prise par G. Kapitän «au Musée national d'Athènes». Pour ma part, le Musée épigraphique d'Athènes, dépendant du Musée national, m’a affirmé ignorer l'existence de cet objet.

${ }^{368}$ Torr 1894 le rapproche justement pour sa forme des deux pièces trouvées dans la région de Cyrène et portant la mention de Zeus Hypatos, et qu'il désigne comme des «bras (arms)»: voir infra.

${ }^{369}$ Loc. cit. L'auteur n'expose pas explicitement son interprétation; mais il l'affirme pour le(s) «bras» portant l'inscription de Zeus Hypatos, qu'il met en parallèle avec celui de Sôteira. La datation est reprise notamment par Moll 1929a, pl. E II 85-86 et légende p. 70 . 
entier, est publié par F. Moll ${ }^{370}$, et c'est ce second dessin qui est désormais repris dans la bibliographie postérieure. Nous ne connaissons donc aucune photographie de l'ancre, mais seulement le détail et deux dessins approximatifs de l'inscription, et très peu de témoignages visuels. En l'absence de l'autre moitié du jas, rien ne permet d'exclure que celle-ci présentait une autre inscription - le nom d'une divinité, comme dans le cas de l'ancre du British Museum -, ou même un décor.

C'est le cas en revanche de l'ancre de Cavalaire (France), qui outre l'inscription $\Sigma \Omega$ TEIPA porte un décor plutôt surprenant : il s'agit d'un "lion bondissant» figuré sur les deux faces opposées à celle inscrite (cat. I11) ${ }^{371}$. Quatre autres ancres de ce type - mais sans décor supplémentaire -, de découvertes plus récentes, sont signalées par P. A. Gianfrotta ${ }^{372}$. Deux d'entre elles sont datées : la première (cat. I12), portant l'inscription $\Sigma$ STIPA, du début de l'époque hellénistique par sa graphie ${ }^{373}$; la seconde (cat. I14), inscrite $\Sigma \Omega T P A$, du $\mathrm{I}^{\mathrm{er}}$ s. a.C. au Bas-Empire d'après le matériel retrouvé à proximité. Ces jas proviennent des eaux de Cagliari et de Propriano, et les deux suivantes (cat. I13 et I15), respectivement $\Sigma \Omega$ TIPA et $\Sigma \Omega$ TPA, de Sardaigne et d'Ischia. Pour ces six exemplaires connus actuellement, nous ne pouvons que constater la large répartition géographique des trouvailles. En l'absence de précisions supplémentaires, seuls des rapprochements, et non des conclusions, peuvent être opérés.

Une dernière ancre peut être rattachée à ce groupe (cat. I16) : il s'agit d'un jas de plomb, provenant des eaux de Ventotene, portant le mot latin Salvia, donc au nominatif féminin, comme dans le cas de Sôteira. Le sens de l'épithète, rapproché de celle de Sôteira, implique un sens de bon augure ${ }^{374}$; il convient de savoir ici si le féminin utilisé s'applique à la navis ou mieux à une divinité féminine particulière ${ }^{375}$.

${ }^{370}$ Moll 1929b : $\mathrm{n}^{\circ}$ 7. L’absence de précisions données pour celle-ci, ainsi que l'erreur signalée plus haut pour le jas du cap Palos, laissent supposer sans difficulté que l'auteur n'a pas vu l'ancre lui-même.

${ }^{371}$ Liou 1973; Carrazé 1973, p. 14-15 et fig. 4. Sur ce motif, voir infra.

${ }^{372}$ Gianfrotta 1980 , p. 109 et note 30 , fig. 16-17, et Gianfrotta 1994, p. $602-603$.

${ }^{373}$ Guarducci 1967-78, III p. 363, note 2.

${ }^{374}$ La forme salvia comme traduction littérale de sôteira n'est pas «académique» : il s'agit de latin populaire, construit sur la base du verbe qui signifie sauver. Rappelons que le terme de salvia en langue latine classique désigne la sauge!

375 Gianfrotta 1986, p. 217-218 reconnaît dans Salvia le nom d'un bateau, par rapprochement avec des attestations d'une trirème homonyme de la flotte de Misène (CIL VI, 3094; X, 3532, 3580 et 3600) et du bateau de l'autel du Musée capitolin inv. 321. 


\section{e) Ancre d'Artémis}

Le nom d'Artémis est présent sur un jas d'ancre retrouvé dans les années 1980 près d'Antibes (cat. I18). L'inscription au génitif APTEMI / $\triangle \mathrm{O} \Sigma$ a ceci de particulier qu'elle est répartie sur les deux bras, et de plus dans un sens de lecture contraire ${ }^{376}$. Répugnant à donner un caractère maritime à la déesse, on a préféré y voir un rappel à un lieu saint d'une cité dont serait originaire le bateau-Délos, Éphèse, Patras, Marseille $^{377}$. Cependant, comme nous l'avons déjà évoqué plus haut, les différentes inscriptions sur jas de Sôteira peuvent s'appliquer très bien à Artémis. De plus, le rapport avec un sanctuaire peut s'expliquer a contrario par la fonction qu'y exerce la divinité; or Artémis entretient plus d'un lien avec le milieu maritime ${ }^{378}$. La datation proposée du $\mathrm{II}^{\mathrm{e}}-\mathrm{III}{ }^{\mathrm{e}}$ s. p.C. sur la base du sigma carré peut être corrigée, pour être repoussée au moins jusqu'à l'époque augustéenne ${ }^{379}$, ce qui ne serait pas contradictoire avec les autres témoignages, qui ne sont pas aussi tardifs, liant la déesse à la mer.

\section{f) Ancre d'Héra}

Le nom d'Héra se retrouve sur une ancre, accompagnée d'un décor répété à deux reprises (cat. I19). Le jas, trouvé sur le littoral de Reggio di Calabria, porte le nom HPA rétrograde suivi d'un motif circulaire, qui est reproduit également seul sur l'autre bras. Le nom d'un personnage figure également sur l'ancre. L'inscription est lue comme le nom du bateau, même si cette hypothèse ne s'appuie sur aucun parallèle connu, et les caractères épigraphiques sont datés du $\mathrm{I}^{\mathrm{er}}$ S. a.C. ${ }^{380}$.

\section{g) Ancre d'Apollon}

Le jas de plomb a été trouvé dans les eaux d'Imperia (catalogue I20). L'inscription donne uniquement le terme suivant : Delphinos; la lecture Delphinios proposée lors de sa publication, basée sur une ligature des dernières lettres, n'est pas assurée ${ }^{381}$. D’après la forme

376 Pomey \& alii 1987-1988.

${ }^{377}$ Gianfrotta 1994, p. 604-605.

${ }^{378}$ Voir supra, $1^{\mathrm{e}}$ partie, ou par exemple l'article de Piccirilli 1981. La divinité apparaît en particulier sur bon nombre de monnaies à types maritimes : cf. Anson 1910-1916, V p. 87-146 et pl. XIV-XXV.

${ }^{379}$ Le sigma carré est précisément déjà attesté entre 14 et 29 p.C. dans une inscription d'Apollonia d'Illyrie mentionnant Livie: Cabanes 1997, p. 42 n 173.

${ }^{380}$ Gianfrotta 1980, loc. cit.

${ }^{381}$ Gianfrotta 1994, p. 605. La photo présentée dans cet article ne permet pas de distinguer une trace de ligature entre le $\mathrm{N}$ et le I. 
des lettres - epsilon et sigma lunaires -, l'objet peut être daté au plus tôt de l'époque hellénistique. Le problème se pose d'y reconnaître, ou bien un génitif $\delta \varepsilon \lambda \varphi \tilde{v} v o \varsigma$ - auquel cas il faudrait supposer que le bateau qui portait l'ancre était baptisé $\Delta \varepsilon \lambda \varphi i ́ s$, Dauphin -, ou bien un nominatif de l'épiclèse $\Delta \varepsilon \lambda$ pívios attribué à Apollon. Le choix de l'épiclèse serait indiscutablement en relation avec l'élément liquide et avec les mythes maritimes du dieu. Elle rappellerait également la présence sur certaines ancres d'un décor animal: le dauphin, consacré à la même divinité.

\section{h) Ancres de Déméter-Cérès et Isis}

Les deux noms de divinités figurent peut-être en latin, au nominatif, sur une même ancre, conservée au musée de Cagliari et de provenance inconnue (cat. I22) ${ }^{382}$. Si le premier apparaît lisiblement, le second est en revanche l'objet d'une reconstitution.

Cette attestation du nom de la divinité éleusinienne sur une ancre ne constitue peut-être pas un unicum. Un jas que nous avons repéré lors d'une visite du musée de Hvar en Croatie présente une inscription répartie sur les deux bras (cat. I21), dont la notice du musée donne la lecture suivante : HMHTP / BPET. Après examen, nous en proposons une autre, avec un delta initial (peu lisible dans l'état actuel de l'objet) : $\triangle$ HMHP / BPET. Le premier mot pourrait alors être reconstitué comme le nom de Déméter, avec des lettres ligaturées. En ce qui concerne le second mot, le bêta n'est pas assuré.

Quant à la présence du nom d'Isis, elle n'est pas très surprenante dans un tel corpus; l'évocation du bateau décrit longuement par Lucien nous vient immédiatement à l'esprit. Le nom de la déesse égyptienne apparaît par ailleurs sur un bateau fluvial représenté sur une peinture de la via Laurentina à Rome, ainsi que sur le grand vaisseau incisé de Nymphaion, en Bosphore Cimmérien (voir supra p. 260; infra p. 404 ss. et fig. 35) ${ }^{383}$. L'association de Cérès et d'Isis peut être comprise dans le cadre des importations de blé par Rome depuis le «grenier» que constitue pour elle l'Égypte.

${ }^{382}$ Gianfrotta 1980, p. 109-110. La référence qui est donnée renvoyant à une note de C. L. Visconti dans un périodique archéologique italien est erronée.

${ }^{383}$ Gianfrotta 1994, p. 604; sur des bateaux nommés Isis, Casson 1971, p. 359 , note 66 . 
Une autre mention du nom d'Isis sur un jas provenant de Cagliari le met, au nominatif, en rapport avec MERCURI (cat. I23) ${ }^{384}$. La restitution de ce dernier en Mercuri(us) ${ }^{385}$ n'est pas la seule lecture possible; on pourrait également supposer Mercuri comme un génitif, l'usage de ce cas étant également attesté parmi les inscriptions sur jas.

Une ancre retrouvée en mer au large de Ponza présente le nom

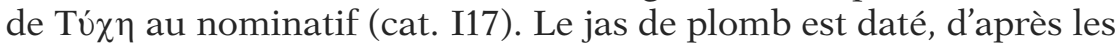
caractères épigraphiques, du début de l'époque impériale. Lors de sa publication, le rapprochement est opéré avec l'unique occurence de ce nom pour un bateau qui est connue sur un papyrus égyptien du $\mathrm{II}^{\mathrm{e}}-\mathrm{III}{ }^{\mathrm{e}}$ s. p.C., ce qui autorise l'auteur à penser qu'il s'agit ici d'IsisTychè ${ }^{386}$. Nous pouvons également penser, à la lumière des autres jas, à Aphrodite à qui elle a pu être assimilée.

\section{i) Ancre de Vesta}

Un jas de plomb, daté d'après le contexte du ${ }^{\text {er }}$ s. de notre ère, trouvé à Capo Vaticano en Calabre, offre la seule évocation de la déesse Vesta (cat. I24). Le nom latin, inscrit au nominatif, renvoyant à celui de plusieurs bateaux, est interprété comme celui de «la déesse titulaire du navire ${ }^{387}$. On cite alors le cas d'une ancre miniature trouvée à Rome, dans l'area sacra de la déesse ${ }^{388}$.

\section{j) Ancre d'Héraclès}

Le nom du héros sur jas ne se manifeste qu'une seule fois, au nominatif, sur un objet provenant des eaux siciliennes, précisément de Capo Zafferano (cat. I25). C'est le seul, apparemment, qui porte des caractères grecs, parmi les ancres provenant de cette zone et conservées au musée de Palerme. Publié en $1973^{389}$, il n’a pas donné lieu, à l'inverse d'autres jas théophores, à de nombreux commentaires. Il est alors simplement supposé avoir un «significato dedicatorio, da parte dell'armatore della nave probabilmente», sans plus amples discussions ou rapprochements. V. Tusa le date, d'après

${ }^{384}$ Gianfrotta 1994, p. 603.

385 Ibid.

${ }^{386}$ Gianfrotta 1994, p. 603 et fig. 6.

${ }^{387}$ Gianfrotta 1994, p. 605-606; Gianfrotta \& alii 1997, fig. p. 113.

${ }^{388}$ Ancre de bronze à la partie supérieure repliée, d'une hauteur totale de 9,2 $\mathrm{cm}$; l'objet provient du puits A de l'area du temple, de son remplissage à l'époque républicaine : Follieri 1961, col. 139-140 et fig. 47; Gianfrotta 1975; Gianfrotta 1977, p. 286 et fig. 1.

389 Tusa 1973, p. 431. 
les caractères épigraphiques - spécialement du A triangulaire -, du

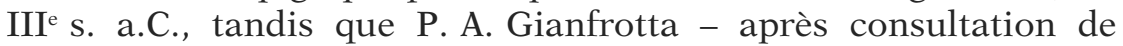
M. Guarducci et M. L. Lazzarini - le situe plutôt deux siècles plus tard et le classe parmi les noms de bateaux, par comparaison avec d'autres ${ }^{390}$. Quoi qu'il en soit, l'allusion à ce demi-dieu dans un contexte maritime n'a suscité qu'un silence prudent. Des monnaies peuvent apporter un certain parallèle, en présentant au droit un buste d'Héraclès et au revers une ancre ou un aplustre ${ }^{391}$.

L'ensemble du catalogue fournit ainsi une liste de vingt-cinq jas de plomb à noms théophores. Zeus s'avère la divinité la plus représentée, mais la totalité des ancres dessine une variété de dieux ainsi mis en relation avec la navigation: Aphrodite, Apollon, Artémis, Héra, Héraclès, Cérès, Isis, Mercure et Vesta auxquels il faut peutêtre ajouter la divinité qualifiée de Sôteira. La majorité des inscriptions sont en grec : dix-sept cas contre la moitié seulement en latin. La plupart de ces jas semblent hellénistiques ou du début de l'époque impériale, même si les datations épigraphiques sont loin d'être assurées ou parfois varient d'une publication à l'autre.

\section{Nom de bateau ou divinité tutélaire?}

a) État de la question

Comme la présentation du matériel l'a laissé entendre, dès les premières apparitions de noms théophores sur jas d'ancre, les érudits et savants se sont interrogés sur le sens à donner à ces inscriptions. Le premier à prendre position fut J. N. Svoronos : selon lui, le nom théophore signifie que le bateau auquel appartient l'ancre se trouve sous protection du dieu. Son argumentation repose sur le fait que le nom des bateaux serait toujours un nom de genre féminin, en accord avec le genre du nom grec désignant le bateau $v \alpha \tilde{v} \varsigma^{392}$ - ce qui en effet éliminerait un certain nombre de nos inscriptions qui renvoie à un nom masculin.

Cette théorie est suivie par M. Guarducci, mais pour une toute autre raison. Elle souligne avec justesse la grande proportion d'ins-

${ }^{390}$ Gianfrotta 1980, p. 109 note 30 et Gianfrotta 1994, p. 605-606, ne donne cependant aucune référence sur le(s) parallèle(s) connu(s).

${ }^{391}$ Anson 1910-16, V, p. 87, no 564 d'Étrurie (= Poole 1873, p. 14, no 11 avec fig.); ibid. no 619 de Gadès. Sur les relations entre Héraclès et la mer, voir notamment García y Bellido 1963; Lacroix 1974; Bonnet 1988; Boardman 1989.

${ }^{392}$ Svoronos 1914, p. 107. Cette théorie est suivie également par Davaras 1980 et par Wachsmuth 1967, p. 260. 
criptions sur jas faisant clairement référence à des divinités salvatrices; c'est donc ce caractère qui est espéré, et ne peut convenir à l'onomastique des bateaux ${ }^{393}$.

En revanche, P. A. Gianfrotta distingue deux cas de figures : d'une part certaines inscriptions théophores se rapportent sans ambiguïté au nom même du bateau, par analogies avec les mêmes noms théophores de bateaux connus par les inscriptions ou les textes; dans d'autres cas, on peut envisager alors une invocation à une divinité sous la protection de laquelle on veut placer l'embarcation $^{394}$.

Par ailleurs, les inscriptions théophores sur jas d'ancres apparaissent, dans l'état actuel de nos connaissances, sous trois formes possibles : le nominatif, le datif ou le génitif. Une première attitude considère que le cas grammatical utilisé importe peu ${ }^{395}$. En revanche si certains commentateurs pratiquent une distinction bien nette entre l'usage de l'un ou l'autre cas, parfois les nuances qu'ils y apportent sont difficiles à saisir. Ainsi par exemple, à l'occasion de la publication des ancres conservées au musée de Palerme, V. Tusa définit une double inscription théophore au datif comme clairement dédicatoire, pour ensuite en déterminer une autre, au nominatif, également dédicatoire, mais où le dieu, «in prima personna, protegevva la nave ${ }^{396}$. G. Kapitän considère en revanche les emplois du génitif et du datif comme ambivalents, pour signifier l'appartenance de l'ancre au(x) divinité(s) en question, et celui du nominatif servant plus précisément à désigner une/des divinité(s) particulière(s) comme protectrice(s) et salvatrice(s) ${ }^{397}$.

${ }^{393}$ Guarducci 1967-78, III p. 363. Cette idée est en particulier reprise par Manganaro 1977, p. 159-160 à propos des ancres Zeus Kasios : «A Pelusion, come a Corcira, probabilmente si fabbricano àncore con il nome di questo dio, nella credenza che attraverso l'àncora la nave fosse posta sotto la protezione dello stesso».

${ }^{394}$ Gianfrotta 1980, p. 109 (reprise dans Gianfrotta \& Pomey 1980, p. 309); quelques lignes plus bas cependant, il interprète comme nom de bateau une inscription théophore sans aucun parallèle connu. Dans son article plus récent de 1994, p. 598, il privilégie la première interprétation, en gardant simplement "quelque doute dans quelques cas» pour lesquels la seconde pourrait être autorisée. Dans l'ouvrage récent collectif Gianfrotta \& alii 1997, p. 113, il concilie finalement les deux tendances en affirmant que «l'appel à la divinité protectrice est encore plus explicite sur quelques jas en plomb portant des inscriptions en grec ou en latin. Le nom de la divinité est presque toujours le même que celui du navire».

${ }^{395}$ Gianfrotta \& Pomey 1980, p. 309.

396 Tusa 1973, p. 427-428 (ancre IOVI / VENERI) et 432 (ancre CASIVS).

${ }^{397}$ Kapitän 1989, p. 152; c'est le seul article où l'on affirme et assume l'existence d'une double inscription théophore sur un même jas. Gianfrotta 1994, p. 608 , se rallie finalement à cet avis, en considérant l'emploi du datif et du 
Cependant l'opinion qui prévaut au travers des différentes publications est que le nom du dieu au nominatif représente le nom du bateau, et que le nom au datif place l'embarcation sous la protection du dieu ainsi invoqué ${ }^{398}$.

\section{b) Analyse}

Avant de confronter la totalité des noms de dieux sur jas de plomb et ceux connus comme noms de bateaux, une remarque s'impose en ce qui concerne l'usage des cas grammaticaux des premiers : leur répartition s'avère inégale. Une vingtaine de noms apparaissent au nominatif, entre trois et cinq au génitif et deux au datif ${ }^{399}$. Ces différences dans le nombre d'occurrences contredisent l'idée d'un usage indifférent de l'un ou l'autre cas. D'autre part, l'emploi du génitif peut renvoyer indifféremment au dieu et au bateau: comme dans le cas de certaines inscriptions sur jas de pierre offerts en ex-voto ${ }^{400}$, l'ancre peut appartenir au dieu; mais elle peut aussi se comprendre comme la propriété du bateau. Si le cas du génitif signifie l'appartenance du jas à un prédicat, celui-ci peut aussi bien être le dieu que le nom du bateau.

La réunion de ces différentes données donne le tableau suivant (voir p. 321).

Une première constatation s'impose. Effectivement, l'analogie entre les noms sur jas et l'onomastique navale est possible pour environ la moitié des cas. Ces rapprochements sont doubles : des noms sur ancres au génitif comme au nominatif sont rattachables à des noms de bateaux. Ainsi les trois cas de génitif Artémidos, Iovis et Mercuri sont rattachables aux bateaux Artémis, Jupiter et Mercurius; de la même manière Sôteira, Venus, Salvia, Déméter, Ceres, Isis et Vesta sont attestées à la fois sur ancres et sur navires.

Cependant, aucune cohérence ne ressort de cet ensemble : les usages du génitif et du nominatif peuvent l'un et l'autre renvoyer à des noms de bateaux, en grec comme en latin. Cependant on ne peut en tirer de conséquence sur l'identification avec les noms de bateaux, car se pose alors le problème des ancres à double nom. Celle figurant Mercuri et Isis porte, semble-t-il, deux noms à deux cas différents. Les autres cas de noms doubles à Zeus et Aphrodite sont formulés au nominatif en latin et au datif en grec. Aucune ligne

génitif comme dédicatoire, de façon à donner un statut particulier à l'objet, qui devient «expression de religiosité maritime».

${ }^{398}$ Par exemple : Boon 1977a, p. 20.

399 À cette liste, il faut ajouter un cas non déterminé : Delphinos (génitif ou nominatif), et un vocatif (?) Kasie.

${ }^{400}$ Voir infra. 
directrice ne se dessine : chaque tentative d'explication se heurte à un contre-exemple. Il est donc impossible pour le moment d'affirmer quelque identification entre l'onomastique navale et les noms sur ancres, ni de donner une valeur à l'usage de tel ou tel cas.

\begin{tabular}{|c|c|c|c|c|}
\hline Ancre & Nominatif & Génitif & Autre cas & Nom de bateau \\
\hline Zeus / Hypatos & $\mathrm{x}$ & & & \\
\hline Iovis & & $\mathrm{x}$ & & (Jupiter) \\
\hline Sozô & $\mathrm{x}$ & & & \\
\hline Dios Kasiou & & $\mathrm{x}$ & & \\
\hline Casius & $\mathrm{x}$ & & & \\
\hline Kase & & & $\mathrm{x}$ & \\
\hline $\begin{array}{l}\text { Zeus Kasios Sozon / } \\
\text { Aphrodite Sozousa }\end{array}$ & $\mathrm{x}$ & & & \\
\hline Veneri / Iovi & & & $\mathrm{x}$ & \\
\hline Venus & $\mathrm{x}$ & & & Venus \\
\hline $\begin{array}{c}\text { Sôteira (3) } \\
\text { Sôtira (2) } \\
\text { Sôtra }\end{array}$ & $\mathrm{x}(6)$ & & & $\begin{array}{l}\text { Sôteira } \\
\text { Sôtèria }\end{array}$ \\
\hline Salvia & $\mathrm{x}$ & & & Salvia \\
\hline Tychè & $\mathrm{x}$ & & & \\
\hline Artemidos & & $\mathrm{x}$ & & (Artemis) \\
\hline Hèra & $\mathrm{x}$ & & & (Juno) \\
\hline Delphinos & $\mathrm{x}(?)$ & $\mathrm{x}(?)$ & & (Delphis) \\
\hline Dèmètr (?) & $\mathrm{x}$ & & & Dèmètèr \\
\hline Ceres / Isis (?) & $\mathrm{x}$ & & & Ceres // Isis \\
\hline Mercuri / Isis & $\mathrm{x}$ & $\mathrm{x}(?)$ & & (Mercurius) // Isis \\
\hline Vesta & $\mathrm{x}$ & & & Vesta \\
\hline Hèraklès & $\mathrm{x}$ & & & Héraklès \\
\hline
\end{tabular}

Si l'on tente de regarder les deux groupes sans a priori, il faut en revanche admettre des différences. Les ancres portent des noms doubles, associant Zeus et Aphrodite, Mercure et Isis. Or, on ne connaît pas de nom double pour l'onomastique navale ${ }^{401}$. Par ailleurs, sur les jas figurent plusieurs cas de nom de divinité suivi

${ }^{401}$ L'exemple du bateau nommé Aphrodite Tychè n'est absolument pas confirmé : sur les discussions épigraphiques concernant ce nom, voir supra. Celui de Casson 1971, p. 345 note 2 repose sur un parasème de Junon et de Jupiter, ce qui ne signifie pas qu'il s'agit du nom du bateau. 
d'une épiclèse - par exemple Zeus Hypatos. Ce type de formulation n'existe pas non plus parmi les noms de bateau.

Il convient alors de s'interroger sur la validité d'un tel rapprochement entre inscriptions sur ancres et noms de bateaux. L'éventail de ces derniers est relativement large, et cependant il ne suffit pas à expliquer les quelques inscriptions théophores, beaucoup moins nombreuses, apparaissant sur les jas. De plus, si l'on examine le pourcentage de noms théophores parmi les listes de bateaux ${ }^{402}$, les inscriptions sur jas devraient nous donner un éventail de noms beaucoup plus diversifié et surtout, proportionnellement, beaucoup moins de noms de dieux. Or, comme nous l'avons déjà signalé, les inscriptions sur jas se répartissent en deux grandes catégories : des noms de personnes et des noms de dieux. Inversement, si l'on considère que les noms théophores sur ancres correspondent aux noms de bateaux, on peut dès lors dire sans avoir besoin de chercher d'autre explication que les deux listes d'inscriptions se complètent pour nous donner un inventaire des noms de bateaux. Or cela ne paraît pas être si simple, puisque certains jas présentent un double nom ${ }^{403}$ : étant donné la technique de fabrication des jas de plomb, il est impossible qu'une même ancre ait été récupérée pour servir sur un deuxième navire ${ }^{404}$.

Une dernière différence est notable au niveau des divinités présentes dans les deux groupes. Le grand nombre de mentions de Zeus sur jas est frappant par rapport à l'absence manifeste d'embarcation portant son nom. Inversement, ni Poséidon ni les divinités marines secondaires ne figurent parmi les inscriptions sur ancres alors qu'ils baptisent des navires de l'époque hellénistique et de la période romaine.

${ }^{402}$ La différence est manifeste, lorsque l'on compare la liste de notre corpus d'inscriptions sur jas à celles des noms de bateaux exposés par exemple par Casson 1971, p. 350 s., où à côté des noms de divinités apparaît un grand nombre d'adjectifs divers se rapportant aux qualités supposées du bateau, de noms exprimant une notion abstraite, un animal, une origine géographique de l'embarcation.

${ }^{403}$ Cf. Gianfrotta 1980, p. 110 : l'existence de doubles inscriptions théophores est bien notée et acceptée, mais sans aucune conséquence sur la lecture de nom comme étant celui du bateau; dans son article de 1994, p. 607, en revanche, l'auteur évoque la possibilité de bateaux au nom double.

${ }^{404}$ La même hypothèse apparaît réfutée chez Chuvin \& Yoyotte 1987, note 82, mais pour des motifs différents (épigraphiques); c'est oublier avant tout que les deux inscriptions apparaissent en relief, et non creusées dans le métal : c'est la technique habituelle, et les photos publiées dans le Boletín de la Real Academia de la Historia le montrent bien. L'argument épigraphique n'est donc qu'une conséquence logique de l'argument technique. Et le terme de "gravés» utilisés par F. Cumont, P. Chuvin et J. Yoyotte est impropre. 
Les inscriptions théophores sur jas de plomb semblent donc témoigner d'une religiosité sur le bateau non forcément liée au nom de celui-ci. Dans certains cas elles peuvent sans doute coïncider avec ce dernier, mais cela ne se révèle pas être la situation la plus courante. En revanche, il est indéniable qu'elles expriment des croyances en des divinités protectrices attachées au bateau, invoquées par l'intermédiaire d'une de ses ancres. En ce qui concerne le matériel grec, l'importance de Zeus et d'Aphrodite correspond à ce que l'on connaît de leur caractère marin.

Si le rapprochement de ces noms avec l'onomastique navale n'est guère probant, en revanche on peut trouver quelques analogies avec des éléments de décoration du bateau. À Zeus Hypatos ou Kasios sur ancre s'apparente la stylis de Zeus Sôter ${ }^{405}$. Plusieurs parasèmes représentant deux divinités sur un même bateau sont attestés par les textes et l'archéologie ${ }^{406}$. La stylis présente la formulation (nom + épiclèse) et les parasèmes une double représentation de dieux. Il n'est pas impossible dès lors de supposer une correspondance entre le jas et le décor religieux du bateau, tous placés sous la/les même(s) divinité(s) tutélaire(s).

\section{L'association nom de dieu + décor}

Deux ancres présentent, on l'a vu, un décor en plus d'un nom théophore. On peut légitimement se demander si les deux peuvent être mis en relation et donc revêtir une valeur religieuse.

\section{a) L'étoile}

La première association entre le nom d'Héra et le motif circulaire (cat. I19) a trouvé une interprétation de cet ordre. P. A. Gianfrotta, qui l'avait d'abord répertorié comme une rosette, y

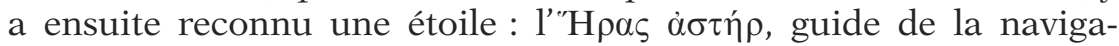
tion $^{407}$. Le motif, plutôt stylisé, ressemble d'ailleurs à l'étoile accompagnant les Dioscures, ou un de leurs attributs - par exemple

${ }^{405}$ Voir supra.

${ }^{406}$ Le papyrus Oxyrhynchos en donne plusieurs exemples, que L. Casson a interprétés comme des noms de bateaux : voir supra note 124; sur les parasèmes, voir également supra p. 255 ss.

${ }^{407}$ Rosette : Gianfrotta 1980, p. 109, note 29, et fig. 12-14; étoile : Hesnard \& Gianfrotta 1989, p. 393-441; Gianfrotta 1994, p. 604 confirme cette interprétation, en postulant sur le rôle d'Héra protectrice de la navigation à travers les sanctuaires de Samos, d'Argos, du cap Lacinion; idée répétée brièvement dans Gianfrotta \& alii 1997, p. 113. 
le bonnet - sur d'autres représentations. Des monnaies présentent également une étoile qui ornemente une proue ${ }^{408}$.

b) L'avant-train de lion

Le rapprochement entre l'inscription Sôteira et l'avant-train de lion tronqué (cat. I11) est particulièrement intéressante. Le motif, qui ne trouve apparemment aucun parallèle iconographique, est différemment commenté comme un symbole apotropaïque ${ }^{409}$, ou comme référant à Héraclès ${ }^{410}$, ou encore Dionysos ${ }^{411}$. Cette dernière hypothèse ${ }^{412}$ repose sur la transformation du dieu, durant l'épisode des pirates Tyrrhéniens, en un lion. Cependant, cette interprétation se heurte à la diversité des traditions concernant cette légende dionysiaque $^{413}$ : le lion n'est rapproché de Dionysos qu'à une époque ancienne; à la date de fabrication de l'ancre, c'est la panthère qui accompagne le dieu.

Par ailleurs, si l'on accepte le rapprochement entre l'étoile et Héra, il faut supposer pour le lion un lien similaire avec une féminine nommée Sôteira. L'animal est associé à diverses divinités féminines : principalement Cybèle, ainsi qu'Héra, Aphrodite ou Artémis ${ }^{414}$. Par ailleurs, nous avons noté l'existence, parallèlement aux inscriptions grecques de Sôteira sur jas, de celle latine de Salvia. Ce nom renvoie également au culte de la Magna Mater et à sa navigation jusque Rome. Cybèle intervient à plusieurs reprises dans la navigation d'Énée et de ses compagnons (Énéide IX, v. 69-122; X, v. 156-255). Le héros apparaît même sur un bateau dont la proue représente des lions phrygiens qui semblent tirer le navire et dont la poupe rappelle le mont Ida (Énéide X, v. 156-158). Il est donc possible de reconnaître dans le décor du lion une allusion religieuse à Cybèle, qui est souvent représentée en compagnie d'un tel animal ${ }^{415}$.

${ }^{408}$ Anson 1910-1916, V, p. 114-115 et pl. XVIII, no $872-873,875,877-882$.

${ }^{409}$ Kapitän 1989, dans son tableau IV.

${ }^{410}$ Carrazé 1973, p. 15-17, qui pousse peut-être le raisonnement un peu loin en y voyant «une représentation d'Héraklès coiffé de la dépouille du lion de Némée»!

${ }^{411}$ Hesnard \& Gianfrotta 1989, p. 393-441, suggèrent cette idée dans la dernière phrase de l'article, sans la développer; auparavant, Gianfrotta 1980, p. 108-109, avouait sa perplexité en qualifiant la signification du motif comme incertaine.

${ }^{412}$ Cette hypothèse a ensuite été explicitée par le même P. A. Gianfrotta dans Gianfrotta \& alii 1997, p. 46-47.

${ }^{413}$ Voir supra.

${ }^{414}$ Hermary 2000a.

${ }^{415}$ Simon 1997, passim. 
Si celle-ci s'avère exacte, l'épiclèse de Sôteira - attestée également parmi les noms de bateaux - peut alors s'appliquer à l'une des formes syncrétiques que la Grande Mère des dieux a revêtues dans le monde grec. On l'a notamment assimilée à Rhéa, Déméter ou Astarté - par l'intermédiaire de laquelle elle put se confondre avec Aphrodite. Cybèle fut honorée en Grèce dans les ports, ce qui la rattache encore à la navigation ${ }^{416}$. Elle était particulièrement vénérée à Phocée où elle possédait un sanctuaire maritime et à Marseille ${ }^{417}$. Le syncrétisme de ces divinités féminines permet de comprendre l'usage de ces épithètes pour invoquer leur aide divine à bord, et ce avant l'époque impériale.

Les deux associations entre inscription théophore et décor trouvent une signification. Dès lors, il nous faut examiner si l'on peut donner un tel sens aux motifs qui apparaissent seuls sur jas de plomb.

\section{INTERPRÉTATION DES DÉCORS}

Les décors sur jas d'ancre sont considérés d'une manière quasi unanime comme revêtus d'une symbolique, plus précisément magico-religieuse; l'expression qui prévaut alors est celle de "rôle apotropaïque» ${ }^{418}$. Certains auteurs vont même plus loin, les reliant à des realia religieux bien déterminés : «Parmi les plus courantes, citons les osselets groupés par quatre et le dauphin; d'autres, plus rares, laissent supposer un rapport avec des coutumes locales, voire des ex-voto» ${ }^{419}$. Les rapprochements tentés dans ce sens par

${ }^{416}$ Sur les formes du culte de Cybèle depuis l'époque classique et celles de son développement sous l'Empire, voir Turcan 1992, p. 36-42, 49-50, 61 ss.

${ }_{417} \mathrm{Ibid}$., p. 64. À Phocée, au lieu-dit Foça, la déesse était honorée au bord du port dans un sanctuaire rupestre créé au début du VI ${ }^{e}$ s., uniquement accessible par mer, où étaient taillées des niches cultuelles dans le tuf: Phocée 1995, p. $55-58$ et photos p. 46 et 54.

${ }^{418}$ Par exemple, dès 1960 par Benoît 1960b, p. 176-177 : «cet emblème (...) est toujours apotropaïque», ou plus tard par Kapitän 1989, p. 152, qui cependant présente une dizaine de lignes plus bas une définition un peu plus large - et énigmatique - de la valeur accordée à ces motifs : "Anchor stocks bearing symbols would make clear that good luck, protection, vigilance, power and deterrence, and so safety and victory, were on the side of the anchor and ship». Wachsmuth 1967, p. 259 aborde le sujet en une phrase : «Le jas d'ancre, i.e. la traverse, en plomb ou revêtue d'une gaine de plomb, fixée à l'extrémité supérieure de la verge, fut porteuse de reliefs prophylactiques et d'inscriptions, parce que l'ancre est laissée en bas dans la profondeur de la mer, "mère des ténèbres", et est ßрúoเко,, "résidant dans la profondeur de la mer"».

${ }^{419}$ Carrazé 1973. 
F. Carrazé pour comparer les motifs à ceux des monnaies de Grande Grèce pour prouver une origine "gréco-italique» de cette tradition ${ }^{420}$, n'est guère concluante : d'une part, le grand nombre d'ancres trouvées dans cette zone ne signifie absolument pas que les bateaux, avec leurs ancres, qui ont navigué dans ces parages en soient originaires et bien d'autres objets de ce type ont été sortis des flots (ou sont encore à découvrir) ailleurs. D’autre part, les types monétaires de dauphins, de bustes d'Héraclès ou de lions ne sont pas seulement avérés pour les villes d'Italie du Sud et de Sicile, mais courants dans toute la numismatique grecque.

Une attitude plus prudente consiste à considérer certains décors difficiles à expliquer comme en simple relation avec le milieu marin ${ }^{421}$. L'unanimité n'est donc pas faite autour de l'interprétation à donner à ces motifs. Constatons cependant que de manière générale les décors sont mis en relation avec des marques - inscriptions onomastiques ou numéraires -; seuls deux exemples sont attestés de décors associés avec une inscription théophore où ils revêtent un sens religieux en référence avec celle-ci. Ceci tend à attribuer au motif un sens plus important que celui de simple marque de type "commercial». Voyons donc quels sont les motifs connus sur jas d'ancre, en les considérant des plus récurrents au moins représentés, et les symbolismes religieux qu'ils peuvent éventuellement évoquer.

\section{Astragales}

a) Fréquence et identification du motif

L'image la plus couramment représentée est celle dite des osselets, ou plutôt astragales comme le désigne la majorité des auteurs $^{422}$. Le nombre de jas présentant ce décor est impossible à déterminer, mais des comptages provisoires atteignent, en 1980, le

${ }^{420} \mathrm{Ibid}$., p. 15-17, et voir infra, à propos des différents motifs. L'idée de base est loin d'être absurde (voir rapprochements identiques infra), mais c'est le traitement qui en est fait, dans le but d'étayer un pré-supposé contestable, qui n'est pas recevable : ainsi la comparaison entre le motif sur ancre des 4 astragales et les types monétaires de 4 dauphins, de la roue à 4 rayons.

${ }^{421}$ C'est entre autre l'attitude de Gianfrotta 1980, p. 108 : «I motivi decorativi che compaiono, in rilievo, sui ceppi di piombo sono ormai numerosi ed in genere simboleggiano, con richiamo più o meno esplicito, l'auspicio di una buona sorte per i naviganti oppure si ricollegano all'ambiente marino» (même idée reproduite dans Gianfrotta \& Pomey 1980, p. 309; dans Gianfrotta \& alii 1997, p. 112); plus loin, p. 109, il ajoute que «mentre tra le decorazione dei ceppi l'elemento divino è poco manifesto, essendo presente a volte in modo indiretto, tra le iscrizioni i nomi divini, greci et latini, compaiono invece con una certa frequenza».

${ }^{422}$ Talus en latin, $\dot{\alpha} \sigma \tau \rho \alpha ́ \gamma \alpha \lambda o \varsigma$ en grec. Le mot astragale désigne plus parti- 
nombre de soixante-dix ${ }^{423}$ et soixante-dix-sept en 1985424; malheureusement tout le matériel compris dans ce groupe n'est pas publié, sans compter celui déjà émergé mais encore inconnu dormant dans des musées ou autres pièces obscures... Ce qui nous donne néanmoins, malgré la pauvreté apparente de notre propre corpus à ce sujet, une écrasante majorité pour le choix de ce motif : 67 cas, soit presque 70\% des ancres avec décors (cat. D1-D43, D68-D81 et D84-93).

L'osselet est un matériel maintenant bien connu et étudié. Une rapide présentation de ses différents aspects en a été donnée par M.-J. Chavane ${ }^{425}$ ou après lui par P. Amandry ${ }^{426}$ qui rappellent, outre son utilisation courante comme jeu, le passage de Pausanias ${ }^{427}$ concernant la mantique par osselets pratiquée en Achaïe près de Boura, ainsi que la présence fréquente, pas toujours bien expliquée, de tels objets dans les sanctuaires ou les tombes ${ }^{428}$; signalons encore la pratique du port d'astragales comme amulette ${ }^{429}$. Un ex-voto de bronze exceptionnel en forme d'osselet, d'un poids de 220 mines, provenant de Didyme, est consacré à Apollon ${ }^{430}$.

Le principe de leur utilisation ludique est qu'ils offrent au total quatre possibilités de présentation (fig. 21), représentant chacune une valeur numérique, lorsqu'ils retombent après avoir été jetés en l'air ${ }^{431}$ : deux côtés plus larges, un dorsal appelé ü $\pi \tau \imath$, valant le

culièrement l'os de cette forme, qui est utilisé en jeu; le mot osselet désigne l'objet du jeu, quel que soit son matériau.

${ }_{423}$ Gianfrotta 1980, p. 108 , qui renvoie en note à Boon 1977a; ce dernier recense en un tableau p. 22 seulement une vingtaine d'exemplaires de ce type.

${ }^{424}$ Tableaux II et IV de Kapitän 1985; p. 152, ses calculs donnent ce nombre pour 111 jas de plomb à décor figuré.

${ }^{425}$ Chavane 1975, p. 185-188, avec une bonne bibliographie.

${ }^{426}$ Amandry 1984.

${ }^{427}$ Pausanias VII, xxv, 10-11; il s'agit d'une grotte-sanctuaire dédiée à Héra-

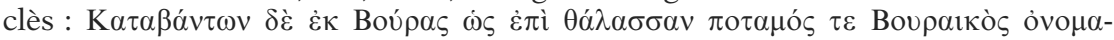

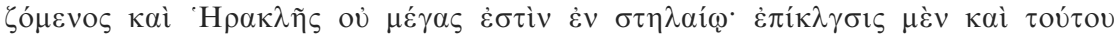

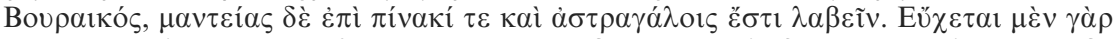

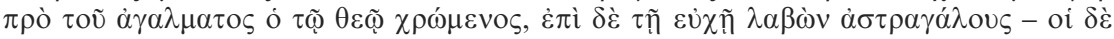

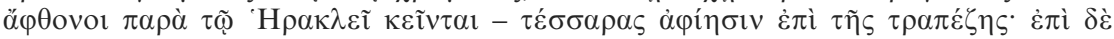

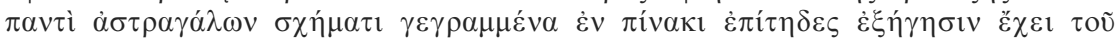
$\sigma \chi \eta \dot{\mu} \mu \alpha \tau$.

${ }^{428}$ Cf. par exemple Bruneau 1970b, p. 527; Beschi 1978, p. 4 et note 15. Tombe de Chypre du bronze récent, avec un modèle de bateau en terre cuite rempli d'osselets : Hermary 2000b, p. 50 note 116.

${ }^{429}$ Amandry 1984, p. 355 et 377.

${ }^{430}$ Musée du Louvre, SB 2719. Forsén 2004, p. 309, 311 (nº 184 et pl. 80) l'interprète comme un poids, peut-être offert par un commerçant.

${ }^{431}$ Pour une description claire et précise, cf. Amandry 1984, p. 349, Queyrel 1987 et Queyrel 1997; ou encore Becq de Fouquières 1869, p. 329-331; Mau 1896; 


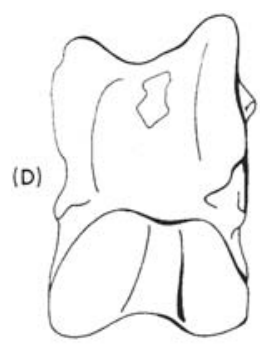

A

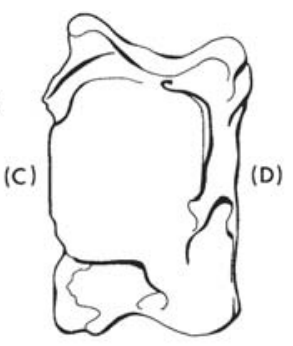

B

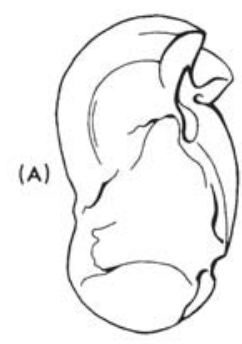

C

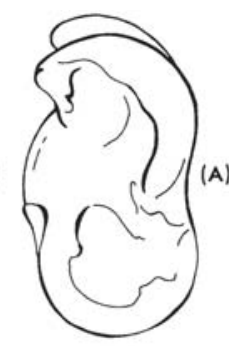

D

Fig. 21 - Différentes faces d'un osselet/astragale : $\mathrm{A}=$ ü $\pi$ ı $\mathrm{B}=\pi \rho \alpha v \eta ́ \varsigma$

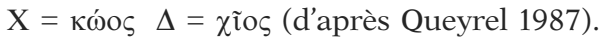

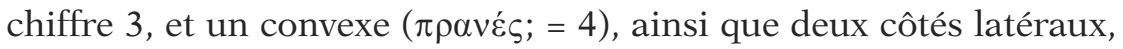

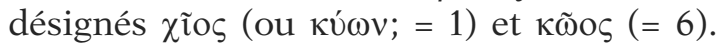

La combinaison des faces sous laquelle chacun des osselets - quatre, cinq le plus souvent ${ }^{432}$ - repose après le lancer ${ }^{433}$ détermine un nombre de points, ou un coup particulier, bon ou mauvais pour le joueur ${ }^{434}$. L'objet, le plus souvent en os, peut aussi se trouver réalisé en céramique, verre, métal, pierre; il a été également retrouvé modifié, percé d'un trou, farci, doré ou encore gravé ${ }^{435}$.

En ce qui concerne leur représentation sur les ancres, c'est sous un aspect simple qu'il apparaît, sans modification particulière; il semble directement avoir estampé le moule destiné à réaliser le jas, à chaque fois sur une face déterminée ${ }^{436}$. Ce motif sur ancre a été

sur la persistance de la tradition à donner un nom aux faces d'astragale, voir Amandry 1984, note 5.

${ }^{432}$ Queyrel 1987, p. 210, distingue d'une part le jeu «féminin » pratiqué à cinq astragales et le jeu masculin à quatre astragales, des jeux de l'enfance à nombre indéterminé.

${ }^{433}$ Penser par exemple à la célèbre et magnifique peinture sur marbre d'Herculanum, aujourd'hui au Musée de Naples (inv. 9562), qui représente un groupe de jeunes femmes s'adonnant à ce jeu : Monument Piot, 1905, p. 49, fig. V.

${ }^{434} \mathrm{Au}$ nombre de trente-cinq, d'après Eustathe : une liste des noms connus, avec une discussion à propos de leur évolution, est donnée par Becq de Fouquières 1869, p. 334-346.

${ }^{435}$ Becq de Fouquières 1869, p. 328; Amandry 1984, 348-349 et note 3. Les inscriptions - de même que les autres opérations - restent inexpliquées; elles ne correspondent pas par ailleurs, comme on aurait pu le supposer, aux nombreux noms connus des coups obtenus en jouant aux astragales. Un lien (?) minime avec le monde maritime est donné par l'attestation du nom de Thétis - au nominatif - sur une astragale trouvée dans l'Antre Corycien (Amandry 1984, p. 370 et fig. 37) et du trident sur une autre de Myrina (Pottier \& Reinach 1887, p. 217).

${ }^{436} \mathrm{La}$ taille des astragales apparaissant sur les jas correspond celle à des 
identifié depuis les premières découvertes comme une marque apotropaïque, de bonne fortune ${ }^{437}$. Ainsi en 1897, à propos de l'ancre conservée au musée Borély de Marseille (cat. D7), W. Froehner exprimait de façon concise cette idée qu' «on s'explique difficilement la présence d'un jeu d'osselets sur une ancre, à moins qu'il n'ait servi de talisman» ${ }^{438}$.

\section{b) Le «coup de Vénus»}

Or, le nombre des astragales figurant sur les jas est le plus souvent fixé à quatre - nombre habituel certes requis pour la pratique de ce jeu ${ }^{439}$-, ce qui a conduit en outre à l'interpréter plus précisément. Lorsque chacune d'elle repose sur une face différente, correspondant aux chiffres 1, 3, 4, 6440, il s'agissait pour les Anciens du coup dit «de Vénus», coup le plus chanceux qui soit. Le motif est ainsi presque unanimement reconnu comme un souhait de chance portant sur le bateau à qui appartient l'ancre en question.

Par ailleurs n'est sans doute pas fortuit le nombre d'osselets utilisés (4), qui est le même que celui de ceux servant à l'astragalomancie de Boura. Jusqu'à présent, la référence à cette pratique mentionnée par Pausanias n'a pas retenu l'attention des commentateurs : elle est mentionnée, pour être aussitôt écartée comme sans grand rapport possible avec le contexte des jas d'ancres. On pourrait pourtant souligner que la frontière entre la pratique du jeu de hasard et celle de la mantique par osselets est plutôt mince : en témoigne l'anecdote de Lucien $^{441}$ à propos du jeune homme amou-

astragales trouvés en fouilles; par ailleurs, chaque représentation est bien nette, comme si l'on avait pris soin à chaque fois de bien imprimer une face.

${ }^{437}$ Magon 1894, p. 221 : «L'osselet chez les Anciens serait le préservatif contre le mauvais œil et les esprits malfaisants; sur plusieurs monuments il figure au nombre d'objets sûrement talismaniques. On peut donc considérer ces reliefs comme devant être la sauvegarde de l'ancre»; idée reprise par Benoît 1951, 1, p. 226; Benoît 1960a, p. 45; Wachsmuth 1967, p. 260; Carrazé 1973; Kapitän 1973, p. 385 note 1; Carrazé 1974, p. 155; Massa 1982-83, p. 167-181.

${ }_{438}^{43}$ Froehner 1897 , p. $4-5, \mathrm{n}^{\circ} 17$.

${ }^{439}$ Sur d'autres rapprochements moins convaincants, voir supra p. 326 note 420.

${ }^{440}$ Mau 1896; Froehner 1897, loc. cit.; Amandry 1984, p. 349; Queyrel 1987, p. 209-210 avec rappel des sources anciennes.

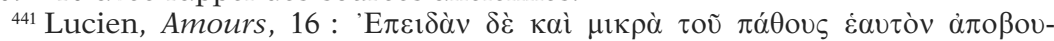

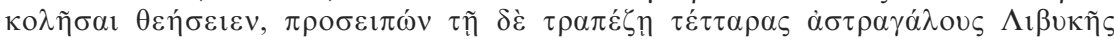

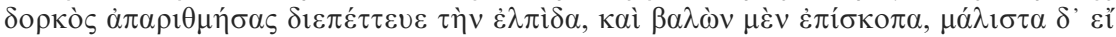

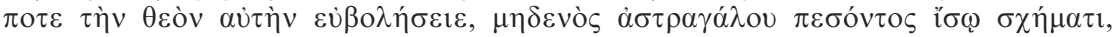

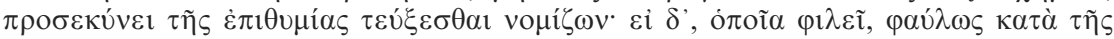

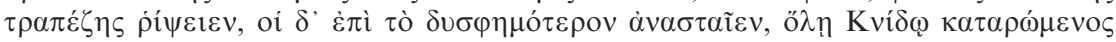


reux de la statue d'Aphrodite de Cnide, qui paraît attendre une réponse favorable à ses espérances du maniement de ces objets. L'astragalomancie, dérivation de la cléromancie ${ }^{442}$, est attestée également épigraphiquement, mais avec cinq osselets, au sanctuaire d'Attalia en Pamphylie ${ }^{443}$; de façon très hypothétique elle était peutêtre aussi pratiquée à Delphes, dans l'Antre Corycien ${ }^{444}$. Il n'est pas à exclure ainsi que la représentation de cette combinaison d'astragales ait un lien avec un usage divinatoire, voire avec un vœu hypothétique d'euploia qu'on suppose alors agréé par la divinité445.

Un texte pourrait d'ailleurs évoquer une relation possible entre les osselets, révélateurs du sort, et l'eau : il s'agit d'un passage de Suétone, concernant les présages favorables survenus durant la jeunesse de Tibère. Le futur empereur, faisant route vers l'Illyrie, fait une halte à Padoue et jette dans l'eau d'une fontaine, suite au conseil de l'oracle de Géryon, des «talos aureos» afin d'en obtenir une réponse à sa consultation; ceux-ci, qui donnent un avis plus que favorable, y sont encore visibles à l'époque où est rapportée l'anecdote $^{446}$. Certes il n'est pas question du coup de Vénus, mais du «summus numerus », autrement dit sans doute le nombre le plus élevé possible qu'on puisse obtenir d'après la valeur numérique attribuée aux faces d'un osselet, c'est-à-dire plusieurs fois le nombre

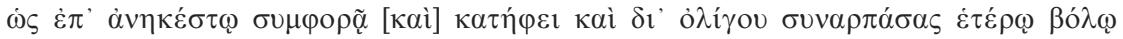
$\tau \grave{\eta} v \pi \rho i ̀ v \dot{\alpha} \sigma \tau o \chi i ́ \alpha v \dot{\varepsilon} \theta \varepsilon \rho \alpha ́ \pi \varepsilon v \varepsilon v$.

${ }^{442}$ Voir surtout Bouché-Leclercq 1882, I p. 189-197; Riess, s. v. «astragalomanteia», R. E. II, 2, 1896; T. Hopfner, s.v. "astragalomanteia», R. E. suppl. IV, 1924.

${ }^{443}$ Kaibel 1876; CIG 4310, 4379, 3956.

${ }^{444}$ Amandry 1984, p. $377-378$ et $410-411$. Beschi 1978 , p. 10 , propose également de la mettre en relation avec la pratique médicale de l'incubation dans des sanctuaires d'Asclépios (cf. Pausanias II, xxvii, 3; Strabon II, 531).

${ }^{445}$ Boon 1977 a, p. 20, exprime d'une autre manière la richesse du symbole : "The symbolism of the astragali is more complex, and three strands may be detected. They are usually shown in fours - the number used in the game disposed, as here, each a different way up : this was the throw known as Aphrodite or Venus, and accordingly astragali so arranged are another symbol of the goddess. Secondly, they may denote "hazard overcome" for the chance of throwing a Venus was not so much remote, as a matter of skill; and thirdly, because this throw required the bones to fall in one particular way, the arrangement of the astragali on the stocks, which illustrates this way must surely have had reference to the wish that the anchor itself would fall in such a manner as to gain firm hold of the sea-bed".

${ }^{446}$ Certains traducteurs tel H. Ailloud dans l'édition Budé, Paris, 1932, p. 15, traduisent plutôt "talus» par «dés». Suétone, Vie des douze Césars. Tibère, 14 : "Cum Illyricum petens juxta Patavium adisset Geryonis oraculum, sorte tracta, qua monebatur ut de consultationibus in Aponi fontem talos aureos jaceret, evenit ut summum numerum jacti ab eo ostenderent; hodieque sub aqua visuntur hi tali». 
$\operatorname{six}^{447}$; on pourrait aussi comprendre, en pensant au texte de Pausanias, le nombre correspondant à la réponse la plus favorable donnée par un tableau d'équivalences se trouvant à proximité. Cependant, nous sommes bien là en présence d'un autre témoignage d'astragalomancie et qui ne se révèle qu'au contact de l'eau, douce ici il est vrai.

\section{c) Discussion}

Tous ces témoignages de la valeur apotropaïque à donner aux astragales figurant au nombre de quatre sont certes convaincants, mais l'examen attentif du matériel et des commentaires laisse subsister des problèmes non résolus.

Tout d'abord, si l'on admet la justesse de l'interprétation des quatre astragales comme une représentation du «coup de Vénus» et par là même d'un signe de chance, il faut rester cependant très prudent sur l'application à donner à l'ancre elle-même : absolument rien ne permet de dire que ce motif s'applique à l'ancre de salut, ou ancre sacrée, utilisée en dernier recours ${ }^{448}$. Dès lors, il faut relativiser l'application du souhait de chance à toutes sortes de manœuvres imposées à l'ancre quelle qu'elle soit, et pas seulement en cas de navigation difficile.

De surcroît les représentations des astragales ne sont pas uniformes: les combinaisons sont multiples, entre le nombre d'astragales représentées, à la fois sur l'ensemble du jas, et sur une face d'un bras, ainsi que leur disposition ${ }^{449}$. Dans notre catalogue, nous avons ainsi distingué, pour le motif apparaissant seul, entre les groupes de quatre astragales et ceux de $4 \times 1$ ou $2 \times 2$ (cat. D1-D26),

${ }^{447}$ C'est l'interprétation de Becq de Fouquières 1869, p. 354, qui voit dans cette anecdote la preuve du déclin du jeu d'osselets qui ne sont plus que des variantes des simples dés.

${ }^{448}$ C'est par exemple ce qu'admet implicitement Queyrel 1987, p. 211 : «Les gens de mer, joueurs eux-mêmes, ne pouvaient manquer d'y voir un signe qui porterait chance à l'ancre : celle-ci, dernier espoir du navire aux moments critiques, doit tomber dans une position aussi favorable que les osselets figurés sur le jas», avec une note signalant le «symbolisme de l'ancre du salut dans l'iconographie chrétienne». Cette hypothèse est également récusée par Zemer 1981.

${ }^{449}$ Ces représentations d'osselets en nombre ou disposition différente sont souvent rapidement évoquées dans les publications, alors que la théorie du coup de Vénus est toujours abondamment reprise. De même il n'est pas certain, comme on le lit dans Queyrel 1987, que la répartition en deux groupes de deux astragales ait la même signification que les quatre en bloc; même point de vue dans Gianfrotta 1980, p. 108 : "sempre in modo che presentino complessivamente tutte e quatro le facce con esito fortunato come nella combinazione del gioco più alta, e cioè quella vicente». 
et les nombres non rattachables au chiffre 4 (cat. D27-D28) ${ }^{450}$. G. Kapitän suggérait, en $1969^{451}$, que ces combinaisons pouvaient varier en fonction de l'usage propre à chaque ancre : ancre de jet, de mouillage, de bossoir... à l'intérieur de la cargaison de chaque bateau. Donner un sens aussi rationnel à ce décor pourrait certes se concevoir, si les astragales apparaissaient sur toutes les ancres et si une même épave nous avait livré plusieurs ancres présentant chacune une combinaison différente d'astragales. Or, cela est loin d'être le cas, et la forte majorité de la combinaison du «coup de Vénus» contredit encore cette hypothèse. Sur les 66 ancres qui portent le motif de l'astragale (voir liste supra p. 327) : au moins 43 en portent 4 (en combinaisons diverses), sans compter les ancres mal publiées pour lesquelles on ignore le nombre de motifs exact. Pour le reste, les nombres différents sous lesquels apparaissent les osselets sur les jas, c'est-à-dire en exemplaire unique ou en combinaisons paires ou impaires, restent à expliciter ${ }^{452}$.

L'interprétation des astragales comme signes apotropaïques ne fait ainsi pas encore l'unanimité : certains préfèrent y voir une marque plutôt qu'une décoration ${ }^{453}$. En leur faveur pourrait être invoqué, il est vrai, le jugement négatif que nous a laissé Artémidore sur l'interprétation du jeu d'osselets vu en rêve : celui-ci est présage de mort, ou pour le moins de dangers ${ }^{454}$. Mais ce symbolisme peut lui aussi être retourné et être utilisé, comme dans le cas de la tête coupée (voir infra p. 336 ss.), pour éloigner les mauvais démons et les mauvais sorts.

${ }^{450}$ Même en opérant cette distinction, il reste néanmoins un jas difficile à classer (celui du golfe de Paestum à 14 astragales, cat. D26) car il porte à la fois des groupes de 4 et des groupes de 3 astragales.

${ }_{451}$ Rapporté par Frost 1969, note 1 p. 439.

${ }^{452}$ Même si la combinaison de paires figure selon une écrasante majorité à travers notre corpus, il existe néanmoins des cas de combinaisons impaires. Le fait est notable car, comme Becq de Fouquières 1869, p. 354, l'avait déjà remarqué, les osselets étaient de façon générale sur les médailles ou les stèles majoritairement représentés par quatre, ou en exemplaire unique.

${ }^{453}$ Par exemple Almagro Gorbea 1969, p. 350.

${ }^{454}$ Artémidore, Onirocriticon III, 1 : «Voir un enfant qui joue aux dés ou aux osselets ou au jeu de dames n'est pas funeste : car il est habituel aux enfants de jouer sans cesse. Mais pour un homme fait et une femme, il est funeste de rêver qu'on joue aux osselets, à moins qu'on ait ce rêve alors qu'on espère un héritage : car les osselets sont tirés de cadavres. Pour la même raison cela prédit des dangers pour tous les autres» (traduction A. J. Festugière, Paris, 1975, p. 185). Cf. le commentaire de Robert 1968, p. 229-231, mais qui insiste seulement sur la présence d'astragales dans des tombes; controverse à ce sujet, voir Bruneau 1970b, loc. cit. 
Une vérification a contrario pourrait s'avérer décisive. S'il est connu que le meilleur coup possible dans le jeu des astragales est celui de Vénus, on sait également que le plus mauvais est celui positionnant toutes les astragales sur la même face latérale, correspondant au chiffre 1, appelé "les chiens» ${ }^{455}$. Or, si les astragales des jas se trouvent sous cette forme, cela contredit l'hypothèse avancée. De même, la face latérale dite $\chi$ ĩos ou kú $\omega v$ revêt une valeur funeste ${ }^{456}$; apparaît-elle également - hormis dans les groupes constituant le coup de Vénus - sur les jas d'ancres?

Malheureusement, il est difficile, pour de nombreux objets, de décider sous quelles faces se présentent les osselets : même quand le motif est bien visible, les publications sont imprécises, les photos ou dessins - quand il y en a - sombres ou peu nets ${ }^{457}$. En tous cas, un exemple de jas avec quatre astragales offrant la même face figure dans notre catalogue (cat. D68) : le coup de Vénus - et la signification qu'on veut lui donner - n'est donc pas systématique, même dans le cas de groupes de quatre osselets.

Dans l'art grec, l'astragale n'apparaît pas comme un motif iconographique isolé, si ce n'est comme jeu pratiqué par enfants ${ }^{458}$ ou adultes alors également représentés. En tant que seule entité, l'astragale est traitée pour sa forme, en trois dimensions en bague ${ }^{459}$ ou en vase plastique $^{460}$. Le motif en céramique n'est attesté que pour des timbres amphoriques ${ }^{461}$. Par ailleurs il est connu comme type monétaire en Grande Grèce, en Asie, en Eubée et à Chypre ${ }^{462}$. L'astragale

${ }^{455}$ Properce IV, 8, 45; Ovide, Art d'aimer II, 205; Becq de Fouquières 1869, p. 340-342.

${ }^{456}$ Anthologie Palatine VII, 422 (Léonidas de Tarente).

${ }^{457}$ Par exemple le dessin du jas de Tarragone inv. 34.330 (cat. D3) - portant d'après les publications 8 astragales, par 4 groupes de deux positionnées sous une face différente -, ne permet pas d'identifier réellement les faces des osselets, et si c'est réellement le même groupe qui est répété d'un bras à l'autre du jas : Berges Soriano 1969-1970, p. 9 et fig. 4.

${ }^{458}$ Deux groupes de monnaies, d'époque tardive - au plus tôt $\mathrm{II}^{\mathrm{e}}$ s. p.C. représentent deux enfants nus jouant aux osselets devant une statue de divinité, pour l'un Artémis d'Éphèse, pour l'autre Héra Samnienne : Lacroix 1949, p. 183 et p. 210, avec réf.

${ }^{459}$ Ninou 1977, p. 47, no 84 , pl. 17; le bijou en or provenant de Pella est daté des $\mathrm{IV}^{\mathrm{e}}-\mathrm{III}^{\mathrm{e}} \mathrm{s}$.

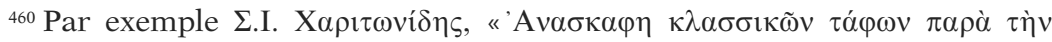

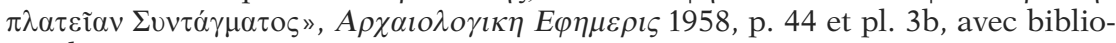
graphie.

${ }^{461}$ À Thasos. L'astragale est toujours représentée seule, non associée à un autre motif : voir Bon \& Bon 1957.

${ }^{462}$ Anson 1910-1916, VI p. 52-53 et pl. XI. Carrazé 1973, p. 15, donnait le motif comme connu sur une monnaie d'Athènes, mais sans donner aucune référence. 
figure en exemplaire unique et sans autre motif sur les revers; une uncia d'Italie centrale la porte à la fois sur le droit et le revers ${ }^{463}$. Elle peut alors être combinée avec des droits ornés de décors également attestés sur ancre: les coquilles de clovisses sur un sextans de Luceria (Apulie) ${ }^{464}$, une tête de lion sur une monnaie de bronze de Selgè (Pisidie) ${ }^{465}$, un Gorgoneion sur une obole de Kelenderis (Cilicie) ${ }^{466}$. Les deux premières associations existent également dans notre corpus ${ }^{467}$, en revanche la troisième n'y figure pas, ni à l'inverse l'association monétaire astragale / dauphin moulée sur jas d'ancre.

Lorsque l'osselet figure sur le droit, il est associé à un autre type. Des monnaies de Selgè présentent également sur le droit la réunion d'une astragale et d'une tête de lion, mais également une astragale avec une tête d'Athéna ${ }^{468}$. Elles sont datées pour les deux premières entre 400 et 300, pour la troisième du $\mathrm{II}^{\mathrm{e}}$ s. a.C.

Or, l'association de ce motif avec d'autres n'a guère jusqu'ici attiré l'attention: le fait est simplement signalée ${ }^{469}$. Le seul commentaire, donné par P. A. Gianfrotta, hasarde deux solutions : pour «renforcer le rôle prophylactique», ou "pour enrichir la décoration ${ }^{470}$. Le nombre de jas présentant cette association osselet(s) + autre motif est cependant suffisamment important - 15 cas (cat. D68-D81 et D84), ce qui représente la quasi totalité des jas à décor multiple - pour qu'on s'y attarde quelque peu ${ }^{471}$. Le motif le plus souvent associé paraît être celui du coquillage ou du dauphin ${ }^{472}$. L'une des deux seules ancres à plusieurs motifs ne comportant pas d'astragale attire notre attention du fait qu'y figure un relief ovale, peut-être un œuf (cat. D83). Or, l'œuf a été rapproché des astragales

${ }^{463}$ Anson 1910-16, n 613; Poole 1873, p. 46, no 10.

${ }^{464}$ Anson 1910-16, no 615; Poole 1873, p. 138, no 14.

${ }^{465}$ Anson 1910-1916, n 620; F. Imhoof-Blumer, Zeitung für Numismatik V, p. 136.

466 Anson 1910-1916, no 621; Hill 1900, p. 53, no 16.

4674 coquilles de clovisse + astragales (cat. D78); 1 coquillage +4 astragales (cat. D75); une tête de lion +4 astragales (cat. D76).

${ }^{468}$ Astragale et lion : Anson 1910-1916, VI no 592 et pl. X (= Hill 1897, p. 257, $\mathrm{n}^{\circ}$ 15-16 et pl. XXXIX, 9). Astragale et tête d'Athéna : Anson 1910-1916, no 590, 591, 594 et pl. X (= Hill 1897, p. 256, no 3 et p. 257, no 9-13 pl. XXXIX, 7,8).

${ }^{469} \mathrm{Cf}$. tableaux de comptage de Kapitän 1985, qui en recense 19 exemplaires.

${ }^{470}$ Gianfrotta 1980 , p. 108.

${ }^{471}$ Impossible par ailleurs d'y voir un message, une sorte de rébus comme en donnent certaines pierres gravées décrites par Becq de Fouquières 1869, p. 354-355 ou l'épigramme funéraire d'Antipater (Anthologie Palatine VII, 427).

${ }^{472}$ Le tableau III de Kapitän 1985, dénombre huit cas astragales / coquillages (dont deux non assurés); en ce qui nous concerne, d'après notre propre catalogue, nous constatons une majorité de cas astragales/dauphins. 
notamment pour sa présence dans des tombes et son symbolisme orphique : dans ce cas, l'œuf pourrait se substituer à l'astragale.

L'ensemble de ces éléments incite à rester prudent en ce qui concerne l'interprétation du motif et son lien avec Aphrodite. L'abondance des exemplaires et les nombres variables d'osselets sur une ancre peuvent laisser supposer, si le décor possédait une réelle signification apotropaïque à l'origine, qu'il s'était banalisé au point de constituer un signe analogue à ceux figurant sur des timbres amphoriques ou des monnaies.

\section{Autres motifs}

a) Dauphin

Le motif le plus souvent représenté après celui de l'astragale est celui du dauphin. Dans notre catalogue dix-huit jas le portent (cat. D44-D52, D60, D68-73, D82 et D96), dont neuf sans aucun autre décor ou inscription. Il apparaît également associé à un trident sur une ancre de pierre en marbre blanc, trouvée en mer au large de l'antique port de Gaeta (Latium) et que l'on date sans certitude de l'époque impériale ${ }^{473}$.

Le dauphin est un motif évoquant l'élément marin: tel est le commentaire général apporté à ce décor ${ }^{474}$. De légères allusions à d'autres significations ont pu être évoquées, mais toujours de façon très discrète: «le dauphin qui sauve les naufragés», à "valeur apotropaïque» 475 , "symbole de la mer sereine et accueillante, et guide du naufragé vers la terre ferme » ${ }^{476}$, "guide de l'ancre, mais aussi guide du bateau dans son élément naturel» ${ }^{477}$.

À de rares occasions cependant, il est mis en relation avec un sens religieux plus précis ${ }^{478}$, par le lien qu'il évoque avec une divinité particulière. Ainsi a-t-on souligné son rapport privilégié avec AphroditeVénus ${ }^{479}$, Aréthuse et Taras ${ }^{480}$, Amphitrite et Poséidon, Nérée et les

${ }^{473}$ Di Bartolomeo 1986, p. 210 et pl. XIIc; Gargiullo \& Okely 1993, p. 137.

${ }^{474}$ Par exemple, Tusa 1973, p. 429. Sur le dauphin, voir Stebbins 1929.

${ }^{475}$ Benoît 1960a, p. 45.

${ }^{476}$ Carrazé 1973, p. 15; repris en d'autres termes par Gianfrotta 1980, p. 108, qui lui ajoute le rôle d' "accompagnatore di navi» (thèmes répétés dans Gianfrotta \& alii 1997, p. 113).

${ }^{477}$ Carrazé 1974, p. 155.

478 À ce sujet, voir supra; Bodson 1978, p. 53-57; Somville 1984, p. 3-24; Wagner 1901, surtout col. 2507-2509; Olmos \& Moreno-Conde 2012, p. 396-397.

${ }^{479}$ Boon 1977a, p. 20; Somville 1984, p. 9.

${ }^{480}$ Carrazé 1973, p. 15, faisant allusion aux monnaies de Syracuse et de Tarente. 
Néréides, Ino et Mélicerte ${ }^{481}$, Apollon ${ }^{482}$, ou encore Artémis $^{483}$ et Dionysos $^{484}$. Si nous cherchons des rapprochements avec des références divines symbolisées sur ancres, c'est du côté d'Aphrodite que les témoignages sont les plus nombreux, puis de façon plus rare Poséidon et d'Artémis ${ }^{485}$. Autre correspondance troublante, l'existence d'une ancre portant l'inscription $\triangle \mathrm{E} \Lambda \Phi I N O \Sigma$ qui pourrait renvoyer à Apollon (cat. I20, voir supra). Parmi les listes des noms de bateaux connus à ce jour il y a aussi Delphis et Delphinia (voir tableau A).

Le dauphin est par ailleurs un type monétaire bien connu, souvent associé à un autre motif (tête de divinité, autre motif marin comme le gouvernail, l'ancre.... ${ }^{486}$.

b) Tête de Méduse et «tête coupée»

Dans une même catégorie sont à regrouper deux motifs différents, apparaissant - non associés à d'autres décors - une fois chacun, mais relevant semble-t-il du même registre.

Le premier est celui dit de la tête de Méduse, qui figure trois fois sur une ancre actuellement exposée dans la première salle du Musée de la Marine (cat. D53) ${ }^{487}$. Les emplois de ce type iconographique, dans l'architecture - antéfixes et acrotères - et sur les objets métalliques - armes, vaisselle, monnaies -, sont connus et rappelés à juste titre $^{488}$; il est en outre rattaché, dans une classification systématique des représentations de la Gorgone, à la Méduse Rondanini, ou encore à son type "beau et calme» ${ }^{489}$ daté de l'époque hellénistique $^{490}$. Le second motif de l'ancre de l'épave Jeaune-Garde B

${ }^{481}$ Carrazé 1974, p. 155.

${ }^{482}$ Gianfrotta \& alii 1997, loc. cit.; Somville 1984, p. 10-13.

${ }^{483}$ Ibidem, p. 8. Rappelons le culte d'une Artémis Delphinia à Athènes.

${ }^{484}$ Ibidem, p. 14-19.

${ }^{485}$ Sur les inscriptions théophores, voir supra: plusieurs occurrences d'Aphrodite, une d'Artémis; un décor de trident, voir infra.

${ }^{486}$ Voir par exemple Anson 1910-1916, V p. 87-146 portant sur les types «navals et marins»; Ringel 1984.

${ }^{487}$ Ancre du cap d'Antibes. Voir principalement Benoît 1951, qui en donne une description détaillée («visage allongé, encadré de longues tresses qui tombent à flots à hauteur du menton, yeux ouverts, traits calmes empreints d'une sérénité parfaite, bouche à demi entrouverte; le front est surmonté de deux ailerons, sans trace apparente des têtes de serpents qui émergent généralement entre les tempes») et un commentaire assez nourri, repris dans toutes les publications postérieures - aussi bien dans les articles suivants du même auteur que dans les études signées par d'autres.

${ }^{488}$ Voir particulièrement Benoît 1959, mais aussi la bibliographie subséquente. Pour les exemples de monnaies massaliotes du VI ${ }^{\mathrm{e}}$ s. a.C. ou gauloises : cf. ibid., p. 147 et fig. 4-5 (avec bibliographie).

${ }^{489}$ Benoît 1951, p. 226-227, renvoyant à Six 1885, p. 72.

${ }^{490}$ Benoît 1959, p. 145. 
(cat. D54), rapproché d'ailleurs du précédent dès sa première publication ${ }^{491}$, est celui dit de la "tête coupée, yeux mi-clos», d'après l'expression utilisée par F. Benoît ${ }^{492}$; mais il se distingue également du précédent par la bouche fermée, "les lèvres serrées » ${ }^{493}$. Le thème est alors relié aux masques celto-ligures trouvés à Entremont ${ }^{494}$.

Une fois de plus, l'ancre présentant ce motif est considérée d'emblée comme "ancre de miséricorde», sans aucune discussion préalable ${ }^{495}$; dans ce contexte, la tête est vue comme "apotropaïque » ${ }^{496}$, un «talisman contre la mort», jouant "le rôle d'ex-voto propitiatoire ${ }^{497}$. On invoque alors l'exemple de la tête de Méduse ornant le flanc de l'Acropole mentionnée par Pausanias ${ }^{498}$. Mais le Périégète ne nous apprend absolument rien sur la valeur qu'on portait à ce motif décoratif, et aucune allusion du texte ne nous permet d'en conclure quoi que ce soit sur cette présence d'une représentation de Méduse, d'autant plus que s'y opposait de l'autre côté une égide. Le motif allait donc par paire et paraît référer au mythe d'Athéna elle-même; ce qui n'aurait rien de surprenant dans la zone de l'Acropole athénienne.

La tête de Méduse est également un type monétaire bien attesté, et ce sur l'ensemble du monde grec ${ }^{499}$. Trois rapprochements pourraient s'avérer particulièrement intéressants : en premier lieu, des monnaies de Selgè (Pisidie) - déjà mentionnées supra p. 334 pour leur présence au droit d'une tête d'Athéna avec astragale - figurent sur le revers un masque de la Gorgone; par ailleurs des monnaies d'Apollonia (Mysie) portent au droit un Gorgoneion et au revers une ancre $^{500}$. Enfin, des pièces d'accastillage des navires de Nemi donnent à voir deux magnifiques têtes de Méduse ${ }^{501}$.

Cependant des critiques peuvent être soulevées à l'examen

${ }^{491}$ Déjà en 1951, lors de la publication du premier jas, p. 225 : «c'est sans doute la valeur qu'avaient certaines têtes coupées sculptées sur les remparts des oppida celto-ligures ou celtibériques»; inversement, en 1960, la publication du deuxième jas aux «têtes coupées» lui attribue «la même valeur apotropaïque que la tête de Méduse» (p. 45).

${ }^{492}$ Benoît 1959, p. 145-146 et 148 et fig. 3; Benoît 1960a, p. 44-45 et fig. 12-13.

${ }^{493}$ Benoît 1959, p. 148.

${ }^{494}$ Ibid. . Les masques d'Entremont ont par ailleurs été principalement étudiés par F. Benoît lui-même (voir bibliographie dans ses articles).

${ }^{495}$ Ceci est valable pour tous les articles de F. Benoît, puis répété par tous.

${ }^{496}$ Benoît 1959, p. 146.

${ }^{497} \mathrm{Ibid}$. p. 149, répété dans Benoît 1960a et 1960b. L'idée est reprise dans Wachsmuth 1967, p. 260 et notes 989-990.

${ }^{498}$ Pausanias I, xxi, 3.

${ }^{499}$ Anson 1910-1916, VI, p. 43-51 et pl. VIII-IX.

${ }^{500}$ Anson 1910-1916, V p. 90 et pl. XIV, no 599-604 (= Wroth 1892, p. 8, n 2 ,

3, 7, 9; p. 9, no 10-11; pl. II); elles sont datées entre 450 et 350 .

${ }^{501}$ Gianfrotta \& Pomey 1980, p. 291; Ucelli 1950, p. 205-207 et fig. 10. 
précis des deux motifs apparaissant sur jas d'ancre. En effet, l'interprétation de F. Benoît a été admise par tous sans discussion. Or, la "tête de Méduse» ne porte pas de serpents, mais de longs cheveux; de surcroît, de part et d'autre du sommet de la tête, partent deux excroissances, vues par F. Benoît comme "deux ailerons» ${ }^{502}$, peutêtre deux oreilles ou deux cornes dirions-nous plutôt. Quant à la "tête coupée», d'une part elle ne ressemble pas au premier motif du jas du cap d'Antibes, mais encore moins à une tête de Méduse. Le crâne, plus large, ne présente pas de cheveux. Dans les deux cas, un trait essentiel empêche de reconnaître un type même dérivé du Gorgoneion : la forme de la tête est très allongée, absolument pas ronde ${ }^{503}$.

De manière générale, l'impression qui se détache du second motif est celle effectivement d'une tête coupée, voire d'un masque humain réduit à l'essentiel. Des comparaisons peuvent être davantage établies avec des phalères décorées trouvées à Augst ou à Manerbio publiées par W. Deonna; celles-ci présentent des masques humains interprétées par le savant également comme apotropaïques $^{504}$. Le premier motif est plus difficile à rattacher à des décors connus, si ce n'est à un masque de théâtre.

\section{c) Lion}

Le lion figure sur deux rares exemplaires, et de façon d'autant plus curieuse qu'il n'apparaît sur aucun des deux en entier. En effet, dans un cas, seule la tête de l'animal est représentée (cat. D76), dans l'autre il l'est à mi-corps sans les pattes avant (cat. I11) ${ }^{505}$. Dans les deux occurences également, le lion n'apparaît pas seul, mais respectivement ou associé à un autre décor, en l'occurrence un groupe de quatre astragales et de quatre coquillages, ou associé à une inscription, Sôteira. Pour ce dernier cas, nous avions proposé de le ratta-

${ }^{502}$ Benoît 1959, qui les explique comme une variante gallo-romaine proche des têtes de Méduse connues sur des sarcophages d'Arles: Espérandieu \& Lantier 1907-1966, I n 166 et 183, III n ${ }^{\circ}$ 2539. Les autres rapprochements qu'il opère avec du matériel trouvé en Gaule (ex. in RA. 1893, p. 4 et pl. I) ne sont pas plus convaincants en termes de similitudes.

${ }^{503}$ Tous les types définis par Six 1885 ont en commun cette particularité, de même que les têtes de Méduse des sarcophages d'Arles.

${ }^{504}$ Deonna 1950, p. 35-57 : voir ressemblance avec la «tête coupée» du jas d'ancre avec les masques humains des fig. 1 et surtout 4 et 5 . Ces phalères de Manerbio (province de Brescia) sont datées vers le III ${ }^{e}$ s. a.C. Dans ce même esprit, nous pouvons agréer la deuxième partie de Benoît 1959, avec autres parallèles.

${ }^{505}$ Premier cas : jas du musée de Sassari en Sardaigne; second cas : jas de Cavalaire (Bon-Porté) : voir supra p. 314. 
cher à Cybèle. Le lion est aussi parfois relié à Apollon ${ }^{506}$. Mais il ne semble pas l'être avec Aphrodite, ce qui aurait pu expliquer l'association lion-astragales-coquillages sur l'ancre D76.

Si l'on regarde les monnaies, la tête de lion constitue un type courant, remontant même aux premiers monnayages lydiens ${ }^{507}$. Le motif est utilisé également comme ornement de bateau : le relief de Cartilius Poplicola d'Ostie (voir supra fig. 15) ${ }^{508}$ le présente sur la caisse de rames; des éperons d'époque hellénistique le portent dans leur partie inférieure ou au-dessus d'eux ${ }^{509}$. On peut évoquer encore

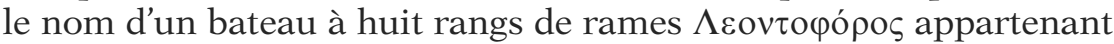
à la flotte de Lysimaque puis récupéré par Ptolémée Kéraunos en 280 a.C. 510.

Il est difficile d'attribuer à la tête de l'animal, motif bien courant à l'époque hellénistique et romaine, une valeur religieuse précise : il doit plutôt être un symbole de la force.

\section{d) Seiche}

La seiche est apparemment présente, en un seul exemplaire, parmi les motifs connus, bien que son identification n'ait pas été immédiate (cat. D81). Dans la première publication ${ }^{511}$, elle fut reconnue comme une tête, sans doute par rapprochement avec la découverte des deux jas (Méduse, tête coupée) dont l'information fut largement diffusée. Ce n'est que vingt ans plus tard que P. A. Gianfrotta en donne une lecture différente ${ }^{512}$, le mettant très brièvement en rapport avec le milieu maritime. Le motif ne se présente pas seul, mais associé à celui des astragales - 4 d'après Gargallo, 3 d'après la photographie reproduite dans l'article. Signalé donc seulement à deux reprises et d'identification encore douteuse, il reste à expli-

${ }^{506}$ Comme symbole de «son pouvoir et sa force originaires d'Orient», pour Olmos \& Moreno-Conde 2012, p. 396 et n 64 (p. 418 : Théra, dédicace hellénistique), no 118 (p. 423 et pl. 51 : sanctuaire d'A. Tyritios, golfe de Nauplie, bronze archaïque avec dédicace), no 138 (p. 426 : Delphes, ivoire archaïque).

${ }_{507}$ Pour le monde grec, voir Anson 1910-1916, VI p. $72-76$ et pl. XIV-XVI.

${ }^{508}$ Sur le décor animal du relief d'Ostie, voir Williams 1989, p. 293; explication de la technique de représentation dans Basch 1987, p. 436, fig. 949-950. Sur ce relief, voir également supra à propos du décor naval.

${ }^{509}$ Basch 1987, p. 390-391 et fig. 814-815

${ }^{510}$ Memnon (II ${ }^{\mathrm{e}}$ s. a.C.), Fgt 1 §8, in FGH IIIB, no 334 p. 334 (cité par Photius,

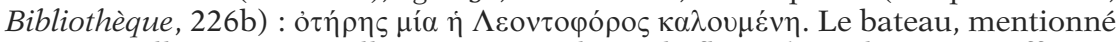
pour sa taille exceptionnelle, appartient alors à la flotte de Ptolémée qui affronte celle d'Antigone. Sur ces événements et l'avénement de Ptolémée Kéraunos, voir Will 1979-1982, I p. 103-104. Le nom est signalé par Sandberg 1954, p. 16.

${ }^{511}$ Ancre de Syracuse; Gargallo 1961, p. 32 et fig. 6.

${ }^{512}$ Gianfrotta 1980, p. 108 et note 24. 
citer; un seul rapprochement a été tenté, avec Aphrodite ${ }^{513}$. Avec toute la prudence qui s'impose - vu les différences de contexte et de datation, sans parler de l'objet lui-même -, nous pouvons néanmoins évoquer l'ancre de Cnossos, en porphyre, portant des poulpes en guise de décoration ${ }^{514}$. Le rapport avec des pratiques cultuelles est possible, au regard des différents témoignages d'offrandes de poissons à diverses divinités comme Aphrodite, Poséidon, Hermès ${ }^{515}$, ou Artémis.

\section{e) Coquillage}

Le coquillage est certes un objet marin par excellence; le rapport avec la navigation n'est pas difficile à déterminer. Cependant, des références supplémentaires peuvent sans doute apporter un éclairage différent sur la présence de ce motif sur des jas. Il occupe par ailleurs une place particulière dans l'iconographie religieuse : la coquille est l'écrin où s'épanouit la belle Aphrodite ${ }^{516}$. De nombreux témoignages de l'Anthologie Palatine le désignent comme humble ex-voto de pêcheurs.

Le motif n'apparaît pas seul sur les jas, mais associé avec un autre, principalement des astragales (cat. D60?, D75, D76, D78, D80, D83 ? $)^{517}$. Ainsi n'est peut-être pas non plus négligeable la fréquente présence commune, remarquée par P. Amandry ${ }^{518}$, de ces deux objets aussi bien dans les sanctuaires que dans les tombes ${ }^{519}$. Ce l'ancre.

${ }^{513}$ Gianfrotta \& alii, p. 113 qui ne donnent par ailleurs aucune indication sur

${ }^{514}$ Cf. Davaras 1980, p. 61-67, avec description, discussion des différentes hypothèses et bibliographie.

${ }_{515}$ Sur les offrandes de poissons et faune marine, Bodson 1978, p. 48-53 et infra p. $505 \mathrm{~s}$. La seiche proprement dite n'y figure pas. En ce qui concerne un éventuel rapprochement numismatique, l'ouvrage de Anson 1910-1916 mentionne la seiche dans son index, mais elle ne se trouve pas au sein de son catalogue.

${ }^{516}$ Voir supra. Lien déjà évoqué brièvement par Boon 1977a, p. 20. Ce rapprochement, qui est opéré également par Gianfrotta 1980, p. 108, mais écarté immédiatement et sans plus ample développement comme "peu probable», est plus tard réaffirmé par le même auteur (Gianfrotta \& alii 1997, p. 113).

${ }^{517}$ Outre les astragales : clé, dauphin (?), tête de lion, œuf (?). Deux cas douteux : D14 et D79.

${ }_{518}$ Amandry 1984, p. 378-380; il n'exclut d'ailleurs pas la présence de ces objets dans l'Antre Corycien comme des offrandes de «pèlerins venus des rives du golfe de Corinthe».

${ }_{519}$ Pour l'interprétation de la présence de coquillages dans les tombes, voir notamment Bruneau 1970b, p. 529-530, avec quelques références : «symbole de vie future», «motif décoratif fréquent», «jouets». 
rapprochement des deux objets sur les ancres, ainsi que leur nombre, a par ailleurs permis à G. Kapitän d'avancer l'hypothèse de l'existence d'un jeu, identique à celui des astragales, mais réalisé avec des coquillages lancés en l'air et offrant deux possibilités de chute; auquel cas la combinaison gagnante serait celle présentant toutes les faces extérieures vers le haut ${ }^{520}$. Si réellement nous étions en présence d'un tel jeu, nous aurions unité du nombre de coquillages représentés sur chaque ancre; or ils diffèrent : soit 1, 3(?) ou en groupes de 4.

Ceux figurés sur ancres apparaissent sous différentes formes ${ }^{521}$ : il n'existe pas un modèle unique, mais la tournure s'apparente plutôt aux coquilles de clovisses ou pétoncles. Le coquillage appartient également aux types monétaires grecs, avec davantage de variété dans les espèces ${ }^{522}$; les exemples les plus approchants proviennent majoritairement de Grande Grèce.

\section{f) Colonne}

La colonne est également un motif peu fréquent sur jas d'ancre (cat. D62-63) ${ }^{523}$. Si l'ornement est l'objet d'une description précise, il n'a jusqu'ici suscité que peu de commentaires explicatifs ${ }^{524}$, en dernier lieu celui-ci, réaliste, supposant une allusion directe au type de cargaison transportée par le bateau, laquelle serait lapidaire ${ }^{525}$. Son symbolisme de puissance évoqué par ailleurs laisse également perplexe $^{526}$. Peut-être est-il à mettre en rapport avec la poétique interprétation de F. Benoît imaginée à l'époque de la découverte, selon laquelle le motif est un «élément constructif divinisé, destiné à préserver le vaisseau de la catastrophe, issu sans doute, comme tant de signes magiques, du lointain Orient, du djed osirien et du pilier minoen» ${ }^{527}$.

Le motif est répertorié comme type monétaire, mais agrémenté d'ornementations diverses (fleurs, autel, statue...) ${ }^{528}$. Il est à noter la

${ }^{520}$ Kapitän 1989, p. 152-153, qui admet cependant qu'«à sa connaissance, ce jeu n'est pas mentionné». Le chercheur recense pour sa part (tableaux III et IV) six cas certains et deux non assurés.

${ }^{521}$ Ibidem : types et nombres différents.

${ }^{522}$ Anson 1910-1916, V p. 128 à 134 et pl. XXI-XXII. Pour les espèces les plus proches des motifs sur jas, p. 128 à 131.

${ }_{523}$ Deux jas identiques à décor unique de Blanes.

${ }^{524}$ Cf. la description donnée par Pascual Guasch 1959, p. 178 sous les numéros 4 et 5 .

${ }^{525}$ Hypothèse proposée avec grande prudence par Gianfrotta 1980, p. 109.

${ }^{526}$ Kapitän 1989, tableau IV.

${ }^{527}$ Benoît 1960b.

${ }^{528}$ Anson $1910-1916$, V p. 5-6 et pl. I. 
figuration commune, sur une monnaie de bronze de Perga (Pamphylie) de l'époque trajane, d'une colonne et une proue de navire $^{529}$.

\section{g) Clé}

La clé, symbole davantage exploité semble-t-il à une époque plus tardive, est de ce fait interprétée comme un motif de bon augure ${ }^{530}$. Elle apparaît sur deux jas, seule ou en association (cat. D60-D61) ${ }^{531}$.

\section{h) Lampe}

À un registre apparenté pourrait appartenir le motif de la lampe attesté à deux ou trois reprises sur jas d'ancres, une fois seul et pour le reste en combinaison avec décor ou inscription (cat. D64, D79 et D98?) ${ }^{532}$. Au premier degré elle pourrait «éclairer le chemin du bateau " ${ }^{533}$, ou mieux dirons-nous celui de l'ancre à travers le gouffre sombre des eaux. Dans une même lecture symbolique, elle pourrait renvoyer également à des cérémonies religieuses dans lesquelles elle est utilisée ou à une divinité comme Isis. Le rapprochement avec la clé dans une optique chrétienne s'avère peu probable au vu de la datation de l'ancre d'après l'examen typologique de la lampe ${ }^{534}$.

\section{i) «Marteau»}

En combinaison avec un couple de dauphins figure un marteau, au manche très long, qu'on a rapproché pour cette raison de l'instrument utilisé par les mineurs; ceci sans doute à cause du contexte réputé minéralier de l'Espagne où a été découverte l'ancre (cat. D82) ${ }^{535}$. Un commentaire très succinct l'a classé parmi les symboles de "pouvoir» ${ }^{536}$. Plus simplement, on pourrait également se demander s'il ne s'agirait pas d'un outil en relation avec la

${ }^{529}$ Anson 1910-1916, n 35; Hill 1897, p. 123, n 25.

${ }^{530}$ Gianfrotta 1980, p. 108 et fig. 9 et Gianfrotta \& alii 1997, p. 113 signalant en outre l'identification de l'ancre avec la clé dans le symbolisme chrétien; à ce sujet, voir les exemples donnés par Guarducci 1967-78, p. 61-62, 464-465 et fig. 242.

${ }_{531}$ Ancres de Palerme et de Filicudi.

532 Jas d'Isola delle Femine et de Filicudi.

${ }^{533}$ Gianfrotta 1980, p. 108 et fig. 10; Gianfrotta \& alii 1997, loc. cit.

${ }^{534}$ Ce type de lampe serait datable au plus tard de la fin du I ${ }^{\text {er }}$ s. p.C. : voir catalogue.

${ }_{535}$ Ancre de Blanes; Pascual Guasch 1959, p. 176-180.

${ }^{536}$ Kapitän 1985, tableau IV. 
construction navale. Le motif trouverait un parallèle parmi les types monétaires ${ }^{537}$.

\section{j) Trident}

Ce motif est présent à deux reprises dans notre catalogue, jamais seul : dans les deux cas, il accompagne une inscription latine (cat. D95 et D97) ${ }^{538}$.

Le trident apparaît dans les quelques publications des jas comme un objet couramment lié au monde maritime. De ce fait, une simple ligne suffit pour classer ce motif ${ }^{539}$. Celui-ci est également bien attesté comme type monétaire ${ }^{540}$. Mais il peut également faire référence au grand dieu de la mer qu'est Poséidon-Neptune.

\section{k) Caducée}

Ce motif apparaît sur quatre ancres de manière assurée, et peutêtre sur une cinquième (cat. D55, D56, D68, D94; D97? ${ }^{541}$; dans les deux premiers cas, il est représenté seul tandis que dans le troisième il accompagne une des quatre astragales du jas; les deux derniers l'associent avec un nom latin et peut-être un trident.

La présence du caducée parmi les motifs sur jas est naturellement rattachée au dieu Hermès/Mercure, alors invoqué comme dieu du commerce ${ }^{542}$ : le symbole mettrait en avant l'espoir de profits réalisés grâce aux transactions maritimes ${ }^{543}$. Une hypothèse originale le met également en relation avec le monde maritime punique $^{544}$. Le caducée existe aussi en tant que type monétaire ${ }^{545}$;

${ }^{537}$ Anson 1910-1916, I p. 138, n ${ }^{\circ} 1360-1364$ inventorie dans son ouvrage un marteau sans en donner d'illustrations : il est donc impossible de voir s'il s'agit du même type d'objet.

${ }^{538}$ Ancre de Sassari, inscription NICIAVILLILS. Ancre d'Isola delle Femine, inscription L. FVLVI. EVTI avec peut-être un caducée. Aucune datation n'est proposée.

${ }_{539}$ Par exemple Tusa 1973, p. 428 note 6, qui renvoie à Benoît 1952, p. 253 et fig. 20; or, cette référence ne concerne que la publication d'un timbre amphorique sur lequel figure un trident, et ce motif n'est nullement discuté par F. Benoît.

${ }^{540}$ Anson 1910-1916; V p. 134-146 et pl. XXII-XXIII.

${ }^{541}$ Ancre de Scirocco; ancre d'Isola delle Femine; ancre de Tarragona, avec astragales, dauphin et divinité (?); ancre de Civitavecchia; ancre d'Isola delle Femine.

${ }^{542}$ Berges Soriano 1969-1970, p. 5; Tusa 1973, p. 433, qui la relie alors directement avec un navire onéraire.

${ }^{543}$ Gianfrotta 1980, p. 108. Le motif figure également pour l'époque romaine sur un lingot de plomb (Weitemeyer \& Döhler 2009).

${ }^{544}$ Tusa 1973, p. 433.

${ }^{545}$ Anson 1910-1916, IV p. 17-27 et pl. III-V. 
une série le fait figurer entre deux astragales ${ }^{546}$, ce qui le rapproche du jas cité plus haut. L'éperon d'Athlit constitue un parallèle dans la décoration navale: on y trouve la même association caducée et trident que sur l'un des quatre jas.

\section{1) Cercle}

Deux jas portent un simple cercle (cat. D57-D58), motif auquel on peut rattacher un cercle constitué de trois petites feuilles (D59) et une couronne (D74). La présence d'un tel objet religieux sur ancre ne serait pas surprenant, les bateaux étant parfois couronnés avant leur départ ${ }^{547}$. L'ancre serait ainsi placée sous la protection divine en mer.

m) Alia

Un motif curieux a été identifié sur un jas conservé à Tarragone comme la représentation de «quelque divinité marine ou protectrice» (cat. D68) ${ }^{548}$. Il s'agit apparemment d'un personnage debout, les bras le long du corps, vu de face, "ventru» (?); sur le dessin publié, il pourrait tenir un objet le long de son bras droit. Cette image est reproduite à deux reprises, associée dans les deux cas à une astragale, tandis que les deux faces restantes du jas présentent également une astragale, accompagnée d'un dauphin ou d'un caducée. La figure a été par ailleurs interprétée comme «a person in attitude of an orante ${ }^{549}$.

Un autre motif encore mal identifié apparaît sur l'ancre du musée de Rosignano (cat. D84). Celle-ci a de plus ceci de particulier qu'elle présente un grand nombre de marques diverses : sept astragales moulées et divers signes incisés ou plus précisément martelés consistant en des noms latins, un chiffre ainsi que le motif en question. Celui-ci, frappé à deux reprises avec l'une plus développée que l'autre ${ }^{550}$, rappellerait un astrolabe; ou alors, a-t-on suggéré en référence au décor bien connu des astragales, une table de jeu. Celle-ci ferait alors référence au hasard, à la chance invoquée dans les

${ }^{546}$ Ibid., $\mathrm{n}^{\circ}$ 200. La monnaie de bronze est datée «d'avant Philippe II».

${ }^{547}$ Wachsmuth 1967, p. 168ss. et surtout 312 ss.; le bateau des théories déliennes était ainsi couronné : voir infra p. 431 et 436.

${ }^{548}$ Berges Soriano 1969-70, p. 5 et 16, fig. 5.

${ }^{549}$ Boon 1977a, p. 28 note 62.

${ }^{550}$ Les figures VI, 3 et 4 montrent cependant, à notre avis, deux marques sensiblement différentes; seulement la 4 pourrait éventuellement faire penser à un astrolabe. 
voyages du bateau; hypothèse très vite nuancée par la simple constatation qu'il n'existe aucune attestation connue de ce type circulaire de table de jeu ${ }^{552}$. Et les commentaires n'ont pas fleuri depuis lors. On pourrait néanmoins souligner le fait que les marques incisées, à l'inverse des astragales moulées, semblent toutes être en rapport avec des données purement commerciales: les noms de deux personnages, peut-être d'un armateur, négociant constructeur...; le chiffre mal lisible. Dans ce cas, le pseudo-astrolabe n'est peut-être qu'une contremarque, sans aucune valeur symbolique ou religieuse, à l'inverse des reliefs apparaissant sur l'ancre et donc contemporains de sa réalisation - pour lesquels ils ont sans doute fait l'objet d'une demande particulière.

D'autres motifs ont été répertoriés par G. Kapitän, tels des yeux, un petit poisson, un requin, un espadon, une limace de mer (?), une méduse, un murex ${ }^{552}$. En l'absence de confirmation, puisqu'aucune réelle publication (ou même photographie) des objets n'est semblet-il parue, il est difficile de discuter l'existence de ces décors ainsi que leurs nombres, combinaisons, etc. Il n'est sans doute pas exclu que l'un de ces motifs corresponde en fait à un autre inventorié sous une autre forme dans ce présent corpus ${ }^{553}$. Le requin cité parmi les signes apotropaïques ${ }^{554}$ pourrait correspondre à un dauphin grossièrement estampé ou érodé.

\section{Analyse}

Que retenir donc de tous ces motifs, et quelle valeur peut-on leur accorder?

Tout d'abord, il faut noter leur diversité : une quinzaine au moins, avec une majorité écrasante d'un seul : l'astragale. Les combinaisons iconographiques, quoiqu'encore assez nombreuses, ne sont pas très variées : le plus souvent, il s'agit de nouveau des astragales. Ces associations, ainsi que la répartition des décors sur les différentes faces des jas, ne trouvent pour le moment aucune explication ou cohérence.

${ }^{552}$ Kapitän 1989, tableau IV; par «limace de mer», j'essaie de traduire le terme sea-slug. Sur le caractère religieux de certains animaux marins et leur offrande, voir Bodson 1978. En ce qui concerne le motif de l'œil, pour rapprochement avec types monétaires : Anson 1910-1916, VI p. 61-63 et pl. XII (yeux, yeux et dauphins); l'œil constitue en outre un ornement naval important sur les coques à l'avant des bateaux.

${ }^{553}$ Ainsi, le motif identifié supra comme seiche (ou poulpe) ne figure pas dans le tableau de Kapitän.

${ }^{554}$ Hesnard \& Gianfrotta 1989, à la dernière ligne du texte; Kapitän 1989, tab. IV, inventorie un seul exemplaire de ce motif. 
L'identification de certains motifs est loin d'être assurée, comme c'est le cas pour les dits «tête de Méduse», «requin», «divinité»... de même que pour leur interprétation. Nous pouvons cependant constater que tous les modèles représentés sur jas d'ancres correspondent à des types monétaires connus par ailleurs, sur l'ensemble du monde grec, avec bien sûr des différences de dimensions ou proportions. Avec la création souhaitable d'un véritable catalogue exhaustif des jas d'ancres figurés, il conviendrait de s'attacher à des rapprochements plus précis avec le matériel numismatique. Est-ce à dire que les motifs qui ornent les jas indiqueraient une certaine origine ou du bateau, ou de l'ancre? Pour le moment, les quelques parallèles évoqués proviennent principalement de la côte orientale de la Méditerranée. Par ailleurs, le choix des thèmes iconographiques sur jas n'est pas exempt de symbolisme et de religiosité - ce qui est le cas très souvent également pour les types monétaires. Nous avons pu évoquer pour beaucoup d'entre eux un rapport possible voire certain avec une ou plusieurs divinités : pour le moins Aphrodite, Hermès, Poséidon, sans oublier Héra et Cybèle. Même si tous les motifs ne trouvent pas de signification religieuse, un certain nombre d'entre eux témoigne de l'existence de ce genre de préoccupation.

\section{CONCLUSION : LES DIVINITÉS ET LE BATEAU}

La multiplicité des documents faisant état de la présence du sacré à bord montre que souvent il n'y a pas une seule divinité rattachée au bateau mais plusieurs - du moins pour l'époque hellénistique et impériale. Les représentations iconographiques en donnent un clair témoignage : le bateau de Nymphaion porte inscrit le nom d'Isis et un parasèmon avec un Dioscure (voir supra p. 256, 260); l'embarcation est de surcroît consacrée à Apollon et Aphrodite. Le navire de Pompéi figure Aphrodite présente à son bord, mais son décor renvoie à Athéna. Deux divinités peuvent être évoquées sur une même ancre, ainsi que sur les parasèmes d'un même navire. À cela s'ajoutent les allusions religieuses de certains motifs sur jas de plomb. L'impression qui se dégage de tous ces realia est une accumulation dynamique des références à divers dieux à bord, afin d'attirer le plus possible sur l'embarcation et ses occupants la protection divine. Par l'utilisation de divers procédés, un bon nombre d'éléments du bateau sont ainsi marqués par cette religiosité à bord. 
Cependant il est possible de distinguer deux correspondances. On a évoqué l'éventualité d'une similitude entre parasèmon ou stylis et ancre. Par ailleurs, on pourrait avancer l'hypothèse qu'il existe une même analogie entre le nom du bateau et le stolos : le dessin de Nymphaeion qui montre le nom du navire sur la coque voit son stolos représenter la tête de la déesse. Le témoignage d'Ovide évoque un parallèle similaire entre le nom de l'embarcation sur laquelle il voyage et l'extrémité de son stolos.

Dès lors il conviendrait dans certains cas de parler de notion de divinités tutélaires du bateau au pluriel. Cette profusion d'invocations, d'après l'état de nos sources, semble relever de l'époque hellénistique. Il est difficile de se faire une idée des pratiques archaïques et classiques.

Parmi les dieux présents de cette manière à bord, notons l'importance minime accordée à Poséidon, contrairement à ce qu'on aurait pu attendre. Il n'incorpore les noms de navires que tardivement et ce dans la marine romaine; il est absent des inscriptions sur ancres et des espaces du bord. Tout au plus peut-on lui rattacher un motif sur jas et sur un éperon : le trident. En revanche, dans les inscriptions et décors (navals et sur ancres) sont attestés Zeus, Aphrodite et Athéna, et dans une moindre mesure d'autres divinités comme Déméter, Héra, Apollon. Mais si le nom de Zeus y apparaît sous forme écrite, aucun décor ne paraît lui être associé. 



\section{LES EX-VOTO À TERRE}

Pour les navigateurs les liens avec le sacré ne sont pas coupés à partir du moment où ils posent pied à terre. Une fois parvenus à bon port, il convient de remercier la ou les divinités d'être arrivé sain et sauf. Cette gratitude peut s'exprimer suite à un vœu prononcé dans un moment critique (tempête, risque de naufrage...) : c'est ce que D. Wachsmuth désigne sous l'expression de vota pro reditu ${ }^{1}$. Mais une traversée sans problème est tout aussi digne de marques de dévotion envers la divinité.

Les offrandes après voyages par mer prennent différentes formes. Néanmoins, un témoignage symbolique de ce pour quoi on remercie les dieux constitue la meilleure offrande qui soit. C'est pourquoi les ex-voto de bateaux ou parties de bateaux représentent la majorité des ex-voto après un tel trajet.

Examiner l'importance de ceux-ci en ce qui concerne les divinités olympiennes, à travers les périodes et le monde grec, peut permettre ainsi de saisir certaines spécificités des cultes maritimes et leurs éventuelles évolutions. Ces offrandes relatives aux bateaux peuvent également mettre en relief le caractère sacré du bâtiment ou du moins de certaines de ses parties en mer : y a-t-il continuité dans la valeur sacrée accordée à certains espaces ou éléments de l'embarcation lors des pratiques religieuses opérées à terre?

Les ex-voto marins n'ont jamais fait l'objet d'un examen systématique et détaillé. Ils ont été englobés dans des études générales², dans lesquelles ils étaient rapidement énumérés. Grâce à de nombreuses découvertes récentes, ou du moins au développement des études d'archéologie navale, l'identification possible de certains objets permet aujourd'hui de constituer un dossier conséquent. Dans le cadre de notre sujet, il se limitera bien sûr aux divinités abordées dans la première partie. Il s'agira alors de considérer l'importance de ce type d'ex-voto en ce qui concerne les divinités olympiennes et également leur répartition interne.

\footnotetext{
${ }^{1}$ Wachsmuth 1967, p. 131-142.

${ }^{2}$ Stengel 1910 consacre seulement un paragraphe sur les sacrifices de poissons (p. 197-202); Rouse 1902, p. 229-230 (voir à ce sujet Mc Cartney 1933, p. 17).
} 
La présentation de l'ensemble de ce matériel, à travers des sources littéraires, épigraphiques, iconographiques et archéologiques, s'organise de manière naturelle, du général au particulier. Ainsi seront abordées tout d'abord les offrandes de bateaux, puis celles des parties de bateaux et enfin celles des ancres. Ces dernières font l'objet d'un développement particulier, à mettre en parallèle avec celui concernant les ancres à bord.

Les pages qui suivent sont loin d'être dénuées de supputations, d'hypothèses et d'incertitudes : ceci est dû au flou entourant un certain nombre d'objets. Beaucoup d'interrogations restent posées, que nous ne prétendons pas résoudre. Le rapprochement et la comparaison de tout ce matériel sont cependant révélateurs de l'existence de pratiques religieuses spécifiques au monde maritime, mais également parfois étroitement liées au monde des terriens par l'intermédiaire notamment de sanctuaires panhelléniques tels Delphes ou Délos. Les ex-voto de bateaux et d'ancres sont alors aussi à mettre en relation avec une religion personnelle, mais aussi des cultes civiques ou le pouvoir.

\section{DONS DE BATEAUX}

Dans le sujet qui nous occupe, comme cela a déjà été noté ${ }^{3}$, on se doit d'abord de distinguer, parmi les différentes sortes de dons de bateaux, d'ancres ou de façon générale de tout objet marin, les véritables ex-voto qui consistent en un don matériel à une entité religieuse en remerciement ou en demande d'une faveur, d'avec les autres dépôts qui visent à d'autres fins le plus souvent funéraires ${ }^{4}$. $S^{\prime}$ il est parfois difficile de trancher certains cas douteux ${ }^{5}$, ne seront

${ }^{3}$ Basch 1981, p. 37.

${ }^{4}$ Basch 1981, évoquant à ce propos les modèles de bateaux retrouvés dans les tombes dans le monde égyptien mais aussi dans le monde grec à l'époque archaïque, envisage deux interprétations : ou une croyance funéraire, ou un rappel d'un aspect de la vie du défunt. Néanmoins, à l'intérieur de ce catalogue d'exposition, dans la présentation et le choix des objets, la distinction entre les deux catégories n'est pas toujours respectée : ainsi sous le $\mathrm{n}^{\circ} 38$, p. 46-47, il est écrit à propos d'un objet romain du $\mathrm{III}^{\mathrm{e}}$ s. a.C. : «La barque ayant été découverte dans une tombe, on peut penser qu'il s'agissait d'une maquette à usage votif, et que peut-être, elle était au cours de cérémonies religieuses, fixée sur un pieu pour être déplacée d'un lieu sacré à un autre». Sur les nombreuses embarcations trouvées dans la nécropole d'Amathonte : Hermary 2000b, p. 48-53.

${ }^{5}$ Ainsi les objets sans origine archéologique précise, trouvés dans la zone de ... ou près de... Dans le doute, ils sont intégrés à cette étude mais avec la réserve nécessaire. 
présentés ici que les cas d'ex-voto manifestes, retrouvés dans un sanctuaire ou portant une dédicace explicite ${ }^{6}$.

La fonction et l'usage religieux du bateau ont rarement été étudiés en tant que tels. L'ouvrage le plus proche de cette thématique - hormis celui de Wachsmuth -, dû à un chercheur allemand que nous avions déjà cité en introduction : A. Göttlicher, s'intitule Kultschiffe und Schiffskulte im Altertum. Ce livre, paru dans les années $1990^{7}$, a bénéficié des conseils de D. Wachsmuth lui-même si l'on en croit la préface ${ }^{8}$. Mais malgré son titre prometteur, peu de pages sont en liaison directe avec notre sujet. En effet, il étudie le rite sous l'angle de l'histoire des religions, ce qui amène un chapitre par civilisation : Égypte, Mésopotamie, Antiquité grécoromaine", "époque des champs d'urnes», Scandinavie préhistorique et un chapitre final sur des survivances et parallèles observables aujourd'hui. L'auteur insiste dans l'introduction sur deux aspects qu'il est intéressant de signaler. Le premier, que nous avons déjà relevé, est le manque de bibliographie sur le sujet malgré l'existence d'une assez riche documentation, éparse, que l'on peut réunir avec beaucoup d'efforts et surtout pourrait-on dire «en brassant large» , c'est-à-dire en consultant aussi bien les articles des encyclopédies à des mots-clefs divers que des catalogues d'exposition portant sur les représentations de bateaux à différentes époques ${ }^{10}$. Ces sources primaires et secondaires restent néanmoins parfois insuffisantes, ce qui amène A. Göttlicher, avec une grande prudence, à compléter sa recherche avec des rituels du même type

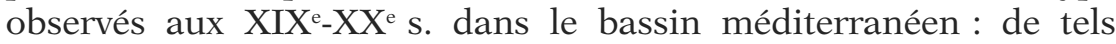
rapprochements ne sont pas considérés comme impliquant un lien direct de rites originaux à cérémonie héritière, mais envisagés comme un effort de compréhension d'un état d'esprit ${ }^{11}$. Le deuxième point à souligner dans ce mémoire est la tentative de délimitation et de définition précise de son sujet et des expressions

${ }^{6}$ Le problème qui se pose ici encore, et qui n'est pas près d'être résolu, est de savoir si tout objet trouvé dans un espace religieux prend de ce fait une valeur religieuse. En ce qui nous concerne, les objets étudiés sont, de par leur nature, assez particuliers pour que leur présence manifeste dans un lieu de ce type soit volontaire

${ }^{7}$ Göttlicher 1992.

${ }^{8}$ Ibid., p. 7.

${ }^{9}$ Ibid., p. 97-131; l'Antiquité grecque ne concerne au sein de ce chapitre que les pages 97 à 110 et 128-131, et parmi celles-ci, les pages 97 à 103 portent sur le monde égéen.

${ }^{10}$ Göttlicher 1992, p. 8-10.

${ }^{11}$ Cf. ibid., introduction p. 10-12 et dernier chapitre p. 166-172. 
annoncées en titre. La même distinction que celle de L. Basch ${ }^{12}$ est opérée entre les bateaux à usage ou contexte funéraire et ceux proprement religieux, mais cette fois ne sont pris en compte que les bateaux faisant office de char, c'est-à-dire transportant de manière rituelle une statue ou un objet de culte. Une catégorie de bateaux «semi-sacrés» - l'expression étonne - prend néanmoins en compte, quoique très succintement, les embarcations vénérées pour leur ancienneté et leur présumée appartenance à un temps héroïque ${ }^{13}$. Néanmoins, cette étude nous laisse sur notre faim : les faits sont présentés de manière rapide ou évasive et manquent de développements archéologiques, analytiques ou religieux concernant le contexte même des différents témoignages. L'absence de toute référence au monde maritime et à ses rites religieux ${ }^{14}$ dans l'ensemble de l'ouvrage est excessif : concentré sur sa théorie, qui voit dans l'usage du char-bateau un rite très ancien, symbole de fertilité, l'auteur exclut d'emblée tout rapport de ces pratiques avec la mer; quant aux bateaux "semi-sacrés", réduits à un rôle de souvenirs d'une glorieuse époque, ils ne paraissent guère être rattachés à l'histoire d'un sanctuaire quel qu'il soit ni aux offrandes qui y ont été déposées.

Aussi notre approche sera différente: ne voulant négliger aucune trace, aucune piste, nous étudierons, à travers la pratique de l'ex-voto et dans leur contexte, tous les bateaux ayant une valeur religieuse dans le monde grec, en examinant aux sanctuaires de quelles divinités ils se rattachent, à quels rites, selon quelles croyances ${ }^{15}$.

Les dons de bateaux s'opèrent sous différentes formes ${ }^{16}$. On peut offrir le bateau réel, entier, grandeur nature : ceci est un cas, évidemment, plutôt rare. On peut ensuite en consacrer un modèle réduit, une maquette, et ce dans des matériaux divers. Une autre option privilégie la representation de l'embarcation par une image : dessiner, sculpter ou encore graver le profil du bateau. Enfin, la dernière possibilité consiste en l'offrande d'une partie: proue,

${ }^{12}$ Voir supra p. 350.

${ }^{13}$ Ceci ne concerne, pour la totalité de l'Antiquité gréco-romaine, que les pages 129-130.

${ }^{14}$ Principe posé d'emblée dans l'introduction p. 9.

${ }^{15}$ L'inventaire de Romero Recio, paru depuis en 2000 (p. 2-28), suit d'une certaine manière l'approche de Göttlicher : il commence à l'âge du Bronze, inclut les rites funéraires et ne développe pas les contextes archéologiques.

${ }^{16}$ Wachsmuth 1967, p. 133-137; Forsén 2004, p. 298-301 (exemples liés à la guerre). 
rostres, éperon... Nous avons choisi de respecter ces formes de dons et d'en constituer le critère de classement du matériel. À l'intérieur de chaque catégorie, une division temporelle en grandes périodes (archaïque, classique, hellénistique) a été suivie autant que faire se peut. Ce cadre chronologique a parfois été dépassé, afin de ne négliger aucun témoignage concernant le monde grec ancien.

En complément de ce chapitre, figurent en annexes: (p. 557561) une liste des mentions épigraphiques d'ex-voto navals dans les inventaires déliens, afin de simplifier les références et les consultations de ces sources; (p. 610-614) des tableaux récapitulatifo par catégorie.

\section{BATEAUX RÉELS}

La consécration de bateaux réels ${ }^{17}$ est une pratique confirmée par des sources diverses ${ }^{18}$ et qui semble être dans l'esprit des Grecs aussi ancienne que la navigation elle-même.

\section{Époque archaïque}

a) Tradition littéraire : Corinthe et la nef Argô

Si nous retenons les propos de Diodore de Sicile (Bibliothèque historique IV, 53, 2) ${ }^{19}$ et du Pseudo-Apollodore (Bibliothèque I, ix, 27), c'est Jason qui inaugura en quelque sorte cette pratique d'offrir un bateau à un dieu en consacrant Argô à Poséidon, dans l'Isthme. Des témoignages du $\mathrm{I}^{\mathrm{er}} \mathrm{s}$. de n.è. témoignent en tous cas de la présence d'un navire reconnu comme tel à Corinthe (Dion Chrysostome, Oratio XXXVII, 15; Martial, Épigramme VII, 19). Les propos du second laissent à penser qu'il ne reste alors que peu de choses de l'embarcation : les termes de fragmentum, parva tabella font deviner quelques débris de bois pourrissants ${ }^{20}$. En revanche, le premier ne

${ }^{17}$ Wachsmuth 1967, p. 133, note 225. Voir infra tableau p. 611.

${ }_{18}^{18}$ Wachsmuth 1967, p. 133 note 255.

${ }^{19}$ Le passage de Diodore est peut-être tiré d'un écrit plus ancien : c'est ainsi que F. Jacoby ( Fgt 14, 53, 2 in $F G H$ I, no 32, p. 255) l'attribue à Dionysos Skytobrachion, écrivain hellénistique du $\mathrm{II}^{\mathrm{e}}$ ou $\mathrm{I}^{\mathrm{er}}$ s. a.C. (?).

${ }^{20}$ Couchoud \& Svoronos 1921, p. 276-277. Gianfrotta 1991, par rapprochement avec une occurrence de l'expression prima carina dans une autre épigramme de Martial (XI, I, v. 12) suppose que ce fragment n'est pas conservé mais en Grèce mais à Rome : dans le portique des Argonautes. Ce morceau proviendrait du bateau exposé à Corinthe sur initiative du créateur du portique, Agrippa, afin de venir enrichir le programme idéologique des constructions édilitaires effectuées dans l'Urbs pour commémorer les victoires d'Auguste sur Octave 
dit rien de l'état de la nef, mais ajoute des détails s'y rapportant. La consécration aurait été consécutive au prix remporté par Argô lors d'une régate faisant partie des jeux Isthmiques ${ }^{21}$ et aurait été explicitée par une épigramme - qu'il cite - attribuée à Orphée. On peut donc penser qu'il existait bel et bien un bateau dans le sanctuaire de Poséidon dans l'Isthme, que l'on faisait remonter à une haute époque; si vieux même dans l'esprit des Anciens qu'il ne pouvait qu'être le premier bateau digne de ce nom ${ }^{22}$ comme l'explicitait la dédicace. Déterminer si celui-ci a été consacré à l'époque archaïque et dans quelles circonstances réelles est impossible en l'absence de mentions plus anciennes.

Ces témoignages littéraires sont suivis d'une unique autre attestation pour l'époque archaïque - historique et non plus mythologique - que nous a seule livrée l'archéologie.

\section{b) Témoignage archéologique : Samos}

À Samos, une longue structure, constituée de neuf murs de soutènement, fut interprétée lors de sa découverte comme une base ayant supporté un bateau long de 25 à $30 \mathrm{~m}$ consacré dans l'Héraion ${ }^{23}$. Située à une vingtaine de mètres de l'autel (carrés MN12), le long de la voie processionnelle venant de la mer, elle est datée du milieu du VII ${ }^{\text {e }}$ s. a.C.; un siècle plus tard, elle fut recouverte par une autre construction ${ }^{24}$. S'il y a eu consécration de bateau à l'air libre à cette date, il est légitime que cent ans plus tard il en reste peu de choses et qu'on réutilise l'emplacement.

et Cléopatre. Pour aussi séduisante qu'elle soit, cette reconstitution repose uniquement sur ce qui ne pourrait être que deux mots dans une périphrase poétique de Martial désignant la figure de Jason.

${ }_{21}^{21}$ Gardner 1881, p. 91.

${ }^{22}$ Sur la primauté d'Argô dans le domaine nautique, voir supra $1^{\text {ère }}$ partie, dans le chapitre consacré à Athéna (p. 24 s. et 59 s).

${ }^{23}$ Werner 1993, p. 9; Kyrieleis 1981, p. 88-90, fig. 65; Höckmann 1985, p. 158; Kopcke 1967, p. 145; Johnston 1985, p. 51; Gauer 1968, p. 72-73.

${ }^{24}$ Walter 1976, p. 58 et fig. 45, 51 date la structure vers 630, tandis que les mentions les plus récentes la placent vers 600. Furtwängler 1997, p. 142-143, lie ces mutations à l'aménagement de la voie sacrée, terminé à la fin de l'époque archaïque, selon l'axe E-O et à l'évolution de la nature des offrandes (de l'individuel et de l'insulaire à «la glorification politique»). 


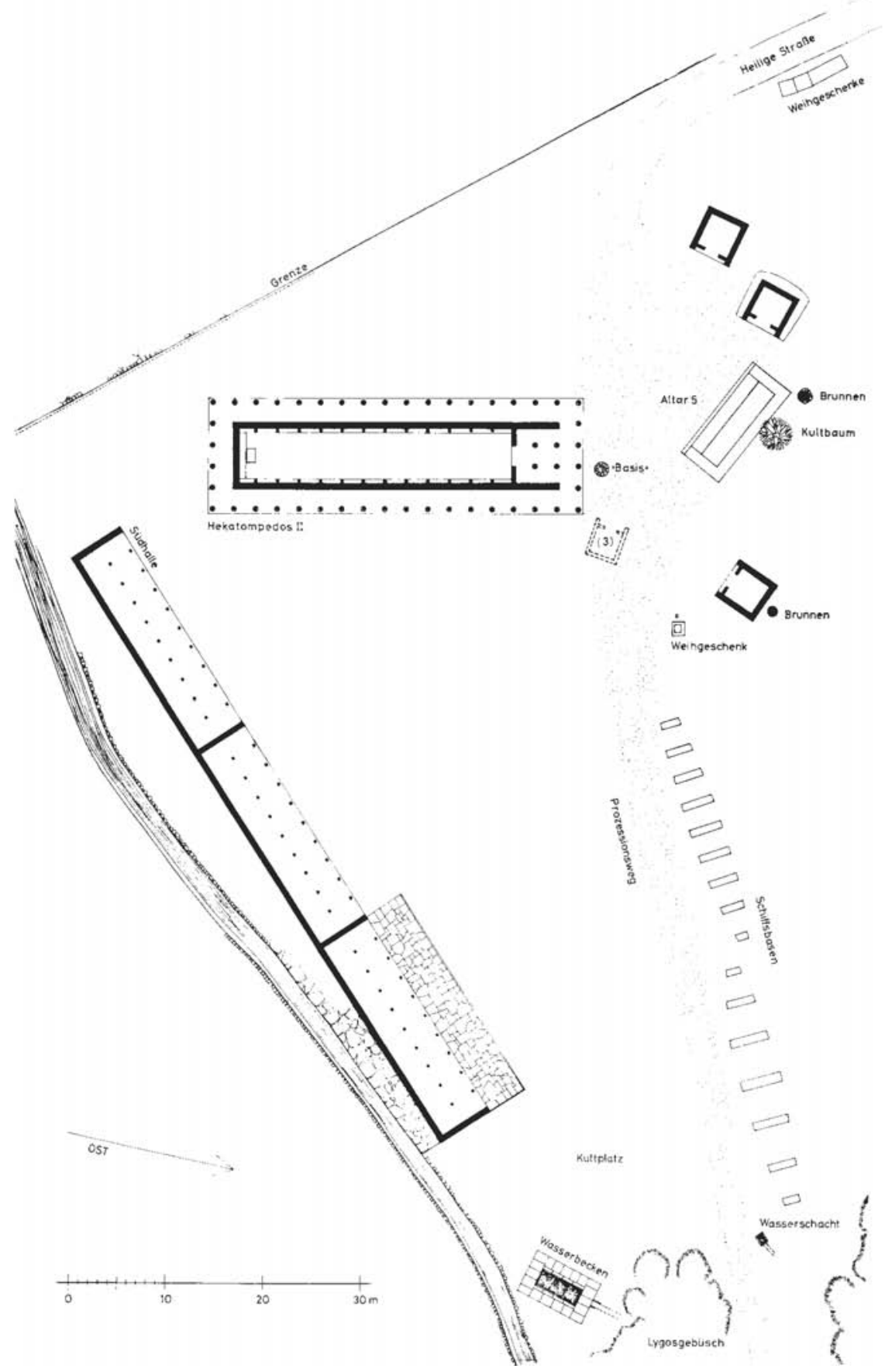

Fig. 22 - L’Héraion de Samos, vers 650 a.C. (d'après Walter 1990). 
Une structure analogue, datée elle aussi du VII ${ }^{e}$ s., fut dégagée dans le prolongement de la première le long de la voie sacrée. Plus longue que la première de $5 \mathrm{~m}$, elle comporte quant à elle sept murs de soutènement (fig. 22).

Ces deux bases montrent la consécration à l'époque archaïque dans le sanctuaire samien de plusieurs offrandes de ce type ${ }^{25}$.

\section{Époque classique}

Les offrandes de bateaux réels à l'époque classique sont dues aux deux grands conflits du $\mathrm{V}^{\mathrm{e}} \mathrm{s}$.

\section{a) Seconde Guerre médique}

Hérodote (VIII, 121-122) nous informe qu'à la suite de la bataille de Salamine, les Grecs remercièrent les dieux de leur victoire en déposant un certain nombre de présents dans différents sanctuaires, en tant que prémices $(\dot{\alpha} \kappa \rho \circ \theta i ́ v 1 \alpha)^{26}$. Trois trières phéniciennes prises sur l'ennemi furent ainsi consacrées : l'une à l'Isthme de Corinthe, la deuxième au cap Sounion et la troisième à Salamine. La première est donc vouée à Poséidon, même si les fouilles du sanctuaire de l'Isthme n'ont livré aucune trace d'une quelconque base d'exposition $^{27}$, tandis que la dernière est exposée près du lieu des hostilités en l'honneur d'Ajax, héros local et du champ de bataille ${ }^{28}$. La deuxième en revanche a pu être dédiée au sanctuaire de Poséidon ${ }^{29}$

${ }^{25}$ Walter 1990, p. 88-89 et fig. 92,98 qui suggère d'y voir une offrande du marchand Kolaios; Brize 1997, p. 130.

${ }^{26}$ Gauer 1968, p. 32-33, 44 et 71-73. L'auteur avance l'hypothèse qu'une offrande du même type aurait pu être visible sur l'Acropole d'Athènes, d'après des blocs portant une dédicace ressemblant selon lui au type de base de Samos citée ci-dessus; cette argumentation nous paraît peu fondée, d'autant plus qu'il serait surprenant qu'une telle offrande n'ait pas été mentionnée par Hérodote - ou d'autres - parmi les nombreux dons connus en relation directe avec les Guerres médiques.

${ }^{27}$ Werner 1993, p. 9 et fig. 6-7 propose, par analogie avec Samos, de reconnaître dans ce qui est appelé communément «le long autel» placé devant le temple les vestiges de la base ayant supporté le bateau consacré à Poséidon. De la même façon, il interprête ce qui est reconnu comme le grand autel de l'Artémision de Corcyre comme une autre base de bateau consacré en ex-voto. Cette structure, longue de plus de $25 \mathrm{~m}$ et large de 2,70 m pour une hauteur d'environ $1 \mathrm{~m}$, est remplie de pierres et de terre et recouverte de plaques. Sur cette structure, voir Speich 1982, p. 127.

${ }^{28}$ L'image du héros - et des Éacides de manière plus large - figurait d'ailleurs parmi la flotte grecque à Salamine et des prières spéciales lui furent adressées (Hérodote VIII, 64, 2; 83-84; V, 80). Sur les fêtes des Aianteia à Salamine en l'honneur d'Ajax, voir Deubner 1932, p. 228.

${ }^{29}$ C'est entre autre l'opinion de Werner 1993, loc. cit. 
comme à celui d'Athéna à l'extrémité de l'Attique. Cependant, certains arguments pourraient aussi faire pencher en faveur de cette dernière ${ }^{30}$ : le fait, plutôt curieux, que Poséidon aurait été remercié de la même façon et en deux endroits différents autres que celui de la bataille, l'importance à cette époque sur le promontoire du sanctuaire de la déesse ${ }^{31}$, et surtout la multiplicité des forces divines que l'on cherche à invoquer et remercier ${ }^{32}$. Le récit que nous donne Hérodote des préparatifs de la victoire (Enquête VIII, 64) voit les

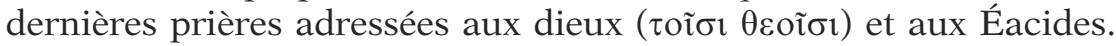
Athéna aurait sa place dans la victoire en tant que maîtresse de l'Attique et dans le signe de bon augure qu'elle aurait manifesté à Thémistocle (Plutarque, Thémistocle 12, 1) ${ }^{33}$. Un argument de type iconographique renforce ce sentiment. Des vases datés des années 480-460 figurent des divinités brandissant des aphlasta, en l'occurrence Poséidon sur un cratère du peintre de Pan et Athéna sur une amphore du peintre Nikon $^{34}$. Ces représentations pourraient constituer une allusion explicite aux bateaux perses consacrés à ces divinités.

Hérodote souligne la présence encore à son époque du bateau de Corinthe, ce qui amène à penser que peut-être les deux autres n'étaient alors plus visibles ${ }^{35}$. Il convient en outre de faire le rapprochement entre celui-là et le bateau reconnu comme la nef Argô et consacré à Poséidon dans l'Isthme ${ }^{36}$. Il serait tentant de les assimiler l'un à l'autre, en considérant que tous les divers témoignages les concernant appartiennent à des périodes bien distinctes. Cependant, un tel changement de tradition semblerait curieux lorsque l'on considère l'impact psychologique laissé par la victoire de Salamine. L'occasion pour laquelle la trière phénicienne avait été dédiée n'est pas de celles à s'effacer de la mémoire collective grecque.

${ }^{30}$ Argumentation défendue par Gauer 1968, loc. cit.

${ }^{31}$ Sur les deux sanctuaires de Sounion, voir supra aux chapitres Athéna et Poséidon (p. 35 ss. et 176 ss.).

${ }^{32}$ Apollon Delphien est également remercié de l'heureuse issue de la Seconde Guerre médique : voir infra, concernant les dons de parties de bateaux.

${ }^{33}$ Gauer 1968, loc. cit. Voir supra, partie 1, chapitre Athéna, p. 65. Le savant allemand voit en outre dans l'anecdote rapportée par Plutarque (Thémistocle 10, 6-7), selon laquelle le stratège aurait utilisé de l'argent provenant de la statue d'Athéna au Pirée, une aide financière de la déesse que les Athéniens se devaient de remercier.

${ }^{34}$ Wade-Gery 1933, p. 99-101. Sur le détail de ces vases, voir supra respectivement à Athéna et Poséidon (p. 55-56 et 178).

${ }^{35}$ Commentaire du texte d'Hérodote dans l'édition Budé, p. 97-98 et p. 120 note 2 .

${ }^{36}$ Voir supra. 
b) Guerre du Péloponnèse

Deux consécrations de bateau réel ont été réalisées dans le contexte de la guerre du Péloponnèse et sont à mettre en relation directe l'une avec l'autre. Elles se produisirent lors des combats qui opposèrent les flottes athéniennes et péloponnésiennes dans le golfe de Corinthe au cours de l'été 429. Les premières, alors sous le commandement de Phormion et faisant voile vers Naupacte suite à la victoire de Patrai, font escale au promontoire de Rhion afin de dresser un trophée et de consacrer un navire à Poséidon (Thucydide, Guerre du Péloponnèse, II, 84, 4; Diodore, Bibliothèque historique XII, 48, 1). Il s'agit certainement de l'une des douze embarcations prises à l'ennemi précédemment mentionnées par Thucydide. L'historien précise en outre ${ }^{37}$ que le territoire de Rhion favorable aux Athéniens se situe sur la rive étolienne, et non sur la rive péloponnésienne : ainsi faut-il sans doute localiser la consécration au lieu plus communément appelé Antirrhion. Pausanias (Livre X, xi, 6), sans nous parler d'offrande de bateau, affirme pour sa part que le sacrifice célébré après la victoire l'était en l'honneur de Poséidon et de Thésée ${ }^{38}$. Par ailleurs, il existe dans cette zone un sanctuaire sur la colline dominant le golfe et son étranglement, attribué à Poséidon et où se déroulaient des fêtes nommées Rheia (Plutarque, Banquet des sept sages, $162 \mathrm{~d}-\mathrm{e})^{39}$. Il est donc fortement probable que c'est à lui que fut voué le bateau.

Les deux flottes livrent à nouveau combat peu après; les Péloponnésiens qui prennent tout d'abord l'avantage en capturant plusieurs vaisseaux athéniens sont finalement battus ${ }^{40}$. Néanmoins ils tiennent à commémorer leur supériorité temporaire par un trophée à Rhion d'Achaïe, à côté duquel ils consacrent le bateau athénien qu'ils avaient réussi à conserver (Thucydide, Guerre du Péloponnèse, II, 92, 5). La divinité ainsi honorée n'est pas mentionnée. Cependant, le contexte de rivalité dans lequel se succèdent les deux offrandes ainsi que leur position face à face de

${ }^{37}$ Thucydide, Guerre du Péloponnèse, II, 86; l'auteur situe en revanche Antirrhion sur la côte péloponnésienne.

${ }^{38}$ Cette allusion intervient à propos de la description du Portique des Athéniens à Delphes, pour laquelle Pausanias commet un certain nombre de confusions. Il semblerait finalement que la victoire de Phormion ait été également célébrée par l'offrande de boucliers à Delphes - accompagnés d'une inscription explicant les circonstances de celle-ci - déposés à l'intérieur du Portique des Athéniens qui servait déjà de cadre commémoratif à d'autres victoires navales athéniennes. Sur ce Portique, voir infra p. 415 ss.

${ }^{39}$ Le sanctuaire a été fouillé au début du siècle (O $\lambda \alpha v \delta$ os 1924-1925), puis dans les années 1970 (Knell 1973); Mylonopoulos 2003, p. 44-45.

${ }^{40}$ Thucydide, Guerre du Péloponnèse II, 90-91. 
part et d'autre du détroit laissent à penser que c'est encore Poséidon le bénéficiaire du don.

\section{Époque hellénistique}

La pratique est encore bien attestée pour l'époque hellénistique au moins par deux exemples célèbres ${ }^{41}$.

\section{a) Délos}

Le cas le plus connu est sans conteste celui de Délos, objet de nombreux débats depuis presque un siècle. Sans prétendre résoudre l'énigme délienne, il convient de tracer un tableau général de toutes les questions posées et les différentes hypothèses proposées concernant cette - ou ces - offrande(s) de bateau(x).

Selon Athénée (Deipnosophistes V, 209e) ${ }^{42}$, Antigone consacra sa

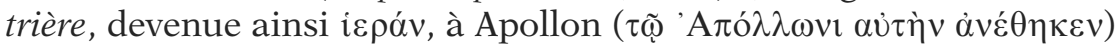
lors de sa victoire sur les troupes ptolémaïques à Leucolla de Kos. Le bâtiment est signalé par Athénée parmi les exemples de plus imposants bateaux connus. Or par ailleurs Pausanias (I, xxix, 1)

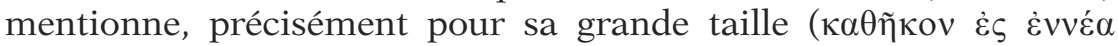

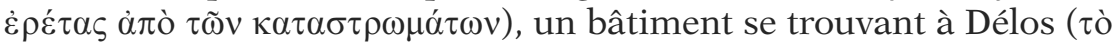
$\delta \grave{\varepsilon} \dot{\varepsilon} v \Delta \eta \dot{\eta} \omega \pi \lambda$ oĩov). Le rapprochement a été opéré entre les deux textes de façon à reconstituer les faits de la manière suivante : il s'agirait sans nul doute du même bateau, consacré à Apollon dans

${ }^{41}$ Höckmann 1985, p. 158-159. Il est un troisième cas que nous n'étudierons pas dans le cadre de ce travail, car il ne concerne pas une divinité olympienne. Dans l'été 332 a.C., Alexandre s'empare de Tyr après un long siège; il célèbre alors en grande pompe cette victoire tout en rendant grâces au dieu de la ville, assimilé

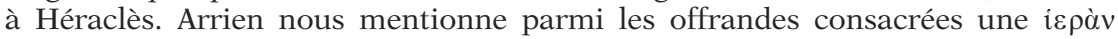
vaṽv, prise aux Tyriens.

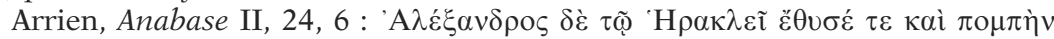

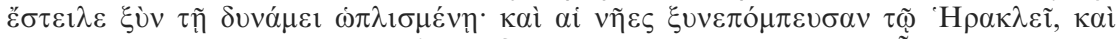

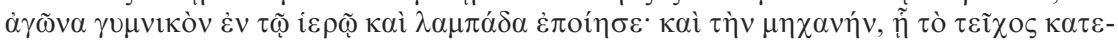

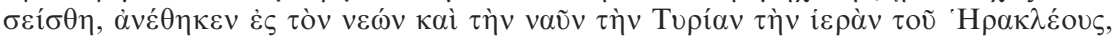

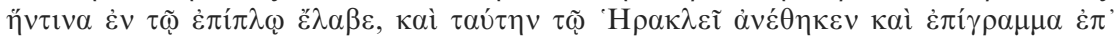

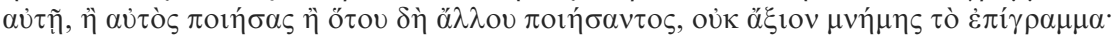

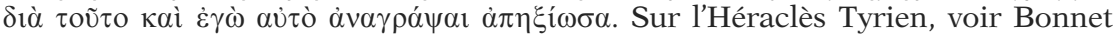
1988, p. 27-115.

${ }_{42}$ Reprécisons que cette allusion au bateau d'Antigone est due à l'un des participants au banquet d'Athénée, Masurius, et non pas à une citation de Moschion reproduite précédemment (206d à 209e) comme tendent à le faire croire certains commentateurs. Il n'est donc pas possible d'attribuer ce bref paragraphe à un auteur particulier, et encore moins de préciser s'il date du $\mathrm{III}^{\mathrm{e}} \mathrm{s}$. a.C. - période à laquelle écrit Moschion - ou de l'époque d'Athénée. 
son île de prédilection ${ }^{43}$. La localisation de cette offrande à Délos s'appuie également sur des inscriptions déliennes, au travers desquelles apparaît un édifice désigné néôrion ${ }^{44}$. Celui-ci n'est signalé qu'au plus tôt en 207 a.C. et jusque l'année 155-154 $4^{45}$. Ces différentes mentions témoigneraient d'un ex-voto exceptionnel par sa taille, son importance, qui avait frappé l'esprit des contemporains mais aussi des Anciens jusqu'au $\mathrm{III}^{\mathrm{e}} \mathrm{s}$. de notre ère au moins.

Le personnage et l'événement commémoré sont connus par ailleurs ${ }^{46}$. Au début du $\mathrm{III}^{\mathrm{e}} \mathrm{s}$. a.C., les royaumes hellénistiques s'affrontent sur terre comme sur mer. La flotte ptolémaïque qui assure la suprématie sur la mer Égée depuis la mort d'Alexandre est à plusieurs reprises menacée et vaincue par celle du roi de Macédoine, Antigone Gonatas, qui régna de 276 à 239; deux batailles navales à Kos et à Andros datées respectivement de 262 et 258 ou $256{ }^{47}$ se concluent ainsi à l'avantage de ce dernier. La consécration à Délos du bateau acteur de la victoire sur les Ptolémées ne serait donc pas exempte de signification politique ${ }^{48}$. Antigone aurait tenu ainsi à manifester ouvertement sa victoire, y compris dans une zone relevant de l'ennemi. D'autres réalisations ont également souligné son faste ostentatoire : la construction au nord du sanctuaire d'un portique monumental doublé d'une base portant les statues des ancêtres du dédicant, appelée communément Monument des Progonoi ${ }^{49}$.

Le bateau consacré n'est pas n'importe quel élément de la flotte

${ }^{43}$ Le premier à avoir fait le rapprochement entre ces deux témoignages littéraires est Tarn 1910, p. 209-222. Dans l'édition du livre I de Pausanias dans la collection Budé, p. 225-226, le texte est compris comme la mention d'un char processionnel en forme de bateau dans l'île et ne tient aucun compte des analyses faites sur ce bateau de Délos (aucune bibliographie, aucune hypothèse évoquée). Par ailleurs on ne connaît absolument aucun témoignage qui évoquerait de près ou de loin la présence d'un tel char-bateau à Délos.

${ }^{44} \mathrm{~F}$. Courby, in $B C H$ XLV, 1921, p. 224, note 1. ID 366 A, 1. 1-2; 442 B, l. 225; 1403 Bb, I, 1. 39-52; 1405, 1. 9-15 (?); 1412 b, 1. 7; 1417 B, II, 1. 110-111. Sur les ralliements à l'identification entre le néorion et le Monument des Taureaux, voir Gallet de Santerre 1982, note 86. Le texte de l'inscription ID 1403, le plus long et le plus instructif, a été republié ensuite par Tréheux 1987, p. 168-184 (repris par Chankowski 2008, p. 268-269); cette relecture a été à son tour critiquée par Roux 1989. Sur le contenu de cet inventaire, voir infra. Le monument est numéroté GD 24 (Bruneau \& Ducat 2005, p. 191-193).

${ }^{45}$ Gallet de Santerre 1982, p. 219.

${ }^{46}$ Will 1979-82, I p. 234 ss.

${ }^{47}$ Ces datations sont celles retenues par Will 1979-82, loc. cit.

${ }^{48}$ Cf. Tarn 1910, p. 215. Sans compter le parallèle avec le geste d'Alexandre, qui consacre un bateau à Héraclès après la prise de Tyr : cf. supra note 41. Sur la suprématie lagide (280-230), voir Cabanes 1995, p. 25-40.

${ }^{49}$ Bruneau \& Ducat 2005, p. 196 (GD 31). 
macédonienne ${ }^{50}$. Il s'agit du navire amiral, baptisé l'Isthmia parce que, d'après Plutarque (Propos de table V, 675d-677b), de l'ache poussa spontanément à sa poupe ${ }^{51}$. Ce navire amiral représentait un prototype unique ${ }^{52}$, conçu suivant la volonté d'Antigone lui-même, dans son désir de surpasser le plus grand bateau connu alors, la Syracusia de Hiéron de Syracuse ${ }^{53}$.

L'emplacement où aurait été exposée la trière a été identifié avec le Monument dit des Taureaux (fig. 23) ${ }^{54}$.

Cette structure se situe au cœur du sanctuaire d'Apollon, à l'Est du prytanée, dans le prolongement de la série des trésors; à l'est et au sud du Monument s'étend le mur de péribole (voir supra fig. 7 : GD24). Sa forme très allongée - composée d'un prodomos, d'une galerie et d'une chambre ${ }^{55}$ - et ses dimensions particulières $(69,40 \mathrm{~m} \times 10,37 \mathrm{~m})$ correspondent sans nul doute à une fonction

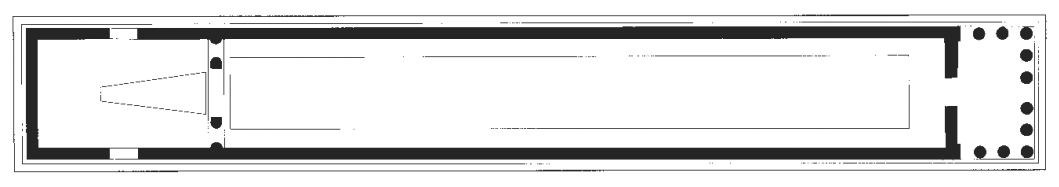

Fig. 23 - Le Monument des Taureaux (ou Néôrion) délien reconstitué (d'après Bruneau \& Ducat 2005, fig. 49).

${ }^{50}$ Tarn 1910, p. 213, et Couchoud \& Svoronos 1921, p. 275, soulignent avec raison que c'est le seul cas connu dans l'Antiquité d'offrande après bataille navale d'un bateau non pris sur l'ennemi.

${ }^{51}$ C'est l'argument avancé par Plutarque pour prouver que la couronne décernée lors des jieux Isthmiques était à l'origine d'ache, et non de pin. Tarn 1910, p. 218-220, pense plutôt que le nom est inspiré du lieu de sa construction, Corinthe.

${ }^{52}$ Une mention de Pollux I, 82, dans une énumération de grands navires, le définit précisément comme un triarmenos, un trois-mâts; cf. Tarn 1910, p. 209-212. Pour une tentative de définition des caractéristiques techniques, voir Basch 1987, p. 345-352; l'auteur reconnaît par ailleurs l'Isthmia dans un des bateaux des graffiti de la maison du Dionysos, celui appelé par le $\mathrm{C}^{\mathrm{dt}}$ Carlini «l'hékatontore» (cf. le catalogue de l'exposition Graffiti Délos 1992, p. 8 et 24). Pour ne pas rentrer dans ces débats éloignés de notre propos, le bateau est désigné sous le terme de trière (en italique), selon les propos d'Athénée.

${ }^{53}$ Ce bateau a été décrit par Moschion (repris par Athénée, Deipnosophistes V, 206d-209e).

${ }^{54}$ Hypothèse lancée par Couchoud \& Svoronos 1921. Il faut prendre surtout en considération la première partie de l'article; la seconde fait preuve de beaucoup d'imagination et d'hypothèses outrancières, notamment en ce qui concerne le mât du navire consacré, renvoyant à "un culte du mât très ancien".

${ }^{55} \mathrm{Le}$ vocabulaire utilisé pour les extrémités du bâtiment varie selon les 
précise $^{56}$, admise par tous comme support d'un bateau. Les fragments de décor ${ }^{57}$ retrouvés représentant notamment un cortège marin et une Nikè-acrotère vont dans le sens de cette interprétation. Quant aux taureaux, qui ont donné le nom à la structure, ils ornaient le chapiteau des colonnes de l'entrée intérieure du thalamos; il est à noter d'ailleurs que le même animal se retrouve sculpté sur les triglyphes du Portique d'Antigone ${ }^{58}$. Cependant, l'identification du Monument des Taureaux à la fois avec le néôrion et l'Isthmia n'a pas été acceptée par tous et les controverses séparent encore les spécialistes. En effet, un problème de datation se pose : la technique de construction ainsi que le style des sculptures situent le bâtiment à la fin du IV ${ }^{\text {e }}$ s. a.C. ${ }^{59}$, bien avant la victoire d'Antigone. Une autre thèse a donc été avancée: le Monument aurait été commencé par Démétrios Poliorcète afin de commémorer sa victoire de Salamine de Chypre en 306, mais c'est son fils qui en aurait finalement eu l'usage ${ }^{60}$.

Selon une description donnée par un inventaire délien daté vers 166 a.C. ${ }^{61}$, le bateau aurait ainsi été placé dans la galerie, tandis qu'au sud la prostasis aurait abrité deux proues de navires dorées et une panoplie de cavalier, et au nord la chambre avec son lanterneau ajouré $^{62}$ un autel (?) ${ }^{63}$ et des statues de bronze d'Apollon, de

articles : pour la partie sud, on parle indifféremment de porche, de prostasis, ou de prodomos, et pour la partie nord de thalamos, de chambre, ou de cella.

${ }^{56}$ Pour une description précise, voir Bruneau \& Ducat 2005, p. 191-193 (n ${ }^{\circ}$ GD 24); Couchoud \& J. Svoronos 1921. La publication complète du Monument des Taureaux prévue par C. Llinas n'a pas eu lieu suite à son décès en 2011.

${ }^{57}$ Pour une description détaillée de la totalité des éléments décoratifs du Monument, voir Marcadé 1951.

${ }^{58}$ Bruneau \& Ducat 2005, p. 192 et p. 195. Pour Couchoud \& Svoronos 1921, p. 279, c'est signe d'«un ensemble architectural». Picard 1952, p. 79-83, Gallet de Santerre 1982, p. 221-222 ainsi que Roux 1981, p. 71, ont remarqué le caractère peu athénien du motif et l'ont rapproché d'un chapiteau de Salamine de Chypre à l'époque de la domination macédonienne sur l'île.

59 Marcadé 1951.

${ }^{60}$ Première attribution à Démétrios : Vallois 1944, p. 33-42. Il est à noter que dans cet ouvrage, le monument est souvent désigné sous le nom de Pythion, car telle était l'identification soutenue par l'auteur. Cette datation a ensuite été reprise par Picard 1952; Roux 1981, p. 61-71 et dernièrement Vlachou 2010.

${ }^{61}$ Inventaire $I D$ 1403; pour l'établissement du texte, les différentes restitutions proposées, nous renvoyons à Roux 1989, qui compare les différentes éditions de l'inscription et commente les passages controversés. Chankowski 2008, p. 268-269 paraît suivre l'édition de Thréheux 1987.

${ }_{62}$ Sur le lanterneau, voir Vallois 1944, p. 255-256.

${ }^{63}$ L'autel est une proposition faite la première fois par Vallois 1944, p. 434 et reprise par Tréheux 1987, p. 176 et par Roux 1989, p. 273. En réalité, le mot $\dot{\varepsilon} \sigma \chi \alpha ́ \rho \alpha \nu$ est restitué à la ligne 49 de l'inscription pour précéder les qualificatifs

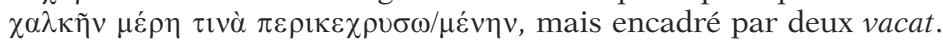


Poséidon et d'Athéna. G. Roux, se fondant sur les problématiques vestiges de la cella ${ }^{64}$, propose que cette partie de l'édifice, originellement conçue pour abriter un autel, ait finalement - compte tenu des proportions hors normes de l'Isthmia - été remaniée pour contenir la poupe du vaisseau; celle-ci, surmontée d'une statue du dieu, aurait été supportée par un "simple étai revêtu de marbre dont nous voyons les pauvres restes aujourd'hui ${ }^{65}$.

Cette hypothèse est contestée par L. Basch, pour qui le Monument des Taureaux est trop petit pour avoir pu supporter le gigantesque bateau: seule une trière normale pouvait y loger. C'est pourquoi il propose quant à lui de situer l'emplacement de l'Isthmia à côté du Monument, au nord, où aucune structure n'apparaît ${ }^{66}$. Pour d'autres, l'argument est insuffisant: il faut considérer que l'espace vide situé au nord de la structure était occupé en partie par le bois sacré du sanctuaire ${ }^{67}$ et que le bateau posé sur le socle pouvait déborder par ailleurs la surface du Monument non clos par des murs ${ }^{68}$.

Une autre proposition envisage encore la possibilité d'une

${ }^{64}$ Dans cette cella, se trouve une fondation trapézoïdale qui ne peut correspondre en aucun cas à un autel; de surcroît sont visibles des remaniements dans cette partie de l'édifice et des incohérences avec la galerie située dans le prolongement. Pour une description précise, voir Vallois 1944, p. 255, p. 279-280 et fig. 3, p. 397-398; Roux 1981, p. 63-67 et fig. 14-16. Gallet de Santerre 1982, p. 217-218, qui juge que cela ressemble davantage à une base de proue de navire - type Victoire de Samothrace - qu'à un autel, passe en revue brièvement, note 82 , toutes les hypothèses énoncées jusqu'alors.

${ }^{65}$ Roux 1981, p. 61-71, qui reconstitue ainsi cette partie nord de l'édifice : «Pourquoi en effet jugea-t-on nécessaire de caler par-dessous, au moyen d'un empilement de blocs de granit enveloppé de marbre, la poupe recourbée du vaisseau placée en porte-à-faux au-dessus du sol du thalamos? C'est qu'elle devait supporter quelque charge pesante, vraisemblablement quelque statue colossale d'Apollon figuré comme un divin pilote à la barre du vaisseau vainqueur. (...)

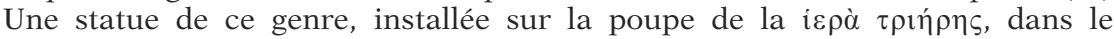
thalamos, bien éclairé par le jour tombant des fenêtres du lanterneau, se présentait esthétiquement de façon satisfaisante et constituait un moyen élégant de conserver au thalamos, encombré par la poupe géante, la fonction cultuelle qui lui avait été dévolue dans le plan initial. (...) Ce n'était pas sur une base de marbre, mais sur le pont du navire lui-même que le culte aurait été célébré»!

${ }^{66}$ Basch 1987, p. 345-352, après avoir comparé les dimensions du Monument avec celles des loges de trières du IV e s. d'Oiniadae (Acarnanie); Basch 1995, p. 43-72. L'un des arguments avancés est la présence toute proche d'un autel à Zeus Sôter, patron des navigateurs; sur cet autel et ce dieu, voir supra, $1^{\text {ère }}$ partie.

${ }^{67}$ Sur ce bois sacré, cf. Gallet de Santerre 1958, p. 111; Bruneau 1979, suivant l'inscription ID1417 B, II, 1. 110-111, y voit plutôt un "jardin sacré». L. Basch suppose que ce bois sacré n'existait plus à l'époque classique, après l'extension du mur de péribole précisément sous Antigone Gonatas, et que le vide archéologique de cet endroit ne peut être comblé que par la présence de l'Isthmia.

${ }^{68}$ Proposition suggérée par Auffray \& Guillerm 1993. 
offrande athénienne d'une trière au milieu du IVe s. a.C., suivie dans les années 330-315 de la construction du bâtiment ${ }^{69}$. Deux idées directrices la sous-tendent: une appréciation stylistique et un témoignage épigraphique. Pour certains en effet, le Monument des Taureaux dénote de particularités architecturales et sculpturales indéniables : il ne peut donc être uniquement le fait d'une construction macédonienne ou lagide ${ }^{70}$. D'un autre côté, même si les inventaires ne mentionnent que tardivement le néôrion, en revanche dès 344 a.C. ${ }^{71}$ ils recensent du matériel d'équipement d'une trière ( $\dot{\pi} \circ \zeta \omega \dot{\omega} \mu \tau \alpha$; voir corpus), que de ce fait on restitue grandeur nature $^{72}$. Celle-ci correspondrait alors à une offrande athénienne au dieu qui reconnaissait implicitement la domination égéenne de la cité, via l'oracle de Delphes saisi d'une plainte déposée par les Déliens entre 345 et 342 .

Un nouvel élément au dossier fut apporté dans les années 1980 par la relecture d'un inventaire délien. La correction qui y voit la mention du mot Né́pıov a pour conséquence directe de proposer ainsi une première attestation épigraphique de l'existence du bâtiment vers 270 a.C., date de cet inventaire - et non plus seulement à l'extrême fin du III ${ }^{e}$ s. Même si cette date se rapproche de celle de la construction du Monument des Taureaux, en revanche elle soulève un nouveau problème: l'édifice, terminé vers 270 , devait déjà contenir un navire et ne pouvait plus être remanié afin d'accueillir l'énorme bateau-amiral d'Antigone ${ }^{73}$.

Suite à toutes ces propositions, que retenir? Deux articles synthétiques aboutissent ainsi à deux conclusions totalement opposées. D'un côté, L. Basch ${ }^{74}$ reconstitue la chronologie des faits de cette manière. La trière athénienne aurait été offerte avant la construction du bâtiment destiné à le recueillir et protégée de manière temporaire, tandis que ses agrès auraient été conservés au sec dans un local

${ }^{69}$ Coupry 1973, suivi semble-t-il finalement par Gallet de Santerre 1982. Contra: Chankowski 2008, p. 266.

${ }^{70}$ Sur les arguments et les tenants de cette analyse stylistique, voir le résumé donné par Gallet de Santerre 1982, p. 223-224.

${ }^{71}$ Selon Coupry 1973, p. 148, peut-être même avant, entre 352 et 344.

${ }^{72}$ Coupry 1973, p. 156. Il s'agit des inscriptions ID 104, 25, 1. 10; 104, 26 B 1. 16ss.; 104-28 Bb, 1. 10ss.; 104, 29 1. 13ss.

${ }^{73}$ Tréheux 1986. L’inventaire concerné, IG XI, 2, 219, est complété par l'auteur par l'assemblage d'autres fragments publiés sur les numéros 220, 221 et 229, ce qui lui permet d'obtenir les lignes 18 à 37 dans leur totalité. Mais ce sont précisément les lignes 42-43 de la face A qui font l'objet de la relecture qui nous intéresse : on y évoquerait des travaux d'ö $\lambda \varepsilon \imath \psi 1 \varsigma$ - badigeonnement à la poix des boiseries - de différents bâtiments, dont le néôrion. Cette leçon paraît suivie par Chankowski 2008, p. 264 et 266.

${ }^{74}$ Basch 1995. 
fermé ${ }^{75}$, en l'occurrence l'Oikos des Naxiens. Dans un second temps, Démétrios aurait achevé le Monument commencé par les Athéniens, dont les travaux auraient été interrompus par leurs problèmes financiers ainsi que l'indépendance de l'île, pour y loger la trière athénienne - et non un de ses bateaux. Enfin, respectant ces précédents, Antigone consacre à son tour, près du Monument réalisé par son père, son navire amiral, l'Isthmia. Le vaisseau, exposé à l'air libre, aurait bien souffert des intempéries et des ravages du ${ }^{\text {er }}$ s. a.C. : Pausanias, même s'il a visité l'île, n'a pas dû voir le bateau, disparu au $\mathrm{II}^{e}$ s. de notre ère. La seconde reconstitution avancée par J. Tréheux ${ }^{76}$ bouleverse quant à elle la plupart des idées admises jusqu'ici. Le bâtiment aurait été construit dans une fourchette comprise entre 314 et 271, et ce par un diadoque; il commémorerait une victoire double, acquise à la fois sur terre et sur mer, et aurait contenu une $\dot{\varepsilon} \nu \delta \varepsilon \kappa \eta ́ \rho \eta \varsigma$ ou une $\delta \omega \delta \varepsilon \kappa \eta ি \rho \eta \varsigma^{77}$. Toutes ces conclusions partielles amènent à réattribuer l'offrande, non plus à Antigone, mais à Démétrios Poliorcète suite aux victoires de Salamine de Chypre en 306. Cet article a vivement été critiqué - à juste titre nous semble-t-il - par G. Roux, qui souligne combien les restitutions épigraphiques, de quelque ordre soient-elles, sont toujours arbitraires et contestables et combien la totalité du dossier reste trop lacunaire pour permettre des conclusions catégoriques ${ }^{78}$. Une troisième voie vient d'être proposée par V. Chankowski, celle de la consécration, dans le néôrion, du bateau dit de Thésée (voir infra p. 430 ss.). Cette hypothèse repose sur le format de l'embarcation : une triacontore - ce qui résoudrait les problèmes de compatibilité entre le bâtiment et l'embarcation qu'il abritait et laisserait de la place pour des pratiques cultuelles autour de la nef -, ainsi que sur les statues conservées dans le prodomos et le décor de l'édifice qui renverraient au mythe de Thésée. Ce sont les Athéniens qui auraient conçu cet ensemble architectural vers la fin du IVe s. a.C. de façon à confirmer les liens entre lîlle et la cité attique après la construction du Pythion dont le programme iconographique évoquait déjà la geste du héros. Cette démonstration ne fait pas l'una-

${ }^{75}$ L'auteur reprend ici l'hypothèse de Coupry 1973.

${ }^{76}$ Tréheux 1987.

${ }^{77}$ Pour le détail des raisonnements, nous renvoyons à l'article cité; nous nous contentons d'en résumer les grandes lignes. Pour le premier argument, l'auteur réfute l'hypothèse athénienne à cause de la mention, dans ID 1403, d'une stéphanè, symbole de royauté, suspendue à une des proues du prodomos; pour la victoire double, il argue de la présence dans l'édifice d'une Athéna portant deux Nikès; enfin le nom du bateau est restitué d'après le nombre de lettres manquantes et le postulat que les administrateurs athéniens s'y connaissent en marine et utilisent un vocabulaire précis.

${ }^{78}$ Roux 1989. 
nimité et a été contestée peu après sur la base d'une étude des frises du néôrion ${ }^{79}$.

Le dossier délien s'avère donc bien complexe et repose sur un bloc de questions de datation non résolues ou mal assurées, ainsi que sur des sources épigraphiques en partie restituées. On souhaiterait pour y voir plus clair une synthèse sur le bâtiment prenant en compte tous les éléments, de façon à en préciser les caractéristiques architecturales et la datation, qui oscille entre 306 a.C. et le premier quart du III ${ }^{\text {e }}$ s. a.C. ${ }^{80}$. L'argumentation de la consécration du bateau de Thésée souffre de l'absence de preuves déterminantes : outre les problèmes stylistiques, il paraît surprenant, en effet, qu'aucune mention n'existe d'un tel don ou d'un tel projet athénien.

En attendant de nouvelles sources épigraphiques ou archéologiques, retenons qu'Apollon et son sanctuaire délien se sont vus consacrer un bateau réel dans un bâtiment construit à cette fin au tournant du $\mathrm{IV}^{\mathrm{e}} \mathrm{s}$., et que quelques décennies plus tard, suite à une victoire navale, Antigone Gonatas a également consacré un bateau au dieu dans un endroit à préciser - du moins dans l'intention ou sous une forme différente, sinon dans les faits -, par exemple à Kos (si l'on s'en tient au terme ö́tov employé par Athénée V, 209e) ou à Samothrace ${ }^{81}$. Le geste du Macédonien aurait été amplement commémoré par une série d'émissions monétaires commémoratives. En effet, un certain nombre de tétradrachmes d'argent signés

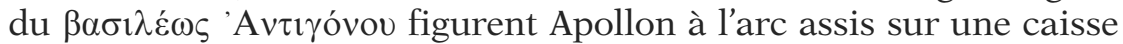
de rame à l'avant d'un bateau ${ }^{82}$.

${ }^{79}$ Chankowski 2008, p. 263-273. Contra : Vlachou 2010, auteur d'une thèse sur le décor sculpté du monument, qui reconstitue une consécration par la dynastie Antigonide d'une double victoire sur terre et sur mer.

${ }^{80}$ Chankowski 2008 , p. 265 , sur la base de la céramique provenant de sondages et de l'étude architecturale par C. Llinas.

${ }^{81}$ Par ailleurs, L. Basch a étudié, en accord avec l’École américaine qui fouille le site, l'édifice longiligne découvert en 1979 dans le sanctuaire de Samothrace : il y reconnait une structure identique au Monument des Taureaux de Délos, destinée à exposer un navire. Les fouilleurs ont conclu également à une offrande d'une trière ptolémaïque capturée par le même Antigone au deuxième quart du $\mathrm{III}^{\mathrm{e}}$ s. a.C., qui aurait manifesté ainsi sa piété envers les Cabires. Pour le spécialiste d'architecture navale, il pourrait donc s'agir d'un ex-voto résultant de la même victoire de Kos, auquel cas le bateau de Samothrace serait un modèle réduit à l'échelle 1/4 de celui dédié à Délos (Basch 1993).

${ }^{82}$ Cette identification est due avant tout à Imhoof-Blumer 1883, p. 128; cf. Tarn 1910, p. 213; Couchoud \& Svoronos 1921, p. 278; Basch 1987, p. 388-390. Elle a été contestée par Merker 1960, qui date les monnaies d'une trentaine d'années plus tard et les attribue à Antigone Doson (229-220) pour célébrer la 


\section{b) Actium}

Suivant l'exemple de ces rois hellénistiques dont il venait précisément de battre les derniers représentants en Cléopatre et Antoine, Octave commémore de façon prestigieuse sa victoire d'Actium. C'est ainsi que, selon Strabon (Géographie VII, 7, 6), il consacre en 31 a.C. au dieu du promontoire, Apollon, dix bateaux pris parmi les dix classes de la flotte de son rival ${ }^{83}$. L'offrande se voulait représentative de la flotte d'Antoine, en comprenant des bateaux de différentes

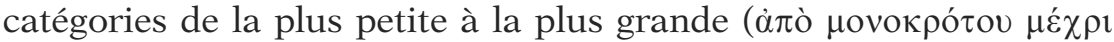
$\delta \varepsilon \kappa \eta ́ \rho o \cup \varsigma)$. Les embarcations, placées dans des cales conçues à cet effet ( $v \varepsilon \omega ́ \rho 1 \alpha)$, brûlèrent peu de temps après l'inauguration : c'est du moins la tradition qui fut rapportée à Strabon. Elles se situaient en contrebas du temple d'Apollon ( $\left.\pi^{\prime} \alpha \hat{\tau} \tilde{\omega}\right)$ des Acarnaniens, dans la plaine d'Actium à côté du bois sacré. Le témoignage de Strabon est partiellement répété plus de deux siècles et demi plus tard par Dion Cassius (Histoire romaine LI, 1, 2-3). Dans ce paragraphe, l'historien énumère les offrandes commémoratives d'Octave suite à la bataille, parmi lesquelles figure en premier lieu celle des bateaux grandeur nature, dont ni le nombre ni l'emplacement ne nous sont précisés. L'anecdote des différentes dimensions des navires y est signalée, mais dans une fourchette moins large que celle définie par Strabon :

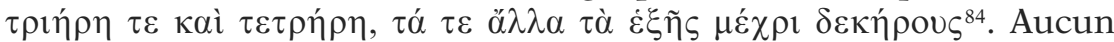
vestige archéologique n'a subsisté de ces ex-voto, le site étant aujourd'hui détruit de façon définitive. Nous devons donc nous contenter de ces deux sources littéraires.

J. Gagé proposait de reconnaître une représentation de cette offrande sur un bas-relief conservé au musée de Budapest ${ }^{85}$. Sur celui-ci, figurent à gauche trois hommes, dont un joueur de flûte et Octave, s'avançant vers Apollon à la cithare assis sur un rocher à côté d'un trépied; à sa droite apparaissent deux proues de navires. Mais la plaque, qui appartient à la frise dite d'Actium, montre une scène de bataille avec, sans doute, 9 nefs. Si elle ne reproduit pas, à

victoire d'Andros en 227; il est suivi notamment par Lambrinudakis \& alii 1984, 1 p. 196 et 2 p. 187.

${ }^{83}$ Höckmann 1985, p. 159; Murray 1993. Sur l'autre offrande d'Octave, c'està-dire l'autel orné d'éperons, voir infra p. $422 \mathrm{~s}$.

${ }^{84}$ Le texte de Dion Cassius pourrait faire envisager l'offrande de huit bateaux, et non de dix comme l'écrit Strabon. Il faudrait alors y voir la dîme due à Apollon, et reconstituer de cette manière la flotte d'Antoine. Cette question de la composition de la flotte rivale a été posée notamment par Murray 1993.

${ }^{85}$ Gagé 1936, précisément p. 45 et pl. I, 1. Sur ce relief, voir le catalogue de l'exposition Antoine (Rome \& Paris, 2014, p. 292-295, cat. 266-269), pour laquelle la frise a été reconstituée à partir des plaques dispersées à Budapest et en Espagne. 
proprement parler, le don naval d'Auguste, l'image célèbrait cependant le dieu maître du golfe d'Ambracie et de la victoire d'Actium ${ }^{86}$.

\section{c) Témoignage littéraire tardif}

Deux épigrammes dues au même auteur Macédonios que l'on date du VI ${ }^{\mathrm{e}}$ p.C., représentent encore pour une période tardive une offrande de bateau, en l'occurence à Poséidon. Les deux poèmes (Anthologie Palatine VI, 69 et 70) évoquent un certain Crantas, que l'on imagine pêcheur ou simple transporteur au vu de la taille modeste de son embarcation et du long temps qu'il y a passé.

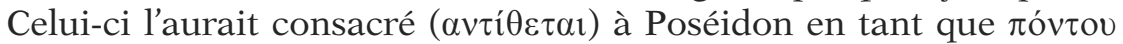
$\beta \alpha \sigma \imath \lambda \varepsilon v ́ s$, au terme de son activité nautique.

L'offrande de bateaux réels est une pratique suivie durant toute l'Antiquité grecque présentant certaines particularités. Sont connus au moins neuf exemples de tels ex-voto en l'honneur des divinités olympiennes, contre deux pour d'autres divinités - les Grands Dieux de Samothrace et l'Héraclès Tyrien. Il s'agit de geste ostentatoires de la part de gouvernants ou cités ${ }^{87}$, dans des lieux stratégiques : sanctuaires importants ou à l'endroit où le vœu a été formulé. La grande majorité des offrandes est due à un contexte militaire d'affrontement naval. Ceci est particulièrement le cas pour l'époque classique, qui voit tous ces bateaux offerts par des groupes politiques - Grecs, Athéniens, Spartiates - en l'honneur d'un dieu unique à Poséidon. En revanche, à l'époque hellénistique c'est Apollon qui est ainsi honoré par des hommes de pouvoir. Pour l'époque archaïque, en revanche, les dédicants ne sont pas connus et les divinités concernées sont variées : Poséidon, Héra, Artémis (?) et Athéna (?).

L'offrande de bateaux réels appartient semble-t-il pour l'Antiquité grecque à la sphère de la religion publique. Ce type de don de la part de particuliers professionnels de la mer est d'ailleurs rarement attesté pour l'Antiquité, et seulement selon des sources

${ }^{86}$ Gagé 1936, loc. cit., basait en particulier son explication sur la distinction entre le type d'Apollon d'Actium à la cithare et celui d'Apollon de Leucade archer. L'auteur présentait cependant une objection à cette identification - la configuration du cap d'Actium serait celle d'une zone plate, sans escarpement - qu'il contournait par l'hypothèse d'une confusion opérée entre le sanctuaire d'Apollon à Actium et celui de Leucade, situé quant à lui sur une hauteur. Cette réserve paraît sans fondement lorsque l'on examine les descriptions antiques du sanctuaire d'Actium (voir supra, p. 159 s.) : la topographie du terrain a beaucoup changé depuis l'Antiquité.

${ }^{87}$ Furtwängler 1997, p. 142-143 y voit un phénomène caractéristique du moment où «le caractère individuel du rapport à la divinité cède le pas à la glorification politique de l'État». 
tardives. Pour les périodes qui nous occupent aucun cas n'est recensable; ensuite ceci concerne plutôt des divinités secondaires ${ }^{88}$.

\section{BATEAUX MODÈLES RÉDUITS}

À défaut de consacrer un bateau réel, ce qui n'est pas simple ni toujours réalisable, on peut en offrir une substitution ${ }^{89}$. Une reproduction courante est celle qui consiste en une réduction de l'embarcation, que nous désignerons sous les expressions de modèles réduits ou maquettes (voir infra tableau p. 611-612).

Un livre essentiel pour la présentation de ce type de documents est paru il y a une trentaine d'années sous le titre Ship and boat models in Ancient Greece. L'auteur, P. F. Johnston, présente un catalogue des modèles réduits - quelque soit le type de matériau utilisé : bois, céramique, métal, pierre - de bateaux grecs connus à ce jour, en les classant par période : âge du bronze, période géométrique, période archaïque, période classique, période hellénistique ${ }^{90}$. Il s'est inspiré pour ce faire du catalogue plus général réalisé précédemment par A. Göttlicher ${ }^{91}$ et le complète à l'aide de nouveaux documents et surtout de bonnes descriptions et notices bibliographiques. Le but de cet ouvrage est avant tout typologique, c'est-à-dire de classer chronologiquement les différentes représentations miniatures de bateaux. En ce qui nous concerne, cet inventaire méthodique constitue un outil de travail précieux car il distingue les ex-voto des offrandes mortuaires ou des objets d'utilisation de la vie quotidienne (jouets, objets décoratifs) ${ }^{92}$.

D'après le matériel présenté par P. F. Johnston, nous avons pu opérer les comptages suivants. Pour les périodes qui nous occupent ${ }^{93}$,

${ }^{88}$ Cf. références données par Wachsmuth 1967, note 226.

${ }^{89}$ Ibidem, p. 134, note 226.

${ }^{90}$ Johnston 1985. À chaque période chronologique correspond un chapitre différent et une numérotation différente : ainsi, le matériel de l'époque géométrique est numéroté Geom. 1 ss., celui de l'époque archaïque Arch. 1 ss., celui de l'époque classique Clas. 1 ss., celui de l'époque hellénistique Hell. 1 ss. Le classement interne à chaque partie suit également l'ordre chronologique.

${ }^{91}$ Göttlicher 1978 : sur cet ouvrage, voir supra.

${ }_{92}$ Nous pouvons signaler également la découverte de bateaux miniatures dans un autre contexte : artisanal, dans la zone même de fabrication. Ainsi un dépotoir de four à Gela (Sicile) a fourni un exemplaire daté environ de 400 a.C. : Adamesteanu 1954; Göttlicher 1978, p. 67 nº 357.

${ }_{93} \mathrm{P}$. F. Johnston remonte aux premiers âges de la Grèce, pour lesquels il recense un certain nombre de cas de bateaux votifs : 2 au moins pour le Bronze moyen, 5 au moins pour le Bronze récent. La pratique paraît donc attestée depuis la plus haute Antiquité. Voir également Wachsmuth 1967, loc. cit. Pour l'époque 
une cinquantaine de bateaux modèle réduit consistent en des ex-voto au sens strict ${ }^{94}$, répartis comme suit : 33 sur 53 à l'époque archaïque, 2 sur 4 à l'époque classique. Pour l'époque hellénistique, le comptage s'avère plus difficile car dominent les cas litigieux et ce qui semble être des monuments commémoratifs. Il conviendra donc d'examiner ces occurences plus en détail et d'affiner l'évolution cultuelle au cours des siècles. Néanmoins les chiffres sont clairs : la pratique du don de bateau «miniature» est une pratique courante, comme le souligne P. F. Johnston en conclusion aux vues des aléas de la recherche archéologique $^{95}$ : il ne s'agit donc pas de cas isolés, mais d'une pratique plutôt usuelle. Aux objets recensés dans son ouvrage, nous avons ajouté quelques découvertes récentes ainsi que d'autres exemples connus grâce à des sources non archéologiques.

\section{Époque archaïque}

\section{a) Samos}

L'Héraion de Samos a livré un grand nombre - en fait le plus grand connu à ce jour - de petits modèles de bateaux archaïques (fig. 24) ${ }^{96}$ : au total, 22 objets de bois sculptés grossièrement constituant un groupe homogène aux proportions réduites ${ }^{97}$. La plupart d'entre eux - quatorze précisément - proviennent de l'area O14, pour la moitié datés du milieu du VII ${ }^{\mathrm{e}}{ }^{98}$, et pour l'autre de la seconde

géométrique, le seul cas provenant d'un sanctuaire (Géom. 6) consiste en un décor de chaudron : il s'agit de la poignée de bronze représentant un bateau de la grotte de l'Ida en Crète (aujourd'hui au musée d'Héraklion).

${ }^{94}$ L'auteur (p. 128) recense, toutes périodes confondues - y compris l'âge du bronze - 18 objets funéraires; il existe en outre un certain nombre de cas douteux ou indéterminés (de provenance inconnue notamment).

${ }^{95}$ Johnston 1985 , p. 125 : «The figure of 137 examples, however, is virtually meaningless, since it is only an indeterminate fraction of the total number of models actually produced. To it may be added, for example, models unexcavated to date, models not recognized as such by their respective excavators, models too fragmentary to be properly identified, unpublished models, models made of perishable materials that have not been preserved, and models destroyed in Antiquity.» L'auteur souligne par ailleurs, p. 127, que plus de la moitié de ce type de matériel est à destination votive et de ce façon continue durant toute l'Antiquité grecque et au-delà.

${ }^{96}$ Signalé rapidement par Höckmann 1985, p. 158 et par Göttlicher 1992, p. 108; Ohly 1953; Kopcke 1967; Kyrieleis 1980; Basch 1987, p. 243-247; Brize 1997, p. 128, 130 et fig. 14; Polignac 1997.

${ }_{97}$ Johnston 1985, p. 46-47, avec description stylistique. La taille des bateaux varie entre 10 et $50 \mathrm{~cm}$ de long. La plupart des bateaux sont désignés comme warships.

${ }_{98}^{98}$ Samos, Vathy Museum no H83-89. Johnston 1985, Arch. 3 à 9; respective- 


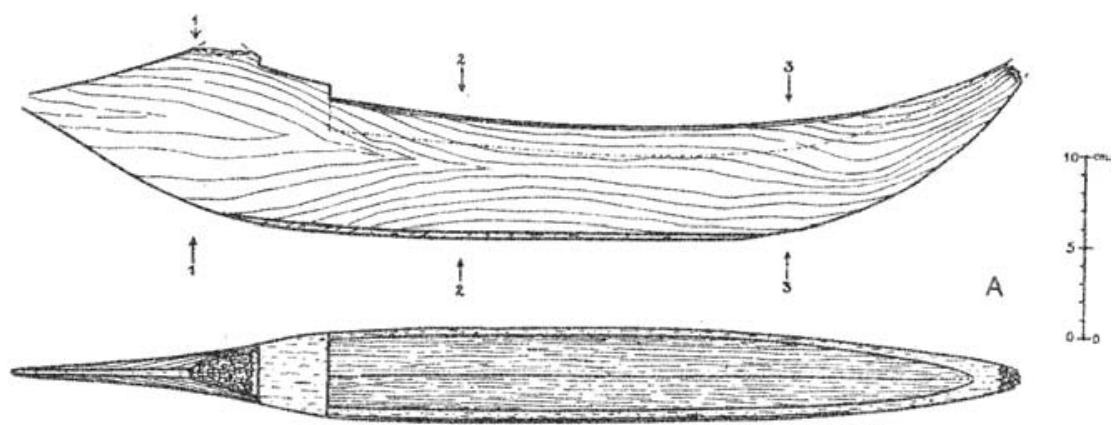

Fig. 24 - Barque en bois provenant de l'Héraion de Samos, vers 600 a.C.

(d'après Basch 1987, fig. 513).

moitié du VII ${ }^{\mathrm{e}}$ s. ${ }^{99}$. Au groupe le plus ancien viennent s'ajouter un exemplaire trouvé dans le lit de la rivière à l'intérieur de l'enceinte sacrée $^{100}$ et quatre sans provenance précise ${ }^{101}$, et au second groupe un bateau mis au jour dans l'area $013^{102}$ ainsi que deux de provenance inconnue ${ }^{103}$. Les areae $\mathrm{O} 13$ et 14 se situent dans la partie sud du téménos; un grand nombre d'objets ont été découverts à l'intérieur et autour d'un bassin ${ }^{104}$.

Plusieurs explications ont été avancées pour expliquer cet ensemble d'ex-voto : l'inondation de l'area du milieu du VII ${ }^{\mathrm{e}}$ s. et les modifications qui ont suivi concernant le temple et la statue de culte $^{105}$, ou gestes de gratitude d'un équipage victorieux après une bataille $^{106}$. De façon plus large, n'importe quel marin, samien ou

ment Göttlicher 1978, no 345, 342, 343, 344, 341, 340, 346; Romero Recio 2000, p. 11.

${ }_{99}^{99}$ Samos, Vathy Museum n H90-96. Johnston 1985, Arch. 15 à 21.

${ }^{100}$ Lieu de conservation inconnu. Johnston 1985, Arch. 10; Göttlicher 1978, $\mathrm{n}^{\circ} 352$.

${ }^{101}$ Lieux de conservation inconnus. Johnston 1985, Arch. 11 à 14; respectivement Göttlicher 1978, no 353 à 345 (le dernier n'étant pas recensé dans cet ouvrage).

${ }_{102}$ Samos, Vathy Museum H07. Johnston 1985, Arch. 22.

${ }^{103}$ Samos, Vathy Museum H98-99. Johnston 1985, Arch. 23 et 24.

${ }^{104}$ Les fouilles de ce secteur ont débuté entre 1961 et 1965 et se sont achevées en 1977. Sur la description et les relevés de fouille, voir Furtwängler 1980, p. 149-159, pl. 41-43 et plans 2-7. Les bateaux appartiennent à la phase I de la zone. Le carroyage général du site est publié dans MDAI(A) LXXIV, 1959, planche centrale.

105 Johnston 1985, p. 50.

${ }^{106}$ Kopcke 1967, p. 145. L'auteur insiste sur le caractère grossier des bateaux, qui ont dû être réalisés et dédiés très vite dans un même secteur par des artisans malhabiles. 
pas $^{107}$, a pu consacrer un tel objet à la déesse, au retour ou au départ d'un voyage, ou après un conflit sur mer, comme le laissent supposer d'autres ex-voto déposés dans le sanctuaire ${ }^{108}$.

Une inscription fragmentaire sur tablette de bronze, datée du

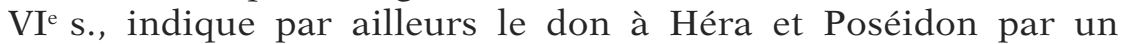
dénommé Amphidemos de sept bateaux ${ }^{109}$. Il peut s'agir d'offrandes en bois comme les autres, mais aussi en céramique. Ceci montre que ce type d'offrande était consacré au moins à titre privé, et de surcroît durant au moins deux siècles.

\section{b) Ischia}

Un dépôt votif, situé à proximité à la fois de l'acropole et de la nécropole de l'antique Pithécusses, a livré trois bateaux de terre cuite. Datés entre 635 et 620 et en partie peints, ils présentent à la poupe un aplustre bien recourbé et une stylis, ainsi qu'une sorte d'éperon défensif, ce qui les apparente à des navires de guerre de type corinthien (fig. 25) ${ }^{110}$.

La stipe dite "des Cavaliers» n'a malheureusement pas été découverte lors de fouilles, mais mise au jour par un particulier faisant construire sa maison sur le versant nord d'une colline à environ $500 \mathrm{~m}$ de la zone de nécropole de la vallée de S. Montano. Le matériel qui a pu être récupéré par les autorités de ce dépôt et suite à l'examen archéologique de la zone perturbée comprend, outre les modèles navals, d'autres objets céramiques datés entre la seconde moitié du VIII ${ }^{\mathrm{e}}$ s. et la fin du VI ${ }^{\mathrm{e}}$ s. a.C. : vases (corinthiens, ioniques et de production locale), chevaux, chariots avec mules, modèles de navires, terres cuites architectoniques, des figurines de pleureuse et d'hermaphrodite (?), poids ou pesons, ainsi qu'un flacon et deux lampes phéniciennes. Les recherches ont cependant permis de retrouver le fond de la fosse contenant du bois carbonisé et, en-dessous d'une couche de terre brune, une couche de terre noire contenant également du bois mais aussi des fruits et quelques ossements humains, le tout carbonisé ${ }^{111}$. L'interprétation qui

${ }^{107}$ Un des bateaux correspondrait précisément à un modèle égyptien (Basch 1987, p. $245 \mathrm{n}^{\circ}$ 517), ce qui élargirait le cercle de provenance des marins en question.

${ }^{108}$ C'est ce que conclut Johnston 1985 (p. 50), et nous le suivons sans conteste sur ce point : voir $1^{\text {ere }}$ partie, chapitre consacré à Héra, p. 72 ss. et $80 \mathrm{~s}$. ${ }^{109}$ Samos, Vathy Museum inv. B423. Ohly 1953, p. 111-112; voir AA 1935, p. 238 et 1937, p. 211 fig. 7.

${ }_{110}$ Johnston 1985, Arch. 26-28; D’Agostino \& Buchner 1994-95, p. 19-22 cat. 13-16, 68-69 et pl. VIII-XI, XXII-XXIII. Type corinthien : cf. Morrison \& Williams 1968, p. 33-36.

${ }^{111}$ D’Agostino \& Buchner 1994-95. 


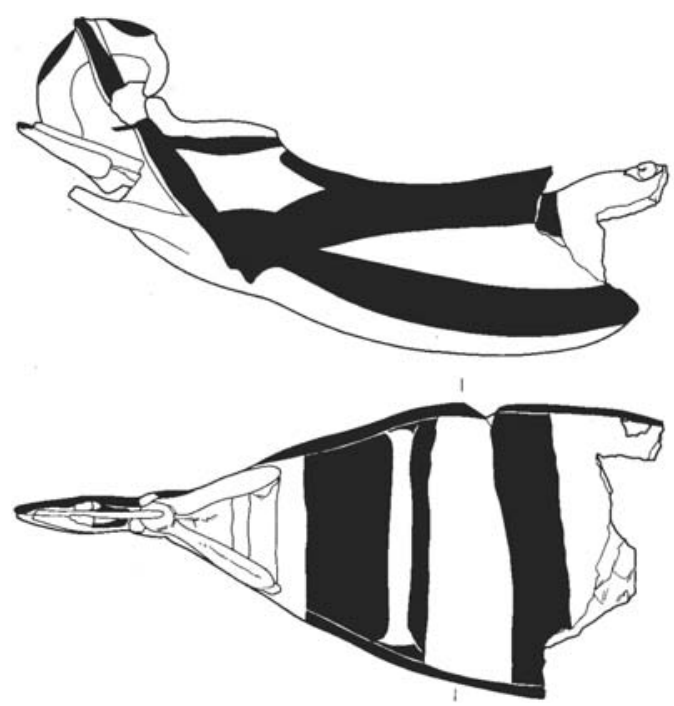

14

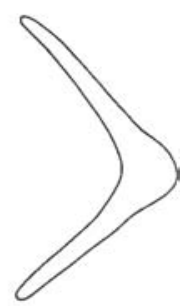

Fig. 25 - Pithécusses : modèle de bateau no 14 (d'après D’Agostino \& Buchner 1994-95, pl. XXII).

prévaut aujourd'hui est celle d'un dépôt votif mis dans un naiskos, qui aurait succédé à une tombe plus ancienne; les ex-voto, très particuliers, s'apparentent aux autres offrandes archaïques connues ailleurs pour Héra ${ }^{112}$. L'emplacement choisi pour cette fondation religieuse est une hauteur, aux pieds de la colline surplombant le port.

\section{c) Égine}

Parmi le petit matériel dégagé dans le sanctuaire d'Aphaia à Égine à été signalée la présence de petits bateaux fragmentaires de terre cuite votifs ${ }^{113}$. Neuf exemplaires semblent être comptabilisables, dont un de facture locale. Malheureusement le contexte archéologique n'a pas été relevé. Le type de ces objets, similaires aux exemplaires d'Ischia ${ }^{114}$, invite à une datation du $\mathrm{VIII}^{\mathrm{e}}$ s. a.C.

112 D'Agostino \& Buchner 1994-95, p. 86-91; Polignac 1997, p. 115 note 10; Romero Recio 2000, p. 16; Breglia 2009, p. 256-262.

${ }^{113}$ Réserve du site, inv. T19-25, T140 (?), T328. Sinn 1988, p. 151-152 et fig. 2.

${ }^{114}$ D’Agostino \& Buchner 1994-95, p. 68-69; Polignac 1997, p. 115. 


\section{d) Corinthe}

Le territoire de Corinthe a livré de nombreux modèles réduits de bateau de terre cuite archaïques, ce qui fait soupçonner que Corinthe était un lieu de production de ce type d'objet ${ }^{115}$. Ceux que l'on peut considérer comme votifs ${ }^{116}$ ont été dégagés dans des contextes bien spécifiques et dans des zones consacrées à des divinités différentes.

Un premier objet, antérieur aux années 580-570, a été mis au jour dans le sanctuaire corinthien d'Apollon ${ }^{117}$. Les fragments retrouvés présentent des traces de peinture rouge. L'objet est supposé votif car il provient d'une zone remaniée en vue de l'agrandissement du sanctuaire d'Apollon.

Deux exemplaires sont à rattacher au contexte du sanctuaire de l'Isthme. Les deux modèles réduits proviennent d'une fosse circulaire à l'extérieur de l'enceinte du sanctuaire et sont datés du $\mathrm{VI}^{\mathrm{e}}$ a.C. ${ }^{118}$. Le premier bateau est en céramique, tandis que le second présente la particularité non seulement d'être de bronze mais encore de type nuragique ${ }^{119}$. De manière hypothétique, on peut attribuer ces deux exemplaires à Poséidon.

Le quartier des Potiers de Corinthe a livré un dépôt votif, consacré semble-t-il à Aphrodite ${ }^{120}$. Parmi les offrandes se trouve un bateau de terre cuite, daté de la fin du VIe-début du Ve $s .{ }^{121}$.

Le bateau corinthien de terre cuite archaïque le plus connu est

11517 ont été recensés pour l'époque archaïque. La grande majorité des bateaux de terre cuite ont d'ailleurs été retrouvés dans le quartier des potiers : Johnston 1985, p. 51. Voir également Walter 1990, p. 37 et fig. 58.

${ }^{116}$ Ces cas sont minoritaires; même si Johnston 1985 suppose pour tous ces bateaux une destination votive, nous n'avons retenu que les cas les plus probables.

${ }^{117}$ Musée de Corinthe, inv. MF-78-57. Johnston 1985, Arch. 31. C'est un des seuls des 17 exemplaires trouvés à Corinthe qui provienne d'un contexte chronologique précis : ibid., p. 51.

${ }^{118}$ Musée de l'Isthme, inv. IM 2429 et 2090. Johnston 1985, Arch. 45-46, où les bateaux sont classés comme votifs, tandis qu'à la p. 51, l'auteur ne les inclut pas parmi les bateaux à destination votive; Göttlicher 1978, no 349-350; Delivorrias 1987, no 84; Broneer 1959, p. 301-303, 338, n 6, pl. 73 c et p. 328 , n 8 , fig. 5; Basch 1987, p. 237-238; Romero Recio 2000, p. 10; Calgano 2006, p. 229 l'attribue à un voyageur sarde.

${ }^{119}$ Sur ce type de modèle de bateau en bronze, Göttlicher 1978, p. 70-76; Basch 1987, p. 404-405.

${ }^{120}$ Le dépôt est constitué de vases et de figurines, dont une coupe qui présente le nom d'Aphrodite; cf. Stillwell 1952, p. 23-D6.

${ }^{121}$ Musée de Corinthe inv. KT 52-5. Johnston 1985, Arch. 47; Werner 1993, p. 38 fig. 58, 4; Stillwell 1952, p. 195-197; Pirenne-Delforge 1994, p. 99-100. Le bateau est considéré comme un warship. 
sans doute celui trouvé à Pérachora ${ }^{122}$. Il provient d'un dépôt votif appelé $2 \mathrm{~d}-3 \mathrm{~d}$, qu'on ne sait à quel temple rattacher. La favissa fut recouverte par l'Agora à l'époque classique et contenait du matériel daté des VII ${ }^{\mathrm{e}}$ et $\mathrm{VI}^{\mathrm{e}} \mathrm{s}$. La facture de l'objet paraît être corinthienne ${ }^{123}$.

\section{e) Amathonte}

Pour Chypre, c'est le site d'Amathone qui s'avère avoir livré le plus grand nombre de modèles archaïques de bateaux en terre cuite de tous types (militaires, de commerce, ou simples nefs) provenant de tombes ou de contexte non-funéraire. Ils sont datés de la deuxième partie de l'époque archaïque et peut-être de l'époque classique. Parmi eux, au moins neuf exemplaires, essentiellement des barques, proviennent du sanctuaire d'Aphrodite situé sur l'acropole. Par rapprochement avec les petits chariots en terre cuite trouvés sur le même site, les aménagements de certaines de ces embarcations et la comparaison avec des scènes navales figurées sur des vases chypriotes, les bateaux sont mis en relation avec des fêtes maritimes célébrées en l'honneur de l'Aphrodite locale ${ }^{124}$.

\section{f) Athènes}

Du flanc nord de l'Acropole, proviennent deux bateaux de terre cuite, considérés comme archaïques ${ }^{125}$. Les précisions manquent pour analyser ces objets et leur contexte; ils sont peut-être à rattacher au culte d'Aphrodite et Éros rendu dans cette zone de la colline $^{126}$. Apparemment, ces céramiques seraient identiques aux modèles trouvés à Corinthe : ils auraient donc été produits dans des ateliers corinthiens ${ }^{127}$.

${ }^{122}$ Musée national d'Athènes. Johnston 1985, Arch. 52; Werner 1993, p. 38 fig. 58, 8; Payne 1940, p. 97, pl. 29, nº 4.

${ }^{123}$ Stillwell 1952, p. 196.

${ }^{124}$ Hermary 2000b. Bateaux du sanctuaire d'Aphrodite : ibidem, cat. 276-284 p. 54 et pl. XIX-XX. Sanctuaire et connaissance partielle du matériel votif VIII ${ }^{\mathrm{e}}$ $\mathrm{IV}^{\mathrm{e}}$ s. a.C. : ibidem, p. 7-8 et plans h.-texte.

${ }^{125}$ Johnston 1985, Arch. 50-51; Morgan 1935, p. 196-197 et fig. 5. Les deux objets sont enregistrés sous les références Agora Museum A-F 346 et 393, mais il semblerait qu'ils se trouvent au musée de l'Acropole (?). Seul le premier est défini comme un warship.

${ }^{126}$ Le matériel n'est pas rattachable à un contexte précis (Morgan 1935, p. 189); confusion entre ce sanctuaire et celui mentionné par Pausanias sur l'Acropole (Pirenne-Delforge 1984, p. 50-51, $72-73$ et fig. 4 p. $55 \mathrm{n}^{\circ} 13$ ). Sur les fouilles du versant nord de l'Acropole, voir Broneer 1935; Holtzmann 2003, p. 204.

${ }^{127}$ Stillwell 1952, p. 196. 


\section{g) Gravisca}

Une lampe de bronze en forme de bateau, de fabrication sarde, est attestée à Gravisca ${ }^{128}$. L'objet appartient au grand dépôt d'objets votifs déposés dans une fosse située dans la pièce $C$ de l'édifice Alpha du sanctuaire, où étaient honorées Aphrodite et Héra. Le tout consistait en une grande quantité de céramiques, grecques dans leur majorité, surtout des lampes, et quelques autres petits objets. Le matériel, daté de la période comprise entre 580 et 480, a livré le nom d'Héra sur quatre céramiques, mais pas le nom d'Aphrodite ${ }^{129}$. Ces graffiti, ainsi que le parallèle avec les autres cas de bateaux connus pour Héra à l'époque archaïque, nous incite à voir dans cet exemplaire une offrande à cette divinité plutôt qu'à sa parèdre. La lampe de bronze, caractérisée par la protomé de cervidé et la colombe posée sur ce qui correspond au mât, est quant à elle datée, par comparaison avec des objets de facture identique, de la fin du VII ${ }^{{ }_{-}}$ début $\mathrm{du} \mathrm{VI}^{\mathrm{e}} \mathrm{s} .{ }^{130}$

\section{h) Crotone}

Le sanctuaire d'Héra Lacinia à Crotone a livré également, parmi les offrandes de la déesse, un bateau de bronze de type nuragique (fig. 26). Il fait partie des découvertes liées à l'édifice B, datées entre le VIII $\mathrm{s}$. et la première moitié du $\mathrm{V}^{\mathrm{e}} \mathrm{s}$.

Cet édifice rectangulaire d'environ $20 \mathrm{~m}$ sur $10 \mathrm{~m}$ possédait vraisemblablement une vocation rituelle aux vues du matériel qui y fut découvert. À l'intérieur se trouvait en outre un horos, à côté duquel étaient réunies les offrandes les plus prestigieuses du bâtiment. Le contexte dans lequel est apparu ce bateau ne peut pas remonter au-delà de la fin du VII ${ }^{\mathrm{e}} \mathrm{s}$. On aurait là les traces les plus anciennes d'un culte à Capo Colona ${ }^{131}$.

${ }^{128}$ Torelli 1970, p. 57-58 ( $n^{\circ}$ 38) et pl. XVIIIa; Lilliu 1971; Luzón Nogué \& Coín Cuenca 1986, p. 66; Romero Recio 2000, p. 15-16. L'objet mesure $21 \mathrm{~cm}$.

${ }^{129}$ Première mention dans Torelli 1970 , p. 57-58 (n $\left.\mathrm{n}^{\circ} 38\right)$ et pl. XVIIIa; Colivicchi 2004, p. 35-36 n 23; Fiorini 2005, p. 130-131 et 189-190. Dédicace (avec une cinquième qui concerne Zeus ou les Dioscures): Johnston \& Pandolfini 2000 , p. 17-19, no $6,21,23,25,56$. Sur le sanctuaire de Gravisca, voir également infra, p. 470 ss.

${ }^{130}$ Lilliu 1971. Sur ce type d'objets en bronze, voir le catalogue d'A. Göttlicher (Göttlicher 1978, p. 70-76), qui en recense 63 exemplaires originaires de Sardaigne, datés pour la grande majorité des VIII et VII e s. a.C.

${ }^{131}$ Inv. 59366. Spadea 1994, p. 22-24, fig. 27-29 no 33 et pl. VII b et e; Spadea 1996, p. 37-56; Spadea 1997, p. 250 et fig. 15; Romero Recio 2000, p. 15; Lilliu 2000, qui date l'objet de la fin du $\mathrm{VII}^{\mathrm{e}} \mathrm{s}$. ou du début du VI ${ }^{\mathrm{e}} \mathrm{s}$. et le rapproche 

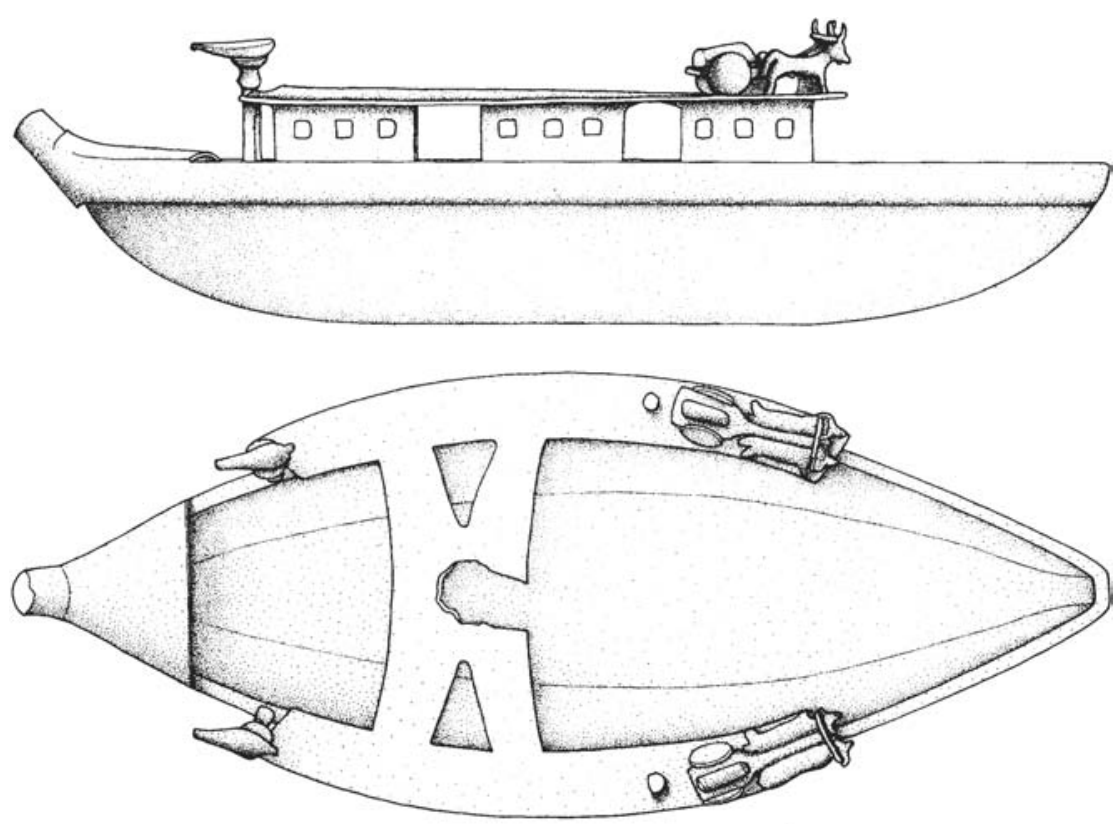

Fig. 26 - Bateau en bonze sarde; sanctuaire d'Héra à Crotone, bâtiment B (d'après Spadea 1997, p. 249).

Pour l'époque archaïque, sont ainsi connus aujourd'hui cinquante-neuf ex-voto naviformes consacrés à des divinités olympiennes : vingt-deux de bois, vingt-sept de céramique, trois de bronze et sept indéterminés.

Époque classique

a) Delphes

L'offrande d'une maquette de bateau pour l'époque classique nous est parvenue renseignée par Plutarque (Vies (Lysandre), 18, 1), d'après un écrivain de la fin du $\mathrm{III}^{\mathrm{e}}$-début $\mathrm{II}^{\mathrm{e}}$ s. a.C., Anaxandrias de Delphes (= Fgt 2, éd. Jacoby). Suite à la victoire d'Aigos Potamoi remportée en 405 par les Spartiates contre les Athéniens, un certain nombre de présents ont été déposés à Delphes pour commémorer Olympie; Calgano 2006, p. 229. Voir également supra, p. 374 et 376. 
l'événement ${ }^{132}$, et tout particulièrement une trière d'or et d'ivoire ${ }^{133}$ exposée dans le Trésor des Acanthiens ${ }^{134}$. Celle-ci, cadeau de Cyrus à Lysandre en souvenir de la victoire, fut donc dédiée par ce dernier au sanctuaire d'Apollon; chryséléphantine, elle mesurait deux coudées de long, c'est-à-dire 88 centimètres. Il est peu probable cependant que Plutarque l'ait vue de ses propres yeux : sans doute avait-elle disparu dès le IV ${ }^{\text {e }}$ s. a.C. au moment du sac de Delphes par les Phocidiens ${ }^{135}$.

\section{b) Athènes}

Le document suivant est bien connu de tous, du moins visuellement. Il s'agit d'une lampe de bronze naviforme, qui porte la mention : IEPON TH $\Sigma$ A $\Theta H N A \Sigma$ (fig. 27) ${ }^{136}$.

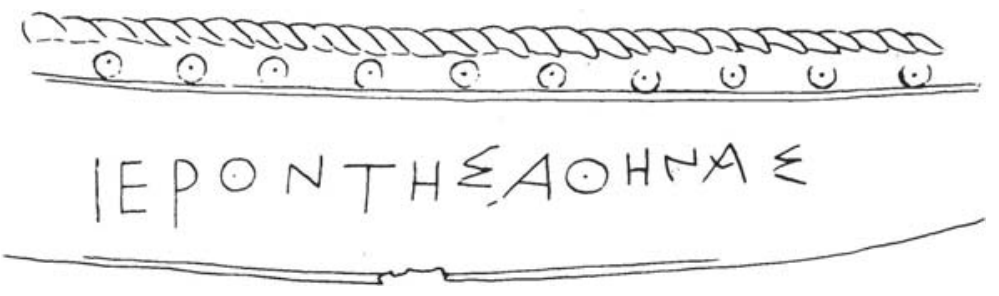

Fig. 27 - Lampe d'Athéna de l'Érechtheion : inscription votive (d'après Basch 1987, fig. 478).

${ }^{132}$ Monument d'Aigos Potamos avec statue de Lysandre couronné par Poséidon : Jacquemin \& alii 2012, p. 51-52 nº 25 (avec biblio.); «étoiles d'or des Dioscures» : infra p. 414.

${ }^{133}$ Johnston 1985, p. 136.

${ }^{134}$ Ce Trésor, peut-être une construction antérieure dédiée à nouveau, est évoqué dès le premier paragraphe de cette biographie de Lysandre (Lysandre, 1, 1) car il abrite une statue du général. Cet oikos a été situé à l'intérieur du sanctuaire, précisément à la fondation dite XVI, c'est-à-dire à droite de la Voie Sacrée lorsqu'elle tourne à l'angle sud-est du temple (Roux 1963, p. 69-77; Jacquemin 1999 , p. 65, 85).

${ }^{135}$ C'est l'avis de R. Flacelière, dans l'édition Budé du texte de Plutarque, vol. VI, p. 166.

${ }^{136}$ L'objet est conservé au Musée archéologique national d'Athènes, sous le numéro d'inventaire 7038. La bibliographie n'est pas très dense sur cet objet : il n'apparaît souvent que sous la forme d'une illustration avec une légende succinte (ainsi, Moll 1929a n'en donne qu'une petite reproduction numérotée B VII, 1). Pour une description récente et la plus minutieuse, voir Johnston 1985 p. 79-81 sous le numéro Cl. 2; Göttlicher 1978, p. 68, no 362 et pl. 27 en donne un bon dessin; Basch 1987, p. 228-230; Kennedy 1976, p. 162; Holtzmann 2003, p. 183; Fenet 2011, p. 408 et pl. 118. 
Elle provient de l'Acropole d'Athènes, plus précisément de l'Érechthéion. La première publication, au moment de la découverte, date de 1862, lorsqu'une fouille est conduite par des archéologues prussiens ${ }^{137}$. La lampe aurait été trouvée "in the central chamber in or close to the west transverse wall» ${ }^{138}$, ce qui lui valut d'être interprétée comme une offrande à Poséidon-Érechtheus qui aurait été vénéré à cet endroit précis du bâtiment. Ce n'est qu'une quarantaine d'années plus tard qu'un nettoyage de l'objet révéla l'inscription, balayant la conclusion précédemment énoncée. Les trois mots sont lus généralement comme une marque de propriété, et non comme une dédicace ${ }^{139}$.

La lampe de bronze ${ }^{140}$, d'assez grandes dimensions $(30 \mathrm{~cm} \times 7 \mathrm{~cm})$, est d'une réalisation soignée. La proue est munie d'un éperon, tandis qu'à la poupe recourbée à l'intérieur se trouvent les deux rames-gouvernails. La dédicace est gravée sur le flanc gauche de l'embarcation - à bâbord - en pointillés.

Des datations diverses ont été proposées, sur la base de l'architecture de bateau représentée sur ce modèle réduit. Ainsi, hésite-t-on entre le VIe s. a.C., le $\mathrm{V}^{\mathrm{e}} \mathrm{s}$. a.C., et les $\mathrm{IV}^{\mathrm{e}}-\mathrm{III}{ }^{\mathrm{e}} \mathrm{s}$. a.C. ${ }^{141}$; cependant, la forme des lettres laisserait plutôt pencher pour cette dernière hypothèse. Certes, il ne serait guère très surprenant que l'on ait dédié au $I V^{\text {e }} \mathrm{s}$. un objet de type archaïsant, en l'occurrence ici un type de bateau de guerre correspondant à un modèle archaïque. Considérant que le bâtiment dans lequel il a été découvert fut achevé vers 406 a.C. il est vraisemblable que la lampe ait été

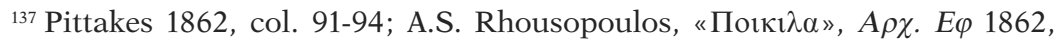
col. 39 (\&9).

${ }^{138}$ Paton 1927, p. 572, fig. 229, qui résume ainsi la description des fouilleurs allemands : «Es war ein seltsames Zusammentreffen dass letzter Fund gerade in der mittleren Cella gemacht wurde, die von mir als oikema des Poseidon bezeichnet ist». Dans la notice grecque de Pittakes 1862, col. 91, la description

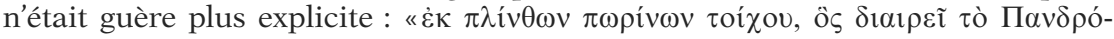

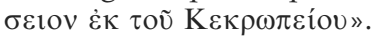

${ }^{139}$ Stais 1910 , p. 276-277 avec fig. Ainsi, la très courte notice légèrement antérieure de Ridder 1896, p. 139-141, n ${ }^{\circ} 425$, fig. 95, n'en fait-elle pas encore mention. Basch 1987, loc. cit.; Holtzmann 2003, p. 183.

${ }^{140}$ L'auteur de Johnston 1985, p. 78 insiste sur le fait que l'usage du bronze pour une lampe de l'âge classique est rare, ce qui accentue sa destination votive.

${ }_{141}$ Archaïque : Basch 1969, p. 442-443 (datation reprise dans ses publications postérieures) : «D’après la forme des lettres gravées sur la coque, elle a été attribuée au IVe s. a.C., mais l'aspect du navire est clairement celui d'une galère du $\mathrm{VI}^{\mathrm{e}} \mathrm{s}$. : ou bien la lampe est une copie du $\mathrm{IV}^{\mathrm{e}} \mathrm{s}$., ou bien les lettres ont été inscrites ultérieurement.»; Ve s. : Morrison \& Williams 1968, p. 49, 178-179 (n ${ }^{\circ}$ Clas. 20, pl. 27) et Romero Recio 2000, p. 12-13; IVe-III e s. : Göttlicher 1978, loc. cit. 
offerte après cette date ${ }^{142}$ ou selon d'autres, re-consacrée à cette occasion $^{143}$.

\section{c) Syracuse}

Dans le sanctuaire syracusain de Déméter et Koré, un bothros a livré notamment un fragment de barque céramique, daté de l'époque de Hiéron, i. e. vers 478-466. Par ailleurs, à Avola, site maritime au sud de Syracuse, une figurine de rameur acéphale, personnage qui accompagne parfois les modèles navals, figure parmi un ensemble d'objets votifs lié au stirpe de Déméter, daté entre le milieu du $\mathrm{IV}^{\mathrm{e}} \mathrm{s}$. et les premières décennies du $\mathrm{III}^{\mathrm{e}} \mathrm{s}$. a.C. Sur les dix-huit bateaux miniatures recensés en Sicile par B. Basile, ce sont les seuls provenant d'espaces consacrés. Étant donné le caractère chtonien du culte de la déesse en Sicile et la présence majoritaire des autres objets de cet type dans des contextes funéraires, ces deux embarcations sont interprétées comme un symbole du voyage vers l'au-delà ${ }^{144}$.

\section{Époque hellénistique}

a) Objets de bronze ou céramiques

\section{- Délos}

Parmi les comptes du temple de l'Apollon délien, figure

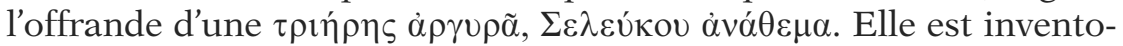
riée avec indication de son poids (1544 drachmes) dans le compte d'Hypsoclès daté de 279 a.C. 145 (voir annexe p. 557). Le même objet figure dans les comptes du hiérope Démarès daté des années 180 a.C. ${ }^{146}$, ainsi que dans ceux d'Amphiclès de 169 av. ${ }^{147}$ (voir annexe, ibidem). Les trois pierres inscrites proviennent des abords

${ }^{142}$ Delivorrias 1987, p. 197 n 97; la notice ajoute qu'elle était «most probably a votive offering from a ship's captain».

${ }^{143}$ Pour Morrison \& Williams 1968, loc. cit., la lampe a pu être consacrée au premier temple d'Athéna, d'où la facture ancienne de l'objet, pour ensuite être redéposée dans le nouveau temple de la déesse et à cette occasion être gravée de la dédicace. Cette hypothèse est reprise dans Johnston 1985, p. 78.

${ }^{144}$ Basile 1991, p. 23 resp. no 12 et 10, p. 34-38; Hermary 2000b, p. 53. Sur le sanctuaire syracusain de Déméter et Koré à Piazza della Vittoria, voir Coarelli \& Torelli 1997, p. 246-247.

${ }^{145} I G$ XI, 2 (= ID), 161, B, 1. 78.

${ }^{146}$ Inventaire $I D 442 \mathrm{~B}, 1$. 31. La première édition du texte fut donnée par Homolle 1882, p. 32, 1. 31.

${ }^{147}$ ID 461, Ba, l. 39. 
du Monument des Taureaux. Lors de sa première publication, l'objet fut interprété comme un "vase», d'après une définition donnée par Athénée d'un rhyton ${ }^{148}$. Cependant rien ne permet d'affirmer catégoriquement cette hypothèse, car l'exemple donné par Athénée renvoie davantage à un hapax poétique qu'à une désignation courante d'un type de vase. Par ailleurs, il suffit de renvoyer à la trière de Lysandre mentionnée ci-dessus pour attester l'existence de modèles réduits naviformes en métal précieux ${ }^{149}$.

Dans un inventaire du milieu du II ${ }^{\text {s. a.C. }}{ }^{150}$ (voir annexe), une offrande du même Séleucos est répertoriée pour le temple d'Apollon, mais il s'agit cette fois d'une tétrère pourvue d'accessoires ${ }^{151}$, pesant au total 1700 drachmes. F. Dürrbach, en opposition avec W. W. Tarn, pense que les deux bateaux ne font qu'un ${ }^{152}$.

Le roi Séleucos auteur de cette offrande ne peut être que Séleucos I ${ }^{\mathrm{er}}$, le fondateur de la dynastie, héritier d'Alexandre, qui mourut en 281. La datation de la première mention de son bateau ex-voto ne permet pas de préciser les circonstances du don, puisqu'elle est postérieure de deux ans à la mort du diadoque. Les occasions n'ont pas dû manquer à cet homme ambitieux de remercier Apollon d'une heureuse issue maritime ${ }^{153}$.

Outre ce cas, des inventaires datés des années 364 à 353 a.C. ${ }^{154}$ (voir corpus p. 559-560) mentionnent comme offrandes sans confu-

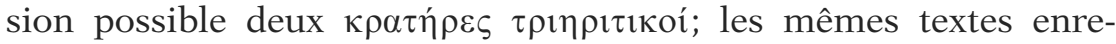

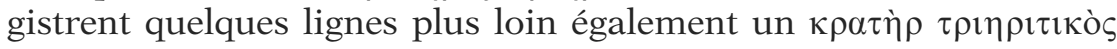

${ }^{148}$ Homolle 1882, p. $108-19,116$ et 130 , note 6.

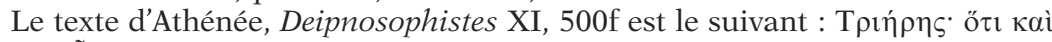

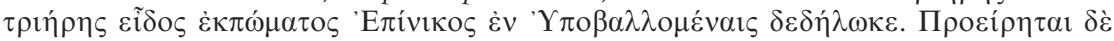

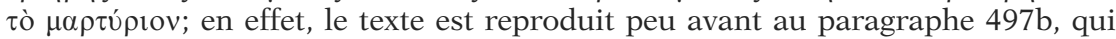
traite des rhytons.

${ }^{149}$ F. Durrbach, auteur des $I D$, p. 164 ainsi que Tarn 1909, p. 282, note 103 rejettent l'interprétation de T. Homolle.

${ }^{150}$ Inventaire dit de Phaidrias (archonte vers 153/2), ID 1432 Ab, II, 1. 55-56; publié pour la première fois avec commentaires par Dürrbach 1903, p. 543, 1. 54-55. La pierre provient de la même zone que les trois citées précédemment.

${ }^{151}$ Sur l'expression utilisée, voir édition du texte en annexe.

${ }^{152}$ F. Durrbach, ID 442, p. 164, suivi par Déonna 1938, p. 197; la vision de Tarn 1909, est quant à elle soutenue par Johnston 1985, p. 134.

${ }^{153}$ Notamment lorsque son royaume acquiert une façade maritime importante et que sont fondés des ports en liaison avec Antioche. Sur Séleucos I ${ }^{\text {er }}$, voir Bouché-Leclercq 1913, p. 21-51; la pl. I présente des monnaies de Séleucos, qui montrent quelques liens avec le monde maritime : la $\mathrm{n}^{\circ} 1$ avec le type de la Nikè à la stylis; la $\mathrm{n}^{\circ} 3$ figurant une ancre «l'emblème de famille des Séleucides».

${ }^{154}$ Le plus ancien, l'inventaire dit de Timocratès de 364/3, ID 104, 1. 131 (première publication Homolle 1886, p. 466, 1. 131, dernière Prêtre 2002, p. 39-47) provient de la même zone que les précédents. Deux autres inventaires fragmentaires presque identiques à celui-ci ont été retrouvés sur l'Acropole d'Athènes : ID 104-11 B, 1. 24-25; ID 104-12, 1. 103. 
$\kappa \alpha \tau \varepsilon \alpha \gamma \omega ́ s \chi \alpha \lambda \kappa \widetilde{0}^{155}$. Ces paragraphes concernent les objets déposés dans le temple d'Apollon des Déliens - à cette date, plutôt dans le Pôrinos $\operatorname{NaOs}^{156}$ - qu'il est tout à fait légitime de reconnaître comme des cratères en forme de trière ${ }^{157}$. On connait pour cette période des vases en forme de proue de bateau ${ }^{158}$, mais ils ne correspondent pas à l'expression utilisée dans cet inventaire; les exemples de vases reproduisant un bateau dans son intégralité sont plus anciens ${ }^{159}$. Il est difficile, en l'absence d'autre témoignage, de savoir si c'est la formulation qui est imprécise, ou s'il s'agit là d'un type inédit de don. Néanmoins le choix de la forme des vases comme offrande est à noter, d'autant que dans ces mêmes listes figure un troisième groupe d'objets marins $^{160}$.

À l'époque hellénistique, sont donc à retenir pour Délos quatre attestations sûres de bateaux miniatures : une en argent et trois vases naviformes. En effet, nous n'avons pas jugé bon de retenir les nombreuses lampes en forme de bateau trouvées à Délos ${ }^{161}$. Leur présence dans l'île et dans le sanctuaire paraît plutôt relever d'un usage pratique : l'emplacement des objets au moment de leur découverte - quand elle est précisée - ${ }^{162}$ ne semble pas suggérer des ex-voto, même si le motif peut être rattaché au caractère maritime du lieu et du dieu.

Enfin les fouilles de Délos ont par ailleurs mis au jour un bateau de plomb de petite taille, peut-être d'époque romaine, mais donc le contexte n'est malheureusement pas précisé ${ }^{163}$.

${ }^{155}$ ID 104, 1. 135; ID 104-11 B, 1. 27-28; ID 104-12, 1. 106.

${ }^{156}$ Le Grand temple n'est en effet pas achevé à cette date : Prêtre 2002, p. 39-47; Bruneau \& Ducat 2005, p. 182-187 (n 11-12).

${ }^{157}$ Nous avons retenu l'interprétation de Déonna 1938, p. 197, plutôt que celle de J. Coupry, ID 104, p. 45, qui propose celle d'«un type de cratère utilisé sur les navires".

${ }^{158}$ Des rhytons : voir par exemple Göttlicher 1978, p. 11 et 358, 360; Basch 1987, fig. 884 (apulien, IVe s.); ibid., fig. 815 (Vulci, ép. hellénistique).

159 Basch 1987, fig. 484-485 (Göttlicher 1978, $\mathrm{n}^{\circ}$ 351) : rhyton et canthare béotiens, respectivement $\mathrm{VII}^{\mathrm{e}}$ et $\mathrm{VI}^{\mathrm{e}} \mathrm{s}$. Rappelons les offrandes déliennes de poissons à Brizô dans des oKápaı (Athénée VIII, $335 \mathrm{a}-\mathrm{b}$ ).

${ }^{160}$ Des éperons de trières : voir infra, sur offrandes de parties de bateaux.

161 Johnston 1985, Hell. 14-30.

${ }^{162}$ C'est finalement la position qu'adopte Johnston dans la synthèse générale sur l'époque hellénistique p. 92 et au travers des commentaires internes au catalogue. Les contextes précisés sont en effet les suivants : quartier du théâtre, remblais du lac sacré, Agora des Italiens, Maison des Comédiens, rue de l'Est: autrement dit pas de réel contexte religieux.

${ }^{163}$ Inv. A 3882, longueur 9 cm. Déonna 1938, p. 197 et pl. xxi, fig. 234. 
- Bouthrotos

Une inscription trouvée à Butrint avant la Première Guerre mondiale évoque la dédicace de bateaux. L'auteur de cette épigramme votive ${ }^{164}$, Barbaros, en a offert deux à Zeus Kassios en remerciement d'une traversée réussie. La forme de ces ex-voto peut être devinée grâce à la promesse du dédicant de consacrer un troisième bateau au dieu, si celui-ci lui octroie la richesse, mais cette fois en or. Les embarcations qu'a réellement offertes Barbaros sont sans conteste des modèles réduits, d'un métal moins noble - bronze, argent - ou même de céramique. Non sans naïveté ou ironie, le dédicant avoue adapter la taille du bateau à la qualité de la navigation. L'inscription est gravée sur un cippe retrouvé dans un édifice thermal de Bouthrote dans de la terre rapportée. L. Robert la date d'après des critères épigraphiques du $\mathrm{II}^{\mathrm{e}}$ s. a.C.; il la suppose venir de Kassiopè, c'est-à-dire de la ville de Corfou située à peu près de l'autre côté du détroit en face de Butrint. Cependant, on conçoit mal comment et pourquoi elle aurait été transportée par voie de mer de Kassiopè à Butrint. On peut tout simplement y voir une dédicace déposée à Bouthrotos concernant un dieu honoré dans cette zone.

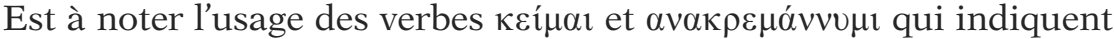
la manière dont sont présentés les ex-voto, les plus nobles accrochés sans doute à hauteur de vue.

- Failaka

Six bateaux fragmentaires de terre cuite modelée ont été mis au jour lors des fouilles du sanctuaire extra-urbain hellénistique d'Artémis sur l'île de Failaka, l'ancienne Ikaros (voir supra, p. 212$213)^{165}$. Même s'ils proviennent de secteurs divers du bâtiment ${ }^{166}$, ils appartiennent tous à la seconde phase du temple, datée de la seconde moitié du $\mathrm{II}^{\mathrm{e}}$ s. a.C. Leur fabrication est locale, mais non pas spécifique car les fouilles antérieures d'Ikaros ont livré dix-sept autres objets de ce type, tous hellénistiques, du $\mathrm{II}^{\mathrm{e}}$ s. a.C. semblet-il ${ }^{167}$. La plupart d'entre eux présentent un trou, à la poupe et/ou à la poupe (fig. 28).

${ }^{164}$ Cabanes \& Drini 2007, no 186 p. 180 et pl. 97; Bull. épigr. 1944, n 119a;

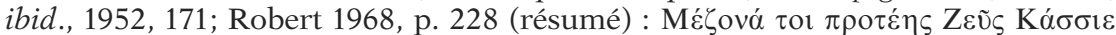

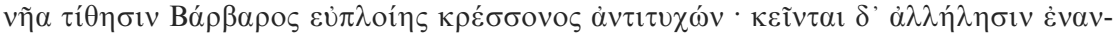

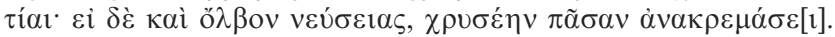

165 Salles 1984, p. $98 n^{\circ} 205$ et fig. $45 ;$ p. 104 n $^{\circ} 255-256$ et fig. 47 et 67 [dans la fig., le no 455 est à lire 255]; p. $116 \mathrm{n}^{\circ} 328-330$ et fig. 52 et 67 ; commentaire p. 141.

${ }^{166}$ Respectivement du locus 117 (pronaos), du locus 128 (cour avec matériel votif) et secteurs indéterminés : cf. ibid., p. 87-90 et relevé général fig. 35.

${ }^{167}$ Ibidem, p. 181; Mathiesen 1982, p. 25-28 n 47-63. 

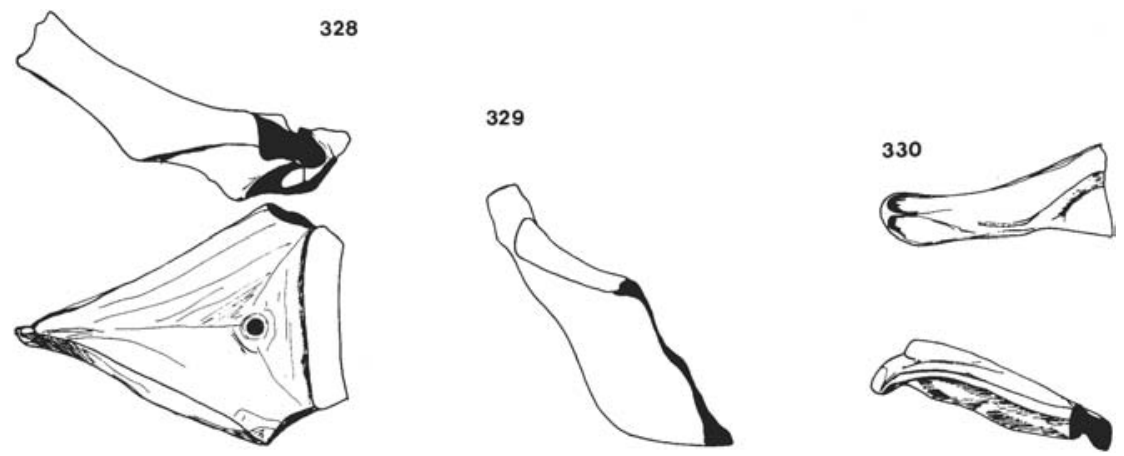

Fig. 28 - Modèle(s) de bateau(x) de Failaka (d'après Salles 1984, p. 117).

Il paraîtrait donc que l'offrande de bateaux miniatures soit une pratique courante dans l'île à cette époque, puisque presque tous ont été trouvés dans un contexte religieux : les six premiers dans ce temple grec d'Artémis, les autres dans un temple gréco-oriental situé à l'intérieur de la forteresse (voir supra p. 212-213) ${ }^{168}$. De surcroît, cette pratique serait plus grecque qu'indigène, développée dans un milieu séleucide sous les règnes d'Antiochos II à Antiochos III.

\section{- Cas-limite : Sparte}

Il convient de signaler, en marge des objets mis au jour dans un contexte religieux déterminé, un dernier cas. Il s'agit d'une maquette de bateau de guerre en terre cuite trouvée dans les eaux de l'ancien port de Sparte, Gytheion, qui semble n'être associée à aucune épave ou quelconque structure. Par son architecture, il est daté entre la seconde moitié du $\mathrm{I}^{\mathrm{er}} \mathrm{s}$. a.C. et la première du siècle suivant. Des appliques devaient orner l'embarcation comme en témoignent des petits trous percés placés de manière régulière, tandis que la poupe est ceinte d'une draperie. L'objet est pour toutes ces raisons considéré comme un ex-voto, peut-être volontairement jeté à la mer ${ }^{169}$.

${ }^{168}$ Ibidem, p. 9-11; c'est devant ce temple que les fouilleurs ont trouvé l'inscription SEG XX, 411. Romero Recio 2000, p. 14-15 les considère comme dédiés à Poséidon. $58 \mathrm{~cm}$.

${ }^{169}$ Basch 1987, p. 428-435; Höckmann 1985, p. 99, 158 fig. 67; longueur : 
- Parallèle d'époque impériale

Un magnifique exemple d'ex-voto naviforme de bronze nous est connu pour l'époque impériale dans la partie orientale de l'empire. Il s'agit du bateau de bronze de Beth-Maré (Syrie), dédié à Zeus Baithmarès en 121/2. L'objet porte en effet l'inscription suivante : ETOY $\Sigma$

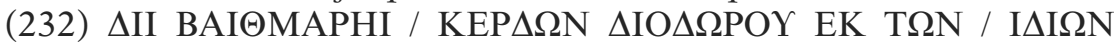
ANE@HKEN ${ }^{170}$. L'épithète du dieu, inconnue par ailleurs, est un toponyme ${ }^{171}$. L'objet, conçu à l'origine pour être suspendu par une chaîne, a été transformé en lampe; cependant l'inscription appartient au premier état du bateau. Celui-ci, de réalisation très soignée et détaillée, s'apparente à une nef de commerce sidonienne.

\section{b) Bases naviformes en pierre}

L'époque hellénistique voit la création d'un nouveau type architectural : celui de la base statuaire monumentale en forme de bateau, ou plus exactement de proue ${ }^{172}$. Un certain nombre d'entre eux constitue des offrandes à des sanctuaires de la part de cités suite à des victoires navales, servant à la fois de monument commémoratif et d'exaltation de puissance ${ }^{173}$. Même si l'on ne peut parler véritablement d'ex-voto de bateau, il nous paraît cependant juste de les intégrer parmi cet inventaire. En effet, la présence du bateau dans le groupe architectural dédié aux divinités renvoie à un contexte marin indéniable, à un événement déroulé dans le monde maritime pour lequel on remercie les dieux. Il rend compte du même esprit que les offrandes simples de bateaux; le groupe architectural en est une variante élaborée, doublement symbolique.

${ }^{170}$ Seyrig 1951; Basch 1987, p. 455-456. Le bateau mesure $38 \mathrm{~cm}$.

${ }^{171}$ Aujourd'hui Bmaria, au nord d'Aithenit (Liban).

${ }^{172} \mathrm{La}$ base de la statue délienne d'Euthycartidès datée de la fin du VII ${ }^{\mathrm{e}} \mathrm{s}$. a.C., parfois considérée comme la première représentation d'une proue de bateau servant de support statuaire, n'est pas admise par P. F. Johnston comme recevable : voir Johnston 1985, Arch. 53 et p. 51-52.

${ }^{173}$ Dans le cadre de notre étude, nous avons exclu quelques exemplaires placés en dehors de sanctuaires et sans dédicace, même si par analogie ces groupes architecturaux peuvent être vraisemblablement considérés comme monuments commémoratifs d'une victoire navale. Ne figurent donc pas dans cet inventaire la base en forme de proue de l'agora de Thasos (Johnston 1985, Hell. 8; Grandjean \& Salviat 2000, p. 77), ni celle de l'agora de Cyrène (Johnston 1985, Hell. 31; Göttlicher 1978, no 485; Basch 1987, p. 391). De la même façon nous ne pouvons retenir dans les limites de cette étude l'exemple le plus connu, celui de la Victoire de Samothrace (Johnston 1985, Hell. 6; Göttlicher 1978, n 369), consacré au sanctuaire des Grands Dieux. 
- Épidaure

La base en forme de bateau qui se trouve sur l'Agora d'Épidaure ${ }^{174}$ est considérée à ce jour comme l'exemple le plus ancien de ce type architectural; il est daté vers 300 a.C. Il s'agit plus précisément de la représentation d'une proue de navire brisant les vagues, servant de socle à une statue aujourd'hui disparue, que certains restituent comme une Nikè ${ }^{175}$. Le groupe est placé à l'angle sud-est du bâtiment $\mathrm{K}$ de l'agora, juste à l'extérieur de l'enceinte du sanctuaire d'Asclépios ${ }^{176}$. Des inscriptions ont été rattachées à ce monument : deux signatures, peut-être du réalisateur de la base et de celui de la statue $^{177}$, ainsi que deux dédicaces ${ }^{178}$. La première d'entre elles, incomplète, qui s'adresse aux $[\pi \tilde{\alpha} \sigma 1($ ?) $] \tau$ oĩ $\theta \varepsilon$ oĩ $\varsigma$, renvoie sans doute

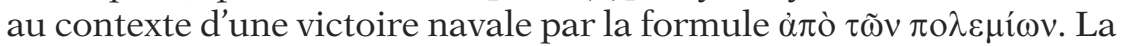
seconde nomme Apollon, Asclépios et Hygie comme divinités ainsi honorées, à la suite du nom du dédicant Lucius Mummius. Le groupe architectural, érigé sur un butin pris à la suite d'une victoire sur mer dans les années 300 a.C. ${ }^{179}$, a ensuite été récupéré et réapproprié par Mummius - le destructeur de Corinthe $-{ }^{180}$ après 146, qui a précisé ou limité les destinataires de l'offrande.

- Lindos

À Lindos, une base de statue fragmentaire présente la forme d'une proue de navire brisant les flots; la statue, quant à elle, a disparu (fig. 29).

Le groupe de marbre, dont les quatre assises de blocs de marbre sont de couleur différente de façon à rendre un dégradé de gris, est daté des années 265-260 ${ }^{181}$. Il se trouve aujourd'hui sur l'acropole, en arrière du mur est de la stoa ${ }^{182}$. La dédicace partiellement

${ }^{174}$ Johnston 1985, Hell. 4; Göttlicher 1978, nº 368.

${ }^{175}$ Hypothèse, on l'imagine aisément, basée sur le modèle de la Victoire de Samothrace : cf. Marcadé 1946, p. 149, note 2; Blinkenberg 1938, p. 32 note 1.

${ }^{176}$ Johnston 1985, p. 93; Cavvadias 1891, p. 38-39 n 18-20. Lehmann \& Lehmann 1973 1973, p. 193 note 16 jugent que le groupe a été remanié et déplacé dans l'Antiquité : la position actuelle ne serait donc pas celle d'origine et l'on serait devant un exemple de «ship-fountain».

${ }^{177} I G \mathrm{IV}^{1}, 1181-1182 ; I G \mathrm{IV}^{2}, 1,306 \mathrm{~b}-\mathrm{c}$.

${ }^{178} I G$ IV $^{1}, 1180$ et 1183 ; IG IV $2,1,306$ A et D.

${ }^{179}$ La datation donnée par M. Fraenkel dans les $I G$ est trop basse : cf. Lehmann \& Lehmann 1973, suivis par Johnston 1985, p. 93, p. 159 note 50.

${ }^{180}$ Sur Mummius, voir Will 1979-82, II p. 394 ss.

${ }^{181}$ Johnston 1985, Hell. 5; Göttlicher 1978, n 367; Marcadé 1946, p. 147-152, avec bibliographie antérieure; Basch 1987, p. 362-363.

${ }^{182}$ Comme pour le groupe d'Épidaure, Lehmann \& Lehmann 1973, p. 193 note 17 , considèrent que l'emplacement actuel des vestiges n'est pas celui d'ori- 

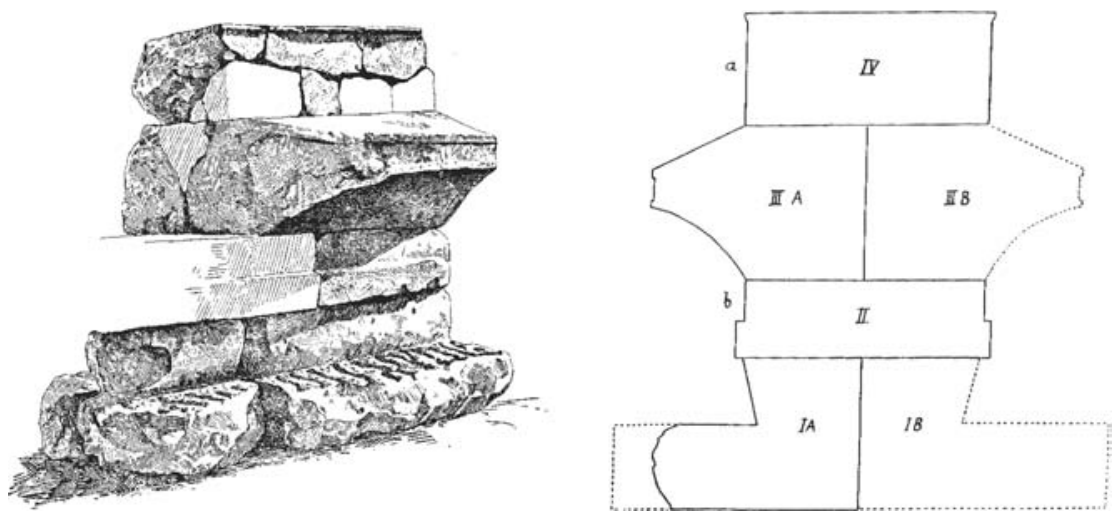

Fig. 29 - Base naviforme de Lindos : vue et coupe (d'après Blinkenberg 1941, p. 304 et 306).

conservée ${ }^{183}$ indique clairement la divinité ainsi honorée, Athéna Lindia, dont le temple est voisin. Le monument devait ainsi commémorer la victoire d'une flotte de six (?) bateaux, de la part des officiers supérieurs et de membres de l'équipage énumérés dans

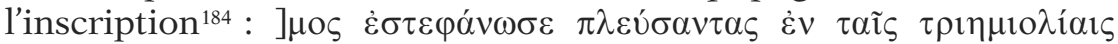

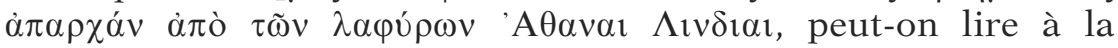
deuxième ligne (fig. 30).

La flotte rhodienne a consacré à sa divinité poliade une part du butin, remporté suite à un combat naval couronné de succès ${ }^{185}$, par cette réalisation architecturale. En considération de la dédicace, il ne semble pas incongru de restituer une Athéna comme figure surplombant la proue ${ }^{186}$.

gine et qu'on ne peut donc rien conclure de leur position; là encore, il s'agirait d'un «ship-fountain». Contra: Johnston 1985, p. 93 et note 55.

${ }_{183}$ Blinkenberg 1938, p. 30-37 et 43-44; Blinkenberg 1941, n 88, col. 301-313 et 1011 avec une description détaillée des vestiges. L'inscription a par ailleurs été partiellement publiée dans IG XII, 1, 766.

${ }^{184}$ Blinkenberg 1941 restitue 288 membres d'équipage. L'un des officiers cités, le triérarque Agathostratos fils de Polyaratos, est connu par ailleurs : il est navarque en 258 lors de la bataille d'Éphèse (Polyen V, 18).

185 Blinkenberg 1941, col. 1011 parle de lutte contre "des pirates», sans que rien ne vienne étayer cette affirmation.

${ }^{186}$ Johnston 1985, p. 94. En rapprochement avec le monument de Samothrace, C. Blinkenberg 1941, col. 301, y place une Nikè. 


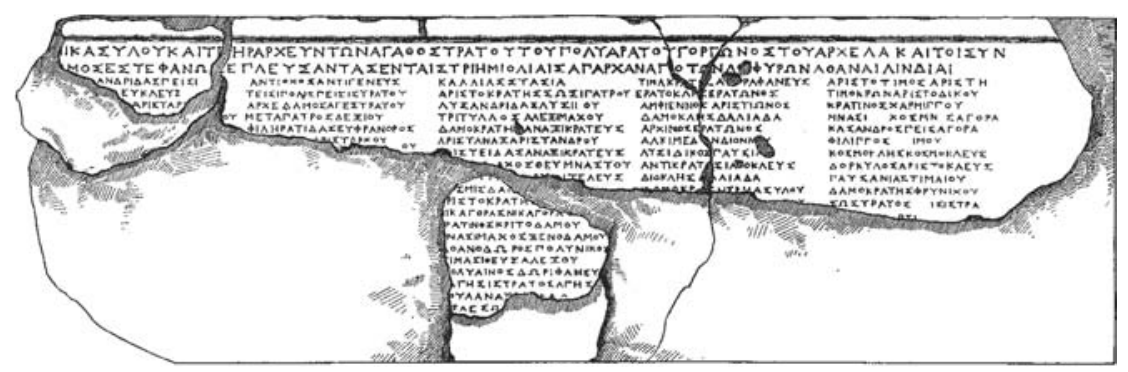

Fig. 30 - Inscription de la base naviforme de Lindos (d'après Blinkenberg 1941, p. 309).

\section{Conclusion}

Pour l'époque archaïque, les exemples sont nombreux : cinquante-neuf objets. Ces découvertes sont d'autant plus intéressantes que certains ont révélé une concentration de ce même type de matériel, révélant ainsi des offrandes multiples. L'inscription de Samos indique par ailleurs qu'un même homme peut faire don de plusieurs bateaux de taille réduite en une fois. Ces inscriptions laissent soupçonner aussi que la pratique de consacrer des modèles réduits de bateaux est plutôt le fait d'individus que de cités ou de gouvernants; au plus peut-il s'agir d'un groupe de personnes naviguant ensemble, comme on l'a supposé pour les ex-voto en bois de Samos.

À l'époque archaïque, ce sont essentiellement des divinités féminines qui sont ainsi honorées: Héra vient en première place ${ }^{187}$, suivie par Aphrodite et Aphaia. Poséidon et Apollon font l'objet de dons plus sporadiques. Il est à noter également que les trois bateaux de bronze archaïques archéologiquement existants ne sont pas grecs mais sardes. Deux d'entre eux sont consacrés à Héra dans deux sanctuaires de Grande Grèce. Deux possibilités sont envisagées par les commentateurs : soit il s'agit de dons dans un sanctuaire grec d'objets acquis ailleurs par un Grec - sur place ou par des intermédiaires - et considérés pour cela même de valeur, soit il s'agit d'offrandes de navigateurs sardes ${ }^{188}$.

${ }^{187}$ Polignac 1997 insiste sur le caractère homogène et sériel des bateaux consacrés à la déesse.

${ }^{188}$ Dans les publications, le plus souvent, c'est la première hypothèse qui est envisagée. La seconde est défendue notamment par Lilliu 2000 qui, après avoir penché pour la première (Lilliu 1971, p. 294), recense plusieurs cas d'offrandes sardes dans des sanctuaires grecs. 
À l'époque classique, la pratique se raréfie. Les seuls exemples connus de terre cuite sont rattachables au culte de Déméter et revêtent peut-être une symbolique davantage funéraire que maritime ${ }^{189}$. Les deux autres bateaux miniatures de cette période consistent en des objets de valeur consacrés respectivement à Apollon et Athéna dans de grands sanctuaires.

De la même manière à l'époque hellénistique, en Méditerranée, l'offrande du bateau de terre cuite n'est peut-être attestée que dans un seul cas tandis que l'on offre des ex-voto précieux, pratique qui se poursuit à l'époque romaine. En revanche, le matériel se diversifie : il ne s'agit plus vraiment d'embarcations mais d'objets en forme de bateau - vases ou bases de statues -. Les dédicants sont variés, du simple particulier qui déplore son manque de richesse à l'équipage d'un navire jusqu'au souverain hellénistique ou conquérant romain. Les motifs de remercier les divinités s'avèrent d'ordre différent, mais chacun s'efforce de s'acquitter de ses devoirs envers elles à la mesure de ses moyens. L'inscription de Bouthrotos montre aussi que l'on peut offrir plusieurs fois le même type d'ex-voto, et ce à la même divinité. Les dieux concernés par ces dons semblent être essentiellement Apollon et Zeus, mais aussi Athéna, ainsi qu' Artémis, à qui l'on voue, aux confins du monde grec, des artefacts de terre cuite.

La pratique de consacrer des modèles réduits de bateaux suit ainsi une évolution bien marquée durant toute l'Antiquité grecque. Très forte à l'époque archaïque, elle paraît se raréfier à l'époque classique pour à nouveau se développer à l'époque hellénistique ${ }^{190}$. Les formes qu'elle peut prendre sont très diversifiées : modèles de bois, céramique, bronze, argent, or, ivoire, pierre. La céramique et le bronze sont des matériaux utilisés de manière continue et simultanée durant les trois périodes. Les métaux précieux n'apparaissent qu'à l'époque classique et leur usage se poursuit durant l'époque hellénistique.

Les dieux à qui sont consacrés ces ex-voto varient cependant d'une époque à l'autre. On peut noter tout d'abord l'absence particulièrement frappante de Poséidon durant toute l'époque classique et l'époque hellénistique, faisant suite à une présence secondaire à

${ }^{189}$ Signalons pour cette période l'existence d'autre bateau fragmentaire de terre cuite, retrouvé sur l'acropole de Lipari (Museo archéo. Eoliano, inv. 15990), dans le bothros d'Éole ou à proximité. Le navire de guerre, daté de la fin du VI ${ }^{\mathrm{e}}$ ou du début du $\mathrm{V}^{\mathrm{e}} \mathrm{s}$. présente un éperon et un œil apotropaïque. Malgré le manque d'informations sur cette découverte, on a proposé d'y voir un ex-voto après les actions navales victorieuses des colons grecs de Lipari contre les Étrusques (Johnston 1985, Clas. 1; Spigo 1991, p. 71-74; Tusa 2010, p. 6 avec fig.).

${ }^{190}$ Dans Johnston 1985 , p. 125, une observation similaire est faite à propos des maquettes de bateaux de façon générale. 
l'époque archaïque. En revanche, la consécration de bateaux miniatures à Apollon est constante durant huit siècles, devenant importante à partir de l'époque classique. Héra et Aphrodite ne reçoivent plus de ces offrandes après l'époque archaïque, tandis qu'Athéna absente à cette période est de nouveau honorée de cette manière pour les deux suivantes.

\section{IMAGES DE BATEAUX}

À défaut d'offrir un bateau réel ou son modèle réduit, se présente une troisième possibilité : sa reproduction imagée ${ }^{191}$. En effet, nous possédons un certain nombre de cas archéologiques d'images de bateaux explicitement dédiées à des divinités ou du moins provenant d'un contexte religieux manifeste ${ }^{192}$. Nous pouvons les classer selon les techniques utilisées; ainsi, viennent en premier lieu les sculptures en bas-relief - intermédiaires entre la représentation en trois dimensions des modèles réduits et celle bidimensionnelle -, puis les exemples de peinture sur support de bois, mural ou encore céramique. Une troisième catégorie concerne les cas problématiques de graffiti (voir infra tableau p. 613).

\section{Sculpture}

a) «Bateaux de pierre»

À la limite entre le don de bateau réel, celui de son modèle réduit - plus précisément les bases naviformes lithiques - et celui de son image, est à placer un témoignage curieux et difficile d'interprétation. Au VI e s. de notre ère, Procope (De Bello Gothico IV, 22, 23-29) signale, dans un passage consacré à Corcyre, deux bateaux de

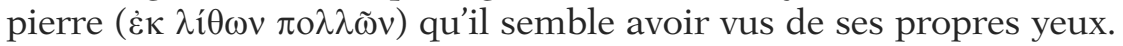

L'un, l'embarcation qui aurait conduit Ulysse vers Ithaque, se trouve sur le rivage des Phéaciens, sur le territoire d'une ville appelée Cassopée. Il porte une dédicace à Zeus Kassios, considéré alors par Procope à l'origine du nom de la cité. Celle-ci doit être

${ }^{191}$ Wachsmuth 1967, p. 141, note 246.

${ }^{192}$ Ainsi certaines représentations connues ne figurent pas dans ce développement: par exemple le fameux relief lindien représentant une poupe de navire (Blinkenberg 1941, col. 431 ss; Dyggve 1960; Lehmann \& Lehmann 1973, p. 189 et fig. 6; voir supra p. 267-268 et fig. 17). 
comprise comme la Kassiopè située au nord-est de l'île de Corfou, face à la côte albanaise ${ }^{193}$.

Le second bateau aurait été consacré par Agamemon, suite au départ enfin réussi des Grecs pour Troie. C'est Artémis que le chef de l'expédition a ainsi remerciée, sur la pointe sud-orientale d'Eubée, à Géraistos ${ }^{194}$. Procope nous rapporte ce qui subsiste de la dédicace figurant sur le vaisseau de pierre, à propos de l'authenticité de laquelle il s'interroge par ailleurs; celle-ci s'adresse à une Artémis Bolosia ${ }^{195}$. L'étude de la formulation de la dédicace a daté celle-ci du $\mathrm{VI}^{\mathrm{e}}$ s. a.C. ${ }^{196}$, ce qui placerait ce bateau ex-voto parmi les plus anciens connus.

Pour P. F. Johnston ${ }^{197}$, il s'agit de deux maquettes de bateaux de type sculptural, qu'il rapproche des exemples hellénistiques présentés dans son corpus. Cependant, ces derniers sont différents des structures décrites par Procope : les représentations hellénistiques en pierre reproduisent des proues de navire, et non des bateaux en entier. Or, Procope parle bien de $\pi \lambda$ oĩov tout au long de ce passage. De plus, l'insistance mise sur la grande quantité de blocs utilisée ${ }^{198}$, de même que l'emplacement de celles-ci, sur des rivages, apparemment sans aucune relation avec un quelconque bâtiment, renvoient à des embarcations de taille relativement conséquente. Il est difficile par ailleurs de dater ces constructions. La tradition les fait remonter tous deux à une date très ancienne, héroïque; mais il paraît douteux de pouvoir même les dater de l'époque géométrique ou archaïque. Cette seule mention, tardive, de Procope tend à les rattacher à une date bien plus basse.

${ }^{193}$ Sur Zeus Kasios et sur son culte dans l'île de Corfou, voir supra chapitre Zeus p. 89 et 101 ss.

${ }^{194}$ Géraistos représente le port d'où fait voile Agésilas vers Éphèse après avoir rassemblé tout un corps expéditionnaire (Xénophon, Helléniques III, 4, 4), ce qui fait supposer qu'il s'agissait d'un endroit stratégique pour la navigation en direction de l'Asie.

${ }^{195}$ Sur cette épiclèse et le culte d'Artémis en Eubée, voir supra p. 192.

${ }^{196}$ Wilamowitz-Moellendorff 1919, p. 61.

${ }^{197}$ Johnston 1985, p. 134-135.

198 À ma connaissance, seul le bateau de l'île Tibérine à Rome peut rendre compte d'une construction similaire : un bateau à peu près grandeur nature, constitué de nombreux blocs, mais présentant seul le côté babord, de surcroît tronqué dans sa longueur; il est daté du Irr s. a.C. : Krauss 1944, p. 159-172; Basch 1987, p. 366-369; Lehmann \& Lehmann 1973, p. 200-201. En ce qui concerne un bateau de pierre de petite taille, on peut évoquer la possibilité d'un rapprochement avec le bateau de marbre dit «navicella», visible à Rome aujourd'hui devant l'église de Santa Maria in Domnica. Il s'agit d'une copie Renaissance d'un modèle antique; cependant la sculpture est réalisée à partir d'un seul bloc de marbre. Sur la «navicella», voir notamment Lehmann \& Lehmann 1973, p. 224-237. 
b) Époque archaïque

- Sparte

Le sanctuaire d'Artémis Orthia fouillé par les Anglais au début du siècle a livré un magnifique ex-voto, aujourd'hui exposé au Musée national d'Athènes ${ }^{199}$. Il s'agit d'une plaque semi-circulaire d'ivoire sculptée, représentant un navire qui semble sur le point d'appareiller (fig. 31). L'équipage s'affaire à des occupations diverses; des boucliers sont fixés le long de la coque.

À la poupe du bateau, un homme s'entretient avec une femme derrière laquelle se trouve un grand oiseau : la scène est interprétée généralement, vu l'origine de la plaque, comme l'enlèvement d'Hélène par Pâris. Une inscription rétrograde incisée sur la coque du bateau côté proue donne l'épithète de la déesse à qui l'offrande est faite : $F$ $o \rho(\theta) \alpha i \alpha^{200}$. L'objet provient de couches antérieures à la construction du temple vers 600; il est ainsi daté du milieu du VII ${ }^{2} .{ }^{201}$.

Deux fragments de représentations sculptées sur plaque calcaire

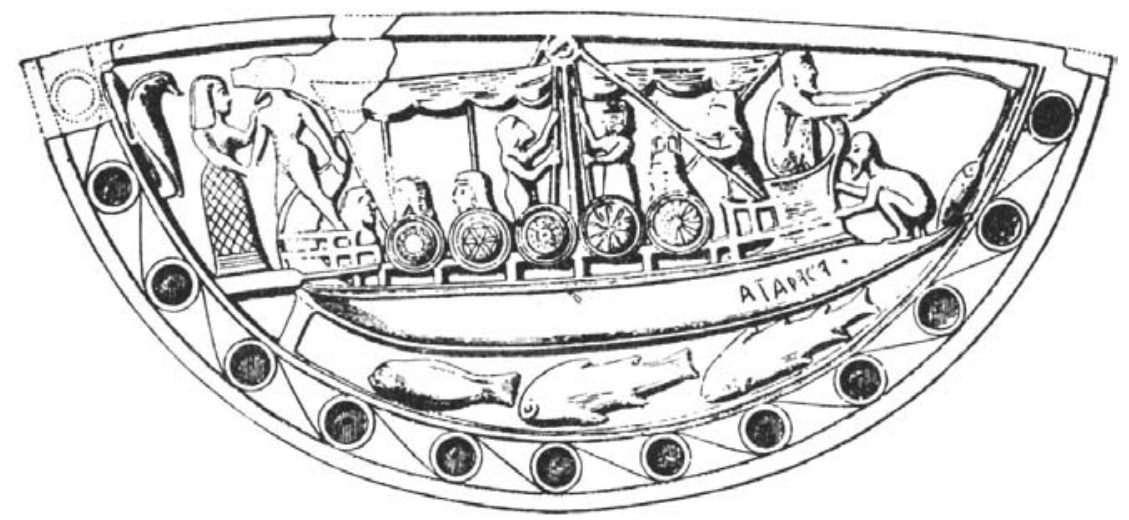

Fig. 31 - Plaque d'ivoire du sanctuaire d'Artémis Orthia à Sparte; Athènes, Musée national inv. 15362 (d'après Bass 1972, p. 42).

${ }^{199}$ Athènes, Musée national inv. 15 362; longueur 23 cm. Basch 1987, p. 239141; Delivorrias 1987, p. 40 n XI; Lacroix 1988; Fenet 2011, p. 413 et pl. 120, 2. La publication des fouilles est due à Dawkins 1929, précisément p. 214-215, pl. CIX-CX.

${ }^{200} I G$ V, 1, 252 b; Dawkins 1929, p. 370; Hondius \& Woodward 1919-1921, p. $103 \mathrm{n}^{\circ} 25$.

${ }^{201}$ Dawkins 1929, p. 211; le relief est classé parmi le «Ve style». Le sanctuaire a reçu bien d'autres offrandes, en particulier des ivoires orientaux, pouvant laisser envisager une fréquentation du sanctuaire par des Phéniciens, qui auraient assimilé la déesse locale à Astarté (Bonnet 1996, p. 95). 
- peut-être appartenant à un même relief -, proviennent du même sanctuaire spartiate d'Artémis Orthia ${ }^{202}$. Le premier, mesurant $16 \mathrm{~cm}$, figure de façon très simple un navire à voile, sous lequel apparaît l'inscription rétrograde $\Pi<\pi>\rho \alpha \xi \tilde{\imath} v o \varsigma$, qui serait celle du dédicant ${ }^{203}$. Le second, d'un travail grossier, ne présente pas d'inscription. Ces fragments sont mis en relation avec la couche de sable sur lequel le temple fut construit vers 600 av. n.è ${ }^{204}$.

\section{- Argô à Delphes}

Dans le sanctuaire de Delphes figurait une représentation archaïque de la nef Argô, sur une construction consacrée à Apollon (fig. 32).

Dans les fondations du Trésor des Sicyoniens érigé au Ve s., les archéologues ont en effet trouvé, utilisées en remploi, des métopes figurées archaïques ${ }^{205}$. Celles-ci appartenaient à un petit édifice
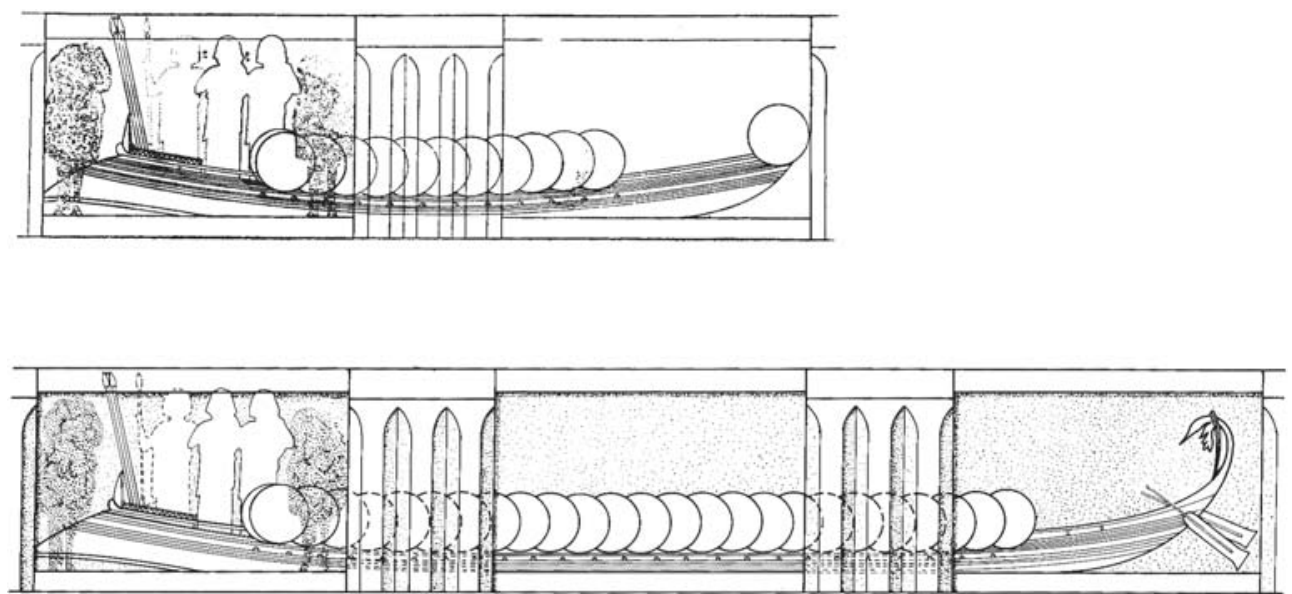

Fig. 32 - Argô à Delphes : reconstitutions à 2 et 3 métopes (d'après Salviat 1984).

${ }^{202}$ Musée de Sparte, inv. 1483. Göttlicher 1978, n 372; la publication essentielle reste celle de Dawkins 1929, p. 195 no 69 et 69a, p. 368, pl. LXXIV (repris par Romero Recio 2000, p. 13).

${ }^{203}$ SEG II, p. 13, no 75; Hondius 1919-21, p. 97-98 no 12 . Le même nom semble apparaître sur un autre fragment de plaque de pierre : ibid., $\mathrm{n}^{\circ} 13$.

${ }^{204}$ Dawkins 1929, p. 187; malheureusement la location exacte de la trouvaille de chacun des deux fragments n'est pas précisée.

${ }^{205}$ Guide Delphes 1991b, p. 42-44 avec fig. 8. 
monoptère de quatre colonnes sur cinq, sans murs, qui devait abriter une offrande offerte à tous les regards ${ }^{206}$. Son emplacement, sous le Trésor attribué par Pausanias aux Sicyoniens ${ }^{207}$, le matériau utilisé - du pôros clair - présent dans la région de Sicyone, et le style raffiné des sculptures que l'on date vers 560 tendent à rattacher le bâtiment à la cité achéenne ${ }^{208}$; nous arguerons de plus du texte d'Ampelius (Aide-mémoire 8, 4-5) qui nous paraît confirmer l'ensemble de ces indices.

Parmi les scènes représentées, figure un bateau dont il subsiste, sur une métope, la proue à gauche de laquelle, à terre, deux cavaliers figurent de face. Deux citharèdes se tiennent debout à l'avant du navire, dont le bordage est protégé de boucliers ${ }^{209}$. Une autre métope fragmentaire représente une autre partie de la même embarcation. Il faut reconnaître dans cette scène Argô et les Dioscures ${ }^{210}$. Une première analyse détaillée de la $\mathrm{P}$. de La Coste-Messelière répartit le bateau sur deux métopes et le voit à l'arrêt, une fois le débarquement terminé, avec une action des Dioscures et d'autres Argonautes représentés dans une troisième métope latérale ${ }^{211}$. Puis F. Salviat, en tentant de reconstituer le type du bateau, est arrivé à la conclusion qu'il s'agissait d'une pentécontère et que dès lors elle occupait non pas deux mais trois métopes, donc l'une des façades de l'édifice voire, avec une quatrième métope, l'un des longs côtés ${ }^{212}$. Le sujet choisi pourrait être celui de l'embarquement, avec le sacrifice à

${ }^{206}$ Guide Delphes 1991a, p. 118-123 avec fig. 41. D'après la restitution de La Coste-Messelière 1936, p. 40-54 et fig. 1, 2 et 4, l'édifice devait mesurer $429 \mathrm{~m}$ sur 557 et présenter trois métopes en façade pour quatre sur chacun des longs côtés.

${ }^{207}$ Pausanias, Description de la Grèce X, 11, 1.

${ }^{208}$ Guide Delphes 1991b, p. 44. Cependant, certains ne sont pas sûrs qu'il faille voir dans ces reliefs un don des Sicyoniens: la pratique des métopes sculptées surtout attestée pour la Grande Grèce ainsi que l'importance des Dioscures parmi les personnages représentés peuvent suggérer une offrande de la part de Grecs d'Italie, par exemple des Locriens après la bataille de la Sagra dans laquelle serait intervenus les Dioscures: La Genière 1983. Reprenant cette théorie, Szeliga 1986 qui voit dans la figure des Dioscures les personnages liés à la consécration de l'édifice, et non pas les Argonautes, interprète la scène comme une représentation des Dioscures protecteurs des marins, en mer, auprès d'Argô avec son équipage symbolisant l'universalité des bateaux depuis l'invention de la navigation.

${ }^{209}$ Devait figurer à leurs côtés un troisième personnage, disparu, signalé par des «arrachements de reliefs» et une inscription: La Coste-Messelière 1936, p. 178 .

${ }^{210}$ T. Homolle, Fouilles de Delphes IV, 1. Monuments figurés, sculpture, Paris, 1909, p. 27-33 et pl. IV, 2. Le nom d'Orphée est inscrit en peinture noire à côté du musicien de droite.

${ }^{211}$ La Coste-Messelière 1936, p. 177-198 avec fig. 8.

${ }^{212}$ Salviat 1984. 
Apollon précédant le départ ${ }^{213}$. Qu'il y ait eu sacrifice ou non, la représentation de la nef Argô, de surcroît au moment de l'embarquement ou du débarquement, évoque la personnalité d'Apollon invoqué en ces occasions. Elle célèbre la puissance du dieu, protecteur des héros et de leur navigation; sa présence sur un édifice érigé au bord de la voie sacrée à l'intérieur du sanctuaire delphien ne peut pas être dénuée de cette connotation spécifique.

\section{c) Époque classique}

\section{- Relief Lenormant}

Le relief le plus connu dans le milieu de l'archéologie nautique est peut-être à intégrer dans la liste des représentations de bateaux offertes en ex-voto (fig. 33).

Le relief Lenormant ${ }^{214}$, puisque c'est de lui dont il s'agit, pose en

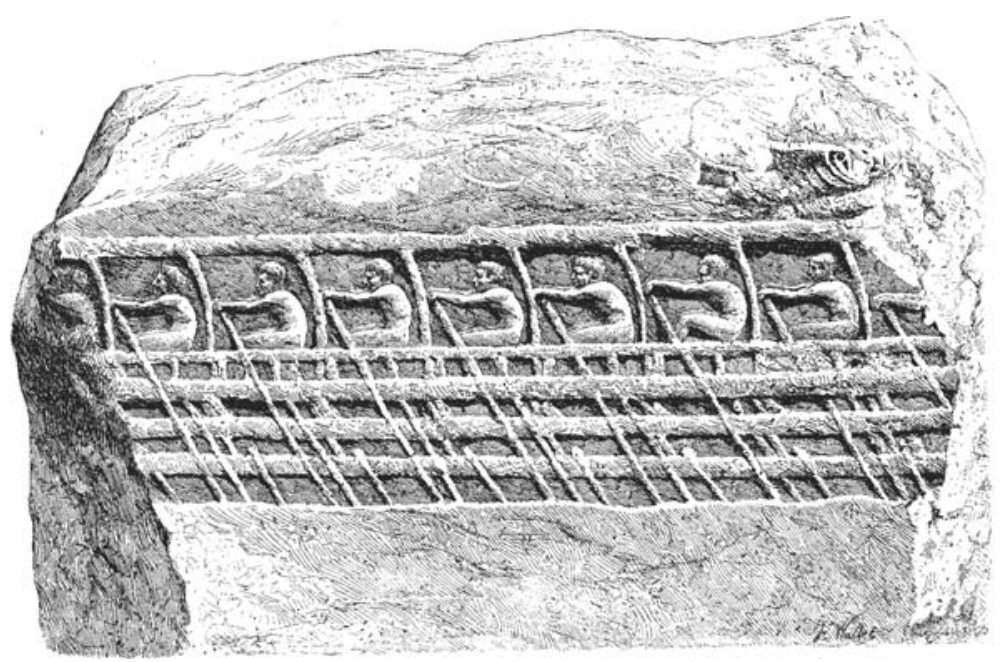

Fig. 33 - Le relief Lenormant (d'après Lemaître 1883).

${ }^{213}$ Il faut donc imaginer une action particulière dans la/une métope disparue : F. Salviat propose par exemple Jason sacrifiant au centre, ou alors à la poupe ou à la droite de celle-ci.

${ }^{214}$ Musée de l'Acropole, inv. 1339; longueur $52 \mathrm{~cm}$. Le relief est apparu dans de très nombreuses publications; nous citerons plus particulièrement Basch 1987, p. 279-283 et p. 290 ss., fig. 604, 608, 609, 621-622 (résumé par Romero Recio 2000, p. 13); Walter 1952; Delivorrias 1987, n 106; Moll 1929a, p. 20, no 82, pl. BII. 
effet un certain nombre de problèmes dus aux conditions de sa découverte. C'est le Français François Lenormant qui contribua à le faire connaître, mais il aurait été trouvé au milieu du XIX ${ }^{\mathrm{e}} \mathrm{s} .{ }^{215}$ sur l'Acropole, pour certains «sur les marches de l'Érechteion » ${ }^{216}$ quand ce n'est pas à l'intérieur du bâtiment ${ }^{217}$. Si l'on accepte ce lien avec l'édifice - mais cela n'est pas assuré -, le document serait plutôt postérieur à la construction de celui-ci, achevé en $406^{218}$.

Le relief fragmentaire, de marbre, représente de profil un bateau à rames avec rameurs à son bord. Depuis un siècle, il suscite de nombreux débats à propos de l'identification du type de navire figuré : est-ce une trière classique, un bateau à un rang de rames? L'opinion qui prévaut finalement aujourd'hui est celle de la représentation d'une trière athénienne de l'époque classique ${ }^{219}$.

La fonction du relief a également fait l'objet d'un certain nombre d'hypothèses. Il a ainsi été considéré tour à tour comme appartenant à un décor de temple sur l'Acropole ou à un monument commémoratif d'une victoire navale de la guerre du Péloponnèse ${ }^{220}$; de même on l'a associé à la trière sacrée envoyée à Délos ou à des concours nautiques ${ }^{221}$.

Signalons enfin qu'un autre fragment de relief représentant un rameur sur une trière a également été retrouvé sur l'Acropole en 1876, précisément dans les déblais de fouilles sur une pente ${ }^{222}$. Il n'est pas certain qu'il appartienne au relief Lenormant ${ }^{223}$; s'il n'en

${ }^{215}$ Les témoignages divergent quant à la date exacte de la trouvaille : 1852 selon le récit de Jal 1861, p. 229; id. pour Cartault 1881, p. 8; 1853 pour Morrison 1941, p. 23; ou encore 1856 selon certaines sources non précisées (Basch 1987, p. 280 et Basch 1990).

${ }^{216}$ Tenne, 1915, p. 54; c'est la localisation retenue dans le catalogue du musée de l'Acropole établi en 1895 par Katsoiotis.

${ }^{217}$ Köster 1923, p. 111; Morrison 1941, loc. cit., précise même «among the foundations of the Erechteum».

${ }^{218}$ L. Basch (Basch 1987, p. 282 et Basch 1990) souligne les incertitudes de la provenance du relief : rien ne signifie qu'il provienne réellement de l'Érechtéion plutôt que de ses alentours; de plus, le bâtiment a subi bon nombre de vissicitudes depuis la fin du $V^{e}$ s., y compris durant les derniers siècles de notre ère : rien ne permet non plus à première vue d'indiquer une datation à la sculpture.

${ }^{219}$ Basch 1987, p. 293 ss.; Casson 1971, p. 80 note 13 et p. 86; Casson 1994, p. 60 ss.; Gianfrotta \& alii 1997, p. 70. Le relief a servi de référence à l'équipe de J. Morrison pour la reconstitution parfaitement réussie d'une trière classique, l'Olympias.

${ }^{220}$ Lemaître 1883, p. 98.

${ }^{221}$ Sur la trière sacrée, voir infra p. 430 ss.

${ }^{222}$ Musée national d'Athènes, inv. 2460; hauteur $17 \mathrm{~cm}$. Le fragment a été trouvé près du mur turc appelé «Serpentzé».

${ }^{223}$ D’après des détails techniques différents : Basch 1987, p. 283 et fig. 610. 
fait pas partie, cela établirait un autre cas de représentation de bateau sur l'Acropole.

- Éleusis

Un relief fragmentaire provenant d'Éleusis, proche du relief Lenormant, est utilisé également pour l'étude de la trière classique $^{224}$. Cette sculpture constitue un cas tout à fait particulier car la plaque de marbre est travaillée de deux côtés. Cet amphiglyphe figure d'un côté Déméter assise sur une ciste, de l'autre une trière dont on distingue les rameurs et des voyageurs sur le pont, surtout un homme nonchalamment allongé sur des coussins. Pour des raisons stylistiques concernant la représentation de la déesse, le fragment est daté vers 350 a.C. ${ }^{225}$ Le contexte exact de la trouvaille n'est précisé dans aucune publication. La présence d'un tel relief dans un sanctuaire et surtout son association avec une iconographie religieuse tend à lui donner un sens cultuel. On a ainsi interprété le document comme une représentation d'une trière sacrée athénienne ${ }^{226}$. Cette hypothèse soulève cependant quelques objections. Les sources ne mentionnent pas de trière sacrée joignant Athènes à Éleusis. De plus s'il s'agit d'une trière sacrée, la présence d'un personnage couché ne se justifie pas véritablement. L'impression générale qui se dégage de ce relief biface est celle d'un voyage paisible mis en relation avec la divinité. Or, nous connaissons une navigation liée aux figures divines de Déméter et de sa fille : celle de Timoléon en 344 (Diodore de Sicile, Bibl. Hist. XVI, 66, 3-5; Plutarque, Vies (Timoléon), 8, 1-9, 1) ${ }^{227}$. Le bateau fit voile vers la Sicile sous la protection des deux déesses ainsi que l'avait prédit leurs prêtresses et leur fut consacré. Il ne serait guère surprenant que l'événement ait été suivi d'un ex-voto, d'une offrande rappelant l'événement et déposée il va de soi dans leur sanctuaire éleusinien. Le rapprochement entre l'anecdote rapporté par les sources littéraires et le relief est d'autant plus troublant que les deux semblent contemporaines : le premier date de 344 et le second est situé vers 350. La sculpture constituerait alors un souvenir visible de ce prodige divin, consacré par Timoléon, sa famille voire la cité. Quoi qu'il en soit, la qualité et le type du relief révèlent une attention toute particulière portée à honorer Déméter en liaison avec la mer.

${ }^{224}$ Basch 1987, p. 288 et fig. 613-617.

${ }^{225}$ Musée d'Éleusis, sans inv. Walter 1952; Beschi 1990, 1 p. 858 n 128.

${ }^{226}$ Sur la notion de trière sacrée, voir infra p. 430 ss. C'est la théorie de Walter 1952, qui met en parallèle le relief Lenormant, celui d'Éleusis et une peinture des Propylées représentant des bateaux (voir infra p. 403 s).

${ }^{227}$ Voir supra p. 282. 
La représentation de bateau sur bas-relief comme ex-voto n'apparaît pas comme une pratique courante. Attestée aux époques archaïque et classique, elle s'avère inexistante à l'époque hellénistique. Les divinités à qui pouvaient cependant s'adresser de telles œuvres sont exclusivement féminines, mais surtout les divinités poliades de deux grandes cités et d'un grand sanctuaire. Il est difficile par ailleurs de définir la nature du ou des dédicants : particuliers ou groupes de citoyens. Ces sculptures d'époque classique témoignent d'une certaine recherche et richesse de la part des donateurs.

\section{Peinture (supports divers)}

a) Époque archaïque

Pour l'époque archaïque, l'usage courant des pinakes touche également le domaine maritime. Le plus souvent, ces plaques de céramique sont fragmentaires et il en découle nécessairement que le thème et l'intention de l'ex-voto ne sont alors pas totalement assurés. L'aperçu général qui suit commence par le groupe le plus important et le plus cohérent de ce type de matériel, pour ensuite aborder les cas isolés.

\section{- Les plaques corinthiennes}

Une plaque corinthienne ${ }^{228}$ fragmentaire - il manque la partie centrale et l'extrémité gauche - datée de l'époque archaïque représente un bateau navigant vers la droite, avec des guerriers à son bord. Un personnage, situé à l'extérieur du bateau, au niveau de l'eau le long de la coque, accompagne le navire; son épaule qui semble recouverte d'écailles, ainsi que le rapprochement avec des scènes identiques sur vases ${ }^{229}$, tendent à faire reconnaître la nef Argô navigant sous la conduite de Triton ${ }^{230}$. L'objet est considéré comme un ex-voto d'un capitaine ralliant le port après une traversée difficile $^{231}$. En effet, il appartient au dépôt de Penteskouphia, localité proche de l'Acrocorinthe où fut découvert au $\mathrm{XIX}^{\mathrm{e}}$ s. par un paysan

${ }^{228}$ Berlin, Staatliche Museen F 654 et 781 . Morrison \& Williams 1968, p. 87-88 (Arch. 40, pl. 12); Moll 1929a, B, VIb, 62-3.

${ }^{229}$ Particulièrement le Vase François (Musée archéologique de Florence $n^{\circ}$ 4209); voir Icard-Gianolio 1997, 1, p. 68-73 et VIII, 2 p. 42 ss.

${ }^{230}$ Cf. Apollonios de Rhodes, Argonautiques IV, v. 1537-1764.

${ }^{231}$ Morrison \& Williams 1968, loc. cit. L'identification avec Argô est réaffirmée avec force par Salviat 1984, p. 222. 
un grand nombre de plaques d'argile peintes; celles-ci furent ensuite cédées à différentes collections européennes, notamment berlinoises (fig. 34). Malgré le manque de précision concernant le contexte de la

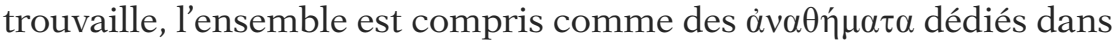
un premier temps dans un sanctuaire à Poséidon et réunis dans un second temps dans une fosse ${ }^{232}$.

Parmi les fragments connus, un certain nombre représentent également des bateaux ${ }^{233}$ : c'est le cas de huit plaques fragmentaires conservées au Musée de Berlin ${ }^{234}$ et d'une au Louvre ${ }^{235}$. Par ailleurs, certaines autres précisent à quelle occasion s'est pratiquée

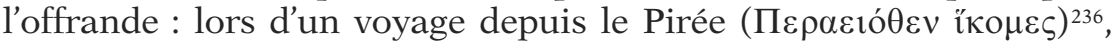
par voie de mer faut-il donc comprendre. C'est pourquoi l'un de ces fragments représentant une poupe de navire surmontée de vases est-il interprété comme un ex-voto d'un marin ayant la charge d'un navire marchand ${ }^{237}$.

D'autres plaques peintes archaïques portent de la même manière des représentations de bateaux, à Athènes et à Sounion ${ }^{238}$.

\section{- Athènes}

À Athènes, le puits A du versant nord de l'Acropole a livré une double plaquette fragmentaire montrant la proue d'un bateau, accompagnée d'un poisson et d'une vague stylisée en zig-zag. Datée du géométrique tardif, elle est rattachée lors de la publication à des sanctuaires disparus de l'Acropole ${ }^{239}$.

Un exemplaire similaire provient également de l'Acropole. Pour des critères stylistiques, il est jugé à peu près contemporain du fragment suivant, c'est à dire vers $700^{240}$.

${ }^{232}$ Collignon 1897, p. 23-24; Werner 1993, p. 35-37 et fig. 57. Les inscriptions donnent par ailleurs le nom de Poséidon mais aussi celui d’Amphitrite.

${ }^{233}$ Basch 1987, p. 234-237; Romero Recio 2000, p. 10.

${ }^{234}$ Morrison \& Williams 1968, p. 88-89 (Arch. 41-44 et 46-49, pl. 12) : respectivement Berlin F650; F833; F835; F621; sans no d'inv.; F647 et F656; F646; F652. Fenet 2011, p. 408 et pl. 119, 1.

${ }^{235}$ Collignon 1897, p. 28-29, no 7 avec fig.; Morrison \& Williams 1968, p. 89 (Arch. 45).

${ }^{236}$ Röhl 1882, p. 6 n 20-5; Furtwängler 1885, I no 838 et n 946.

${ }^{237}$ Berlin, F381; Van Straten 1981, p. 95 et fig. 38; Casson 1971, fig. 98.

${ }^{238}$ Romero Recio 2000, p. 13.

${ }^{239}$ Athènes, inv. AP 1682; Boardman 1954, p. 195-196 (Athènes nº 1) et fig. 2.

${ }^{240}$ Athènes, Musée national. Boardman 1954, p. 196 (Athènes no 2) et 

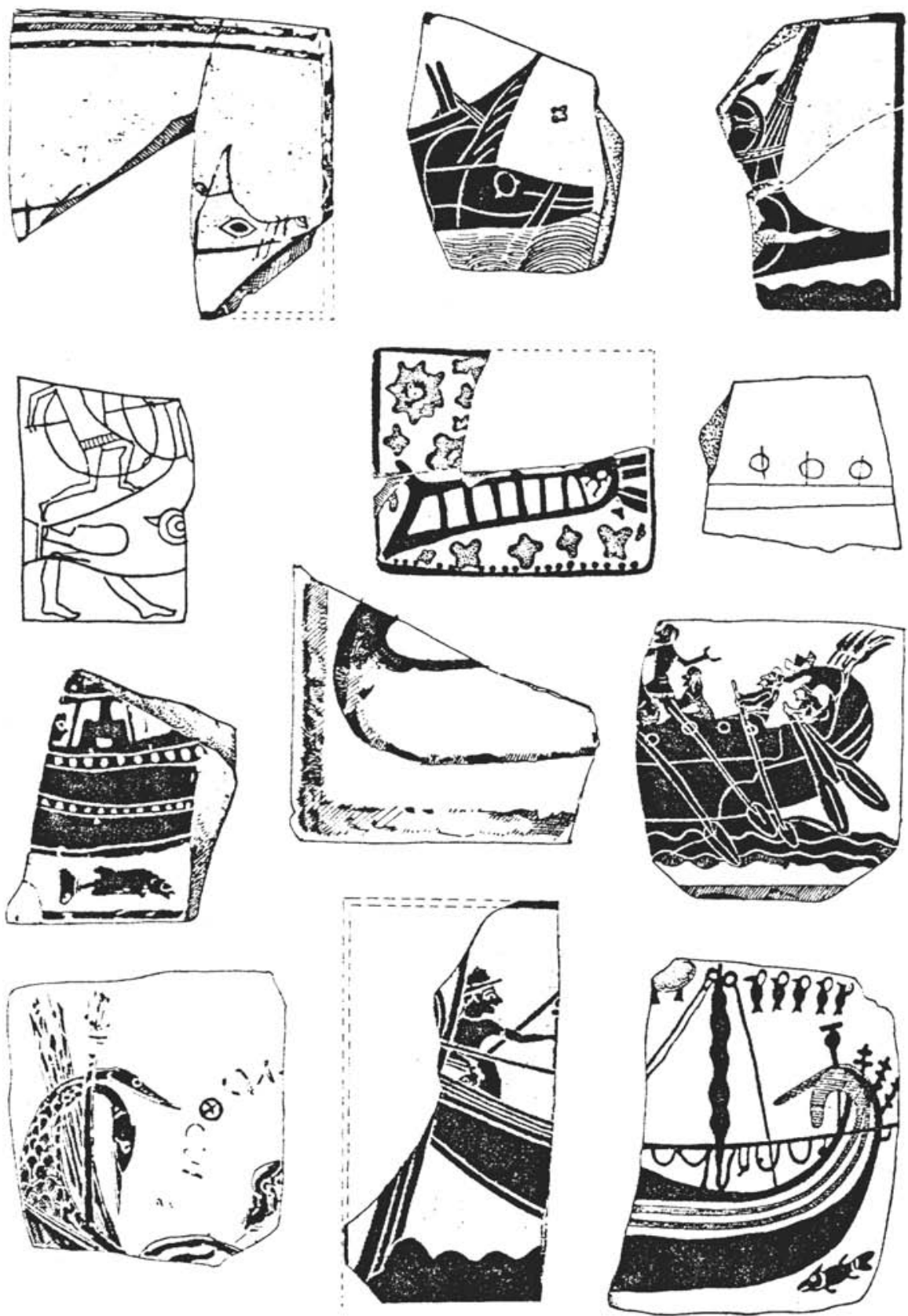

Fig. 34 - Pinakes navals de Penteskouphia (d'après Werner 1993). 
- Sounion

Un autre exemplaire provient du promontoire de Sounion. Parmi les débris d'un petit temple d'Athéna détruit par les Perses, nivelés pour la construction du temple postérieur de la déesse, se trouvait le côté droit d'un pinax percé d'un trou de fixation. Y figure un bateau de guerre avec son équipage : rameurs et kubernétès; le style pictural fait attribuer l'objet au peintre Analatos et le situer vers 700 a.C. ${ }^{241}$ On a pu y reconnaître le pilote de Mélénas, Phrontis, dont l'hérôon se trouvait à Sounion ${ }^{242}$; cette hypothèse est contestée par la provenance de la plaque dans le sanctuaire d'Athéna et loin de l'emplacement présumé du dit hérôon, ainsi que par les différences avec les autres représentations connues de Phrontis ${ }^{243}$. La localisation de la trouvaille empêche toute autre attribution qu'à Athéna, excluant également quelconque rapprochement avec le sanctuaire de Poséidon.

- Égine

En comparaison avec ces modèles, J. Boardman propose un nouveau cas de pinax naval pour un fragment attique provenant d'Égine représentant un guerrier, daté vers 720-710, qui portait une

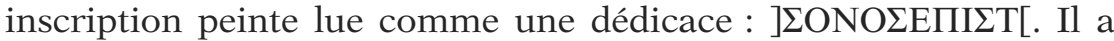
été découvert au lieu-dit Kolonna, à $2 \mathrm{~m}$ des fondations du temple d'Apollon. On évoque alors la possibilité d'une offrande à Apollon, bien vénéré sur le port, ou encore à Aphrodite Épiliménia ${ }^{244}$.

Pour l'époque archaïque, quatorze pinakes à motif nautique peuvent ainsi être comptabilisés. Leur interprétation n'est pas soumise à controverse : ils servent à remercier la divinité d'une victoire sur mer ou d'une vie sauve après un naufrage ${ }^{245}$. Si le groupe

pl. XVI, 2. L'article auquel renvoie l'auteur pour les circonstances de la découverte ne comporte aucune information concernant ce fragment.

${ }^{241}$ Athènes, Musée national inv. 3588. Stais \& Orlandos 1917, p. 208-209, fig. 19.

${ }^{242}$ Picard 1940.

${ }^{243}$ Boardman 1954, p. 198 (Sounion $n^{\circ}$ 1); l'auteur propose quant à lui l'hypothèse d'une représentation d'une course nautique.

${ }^{244}$ Collection de la British School d'Athènes. Ibid., p. 184-186, 198 et 200, pl. XVI, 1 et fig. 1; l'attribution à Aphrodite repose essentiellement sur l'ancre de pierre éginète portant le nom de la déesse : sur cette ancre, voir infra (cat. V2).

${ }^{245}$ Stais \& Orlandos 1917, loc. cit. 
le plus important est consacré à Poséidon - ce qui est loin d'être surprenant vu la localisation de la trouvaille dans l'Isthme et le lieu de fabrication de ces objets céramiques -, d'autres divinités s'en trouvent néanmoins dotés: Athéna, Apollon ou Aphrodite.

b) Époque classique

\section{- Samos}

La Seconde Guerre médique est encore cette fois le contexte dans lequel apparaît pour la période classique un exemple de représentation figurée navale à but votif. Le tableau, aux dires d'Hérodote (Enquête IV, 87-88) représente non pas véritablement une embarcation, mais le fameux pont de bateaux réalisé afin de faciliter le passage des Perses en terre européenne ${ }^{246}$. Dans cette peinture $(\zeta \tilde{\Phi} \alpha)$, figuraient l'ouvrage lui-même, ainsi que Darius regardant la traversée de ses troupes. L'œuvre fut consacrée par le constructeur du pont, Mandroclès, en prémices des récompenses qu'il obtint du Grand Roi, dans le sanctuaire d'Héra à Samos, sa ville natale. La dédicace - reprise dans l'Anthologie Palatine (VI, 341) sans nom d'auteur - cite les différentes personnes intéressées à la construction : lui-même, Darius et les Samiens, qui en ont retiré de la gloire; il mentionne également le nom de la déesse ainsi honorée par ce qu'il appelle ce $\mu v \eta \mu o ́ \sigma v v o v$. L'accent est mis sur le caractère extraordinaire de la construction qui a permis de vaincre le Bosphore poissonneux, et c'est à ce titre qu'Héra est remerciée.

- Alia

Hormis ce passage d'Hérodote, il n'existe pas d'autre témoignage littéraire sur l'existence de tableau votif marin à l'époque classique $^{247}$. Les représentations picturales de bateaux consacrées à une divinité sont bien attestées par les écrivains latins de la fin de la République et de l'Empire ${ }^{248}$, notamment par des sources explicites à ce sujet. Des tableaux votifs (tabuli picti) navals sont

${ }^{246}$ Une description de l'installation de ce pont est donnée par Hérodote dans les pages qui précèdent l'anecdote : IV, 83-87.

${ }^{247}$ De manière plus générale, $C$. Picard constate que les marines ne font leur apparition dans la peinture grecque qu' «à partir de l'époque alexandrine seulement» (Picard 1952, p. 78; Picard 1959, p. 49-50).

${ }^{248}$ À ce sujet et de façon plus large sur les suspensions d'ex-voto à l'air libre, voir Cazanove 1993. Voir aussi Wachsmuth 1967, p. 142, note 246. On peut aussi évoquer comme parallèle - avec une certaine réserve - le tableau peint votif décrit au début du Roman de Leucippé et Clitophon (I, 2 ss.) par Achille Tatios, qui figure «à la fois la terre et la mer» et le mythe d'Europe. 
mentionnés par Cicéron (De natura deorum III, 37, 89) pour Samothrace et Juvénal (XII, 27-28) à propos d'Isis, tandis que deux vers d'Horace (Odes I, v, v. 13-16) semblent nous préciser qu'ils étaient placés sur une paroi de la cella du temple ${ }^{249}$. On peut ainsi supposer qu'il en était déjà de même dans le monde grec à l'époque classique, d'autant plus si l'on envisage une continuité rituelle entre les pinakes archaïques et les tabuli picti hellénistiques; mais il est difficile de préciser si les divinités olympiennes étaient concernées par cette pratique.

Deux passages de Pline (Histoire naturelle XXXV, 101; 135), concernant les activités du peintre grec de la seconde moitié du $\mathrm{IV}^{\mathrm{e}} \mathrm{s}$. a.C. Protogénès et du peindre macédonien de la première moitié du $\mathrm{II}^{\mathrm{e}}$ s. a.C. Héracleidès, constituent peut-être un témoignage de l'existence de tels tableaux votifs à ces époques. Deux interprétations sont données à l'expression naves pinxisse ${ }^{250}$. Selon la première, c'est la décoration de parties de navires (parasèma, proue...) à laquelle ces hommes ont contribué; la seconde, celle de la réalisation de peintures votives, est tout aussi recevable: elle s'accorde en effet avec l'anecdote qui voit le premier artiste, dans ses heures de gloire, rappeler avec humour ses anciens travaux en insérant des bateaux de petite taille dans ses compositions. Cette seconde hypothèse s'accorde mieux aux qualités des personnages et à leur parcours. Il est à noter cependant que le ton des paragraphes est plutôt péjoratif; s'il s'agit bien de tableaux votifs, ils sont considérés comme revêtant peu de valeur artistique et ne constituant qu'une source de revenus pour leur exécutant ${ }^{251}$.

\section{- Athènes}

On connaît sur l'Acropole d'Athènes l'existence d'un tableau à l'interprétation controversée qui, s'il ne constitue pas un cas d'exvoto consécutif à une navigation, est une consécration à Athéna d'une représentation de deux bateaux ou du moins d'une scène marine.

Toujours d'après Pline (Histoire naturelle XXXV, 101), les Propylées conservaient, parmi les peintures exposées, une œuvre du même Protogénès représentant Paralum et (H)ammonias c'est-à-dire les

${ }^{249} \mathrm{Ibid}$. Il s'agit cependant dans le poème d'un tableau d'un type légèrement différent : celui d'une représentation de l'ex-voto réel qui consistait en vêtements trempés d'eau de mer. Un autre exemple de cette pratique auprès d'une divinité italique est donné par Virgile, Énéide XII, v. 766 ss.

${ }^{250}$ Voir le commentaire du passage par J.-M. Croisille dans l'édition Budé, p. 213 note 4, avec bibliographie.

${ }^{251}$ Pour cette raison, nous n'avons pas relevé l'interprétation de Reinach 1915, p. 68 qui pense à des marines. 
deux trières sacrées d'Athènes ${ }^{252}$. La question qui partage les commentateurs de Pline est de savoir comment celles-ci étaient représentées - de manière réelle ou personnifiées - et pourquoi la seconde était comprise par certains comme une Nausicaa ${ }^{253}$. Il est tout aussi intéressant de considérer la commande et la réalisation même de cette scène dans le contexte du sanctuaire d'Athéna, à la fin du IV $\mathrm{s}$ a.C. Il doit s'agir d'une commande de type officiel, vu l'emplacement de l'œuvre et la notoriété de l'artiste à cette époque ${ }^{254}$. Quel que soit le commanditaire, le choix d'une marine pour un tableau décorant le sanctuaire de la déesse poliade ne devait pas être anodin.

c) Époque hellénistique : Nymphaion

Bien qu'il ne s'agisse pas d'une fresque, la découverte faite au début des années 1980 sur le littoral nord du Pont-Euxin est d'importance. Tel qu'on l'annonce alors, dans le site de Nymphaion, un sanctuaire hellénistique, daté de la première moitié du III ${ }^{\mathrm{e}} \mathrm{s}$ a.C. et consacré à Aphrodite et Apollon, a livré un mur recouvert d'une grande image nautique, réalisée par incision sur le mur peint à la manière du $1^{\text {er }}$ style pompéien. Le sujet principal de celle-ci est un bateau, d'1,14 m de long, peut-être baptisé l'Isis comme il est écrit en grec à la proue (fig. 35) ${ }^{255}$.

Le bâtiment, qui se répartit sur 3 terrasses d'un terrain orienté vers la mer en situation dominante, a été construit fin IVe-début $\mathrm{III}^{\mathrm{e}}$ s. a.C.; d'après le responsable des fouilles, il a été détruit au milieu du III e s. a.C., pour des raisons inconnues. Le décor appartient à l'une des pièces entourant une cour pavée; c'est le stuc détaché des murs de brique crue, morcelé en des milliers de morceaux, que les archéologues ont patiemment reconstitué. Le

${ }^{252}$ Reinach 1915, p. 62-69; Walter 1952; Picard 1959, p. 24. Sur les trières sacrées, voir infra p. 430 ss.

${ }^{253}$ Cf. J.-M. Croisille, commentaire du texte de Pline dans l'édition Budé, p. 214 note 6. Pfuhl 1900, p. 767 § 840; Reinach 1985, p. 144 et 364-365. On a également débattu du support de l'œuvre : mur ou panneau de bois?

${ }^{254}$ Cette peinture comportait peut-être une signification politique : le changement de nom d'une des trières sacrées d'Athènes en Ammonias, en l'honneur d'Alexandre. Dans cette éventualité, Reinach 1985, p. 365, envisage que le commanditaire soit Démétrios Poliorcète. Sur ce changement de nom, voir infra.

${ }^{255}$ Publications utilisées pour l'exposé qui suit: Grach 1984; Basch 1985; Basch 1987; Grač 1987; Höckmann 1998; Nowicka 1999 (bon résumé sur l'état de la question à la fin des années 1990); Murray 2001. La décoration murale, restaurée, est aujourd'hui exposée au musée de l'Ermitage, inv. $\mathrm{H} \varphi$ 82.526 (Fenet 2011, p. 408 et pl. 118, 3). Sur les arguments en faveur ou contre Isis comme nom du bateau : Murray 2001. 

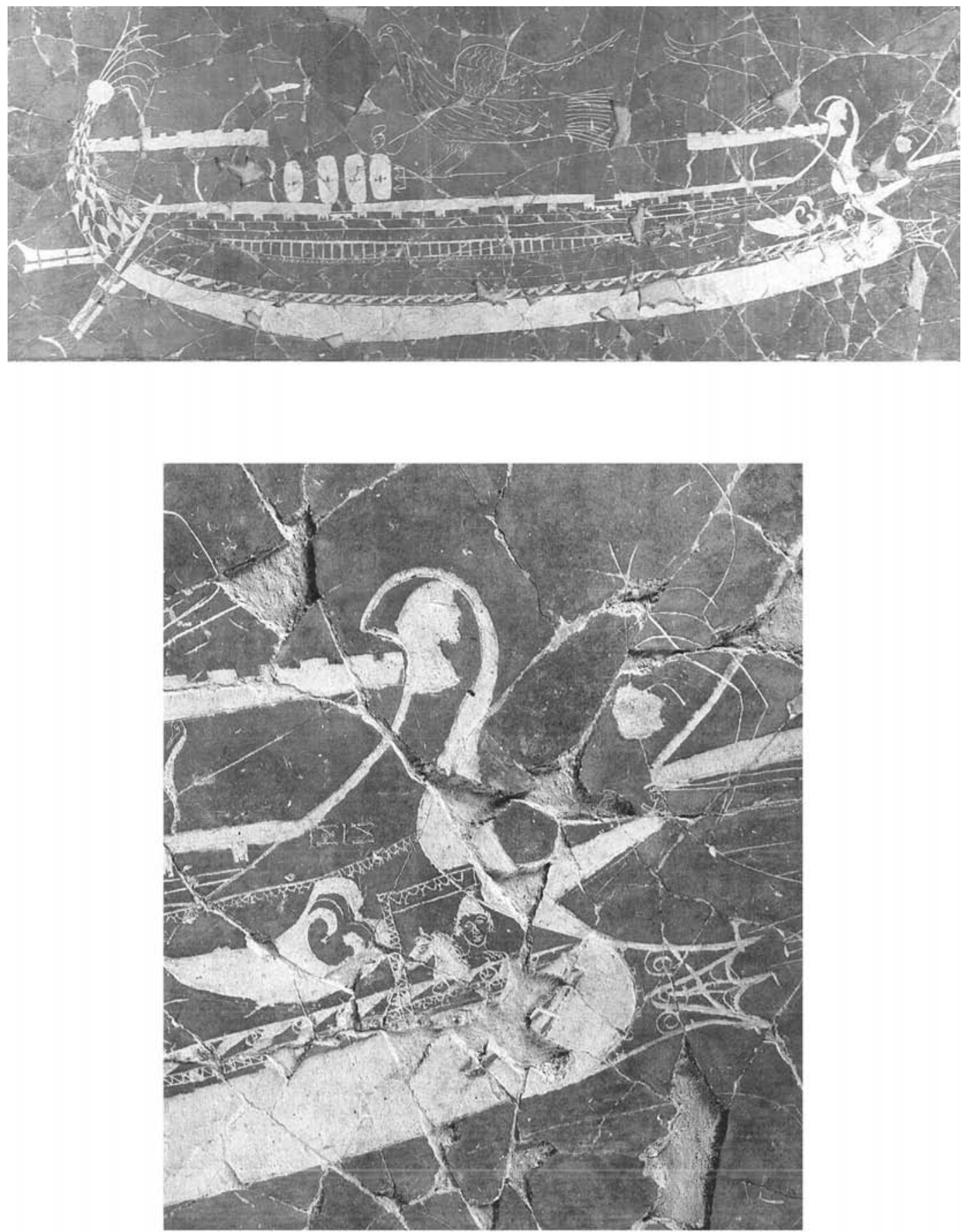

Fig. 35 - Le grand navire de Nymphaion (d'après Grač 1987) et détail. 
bateau figurait sur le mur de droite. Les traces d'incision montrent que le dessin du navire est contemporain des revêtements muraux. Outre celui-ci, ont été ajoutés ensuite de nombreux graffiti, sans ordre et à des dates diverses semble-t-il : au total environ 80 représentations de "bateaux, figures d'hommes et animaux», ainsi que des inscriptions : de nature religieuse, mais aussi profanes («des notes concernant les dates de départ de bateaux, des comptes, des quittances de dettes, des aphorismes, des vœux de bonne santé, des notices concernant les habitants de Nymphaion, des noms des rois $\mathrm{du}$ Bosphore et des poèmes»)256. Les mentions d'Aphrodite et d'Apollon ont fait d'abord attribuer le sanctuaire à ces deux divinités; il semble aujourd'hui qu'il ne soit désigné que sous le nom de la première ${ }^{257}$. Pour L. Bricault, il s'agirait d'un lieu dédié au culte d'Aphrodite-Arsinoè, assimilée à Isis, ce qui expliquerait la présence du bateau et du nom de la divinité égyptienne ${ }^{258}$.

En ce qui concerne le navire, la richesse des détails en fait un document très intéressant pour l'architecture navale, car il s'agirait d'un bâtiment appartenant aux hypergalères hellénistiques pour lesquelles les informations iconographiques font défaut ${ }^{259}$. Son identification et sa fonction restent pour le moment très discutées. On a cru d'abord, d'après le nom et certains détails, à une origine égyptienne, peut-être liée à la flotte ptolémaïque ${ }^{260}$. La taille du bateau et son équipement tendent à le rattacher à un navire de tradition phénicienne, non vraiment adapté à la guerre : plutôt un bâtiment ostentatoire et de prestige.

Par ailleurs, un aigle surplombe le navire, tenant dans ses serres un trident : pour L. Basch, l'oiseau symboliserait la dynastie des Lagides et sa domination sur les mers ${ }^{261}$. Un des graffiti ayant livré le nom de Pairisades, l'hypothèse a été avancée qu'un bateau de Ptolémée II serait venu à Nymphaion, pour des raisons diplomatiques, sous le règne de Pairisades II (circa 284/245) ${ }^{262}$. Une autre

${ }^{256}$ D'après Nowicka 1999. Voir dessin d'ensemble et photos de détails dans Grač 1987, p. 92-93 et pl. XXVII-XXXIX. La totalité des graffiti a fait l'objet d'un long article détaillé et bien illustré : Höckmann 1998.

${ }^{257}$ Grač 1987 : dédicaces à Aphrodite pl. XXXII. Le nom d'Apollon apparaît au moins 11 fois (Murray 2001). Höckmann 1998 et Nowicka 1999 considèrent le sanctuaire voué à Aphrodite.

${ }^{258}$ Bricault 2006, p. 22-36.

${ }^{259}$ Basch 1985; Basch 1987, p. 493 et fig. 1128-1131.

${ }^{260}$ Grach 1984. Selon l'archéologue, d'autres détails renvoient à la vie quotidienne de la cité sous le règne de Pairisades II.

${ }^{261}$ Basch 1985 : le symbole habituel des Ptolémée, l'aigle avec le foudre, est ici modifié intentionnellement.

${ }^{262}$ Grach 1984; Basch 1985; Basch 1987; Höckmann 1999a; Bull. épig. 103, $1990, \mathrm{n}^{\circ} 590$. 
interprétation voit dans le navire une délégation sacrée de Ptolémée II, arrivée au royaume du Bosphore pour y introduire le culte d'Isis, Sérapis et Anubis ${ }^{263}$. Le dessin aurait été réalisé à l'occasion de l'un ou l'autre de ces événements. Mais aujourd'hui, la datation du décor et du bâtiment est remise en cause : il faudrait peut-être baisser la datation plus avant dans l'époque hellénistique. La destination du sanctuaire et celle de la pièce posent également problème ${ }^{264}$.

En dehors des considérations architecturales, le bateau présente également des détails de type religieux : une figuration en parasèmon d'un Dioscure à cheval et celle d'Isis sur le stolos (voir supra p. 255-256 et 260).

Il faut espérer une publication prochaine complète et détaillée de ce document exceptionnel, incluant aussi bien les inscriptions que les structures.

Les peintures de bateaux dans un but votif souffrent du manque de documentation. Le support doit y être pour beaucoup : ainsi les exemples de l'époque archaïque sur céramique ont-ils mieux survécu au temps. Ces pinakes et le tableau de Mandroclès, ainsi que les mentions des tableaux votifs en général, suggèrent qu'il s'agit d'un type d'ex-voto essentiellement individuel. En revanche, l'image murale de Nymphaion et le tableau de Protogénès répondent sans doute à la demande d'une collectivité, ou du moins d'une élite politique. La taille des scènes et le choix de l'artisan ou de l'artiste varient aux époques classique et hellénistique en fonction des commanditaires et des moyens disponibles.

\section{Le cas des graffiti}

La pratique est couramment attestée, depuis une haute Antiquité ${ }^{265}$, de représenter des bateaux en incisant la roche. Mais il est difficile parfois de reconnaître s'il s'agit réellement d'un ex-voto ou d'une simple marque de passage ou d'amusement ${ }^{266}$. L'interprétation est d'autant plus malaisée que ces types de documents sont souvent

${ }^{263}$ Murray 2002.

${ }^{264}$ Nowicka 1999.

${ }^{265}$ Basch 1981, p. 38 rappelant les exemples du temple mégalithique de Hal Tarxien de Malte (III ${ }^{e}$ millénaire a.C.) et du temple chypriote de Kition (1200 a.C.); Romero Recio 2000, p. 18-22. Un exemple de l'âge du Bronze également présent à Lemnos est peut-être à mettre en relation avec le culte de CybèleArtémis (Marangou 1995; Marangou 2006).

${ }^{266} \mathrm{Il}$ est à noter que les sites d'euploia évoqués au début de cette seconde partie (Proté, Syros, Aliki, Santa Maria di Leuca, baie de Roca) ne comportent 
très difficiles à dater : les critères d'architecture navale ne sont pas toujours suffisants dans des cas de dessins malhabiles ou imprécis. C'est pourquoi nous présentons ici deux témoignages assimilables à des ex-voto, sans que le fait puisse être énoncé avec certitude, pour ensuite discuter des graffiti de bateaux les plus connus, ceux de Délos.

\section{a) Samos}

L'Héraion de Samos a livré un dessin nautique, incisé dans un bloc de pierre de taille, daté du dernier tiers du VI ${ }^{\text {e }}$. a.C. ${ }^{267}$. En fait, il s'agit de la représentation de deux bateaux, l'un placé au-dessus de l'autre. Ils ont fait l'objet d'une étude historique, dans le sens où on pense y voir une représentation d'exemplaires appartenant à la flotte de Polycrate ${ }^{268}$. Des traces de lettres sont visibles sur la pierre, mais ne permettent pas de reconstituer un nom ou un mot. Malheureusement, l'origine et le contexte de la trouvaille à l'intérieur du sanctuaire ne sont pas connus. Il convient cependant de noter l'existence de ce graffito dans un lieu sacré où sont répertoriés d'autres types de représentations navales (voir supra p. 354, 370 s. et 402).

\section{b) Vouliagmeni}

En Attique, dans les années 1930, aux environs proches du temple d'Apollon Zôstèr de Vouliagmeni, un édifice qui semble dépendre directement du sanctuaire a été mis au jour. Ce bâtiment, qui remonterait au $\mathrm{VI}^{\mathrm{e}}$ s. a.C., fut agrandi au $\mathrm{IV}^{\mathrm{e}}$ ou $\mathrm{III}^{\mathrm{e}}$ s. par une dizaine de pièces servant sans doute de logements; le tout a livré

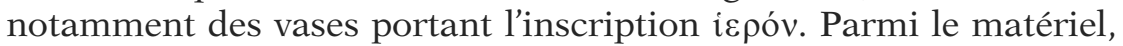
il faut noter la présence dans les couches les plus anciennes d'une tuile portant un graffito de bateau, daté probablement de la seconde moitié du VI ${ }^{\mathrm{e}} \mathrm{s}$ a.C. Un certain nombre d'hameçons est également recensé $^{269}$. Il est difficile d'affirmer catégoriquement la nature reli-

pas ce genre de dessins, qui sont attestés en revanche pour l'époque médiévale (ex. de la grotte San Christoforo à Roca).

${ }^{267}$ Inv. I 80. Signalé par Höckmann 1985, fig. 68 sans indication d'origine. La pierre a été publiée par Freyer-Schauenburg 1974, p. 186-188 n 105, pl. 77, qui la signale «disparue».

${ }^{268}$ Sur la flotte samienne du VI ${ }^{e}$ s., voir Casson 1971, p. 63; Torr 1894, p. 65; Basch 1987, p. 333. Ce type de bateau est connu par une mention de Plutarque, Péricles 26, 3-4.

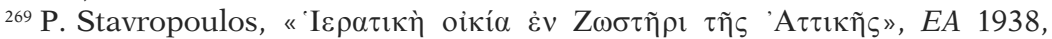
p. 1-31, précisément p. 21-22; P. Lemerle, «Chronique des fouilles et découvertes archéologiques en Grèce», BCH LX, 1936, p. 460; Basch 1987, p. 227-229; Romero Recio 2000, p. 21. 
gieuse du dessin, même si la proximité du temple d'Apollon, l'emplacement au bord du rivage (voir supra p. 152) et le caractère votif de la globalité des objets fouillés témoignent en sa faveur.

\section{c) Délos}

Les graffiti de bateaux de Délos sont connus depuis le début du $\mathrm{XX}^{\mathrm{e}}$ s., grâce au Commandant Carlini, un officier français de passage dans l'île, qui en comprit l'intérêt pour l'architecture navale et en entreprit un relevé systématique ${ }^{270}$. D'autres cas ont ensuite été découverts lors des fouilles menées par l'École française d'Athènes. Aujourd'hui, bien des exemplaires ont disparu ${ }^{271}$ et les documents ont été étudiés essentiellement par L. Basch ${ }^{272}$. Ces dessins se trouvent incisés dans le stuc des murs des quartiers d'habitation de Délos, essentiellement répartis entre la maison du Dionysos, celle aux Stucs et des pièces de l'îlot des Bijoux ${ }^{273}$.

Ils doivent donc avoir été réalisés à une époque où les habitations étaient abandonnées; on a proposé d'y voir des traces laissées par les soldats de Mithridate et ceux de Triarius ${ }^{274}$. Les raisons qui auraient motivé la réalisation de ces graffiti seraient alors religieuses; en témoigneraient une signature $\mathrm{A} \Lambda \mathrm{E} \Xi \mathrm{A} \Sigma \mathrm{ME \Pi OIE \Sigma EN}$ et une divinité représentée au-dessus d'une embarcation. Le grand nombre de divinités protectrices de la navigation honorées à Délos serait révélateur du caractère sacré de l'île, elle-même considérée comme un bateau à la dérive avant la naissance d'Apollon ${ }^{275}$.

L'ensemble des arguments développés par L. Basch ne suffit pas cependant à convaincre ${ }^{276}$. Les ex-voto ne se déposent pas à n'importe quel endroit. Même dans le cas de simples inscriptions, l'endroit choisi n'est pas dû au hasard, il est revêtu lui-même d'une

${ }^{270}$ Sur le travail du Commandant Carlini, voir Graffiti Délos 1992. La plupart des documents est divisée aujourd'hui entre la collection privée familiale et le musée de la Marine à Paris.

${ }^{271}$ Par exemple il ne reste presque plus rien de ceux de la Maison aux Stucs, aujourd'hui envahie par la végétation et difficile d'accès.

272 Basch 1989, p. 17-23; Basch 1987, p. 371-384 et p. 497-499.

${ }^{273}$ Sur ces différents édifices, voir Bruneau \& Ducat 2005, respectivement p. 305 ( $\left.\mathrm{n}^{\circ} 120\right), 261$ ( $\left.\mathrm{n}^{\circ} 87\right), 232-233$ ( $\mathrm{n}^{\circ}$ 59A). Une carte est donnée par Basch 1987, p. 372.

${ }^{274}$ Mithridate ravagea l'île en 88 et Triarius intervint lors de l'attaque de pirates en 69 a.C.; ensuite l'île fut encore habitée, mais de manière beaucoup plus réduite. Contre cette datation des graffiti, Bruneau \& Ducat 2005, p. 305.

${ }^{275}$ Basch 1987, p. 381-382, fig. 804, 22a et 804, 44.

${ }_{276}$ Ainsi Janni 1996, p. 400 note 47, sans en donner les raisons, ne s'avoue pas convaincu; plus récemment encore, Duchêne \& Fraisse 2001, p. 56-58 ont soulevé des objections à une telle interprétation. 
certaine sacralité. Ainsi, lors des inscriptions d'euploia, le support utilisé est un lieu, un espace sacré : falaise, rocher, promontoire. Or, dans le cas des graffiti de Délos, les supports utilisés sont des murs d'habitations privées, abandonnées. Il ne suffit pas alors de dire que l'île entière est considérée comme consacrée à Apollon - ce qui de surcroît est loin d'être assuré - pour que ces murs le soient aussi, de même que les dessins qu'ils supportent. Par ailleurs, les autres graffiti signatures retrouvés à Délos ne sont pas de type religieux, et aucun nom de dieu ou vœu n'accompagne les dessins de bateaux pour expliciter quelconque intention votive ${ }^{277}$. Ainsi, jusqu'à preuve du contraire, les graffiti navals de Délos ne peuvent pas être considérés comme des ex-voto ni envers Apollon ni envers quelque autre divinité protectrice de la navigation.

L'offrande d'une représentation figurée de bateau existe dans l'Antiquité grecque. Malheureusement, ce type de matériel souffre de grosses lacunes tant littéraires qu'archéologiques : l'imprécision des notes de fouilles empêche toute analyse poussée; en ce qui concerne les graffiti, il faut espérer davantage d'attention envers ce type de matériel lors de leur découverte. De façon générale, on observe encore une majorité de cas à l'époque archaïque. La période classique est relativement bien documentée, tandis qu'un seul cas de taille - est connu pour l'époque hellénistique. Les divinités ainsi honorées sont variées, sans que puisse se détacher particulièrement l'une d'entre elle. La présence parmi elles de Déméter est à noter, peu attestée parmi les ex-voto navals.

\section{PARTIES DE BATEAUX}

Moins encombrant que le bateau dans sa totalité, un morceau de celui-ci est une offrande tout aussi riche de signification. C'est un ex-voto personnel, qui renvoie à des moments précis pendant lesquels le fidèle entretenait des liens privilégiés avec la divinité ${ }^{278}$. Si la partie de bateau consacrée est variable ${ }^{279}$ d'un dédicant à l'autre, la pratique en elle-même paraît très ancienne. Elle semble prendre

${ }^{277}$ Une seule dédicace a été recensée, dans une pièce de l'îlot aux Bijoux qui lui a livré 12 graffiti de navires : Basch 1987, p. 497-498. Apparemment, ceux-ci ne se trouvaient dans la même salle que l'inscription; on ne peut donc affirmer qu'ils constituaient un ensemble. En outre le petit texte ne comporte en soi aucune allusion particulière à une situation maritime (euploia, bateau, ...).

${ }^{278}$ Wachsmuth 1967, p. 135-136.

${ }^{279}$ Pour des définitions de termes navals techniques, voir supra le chapitre traitant du décor des bateaux. 
appui sur des exemples mythiques, liés aux navigations de la guerre de Troie : traditions verbales certes, mais aussi parfois rattachées à un objet visible dans un sanctuaire (voir infra tableau p. 613).

\section{Exemples mythiques}

\section{a) Samos}

Une tradition, qui ne nous est connue que par l'entremise de Callimaque (Hymne III, v. 228-232), rapporte qu'au cours de leur voyage par mer vers Troie, à Samos, les Grecs auraient souffert de l'absence de vents. Agamemnon aurait alors offert son propre

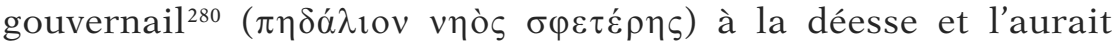
suspendu dans son temple. Artémis est alors invoquée à l'aide de deux localisations géographiques samiennes : celle du promontoire du Chésion et celle du fleuve Imbrasos. Aucun cap de ce nom n'est cité par d'autres sources, pas même par Strabon ou Pline. Le problème de l'identification de ce sanctuaire consacré à la déesse n'est pas encore résolu ${ }^{281}$. L'anecdote évoque l'épisode d'Aulis où Agamemnon dut sacrifier sa propre fille aux vents contraires. Il faut sans doute considérer cet épisode samien comme un ajout, une sorte de variante locale à l'expédition grecque contre Troie marquée par un ex-voto plus traditionnel à un contexte naval. Il est vraisemblable par ailleurs que cette anecdote était rapportée à propos d'un tel objet, d'apparence ancien, visible à l'époque de Callimaque dans le sanctuaire de la déesse.

\section{b) Lindos}

À Lindos ont été trouvées des inscriptions riches d'enseignements sur le sanctuaire d'Athéna. L'une d'entre elle, appelée «chronique», a été réutilisée avec d'autres pierres inscrites à l'époque byzantine pour un dallage en relation avec l'église qui a précédé celle, visible aujourd'hui, d'Haghios Stéphanos. Le texte de cette chronique a été attribué à un auteur connu par la tradition littéraire, Timachidas de Rhodes; il est daté précisément de 99 a.C. Parmi la liste chronologique établie par le chroniqueur des ex-voto les plus marquants consacrés à la déesse, figure l'offrande de Kanopos,

${ }^{280}$ Mc Cartney 1933, p. 3. Sur les différentes formes et le fonctionnement des gouvernails dans l'Antiquité, voir Torr 1894, p. 74-77; Rougé 1974, p. 66-71; Casson 1971, p. 224 note 2.

${ }^{281}$ Voir supra, chapitre Artémis p. 192. 
consistant en des gouvernails (oǐ $\alpha \kappa \alpha \varsigma)^{282}$ (Timachidas de Rhodes, Fragment 12) ${ }^{283}$. Ils sont consacrés à Athéna associée à Poséidon. Le dédicant est un marin célèbre, le pilote de Ménélas, dont le nom fut donné à une étoile visible seulement depuis l'île de Rhodes ${ }^{284}$ : il s'agirait alors dans ce cas d'une donation mythique. Timachidas appuie cependant cette mention sur un certain nombre de sources qu'il énumère, affirmant ainsi une tradition bien ancrée dans l'île. Le classement opéré dans les offrandes au travers de l'inscription montre que de toute manière, les oiakes - de quelque époque et de quelque origine qu'ils soient - n'existaient plus au début du $\mathrm{I}^{\mathrm{er}}$ S. a.C. ${ }^{285}$

c) Cyzique

Selon une épigramme de l'Anthologie Palatine (VI, 342), les habitants de Cyzique possédaient, dans un endroit appelé Portiques des Grâces, une stylis sacrée, considérée comme la première de ce nom et offerte par Athéna elle-même. Le poème, anonyme, ne peut malheureusement pas être daté. En dehors de la tradition s'y rapportant, il atteste la consécration d'un tel objet probablement à Athéna ${ }^{286}$.

En dehors de ces traditions, la pratique est assurée de manière continue de l'époque archaïque à l'époque hellénistique par des sources diverses.

\section{Époque archäque}

a) Égine

Dès l'époque archaïque, ce type de don et mentionné par quelques sources littéraires et en premier lieu par Hérodote (Enquête III,

${ }^{282} \mathrm{La}$ formulation utilisée appelle deux remarques. Le mot oiax désigne, selon Rougé 1974, p. 69, la barre perpendiculaire à la barre du gouvernail - autrement dit une partie de gouvernail - ce qui relève d'un instrument déjà élaboré et non primitif. De surcroît, l'usage du pluriel surprend : s'agit-il de la part d'un non spécialiste de la désignation des différentes parties - y compris un oiax - constituant un gouvernail, ou réellement de plusieurs gouvernails?

${ }^{283}$ Le texte épigraphique a été publié et commenté par Blinkenberg 1941, $\mathrm{n}^{\circ}$ 2, col. 148-200 et Higbrie 2003; Higbrie 2001 en explicite la portée religieuse. Voir également F. Jacoby ( $F G H$ III B, no 532 ).

${ }^{284} \mathrm{Il}$ est le personnage central d'un poème d'Apollonios; cf. «s.v. Kanobus 2 », RE X, 2, Stuttgart, 1919, col. 1870.

${ }^{285}$ Blinkenberg 1938, p. 158. réduit.

${ }^{286}$ Voir supra p. 46-47. Trippé 2008, p. 385 pense qu'il s'agissait d'un modèle 
59), dans son livre consacré à la guerre de Samos et à son principal artisan Polycrate. Les Samiens opposants à ce dernier, bannis, furent, après un temps d'errance, finalement battus lors d'un engagement naval et réduits en esclavage par les Éginètes aidés des Crétois. Les premiers commémorèrent leur victoire par des

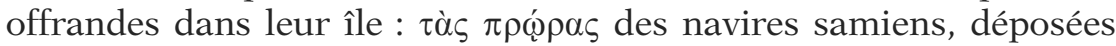
selon Hérodote dans le sanctuaire d'Athéna. L'épisode serait survenu plus de six ans après la fin de la guerre samienne, c'est-àdire dans la seconde moitié du VI ${ }^{\mathrm{e}} \mathrm{s}$ a.C. Si le fait de vouer ce type d'objet en guise de trophée est tout à fait concevable, l'affirmation de la consécration à Athéna surprend dans ce contexte. Il n'existe en effet aucun autre témoignage de l'existence d'un temple important lui étant dédié à Égine. Le sanctuaire dans lequel on s'attendrait à trouver un dépôt de ce type est celui bien connu d'Aphaia, situé au centre de lî̀le. Il faut donc considérer ce témoignage avec prudence, et vraisemblablement corriger une erreur d'Hérodote en ce qui concerne l'attribution du temple majeur d'Égine ${ }^{287}$.

\section{b) Mégare}

Parmi les sanctuaires connus à Mégare et décrits par Pausanias à la fin du livre $\mathrm{I}^{\mathrm{er}}$ de sa Périégèse, celui de Zeus Olympien est dépositaire d'un embolos de bronze (Pausanias, Livre I, 40, 5). Ce dernier fut consacré au dieu dans le contexte des luttes qui ont opposé, aux $\mathrm{VII}^{\mathrm{e}}$ et VI ${ }^{\mathrm{e}} \mathrm{s}$ a.C., les Athéniens aux Mégariens pour la possession de Salamine. Ces derniers célébrèrent alors la capture d'un navire ennemi au large de l'île par l'offrande d'une partie de celui-ci à Zeus. Il est difficile de savoir néanmoins si une telle pièce pouvait être encore visible environ huit siècles plus tard; peut-être s'agit-il plus simplement d'une offrande réalisée dans une époque plus proche de celle de Pausanias, au compte de laquelle on a rapporté une histoire plus ancienne $\mathrm{e}^{288}$.

\section{c) Samos}

Une base de statue, placée à proximité de l'autel et du temple de l'Héraion de Samos, présente sur une face incisée une proue de bateau surmontée d'une inscription, tandis qu'au verso est gravé un

${ }^{287}$ C'est également l'idée brièvement exprimée par Ph.-E. Legrand dans l'édition Budé (note 4 p. 80). Sur le sanctuaire d'Aphaia et une tentative d'explication à cette confusion, voir supra le chapitre consacré à Artémis, p. 198.

${ }^{288}$ D'autant plus que le temple de Mégare entrepris au $\mathrm{V}^{\mathrm{e}} \mathrm{s}$. est resté inachevé, d'après la description qu'en donne Pausanias (I, xl, 4 ss.). 
bouclier. La pierre de poros devait supporter une statue de Leuskapis, commémorant une double victoire sur terre et sur mer. L'offrande est datée de la première moitié du $\mathrm{VI}^{\text {e }}$ s. a.C. ${ }^{289}$ Le contexte laisse supposer que le bouclier et la proue sont considérés comme des prises sur l'ennemi que l'on consacre après l'heureuse issue des combats.

\section{Époque classique}

a) Delphes

Hérodote (VIII, 121-122) nous apprend qu'en remerciement des victoires de la Seconde Guerre médique, outre les trois trières phéniciennes ${ }^{290}$, les Grecs consacrèrent grâce au butin un certain nombre d'offrandes à Apollon Delphien ${ }^{291}$. Il s'agit tout d'abord d'une statue d'homme haute de douze coudées (soit près de $6 \mathrm{~m}$ !) tenant à la

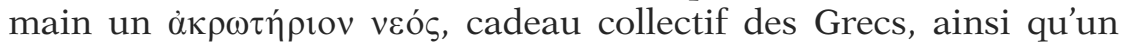
mât (iøđós) de bronze surmonté de trois étoiles d'or, présent des Éginètes. D'après cette description, il est difficile de savoir si le mât tout comme l'akrôtèrion étaient des objets originaux pris sur la flotte ennemie; vu le matériau du premier, sans doute celui-ci devait résulter de l'œuvre du sculpteur ${ }^{292}$.

La statue masculine en question serait reconnue par le Périégète (Description de la Grèce X, 14, 5) comme une représentation d'Apollon, mais cette mention ne signale rien de particulier. Sa base et son emplacement, en face de l'autel d'Apollon, sont aujourd'hui identifiés ${ }^{293}$. Le mât des Éginètes, placé "près du cratère de Crésus», était quant à lui situé dans le pronaos du temple des Alcméonides ${ }^{294}$; le tout avait disparu lors de la visite de Pausanias. Le choix de trois étoiles n'est pas anodin, il convient d'essayer de le comprendre. Au nombre de deux, elles évoqueraient immédiatement les Dioscures et seraient à rapprocher des étoiles d'or offertes par les Spartiates dans ce même sanctuaire après la bataille d'Aigos Potamos (Cicéron, De

${ }^{289}$ Walter 1990, p. 135 et fig. 153. Aucune référence n'étant donnée, nous ne pouvons que répéter les informations de l'archéologue allemand; la victoire aurait été remportée contre les Sikaner (?).

${ }^{290}$ Voir supra.

${ }^{291}$ Gauer 1968, p. 33 et 71-74.

${ }^{292}$ Amandry 1954, p. 306-307 donne à ce mât un rôle de support des étoiles qui constituent l'offrande essentielle; il en vient à douter même de la précision du terme utilisé par Hérodote et à supposer le mât comme fabriqué et proportionné pour l'occasion.

${ }^{293}$ Jacquemin \& alii 2012, p. 42 no 16.

${ }^{294}$ Amandry 1954, loc. cit.; Jacquemin 1999, p. 153 note 319, 251 et 258. 
la divination I, 75; Plutarque, Vies (Lysandre), 18, 1) 295; la troisième en revanche pose problème. Certains y ont vu un symbole se rapportant à une divinité adjutrice des Grecs, en l'occurrence Apollon Delphinios ou Hélène ${ }^{296}$.

Quoi qu'il en soit, cette présence d'ex-voto marins dans le sanctuaire delphique est renforcée en outre par d'autres témoignages archéologiques concernant la Stoa des Athéniens, située en-dessous de la terrasse du temple ${ }^{297}$. Cette stoa, longue d'environ 27 mètres en façade et $3 \mathrm{~m}$ de largeur intérieure, repose sur sept colonnes ioniques ${ }^{298}$. Le mur polygonal du temple d'Apollon constitue le fond du portique, mais il n'est que partiellement recouvert d'actes d'affranchissement disposés en panneaux rectangulaires. La dédicace se lit sur la face antérieure du stylobate, sur une longueur

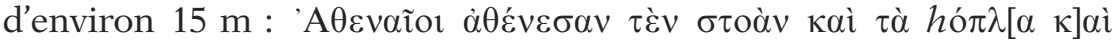

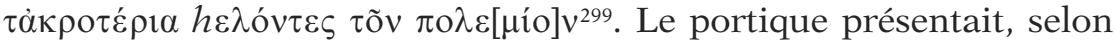

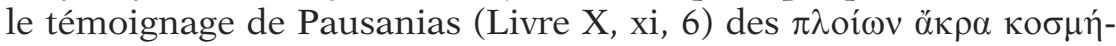
$\mu \alpha \tau \alpha$ et des $\dot{\alpha} \sigma \pi \hat{i} \delta \varepsilon \varsigma^{300}$

Les caractéristiques architecturales et épigraphiques tendent à dater l'édifice de la première moitié du Ve $\mathrm{s}$. a.C.; parmi les batailles navales de cette période, c'est celle du cap Mycale qui marque la fin de la flotte perse et la prise de Sestos par les Athéniens en 479-478 301 qui doit avoir suscité la construction de ce monument. C'est à P. Amandry que l'on doit cette hypothèse, qu'il étaye d'arguments très convaincants. Hérodote (Enquête IX, 121) nous rapporte en effet

${ }^{295}$ Ces étoiles d'or dites de Lysandre ont disparu au IVe S. a.C., ce qui a été interprété comme un mauvais présage avant la bataille de Leuctres (Plutarque, De Pythiae orac., 397F) : Amandry 1954, p. 307 note 4; Jacquemin 1999, p. 57, 153 note 139,191 note 279,258 et 273.

${ }^{296}$ Chapouthier 1935a, p. 131-132 et 142. Amandry 1954, loc. cit. rappelle ces hypothèses sans prendre position. Jacquemin 1999, p. 185, a également suggéré, en renvoyant à un article numismatique de Svoronos (1894, p. 108-109), de voir dans ces trois étoiles la constellation de la lyre appelée par les Grecs «tortue», ce qui renverrait au type monétaire éginète; mais trois étoiles paraissent très insufissantes pour représenter un tel ensemble astronomique (l'explication de Svoronos s'applique ainsi à tout un groupe de points).

${ }^{297}$ Amandry 1946; Amandry 1953, p. 35 ss.; résumé dans Gauer 1968, p. 101-102.

${ }^{298}$ Ce nombre n'est pas assuré, on avance également celui de huit. L'éventualité que privilégie P. Amandry est celle de sept colonnes entre deux antes (Amandry 1953, p. 82).

${ }^{299}$ Amandry 1953, p. 39 et pl. XXIII; Tod 1946, p. 21 n 18; Syll I, 29; Jacquemin \& alii 2012, p. 46-47 $\mathrm{n}^{\circ} 20$.

${ }^{300}$ Pausanias aurait ainsi opéré une confusion entre les événements de la Seconde Guerre médique et ceux de la guerre du Péloponnèse, en regroupant des offrandes - et des dédicaces - appartenant à des époques différentes. Sur l'épisode de Phormion et les actes religieux qui ont suivi, voir supra p. 358.

${ }^{301}$ Sur cette expédition, voir Will 1972, p. 125-130. 
que les Athéniens en rapportèrent notamment les ö $\pi \lambda \alpha$, c'est-à-dire les câbles des ponts de bois de Xerxès ${ }^{302}$, en vue de les consacrer : $\dot{\omega} \varsigma$

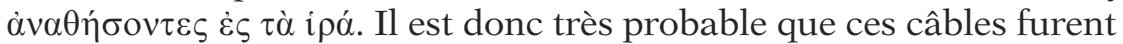
déposés ${ }^{303}$ à Delphes, dans un endroit conçu pour recevoir les

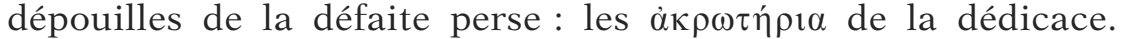
L'emplacement de la stoa, à proximité du mât des Éginètes, n'était pas dénuée de sens. Si Pausanias ne signale pas ces câbles, c'est qu'ils avaient naturellement disparu après plusieurs siècles. Le portique devait ainsi présenter, à l'époque classique, des ornements de bateaux ennemis dans la partie basse du fond du portique, surmontés des câbles, déroulés tout le long du mur polygonal peutêtre en plusieurs rangées ${ }^{304}$. Des boucliers, comme ceux mentionnés par Pausanias, pouvaient déjà y figurer à l'époque classique; d'autres - en particulier ceux du butin des victoires navales de Phormion sur les Péloponnésiens de 429 a.C. vus par le Périégète - ont pu être rajoutés au fils des années et des victoires navales.

W. Gauer a de surcroît avancé l'idée qu'une partie de ces cordages ait été déposée à Athènes même, sur l'Acropole : ceci justi-

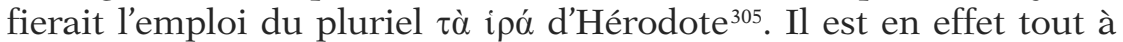
fait plausible que les Athéniens aient voulu présenter chez eux un souvenir de cette victoire sur les Perses, mais rien ne permet de l'affirmer avec certitude.

Les remises en cause de l'interprétation de P. Amandry n'ont jusqu'ici pas apporté de solution parfaitement convaincante ${ }^{306}$. En

${ }^{302}$ Sur ces câbles, cf. Athénée V, 209d; sur leur importance symbolique aux yeux des Grecs et l'emploi du mot comme terme de marine : Amandry 1953, p. 110-111. Gauer 1968, p. 32 et p. 36-37 lit le texte d'Hérodote avec le terme d'akrothinia - sans doute à la place de $\chi \rho \eta \dot{\mu} \mu \alpha \tau \alpha$ - qu'il utilise tout au long de son exposé. Pour certains commentateurs, le terme d'hopla est à traduire par armes; son association avec les akrôtèria renverrait à une double victoire, sur terre et sur mer (Walsh 1986; Mercanti 2006).

${ }^{303}$ Pour Amandry 1946, p. 1-8, les câbles étaient maintenus le long du mur au moyen de piliers de bois larges d'une trentaine de centimètres, espacés d'environ $60 \mathrm{~cm}$. La présence d'actes d'affranchissement datés au plus tôt de 157 a.C. dans ces intervalles, ainsi que la disparition de certains de ces piliers au $\mathrm{I}^{\mathrm{er}} \mathrm{s}$. a.C., signifierait que ces câbles n'étaient plus visibles dès cette époque.

${ }^{304}$ Amandry 1953, p. 117 ss. Doutes sur la présence de ces cordages dans le Portique : Jacquemin \& alii 2012, loc. cit.

${ }^{305}$ Gauer 1968, p. 37, 44, 73 et 101, déjà envisagée rapidement par Amandry 1953, p. 110. Dans le cas de W. Gauer, l'hypothèse est mise en relation avec une autre, beaucoup plus douteuse, de la présence d'un bateau sur l'Acropole : voir supra note 26 p. 356 . Par ailleurs, Amandry 1953, ibid., note 6, s'interroge sur cette expression qui surprend par son imprécision dans un domaine où Hérodote sait se montrer prodigue d'informations.

${ }^{306}$ La théorie de Walsh 1986, selon laquelle le portique aurait d'abord abrité des offrandes de victoires des Athéniens sur des Grecs puis de celles de Phormion 
attendant de nouvelles données, les sources littéraires restent unanimes : ce sont bien des éléments de bateaux qui ont été consacrés à Apollon à Delphes, suite à une ou des victoires navales.

Une question reste cependant à résoudre : en quoi consistent ces akrôtèria? P. Amandry avoue pour sa part sa perplexité devant le manque de largeur de la stoa qui rend impossible la présence de proues ou de poupes de navires de guerre à cet endroit ${ }^{307}$. Le problème se règle de lui-même si l'on définit précisément le terme d'architecture navale. Il est utilisé couramment en concurrence avec celui d'aphlaston, ce qui signifie qu'il ne s'agit ni de la proue ni de la poupe d'un bateau, mais de l'extrémité de cette dernière ${ }^{308}$. Le portique ne nécessitait pas pour cette raison une grande largeur; de la même manière, la statue monumentale d'Apollon ne doit pas être reconstituée avec un éperon à la main ${ }^{309}$, mais un aphlaston, ce qui lui donne un aspect tout à fait différent ${ }^{310}$.

\section{b) Phlyées}

Toujours parmi les offrandes déposées dans le contexte de la Seconde Guerre médique, Plutarque (Thémistocle 15, 3) nous signale à son tour celles du triérarque athénien Lycomédès. Celui-ci fut en effet le premier à prendre un navire perse ${ }^{311}$ et il en consacra les $\pi \alpha \rho \alpha ́ \sigma \eta \mu \alpha$ au sanctuaire d'Apollon Daphnèphore à Phlyées ${ }^{312}$.

une trentaine d'années plus tard, est contredite par la datation de la dédicace, proche de l'époque des guerres Médiques (Mercanti 2006; Jacquemin \& alii 2012, loc. cit.). Une autre suggestion renvoie à l'épisode de la soumission de Naxos à l'autorité d'Athènes, vers 470 a.C. (Mercanti 2006).

${ }^{307}$ Amandry 1953, p. 115-117.

${ }^{308}$ Sur cette définition, voir Casson 1971, p. 86 et note 49 ainsi que WadeGery 1933. Walsh 1986, p. 329 considère pour sa part que l'expression utilisée par Pausanias correspond tout à fait à la réalité de ce qui était accroché : des "ships' figure-heads», la dédicace du portique n'exprimant que le double champ des conflits, sur terre et sur mer.

${ }^{309}$ C'est la traduction adoptée dans l'édition du texte d'Hérodote dans la collection Budé.

${ }^{310}$ Wade-Gery 1933 donne des exemples similaires sur vases. C'est sans doute pour cela que Pausanias ne s'attarde pas sur la description d'une statue qui ne présente pas de caractère extraordinaire - ce qui n'aurait sans doute pas été le cas si Apollon avait tenu une proue de la main.

${ }^{311}$ Ce fait est également signalé par Hérodote, Enquête VIII, 11, mais pour la bataille de l'Artémision, tandis que Plutarque évoque les événements de Salamine.

${ }^{312}$ Gauer 1968, p. 35-36. Le sanctuaire est par ailleurs mentionné par Athénée, Deipnosophistes X, 24, 424 f. 
c) Délos

Des inventaires athéniens postérieurs à 146 a.C. répertorient pour le temple d'Apollon dit des Athéniens (voir fig. 7 n GD4) ${ }^{313}$ deux groupes d'akrostolia déposés suite à deux victoires navales remportées par les Athéniens et leurs alliés ${ }^{314}$ (voir annexe p. 558559). La localisation indiquée pour ces deux batailles a permis de les identifier. La première contre Naxos qui se déroula en 376 rétablit la suzeraineté des Athéniens dans les Cyclades. La seconde contre Leucade remportée en mer Ionienne en 374 ou 373 est connue par un passage de Xénophon ${ }^{315}$. Curieuse en revanche serait la précision donnée quant à la présentation de ces ex-voto : غ̇ं $\theta \hat{n}[\kappa \eta 1$.

Trois autres inventaires ${ }^{316}$ (voir annexe p. 558), classiques ceux-là, nous indiquent pour l'année 364/3 a.C. l'existence de trois

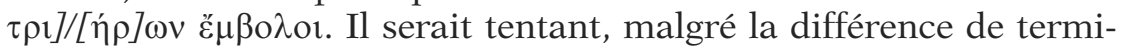
nologie et le manque de précisions, de réunir ces éperons à ceux dédiés dans les années 370, mais ceux recensés en 364/3 sont rattachés au temple des Déliens ${ }^{317}$.

Enfin, signalons que dans un inventaire de 343/342, très frag-

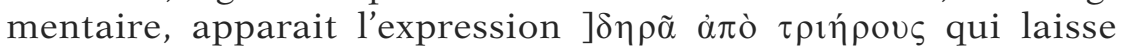
supposer la présence d'une partie de trière (voir annexe p. 558) ${ }^{318}$. Le problème est de savoir laquelle et également s'il ne s'agit pas d'une formulation différente pour un objet mentionné et connu par ailleurs, d'autant plus que nous ignorons de quel édifice il est question pour ce texte.

\section{«Antiquités» de l'époque hellénistique}

Deux passages de Strabon évoquent des offrandes de parties de bateaux, qui doivent cependant être datées bien avant la fin de l'époque hellénistique. C'est pourquoi il nous a paru bon de les présenter à part, car elles peuvent appartenir à l'époque classique ou au début de l'époque hellénistique. S'y ajoutent un passage de

313 Appelé aussi dans les $I D$ «temple aux sept statues»; cf. F. Courby, EAD XII. Les temples d'Apollon, p. 226 ss.

${ }^{314}$ ID 1443 B, II, 1. 49-51; ID 1446, 1. 21-23; ID 1449 d, 1. 12-14. Deonna 1938, p. 197-198. Wachsmuth 1967, note 236, a mal lu l'inscription : il signale l'ex-voto déposé dans le temple d'Athéna alors qu'il s'agit d'une offrande des Athéniens.

${ }^{315}$ Xénophon, Helléniques V, 65-66.

${ }^{316} I D$ 104, 1. 137-138; D 104-11 B, 1. 30; D 104-12, 1. 108.

317 J. Coupry, ID 104, p. 45 y met une autre objection : le chiffre 3 ne peut pas renvoyer à deux groupes akrostolia; il en faudrait au moins 4 . Sur le lieu de dépôt des offrandes du temple des Déliens, voir supra p. 382.

${ }^{318}$ ID 104-26 B, p. 97, 1. 10, 
Pausanias et un d'Ampelius mentionnant des objets selon eux très anciens.

\section{a) Massalia}

En évoquant l'histoire de Massalia avant les guerres civiles - au cours desquelles la ville opéra un choix malheureux -, Strabon (Géographie IV, 1, 5) conclut sur les nombreuses luttes que la ville eut à mener pour sauvegarder son territoire et sa maîtrise du

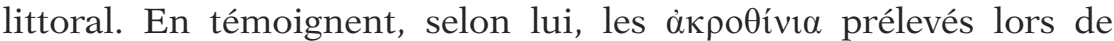

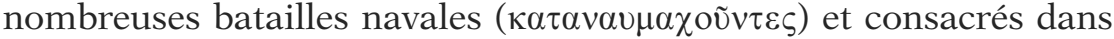
la ville. Le géographe n'en dit pas plus, mais ces propos laissent

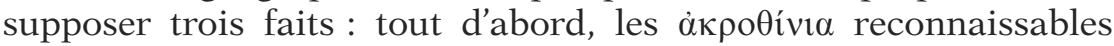
comme originaires d'une bataille navale sont aisément imaginables sous la forme d'éperon ou de quelque autre partie de navire; ceux-ci sont visibles à l'époque de Strabon ou au moins ont été vus par les auteurs hellénistiques qu'il a utilisés ${ }^{319}$; en dernier lieu, le ou la divinités à qui ils sont dédiés, à la lumière de ce qui a été exposé précédemment par Strabon à propos des cultes de la ville (Géographie, IV, 1,4) s'imposent comme étant Apollon et/ou Artémis.

\section{b) Odysseia}

Le second cas concerne un sanctuaire ibérique. La Périégèse d'Asclépiade de Myrleia (Fgt 7 = Strabon III, 4, 3), datée du I ${ }^{\text {er }}$ s. a.C., signale que le sanctuaire d'Athéna de la ville d'Odysseia possède des

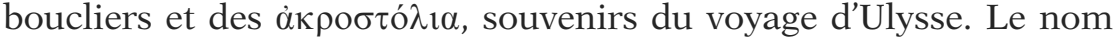
d'Odysseia témoigne par ailleurs de la tradition homérique attachée non seulement à ces objets mais à la cité entière, ce que ne manque pas d'ailleurs de commenter ensuite Strabon $^{320}$. Cette dernière se situe dans la montagne, dans l'arrière-pays d'Abdéra présentée quant à elle comme une fondation phénicienne ${ }^{321}$. Cette anecdote constitue ainsi vraisemblablement un témoignage de la présence de

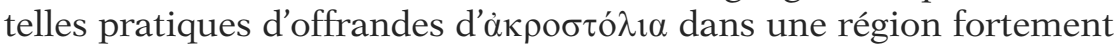
marquée par les traditions phéniciennes. De plus, si ces objets ont pu être attribués à Ulysse, c'est qu'ils devaient présenter un aspect

319 Selon F. Lasserre, éditeur du livre IV de Strabon dans la collection Budé, p. 126 note 4, estime que les paragraphes 1, 4-5 correspondent à la situation politique de la fin du $\mathrm{II}^{\mathrm{e}} \mathrm{s}$ a.C. et doivent donc être dus à Poseidonios.

${ }^{320}$ Sur la tradition odysséenne en Espagne et cette cité nommée selon Strabon Odysseia, voir García y Bellido 1948, I p. 17. Le savant espagnol propose un rapprochement avec une cité appelée Oducia (CIL II, 1956 et 1182).

${ }^{321}$ Aujourd'hui Adra, province d'Almeria, à l'ouest de cette dernière; voir ibidem, I p. 134-135. 
ancien, antérieur au I ${ }^{\mathrm{er}}$ s. a.C. Le lien privilégié qu'entretient Ulysse avec Athéna suffit à justifier la présence d'éperons dans un de ses temples.

\section{c) Sicyone}

Aux dires d'Ampelius (Aide-mémoire 8, 5), le sanctuaire d'Apollon de Sicyone figure parmi les curiosités dignes d'être vues au $\mathrm{II}^{\mathrm{e}} \mathrm{s}$. de notre ère. En effet, y sont déposés de nombreux ex-voto illustres, ayant appartenu dit-on à de nombreux héros. Entre autres, y sont consacrés les remi et les gubernaculis bracchia des Argonautes $^{322}$. Comme dans le cas précédent, des objets anciens ont dû faire l'objet d'attributions glorieuses pour la cité; cette construction mythologique n'est pas surprenante dans une cité où la tradition argonautique est anciennement ancrée ${ }^{323}$.

\section{d) Thèbes}

D'après Pausanias (Description de la Grèce IX, xvi, 3-4), les trois statues de bois d'Aphrodite de Thèbes ont été réalisées, selon la tradition, à partir des akrostolia des navires de Cadmos pour être offertes à la déesse par son épouse. Le Périégète confirme qu'en tant que xoana, elles paraissent très anciennes au point d'être dignes de remonter à l'époque d'Harmonie. Si le fait est en lui-même très discutable, il n'en reste pas moins que l'histoire racontée à Thèbes repose sur une pratique qui ne paraît pas surprenante à l'esprit d'un Grec; ce qui est digne d'admiration dans ces statues n'est pas comment elles ont été fabriquées, mais à quelle époque et avec quel mythe elles sont à mettre en relation.

\section{Époque hellénistique}

a) Délos

Les inventaires déliens témoignent de l'existence d'un certain nombre de dons de parties de bateaux également pour l'époque hellénistique.

${ }^{322}$ L'usage de cette expression pour désigner le gouvernail ne semble pas attesté ailleurs; sans doute faut-il la comprendre comme l'ensemble constitué de la barre du gouvernail et de l'oiax perpendiculaire à celle-ci.

${ }^{323}$ Le Trésor de Sicyone à Delphes du VI ${ }^{\mathrm{e}}$ s. a.C. montre la nef Argô et quelques membres de l'expédition: Guide de Delphes 1991b, p. 42-44; Blatter 1984, II,1 p. $593 \mathrm{n}^{\circ} 2$ et II, 2 p. 430 . Voir supra, p. 393 ss. 
Tout d'abord, un certain nombre d'inventaires datables entre 179 et 174 a.C. enregistrent dans l'édifice des Andriens (voir fig. 7

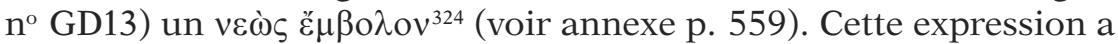
été par analogie restituée dans une liste de 240 a.C., mais cela reste douteux ${ }^{325}$.

Un inventaire plus ancien, daté de 229 a.C., recense pour l'édifice des Andriens, quant à lui, un $\ddot{\varepsilon} \mu \beta 0 \lambda \circ \varsigma \chi \alpha \lambda \kappa o v \tilde{\varsigma} \varsigma^{326}$. Malgré le lieu de dépôt identique, il est difficile d'affirmer qu'il s'agit bien du même objet, pour lequel il n'existerait aucune mention durant un demi-siècle.

À l'intérieur du Monument des Taureaux, dans le prodomos, se trouvaient selon un inventaire délien exposées deux proues dorées :

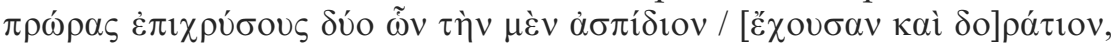

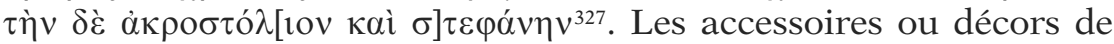
ces proues ne sont pas clairement explicités; G. Roux propose de reconnaître dans les termes d'aspidion, doration et stéphanè, parallèlement à celui d'akrostolion, des mots techniques de marine ${ }^{328}$. L'inventaire est daté de 166 a.C., mais on ne peut savoir si ces offrandes datent de cette époque ou remontent à celle de la construction du bâtiment, c'est-à-dire à la fin du IV ${ }^{\mathrm{e}} \mathrm{s}$., ou lui sont encore antérieures $^{329}$. En outre, il est impossible de déterminer si ces proues provenaient de bateaux pris sur l'ennemi, comme c'est le cas général, ou de bâtiments d'une flotte ayant remporté une victoire navale, à l'exemple du bateau-amiral consacré par Antigone suite à la victoire de Kos. Cependant, la présence, dans ce même prodomos, d'une panoplie de cavalier fait davantage pencher pour la première solution : les proues et la panoplie correspondraient à des trophées d'une victoire navale ${ }^{330}$.

${ }^{324}$ ID 442 B, p. 151, 1. 167 (Homolle 1882, p. 47, 1. 167); ID 443 Bb, p. 184, 1. 90; ID 444 B, p. 192, 1. 6; ID 457, p. 229, 1. 17).

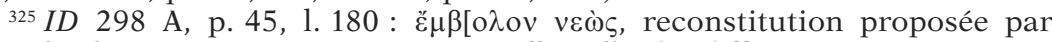
F. Durrbach. Nous pourrions opposer à celle-ci l'ordre différent que présenterait l'ordre de l'énumération des offrandes, et surtout l'interversion nominatif + génitif. L'épigraphiste délien propose également une autre possibilité de reconstitution.

${ }^{326}$ ID 320 B, l. 69.

${ }^{327}$ ID 1403 (voir supra, p. 359 ss.).

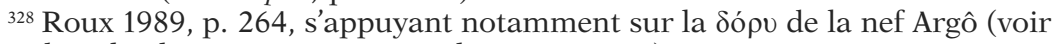
supra, dans le chapitre consacré à Athéna, p. 24-25).

${ }^{329}$ Sur les problèmes de datation du Monument des Taureaux et de l'offrande du navire entier qu'il a contenu, voir supra p. 359 ss.

${ }_{330} \mathrm{O}$. Picard et G. Roux envisagent également la possibilité d'une panoplie royale, à cause du casque doré muni de cornes : Roux 1989, p. 275. 


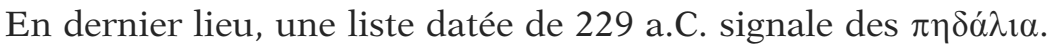
Le mot est en partie restitué, mais le petit nombre de lettres manquantes laisse peu de possibilités pour un autre terme ${ }^{331}$. De surcroît, toute cette partie de l'inventaire, bien fragmentaire, ne peut assurer le lieu où ces gouvernails étaient déposés : peut-être dans «le sanctuaire de l'̂̂le» cité quelques lignes plus haut ${ }^{332}$, qui correspondrait à un Artémision, situé à Rhénée, et serait à reconnaître sur la colline de Khomasovouni visible depuis le sanctuaire délien ${ }^{333}$.

\section{b) Actium}

Outre les bateaux grandeur réelle consacrés à Apollon après Actium, Octave fait ériger près du lieu de la bataille un autel muni d'éperons provenant également de la flotte d'Antoine ${ }^{334}$. Cette offrande est mieux documentée que la première, car elle fut visible durant toute l'Antiquité et subsiste encore partiellement aujourd'hui. Le premier à l'évoquer est Plutarque, dans la biographie consacrée à Antoine, qui y fait allusion à propos d'un heureux présage survenu à son rival avant la bataille décisive ${ }^{335}$ (Antoine, 65,5$)$ : des emboloi sont simplement mentionnés comme ornementation du lieu par l'empereur. La description de Dion Cassius de la bataille et des événements qui ont suivi est plus précise à ce sujet. Il évoque donc (Histoire romaine LI, 3), parmi les actes destinés à célébrer la victoire sur place, ce qu'il est advenu de l'emplacement de la tente d'Auguste. Il fut pavé de pierres carrées et orné d'è $\mu \beta{ }_{0} \lambda o r \varsigma$ de la flotte ennemie, constituant ainsi un hiéron à ciel ouvert consacré à Apollon ${ }^{336}$.

Les vestiges de cet autel avec éperons de bronze encastrés, contruit par Auguste à Actium, ont été dégagés au flanc du Mont Michalitsi, près du village de Smyrtoula, c'est-à-dire dans la partie nord du golfe d'Ambracie, dominant la cité de Nicopolis ${ }^{337}$. Le

${ }_{331}^{3}$ ID 320 B, 1. 75. Bruneau 1970a, p. 202.

${ }_{332}$ F. Durrbach, ID 290-371, p. 93.

${ }^{333}$ Couilloud-Le Dinahet 1978; Tréheux 1976. Avant cette hypothèse, non confirmée encore, on situait le sanctuaire sur le grand Rhevmatiaris : Gallet de Santerre 1958, p. 155.

${ }^{334}$ Sur les bateaux grandeur réelle, voir supra p. 367 s. Il est à noter que Strabon parle de ceux-ci qui ont disparu, mais ne mentionne pas l'autel orné d'éperons.

${ }^{335}$ L'anecdote qui figure également chez Suétone, Auguste 96, 5, qui raconte la rencontre d'Octave avec un homme monté sur un âne, nommés respectivement Eutychos et Nikôn.

${ }^{336}$ Le commentaire de l'édition du texte dans la collection Budé, p. 121, note 6, mêle les deux offrandes d'Octave (bateaux entiers d'une part, autel avec éperons d'autre part). Cette confusion est peu compréhensible puisque le texte de Dion Cassius distingue les deux actes religieux.

${ }^{337}$ Höckmann 1985, p. 159; Murray 1993, p. 66-73. 
monument se présente comme une large terrasse pourvue d'une stoa; tout autour de la façade du mur de soutènement de cette terrasse sont incrustés les éperons de bronze au moyen d'alvéoles conçues à cet effet (fig. 36-37). Ceux-ci devaient être au nombre de 33 ou 35, ce qui devait constituer la dîme des prises ${ }^{338}$.

Une inscription monumentale longue d'environ 55 mètres surmontait ces rostres. Plusieurs fragments d'entre elle ont été retrouvés sur le site et on peut ainsi reconstituer la dédicace originale ${ }^{339}$. Elle contredit en partie le témoignage de Dion Cassius, en mentionnant Neptune et Mars : ainsi, ce monument n'aurait pas été consacré au dieu d'Actium, mais à deux autres tout aussi partie prenante dans une bataille navale. Dion Cassius a pu confondre les informations concernant les deux offrandes d'Octave, les bateaux entiers à Apollon et les proues à un autre endroit et à d'autres divinités.

Par ailleurs, le vainqueur conserva également quelques rostres des navires ennemis afin de les intégrer dans ses projets architecturaux romains. Ils furent placés pour la plupart dans le Forum de l'Urbs, sur le podium du temple de César, et peut-être pour quelques uns au sanctuaire d'Apollon au Palatin ${ }^{340}$. Le dieu d'Actium se devait d'être également publiquement honoré à Rome.

\section{c) Dodone}

Nous terminerons cet inventaire par une offrande impossible à dater à cause du caractère mal défini de sa source. Les Lexeis rhetorikai développent une entrée Zeus Naios en l'illustrant d'une consécration réalisée par un certain Périros (voir corpus p. 540). Celui-ci en effet, ayant échappé à un naufrage grâce à la poupe du bateau sur lequel il trouva refuge, la voua au dieu dans son hiéron de Dodone. L'épiclèse de Zeus Naval n'est pas connue par ailleurs, mais le maître de l'Olympe est honoré dans son grand sanctuaire épirote

${ }^{338}$ Ceci correspond aux dires de Plutarque, op. cit., qui donne le chiffre de 300 bateaux capturés, qui doit être un chiffre "arrondi».

339 Oliver 1969; Carter 1977. Le texte restitué par le premier est le suivant : [Nep]tuno [et Ma]rt[i Imp. Caesa]r div[i Iuli ] f. vict[oriam consecutus bell]o quod pro [re pu]blic[a] ges[si]t in haec region[e cons]ul [quintum i]mperat[or se]ptimum pace parta terra [marique c] astra [ex] quibu[s in] equ[endum egr]essu[s est spoli]is [ornat]a [dedicavit.

${ }^{340}$ Gagé 1936, p. 43-44; Jucker 1982. Sur les rostres du Forum, voir F. Coarelli, Guida archeologica di Roma, Milan, 19895, p. 86. Des allusions concernant cet ornement du temple ou son lien avec Actium figurent dans Virgile, Énéide VIII, v. 720 ss.; id., Géorgiques III, v. 29; Properce, Élégie IV, 6, v. 11 ss.; voir à ce sujet O. L. Richmond, "The augustan Palatium», JRS IV, 1914, p. 219 ss. 


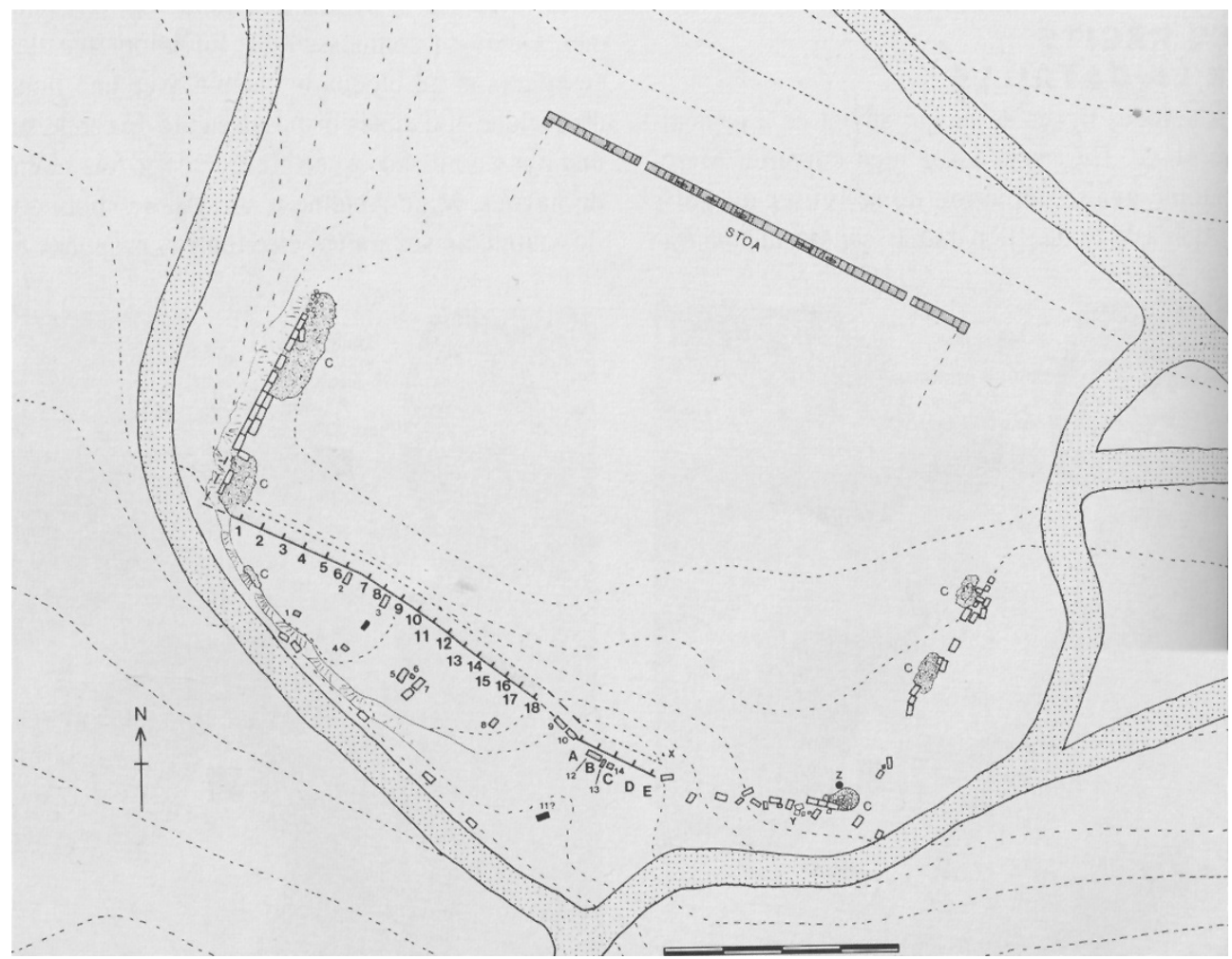

Fig. 36 - Plan du grand autel d'Actium (d'après Murray 1993, p. 68).

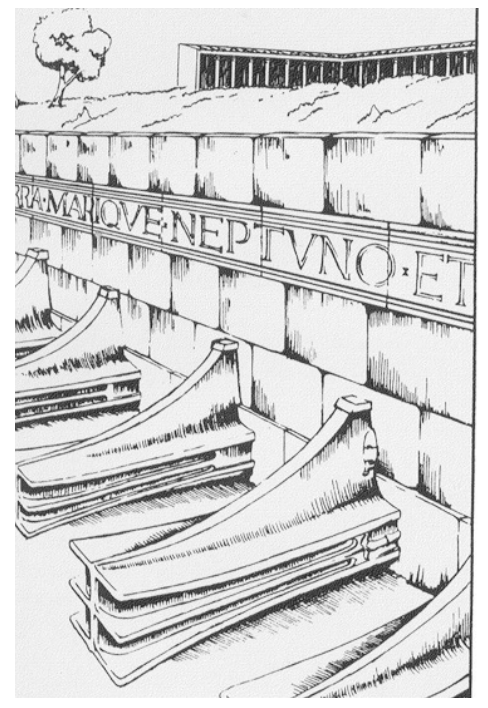

Fig. 37 - Grand autel d'Actium : restitution (détail) (d’après Murray 1993, p. 73). 
sous le nom de Naos ou Naios. Le type de l'ex-voto dut inciter l'auteur du lexique à rapprocher l'épiclèse Naios de vaṽ $\varsigma^{341}$, étymologie sans fondement. L'anecdote montre cependant que des individus, à titre privé, pouvaient réaliser ce genre de don dans un grand sanctuaire oraculaire; dans la pratique il faut supposer une embarcation de petite taille voire même quelques planches.

\section{Conclusion}

La consécration de parties de bateaux à des divinités olympiennes est continue et régulière depuis l'époque archaïque jusqu'à l'époque hellénistique. Des traditions mythiques s'y rattachent, entourant cette pratique d'antécédents prestigieux. À l'époque archaïque, les offrandes sont des prises sur l'ennemi - ou dans un cas sa représentation - que l'on voue au sanctuaire de la cité ${ }^{342}$, en l'occurrence pour les trois cas connus ceux de Zeus, Artémis et Héra. Trois des six traditions concernant des objets à dimension mythique se rapportent quant à elles à Athéna. À l'époque classique, toutes les offrandes honorent Apollon. Il s'agit essentiellement de prises de guerre, mais aussi semble-t-il d'objets réalisés sur commande. Les ex-voto sont déposés dans les grands sanctuaires panhelléniques (Delphes, Délos). À l'époque hellénistique, les sources moins précises ne définissent pas l'origine des dons, mais on peut supposer par analogie des prises de guerre. Apollon est encore l'objet de ces marques d'honneurs. Des situations malheureusement difficiles à dater montrent qu'Artémis, Athéna, Aphrodite et Poséidon se voient également consacrer des parties de bateaux. Poséidon est alors associé à une autre divinité, mais ne reçoit pas seul la reconnaissance du ou des dédicants.

Dans les cas où ils sont définissables, ceux-ci correspondent ou bien à des habitants d'une cité ou à des détenteurs d'une autorité militaire (Lycomédès, Auguste), ou bien à des personnages mythiques (Agamemnon, Kanopos, Ulysse, Harmonie). A priori, l'offrande d'une partie de bateau n'est pas le fait de simples particuliers, à moins que ce ne soit le cas pour les objets recensés dans les inventaires déliens dont les dédicants ne sont pas nommés ${ }^{343}$, à l'exemple du fidèle de Dodone. En revanche celles-ci sont variées : elles consistent en gouvernails (4 cas), emboloi (4), akrostolia (3), akrôtèria (2), proues

${ }^{341}$ Nilsson 1955, p. 427.

${ }^{342}$ Caractère observé également par Davaras 1980, p. 55.

${ }^{343}$ Parmi les modèles réduits, le bateau d'argent de Séleucos était recensé avec le nom de son dédicant dans l'inventaire délien (voir supra) : faut-il en conclure pour autant que les offrandes prestigieuses étaient attribuées à une onomastique à l'inverse de celles des simples particuliers? 
(3), poupe (1), hopla (1), parasèma (1), stylis (1) - auxquels s'ajoute un élément indéfini. La proportion entre éléments de proue et de poupe est à peu près égale, avec une légère majorité pour les parties de proues. Les éléments de poupe représentent pour la plupart des ex-voto particuliers. L'unique stylis et trois des quatre gouvernails sont tous considérés comme des curiosités, des antiquités remontant à la naissance de l'architecture navale ou aux navigateurs homériques. Ceux-là constituent par ailleurs des éléments navals amovibles, qu'on peut consacrer au cours d'une navigation et remplacer par d'autres; les gouvernails sont en outre signalés par Maxime de Tyr au $\mathrm{II}^{\mathrm{e}}$ s. p.C. comme l'offrande de marin par excellence $^{344}$. Les seuls akrôtèria attestés sont ceux des navires perses. L'impression qui se dégage de cet ensemble tend à attribuer une signification particulièrement forte à ces dons de parties arrières de bateau. Dans le même ordre d'idée, notons également que les seuls parasèma consacrés sont perses. Il est curieux que cet élément pourtant porteur de sacralité ne figure pas parmi les ex-voto courants, ce qui par ailleurs met en relief la valeur majeure accordée à la victoire des Guerres médiques et aux consécrations qui ont suivi.

\section{CONCLUSION GÉNÉRALE}

Les dieux olympiens se voient consacrer des bateaux sous des formes variées de façon continue durant toute l'Antiquité grecque. Les marques de dévotion de la part des fidèles se font, d'après les sources littéraires et épigraphiques, en remerciement d'une traversée réussie ou d'une victoire navale - même si toute relative dans le cas des Lacédémoniens durant la guerre du Péloponnèse. Ces offrandes ont pu ainsi pour certaines constituer le pendant d'un veu d'euploia. Les dons sont réalisés par des individus à titre privé dont le manque d'informations empêche de dresser le portrait: simple voyageur, marin, propriétaire de bateau? Un certain nombre de ces ex-voto sont attribués à des personnages héroïques : les Argonautes, Ulysse, Agamemnon, Kanopos qui appartiennent aux deux grandes épopées maritimes de la tradition grecque. Il est à noter que tous à l'exception de Kanopos sont vus comme auteurs de deux dons navals qui ne sont pourtant pas contradictoires ou incompatibles : bateau et gouvernail séparés; modèle réduit et partie d'une embarcation.

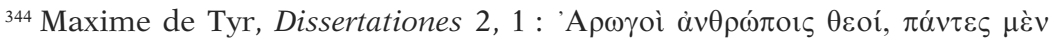

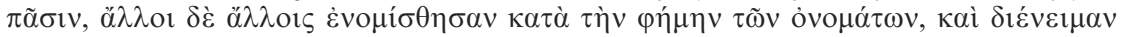

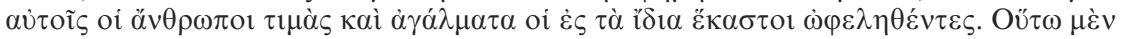

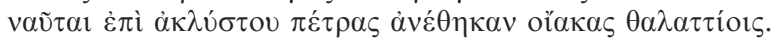


Des équipages consacrent des embarcations de façon collective, même si cela est peu documenté. Enfin, quand la cité ou un homme de la sphère du pouvoir réalise ce type de don, l'événement est mieux connu par les textes. L'impression générale dessinée à l'intérieur de chaque série se vérifie dans le tableau d'ensemble : les offrandes sont nombreuses à l'époque archaïque, moindres à l'époque classique et à nouveau courantes à l'époque hellénistique. Plutôt qu'un désintérêt religieux ou un manque de sources, ces différences chronologiques doivent refléter des réalités historiques. L'importance du processus de colonisation durant l'époque archaïque et l'établissement de courants commerciaux lancent un grand nombre d'hommes à l'assaut de la Méditerranée. À l'époque classique, les traversées sont moins porteuses d'inconnu et fondées sur des antécédents éprouvés. Les routes maritimes sont établies, les flux migratoires moindres et l'architecture navale repose sur des techniques solides. L'époque hellénistique accorde à la mer une place notable et pour la domination de cette dernière les souverains s'affrontent. C'est également une époque d'intenses mouvements des gens et des marchandises et d'échanges entre les diverses communautés méditerranéennes.

Offrandes de bateaux entiers, reproductions miniatures et morceaux de bateau peuvent coexister dans les actes religieux consécutifs à un même événement : c'est spécialement le cas pour les Guerres médiques, commémorées de façon multiple et variées en ce qui concerne le domaine maritime. De la même manière, la plupart des dieux sont remerciés par ces différentes formes de dons ${ }^{345}$.

Sept dieux olympiens sont essentiellement concernés : Zeus, Héra, Poséidon, Apollon, Artémis, Athéna, Aphrodite. Poséidon est loin d'y occuper la première place : c'est sans conteste Apollon qui est davantage impliqué. En effet, à l'époque archaïque, l'Ébranleur du sol reçoit des offrandes navales : ce qui tient lieu de nef Argô et vraisemblablement des modèles de terre cuite à l'Isthme. En dehors de ce sanctuaire, il est alors associé à une autre divinité avec laquelle il partage ces marques de dévotion : pinakes avec Amphitrite, gouvernails avec Athéna et bateaux miniatures avec Héra. Si dans le premier cas on peut lui accorder la primauté, en revanche les deux autres occurrences s'adressent plutôt aux divinités dans le sanctuaire desquelles les objets sont déposés - Lindos pour Athéna et Samos pour Héra. Le dieu partage également les emboloi d'Actium avec Mars sur l'autel d'Octave, qui représentent la seule offrande navale à Poséidon pour l'époque hellénistique. Ces associations sont notables car uniques pour la globalité de ces ex-voto. Apparemment, en dehors du

${ }^{345}$ Ceci rejoint la conclusion de Vian 1968, p. 58, selon laquelle «après Homère, (...] il n'y aura plus de dieu de la fonction guerrière». 
sanctuaire de l'Isthme, la personnalité navale de Poséidon n'est guère suffisamment forte dès l'époque archaïque pour recevoir un grand nombre de dons et de surcroît pour qu'ils s'adressent à lui seul. En revanche, il semble recevoir un culte public marquant lors des guerres $\mathrm{du} \mathrm{Ve}$ s. a.C. pour lesquelles les cités lui consacrent trois bateaux pris sur leurs ennemis respectifs. À partir du IV e s. a.C., il est absent de la liste des offrandes navales y compris pour son téménos corinthien.

En ce domaine c'est donc Apollon qui tient le premier rang. Présent dès l'époque archaïque mais de façon discrète, il s'affirme comme le grand bénéficiaire des dons de bateaux dès les Guerres médiques jusqu'aux débuts de l'Empire romain. Les offrandes classiques et hellénistiques sont souvent à mettre en relation avec des batailles navales ou des luttes de pouvoir, depuis le conflit contre les Perses jusqu'aux conquérants romains Mummius ou Octave qui exploitent cette facette du dieu. Le caractère panhellénique des deux sanctuaires principaux pour lesquels sont attestés la majorité de ces ex-voto - Délos et Delphes - n'est sans aucun doute pas étranger au phénomène. Cependant l'autorité navale d'Apollon se manifeste aussi dans d'autres sites: Actium, Épidaure, Sicyone et plus loin Nymphaion et peut-être Marseille. Par ailleurs, des dons plus modestes recensés dans les inventaires déliens et les objets archaïques laissent supposer des marques de dévotion privées tout autant que publiques, sans qu'il soit réellement possible d'en apprécier les caractéristiques.

À l'époque archaïque, deux divinités reçoivent un culte naval important : Héra et Artémis. À la première sont dédiés de nombreux modèles réduits et un graffito mais aussi deux embarcations réelles. Elle est ainsi honorée à Samos, mais aussi à Péracora et en Grande Grèce : Crotone, Gravisca. L'offrande la plus récente consiste dans le tableau du pont de bateaux de la Seconde Guerre médique. L'ensemble des témoignages laisse supposer des marques de dévotion privées et individuelles. Au-delà du début du Ve s. a.C., Héra ne paraît plus remerciée de cette manière pour des navigations réussies. En parallèle, Artémis est invoquée durant la période archaïque, notamment à Sparte. Deux ex-voto navals qui lui sont consacrés dans les îles d'Eubée et Samos sont attribués selon la tradition à Agamemnon et rattachés au contexte du voyage des Achéens vers Troie. Les bateaux de terre cuite du sanctuaire d'Aphaia sont sans doute à rattacher au culte d'Artémis. La déesse continue à recevoir des offrandes de parties de bateaux à l'époque hellénistique à Délos et probablement durant les siècles précédents à Marseille.

Il est en revanche beaucoup plus difficile de dater les consécrations à Athéna. Pour l'époque archaïque, est assuré un pinax du sanctuaire de Sounion; à des traditions héroïques sont en outre liées trois mentions de parties de bateaux qui lui sont dédiées. Au 
$V^{e}$ s. a.C., la grande divinité athénienne se voit consacrer sur l'Acropole une lampe en bronze et des reliefs de marbres représentant des bateaux; ce caractère naval du culte d'Athéna à Athènes existait peut-être déjà à l'époque archaïque si on attribue certaines découvertes céramiques à la déesse. Les Guerres Médiques constituent sans doute également une occasion de la remercier à l'extrémité de l'Attique. À l'époque hellénistique, c'est à Lindos qu'Athéna reçoit une offrande navale. Tout cela reconstitue un culte disparate, hétérogène, que l'insuffisance des sources aussi bien littéraires qu'archéologiques ne permet pas de définir plus précisément. Il est à noter cependant la richesse des offrandes classiques et hellénistiques qui laisse supposer, grâce à l'inscription de Lindos, qu'elles sont dues à des groupes voire même à des cités.

Enfin Aphrodite et Zeus ont en commun des attestations archaïques et hellénistiques entrecoupées par un vide apparent à l'époque classique. Des modèles de terre cuite sont dédiées à Aphrodite en Grèce continentale à l'époque archaïque; quelques siècles plus tard, en mer Noire, on lui consacre une scène navale. Si les premiers évoquent plutôt un culte de la part de simples particuliers, le grand dessin témoigne d'un événement politique. Quant aux akrostolia thébains de Cadmos, leur existence est difficilement datable et leur origine indéterminable. À l'image d'Athéna, les offrandes navales d'Aphrodite constituent un ensemble disparate tant au niveau chronologique que géographique, qu'au niveau des objets et des dédicants. Zeus possède un embolos à Mégare, offrande archaïque de la cité. Les deux autres cas concernent le culte de Zeus Kasios dans la région de l'île de Corfou. L'une d'époque hellénistique consiste en une marque de dévotion privée. La seconde rattachée à la tradition odysséenne n'est pas datable; le type de l'offrande laisserait cependant plutôt supposer un don collectif. Enfin signalons la présence d'un document faisant figurer Déméter parmi les sujets de dévotion liée à la navigation.

Face à cette multiplicité des dieux concernés et à leur diversité de caractère, il est frappant de constater la concentration d'ex-voto navals dans certains sanctuaires. Même si la carte de répartition de ces dons concerne tout le bassin méditerranéen et même au-delà la mer Noire, quelques sites en sont particulièrement riches. Des sanctuaires panhelléniques : Delphes, Délos, l'Isthme de Corinthe, ou du moins de grand prestige comme l'Acropole d'Athènes, ainsi que ceux de divinités poliades insulaires : Samos et Lindos. Notons enfin la présence de quelques uns de ces ex-voto à l'intérieur des terres, comme à Sparte ou à Thèbes. Les sanctuaires littoraux ne sont ainsi pas les seuls concernés par les dons navals, mais sans doute aussi ceux de la cité dont est originaire le dédicant qui rend grâce d'être rentré chez lui sans encombre. 


\section{BATEAUX SACRÉS}

Jusqu'ici ont été recensés les bateaux consacrés à l'intérieur d'un sanctuaire ou du moins dans un espace ressenti comme sacré, fixés à un endroit précis. Il existe par ailleurs des bateaux mobiles auxquels est attribuée une fonction religieuse et qui sont pour cela même considérés comme propriétés de la divinité. Ils constituent ainsi une catégorie particulière ${ }^{346}$ qu'il ne faut cependant pas occulter, à l'intérieur de laquelle nous avons distingué deux groupes - même si les sources sont loin d'être aussi explicites à cet égard.

\section{Bateaux mythiques}

Le premier ensemble peut comprendre les bateaux dits «sacrés». Ceux-ci sont des embarcations que les Anciens attribuaient à des héros. Ces bateaux conservés comme des reliques n'étaient pas forcément rattachés à une divinité ou à un sanctuaire précis, du moins les témoignages littéraires ne le précisent pas toujours. Cette pratique est également suivie dans le monde romain, puisque Procope (De Bello Gothico IV, 22, 5-16) au VI ${ }^{\mathrm{s}}$ s. de notre ère affirme avoir vu à Rome le navire d'Énée ${ }^{347}$.

\section{a) Bateau de Thésée à Athènes}

Callimaque (Hymne IV (à Délos), v. 314-315) fait allusion à un bateau, celui du voyage crétois de Thésée, qui serait consacré à Apollon. Cependant, le poète indique qu'il ne s'agit pas du bâtiment dans son intégralité, mais d'une partie de celui-ci : précisément les

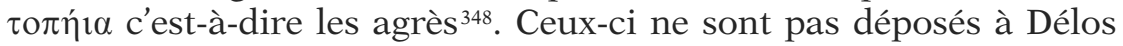
même ${ }^{349}$, mais seraient intégrés à l'intérieur du bateau des théores $(\theta \varepsilon \omega \rho i ́ \delta \text { os })^{350}$. Ces deux vers quelque peu sybillins sont heureusement éclairés par d'autres sources littéraires.

${ }^{346}$ Le ThesCRA catégorie ces bateaux parmi les «instruments de culte»: Schipporeit 2011, p. 293-295.

${ }^{347}$ Couchoud \& Svoronos 1921, p. 276; Gianfrotta 1991, p. 85-88; Göttlicher 1992, p. 130-131.

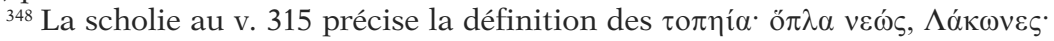

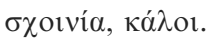

${ }^{349} \mathrm{Au}$ début du siècle, on envisagea la possibilité que la poupe du bateau de Thésée ait été consacrée dans la chambre du Monument des Taureaux délien : cf. Couchoud \& Svoronos 1921, p. 281 ss. Cette interprétation fut ensuite contestée par Tarn 1910, p. 216-217.

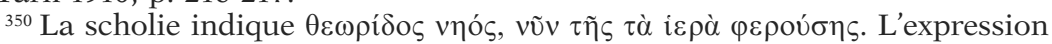

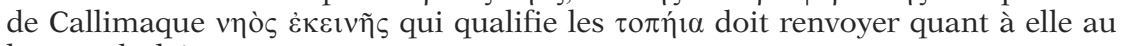
bateau du héros. 
Ainsi, on connaît par l'épisode de la mort de Socrate (Platon, Phédon 58a-c) l'existence d'un bateau sacré emmenant une théorie athénienne vers Délos ${ }^{351}$. L'exécution du philosophe fut en effet retardée pour cause de tabou religieux, aucune exécution ne pouvant être réalisée entre le départ du bateau et son retour ${ }^{352}$. Selon la tradition, ce voyage commémore celui effectué par Thésée pour la Crète, dont il était revenu vainqueur du Minotaure. Le vœu avait été prononcé - Platon ne nous précise pas par qui, sans doute faut-il comprendre le peuple des Athéniens - de réaliser en l'honneur

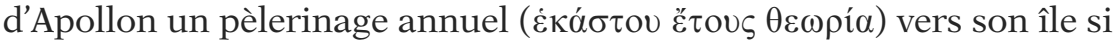
l'expédition revenait saine et sauve. La théorie - et donc la trêve commence à partir du moment où le prêtre d'Apollon couronne la poupe du navire juste avant son départ. Or, ce bateau, aux dires des Athéniens, est précisément celui sur lequel leur héros se serait embarqué. Le passage de Platon complète ainsi celui de Callimaque,

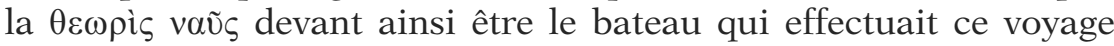
annuel vers Délos et que les Athéniens identifiaient comme celui de leur héros local ${ }^{353}$.

Pour sa part, Démétrios de Phalère (Fgt 23) rapporte que la nef qui conduisit et ramena Thésée de Crète était visible à Athènes à son époque, c'est-à-dire à la fin du $\mathrm{IV}^{\mathrm{e}}$-début $\mathrm{III}^{\mathrm{e}} \mathrm{s}$. a.C. Il précise à ce propos que l'embarcation était régulièrement restaurée par les Athéniens qui remplaçaient les planches abimées par de nouvelles. Plutarque (Si la politique est l'affaire des vieillards, 6) reprend pour son compte cette dernière information, l'utilisant comme métaphore pour la gloire humaine.

${ }^{351}$ Aristote, Constitution d'Athènes LVI, 3 mentionne par ailleurs la désignation par l'archonte d'un archithéore pour le vaisseau dit "trente» chargé de conduire les jeunes gens à Délos.

${ }^{352}$ Cette durée était très variable en fonction des conditions météréologiques : l'exécution de Socrate a ainsi été retardée de 30 jours d'après Xénophon, Memorabilia IV, 8, 2. Les problèmes de navigation sur ce parcours étaient courants, comme le montre par ailleurs un récit de voyage de Cicéron (Lettres à Atticus V, 12 = Correspondance CCI).

${ }^{353}$ Le commentaire de la Souda répète en substance la même information :

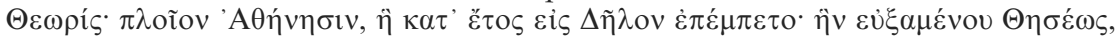

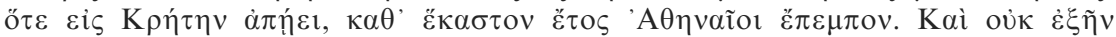

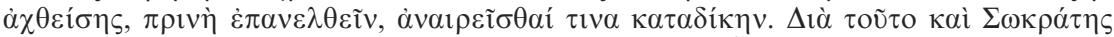

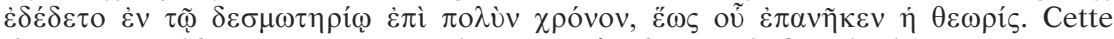
théorie prend la mer pour se rendre aux Délia, la grande fête du dieu qui a connu des aléas au gré de l'histoire politique de Délos. Après beaucoup d'incertitudes, on date aujourd'hui ces fêtes en Thargélion (calendrier athénien), en liaison avec la date anniversaire de la naissance d'Apollon et Artémis : Bruneau 1970a, p. 81-88; Chankowski 2008, p. 90-106, 110-114. Signalons cependant que selon la tradition, le retour de Thésée eut lieu au mois de Pyanopsion athénien (= Apatourion délien) : Plutarque, Thésée, 22. 
Toutes les informations paraissent converger sur deux points : la possession par les Athéniens d'un bateau reconnu comme sacré par ses rapports avec le voyage crétois de Thésée et par ses liens avec le culte d'Apollon délien, ainsi que les modifications nombreuses qui malgré tout laissaient douter de l'authenticité des pièces dites anciennes. Et il est vrai que si le navire devait être en état, au IV $\mathbf{s}$. a.C., de prendre la mer au moins une fois par an, il nécessitait un entretien constant ${ }^{354}$.

Les listes des bâtiments de la flotte athénienne du $\mathrm{IV}^{\mathrm{e}} \mathrm{s}$. recensent par ailleurs une trière nommée 'I $\varepsilon$ pó entre 326 et $323^{355}$. Il serait tentant d'y reconnaître le bateau dit de Thésée; dans le même

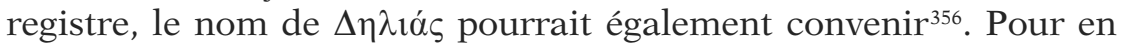
discuter, il convient d'étudier d'autres bateaux sacrés athéniens.

\section{b) Théories athéniennes}

La notion de bateau sacré s'étend pour les Athéniens également aux embarcations servant aux théories envoyées dans les grands sanctuaires ${ }^{357}$.

À l'époque classique, il semble y avoir eu deux trières désignées comme telles ${ }^{358}$ : la Paralos et la Salaminia, d'après des commentateurs tardifs parmi lesquelles vient se glisser aussi le nom d'une Olympias $^{359}$. Un premier problème se pose de savoir s'il y a identité entre l'une d'entre elles et le pseudo-bateau de Thésée. À ces deux mentions s'ajoutent d'autres sources littéraires et épigraphiques qui dessinent un tableau confus des trières sacrées grecques.

${ }^{354}$ Salviat 1989 reconnait cette trière sur le vase François et l'identifie comme une triacontore. Cette trière aurait également connu des vicissitudes historiques. Démosthène rapporte (1êre Philippique, 34) que Philippe, lors de l'une de ses incursions en Attique, s'empara de «la trière sacrée»; le fait est datable de

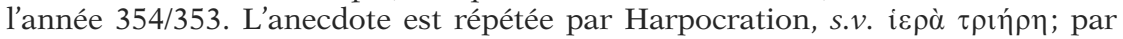
FGH IIIB, no 324, p. 327, fgt 24 : sans doute s'agit-il du même bateau. Cette glose émet l'hypothèse que la trière portait le nom de Paralos mais avec prudence,

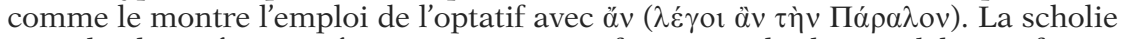
à Sophocle, Edipe à Colone v. 1047 nous informe que la théorie délienne faisait un arrêt à Marathon pour sacrifier au Dèlion.

${ }^{355}$ Schmidt 1931, p. 48 n 255.

${ }^{356} \mathrm{Ibid}_{\text {. , p. }} 11 \mathrm{n}^{\circ} 35$.

${ }^{357}$ Wachsmuth 1967, p. 285.

${ }^{358}$ Böckh 1840, p. 77 ss.; Schmidt 1931, p. 77-80.

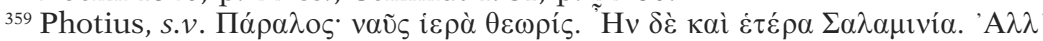

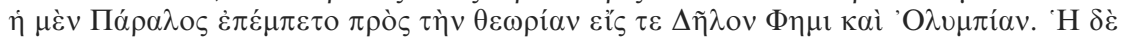

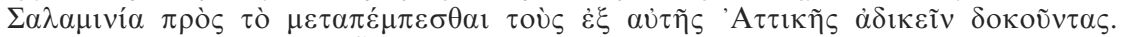

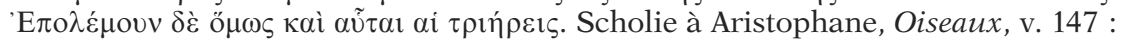

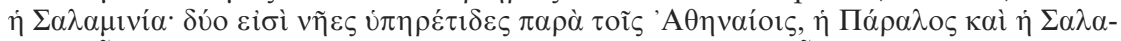

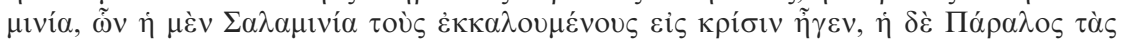


Une scholie de Démosthène signale quant à elle cinq bateaux sacrés : dans un premier temps la Paralos et la Salaminia appelée également Dèlia, puis 1,Antigonis, la Ptolémais et 1,Ammonias ${ }^{360}$. Les listes navales du $\mathrm{IV}^{\mathrm{e}}$ s. a.C. recensent de leur côté l,existence successive, dans la flotte athénienne, de quatreSalaminia dont deux coexistant dans les années 357-356 ; de trois Paralia et d,une ou deux Dèlias $^{361}$. Aristote indique en outre celle $\mathrm{d}$, une Paralos et d, une trière $\mathrm{d}$,Ammon dès les années $326^{2}$. Devant ces différents témoignages, on en a conclu un changement de nom de laSalaminia en Ammonias par hommage au roi macédonien ${ }^{363}$. Ceci aurait été notamment commémoré par le tableau de Protogénès représentant Paralum et Hammonias visible dans les Propylées de 1,Acropole d,Athènes (Plin\&Histoire naturelle XXXV, 101) ${ }^{364}$. Dans la première moitié du IIIs. a.C., le nom $\mathrm{d}$,Ammonias accompagne celui de Paralos dans une évocation des trières sacrées par Philochoros qui en ajoute deux autreDèmètrias et Antigonis $^{365}$. Enfin un dernier commentaire de Photius cite quant à lui la Paralos et la Salaminia d,,un côté, 1,Antigonis et la Dèmètrias de 1,,autre, et 1,Ammonias isolément ${ }^{366}$.

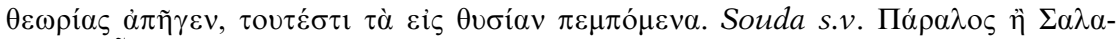

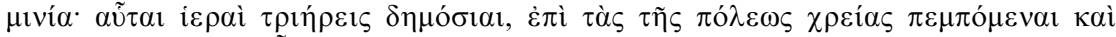

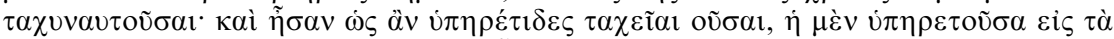

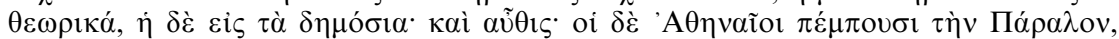

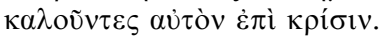

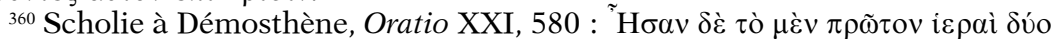

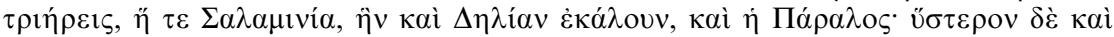

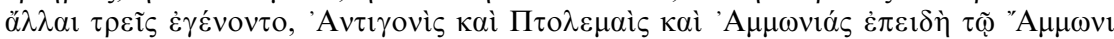

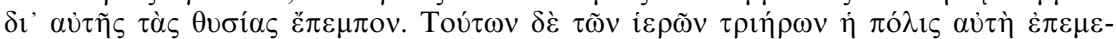

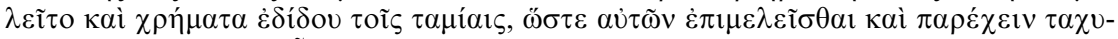

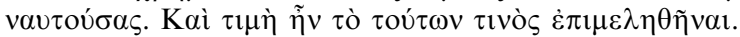

${ }^{361}$ Schmidt 1931, respectivement p. $37 \mathrm{n}^{\circ} 186$, p. $36 \mathrm{n}^{\circ} 181$ et p. $11 \mathrm{n}^{\circ} 35$.

${ }^{362}$ Aristote, Constitution des Athéniens 61, 7, mentionne 1,,élection de tréso-

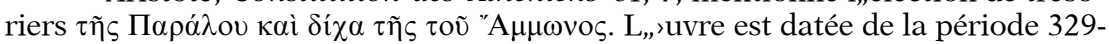
322 : voir commentaire de l,édition Budé.

${ }^{363}$ Reinach 1985, p. 365. La date de cet événement est placée en 324 pour certains, pour $d$,,autres en 318 car elle correspondrait d, une part avec l,arrivée au pouvoir de Démétrios de Phalère et constituerait $d$,,autre part une sanction contre les Salaminiens suite à leur révolte. Mais cette dernière datation n,,est pas compatible avec la mention d,Aristote, puisque celui-ci meurt en 322 ; la remarque de Schmidt 1931 (note 1 p. 80), selon lequel l,épigraphie pourrait confirmer ce changement de nom par l,absence de mention d,,une Salaminia après 323/2, ne tient donc pas. Sur Démétrios de Phalère à Athènes, voir E. Will 1979-82, I p. 48-51.

${ }^{364}$ Sur ce tableau, voir supra.

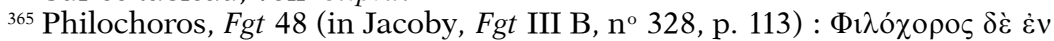

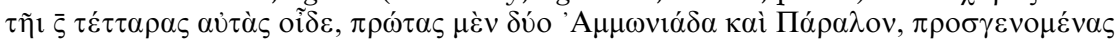

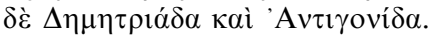

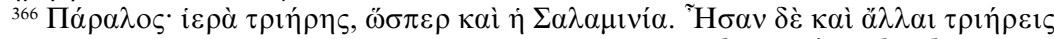

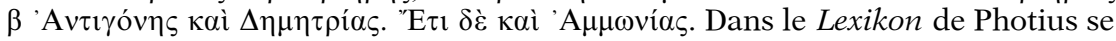
trouvent au total trois entrées ' Paralos'. 
K. Schmidt critique la validité de ces sources, arguant du fait qu'elles sont tardives et surtout en contradiction les unes avec les autres. Il en tire la conclusion que dès l'époque classique, il y avait plus de deux bateaux de théories : au minimum trois - Paralos, Salaminia, Ammonias -, si ce n'est plus si l'on suppose l'existence simultanée d'homonymes ${ }^{367}$. Toutes les sources laissent cependant supposer l'existence à l'époque classique d'une paire de trières sacrées; l'emploi systématique de l'article défini et au singulier ne permet pas d'envisager plus de deux bateaux bien définis à la fois. Par ailleurs les noms des inscriptions diffèrent de ceux des textes littéraires : Paralos n'est pas Paralia ${ }^{368}$, ni Dèlia Délias tandis qu'Ammonias ne figure pas non plus parmi la liste de la flotte athénienne $\mathrm{du} \mathrm{IV}^{\mathrm{e}} \mathrm{s}$. De plus, le tableau suivant de regroupement des mentions épigraphiques montre les enchevêtrements.

\begin{tabular}{|c|c|c|c|c|c|c|c|}
\hline Année & Dèlias & Dèlos & Paralia & Salaminia & Hiéra & $\begin{array}{c}\text { Ammonias } \\
+ \text { Paralos } \\
\text { [Aristote] }\end{array}$ & Dèlia \\
\hline $377 / 6$ & + & & & & & & \\
\hline $370 / 69$ & & + & & & & & \\
\hline $357 / 6$ & & + & + & ++ & & & \\
\hline $356 / 5$ & & & & ++ & & & \\
\hline $334 / 3$ & + & & + & & & & \\
\hline $333 / 2$ & & & & & & & \\
\hline $332 / 1$ & & & & & & & \\
\hline $331 / 0$ & & & & & & & \\
\hline $330 / 29$ & & & & & & & \\
\hline $329 / 8$ & & & & & & & \\
\hline $328 / 7$ & & & & & & & \\
\hline $327 / 6$ & & & & & & & \\
\hline $326 / 5$ & + & & + & & + & & \\
\hline $325 / 4$ & + & & & + & & \multirow{3}{*}{$\begin{array}{c}+ \\
(\operatorname{avant} 322)\end{array}$} & \\
\hline $324 / 3$ & & & & & & & \\
\hline $323 / 2$ & + & & + & ++ & + & & \\
\hline
\end{tabular}

${ }^{367}$ Schmidt 1931, p. 77-80, qui s'appuie également sur des attestations au Ve et au IVe s. a.C. du culte d'Ammon.

${ }^{368}$ Pour Casson 1971, p. 353, c'est le même bateau. Sinon, le nom de Paralos est celui d'un fils de Poséidon, qui était honoré d'un culte au Pirée : Wachsmuth 1967, p. 332. 
Ainsi de 357 à 355 coexistent une Paralia, deux Salaminia et une Olympias; en 326/5 une Hièra, une Dèlias et une Paralia ; en 323/2 plus de quatre navires aux noms distincts. L'absence de cohérence de ces listes du $\mathrm{IV}^{\mathrm{e}} \mathrm{s}$. d'une part et la répétition de certaines informations dans les sources d'autre part amènent à conclure qu'à l'époque classique, les bateaux sacrés sont au nombre de deux et que leurs noms sont sans doute indépendants des listes de la flotte de guerre athénienne. La première trière se nomme Paralos. La seconde, Salaminia, voit son nom changé pour celui d'Ammonias, au moment où Aristote écrit son traité politique sur Athènes. L'expression utilisée de «bateau d'Ammon» - et non pas d'Ammonias - montre que le nouveau nom n'était pas encore rentré dans les habitudes athéniennes ${ }^{369}$. Après cela, leur nombre a pu se multiplier.

D'après les commentaires tardifs néanmoins, l'utilisation prêtée à ces bateaux, religieuse mais aussi publique, donne l'impression que d'une certaine manière ils appartenaient cependant à la flotte athénienne, n'ayant qu'un rôle religieux occasionnel ${ }^{370}$. Ils devaient alors s'apparenter aux embarcations qui servaient lors de régates festives qualifiées également de sacrées ${ }^{371}$. Il s'agit là sans doute d'usages hellénistiques et peut-être romains concernant les Antigonis, Dèmètrias et Ptolémaïs des sources byzantines; nous sommes loin alors de bateaux consacrés aux dieux.

La notion de trière sacrée est extensible en ce qui concerne la cité d'Athènes ${ }^{372}$. Elle se rapporte à des réalités et des traditions différentes : des bateaux consacrés aux dieux dans des sanctuaires, un bateau considéré comme mythique utilisé pour la célébration d'un rite annuel et des embarcations servant au transport de personnages officiels vers de grands sanctuaires. Ces derniers, c'est-à-dire les bateaux sacrés servant à des usages religieux au nombre de deux à l'époque classique, se muliplient à l'époque hellénistique. Ils prennent alors des noms à consonance politique et assument des fonctions variées.

La question reste posée de savoir si la pseudo-embarcation de

${ }^{369}$ La dernière mention de Photius citée supra plaçant Ammonias à part s'explique par rapport aux autres où il associe Paralos à Salaminia : il apparaît visiblement que l'érudit byzantin ne savait que faire de cette Ammonias et pour cela la cita en fin de commentaire.

${ }^{370}$ Le problème est bien résumé par Jordan 1971, p. 205. Rappelons la phrase

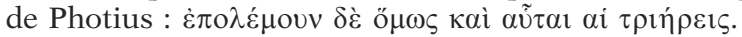

${ }^{371}$ Par exemple $I G \mathrm{II} / \mathrm{III}^{2}$, 1011, 16. Wachsmuth 1967, p. 285.

372 Wachsmuth 1967, p. 285, pense reconnaître un bateau sacré à Rhodes. En ce qui nous concerne, nous n'avons observé le phénomène qu'à Athènes. 
Thésée, envoyée en pèlerinage à Délos, faisait partie des deux bateaux de théorie de l'époque classique. Dans les deux cas, quel nom lui donnait-on - si on lui en donnait un - : Hièra, Dèlias, Dèlia, Paralios ou Salaminia?

Sans vouloir apporter de réponse catégorique, nous voudrions préciser quelques observations. Du fait de son caractère exceptionnel, il est peu probable que, parmi les listes épigraphiques du $\mathrm{IV}^{\mathrm{e}}$ s., figure le bateau de Thésée : il faut donc éliminer Hièra ${ }^{373}$ et Dèlias. Il ne peut s'agir non plus du Salaminia débaptisé en Ammonias : le premier nom n'évoque en rien Apollon et il serait absurde de déposséder le dieu de son bateau en faveur d'Ammon, d'autant plus que les marques de dévotion d'Alexandre et de ses héritiers en faveurs d'Apollon ne manquent pas. Si l'embarcation de Thésée appartient aux trières sacrées, elle ne peut être que la Paralos. En admettant cette possibilité, il paraît dès lors surprenant que le second bateau n'ait pas été dédié à un dieu ni surtout rattaché à un épisode particulier de l'histoire mythique d'Athènes. Selon Photius la Paralos naviguait vers Délos et Olympie, tandis que les sources mentionnant le bateau de Thésée ne le mettent en relation qu'avec l'île. Ces indices laisseraient plutôt penser à des navires différents : le navire de Thésée sans nom, et les deux à caractère officiel la Paralos et la Salaminia.

Le premier est consacré à Apollon comme le montre notamment le couronnement de sa poupe par le prêtre du dieu (Platon, Phédon $58 \mathrm{a}-\mathrm{c})$; à l'époque classique les deux autres semblent cependant être mis en relation avec Athéna par leur représentation sur l'Acropole ${ }^{374}$. Ces navires étaient ainsi doublement considérés comme sacrés : par leur fonction et par la divinité à qui ils étaient censés appartenir.

V. Chankoswki, qui s'est penché sur le dossier dans le cadre de son étude sur l'administration athénienne du sanctuaire délien, aboutit à des conclusions analogues par des voies différentes. Elle considère en effet qu'il y a deux bateaux distincts : une trière transportant le chœur des Délia et une triacontore - type d'embarcation mentionné à plusieurs reprises dans les actes des amphictyons et dans un passage négligé d'Aristote (Constitution des Athéniens 56, 3) -, emmenant les jeunes gens dans l'île pour les rites liés à Thésée.

\footnotetext{
${ }^{373}$ Wachsmuth 1967, note 1163 et Schmidt 1931, p. 63 écartent également cette possibilité.

${ }^{374}$ Selon la même optique, certains considèrent que le relief Lenormant pourrait être la représentation d'une trière sacrée utilisée pour les délégations de fêtes, dédiée à Athéna. Sur les termes du débat, voir Walter 1952, p. 131-140 qui donne la même signification au relief d'Éleusis mais en l'honneur de Déméter; Höckmann 1985, p. 157.
} 
Ce second bateau, pour laquelle une inscription indiquerait des réparations, aurait cessé de naviguer au temps de Démétrios Poliorcète ${ }^{375}$.

\section{Chars-bateaux}

Notre second groupe concerne encore essentiellement Athènes, qui connaît des fêtes dans lesquelles interviennent des chars en forme de bateau ${ }^{376}$. Pour le monde grec, trois circonstances nous renvoient à l'usage d'un bateau utilisé comme char de procession religieuse: la première lors des Panathénées en relation avec Athéna; la seconde à Smyrne en l'honneur de Dionysos; la troisième lors des Anthestéries, portant la figure de Dionysos. À celles-ci s'ajoute une quatrième tout à fait hypothétique qu'il convient d'évoquer ici.

\section{a) Procession des Panathénées}

L'existence d'un char-bateau à Athènes, utilisé lors des Grandes Panathénées ${ }^{377}$, bien qu'attestée par un certain nombre de sources, reste cependant problématique à cause de la précision bien inégale de celles-ci. En effet, à côté d'un certain nombre d'allusions litté-

${ }^{375}$ Chankowski 2008, p. 86-89. Réparation : ID 100, datée entre 373 et 369 a.C. (ibid., p. 81 et 425-429). C'est cette triacontore que l'auteur suppose avoir été consacrée dans le Monument des Taureaux (voir supra p. 436).

${ }^{376}$ C'est sur ce type de rituel que porte donc réellement l'étude d'A. Göttlicher citée supra p. 351-352 qui, pour l'Antiquité grecque, y aborde quatre cas, malheureusement de façon trop générale et vague (Göttlicher 1992, p. 103-107 : Anthestéries; p. 108 : Smyrne et Poseidonia; p. 108-110 : Panathénées). Dernièrement, Romero Recio 2010 a développé une théorie sur l'existence supposée de fêtes maritimes à Athènes depuis un temps très ancien qui, dédaignées par les aristocrates grecs propriétaires de la terre, auraient été redynamisées après les guerres Médiques avec le retour du prestige de l'art nautique. L'auteur reconstitue ainsi, en suivant le calendrier de la navigation, Anthestéries (fin hiver, début saison navigable longue), Mounychies (début saison navigable courte), Plyntéries, Panathénées (au moment le plus actif de la saison), Kybernésies (fin de la saison navigable courte), Pianopsies et Oschophories (fin de la saison navigable longue). La démonstration, confuse pour certaines parties et reposant parfois sur des associations de sources ou des impressions sans réels fondements, peine à convaincre. Les pages qui suivent reproduisent pour l'essentiel le texte de Fenet 1998.

${ }^{377}$ Sur les Panathénées, voir par exemple Jost 1992, p. 150-157, Wachsmuth 1967, note 1728 et surtout, en ce qui nous concerne Deubner 1932, p. 22-35, spécialement p. 32-34. Le cortège a lieu le 28 du mois Hécatombaion (juillet). Pour Romero Recio 2010, p. 106-110, les Panathénées montreraient, au plus fort de la saison maritime - comme la fête de la Virgen del Carmen, protectrice de la navigation, en juillet -, «le pouvoir de la déesse dans ce milieu». 
raires très évasives, il n'existe que trois descriptions dignes de ce nom, de surcroît tardives et non dépourvues d'ambiguïtés. Les sources épigraphiques quant à elles ne révèlent pas explicitement le bateau, qu'un seul document iconographique ne nous permet pas non plus de représenter précisément.

\section{- Les sources littéraires}

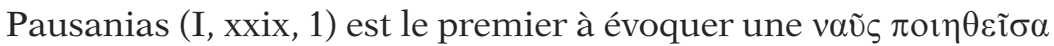

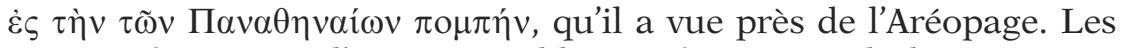
termes choisis par l'auteur semblent indiquer que le bateau a été construit dans ce but unique, n'étant donc ni une embarcation qui aurait navigué pour ensuite être récupérée en vue de la procession, ni un véhicule servant pour d'autres fêtes que celles liées à la remise du péplos à Athéna. Cela posé, le reste suscite plusieurs interrogations. L'endroit où était visible ce char au $\mathrm{II}^{\mathrm{e}}$ s. p.C. manque de précision, d'autant plus que dans le paragraphe suivant, Pausanias change tout à fait de lieu pour se rendre à l'Académie ${ }^{378}$. De plus, l'absence d'article défini pour la mention de cette vaúc est à noter : y avait-il à Athènes plusieurs bateaux voués à cet effet à la même période, ou en a-t-on construit plusieurs au fil du temps, l'un remplaçant l'autre? Enfin, le Périégète se permet cependant un commentaire sur cette embarcation, qui a été "surpassée» (نં $\varepsilon \rho \varepsilon \beta \alpha ́$ $\lambda \varepsilon \tau 0)$, spécialement par celle qui se trouve à Délos. Le sens général à donner à la phrase est sujet à controverse, les termes de la relation étant tous les deux mal connus ${ }^{379}$. L. Basch explique la formulation curieuse de Pausanias de la façon suivante : le char des Panathénées fut remplacé à l'époque du Périégète, peu de temps après le voyage de celui-ci et avant la fin de la rédaction de la Description de la Grèce, par un véhicule plus technique et plus impressionnant, que décrit un peu plus tard Philostrate ${ }^{380}$.

Ce dernier est en effet dans les années 230 p.C. l'auteur d'une description détaillée concernant le char des Panathénées (Vie des sophistes II, 1, 550 = voir corpus p. 536). Dans son éloge d'Hérode

${ }^{378}$ Après reconstitutions du trajet de Pausanias et fouilles archéologiques, le lieu a été situé sur le versant nord de l'Acropole, près de la fontaine de la Clepsydre et sous la grotte d'Apollon Hypoakraios : Musti \& Beschi 1982, p. 372-373; Travlos 1971, p. 323 ss. et 391.

${ }^{379}$ Le texte de Pausanias a beaucoup été discuté à propos de la comparaison peu évidente avec le bateau de Délos, identifié comme le bateau consacré dans l'île par Antigone Gonatas (voir supra p. 359 ss.). Pour certains, c'est le critère de taille qui est pris en considération par le Périégète, pour d'autres celui d'invincibilité - Pausanias procédant alors par association d'idées - : cf. Tréheux, 1987;

Basch 1987, p. 346-347; Basch 1995, p. 43-72.

${ }^{380}$ Basch 1995, p. 59-60. 
Atticus et l'énumération des bienfaits qu'il a rendus à la cité d'Athènes ${ }^{381}$, l'écrivain rappelle l'embellissement de la procession panathénaïque. Selon la description qu'il en donne, le péplos de la déesse était suspendu ( $\dot{\alpha} v \tilde{\eta} \varphi \theta \alpha \imath)$ au bateau et flottait au vent, telle une voile.

Ce détail est également connu par trois mentions littéraires. Un auteur de comédies attique des années 400 a.C., Strattis (Fgt $30=$ voir corpus p. 534) ${ }^{382}$, compare le vêtement hissé en hauteur au moyen d'une poulie à une voile sur un mât, ce que décrit plus préci-

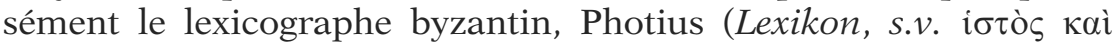

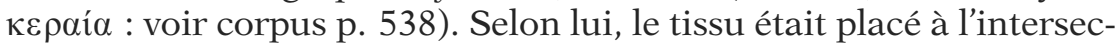
tion du mât et de la vergue, formant un $\mathrm{T}$. Le fait que le péplos était transporté sur le char figure également dans un poème attribué dans l'Antiquité à Virgile, qu'on peut néanmoins dater de l'époque augustéenne. Son auteur (Pseudo-Virgile, Ciris, v. 21-26) décrit le péplos de la déesse sur laquelle il voudrait broder la figure de son ami. À ce propos, il évoque le currum poussé par le Zéphyr, prono gravidum (...) pondere (char lourd du poids qui s'incline en avant) ${ }^{383}$ : le péplos devait se trouver à l'avant du char.

Pour en revenir à Philostrate, l'innovation d'Hérode Atticus consista dans le moyen de déplacement du char-bateau : auparavant tiré par des animaux, il avança désormais grâce à un dispositif caché

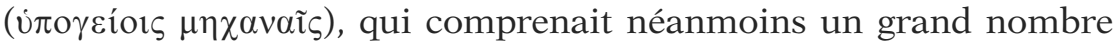
de rames $(\chi \imath \lambda \imath \alpha \kappa \omega ́ \pi \eta)$. Le parcours suivi partait du Céramique, passait près de l'Éleusinion et du Pélasgicon pour finir sa course au Pythion $^{384}$. Il est difficile de saisir la portée réelle du verbe $\dot{\varepsilon} \pi \mathrm{o} \lambda \iota \theta \alpha \hat{i}^{-}$ veıv utilisé par Philostrate pour décrire le mouvement du bateau : est-ce une image poétique le comparant à une nef dans l'élément liquide ${ }^{385}$, ou l'expression précise de celui-ci lors du fonctionnement du mécanisme?

${ }^{381}$ Sur les actions, y compris religieuses, d'Hérode Atticus, voir P. Graindor, Un milliardaire antique, Hérode Atticus, Le Caire, 1930.

${ }^{382} \mathrm{La}$ pièce dont est extrait le fragment est datée précisément de 402 : J. M. Edmonds, Fragments of Attic comedy, Leiden, 1957, vol. I, p. 998.

${ }^{383}$ Le texte n'autorise cependant pas la traduction proposée par A. Haury dans l'édition Budé : «le char dont le mât ploie en avant sous le faix». Il n'est fait aucune mention de mât ou de vergue dans ces quelques vers.

${ }^{384}$ Le parcours évitait ainsi des montées trop rudes. Sur le parcours suivi, voir Harrison 1890, p. 564-566; Travlos 1971, fig. 540. Musti \& Beschi 1982, p. 408 propose de comprendre l'oracle cité par Pausanias (I, xxxvii, 6-xxxviii, 1) nommant une «trière courant sur la terre» comme une allusion au parcours du char des Panathénées jusqu'au Pythion.

${ }^{385}$ Des image poétiques du même registre apparaissent dans la description d'Himerius, Orationes XLVII, 12-16 : voir infra. 
Le récit imagé et enthousiaste qu'a composé un orateur du IVe $\mathrm{s}$. de notre ère, Himerius (Orationes XLVII, 12-16 = voir corpus p. 537), comporte un certain nombre de similitudes avec le précédent. Le point de départ de la procession est constitué par les Pylai, qui sont probablement les portes principales de la ville, situées au Céramique. Le parcours mène le bateau jusqu'en bas de l'Acropole, en bonne escorte et sous le regard d'Athéna. La vision de ce véhicule est enchanteresse : il paraît glisser sur les eaux sans efforts, à l'image des embarcations nilotiques au moment des crues du fleuve. Cette faculté du bateau de «naviguer sur la terre» est également signalée par une scholie à Aristophane (Paix, v. $418=$ voir corpus p. 534).

Mais le texte d'Himerius suscite par ailleurs plusieurs interrogations, dues notamment à son style poétique et déclamatoire. L'équipage $(\pi \lambda \eta \dot{\eta} \omega \mu \alpha)$ du bateau signifie-t-il que les personnes en question se trouvent à l'intérieur du bateau? Il est composé de "prêtres», "prêtresses» et "eupatrides» "couronnés». Même si cela représente un certain nombre de gens, le témoignage de Philostrate à propos du bateau de Smyrne (Vie des sophistes, I, 25, 530-531 = voir corpus p. 536) signifie sans aucun doute possible qu'il y avait des individus à bord ${ }^{386}$. Plus énigmatique encore, le mouvement du bateau. Celui-ci est monté sur roues, qui sont selon les termes d'Himerius

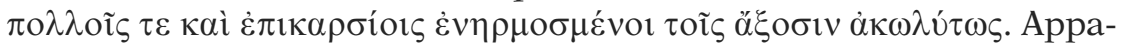
remment, le char était muni d'un grand nombre de roues, nécessitant un aussi grand nombre d'essieux. Ceci réfute l'interprétation selon laquelle celui-ci se déplaçait sur un rail ${ }^{387}$. Il est vrai que l'allure générale du parcours du bateau se fait, précise à deux reprises Himerius, en ligne droite; la taille ou le manque de maniabilité de l'engin doivent expliquer cette caractéristique. Aucune bête de somme ne hale le char, semble-t-il, ce qui correspond au témoignage de Philostrate, mais pas de mention non plus de rames en action. Le problème des mèchanai reste entier; de même, Himerius ne souffle mot du péplos de la déesse.

Il est en revanche plus disert en ce qui concerne le déroulement du rite. Il nous décrit ainsi la musique et le chant accompagnant le

${ }^{386}$ Sur bateau de Smyrne, voir infra. Par ailleurs, pourquoi noter ce groupe de personnes s'il s'agissait de l'escorte habituelle du péplos de la déesse? Sur la composition du cortège, voir Jost 1992, p. 153.

${ }^{387}$ Basch 1995. On peut penser à un parallèle antique : le transport des bateaux à Corinthe sur le diolkos, opéré grâce à des roues placées sous les embarcations. À ce sujet voir les études de Raepsaet \& Tolley 1993 et Werner 1993, p. 12-22. Un autre parallèle, quoique de plus petite taille, apparaît sur une magnifique peinture provenant d'une maison d'Ostie et représentant un groupe de jeunes garçons se préparant à une procession - l'interprétation admise généralement y voit une représentation du navigium Isidis - où deux d'entre eux tirent un chariot à deux roues qui supporte un bateau gréé : Nogara 1907, pl. XLIX; Deubner 1927, p. 186; Huet 2011, p. 234 et pl. 31, 1. 
bateau, qui sont destinés à faire souffler le vent censé pousser l'embarcation - ce à quoi celle-ci ne manque pas d'obtempérer. Le chant est attribué à Simonide, dont la mer aurait été l'inspiratrice à

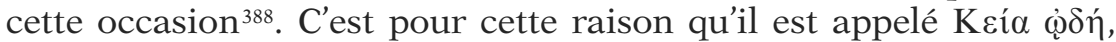
l'île de Kéos étant la patrie du poéte. Si cette attribution s'avère exacte, le chant date de la fin de l'époque archaïque ou du début de l'époque classique (fin $\mathrm{VI}^{\mathrm{e}}$-début $\mathrm{V}^{\mathrm{e}} \mathrm{s}$.). La musique instrumentale est assurée par des flûtes, dont le son est comparé à celui du vent. Sensible à l'aspect religieux, Himerius est ainsi le premier à qualifier

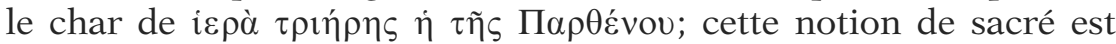
reprise dans le terme de $\dot{\eta} \theta \varepsilon \omega p i ́$.

Des scholies malheureusement non datées au Panathénaïque d'Aelius Aristide, discours prononcé en 155 p.C. lors des Panathénées (197, 8 éd. Dindorf = voir corpus p. 534) indiquent elles aussi la

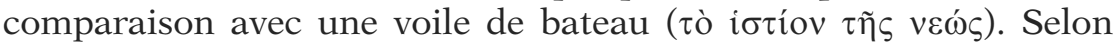
elles, le péplos serait équipé de roues et ainsi emmené jusque l'Acropole. Il y est aussi question d'agrès (ä $\rho \mu \varepsilon v o v)$. Le texte paraît préciser également l'ornementation du tissu tissé par les parthénoi.

Il convient d'ajouter au dossier une pièce qui ne semble jamais avoir été exploitée jusqu'ici ${ }^{389}$. Aristote, dans l'un de ses traités biologiques (De la génération des animaux I, 18, 724ab) rédigé à la fin de sa vie, traite de la nature du sperme; une analogie plutôt surpre-

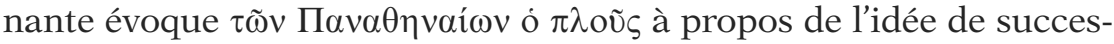
sion $(\tau o ́ \delta \varepsilon \mu \varepsilon \tau$ à $\tau o ́ \delta \varepsilon)$. Si le sens de cette dernière est quelque peu complexe à saisir, il importe surtout qu'un auteur du IVe s. a.C. mentionne l'existence de ce bateau ${ }^{390}$.

- Sources épigraphiques

Quatre inscriptions font référence au péplos des Panathénées et à la façon dont il était transporté à travers la ville lors des fêtes en

${ }^{388}$ Voir Wachsmuth 1967, note 1738, sur les chants marins. Notons par

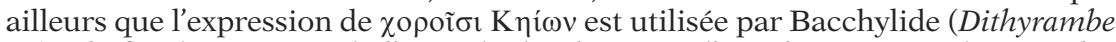
III) à la fin de son récit de l'épisode de Thésée et d'Amphitrite pour désigner les chœurs dédiés à Apollon.

${ }^{389}$ Göttlicher 1992, p. 110 seul la mentionne dans ses lignes sur le char des Panathénées sans la commenter.

${ }^{390}$ L'attribution de ce traité à Aristote est assurée : cf. commentaire de l'édition du texte dans la collection Budé, p. vii ss. En revanche, l'expression a été mal comprise : le bateau y apparait comme étant la trière sacrée de la théorie délienne (ibid., p. 211); il est vrai que l'idée exprimée par Aristote ressemble à l'image évoquée par Démétrios de Phalère (Fragment 23) et Plutarque (Si la politique est l'affaire des vieillards, 6) du bateau qu'on restaure sans cesse. Cela renvoie également à notre remarque concernant l'emploi de l'indéfini par Pausanias : un char serait régulièrement reconstruit pour la procession panathénaïque. 
l'honneur d'Athéna. Toutes sont d'époque hellénistique: trois d'entre elles concernent le $\mathrm{III}^{\mathrm{e}} \mathrm{s}$. et la quatrième le $\mathrm{II}^{\mathrm{e}} \mathrm{s}$.

La première attribue la paternité de l'idée du mât et de la vergue à laquelle est accroché le péplos à Lysimaque, inspiré lui-même par l'auteur comique Philippidès; le projet aurait été réalisé en 299/8 ${ }^{391}$. Cette affirmation signifierait en substance qu'avant cette date, cette pratique ou du moins ce type d'exposition n'étaient pas opérés.

Les deux autres inscriptions du $\mathrm{III}^{\mathrm{e}} \mathrm{s}$. a.C. célèbrent également les bienfaits de deux personnages concernant les Panathénées. L'une est gravée en l'honneur de Callias qui s'est chargé, lors du rétablissement de la fête en 278 , des ö $\pi \lambda \alpha$ pour le péplos ${ }^{392}$, terme que l'épigraphiste T. L. Shear entend au sens de cordages, gréement ${ }^{393}$. Le texte n'est pas plus explicite à cet égard. L'autre en revanche est plus parlante en ce qui concerne le véhicule censé transporter le tissu sacré. Dans les années 260 a.C., l'agonothète des Grandes Panathénées Dexippos y est loué pour avoir restauré l'akrostolion de l'embarcation panathénaïque ${ }^{394}$.

Enfin, au $\mathrm{II}^{\mathrm{e}}$ s., parmi les offrandes réalisées par Miltiadès de Marathon, figure celle réalisée pour les Panathénées de 142. Le décret honorifique fragmentaire évoque alors des négligences concernant le transport du péplos, que pallie Miltiadès par le don notamment d'ö $\pi \lambda \alpha^{395}$.

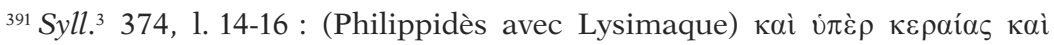

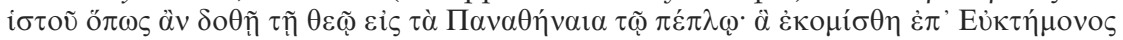

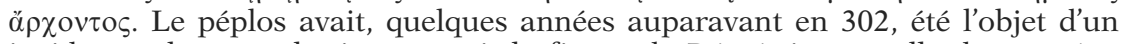
incident : alors que le tissu portait la figure de Démétrios et celle de son père Antigone, le vent l'arracha; cela fut interprété comme un signe de mauvais augure, qui se réalisa peu après par la mort d'Antigone (Plutarque, Démétrios 12, 3). Le texte ne mentionne ni mât ni bateau : il est donc impossible de reculer la datation de l'usage du mât sur le bateau pour l'exposition du péplos avant Lysicrate sur la foi de Plutarque comme le fait Göttlicher 1992, loc. cit. Par ailleurs, il est possible de lier les deux événements et de supposer une modification apportée au rituel suite à l'incident de 302 : cf. Shear 1978, p. 42.

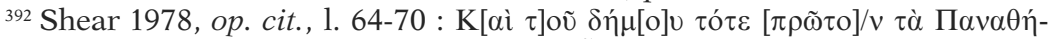

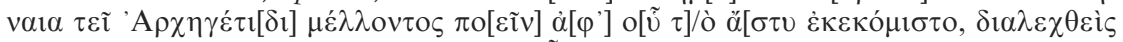

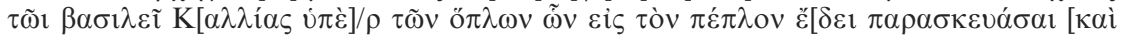

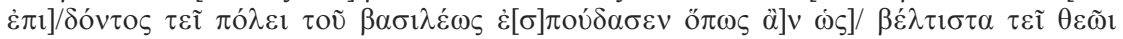

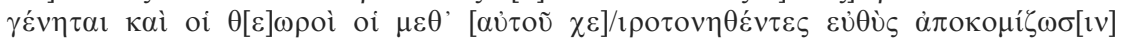

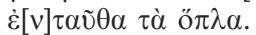

${ }^{393}$ Shear 1978, p. 39-44, s'appuyant sur la définition d'Erotianus à ce terme. Sur d'autres hopla, voir supra p. 416.

${ }^{394} I G \mathrm{II} / \mathrm{III}^{2}$, 3198; Schipporeit 2011, p. 295 n 940 : ['O $\left.\sigma \varepsilon\right] \mu v o ́ \tau \alpha \tau o \varsigma$

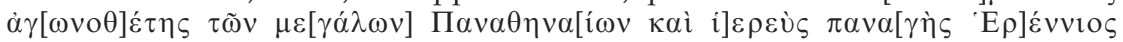

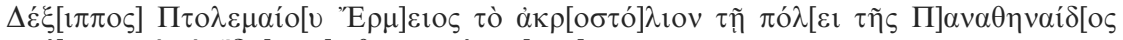

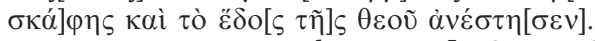

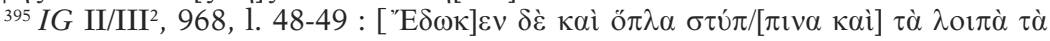

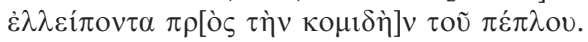


- Source iconographique

Une source iconographique complète les descriptions littéraires. Un bas-relief, visible aujourd'hui sur la façade extérieure de la Petite Métropole d'Athènes ${ }^{396}$ dans laquelle il a été intégré, montre, parmi d'autres représentations de fêtes attiques ${ }^{397}$, le char-bateau (fig. 38).

Malheureusement, le relief à cet endroit précis est en partie recouvert d'une croix de malte, qui a mutilé à une époque plus récente le décor initial. La frise est datée du $\mathrm{II}^{\mathrm{e}}$ s. p.C. La taille du bateau n'est pas bien grande; on pourrait même se demander s'il n'était pas représenté en partie seulement. Sont discernables, à droite de la croix, deux roues et ce qui ressemblerait à un éperon. Rien ne permet de reconnaître sous la croix un mât ou une voile quelconque. L'enseignement donné par ce relief est le caractère représentatif du char : dans un calendrier censé représenter, symboliser les principales fêtes et leur succession, le bateau monté sur

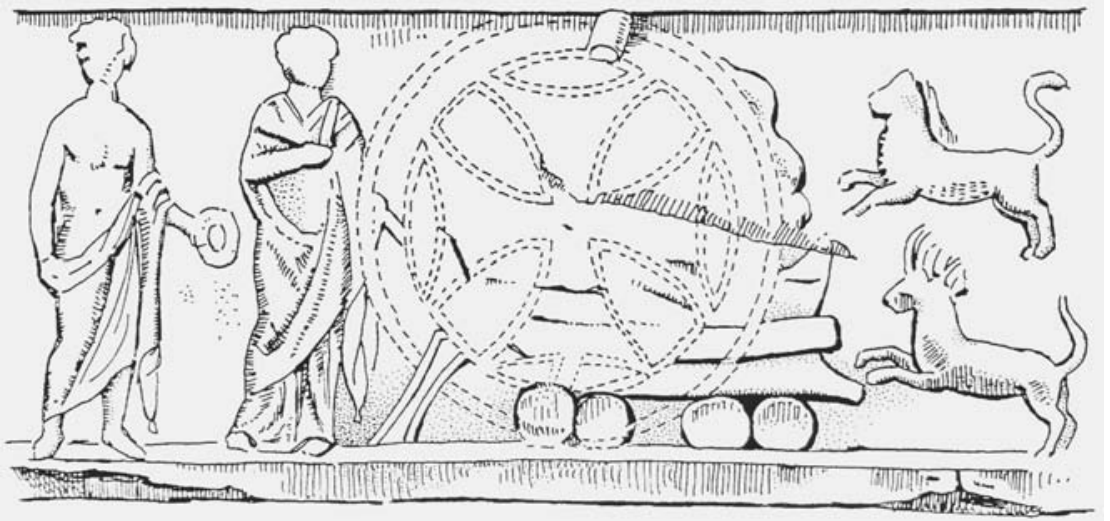

Fig. 38 - Relief de la Petite Métropole, à Athènes : détail du calendrier athénien (d'après Göttlicher 1992).

${ }^{396}$ Église Panaghia Gorgoepikoos, XII ${ }^{\mathrm{e}}$ s., située à droite de la cathédrale athénienne. Le relief est reproduit et commenté par Deubner 1932, p. 32 et pl. 40; Basch 1987, p. 347 n $^{\circ} 732$.

${ }^{397}$ Sur l'ensemble de ce calendrier, voir Deubner 1932, p. 248-254; l'une des meilleures exégèses de ce document a été réalisée par Svoronos 1899; synthèse des analyses par Krauskopf 2011, p. 95-101, fig. 15 et pl. 6-7. L'identification de cette figure au sein du calendrier est établie par la succession des fêtes et des mois connue pour Athènes; le bateau se situe précisément à l'intérieur de la séquence du mois Hékatombaion. 
roues devait signifier à tout Grec la procession des Panathénées et devait constituer un élément important de celles-ci.

Antérieurement à ce bas-relief, il est à noter que le bateau ne figure pas sur la fameuse frise des Panathénées de l'Acropole, qui montre les membres de la procession et les dieux spectateurs : ceci n'est cependant pas déterminant pour en déduire qu'il n'existait pas vers le milieu du $\mathrm{V}^{\mathrm{e}} \mathrm{s}$., car ce chef-d'œuvre représente des morceaux choisis de la fête ${ }^{398}$. La découverte récente, dans le quartier de Plaka, d'un fragment de marbre sculpté représentant une canéphore et un bateau - une trirème, semble-t-il - pourrait constituer la représentation figurée la plus ancienne à ce jour du char-bateau : du milieu ou $3^{\text {e }}$ quart du IV ${ }^{\text {e }}$ s. a.C. ${ }^{399}$

\section{- Analyse}

Tous ces renseignements ne doivent pas nous faire perdre de vue que dans l'état actuel de nos connaissances, presque rien n'est connu à propos de ce char-bateau avant le début de notre ère. Simplement peut-on dire que cette pratique existait au plus tard au dernier tiers du IVe s. a.C., mais que des modifications y ont été faites au moins à deux reprises, tout d'abord sous Lysimaque au tout début du $\mathrm{III}^{\mathrm{e}}$ s. a.C., puis par Hérode Atticus c'est-à-dire avant les années 130 p.C. Ce point est à signaler, car depuis la première célébration de cette fête par Pisistrate en 565, cela représente presque deux siècles et demi d'absence de sources ${ }^{400}$. L'argument d'un déroulement nouveau de la procession à une époque postérieure est contredit par le caractère conservateur des fêtes panathénaïques, pour lesquelles on voit mal une telle innovation apparaître après des siècles de tradition ${ }^{401}$. Le chant d'inspiration marine attribué à Simonide laisse également supposer que le caractère maritime de la procession existait déjà au début de l'époque classique - à moins que l'on ait dans un second temps adapté la musique aux innovations. De toute manière, le bateau ne montait pas jusqu'au terme de la procession, l'Acropole et l'Érechthéion ${ }^{402}$. Les participants au cortège devaient donc finir le chemin sans ce char, et emporter avec eux le péplos. Le véhicule est désigné sous l'appellation commune de $\pi \lambda$ oṽs, vaṽ ou $\sigma \kappa \alpha ́ \varphi \eta$, et de char (currus); seul Himerius le qualifie de trière.

${ }^{398}$ Holtzmann 2003, p. 126-136.

${ }^{399} \Sigma \pi \varepsilon \tau \sigma \iota \varepsilon \dot{\rho} \rho \eta-X \omega \rho \varepsilon ́ \mu \eta ~ 2000$. Découverte fortuite lors de travaux de voirie, dans un secteur qui doit correspondre à l'emplacement de l'Éleusion antique.

${ }^{400}$ Le fait a été noté par Pfuhl 1900, p. 10.

${ }^{401}$ Shear 1978, p. 42.

${ }^{402}$ Jost 1992, p. 150-157. 
Peut-on reconnaître dans le char-bateau des Panathénées le bateau attribué à Thésée? Leur utilisation différente, et sans aucun doute leur taille, rendent cette hypothèse difficile à accepter ${ }^{403}$. Seul l'emploi par Himerius du terme de $\theta \varepsilon \omega p i ́ s$, qui désigne au sens propre le bateau des théores effectuant le voyage entre Athènes et Délos, plaide en faveur de cette idée; mais il doit plutôt désigner dans ce contexte le vaisseau sacré en mouvement. Cependant, les commentateurs ont souvent tenté d'expliquer l'usage du char-bateau lors des Panathénées par le culte de Thésée ${ }^{404}$. Plus souvent, le rite est rapproché du char de Dionysos utilisé lors de Anthestéries : le bateau panathénaïque serait alors directement dû à une inspiration du rite dionysiaque ${ }^{405}$; plus concrètement, il s'agirait du même char lors des deux fêtes ${ }^{406}$, équipé de manière différente c'est-à-dire sans mât ni voile pour Dionysos, avec mât, gréement et voile-péplos pour Athéna ${ }^{407}$. Cette hypothèse est contestable à cause de la représentation du char des Panathénées sur la frise de la Petite Métropole tout à fait différente de celles du char des Anthestéries.

Plus que le char lui-même, les sources hellénistiques portent leur attention de manière générale sur le péplos et la manière dont il est exposé : seule l'inscription de Dexippos fait allusion à la skaphè (barque), plus précisément à son akrostolion. En revanche, les trois autres inscriptions s'occupent uniquement du vêtement de la déesse; deux de ces sources le mettent en relation avec des ö $\pi \lambda \alpha$, la dernière

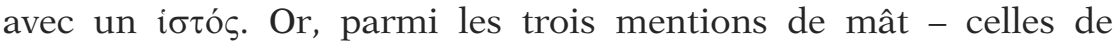
Strattis, de l'inscription de Philippidès et de Photius - d'eux d'entre elles interviennent dans les termes d'une comparaison : $\dot{\omega} \sigma \pi \varepsilon \rho$ selon Strattis, $\sigma \chi \tilde{\eta} \mu \alpha$ pour Photius; les scholies d'Aristide ne parlent que d'un voile. Par ailleurs, absolument aucun document n'associe ni le mât au char-bateau, ni à la fois le péplos au mât et au bateau. La présence d'un mât réel n'est donc absolument pas assurée ${ }^{408}$; le charbateau pouvait être similaire en ce sens à celui des Antesthéries qui n'en possédait pas. Le péplos devait être accroché à un simulacre de mât, une sorte de poteau de bois dont on ne peut deviner ni la taille ni l'emplacement exact; et c'est en cela qu'il y aurait eu innovation à l'époque hellénistique ${ }^{409}$. Or, cette datation est contredite par les vers

${ }^{403}$ C'est pourtant l'opinion de Tarn 1910, p. 217.

${ }^{404}$ Sur l'existence d'un lien entre Thésée et Panathénées: Deubner 1932, p. 22-23; L. R. Farnell 1896-1909, I p. 295.

${ }^{405}$ Deubner 1932, p. 33-34; Shear 1978, p. 40.

${ }^{406}$ Frickenhaus 1912a, p. 73.

${ }^{407}$ Shear 1978, p. 43-44.

${ }^{408}$ Wachsmuth 1967 , p. 377 , note 1728 , exprime lui aussi ce doute quant à l'existence d'un tel mât.

${ }^{409}$ C'est l'opinion développée par Shear 1978, p. 43-44. 
de Strattis, qui évoque dès la fin du Ve $\mathrm{s}$. a.C. l'image du mât et de la voile ${ }^{410}$. En fait, seuls deux auteurs tardifs associent le péplos et le bateau : Philostrate de façon explicite, le Pseudo-Virgile de manière beaucoup plus allusive, mentions auxquelles s'ajoutent les sholies non datées d'Aelius Aristide. Il n'est donc pas assuré qu'avant une date tardive, le péplos ait été réellement transporté par le charbateau : le char pouvait tout aussi bien faire partie du cortège, sans porter l'objet sacré; l'idée de Lysimaque fut peut-être d'associer les deux.

Les descriptions données par les auteurs tardifs et les termes dans lesquels elles sont exprimées donnent à penser que ce cortège du char-bateau revêtait - au moins à l'époque impériale - un caractère particulier, à la fois poétique et magique, qui laissait une forte impression sur les spectateurs. Le fait que l'embarcation se déplaçait sans animal de trait devait compter pour beaucoup, ainsi que le péplos de la déesse, richement décoré et rutilant de couleurs ${ }^{411}$, déployé au gré des souffles du vent. Les descriptions du défilé du char panathénaïque ainsi que le chant entonné à cette occasion sont unanimes sur le caractère nautique et maritime du rite à cette période.

Le tableau que nous pouvons nous faire de ce bateau et du péplos gonflé par le vent n'est pas sans rappeler des images d'Isis ${ }^{412}$. L'inventrice de la navigation, la déesse qui la première conçut la voile en usant de son vêtement, est transportée, lors de son culte à Corinthe particulièrement, elle aussi sur un bateau. Même si dans la cérémonie isiaque il s'agit d'un vrai bateau, la description donnée par Apulée présente des détails similaires: la voile brillante et décorée d'or, le mât élancé, la nef libérée de ses amarres confiée à la mer et à la brise ${ }^{413}$. Isis est honorée en Attique depuis les années 330, où l'on autorisa l'implantation d'un sanctuaire au Pirée. L'idée de Lysimaque fut donc peut-être influencée par le développement du culte isiaque dans le monde $\operatorname{grec}^{414}$.

${ }^{410}$ Parker 2005, p. 262, qui note la récurrence du vocabulaire nautique dans les diverses sources, pense que le mât ou bateau ne peut signifier, pour Athéna, que le pouvoir de la cité sur la mer.

${ }^{411}$ Sur la décoration du péplos, voir «s.v. Panathenai», RE XVIII, 3, Stuttgart, 1949, précisément col. 460-463; Jost 1992, p. 151; la description du PseudoVirgile, Ciris v. 21 ss.

${ }^{412}$ Remarque également exprimée par R. Flacelière et É. Chambry, édition de Plutarque, Démétrios dans la collection Budé, p. 196 note 32.

${ }^{413}$ Apulée, Métamorphoses XI, 16, 6-10. Sur cette fête, voir spécialement Bricault 2006, p. 134-150; Göttlicher, 1992, p. 114-128; Veyne 1965.

${ }^{414}$ Lysimaque était par ailleurs loin d'être négligent vis-à-vis des divinités liées à la mer : entre 288 et 281, il est célébré pour ses bienfaits à Samothrace et à ses dieux (Syll. $\left.{ }^{3}, 372\right)$. 


\section{b) Smyrne}

Le rite du bateau smyrniote est attesté par trois sources littéraires $^{415}$. Cependant, comme dans le cas de la plupart de celles concernant le char des Panathénées, ces témoignages sont tardifs. Rien n'est donc connu pour les époques antérieures ${ }^{416}$.

Le rhéteur du $\mathrm{II}^{\mathrm{e}}$ s. p.C. Aelius Aristide ${ }^{417}$ (Prosphonétique de Smyrne, 473-474 = voir corpus p. 535), dans un discours adressé à la ville de Smyrne, mentionne pour cette cité l'existence de Dionysia. Durant cette fête, on promenait à l'agora une trière, souvenir d'une victoire remportée par les Smyrniotes contre les Chiotes. L'auteur ajoute foi à ses sources, notamment les Kataploi ${ }^{418}$ qui doivent consister en des textes anciens versifiés de marins décrivant des littoraux et des traditions s'y rapportant. Aelius Aristide précise les faits dans un autre écrit traitant également de Smyrne (Politique de Smyrne, 402-403 = voir corpus p. 534). La fête a lieu au début du printemps. Le bateau, à ce qu'il affirme encore visible à son époque, est consacré à Dionysos depuis cet affrontement entre Smyrniotes et Chiotes. Ces derniers tentèrent en effet de prendre la ville durant l'absence d'une grande partie de ses habitants, ce en quoi ils échouèrent et furent victimes des fureurs bacchiques des Smyrniotes. Cet épisode semble situé dans un passé très lointain ( $\pi \mathrm{o} \tau \dot{\varepsilon})$ d'autant plus qu'il est mis en parallèle avec la guerre entre Athéniens et Amazones ${ }^{419}$. Le bateau, si l'on suit la logique d'Aelius Aristide, constitue en quelque sorte une prise de guerre : la dîme du butin

${ }^{415}$ Crusius 1889, p. 209 note 33; Frickenhaus 1912a, p. 74 note 2; Tarn 1910, p. 217; Eitrem p. 59-60. Voir aussi Göttlicher 1992, p. 107; Wachsmuth 1967, note 1727; Krauskopf 2011, p. 107-108.

${ }^{416}$ Nilsson 1906, p. 268 note 4 (avec références antérieures) reconnaissait sur des monnaies impériales smyrniotes le bateau de procession. En réalité, celles-ci portent au revers un éperon de navire ou une galère - types connus pour bien d'autres cités et tout à fait concevables pour une ville portuaire - sans aucun signe particulier ou distinctif. À ce sujet, voir D.O.A. Klose, Die Münzprägung von Smyrna in der römischen Kaiserzeit, Berlin, 1987, p. 38.

${ }^{417}$ Le texte d'Aelius Aristide n'a jamais été traduit et il faut reconnaître que sa langue est souvent difficile. C'est pourquoi la traduction que nous proposons s'avère assez libre, afin d'en rendre le contenu le plus clair possible. G. Dindorf, l'éditeur du texte, avoue lui-même parfois sa perplexité dans l'apparat critique.

${ }^{418}$ Le mot signifie littéralement débarquement; à propos de ces Kataploi, voir Nilsson 1905; G. Dindorf, note à l'édition du texte.

${ }^{419}$ Ainsi, pour Farnell 1896-1909, V p. 191-192, le témoignage d'Aelius Aristide représente une narration exemplaire d'un Grec cultivé qui cherche à expliquer un rituel primitif par un fait historique. Cadoux 1938, p. 114 pense au contraire que le texte est révélateur des rivalités parfois violentes qui existaient entre les deux cités. 
consacré au dieu qui a permis la victoire. La version que donne le rhéteur est tout à fait dans la lignée des exemples de consécration de bateaux; mais il s'agit d'une interprétation a posteriori.

$\mathrm{Au} \mathrm{III}^{\mathrm{e}}$ s. p.C., Philostrate (Vie des sophistes I, 25, 530-531 = voir corpus p. 536) décrit de façon précise le cérémonial dionysiaque de Smyrne, à propos des honneurs décernés au sophiste Polémôn et à ses descendants. Lors du mois Anthestérion, une procession mène un bateau jusqu'à l'agora de la ville, sous la direction du prêtre du dieu. Le véhicule est précisément qualifié de trière sacrée, précisée par ailleurs de $\mu \varepsilon \tau \alpha \rho \sigma i ́ \alpha$. Ce terme apparaît également dans la description d'Himerius (Orationes XLVII, 12-16) relative au char-bateau des Panathénées; il est à comprendre comme élevé par rapport au niveau du sol : par des roues peut-on supposer par analogie. La ressemblance entre les deux textes ne s'arrête pas là : la même mention est faite du bateau mis en branle une fois libéré de ses $\pi \varepsilon i ́ \sigma \mu \alpha \tau \alpha$, la présence du prêtre de Dionysos, qui joue un rôle actif dans cette céré-

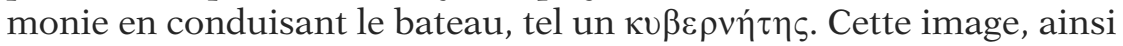
que la présence à bord de Polémôn - embarquer (غ̇ंı $\beta \alpha \tau \varepsilon v ́ \varepsilon ı v)$ est une marque d'honneur considérable à Smyrne, la plus importante avec la présidence des jeux - qui rappelle l'équipage des prêtres décrit par Himerius, pourrait indiquer que le prêtre est également assis dans le bateau au moment de la procession.

Aelius Aristide et Philostrate nous dressent finalement un tableau assez complémentaire du rituel. Malheureusement, celui-ci vaut pour les $\mathrm{II}^{\mathrm{e}}$ et $\mathrm{III}^{\mathrm{e}} \mathrm{s}$. de notre ère. Même si ce qu'ils en rapportent paraît remonter à un passé ancien, il est impossible de fixer des limites chronologiques. Dans le cas de Smyrne, il semble qu'il s'agissait d'un vrai bateau. Les textes ne parlent pas en terme de comparaison, comme c'est le cas pour celui des Panathénées, pas plus qu'ils ne parlent de char. Aucune mention n'est faite d'objet sacré à bord, pas même de statue : l'accent est mis sur le bateau luimême et la circonstance de la procession en février-mars. Soulignons l'accompagnement musical de la procession - comme aux Panathénées - en relation directe avec la mer.

Par analogie avec le bateau dionysiaque de Smyrne, d'autres cités ont été supposées servir de cadre à un tel rituel. C'est le cas de Délos ou encore de Massilia. Cependant rien ne permet d'affirmer ces hypothèses car, dans les deux cas, les sources parlent simplement de char (ö $\mu \alpha \xi \alpha$ ou vehiculum $)^{420}$. Le parallèle le plus souvent évoqué est celui d'un rituel dionysiaque athénien.

${ }^{420}$ Frickenhaus 1912a, p. 68-69, 74. Pour Délos, sur la base de textes épigraphiques : cf. Homolle 1882, p. 135; Homolle 1890, p. 502-504; F. Dürrbach, E. Schulhof, "Fouilles de Délos», BCH XXXIV, 1910, p. 177; pour Marseille (cf. Salviat 1992, p. 144-145), un auteur tardif (Justin 43, 4, 6) mentionne des Floralia - équivalent latin des Anthestéries - pendant lesquelles sont promenés des chars 


\section{c) Procession des Anthestéries athéniennes}

Le char dionysiaque des Anthestéries athéniennes ${ }^{421}$ est connu uniquement par des sources iconographiques. Il a fait notamment l'objet d'articles développés de la part de savants éminents, que nous ne reprendrons pas en détail ${ }^{422}$.

\section{- Sources iconographiques}

Le char figure sur trois skyphoi attiques à figures noires datés vers 500 a.C., exposés dans trois musées de pays différents ${ }^{423}$; leur provenance est également variée : respectivement une tombe de Bologne, le site d'Akrai en Sicile et l'Acropole d'Athènes. Les trois vases montrent, à quelques détails près, une image similaire du véhicule et de son contenu (fig. 39-41).

La caisse du char, à peu près rectangulaire, est montée sur deux roues ou plutôt, en tenant compte du traitement de la perspective en peinture à cette époque, deux essieux et quatre roues. La proue se termine par une protomé de sanglier, tandis que la poupe est recourbée par un aphlaston simple ou double ${ }^{424}$. À cet endroit du char également, figure un élément rectangulaire orné de croisillons obliques. L. Basch interpète cela comme une draperie à laquelle il donne une signification religieuse ${ }^{425}$. Le gaillard d'avant, décoré

à travers la ville; mais rien ne permet de savoir de quel type de chars il s'agissait. Doutes également exprimés par Guarducci 1983, p. 108 note 10.

${ }^{421}$ Sur les Anthestéries athéniennes, voir Jost 1992, p. 167-170; H. Jeanmaire, Dionysos, histoire du culte de Bacchus, Paris, 1951, p. 48-56; Deubner 1932, p. 93123; Guarducci 1980, p. $49-50$ note 19; Eitrem 1935, p. 60-65; Krauskopf 2011, p. 107-108.

${ }^{422}$ Frickenhaus 1912a, p. 61-79; Deubner 1927; Guarducci 1980; Guarducci 1983. L'idée générale a été amplement résumée et reproduite dans tous les ouvrages traitant de Dionysos. Il est surprenant que le cas d'Athènes, pour lequel il n'existe finalement que peu de sources, ait été l'objet d'une littérature beaucoup plus abondante que celui de Smyrne.

${ }^{423}$ Musée de Bologne, inv. DL 109 (Gasparri 1986, 1 p. 492, no 829; Krauskopf 2011, p. 107 et pl. 12, 2); British Museum, inv. B 79 (Deubner 1927, fig. 18; Moll 1929a, pl. BVI, b, n 115; Gasparri 1986, 1, p. 492, n 828); Musée National d'Athènes, inv. Acropole 1281 (B. Graef, E. Langlotz, Die antiken Vasen von der Akropolis zu Athen I, Berlin, 1925, p. 143 et pl. 74; Gasparri 1986, 1 p. 492, $\mathrm{n}^{\circ}$ 827). Les trois motifs figurent conjointement dans Basch 1987, p. $228 \mathrm{n}^{\circ}$ 475; Frickenhaus 1912a, pl. hors-texte I, 1, 2b, 3; Guarducci 1983.

${ }^{424}$ C'est un des seuls points de divergence des représentations : dans le cas du skyphos de Bologne, il y a deux aphlasta en forme de cornes; celui du British Museum présente un aphlaston en forme de cou de cygne courbé vers l'intérieur; le troisième vase, fragmentaire, ne laisse rien voir de la partie arrière du bateau.

${ }^{425}$ Basch 1987, p. 227, qui rapproche cet élément d'une autre représentation de bateau dionysiaque (ibid., $\mathrm{n}^{\circ}$ 470; Musée de Tarquinia, inv. 678). Sur ce détail, voir aussi Göttlicher 1992, p. 104-105. 


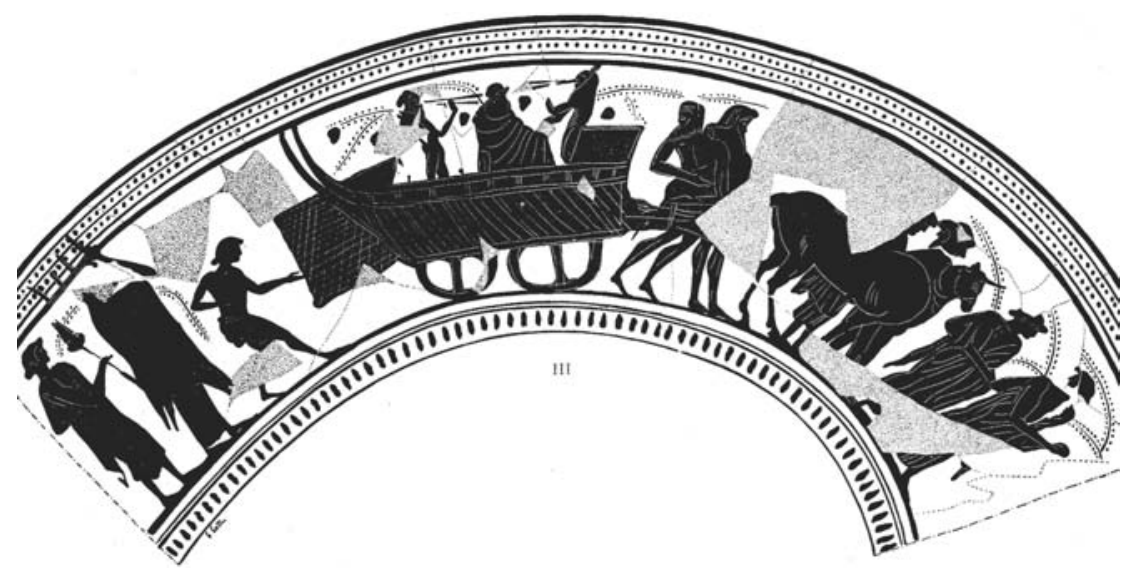

Fig. 39 - Dionysos et le char-bateau : vase de Bologne, inv. DL 109 (d'après Frickenhaus 1912a).

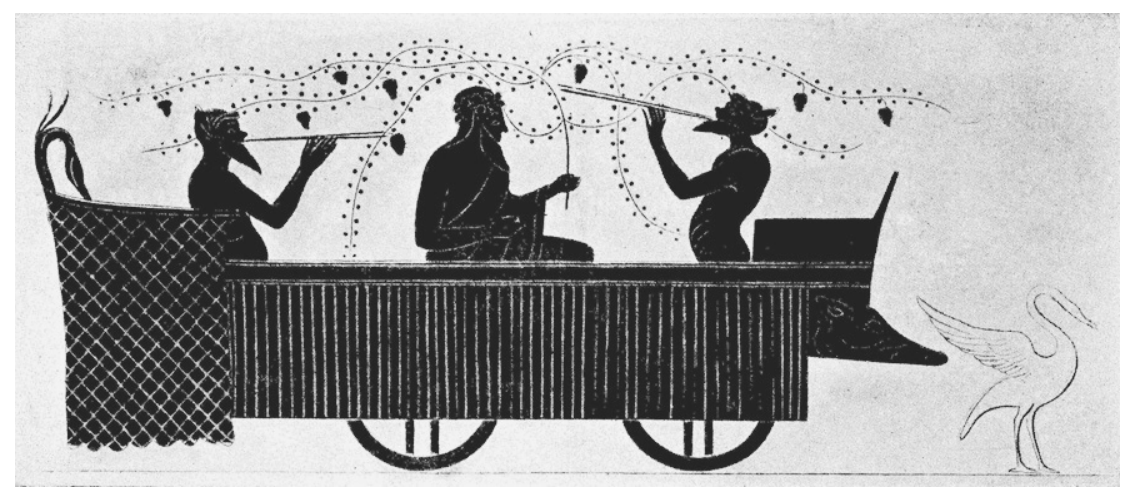

Fig. 40 - Dionysos et le char-bateau : vase du British Museum, inv. B79 (d'après Frickenhaus 1912a).

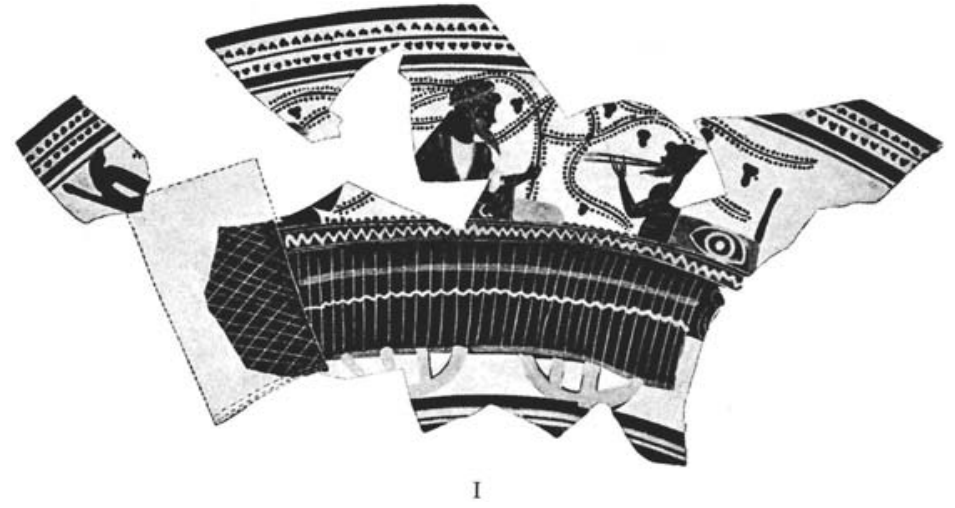

Fig. 41 - Dionysos et le char-bateau : vase du Musée national d'Athènes, inv. Acropole 1281 (d'après Frickenhaus 1912a). 
dans un cas d'un œil apotropaïque ${ }^{426}$, est surmonté d'un stolos sur deux exemplaires ${ }^{427}$. L'embarcation ne comporte ni mât, ni voile, ni rames, ni éperon. Au centre du char se tient assis Dionysos barbu, couronné, tenant à la main un rinceau de vigne qui semble se développer en treille portant grappes tout autour du dieu. Sur le vase d'Athènes, le dieu a l'air de tenir de l'autre main une fleur blanche. Il est encadré par deux Satyres jouant de l'aulos double. Sur le vase de Bologne, le char fait partie d'une pompè : à l'arrière, un jeune homme suit le bateau qui est lui-même précédé d'hommes adultes et d'un bœuf. Un groupe processionnel composé de six hommes dont un joueur de flûte et un bœuf est dessiné sur l'autre partie du vase du British Museum.

À ces trois vases bien connus il faut cependant rajouter trois ou quatre autres représentations similaires ${ }^{428}$. Un fragment d'un autre skyphos, datable de la même époque et conservé à Tübingen ${ }^{429}$, montre la partie centrale du char, depuis la roue jusqu'au plat-bord; on y reconnaît également le début de la proue en forme de tête de sanglier. La carène du char est décorée en damier croisé avec ce qui s'apparente à des petites fleurs blanches. Un fragment de coupe à figures noires de Berlin reproduit le même détail ${ }^{430}$. Quelques tessons d'un vase provenant de Karnak, daté vers 550-540 a.C. et aujourd'hui conservé à l'Asholean Museum, ont été interprétés par J. Boardman comme une représentation du bateau de Dionysos transporté par des Silènes, mais à regarder les pièces la lecture reste très hypothétique ${ }^{431}$. Le dernier document, originaire de Sicile, s'avère particulièrement intéressant (fig. 42).

Le support tout d'abord est différent : il s'agit d'un fragment de feuille de plomb, à peu près contemporain. Cet artefact provient d'une collection privée réunissant des objets provenant de la région de Montagna di Marzo (province d'Enna) où sévissaient les clandestins jusque dans les années 1980. Le lieu de trouvaille restitué est la nécropole avec tombes à chambres datées des $\mathrm{VI}^{\mathrm{e}}-\mathrm{V}^{\mathrm{e}} \mathrm{s}$. On suppose

${ }^{426}$ Sur le fragment du Musée national d'Athènes.

${ }^{427}$ Skyphoi de Londres et d'Athènes.

${ }^{428}$ Elles sont signalées par Göttlicher 1992, p. 104-105 et pour deux d'entre elles par Morrison \& Williams 1968, p. 116 (Arch. 104-105).

${ }^{429}$ Université de Tübingen, inv. 1497; Göttlicher 1992, p. 105 fig. 60; C. Watzingen, Griechische Vasen in Tübingen, Tübingen, 1924, nº D53 p. 31 et pl. XV.

${ }^{430}$ Inv. 2961. Moll 1929a, B, VIb, III; J.D. Beazley, Attic black-figure vasepainters, Oxford, 1956, p. $399 \mathrm{n}^{\circ} 100$.

${ }^{431}$ Inv. 1924-264. Boardman 1958 qui, rapprochant le motif avec les processions égyptiennes de Karnak et Louxor, suggère de voir dans l'objet un vase grec fabriqué en Égypte; Bacci \& Lentini 1994, p. 171, 173 et fig. 7. 


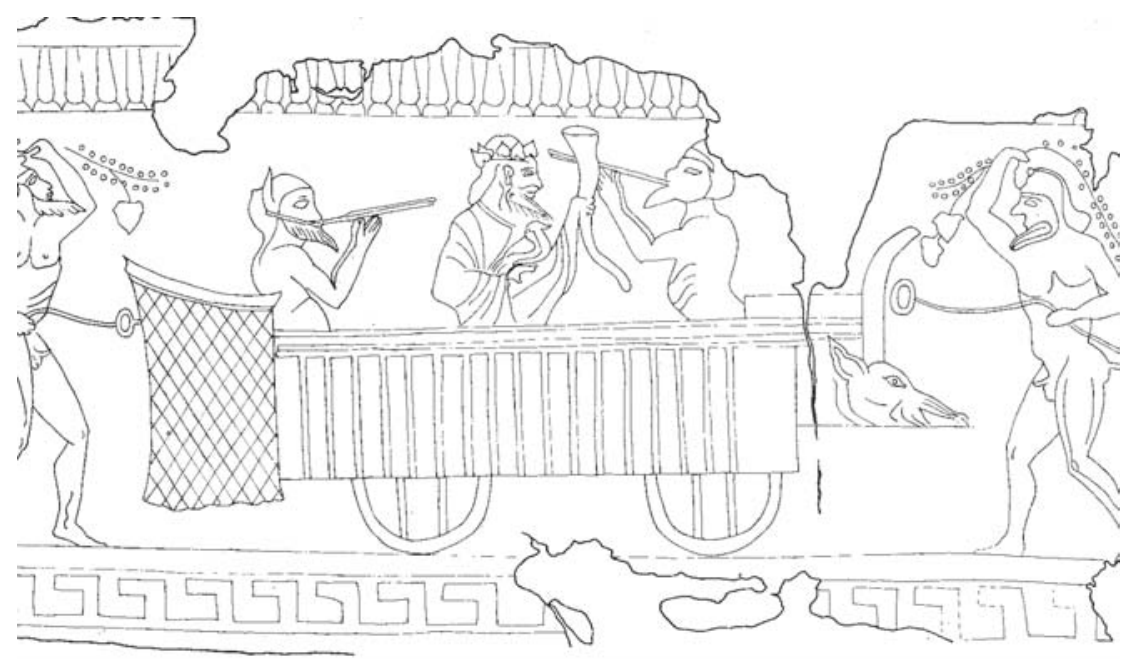

Fig. 42 - Dionysos et le char-bateau : feuille de plomb; musée d'Agrigente, inv. AG 21065 (d'après De Miro 1982, vol. III pl. XLV).

que ce décor de plomb devait décorer un sarcophage ${ }^{432}$. Le charbateau qui y figure présente exactement les mêmes caractéristiques que celles des exemples céramiques. En revanche, Dionysos paraît porter de sa main droite un oiseau et de sa main gauche un rhyton, tandis que le cortège qui encadre le bateau est constitué de satyres dansant, soutenant des treilles de vigne d'une main et de l'autre une corde rattachée au bateau par un anneau - une à la proue, une à la poupe.

\section{- Analyse}

L'identification de la fête durant laquelle se déroulait une telle procession est due en partie à Nilsson, et surtout à Frickenhaus ${ }^{433}$. L'argumentation repose sur l'existence, lors des Anthestéries athéniennes durant le mois d'Anthestérion, d'une pompè ${ }^{434}$. Des mentions tardives précisent que lors de fêtes en l'honneur de

${ }^{432}$ Musée d'Agrigente (inv. AG 21065). De Miro 1982; R. J. A. Wilson, "Archaeology in Sicily 1982-1987», JHS CVIII, 1988, p. 135, fig. 36; Göttlicher 1992, p. 105, fig. 61; Bacci \& Lentini 1994, p. 163-164, 171-173 et fig. 8.

${ }^{433}$ Nilsson 1900, p. 26; Nilsson 1906, p. 268-269 surtout note 5; Frickenhaus 1912a.

${ }^{434}$ Deubner 1966, p. 103 avec références. Une démarche ethnologique et comparatiste analogue au cap Palinuro a été réalisée par Neutsch 1965b. 
Dionysos était fait usage de chars $(\ddot{\alpha} \mu \alpha \xi \alpha)^{435}$. Cette fête qui marque le début du printemps est caractérisée par l'ornementation végétale et florale, signes distinctifs des images des skyphoi. On situe cette procession du char naval de Dionysos le deuxième jour des festivités - qui en comptaient trois -, dit des Xó $\varepsilon \varsigma^{436}$. Le char devait transporter la statue du dieu, placé au centre, jusqu'au Boukolion ${ }^{437}$. Les représentations iconographiques montrent que la pompè défilait en ordre. Le bœuf visible sur le vase de Bologne peut être compris comme l'animal de trait tirant le bateau, ou comme un animal de sacrifice. Telle est l'interprétation admise par tous, que l'on applique par analogie aux Dionysies smyrniotes.

En réalité, rien n'est véritablement assuré en l'absence de sources plus explicites ${ }^{438}$. Lorsqu'il est fait mention d'usage de char pour la fête des Anthestéries, le terme est employé au pluriel : il n'y a pas un char, mais plusieurs. Or, les skyphoi n'en montrent qu'un, suivi de gens à pied. Le jour des Choes était également marqué par l'union du dieu avec la femme de l'archonte roi; aucune trace de celle-ci non plus sur les chars-bateaux. Aucun lien, même ténu, n'apparaît entre les chars et le déroulement de la journée des sources littéraires et un éventuel bateau monté sur roues. De la même manière, rien de tel ne transpire des fêtes analogues célébrées dans d'autres cités, notamment à Délos. La description donnée de la fête de Smyrne est tout à fait différente du cérémonial des Anthestéries athéniennes. Il est à noter d'ailleurs que les fêtes ne portent pas le même nom : Dionysies pour Smyrne, Anthestéries pour Athènes, même si le mois dans lequel elles se déroulent toutes deux porte la même appellation d'Apatourion. Aelius Aristide et Philostrate semblent de surcroît évoquer le bateau processionnel comme étant une curiosité de Smyrne; les deux auteurs n'établissent aucune comparaison avec la cité d'Athènes, qu'ils connaissent cependant tous deux. L'existence dans les deux villes de fêtes consacrées au même dieu et célébrées durant le mois du même nom ${ }^{439}$ ne signifie pas pour autant qu'elles se déroulaient de

${ }^{435}$ Souda, s.v. $\tau \grave{\alpha} \dot{\varepsilon} \kappa \tau \tilde{\omega} v \dot{\alpha} \mu \alpha \xi \tilde{\omega} v ;$ Harpocration, s.v. $\pi$ o $\mu \pi \varepsilon i ́ \alpha$ s. Sur ces références et d'autres plus incertaines, voir Deubner 1927, p. 176.

${ }^{436}$ Guarducci 1980, p. 49 ss.

${ }^{437}$ Pickard-Cambridge 1988, p. 11-12. tionnel.

${ }^{438}$ Jost 1992, p. 169 , est la seule à présenter cette identification au condi-

${ }^{439}$ Thucydide II, 15, 4 souligne l'ancienneté de cette fête des Anthestéries et leur existence commune aux Athéniens et aux Ioniens. Guarducci 1983, p. 108 voit dans cette fête une tradition attique très ancienne, antérieure aux fondations des colonies ioniennes en Asie Mineure. 
manière totalement identique. Il convient donc de rester prudent vis-à-vis de cette identification et reconnaître son caractère tout à fait hypothétique. D'autres commentateurs jugent la place de la procession au début du printemps comme une indication pour sa signification ${ }^{440}$.

Deux remarques s'imposent vis-à-vis des sources iconographiques. Celles-ci sont concentrées sur une période courte, la fin de l'époque archaïque ${ }^{441}$; le thème se révèle en outre attique ${ }^{442}$. Cependant il ne figure pas parmi le relief de la petite Métropole. D'après la succession du calendrier, on a reconnu sur la frise les séquences correspondant aux Anthestéries et aux Dionysies ${ }^{443}$ mais aucune ne peut être mise en relation avec le char-bateau: si celui-ci était représentatif de cette fête, on s'attendrait à le voir illustré d'une manière ou d'une autre. Par ailleurs, l'exemplaire sicilien sur feuille de plomb pourrait donner à la scène un sens funéraire.

\section{d) Poseidonia}

L'hypothèse est également admise de l'existence d'une quatrième fête comportant une procession avec un bateau à Poseidonia en l'honneur d'Héra ${ }^{444}$. Aucune source antique ne vient l'étayer, seulement des rapprochements avec des rituels d'époques moderne et contemporaine. Héra possédait un sanctuaire à l'Héraion du Sele, à l'embouchure de la rivière; aujourd'hui se trouve un peu plus loin à l'intérieur des terres, sur une hauteur, une chapelle consacrée à la Madonna del Granato (grenade), fruit qu'on attribuait également à Héra. Un pèlerinage a lieu à cet endroit, dans

${ }^{440}$ Pour Parker 2005, p. 302-303, elle prouve que le dieu peut arriver par bateau en dehors de la saison maritime, tandis que Romero Recio 2010, p. 101-106, estime que cette fête marque le tout début de la saison navigable.

${ }^{441}$ Frinckenhaus 1912a rapproche de ces trois vases deux autres représentations de procession qu'il nous est difficile de retenir, car elles n'offrent aucune figure du char-bateau; Dionysos n'est pas le seul en l'honneur de qui on menait des cortèges et aucun caractère spécifique aux Anthestéries ou même dionysiaque n'apparaît sur ces deux images de pompè.

${ }^{442} \mathrm{La}$ représentation sur support métallique est vraisemblablement due à une copie d'un motif attique.

${ }^{443}$ Voir liste établi par Deubner 1932, p. 248-254, spécialement les no 12, 13, $18,19$.

${ }^{444}$ Cette hypothèse a été formulée dès le XIX ${ }^{\mathrm{e}}$ s. et explicitée lors de la publication des fouilles du sanctuaire par Zancani Montuoro \& Zanotti-Bianco 1951-54 (I p. 17-19 et photos fig. 1 et 2), et repris et enrichi dans une intervention (Zancani Montuoro 1965); voir également Neutsch 1965. La procession a lieu le 15 août et également lors de circonstances exceptionnelles. Depuis l'idée semble reprise de façon unanime : récemment encore par Sinn 1988, p. 152; Polignac 1997, p. 115 note 8; Brize 1997, p. 130; Romero Recio 2010, p. 96-97. 
lequel on porte un bateau. La figure de la Madonne, ainsi que le caractère non maritime du lieu où se déroule la procession et des fidèles - montagnards, citadins - tend à faire remonter la cérémonie à une époque plus ancienne que le Moyen Âge. Cette tradition est considérée comme la survivance d'un culte ancestral voué à Héra. La fête aurait comme dans le cas de celles de Dionysos une fonction fécondatrice, mais rappellerait également le lien antique d'Héra avec la mer ${ }^{445}$. Des divergences sont à souligner par rapport à ce que nous pouvons savoir des rituels antiques : il ne s'agit pas d'un bateau, mais de plusieurs. De plus ceux-ci ne sont pas véhiculés sur roues ou quelque chariot, mais portés par les fidèles sur leurs têtes.

L'absence de sources antiques, ces différences et la prudence avec laquelle il faut opérer ce type de rapprochement ne permettent pas d'affirmer l'existence d'une cérémonie à l'Héraion du Sele mettant en scène des bateaux, même s'il est très séduisant d'admettre cette hypothèse.

\section{Conclusion}

La notion de char-bateau est loin d'être uniforme ni même bien définie. Elle revêt semble-t-il des aspects différents selon les lieux et les fêtes, tant dans son utilisation que dans sa conception ou son aspect général. C'est à Smyrne qu'il est explicitement mis en relation avec la mer: par son apparence extérieure ainsi que par sa légende étiologique. Celui des Panathénées est également considéré comme un bateau, comme le montre le vocabulaire utilisé au travers des sources, et à partir de l'époque hellénistique on s'efforce d'insister sur l'aspect maritime de celui-ci. Le sens que lui donnaient les Athéniens est pour le moment impossible à saisir.

Beaucoup plus sobre, l'apparence du char des vases attiques se réduit au strict minimum : pas de mâts, pas de voiles, pas de rames, mais une sorte de proembolon en forme de tête et des yeux ${ }^{446}$. Mis à

${ }^{445}$ Le rapprochement est alors opéré avec une statuette archaïque provenant de Tirynthe la représentant portant des fleurs contenues dans une barque (?) : Frickenhaus 1912b, p. 63 no 9 pl. III8, et p. 124-125 fig. 47-48. À partir de cette présumée origine argienne du rite, celui-ci est supposé avoir existé dans d'autres sanctuaires d'Héra, notamment à Pérachora (Payne 1940, p. 196, 244 n 245 fig. 110) : voir supra, chapitre Héra.

${ }^{446}$ Signalons à cet égard trois fragments d'yeux de bateaux en marbre, trouvés dans des contextes du $\mathrm{V}^{\mathrm{e}} \mathrm{s}$. a.C. sur l'Agora d'Athènes et interprétés par Carlson 2009 comme ayant appartenu soit à des monuments navals honorifiques, soit à des équipements nautiques stockés dans le Stratégéion, soit à un charbateau du type de celui des Anthestéries ou des Panathénées. 
part son lien avec Dionysos, il est difficile d'évaluer dans quel contexte il prenait place à l'extrême fin du VI' ${ }^{\mathrm{e}}$ s. a.C.

Tous ces témoignages concourent à montrer que, hormis peutêtre à Smyrne, l'usage de pseudo chars-bateaux ne relevait pas à l'origine d'un culte en liaison avec la mer; ce n'est que plus tard qu'on a pu établir le lien avec le milieu marin et renforcer dès lors la comparaison.

\section{L'OFFRANDE À TERRE : LE CAS DES ANCRES}

\section{INTRODUCTION}

Parmi les objets présents à bord d'un bateau et les plus représentatifs de la vie maritime, se classe en priorité l'ancre. Or, nous l'avons vu, cet instrument nautique est de surcroît investi d'une valeur religieuse lors de son utilisation. Il paraît donc peu surprenant qu'il soit également offert en remerciement à la divinité, après une traversée réussie, avec une dédicace qui permette de l'identifier sans aucun doute comme ex-voto.

Quelques ancres avec dédicaces nous sont ainsi parvenues, exprimant un acte de dévotion à une divinité dans un contexte de navigation. Par ailleurs, un certain nombre d'ancres anépigraphes ont été mises au jour lors de fouilles dans des contextes cultuels ${ }^{447}$. Nous examinerons donc ces différents ex-voto, en commençant par les plus manifestes, présentant une inscription, pour ensuite étudier le cas des jas anépigraphes.

Tous les exemplaires répertoriés provenant de découvertes terrestres et apparemment en relation avec des sanctuaires sont en pierre ${ }^{448}$. Aucun jas de plomb n'ayant été jusqu'ici retrouvé en relation avec un bâtiment terrestre ${ }^{449}$, on pourrait conclure $a$ priori que

${ }^{447}$ Romero Recio 2000, p. 29-54.

${ }^{448}$ Plusieurs types de pierre sont usités, y compris l'emploi du marbre, qui pourrait dès lors aider à définir l'origine de l'objet : cf. Gianfrotta 1977, p. 290-291 et note 8; Gianfrotta \& Pomey 1980, p. 304-305.

${ }^{449}$ À part les ancres miniatures de Calydon (voir supra p. 203), parmi un matériel toujours pas publié. Signalons aussi deux autres retrouvées dans un contexte romain : l'une, longue de $3 \mathrm{~cm}$, de Foci del Garigliano : Mingazzini 1938, col. 913, pl. XLII, 10; Gianfrotta 1977, p. 286; Davaras 1980, p. 54-55. Une seconde, du puits A de l'area du temple de Vesta à Rome: Follieri 1961, col. 139-140 et fig. 47; Gianfrotta 1975, p. 311-318; Gianfrotta 1977, p. 286 et fig. 1. 
le don d'une ancre réelle comme ex-voto relève d'un rituel ancien, moins sinon non accompli à des époques plus récentes. De fait, à considérer des époques plus reculées, les consécrations d'ancres apparaissent comme une pratique courante et aujourd'hui assez bien connue. De même, pour les périodes qui nous intéressent, un certain nombre de sources littéraires ont gardé trace de tels actes religieux.

Enfin cette différence de matériel - jas métalliques avec inscriptions trouvées en mer, jas de pierre inscrits dégagés à terre -, invite à se poser ces dernières questions : l'inscription est-elle contemporaine de la fabrication de l'ancre - comme pour les noms figurant sur jas de plomb -, ou gravée dans un second temps lors de l'offrande? L'ancre de pierre a-t-elle servi réellement ou a-t-elle été réalisée uniquement dans le but d'un ex-voto? L'étude des cas archéologiques concernant notre période est donc à considérer dans cette double perspective, à la lumière des nombreuses découvertes de ces cinquante dernières années.

\section{PratiQue ANCIENNE}

Le dépôt d'ancre dans l'enceinte d'un sanctuaire est une pratique plurimillénaire dans le monde méditerranéen, en particulier dans sa partie Est. Les nombreuses et riches études de H. Frost à ce sujet sont exemplaires ${ }^{450}$. Ces ancres - de pierre, auxquelles s'applique le terme d'ev̉ví ${ }^{451}$ - ont en outre la particularité de se trouver dans des contextes archéologiques bien datés. Les exemples les plus anciens remonteraient entre 2850 et 2650 a.C., dans la région de la mer de Galilée ${ }^{452}$. Une autre un peu plus récente (XXIII ${ }^{\mathrm{e}}$ s. a.C.) est égyptienne et provient de Byblos; elle présente en outre une inscription hiéroglyphique de bon augure, qui est reproduite ailleurs dans un même contexte maritime, sur la coque du bateau découvert à Chéops datant d'environ 2600 a.C. Cette inscription est rapprochée à juste titre par H. Frost des ancres avec astragales, dauphins ou têtes de Méduse dont nous traiterons ici $^{453}$. Des dépôts d'ancres sont attestés à l'âge du bronze

${ }^{450}$ Frost 1969; Frost 1970a; Frost 1973; Frost 1982; Frost 1986.

${ }^{451}$ Ce terme désigne dans les sources grecques l'ancre de type primitif, constituée d'une pierre, percée généralement d'un ou trois trous (et donc sans jas). Cf. surtout Mac Caslin 1980, p. 53 ss; Casson 1971, p. 48 note 45.

${ }^{452}$ Wachsmann 1986, qui, à la suite des études de H. Frost, identifie comme ancres des pierres jusque là reconnues comme shfifons.

${ }^{453}$ Frost 1969, p. 439; Frost 1970a, p. 379-380; Frost 1973, p. 400-403, no 2; à noter également la localisation de cet objet dans un lieu mythologiquement en rapport avec Isis et Osiris. Signalons encore, à propos de l'Égypte, une autre 
pour Ugarit, dans l'area du temple de Baal - dont une avec une inscription (?) non déchiffrée ${ }^{454}$. À Kition, le grand nombre d'objets de ce type trouvés en remploi incitait en 1970 à imaginer un usage cultuel plus ancien, qui fut confirmé par des fouilles postérieures: plus d'une centaine d'exemplaires trouvés in situ dans le contexte des 5 temples, dans des positions non équivoques $^{455}$. L'usage est également observé, déjà à date très haute comme le montre l'ancre égyptienne, à Byblos. Ce dernier site est particulièrement intéressant, car la présence des ancres témoigne d'une pratique cultuelle continue durant au moins sept siècles, malgré les aléas d'occupation de la ville : les dépôts votifs, outre l'ancre égyptienne, sont datés des $\mathrm{XIX}^{\mathrm{e}} \mathrm{s}$. et $\mathrm{XVI}^{\mathrm{e}}$ a.C. ${ }^{456}$. Les ancres y sont placées dans la position verticale, comme à Chypre, ce qui n'est pas sans évoquer des dispositions parallèles dans des sites plus récents (cf. infra). La plupart des ancres semblent en outre n'avoir jamais servi comme telles : elles n'auraient d'ailleurs pu le faire avec succès, à cause de leur matériau très fragile, le calcaire $^{457}$. Il s'agirait donc d'objets fabriqués en vue d'ex-voto. $\mathrm{H}$. Frost avance l'hypothèse suivante à propos de certaines ancres retrouvées dans l'Enclos sacré de Byblos, ainsi qu'à Chypre, en relation possible avec un puits : l'offrande d'ancres tenterait de conjurer la pénurie d'eau fraîche à bord ${ }^{458}$. Le passage d'Apollonios de Rhodes (I, v. 953-971) ${ }^{459}$ sur lequel s'appuie cette tentative d'explication ne dit rien de tel: le poète localise simplement l'endroit où se situe l'épisode, en précisant bien que l'ancre ne serait consacrée que plus tard, et dans un autre lieu. La préoccupation du manque d'eau potable à bord n'apparaît pas majeure dans les inquiétudes des navigateurs ${ }^{460}$; à notre connaissance, elle

ancre, de type chypriote, retrouvée dans l'enceinte du temple d'Amon à Karnak : Basch 1981, p. 38.

${ }^{454}$ Frost 1973, p. 397-409, no 7, 1; Davaras 1980, p. 59-60; Frost 1991 (spéc. p. 356-359 pour les arguments religieux).

${ }^{455}$ Frost 1970a, p. 381-384; Frost 1982b; Davaras 1980, p. 59; Frost 1985 (publication la plus complète); Bonnet 1988, p. 324.

${ }^{456}$ Frost 1970, p. 381-384; Frost 1973, no 4; Davaras 1980, p. 60-61.

${ }^{457}$ Frost 1969, p. 438.

${ }^{458}$ Ibidem, p. 440-441; Frost 1970b, p. 14-24; théorie répétée dans de nombreux autres articles (pour exemple, citons Davaras 1980, p. 58-59). Peutêtre aussi sur le site de Marathos en Syrie, cf. ibidem p. 20, n. 1.

${ }^{459}$ Ce passage est commenté supra (p. $46 \mathrm{~s}$. : à propos Athéna et des Argonautes) et infra (p. 460 s. : sources littéraires sur dons d'ancres).

${ }^{460}$ Sur cette difficulté particulière de navigation et ses solutions religieuses, cf. Wachsmuth, p. 449-450. 
n'apparaît à travers aucune manifestation religieuse dans l'Antiquité, ni même à des époques plus récentes. Plutôt que l'absence d'eau elle-même, c'est l'absence de vents qui est incriminée ${ }^{461}$. Rien ne permet donc d'affirmer une telle interprétation; une raison beaucoup plus rationnelle peut tout aussi bien expliquer la présence de jas d'ancres dans un puits ${ }^{462}$. Pour compléter ce tour d'horizon, il reste à signaler quelques objets, pour certains d'interprétation très controversée, provenant de la Crète minoenne ${ }^{463}$; malgré l'absence de contexte religieux sûr, et par comparaison avec les exemples cités précédemment, on tend actuellement à définir comme votives certaines ancres datables de l'époque dite des premiers palais crétois (2000-1700 a.C. $)^{464}$.

Pour l'âge du bronze on trouve également des traces de dépôt d'ancres dans des tombes ${ }^{465}$. À Ugarit, outre les cas à mettre en relation avec le sanctuaire, a été mise au jour une tombe datée de 1800 a.C. contenant deux pseudo-ancres - modèles de calcaire - ${ }^{466}$; à Rhodes la même coutume se manifeste peut-être dans la sépulture XXVII de la nécropole mycénienne de Jalysos ${ }^{467}$.

${ }^{461}$ Voir par exemple Anthologie Palatine VII, 293, dans laquelle un navigateur meurt de soif, faute de vents - et c'est ainsi que D. Wachsmuth paraît considérer le problème. Davaras 1980, p. 58-59 note 103, rapproche cet usage éventuel, énoncé par H. Frost, de l'offrande faite par Agamemnon de son gouvernail contre le mauvais temps (Callimaque, Hymne III, v. 228-232) : ici encore, c'est la météo que l'on voudrait modifier, et de surcroît par un don d'une autre nature.

${ }^{462}$ Davaras 1980, note 102, suggère également la possibilité d'un remploi de ces ancres comme poids de levée pour le puits, songeant sans doute à l'interpréta-

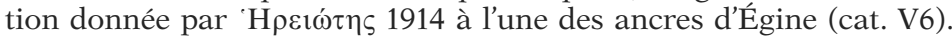

${ }^{463}$ C'est le sujet de l'article de C. Davaras, qui est partisan d'une lecture magico-religieuse, en relation avec la Grande Déesse minoenne, de tous les objets de ce type trouvés dans l'île.

${ }^{464}$ Poursat 1992, p. 24 et fig. 12 , à propos de deux ancres de pierre tendre (grès dit ammouda) mises au jour trouvées dans le bâtiment $\mathrm{B}$, salle IV 14, supposées avoir trouvé place dans une niche aménagée dans cette même pièce.

${ }^{465}$ Par ex. à Chlomatiana (Corfou) : on signale la présence d'un objet de terre cuite en forme d'ancre dans une tombe datée du HA II-III (cf. BCH CXV, 1991, 2, p. 875); Frost 1984.

${ }^{466}$ Frost 1969, p. 425; Frost 1970a, p. 387-388; Frost 1973, p. 401-402, n 7 (V); Davaras 1980, p. 60, y voit hâtivement la marque de «l'existence de relations entre les idées sur la valeur magico-religieuse de l'ancre et sur la vie d'outretombe ou le culte des morts".

${ }^{467}$ Davaras 1980, p. 60 (avec bibliographie), les rapproche également d'un exemple chypriote non assuré. 


\section{ATtESTATIONS LITTÉRAIRES ET ÉPIGRAPHIQUES}

\section{Sources littéraires}

Si les témoignages littéraires d'ex-voto d'ancre dans un sanctuaire existent, aucun n'est antérieur à l'époque hellénistique. Cependant la plupart de ces citations renvoient à un âge plus ancien, que certains auteurs attribuent à des temps mythiques. Ainsi, les deux premières mentions, contemporaines, faites par Callimaque et Apollonios de Rhodes au $\mathrm{III}^{\mathrm{e}}$ s. a.C., réfèrent à l'expédition des Argonautes. Le premier fait allusion à l'ancre abandonnée par les aventuriers à l'occasion de leur escale à Cyzique ${ }^{468}$. Cet épisode nous est en réalité mieux connu par le second poète (Argonautiques I, v. 953-960; scholie aux v. 955-960), qui précise trois aspects intéressants. Tout d'abord, l'objet est de type ancien : c'est une Ev่vaíns ò $\lambda \dot{\gamma}$ ov $\lambda i ́ \theta$ ov, et non pas encore une $\ddot{\alpha} \gamma \kappa v \rho \alpha^{469}$. Ensuite, la pierre est consacrée à Athéna Jasonienne, mais sur l'ordre d'Apollon; enfin, ce ne sont pas les héros eux-mêmes qui effectuent ce geste, mais les Ioniens Néléides - que le scholiaste désigne comme des Milésiens - à une époque postérieure ${ }^{470}$. Tout cela signifie que l'objet déposé dans ce sanctuaire d'Athéna, s'il existait réellement, ne devait pas présenter la forme d'un jas, mais celle d'une pierre percée d'un ou plusieurs trous; de surcroit que l'objet éventuellement visible à Cyzique était considéré comme très ancien pour les Grecs de l'époque hellénistique, qui le rattachaient donc à une origine argonautique tout en lui donnant néanmoins des dédicants plus proches d'eux et autochtones. Le lien entre Apollon et Athéna semble plus difficile à comprendre : de quel oracle s'agit-il, à la suite de quelles circonstances l'oracle a-t-il été sollicité et a-t-il motivé un tel geste? L'explication la plus logique relie le lieu géographique et la divinité honorée localement : l'ancre est dédiée au sanctuaire le plus important de la zone.

Une troisième source encore plus tardive, du $\mathrm{I}^{\mathrm{er}}$ s. p.C. (Pline, Histoire naturelle XXXVI, 99), nous apprend cette fois que la pierre est réellement visible à Cyzique, et non pas dans le sanctuaire d'Athéna mais dans un lieu appelé prytanée; de plus, elle est garnie d'une chaîne de plomb. À l'époque augustéenne donc la tradition

${ }^{468}$ Callimaque, Origines VIII, Lemme XVI, col. V 1. 33-39: 'A $\gamma$

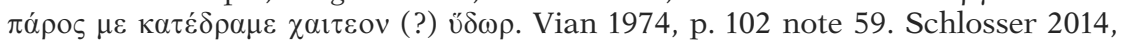
p. 276-277.

${ }^{469}$ Le scholiaste explique d'ailleurs cet abandon par l'érosion de la pierre.

${ }^{470}$ Sur l'abandon de cette ancre et le rapport Athéna-Argonautes, voir supra, $1^{\text {ère }}$ partie, chapitre "Athéna» (p. 24 ss. et 46 s.); sur le rapport éventuel de cet abandon d'ancre avec un chargement d'eau douce à bord, voir paragraphe précédent p. 457 ss. 
perdure au sujet de l'origine mythique de la pierre, même si la fantaisie compense certaines incompréhensions. En revanche, la curiosité locale n'est plus rattachée à un sanctuaire ni à une divinité, mais à un bâtiment profane; l'adjectif humoristique fugitiuus appliqué à l'ancre pourrait se comprendre par un transfert de la pierre de l'emplacement qu'elle occupait trois siècles auparavant, voire même à la disparition pure et simple de celle-ci substituée par une nouvelle garnie de métal évoquée par Pline. En tous cas, l'objet quel qu'il soit a perdu toute valeur religieuse : il n'est plus un ex-voto mais un témoignage du passage des Argonautes dans la région.

Un itinéraire côtier du $\mathrm{II}^{\mathrm{e}}$ s. p.C. renforce cette impression. Denys de Byzance (Anaplus Bospori 87) signale un promontoire appelé Ancyreum où aurait été abandonnée l'ancre ${ }^{471}$ (carte 8). Ceci confirmerait donc, d'une part, que l'objet a été déplacé et que le sanctuaire où il a été déposé se trouve ailleurs que sur ce promontoire, d'autre part que l'ancre n'a plus à cette époque de valeur religieuse ou même simplement d'existence.

Enfin Arrien (Périple du Pont-Euxin 9, 1-2) vers 130 ap. J.-C. fait état quant à lui, pour l'embouchure du Phase, des mirabilia que l'on montre aux visiteurs de passage (carte 7). Il s'agit de l'ancre des Argonautes, dont le voyageur doute de l'authenticité à cause de son matériau qui est métallique, même s'il lui trouve quelques particularités ${ }^{472}$. En revanche, une autre ancre - apparemment fragmentaire - de pierre a attiré davantage son attention et lui a paru plus digne d'être celle du navire Argô. Ce témoignage est très instructif : s'il ne désigne pas précisément l'endroit ou le type d'endroit - bâtiment public, temple, plein air...- où étaient visibles ces ancres, il révèle en tous cas que dans un même lieu se trouvaient concentrés plusieurs objets de cet ordre; au II $\mathrm{s}$., assimilés à une même origine mythique, ils sont peut-être le résultat de différents dépôts - votifs? - à des époques diverses.

Un autre témoignage se rapporte à une ancre dédiée cette fois à Ancyre. Pausanias (I, iv, 5) nous rapporte qu'à son époque encore, une ancre était conservée dans le sanctuaire de Zeus, considérée comme étant celle du roi Midas et à l'origine du nom de la citét73. Un

${ }^{471}$ Sur l'endroit présumé de l'abandon de la pierre par les Argonautes, voir Delage 1930, p. 98 ss. L'auteur place l'épisode dans un avant-port, sans signaler le texte de Denys de Byzance.

${ }^{472}$ Rapide commentaire dans Gianfrotta 1975, p. 314. Texte mal lu par Svoronos 1914, p. 110. L'endroit où se trouvent les ancres est défini comme un sanctuaire de Rhéa.

${ }^{473}$ Sur cette tradition, Tzetzès au XII ${ }^{e}$ s. nous donne deux versions (Chiliades

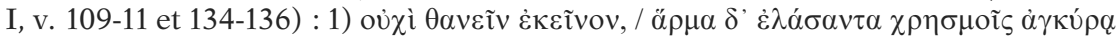

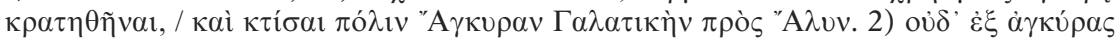


monnayage impérial doit illustrer cette tradition, montrant un Zeus reconnaissable à son sceptre tenant une ancre de l'autre main ${ }^{474}$. Si l'on en croit une tradition rapportée par Stéphane de Byzance (s.v. "A $\gamma \kappa \nu \rho \alpha=$ corpus p. 538) ${ }^{475}$, la ville aurait été fondée et aurait pris son nom à la suite d'une victoire des Galates, venus en aide à Mithridate et à Ariobarzane contre les troupes égyptiennes d'un Ptolémée. Les vainqueurs poursuivirent leurs ennemis jusqu'à la mer et s'emparèrent de leurs ancres puis, grâce à leur salaire, bâtirent une cité à cet endroit. Il faut rétablir le chaînon manquant sans doute de cette manière : les ancres prises aux navires égyptiens afin de les laisser partir à la dérive pouvaient constituer des sortes de trophées. Cette anecdote étiologique montre qu'implicitement, dans l'Antiquité, on pouvait considérer des ancres comme des trophées d'une victoire militaire, dignes d'être déposés dans un sanctuaire ou du moins d'expliquer un toponyme.

Les trois témoignages de l'Anthologie Palatine (VI, 27 à 29; 38 = Philippe X) relèvent d'un autre registre. Il s'agit de l'offrande, par un pêcheur cessant toute activité, de ses outils de travail au sanctuaire qu'il fréquente. La pratique aperçue ici est plus humble, mais elle exprime un même état d'esprit : remercier la divinité de ses bienfaits et d'une vie de labeur maritime arrivée à terme. Ces poèmes sont d'époque romaine, du début du $\mathrm{I}^{\mathrm{er}}$ s. p.C. jusqu'au VI ${ }^{\mathrm{e}}$ s. Y sont précisés les noms des dieux ainsi honorés : Hermès (VI, 29) que l'on peut également restituer dans l'épigramme précédente (VI, 28) ${ }^{476}$, Poséidon (VI, 38) tandis que la première épigramme est dédiée aux

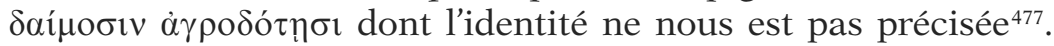

\section{Sources épigraphiques}

Outre les sources littéraires, des textes épigraphiques prouvent l'existence d'ancres dans les sanctuaires, inventoriées parmi les

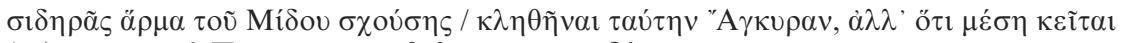

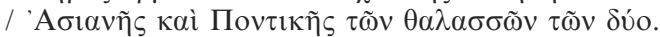

${ }^{474}$ Head 1906, p. 62 no 22 et pl. IX, 4; Svoronos 1914, p. 109; Volkommer 1997, I p. 378 et II pl. 244. L'ancre représentée sur la monnaie n'a rien d'ancien, mais semble plutôt une ancre métallique, du type ancre de Nemi.

${ }^{475}$ Stéphane de Byzance répète les écrits d'Apollonios d'Aphrodisias, dont on ne connait malheureusement pas la datation - probablement d'époque impériale. Le passage en question figure dans F. Jacoby, FGH III C, n 740, p. 717, fgt 14. Idem in Etymologicum magnum, 184, 36-42.

${ }^{476}$ Dans A.P. VI, 28, il est en effet mention d'une divinité, et l'auteur de cette épigramme est le même que celui de la suivante.

${ }^{477}$ Sur ces offrandes de l'Anthologie Palatine, voir Mazaubert 1937. 
ex-voto déposés par les fidèles. C'est le cas de Délos (voir fig. 7) où l'on trouve un certain nombre d'objet à vocation maritime ${ }^{478}$. Des comptes des hiéropes ${ }^{479}$ enregistrent ainsi, à plusieurs reprises à partir de 240 jusqu'en 169 a.C. des ancres qui apparaissent au moins au nombre de deux parmi les offrandes de l'édifice des Andriens ${ }^{480}$ (voir annexe épigraphique p. 560-561). En outre, des inventaires de fonctionnaires athéniens notent la présence d'ancres à l'intérieur du Samothrakeion (voir ibidem) ${ }^{481}$. À travers toutes ces mentions, comme l'explique P. A. Gianfrotta, apparaissent toutes les sortes d'ancres connues à présent, «de l'ancre à jas de pierre à celle de bois avec jas de plomb, à celle de fer avec pierre de plomb ou de fer sans pierre» ${ }^{482}$; même le poids de celles-ci est précisé483. Ce qui implique en outre une pratique continue de ce type d'ex-voto, puisque l'utilisation de l'ancre de fer est plus récente que celle de l'ancre à jas de pierre. Si dans un cas, l'attribution de ces objets est assurée - aux dieux de Samothrace, les Cabires -, en revanche le dépôt dans l'Oikos des Andriens laisserait supposer naturellement des offrandes à Apollon, dieu majeur du sanctuaire.

Les ancres retrouvées dans les sanctuaires ${ }^{484}$ sont en pierre; mais les sources littéraires contredisent l'idée d'une pratique

${ }^{478}$ Cf. EAD XVIII, Paris, 1938, p. 197-203.

${ }^{479}$ ID 298 A, p. 45, 1. 180; 300 B, p. 55, 1. 29; 313 i, p. 66, 1. 16-17; 346 B, p. $116,1.1 ; 372$ B, p. $10,1.36-37 ; 372$ B, p. 10, 1. 40; 421, p. $99,1.17 ; 430$, p. 110, 1. $5 ; 439$ b, p. $119,1.13 ; 442$ B, p. $151,1.168 ; 442$ B, p. $151,1.171 ; 443$ Bb, p. 184 , 1. $92 ; 443$ Bb, p. 184 , 1. $95 ; 444$ B, p. 193 , 1. 8; 444, p. $193,1.11 ; 457$, p. 229, 1. 21; $461 \mathrm{Bb}$, p. 268, 1. 5. Cf. Homolle 1882, p. 1-167, précisément p. 47, 1. 168 et 171. Dans ces mêmes comptes figure l'indication d'un embolos : voir supra, sur les offrandes de bateaux et de parties de bateaux.

${ }^{480}$ Nous reprenons ici la désignation de F. Durrbach (voir corpus p. 557) pour l'oikos d'Andros. Ce bâtiment, signalé par les comptes, n'a pas été identifié avec certitude; R. Vallois proposait de le reconnaître au nord-ouest de la stoa des Naxiens, aligné avec ce dernier (contra : Bruneau \& Ducat, 2005, p. 205, no 43). Les arguments de R. Vallois, leur critique et la description du bâtiment en question sont publiés par Hellmann \& Fraisse 1979, p. 10-11, p. 79-81 et pl. IV.

${ }^{481}$ Roussel 1987, p. 231.

${ }^{482}$ Gianfrotta 1975 , p. 315-316.

${ }^{483}$ Sur l'analyse des types et des poids de ces différentes ancres, voir Casson 1971, p. 253 note 115 et p. 256 note 131.

${ }^{484} \mathrm{Ne}$ seront pas abordées dans cette étude les ancres qui ne présentent aucun rapport possible avec la vie religieuse. C'est pourquoi en est exclu le jas de pierre trouvé à Milet (Boetto 1997, p. 55); en effet, il appartient à une maison archaïque devant l'entrée de laquelle il sert en quelque sorte de décoration (ou d'enseigne) - sans rapport avec le sanctuaire d'Athéna voisin - : Kleiner 19591960 , p. 86-87 et pl. 78, 2. Nous n'avons pas retenu non plus le cas de Locri Epizephiri, avancé par Boetto 1997, qui présente un jas et en signale deux autres disparus, qui n'ont pas été reconnus comme tels au moment de leur découverte et 
ancienne relevant d'une époque où seule existait l'ancre de pierre. Les textes témoignent qu'étaient consacrées aussi des ancres de métal, et même de métal précieux, et ce encore à l'époque hellénistique. Les conditions de conservation et de protection au cours des siècles ont dû jouer et ne nous laisser que ces exemples de pierre.

\section{LES DOCUMENTS ARCHÉOLOGIQUES}

Le matériel connu aujourd'hui comporte à la fois des jas inscrits et des jas anépigraphes. C'est cette division que nous respecterons, tout en suivant l'ordre des divinités observé pour les jas de plomb.

\section{Ancre de Zeus Meilichios}

Ce jas d'ancre (cat. V1), plus connu sous l'appellation de dédicace de Phaullos, fut trouvé fortuitement en 1934 près de Crotone, précisément sur la plage à deux kilomètres au nord du cap Cimmiti ${ }^{485}$, situé entre le cap Colonna, connu pour son sanctuaire d'Héra Lacinia, et le cap Rizzuto ${ }^{486}$. La découverte eut donc lieu entre Capo Colonna et Capo Cimmiti; mais les prospections menées tout autour de ce dernier promontoire n'ont donné aucun résultat. L'inscription, sur deux faces perpendiculaires offrant chacune deux lignes horizontales gravées dans le sens de la longueur, semble

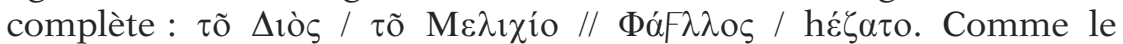
souligne G. Iacopi, le verbe précise une installation spatiale par le donateur ${ }^{487}$. Ce dernier a très vite été reconnu comme étant le célèbre athlète de Crotone dont nous parle Hérodote ${ }^{488}$ ainsi que

dont l'emplacement n'a pas été noté précisément : ils se seraient trouvés dans la même zone que le premier. Or, le contexte archéologique de celui-ci ne présente rien de religieux : l'ancre se trouvait en remploi dans un mur daté de la fin du $\mathrm{VI} /$ début $\mathrm{V}^{\mathrm{e}} \mathrm{s}$. qui appartenait aux constructions situées à l'ouest d'une stoa dite «en U» et servait de fondation à la structure qui a précédé la stoa S1 (voir Barra Bagnasco 1977, p. 21-22 et fig. 11, où l'objet est reconnu alors comme un horos). L'ensemble paraît bien hasardeux : l'existence d'une seule ancre est assurée, en remploi dans un contexte urbain ou commerçant. On comprend d'autant moins le rapprochement opéré par G. Boetto avec l'ancre d'Égine à Aphrodite (cat. V2) et sa volonté d'attribuer le(s) jas de Locri à la déesse, d'autant plus qu'à Locri sont tout aussi attestés Zeus, Athéna, Perséphone.

${ }^{485}$ L'orthographe du nom donné à ce promontoire varie d'une référence et d'une carte à l'autre. Nous n'avons pas su trancher entre la présence d'un seul ou de deux «m».

${ }^{486}$ Iacopi 1952, p. 167-176.

${ }^{487} \mathrm{Ibid}$.

${ }^{488}$ Hérodote VIII, 47. Avant la description de la bataille de Salamine, l'histo- 
Pausanias, à propos de sa visite de Delphes ${ }^{489}$. Ce personnage, par trois fois vainqueur aux jeux Pythiques, prit part en outre à la bataille de Salamine, avec un bateau équipé à ses frais, le seul venu d'Occident. D'autres sources littéraires louent encore ses prouesses physiques devenues proverbiales ${ }^{490}$. La datation de l'inscription à la fin du VI ${ }^{\mathrm{e}}$-début du $\mathrm{V}^{\mathrm{e}}$ s. a.C. est en accord avec la chronologie du personnage ${ }^{491}$.

L'objet fut d'abord identifié comme un cippe $^{492}$. Plus précisément encore, on y vit une représentation aniconique de la divinité, en relation avec son caractère chtonien, placée là comme monument isolé et individuel ${ }^{493}$. Ce n'est que quarante ans après sa découverte que la pierre, d'après sa forme et par rapprochement avec l'ancre de Gravisca (cat. V3), fut classée dans la catégorie des jas de pierre ${ }^{494}$. Et dès lors, sa signification ne fait pas l'ombre d'un doute pour P. A. Gianfrotta : «this anchor from Crotone is also dedicated to a

rien énumère tous les forces navales placées sous le commandement d'Eurybiade qui vont bientôt s'opposer aux Perses; toutes viennent de Grèce continentale ou

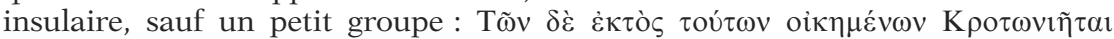

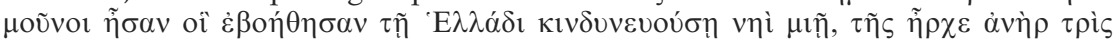

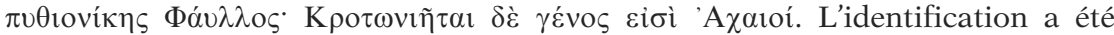
proposée pour la première fois par Dunbabin 1948, p. 85, note 3 et p. 375 , avant d'être reprise et dévelopée par G. Iacopi.

${ }^{489}$ Pausanias X, 9, 2 : le Périégète décrit les offrandes qui se trouvent les plus

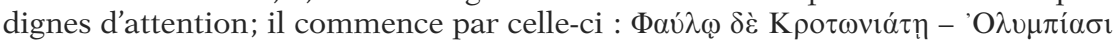

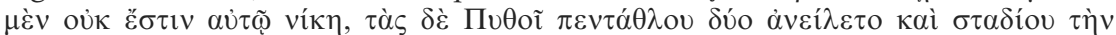

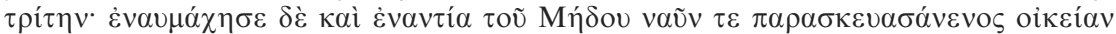

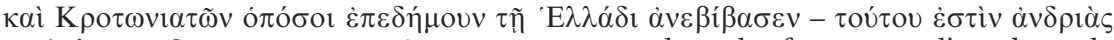

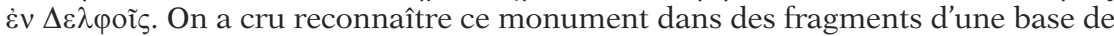
marbre portant une inscription mentionnant les Crotoniates : Homolle, in $B C H$ point XXI, p. 274; Pomtow, in Ath. Mitt. 1906, p. 446 ss; Syll. ${ }^{3}$, 30. À ce propos et pour d'autres attestations possibles, Iacopi 1952, p. 171 ss, et Gianfrotta 1975, note 25.

${ }^{490}$ Aristophane, Les guèpes, v. 1206; id., Les Acharniens, v. 215 ss et scholie;

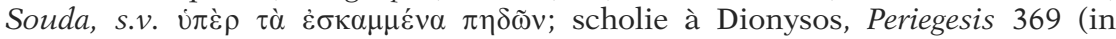
G.G.M. II, p. 445); cf. Iacopi 1952.

${ }^{491}$ Ibid., p. 168, la qualifie "di già maturo arcaismo» et la situe plutôt aux premières décennies du Ve s., tandis que M. Guarducci 1967-78, I p. 113-115 la place dans cette fourchette plus large.

${ }^{492}$ C'est sous la désignation de «stela» que la pierre est répertoriée dans $S E G$ XVII, 442.

${ }^{493}$ Iacopi 1952, qui replace cela dans la nature de la Grande Grèce «profundamente imbevuta di credenze e rituali orfici», n'exclut pas cependant totalement la possibilité d'un monument placé sur un promontoire à un dieu protecteur de la navigation. Même interprétation pour M. Guarducci 1967-78, loc. cit., qui met la pierre en relation avec la pyramide consacrée au dieu à Sicyone (Pausanias II, 9, 6).

${ }^{494}$ Gianfrotta 1975, p. 316 : «Ma anche questa volta la pietra iscritta, invece che raffigurazione aniconica della divinità, sembra piuttosto la metà di un ceppo d'àncora». La rectification est faite également dans SEG XXVIII, 1596. 
protective divinity, possibily in commemoration of perils encountered at sea by the navigator who had owned it» ${ }^{495}$.

Il est tentant dans ces conditions, et d'après les autres exemples connus, de la mettre en relation avec le sanctuaire voisin d'Héra Lacinia, divinité elle-même à connotation maritime d'après les sources antiques ${ }^{496}$. Par ailleurs, le bâtiment $\mathrm{B}$ du hiéron, évoqué précédemment à propos d'un ex-voto de bateau, a livré un cippe qui paraissait revêtu d'une valeur religieuse importante; à côté de lui se trouvaient les offrandes des plus prestigieuses de l'édifice ${ }^{497}$. Il semblerait que ce dernier - ainsi que l'horos qu'il renferme - constituent les faits archéologiques les plus anciens du sanctuaire. La technique du mur contre lequel s'adosse la pierre tend à montrer que celle-ci, antérieure à la phase de construction, fut respectée à ce moment. L'archéologue du site propose de rapprocher ce cippe de l'ancre de Phayllos retrouvé plus loin sur le rivage crotoniate et de le mettre en relation avec un culte lithique.

Cependant, il n'est pas à exclure que le dieu Zeus Meilichios ait possédé son propre téménos aux limites de l'Héraion ${ }^{498}$.

\section{Ancre d'Aphrodite à Égine}

Le jas portant le nom d'Aphrodite (cat. V2) fut trouvé au début du siècle par les Allemands fouillant à Égine, dans le secteur appelé Kolona bordant la mer. L'objet ne fut pas de suite interprété comme une ancre - mais comme une borne, un horos du sanctuaire -, et de surcroît servit de preuve pour confirmer l'hypothèse selon laquelle le temple situé près du rivage, sur une colline, serait celui d'Aphrodite, nommé par Pausanias (II, 29, 6) ${ }^{499}$. C'est à G. Welter ${ }^{500}$ que revient l'identification exacte de l'objet, ainsi qu'une relecture de l'inscrip-

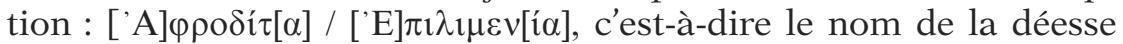
suivie de son épithète cultuelle - et non plus d'un complément de lieu comme l'avait lu Wolters ( $\dot{\varepsilon} \pi \grave{\lambda} \lambda \mu \mu \dot{\varepsilon} v)$ ). Cette lecture est unanime-

${ }^{495}$ Gianfrotta 1977, p. 288-289 et fig. 8.

${ }^{496}$ Voir supra p. 74 ss., sur Héra Lacinia.

${ }^{497}$ Spadea 1994, p. 5-6 et fig. 4; Spadea 1996, p. 37-48. L'auteur désigne la pierre autant sous le terme de horos que celui de cippe.

${ }^{498}$ Hypothèse proposée par Lazzarini 1996, p. 242-243, qui opère le rapprochement avec Sélinonte où, à proximité du sanctuaire de Déméter Malophoros, se situe un lieu consacré à Zeus Meilichios. Sur les parallèles avec Sélinonte, voir infra.

${ }^{499}$ Wolters 1925b; Wolters 1925a. Cette erreur d'interprétation fut reprise par plusieurs commentateurs, qui pensaient que l'identification de la divinité honorée était antérieure à la découverte de l'ancre.

${ }^{500}$ Welter 1938. Cf. SEG XI, 18, et XXVIII, 1596. 
ment reprise dans tous les mentions postérieures. Malheureusement, l'état de la pierre ne permet pas de trancher, ni de déterminer le cas grammatical auquel appartient le nom de la déesse : est-ce un datif, ou un nominatif - puisque l'usage de ces deux cas est attesté dans les inscriptions sur ancres -? La datation avancée, d'après les caractères épigraphiques, est la première moitié du Ve s. a.C. ${ }^{501}$.

Les recherches et fouilles postérieures menées à Égine ont déterminé qu'en réalité le temple était consacré à Apollon ${ }^{502}$. A priori, il se pourrait ainsi que l'ancre appartenait au sanctuaire du dieu, auquel cas la dédicace à Aphrodite ne se justifie plus, à moins qu'on ne se trouve devant un cas identique à celui de Sostratos d'Égine offrant une ancre à Apollon dans un sanctuaire dédié à Héra. C'est oublier l'imprécision du lieu de la découverte de l'ancre, que les deux premières publications signalent «près des ruines du temple sur la colline»; elle semble bien en outre être une découverte fortuite, et non trouvée in situ. Il paraît donc plus logique de bien la rattacher au sanctuaire d'Aphrodite indiqué par Pausanias, non localisé encore, mais en relation avec le port marchand voisin ${ }^{503}$.

G. Welter, en précisant la lecture de l'inscription, l'interprétait comme le nom du bateau auquel elle appartenait, en faisant référence à l'article de Moll ${ }^{504}$ qui pourtant, sans vouloir s'avancer outre mesure, voyait simplement dans les noms de dieux figurant sur les ancres une manifestation de la protection de la divinité. Mais cette lecture est à son tour critiquable, par rapprochements avec les autres noms connus, de façon sûre, pour les embarcations ${ }^{505}$. M. Guarducci, envisageant les deux possibilités, penche plutôt pour celle de l'invocation à la divinité protectrice, à cause notamment de l'existence du temple à proximité ${ }^{506}$. De façon générale, l'impression que l'on ressent à la lecture de toute la bibliographie de l'ancre est

${ }^{501}$ Guarducci 1967-78, III p. 362-363.

${ }_{502}$ Erreur corrigée par Welter 1962, p. 29-31, mais sans aucun commentaire sur l'objet, seulement inventorié parmi la liste des inscriptions concernant l'île; Walter 1993, n'en dit absolument rien et ne signale (p. 54) qu'en passant l'existence d'un temple d'Aphrodite près du port, sans même tenter de le localiser sur son plan (fig. 48).

${ }^{503}$ Pirenne-Delforge 1994, p. 176, a bien vu la confusion opérée entre les deux sanctuaires. Mais encore une fois, on ne peut absolument pas affirmer, comme on continue de le faire (par ex. Boetto 1997), que le jas été trouvé «dans le temple d'Aphrodite».

${ }^{504}$ Moll 1929b. La même interprétation est donnée par SEG XI, 18, avec renvoi à quelques références bibliographiques.

${ }^{505}$ Voir supra; Davaras 1980, p. 55, s'appuyant sur Svoronos 1914 et Wachsmuth 1967, p. 98 ss.

${ }^{506}$ Guarducci 1967-78, loc. cit. 
celle d'une hésitation permanente sur la nature ou la fonction même de l'objet. Seul P. A. Gianfrotta s'est d'emblée affirmé en faveur d'une ancre dédiée à terre à une divinité ${ }^{507}$. La trouvaille d'autres ancres de pierre dans la même cité de l'île permet en effet de créditer cette hypothèse. On connaît au moins un second jas à inscription (voir infra, V6) et un jas anépigraphe en trachyte ${ }^{508}$; d'autres fragments seraient repérables ${ }^{509}$.

En examinant cependant attentivement la photo de l'inscription, ainsi qu'à la lecture de la description donnée par G. Welter, un détail important se manifeste: l'inscription est gravée sur l'extrémité gauche de ce qui doit être le bras droit du jas. Or il manque au moins la première lettre des deux mots, ce qui signifie vraisemblablement que celles-ci se trouvaient dans le milieu, au creux du jas, ce qui prouverait que l'inscription a été gravée après utilisation (si utilisation de l'ancre il y a eu). En poussant la restitution plus loin, il paraîtrait absurde de vouloir commencer une inscription en un endroit de dépression de l'objet ${ }^{509}$; il faut supposer un texte plus long que le simple nom de la divinité.

\section{Autre ancre d'Égine}

L'inscription qui apparaît sur cette ancre de pierre (cat. V6) est marginale dans le corpus : elle ne porte en effet aucun nom de dieu. Seulement y figure une interdiction, formulée de façon caté-

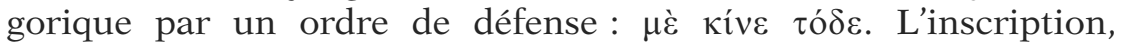
d'après les caractères épigraphiques, est datée du milieu du $\mathrm{V}^{\mathrm{e}}$ s. a.C. ${ }^{510}$ L'objet, simplement désigné dans l'inscription par un

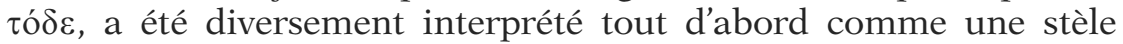
funéraire ${ }^{511}$, puis comme un contrepoids servant pour un puits ${ }^{512}$, enfin comme ancre par G. Welter, le même qui identifia le jas

${ }^{507}$ Gianfrotta 1975, p. 315; Gianfrotta 1977, note 5.

${ }^{508}$ Il est photographié et dessiné par Welter 1938, col. 489 et fig. 12-13, qui en donne les dimensions (long. 1,78 m; haut. max. 0,295 m; ép. 0,13 m), mais pas la provenance. La forme de celui-ci a permis de reconnaître les deux autres avec inscriptions comme étant réellement des jas.

${ }^{509}$ Gianfrotta 1977, p. 288 et note 5, signale plusieurs fragments de jas de pierre présentés dans le jardin du musée d'Egine. Pour le moment, il est impossible de connaître leur origine (terrestre ou maritime?) : c'est pourquoi ils ne figurent pas dans notre corpus.

${ }^{510}$ Guarducci 1967-78, III p. 363-364.

${ }^{511} I G$ IV, 176, qui émet cependant des doutes; Röhl 1907, p. 69, no 12.

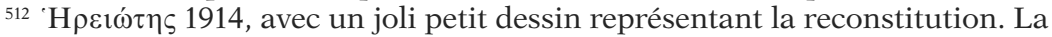
pierre a en effet, semble-t-il, été trouvée au fond d'un puits et «in der $\tau$ o $\pi$ o $\theta \varepsilon \sigma i ́ \alpha$

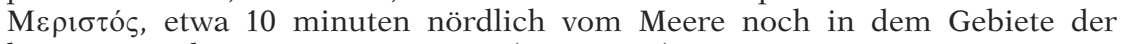
heutigen Stadt, in einem Brunnen» (IG IV, 176). 
portant l'inscription à Aphrodite trouvée dans la même ville ${ }^{513}$. On est donc passé d'une interdiction humaine, c'est-à-dire s'adressant au premier passant venu, de toucher la pierre sépulcrale ou le dispositif de levée, à une invocation de type magique destinée aux "démons de la mer», afin qu'ils ne bougent pas l'ancre posée au fond de l'eau ${ }^{514}$. L'inscription rejoint alors les décors dits "apotropaïques» - astragales, têtes de Méduse -, ayant pour fonction commune d'éloigner les mauvais fluides de cet instrument de navigation. Cette interprétation ne fait pas l'unanimité : ainsi M. Guarducci lui préfère-t-elle encore celle du contre-poids de puits, car la tournure impersonnelle de la défense ne lui paraît pas correspondre au contexte religieux invoqué ${ }^{15}$. Une vision beaucoup plus

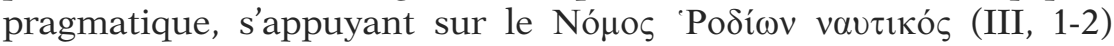
consiste à y voir seulement un avertissement aux éventuels voleurs, supposés fréquents dans les lieux maritimes ${ }^{516} \ldots$

C. B. Kritzas ${ }^{517}$ propose, à la suite de l'identification de P. A. Gianfrotta, de voir dans ce jas le $\sigma \tilde{\eta} \mu \alpha$ d'une tombe, probablement dans ce cas d'une personne liée à la navigation. Cette hypothèse, qu'il place cependant en seconde position, est étayée par les quelques références littéraires se rapportant à la pratique de signaler une tombe de marin par une rame ${ }^{518}$; or, il s'agit bien dans les textes d'un $\dot{\varepsilon} \rho \varepsilon \tau \mu o ̀ v$, et rien d'autre. Néanmoins l'hypothèse est séduisante,

${ }^{513}$ Welter 1938, col. 490-491 et fig. 14-15; sur l'ancre d'Aphrodite, voir supra.

${ }^{514}$ Entre autres Wachsmuth 1967, p. 260; Davaras 1980, p. 56-57.

${ }^{515}$ Guarducci 1967-78, loc. cit.; l'auteur en vient même à douter que l'objet soit une ancre (cf. l'expression de la dernière phrase : «pseudo-ancre»).

${ }^{516}$ Gianfrotta 1980, p. 110; Gianfrotta \& Pomey 1980, p. 303; le texte est

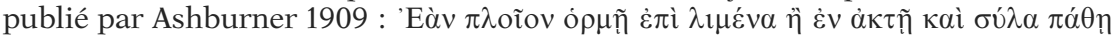

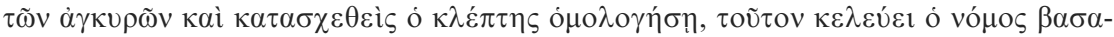

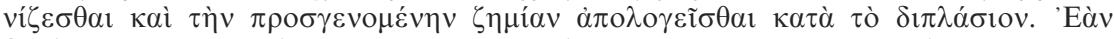

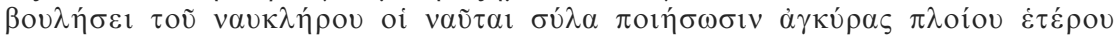

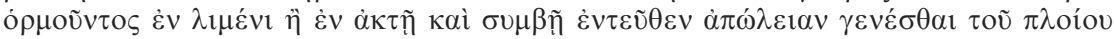

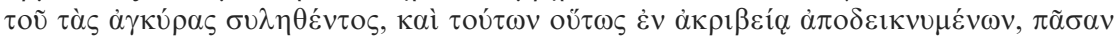

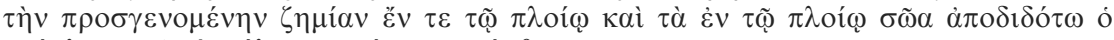

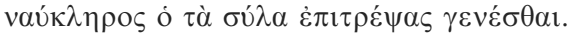

${ }^{517}$ Kritzas 1989.

${ }^{518}$ Pour les références littéraires, voir ibid. Il existe également des témoignages archéologiques connus de trouvailles d'ancres dans des tombes; voir surtout le cas bien débattu de la sépulture étrusque de Klutikuna (Valle Trebba) $\mathrm{du} \mathrm{V}^{\mathrm{e}}$ s. a.C., dans laquelle se trouvait un jas d'ancre en pierre. L'ancre y fut peutêtre déposée complète, mais le bois par la suite se décomposa : Gianfrotta 1982b; Kapitän 1986. 
surtout si l'on considère que le lieu de trouvaille correspondrait peut-être à une nécropole ancienne.

En tous cas, plusieurs de ses remarques sont parfaitement pertinentes : la position de l'inscription qui couvre tout le jas - y compris la partie centrale, normalement recouverte par la verge de bois montre bien que l'inscription a été gravée après usage, si usage il y a eu, et qu'alors l'inscription n'est pas à mettre en relation avec l'utilisation concrète de l'objet. De même, la forme neutre du pronom démonstratif ne renvoie pas aux mots désignant les ancres de cette période $^{519}$ : elle pourrait ne pas désigner l'objet en tant qu'ancre. Ces indices laissent plutôt supposer un remploi du jas pour une quelconque utilisation.

\section{Ancre de Gravisca}

a) L'objet

C'est une inscription bien connue que celle-ci (cat. V3), depuis la lecture donnée par M. Torelli dès 1970 et reprise par M. Guarducci et P. A. Gianfrotta en 1974-75 ${ }^{520}$. C'est en effet un exemple très intéressant de convergence de texte épigraphique et de source littéraire. Le premier porte simplement six mots inscrits dans le sens de la largeur de la pierre (il en manque au moins un, sans doute le patro-

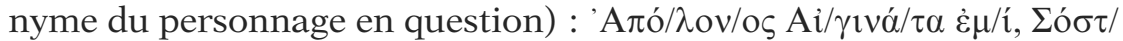
$\rho \alpha \tau$ / $/ \dot{\varepsilon} \pi \circ i_{\varepsilon} / \sigma \varepsilon h \mathrm{o}$ [...], exprimant l'acte d'offrande - la pierre, ou plutôt l'ancre en question - de la part d'un Grec appelé Sostratos à une divinité désignée comme Apollon Éginète. Les deux verbes

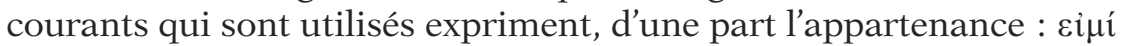
suivi du génitif, et d'autre part le don réalisé : $\pi$ oízıv. Le texte littéraire mis en relation avec l'inscription est un passage d'Hérodote $(I V, 152)^{521}$, évoquant un Sostratos fils de Laodamas d’Égine, réputé dans l'Antiquité pour son immense fortune ${ }^{522}$, gagnée semble-t-il

${ }^{519}$ Voir supra, note 260 p. 292 et p. 457, 460.

${ }^{520}$ Torelli 1970, p. 55-56 (n 36 ) et pl. XIX; Guarducci 1967-78, III p. 23-25; Gianfrotta 1975, p. 311-318. Résumé dans Colivicchi 2004, p. 141-142 et pl. 22 $\left(n^{\circ} 458\right)$.

${ }^{521}$ À signaler, l'erreur d'interprétation du texte commise par Welter 1962, p. 51, qui s'avère comprendre, par une lecture trop rapide du passage, que c'est Sostratos d'Égine qui mène la première flotte vers Tartessos, à une date qu'il situe vers 750 a.C.

${ }^{522}$ Sur le personnage et les relations possibles entre Égine et l'Étrurie à son époque, voir Harvey 1976, p. 206-214. Sostratos est également lié à Naucratis et au commerce des vases (Johnston \& Pandolfini 2000, p. 15-15 ( $\mathrm{n}^{\circ}$ 1); Colivicchi, 2004, loc. cit.). 
dans le commerce maritime avec la contrée ibérique de Tartessos. Le rapprochement est confirmé par la datation de l'inscription à la fin du VI ${ }^{\mathrm{e}} \mathrm{s}$. a.C., d'après les caractères appartenant à l'alphabet archaïque d'Égine ${ }^{523}$.

Si le sens de l'inscription apparaît bien clair à présent, il n'en est pas de même de la pierre en question. M. Guarducci l'incorpora dans son ouvrage car elle constituait à ses yeux un cas très intéressant d'offrande de "symbole aniconique» du dieu, désigné sous le

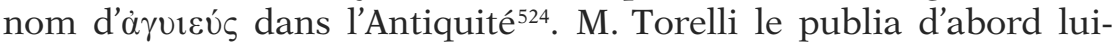
même comme un cippe, ou plutôt un bétyle d'Apollon Agyieus ${ }^{525}$. Pour P. A. Gianfrotta, il s'agit en revanche sans aucun doute d'un jas d'ancre - ex-voto qui ne serait guère surprenant de la part d'un homme ayant fait fortune sur les mers -, dont il restitue la longueur originale à environ 2,50 mètres ${ }^{526}$ et qui porterait dès lors le nom du dédicant, $i$-e. "le propriétaire du bateau auquel l'ancre appartenait ${ }^{527}$. Cette interprétation est aujourd'hui acceptée par tous $^{528}$.

b) Le contexte archéologique

La pierre a été dégagée, en 1970, lors de fouilles dirigées par M. Torelli sur le site de Gravisca, considéré un emporion de fondation phocéenne ou samienne, en relation avec la cité étrusque voisine de Tarquinia ${ }^{529}$. Elle était située précisément le long d'une voie, contre un mur, à côté de la porte d'un sanctuaire de type grec que des graffiti sur céramique trouvés à l'intérieur du bâtiment désigné ensuite à l'aide de la lettre Alpha - indiquaient alors comme voué à Héra ${ }^{530}$.

${ }^{523}$ Guarducci 1967-78, loc. cit. Le texte d'Hérodote ne nous donne aucune indication précise sur la chronologie du personnage, même s'il sous-entend que celui-ci est bien connu non seulement de lui-même mais de tous les Grecs; nous pouvons donc seulement affirmer qu'il est antérieur à Hérodote!

${ }^{524}$ Ibidem.

${ }^{525}$ Torelli 1970, repris dans SEG XXVI, 1137.

${ }^{526}$ Gianfrotta 1975 , p. 312, qui situe en outre le patronyme sur le logement central de l'ancre (comme les lettres manquantes de l'ancre d'Égine V2, faut-il supposer).

${ }^{527}$ Gianfrotta 1977, p. 286.

${ }^{528}$ Par Torelli 1977, p. 412-413 en premier lieu, qui l'évoque dès 1977 avant même la parution de l'article de P. A. Gianfrotta; la rectification est également signalée dans SEG XXVIII, 1596. L'objet est intégré parmi les offrandes recensées par Forsén 2004, p. 309, 311 (n 183 et pl. 80) et Colivicchi 2004, loc. cit.

${ }^{529}$ De Torelli 1971 à Haack 2007, la question de la fondation du sanctuaire continue de susciter de nombreuses réflexions.

${ }^{530}$ Le nombre de dédicaces à Héra s'élevait alors à trente-deux exemplaires (Torelli 1982, tableau C). 
Le bloc était placé là en remploi (fig. 43 : au-dessus du n 34 ), afin de couvrir une petite canalisation servant à l'écoulement des eaux $^{531}$. Remploi que confirmerait dès lors la cassure antique de la pierre - et l'interruption de l'inscription. Malgré cette réutilisation, l'objet est d'abord considéré comme un bétyle de protection à la porte du sanctuaire ${ }^{532}$. Jusqu'à la fin des années 1990, quelques articles ont mentionné la découverte, lors de la poursuite des fouilles, d'autres pierres identiques mais anépigraphes : au nombre

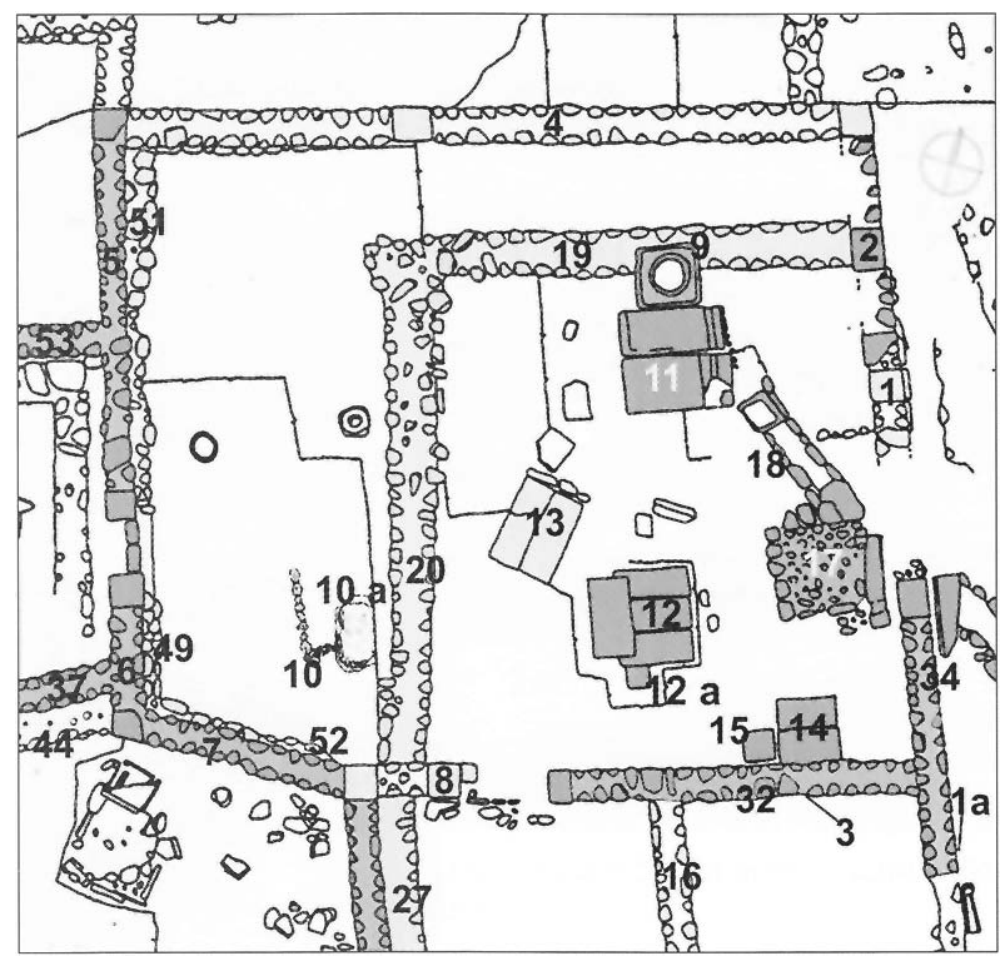

Fig. 43 - Gravisca, édifice Alpha, cour A : emplacement de l'ancre de Sostratos (cat. V3) et d'un autre jas (cat. V8) (d'après Fiorini 2005, fig. 140).

531 Torelli 1970; Torelli \& alii 1971, p. 227 et fig. 57; Torelli 1971, p. 55 ss.; Fiorini 2005, p. 119-120 avec fig. 140-142.

${ }^{532}$ Torelli 1970 - qui précise son raisonnement en 1971, en jugeant néanmoins «le lieu de découverte suffisamment éloquent» - et Guarducci 1967-78, loc. cit., qui le mettent ainsi en relation avec Apollon Agyieus et Apollon Patrôos. 
total d'une quinzaine, toutes de pierre commune à l'exception d'un exemplaire en marbre de l'Hymette (cat. V7), et toutes également trouvées en remploi dans un contexte de la seconde moitié du $\mathrm{V}^{\mathrm{e}} \mathrm{s}$. a.C. ${ }^{533}$. Une seule (cat. V8) pouvait être repérée à travers les premiers dessins publiés du sanctuaire (fig. 43 : à droite du $n^{\circ} 17$ ); elle était alors décrite comme "cippe», installé en remploi, cette fois à l'intérieur du même bâtiment dans la cour principale (cour A), du côté SE, près de la même porte à l'extérieur de laquelle fut trouvée l'ancre avec inscription. La pierre sert de délimitation à une structure carrée, considérée comme base d'offrande ${ }^{534}$.

Cependant, avec la connaissance progressive du site et de sa chronologie, la problématique est réorientée dans un sens différent. Le sanctuaire, comportant dans son développement maximum cinq bâtiments distincts (désignés Alpha-Epsilon : fig. 44), a livré du matériel témoignant de cultes rendus à Héra, Aphrodite, Déméter, Apollon et Adonis ${ }^{535}$.

Ce n'est plus Héra, mais Aphrodite qui s'avère être la divinité principale honorée dans le sanctuaire dès le $\mathrm{VI}^{\mathrm{e}} \mathrm{s}$. et au moins pendant deux siècles, ce qu'attesteraient deux statuettes archaïques représentant la déesse armée ${ }^{536}$. Les ancres sont alors assimilées aux ex-voto offerts à cette dernière, pour laquelle on rappelle ses

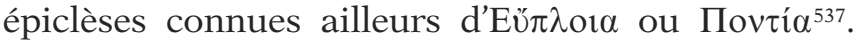

La publication des fouilles, dont un certain nombre de volumes sont aujourd'hui parus, établissent un nombre total de 11 jas, dont 10 anépigraphes (cat. V7-V16). Aucun, sauf deux, ne paraît avoir été trouvé in situ : l'un, on l'a vu, en remploi dans la cour C de l'édifice Alpha; cinq dans la rue N/S qui a été établie lors de la phase IV de

${ }^{533}$ Gianfrotta 1975, p. 312-313; Gianfrotta 1977, p. 287-288 et fig. 5-6, qui ajoute que «the fact that they were re-used is no indication that stone stocks were becomming obsolete; it may rather be connected with the vicissitudes suffered by the sanctuary itself». D'accord pour l'usage commun de l'ancre de pierre, mais la pratique rituelle semble quant à elle disparaître à Gravisca même.

${ }^{534}$ Torelli \& alii 1971, p. 230 et fig. 41, 45; Torelli 1971, p. 48; dans les deux articles, l'objet est visible sur le plan d'ensemble. Il est publié comme ancre dans Colivicchi 2004, p. 141 et pl. 23 ( $\mathrm{n}^{\circ}$ 460); Fiorini 2005, p. 121 et fig. 145.

${ }^{535} \mathrm{Ou}$ encore dans le guide Laterza de l'Étrurie du même auteur : Etruria, Roma-Bari, $1982^{2}$, p. 157-162.

${ }^{536}$ Torelli 1977; Torelli 1986, p. 46-53; Fiorini 2005, p. 23-28, 181-187. C'est principalement la raison pour laquelle on restitue une première implantation, ou plutôt «ouverture» de l'emporion par des Phocéens, implantant un culte d'Aphrodite présentant des caractères phéniciens; les Phocéens auraient été ensuite très rapidement supplantés par les Samiens, qui auraient alors introduit le culte d'Héra.

${ }^{537}$ Torelli 1977, p. 427-435. Ce rapprochement est en fait le seul argument de l'auteur pour justifier sa préférence pour la déesse; lui-même reconnaît finalement la fragilité de son hypothèse, en évoquant Héra et Apollon. 


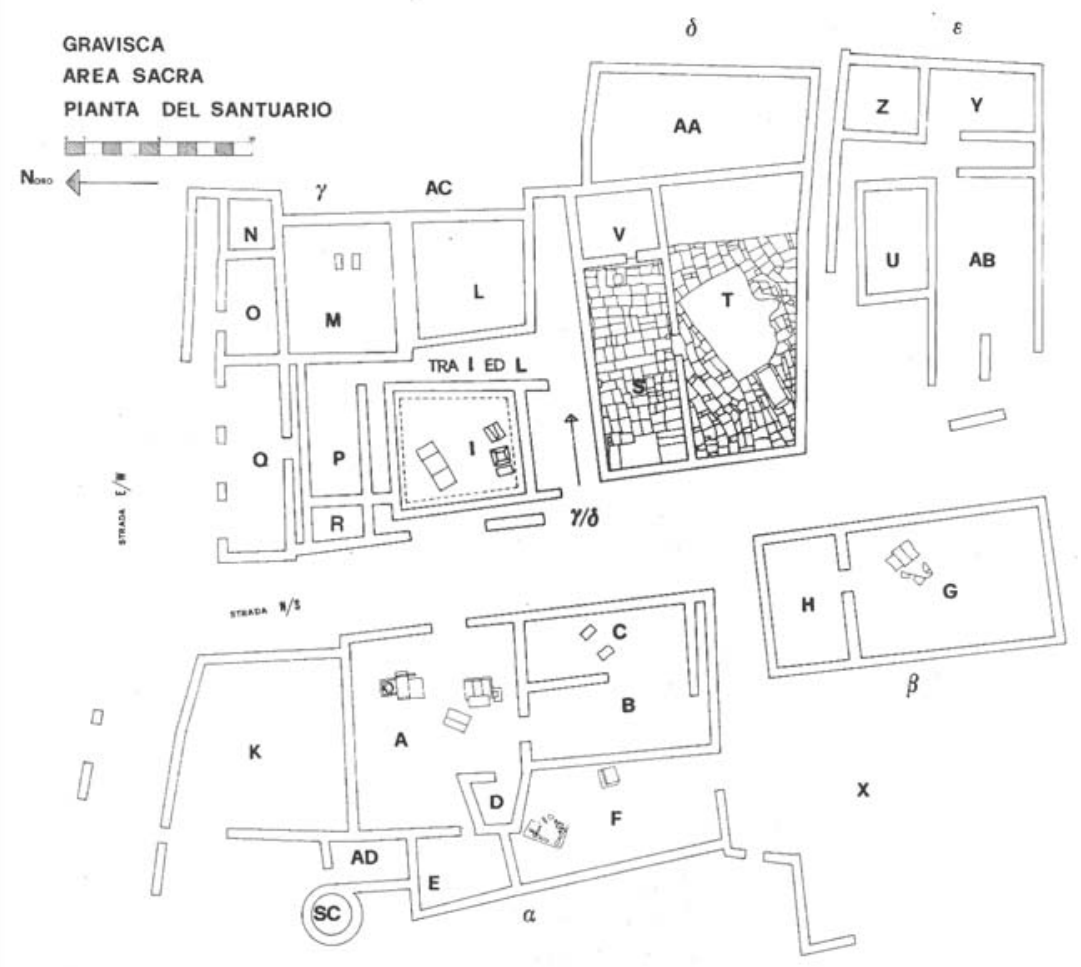

Fig. 44 - Sanctuaire de Gravisca : édifices Alpha-Epsilon de part et d'autre de la rue N/S (d'après Colivicchi 2004, p. 6).

construction du sanctuaire (à partir de 480 a.C.); deux entre les édifices Alpha et Bêta; deux dans la cour I de l'édifice Gamma ${ }^{538}$. Deux exemplaires de la rue étaient, selon les fouilleurs «encore plantés dans le sol, l'un entier (...) l'autre cassé, placés pour signaler les limites de la propriété privée et publique et en rapport direct avec

${ }^{538}$ Colivicchi 2004, p. 141-144 et pl. 22-23 : no 458 (Sostratos); $\mathrm{n}^{\circ} 461,463$, 465 et 466 (voie N/S); no 462 et 468 (entre Alpha et Bêta); no 464 et 467 (I); no 459 (prov. inc.). Aménagement de la voie N/S : Fiorini 2005, p. 173-178, 188-189. Dans 
un égout situé derrière», et ce au niveau "de l'angle sud-est de la première phase de l'édifice» ${ }^{539}$. Là encore, la topographie générale du sanctuaire laisse supposer qu'ils étaient en remploi. Celui-ci, en effet, ne compte pas moins de six phases de construction entre 580 a.C. et la fin du $\mathrm{IV}^{\mathrm{e}}$ s. a.C.; son sol a sans cesse été modifié et les ex-voto déposés dans des fosses creusées à diverses étapes de l'histoire du site. Il est donc impossible d'attribuer ces ancres à un secteur précis ou à un ensemble cohérent d'ex-voto réuni à un moment donné et/ou voué à une divinité en particulier. Par ailleurs, aucune ne porte la mention d'Aphrodite ni d'Héra, et le matériel trouvé à Gravisca qui peut être mis en liaison avec Aphrodite définirait plutôt un culte de type féminin (vases pour la toilette, représentations d'organes féminins) ou pour la phase la plus ancienne en relation avec la métallurgie : en aucun cas lié à la mer ou à la navigation ${ }^{540}$. Si l'on s'en tient aux dédicaces sur céramique datées entre circa 550 et 475 a.C. - donc contemporaines de l'ancre de Sostratos -, quarante-quatre sont dédiées à Héra et proviennent majoritairement de l'édifice Alpha, tandis que six inscriptions renvoient Aphrodite, dont quatre provenant du secteur de l'édifice Gamma ${ }^{541}$. Le rapprochement avec ces inscriptions n'apporte donc pas d'élément nouveau pour déterminer à laquelle des deux déesses ces ancres pourraient éventuellement avoir été consacrées ${ }^{542}$.

Le problème que pourrait poser une dédicace au dieu d'une cité vouée dans le sanctuaire très éloigné d'une autre divinité ${ }^{543}$ a encore été contourné par une nouvelle hypothèse : celle de l'existence d'un

ces monographies, rien ne précise à quels niveaux ou faits archéologiques de ces zones du sanctuaire sont apparus les jas anépigraphes.

${ }^{539}$ Torelli \& alii 1971, p. 227-228 et fig. 42. Le jas entier correspond à Colivicchi 2004, p. 143 , no 463 et apparaît sur la photo fig. 160 de Fiorini 2005. En revanche, le jas brisé ne semble pas figurer sur les clichés; par recoupements, nous pensons qu'il s'agit du $\mathrm{n}^{\circ} 461$ de Colivicchi 2004. L'angle S.E. correspond aux murs 28-29/26 de l'oikos B (Fiorini 2005, p. 126).

${ }^{540}$ Fiorini 2005, p. 183-186. La prostitution sacrée est bien sûr également envisagée.

${ }_{541}$ Johnston \& Pandolfini 2000, p. 19 et 23-24 ( $n^{\circ}$ 47-52).

${ }^{542}$ Notons qu'un ex-voto céramique de Naucratis (autre colonie samnienne) d'un Sostratos qui pourrait être un ascendant du Sostratos de Gravisca, est dédié à Aphrodite. Bernand 1970, II p. 676 n 355 (graffito); Johnston \& Pandolfini 2004, p. 16 (liens entre les Sostratos). Pour sa part, Haack 2007 conteste la primauté du culte d'Aphrodite à Gravisca, en soulignant la faiblesse des arguments épigraphiques et des attributions de matériel à telle ou telle divinité.

${ }^{543}$ Alroth 1989 aborde ce problème au travers de l'offrande de figurines de terre cuite représentant une divinité dans les sanctuaires d'une autre. Mais le cadre de son sujet ne permet pas de rapprochement particulier avec les offrandes d'ancres de Grande Grèce. 
culte d'Apollon à Gravisca ${ }^{544}$. Le site paraissant avoir livré deux autres dédicaces grecques à Apollon sous la forme de graffiti sur des vases, dont une provenant de la pièce $\mathrm{E}$ de l'édifice Alpha située au nord-ouest, on restitue un culte d'Apollon à cet emplacement : deux murs perpendiculaires plus anciens, visibles dans cette salle, correspondraient à un bâtiment rectangulaire élevé en l'honneur du dieu lors de la phase IV de construction du sanctuaire (vers 480 a.C. ${ }^{545}$. Force est de reconnaître que la proposition reste très conjoncturelle. La dédicace, tout d'abord, est incomplète : elle ne donne, sur un vase daté de 520-510, que le nom du dédicant, Eǔ $\alpha \chi 0 \varsigma$, avec des caractères éginètes. Seul un graffito en caractères ioniens qui provient de l'est de l'édifice Delta - i. e. de l'autre côté du sanctuaire -, donne le nom d'Apollon ${ }^{546}$. Si l'on prend en compte également que les jas ont été disséminés sur une bonne partie du site, rien ne permet en vérité de reconstituer un lieu de culte spécifique à Apollon, de surcroît dans cette partie nord-ouest du sanctuaire.

Le problème de l'attribution de ces ancres reste donc entier. La dédicace d'Euarchos montre que le cas de Sostratos n'est pas isolé et que d'autres Éginètes fréquentaient, à la même époque que lui, le sanctuaire de l'emporion.

Le matériau des jas provient de zones géographiques distinctes. Sur les 11 exemplaires, deux sont en marbre : le premier, celui de Sostratos (cat. V3), en marbre de l'Égée, sans doute naxien ${ }^{547}$, et le second de l'Hymette (cat. V7). Les neuf autres ont, semble-t-il, été réalisés en pierre locale, ce qui laisse supposer des offrandes de marins d'origine tyrrhénienne ${ }^{548}$. La pratique cultuelle du don d'ancre à Gravisca, que ce soit dans un lieu consacré à Apollon, à Aphrodite ou Héra, est ici réalisée par des fidèles de divers horizons afin de rendre grâces sans doute d'une bonne traversée et de transactions commerciales réussies.

À la même période, est offert dans le sanctuaire, vraisemblablement à Héra, un autre type d'objet naval, d'origine sarde : une lampe de bronze en forme de bateau (voir supra p. 376). Il n'est pas inutile

${ }^{544}$ Dès 1971, M. Torelli avait soulevé cette question, en envisageant - pour le récuser aussitôt - l'éventualité d'un culte du dieu plus ancien ou coexistant à celui d'Héra (Torelli 1971, p. 58-59).

${ }^{545}$ Inscriptions : Johnston \& Pandolfini 2000, p. 19 (nº 53-54). Hypothèse : Fiorini 2005, p. 137, 190.

${ }_{546}$ Torelli 1977, p. 405-406; Johnston \& Pandolfini 2000, p. 19 (n 53-54).

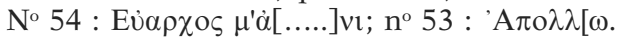

${ }^{547}$ Gianfrotta 1975, p. 311-312, se rapportant aux analyses de J. B. Ward Perkins. Des jas d'ancre de marbre étaient usés dans la navigation antique, comme l'attestent des exemplaires trouvés en mer (ibid., p. 313-314), ce qui laisse ouverte la possibilité d'une fabrication spéciale en vue d'un ex-voto.

${ }^{548}$ Colivicchi 2004, p. 141. 
de rappeler à cet égard le texte d'Hérodote (IV, 152) où il est fait mention de Sostratos. L'historien raconte que sur le gain obtenu par les Samiens grâce à la découverte de Tartessos, ceux-ci en offrirent le dixième à l'Héraion - de Samos, il va de soi $^{549}$. De même que ces navigateurs consacrèrent leur don à la grande divinité de leur cité, en l'occurrence Héra, ainsi Sostratos invoque-t-il Apollon Éginète, le dieu de sa cité d'origine. Il n'est pas à exclure non plus qu'il le fasse dans un sanctuaire d'Héra, qui pourrait être associée dans l'esprit des contemporains avec Tartessos ou les voyages entrepris vers cette destination.

\section{Ancres de Métaponte}

Le site de Métaponte (fig. 45) est un des exemples les plus curieux et complexes que nous ayons à traiter.

C'est à son archéologue, D. Adamesteanu, que revient la formulation de l'hypothèse qui est pour beaucoup dans l'élaboration de notre travail sur les ancres ${ }^{550}$. Ses fouilles de l'«area sacra» ont en effet livré, dès les années 60 , un grand nombre de pierres - dont certains exemplaires apparaissent être des jas -, qu'il met en relation directe avec les argoi lithoi de Pausanias. De nombreux articles ont été publiés sur ce site et sur les découvertes archéologiques successives, à tel point qu'aujourd'hui il est difficile de s'y retrouver d'une étude à l'autre et surtout d'identifier précisément le matériel dont il est question. Pour cette raison, il convient de considérer l'ensemble du dossier métapontin pour resituer les ancres dans leur contexte.

\section{a) Historique des trouvailles}

Un premier fragment irrégulier de bloc de pierre fut dégagé dès le XIX ${ }^{\mathrm{e}}$ siècle, à l'extérieur du côté nord du temple désigné plus tard sous l'appellation de temple $\mathrm{A}^{551}$. Il présente une dédicace de Théagès fils de Byrros ${ }^{552}$ à Apollon Lyk(eios), sous la forme ei $\mu 1+$

${ }^{549}$ À leur tête, un certain Kolaios : Vélissaropoulos 1980, p. 27ss.; Bürchner, «S.v. Samos», in RE XXIV, Stuttgart, 1920, col. 2203.

${ }^{550}$ Hypothèse qu'il a soutenue jusqu'à ses vieux jours. J'ai une pensée émue pour D. Adamesteanu, rencontré durant l'été 1994 en Italie du sud, dont l'extrême gentillesse s'est manifestée non seulement par ses réponses à mes questions, mais aussi par mon accès aux réserves du site et à ses archives de fouilles.

${ }_{551}$ Manni Piraino 1968, p. 419-457, no 6. 1962.

${ }^{552}$ L'origine messapienne ou illyrienne du dédicant a été discutée par Ferri 


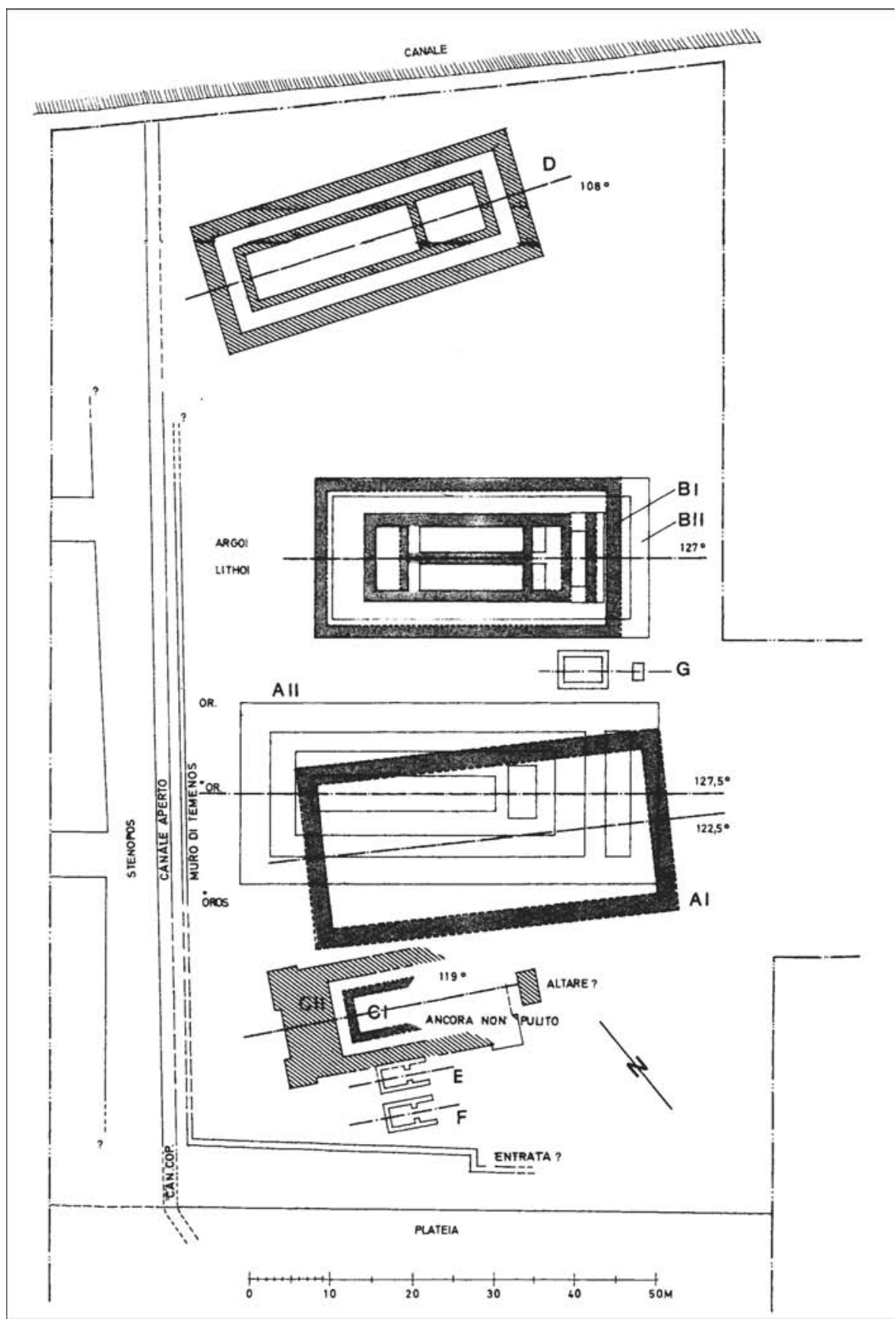

Fig. 45 - Métaponte, plan des temples A-D, avec indications de leurs diverses phases de construction (d'après De Juliis 2001, fig. 28). 
nom du dieu au génitif. Cette inscription archaïque ${ }^{553}$, aujourd'hui conservée au musée de Potenza, fit attribuer le temple métapontin à Apollon Lykeios et laissa supposer l'existence d'un culte aniconique ${ }^{554}$.

La zone fouillée durant plusieurs campagnes successives se révéla d'une grande complexité. Aujourd'hui, y sont visibles au moins trois temples, disposés plus ou moins parallèlement, appelés A, B, et C ${ }^{555}$. En 1969, parmi les informations archéologiques d'un colloque $^{556}$, D. Adamesteanu publie pour la première fois, dans le secteur du temple A identifié comme étant celui d'Apollon ${ }^{557}$, la découverte du temple $\mathrm{B}$, daté des années $500-480^{558}$ et attribué à Héra $^{559}$ d'après les terres cuites architectoniques retrouvées sur place. Lors de la poursuite des fouilles furent dégagées d'une part, sur le côté nord du temple $\mathrm{A}^{560}$ - autrement dit donc entre les deux

${ }^{553} I G$ XIV, 647, cf. Jeffery 1990, 255 et 260, no 14 et Giacometti 2005, p. 28-29. Dédicace en partie boustrophédon, datée de 550-525 (?) pour Jeffery, jugée «trop basse» par Manni Piraino 1968, qui opte pour la fin du VII / tout début VI ${ }^{\mathrm{e}}$ S., ou encore de la première moitié du VI ${ }^{\mathrm{e}}$ s. pour Burzachechi 1979, p. 279-295.

${ }^{554}$ Cette hypothèse fut formulée en premier lieu par Jeffery 1990, loc. cit. Seul Ferri 1962 a proposé de reconnaître le bloc comme étant la cuisse d'un Sphinx. Cette hypothèse est acceptée comme plausible par Adamesteanu \& alii 1980, p. 120 note 264 .

${ }^{555}$ Une très belle photo aérienne du site est publiée dans Megale Hellas, Milan, 1986, fig. 268. Sur le site de Métaponte et sa chora, l'implantation de ses sanctuaires, voir l'article de synthèse de J. Coleman Carter, "Sanctuaries in the Chora of Metaponto", Placing the Gods. Sanctuaries and sacred space in Ancient Greece, Oxford, 1996, p. 161-198.

${ }^{556}$ Adamesteanu 1969.

${ }^{557}$ Signalé par Hérodote IV, 15 et Plutarque, De l'oracle de la Pythie, 8, le temple a été reconnu dès le milieu du XIX $^{\mathrm{e}} \mathrm{s}$. et fut fouillé surtout par P. C. Sestieri dans les années 30, qui a alors confirmé son attribution à Apollon. D. Adamesteanu a ensuite repris les fouilles à partir de 1965. Un autre bilan des premières recherches sur le site est également proposé par Adamesteanu 1976 et Adamesteanu \& alii 1980, p. 17 ss. L'attribution au dieu ne fut que renforcée par les découvertes postérieures : Adamesteanu 1974, p. 20 ss.

${ }^{558}$ Adamesteanu 1970, p. 307-324, précisément p. 321-323. Il est à noter que tout ce secteur a énormément souffert des vagues de récupérations de blocs durant la fin du $\mathrm{XIX}^{\mathrm{e}}$ s. et le début du $\mathrm{XX}^{\mathrm{e}}$ s., qui ont parfois perturbé la stratigraphie et détruit ou mélangé des vestiges en place.

${ }^{559}$ Adamesteanu 1976, p. 162; Adamesteanu \& alii 1980, p. 117 et 128 ss. Ne pas tenir compte de l'hypothèse fantaisiste de Manni Piraino 1968 qui voyait le temple $\mathrm{B}$ consacré à Apollon et le $\mathrm{A}$ aux Muses.

${ }^{560}$ Par commodité, comme dans les différents articles de D. Adamesteanu, le temple $\mathrm{A}$ désigne l'état $\mathrm{A} 2$, c'est-à-dire la seconde phase du temple datée des années 530-520, avec un édifice plus grand et d'une orientation différente de celle de la première phase, appelée A1, dont on a retrouvé en négatif les fondations. L'implantation urbaine de Métaponte est orientée dans le même sens que 
structures A et B -, outre des fragments de blocs et de terres cuites, des "pierres grossières en partie semblables» ${ }^{561}$ à celle portant la dédicace à Apollon Lykeios $^{562}$, mais anépigraphes. Et d'autre part, durant le nettoyage de l'espace entre la cella et la peristasis méridionales du temple $\mathrm{B}^{563}$, est apparue toute une série de pierres - travaillées ou non - intercalées d'argile, disposées avec soin de manière horizontale, et présentant pour certaines des inscriptions archaïques (fig. 46). «La plus grande partie de ces pierres était informe et rappelait de près l'exemplaire conservé au musée de Potenza ou ceux retrouvés épars entre le temple d'Apollon et le temple $\mathrm{B} »{ }^{564}$.

Ces $157^{565}$ pierres sont immédiatement interprétées comme une

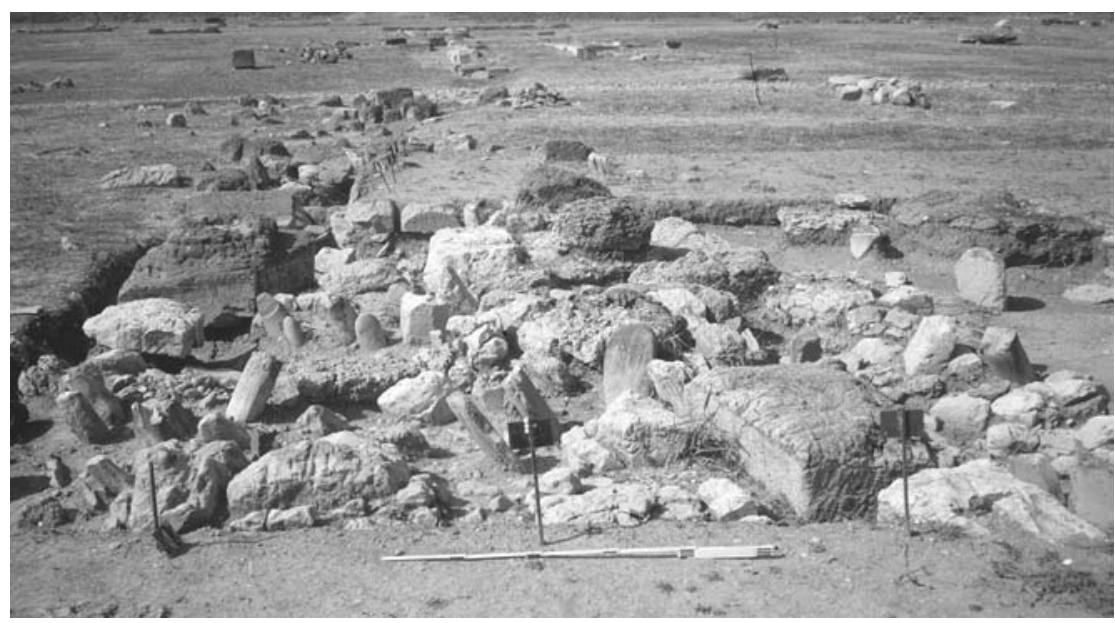

Fig. 46 - Métaponte : «champ de pierres» à l'est du temple B (Photo de l'auteur).

les temples $\mathrm{A} 2$ et $\mathrm{B}$; on la date alors entre le deuxième et le troisième quart du $\mathrm{VI}^{\mathrm{e}}$ s. a.C. : Adamesteanu 1976, p. 164.

${ }^{561}$ Adamesteanu 1969, p. 169.

562 Il est envisageable d'ailleurs, à la relecture de la description de la trouvaille de la pierre avec inscription à Apollon Lykeios, que celle-ci provienne de ce même groupe de blocs situé entre les temples A et B : Adamesteanu \& alii 1980, p. 115 et $119-120$.

${ }^{563}$ Adamesteanu \& alii 1980, p. 117 et note 257. La description n'est pas toujours très claire : "entre les deux peristasis méridionales» (Adamesteanu 1976 par ex.) résume de façon beaucoup plus ambiguë la situation.

${ }_{564}$ Adamesteanu 1969, p. 172.

${ }^{565}$ Adamesteanu 1976, et dans Adamesteanu \& alii 1980, p. 116. Le nombre 
"stipe votiva», "un dépôt sacré» de "favissa» ${ }^{566}$, d'autant plus que l'une d'entre elles, plantée in situ dans le sol, semble garder le témoignage de la position originelle des autres. La poursuite des fouilles à l'ouest du temple B, sous la couche de destruction de ses fondations, met au jour un autre "champ de cippes et pierres grossières» - «en partie encore pris dans la terre, en partie tombés»-, les secondes étant enfoncées plus profondément que les premières, et ce dans la terre vierge ${ }^{567}$. Le rapprochement est alors proposé 568 entre cette découverte archéologique inédite et la description du sanctuaire

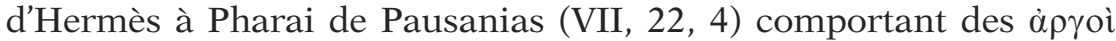
$\lambda i \theta o$. Le Périégète les avait alors compris comme des témoignages anciens d'adoration envers la divinité, ce que reprend D. Adamesteanu considérant dès lors l'usage des cippes et stèles, à son avis correspondant aux tétragônoi lithoi de Pausanias ${ }^{569}$, cultuellement postérieurs ${ }^{570}$. Le contenu de la favissa du temple B et l'ensemble du "campo di pietre rozze» - qu'on retrouve encore au sud du temple $\mathrm{A}^{571}$-, sont rattachés à un même sanctuaire, celui d'Apollon, le plus grand et le plus important de la colonie, daté au plus tôt du milieu du VII ${ }^{e}$ s. a.C. et abandonné apparemment à la fin du $\mathrm{IV}^{\mathrm{e}} \mathrm{s}$. av. a.C. ${ }^{572}$. Si certaines pierres ont été déplacées du contexte du téménos d'Apollon, c'est lors de constructions nouvelles et réaménagements de la zone réalisés durant le Ve $\mathbf{s}{ }^{573}$. Quelques unes de ces pierres travaillées sont rapprochées l'année suivante d'autres connues à Crotone ${ }^{574}$ et Sélinonte, et l'identification comme ancres

est ramené à 152 dans l'article de 1970 (Adamesteanu 1970) ou à 147 (Adamesteanu 1974).

${ }^{566}$ Adamesteanu \& alii 1980, p. 117, qui précise que le dépôt s'est opéré en une seule fois après le milieu du VI ${ }^{\mathrm{e}} \mathrm{s}$. a.C.

${ }^{567}$ Adamesteanu 1970, p. 313-314; Adamesteanu \& alii 1980, p. 126 ss, fig. 126,128 et 132 .

568 Jeffery 1990, loc. cit., avait dès 1961, avait déjà opéré ce rapprochement pour l'inscription à Apollon de Théagès.

${ }^{569}$ Adamesteanu 1969, p. 173; Adamesteanu 1970, p. 316; Adamesteanu 1976, p. 157-158. Dans Adamesteanu \& alii 1980, p. 121, l'hypothèse est clairement confirmée de la pré-existence des argoi lithoi par rapport à une structure bâtie en l'honneur du dieu, délimitant ainsi l'area sacrée.

${ }^{570}$ Pour Métaponte, G. Pugliese Carratelli (Convegno sulla Magna Grecia 1973, p. 65-66) pense avoir trouvé un témoignage littéraire de ces argoi lithoi dans les Histoires philippiques de Trogue Pompée - ou plus exactement dans le résumé qu'en a donné Justin - (Epitoma historiarum philippicarum Pompei Trogi $\mathrm{XX}, 2)$, qui indique pour la cité des lapidea simulacra.

${ }_{571}$ Adamesteanu 1969, p. 176.

${ }^{572}$ Ibid., p. 321.

${ }^{573}$ Adamesteanu 1969, p. 127-128. Il est alors réducteur d'évoquer la présence dans un sanctuaire consacré à Héra d'une dédicace à Apollon (Gianfrotta 1977, p. 286).

${ }^{574}$ En fait celle avec l'inscription de Phayllos à Zeus Meilichios (cat. V1). 
est prudemment avancée. Parmi le second dépôt, outre donc des pierres informes, des pierres légèrement travaillées en forme de "statue de type dédalique ${ }^{575}$ ", des cippes et des stèles, il existe un autre groupe comprenant cinq jas de pierre, plus précisément trois de marbre et deux d'une pierre locale proche du marbre ${ }^{576}$. Quant au troisième dépôt, la poursuite de la fouille le met en évidence sur une plus grande étendue et confirme la présence de pierres grossières, portant des traces d'inscriptions plus anciennes que les cippes pyramidaux, d'ailleurs répartis sur un niveau supérieur ${ }^{577}$. Le matériel archéologique trouvé dans ces couches, depuis la base des pierres non travaillées jusqu'aux niveaux supérieurs, est bien daté entre la seconde moitié du VII ${ }^{\mathrm{e}} \mathrm{s}$. jusqu'à la fin du IVe s. a.C. ${ }^{578}$.

La totalité de ces dépôts de pierres (plus de 200) est répartie sur une aire très vaste, et ce tant autour du temple A que du temple $\mathrm{B}^{579}$. D. Adamesteanu note justement à cette occasion que, dans la description de Pausanias, les argoi lithoi sont disposés autour de la statue, mais aussi dans un nombre plus limité : une trentaine.

Un troisième temple, dénommé $C$, est dégagé au sud-ouest du temple A : plus petit, plus ancien (vers la fin du VII ${ }^{\mathrm{e}}$ s. /début VIe ${ }^{\mathrm{e}}$ ) et agrandi au début du V ${ }^{\text {e }}$ s. a.C., d'une orientation différente des deux autres - proche de celle du premier état du temple $\mathrm{A}-$, dans un contexte archéologique incertain, son attribution reste à définir. Deux inscriptions du premier quart du $\mathrm{V}^{\mathrm{e}} \mathrm{s}$. mentionnant Athéna trouvées à l'intérieur et au sud de ce bâtiment peuvent faire penser à un Athénaion ${ }^{580}$. L'attribution à Aphrodite peut être également défendue, sur la base de deux inscriptions retrouvées également dans le temple ${ }^{581}$. Sur le côté occidental de l'area du temple C, un nouvel ensemble d'argoi lithoi est dégagé, sur lequel fut élevée en

${ }^{575}$ Des statuettes de ce type ont par ailleurs été retrouvées dans le sanctuaire : Adamesteanu 1969, p. 48 ss., fig. 31-33.

${ }^{576}$ Adamesteanu 1970, p. 312 , après une première communication rapide dans Adamesteanu 1969 (repris par Gianfrotta 1975). Mais dans son article de 1974 , p. 28, il est question uniquement de deux ancres, dont une en marbre; même chose dans Adamesteanu \& alii 1980, p. 116 ss., fig. 119 et 121f. Le fouilleur date leur installation définitive à cet endroit au Ve s. (1974, p. 31) : pourquoi?

${ }^{577}$ Adamesteanu 1970, p. 314 : jusqu'à $10 \mathrm{~m}$ du temple à l'ouest, ainsi que du côté sud-ouest.

${ }^{578}$ Adamesteanu \& alii 1980, p. 127.

${ }^{579}$ Adamesteanu 1970, p. 316.

${ }^{580}$ Adamesteanu 1974, p. 34-36; Adamesteanu 1976, p. 161-163; De Juliis 2001, p. 142-144.

${ }^{581}$ Burzachechi 1979, p. 279-280. Dans la note 4 de l'article, l'auteur propose aussi que le temple ait été dédié aux deux divinités; il faudrait examiner la datation et le support du matériel concerné pour déjà déterminer s'il est contemporain. 
partie une maison au $\mathrm{IV}^{\mathrm{e}} / \mathrm{III}^{\mathrm{e}}$ s. a.C. ${ }^{582}$. Une quatrième structure, appelée $\mathrm{D}$, identifiée comme un temple ionique mais dont la divinité reste inconnue (Artémis?), vient s'ajouter aux précédents, au nord du temple $\mathrm{B}^{583}$.

Un groupe de terres cuites architectoniques très fragmentaires, représentant deux cavaliers d'assez grande taille identifiés comme Dioscures, sont rattachés à l'ornementation du temple $\mathrm{B}^{584}$. Dionysos et Artémis-Bentis sont les autres divinités attestées parmi les éléments décoratifs (statuettes ou fragments architectoniques) du sanctuaire retrouvées sur différentes zones des fouilles ${ }^{585}$, ainsi qu'Aphrodite dont des graffites sur fonds de kylix attiques donnent le nom ${ }^{586}$. Les deux déesses semblent à mettre en relation avec deux petits sacella, désignés $\mathrm{E}$ et $\mathrm{F}$, situés au sud du temple $\mathrm{C}^{587}$. Toutes ces structures sont délimitées, au sud, au nord et à l'ouest, par des murs de téménos ou de fortification; à l'est en revanche aucune trace n'apparaît, laissant peut-être le sanctuaire s'étendre jusqu'à la zone du théâtre ${ }^{588}$. Enfin, quelques argoi lithoi sont encore apparus çà et là au cours du nettoyage des différents édifices, cette fois en remploi dans des fondations ou élévations de murs ${ }^{589}$ et des dépôts votifs ${ }^{590}$.

\section{b) Attribution des pierres}

Étant donné que seul le nom d'Apollon est cité dans les inscriptions lisibles de ces argoi lithoi, et que ceux trouvés entre les péristasis méridionales du temple $\mathrm{B}$ ou à l'ouest de celui-ci ont été déplacés dans l'Antiquité, sans doute au moment de la construction de ce bâtiment, la conclusion logique amène à penser que, même si ces pierres se trouvent dans le secteur du temple considéré comme consacré à Héra, elles appartenaient et étaient dédiées au sanctuaire d'Apollon ${ }^{591}$. Ces éléments, ainsi que la découverte de statuettes

${ }^{582}$ Adamesteanu \& alii 1980, p. 171.

${ }^{583}$ De Juliis 2001, p. $142-143$ et 148-151, avec bibliographie.

${ }^{584}$ Adamesteanu 1974, p. 32-34; Adamesteanu 1976, p. 158-159; Adamesteanu \& alii 1980 , p. 160-164.

${ }_{585}$ Adamesteanu 1974, p. 40; Adamesteanu 1976, p. 158 et Adamesteanu \& alii 1980 , p. 93 ss, 144 ss, 200 ss, 273 ss.

${ }_{586}$ Adamesteanu 1976, p. 162.

${ }^{587} \mathrm{Ibid}$.

${ }_{588}$ Adamesteanu 1976, p. 163-164.

${ }^{589}$ Un exemplaire, avec trace d'une inscription sur deux lignes, dans l'assise inférieure du soubassement du temple C : Adamesteanu \& alii 1980, p. 167; un autre avec une inscription $\Lambda$ YKOM réutilisé dans la fortification nord de l'area urbaine : ibid., p. 246.

${ }^{590}$ Ibid., p. 238-239, fig. 256.

${ }^{591}$ Adamesteanu 1970, p. 321-324; Adamesteanu \& alii 1980, p. 117-118 et 127-128. 
féminines auprès de l'autel du temple $\mathrm{A}$, ont induit finalement les archéologues à réattribuer le temple $\mathrm{B}$, non plus à Héra, mais à Apollon $^{592}$. Le dépôt retrouvé dans l'area du temple B s'est fait en une seule fois, avec grand soin par l'utilisation de couches d'argile séparant les pierres les unes des autres, après le milieu du VI ${ }^{\mathrm{e}} \mathrm{s}$. et avant le milieu du V ${ }^{e}$ s. a.C. ${ }^{593}$ De fait, la majorité des pierres est localisée à l'ouest de l'area sacra, sur un vaste téménos destiné à les accueillir, dans un laps de temps étendu sur deux siècles. La restructuration du sanctuaire au $\mathrm{V}^{\mathrm{e}} \mathrm{s}$. a conduit à y rassembler en dernier lieu des pierres auparavant disposées ailleurs, ce dont témoigne également la présence autour des «nouveaux» temples des pierres anciennes qui ne gênaient pas les nouvelles constructions ${ }^{594}$. Le dieu est le plus souvent appelé sous l'épithète de Lykeios $^{595}$ : à celle déjà connue se sont ajoutées d'autres mentions, au nombre de huit, datées depuis la première moitié du VI ${ }^{\mathrm{e}} \mathrm{s}$. a.C. jusque la seconde moitié du siècle suivant ${ }^{596}$. Mais elle est aussi dans un cas complétée par une nouvelle épiclèse, celle de Nikaios, qui apparaît dans l'inscription : $\Lambda$ épigraphiques, de la moitié du VIe s. a.C. Dinu Adamesteanu énonce également celle d'Archégétès, absente épigraphiquement, mais à laquelle font allusion les ancres, évoquant la fonction colonisatrice et de meneur d'expéditions du dieu delphien ${ }^{598}$. Les inscriptions des pierres de l'area sacra de Métaponte, quand celles-ci sont plantées, se lisent toutes de manière verticale, à l'exception d'une ${ }^{599}$.

Une inscription est à signaler plus particulièrement. Il s'agit de quatre lignes, groupées par deux sur deux côtés d'une pierre taillée (précisément du marbre) qui semble être un fragment de jas, auquel

592 Boetto 1997, note 19; Adamesteanu 1999, p. 231 et 258; De Juliis 2001, p. 140 et 145; Giacometti 2005, p. 37.

${ }^{593}$ Adamesteanu \& alii 1980 , p. 117 et note 254 : aucune inscription n'est postérieure à cette date; ibid., p. 336 : vers 530 av. J.-C., les travaux du temple B reprennent, dans des dimensions plus grandes que celles de la première ébauche inachevée de la première moitié du $\mathrm{VI}^{\mathrm{e}} \mathrm{s}$.

${ }^{594}$ Burzachechi 1979.

${ }^{595}$ Nous ne consignons ici que les inscriptions les plus lisibles; il en existe en outre un certain nombre, très fragmentaires, qui réfèrent cependant sans nul doute au nom d'Apollon, sans qu'il soit possible d'en dire davantage : cf. Adamesteanu 1970, p. 312.

${ }^{596}$ Manni Piraino 1968 en publie deux (no 8 et 10); Buzarchechi 1979, en propose six de plus $\left(\mathrm{n}^{\circ} 2,3,4,5,8\right.$ ? , 10?); en dernier lieu, voir Giacometti 2005, p. 29-35.

${ }^{597}$ Manni Piraino 1968, no 7; Buzarchechi 1979, p. 282.

${ }^{598}$ Adamesteanu 1970, p. 321-324.

${ }^{599}$ Burzachechi 1979, p. 281 et note 9. 
on rattache un autre fragment anépigraphe (cat. V4). La dédicace est restituée comme suit: [A $\pi \mathrm{o} \lambda \lambda \mathrm{ov}] \mathrm{o} \varsigma /[\Lambda \nu \kappa \varepsilon 1] \mathrm{o} \varepsilon \mu \mathrm{l} / /[. . \alpha v] \varepsilon \theta \varepsilon /$ $[\kappa \varepsilon ..] \alpha \sigma \cup \varsigma^{600}$. Elle est alors rapprochée de celle de Zeus Meilichios provenant de Crotone (cat. V1), non seulement pour sa formulation mais encore pour sa présentation en deux lignes sur deux côtés de l'objet, quoique ceux-ci ne soient pas identiques dans les deux cas ${ }^{601}$. Datée, toujours suivant les caractères épigraphiques, de la seconde moitié du Ve s., elle lui serait donc postérieure d'un demi-siècle au moins ${ }^{602}$. Le nom présumé du dédicant présente une terminaison en - v s peu courante dans le monde grec, qui a fait penser à une origine illyrienne ou messapienne ${ }^{603}$ et suggère également l'inscription fragmentaire du jas de Corfou (cf. infra cat. V5). L'objet provient des environs de la cloaca au nord du temple B.

Outre cette ancre inscrite, l'area sacra de Métaponte en a livré environ six autres anépigraphes, d'après l'examen du matériel lithique par G. Boetto ${ }^{604}$. L'une d'entre elle pourrait même être du type le plus ancien, à trous, antérieur à l'usage du jas (cat. V17) ${ }^{605}$; les cinq autres, des bras d'ancres (cat. V18-V22) proviennent tous du dépôt votif situé entre la peristasis $\mathrm{E}$ et la peristasis de la cella du temple $\mathbf{B}^{606}$. Deux sont en marbre, pentélique et de l'Hymette, un en schiste, un en granit et un en calcaire; seul ce dernier est complet, présentant une longueur totale d'1,85 $\mathrm{m}^{607}$. Il faudrait en outre ajouter un jas inédit, retrouvé dans des fouilles plus récentes effectuées dans l'area du temple B et conservé in situ ${ }^{608}$. Le marbre utilisé

${ }^{600}$ SEG XXIX, 962. Publiée pour la première fois sous le $\mathrm{n}^{\circ} 10$ par Burzachechi 1979, p. 289-291; description détaillée par Boetto 1997, catalogue M5, avec fig.; Giacometti 2005, p. 34-35.

${ }^{601}$ Dans le cas de l'inscription à Zeus Meilichios, il s'agit de deux côtés perpendiculaires, tandis que pour celle de Métaponte les lettres apparaissent sur les deux faces opposées de l'épaisseur.

${ }^{602} \mathrm{~L}$ 'inscription du jas de Crotone est datée de la fin du $\mathrm{VI}^{\mathrm{e} / d e ́ b u t} \mathrm{~V}^{\mathrm{e}}$ s. Toutes ces datations ne concernent bien entendu que les dédicaces écrites: nous ne pouvons déterminer si les jas leur sont contemporains ou plus anciens.

${ }^{603}$ Boetto 1997, note 6. L'auteur avance également la possibilité d'un nom lucanien, ce qui ferait «descendre la datation de l'inscription au début du IV ${ }^{\text {e }} \mathrm{s}$.» : idée peu recevable d'après le contexte archéologique et les caractères épigraphiques.

${ }^{604}$ Boetto 1997. Deux de ces jas ont été reconnus comme tels pour la première fois par Adamesteanu 1974, p. 28.

${ }^{605}$ Catalogue M7 de G. Boetto, avec réserve. Le lieu de la découverte n’est par ailleurs pas précisé.

${ }^{606}$ Catalogue M1-M2-M3-M4 et M6 de Boetto 1997.

${ }^{607} \mathrm{Il}$ a été trouvé fractionné en deux morceaux, qu'on a rapprochés plus tard. La moitié du jas figure sous le $\mathrm{n}^{\circ} 9$ dans Adamesteanu 1970, et dans Adamesteanu \& alii 1980, p. 118 fig. 119.

${ }^{608}$ Information orale transmise par Boetto 1997, note 19. 
pour trois d'entre eux montre un soin particulier au choix de l'objet consacré et peut-être même leur caractère davantage votif que réellement utilitaire ${ }^{609}$; de plus, le marbre athénien donne une indication de l'origine de certains des fidèles fréquentant le sanctuaire ${ }^{610}$. Un jas supplémentaire pourrait être reconnu dans une pierre de grès cassée sur place, réutilisée comme élément de délimitation et de protection d'un autre dépôt votif de la fin du $\mathrm{IV}^{\mathrm{e}} \mathrm{s}$. a.C. situé au NO. du temple $\mathrm{A}^{611}$.

\section{Ancre de Corfou}

Une ancre fragmentaire a été reconnue dans une pierre portant une inscription provenant de Corfou (cat. V5). Sa forme particulière ainsi que le type d'inscription - incomplète elle aussi - ont contribué à l'identifier comme provenant d'un "centre de culte» ${ }^{612}$. Le texte, boustrophédon, semble consister en effet en l'expression d'un ex-voto, avec un nom de personne, suivi du pronom personnel dési-

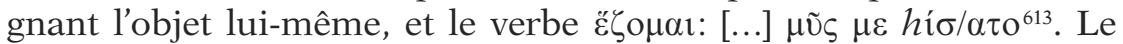
tout, de caractère archaïque, est daté du VI ${ }^{\mathrm{e}} \mathrm{s}$. L'objet fut identifié, de la même manière que d'autres cités plus haut, comme un «Apollonis Agyiei simulacrum ${ }^{614}$. Par la forme du nom du dédicant, l'inscription peut être rattachée à un exemplaire inscrit provenant du site de Métaponte (cat. V4) et paraît procéder d'une origine illyrienne ou messapienne ${ }^{615}$ - ce qui ne serait guère surprenant vu la position géographique de l'île.

Malheureusement, sans lieu de provenance connu, on ne peut que se perdre en conjectures.

${ }^{609}$ Sur l'utilisation de marbre pour des ancres à usage réel, voir supra p. 293, 335 et p. 456, note 448. Certaines ancres de Gravisca sont aussi taillées dans ce matériau (cat. V3 et V7).

${ }^{610}$ Pour les autres spécimens de jas de marbre dans le milieu de la Grande Grèce et de la Sicile, cf. Boetto 1997, note 11.

${ }^{611}$ Adamesteanu \& alii 1980, p. 238-239 et fig. 256.

${ }^{612}$ Gianfrotta 1977, p. 286-287, repris dans SEG XXVIII, 1596.

${ }^{613}$ Brugmann 1893.

${ }^{614}$ IG IX, 1, 704, qui rapproche la pierre du bétyle connu pour Apollonia d'Illyrie, sur le rivage opposé, à défaut d'en trouver des attestations dans l'île; lecture et commentaires repris brièvement par Schwyzer 1923, 132, qui décrit l'objet comme «lapis calcarius coni figura».

${ }^{615}$ Rapprochement opéré par Boetto 1997. 
Cette ancre (cat. V23) appartient à une grotte-sanctuaire remarquable par sa situation et ses inscriptions pariétales. La dite Porcinara se situe en effet à l'extrémité du talon de la botte italienne, à la pointe de l'Iapygie antique. Aujourd'hui elle appartient au territoire de la petite station balnéaire de Santa Maria di Leuca, plus précisément au cap situé à l'ouest de la ville actuelle nommé Punta Ristola ${ }^{616}$. Cette zone était à l'époque classique un lieu de passage pour les Grecs qui faisaient voile vers la Sicile, comme en témoigne notamment Diodore de Sicile (Bibliothèque historique XIII, 3, 1-4) ${ }^{617}$.

À l'entrée de la grotte (voir supra fig. 5) se trouve une sorte de terrasse, surplombant aujourd'hui les flots d'environ $12 \mathrm{~m}^{618}$, accessible depuis la mer et depuis la terrasse supérieure par un escalier ${ }^{619}$. Sur cette plate-forme le long des marches, les fouilles ont mis en évidence l'existence d'une eschara: un monceau de pierres, terre brune, charbons de bois, os et tessons brûlés, délimité de façon à peu près circulaire par des blocs. La céramique permet de dater le fait archéologique de l'ensemble du VII $\mathrm{s}^{620}$.

La grotte se présente comme une grande anfractuosité naturelle du rocher, divisée en 3 salles $^{621}$. Ses parois sont gravées d'inscriptions ${ }^{622}$, en latin et en grec, détériorées par des grafittes plus récents et par le salpètre ${ }^{623}$. De façon générale, elles sont datées entre la fin du $\mathrm{I}^{\mathrm{er}}$ s. a.C et la première moitié du $\mathrm{III}^{\mathrm{e}}$ s. p.C.; certaines d'entre elles figurent dans un cadre conçu à cet effet. La roche a été également taillée dans un coin afin d'y aménager une sorte de banquette.

${ }^{616}$ Voir photo aérienne du site parue dans Van Compernolle \& alii 1978, pl. I.

${ }^{617}$ Le trajet suivi par la flotte athénienne lors de l'expédition de Sicile avait été auparavant indiqué dans ses grandes lignes par Thucydide, VI, 44, 1-2; voir ibidem, p. 1-6, qui fournit toutes les références antiques concernant cette zone. Sur les routes maritimes et la configuration générale des Pouilles antiques, voir Pagliara 1991, p. 503-508, qui donne également une présentation générale du site de la grotte Porcinara (p. 508-511); Semple 1932, p. 631.

${ }^{618}$ F. d'Andria dans Van Compernolle \& alii 1978, p. 86-87 et coupes pl. 99-100.

${ }^{619}$ Id. dans ibid., p. 58-59, pl. 20B et 21 , A et B.

${ }^{620} \mathrm{Ibid}$., p. 68 ss., pl. 20 D-E, 21 D-E, 22, 23; une reconstitution est proposée pl. 96.

${ }^{621}$ Voir plan donné dans ibid., pl. 101.

${ }^{622}$ Celles-ci ont été publiées une première fois dans Pagliara 1971-1973, puis une seconde fois lors de la publication générale Van Compernolle \& alii 1978, p. 177 à 221, pl. 76 à 85. Désormais, les références concernant les inscriptions ne renverront qu'à la publication la plus récente.

${ }^{623}$ Le site s'est beaucoup dégradé depuis les fouilles : lors de mon passage en 1994, les inscriptions étaient difficilement discernables et la grotte non protégée contenait quelques ordures et des traces de feu. 
Quelques inscriptions ont permis d'identifier la divinité honorée dans la grotte (fig. 47). Il s'agit de Zeus, désigné dans les inscriptions latines sous les trois lettres I(uppiter) O(ptimus) M(agnus). Trois dédicaces sont explicites à cet égard : l'une en grec ${ }^{624}$ dédiée à $\Delta \mathrm{t}$ et les deux autres en latin ${ }^{625}$.

Par ailleurs, l'étude du matériel mis au jour lors des fouilles, surtout de la céramique présentant des inscriptions, a permis d'établir l'existence d'un culte à cet endroit, dès le VI ${ }^{\mathrm{e}} \mathrm{s}$. a.C., rendu vraisemblablement à une divinité nommée Zis Batias, équivalent messapien de Zeus Batios ${ }^{626}$. Les inscriptions pariétales déchiffrées ne représenteraient dès lors que quelques marques de dévotion parmi de nombreuses autres, offertes au moins depuis l'époque archaïque $^{627}$ jusqu'à l'époque impériale au dieu Zis/Zeus/Jupiter.

Un demi-jas d'ancre de pierre (cat. V23) a été trouvé dans le remplissage de l'eschara. Il est d'une pierre riche en micas, non locale : l'objet déposé à cet endroit vient d'ailleurs ${ }^{628}$. Il appartient peut-être à une série d'offrandes réalisées au VI ${ }^{\mathrm{e}} \mathrm{s}$. qui paraissent
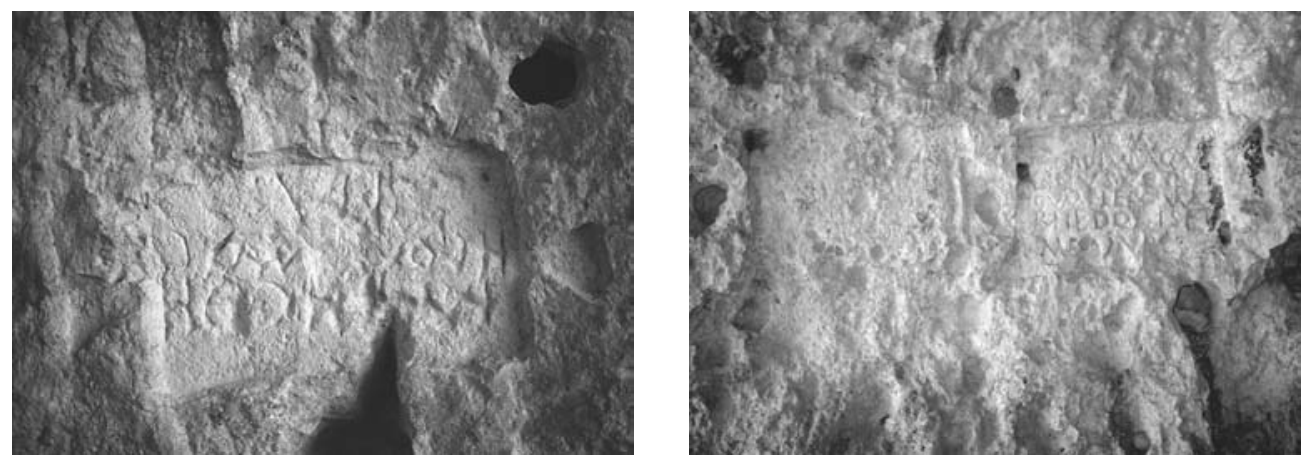

Fig. 47 - Grotte Porcinara : inscriptions no 6 et no 16-17 (Photos de l'auteur).

${ }^{624}$ Pagliara in Van Compernolle \& alii 1978, p. 197-198 $\mathrm{n}^{\circ}$ 6, pl. 77.

${ }^{625} \mathrm{Ibid}$., p. $200-202 \mathrm{n}^{\circ} 14$ et p. 203-204 no 17 , pl. $79 \mathrm{~b}$ et 81 a. Il faut peut-être ajoutée une troisième inscription, disparue mais mentionnée par un voyageur du $\mathrm{XIX}^{\mathrm{e}}$ s. : ibid., p. $208 \mathrm{n}^{\circ} 31$.

${ }^{626}$ Ibidem, p. $187-188$ et p. $218-221$.

${ }^{627}$ La céramique grecque du site étudiée par A. Rouveret remonte jusqu'au

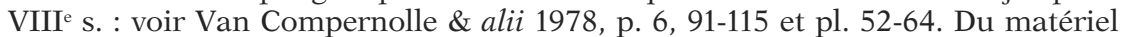
de l'âge du bronze a été retrouvé sur la pointe voisine de S. Maria di Leuca : ibid., p. 27-43 et pl. 13-17; une grotte proche nommée Grotta del Diavolo a livré quant à elle du matériel néolithique : ibid., p. 13-25.

${ }^{628}$ F. d'Andria in Van Compernolle \& alii 1978, p. 69, pl. 34. L'information est livrée dans Gianfrotta 1975, p. 315 et note 19, et Gianfrotta 1977. 
avoir été déposées au-dessus ou autour de l'eschara.629. Par ailleurs, le savant italien met l'ancre en relation ${ }^{630}$ avec une inscription de la grotte consacrée, non pas à Zeus, mais à Ino. Celle-ci mentionne l'offrande de $\sigma \chi \tilde{\eta} \tau \alpha \varsigma$, hapax que l'épigraphiste comprend comme un terme nautique désignant une sorte d'ancre ${ }^{631}$. Si cette définition s'avère exacte, l'offrande d'ancres dans ce sanctuaire relèverait d'une tradition archaïque, poursuivie jusqu'à l'époque romaine.

\section{Ancres de Sélinonte}

Dans les années 1990, deux nouveaux jas d'ancres de pierre ont été identifiés à l'intérieur du sanctuaire dit de la Malophoros (cat. V24-V25). Il s'agit de deux pierres fichées dans le sol devant le temple de Zeus Meilichios, qui ont bel et bien la forme de jas de pierre ${ }^{632}$. L'archéologue G. Purpura ${ }^{633}$ avance l'hypothèse d'un dépôt votif lié au temple "en réutilisation" : il présuppose ainsi une réelle utilisation des ancres avant le don. La photo jointe à sa très brève publication permet de distinguer au moins deux demi-jas placés à peu de distance l'un de l'autre; in situ, ils ne laissent rien voir de leur longueur totale ni de la présence éventuelle d'une inscription, d'une marque ou d'un décor. Le contexte archéologique n'est pas précisé au niveau chronologique.

Le même téménos de Zeus à Sélinonte avait livré, lors des fouilles menées dans le premier quart du $\mathrm{XX}^{\mathrm{e}}$ s., outre le naiskos du dieu et un autel sans base considéré comme eschara, un espace planté de pierres dont certaines portaient des inscriptions ${ }^{634}$. Ce «champ de stèles» qui se situe à l'ouest du hiéron de Zeus semblait ancien; quelques blocs ont par ailleurs glissé et été retrouvés plus bas. Les recherches récentes ont confirmé qu'il correspond à une première phase de fréquentation par des groupes gentilices dans les

${ }^{629}$ C. Pagliara in Van Compernolle \& alii 1978, p. 219.

${ }^{630}$ Pagliara 1991, p. 511.

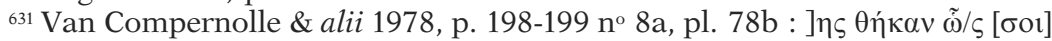

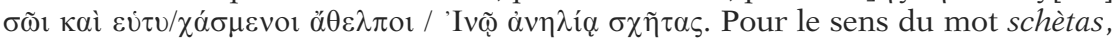
C. Pagliara renvoie à Hésychius, s.v. $\sigma \chi \eta \tau \eta \rho i ́ \alpha v \cdot \ddot{\alpha} \gamma \kappa v \rho \alpha v$.

${ }_{632}$ Sur le culte chtonien de Zeus à Sélinonte, Carratelli 1996, p. 490-491. Zeus Meilichios à Sélinonte ne connaît pas de représentation iconographique avant la fin du $V^{\text {e }}$ s., ce qui pourrait confirmer le caractère aniconique du dieu : Jameson \& alii 1993, p. 98-103; Gabrici 1927, col. 405; voir Pausanias II, 9, 6.

${ }_{633}$ Purpura 1993, no 126 Cat et fig. 34.

${ }^{634}$ Gabrici 1927, col. 91-107 et pl. II, XVI, XVII; Jameson \& alii 1993, p. 89-91 et pl. 6-8. Les journaux de fouilles 1915-1922 ont été publiés par Grotta 2010, p. 233-277, avec commentaire et historique p. 1-6 et 63-100. 


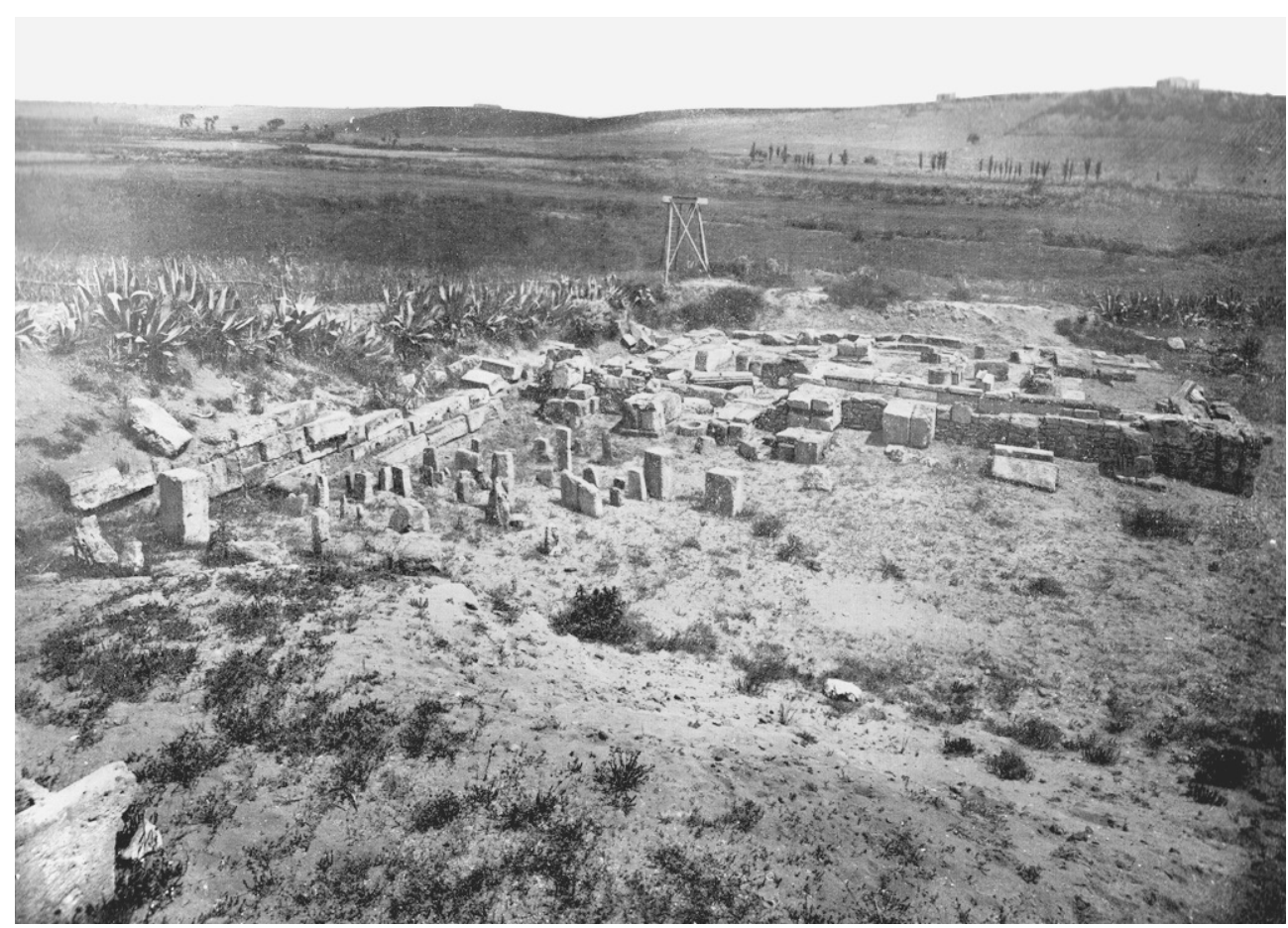

Fig. 48 - «Champ de stèles» à Sélinonte (d'après Gabrici 1927, pl. 17).

$\mathrm{VI}^{\mathrm{e}}-\mathrm{V}^{\mathrm{e}}$ s. a.C. Puis, à partir du $\mathrm{IV}^{\mathrm{e}}$ s., le mur d'enceinte du téménos de Zeus l'a exclu en quelque sorte de l'espace consacré au dieu ${ }^{635}$. Les «stèles» présentent des formes variées : parallépipèdes ou grossièrement pyramidales, avec parfois un appendice dans la partie supérieure. Les inscriptions appartiennent à une période allant du $\mathrm{VI}^{\mathrm{e}} \mathrm{s}$. au milieu du $\mathrm{V}^{\mathrm{e}} \mathrm{s}$. et mentionnent le nom de Meilichios ainsi que parfois celui du dédicant ${ }^{636}$. Le premier fouilleur restituait ainsi le rituel archaïque du sanctuaire: les offrandes sont brûlées à l'eschara; les cendres recueillies, enterrées, sont signalées par une pierre, anépigraphe ou inscrite ${ }^{637}$. Les pierres du sanctuaire de Zeus Meilichios ont été rapprochées de celles trouvées à Métaponte, et

${ }^{635}$ Grotta 2010, p. 229-230.

${ }^{636}$ Corpus récapitulatif par Grotta 2010, p. 101-136 (16 inscriptions). Les noms des dédicants ne fournissent aucune indication sur leur origine éventuelle.

${ }^{637}$ Gabrici 1927, col. 403. Grotta 2010, p. 230-231, semble d'accord avec cette analyse pour les stèles inscrites qui indiquent bien une pratique de fondation 
considérées dès lors comme des argoi lithoi ${ }^{638}$. En l'absence de précisions supplémentaires concernant l'emplacement des deux ancres, il est difficile de faire un lien entre les différentes pierres. Les ancres font-elles partie de la zone du «champ de stèles»? Y ont-elles appartenu pour ensuite être récupérées en vue d'une autre utilisation?

Une base inscrite, trouvée dans la grande enceinte du sanctuaire, est à mettre en relation avec la présence d'ancres. Elle fut dégagée à la fin du XIX ${ }^{\mathrm{e}}$ s. dans le téménos de la Malophoros, au sud des Propylées dans l'angle de l'enclos d'Hécate ${ }^{639}$. La dédicace a été publiée à de nombreuses reprises et a fait spécialement l'objet d'une mise au point par M. Guarducci, corrigée elle-même par G. Manganaro. L'inscription datée du début ou du second quart du $\mathrm{V}^{\mathrm{e}} \mathrm{s}$. doit

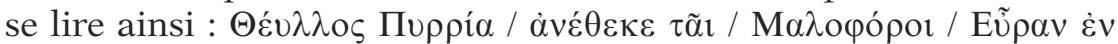

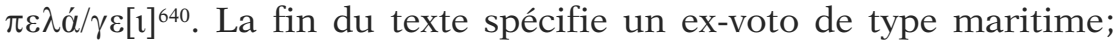
l'objet consacré devait être porté par la base en question. Certains voient dans cette Eura une forme dialectale, contaminée par le nom Euros, d'Aura. Celle-ci serait donc la statuette offerte par Theyllos, représentée en train de voler, ce qui renverrait à l'image infernale de la déesse du sanctuaire ${ }^{641}$. Sans chercher des allégories aussi poussées, peut-être la raison de cette offrande s'éclaire-t-elle devant la présence d'ancres dans le sanctuaire de la Malophoros à laquelle est associé Zeus Meilichios. Même si les jas sont antérieurs à la base, celle-ci pourrait témoigner d'une continuité de la fréquentation du site pour des raisons en partie liées à la navigation.

d'un culte gentilice; en revanche, il considère que les stèles anépigraphes trouvées à l'intérieur de l'enceinte «représentent un vrai mystère archéologique». L'examen des carnets de fouilles lui permet d'affirmer qu'elles ne proviennent pas du «champ de stèles» et qu'elles ont dû arriver à cet endroit à partir du IV ${ }^{e}$ s. a.C., i.e. ou avant la construction de l'enceinte ou après celle-ci dans une fosse.

${ }^{638}$ Premier rapprochement opéré par Adamesteanu 1970, p. 312. Récapitulatif du dossier par Grotta 2010, p. 180-188, qui n'évoque pas le problème des ancres.

${ }^{639}$ Gabrici 1927, col. 380-381 et pl. XCVI, 2; Notizie di scavi 1889, p. 254; 1894, p. 208-210.

${ }_{640}$ Manni Piraino 1972, p. 86-88 n 56 et pl. XXXIII, qui reprend la dernière lecture de Manganaro 1968-1969; Guarducci 1966b (avec bibliographie antérieure); Grotta 2010, p. 8-9 et pl. II. L'article de 1996 fut écrit en réponse à la lecture proposée par un jeune savant hollandais, J. A. K. de Waele. Celui-ci suggérait de corriger le nom du dédicant en Phayllos (Waele 1963); cette interprétation, très séduisante pour nous car elle serait à mettre en parallèle avec l'ancre de Crotone (cat. V1), fut solidement contestée par M. Guarducci.

${ }^{641}$ Interprétation de G. Manganaro, reprise par M.T. Manni Piraino. 


\section{Cas moins assurés}

\section{a) Ancre de Mozia}

Lors des fouilles de Mozia, l'établissement phénicien de Motyé, reprises à la fin des années 1970 dans le voisinage du sanctuaire extra-urbain dit Cappiddazzu et d'où provient la fameuse statue de marbre ${ }^{642}$, une ancre de pierre de grande taille (cat. V26) a également été mise au jour.

Une moitié de celle-ci a été bien publiée : elle se trouvait dans le carré 45 de la zone $K$, à proximité et dans la même couche que la statue, sur un pavement et au bord d'une petite fosse circulaire (fig. 49). Ce qu'il faut peut-être considérer comme l'autre moitié de l'objet a été dégagée à l'extérieur de ce secteur ${ }^{643}$. La stratigraphie permet de préciser un terminus ante quem : le bâtiment fut détruit au tout début du IV ${ }^{\text {e }}$ s. a.C., certainement en 397 lors de la destruction du site par Denys ${ }^{644}$. La statue quant à elle est datée, malgré de nombreuses controverses, de la première moitié du Ve s. av. J.-C. d'après les critères stylistiques. Elle s'apparente directement à un ex-voto, ce qui amène à attribuer la même fonction à l'ancre voisine. La statue est diversement interprétée comme une représentation de Melqart ou d'un aurige grec et la même incertitude règne sur les divinités qui étaient honorées à Cappiddazzu ${ }^{645}$ : il est donc impossible, dans l'état actuel de nos connaissances, d'associer l'ancre à un culte en particulier.

\section{b) Ancres de Salamine (Chypre)}

Les fouilles de Salamine de Chypre ont livré au total sept ancres de pierre (cat. V27-V33), non rattachables à un milieu ou une chronologie précis ${ }^{646}$.

Cinq ancres de type ancien, c'est-à-dire sous la forme de pierres percées, ont été retrouvées en remploi, semble-t-il, dans des structures diverses. L'une d'elle, peut-être datée de l'âge du bronze, a été sortie d'un puits avec un contexte daté du $\mathrm{II}^{\mathrm{e}}$ s. a.C.; il est difficile d'en tirer des conclusions décisives, hormis la comparaison avec les

${ }^{642}$ La situation de Mozia, sur une route maritime, fait que s'y implanta une colonie phénicienne qui y aménagea un port militaire artificiel, le kothon. Bonnet 1988, p. $274-276$ et fig. 22 pl. VII; Carratelli 1996, p. 127 ss.; Coarelli \& Torelli 1997, p. $58-65$.

${ }^{643}$ Falsone 1988, p. 15, 24 et fig. 1; Carratelli 1996, p. 418.

${ }^{644}$ Sur la destruction de Mozia, lire par exemple le récit qu'en donne Diodore de Sicile au livre XIV, 51-53.

${ }^{645}$ Bonnet 1988, p. 274-276.

${ }^{646}$ Chavane 1975, p. 114-117, nº 355 à 361. 


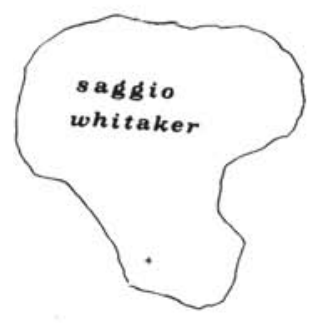

MOZIA 1981 ZONA K

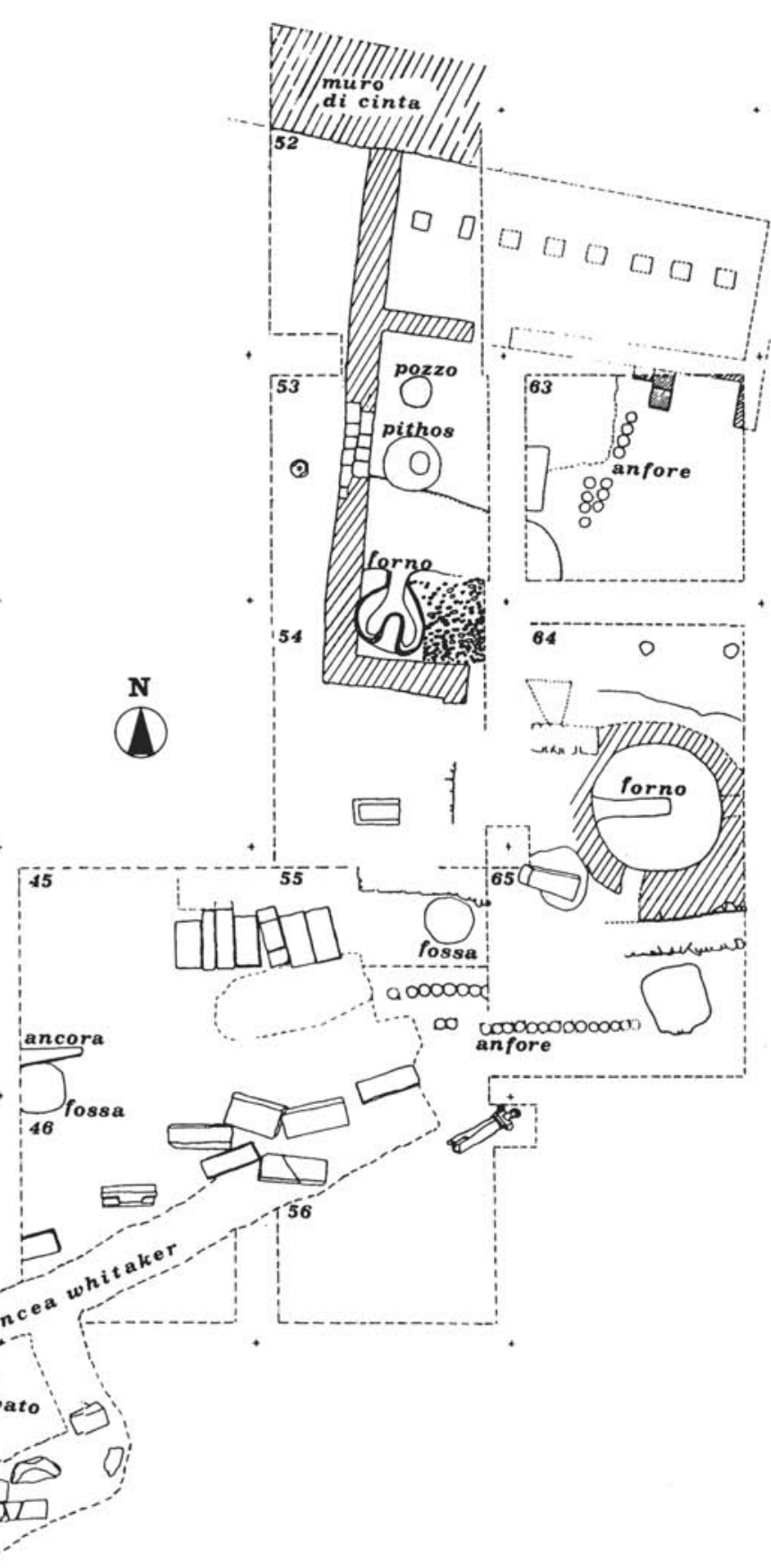

Fig. 49 - Fouilles de Mozia, zone K (d'après Falsone 1988, p. 11). 
ancres sacrées que H. Frost a identifiées à Byblos et Ugarit ${ }^{647}$. Une autre était placée sous une couche de céramique archaïque, tandis qu'une troisième se trouvait mêlée à de la céramique des Ve-VII ${ }^{\mathrm{e}}$ p.C.

En outre, deux jas d'ancres de pierre de date plus récente (cat. V32 et V33) ont également été dégagés, l'un dans l'angle nord-ouest de la basilique byzantine de la Campanopetra, apparemment hors stratigraphie; pour l'autre, aucune indication de provenance n'est détaillée. Difficile dans ces conditions d'en tirer quelque chose; ces ancres peuvent évidemment provenir du port voisin, même s'il est très tentant d'y voir plutôt des dons adressés à un sanctuaire ${ }^{648}$.

\section{c) Ancres d'Alexandrie}

En dernier lieu, il convient de présenter deux groupes d'ancres, de type composite ${ }^{649}$, au contexte mal précisé qui témoignent de l'existence de ce matériel votif sinon à l'époque hellénistique, du moins encore après la seconde moitié du $\mathrm{II}^{\mathrm{e}}$ s. p.C. (cat. V34-V37).

C'est à Alexandrie qu'elles apparaissent, au lieu dit Ras el Soda où fut découvert un temple romain dans les années $1930^{650}$. Lors de son dégagement furent mises au jour deux ancres, mais ce n'est que récemment qu'elles ont été reconnues comme telles et mises en relation avec le temple ${ }^{651}$. Ce dernier était dédié au culte d'Isis et fut construit à une date tardive aux dires du fouilleur ${ }^{652}$. La récente trouvaille in situ dans des couches inférieures du temple par A. Nibbi de deux autres ancres du même type composite ${ }^{653}$ l'invite à

${ }^{647}$ Voir supra p. 457 ss.

${ }^{648}$ Gianfrotta 1977, p. 287.

${ }^{649}$ Pour une définition de ce type, voir Frost 1970a, p. 380 ss.; Mac Caslin 1980, p. 61 ss.

${ }_{650}$ Adriani 1935-39.

${ }^{651}$ Nibbi 1991, p. 185-194, qui corrige en outre des mentions imprécises faites par H. Frost à plusieurs reprises. En réalité, la provenance de ces deux ancres est assurée pour l'une, très probable pour l'autre. En effet, le registre du Musée d'Alexandrie où elles sont conservées a noté pour la seconde le site de Ras el Soda et pour la première Alexandrie; les deux ancres ayant deux numéros d'inventaire consécutifs (28811 et 28812), elles ont vraisemblablement un même lieu d'origine. Nous ne prenons pas en compte la cinquième ancre recensée dans l'article de A. Nibbi du fait de sa localisation trop vague et sans rapport manifeste avec les autres : l'objet fut trouvé à El Mahmoura, dans les eaux d'un canal proche de la mer.

${ }^{652}$ D'après les caractères stylistiques des statues et épigraphiques d'une inscription votive, le temple ne serait pas antérieur à la seconde moitié du $\mathrm{II}^{\mathrm{e}} \mathrm{s}$.

${ }^{653}$ Déplacées par A. Nibbi elle-même au musée gréco-romain d'Alexandrie et enregistrées sous les appellations d'ancres A et B de Ras El Soda. 
les joindre aux deux précédentes et à les dater toutes de l'époque impériale. Or cette attribution des deux groupes d'ancres au temple isiaque et leur datation sont un peu trop hâtives.

En effet, un ensemble d'objets fut retrouvé également lors des fouilles des années 30 dans cette même zone de Ras el Soda ${ }^{654}$, mais à "quelques centaines de mètres" du temple et indépendant de ce dernier, aussi bien par la stratigraphie que par la chronologie. Le fouilleur A. Adriani nota avec surprise que «la couche archéologique apparut isolée entre une couche vierge de sable, sur laquelle elle s'était étendue, et la couche supérieure de sable qui l'avait recouverte ensuite». Il en déduisit donc qu'il s'agissait d'un dépôt votif déplacé à cet endroit à une époque tardive. La concentration du matériel sur un petit espace ainsi que l'homogénéité chronologique confirment cette hypothèse. Mais ces objets sont loin de dater du $\mathrm{II}^{\mathrm{e}}$ ou III ${ }^{\mathrm{e}}$ s. p.C. : ils remontent à l'époque hellénistique ${ }^{655}$. Ainsi, à Ras el Soda, sont attestés deux faits archéologiques distincts et séparés temporellement de plusieurs siècles, et aucune de leur publication respective ne fait état d'objets ressemblants de près ou de loin à deux ancres. Elles peuvent donc provenir autant du temple impérial que du dépôt hellénistique, même si leur numérotation tend plutôt à la rattacher au second cas $^{656}$. Parmi le matériel de la favissa, se trouvent de nombreuses statuettes représentant Aphrodite-Isis, à qui des offrandes d'ancres ne seraient pas impossibles. Encore une fois, le manque de renseignements empêche toute conclusion définitive.

En outre, en ce qui concerne les deux autres ancres récemment dégagées par Alessandra Nibbi, la datation paraît sujette à caution : lorsque l'auteur, citant A. Adriani, affirme l'inexistence de couche d'occupation antérieure au temple ${ }^{657}$, elle opère en réalité une confusion entre la situation stratigraphique de celui-ci et celle du dépôt. Cette caractéristique est celle signalée pour la seconde fouille ${ }^{658}$; rien n'est précisé en revanche pour les niveaux inférieurs du temple ${ }^{659}$. Rien ne permet donc de confirmer cette datation tardive de ces

${ }^{654}$ Adriani 1940-50.

${ }^{655}$ Ibid., p. 45-46.

${ }^{656}$ Leur numéros d'inventaire 28811 et 28812 sont plus proches des numéros attribués aux objets provenant du dépôt hellénistique (d'environ 25800 à 2610 pour ceux publiés dans l'article de A. Adriani) que ceux du matériel du temple isiaque (d'environ 400 à 500).

${ }_{657}^{65}$ Nibbi 1991, p. 185-186, réaffirmé avec force p. 192.

${ }^{658}$ Adriani 1940-1950, p. 28.

${ }^{659}$ Adriani $1935-39$, p. $137-138$ et plan fig. 61, ne donne qu'une description synchronique du sanctuaire. 
ancres V36-37, si ce n'est la conduite rigoureuse de nouveaux sondages ou de fouilles à cet endroit. Nous ne pouvons donc que constater la présence de plusieurs ancres - deux au moins, si ce n'est quatre - dans un contexte religieux peut-être plus particulièrement isiaque ${ }^{660}$, et ajouter cet exemple à notre dossier sans pouvoir les dater plus précisément: époque hellénistique ou romaine.

\section{DON D'ANCRES ET CULTE DE PIERRES}

\section{Problème de vocabulaire}

Il convient, pour plus de clarté, de définir précisément les termes utilisés pour désigner chaque type de matériel. Entre les cippes, les stèles, les argoi lithoi, les tétragônoi lithoi et les ancres, la confusion est facile, surtout vu l'état de la plupart des objets, souvent fragmentaires. Difficulté que ne nie pas D. Adamesteanu lui-même ${ }^{661}$, même s'il essaie d'établir une classification en désignant d'une part argoi lithoi toutes les pierres non travaillées, et d'autre part en distinguant parmi celles travaillées à la fois les stèles, les cippes comprenant les tétragônoi lithoi et les pyramides, les bases de cippes et les fragments architectoniques ${ }^{662}$. Notons par ailleurs que les jas d'ancres ne figurent pas dans cette énumération. D. Adamesteanu utilise également le terme de pyramides, qu'il rapproche du passage de Pausanias sur Pharai alors qu'il ne s'y trouve pas ${ }^{663}$. En revanche, le mot est mentionné à propos du sanctuaire de Zeus Meilichios à Sicyone (Pausanias II, 9, 6) 664. $^{64}$

M. Burzachechi, lors de l'étude des inscriptions, précise d'emblée que, pour elle, la notion de cippe désigne l'ensemble des pierres qu'elles soient travaillées ou non ${ }^{665}$.

Le problème que recouvre cette confusion dans l'emploi du

${ }^{660}$ En ce qui concerne le dépôt hellénistique, la diversité du matériel empêche toute attribution à une divinité particulière : Adriani 1940-50, p. 45-46; si les ancres sont en relation avec le temple, leur présence ici n'est guère surprenante, vu le caractère maritime accordé à Isis à cette période. Notons également l'existence d'un objet de forme pyramidale conservé à Cambridge (Musée Fitzwilliam, inv. EGA 288-1949) identifié comme une «ancre votive romaine» portant sur une face une représentation d'un serpent, lui aussi mis en relation avec Isis : cf. Nibbi 1984.

${ }^{661}$ Adamesteanu \& alii 1980 , p. 119 , note 258.

${ }^{662} \mathrm{Ibid}$., p. 119. On pourrait y ajouter l'expression de lusus utilisée par Ferri 1972.

${ }^{663}$ Par exemple dans son ouvrage de 1974, p. 31.

${ }^{664}$ Adamesteanu 1970, p. 316.

${ }^{665}$ Burzachechi 1979, note 7. 
vocabulaire est de savoir ce que représentaient pour les fidèles ces pierres dressées. Faisaient-ils la différence entre les pierres travaillées ou non travaillées, selon leurs formes, et, dans le cas qui nous occupe, les jas gardaient-ils une valeur nautique ou au contraire perdaient-ils tout caractère propre au profit d'une simple représentation aniconique du dieu ${ }^{666}$ ?

Par ailleurs, il faut se garder de généralisations et assimilations trop rapides. Le rapprochement a été opéré entre ces argoi lithoi et le culte d'Apollon Agyieus ${ }^{667}$. Certes, il s'agit de la même divinité et de l'utilisation de blocs de pierre dans le culte qui lui est rendu. Mais il suffit de regarder les monnaies sur lesquelles apparaissent des bétyles d'Apollon Agyieus et que l'on a parfois apportées au dossier $^{668}$, pour se rendre compte qu'il s'agit de deux choses bien distinctes. Le bétyle des monnaies d'Apollonia d'Illyrie ou de Mégare $^{669}$ ne ressemble en rien aux pierres, travaillées ou non, retrouvées à Métaponte, et celles-ci n'offrent guère non plus de similitude avec des colonnes érigées en l'honneur du dieu. Les pierres de Métaponte ou de Sélinonte ne rappellent pas non plus le bétyle d'Aphrodite à Paphos ${ }^{670}$. Outre la forme, une différence essentielle sépare les pierres de Grande Grèce des bétyles d'Apollon ou Aphrodite : leur grand nombre et leur concentration en un même endroit.

Ceci nous mène à une réflexion sur le passage de Pausanias (VII, $22,4)$, déjà allégué à plusieurs reprises. Le Périégète n'a peut être pas non plus bien compris le sens des pierres de Pharai. Celles-ci entourent la statue du dieu, ce qui tend à signifier que les pierres sont distinctes de la notion de représentation du dieu : lorsque Pausanias évoque les pierres vénérées à la place $(\dot{\alpha} v \tau i)$ d'une statue divine, cela ne correspond pas au cas du sanctuaire qu'il décrit : il ne peut y avoir trente statues du dieu. L'explication de Pausanias peut s'appliquer aux bétyles ou à des pierres pyramidales individualisées,

${ }^{666}$ C'est l'opinion que défend M. Burzachechi qui ne nie pas la présence d'ancres, mais leur ôte toute signification maritime au profit de la réutilisation d'un bloc de pierre : ibidem, note 32.

${ }^{667}$ Sur Apollon Agyieus, voir notamment Six 1894; Kron 1992, p. 61 ss.

${ }^{668}$ Par exemple Boetto 1997, voulant ainsi insister sur le lien d'Apollon Agyieus avec la mer, faisant référence à des as romains d'époque augustéenne présentant un bétyle sur une proue de navire.

${ }^{669}$ Blatter 1984, 1 p. 329 et 2 p. 281.

${ }^{670}$ Kron 1992, p. 61 et fig. 16, 2-3; Boetto 1997. À la fin du XIX ${ }^{\mathrm{e}}$ s., bien avant les découvertes archéologiques des argoi lithoi, M. Collignon rapprochait le texte de Pausanias avec les «bétyles, ou aérolithes» sémitiques, i. e. des pierres brutes, et voyait dans le bétyle grec une "pierre taillée en cône»: "d'autres fois, et sans qu'il soit possible d'établir un ordre chronologique entre ces diverses transformations, la pierre affecte la forme pyramidale, ou bien elle s'allonge et s'effile, et devient une colonne ou un pilier» (Collignon 1883, p. 10-12). 
mais pas à une réunion de pierres autour d'une statue comme c'est le cas d'Hermès ni aux espaces plantés de pierre comme Métaponte ou Sélinonte ${ }^{671}$. Des blocs tétragônoi en relation avec Hermès peuvent en outre faire penser aux «hermès» ou piliers hermaïques arcadiens ${ }^{672}$. Dès lors, il faudrait considérer que cette multiplicité et concentration des pierres brutes ou taillées s'avèrent une spécificité de ces sites de Grande Grèce, qui ne s'approche d'aucune mention littéraire de pierre sacrée grecque ${ }^{673}$. Dans cette perspective, U. Kron a suggéré de reconnaître dans les objets lithiques de Métaponte des consécrations de phratries ${ }^{674}$.

Le dossier de ces dits argoi lithoi pose un certain nombre de problèmes non résolvables dans l'état actuel. Le manque de trouvailles en place ne peut laisser place qu'à des conjonctures. Une chose est certaine : le texte de Pausanias s'applique à Hermès, qui n'est nullement attesté ici. La pratique semble concerner principalement deux dieux : Apollon et Zeus dans une zone géographique bien précise : la Grande Grèce.

Analyse

Le don d'ancre à terre est une pratique confirmée par les sources littéraires et les inscriptions déliennes. En ce qui concerne le matériel archéologique à notre disposition, relativement nombreux, il se répartit - pour les cas les mieux assurés - de la façon suivante :

${ }^{671}$ Le rapprochement opéré avec le site messapien de Vaste-Fondo Melliche ne nous paraît pas totalement justifié. Cette nécropole présente aux niveaux les plus anciens (seconde moitié du VI ${ }^{\mathrm{e}} \mathrm{s}$.) des cippes travaillés accompagnés de petites offrandes. Ces cippes, même si pour certains similaires à des cippes de Métaponte, offrent déjà une forme élaborée; il est impropre de parler d'argoi lithoi à leur sujet. De plus le contexte est différent : du matériel votif est joint aux cippes de Valle, et le lieu doit revêtir une fonction funéraire plutôt que religieuse. Voir Andria 1990, p. 57-62; Kron 1992, p. 67-68.

${ }^{672}$ Jost 1985, p. 233 note 3 et pl. 38, 3-4-6; A. S. Arvanitopoullos, in AE 1906, col. 47-49; Kron 1992, p. 57. Par ailleurs, Pausanias (VIII, xlviii, 6) à propos de Tégée parle d'un Zeus comme agalma tétragônon, forme privilégiée des Arcadiens.

${ }^{673}$ Voir l'ensemble des informations réunies par Kron 1992 : à chaque fois, il s'agit d'une pierre - quelle que soit la forme prise par celle-ci ou son origine.

${ }^{674}$ Kron 1992, p. 67 et note 93. Une autre hypothèse voit en Métaponte un Apollon oraculaire et une "théôn agora», à l'image de celle qu'évoquerait pour Pharai le texte de Pausanias (Giacometti 2003; Giacometti 2005, p. 41-42). 
- trois ancres avec inscriptions votives trouvées en dehors de tout contexte archéologique : jas d'Égine à Aphrodite; jas de Crotone à Zeus Meilichios; jas de Corfou;

- des ancres anépigraphes trouvées isolées dans un contexte religieux : à Santa Maria di Leuca; en Égypte;

- des groupes d'ancres trouvées dans un sanctuaire d'argoi lithoi : une quinzaine à Gravisca, dont une avec inscription à Apollon Éginète; la moitié à Métaponte dont une avec inscription à Apollon Lykeios; les deux ancres anépigraphes du sanctuaire de Zeus Meilichios à Sélinonte.

Les deux premiers groupes renvoient à des consécrations de jas. Les inscriptions, l'origine des pierres pour la plupart trouvées sur le littoral ou même dans un sanctuaire marin permettent de les identifier comme des ex-voto, principalement destinés à Zeus et Aphrodite.

En revanche les cas du dernier groupe demandent à être discutés. De façon générale, les inscriptions des ancres se ressemblent sur un point deux par deux : celles de Gravisca et Métaponte présentent la même formulation ${ }^{675}$; celles de Crotone et de Corfou de leur côté également; la disposition du texte de l'ancre de Métaponte s'apparente à celle du texte de l'ancre de Crotone par la répartition des lignes sur deux faces du jas ${ }^{676}$. Par ailleurs, parmi les inscriptions de ces sanctuaires sur autre support, la dédicace de Théagès à Métaponte avoisine celle d'Euménide de Sélinonte ${ }^{677}$. Tout ceci dessine des similitudes entre les dédicants, qui paraissent pour beaucoup être d'origine messapico-illyrienne: Byrros (?) à Métaponte, les noms en -vऽ sur les ancres inscrites de Métaponte et de Corfou, Phayllos de Crotone et les fidèles de la grotte Porcinara. L'importance du culte marin de Zeus dans cette région, la formulation de la dédicace du jas de Corfou permettent d'énoncer l'hypothèse que le jas de Corfou est également dédié à Zeus.

Par ailleurs, les ancres de la grotte Porcinara et de Crotone témoignent de la vivacité d'un culte marin et de l'offrande d'ancres dans cette zone. Pour cette raison, le choix d'une ancre comme pierre offerte dans le cadre d'un culte aniconique ne doit pas être le fait d'un hasard ou d'une récupération : il s'agit bien d'ex-voto d'ancres ${ }^{678}$. Ceci

${ }^{675}$ Burzachechi 1979, p. 291.

${ }^{676}$ Burzachechi 1979, p. 291

${ }^{677}$ Burzachechi 1979, p. 282, renvoie à l'inscription de Sélinonte publiée par Manni Piraino, Kokalos XVI, 1970, p. 279.

${ }^{678}$ Gianfrotta \& Pomey 1980, p. 302, rapprochent cette pratique de rites actuels analogues en Italie; Lazzarini 1996, p. 242-243 la juge comme un compromis entre les deux types de culte; Boetto 1997. 
va à l'encontre de la position de M. Burzachechi, qui au contraire considère que l'ancre perd toute connotation maritime lorsqu'elle est intégrée à un ensemble d'argoi lithoi, et que seul est pris en compte le caractère matériel, lithique, de l'objet ${ }^{679}$. Le don d'une ancre, de quelque nature qu'il soit, montre un lien direct avec le monde de la navigation. Toutes proviennent de sanctuaires situés sur le littoral ce qui suffirait certes à expliquer la présence de fidèles travaillant avec le monde de la mer et donc la présence d'ancres en ces lieux -, mais plus précisément des sanctuaires liés étroitement avec un port ou une passe maritime particulière. Sans nul doute le marin qui y abandonnait une ancre gardait-il à l'esprit cette préoccupation première : s'octroyer la protection divine pour lui et son embarcation.

À l'inverse, établir un lien direct entre les jas d'ancre retrouvés dans les sanctuaires et des cultes aniconiques rendus aux divinités procède d'un jugement hâtif et sans fondement. Dans le cas d'Égine, du sanctuaire d'Héra à Crotone, aucun culte aniconique n'est renseigné, ni même ailleurs pour Héra précisément. La présence d'un jas d'ancre n'est pas due systématiquement à l'existence d'un culte aniconique attesté pour le dieu ou pour le sanctuaire en question, pas plus qu'elle n'implique inversement la pratique de ce type de culte. À partir de ce raisonnement cependant, certains en concluent que dans la majorité des cas, les ancres sont en réalité des argoi lithoi de type particulier, et dédiés à une même divinité, Apollon, qu'il faut mettre en relation avec une origine achéenne du dieu et de son culte ${ }^{680}$. Or, c'est oublier, d'une part, que la description donnée par Pausanias d'argoi lithoi achaiens réfère à un sanctuaire dédié au dieu Hermès, et d'autre part qu'Apollon, nous l'avons vu, est loin d'être le seul dieu concerné aussi bien par le don d'ancre que par celui d'argoi lithoi. En ce qui concerne les ancres votives, une majeure place revient à Zeus, dont il faut rappeler le culte à Ancyre.

Deux remarques de type géographique s'imposent. Tout d'abord le matériel est essentiellement concentré en Grande Grèce; en Grèce continentale, seule Égine révèle deux offrandes de ce type : l'une sur place, l'autre à Gravisca. Par ailleurs, les dédicaces semblent montrer que ces offrandes peuvent s'opérer ailleurs, à des milles de sa patrie, et de surcroît dans le sanctuaire d'autres divinités. Ceci rappelle l'ancre des Argonautes, abandonnée en cours de voyage.

${ }^{679}$ Burzachechi 1979, p. 291.

${ }^{680} \mathrm{Ibid}$. 
L'ancre représente donc un témoignage de la religiosité exercée à bord comme à terre : cet objet maritime par excellence est intégré dans un système de croyances et de dévotions. Elle se trouve ainsi à la croisée des deux espaces religieux. Par ailleurs, deux divinités sont honorées, par l'intermédiaire de l'ancre, sur les deux espaces : Zeus et Aphrodite. Ceci procède d'une certaine continuité : la même divinité est invoquée au moyen du même objet sur le bateau et, après la navigation, à terre.

\section{AUTRES OFFRANDES MARINES}

En dehors du bateau et des ancres, d'autres ex-voto marins dédiés aux divinités olympiennes sont employés dans l'Antiquité grecque, quoiqu'en nombre beaucoup plus réduit ${ }^{681}$. Ceux-ci concernent la pêche, autrement dit ce qui concerne un rapport plus littoral de la mer, dans le cadre d'une activité quotidienne rythmée par le contact avec la terre.

\section{AtTIRAIL DU PÊCHEUR}

Des sources littéraires, épigraphiques et archéologiques manifestent la pratique de ce type d'offrande à des divinités olympiennes ${ }^{682}$.

\section{Témoignages écrits}

Un bouquet d'épigrammes compilées dans le livre VI de l'Anthologie Palatine célèbrent ainsi en vers ces ex-voto d'outils de travail de pêcheurs. Plusieurs panoplies de ce genre sont consacrées à Hermès (Anthologie Palatine VI; 5; 23; 28; 29). Elles comportent tous les instruments de la profession : hameçon, ligne, panier, filets ${ }^{683} \ldots$ et sont ainsi abandonnées au terme d'une vie de labeur. Les poèmes

${ }^{681}$ Wachmuth 1967, p. 140-142 (la plupart des sources données par le savant allemand sont tardives et concernent des divinités marines secondaires); Romero Recio 2000, p. 61-78; Icard \& alii 2011.

${ }^{682}$ Icard \& alii 2011, p. 383-384.

${ }^{683}$ Le filet seul est davantage attesté comme offrande dans le livre VI de l'Anthologie Palatine pour Pan (no 11, 12, 13, 14, 15, 167, 179, 180, 181, 182, 183, 184, $185,186,187)$; l'image récurrente de ces épigrammes est celle de la prise au filet d'animaux aériens, terrestres et aquatiques. Le filet seul est consacré à Atargatis (VI, 24) dans un poème non daté (voir O. Mazaubert, op. cit., p. 315-316), ainsi 
s'étalent sur une large fourchette chronologique, depuis le milieu du $\mathrm{III}^{\mathrm{e}}$ s. a.C. jusqu'au VI ${ }^{\mathrm{e}}$ s. p.C. De mêmes offrandes sont effectuées, de la part de simples pêcheurs au soir de leur existence, à Poséidon (Anthologie Palatine VI, 4; 30; 38) dans des poèmes de l'époque impériale ${ }^{64}$. Enfin, une épigramme tardive (ibid., VI, 27, de Théai-

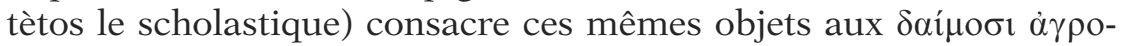

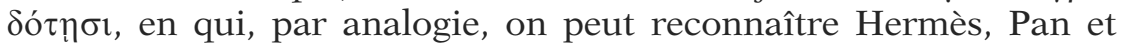
Priape. En dehors de ce recueil poétique, une seule source littéraire - tardive - mentionne l'existence d'un ensemble de pêche offert en ex-voto à une divinité olympienne. Selon Lucien (Piscator 47), un halieus a voué à Athéna dans son sanctuaire de l'Acropole une canne avec sa ligne et son hameçon.

Du matériel de pêche est surtout attesté à Délos, en raison de l'abondance de la documentation épigraphique ${ }^{685}$. Des tridents ( $\tau$ píavval) sont déposés dans l'édifice des Andriens vers 190 a.C., probablement donc à l'intention d'Apollon ${ }^{686}$. Un inventaire du temple de Zeus et Athéna Cynthiens cite pour 156/155 deux tridents dont un abîmé, pour 146/145 un trident de fer entier et un harpon à deux pointes conservés dans le second oikos ${ }^{687}$. L'état des objets contenus dans cette pièce en 156 laisse supposer des offrandes anciennes et un sanctuaire peu fréquenté; celui-ci connaît un regain de fréquentation à partir d'environ 150 a.C. ${ }^{688}$

\section{Matériel archéologique}

En ce qui concerne les témoignages archéologiques, on peut supposer des exemples beaucoup plus nombreux mais non définis comme tels. Des hameçons ou des pesons issus de fouilles ne sont pas systématiquement inventoriés parmi le matériel publié; de plus, il n'est pas toujours facile, pour des sites situés en bord de mer, de distinguer un objet usuel d'une offrande ${ }^{689}$ ou simplement de déter-

qu'à Priape (VI, 193). Ce dernier se voit, comme Hermès, offrir l'attirail complet du pêcheur (VI, 192).

${ }^{684}$ Nous suivons l'avis de Mazaubert 1937, p. 313-315 en ce qui concerne l'attribution de ces ex-voto à Poséidon, surtout pour une raison littéraire : le nom du dieu, énoncé à propos de son attribut, ne devait pas être répété une seconde fois en quelques vers.

${ }_{685}$ Deonna 1938, p. 200.

${ }^{686}$ ID 421, p. 99 l. 20.

${ }^{687}$ Plassart 1928, respect. p. 122 et 123. Kynthion : Bruneau \& Ducat 2005, p. 285-287 (no 105).

${ }^{688}$ Roussel 1987, p. 224-225.

${ }^{689}$ Autre possibilité d'usage : le recyclage du métal. Ainsi, pour les quatre 
miner sa datation. Les pesons de filets peuvent de surcroît passer pour des pesons de métiers à tisser ${ }^{690}$.

En ce qui concerne Délos, les offrandes supposées d'hameçons sont dues à l'emplacement de ceux-ci ${ }^{691}$. Parmi les trouvailles opérées dans des bâtiments sacrés, on recense des exemplaires provenant du téménos d'Apollon délien (?) ${ }^{692}$, un de l'Héraion ${ }^{693}$, deux du voisinage temple d'Artémis (?) ${ }^{694}$. Par comparaison, certaines des navettes à réparer les filets récupérées sur le site pourraient correspondre également à des ex-voto ${ }^{695}$, mais rien ne permet d'être catégorique en l'absence de contexte religieux particulier.

L'Héraion du Sele à Poseidonia paraît avoir livré des ex-voto de pêcheurs en grande quantité696. Ces derniers ont surtout été mis au jour devant l'entrée du temple et près de l'autel. À propos d'Apollon, nous avons évoqué les trouvailles d'hameçons des sanctuaires de Vouliagmeni et de Coroné. Mais de façon générale, il est difficile de recenser ce type de matériel souvent négligé dans les publications de fouilles.

\section{RAMES}

Des rames ${ }^{697}$ sont offertes en ex-voto à Poséidon et à Hermès, comme en témoignent quelques épigrammes de l'Anthologie Palatine (VI, 4; 38; 90 : Poséidon; VI, 5; 28, 29 : Hermès). Elles accompagnent alors tout l'attirail du pêcheur, c'est pourquoi elles n'ont pas été intégrées parmi les parties de bateaux : elles en sont en quelque sorte un accessoire. Ces petites pièces poétiques sont datées entre le III ${ }^{\mathrm{e}}$ a.C. et le VIe p.C.

exemplaires d'hameçons catalogués pour le sanctuaire de Gravisca, trois proviennent de l'édifice Bêta consacré à Déméter, mais semblent devoir être rattachés à une installation métallurgique antérieure (Colivicchi 2004, p. 51 et pl. 4, no 124-127; Fiorini 2005, p. 153).

${ }_{690}$ Déonna 1938, p. 152; Chavane 1975, p. 77 et note 1.

${ }^{691}$ Déonna 1938, p. 201.

${ }^{692}$ Le fait est signalé en note par Daremberg \& Saglio dans leur Dictionnaire, II, 1, s.v. donarium, p. 377, note 174c, sans aucune précision d'aucune sorte.

${ }^{693}$ Inv. B5599. Sur l'Héraion, voir Bruneau \& Ducat 2005, p. 279-281 $\left(\mathrm{n}^{\circ} 101\right)$.

${ }^{694}$ Inv. B1113, 7804. Sur l'Artémision, voir ibid., p. 207-209 (n 46).

${ }^{695}$ Déonna 1938, p. 202.

${ }^{696}$ Zancani Montuoro \& Zanotti-Bianco 1951-54, I p. 17 et 19 note 2.

${ }^{697}$ Wachsmuth 1967, p. 135 note 229; Romero Recio 2000, p. 22 s. (y compris dans des contextes funéraires). 


\section{Coquillages}

Une fois encore, ce type d,,offrande n,,est pas toujours détectable comme tel ${ }^{698}$. Des coquilles ${ }^{699}$ retrouvées en fouilles peuvent correspondre à des vestiges de repas ou déchets quelconques. De plus, ce matériau se décompose rapidement dans certains sols.

A Délos cependant, on pense que le dépôt de coquillages de grande taille, retrouvés dans le sanctuaire de l,établissement des Poseidoniastes de Bérytos ${ }^{700}$, est intentionnel. Ils représenteraient des offrandes hellénistiques à Poséidon ou plutôt à Aphrodite Astarté ${ }^{701}$. Parallèlement, un inventaire de Délos signale la présence de deux coquilles avec extrémités en bois doré, contenues dans un coffret $^{702}$.

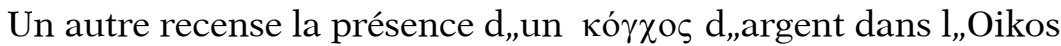
Porinos entre 177 et $174^{703}$, ce que W. Déonna interprète comme un vase revêtant cette forme, céramique attestée parmi le mobilier

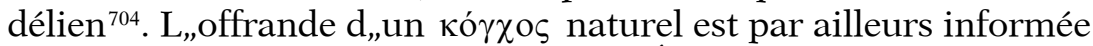
par une épigramme de Callimaque ( Épigramme V) en 1,,honneur d,„Aphrodite-Arsinoè en Égypte. C,,est une femme, Sélénaia fille de Clinias, originaire de Smyrne, qui a déposé ce don dans 1,,espoir de la charis de la déesse. Ÿ Failaka, l,,ancienne île d,,Ikaros du golfe Arabique, le pronaos du sanctuaire hellénistique d,Artémis (voir supra p. 212 s.) a livré, dans un dépôt votif, des fragments de coquillages et fragments osseux d,,un cétacé, ainsi qu,,un fragment de corail, soigneusement placé derrière un autel ${ }^{705}$.

Les dépôts archaïques ont aussi livré un certain nombre de coquillages et de coraux qu,,il convient de considérer comme des offrandes. Ils font ainsi conjointement partie du matériel votif du sanctuaire de Poséidon dans 1,,Isthme, à Rhodes, on les trouve parmi les objets mis dans le rocher sur lequel est érigé le temple d,Athéna

${ }^{698}$ Comme le souligne Tassignon 2005, p. 289 au sujet de tous les naturalia offerts dans les sanctuaires.

${ }^{699}$ Des coquillages sont aussi des offrandes mortuaires : voir supra p. 340 s., à propos du motif sur ancre de plomb.

${ }^{700}$ Voir Bruneau \& Ducat 2005.

${ }^{701}$ Picard 1921, p. 132, note 2 ; Bruneau 1970, p. 628. Le bâtiment comporte plusieurs chapelles, dédiées à Rome, Poséidon de Bérytos et Astarté (Bruneau \& Ducat 2005, p. 227-231: $\mathrm{n}^{\circ}$ 57).

${ }^{702}$ Noter le parallèle avec les deux coquilles d,,huitre montées sur des colonnettes en bois d,,Agathé Tuché : Vallois 1929, p. 34-35; Roussel 1987, p. 246; Tassignon 2005, p. 293-294.

${ }_{703} I D$ 444, p. 193, 1. 19; ID 457, p. 230, 1. 28.

${ }^{704}$ Déonna 1918, p. 201 et note 7.

${ }^{705}$ Salles 1984 , respectivement p. $84 \mathrm{n}^{\circ} 152$, p. 132 et fig. 71 [dans la fig. 71 , il faut lire 152 au lieu de 162]; p. 100 n $^{\circ} 229$ et p. 138-139. 
Lindia (dont certains coquillages de grande dimension) ${ }^{706}$. Le corail semble être, à cette époque, considéré comme un don particulier, peut-être venu de l'Ouest et confiés à des sanctuaires à forte connotation maritime, tels ceux de Pérachora consacrés à Héra Akraia et Liménia. ${ }^{707}$

\section{POISSONS ET FRUITS DE MER}

\section{Offrandes}

Les offrandes de poissons ${ }^{708}$ sont encore connues par quelques épigrammes du livre VI de l'Anthologie Palatine ${ }^{709}$. La première (VI, 105 d'Apollides), de l'époque augustéenne, consacre à Artémis avec un peu de vin et de pain deux produits de la mer: un surmulet

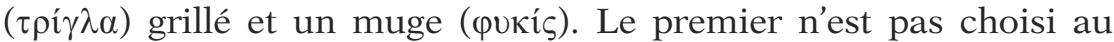
hasard, car il s'agit d'un animal voué à la déesse ${ }^{710}$. Le dédicant espère en échange des pêches fructueuses.

Le second poème (VI, 230), malheureusement non daté mais d'époque romaine d'après le nom de son auteur Quintus, est pour sa part destiné à Phoibos Akritas. Le pêcheur bithynien lui rend hommage par le don d'un buccin $(\kappa \tilde{\eta} \rho v \xi)$ dans l'espoir d'une mort paisible après une vie de labeur.

À Failika, l'ancienne Ikaros (voir supra p. 96), dans un atelier voisin de deux temples gréco-oriental du $\mathrm{II}^{\mathrm{e}} \mathrm{s}$. a.C., ont été retrouvés deux fragments de moules servant à fabriquer des poissons de terre cuite $^{711}$. Ainsi, à défaut d'un vrai poisson, pouvait-on offrir sa reproduction céramique, voire métallique. De la même manière, dans le sanctuaire d'Artémis Orthia à Sparte, parmi le nombreux matériel votif figurent deux petits poissons de plomb ${ }^{712}$.

706 Tassignon 2005, avec références.

${ }^{707}$ Tassignon 2005, p. 295-296 et 303.

${ }^{708}$ Bodson 1978, p. 48-50; Sébillot 1901, p. 116 ss.; Stengel 1910, p. 197-202.

${ }^{709}$ Par ailleurs, Priape se voit consacrer une langouste (VI, 89) et Pan une sorte de crabe (VI, 196) dans des poèmes datés du I ${ }^{\mathrm{er}}$ S. a.C.

${ }^{710}$ Athénée, Deipnosophistes VII, 325a (cite Platon, auteur comique de la fin

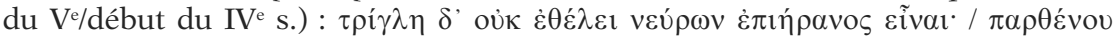

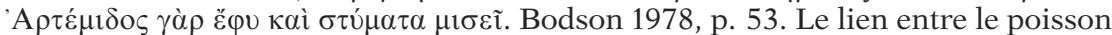
et Artémis fait inévitablement penser à celui établi entre ce même animal et la syrienne Atargatis : voir par exemple Teixidor 1979, p. 71-76.

${ }_{711}$ Mathiesen 1982, p. 61-62 no 100-101. L'un des deux temples voisins a livré quant à lui des bateaux de terre cuite : voir supra p. 213 et 383 s. Ceci peut laisser supposer la production de poissons de terre cuite servant d'offrandes pour un culte marin. Voir également Jeppesen 1965.

${ }^{712}$ Dawkins 1929 , p. 263 et 269 , pl. $184 \mathrm{n}^{\circ} 17$ et pl. $189 \mathrm{n}^{\circ} 22$; ils appartiennent au deux premiers groupes de son classement des figurines en plomb, des 
Une offrande particulière est signalée par une autre épigramme (Anthologie Palatine VI, 251) datée du I ${ }^{\mathrm{er}}$ s. de notre ère. Le dieu de Leucade est honoré d'une libation, d'une lampe et d'une $\pi \lambda \omega \tau \eta \dot{\rho} \rho \omega v$ $\mu \alpha ́ \xi \eta$. Celle-ci consiste en une sorte de galette séchée, ce que nous pourrions appeler un biscuit de conserve ${ }^{713}$, pratique pour emmener à bord. Le vœu formulé est que la navigation soit favorable jusqu'au port d'Actium.

Tous ces ex-voto «alimentaires» veulent signifier l'ordinaire de leurs dédicants, lié au milieu dans lequel ils vivent ${ }^{714}$. Poséidon se voit ainsi offrir à Halai, en Éolie, les prémices de la pêche au thon (Athénée VII, 297e) ${ }^{715}$.

\section{Consécrations}

Certains animaux marins sont consacrés à des divinités particulières $^{716}$. Ainsi, par exemple, la daurade renvoie à Aphrodite de Cythère (Athénée VII, 328a-b). Le pompile est également consacré à la déesse de l'écume, mais aussi à Poséidon et aux Dieux de Samothrace ${ }^{717}$. On attribue ainsi le dauphin à Apollon, Aphrodite et Artémis, ou le surmulet aux déesses des mystères, ou le mulet à Héra Argienne (Plutarque, De sollertia animalium 983e-984c). Les traditions varient d'un auteur à l'autre, d'une cité ou d'une région à l'autre.

\section{Interdictions}

Le poisson présente ceci de particulier, dans les pratiques cultuelles grecques, qu'il est tabou pour certaines divinités ou

première et seconde moitiés du $\mathrm{VII}^{\mathrm{e}} \mathrm{s}$. L'archéologue rapproche d'ailleurs le premier exemplaire des animaux représentés sur la fameuse plaque d'ivoire provenant du même sanctuaire (voir supra p. 392 et fig. 31). Autres exemples de représentations de poissons dans Icard \& alii 2011, p. 384.

${ }^{713}$ Parfois de poisson séché : Arrien, Indica 29, 12.

${ }^{714}$ La pratique est ancienne : à Délos, le dépôt sacré mycénien de l'Artémision contenait, outre des objets précieux, de nombreux ossements qu'on peut supposer appartenir aux animaux sacrifiés; y sont attestés également des coquilles de mollusques (Gallet de Santerre 1958, p. 131). Voir également le cas d'Éphèse (Picard 1922, p. 60).

${ }^{715}$ Répété dans Athénée, 303b; id., VIII, 346c indique par ailleurs que le thon est un des attributs du dieu.

${ }^{716}$ Sur ce thème, voir l'ouvrage de Bodson 1978; Sébillot 1901, p. 341 ss.; sur les poissons d'Aphrodite, Pirenne-Delforge 1994, p. 417-418; sur les dauphins, Somville 1984, p. 3-24 et Dumont 1975, p. 57-85.

${ }^{717}$ Athénée, Deipnosophistes VII, 282f-283a; Élien, De la nature des animaux $\mathrm{XV}, 23$. 
certains sanctuaires ${ }^{718}$. Ces interdictions, qui se situent en marge des croyances pythagoriciennes, montrent des caractères variés.

Le sanctuaire d'Éleusis comporte des effluves d'eau de mer poissonneuses, où seuls les prêtres des deux déesses ont le droit de pêcher, aux dires de Pausanias (I, xxxviii, 1) ${ }^{719}$. Ce dernier donne une information du même genre pour le sanctuaire d'Hermès à Pharai, où l'on ne peut capturer les poissons du dieu (VII, xxii, 4). À Argos, seule la prêtresse d'Héra Argienne a le droit de consommer du surmulet $(\tau \rho i \gamma \lambda \eta)^{720}$. Ce poisson fait partie également des denrées maritimes interdites lors des Halôa attiques célébrées en l'honneur de Déméter, Koré et Dionysos ${ }^{721}$. Dans l'île de Délos, Brizô refuse les offrandes de poissons (Eustathe, Ad Odyss. M, 252 : voir supra).

\section{Conclusion}

Les offrandes concernant le monde de la pêche au sens strict ne sont pas nombreuses. Ou plutôt, peut-on nuancer en arguant du caractère modeste de celles-ci, elles échappent ainsi aux témoignages littéraires, épigraphiques et archéologiques de la plupart des sanctuaires. Pour les quelques attestations connues, les divinités olympiennes sont assez diverses ${ }^{722}$ : Aphrodite, Apollon, Artémis, Hermès, Poséidon, Zeus ou Athéna. Aucun exemple ne semble antérieur à l'époque hellénistique, mais il ne faut pas pour autant en conclure trop précipitamment l'absence de telles pratiques aux époques archaïques et classiques. Ces offrandes sont réalisées dans l'espoir de bonnes pêches, mais aussi à la fin d'une vie de labeur afin de remercier la divinité de sa bienveillance. Une seule épigramme espère en retour une traversée heureuse. Les tabous concernant les poissons dans certains sanctuaires correspondent à une protection de ces animaux, qu'on considère comme sacrés et propriété des dieux.

${ }^{718}$ Bodson 1978, 50-51; Icard \& alii 2011,p. 385-386.

${ }^{719}$ Également chez Élien IX, 51; 65. L'interdiction du poisson figure, parmi d'autres moins anciennes, chez Porphyre, De l'abstinence IV, 16, 6 de façon allusive.

${ }^{720}$ Élien, IX, 65.

${ }^{721}$ Scholie à Lucien, Dialogii meretricii VII, 4. Sur cette fête, voir Deubner 1932, p. 60-67.

${ }_{722}$ Cf. Mazaubert 1937. 

CONCLUSION 

$\mathrm{Au}$ terme de cette enquête, dans laquelle les sources, tant littéraires qu'archéologiques, s'avèrent extrêmement nombreuses et riches, il est impossible de nier que les divinités olympiennes reçoivent des cultes et des traditions en rapport avec la mer, et que dans ce domaine Poséidon est loin d'y occuper la première place. Au delà de leur aspect parfois tragique ou comique, les anecdotes religieuses maritimes révèlent une grande sensibilité des Anciens à l'aspect géographique des rivages, ainsi que leur sentiment intime de fragilité ou d'impuissance face à un espace que l'on ne peut se concilier sans l'aide de dieux puissants.

Cette multiplicité des cultes n'est pas surprenante, au vu de l'omniprésence des situations maritimes dans le monde grec et du caractère polythéiste de la religion antique. Malgré leur diversité, il ressort néanmoins une impression générale de cohérence. Chaque dieu reste fidèle aux traits de caractère ou prérogatives qu'il affirme par ailleurs en s'adaptant au milieu maritime ${ }^{1}$. Chaque divinité paraît ainsi individualisée par un certain nombre de points : moyens d'actions et lieux d'implantation, nature des actes de dévotion qui lui sont rendus. La dévotion des marins s'attache à l'éventail divin le plus large qui soit, en respectant cependant une certaine cohérence vis-à-vis des traditions, et particulièrement des textes homériques.

\section{LES DIEUX}

En ce qui concerne les secteurs d'activité des divinités olympiennes dans le domaine maritime, le plus souvent ils s'entrecroisent d'une attestation à l'autre : les dieux favorisent ainsi la navigation comme la pêche. Zeus semble le seul à ne pas avoir de rapport avec l'halieutique, à l'inverse de Poséidon. La séparation de leurs pouvoirs respectifs n'est pas aussi stricte qu'il y paraît : Zeus

${ }^{1}$ Ceci correspond tout à fait aux réflexions de Brelich 1960 qui développe l'idée non pas d'un polythéisme mais de polythéismes, c'est-à-dire que les êtres divins eux aussi sont divers. 
est souvent associé à la navigation au détriment de son frère; même, son culte dans ce registre s'avère primordial.

Quelques points communs unissent les dieux olympiens dans leur rapport avec la mer. Il est frappant de constater comme leur intervention s'exerce en grande majorité au moyen des vents - et c'est sur cette différence que se pose en fait la spécificité exclusive de Poséidon. Ceci renvoie sans nul doute à leur nature de divinité «olympienne»: aérienne et non marine. Ainsi, à la différence des divinités marines secondaires, ils ne sont jamais imaginés dans l'eau. Même lors de leurs interventions ou épiphanies marines, ils arrivent du ciel - depuis l'Olympe peut-on supposer - pour se poser sur un rocher comme Apollon, Athéna, Héra, ou à bord d'un bateau comme le fait encore Apollon. Même Aphrodite se déplace au-dessus de l'eau dans une coquille ou un dauphin. Finalement aucun ne paraît avoir de réel contact avec l'eau, hormis Poséidon qui habite dans les profondeurs de la mer et Dionysos qui y trouve refuge dans son enfance.

Ces points communs entre les divinités olympiennes se traduisent par l'attribution de mêmes épiclèses définissant une prérogative marine. Par exemple celle d'Apobatèrios s'applique à plus de quatre dieux, celle d'(Épi)liménia à Aphrodite et Héra et celle de Sôter à Zeus, Athéna et Artémis. Les attributs et pouvoirs de chacun se montrent interchangeables au gré des circonstances.

À cet égard est significative l'absence de type iconographique spécifique au culte marin de ces divinités: dans les sanctuaires maritimes, Apollon est représenté en citharède ou archer, Dionysos au canthare, Artémis au carquois ou à la torche avec un chien. Seul un objet associé à la divinité - un aplustre, une ancre - ou le contexte - un bateau, une proue, un port - permet d'orienter la nature du dieu. Il est à noter par ailleurs le grand nombre d'occurrences de "xoana» dans les sanctuaires marins, terme qui doit indiquer que pour Plutarque et Pausanias du moins ces cultes étaient anciens.

De manière générale, les cultes marins des divinités olympiennes présentent des liens très forts avec des cultes chtoniens ${ }^{2}$ : sous une même épiclèse comme Zeus Meilichios, Apollon Lykeios ou Artémis-Eurynomé, dans un sanctuaire comme celui de Ténare. Même certaines pratiques s'avèrent proches, comme les dépôts d'ancres ou d'astragales dans des tombes. La mer et la mort ne sont jamais dissociés: le sacrifice d'Iphigénie, le saut de Leucade en constituent des survivances dans la mémoire collective. Les cultes ou sanctuaires des divinités auxquelles on s'adresse pour une dévo-

${ }^{2}$ Même analyse dans Romero Recio 2000, p. 49-54. 
tion en relation avec la mer peuvent ainsi être de nature initiatique, mais encore oraculaire (Apollon à Delphes), ou a priori de toute autre nature.

Couramment, les cultes maritimes ne craignent pas le cumul : en effet, dans des environnements maritimes difficiles ou inhospitaliers, il vaut mieux ne pas prendre le risque d'oublier une divinité ${ }^{3}$. Dans un tel contexte, si l'on peut ainsi faire acte de dévotion à plusieurs divinités olympiennes, celles-ci sont également plus ou moins compatibles avec d'autres divinités marines. Au cours de notre enquête, nous avons ainsi croisé Asclépios Apobatèrios à Iasos ${ }^{4}$, Héraclès, plusieurs divinités orientales (Astarté, Melqart, Baal, Isis...), Leucothée, Palémon, les Dioscures, ainsi que des figures du thiase marin (Amphitrite et Néréides, Triton, Nérée). D'autres divinités, en revanche, ne semblent pas associées à des dieux olympiens dans des prérogatives maritimes : ni Achille et Diomède ${ }^{5}$, honorés dans le Pont-Euxin, ni les Grands dieux de Samothrace - le culte à mystères constituant peut-être une barrière exclusive et une protection suffisante au fidèle initié.

\section{Circonstances}

$\mathrm{Au}$ travers des sources se dessinent plusieurs circonstances permettant d'expliquer l'origine de ces cultes marins. Malgré des permanences, ceux-ci évoluent au fil du temps en fonction du contexte historique.

Leur importance à l'époque archaïque est particulièrement liée au processus de colonisation. Les légendes de fondation auxquels ils sont souvent rattachés expliquent comment une divinité a pu être transportée par les colons depuis la métropole, et comment son culte dans la colonie a évolué en fonction de la navigation et de son déroulement. Ce phénomène n'est pas spécifique à la colonisation : en fait, tout marin au long cours peut ainsi véhiculer un culte avec lui. Le culte de Zeus s'échelonne ainsi depuis Butrint par Kassiopè, Otrante, jusqu'Santa Maria di Leuca et peut-être Crotone; Aphrodite de Chypre arrive à Naucratis. Les divinités voyagent avec les navigateurs et au fur et à mesure de leur progression spatiale, leur physionomie évolue également au contact des uns et des autres ou des aléas de la route.

${ }^{3}$ Telle la fondation de l'autel des Douze Dieux par les Argonautes (Georgoudi 1998, p. 75-76).

${ }^{4}$ Robert 1969; Jacquemin 2002.

${ }^{5}$ Voir en dernier lieu Parker 2011, p. 244-246, avec bibliographie. 
Ceci renvoie par ailleurs au culte des théoi patrôoi, selon la formule d'Ésope (Fable CCCVIII). La divinité poliade d'une cité maritime reçoit naturellement des marques de dévotion de la part des habitants qui vivent de la mer et s'adapte au caractère du lieu. Mais il arrive aussi que le dieu d'une ville située à l'intérieur des terres suive les pérégrinations de ses habitants sur les flots, comme c'est le cas pour Artémis à Sparte.

En de nombreux endroits, les divinités rentrent alors en concurrence ou se substituent à des cultes locaux plus anciens. Ces confrontations ou assimilations créent des figures originales propres à une région : ainsi pour Athéna, Artémis, Aphrodite ou Dionysos.

Après cette prolixité de la période archaïque, on discerne pour l'époque classique, malgré le manque de sources, une continuité de culte. L'époque hellénistique paraît constituer une sorte de renouveau des cultes maritimes, même s'ils ne s'adressent plus aux mêmes divinités ou alors de manière différente. Cependant, à cette période ne se répète pas une extension similaire à celle de l'époque archaïque : la cause en est sûrement la faveur des divinités orientales et la vogue de la divinisation des souverains hellénistiques. Ceux-ci ont pourtant grandement valorisé le caractère ou le culte marin des divinités olympiennes - manière indirecte d'affirmer leur pouvoir sur l'espace méditerranéen.

Plusieurs facteurs s'entremêlent ainsi pour façonner des facettes marines aux divinités olympiennes. L'élément essentiel qui se dégage de ce tableau est la grande souplesse, l'adaptabilité des dieux devant les circonstances.

\section{LES FIDÈLES}

Quelles sont les personnes qui accomplissent ces cultes? Les sources omettent le plus souvent de le préciser. Il faut tout d'abord distinguer entre dévotion publique et privée. Un certain nombre de témoignages renvoie à des pratiques cultuelles de type officiel ou civique : les offrandes les mieux connues sont celles qui revêtent un caractère historique, commémorant quelque victoire ou fait politique; celles-ci, de manière générale, ont l'air de s'affirmer à partir du $V^{\text {e }}$ s., comme on le constate à l'Héraion de Samos et en d'autres sanctuaires ${ }^{6}$. On notera d'ailleurs que c'est à ce moment aussi, vers la fin de l'époque archaïque et au début de la suivante, que dans plusieurs sites religieux (par ex. Samos, Crotone, Gravisca),

\footnotetext{
${ }^{6}$ Furtwängler 1997, p. 142-143.
} 
l'archéologie révèle des changements de voies sacrées ou des aménagements nouveaux qui, en privilégiant l'accès depuis la terre par rapport à la mer ou en restructurant les espaces, transforment les cultes et renouvellent semble-t-il les populations qui les fréquentent comme la nature des offrandes.

À côté de pratiques liées à la cité ou aux détenteurs du pouvoir (notamment les stratèges, pour lesquels il est difficile de démêler la part de dévotion privée de la façade publique), les marques de dévotion marine apparaissent souvent liées à la catégorie des commerçants ou négociants, à titre individuel ou regroupés en association. D'autres fidèles, en groupes ou isolés, se laissent deviner : pêcheurs, marins de la flotte, voyageurs occasionnels. Lorsque l'on peut en identifier le dédicant, les manifestations de culte en milieu maritime émanent, de façon presque exclusive, d'hommes : les femmes sont comme absentes - hormis quelques attestations pour Aphrodite et Brizô - ou du moins silencieuses ou discrètes.

\section{Pratiques}

Une grande diversité caractérise les pratiques cultuelles marines vouées aux divinités olympiennes. Les hiéra possèdent une physionomie très différente de l'un à l'autre: sanctuaires construits, statues, autels, grottes ${ }^{7}$, lieux consacrés. Au niveau des espaces architecturés, on trouve aussi bien des sanctuaires poliades, fédéraux ou panhelléniques, que des sanctuaires emporiques, de port ou péri-urbains. Le culte se caractérise de façon générale par sa mobilité : il peut se rendre partout, sur une plage, un promontoire, une île déserte, et bien sûr à bord. La décoration navale, le nom du bateau, l'ancre utilisée, voire même des objets qu'on emporte à la manière d'amulettes - ce à quoi s'apparente finalement la statue chypriote du nauclère de Naucratis - : tout est occasion à rechercher la protection des dieux. À cet égard, la multiplicité des références aux divinités est révélatrice : comme on l'a noté pour la présence du sacré à bord, il y a surenchère des protections : lors des invocations et sacrifices marins sont souvent sollicités plusieurs dieux à la fois. L'exemple de Naucratis et les énumérations de sanctuaires côtiers montrent également que le navigateur honore le dieu qu'il trouve sur sa route. Le périple de Néarque ou les instructions nautiques de géographes antiques témoignent aussi du caractère actif de la reli-

${ }^{7}$ Ce qui n'est pas sans évoquer des pratiques bien établies dans la culture phénicienne : Grotanelli 1981; Gómez Bellard \& Vidal González 2000; Medas 2000, p. 42-48; Brody 2005, p. 179-180. 
gion des marins qui consacrent et baptisent un lieu qu'ils découvrent depuis le large d'après les caractères attribués à une divinité.

De la même manière, les ex-voto sont consacrés pour leur grande majorité dans un sanctuaire littoral (de port ou extra-urbain) sans que cela constitue cependant une règle absolue : tout téménos peut recevoir une offrande de navigateur, y compris à l'intérieur des terres dans un sanctuaire panhellénique comme celui de Delphes ou Dodone. Elle peut également être déposée dans le sanctuaire d'un autre dieu que celui auquel il est consacré. A l'image des dieux, les pratiques cultuelles maritimes sont très souples, mobiles, s'adaptant à toutes les situations; chacun adopte à sa convenance un culte poliade, local ou étranger.

Le tout donne l'image d'un culte vivant et concret, surtout en ce qui concerne les sanctuaires de bord de mer. Plusieurs légendes mettent en scène des statues transportées à bord et les actions "physiques» de celles-ci; d'autres rapportent des vols de statue emmenée de force sur un navire. Au travers des discours de Cicéron contre Verrès et d'allusions d'autres auteurs - par exemple Plutarque, Pompée 24, 6-, on devine la vitalité et la fréquentation de ces sanctuaires de bord de mer. L'impression qui s'en dégage est celle de sites, fréquentés par des gens de toutes origines géographiques ou sociales, en quelque sorte ouverts à touts vents. Ces lieux sont souvent auréolés d'une grande sacralité - même les pirates ou barbares ne s'y attaquent pas, est-il affirmé -, due en partie au syncrétisme qui se manifeste particulièrement dans ce type de sanctuaire de passage ${ }^{8}$. Malgré tout, les attaques perpétrées par les pirates à l'époque hellénistique laissent supposer aussi des sanctuaires riches et isolés.

\section{GÉOGRAPHIE DU CULTE}

La répartition géographique de ces cultes olympiens maritimes s'étend à tout le bassin méditerranéen et même au-delà. Certaines zones sont particulièrement favorables à leur multiplication : la Laconie et le sud de la Messénie, le golfe Saronique et celui de Corinthe, le littoral d'Asie Mineure et le Bosphore, la mer Ionienne

${ }^{8}$ Comme l'ont mis en évidence Bonnet \& Pirenne-Delforge 1999 pour Aphrodite et Astarté, il faut voir dans ce syncrétisme «un processus menant à l'élaboration d'une entité complexe qui est toujours davantage que la somme des parties qui la composent». 
et la Sicile. En revanche d'autres constituent des vides : tout le littoral nord-ouest de la mer Égée, la côte ouest de la Messénie ${ }^{9}$, la façade est de la péninsule italienne. Ceci contredit l'image d'un monde grec tourné vers la mer : dans le nord, l'absence de tout sanctuaire maritime montre que ces régions privilégiaient l'intérieur des terres ${ }^{10}$.

Se dessinent ainsi des routes maritimes, déjà connues. L'une se dirige depuis la mer Egée vers l'Espagne, en passant au sud de la Sicile, jusqu'aux Colonnes d'Hercule et même sur la façade atlantique. Une autre beaucoup plus fréquentée remonte le littoral ouest de la Grèce continentale jusqu'au détroit d'Otrante pour le traverser et continuer vers l'Étrurie en suivant le sud de l'Italie. Le nombre de sanctuaires marins consacrés aux divinités olympiennes en Grande Grèce et Sicile confirme l'importance de leur culte à l'époque archaïque.

L'implantation d'un sanctuaire maritime répond à un certain nombre de critères. Il est des lieux propices à l'association avec une divinité : anse naturelle, promontoire, mont surplombant la mer, île. De plus les vents, la possibilité de mouillage déterminent le choix d'un emplacement. Ces différents éléments écologiques, répondant à un certain nombre de fonctions recherchées par les marins ${ }^{11}$, doivent expliquer le développement particulier du culte marin des divinités olympiennes en Grande Grèce.

Les caps sont essentiels comme jalons des itinéraires: ils servent d'amers et de points de repère pour les navigateurs ${ }^{12}$. La manière dont sont formulés les périples nautiques antiques repose sur la manière de calculer les distances d'un cap à un autre dans un contexte de navigation de cabotage et de navigation à vue ${ }^{13}$. La position géographique des sanctuaires marins en bord de mer rythme le découpage du paysage : de promontoires en promontoires, de golfes en golfes, de ports en ports. Les temples eux-mêmes constituent d'excellents amers, visibles de loin par leur élévation et leurs couleurs ${ }^{14}$.

${ }^{9}$ Fenet 2002.

${ }^{10}$ Semple 1932, p. 595-596.

${ }^{11}$ C'est ce que Kowalski 2012 (p. 66-67, avec lexique p. 177-221) met en évidence sous le nom d' «affordances».

${ }_{12}$ Semple 1932, p. 584; Cabantous 1990, p. 100-101.

${ }^{13}$ Semple 1932, p. $586-587$

${ }^{14}$ Pagliara 1991, p. 508 : "Alcune fonti esplicitamente ricordano, invece, alcune caratteristiche dei punti di approdo in terra iapigia : il navigante doveva individuare da lontano un akron e più presso la costa, scorgere uno hiéron che segnava il luogo dell'approdo.» 
Ces sanctuaires maritimes peuvent être souvent perçus comme des sanctuaires de confins, fixant les limites de territoire des cités. J. Rougé a posé le problème de la notion territoriale des eaux et de l'existence dans l'Antiquité ${ }^{15}$. Cela nous amène à penser que peutêtre les sanctuaires du littoral servaient non seulement comme amers, mais aussi pour délimiter les zones maritimes de chaque cité. Ainsi le règlement de Gortyne, concernant l'île de Gaudos ${ }^{16}$ à propos de la récupération des épaves qui s'y trouvent, attribue la dîme des bénéfices obtenus à Apollon Pythien; la loi d’Érétrie du $\mathrm{VI}^{\mathrm{e}}$ s. a.C. délimite des zones maritimes en-deçà du promontoire Kènaion, qu'on sait par ailleurs consacré à Zeus ${ }^{17}$. R. Chevallier a de son côté mis en avant la valeur de la divinité dans le choix d'un site portuaire car elle sert de garantie dans les échanges commer$\operatorname{ciaux}^{18}$. Les deux faits se rejoignent dans le sens où la divinité et son sanctuaire fixent les bornes de ce qui est permis aux uns et aux autres, notamment en termes de droit commercial. L'étude de J. Vélissaropoulos sur les nauclères, bien que reposant parfois sur des restitutions de textes à observer avec prudence, a montré la part que les dieux prenaient aux activités d'import-export : patrons d'associations, taxes imposées en leur nom ou au profit de leurs sanctuaires, ils renvoient l'image d'un monde social où les croyances religieuses constituent l'un des fondements des procédés d'échanges. Les études les plus récentes insistent ainsi sur le caractère spécifique de ces espace consacrés en contexte maritime, qui servent ainsi de lieu de lieux pacifiés, neutres où les marins peuvent faire escale, trouver refuge et éventuellement se retrouver, pratiquer le commerce sous la protection de la divinité ${ }^{19}$. La notion de «culture maritime» trouve ici tout son sens, dans l'imbrication de conditions matérielles et d'un imaginaire à la fois individuel et collectif ${ }^{20}$.

L'étude des cultes marins, on le voit, nécessite d'élargir les champs de vision et cadres traditionnels. Pour réellement saisir leur

${ }^{15}$ Rougé 1974a différencie spécialement le port comme «une partie de l'espace civique de la cité», de son rivage et de ses eaux.

${ }^{16}$ Vélissaropoulos 1980, p. 158.

${ }^{17}$ Vélissaropoulos 1980, p. 138. Cf. les sanctuaires de Pérachora et de Sounion considérés comme des sanctuaires de limites géographiques, l'un des eaux du golfe de Corinthe et l'autre de celles de l'Attique.

${ }^{18}$ Chevallier 1968 : ceci est particulièrement notable en Grande Grèce où des trouvailles préhistoriques ont souvent été faites à l'emplacement des principaux sanctuaires grecs.

${ }^{19}$ Par ex. Medas 2000, p. 42-48; Ruiz de Arbulo 2000, p. 9-32; Ruiz Cabrero 2010, p. 19-20 et 26-29.

${ }^{20}$ Virlouvet 1998. 
origine, leur sens et leur portée, il faut tenir compte d'un ensemble de facteurs que nous ne maîtrisons pas encore suffisamment, concernant la pratique de la navigation dans l'Antiquité et des contingences du milieu maritime: par exemple l'utilisation de l'oiseau dans l'art nautique, pour annoncer la terre ou la tempête à venir; les conditions naturelles de voyage maritime, en particulier les courants et les vents. De nombreux rites célébrés à bord, l'apparence et l'intérêt de nombreux sanctuaires abordés depuis la mer ne peuvent pas se percevoir selon un angle de vue terrestre. C'est dans ce sens et dans la grande souplesse de ces cultes que l'on peut parler, non pas de divinités marines, mais d'une religion marine grecque. 

CARTES 



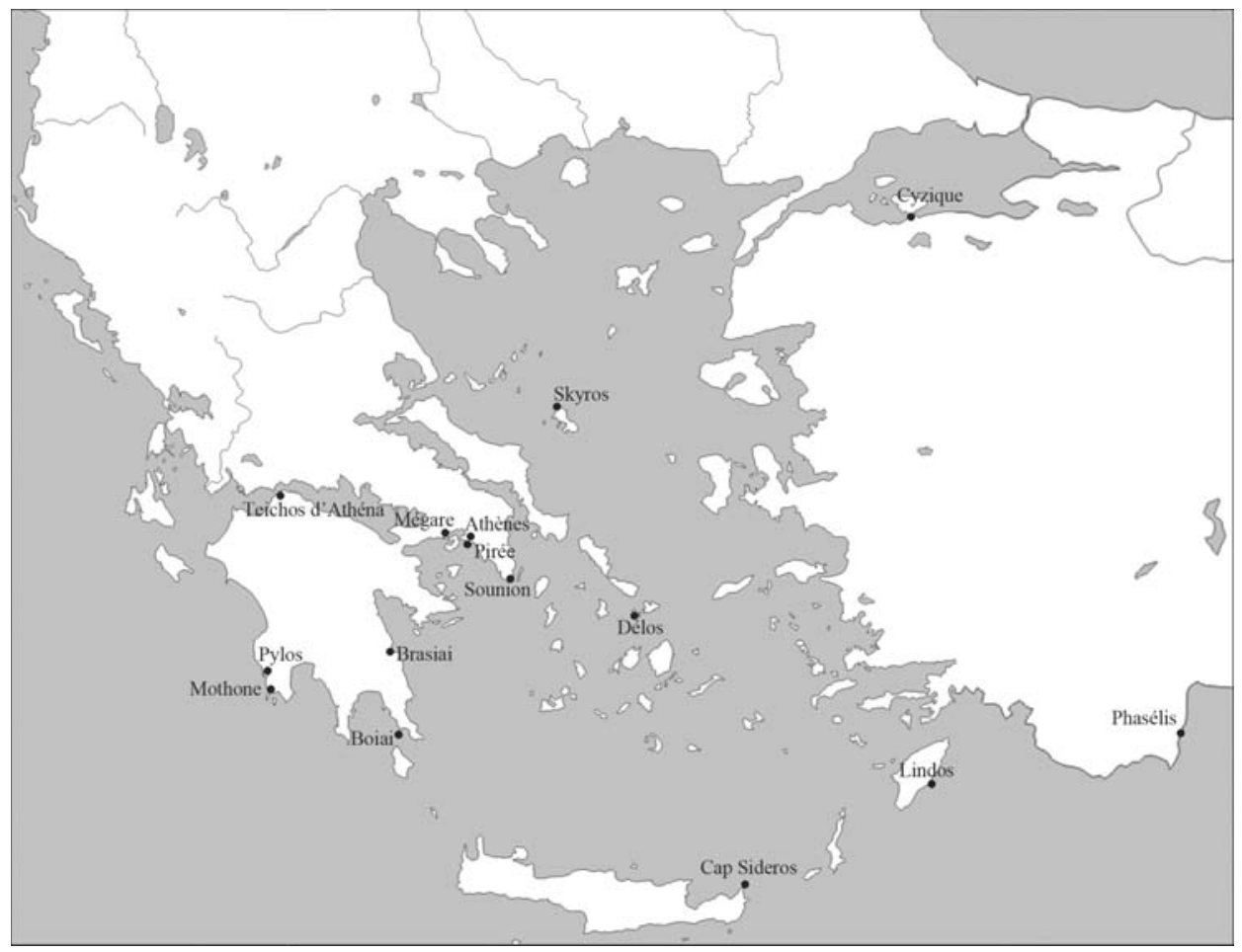

Carte 1 - Attestations du culte marin d'Athéna dans le monde égéen en Lycie et en Propontide (๔ F. Ory-UMR 8546 - CNRS).

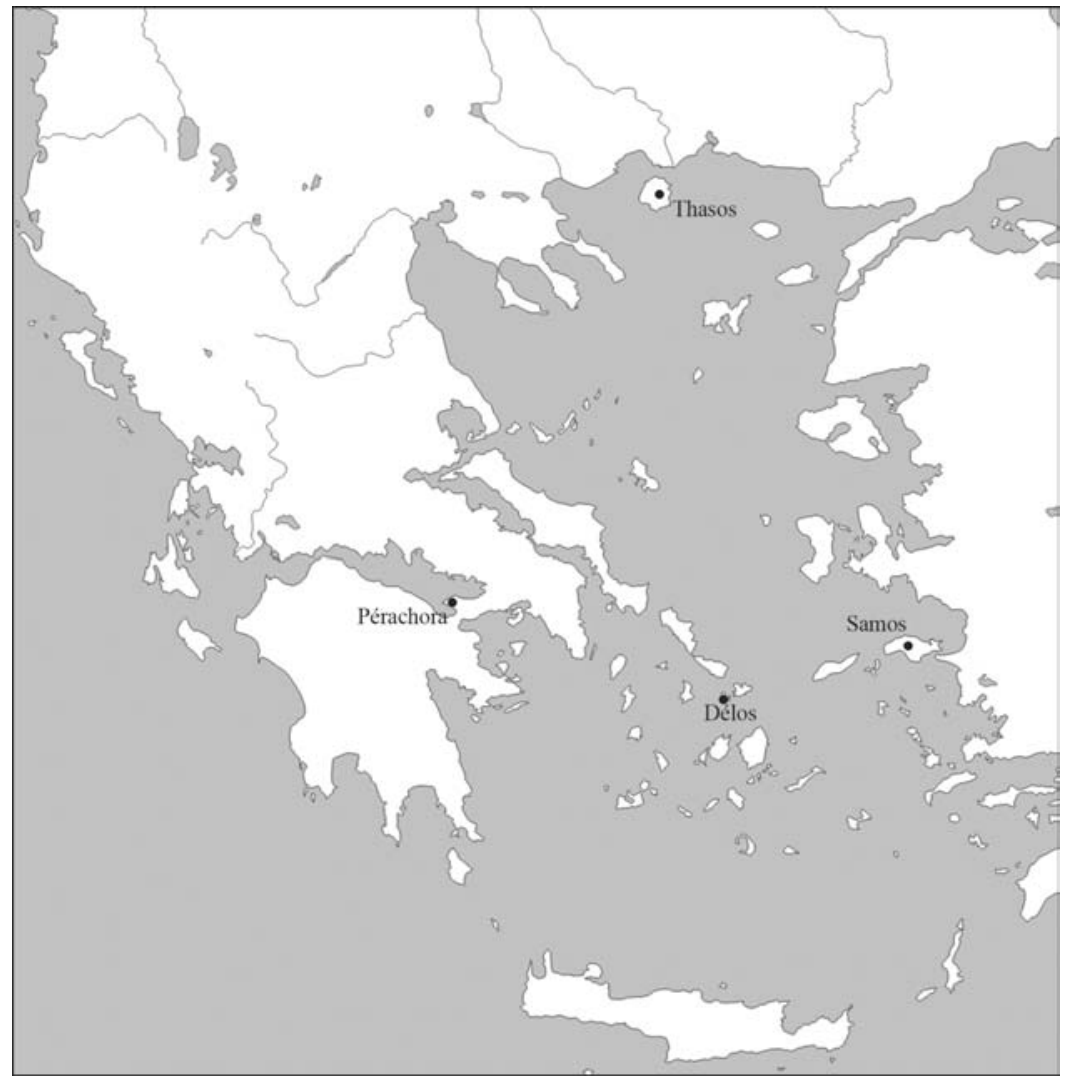

Carte 2 - Attestations du culte marin d'Héra dans le monde égéen (@ F. Ory-UMR 8546 - CNRS). 


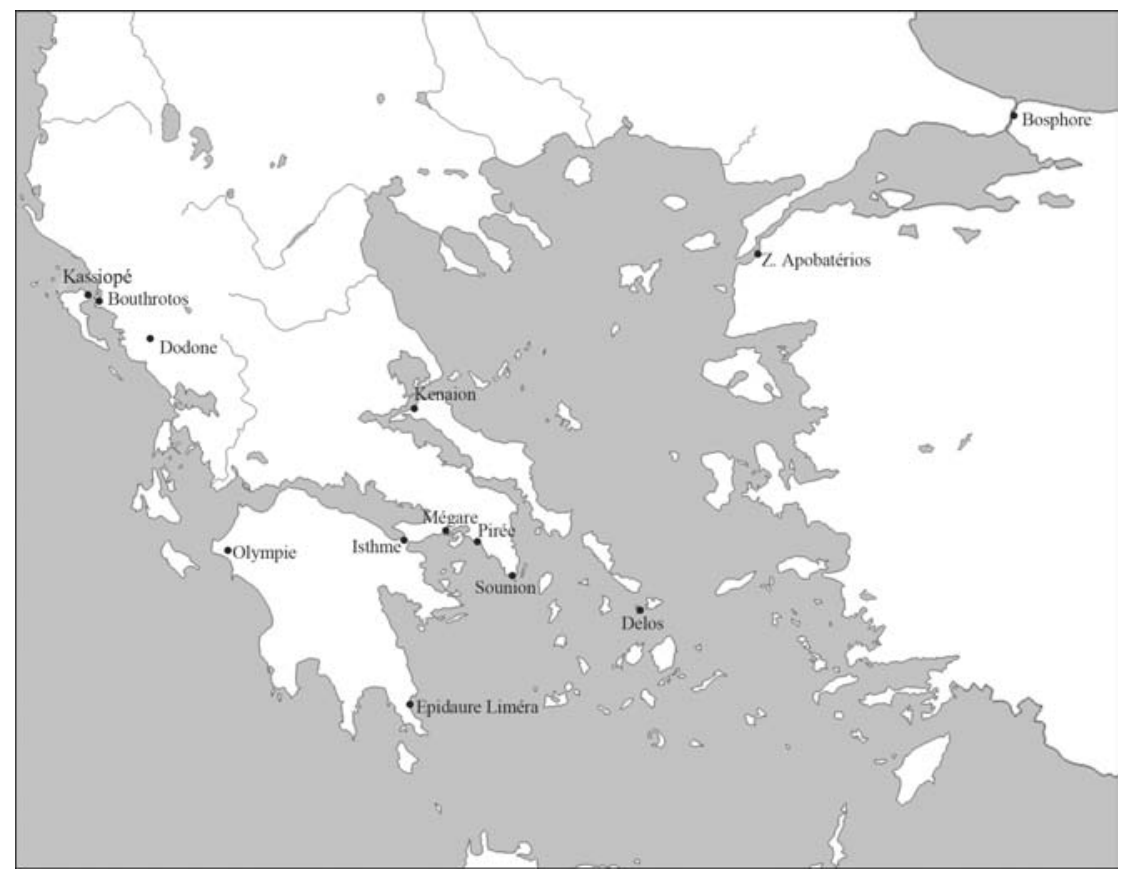

Carte 3 - Attestations du culte marin de Zeus dans le monde égéen et en Propontide (ㄷ) F. Ory-UMR 8546 - CNRS).

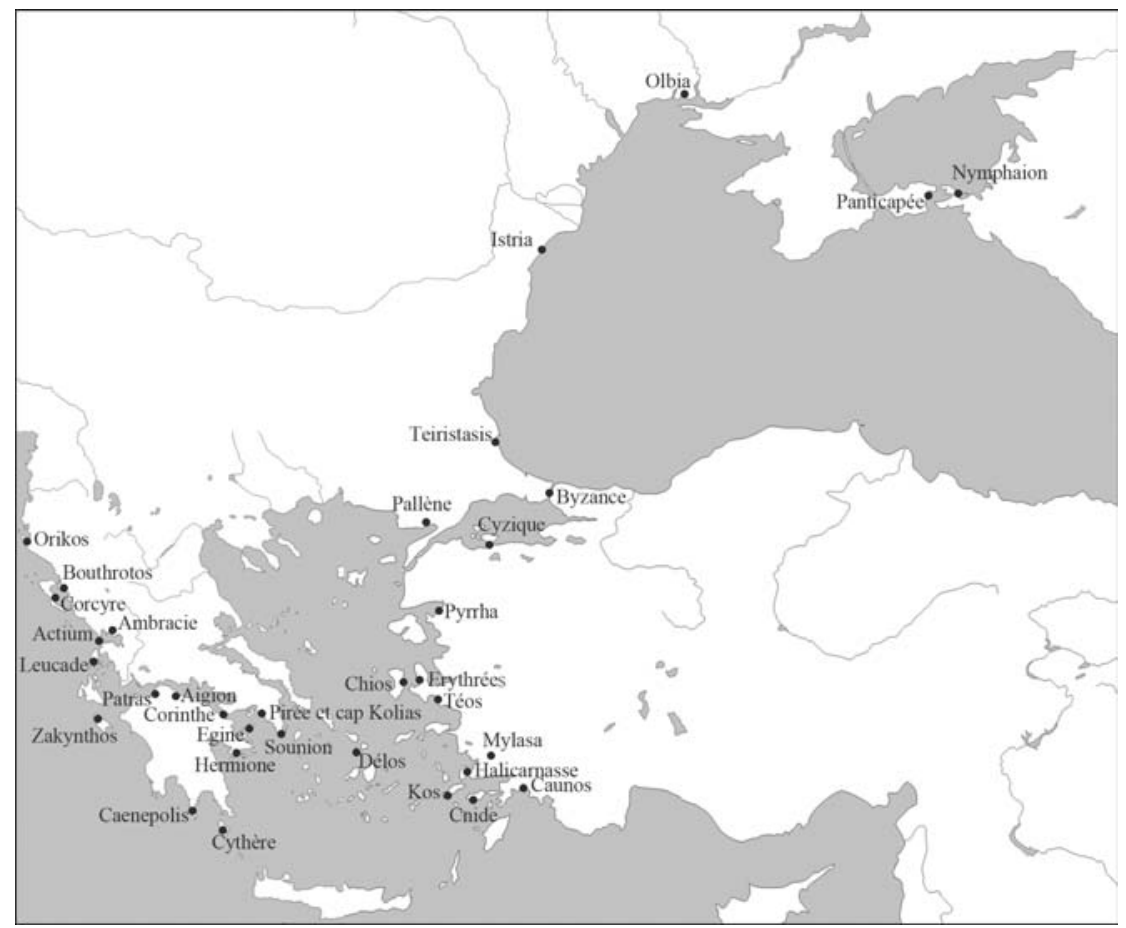

Carte 4 - Attestations du culte marin d'Aphrodite dans le monde égéen et dans le Pont-Euxin (ㄷ F. Ory-UMR 8546 - CNRS). 


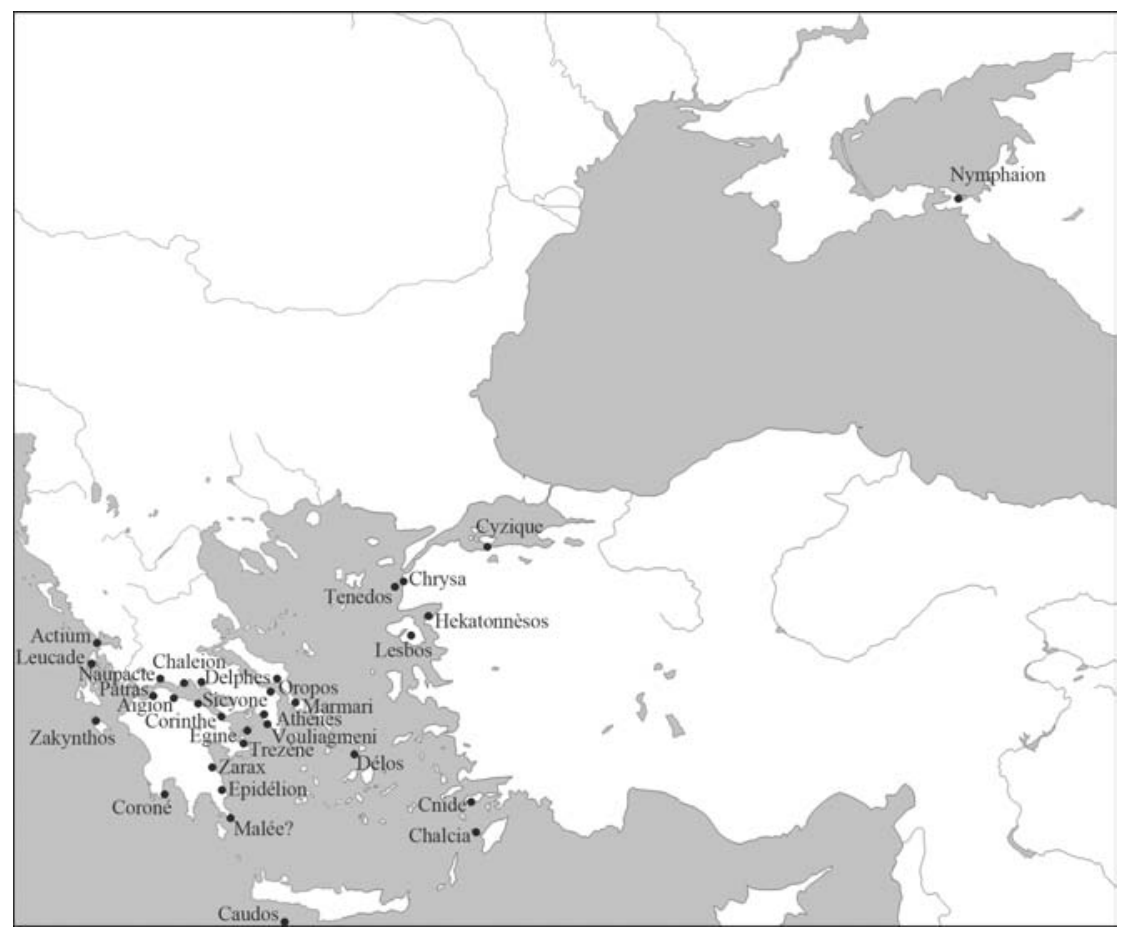

Carte 5 - Attestations du culte marin d'Apollon dans le monde égéen et dans le Pont-Euxin (ㄷ F. Ory-UMR 8546 - CNRS).

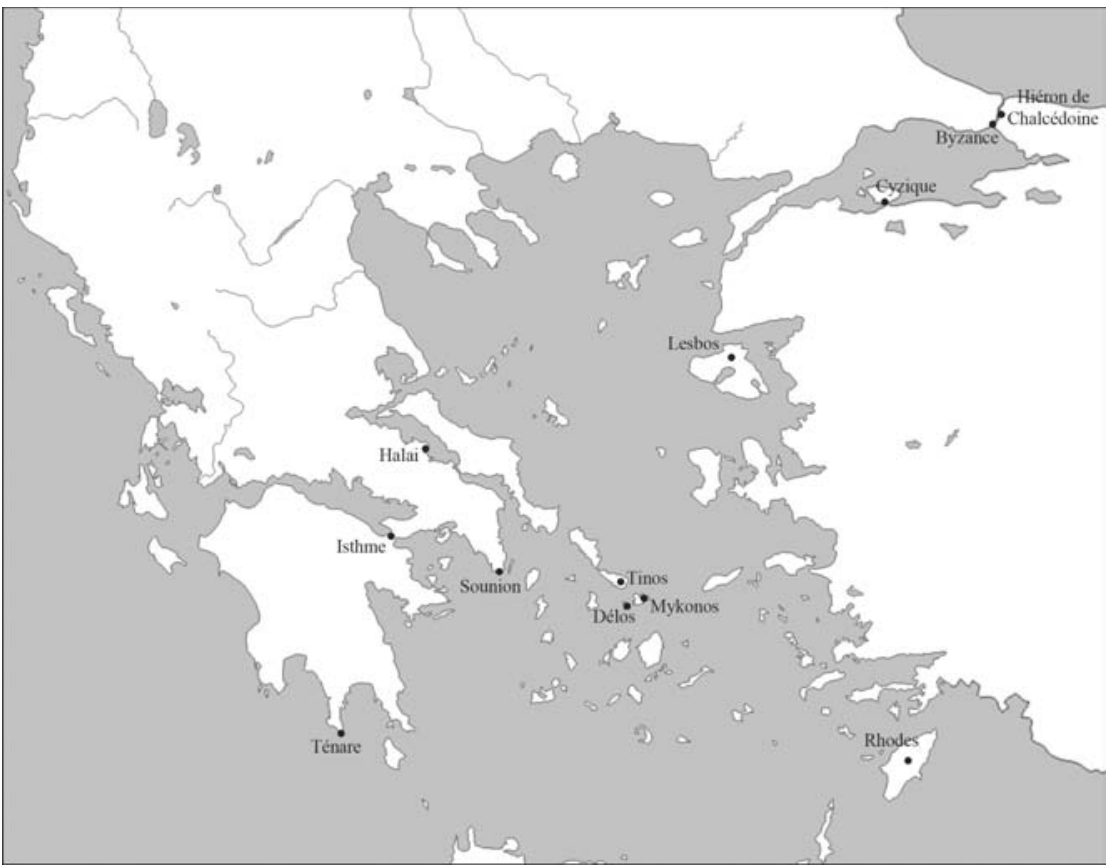

Carte 6 - Attestations du culte marin de Poséidon dans le monde égéen et en Propontide (c F. Ory-UMR 8546 - CNRS). 


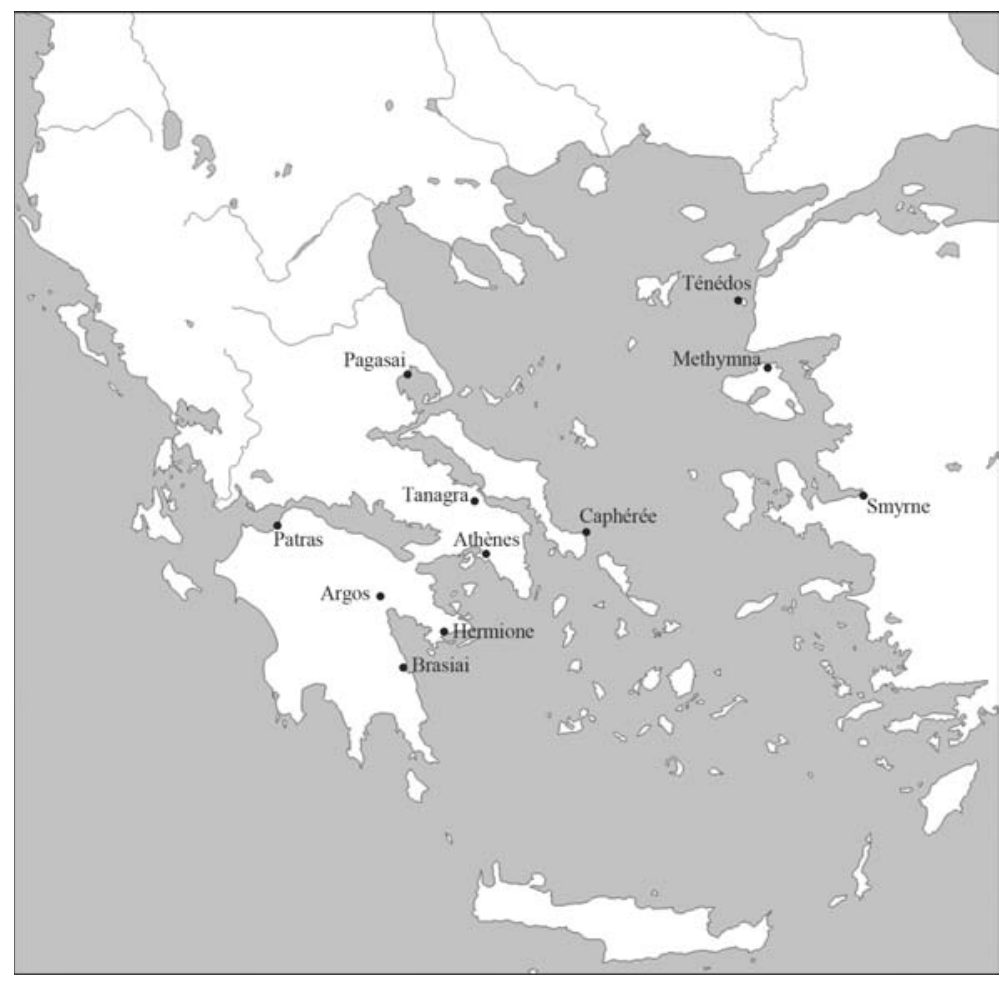

Carte 7 - Attestations du culte marin de Dionysos dans le monde égéen (c) F. Ory-UMR 8546 - CNRS).

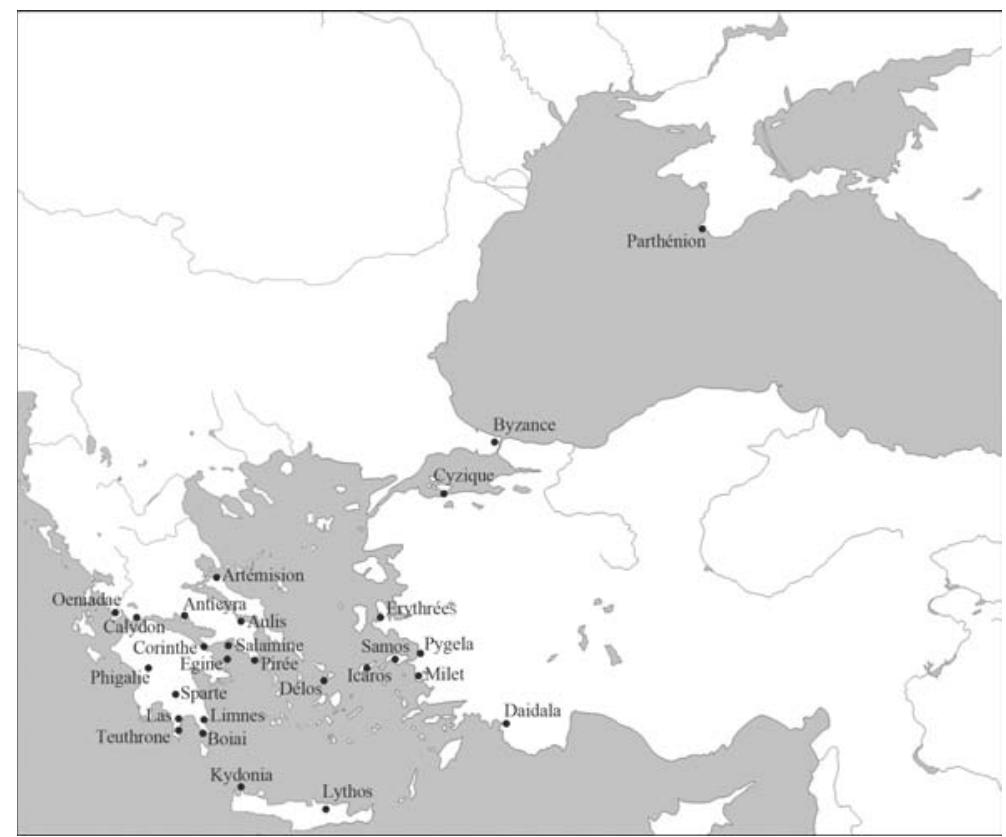

Carte 8 - Attestations du culte marin d'Artémis dans le monde égéen et dans le Pont-Euxin (ㄷ) F. Ory-UMR 8546 - CNRS). 


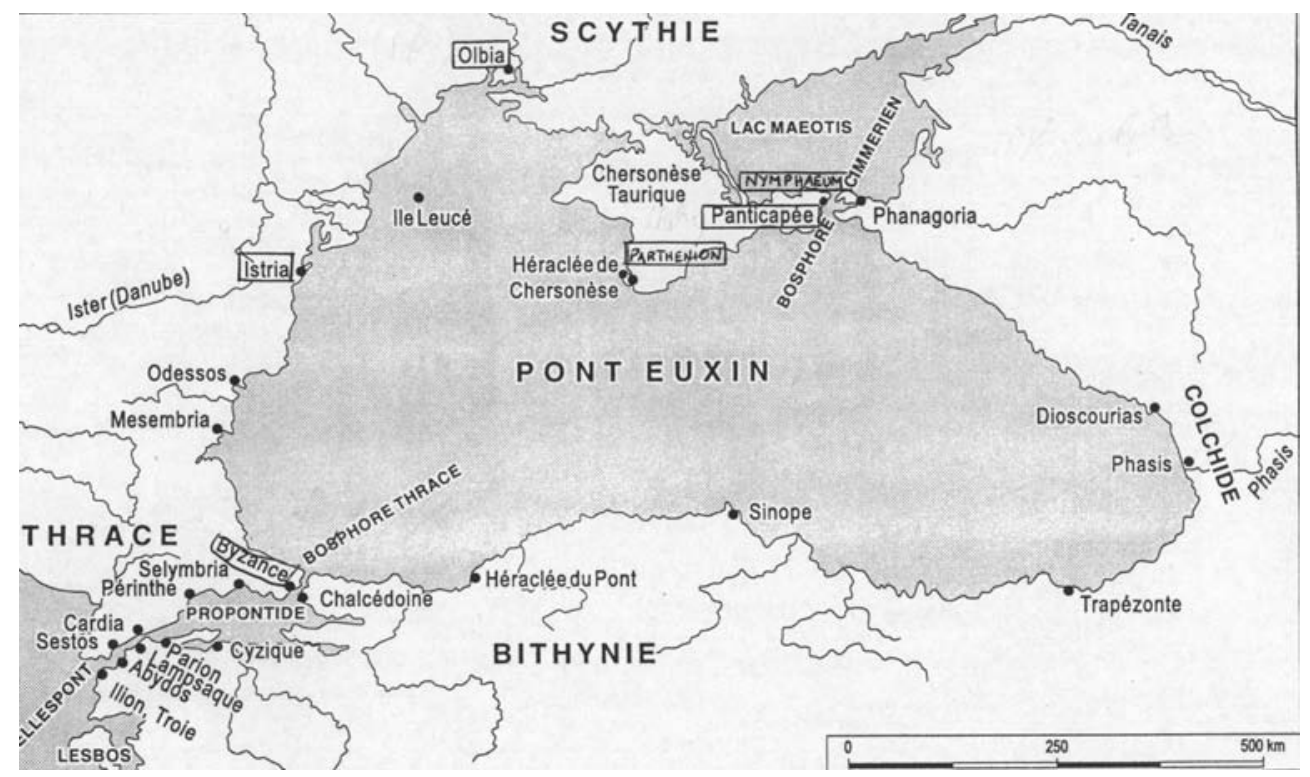

Carte 9 - Attestations des cultes marins dans le Pont-Euxin (noms encadrés; d'après Murray 1995, p. 329).

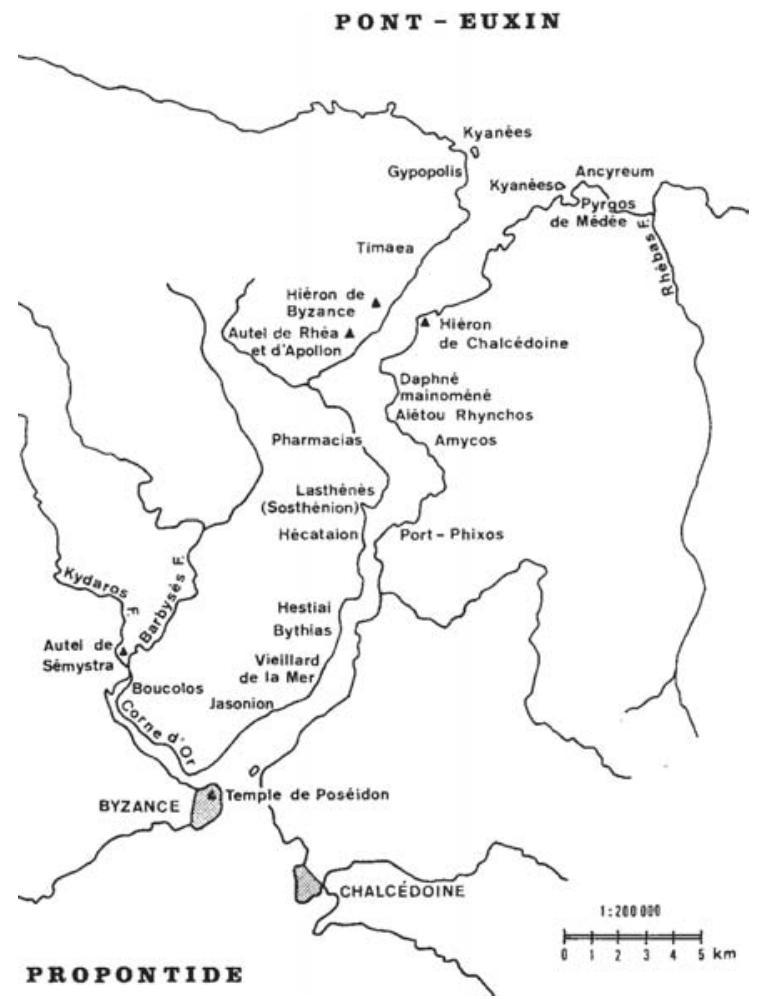

Carte 10 - Géographie religieuse du Bosphore (d'après Vian 1974, p. 92). 


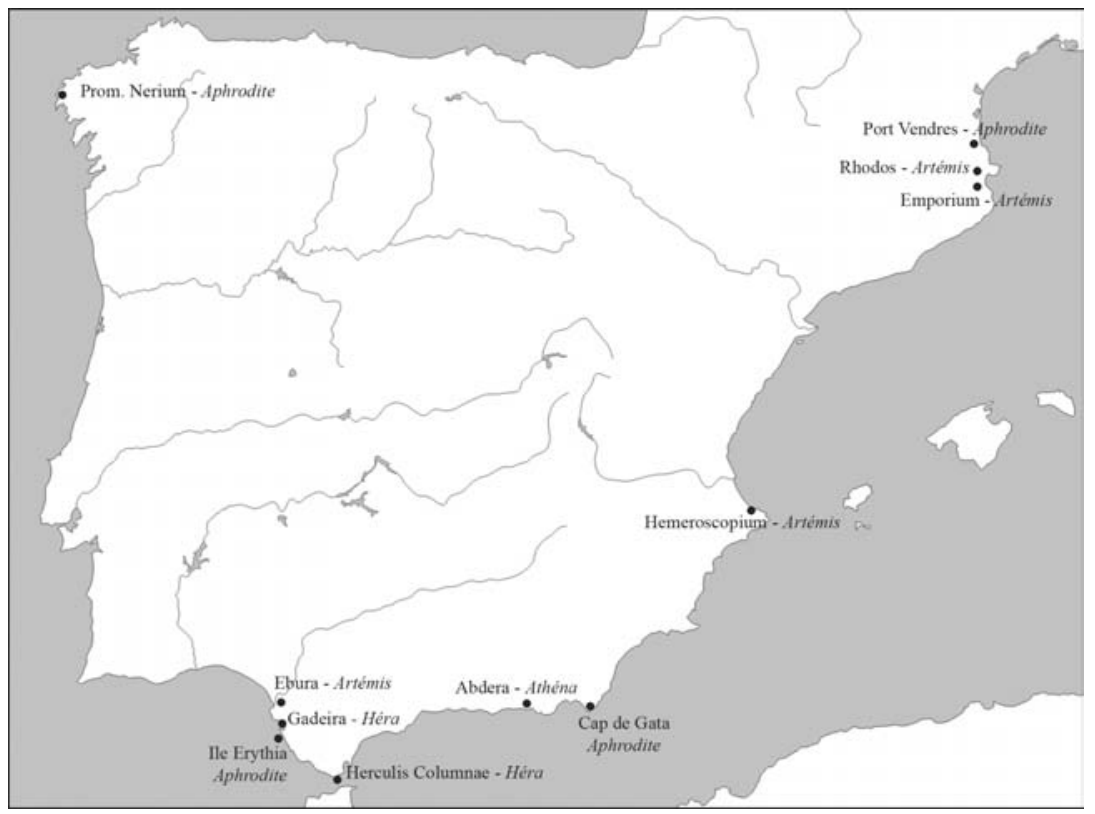

Carte 11 - Attestations des cultes marins dans la péninsule Ibérique (ㄷ F. Ory-UMR 8546 - CNRS).

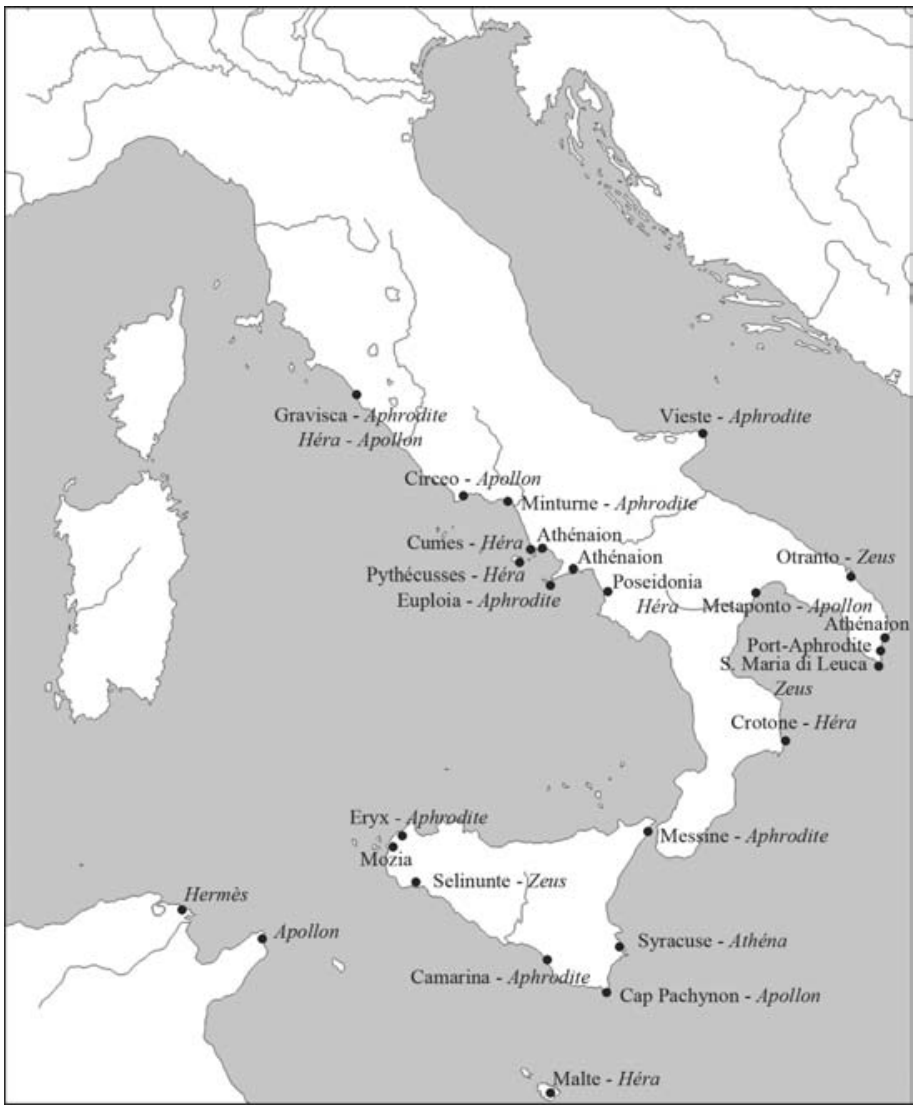

Carte 12 - Attestations des cultes marins en Méditerranée centrale (@ F. Ory-UMR 8546 - CNRS). 


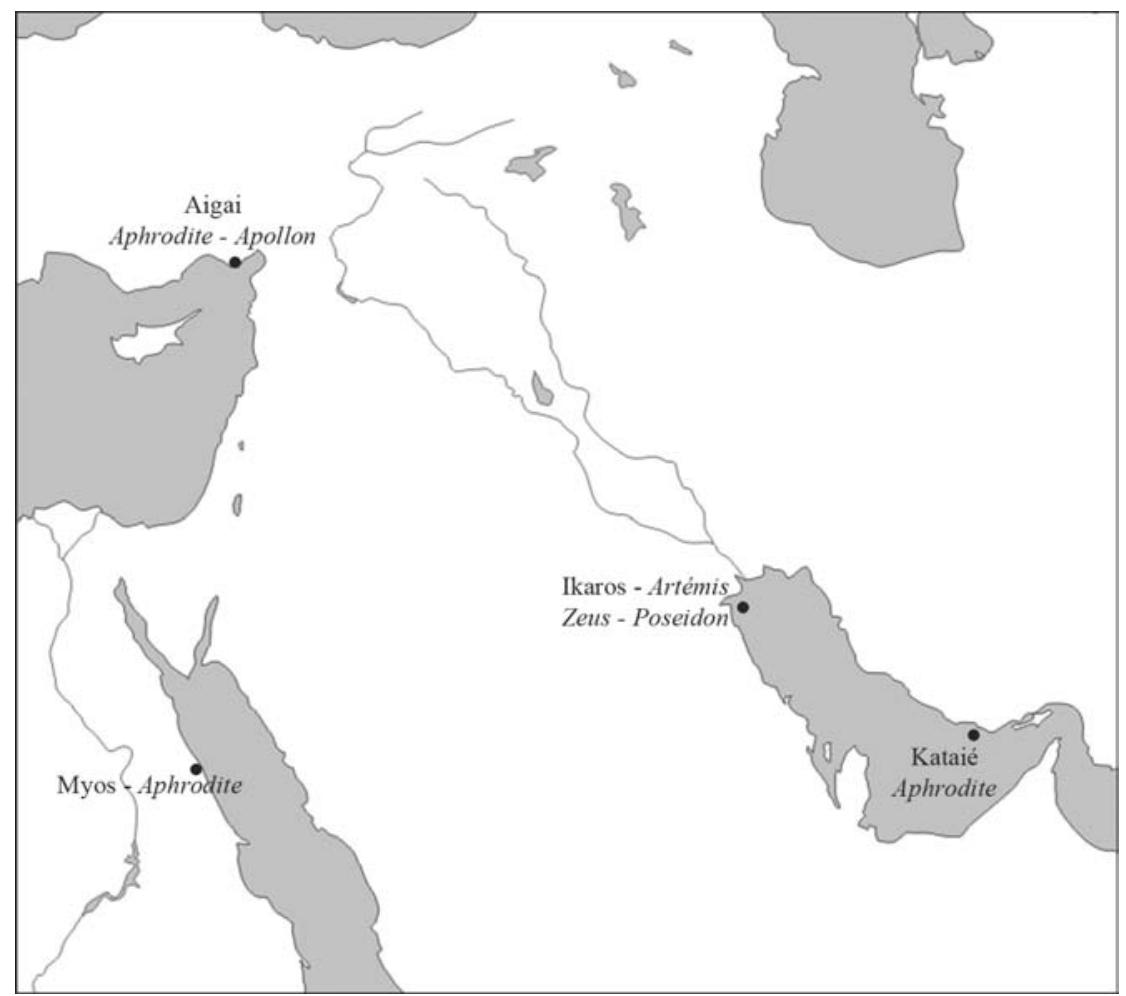

Carte 13 - Attestations des cultes marins en Méditerranée orientale, mer Rouge et golfe Persique (ㄷ) F. Ory-UMR 8546 - CNRS).

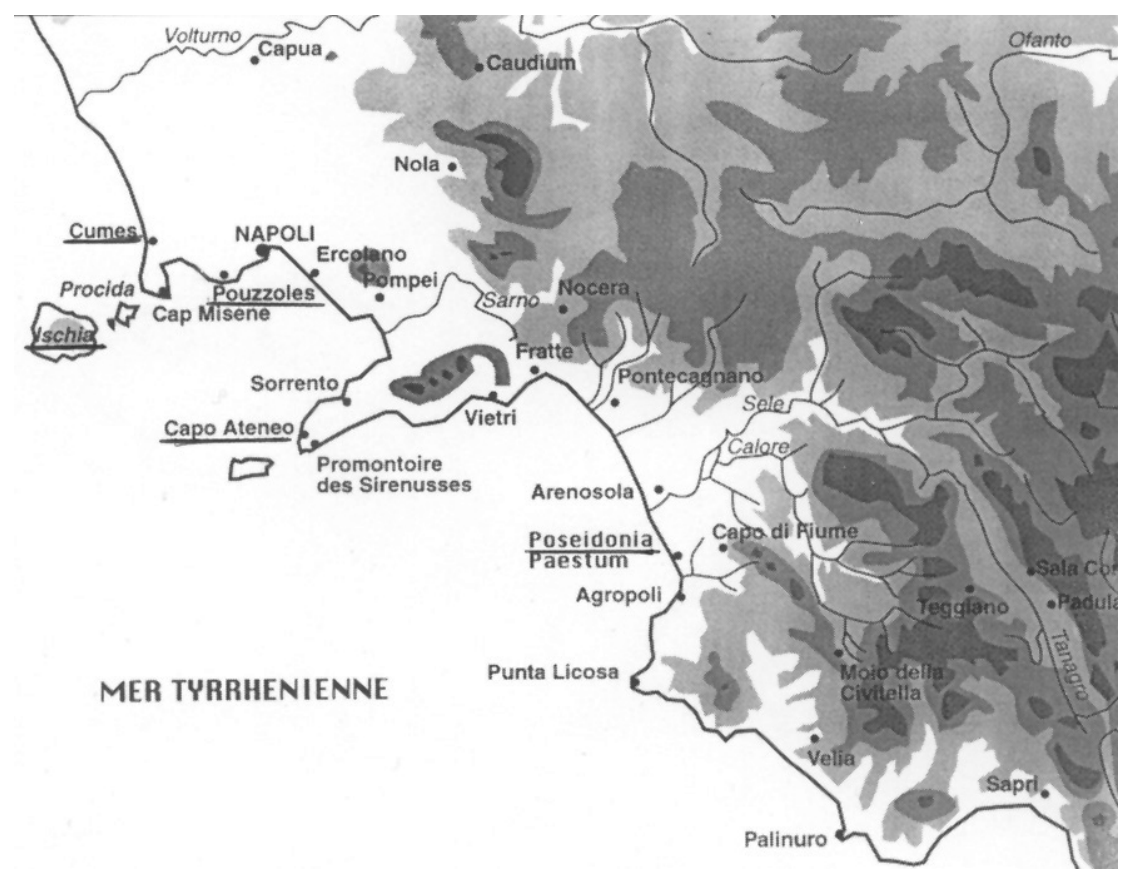

Carte 14 - La Campanie et Lucanie occidentale (d'après Greco 1996, fig. 44). 


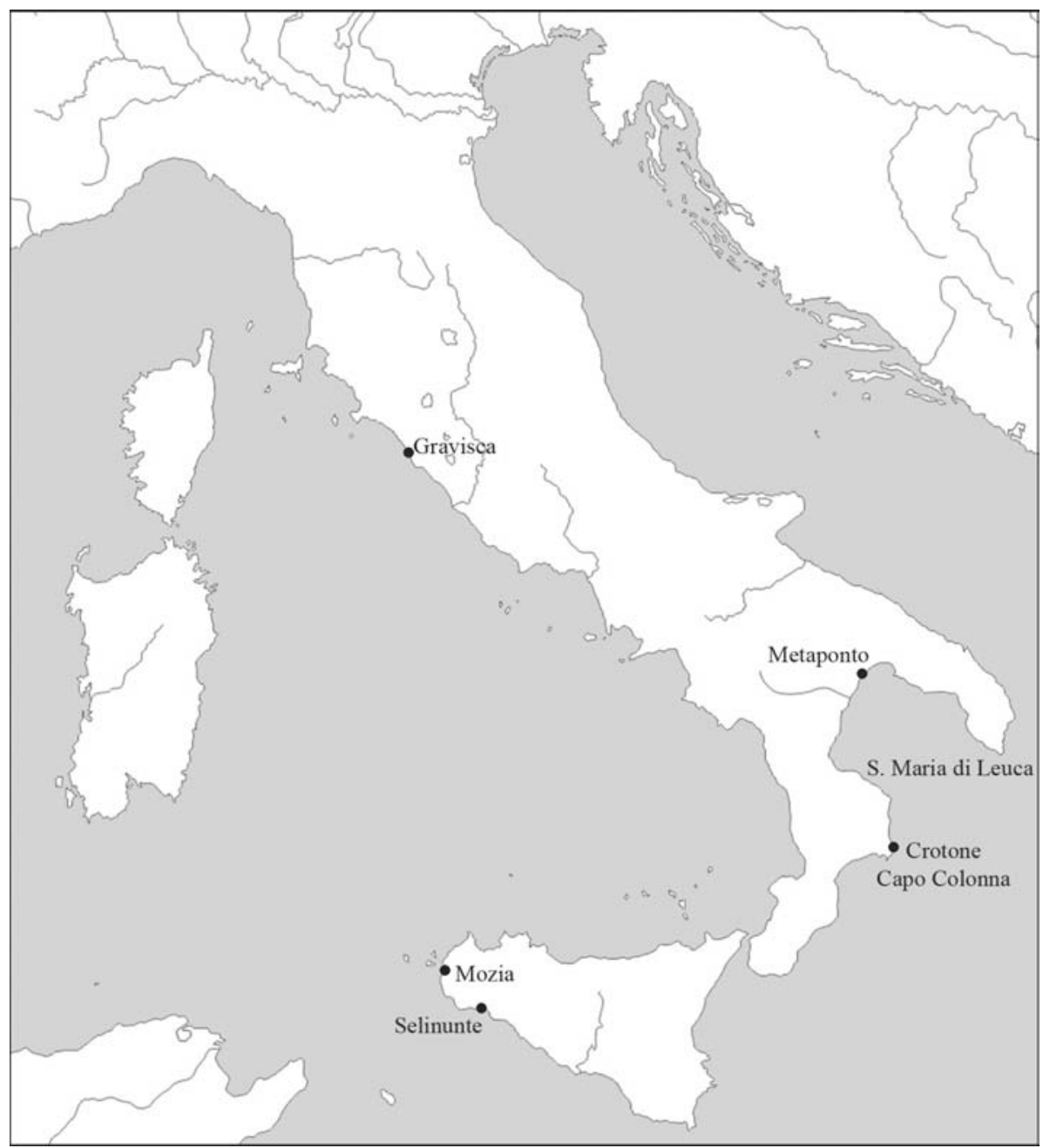

Carte 15 - Localisation des ancres votives de Grande Grèce (ㄷ F. Ory-UMR 8546 - CNRS). 
ANNEXES 



\section{CORPUS DE SOURCES LITTÉRAIRES CHOISIES}

Ce corpus est constitué de textes peu aisément consultables ou pour lesquels il n'existe pas à l'heure actuelle de traduction en langue moderne (scholies, fragments...), ainsi que quelques passages importants pour notre propos. Ils apparaissent, à l'exception de scholies non datées, dans l'ordre chronologique.

EURIPIDE (vers 485-406)

- Scholie à Hécube (424 a.C.), v. 78 (voir supra p. 296) :

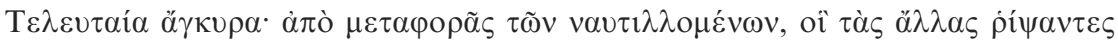

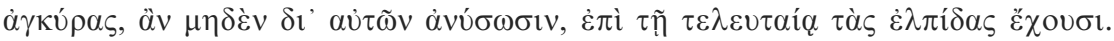

Traduction :

Dernière ancre : d'après une métaphore de marins, ceux qui après avoir jeté les autres ancres ne sont parvenus à rien placent leurs espoirs dans cette dernière ancre.

Aristophane (vers 445-385)

- Scholie à Acharniens, v. 547 (voir p. 60) :

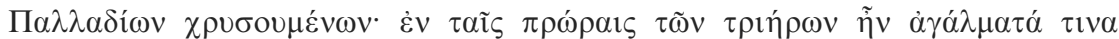

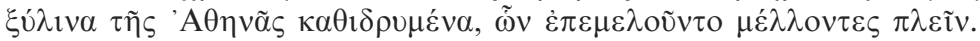

Traduction :

Statues de Pallas dorées : aux proues des trières il y avait fixées des images de bois d'Athéna, dont s'occupaient ceux qui s'apprêtaient à prendre la mer.

- Scholie à Acharniens, v. 682 (voir p. 178) :

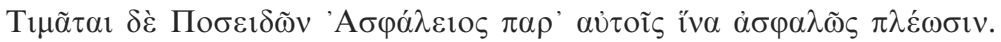

Traduction :

Poséidon Asphaleios est honoré par eux [les Athéniens], pour qu'ils naviguent en sûreté. 
- Scholie à Paix, v. 418 : à propos des grandes Panathénées (voir p. 440) :

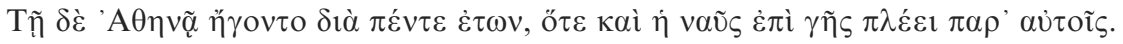
Traduction :

Elles étaient célébrées tous les quatre ans en l'honneur d'Athéna : à cette occasion, le bateau navigue sur la terre.

Strattis (fin Ve-début IVe s. a.C.)

- Fragment 30 (voir p. 439 et 445-6)

Ces quelques vers sont tirés de la pièce Les Macédoniens (402 a.C.) :

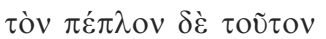

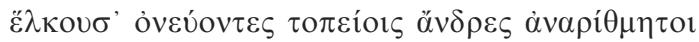

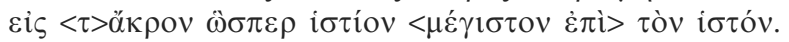

Traduction :

Ce péplos, de très nombreux hommes le hissent au sommet en tirant au cabestan comme une immense voile sur le mât.

Polémon le Périégète (fin $\mathrm{III}^{\mathrm{e}}$-déb. $\mathrm{II}^{\mathrm{e}}$ s. a.C.)

- Fragment 75, in Preller, p. 112 = Athénée, Deipnosophistes XI, 462b-c.

Parmi les anecdotes concernant les vases à boire, Athénée cite celle-ci (voir p. 51-52) :

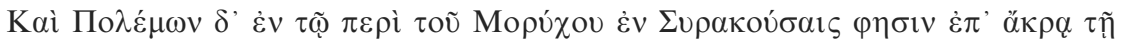

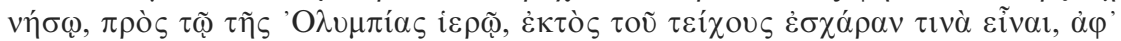

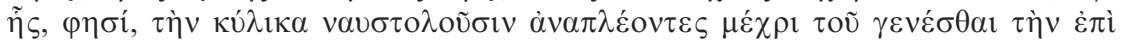

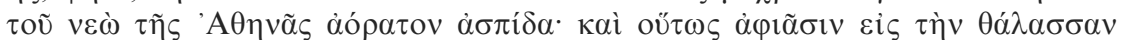

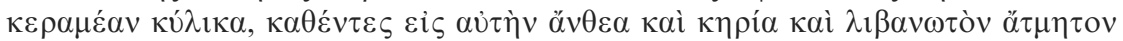

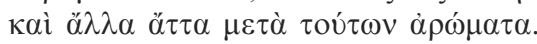

Traduction :

Polémon, dans son ouvrage sur Morichos, dit qu'à Syracuse, à la pointe de l'île, à côté du sanctuaire de Gè Olympienne à l'extérieur du mur, il y a une eschara de laquelle, dit-on, ceux qui naviguent vers le large transportent la coupe à bord jusqu'à ce que le bouclier sur le temple d'Athéna soit invisible. Et donc ils jettent une coupe d'argile à la mer, laissant tomber dans celle-ci des fleurs, du miel et de l'encens non coupé ainsi que d'autres plantes aromatiques.

Aelius Aristide (117-189)

- Politique de Smyrne, 402-403 (voir p. 447 s.)

La cité de Smyrne n'est pas en reste par rapport à d'autres cités en ce qui concerne des rivalités légendaires :

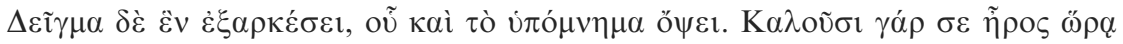

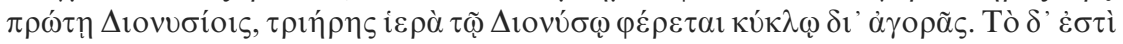




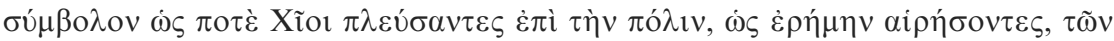

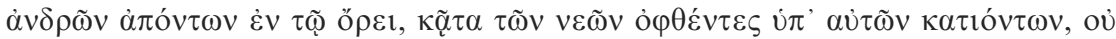

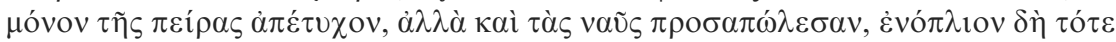

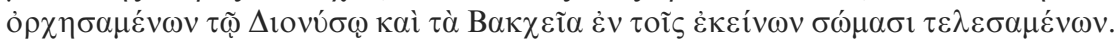

Traduction :

Un exemple, dont tu peux voir encore le souvenir, suffira. On te convie aux premiers jours du printemps aux Dionysies : la trière consacrée à Dionysos est portée tout autour de l'agora. C'est le symbole qu'un jour les Chiotes firent voile contre la cité, pour s'en emparer alors qu'elle était désertée de ses hommes partis dans la montagne. Mais ceux-là furent aperçus débarquant de leurs navires par les Smyrniotes qui redescendaient : non seulement ils échouèrent dans leur tentative, mais ils perdirent aussi leurs bateaux, car les Smyrniotes exécutèrent une danse armée en l'honneur de Dionysos et accomplirent les fureurs bacchiques sur les corps des Chiotes.

- Prosphonétique de Smyrne, 473-474 : Dionysos, fête des Smyrniotes (voir p. 447).

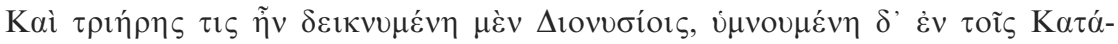

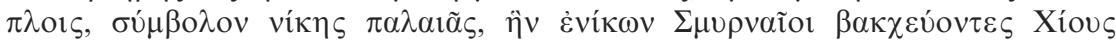

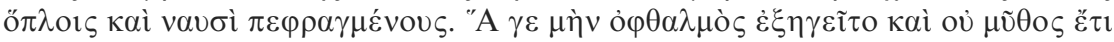

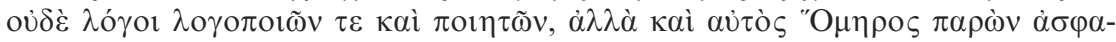

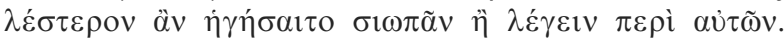

Traduction :

Une trière était montrée lors des Dionysies, chantée dans Kataploi comme le symbole d'une vieille victoire qu'avait remportée les Smyrniotes, saisis d'un délire bacchique, sur les Chiotes munis d'armes et de bateaux. Oui, ces événements un témoin les a expliqués en détail; ils ne sont pas dus à une légende ni non plus à des fables de poètes conteurs de fables, mais Homère lui-même, s'il avait été présent, aurait pensé plus prudent de se taire que de parler à ce sujet.

- Scholie à Aelius Aristide, Panathénaïque 197, 8 (éd. Dindorf)

Le discours d'Aelius Aristide a été prononcé en 155 p.C. lors des Panathénées. Extraits de commentaires de scholiastes (voir p. 441) :

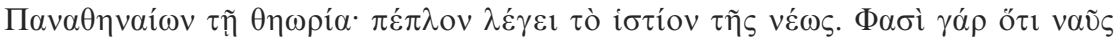
$\tilde{\eta} v$ vं

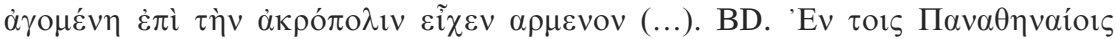
ü

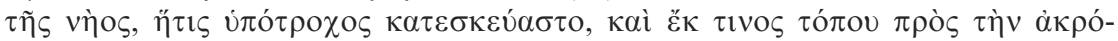

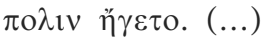

Traduction :

Théorie des Panathénées : on dit que le péplos est la voile du bateau. On raconte en effet que le bateau était garni et équipé de roues, et était lors des Panathénées de cette façon emmené à l'Acropole avec les agrès (...). 
BD. Lors des Panathénées les jeunes filles confectionnaient à Athènes un péplos (...). On faisait de ce péplos une voile du bateau, qui était équipé de roues, et de cette manière le péplos était emmené à l'Acropole.

Pollux ( $\mathrm{II}^{\mathrm{e}}$ s. p.C.)

- Onomasticon I, 93 (voir p. 295)

Parmi le vocabulaire nautique réuni par Pollux, apparaissent les ancres :

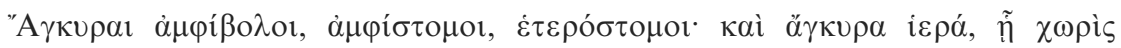

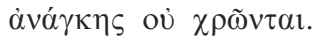

Traduction :

Il y a des ancres amphiboloi, amphistomoi et hétérostomoi, ainsi que l'ancre sacrée, qu'on n'utilise qu'en cas de nécessité.

Flavius Philostrate (vers 165- 245)

- Vie des sophistes I, 25, 530-531 (publié entre 230 et 238)

Le sophiste Polémôn, quoique non originaire de Smyrne, a reçu les honneurs de ses habitants (voir p. 440 et 448):

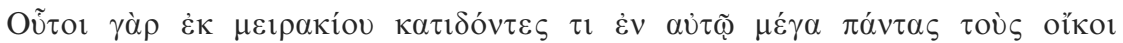

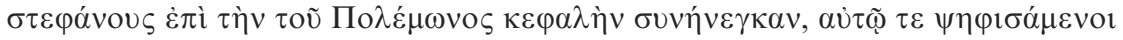

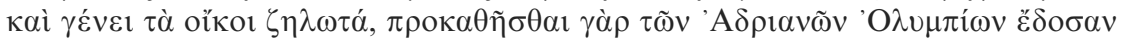

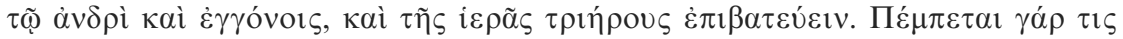

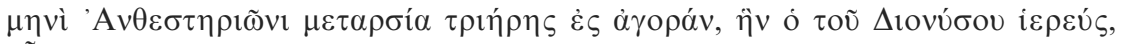

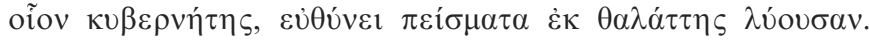

Traduction :

Ceux-ci ayant distingué en lui de la grandeur dès son adolescence, ils rassemblèrent sur la personne de Polémôn toutes les marques d'honneur locales, stipulant par décret pour lui et son génos les mesures les plus enviables pour Smyrne; c'est ainsi qu'ils accordèrent à l'homme et à ses descendants de présider les jeux Olympiques d'Hadrien et d'embarquer sur la trière sacrée. En effet le mois d'Anthestérion, on mène en procession sur l'agora une trière surélevée que le prêtre de Dionysos dirige comme un pilote quand elle est de la mer déliée de ses amarres.

- Vie des sophistes II, 1, 550 (voir p. 438 ss.)

Apollonios énumère les bienfaits d'Hérode Atticus envers les Athéniens, notamment ceux concernant les fêtes Panathénaïques :

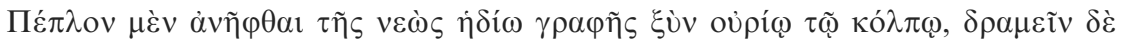

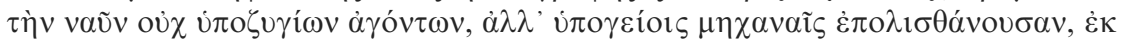

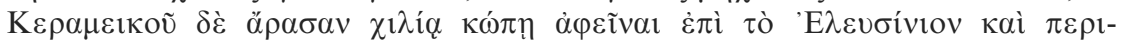

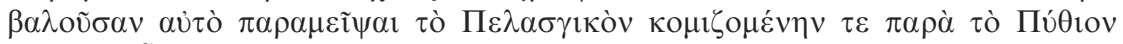
$\dot{\varepsilon} \lambda \theta \varepsilon \tilde{\imath} v$, oĩ $v \tilde{v} v \omega ̋ \rho \mu \imath \sigma \tau \alpha$. 
Traduction :

Le péplos suspendu au bateau fut plus charmant qu'une peinture avec ses plis gonflés par la brise, et le bateau n'avança plus sous l'action de bêtes de somme; mais glissant au moyen de machineries secrètes, il faisait voile depuis le Céramique avec un millier de rames jusqu'à l'Éleusinion, après l'avoir contourné passait devant le Pelasgicon, et escorté allait au Pythion, où il était amarré.

\section{Himerius (IVe s. p.C.)}

\section{- Orationes XLVII, 12-16}

Himerius célèbre avec les Panathénées le début du printemps (voir p. 440-441 et 448) :

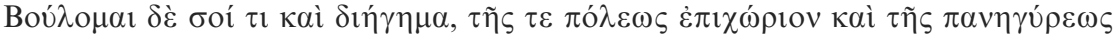

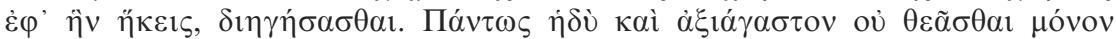

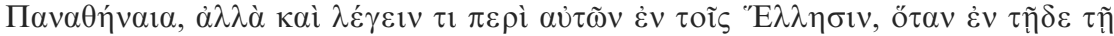

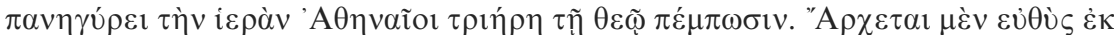

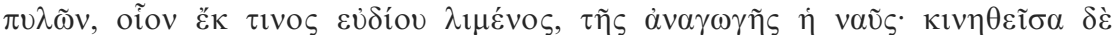

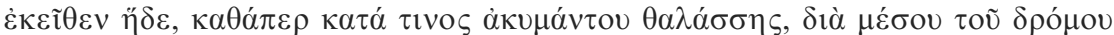

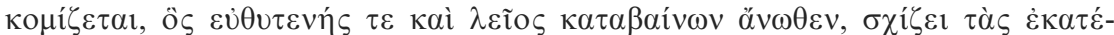

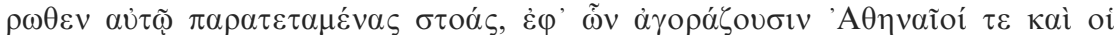

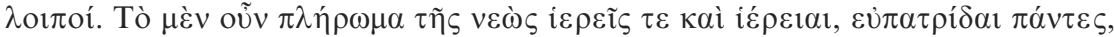

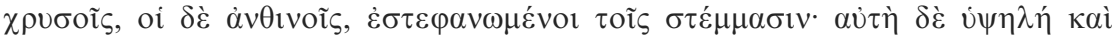

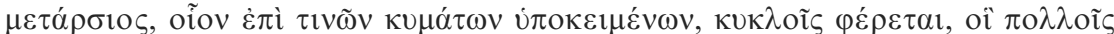

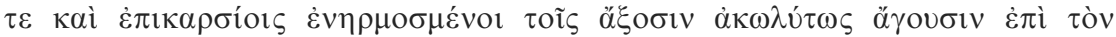

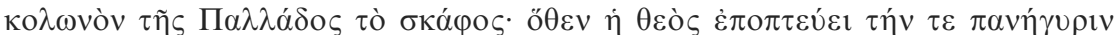

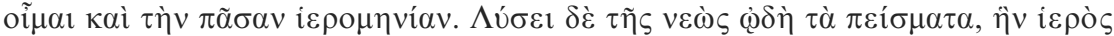

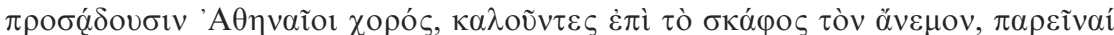

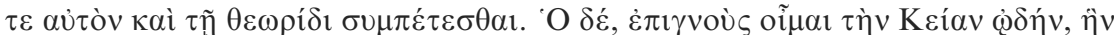

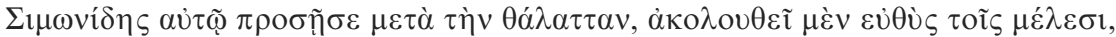

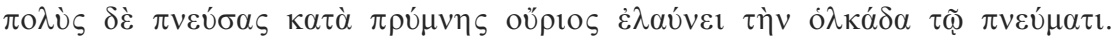

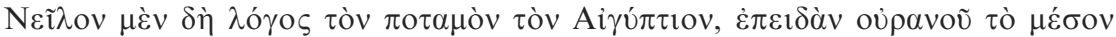

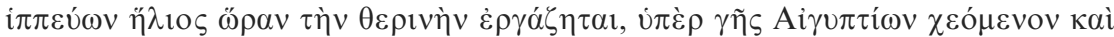

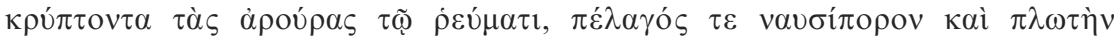

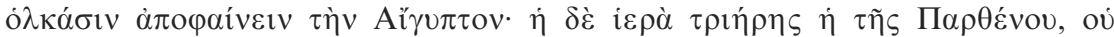

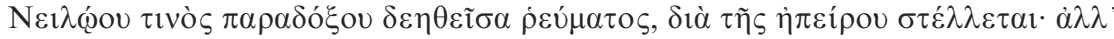

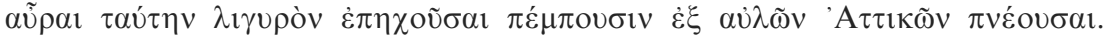

Traduction :

Je veux aussi t'exposer en un récit détaillé la coutume et la fête de la cité pour laquelle tu es venu. Non seulement les Panathénées sont tout à fait charmantes et admirables à regarder, mais aussi à évoquer devant les Grecs, lorsqu'au cours de cette fête les Athéniens envoient à la divinité la trière sacrée. Le bateau commence en ligne droite depuis les Portes, comme s'il gagnait le large depuis quelque port à l'abri du vent. Une fois mis en branle, de même que sur quelque mer sans rides, il est amené au milieu de la route, qui descend directement et uniformément et qui sépare les stoai s'étendant d'un côté et de l'autre, où flânent les Athéniens et les autres. L'équipage du navire est composé de prêtres et prêtresses, de tous les eupatrides ceints de couronnes, les unes de 
végétaux les autres d'or. Le bateau haut et élevé, comme sur un fond de vagues, est porté par des roues, qui s'adaptent aux nombreux essieux transversaux, menant sans obstacle l'embarcation jusqu'à la colline de Pallas, d'où la déesse observe, je pense, la fête et tout le mois sacré. Avec le lâcher des amarres du bateau vient l'hymne que les Athéniens chantent en chœur sacré, invoquant le vent sur la nef, afin qu'il accompagne de sa présence et de son vol le vaisseau théore. Le vent, ayant reconnu je crois le chant de Kéos, que Simonide chanta avec la mer, accompagne aussitôt les chants, et soufflant fort et favorablement à la poupe, pousse le vaisseau de son souffle. On dit que, quand le soleil produit la saison d'été en parcourant la moitié du ciel, le Nil fleuve d'Égypte se répand sur la terre des Égyptiens et cache les champs par son courant: il transforme l'Égypte en une mer navigable et accessible aux vaisseaux. La trière sacrée de la Parthénos, sans avoir besoin de quelque écoulement extraordinaire du Nil, fait voile à travers la terre ferme. Mais des brises soufflant de flûtes attiques l'escortent en retentissant de façon mélodieuse.

StÉPHANe DE ByzANCE (VI' s. p.C.) (voir p. 462)

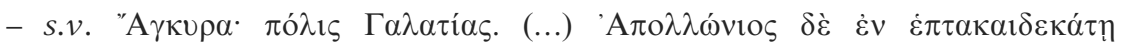

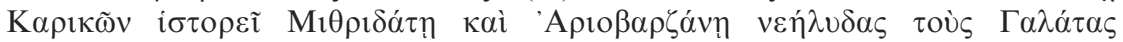

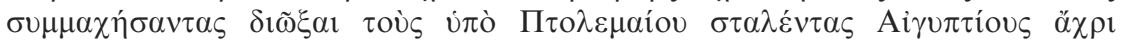

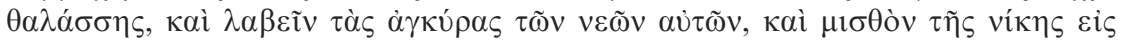

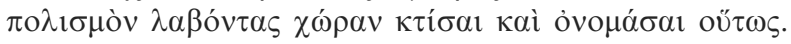

Traduction :

Ancyre: ville de Galatie. Apollonios dans son 17e livre des Cariens rapporte que les Galates, nouveaux venus alliés à Mithridate et à Ariobarzane, chassèrent les Égyptiens sous la conduite de Ptolémée jusque la mer et qu'ils prirent les ancres de leurs navires. Ayant reçu comme salaire de la victoire une fondation de ville, ils bâtirent le territoire et l'appelèrent ainsi.

Pнотіus (seconde moitié du IX ${ }^{\mathrm{e}}$ s. p.C.) (voir p. 439 et 445)

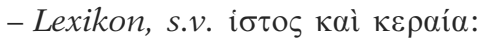

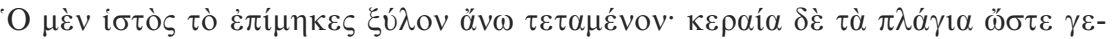

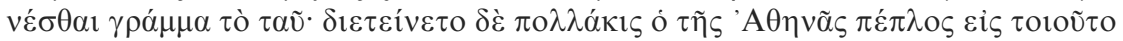

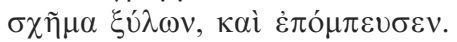

Traduction :

Mât et vergue : le mât, long tronc de bois placé verticalement; la vergue, élément transversal de sorte à constituer la lettre T. Souvent le péplos d'Athéna était étendu sur une telle forme, et on le menait en procession. 
SoudA (X ${ }^{\text {e }}$ s. p.C.) (voir p. 296)

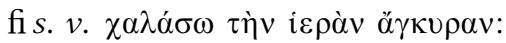

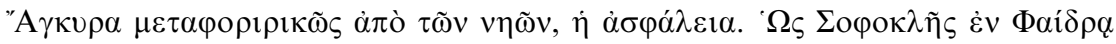

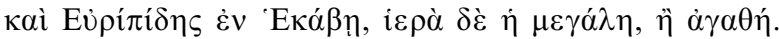

Traduction :

Lâcher l,,ancre sacrée : métaphoriquement, la sécurité des bateaux, c,est l,ancre. Comme le disent Sophocle dans Phèdre et Euripide dans Hécube, la grande ancre, ou la bonne, est l,ancre sacrée.

TzeTz-s (fin XII ${ }^{\mathrm{e}}$ s. p.C.) (voir p. 59 et 63)

fi Alexandra, Scholie au v. 359 qui mentionne Aithyia (extrait) :

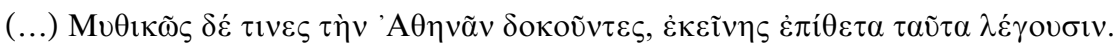

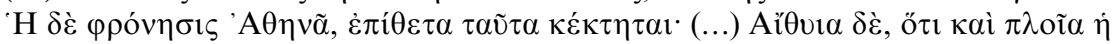

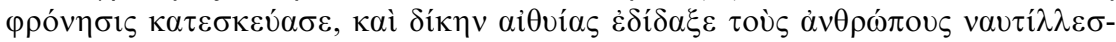

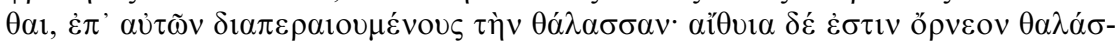

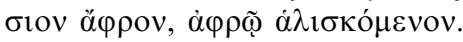

Traduction :

Certains pensent de manière mythologique à Athéna, disant que ces épithètes lui appartiennent. Athéna est la prudence, et elle possède ces épithètes : (...) Aithyia, parce que sa prudence construisit aussi des bateaux et qu,,à la manière $d$,,un oiseau elle enseigna aux hommes à naviguer, à traverser sur eux la mer. Mais une aithyia est un oiseau de mer déraisonnable, condamné à la folie.

\section{Maxime Planude (fin XIII ${ }^{\mathrm{e}}$-début XIV ${ }^{\mathrm{e}} \mathrm{s}$.)}

fi Scholies à Hermogène, $\Pi \varepsilon \rho i$ i $\delta \varepsilon \tilde{\omega} v /$ De ideis, 407 :

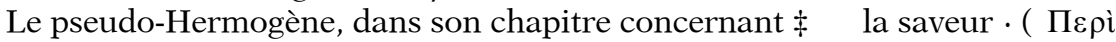
$\gamma \lambda \cup \kappa u ́ \tau \eta \tau \varsigma \varsigma)$, inclut comme $3{ }^{\text {e }}$ catégorie les $\$$ récits qui, par petits bouts en quelque sorte, rejoignent le mythe, mais auxquels on accorde plus de créance qu,,aux mythes - (ps.-Hermogène, Les catégories stylistiques du discours II, iv, 4, trad. éd. Budé ; texte du II ${ }^{\text {e }}$ s. p.C.). Le commentateur en donne quelques exemples, dont ceux-ci ; il cite à cette occasion un Ammonios, auteur dont on sait peu de chose par ailleurs ( ${ }^{\text {er }}$ s. p.C.?) (voir p. 65 et 115) :

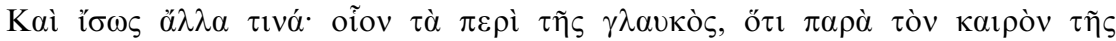

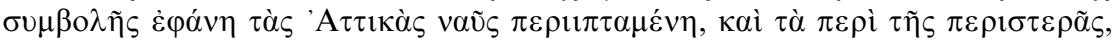

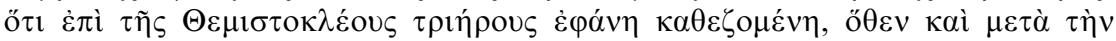

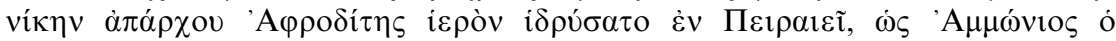

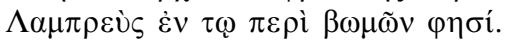

Traduction :

'Et peut-être quelques autres ' : tel le récit sur la chouette, qui parut voler autour des bateaux attiques pendant le moment du combat, et celui sur la colombe, qui parut se poser sur la trière de Thémistocle, ce pourquoi aussi 
on fonda au Pirée le hieron d'Aphrodite après la victoire, comme le dit Ammonios de Lampra dans son Peri bômon (Des autels).

LEXEIS RHETORIKAI (datation inconnue) (voir p. 88 et 423 ss.)

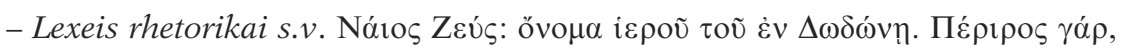

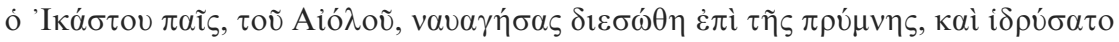

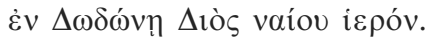

Traduction :

Zeus Naios, nom d'un sanctuaire à Dodone. En effet Périros, fils d'Ikaste, fils d'Aiolos, naufragé ayant été sauvé sur une poupe, la consacra à Dodone dans un temple de Zeus Naios. 


\section{INDEX THÉMATIQUE DES SOURCES LITTÉRAIRES}

L'index qui suit se veut un instrument de travail pratique à utiliser, tout en conservant un intérêt historique. C'est pourquoi nous avons choisi de recenser les textes par divinité ou notion, et à l'intérieur de chaque rubrique dans un ordre chronologique. N'y sont pas recensées toutes les sources citées dans ce volume, mais celles essentielles pour notre sujet.

ANCRE

Apollonios de Rhodes I, v. 953-971

Pline, Histoire naturelle XXXVI, 99

Plutarque, Préceptes politiques $812 \mathrm{~b}$

Plutarque, Préceptes politiques $815 \mathrm{c}-\mathrm{d}$

Plutarque, Coriolan 32, 1-2

Arrien, Périple du Pont-Euxin 9, 1-2

Pausanias I, iv, 5

Lucien, Fugitifs 13

Lucien, Juppiter tragoedus 51-52

Denys de Byzance, Anaplus Bospori 87

Héliodore, Éthiopiques VIII, 6, 9

Pollux, Onomasticon I, 93.

Libanius, Epistula 230, 1

Libanius, Progymnasmata - laudationes 2, 13

Anthologie Palatine VI, 27

Anthologie Palatine VI, 28

Anthologie Palatine VI, 29

Stéphane de Byzance, s.v. "А $\gamma \kappa \nu \rho \alpha$

Etymologicum Magnum, s.v. "А $\gamma \kappa \nu \rho \alpha$

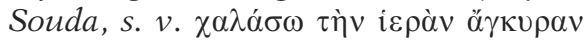

ApHaia

Pseudo-Virgile, Ciris, v. 301-305

Pausanias II, xxx, 3

Antoninus Liberalis, Métamorphoses XL

Hésychius, s.v. Aphaia 


\section{ApHrodite}

Hésiode, Théogonie, v. 187-197

Hymne homérique à Aphrodite I, v. 58-59

Hymne homérique à Aphrodite II, v. 1-5

Sappho, Fragment 193

Euripide, Hippolyte, v.415-418

Euripide, Hippolyte, v. 522-523

Euripide, Hélène, v. 1022-1027

Callimaque, Hymne IV (à Délos), v. 307-326

Callimaque, Épigramme V

Anytè, Épigramme XV = Anthologie Palatine IX, 144

Mnasalces, Épigramme XV = Anthologie Palatine IX, 333

Poseidippos, Fragment 116

Théocrite, Idylle VII, v. 52-62

Athénée V, 207e = Moschion, Fgt 575

Athénée V, 205d = Callixène, Fgt 627

Polybe, Histoires I, 55, 5-10

Phanias, Épigramme V = Anthologie Palatine VI, 299

Athénée XV, 675f-676c (citant Polycharme de Naucratis)

Horace, Odes I, iii, v. 1-8

Horace, Odes III, xxviii

Hygin, Astronomie II, 30

Vitruve, De l'Architecture II, 8

Argentarius, Épigramme I = Anthologie Palatine Livre V, 16

Strabon IV, 1, 3

Strabon IV, 1, 6

Strabon IX, 1, 21

Strabon XIII, 1, 51

Strabon XIV, 6, 3

Strabon XVI, 4, 5

Strabon XVII, 1, 16

Denys d'Halicarnasse, Antiquités romaines I, 49, 3-4

Denys d'Halicarnasse, Antiquités romaines I, 50, 1

Denys d'Halicarnasse, Antiquités romaines I, 50, 3-4

Denys d'Halicarnasse, Antiquités romaines I, 51, 2

Denys d'Halicarnasse, Antiquités romaines I, 51, 3

Antipater, Épigramme XCIII = Anthologie Palatine IX, 143

Ovide, Métamorphoses IV, v. 523-540

Ovide, Fastes II, v. 459-474

Ovide, Fastes IV, v. 61-62

Ovide, Fastes IV, v. 131-132

Pomponius Mela, Chorographie I, 16, 84

Pomponius Mela, Chorographie II, 6, 84

Pomponius Mela, Chorographie II, 7, 102

Pline l'Ancien, Histoire naturelle III, 62

Pline l'Ancien, Histoire naturelle IX, 80

Stace, Silves II, 2, v. 76-80

Plutarque, Vies (Thésée), 18, 1-3 
Plutarque, Vies (Antoine), 26, 1-5

Plutarque, Quaestiones graecae, 303c-d

Plutarque, Propos de table V, 685e

Pseudo-Apollodore, Bibliothèque I, ix, 25

Arrien, Peripl. Pont. Eux. 12, 2-3

Arrien, Indica XXXVII, 10-11

Pausanias I, i, 3

Pausanias I, i, 5

Pausanias II, i, 7- ii, 1

Pausanias II, ii, 3

Pausanias II, ii, 8

Pausanias II, xxix, 6

Pausanias II, xxxiv, 11

Pausanias III, xxii, 1-2

Pausanias III, xxiii, 1-4

Pausanias III, xxv, 9

Pausanias V, xi, 8

Pausanias VII, xxi, 10-11

Pausanias VII, xxiv, 2

Apulée, Métamorphoses IV, 31

Apulée, Métamorphoses XI, 3-5

Denys de Byzance, Anaplus Bospori 35-36

Hymne orphique LV

Aviénus, Ora maritima, v. 158-160

Aviénus, Ora maritima, v. 308-321

Aviénus, Ora maritima, v. 425-438

Servius, Comm. in Eneid. VII, 47

Nonnos IV, v. 114-118

Nonnos IV, v. 236-246

Nonnos XIII, v. 61-62

Nonnos XIII, v. 432-443

Hésychius, s. v. $\dot{\varepsilon} \pi \imath \pi \mathrm{ov} \tau \dot{i} \alpha$

Chariton, Aventures de Chairéas et de Callirhoé III, 2, 14

Chariton, Aventures de Chairéas et de Callirhoé VIII, 4, 10

Anthologie Palatine V, 10

Anthologie Palatine IX, 601

Athénée VII, 328a

Maxime Planude, scholie à Hermogène, $\Pi \varepsilon \rho i$ i $\delta \varepsilon \tilde{\omega} v 407$

APOLLON

Iliade I, v. 477-479

Hymne à Apollon Délien, v. 22-23

Hymne à Apollon Délien, v. 70-88

Hymne à Apollon Délien, v. 388-512

Bacchylide, Dithyrambe III

Hérodote VIII, 121-122

Euripide, Iphigénie en Tauride, v. 1123-1136 
Thucydide II, 91

Thucydide VIII, 35, 2

Platon, Phédon 58 a-c

Callimaque, Hymne IV (à Délos), v. 307-326

Apollonios de Rhodes I, v. 351-362

Apollonios de Rhodes I, v. 402-438

Apollonios de Rhodes I, v. 953-971

Scholie à Apollonios de Rhodes, I v. 966

Apollonios de Rhodes I, v. 1185-1186

Apollonios de Rhodes II, 927-929

Apollonios de Rhodes IV, v. 1691-1731

Polémon le Périégète, Fragment 70

Cicéron, Seconde action contre Verrès I, xvii-xviii, 46

Virgile, Énéide III, v. 73-79

Virgile, Énéide III, v. 274-275

Virgile, Énéide X, v. 156-255

Hygin, Astronomie II, 37

Strabon VII, 7, 6

Strabon VIII, 6, 1

Strabon IX, 2, 6

Strabon X, 1, 6

Strabon X, 1, 10

Strabon X, 2, 7

Strabon X, 2, 8-9

Strabon X, 5, 1

Strabon X, 5, 15

Strabon XIII, 1, 46

Strabon XIII, 1, 47-48

Strabon XIII, 1, 62-63

Strabon XIII, 2, 5

Strabon XIV, 6, 3

Strabon XVII, 3, 13

Strabon XVII, 3, 20

Antipater de Thessalonique, Épigramme XL = Anthologie Palatine X, 25

Properce, Élégie III,11, v. 69-72

Properce, Élégie IV, 6, v. 11-68

Ovide, Tristes V, 2b, v. 29-34

Pomponius Mela, Chorographie I, 7, 34

Stace, Achilléide I, v. 679-688

Antiphilos, Épigramme XI = Anthologie Palatine X, 17

Philippe, Épigramme VII = Anthologie Palatine VI, 251

Plutarque, Vies (Thésée ), 18, 1-3

Plutarque, Vies (Timoléon), 8, 1-9, 1

Plutarque, Vies (Thémistocle), 15, 3

Plutarque, Banquet des sept sages $160 \mathrm{e}-162 \mathrm{e}$

Plutarque, De Sollertia animalium 983e-984c

Pseudo-Apollodore, Bibliothèque I, ix, 26

Arrien, Indica XXXVI, 3

Pausanias I, xxxvii, 6-7 
Pausanias II, xxxii, 2

Pausanias III, xxiii, 1-4

Pausanias III, xxiv, 1

Pausanias IV, xxxiv, 7

Pausanias $\mathrm{X}, \mathrm{xi}, 6$

Pausanias $\mathrm{X}$, xiii, 10

Pausanias $\mathrm{X}$, xiv, 5

Pausanias $\mathrm{X}, \mathrm{xvi}, 7$

Pausanias X, xix, 3

Ampelius, Aide-mémoire 8, 4-5

Pollux, Onomasticon VIII, 119

Athénée V, 209e

Dion Cassius, Histoire romaine L, 12, 7

Dion Cassius, Histoire romaine LI, 1, 2-3

Hymne orphique XXXIV, v. 16-27

Macrobe, Saturnales I, 17, 24

Servius, Comm. in Buc. VIII, 55

Argonautiques orphiques, v. 1298-1299

Etymologicum Magnum, s. v. 'E $\pi$ ì $\Delta \varepsilon \lambda \varphi \imath v i ́ \omega$

Quintus, Épigramme I

Anthologie Palatine VI, 342

ARÈS

Pseudo-Skylax, Périple 38

ARGOI LITHOI

Pausanias VII, xxii, 4

ARTÉmis

Hymne homérique à Artémis II, v. 1-10

Eschyle, Agamemnon, v. 146-151

Eschyle, Agamemnon, v. 184-204

Hérodote III, 59 (?)

Hérodote IV, 103

Hérodote VII, 176

Hérodote VII, 188-192

Hérodote VIII, 77

Euripide, Hippolyte, v. 227-231

Euripide, Iphigénie en Tauride, v. 4-30

Euripide, Iphigénie à Aulis, v. 87-93

Euripide, Iphigénie à Aulis, v. 1491-1497

Euripide, Iphigénie à Aulis, v. 1563-1603

Xénophon, Helléniques II, 4, 11 
Xénophon, Helléniques III, 4, 3-4

Callimaque, Hymne III (à Artémis), v. 31-40

Callimaque, Hymne III (à Artémis), v. 183-203

Callimaque, Hymne III (à Artémis), v.225-232

Callimaque, Hymne III (à Artémis), v. 237-239

Callimaque, Hymne III (à Artémis), v. 259

Apollonios de Rhodes I, v. 569-579

Apollonios de Rhodes IV, v. 329-335

Diodore, Bibliothèque historique V, 76, 3-4

Strabon III, 4, 6

Strabon III, 4, 8

Strabon IV, 1, 4

Strabon VII, 4, 2

Strabon XIV, 1, 19

Strabon XIV, 1, 20

Strabon XIV, 1, 29

Strabon XIV, 2, 2

Ovide, Métamorphoses XII, v. 8-38

Apollonidès, Épigramme I = Anthologie Palatine VI, 105

Stace, Achilléide I, v. 447-451

Plutarque, Vies (Thémistocle), 8, 3-6

Plutarque, Vies (Agésilas), 6, 6-11

Plutarque, Mulierum Virtutes, 247d-f

Plutarque, De Sollertia animalium 965c-d

Plutarque, De Sollertia animalium 983e-984c

Arrien, Anabase VII 20, 3-4

Pausanias I, i, 4

Pausanias I, xxxvi, 1

Pausanias I, xliii, 1

Pausanias II, ii, 3

Pausanias II, xxx, 3

Pausanias III, xiv, 2

Pausanias III, xxii, 12

Pausanias III, xxiii, 10

Pausanias III, xxiv, 9

Pausanias III, $x x v, 4$

Pausanias VIII, xli, 4-6

Pausanias X, 36, 5

Apulée, Métamorphoses XI, 3-5

Antoninus Liberalis, Métamorphoses XL

Procope, De Bello Gothico IV, 22, 23-29

Denys de Byzance, Anaplus Bospori 35-36

Denys de Byzance, Anaplus Bospori 56-57

Hésychius, s.v. Aphaia

Hésychius, s.v. Britomartis

Mythographi Vaticani II, 36 
Astarté

Achille Tatios, Les aventures de Leucippé et Clitophon I, 1, 2

AtARgATIS

Ovide, Fastes II, v. 459-474

Hygin, Astronomie II, 30

Anthologie Palatine VI, 24

\section{ATHÉNA}

Odyssée I, v.319-323

Odyssée II, v. 382-433

Odyssée IV (Télémachie), XV, v. 33-35

Hymne homérique à Athéna I, v. 9-16

Esope, Le naufragé

Bacchylide, Dithyrambe II, v. 13-18

Bacchylide, Dithyrambe III

Hérodote III, 59

Euripide, Troyennes, v. 75-94

Euripide, Iphigénie en Tauride, v. 1486-1489

Euripide, Iphigénie à Aulis, v. 235-257

Euripide, Cyclope, v. 290-295

Aristophane, Cavaliers, v. 1181-1186

Aristophane, scholie à Paix, v. 418

Strattis, Fragment 30

Aristote, De la génération des animaux I, 18, 724ab

Lycurgue, Contre Léocrate, 17

Lycophron, Alexandra, v. 348-386

Tzetzès, scholie à Lycophron, Alexandra v. 359

Apollonios de Rhodes I, v. 18-19

Apollonios de Rhodes I, v. I, 519-535

Apollonios de Rhodes I, v. 953-971

Apollonios de Rhodes II, 593-614

Apollonios de Rhodes IV, v. 294-297

Apollonios de Rhodes IV, v. 576-595

Apollonios de Rhodes IV, v. 1537-1764

Polémon, Fgt 75 = Athénée XI, 462b-c

Virgile, Énéide III, v. 525-553

Hygin, Astronomie II, 37

Vitruve, De l'architecture IV, 8, 4

Strabon I, 2, 12

Strabon III, 4, 3

Strabon V, 4, 3

Strabon V, 4, 8

Strabon VI, 3, 5

Denys d'Halicarnasse, Antiquités romaines I, 51, 3 
Tite-Live, Histoire romaine XLII, 20, 3-4

Ovide, Métamorphoses XIV, v. 466-476

Ovide, Tristes I, 10, v. 1-44

Sénèque, Lettres à Lucilius 77, 2

Pline l'Ancien, Histoire naturelle III, 62

Antiphilos, Épigramme XL = Anthologie Palatine IX, 306

Stace, Silves II, 2, v. 1-3

Stace, Silves III, 2, v. 1-55

Stace, Silves V, 3, 162-166

Stace, Achilléide I, v. 695-698

Valerius Flaccus, Argonautiques I, v. 91-99

Valerius Flaccus, Argonautiques I, v. 120-126

Valerius Flaccus, Argonautiques II, v. 47-68

Valerius Flaccus, Argonautiques III, v. 487-491

Valerius Flaccus, Argonautiques IV, v. 670-693

Valerius Flaccus, Argonautiques VIII, v. 202-203

Plutarque, Vies (Thémistocle) 12, 1

Plutarque, Vies (Cimon) 5, 2

Pseudo-Apollodore, Bibliothèque I, ix, 16

Pseudo-Apollodore, Bibliothèque II, i, 4

Ptolémée, Géographie IV, 7, 11

Pausanias I, i, 1

Pausanias I, i, 3

Pausanias I, v, 3

Pausanias I, xxix, 1

Pausanias I, xli, 6

Pausanias III, xxii, 10

Pausanias III, xxiv, 5

Pausanias IV, xxxv, 8

Pausanias IV, xxxvi, 2

Pausanias VII, xxii, 10

Scholie à Aelius Aristide, Panathénaïque 197, 8

Apulée, Métamorphoses XI, 3-5

Lucien, Piscator 47

Denys de Byzance, Anaplus Bospori, fgt 8

Élien, De la nature des animaux VII, 7

Philostrate, Vie des Sophistes II, 1, 550

Quintus de Smyrne, La suite d'Homère IX, 436-437

Himerios, Orationes XLVII, 12-16

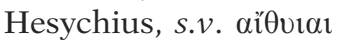

Hesychius, s.v. $\dot{\varepsilon} v \delta$ ' Aḯvia

Argonautiques orphiques, v. 59-69

Argonautiques orphiques, v. 266-271

Argonautiques orphiques, v. 680-711

Argonautiques orphiques, v. 1155-1170

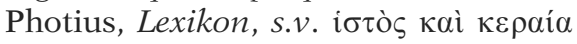

Stadiasmus, sive Periplus Maris Magni, 318

Anthologie Palatine, Livre VI, 342

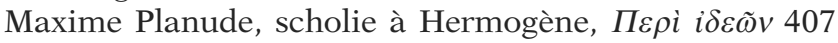


Bateau (EX-VOto)

Hérodote III, 59

Hérodote IV, 88-89

Hérodote VIII, 121-122

Hérodote IX, 121

Aristophane, scholie à Paix, v. 418

Thucydide II, 84, 4

Thucydide II, 92, 5

Strattis, Fragment 30

Platon, Phédon 58 a-c

Aristote, De la génération des animaux I, 18, 724ab

Callimaque Hymne III, v. 228-232

Callimaque, Hymne IV (à Délos), v. 307-326

Diodore de Sicile, Bibl. Hist. IV, 53, 2

Diodore de Sicile, Bibl. Hist. XII, 48, 1

Diodore de Sicile, Bibl. Hist. XVI, 66, 3-5

Ovide, Tristes I, 10, v. 1-14

Strabon III, 4, 3

Strabon IV, 1, 5

Strabon VII, 7, 6

Pline l'Ancien, Histoire naturelle XXXV, 101

Pline l'Ancien, Histoire naturelle XXXV, 136

Martial, Épigramme VII, 19

Plutarque, Vies (Thésée), 23, 1

Plutarque, Vies (Timoléon), 8, 1-9, 1

Plutarque, Vies (Lysandre), 18, 1

Plutarque, Vies (Thémistocle), 15, 3

Plutarque, Vies (Antoine), 65, 5

Plutarque, Si la politique est l'affaire des vieillards 6

Plutarque, Compendium argumenti stoicos absurdoria poetis dicere, 1057e

Pseudo-Apollodore, Bibliothèque I, ix, 27

Dion Chrysostome, Oratio XXXVII, 15

Pausanias I, xxix, 1

Pausanias I, xl, 5

Pausanias IX, xvi, 3-4

Pausanias $\mathrm{X}, \mathrm{xi}, 6$

Aelius Aristide, Prosphonétique de Smyrne, 473-474

Aelius Aristide, Politique de Smyrne, 402-403

Scholie à Aelius Aristide, Panathénä̈que 197, 8

Ampelius, Aide-mémoire 8, 5

Athénée V, 209e

Philostrate, Vie des sophistes, I, 25, 530-531

Philostrate, Vie des sophistes, II, 1, 550

Dion Cassius, Histoire romaine LI, 1, 2-3

Himerios, Orationes XLVII, 12-16

Procope, De Bello Gothico IV, 22, 5-16

Procope, De Bello Gothico IV, 22, 23-29

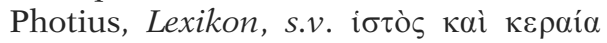


Anthologie Palatine VI, 69

Anthologie Palatine VI, 70

Anthologie Palatine VI, 341

Anthologie Palatine VI, 342

Lexeis rhetorikai, s.v. Nátos Zeús

\section{BRITOMARTIS}

Callimaque, Hymne III (à Artémis), v. 183-203

Diodore, Bibliothèque historique V, 76, 3-4

Pseudo-Virgile, Ciris, v. 301-305

Strabon X, 4, 12-13

Strabon X, 4, 14

Pausanias II, xxx, 3

Pausanias III, xiv, 2

Antoninus Liberalis, Métamorphoses XL

Nonnos, Dionysiaques XXXIII, v. 330-335

Hésychius, s.v. Britomartis

BRIZÔ

Sémos de Délos, Fragment 4 = Athénée VIII, 335ab

Hésychius, s. v. Bpı ¿́ó

Eusthate, Ad Odyss. M, v. 252

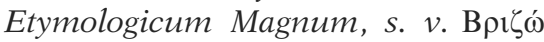

DeuX DÉEsSES

Diodore de Sicile, Bibliothèque historique XVI, 66, 3-5

Plutarque, Vies (Timoléon), 8, 1-9, 1

Plutarque, De Sollertia animalium 983e-984c

Pausanias I, xxxviii, 1

\section{DIKTYNNA}

Hérodote III, 59

Callimaque, Hymne III (à Artémis), v. 183-203

Diodore, Bibliothèque historique V, 76, 3-4

Pseudo-Virgile, Ciris, v. 301-305

Strabon X, 4, 12-13

Plutarque, De Sollertia animalium 965c-d

Plutarque, De Sollertia animalium 983e-984c

Pausanias II, $\mathrm{xxx}, 3$

Pausanias III, xii, 8

Pausanias III, xxiv, 9 
Pausanias X, 36, 5

Apulée, Métamorphoses XI, 3-5

Antoninus Liberalis, Métamorphoses XL

Hésychius, s.v. Aphaia

Mythologi Vaticani II, 36

\section{Dionysos}

Iliade VI, 132-137

Hymne homérique à Dionysos

Hermippos, Fragment 63

Théopompe de Chios, Fragment 352

Théophraste, Caractères III, 3

Timée de Tauroménium, Fragment 149

Philochoros, Fragment 194

Hygin, Astronomie II, 17

Hygin, Astronomie II, 21, 1

Ovide, Métamorphoses III, v. 600-691

Plutarque, Isis et Osiris 364d

Plutarque, Isis et Osiris 365a

Plutarque, Propos de table V, 675d-676d

Pseudo-Apollodore, Bibliothèque III, v, 1

Pseudo-Apollodore, Bibliothèque III, v, 3

Pausanias II, xxiii, 1

Pausanias II, xxxv, 1

Pausanias III, xxiv, 3-4

Pausanias VII, xix, 6-10

Pausanias IX, $\mathrm{xx}, 4-5$

Pausanias $\mathrm{X}$, xix, 3

Aelius Aristide, Prosphonétique de Smyrne, 473-474

Aelius Aristide, Politique de Smyrne, 402-403

Athénée I, 26b

Élien, De la nature des animaux XII, 34

Philostrate, Vie des sophistes I, 25, 530-531

Philostrate l'Ancien, Imagines I, 19

Hymne orphique LXXIV

Hymne orphique LXXV

Nonnos XXI, v. 170-184

Nonnos XXIII, v. 18-26

Héraclite, Allégories d'Homère 35, 6-8

Douze DIEuX

Hymne homérique à Apollon Délien, v. 388-512

Apollonios de Rhodes II, v. 528-533

Scholie à Argonautiques II, v. 531-532

Polybe, Histoires IV, 39, 4-6 
HÉRA

Odyssée IV, v.466-520

Odyssée XII, v. 55-100

Hérodote IV, 87-88

Hérodote IV, 152

Euripide, Hélène, v. 998-1027

Aristote, De mirabilibus auscultationibus, 96 = Athénée XII, 541a-b

Théocrite, Idylle IV, v. 33

Lycophron, Alexandra, v. 856-858

Tzetzès, scholie à Lycophron, Alexandra, v. 856

Apollonios de Rhodes IV, v. 576-595

Apollonios de Rhodes IV, v. 640-653

Apollonios de Rhodes IV, v. 756-967

Ménodotos de Samos, Fgt 1 = Athénée XV, 672a-e

Cicéron, $2^{\text {nde }}$ action contre Verrès IV, xlvi, 103-xlvii-104

Diodore, Bibliothèque historique XIII, 3, 1-4

Virgile, Énéide III, v. 525-553

Virgile, Énéide V, v. 789-795

Strabon III, 5, 3

Strabon III, 5, 5

Strabon VI, 1, 1

Strabon VI, 1, 11

Strabon VI, 3, 5

Strabon VIII, 6, 22

Tite-Live, Histoire romaine XXIV, 3, 3-7

Tite-Live, Histoire romaine XXXII, 23, 10

Denys d'Halicarnasse, Antiquités romaines I, 51, 3

Pomponius Mela, Chorographie II, 6, 96

Pomponius Mela, Chorographie III, 1, 4

Pline l'Ancien, Histoire naturelle II, 240

Valerius Flaccus, Argonautiques I, v. 91-99

Valerius Flaccus, Argonautiques IV, v. 670-693

Pseudo-Apollodore, Bibliothèque I, ix, 25

Ptolémée, Géographie IV, 3, 13

Pausanias VII, iv, 4

Xénophon d'Éphèse, Éphésiaques I, xi, 2

Argonautiques orphiques, v. 59-69

Argonautiques orphiques, v. 329-362

Argonautiques orphiques, v. 680-711

Anthologie Palatine VI, 341

Stéphane de Byzance, s.v. "H $\rho \alpha 1 \alpha$

HERMÈs

Callimaque, Iambe III (L'Hermès d'Ainos)

Léonidas de Tarente, Épigramme LII = Anthologie Palatine VI, 4

Strabon XVII, 3, 13 
Strabon XVII, 3, 16

Pomponius Mela, Chorographie I, 7, 34

Philippe de Thessalonique, Épigramme VIII

Arrien, Indica XXXVII, 10-11

Pausanias VII, xxii, 4

Anthologie Palatine VI, 28

Anthologie Palatine VI, 29

Anthologie Palatine VI, 23

Phanias, Épigramme V

Hymne orphique XXVIII, v.8-10

\section{INDÉFINIS}

Hérodote VIII, 64

Apollonios de Rhodes, Argonautiques IV, v. 576-595

Stace, Achilléide II, v. 12-22

Arrien, Indica XLII, 6

Arrien, Indica XLII, 8

Anthologie Palatine VI, 27

MARINS (DIEUX)

Arrien, Indica XX, 10

Arrien, Indica XXXVI, 3

PosÉIDON

Iliade XIII, v. 10ss.

Iliade XV, v. 185-199

Odyssée IV, v. 380 ss.

Odyssée I, v. 68 ss

Odyssée III, v. 5-12

Odyssée III, v. 178-179

Odyssée V, v. 282 ss.

Hymne homérique à Poséidon, v. 5 et 7

Hésiode, Théogonie v. 930

Pindare, Isthmiques VI, v. 1-6

Pindare, Isthmiques VIII, 32

Pindare, Olympiques VI, 103

Pindare, Olympiques XIII, 4

Pindare, Pythiques IV, v. 360-371

Bacchylide, Dithyrambe III

Hérodote II, 50-51

Hérodote VI, 87

Hérodote VII, 192

Hérodote VIII, 121-122 
Hérodote VIII, 129

Sophocle, Edipe à Colone, v. 707-719

Sophocle, Edipe à Colone, v. 1071

Euripide, Troyennes, v. 1-3

Euripide, Troyennes, v. 75-94

Euripide, Hélène, v. 1581 ss.

Eupolis, Fgt 140

Scholie à Aristophane, Acharniens, v. 682

Aristophane, Cavaliers, v. 551 ss.

Aristophane, Cavaliers, v. 560

Aristophane, Oiseaux, v. 869

Aristophane, Oiseaux, v. 1519

Aristophane, Thesmophories, v. 312-330

Platon, Critias 116c-117a

Lysias, Discours XXI, 5

Callimaque, Hymne IV, v. 271

Léonidas de Tarente, Épigramme LII = Anthologie Palatine VI, 4 Théocrite, Les pêcheurs, v. 54-55

Apollonios de Rhodes, Argonautiques IV, v. 1325-1392

Skylax in GGM I p. $46 \mathrm{n}^{\circ} 57$

Diodore de Sicile V, 55

Diodore de Sicile V, 58

Diodore de Sicile V, 69, 4

Philodémos, Épigramme XIX = Anthologie Palatine VI, 349

Virgile, Énéide V, 816-826

Hygin, Astronomie II, 17

Hygin, Astronomie II, 22

Strabon VIII, vii, 1-2

Strabon VIII, v, 1

Ovide, Métamorphoses IV, v. 523-540

Philippe, Épigramme X = Anthologie Palatine VI, 38

Stace, Achilléide II, v. 12-22

Valerius Flaccus, Argonautiques II, v. 470

Plutarque, Isis et Osiris, 381e

Plutarque, Propos de table V, 675d-676d

Plutarque, Propos de table VII, 20

Plutarque, Banquet des sept sages, 163b-d

Pseudo-Apollodore, Bibliothèque I, iv, 5

Pseudo-Apollodore, Bibliothèque II, v, 9

Arrien, Anabase I, 11, 6-7

Arrien, Indica XVIII, 11-12

Arrien, Indica XXXVI, 3

Appien, Mithridate 70

Pausanias I, i, 1

Pausanias II, i, 7-9

Pausanias II, ii, 3

Pausanias III, xxv, 4

Pausanias VII, 21, 7

Pausanias VIII, vii, 1-2 
Pausanias IX, xxiv, 5-6

Pausanias X, 9, 3-4

Lucien, Piscator 47

Achille Tatios, Les aventures de Leucippé et Clitophon III, 6

Athénée VII, 297e

Athénée VIII, 346c

Élien, De la nature des animaux XII, 45

Hésychius, s.v. Epilimnios

Souda, s.v. $\pi \varepsilon \rho i ́ \psi \eta \mu \alpha$

Anthologie Palatine VI, 30

Anthologie Palatine VI, 69

Anthologie Palatine VI, 70

Anthologie Palatine VI, 164

Anthologie Palatine VII, 256

Proue-Poupe (DÉCOR NAVAL)

Hérodote III, 37

Euripide, Iphigénie à Aulis, v. 235-257

Scholie à Aristophane, Acharniens v. 547

Diodore, Bibliothèque historique XIII, 3, 1-4

Virgile, Énéide X, v. 156-255

Ovide, Tristes I, 4, v. 7-8

Ovide, Tristes I, 10, v. 1-14

Properce, Élégie IV, 6, v. 11-68

Valerius Flaccus, Argonautiques VIII, v. 202-203

Plutarque, Propos de table V, 675d-677b

Philostrate l'Ancien, Imagines I, 19

\section{SACRIfice / Libation À BORD}

Euripide, Hélène, v. 1554-1588

Thucydide VI, 32, 1-2

Xénophon, Helléniques III, 4, 3-4

Polémon, Fgt 75 = Athénée XI, 462b-c

Apollonios de Rhodes IV, v. 1537-1764

Diodore de Sicile, Bibliothèque historique XIII, 3, 1-4

Virgile, Énéide III, v. 525-553

Stace, Achilléide I, v. 679-688

Stace, Silves III, 2, v. 1-55

Arrien, Anabase I, 11, 6

Zeus

Odyssée IV, v. 466-520

Odyssée V, v. 299-305

Odyssée XII, v. 407-419 
Odyssée XIV, v. 303-313

Hymne à Apollon Délien, v. 388-512

Eschyle, Fragment 30

Pindare, IVe Pythique, v. 191-209

Bacchylide, Dithyrambe II, v. 13-18

Sophocle, Trachiniennes, v. 237-238 et et 750-805

Euripide, Troyennes, v. 75-94

Euripide, Iphigénie à Aulis, v. 1319-1329

Lycurgue, Contre Léocrate, 17

Diphile, Fragment 43

Callimaque, Hymne I (à Zeus), v. 70-75

Callimaque, Fragment 400

Poseidippos de Pella, Épigramme XI

Théocrite, Idylle XXVIII (la Quenouille), v. 5-6

Méléagre, Épigramme LXVI

Cicéron, Seconde action contre Verrès, IV, 128-130

Julius Polyen, Épigramme IIIa = Anthologie Palatine IX, 9

Virgile, Énéide IX, v. 69-122

Strabon IX, 1, 15

Tite-Live, Histoire romaine XLII, 20, 3-4

Properce, Élégie IV, 6, v. 11-68

Pomponius Mela, Chorographie I, 19, 101

Pline l'Ancien, Histoire naturelle IV, 52

Philon de Byblos, Fgt 2

Arrien, Peripl. Pont. Eux. 12, 2-3

Arrien, Anabase I, 11, 6-7

Arrien, Indica XXI, 2

Arrien, Indica XXXVI, 3

Arrien, Indica XXXVI, 9 - XXXVII, 1

Ptolémée, Géographie III, 14, 32

Pausanias I, i, 3

Pausanias I, iv, 5

Pausanias I, xl, 5

Pausanias III, xxiii, 10

Pausanias $\mathrm{X}$, xiv, 5

Eusèbe de Césarée, Préparation évangélique I, 10, 20

Marcien d'Héraclée, Epitome Peripli Menippei 7

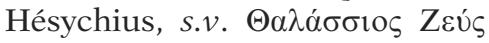

Procope, De Bello Gothico IV, 22, 23-29

Lexeis rhetorikai, s.v. Nóios Zeús 


\section{EX-VOTO NAVALS DES INVENTAIRES DÉLIENS}

Abréviations $=$ Homolle, l'inventoire de Démarès $=$ Homolle 1882; Homolle 1886; Durrbach 1905; Coupry = ID 89-10433; Durrbach = ID 290509; Durrbach-Roussel = ID 1400-1489; Prêtre 2002. Les chiffres apparaissant dans le texte des inventaires sont indiqués entre parenthèses en chiffres arabes.

\section{BATEAUX MINIATURES}

- IG XI, 2 (=ID), 161, B, 1. 78-79, daté de 279 a.C., qui concerne le temple d'Apollon :

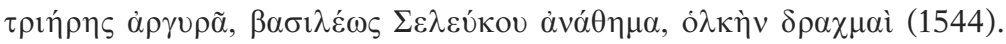

Traduction :

Une trière d'argent, don du roi Séleucos, poids 1544 drachmes.

- Durrbach 442 B, p. 143, l. 31 (= Homolle, l'inventaire de Démarès, no 31), daté de 179 a.C., dans le paragraphe concernant le temple d'Apollon (vraisemblablement la cella) :

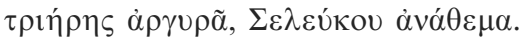

Répétition de ce même paragraphe dans Durrbach 461 Ba, p. 267, 1. 39, daté de 169 a.C.

- Durrbach-Roussel 1432 Ab, II, p. 114, 1. 55-56 (= Durrbach 1905, p. 543, l. 54-55), dans un acte de fonctionnaires athéniens daté de 153/152, dans le paragraphe consacré au temple d'Apollon :

$\tau \varepsilon \tau \rho \eta ́ \rho \eta, ~ \tilde{\eta ் ~}$ $\beta \alpha \sigma \lambda \lambda \varepsilon \dot{\varepsilon} \omega \varsigma \Sigma \varepsilon \lambda \varepsilon \cup ́ \kappa o v$.

Traduction :

Quadrirème, poids avec leurs agrès de bronze 1700 [drachmes], don du roi Séleucos.

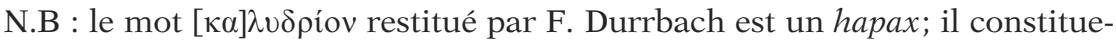

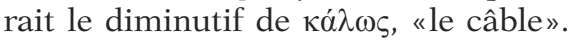


Parties de Bateaux

- Coupry 104, p. 39, 1. 137-138 (= Homolle 1886, p. 466, 1. 137-8; Prêtre 2002, p. 39-47), daté de 364 a.C., dans le paragraphe qui concerne le temple des Déliens :

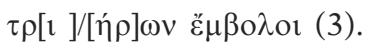

Traduction :

Trois éperons de trières.

Répété dans ID 104-11 B, 1. 30, de l'Acropole d'Athènes, daté vers 354 a.C.; répété dans ID 104-12, 1. 108, de l'Acropole d'Athènes, daté vers 353 a.C.

- Coupry 104-25, p. 95, 1. 10, dans un acte amphictyonique, daté vers 344/343, concernant l'Oikos des Naxiens (fig. 28, n $^{\circ} 14$ ) :

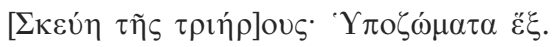

Répété en ce qui concerne la première partie en 104-26 B l. 16 (vers 343/ 342); 104-28 Bb, 1.10 (année 341/340); en ce qui concerne la deuxième en 104, 29 1. 13-14.

- Coupry 104-26 B, p. 97, 1. 10, dans un acte amphictyonique, daté vers 343/ 342; inscription trop fragmentaire pour être rattachée à un bâtiment :

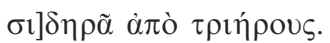

- Durrbach-Roussel 1443 B, II, p. 161, 1. 49-51, dans un acte de fonctionnaires athéniens postérieur à 146 a.C., dans le paragraphe consacré au temple des Athéniens :

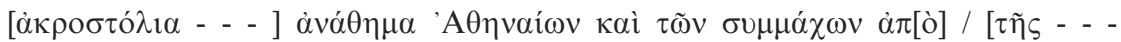

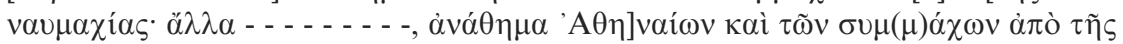

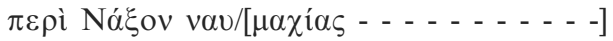

Le texte est complété par deux autres inventaires :

- Durrbach-Roussel 1446, 1. 21-23 (non daté) :

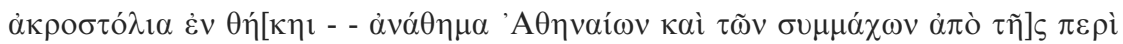

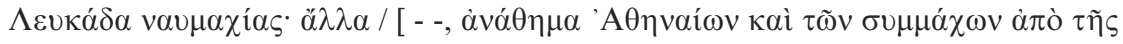
$\pi \varepsilon \rho i ̀ ~ N a ́ \xi o] v ~ v a v \mu \alpha \chi i ́ a s$.

- Durrbach-Roussel 1449 d, p. 184, 1. 12-14 (non daté) :

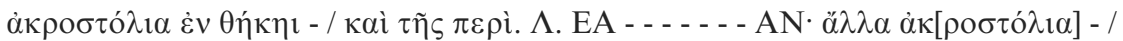

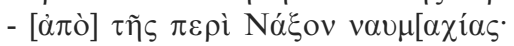


Traduction :

Des akrostolia en coffre, don des Athéniens et de leurs alliés du combat naval contre Leucade; d'autres ..., don des Athéniens et de leurs alliés du combat naval contre Naxos.

- Durrbach 320 B, p. 91, 1. 69, daté de 229, dans le paragraphe concernant l'édifice des Andriens :

$\ddot{\varepsilon} \mu \beta \mathrm{o} \lambda \mathrm{\sigma} \chi \alpha \lambda \kappa \mathrm{\kappa} \varsigma$.

- Durrbach 320 B, p. 91, 1. 75-76, daté de 229, dans le paragraphe concernant peut-être le «sanctuaire de l'Ile» :

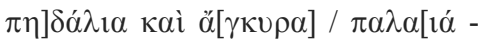

- Durrbach 442 B, p. 151, l. 167 (= Homolle, l'inventaire de Démarès, n 168), daté de 179 a.C., dans le paragraphe concernant l'édifice des Andriens :

ve⿳亠ऽ $\check{\varepsilon} \mu \beta \mathrm{o} \lambda \mathrm{ov}$.

Répétition de ce même paragraphe dans Durrbach 443 Bb, p. 184, 1. 90 (= Homolle, l'inventaire de Démarès, $n^{\circ} 167$ ), daté de 178 a.C.; dans Durrbach 444 B, p. 192, 1. 6, daté de 177; dans Durrbach 457, p. 229, 1. 17, daté vers 174; reconstitué (hypothétique) dans Durrbach 298 A, p. 45, 1. 180, daté de 240 a.C.

\section{VASES NAVIFORMES}

- Coupry 104, p. 39, l. 131 (= Homolle 1886, p. 466, l. 131; Prêtre 2002, p. 39-47), daté de 364/3 a.C., dans le paragraphe qui concerne le temple des Déliens :

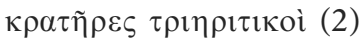

Traduction :

Deux cratères en forme de trière.

Répété dans ID 104-11 B, 1. 24-25, de l'Acropole d'Athènes, daté vers 354 a.C.; répété et restitué dans $I D$ 104-12, l. 103, de l'Acropole d'Athènes, daté vers 353 a.C.

- Coupry 104, p. 39, 1. 135 (= Homolle 1886, p. 466, 1. 135; Prêtre 2002, p. 39-47), daté de 364/3 a.C., dans le paragraphe qui concerne le temple des Déliens :

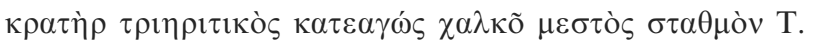

Traduction :

Cratère en forme de trière cassé rempli de bronze, poids un talent.

Répété dans ID 104-11 B, 1. 27-28, de l'Acropole, daté vers 354 a.C.; répété 
partiellement (absence de $\kappa \alpha \tau \varepsilon \alpha \gamma \omega ́ \varsigma$ ) dans ID 104-12, 1. 106, de l'Acropole d'Athènes, daté vers 353 a.C.

\section{ANCRES}

- Durrbach 298 A, p. 45, 1. 180, daté de 240 a.C., dans le paragraphe concernant l'édifice des Andriens :

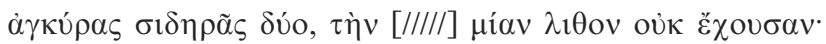

Traduction :

Deux ancres de fer, une n'ayant pas de pierre.

Répétition dans Durrbach 300 B, p. 55, 1. 29, non daté (III ${ }^{\text {e }}$ s. a.C.?); dans Durrbach 313 i, p. 66, 1. 16-17, dans un compte daté de 235 ou 234, avec objets au nominatif au lieu de l'accusatif.

- Durrbach 346 B, p. 116, 1. 1, non daté (fin $\mathrm{III}^{\mathrm{e}}$ ou début $\mathrm{II}^{\mathrm{e}} \mathrm{s}$.), sans doute à propos de l'édifice des Andriens :

$\ddot{\alpha} \gamma \kappa \cup \rho \alpha \lambda-$

- Durrbach 372 B, p. 10, l. 36-37, daté de 200 a.C., dans le paragraphe concernant l'édifice des Andriens :

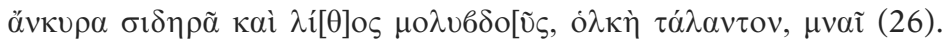

Traduction :

Ancre de fer et pierre de plomb, poids d'un talent, 26 mines.

Répétition dans Durrbach 430, p. 110, 1. 5, daté vers 185 a.C.

- Durrbach 442 B, p. 151, 1. 168 (= Homolle, l'inventaire de Démarès, $\mathrm{n}^{\circ}$ 168), daté de 179 a.C., dans le paragraphe concernant l'édifice des Andriens :

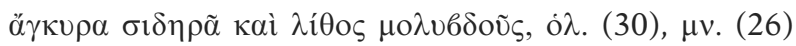

Répétition de ce même paragraphe dans Durrbach 443 Bb, p. 184, 1. 92, daté de 178 a.C.; dans Durrbach 444 B, p. 193, 1. 8, daté de 177, avec indication d'un poids différent (4 talents, 20 mines); dans Durrbach 439 b, p. 119, 1. 13, daté de 181 a.C., restitué en partie; dans Durrbach 421, p. 99, 1. 17, daté vers 190 a.C.

- Durrbach 442 B, p. 151, l. 171 (= Homolle, inventaire de Démarès, n 171), id. :

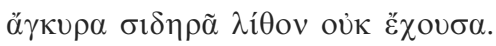

Répétition de ce même paragraphe dans Durrbach 443 Bb, p. 184, 1.95 daté de 178 a.C. Restitué en partie dans Durrbach 430, p. 110, 1. 6-7, daté vers 185 a.C., dans paragraphe concernant l'édifice des Andriens :

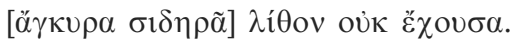


Répété dans Durrbach 444, p. 193, 1. 11, daté de 177, dans paragraphe concernant l'édifice des Andriens. Répété (restitué en partie) dans Durrbach 457, p. 229, 1. 21, daté de 174 (?) a.C. pour l'édifice des Andriens; id. dans Durrbach 461 Bb, p. 268, 1. 5, daté de 169 a.C.; id. dans Durrbach 372 B, p. 10, 1. 40, daté de 200 a.C.

- Durrbach-Roussel 1417 A col. I, p. 59, 1. 163-67 (= F. Chapouthier, EAD XVI. Le sanctuaire des dieux de Samothrace, Paris, 1935, p. 88), dans un acte de fonctionnaires athéniens daté de 155 a.C., dans le paragraphe consacré au Samothrakeion :

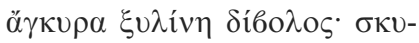

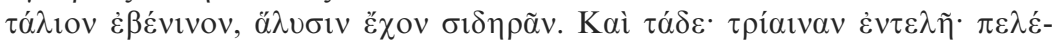

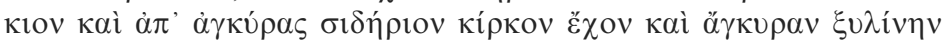

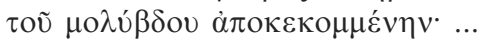

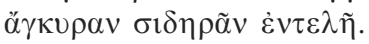

Traduction :

Ancre de bois à double pointe; bâton d'ébène garni d'une chaîne de fer. Et cela : trident en parfait état; pélékion et un morceau de fer d'une ancre avec un anneau et ancre de bois coupée de métal; (...) ancre de fer en parfait état.

Répété en partie et reconstitué dans Durrbach-Roussel 1403 Bb, col. II, p. 11, 1. 4-6, dans un acte de fonctionnaires athéniens daté entre 166 et 155 a.C., dans le paragraphe consacré au Samothrakeion. Id. dans Durrbach-Roussel, 1412 a, p. 32, 1. 27-28, dans un acte de fonctionnaires athéniens (d'après 166 a.C.), dans le paragraphe consacré au Samothrakeion.

- ID 320 B, 1. 75 : voir ci-dessus, à parties de navires. 



\section{CATALOGUES DES ANCRES DE PLOMB AVEC INSCRIPTIONS THÉOPHORES ET/OU DÉCORS}

Le corpus constitué par A. Hesnard et P. A. Gianfrotta (Hesnard \& Gianfrotta 1989) a servi de base pour la présentation de celui-ci. Cependant, plusieurs rubriques ont été ajoutées afin, si possible, de donner une description la plus précise qui soit. Dans le but de clarifier des explications souvent peu compréhensibles, il nous a paru nécessaire de créer un système simple pour expliquer la répartition des décors et inscription sur les jas. Considérant que le jas présente deux bras, et chacun d'eux deux faces sur lesquelles figurent des signes (hormis rares cas particuliers, voir infra), ces quatre surfaces, selon respectivement la présence ou l'absence de motifs, sont symbolisées chacune par X ou 0. La présentation commence par une face d'un bras (celui considéré alors comme gauche), puis par la même face de l'autre bras (fig. 50); ensuite vient l'autre face du bras gauche et celle du bras droit.

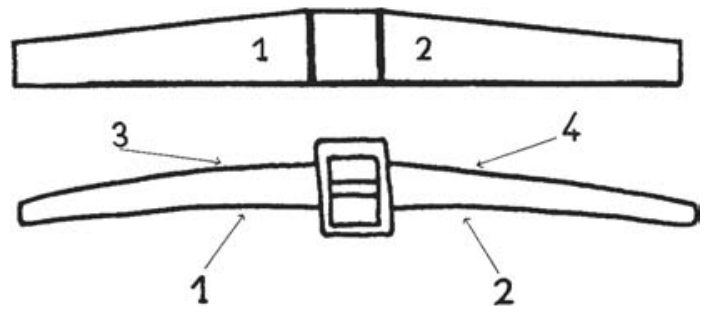

Fig. 50 - Jas de plomb.

Neuf combinaisons sont donc possibles (en effet, par commodité, nous commençons toujours la description du jas par le côté où apparaît le décor ou l'inscription, et si c'est le cas par le côté où les deux bras apparaissent décorés) :

X000 : le figure apparaît sur une seule face, la première du bras gauche 0X00 : le figure apparaît sur une seule face, la première du bras droit XX00 : le figure apparaît sur la même face des deux bras

XXX0 : le figure apparaît sur les deux faces du bras gauche, et sur la première face du bras droit

XXXX : le figure apparaît sur les quatre faces du jas

XX0X : le figure apparaît sur la première face du bras gauche et les deux faces du bras droit

X00X : le motif apparaît croisé, sur la première face du bras gauche et la deuxième face du bras droit 
0XX0 : le motif apparaît croisé, sur la première face du bras droit et la deuxième face du bras gauche

X0X0 : le motif apparaît sur les deux faces du bras gauche.

Pour simplification, les jas de plomb avec inscriptions théophores portent les numéros I1, I2, etc. (I pour inscription), tandis que ceux avec décor sont désignés sous les numéros D1, D2... Tous les champs ne sont pas renseignés (informations manquantes dans les publications). Les datations sont pour l'essentiel celles proposées par la bibliographie. Les articles référencés que nous n'avons pas pu consulter sont également signalés.

Ce catalogue, nous voulons insister sur ce point, y compris dans sa présentation, constitue un outil de travail, une ébauche. Il pourrait servir de point de départ pour un travail collectif, du type base de données, qui permettrait l'enrichissement progressif du corpus à partir d'une meilleure connaissance des objets eux-mêmes et d'une extension des exemplaires recensés.

\section{Organisation du catalogue}

Ancres de plomb avec inscriptions théophores (I1-I25)

Zeus (I1-I6)

Zeus-Aphrodite (I7-I8)

Aphrodite (I9)

Sôteira / Tychè (I10-I17)

Autres dieux (I18-25)

Ancres de plomb avec décor (D1-D97)

A. Décor simple

1) Astragales/osselets

- Groupe(s) de 4 astragales (classement interne par zones géographiques) (D1-23)

- Nombreuses astragales avec combinaison(s) de 4 (D24-D26)

- Nombre non rattachable à une ou des combinaison(s) de 4 (D27D28)

- Nombre indéterminé (D29-D43)

2) Dauphins (D44-D52)

3) «Tête coupée» (D53-D54)

4) Alia (motifs uniques) (D55-D67)

B. Décor complexe

1) Avec dauphins et astragales (D68-D73)

2) Autre(s) motif(s) avec astragales (D74-D81)

3) Combinaisons de motifs sans astragales (D82-D83)

C. Décor avec inscription onomastique ou numéraire
1) Avec astragales + autre décor (D84)
2) Avec astragale(s) seule(s) (D85-D93)
3) sans astragales (D94-D98). 
ANCRES DE PLOMB AVEC INSCRIPTIONS THÉOPHORES

Zeus

$\mathbf{n}^{\mathbf{o}} \mathbf{I 1}$ = ZEYC / YПАTOC (avec le Z inversé), sur deux bras différents (0XX0 en suivant la reconstitution de C. Torr) (fig. 51 et supra p. 302 ss.)

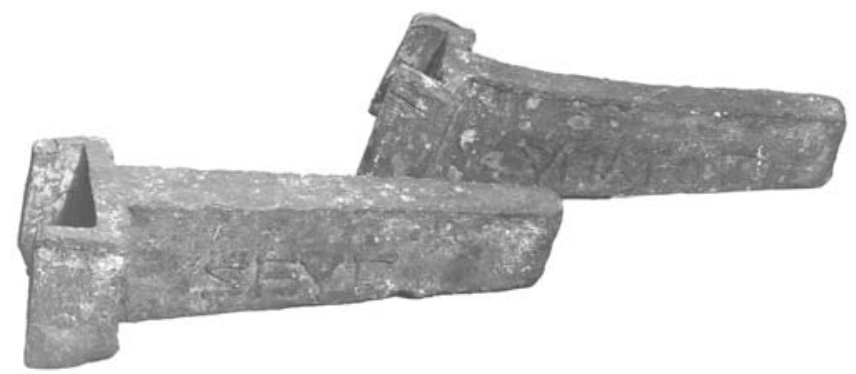

Fig. 51 - Deux demi-bras de jas: inscription «Zeus Hypatos»; British Museum, inv. GR 1893-11-13-1 (ㄷ British Museum).

Objet : 2 bras de jas en plomb, paraissant appartenir à un même jas; long. $1,70 \mathrm{~m}$, larg. max. $23 \mathrm{~cm}$; poids : 472 et $473 \mathrm{lbs}$ (environ $429 \mathrm{~kg}$ ensemble)

Site : côte de Cyrénaïque

Conservation : British Museum, Londres, inv. GR 1893-11-13-1

Datation : d'après Torr, caractères épigraphiques dateraient du milieu du Ier s. a.C.

Bibliographie: Torr 1894, p. 71-72, pl. VIII; Froehner 1897; Merlin 1912, p. 383-397 (pour lui, 2 exemplaires); Cook 1914-40, II, 2, p. 876 et fig. 815; Svoronos 1914, p. 106-109; Moll 1929, col. 266-271; Moll 1929a, pl. E II 86; Robert 1936, p. 2 n. 1; Ucelli 1950; Wachsmuth 1967, note 991; Casson 1971, p. 255 et note 126; Davaras 1980, p. 56; Gianfrotta 1980, p. 109 et fig. 18; Gianfrotta \& Pomey 1980, p. 309; Gianfrotta 1994, p. 600; Romero Recio 2000, p. 58-59.

$\mathbf{n}^{\mathbf{0}} \mathbf{I 2}$ = IOVIS; sur même face de l'autre bras le chiffre IV (XX00) (supra p. 304)

Objet : jas de plomb

Site : près de la secca de Tor Paterno, à Ostie (d'où un navire militaire?)

Conservation : magasins de la Soprintendenza, Ostie

Datation : inscription tardo-républicaine

Bibliographie : Gianfrotta 1994, p. 600. 
$\mathbf{n}^{\circ} \mathbf{I} 3=\operatorname{COZ} \Omega(\mathrm{X} 000)[=\Sigma$ ó $\zeta \omega(v)]$ (Gianfrotta 1994 et Perea Yébenes 2004); COSM (Mas García 1979) (fig. 52 et supra p. 309)

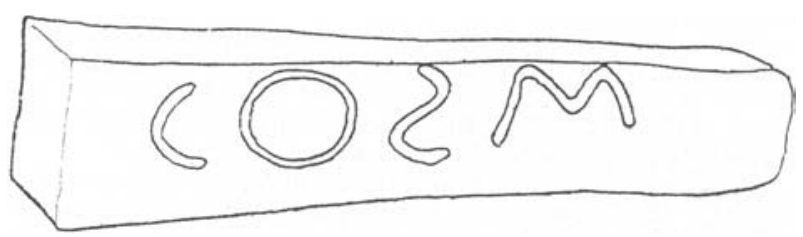

Fig. 52 - Jas : inscription «Sozô» (?) de Carthagène (d'après Gianfrotta 1994, fig. 4).

Objet : jas; long. 1,20 m (Perea Yébenes 2004)

Site : Carthagène (Gianfrotta 1994); cap Palos, entre l'île d'Escombreras et la côte (Perea Yébenes 2004)

Conservation: Musée archéologique municipal de Carthagène (Perea Yébenes 2004)

Datation : $\mathrm{II}^{\mathrm{e}}$ s. p.C. ou au plus tard $1^{\mathrm{er}}$ quart du $\mathrm{III}^{\mathrm{e}} \mathrm{s}$. (Perea Yébenes)

Bibliographie : Mas García 1979, p. 126 et fig. 131; Gianfrotta 1994, p. 602 et fig. 4; Romero Recio 1999; Perea Yébenes 2004, avec fig. 2; García Cardiel 2013, p. 48-49 et fig. 49-51.

\section{Zeus Kasios}

$\mathbf{n}^{\mathbf{0}} \mathbf{I} \mathbf{4}=\Delta \mathrm{IOC} / \mathrm{KACIOY}$ répartie sur deux faces (0X0X ou 0XX0?) (fig. 53 et supra p. 310 s.)

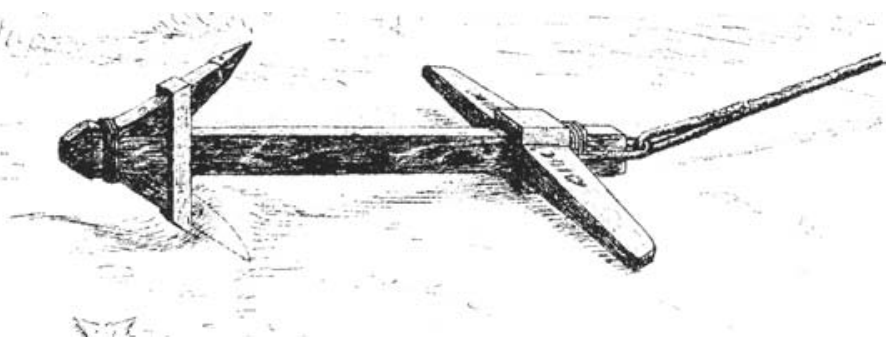

Fig. 53 - Reconstitution : ancre de Zeus Kasios de Syracuse (d'après Kapitän 1973, p. 384, fig. 1).

Objet: jas de plomb

Site : port de Syracuse

Conservation : Syracuse (?)

Datation : $\mathrm{II}^{\mathrm{e}}$ s. a.C.

Bibliographie : Manganaro 1972, p. 452, n. 50; Kapitän 1973, p. 384, fig. 1; Manganaro 1977, p. 159 et pl. XLVII, 5; Gianfrotta 1980, p. 109; Chuvin \& Yoyotte 1986; Gianfrotta 1994, p. 600. 
$\mathbf{n}^{\circ} \mathbf{I 5}$ = CASIVS, sur une seule face (0X00); nouvelle lecture par A. Hesnard et P.A. Gianfrotta CASTVS (supra p. 311)

Objet: jas de plomb de type fixe; long. 1,26 m; larg. max. 0,165 m

Site : Mondello, près de Palerme (Sicile)

Conservation: Musée de Palerme, inv. 4646

Datation :

Bibliographie: Tusa 1971, p. 285; Tusa 1973, p. 432; Manganaro 1977, p. 159 et pl. XLVII, 6; Gianfrotta 1980, p. 109; Chuvin \& Yoyotte 1986; Hesnard \& Gianfrotta 1989, p. 393-441; Gianfrotta 1994, p. 600.

$\mathbf{n}^{\circ} \mathbf{I} \mathbf{6}=\mathrm{KA \Sigma E}$; sur une face d'un bras (0X00?) (supra p. 312)

Objet: jas de plomb

Site : près du cap Peloro

Conservation: Musée de Messine, inv. 5176

Datation :

Bibliographie: Manganaro 1977, p. 159 et pl. XLVII, 7.

\section{Zeus-Aphrodite}

$\mathbf{n}^{\text {* }} \mathbf{I 7}$ = ZEYCKAC / IOCCOZON sur une face, répartie sur les deux bras

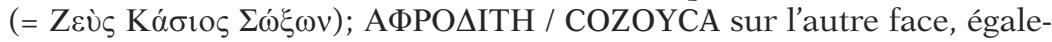

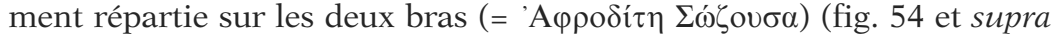
p. 304 ss.)
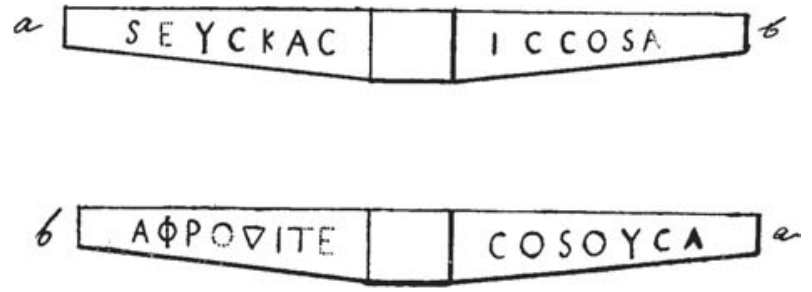

Fig. 54 - Jas du cap de Palos avec les noms de Zeus et Aphrodite (seul dessin connu : Laymond \& Jiménez 1906).

Objet : jas de plomb; long. 1,60 m; $196 \mathrm{~kg}$.

Site : cap Palos, entre l'île d'Escombreras et la côte

Conservation : Madrid ou Carthagène (?), auj. semble disparu

Datation: $\mathrm{III}^{\mathrm{e}}$ s. a.C. (Fíta); ép. impériale (Cumont); $\mathrm{I}^{\mathrm{er}}$ s. a.C. (F. Moll); $1^{\text {ers }}$ siècles p.C. (Pérea Yébenes 2004)

Bibliographie : Laymond \& Jiménez 1906, p. 153-155; Fíta 1906, p. 155163; Paris 1906, col. 168-169; Merlin 1912, p. 383-397; Adler 1919; Salač 1922, p. 188; Cumont 1927; Cumont 1929, p. 254 note 35; Moll 1929, col. 266-271; Moll 1929a, pl. E II 81-82; Martínez de Hidalgo 1943, p. 771 [réf. non lue]; Jáuregui \& Beltrán 1947; Ucelli 1950, p. 244, fig. 276; Benoît 1951; Beltrán 1952, p. 19-22, fig. 13-14; Benoît 1952, 
p. 272-273; García 1967, p. 100-102; Wachsmuth 1967, note 991 et p. 396-397; Casson 1971, p. 255 et note 126; Liou 1973, p. 593 note 62; Manganaro 1977, p. 159; Davaras 1980, p. 55-56; Gianfrotta 1980, p. 109 et fig. 18; Gianfrotta \& Pomey 1980, p. 309; Chuvin \& Yoyotte 1986; Gianfrotta 1994, p. 600-601; Romero Recio 2000, p. 48, 57-58; Pérea Yébenes 2004; García Cardiel 2013, p. 48-49 et fig. 49-51.

$\mathbf{n}^{\circ} \mathbf{I} 8$ = VENERI; IOVI, sur deux faces opposées des deux bras (X00X) (supra p. 309-310)

Objet : jas de plomb de type fixe; long. 1,44 m; larg. max. 0,29 m

Site : près de l'Isola delle Femine (eaux du Nord de la Sicile)

Conservation : Musée de Palerme, inv. 3333

Datation : données épigraphiques dateraient de l'ép. augustéenne

Bibliographie: Tusa 1959; Casson 1971, p. 255 et note 126; Tusa 1971, p. 280-281; Tusa 1973, p. 427-28; Manganaro 1977, p. 159; Davaras 1980, p. 54; Gianfrotta 1980, p. 110; Gianfrotta \& Pomey 1980, p. 309 et fig. p. 308; Chuvin \& Yoyotte 1986; Purpura 1986, p. 144 et fig. 10; Gianfrotta 1994, p. 601; Gargiullo \& Okely 1993, III p. 15 et fig. 16; Fenet 2011, p. 410 et pl. 119, 4.

\section{Aphrodite}

$\mathbf{n}^{\circ} \mathbf{I 9}=$ VENUS (rétrograde) (X000) (supra p. 310)

Objet : jas de plomb

Site : eaux de Maratea

Conservation : Santo Janni, inv. 275484

Datation :

Bibliographie : Bottini \& Fresci 1993, p. 32 et fig. p. 33, 66, 142; Bottini \& Freschi 1994, p. 33 et fig. 2; Gianfrotta 1994, p. 601 et fig. 3; Boetto 1997.

\section{Sôteira / Tychè}

$\mathbf{n}^{\mathbf{0}} \mathbf{I 1 0}=\Sigma$ STEIPA (rétrograde) (fig. 55 et supra p. 312 ss.)

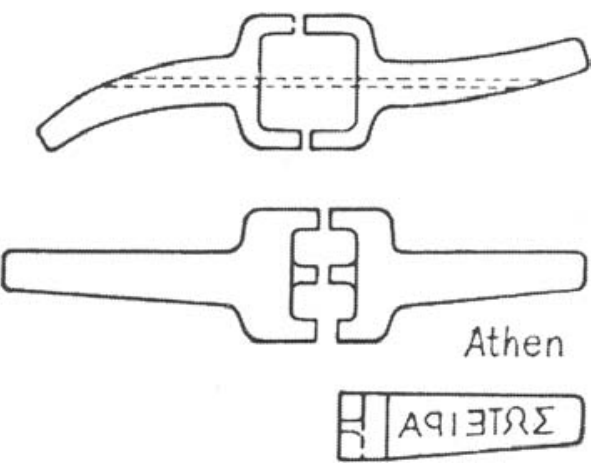

Fig. 55 - Jas d'Athènes : inscription «Sôteira» (d'après Gianfrotta 1980, fig. 18). 
Objet : jas de plomb; un seul bras (ancre borgne?); long. environ $70 \mathrm{~cm}$; environ $80 \mathrm{~kg}$

Site : près de l'île de Symè (côte de Carie)

Conservation : Collection de la Société archéologique d'Athènes (en 1894), ou au Pirée (en 1980), ou Musée National d'Athènes (1994)

Datation : d'après Torr, caractères épigraphiques dateraient vers début de notre ère (milieu $\mathrm{I}^{\mathrm{er}} \mathrm{s}$. p.C.)

Bibliographie: Schlumberger 1880; Torr 1894, p. 71-72, notes 159-160; Froehner 1897; A. Merlin 1912, p. 383-397; Svoronos 1914, p. 107-109; Moll 1929, col. 266-271; Moll 1929a, pl. E II 85; Robert 1936, p. 2 n. 1; Ucelli 1950; Wachsmuth 1967, note 991; Casson 1971, p. 255 et note 126; Liou 1973, p. 593 note 62; Davaras 1980, p. 55; Gianfrotta 1980, p. 109 et fig. 18; Gianfrotta 1994, p. 602 et fig. 5; Romero Recio 2000, p. 56-57.

$\mathbf{n}^{\circ} \mathbf{I 1 1}=\Sigma \Omega$ TEIPA une seule fois (X000); lion, dépourvu de pattes avant, sur la même face des deux bras $(00 \mathrm{XX})$, opposée à celle portant l'inscription (donc au total X0XX) (fig. 56 et supra p. 314, 324 s. et 338)

Objet : jas de plomb de type fixe; long. 1,50 m; larg. max. 0,25 m; $150 \mathrm{~kg}$

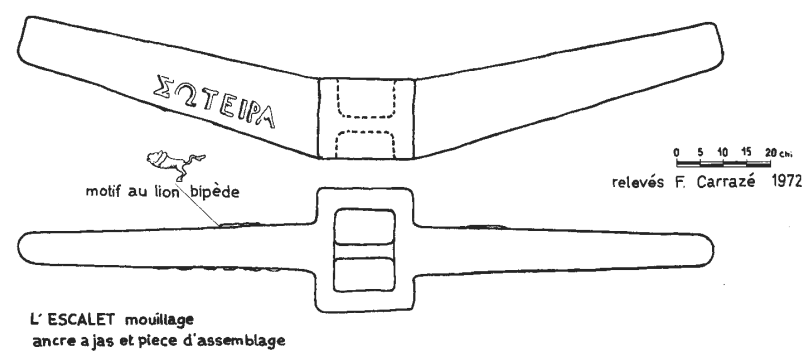

Fig. 56 - Jas de l'Escalet : inscription «Sôteira» et motif de lion (d'après Carrazé 1973, p. 14).

Site : Cavalaire, entrée de la baie de Bon-Porté, entre les caps Taillat et Camarat

Conservation :

Datation :

Bibliographie : Carrazé 1973, p. 14-15 et fig. 4; Liou 1973, p. 592 et fig. 24; Carrazé 1974, p. 155; Rochier 1975; Zemer 1981; Gianfrotta 1980, p. 109; Gianfrotta 1994, p. 603; Gianfrotta \& alii 1997, p. 47; Romero Recio 2000, p. 56-57.

$\mathbf{n}^{\circ} \mathbf{I 1 2}=\Sigma \Omega$ TIPA (rétrograde), sur les 4 faces (XXXX) (supra p. 314)

Objet : jas de plomb; long. 1,62 m; larg. max. 0,17 m

Site : Villasimius, près de Cagliari

Conservation : Musée de Cagliari 
Datation : ép. hellénistique non tropo avanzata Guarducci 1957-1948)

Bibliographie: Guarducci 1967-1978, III, p. 363, note 2; Gianfrotta 1980, p. 109 et fig. 16-17; Gianfrotta 1994, p. 602-603; Romero Recio 2000, p. 57.

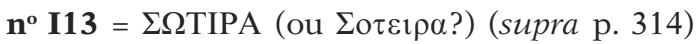

Objet :

Site : Sardaigne méridionale

Conservation : collection privée

Datation :

Bibliographie: Gianfrotta 1980, p. 109; Gianfrotta 1994, p. 603; Romero Recio 2000, p. 57.

$\mathbf{n}^{\mathbf{0}} \mathbf{I 1 4}=\Sigma \Omega$ TPA (rétrograde) (supra p. 314)

Objet : jas de plomb; poids estimé $600 \mathrm{~kg}$ (Liou 1975)

Site : Propriano (Corse); précisément golfe de Valinco (Liou 1975)

Conservation : coll. privée (Liou 1975)

Datation : du $\mathrm{I}^{\text {er }}$ s. a.C. au Bas-Empire (matériel archéologique environnant : Liou 1975)

Bibliographie : Liou 1975; Gianfrotta 1980, p. 109; Gianfrotta 1994, p. 603; Romero Recio 2000, p. 57.

$\mathbf{n}^{\circ} \mathbf{I 1 5}=\Sigma$ STIPA (rétrograde) (supra p. 314)

Objet : jas de plomb

Site : Ischia

Conservation :

Datation :

Bibliographie : Gianfrotta 1994, p. 603.

$\mathbf{n}^{\mathbf{o}} \mathbf{I 1 6}=$ SALVIA (0X00), avec «S» rétroverse; astragales et dauphin (?) (X000) (supra p. 314)

Objet : jas de plomb; long. 1,41 m

Site : eaux de l'île de Ventotene

Conservation :

Datation : fin époque républicaine/Haut-Empire

Bibliographie : Gianfrotta 1986, p. 217-218 et fig. 377-378; Gianfrotta 1994, p. 607 et fig. 11 .

$\mathbf{n}^{\mathbf{0}} \mathbf{I 1 7}=$ TYXH (supra p. 317)

Objet : jas de type mobile; long. 1,09 m; larg. max. 9,5 cm; ép. 4,7 cm

Site : au large de Ponza

Conservation : collection privée

Datation : début de l'ép. impériale (?) d'après les caractères épigraphiques

Bibliographie : Gianfrotta 1994, p. 603 et fig. 6. 
Autres dieux

$\mathbf{n}^{\circ} \mathbf{I 1 8}=$ APTEMI / $\Delta \mathrm{O} \Sigma$ réparti sur deux faces en vis-à-vis (XX00), avec sens de lecture opposés (fig. 57 et supra p. 315)

Objet : jas de plomb avec un bras replié vers l'intérieur; long. 1,85 m; poids : entre 300 et $500 \mathrm{~kg}$

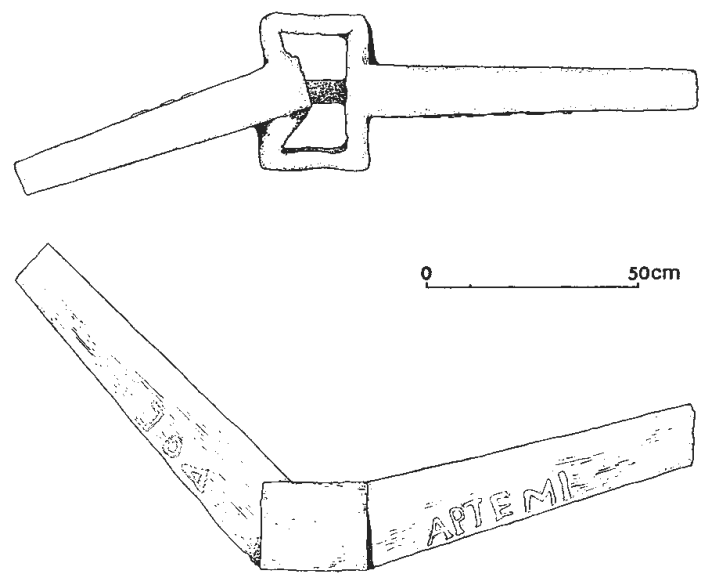

Fig. 57 - Jas I18 : inscription «Artemidos» (d'après Gianfrotta 1994, fig. 7).

Site : Cap Gros, plateau du Raventurier (près d'Antibes)

Conservation: Musée d'Histoire et d'archéologie d'Antibes

Datation : $\mathrm{II}^{\mathrm{e}}-\mathrm{III}{ }^{\mathrm{e}}$ s. p.C. d'après les caractères épigraphiques (Pomey); datation trop tardive peut être rabaissée jusqu'au premier quart du I ${ }^{\text {er }}$ s. p.C. Bibliographie : Pomey \& alii 1987-88; Gianfrotta 1994, p. 604-605 et fig. 7.

$\mathbf{n}^{\circ} \mathbf{I 1 9}$ = HPA (rétrograde) suivie d'une (rosette, Gianfrotta 1980) ou étoile (Hesnard, Gianfrotta 1989); sur la même face de l'autre bras une autre étoile (XX00); AVR(elius?) ligaturés, incisés à chaud deux fois sur la face sup. d'un bras (fig. 58 et supra p. 315, 323)

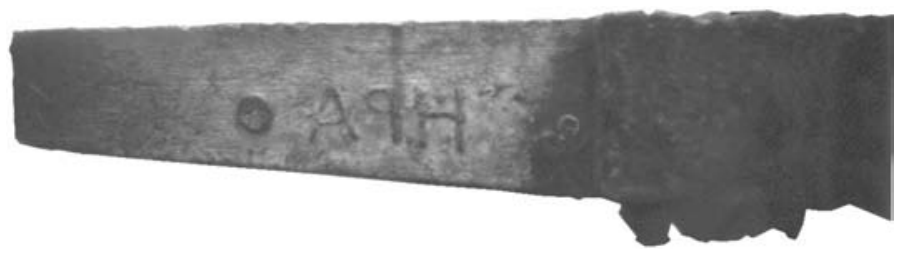

Fig. 58 - Jas I19 : inscription «Héra»; Reggio di C. inv. 50456 (Photo de l'auteur; avec l'autorisation du Ministero dei Beni e delle Attività culturali e del Turismo $\mathrm{n}^{\circ} 27 \mathrm{du}$ 03/03/2014, Soprintendenza per i Beni archeologici della Calabria). 
Objet : jas de plomb; long. 2,18 m; larg. max. 0,24 m

Site : Lido de Reggio di Calabria (rade Giunchi)

Conservation : Musée de Reggio di Calabria, inv. 50456

Datation: caractères épigraphiques dateraient du $\mathrm{I}^{\mathrm{er}} \mathrm{S}$. a.C. (ou I $^{\text {er }}$ p.C. d'après E. Lattanzi)

Bibliographie : Gianfrotta 1980, p. 109 et note 29, fig. 12-14; Gianfrotta \& Pomey 1980, p. 309 et fig. p. 308; Lattanzi 1987, p. 172-173; Hesnard \& Gianfrotta 1989, p. 393-441; Gianfrotta 1994, p. 604.

$\mathbf{n}^{\circ} \mathbf{I 2 0}=\Delta \mathrm{E} \Lambda$ ФNOC [peut-être avec NI ligaturés] (rétrograde) sur une face d'un bras (X000?) (supra p. 315)

Objet : jas de plomb; long. 1,94 m; larg. max. 8,5 cm

Site : au large d'Imperia

Conservation : Musée naval d'Imperia

Datation : au plus tôt de l'époque hellénistique

Bibiographie : Gianfrotta 1994, p. 605 et fig. 8.

$\mathbf{n}^{\circ} \mathbf{I} 21=\Delta$ HMHTP/BPET réparti sur la même face des deux bras (XX00), avec HMH ligaturé (fig. 59 et supra p. 316)

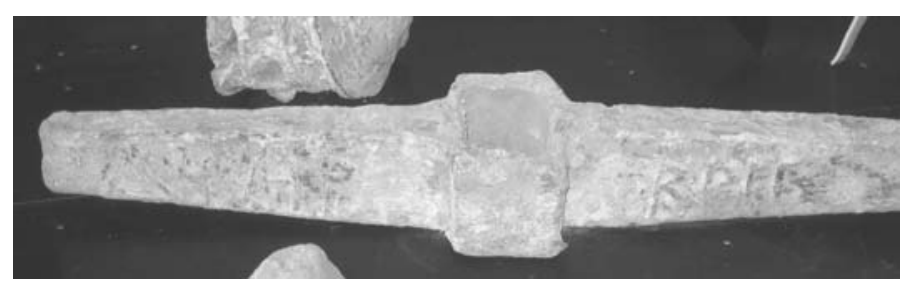

Fig. 59 - Jas avec inscription «Déméter» (?); musée de Hvar, Croatie (Photo P. Cabanes).

Objet : jas de plomb

Site :

Conservation : musée de Hvar (Croatie)

Datation :

Bibliographie: inédite (?); la notice du musée donne comme lecture : HMHTR BRET.

$\mathbf{n}^{\mathbf{0}} \mathbf{I} 22$ = CERES; sur face opposée de l'autre bras [I]S[I]S (?) (X00X) (supra p. 316)

Objet : jas; long. 1, $69 \mathrm{~m}$; larg. max. 0,22 m

Site : inconnu (peut-être Nora)

Conservation : Musée de Cagliari

Datation :

Bibliographie : Gianfrotta 1980, p. $109-110$ et fig. C et 20; Gianfrotta \& Pomey 1980, p. 309; Gianfrotta 1994, p. 603.

$\mathbf{n}^{\mathbf{o}} \mathbf{I} 23$ = MERCURI; sur une autre face ISIS (disposition inconnue) (supra p. 317)

Objet : jas de plomb 
Site : Cagliari

Conservation :

Datation :

Bibliographie : Gianfrotta 1994, p. 603.

$\mathbf{n}^{\mathbf{o}} \mathbf{I 2 4}$ = VESTA (X000?) (supra p. 317)

Objet : jas de plomb; long. 1,87 m; larg. max. $23 \mathrm{~cm}$

Site : près du cap Vaticano (Calabre)

Conservation : musée de Nicotera

Datation : ${ }^{\text {er }}$ s. p.C.

Bibliographie : Gianfrotta 1994, p. 605 et fig. 9-10; Gianfrotta \& alii 1997, fig. p. 113.

$\mathbf{n}^{\mathbf{o}} \mathbf{I} 25$ = HPAK $\Lambda \mathrm{H} \Sigma$ (rétrograde) une seule fois (X000) (supra p. 317 ss.)

Objet : jas de plomb de type fixe; long. 1,74 m; larg. max. 0,16 m

Site : Capo Zafferano (Sicile occidentale)

Conservation : Musée de Palerme, inv. 3452

Datation : III ${ }^{\mathrm{e}}$ s. a.C. (Tusa 1973); $\mathrm{I}^{\mathrm{er}}$ s. a.C. (Gianfrotta 1980 : caractères épigraphiques)

Bibliographie: Tusa 1973, p. 431; Gianfrotta 1980, p. 109 et note 30, et fig. 15; Gianfrotta 1994, p. 605-606.

\section{ANCRES DE PLOMB AVEC DÉCOR}

\section{Décor simple}

1) Astragales/osselets (supra p. 326 ss.)

- Groupe (s) de 4 astragales (classement interne par zones géographiques)

$\mathbf{n}^{\circ} \mathbf{D 1}=4$ osselets, sur chacun des côtés $(\mathrm{XXXX})$, présentés sur des côtés différents à l'intérieur de chaque groupe (coup dit «de Vénus»), groupe qui lui est identique sur les 4 faces du jas (selon Berges Soriano, 2 osselets seulement; pour Boon, 4 mais sur deux faces)

Objet : jas de plomb; long. 1,78 m; larg. 0,145 m; haut. max. 0,15 cm

Site : Portinaixt (au nord-est d'Ibiza)

Conservation: Musée archéologique d'Ibiza, section d'Archéologie sousmarine

Datation :

Bibliographie : Almagro Gorbea 1969; Berges Soriano 1969-70, p. 5 note 3; Boon 1977a.

$\mathbf{n}^{\circ} \mathbf{D 2}$ = 1 osselet, sur chaque côté des branches (XXXX), «un astrágalo izquierdo de carnero" (Fernandez Izquierdo 1983)

Objet : jas en plomb; long. 1,675 m (? incohérent avec dessin/échelle); larg. max. $0,10 \mathrm{~m}$; haut. max. $0,20 \mathrm{~m}$

Site : au large de la plage Ben-Afelí, Almazora (Espagne), épave 
Conservation :

Datation: vers 40 p.C. (Fernandez Izquierdo 1980); autre indéterminée (Parker 1992)

Bibliographie : Fernandez Izquierdo 1980, p. 182 et fig. 11.10; Ramos \&alii 1984, p. 128 et fig. 3 b; Parker 1992, p. 71.

$\mathbf{n}^{\circ} \mathbf{D} 3=2$ osselets présentés sur deux côtés différents, sur chaque face $(\mathrm{XXXX})$

Objet : jas de plomb de type fixe; long. 0,74 m; larg. 0,105 m; haut. 0,08 m; poids $15 \mathrm{~kg}$

Site : littoral de Tarragona (Espagne)

Conservation : Musée archéologique de Tarragona (inv. 34.330)

Datation :

Bibliographie : Berges Soriano 1969-70, p. 5 et 9, fig. 4; Boon 1977a.

$\mathbf{n}^{\circ} \mathbf{D} 4$ = 4 osselets, sur chaque face des bras (XXXX)

Objet : jas en plomb de type fixe; long. 1,89 m; $280 \mathrm{~kg}$ environ

Site : épave A du Grand Ribaud (entre Porquerolles et la presqu'île de Giens)

Conservation : Musée des docks romains, Marseille

Datation : dernier tiers du $\mathrm{II}^{\mathrm{e}}$ s. a.C.

Bibliographie : Carrazé 1973, p. 13-19 avec fig.; Carrazé 1974, p. 154 et fig. 2a-b; Boon 1977a; Mercanti 1979, p. 39-40 et pl. XI.

n' D5 et D6 = 4 osselets représentés sur un côté différent, "sur la même face des 2 bras» (XX00?)

Objet : 2 jas; $+250 \mathrm{~kg}$

Site : entrée de la baie de l'Escalet, entre les caps Taillat et Camarat

Conservation :

Datation :

Bibliographie : Carrazé 1973, p. 15; Carrazé 1974, p. 155; Boon 1977a.

$\mathbf{n}^{\mathbf{0}}$ D7 = 1 osselet, sur chaque face du jas (XXXX), présentant les 4 combinaisons (chiffres 1, 3, 4 et 6)

Objet : jas en plomb; long. 2,16 m; larg. max. 0,33 m; +300 kg

Site : sur la cote de Carry-le-Rouet, à l'est de Port-Bouc

Conservation: Musée Borély, Marseille (inv. 1517)

Datation :

Bibliographie: Magon 1894; Froehner 1897; Merlin 1912, p. 383-397;

Benoît 1951; Beltrán 1952, p. 22-23; Benoît 1952, p. 270; Benoît 1960a, p. 45 note 8; Berges Soriano 1969-70, p. 5 note 3; Carrazé 1974, p. 156; Boon 1977a.

$\mathbf{n}^{\circ} \mathbf{D 8}$ = osselets, "arrangés en paires sur chaque bras» (XX00?)

Objet : jas de plomb; long. 1,15 m

Site : Villefranche/mer

Conservation :

Datation :

Bibliographie : Carrazé 1974, p. 156; Boon 1977a. 
$\mathbf{n}^{\circ} \mathbf{D 9}=4$ osselets, deux fois sur un bras (XX00 ou X00X?)

Objet : jas de plomb; 1,02 m de long; $70 \mathrm{~kg}$; même type que le jas de l'épave A du Grand Ribaud

Site : à $30 \mathrm{~m}$ au sud-est de l'îlot Maestro Maria (îles Cerbicales en face de Porto Vecchio), Corse

Conservation: Musée de Bastia

Datation :

Bibliographie : Jehasse \& Boucher 1959, p. 73 et pl. h.-texte; Benoît 1960a, p. 45 note 8, 54 et fig. 24; Bravo 1970; Carrazé 1974, p. 156; Boon 1977a.

$\mathbf{n}^{\circ} \mathbf{D 1 0}=4$ osselets

Objet : jas de plomb de type mobile

Site : au large de l'île Molara, au sud-ouest d'Olbia (Sardaigne)

Conservation :

Datation :

Bibliographie : Gargiullo \& Okely 1993, II p. 19

$\mathbf{n}^{\circ} \mathbf{D 1 1}=4$ osselets sur une face d'un bras (X000)

Objet : jas de plomb mobile

Site : embouchure du port de Civitavecchia

Conservation : Musée de Civitavecchia

Datation :

Bibliographie : Gianfrotta 1982b, p. 24, fig. 30.

$\mathbf{n}^{\circ} \mathbf{D 1 2}=4$ osselets, sur une seule face (X000) en différentes positions

Objet : élément de jas de plomb de type mobile; long. 0,75 m; larg. max. $0,10 \mathrm{~m}$

Site :

Conservation : Santo Janni, inv. 275648

Datation :

Bibliographie : Bottini \& Fresci 1993, p. 32-33, 74, 139 et fig. 25; Bottini \& Freschi 1994, p. 31 et fig. 2.

$\mathbf{n}^{\circ} \mathbf{D} 13$ = 4 osselets dans une position différente, alignés sur un bras (X000) Objet : jas de plomb de type mobile

Site : près de punta della Madonna à Ponza

Conservation : Comando dei Carabinieri, Ponza

Datation :

Bibliographie : Galli 1997, p. 157 et fig. 3-4, 18.

$\mathbf{n}^{\circ}$ D14 $=2$ osselets (ou coquillages?) sur chaque bras, face opposée (X00X) Objet : jas en plomb; lg. environ 1,49 m; ht max. 14,5 cm; ht min. $8 \mathrm{~cm}$ Site : eaux de Pietra del Bagno, façade occidentale de l'île de Lipari Conservation : Museo Eoliano, inv. 10452

Datation : fin $\mathrm{III} /$ début $\mathrm{II}^{e}$ s. a.C. (?) d'après amphores trouvées sur place Bibliographie: Cavalier 1985a, p. 65 et fig. 45; Parker 1992, p. 395; Gargiullo \& Okely 1993, III p. 71. 
$\mathbf{n}^{\circ} \mathbf{D} 15=4$ osselets sur une face (X000)

Objet : jas mobile en plomb; long. 0,70 m; larg. 0,075 m au centre et 0,05 m aux extrémités; ép. de 0,05 à $0,03 \mathrm{~m} ; 18,9 \mathrm{~kg}$

Site : côte nord de Syracuse

Conservation : Musée Borély (inv. 6666), Marseille

Datation :

Bibliographie : Benoît 1955; Benoît 1960a, p. 45, note 8; Benoît 1961, p. 174; Berges Soriano 1969-70, p. 5 note 3; Carrazé 1973, p. 17; Kapitän 1973, p. 390 et fig. 6b.

$\mathbf{n}^{\circ} \mathbf{D} 16=4$ osselets sur une face d'un bras (X000)

Objet : jas en plomb de type mobile

Site : eaux de la baie de San Nicola, au nord-ouest de Taormine (Sicile)

Conservation :

Datation :

Bibliographie : Tronchet Bonaventura 1994, p. 152 et fig. 4-5.

$\mathbf{n}^{\circ} \mathbf{D 1 7}=4$ osselets sur une face (X000)

Objet : jas mobile en plomb

Site : Syracuse (?)

Conservation: Syracuse (inv. SIR A 38)

Datation :

Bibliographie : Kapitän 1973, p. 390 et fig. 6 a.

$\mathbf{n}^{\circ} \mathbf{D 1 8}$ = 4 osselets, disposées sur des côtés différents; sur une face opposée de chaque bras (X00X) (fig. 60)

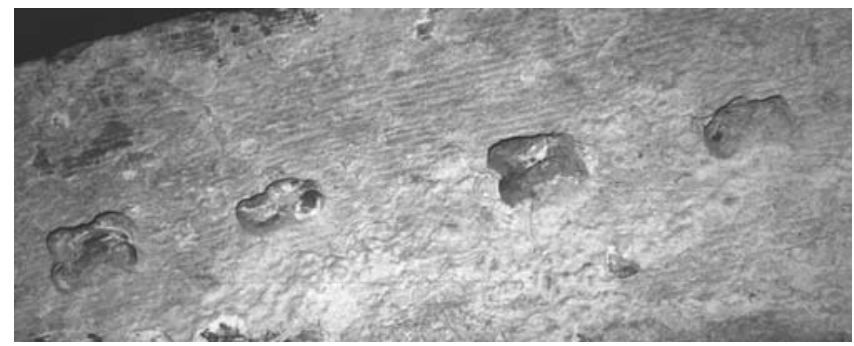

Fig. 60 - Jas D18: motif de 4 astragales (détail), musée de Lecce, inv. 5268. (Photo de l'auteur; avec l'autorisation du Ministero dei Beni e delle Attività culturali e del Turismo, Soprintendenza per i Beni archeologici della Puglia).

Objet : jas de plomb

Site : Porto Cesario, en 1965

Conservation: Musée de Lecce, inv. 5268

Datation :

Bibliographie : inédite (?) 
$\mathbf{n}^{\circ} \mathbf{D 1 9}=4$ osselets $(\mathrm{X} 000)$

Objet : jas de type mobile en plomb; long. 1,03 m (Sciarra 1966) ou 1,16 m

(Sciarra 1976); environ $92 \mathrm{~kg}$

Site : sur le littoral de Brindisi, entre Punta della Contessa et Torre Cavallo

Conservation : Musée de Brindisi, salle De Leo (inv. 5968?)

Datation :

Bibliographie : Sciarra 1966, p. 343 et fig. 3; Sciarra 1976, p. 10-12, n 69; Gianfrotta 1980, p. 106, 108 et fig. 2; Radić \& Jurisić 1993, p. 136.

$\mathbf{n}^{\circ} \mathbf{D 2 0}=4$ osselets, sur une seule face (X000), position dite "coup de Vénus" Objet: jas de plomb de type mobile

Site : inconnu

Conservation : Musée de Susa (Apollonia, Cyrénaïque)

Datation : époque hellénistique ou impériale

Bibliographie : Queyrel 1987; Queyrel 1997.

$\mathbf{n}^{\circ} \mathbf{D 2 1}=4$ osselets, sur une seule face $(0 \mathrm{X} 00)$, représentés sur un côté différent

Objet : jas de plomb de type mobile; long. 1,18 m; environ $50 \mathrm{~kg}$

Site : île de Mljet (Croatie), au large du cap Glavat, épave

Conservation : Musée maritime de Dubrovnik

Datation : fin du Ir s. p.C.

Bibliographie : Radić \& Jurisić 1993, p. 135-136 et fig. 16.2; Jurisić 2000, p. 61-63.

$\mathbf{n}^{\circ} \mathbf{D 2 2}=4$ osselets (?)

Objet : jas de plomb type fixe

Site :

Conservation : Musée ethnographique de Nesebar (Bulgarie)

Datation :

Bibliographie : Kapitän 1980, p. 47-48 n. 2 (qui ne l'a pas vu lui-même).

$\mathbf{n}^{\circ} \mathbf{D 2 3}=4$ osselets une seule fois (0X00), présentés sur différents côtes

Objet: jas de plomb de type fixe; long. 1,18 m; 71,5 kg

Site : Porth Felen, presqu'île de Llyn (Galles du Nord)

Conservation : Musée national du Pays de Galles

Datation : $\mathrm{II}^{\mathrm{e}}$ ou $\mathrm{I}^{\mathrm{er}} \mathrm{s}$. a.C. (d'après type du motif pour Boon)

Bibliographie : Boon 1977a, avec fig. 2, 3 et pl. II-III; Boon 1977b.

- nombreuses astragales avec combinaison(s) de 4

$\mathbf{n}^{\mathbf{0}} \mathbf{D 2 4}=4$ osselets dans des positions différentes à gauche du bras (X000) et une astragale sur chaque face du bras opposé (0X0X)

Objet : jas de plomb de type fixe; long. 1,58 ou 1,64 m; haut. max. 13,5 cm; ép. max. $8 \mathrm{~cm} ; 140 \mathrm{~kg}$

Site : Ile éolienne de Filicudi, près du cap Graziano; épave A (?)

Conservation : Lipari, Museo eoliano, inv. 10447

Datation : 1 ${ }^{\text {ère }}$ moitié du II ${ }^{\mathrm{e}}$ s. a.C. (matériel associé); I ${ }^{\text {er }}$ s. a.C. (Roghi 1971)

Bibliographie : Roghi 1971, p. 258-260 et fig. 3, 4, 9; Cavalier 1985b, p. 110 et fig. 125; Parker 1992, p. 117; Gargiullo \& Okely 1993, p. 78-80. 
$\mathbf{n}^{\circ}$ D25 $=6$ osselets, sur une seule face (X000?), dont 4 petits en différentes positions et 2 plus grands (fig. 61)

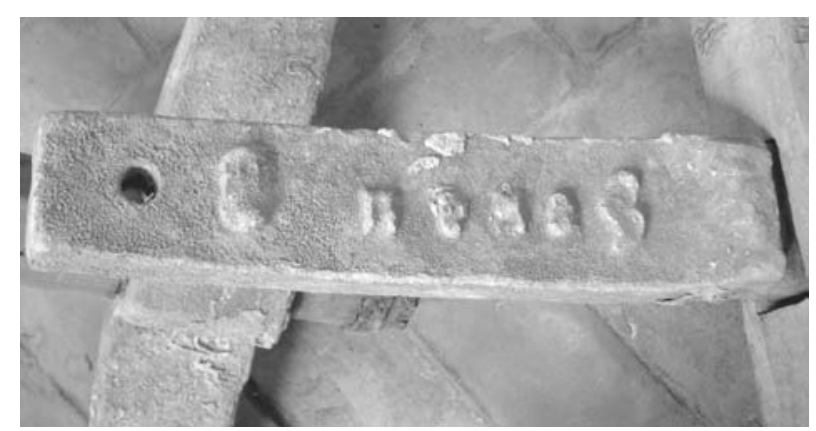

Fig. 61 - Jas D25 : motif de 6 astragales, musée de Palerme.

(Photo de l'auteur; avec l'autorisation du Museo archeologico regionale «Antonino Salinas» de Palerme).

Objet : jas de plomb de type mobile; long. 0,97 m; larg. max. 0,09 m

Site : au large d'Arenella, près de Palerme (Sicile occidentale)

Conservation : Musée de Palerme, inv. 7276

Datation :

Bibliographie: Tusa 1971, p. 285-288; Tusa 1973, p. 434; Boon 1977a;

Purpura 1986, p. 144; Gargiullo \& Okely 1993 III, p 13.

$\mathbf{n}^{\mathbf{0}} \mathbf{D 2 6}=14$ osselets au total, disposés sur chaque face de chaque bras (XXXX) alternativement en groupes de 3 et 4 (7 sur chaque bras)

Objet : jas de plomb de type fixe; long. 1,60 m; larg. max. 0,20 m

Site : entre la Punta Licosa et San Marco di Castellabate (golfe de Paestum) Conservation : siège local du Centro Subacqueo à S. Maria di Castellabate Datation :

Bibliographie : Gianfrotta 1974, p. 91-93 et fig. 11.

- nombre non rattachable à une ou des combinaison(s) de 4

$\mathbf{n}^{\circ} \mathbf{D 2 7}=1$ osselet

Objet : jas de plomb

Site : près de Haifa

Conservation : Museum of Ancient Art (Israël)

Datation :

Bibliographie : Zemer 1981.

$\mathbf{n}^{\mathbf{0}} \mathbf{D 2 8}=3$ osselets

Objet : jas de plomb; environ $190 \mathrm{~kg}$

Site : au sud-ouest de Porto Ercole, épave (?) 
Conservation : Antiquarium d'Orbetello

Datation : $\mathrm{II}^{\mathrm{e}}$ s. a.C. (amphores associées)

Bibliographie : Parker 1992, p. 336; Gargiullo \& Okely 1993, I p. 58

- nombre indéterminé

$\mathbf{n}^{\circ} \mathbf{D 2 9}=$ osselets

Objet : jas de plomb

Site : Tarragona

Conservation :

Datation :

Bibliographie : Boon 1977a, p. 19 (mentionné comme inédit).

$\mathbf{n}^{\mathbf{0}} \mathbf{D} 30$ = osselet $(\mathrm{s})$

Objet : Jas de plomb

Site : Cap Ferrat

Conservation : Club de l'exploration sous-marine de Nice (?)

Datation :

Bibliographie : Benoît 1960a, p. 45, note 8 .

$\mathbf{n}^{\circ} \mathbf{D 3 1}=$ osselets

Objet : Jas de plomb

Site :

Conservation : Saint-Tropez, Musée naval

Datation :

Bibliographie : Benoît 1960a, p. 45, note 8 .

$\mathbf{n}^{\circ} \mathbf{D 3 2}=$ osselets

Objet: jas de plomb; long. 2,37 m; $510 \mathrm{~kg}$

Site : eaux du Château d'If, Marseille

Conservation :

Datation :

Bibliographie : Carrazé 1973, p. 19; Carrazé 1974, p. 156; Boon 1977a.

$\mathbf{n}^{\mathbf{0}} \mathbf{D} 33$ = osselets

Objet : jas de plomb; poids estimé $800 \mathrm{~kg}$ (Liou 1975)

Site : Propriano (Corse), golfe de Valinco

Conservation : coll. privée (Liou 1975)

Datation: du I $^{\text {r }}$ s. a.C. au Bas-Empire (matériel archéologique environnant : Liou 1975)

Bibliographie : Liou 1975; Romero Recio 2000, p. 57.

n $^{\circ}$ D34 = osselets

Objet : jas de plomb

Site : au large de l'île Rossa, près de la pointe Nord (au nord de la Sardaigne)

Conservation :

Datation :

Bibliographie : Gargiullo \& Okely 1993, II p. 43-44. 
$\mathbf{n}^{\mathbf{o}} \mathbf{D 3 5}=$ osselets

Objet : jas de plomb de type fixe

Site : au large de la Punta Tramontana (au nord de la Sardaigne)

Conservation :

Datation :

Bibliographie : Gargiullo \& Okely 1993, II p. 45.

$\mathbf{n}^{\circ}$ D36 = osselets (?)

Objet : jas en plomb de type fixe; long. 1,87 m

Site : près de l'île Mal di Ventre, à l'ouest de la Sardaigne, épave

Conservation : Antiquarium arborense di Oristano (?)

Datation : $1^{\text {ère }}$ moitié du ${ }^{\text {er }}$ s. a.C. (matériel associé)

Bibliographie : Zucca 1985, p. 150-151; Salvi 1991, p. 148; Parker 1992, p. 255-256; Gargiullo \& Okely 1993, II p. 60.

$\mathbf{n}^{\circ} \mathbf{D} 37$ = osselets (?)

Objet: jas en plomb de type fixe; long. 1,44 m

Site : près de l'île Mal di Ventre, à l'ouest de la Sardaigne, épave

Conservation : Antiquarium arborense di Oristano (?)

Datation : $1^{\text {ère }}$ moitié du ${ }^{\text {er }}$ s. a.C. (matériel associé)

Bibliographie : Zucca 1985, p. 150-151; Salvi 1991, p. 148; Parker 1992, p. 255-256; Gargiullo \& Okely 1993, II p. 60.

$\mathbf{n}^{\mathbf{0}} \mathbf{D} 38$ = osselets (?)

Objet : jas de plomb de type fixe

Site : sur le littoral de Civitavecchia

Conservation : Musée de Civitavecchia

Datation :

Bibliographie : Gianfrotta 1982b, p. 24, fig. 49.

$\mathbf{n}^{\circ} \mathbf{D} 39$ = osselets (?), "en position spectaculaire, sur deux bras»

Objet : jas de plomb; long. 1,56 m; larg. max. 0,11 m

Site :

Conservation : Santo Janni, inv. 278208

Datation :

Bibliographie : Bottini \& Fresci 1993, p. 32-33, 75 et 142.

$\mathbf{n}^{\mathbf{0}} \mathbf{D} \mathbf{4 0}=$ osselets (nombre indéterminé)

Objet: jas de plomb de type mobile

Site : au large de Capo Rasocolmo (Sicile), épave

Conservation :

Datation : vers 36 a.C. (période de la Guerre civile, bateau supposé du parti de Pompée)

Bibliographie : Parker 1992, p. 121-122.

$\mathbf{n}^{\circ} \mathbf{D} 41$ = osselets

Objet : jas en plomb de type mobile

Site : Secca Priolo, près de Palerme (Sicile)

Conservation : 
Datation :

Bibliographie : Gargiullo \& Okely 1993, III p. 13.

$\mathbf{n}^{\mathbf{0}} \mathbf{D} 42$ = osselets

Objet : plusieurs jas en plomb

Site : eaux d'Aci Trezza, au nord de Catane (Sicile)

Conservation :

Datation :

Bibliographie : Gargiullo \& Okely 1993, III p. 59

$\mathbf{n}^{\circ}$ D43 = osselets

Objet : jas de plomb démontable avec «échelon d'arrêt» (Haltestufe)

Site : Varna (Bulgarie)

Conservation : Marine-Museum de Varna (?)

Datation :

Bibliographie : Kapitän 1980, n. 2.

2) Dauphins (voir supra p. 335 s.)

$\mathbf{n}^{\circ}$ D44 = 1 dauphin, sur chacune des faces latérales (XX00?); tous orientés dans le même sens

Objet : jas de plomb; long. 0,85 m; $45 \mathrm{~kg}$

Site : cap Ceuta

Conservation : Club Náutico de Ceuta?

Datation :

Bibliographie : Bravo Perez 1966 [réf. non lue]; Bravo \& Muñoz 1966-1968; Bravo 1970, p. $825 \mathrm{n}^{\circ} 10$ et fig. 2 et pl. II.

$\mathbf{n}^{\circ} \mathbf{D} 45$ = un dauphin

Objet : jas de plomb; long. 0,94 m; larg. 0,16 m; ép. 0,09 cm

Site :

Conservation : Musée de Cadiz

Datation :

Bibliographie : García \& López 1979-1980.

$\mathbf{n}^{\circ} \mathbf{D} 46$ = dauphins, sur les 2 bras et faces $(\mathrm{XXXX})$, tournés vers l'anneau central

Objet : jas de plomb

Site : zone d'El Saler (Valencia)

Conservation :

Datation :

Bibliographie : Martin \& Saludes 1966.

$\mathbf{n}^{\circ}$ D47 = dauphins (sur une des faces des deux bras 0XX0 ou 0X0X? ou XXXX?), dont un groupe excentré

Objet : jas de plomb de type fixe; (F. Carrazé : long. 1,18 m; type du jas (lequel?) de l'épave B Jeaune-Garde); R. Pascual Guasch : long. 1,49 m 
Site : au sud de la pointe Santa Anna à Blanes (golfe de Barcelone)

Conservation : Musée archéologique de Gerona

Datation : vers le milieu du $\mathrm{I}^{\mathrm{er}}$ s. a.C. (?)

Bibliographie : Barbéra 1959 [réf. non lue]; Pascual Guasch 1959; Benoît 1960a, p. 41-56, note 9; Prat 1961; Ripoll Perelló 1962; Berges Soriano 1969-70, p. 5 note 3; Benoît 1971, p. 395-396; Carrazé 1974, p. 156; Mercanti 1979, p. 56-58 et pl. XVII, 3.

$\mathbf{n}^{\circ} \mathbf{D 4 8}=1$ dauphin, sur une seule face (X000)

Objet : jas de plomb; long. 1,64 m

Site : Cap Gros (près d'Antibes)

Conservation :

Datation :

Bibliographie : Fiori 1974.

$\mathbf{n}^{\circ} \mathbf{D} 49$ = 4 dauphins

Objet : jas de plomb

Site : port de Syracuse

Conservation :

Datation :

Bibliographie : Gargallo 1961.

$\mathbf{n}^{\circ} \mathbf{D 5 0}$ = un dauphin, sur une face opposée de chaque bras (X00X) (fig. 62)

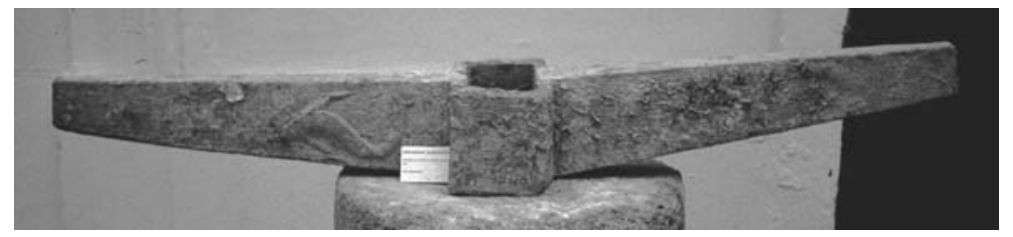

Fig. 62 - Jas D50 : dauphin, Surint. Crotone inv. 18603. (Photo de l'auteur; avec l'autorisation du Ministero dei Beni e delle Attività culturali del Turismo n. $27 \mathrm{du}$ 03/03/2014, Soprintendenza per i Beni archeologici della Calabria).

Objet : jas de plomb

Site : prov. inconnue (près de Colonna?)

Conservation : cour intérieure de la Surintendance de Crotone, inv. 18603

Datation : «hellénistique»

Bibliographie : inédite (?)

$\mathbf{n}^{\mathbf{0}} \mathbf{5 1}$ = 1 dauphin

Objet : jas de plomb

Site : près de Haïfa

Conservation : Museum of Ancient Art (Israël)

Datation :

Bibliographie : Zemer 1981. 
$\mathbf{n}^{\circ} \mathbf{D 5 2}$ = 3 dauphins

Objet : jas de plomb

Site : près de Haïfa

Conservation : Musée de Haïfa

Datation :

Bibliographie : Zemer 1981.

3) «Tête coupée» (voir supra p. 336 ss.)

$\mathbf{n}^{\circ} \mathbf{D 5 3}=3$ têtes dites "de Méduse» $(1 \times 2$ sur 1 face, 1 sur l'autre $)$

Objet : jas en plomb de type fixe; long. 1,90 m; +300 kg

Site : haut-fond du lieu-dit la Péquerolles, à l'est du Cap d'Antibes

Conservation : Musée de la Marine, Paris.

Datation : époque hellénistique d'après le type de la tête (F. Benoît)

Bibliographie : Benoît 1950, p. 130; Benoît 1951; Beltrán 1952, p. 23; Benoît 1952, p. 270-272 et fig. 34-35; Benoît 1959, p. 143-150 et fig. 2; Espérandieu \& Lantier 1907-1966, no 8622; Wachsmuth 1967, note 234 et p. 259260; Carrazé 1973, p. 15; Davaras 1980, p. 57; Gianfrotta 1980, p. 108.

$\mathbf{n}^{\circ}$ D54 = une tête "coupée humaine, yeux mi-clos», sur chaque face de chaque bras (XXXX)

Objet : Jas de plomb de type fixe; long. 1,41 m; haut. $15 \mathrm{~cm}$; $160 \mathrm{~kg}$ environ Site : épave B de la Jeaune-Garde, pointe nord-ouest de Porquerolles Conservation: Musée des docks romains, Marseille, inv. C130

Datation : III ${ }^{\mathrm{e}}$ s. a.C. (d'après contexte céramique : Benoît 1960b); circa 140 a.C. (d'après contexte céramique : Carrazé 1974); circa 200-140 a.C. (Parker 1992)

Bibliographie : Benoît 1959, p. 143-150 et fig. 3; Benoît 1960a, p. 44-45 et fig. 12-13; Benoît 1960b, p. 176-177; Wachsmuth 1967, note 234 et p. 259-260; Casson 1971, p. 255 et note 125; Carrazé 1973, p. 15; Carrazé 1974, p. 153-154; Mercanti 1979, p. 34-35 et pl. VIII, 1-2; Gianfrotta 1980, p. 108; Zemer 1981; Musée docks 1987, p. 96; Hesnard \& Gianfrotta 1989, p. 393-441; Parker 1992, p. 222.

4) Alia (motifs uniques)

- Caducée (voir supra p. 343 s.)

$\mathbf{n}^{\circ} \mathbf{D 5 5}$ = caducée

Objet: jas de plomb de type mobile

Site : Cala Scirocco / Cala i Grottoni (île de Giannutri)

Conservation: Antiquarium d'Orbetello, inv. 88292

Datation : $\mathrm{II}^{\mathrm{e}}$ s. a.C. (?)

Bibliographie: Pallarés Salvador 1971, p. 392; Mercanti 1979, p. $54-55$ et pl. XVI, 2; Gianfrotta 1980, p. 108 et note 24; Rendini 1982, p. 52; Parker 1992, p. 91-92; Gargiullo \& Okely 1993, I p. 92. 
$\mathbf{n}^{\circ} \mathbf{D 5 6}$ = un caducée, sur les faces opposées des deux bras (X00X) (fig. 63)

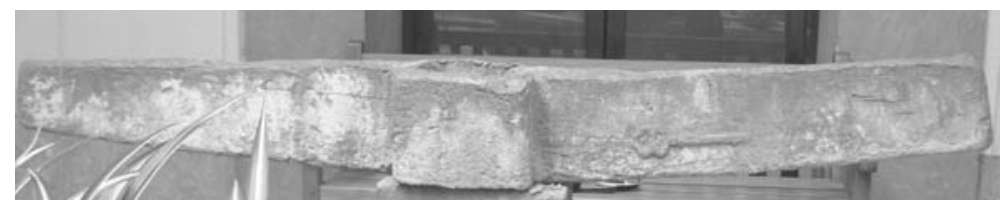

Fig. 63 - Jas D56 : motif de caducée; musée de Palerme (Photo de l'auteur; avec l'autorisation du Museo archeologico regionale «Antonino Salinas» de Palerme).

Objet: jas de plomb de type fixe; long. 1,72; larg. max. 0,20 m

Site : près de l'Isola delle Femine (eaux du nord de la Sicile)

Conservation: Musée de Palerme, inv. 3337

Datation :

Bibliographie: Tusa 1959; Carrazé 1973, p. 15; Tusa 1973, p. 432-433; Gianfrotta 1980, p. 108 et fig. 7.

- Cercle/couronne (voir supra p. 344)

$\mathbf{n}^{\circ} \mathbf{D 5 7}$ = un cercle, sur deux faces croisées du jas (X00X)

Objet: jas de plomb de type fixe; long. 1,05 m; larg. 0,17 m; haut. 0,13 m Site : Littoral de Tarragona (Espagne)

Conservation: Musée archéologique de Tarragona (inv. 34.336)

Datation :

Bibliographie: Berges Soriano 1969-70, p. 5 et 9, fig. 3.

$\mathbf{n}^{\circ} \mathbf{D 5 8}=$ un cercle $(\mathrm{X} 000)$

Objet : jas de plomb de type fixe; long. 1,50 m; larg. max. 0,13 m

Site : entre la Punta Licosa et San Marco di Castellabate (golfe de Paestum) Conservation : siège local du Centro subacqueo à S. Maria di Castellabate Datation :

Bibliographie: Gianfrotta 1974, p. 95 et fig. 12.

$\mathbf{n}^{\circ} \mathbf{D 5 9}$ = trois feuilles presque disposées en cercle, sur une seule face (X000) Objet: jas de plomb de type mobile; long. 0,79 m; larg. max. 0,09 m Site : eaux de Terrasini (Sicile occidentale)

Conservation: Musée de Palerme, inv. 3427

Datation :

Bibliographie: Tusa 1973, p. 433-434.

- Clé (voir supra p. 342)

$\mathbf{n}^{\circ} \mathbf{D 6 0}=$ une clé entre deux motifs sphériques différents (coquillages?), sur une face des deux bras (XX00); sur les autres faces, un dauphin (?) entre les mêmes motifs sphériques (00XX); un anneau sur l'épaisseur de chaque bras 
Objet : jas de plomb de type fixe; 1,60 m; hteur max. $19 \mathrm{~cm} ; 222 \mathrm{~kg}$

Site : eaux du cap Graziano, île éolienne de Filicudi; épave A (?)

Conservation: Musée de Lipari, inv. 10446

Datation : première moitié du $\mathrm{II}^{\mathrm{e}} \mathrm{s}$. a.C. (?) (matériel associé)

Bibliographie : Gianfrotta 1980, p. 108; Cavalier 1985b, p. 110 et fig. 125126; Parker 1992, p. 117; Gargiullo \& Okely 1993, III p. 78-80.

n' D61 = clé

Objet :

Site :

Conservation : Palerme

Datation :

Bibliographie: Gianfrotta 1980, p. 108 et fig. 9.

- Colonne (voir supra p. 341)

$\mathbf{n}^{\circ}$ D62 = une colonne en relief (une sur chaque face XXXX), avec une base très haute composée de deux éléments, un fût strié et un chapiteau à volutes ioniques (fig. 64). Modèle identique à D63
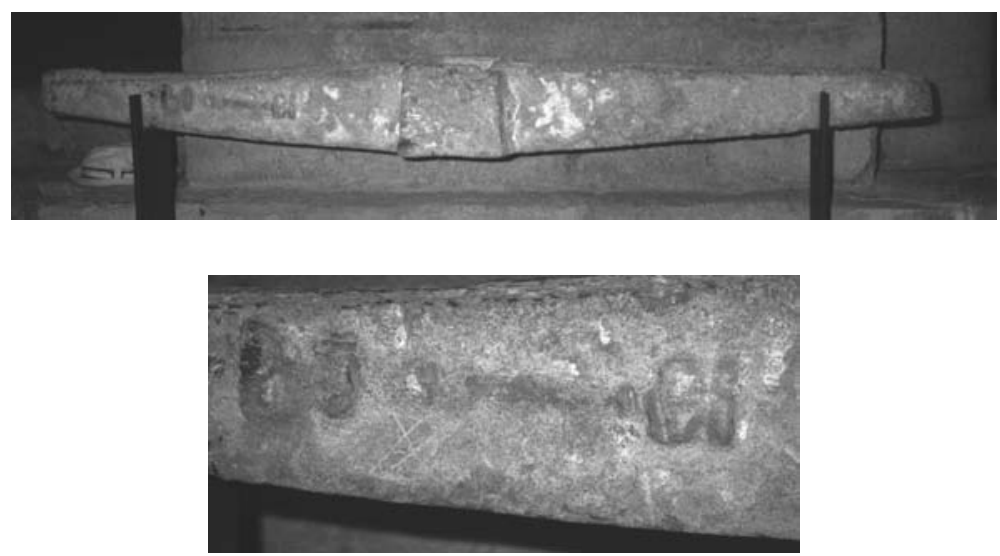

Fig. 64 - Jas D62 : colonne, Museu d'arquelogia de Catalunya-Gerona. (Photo de l'auteur).

Objet: jas de plomb de type fixe; long. 1,52 m; du type du jas du Grand Ribaud

Site : au sud de la pointe Santa Anna de Blanes (golfe de Barcelone) Conservation: Musée archéologique de Gerona

Datation : vers la moitié du $\mathrm{I}^{\mathrm{er}}$ s. a.C. (?)

Bibliographie : Barbéra 1959 [réf. non lue]; Pascual Guasch 1959; Prat 1961; Ripoll Perelló 1962; Benoît 1971, p. 395-396; Carrazé 1973, p. 15; Carrazé 1974, p. 156; Mercanti 1979, p. 56-58 et pl. XVII, 1-2; Gianfrotta 1980, p. 109; Zemer 1981. 
$\mathbf{n}^{\circ} \mathbf{D 6 3}$ = une colonne en relief (une sur chaque face XXXX), avec une base très haute composée de deux éléments, un fût strié et un chapiteau à volutes ioniques. Modèle identique à D62

Objet : jas de plomb de type fixe; long. 1,52 m; type du jas du Grand Ribaud Site : au sud de la pointe Santa Anna de Blanes (golfe de Barcelone) Conservation: Musée maritime de Barcelone

Datation: vers la moitié du $\mathrm{I}^{\mathrm{er}}$ s. a.C. (?)

Bibliographie : Barbéra 1959 [réf. non lue]; Pascual Guasch 1959; Benoît 1960b, p. 176-177 et fig. 2; Prat 1961; Ripoll Perelló 1962; Benoît 1971, p. 395-396; Carrazé 1973, p. 15; Carrazé 1974, p. 156; Mercanti 1979, p. 56-58 et pl. XVII, 1-2; Gianfrotta 1980, p. 109; Zemer 1981.

- Lampe (voir supra p. 342)

$\mathbf{n}^{\circ}$ D64 = lampe à huile à volute, sur deux bras, sur la même face (XX00) (fig. 65)

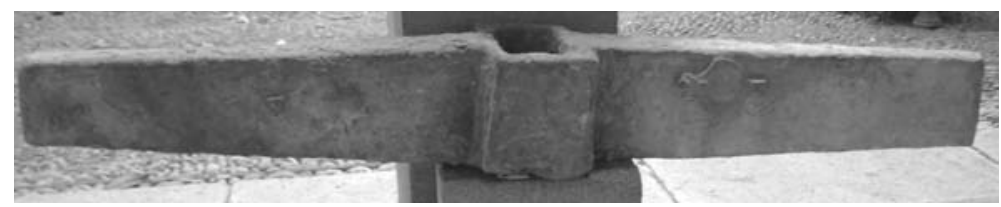

Fig. 65 - Jas D64 : motif de lampe, musée de Palerme. (Photo de l'auteur; avec l'autorisation du Museo archeologico regionale "Antonino Salinas» de Palerme).

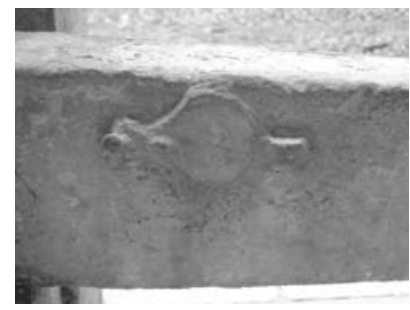

Objet : jas de plomb de type fixe; long. 1,14 m; larg. max. 0,145 m; type du jas (lequel?) de l'épave B de Jeaune-Garde

Site : Isola delle Femine (eaux du nord de la Sicile)

Conservation: Musée de Palerme, inv. 3342

Datation : type de lampe représenté appartient au $\mathrm{I}^{\mathrm{er}} \mathrm{s}$. ap. (plutôt fin?), d'après Tusa; fabrication de ce type de lampe commence un siècle plus tôt selon Boon

Bibliographie: Tusa 1971, p. 279; Tusa 1973, p. 411-437; Carrazé 1973, p. 15; Carrazé 1974, p. 156; Boon 1977a; Gianfrotta 1980, p. 108 et fig. 10; Zemer 1981; Purpura 1986, p. 144; Gargiullo \& Okely 1993, III p. 14 . 
- Indéterminé

$\mathbf{n}^{\circ}$ D65 = motif indéterminé, sur la même face de chaque bras (XX00) (fig. 66)

Objet : jas de plomb de type fixe; dimensions id. à celle du jas de l'épave A du Grand Ribaud (voir supra cat. D4)

Site : la Capte (presqu'île de Giens)

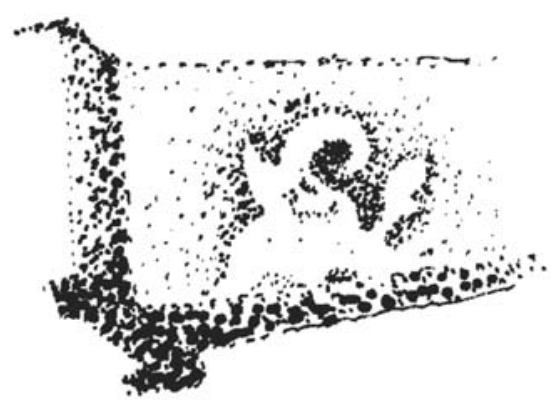

Fig. 66 - Jas D65, de l'épave la Capte : motif indéterminé (d'après Carrazé 1973, p. 14).

Conservation :

Datation :

Bibliographie : Carrazé 1973, p. 14-15 et fig. 6; Carrazé 1974, p. 156.

$\mathbf{n}^{\circ}$ D66 = motifs indéterminés (X000?)

Objet: jas de plomb de type fixe

Site : eaux entre l'Isola Piana et la côte de Stintino (au nord-ouest de la Sardaigne)

Conservation :

Datation :

Bibliographie: Gargiullo \& Okely 1993, II p. 52.

$\mathbf{n}^{\mathbf{0}} \mathbf{D 6 7}=$ un seul motif indéterminé $(\mathrm{X} 000)$

Objet: jas de plomb de type fixe; long. 0,83 m; larg. max. 0,095 m

Site : Cap Zafferano (Sicile)

Conservation: Musée de Palerme, inv. 3332

Datation :

Bibliographie: Tusa 1973, p. 426. 
Décor complexe:

Combinaisons de plusieurs motifs sur une même ancre

1) avec dauphins et astragales (supra p. 326 s.)

$\mathbf{n}^{\circ} \mathbf{D 6 8}=1$ osselet présenté sur le même côté, mais positionné et orienté différemment, sur chaque face (XXXX); respectivement accompagné d'un dauphin (X000), à deux reprises d'une divinité (?) (0XX0), et d'un caducée (000X). L'astragale est toujours placée près du centre, sauf sur la dernière face. (Divinité : cf. supra p. 344).

Objet : jas de plomb de type fixe; long. 0,66 m; larg. 0,10 m; haut. 0,085 m Site : littoral de Tarragona, plage de Creixell (Espagne)

Conservation: Musée archéologique de Tarragone (inv. 34.243)

Datation :

Bibliographie : Berges Soriano1969-70, p. 5, 9 et 16, fig. 5; Boon 1977a.

$\mathbf{n}^{\circ}$ D69 = un dauphin et quatre osselets (sur un côté différent), sur les deux bras sur une seule face (XX00), avec le dauphin dans le même sens mais à chaque fois proche de la verge (fig. 67)
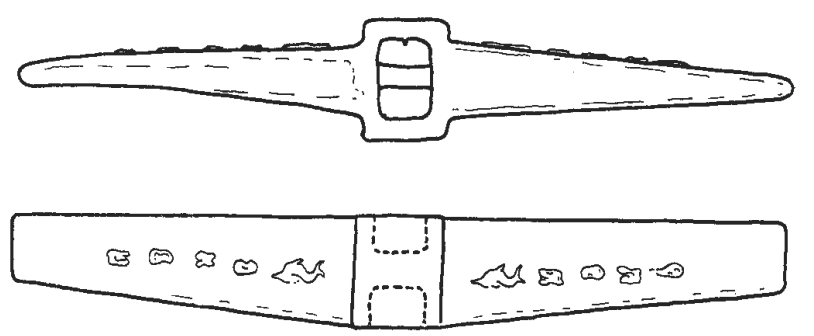

Fig. 67 - Jas D69, de l'épave Jeaune-Garde B : astragales et dauphins (d'après Carrazé 1973, p. 14).

Objet: jas en plomb de type fixe; long. 1,20 m; $135 \mathrm{~kg}$ environ

Site : épave B de la Jeaune-Garde, au nord-ouest de Porquerolles (baie du Langoustier)

Conservation :

Datation : circa 140 a.C. (d'après contexte céramique : Carrazé 1974); circa 200-140 a.C. (Parker 1992)

Bibliographie : Carrazé 1973, p. 13-15 et fig. 7; Carrazé 1974, p. 156; Boon 1977a, avec fig. 4.3; Mercanti 1979, p. 34-35 et pl. VIII, 3; Zemer 1981; Parker 1992, p. 222.

$\mathbf{n}^{\circ}$ D70 = 4 osselets et un dauphin «sur les bras opposés» (XX00?)

Objet: jas en plomb; long. un peu plus de $2 \mathrm{~m}$; plus de $500 \mathrm{~kg}$

Site : près de l'île Mal di Ventre, à l'ouest de la Sardaigne, épave

Conservation: Antiquarium arborense di Oristano (?)

Datation : 1e moitié du I $^{\text {er }}$ s. a.C. (matériel associé) 
Bibliographie: Salvi 1991, p. 147-153 et fig. 1; Parker 1992, p. 255-256; Gargiullo \& Okely 1993, II p. 60.

$\mathbf{n}^{\circ}$ D71 = 4 osselets dans des positions différentes, sur au moins une face d'un bras (X000?); un dauphin (?) sur bras opposé (0X00)

Objet : jas de plomb

Site : pointe Biscione (entre Marsala et Mazara, Sicile)

Conservation : collection privée

Datation :

Bibliographie : Falsone \& Bound 1986, p. 169 et fig. 15.2, 16; Purpura 1993, $\mathrm{n}^{\circ} 128$ Cat; Gargiullo \& Okely 1993, III p. 30.

$\mathbf{n}^{\circ} \mathbf{D 7 2}=$ un osselet $(\mathrm{X00X})$ et un dauphin (0XX0), alternativement sur chaque face de chaque bras (au total XXXX)

Objet : jas de plomb de type fixe; long. 1,40 m; larg. max. 0,19 m; du type du jas du Grand Ribaud

Site : Arenella, près de Palerme (Sicile occidentale)

Conservation: Musée de Palerme, inv. 3089

Datation :

Bibliographie: Tusa 1959; Tusa 1971, p. 282; Tusa 1973; Carrazé 1974, p. 156; Boon 1977a; Zemer 1981; Purpura 1986, p. 144; Gargiullo \& Okely 1993, III p. 13.

$\mathbf{n}^{\circ} \mathbf{D 7 3}=$ dauphins et osselets

Objet : jas en plomb

Site : Secca Priolo, près de Palerme (Sicile)

Conservation :

Datation :

Bibliographie : Gargiullo \& Okely 1993, III p. 13.

2) autre(s) motif(s) avec astragales (voir supra p. 326 ss.)

$n^{\circ}$ D74 = un grand cercle avec appendice sur partie supérieure (couronne?) près de la verge; 4 osselets; sur les 4 faces (XXXX); mais d'après photos et dessins : irrégularités dans le nombre d'astragales (?); d'après Boon, sur 2 faces seulement (fig. 68) (voir supra p. 344)

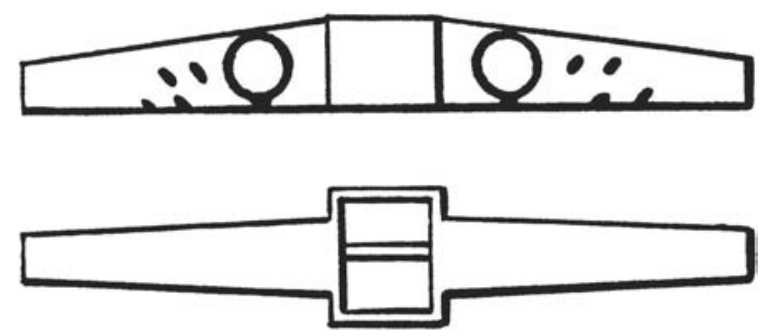

Fig. 68 - Jas D74, de Ceuta, avec cercles et osselets (d'après Ciabatti 1984, fig. 22). 
Objet : jas de plomb de type fixe; long. 1,16 m (selon J. Bravo Perez 1970) et 1,05 m (selon J. Bravo 1964 et F. Carrazé et Boon); 82 kg; identique pour la forme à celui (lequel?) de l'Escalet

Site : cap Ceuta

Conservation :

Datation :

Bibliographie : Bravo 1964; Bravo \& Muñoz 1966-1968; Berges Soriano 1969-70, p. 5 note 3; Bravo 1970, p. 823-825 no 9 et fig. 1 et pl. II; Carrazé 1973, p. 15; Carrazé 1974, p. 156; Boon 1977a avec fig. 4.4; Zemer 1981; Ciabatti 1984, fig. 22.

$\mathbf{n}^{\circ}$ D75 = 4 osselets, sur une seule face, disposés sur un côté différent; un coquillage, sur la face opposée de l'autre bras (X00X)

Objet: jas de plomb; long. 1,36 m

Site : Cap Gros (près d'Antibes)

Conservation :

Datation :

Bibliographie : Fiori 1974, III p. 81-102.

n' D76 = une tête de lion "sur les deux faces des bras» (XXXX?), accompagné de 4 astragales sur une face (XX00?) et de quatre coquillages de l'autre (00XX?) (supra p. 338 et 340 s.)

Objet : jas de plomb

Site : à l'est de l'Isola Marmorata, Sardaigne septentrionale

Conservation: Musée de Sassari (Sardaigne)

Datation :

Bibliographie : Gianfrotta 1980, p. 108 et fig. 11; Gianfrotta \& Pomey 1980, fig. p. 308; Gianfrotta \& alii 1997, p. 47 avec fig.; Gargiullo \& Okely 1993, II p. 38.

$\mathbf{n}^{\circ} \mathbf{D 7 7}=4$ astragales disposées sur un côté différent, sur une face des 2 bras (X00X); 3 rosettes à 8 pétales «à goutte» séparées par une composition verticale de gouttes, sur autres faces (0XX0)

Objet : jas de plomb fixe; long. 1,22 m; larg. max. 0,18 m

Site : devant l'aéroport militaire de Furbara, près d'Alsium et Pyrgi (Étrurie méridionale)

Conservation :

Datation : «époque romaine»

Bibliographie : Arata 1985; Gargiullo \& Okely 1993, I p. 119.

$\mathbf{n}^{\circ} \mathbf{D 7 8}=$ quatre coquillages (type : clovisse nervurée); 4 astragales sur autre bras, disposés sur un côté différent (XX00) (supra p. 340 s.)

Objet: jas de plomb; long. 1,65 m; larg. max. 0,19 m

Site : eaux de l'île de Ventotene

Conservation: Ventotene, magazzino communale

Datation : fin époque républicaine/Haut-Empire

Bibliographie : Gianfrotta 1980, p. 108 et fig. 8; Gianfrotta 1986, p. 217-218 et fig. 375-376; Kapitän 1989, p. 152-153 et note 4; Gianfrotta \& alii 1997, fig. p. 112. 
$\mathbf{n}^{\circ}$ D79 = 4 osselets (ou coquillages?) et une lampe, en miroir sur la même face des deux bras (XX00) (supra p. 342)

Objet: jas de plomb, de type fixe; long. 1,74 m

Site : île éolienne de Filicudi, près du cap Graziano; épave H (?)

Conservation : Lipari, Museo eoliano, inv. 14959

Datation: 1e moitié du ${ }^{\text {er }}$ s. a.C. (matériel associé); époque augustéenne (type de lampe)

Bibliographie : Mercanti 1979, p. 42-43 (sans décor); Kapitän 1985, p. 93-94 et fig. 102-103; Parker 1992, p. 119; Gargiullo \& Okely 1993, p. 82

$\mathbf{n}^{\circ} \mathbf{D 8 0}=4$ osselets dans des positions différentes, sur une face d'un bras (X000), et sur l'autre quatre reliefs non identifiables (coquillages?) (0X00)

Objet: jas de plomb, de type fixe; long. 1,65 ou 1,66 m

Site : île éolienne de Filicudi, près du cap Graziano; épave H (?)

Conservation : Lipari, Museo eoliano, inv. 14960

Datation : $1^{\text {ère }}$ moitié du $\mathrm{I}^{\mathrm{er}}$ s. a.C. (matériel associé)

Bibliographie : Mercanti 1979, p. 42-43 avec fig.; Kapitän 1985, p. $93-95$ et fig. 102-103; Parker 1992, p. 119; Gargiullo \& Okely 1993, p. 82.

$\mathbf{n}^{\circ} \mathbf{D 8 1}=$ une seiche (ou poulpe); 4 osselets (supra p. 339 s.)

Objet : jas de plomb

Site : port de Syracuse

Conservation :

Datation :

Bibliographie : Gargallo 1961, p. 31-35, fig. 6 (pour lui, une tête et 4 osselets; mais sur la photo les 4 osselets ne sont pas clairement visibles : plutôt 3?); Gianfrotta 1980, p. 108.

3) combinaisons de motifs sans astragales

$\mathbf{n}^{\circ} \mathbf{D 8 2}$ = deux dauphins sur une face, et sur une autre de l'autre côté deux dauphins associés à un marteau de mineur (?) à manche très long (X0X0 ou X00X) (fig. 69 et supra p. 342)

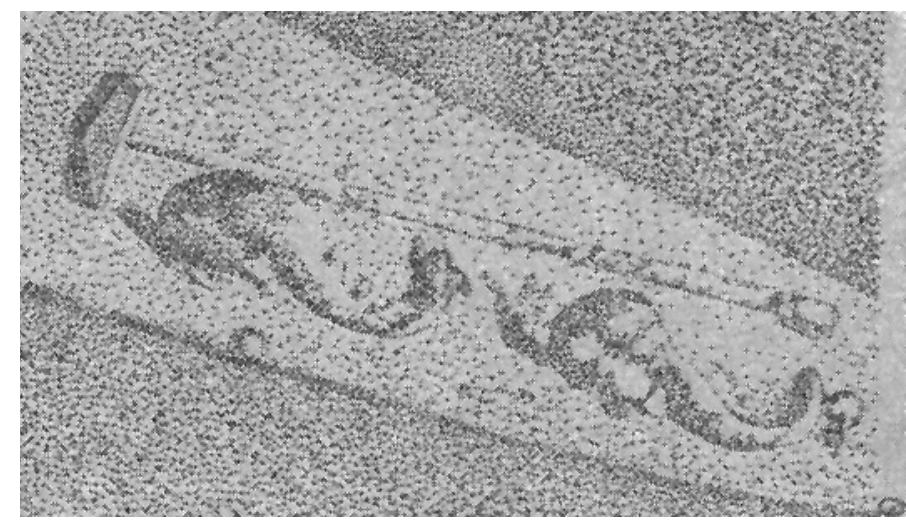

Fig. 69 - Jas D82 : dauphins et marteau (d'après Benoît 1960b). 
Objet: jas de plomb de type fixe; long. 1,59 m

Site : au sud de la pointe Santa Anna à Blanes (golfe de Barcelone)

Conservation: Musée maritime de Barcelone

Datation : vers la moitié du $\mathrm{I}^{\mathrm{er}}$ s. a.C. (?)

Bibliographie : Pascual Guasch 1959; Barbéra 1959 [réf. non lue]; Benoît 1960b, p. 176-177 et fig. 1; Benoît 1960a, p. 41-46, note 8; Ripoll Perelló 1962; Mercanti 1979.

$\mathbf{n}^{\circ} \mathbf{D 8 3}=3$ coquilles (?), sur une face d'un bras (0X00) (pas tout à fait à intervalles réguliers comme le commente Meis 1978); sur l'anneau central, un relief ovale en sens oblique (un œuf?) (supra p. 334)

Objet : jas de plomb de type fixe; long. 1,41 m; larg. max. 0,23 m

Site : Anzio

Conservation : collection privée

Datation :

Bibliographie: Meis 1978, p. 46 et pl. I, 6.

\section{Décor avec inscription onomastique ou numéraire}

1) avec astragales + autre décor

$\mathbf{n}^{\circ}$ D84 = D.ORI plusieurs fois sur une face d'un bras (X000) et sur anneau; A. MVNIO deux fois sur bras droit (0X00); osselets, sur une face des deux bras (X0X0), au nombre de 4 et de 3, représentés sur un côté différent; nombreux autres signes non identifiés sur le bras droit (0X00) : sigles, un chiffre, et le dessin d'un astrolabe (?) (supra p. 344)

Objet : jas de plomb de type fixe; long. 1,78 m; larg. max. $25 \mathrm{~cm}$; poids : environ $305 \mathrm{~kg}$

Site : côte entre Castiglioncello et Vada

Conservation : Museo civico de Rosignano Marittimo (province de Livorno)

Datation : $\mathrm{II}^{\mathrm{e}}$ s. a.C. (?) d'après données épigraphiques

Bibliographie : Massa 1982, p. 60 (avec une erreur de poids); Massa 19821983.

2) avec astragale(s) seule(s)

no D85 = inscription (?); astragales représentées sur des faces différentes, sur les 4 côtés (XXXX?)

Objet: jas de plomb; long. 1,09 m; larg. 0,165 m; ép. 0,125 m

Site :

Conservation: Musée de Cadiz

Datation :

Bibliographie : García \& López 1979-1980.

$\mathbf{n}^{\circ}$ D86 = cartouche (inscription?); une astragale

Objet :

Site : face au lieu-dit Torre d'en Penjat (Minorque) 
Conservation :

Datation :

Bibliographie : Nicolás 1974.

n $^{\circ}$ D87 et D88 (un ex. publié, il en existe un 2e id.) = AHENOBARBI (écrit de droite à gauche); 4 osselets sur face opposée de l'autre bras (X00X) Objet: jas de plomb de type fixe; long. 1,45 m; larg. max. 0,11 m;

Site : Isola delle Femine (eaux du nord de la Sicile)

Conservation: Musée de Palerme, inv. 3344

Datation : la forme d'une lettre s'apparenterait au $\mathrm{II}^{\mathrm{e}}$ s. p.C. (?)

Bibliographie : Tusa 1971, p. 274; Tusa 1973, p. 423-424; Boon 1977a; Gianfrotta 1980, p. 111 ss; Hesnard \& Gianfrotta 1989, p. 393-441.

$\mathbf{n}^{\circ} \mathbf{D 8 9}$ = MAT; osselets

Objets : jas de plomb

Site : entre Isola delle Femine et Ustica

Conservation :

Datation :

Bibliographie : Gianfrotta 1980, p. 110 et fig. 24; Hesnard \& Gianfrotta 1989, p. 393-441.

$\mathbf{n}^{\circ} \mathbf{D 9 0}=$ une inscription (à déchiffrer; mauvais état de conservation); 6 osselets (?) sur l'autre face du bras opposé (X00X) (d'après Tusa, ne ressemblent pas aux autres représentations d'osselets)

Objet: jas de plomb de type fixe; long. 1,48 m; larg. max. 0,11 m

Site : Isola delle Femine (eaux du nord de la Sicile)

Conservation: Musée de Palerme, inv. 3346

Datation :

Bibliographie : Tusa 1971, p. 275; Tusa 1973, p. 424; Boon 1977a; Gargiullo \& Okely 1993, III p. 14.

$\mathbf{n}^{\circ}$ D91 et D92 = TAELI; osselets

Objets : jas de plomb

Site : port de Syracuse

Conservation :

Datation :

Bibliographie: Gargallo 1961; Hesnard \& Gianfrotta 1989, p. 393-441.

$\mathbf{n}^{\circ} \mathbf{D 9 3}$ = ZHNOBI, avec 4 osselets en carré (X000)

Objet: jas de plomb de type fixe

Site : Acque Chiare (Brindisi)

Conservation: Musée archéologique de Brindisi, salle De Leo

Datation : circa 150-circa 25 a.C. (contexte céramique : Parker 1992)

Bibliographie : Sciarra 1976, p. 10-12 no 68; Sciarra 1985, p. 145; Hesnard \& Gianfrotta 1989, p. 393-441; Parker 1992, p. 242-243. 
3) sans astragales

n' D94 = ME suivi d'un caducée sur une face d'un bras (X000); NC TITLE AT sur la face de l'autre bras (0X00)

Objet : jas de plomb de type fixe; long. environ $2 \mathrm{~m}$

Site : Civitavecchia

Conservation :

Datation :

Bibliographie: Sonno 1997, p. 76.

$\mathbf{n}^{\circ}$ D95 = NICIAVILLILS; suivie d'une pointe de trident (?) (supra p. 343)

Objet : jas de plomb

Site : Sassari (Sardaigne)

Conservation :

Datation :

Bibliographie: Hesnard \& Gianfrotta 1989, p. 393-441.

$\mathbf{n}^{\circ}$ D96 = inscription sur un seul bras, des deux côtés (X0X0) IVLIOO et NAVIID, de droite à gauche (?); dauphins sur autre bras

Objet: Jas de plomb de type fixe; long. 1,83 m; larg. max. 0,30 m

Site : Anzio, Secca di Levante

Conservation : collection privée

Datation :

Bibliographie : De Meis 1978, p. 47 et fig. 4.

$\mathbf{n}^{\circ}$ D97 = L. FVLVI. EVTI de droite à gauche sur les faces opposées des deux bras (X00X), entre deux pointes de trident (selon Tusa) ou entre un caducée et une pointe de trident (selon Hesnard \& Gianfrotta) (supra p. 343)

Objet: jas de plomb de type fixe; long. 1,60 m; larg. max. 0,18 m

Site : Isola delle Femine (eaux du Nord de la Sicile)

Conservation: Musée de Palerme, inv. 3090

Datation :

Bibliographie : Tusa 1971, p. 281; Tusa 1973, p. 428-429; Hesnard \& Gianfrotta 1989, p. 393-441; Gargiullo \& Okely 1993, III p. 15.

$\mathbf{n}^{\circ} \mathbf{D 9 8}=$ C.F.M.; lampe (?) sur même bras et même face, et sur la face opposée de l'autre bras (X00X) (supra p. 342)

Objet : jas de plomb de type fixe; long. 1,62 m; larg. max. 0,115 m

Site : Isola delle Femine (eaux du nord de la Sicile)

Conservation: Musée de Palerme, inv. 3345

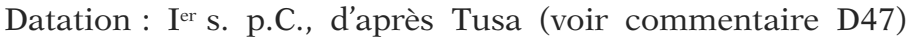

Bibliographie : Tusa 1971, p. 275-276; Tusa 1973, p. 425; Hesnard \& Gianfrotta 1989, p. 393-441; Gargiullo \& Okely 1993, III p. 14. 


\section{CORPUS DES ANCRES DE PIERRE VOTIVES}

Pour éviter toute confusion avec les précédents catalogues, ces ancres sont numérotées V1, etc.

Jas avec inscriptions

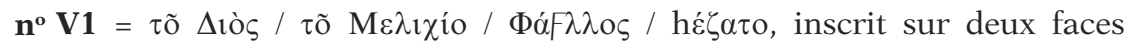
perpendiculaires (fig. 70; supra p. 464 ss.)
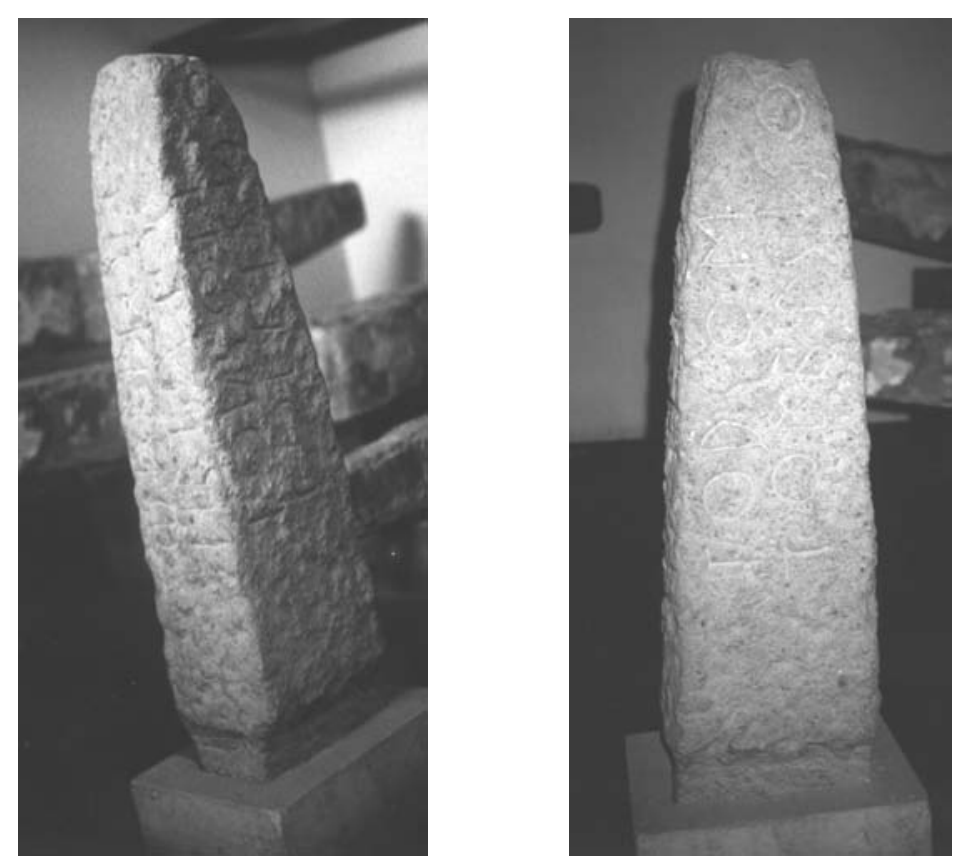

Fig. 70 - Jas de Zeus Meilichios (musée de Reggio, inv. 10917. Photo de l'auteur; avec l'autorisation du Ministero dei Beni e delle Attività culturali e del Turismo n. 27 du 03/03/2014, Soprintendenza per i Beni archeologici della Calabria).

Objet : demi-jas de pierre; long. 1,30 m environ

Site : entre cap Colonna et cap Cimmiti (Calabre); plus précisément au nord du cap Cimmiti, entre le cap Colonna et le cap Rizzuto (Boetto)

Conservation: Musée de Reggio di Calabria, inv. 10917

Datation : fin $\mathrm{VI}^{\mathrm{e}}$ s.-début $\mathrm{V}^{\mathrm{e}}$ s. a.C. (épig.)

Bibliographie : SEG XVII, 442; SEG XXVIII, 1596; Dunbabin 1948, p. 85, note 3 et p. 375; Iacopi 1952; J. et L. Robert, in REG LXVII, 1954, p. 192-3, n. 291; Guarducci 1967; Burzachechi 1971, p. 131 ; Gianfrotta 1975, p. 316-318 et fig. 3; Gianfrotta 1977, p. 288-289 et fig. 8; Davaras 1980, p. 56; Gianfrotta \& Pomey 1980, p. 302 et fig. p. 303; Mac Caslin 1980, p. 50; Lattanzi 1987, p. 172; Jeffery 1990, p. 257-258; Boetto 1997, p. 54-55; Romero Recio 2000, p. 45-46. 


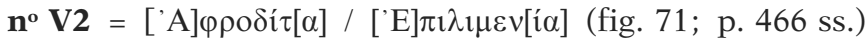

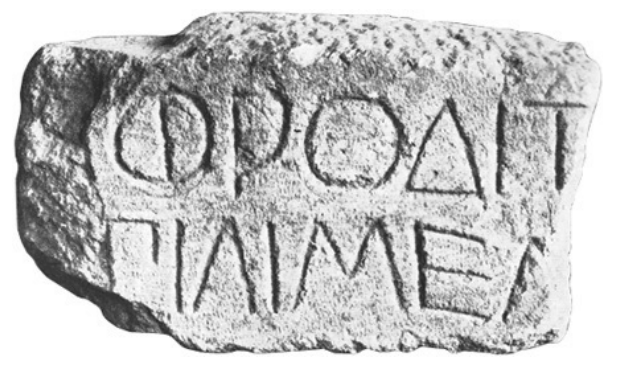

Fig. 71 - Jas d'Égine à Aphrodite (d'après Welter 1938 fig. 11).

Objet : fragment de jas en pierre (extrémité gauche du bras droit?)

Site : Égine, près du temple d'Apollon (?), près du port

Conservation : Musée d'Égine

Datation : pemière moitié du Ve s. a.C. (épig.)

Bibliographie : SEG XI, 18; SEG XXVIII, 1596; Wolters, Hellas IV, 1924, 5/6, p. 71-72 [réf. non vue]; Chronique 1924; Wolters 1925a; Wolters 1925b; Welter 1938, col. 489-491 et fig. 11 ; Wachsmuth 1967, note 991; Casson 1971, p. 255 et note 126; Gianfrotta 1975, p. 315 et fig. 2; Guarducci 1967-78, III p. 362-363; Gianfrotta 1977, p. 288 et note 5, fig. 7; Davaras 1980, p. 55 ; Gianfrotta \& Pomey 1980, p. 302; Mac Caslin 1980, p. 48-49; Jeffery 1990, p. 113, n. 14; Pirenne-Delforge 1994, p. 176; Boetto 1997, p. 55-56; Romero Recio 2000, p. 39.

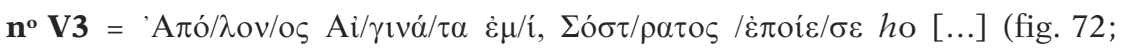
p. 470 ss.)
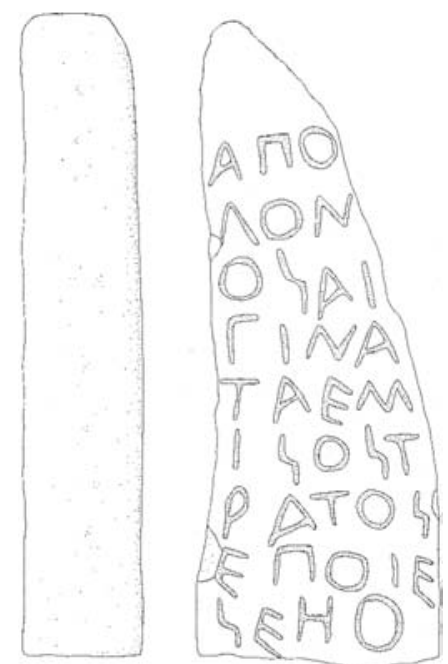

Fig. 72 - Gravisca : jas avec inscription de Sostratos (d'après Colivicchi 2004, p. 140). 
Objet : jas fragmentaire en marbre, peut-être de Naxos; long. 1,14 $\mathrm{m} \times$ larg. 0,39 m, x ép. max. 0,17 m

Site : sanctuaire de Gravisca, en remploi sur une canalisation de la rue N/S située contre le mur de la cour de l'édifice Alpha (voir fig. 43)

Conservation : musée de Tarquinia, inv. II 4094

Datation : vers 500 a.C. (épig.)

Bibliographie : SEG XXVI, 1137 et XXVIII, 1596; Torelli 1970, p. 55-56 (n 36) et pl. XIX; Torelli \& alii 1971, p. 227 et fig. 41, 57; Torelli 1971; Gianfrotta 1975, p. 311-318; Guarducci 1967-78, III p. 23-25; Harvey 1976; Gianfrotta 1977, p. 287; Torelli 1977; Davaras 1980, p. 54; Gianfrotta \& Pomey 1980, p. 302; Mac Caslin 1980, p. 50; Torelli 1982; Torelli 1986; Jeffery 1990, p. 439-440; Boetto 1997, p. 54-55; Johnston \& Pandolfini 2000, p. 15-16 n 1; Romero Recio 2000, p. 53; Forsén 2004, p. 309, 311 (n 183 et pl. 80); Colivicchi 2004, p. 141-144, no 458 et pl. 22; Fiorini 2005, p. $119-120$.

$\mathbf{n}^{\circ} \mathbf{V 4}=[\mathrm{A} \pi \mathrm{o} \lambda \lambda \mathrm{ov}] \mathrm{o} \varsigma /[\Lambda \nu \kappa \varepsilon 1] \mathrm{o} \varepsilon \mu \mathrm{t} / /[. . \alpha v] \varepsilon \theta \varepsilon /[\kappa \varepsilon ..] \alpha \sigma \nu \varsigma$, sur deux lignes sur les deux épaisseurs, à lire dans le sens de la longueur (fig. 73; p. 485)

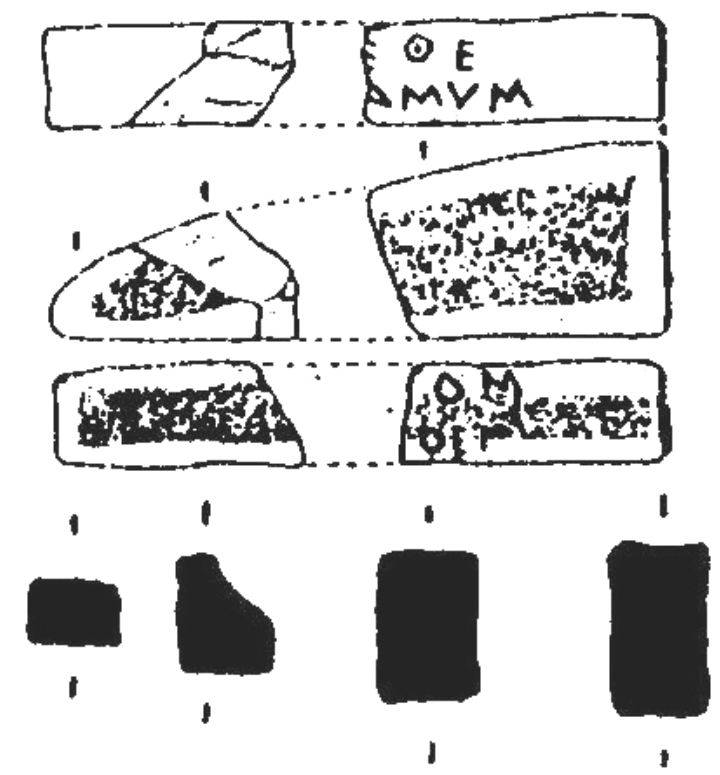

Fig. 73 - Jas de Métaponte : Apollon Lykeios (d'après Boetto 1997, pl. III).

Objet : jas de marbre fragmentaire (un $2^{\mathrm{e}}$ fgt anépigraphe y est rattaché); long. cons. 22,5 cm; larg. max. $14 \mathrm{~cm}$; ép. 7 à $8 \mathrm{~cm}$; long. du jas entier ne devait pas dépasser $1 \mathrm{~m}$.

Site : Métaponte, alentours de la «cloaca», aire nord du temple d'Héra Conservation : dépôts de fouilles de Métaponte

Datation : seconde moitié du Ve s. a.C., ou peut-être avant (épig.)

Bibliographie: Burzachechi 1979, p. 289-291 no 10; Davaras 1980, p. 54; Boetto 1997, p. 51-52, $60 \mathrm{n}^{\circ}$ M5, pl. III et fig. 3-5. 


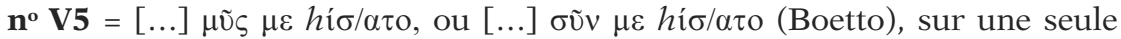
face (X000) (fig. 74; p. 486)

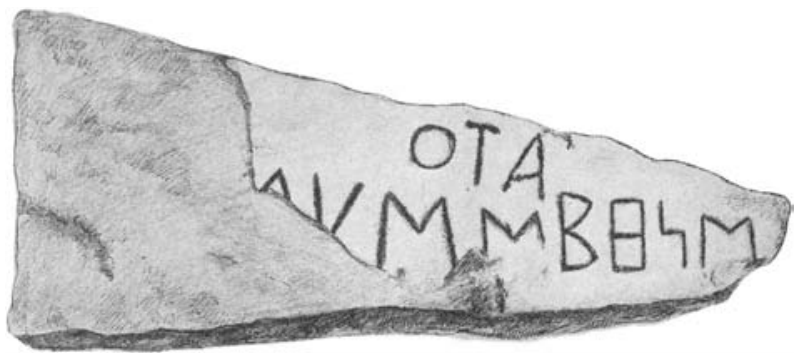

Fig. 74 - Jas de Corfou (d'après Brugman 1893).

Objet : fragment de jas (?) de pierre calcaire; long. 0,41 m; larg. 0,16 m; $0,11 \mathrm{~m}$ ép. (si entier, $+1 \mathrm{~m}$ )

Site : provenance inconnue

Conservation : Musée de Corfou, inv. 212.

Datation : $\mathrm{VI}^{\mathrm{e}}$ a.C.; fin $\mathrm{VII} /$ début $\mathrm{VI}^{\mathrm{e}}$ (Burzachechi) (épig.)

Bibliographie : IG IX, 1, 704; SEG XXVIII, 1596; Brugmann 1893, avec pl.; Schwyzer 1923, 132; Six 1894; Burzachechi 1962, p. 13-15; Torelli 1971, p. 57-58; Gianfrotta 1977, p. 286-287 et fig. 3 ; Mac Caslin 1980, p. 50; Boetto 1997, p. 52, 54 et fig. 6; Romero Recio 2000, p. 40.

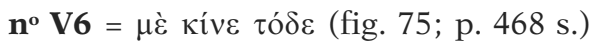
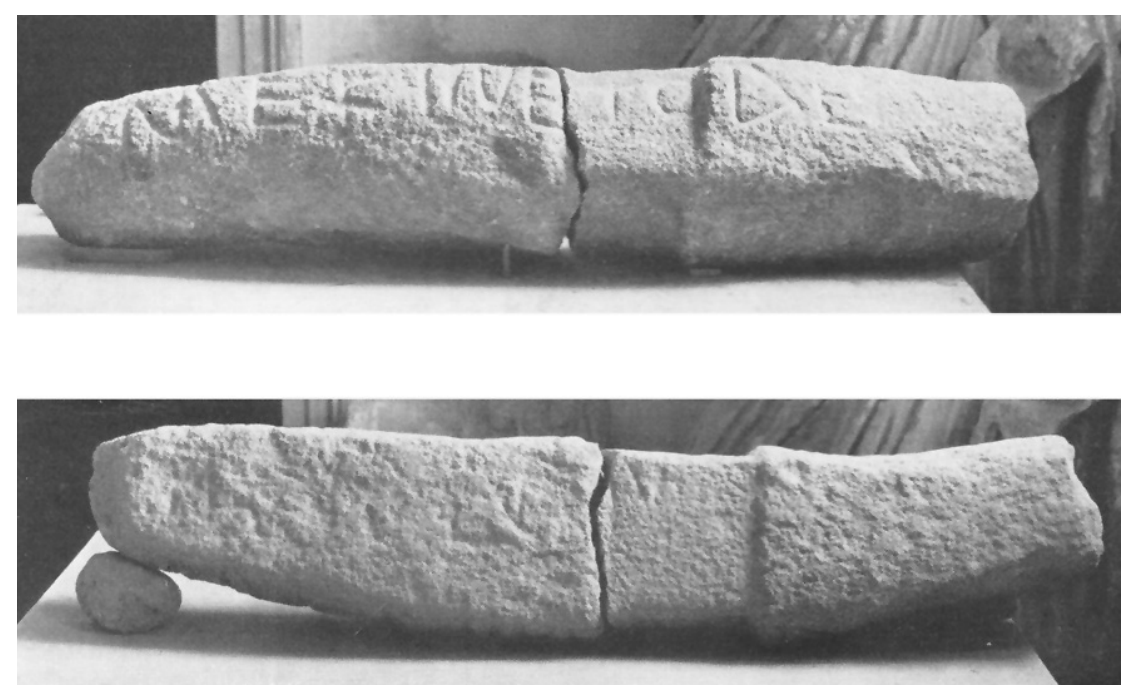

Fig. 75 - Jas d'Égine : «me kine tode» (d'après Welter 1938, fig. 15). 
Objet : jas de pierre

Site : Égine, lieu-dit Meristos area, près du port moderne

Conservation : Musée d'Égine

Datation : milieu du Ve s. a.C. (épig.)

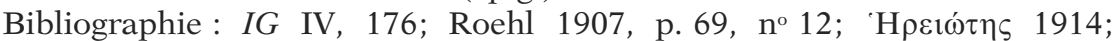
Schwyzer 1923, 117; Welter 1938, col. 489-491 et fig. 14-15; Welter 1962, p. 51, fig. 7; Wachsmuth 1967, note 234 et p. 259-260; Guarducci 1967-78, III p. 363-364 ; Davaras 1980, p. 56-57; Gianfrotta 1980, p. 110; Gianfrotta \& Pomey 1980, fig. p. 303; Mac Caslin 1980, p. 49; Kritzas 1989; Jeffery 1990, p. 113, n. 20.

\section{Anépigraphes}

$\mathbf{n}^{\mathbf{0}} \mathbf{V 7}$ = jas fragmentaire (fig. 76; p. 472 ss.)

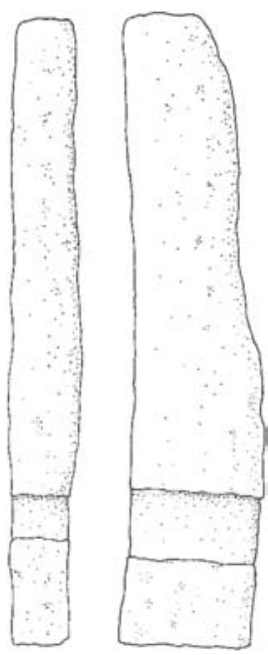

Fig. 76 - Gravisca : jas inv. 459 (d'après Colivicchi 2004, p. 142).

Objet : en marbre de l'Hymette; long. $110 \mathrm{~cm} \times$ larg. base $28 \mathrm{~cm} \times$ ép. max. $22 \mathrm{~cm}$

Site : sanctuaire de Gravisca, prov. inc.

Conservation :

Datation :

Bibliographie : Gianfrotta 1975, p. 312-313; Gianfrotta 1977, p. 287-288 et fig. 5-6; Torelli 1977; Gianfrotta \& Pomey 1980, p. 302 et fig. p. 304; Torelli 1986, p. 46-53; Boetto 1997, p. 51 ss.; Colivicchi 2004, p. 140, $\mathrm{n}^{\circ} 459$ et pl. 23. 
$\mathbf{n}^{\circ} \mathbf{V 8}=$ jas fragmentaire (fig. $77 ; 472$ ss.)

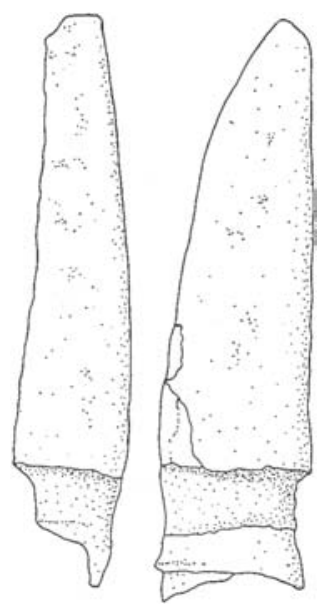

Fig. 77 - Gravisca : jas inv. 460 (d’après Colivicchi 2004, p. 142).

Objet : de pierre; long. $131 \mathrm{~cm} \times$ larg. base $27 \mathrm{~cm} \mathrm{x} \mathrm{ép.} \mathrm{max.} 15 \mathrm{~cm}$

Site : sanctuaire de Gravisca, cour A de l'édifice Alpha, en remploi le long d'une structure carrée (voir fig. 43)

Conservation :

Datation :

Bibliographie : Torelli \& alii 1971, p. 230 et fig. 41, 45; Torelli 1971, p. 48; Gianfrotta 1975, p. 312-313; Gianfrotta 1977, p. 287-288 et fig. 5-6; Torelli 1977; Gianfrotta \& Pomey 1980, p. 302 et fig. p. 304; Torelli 1986, p. 46-53; Boetto 1997, p. 51 ss.; Colivicchi 2004, p. 141, no 460 et pl. 23.

$\mathbf{n}^{\circ} \mathbf{V 9}$ = jas fragmentaire (p. 472 ss.)

Objet : de pierre; long. visible $125 \mathrm{~cm}$ x larg. max. $25 \mathrm{~cm}$ x ép. max. $12 \mathrm{~cm}$

Site : sanctuaire de Gravisca, voie N/S, près du mur oriental de l'édifice Alpha, fiché en terre au niveau du mur 29

Conservation : (en place?)

Datation :

Bibliographie : Torelli \& alii 1971, p. 227 et fig. 42; Gianfrotta 1975, p. 312313; Gianfrotta 1977, p. 287-288 et fig. 5-6; Torelli 1977; Gianfrotta \& Pomey 1980, p. 302 et fig. p. 304; Torelli 1986, p. 46-53; Boetto 1997, p. 51 ss.; Colivicchi 2004, p. 143, no 463.

$\mathbf{n}^{\circ} \mathbf{V 1 0}=$ jas fragmentaire (p. 472 ss.)

Objet : de pierre; long. visible $95 \mathrm{~cm}$ x larg. max. $24 \mathrm{~cm} \times$ ép. max. $12 \mathrm{~cm}$ Site : sanctuaire de Gravisca, voie N/S, fiché en terre au niveau du mur 29 Conservation : (en place?)

Datation : 
Bibliographie : Torelli \& alii 1971, p. 227 et fig. 42; Gianfrotta 1975, p. 312313; Gianfrotta 1977, p. 287-288 et fig. 5-6; Torelli 1977; Gianfrotta \& Pomey 1980, p. 302 et fig. p. 304; Torelli 1986, p. 46-53; Boetto 1997, p. 51 ss.; Colivicchi 2004, p. 141, n 461.

$\mathbf{n}^{\circ} \mathbf{V 1 1}$ = jas fragmentaire (p. 472 ss.)

Objet : de pierre; long. $70 \mathrm{~cm} \times$ larg. max. $22 \mathrm{~cm} \times$ ép. max. $22 \mathrm{~cm}$

Site : sanctuaire de Gravisca, entre l'édifice Alpha et l'édifice Bêta

Conservation :

Datation :

Bibliographie : Gianfrotta 1975, p. 312-313; Gianfrotta 1977, p. 287-288 et fig. 5-6; Torelli 1977; Gianfrotta \& Pomey 1980, p. 302 et fig. p. 304; Torelli 1986, p. 46-53; Boetto 1997, p. 51 ss.; Colivicchi 2004, p. 141, no 462 et pl. 23.

$\mathbf{n}^{\circ} \mathbf{V 1 2}=$ jas fragmentaire (p. 472 ss.)

Objet : de pierre; long. $84 \mathrm{~cm} \times$ larg. max. $25 \mathrm{~cm} \times$ ép. max. $12 \mathrm{~cm}$

Site : sanctuaire de Gravisca, édifice Gamma, cour I

Conservation :

Datation :

Bibliographie : Gianfrotta 1975, p. 312-313; Gianfrotta 1977, p. 287-288 et fig. 5-6; Torelli 1977; Gianfrotta \& Pomey 1980, p. 302 et fig. p. 304; Torelli 1986, p. 46-53; Boetto 1997, p. 51 ss.; Colivicchi 2004, p. 143, $\mathrm{n}^{\circ} 464$.

$\mathbf{n}^{\circ} \mathbf{V 1 3}=$ jas fragmentaire (p. 472 ss.)

Objet : de pierre; long. $75 \mathrm{~cm} \times$ larg. $\max .28 \mathrm{~cm} \times$ ép. max. $12 \mathrm{~cm}$

Site : sanctuaire de Gravisca, voie N/S

Conservation :

Datation :

Bibliographie : Gianfrotta 1975, p. 312-313; Gianfrotta 1977, p. 287-288 et fig. 5-6; Torelli 1977; Gianfrotta \& Pomey 1980, p. 302 et fig. p. 304; Torelli 1986, p. 46-53; Boetto 1997, p. 51 ss.; Colivicchi 2004, p. 143, $\mathrm{n}^{\circ} 465$.

$\mathbf{n}^{\circ} \mathbf{V 1 4}=$ jas fragmentaire (p. 472 ss.)

Objet : de pierre; long. $72 \mathrm{~cm} \times$ larg. max. $27 \mathrm{~cm} \times$ ép. max. $14 \mathrm{~cm}$

Site : sanctuaire de Gravisca, voie N/S

Conservation :

Datation :

Bibliographie : Gianfrotta 1975, p. 312-313; Gianfrotta 1977, p. 287-288 et fig. 5-6; Torelli 1977; Gianfrotta \& Pomey 1980, p. 302 et fig. p. 304; Torelli 1986, p. 46-53; Boetto 1997, p. 51 ss.; Colivicchi 2004, p. 143, $\mathrm{n}^{\circ} 466$.

$\mathbf{n}^{\mathbf{o}} \mathbf{V 1 5}=$ jas fragmentaire (p. 472 ss.)

Objet : de pierre; long. $71 \mathrm{~cm} \times$ larg. max. $27 \mathrm{~cm} \times$ ép. $\max .15 \mathrm{~cm}$

Site : sanctuaire de Gravisca, édifice Gamma, cour I

Conservation : 
Datation :

Bibliographie : Gianfrotta 1975, p. 312-313; Gianfrotta 1977, p. 287-288 et fig. 5-6; Torelli 1977; Gianfrotta \& Pomey 1980, p. 302 et fig. p. 304; Torelli 1986, p. 46-53; Boetto 1997, p. 51 ss.; Colivicchi 2004, p. 143, n 467.

$\mathbf{n}^{\circ} \mathbf{V 1 6}$ = jas fragmentaire (p. 472 ss.)

Objet : de pierre; long. $69 \mathrm{~cm} \times$ larg. max. $20 \mathrm{~cm} \times$ ép. max. $10 \mathrm{~cm}$

Site : sanctuaire de Gravisca, entre l'édifice Alpha et l'édifice Bêta

Conservation :

Datation :

Bibliographie : Gianfrotta 1975, p. 312-313; Gianfrotta 1977, p. 287-288 et fig. 5-6; Torelli 1977; Gianfrotta \& Pomey 1980, p. 302 et fig. p. 304; Torelli 1986, p. 46-53; Boetto 1997, p. 51 ss.; Colivicchi 2004, p. 143, $\mathrm{n}^{\circ} 468$.

$\mathbf{n}^{\circ} \mathbf{V 1 7}=1$ ancre «à trous»? (p. 485 s.)

Objet : de pierre calcaire?

Site : Métaponte, sanctuaire d'Apollon (sans indic. suppl.)

Conservation : Métaponte?

Datation : date ancienne

Bibliographie : Boetto 1997, p. 61 n M7 et fig. 8.

$\mathbf{n}^{\circ} \mathbf{V 1 8}$ à V22 = 5 jas (fig. $78 ;$ p. 485 s.)

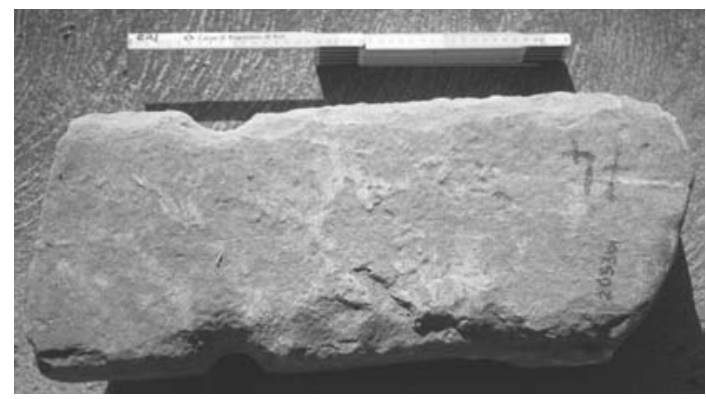

Fig. 78 - Jas de Métaponte, inv. 20536-74 (Photo de l'auteur; avec l'autorisation du Ministero dei Beni e delle Attività culturali e del Turismo Direzione regionale per i Beni culturali e Paesaggistici della Basilicata, Soprintendenza per i Beni archeologici della Basilicata).

Objets: pierres diverses (marbre pentélique et de l'Hymette, calcaire, schiste, granit)

Site : Métaponte, dépôt votif entre la peristasis méridionale et celle de la cella du temple B

Conservation: Métaponte (dont inv. 20591, 20668-144, 20592-124, 20536-74) 
Datation : dépôt rassemblé au $\mathrm{V}^{\mathrm{e}}$ s. a.C.

Bibliographie: D. Adamesteanu, 1970, p. 309, fig. 2 et p. 312, fig. 8-9; Adamesteanu \& alii 1980, p. 118, fig. 118-119; Boetto 1997, p. 57-61 n M1-M2-M3-M4-M6, pl. III et fig. 1-2, 7; Romero Recio 2000, p. 42.

$\mathbf{n}^{\circ} \mathbf{V 2 3}=$ jas fragmentaire (fig. $79 ;$ p. 487 ss.)
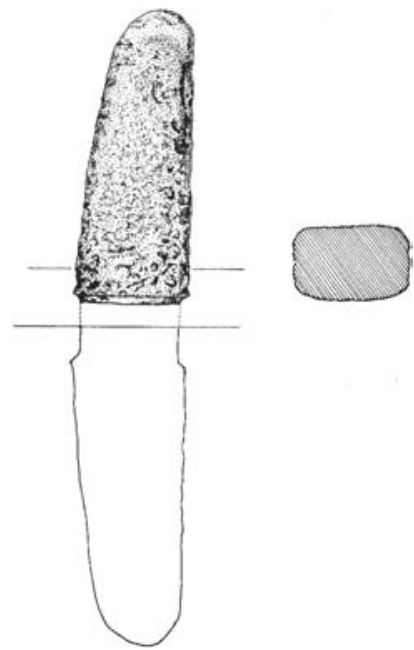

Fig. 79 - Jas de Porcinara (d'après Van Compernolle \& alii 1978, fig. 34).

Objet : de pierre

Site : sanctuaire messapien de Punta della Ristola (S. Maria de Leuca)

Datation : avec matériel votif du $\mathrm{VII}^{\mathrm{e}} \mathrm{s}$. a.C.

Bibliographie: Gianfrotta 1975, p. 315 note 18; Gianfrotta 1977, p. 286;

Davaras 1980, p. 54; Van Compernolle \& al. 1978, p. 219 et fig. 34;

Boetto 1997, p. 55; Romero Recio 2000, p. 41.

$\mathbf{n}^{\text {o }}$ V24 et V25 = 2 jas (p. 489 ss.)

Objet : de pierre

Site : Sélinonte, aire sacrée de la Malophoros, devant le temple de Zeus Meilichios

Conservation :

Datation : époque archaïque (Purpura)

Bibliographie : Purpura 1993, p. 163-184, no 126 Cat. et fig. 34; Boetto 1997, p. 54-55; Romero Recio 2000, p. 44-45.

$\mathbf{n}^{\circ} \mathbf{V 2 6}$ = jas fgtaire (environ la moitié) (p. 492)

Objet : de pierre ; long. max. 1,60 m (long. tot. $+3 \mathrm{~m}$ )

Site : Mozia, zone «K», carré 45 : au bord du pavement et d'une fosse circulaire (voir fig. 49)

Conservation : 
Datation : proviendrait d'un édifice sacré détruit par le siège de Denys en 397 a.C.; contemporain de la statue de marbre de Mozia

Bibliographie : Falsone 1988, p. 15, 24 et fig. 1; Boetto 1997, p. 55-56.

$\mathbf{n}^{\text {o }}$ V26 bis = jas fgtaire (environ la moitié) : moitié correspondante au jas trouvé dans l'area 45? (p. 492)

Objet : de pierre

Site : Mozia, zone «K», au-delà de la limite ouest du carré 45

Conservation :

Datation : proviendrait d'un édifice sacré détruit par le siège de Denys en 397 a.C.

Bibliographie : Falsone 1988, p. 15 et 24; Boetto 1997, p. 55-56.

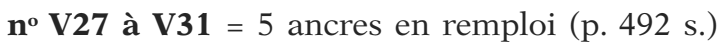

Objets : ancres de pierre, anépigraphes, de forme ancienne («lourdes pierres percées»)

Site : Salamine de Chypre

Conservation : Salamine, inv. Sal. 3283, 5813, 6631, 5853, 6739.

Datation : une de l'âge du bronze (?), autres non datables

Bibliographie : Chavane 1975, p. 114-117, no 355 à 359 et pl. 33-34; Gianfrotta 1977, p. 287.

$\mathbf{n}^{\circ} \mathbf{V 3 2}$ et V33 = deux jas (p. 494)

Objet : jas de pierre (calcaire); semblables pour la forme au jas d'Égine V6

Site : Salamine de Chypre

Conservation : Salamine, inv. Sal. 6628, 6629.

Datation :

Bibliographie : Chavane 1975, p. 114-117, no 360 et 361; Gianfrotta 1977, p. 285-292.

$\mathbf{n}^{\mathbf{0}} \mathbf{V 3 4}=$ ancre (p. 494 ss.)

Objet : ancre de pierre calcaire de type composite et oriental : percée de deux trous circulaires, et d'une encoche dans le sens de l'épaisseur; long. $102 \mathrm{~cm}$; larg. min. $11 \mathrm{~cm}$; larg. max. $45 \mathrm{~cm}$; poids : $161 \mathrm{~kg}$

Site : Alexandrie, zone dite de Ras el Soda

Conservation : jardin du Musée gréco-romain d'Alexandrie, inv. 28812

Datation : époque hellénistique si appartient au dépôt votif; ép. romaine (après $\mathrm{II}^{\mathrm{e}}$ s. p.C) si appartient au temple isiaque

Bibliographie : Frost 1970a, p. 382-383; Frost 1970c, p. 61; Nibbi 1991.

$\mathbf{n}^{\mathbf{0}} \mathbf{V 3 5}=$ ancre (p. 494 ss.)

Objet : ancre de pierre calcaire de type composite et oriental : percée d'un trou circulaire, et d'une encoche dans le sens de l'épaisseur; long. $83 \mathrm{~cm}$; larg. min. 30,5 cm; larg. max. $83 \mathrm{~cm}$; poids : $107 \mathrm{~kg}$

Site : Alexandrie (vraisemblablement de Ras el Soda)

Conservation : jardin du Musée gréco-romain d'Alexandrie, inv. 28811

Datation : (si même provenance que précédente, mêmes possibilités de datation) 
Bibliographie : Frost 1970a, p. 382-383; Frost 1970c, p. 61; Nibbi 1991.

$\mathbf{n}^{\circ} \mathbf{V} 36$ et V37 = 2 ancres fragmentaires (p. 494 ss.)

Objets : ancres de pierre calcaire de type composite et oriental : percées de deux trous circulaires, et d'une encoche dans le sens de l'épaisseur.

a) long. max. $57 \mathrm{~cm}$; larg. max. $40 \mathrm{~cm}$; poids : $47 \mathrm{~kg}$; b) long. max. $97 \mathrm{~cm}$; larg. max. $41 \mathrm{~cm}$; poids : $185 \mathrm{~kg}$

Site : Alexandrie, couches inférieures du sol du temple de Ras el Soda

Conservation : jardin du Musée gréco-romain d'Alexandrie, inv. A et B Ras el Soda

Datation : au moins $2^{\mathrm{e}}$ moitié du $\mathrm{II}^{\mathrm{e}}$ s. p.C. (?) si en relation avec le temple; peut-être antérieure (si niveaux plus anciens)

Bibliographie : Frost 1970a; Frost 1970c, p. 61; Nibbi 1991. 



\section{LES NOMS THÉOPHORES DE BATEAUX}

\begin{tabular}{|c|c|c|c|c|c|}
\hline Divinité & $\begin{array}{l}\text { Époque } \\
\text { classique }\end{array}$ & $\begin{array}{c}\text { Époque } \\
\text { hellénistique }\end{array}$ & $\begin{array}{l}\text { Inscriptions } \\
\text { d'euploia }\end{array}$ & $\begin{array}{c}\text { Classes } \\
\text { romaines }\end{array}$ & $\begin{array}{c}\text { Nom } \\
\text { du bateau }\end{array}$ \\
\hline \multirow[t]{11}{*}{ Athéna } & & $\begin{array}{l}\text { Milet et } \\
\text { Smyrne }\end{array}$ & 2 (Protè) & & Athéna \\
\hline & & Ovide & & & Athéna (?) \\
\hline & & & & $6(+1 ?)$ & Minerva \\
\hline & 1 ath. & $\begin{array}{l}\text { Milet et } \\
\text { Smyrne }\end{array}$ & & & Parthénos \\
\hline & 1 ath. & Rhodes & & & Polias \\
\hline & & Corcyre & & & Pallas \\
\hline & 1 ath. & & & & Tritogénès \\
\hline & 1 ath. & & & & Gorgôpis \\
\hline & 1 ath. & & & & Gorgophonè \\
\hline & 1 ath. & & & & Pallènis \\
\hline & 1 ath. & & & & Sounias \\
\hline \multirow[t]{7}{*}{ Aphrodite } & & & Protè, Leuca & & $\begin{array}{l}\text { Aphrodite } \\
\text { (-Tychè?) }\end{array}$ \\
\hline & & & & $2(+2 ?)$ & Vénus \\
\hline & 1 ath. & & & & Aphrodisia \\
\hline & 1 ath. & & & & Aphrodisias \\
\hline & 1 ath. & & & & Kôlias \\
\hline & 2 ath. & & & & Kythèria \\
\hline & & & Corcyre & & Kypris \\
\hline
\end{tabular}

(à suivre) 


\begin{tabular}{|c|c|c|c|c|c|}
\hline Divinité & $\begin{array}{l}\text { Époque } \\
\text { classique }\end{array}$ & $\begin{array}{c}\text { Époque } \\
\text { hellénistique }\end{array}$ & $\begin{array}{l}\text { Inscriptions } \\
\text { d'euploia }\end{array}$ & $\begin{array}{l}\text { Classes } \\
\text { romaines }\end{array}$ & $\begin{array}{c}\text { Nom } \\
\text { du bateau }\end{array}$ \\
\hline \multirow[t]{6}{*}{ Apollon } & & & & 3 & Apollo \\
\hline & & & Aliki & & Smin(theus) \\
\hline & 1 ath. & & & & Delphis \\
\hline & 1 ath. & & & & Delphinia \\
\hline & 1 ath. & & & & Dèlias \\
\hline & 1 ath. & & & & Dèlos \\
\hline \multirow{5}{*}{$\begin{array}{l}\text { Déméter } \\
\text { et Koré }\end{array}$} & Timoléon & & & & (?) \\
\hline & 1 ath. & & & & Mystis \\
\hline & & & Protè & & Déméter \\
\hline & & & Aliki & & Déméter (?) \\
\hline & & & & 1 & Cérès \\
\hline \multirow[t]{4}{*}{ Artémis } & & & Aliki & & Artémis \\
\hline & 1 ath. & & & & Artémisia \\
\hline & 2 ath. & & & & Tauropole \\
\hline & 1 ath. & & & & Ortygie \\
\hline \multirow[t]{4}{*}{ Dionysos } & & & Protè & & Dionysos \\
\hline & & & & 1 & Liber Pater \\
\hline & 1 ath. & & & & Bacchè \\
\hline & 1 ath. & & & & Euia \\
\hline \multirow[t]{2}{*}{ Zeus } & & & & 2 & Jupiter \\
\hline & 1 ath. & & & & Dia \\
\hline \multirow[t]{2}{*}{ Zeus (?) } & 2 ath. & & & & Olympias \\
\hline & 3 ath. & & & & Néméas \\
\hline \multirow[t]{2}{*}{ Arès } & 1 ath. & & & & Areia \\
\hline & & & & 3 & Mars \\
\hline Héphaistos & 1 ath. & & & & Hèphaistia \\
\hline \multirow[t]{2}{*}{ Poséidon } & & & Aliki & & Poséidon \\
\hline & & & & 6 & Neptunus \\
\hline $\begin{array}{l}\text { Poséidon (?, } \\
\text { ou Palaimon) }\end{array}$ & & 1 & & & Isthmia \\
\hline
\end{tabular}


ANNEXES

\begin{tabular}{|c|c|c|c|c|c|}
\hline Divinité & $\begin{array}{l}\text { Époque } \\
\text { classique }\end{array}$ & $\begin{array}{c}\text { Époque } \\
\text { hellénistique }\end{array}$ & $\begin{array}{l}\text { Inscriptions } \\
\text { d'euploia }\end{array}$ & $\begin{array}{c}\text { Classes } \\
\text { romaines }\end{array}$ & $\begin{array}{c}\text { Nom } \\
\text { du bateau }\end{array}$ \\
\hline Hermès & & & & 5 & Mercurius \\
\hline \multirow[t]{2}{*}{ Hestia } & & & Protè & & Hestia \\
\hline & & & & 4 & Vesta \\
\hline Héra & & & & 1 & Junon \\
\hline \multirow{2}{*}{$\begin{array}{l}\text { Artémis, } \\
\text { Déméter ou } \\
\text { Aphrodite (?) }\end{array}$} & 3 ath. & Corcyre & & & Phôsphoros \\
\hline & & & & 1 & Lucifer \\
\hline \multirow[t]{5}{*}{ Aphrodite (?) } & 3 ath. & & (Plutarque) & & Euploia \\
\hline & 2 ath. & & (Plutarque) & & Sôzousa \\
\hline & 2 ath. & & & & Sôtèria \\
\hline & 1 ath. & $\begin{array}{l}1 \text { Corcyre; } \\
1 \text { partisans } \\
\text { de César }\end{array}$ & & & Sôteira \\
\hline & & & & 1 & Salvia \\
\hline
\end{tabular}




\section{EX-VOTO DE BATEAUX RÉELS}

\begin{tabular}{|l|l|l|l|l|}
\hline \multicolumn{1}{|c|}{ Dieu } & \multicolumn{1}{|c|}{ Bateau } & \multicolumn{1}{c|}{ Lieu } & \multicolumn{1}{c|}{ Dédicants } & \multicolumn{1}{c|}{ Datation } \\
\hline Poséidon & Argô (?) & $\begin{array}{l}\text { sanctuaire de } \\
\text { l'Isthme }\end{array}$ & Argonautes (?) & $\begin{array}{l}\text { (archaïque?) au } \\
\text { moins hellén. }\end{array}$ \\
\hline Héra & deux bateaux & $\begin{array}{l}\text { Héraion de } \\
\text { Samos }\end{array}$ & & milieu VII ${ }^{\text {s. } \text { a.C. }}$ \\
\hline Poséidon & trière phénicienne & Isthme & Grecs & après Salamine \\
\hline (Ajax) & id. & Salamine & id. & id. \\
\hline $\begin{array}{l}\text { Athéna ou } \\
\text { Poséidon(?) }\end{array}$ & id. & Sounion & id. & id. \\
\hline Poséidon & $\begin{array}{l}\text { bateau } \\
\text { lacédémonien }\end{array}$ & Rhion & Athéniens & $\begin{array}{l}\text { guerre du } \\
\text { Péloponnèse }\end{array}$ \\
\hline Poséidon & bateau athénien & Antirrhion & Lacédémoniens & id. \\
\hline Apollon & l'Isthmia & Délos & Antigone Gonatas & milieu III ${ }^{e}$ s. a.C. \\
\hline Apollon & $\begin{array}{l}10 \text { bateaux } \\
\text { d'Antoine }\end{array}$ & Actium & Octave & fin Irr s. a.C. \\
\hline Poséidon & une barque & & un pêcheur (?) & tardif \\
\hline
\end{tabular}




\section{EX-VOTO DE BATEAUX MODÈLES RÉDUITS}

\begin{tabular}{|c|c|c|c|c|}
\hline Dieu & Type d'objet & Lieu & Dédicant & Datation \\
\hline Héra & 22 en bois & Héraion de Samos & & $\begin{array}{l}\text { milieu et } 2^{\mathrm{e}} \text { moitié } \\
\mathrm{VII}^{\mathrm{e}} \text { s. a.C. }\end{array}$ \\
\hline $\begin{array}{l}\text { Héra et } \\
\text { Poseidon }\end{array}$ & $\begin{array}{l}7 \text { (matériau } \\
\text { indéterminé) }\end{array}$ & id. & $\begin{array}{l}\text { un dénommé } \\
\text { Amphidemos }\end{array}$ & $\mathrm{VI}^{\mathrm{e}}$ s. a.C. \\
\hline Héra (?) & 3 en terre cuite & Ischia & & entre 635 et 620 a.C. \\
\hline Aphaia & 9 en terre cuite & $\begin{array}{l}\text { Égine, sanctuaire } \\
\text { d'Aphaia }\end{array}$ & & $\begin{array}{l}\text { archaïque }\left(\mathrm{VII}^{\mathrm{e}} \mathrm{s} .\right. \\
\text { a.C. ?) }\end{array}$ \\
\hline Apollon & 1 en terre cuite & Corinthe & & début $\mathrm{VI}^{\mathrm{e}}$ s. a.C. \\
\hline Poseidon (?) & $\begin{array}{l}1 \text { terre cuite } \\
+1 \text { sarde en bronze }\end{array}$ & Isthme & & VIe s. a.C. \\
\hline Aphrodite & 1 en terre cuite & Corinthe & & $\begin{array}{l}\text { fin } \mathrm{VI}^{\mathrm{e}} \text {-début } \mathrm{V}^{\mathrm{e}} \mathrm{s} \text {. } \\
\text { a.C. }\end{array}$ \\
\hline Héra & 1 en terre cuite & $\begin{array}{l}\text { Héraion de } \\
\text { Pérachora }\end{array}$ & & archaïque \\
\hline Aphrodite & $\begin{array}{l}\text { au moins } 9 \\
\text { en terre cuite }\end{array}$ & $\begin{array}{l}\text { Amathonte, sanc- } \\
\text { tuaire d'Aphrodite }\end{array}$ & & VI $-V^{\mathrm{e}}$ s. a.C. \\
\hline Aphrodite (?) & 2 en terre cuite & Acropole d'Athènes & & archaïque \\
\hline Héra & $\begin{array}{l}1 \text { bateau sarde } \\
\text { en bronze }\end{array}$ & $\begin{array}{l}\text { Héraion de } \\
\text { Gravisca }\end{array}$ & & $\mathrm{VI}^{\mathrm{e}}-\mathrm{V}^{\mathrm{e}}$ s. a.C. (dépôt) \\
\hline Héra & $\begin{array}{l}1 \text { bateau sarde } \\
\text { en bronze }\end{array}$ & Héraion de Crotone & & $\begin{array}{l}\text { entre fin VII }{ }^{\mathrm{e}} \text {-début } \\
\mathrm{V}^{\mathrm{e}} \text { a.C. }\end{array}$ \\
\hline Apollon & 1 trière en or et ivoire & Delphes & Lysandre & classique \\
\hline Athéna & $\begin{array}{l}1 \text { lampe en bronze } \\
\text { naviforme }\end{array}$ & $\begin{array}{l}\text { Acropole, } \\
\text { Érechthéion }\end{array}$ & & classique (?) \\
\hline Déméter & 1 en terre cuite & \begin{tabular}{|l|} 
Syracuse, \\
sanctuaire \\
de Déméter et Korè
\end{tabular} & & $2^{\mathrm{e}}$ quart du $\mathrm{V}^{\mathrm{e}}$ s. a.C. \\
\hline Déméter & 1 (?) en terre cuite & $\begin{array}{l}\text { Avola (Syracuse), } \\
\text { sanctuaire de } \\
\text { Déméter et Korè }\end{array}$ & & $\begin{array}{l}\text { milieu IVe } \text { s.- } 1^{\text {ères }} \\
\text { décennies } \\
\text { du III }{ }^{e} \text { s. a.C. }\end{array}$ \\
\hline
\end{tabular}




\begin{tabular}{|c|c|c|c|c|}
\hline Dieu & Type d'objet & Lieu & Dédicant & Datation \\
\hline Apollon & 1 en argent & $\begin{array}{l}\text { Délos, temple } \\
\text { d'Apollon }\end{array}$ & Séleucos & hellénistique \\
\hline Apollon & $\begin{array}{l}2 \text { cratères } \\
\text { naviformes }\end{array}$ & $\begin{array}{l}\text { Délos, temple } \\
\text { d'Apollon }\end{array}$ & & hellénistique \\
\hline Apollon & $\begin{array}{l}1 \text { cratère naviforme } \\
\text { rempli de bronze }\end{array}$ & $\begin{array}{l}\text { Délos, temple } \\
\text { d'Apollon }\end{array}$ & & hellénistique \\
\hline Apollon (?) & 1 en plomb & $\begin{array}{l}\text { Délos, temple } \\
\text { d'Apollon }\end{array}$ & & romaine (?) \\
\hline Zeus Kasios & $\begin{array}{l}2 \text { en terre cuite (?), } \\
\text { promesse d'1 en or }\end{array}$ & Bouthrotos & $\begin{array}{l}\text { un dénommé } \\
\text { Barbaros }\end{array}$ & hellénistique \\
\hline Artémis & 6 en terre cuite & $\begin{array}{l}\text { île d'Ikaros } \\
\text { (Failaka), sanc- } \\
\text { tuaire d'Artémis }\end{array}$ & & $\begin{array}{l}2^{\mathrm{e}} \text { moitié du } \mathrm{II}^{\mathrm{e}} \mathrm{s} . \\
\text { a.C. }\end{array}$ \\
\hline (?) & $\begin{array}{l}\text { une 10aine en terre } \\
\text { cuite }\end{array}$ & $\begin{array}{l}\text { île d'Ikaros } \\
\text { (Failaka), sanc- } \\
\text { tuaire gréco- } \\
\text { oriental de la } \\
\text { forteresse }\end{array}$ & & $\mathrm{II}^{\mathrm{e}}$ s. a.C. \\
\hline Zeus & $\begin{array}{l}1 \text { lampe en bronze } \\
\text { naviforme }\end{array}$ & Syrie, Beth-Maré & $\begin{array}{l}\text { un dénommé } \\
\text { Kerdôn fils de } \\
\text { Diodôros }\end{array}$ & $\mathrm{II}^{\mathrm{e}}$ s. p.C. \\
\hline (?) & 1 en terre cuite & port de Sparte & & hellénistique \\
\hline $\begin{array}{l}\text { Divers dieux } \\
\text { (?) / Apollon, } \\
\text { Asclépios et } \\
\text { Hygie }\end{array}$ & $\begin{array}{l}1 \text { base en forme de } \\
\text { proue en pierre }\end{array}$ & Épidaure & $\begin{array}{l}\text { (?) / puis } \\
\text { reconsacré } \\
\text { par } \\
\text { Mummius }\end{array}$ & $\begin{array}{l}\text { vers } 300 \text { a.C. / après } \\
146 \text { a.C. }\end{array}$ \\
\hline Athéna & $\begin{array}{l}1 \text { base en forme de } \\
\text { proue en pierre }\end{array}$ & Lindos & équipage & $\begin{array}{l}\text { vers milieu du III }{ }^{\mathrm{e}} \mathrm{s} \text {. } \\
\text { a.C. }\end{array}$ \\
\hline Zeus Kasios & $\begin{array}{l}\text { un «bateau } \\
\text { de pierres» }\end{array}$ & Kassiopè (Corcyre) & Ulysse (?) & $\begin{array}{l}\text { «ancien» au } \mathrm{VI}^{\mathrm{e}} \mathrm{s} . \\
\text { p.C. }\end{array}$ \\
\hline Artémis & $\begin{array}{l}\text { un «bateau } \\
\text { de pierres» }\end{array}$ & Géraistos (Eubée) & Agamemnon & id. \\
\hline
\end{tabular}




\section{EX-VOTO D'IMAGES DE BATEAUX}

\begin{tabular}{|c|c|c|c|c|}
\hline Dieu & Type & Origine & Dédicant & Datation \\
\hline Artémis & plaque d'ivoire & $\begin{array}{l}\text { Sparte, sanctuaire } \\
\text { d'Artémis Orthia }\end{array}$ & & milieu VII ${ }^{e}$ s. a.C. \\
\hline Artémis & plaque de pierre & $\begin{array}{l}\text { Sparte, sanctuaire } \\
\text { d'Artémis Orthia }\end{array}$ & $\begin{array}{l}\text { un dénommé } \\
\text { Praxinos }\end{array}$ & vers 600 a.C. \\
\hline Artémis & plaque de pierre & $\begin{array}{l}\text { Sparte, sanctuaire } \\
\text { d'Artémis Orthia }\end{array}$ & & archaïque \\
\hline Apollon & métopes & $\begin{array}{l}\text { Delphes, Trésor des } \\
\text { Sicyoniens }\end{array}$ & Sicyoniens & vers 560 a.C. \\
\hline Athéna (?) & relief Lenormant & $\begin{array}{l}\text { Acropole } \\
\text { (Érechthéion?) }\end{array}$ & & IV e s. a.C. (?) \\
\hline Athéna (?) & $\begin{array}{l}\text { relief (fgt du } \\
\text { précédent?) }\end{array}$ & Acropole & & classique \\
\hline Déméter & relief biglyphe & Éleusis & & vers 350 a.C. \\
\hline $\begin{array}{l}\text { Poseidon } \\
\text { (et Amphi- } \\
\text { trite) }\end{array}$ & $\begin{array}{l}\text { une 10aine } \\
\text { de pinakes }\end{array}$ & $\begin{array}{l}\text { Corinthe, } \\
\text { Penteskouphia }\end{array}$ & $\begin{array}{l}\text { marins } \\
\text { marchands } \\
(?)\end{array}$ & géométrique tardif \\
\hline (?) & 2 pinakes & Acropole & & vers 700 a.C. \\
\hline Athéna & 1 pinax & $\begin{array}{l}\text { Sounion, sanctuaire } \\
\text { d'Athéna }\end{array}$ & & vers $720-710$ a.C. \\
\hline Apollon (?) & 1 pinax & Égine & & vers $720-710$ a.C. \\
\hline Héra & $\begin{array}{l}\text { tableau du Pont de } \\
\text { bateaux }\end{array}$ & Samos, Héraion & $\begin{array}{l}\text { architecte } \\
\text { samien } \\
\text { Mandroclès }\end{array}$ & fin $\mathrm{VI}^{\mathrm{e}}$ s. a.C. \\
\hline Athéna & $\begin{array}{l}\text { peinture de Paralos } \\
\text { et Ammonias }\end{array}$ & Acropole, Propylées & & fin $I^{\mathrm{e}}$ s. a.C. \\
\hline $\begin{array}{l}\text { Aphrodite (et } \\
\text { Apollon?) }\end{array}$ & $\begin{array}{l}\text { dessin incisé } \\
\text { de grande taille }\end{array}$ & $\begin{array}{l}\text { Nymphaion (mer } \\
\text { Noire) }\end{array}$ & & $\begin{array}{l}\text { fin } \mathrm{IV}^{\mathrm{e}}-1^{\text {ère }} \text { moitié du } \\
\mathrm{IIII}^{\mathrm{e}} \text { s. a.C. }\end{array}$ \\
\hline Héra & graffiti & Samos & & $\begin{array}{l}\text { dernier tiers } \mathrm{VI}^{\mathrm{e}} \mathrm{s} \text {. } \\
\text { a.C. }\end{array}$ \\
\hline Apollon? & graffiti & $\begin{array}{l}\text { Vouliagmeni, } \\
\text { sanctuaire } \\
\text { d'Apollon Zôstèr }\end{array}$ & & vers 350 a.C. \\
\hline
\end{tabular}




\section{EX-VOTO DE PARTIES DE BATEAUX}

\begin{tabular}{|c|c|c|c|c|}
\hline Dieu & Partie de bateau & Lieu & Dédicant & date \\
\hline Artémis & gouvernail & $\begin{array}{l}\text { Artémision } \\
\text { de Samos }\end{array}$ & Agamemnon & (?) \\
\hline $\begin{array}{l}\text { Athéna et } \\
\text { Poséidon }\end{array}$ & gouvernails & $\begin{array}{l}\text { Athénaion } \\
\text { de Lindos }\end{array}$ & Kanopos & (?) \\
\hline Athéna (?) & stylis (la "première») & Cyzique & $\begin{array}{l}\text { habitants de } \\
\text { Cyzique }\end{array}$ & (?) \\
\hline $\begin{array}{l}\text { Aphaia } \\
\text { («Athéna») }\end{array}$ & proues de navires samiens & Égine & Éginètes & $2^{\mathrm{e}}$ moitié $\mathrm{VI}^{\mathrm{e}}$ s. a.C. \\
\hline Héra & proue sur base de statue & $\begin{array}{l}\text { Héraion de } \\
\text { Samos }\end{array}$ & $\begin{array}{l}\text { un dénommé } \\
\text { Leukaspis }\end{array}$ & $1^{\mathrm{e}}$ moitié $\mathrm{VI}^{\mathrm{e}}$ s. a.C. \\
\hline Zeus & embolos athénien & Mégare & Mégariens & archaïque \\
\hline Apollon & akrôtèrion / mât & Delphes & \begin{tabular}{|l} 
Grecs / \\
Éginètes
\end{tabular} & après 480 a.C. \\
\hline Apollon & hopla et akrôtèria perses & Delphes & Athéniens & après $479-478$ a.C. \\
\hline Apollon & parasèma d'un bateau perse & Phlyées & $\begin{array}{l}\text { Lycomédès, } \\
\text { stratège ath. }\end{array}$ & 480 a.C. \\
\hline Apollon & akrostolia (= emboloi?) & Délos & Athéniens & IV e s. a.C. \\
\hline $\begin{array}{l}\text { Apollon ou } \\
\text { Artémis }\end{array}$ & $\begin{array}{l}\text { akrothinia de batailles } \\
\text { navales }\end{array}$ & Marseille & Massaliotes & $\begin{array}{l}\text { hellénistique, sans } \\
\text { doute avant }\end{array}$ \\
\hline Athéna & akrostolia & $\begin{array}{l}\text { Odysseia } \\
\text { (Ibérie) }\end{array}$ & Ulysse & $i d$. \\
\hline Aphrodite & akrostolia & Thèbes & Harmonie & $i d$. \\
\hline Apollon & rames et gouvernail d'Argô & Sicyone & Argonautes (?) & hellénistique \\
\hline Apollon & embolos & Délos & & hellénistique \\
\hline Apollon & embolos de bronze (= id.?) & Délos & & hellénistique \\
\hline Apollon & 2 proues & Délos & & hellénistique \\
\hline Artémis & pèdalia & Délos & & hellénistique \\
\hline $\begin{array}{l}\text { Poséidon et } \\
\text { Arès }\end{array}$ & emboloi & Actium & Octave & fin $I^{\text {er }}$ s. a.C. \\
\hline Zeus Naios & proue & Dodone & $\begin{array}{l}\text { un dénommé } \\
\text { Périros }\end{array}$ & (?) \\
\hline
\end{tabular}




\section{BIBLIOGRAPHIE}

En ce qui concerne les abréviations utilisées pour les revues, se reporter à

L'année philologique.

Autres abréviations :

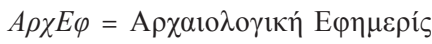

$M M=$ The Mariner's Mirror

Pour alléger les notes, le principe de la bibliographie thématique qui avait été choisi pour la thèse a été abandonné.

Abramson $1979=$ H. Abramson, A hero shrine for Phrontis at Sounion?, dans Californian studies in classical Antiquity, 12, 1979, p. 1-19.

Acquaro \& alii $2010=\mathrm{E}$. Acquaro, A. Filippi et S. Medas, La devozione dei naviganti. Il culto di Afrodite Ericina nel Mediterraneo. Atti del Convegno di Erice (27-28 nov. 2009), Lugano, 2010.

Adamesteanu 1954 = D. Adamesteanu, Uno scarico di fornace ellenistico a Gela, dans ArchClass, 6, 1954, p. 129-132 et pl. XXXIV.

Adamesteanu 1969 = D. Adamesteanu, L'attività archeologica in Basilicata, dans Atti dell'VIII Convegno di studi sulla Magna grecia (Taranto 6-11 ott. 1968), Naples, 1969, p. 168-177 et pl. XII-XIV.

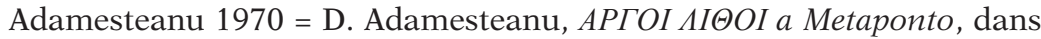
Adriatica, 1970, p. 307-324.

Adamesteanu 1974 = D. Adamesteanu, La Basilicata antica. Storia e monumenti, Cava dei Tirreni, 1974.

Adamesteanu 1976 = D. Adamesteanu, Santuari Metapontini, dans Neue Forschungen in griechischen Heiligtümern (Symposion in Olympia, 10-12 Okt. 1974), Tübingen, 1976, p. 151-166.

Adamesteanu 1999 = D. Adamesteanu (éd.), Storia della Basilicata. I. L'antichità, Bari, 1999.

Adamesteanu \& alii 1980 = D. Adamesteanu, D. Mertens et F. d'Andria, Metaponto I, Rome, 1980 (NSA suppl., 29).

Adiuto Putignani 1965 = P. Adiuto Putignani, [intervention sans titre], dans Taranto 1965, p. 223-227.

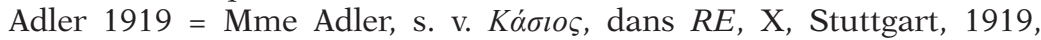
col. 2265-2267.

Adriani 1935-39 = A. Adriani, Sanctuaire de l'époque romaine à Ras el Soda, dans Annuaire du musée gréco-romain, 1935-39, p. 136-148.

Adriani 1940-50 = A. Adriani, Trouvaille à Ras el Soda, dans Annuaire du musée gréco-romain, 1940-50, p. 28-46.

Alaya 1985 = P. G. d'Ayala, Interdictions et périls de la mer en 
Méditerranée. Notes pour une anthropologie maritime, dans Homme médit., 1985, p. 370-378.

Almagro Gorbea 1969 = M. Almagro Gorbea, Hallazgos arqueológicos submarinos en la isla de Ibiza, dans Trabajos de prehistoria, 26, 1969, p. 349355 et pl. I-II.

Alroth 1989 = B. Alroth, Greek gods and figurines. Aspects of the anthropomorphic dedications, Uppsala, 1989.

Altheim \& Stiehl $1965=$ F. Altheim et R. Stiehl, Die Seleukideninschrift aus Failaka, dans Klio, 46, 1965, p. 273-281.

Alvar \& Romero Recio 2005 = J. Alvar et M. Romero Recio, La vie religieuse en mer, dans Hommage à Pierre Lévêque, 2005 (DHA suppl., 1), p. 167-189.

Amandry 1946 = P. Amandry, Le portique des Athéniens à Delphes, dans $B C H, 70,1946$, p. $1-8$.

Amandry 1949 = P. Amandry, Le monument commémoratif de la victoire des Tarentins sur les Peucétiens, dans BCH, 73, 1949, p. 447-463.

Amandry 1953 = P. Amandry, Fouilles de Delphes. II. Colonne des Naxiens et portique des Athéniens, Paris, 1953.

Amandry 1954 = P. Amandry, Notes de topographie et d'architecture delphiques, dans $B C H, 78,1954$, p. 295-315.

Amandry 1984 = P. Amandry, Os et coquilles, dans L'Antre Corycien II, 1984 (BCH suppl., 9), p. 347-380.

Amit 1965 = M. Amit, Athens and the sea. A Study in Athenian seapower, Bruxelles, 1965 (Latomus, 74).

Andreadaki-Blasaki 1997 = M. Andreadaki-Blasaki, The county of Khania through its monuments, Athènes, 1997.

Andria 1990 = F. d'Andria, Archeologia dei Messapi, Bari, 1990.

Anson 1910-16 = L. Anson, Numismata graeca. Greek coin-types classified for immediate identification, Londres, 1910-1916, 6 fasc.

Anti 1920 = C. Anti, Athena marina e alata, dans Monumenti Antichi, 26, 1920, p. 270-318.

Antonetti 1990 = C. Antonetti, Les Étoliens, image et religion, Paris, 1990 (Annales littéraires de l'université de Besançon, 405).

Arata 1985 = F. P. Arata, Recupero di ceppi d'ancora in Etruria meridionale, dans Arch. sub. Eolie, 1985, p. 151-154.

Arata 2005 = F. P. Arata, Opere d'arte dal mare. Testimonianze archeologiche subacquee del trasporto e del commercio marittimo di produtti artistici, Rome, 2005 (Monografie di archeologia subacquea. Studi, ricerche e documenti, univ. della Tuscia-Viterbo).

Arch. sub. 1982 = Archeologia subacquea [I], Rome, 1982 (BA suppl., 4).

Arch. sub. Eolie 1985 = Archeologia subacquea. II. Isole Eolie, Rome, 1985 (BA suppl., 29).

Arch. sub. Studi 1997 = Archeologia subacquea. Studi, ricerche e documenti II, Rome, 1997.

Arnaud 2005 = P. Arnaud, Les routes de la navigation antique. Itinéraires en Méditerranée, Paris, 2005.

Ashburner 1909 = W. Ashburner, The Rhodian sea-law, Oxford, 1909.

Atti Barcellona 1971 = Atti del III Congresso internazionale di archeologia sottomarina (Barcellona, 1961), Bordighera, 1971. 
Auffray \& Guillerm 1993 = D. Auffray et A. Guillerm, Une explication aux hyper-galères hellénistiques, dans Marine antique. Dossiers de l'archéologie, 183, juin 1993, p. 74-75.

Augeron \& alii $2004=$ M. Augeron, A. Fenet et M. Tranchant, Peurs bleues. Prendre la mer à la Renaissance, Rochefort, 2004 (Cahiers de la Corderie, 1).

Bacci \& Lentini 1994 = G. M. Bacci et M. C. Lentini, Dioniso e il mare. Catalogo della mostra (Museo archeologico di Giardini Naxos, 26 ott.-25 nov. 1991), dans Rassegna arch. sub., 1994, p. 163-181.

Bader 1986a = F. Bader, An Indo-European myth of immersionemergence, dans Indo-European studies, 14, 1986, p. 39-123.

Bader $1986 \mathrm{~b}=\mathrm{F}$. Bader, Autour de Thétis la Néréide, dans F. Jouan (éd.), Mort et fécondité dans les mythologies. Actes du Colloque de Poitiers 13-14 mai 1983, Paris 1986, p. 19-37.

Baladié 1980 = R. Baladié, Le Péloponnèse de Strabon. Étude de géographie historique, Paris, 1980.

Barbantani 2005 = S. Barbantani, Goddess of love and mistress of the sea. Notes on a hellenistic hymn to Arsinoe-Aphrodite (P. Lit. Goodsp. 2, I-IV), dans AncSoc, 35, 2005, p. 135-165.

Barbéra 1959 = J. Barbéra, El CRIS y la arqueologia, dans CRIS. Revista del mar, 1, fév. 1959, p. 19.

Barra Bagnasco 1977 = M. Barra Bagnasco, Lo scavo, dans Locri Epizefiri I. Ricerche nella zona di Centocamere, Florence, 1977, p. 3-49.

Barresi $2010=$ P. Barresi, Il culto di Venere ad Erice in età romana : le testimonianze archeologiche, dans Acquaro \& alii 2010, p. 161-171.

Bartolomeo 1986 = E. di Bartolomeo, Lazio. Gaeta, dans Archeologia subacquea III, Rome, 1986 (BA suppl., 37-38), p. 210 et pl. XII.

Basch 1969 = L. Basch, Trois modèles de navires en marbre au musée de Sparte, dans AC, 38, 1969, p. 431-446 et pl. I-V.

Basch 1978 = L. Basch, Éléments d'architecture navale dans les lettres grecques, dans $A C, 47,1978$, p. 24-25.

Basch 1981 = L. Basch, Ex-voto marins dans l'Antiquité, dans Ex-voto marins dans le monde de l'Antiquité à nos jours (Catalogue de l'expo. au musée de la Marine, Paris), Paris, 1981, p. 37-43 et cat. p. 44-57.

Basch 1985 = L. Basch, The Isis of Ptolemy II. Philadelphus, et The "Isis» and the Dioscuri: a postscript, dans MM, 71, 1985, p. 129-152 et p. 356.

Basch 1987 = L. Basch, Le musée imaginaire de la marine antique, Athènes, 1987.

Basch 1989 = L. Basch, Les graffiti de Délos, dans Tzalas 1989, p. 17-23.

Basch 1990 = L. Basch, Relief Lenormant ou relief Pervanoglu? En tous cas, un relief non daté, dans Tzalas 1990, p. 31-34.

Basch 1993 = L. Basch, Samothrace, un navire sacré consacré aux dieux, dans Marine antique. Dossiers de l'archéologie, 183, juin 1993, p. 24-31.

Basch 1995 = L. Basch, Le "navire invaincu à neuf rangées de rameurs" de Pausanias $(I, 29,1)$ et le "Monument des Taureaux», à Délos, dans Tzalas 1995, p. 43-72.

Basile 1991 = B. Basile, Modellini fittili di imbarcazioni della Sicilia occidentale, dans Rassegna arch. sub. 1991, p. 11-50. 
Baslez 1977 = M.-F. Baslez, Recherches sur les conditions de pénétration et de diffusion des religions orientales à Délos (II ${ }^{e}-I^{e r}$ s. avant notre ère), Paris, 1977.

Baslez 1986 = M.-F. Baslez, Cultes et dévotion des Phéniciens en Grèce : les divinités marines, dans Religio phoenicia, Namur, 1986 (Studia phoenicia, 4), p. 288-305.

Baslez 1999 = M.-F. Baslez, Le culte de la Déesse Syrienne dans le monde hellénistique. Traditions et interprétations, dans Bonnet \& Motte 1999, p. 229-248.

Bass 1972 = G. F. Bass (dir.), Archéologie sous-marine. 4000 d'histoire maritime, Paris, 1972.

Bass 1977 = G. F. Bass (éd.), A history of seafaring based on underwater archaeology, Londres, 1977.

Beazley 1931 = J. D. Beazley, Der Pan-Maler, Berlin, 1931.

Becatti 1971 = G. Becatti, Ninfe e divinità marine, ricerche mitologiche iconografiche e stilistiche, Rome, 1971 (Studi miscellanei, 17).

Becq de Fouquières 1869 = L. Becq de Fouquières, Les jeux des Anciens, Paris, 1869.

Beltrame 2002 = C. Beltrame, Vita di bordo in età romana, Rome, 2002.

Beltrán 1952 = A. Beltrán, Sobre las excavaciones submarinas, dans Publicaciones del Seminario de arqueología y numismatica aragonesas, 3, 1952, p. 18-24.

Benoît 1950 = F. Benoît, Informations archéologiques. XII circonscription, dans Gallia, 8, 1950, p. 116-132.

Benoît 1951 = F. Benoît, Jas d'ancre à tête de Méduse, dans RA, 37, 1951, 1, p. 223-228.

Benoît 1952 = F. Benoît, L'archéologie sous-marine en Provence. Jas d'ancre et organeaux de plomb, dans RStudLig, 18, 1952, p. 266-275.

Benoît 1953 = F. Benoît, Informations archéologiques. XII circonscription (Bouches-du-Rhône), dans Gallia, 11, 1953, p. 100-119.

Benoît 1955 = F. Benoît, Jas d'ancre et pièces d'outillage des épaves de Provence, dans RStudLig, 21, 1955, p. 117-128.

Benoît 1959 = F. Benoît, Têtes coupées de l'époque grecque au Moyen Âge, dans Cahiers ligures de préhistoire et d'archéologie, 8, 1959, p. 143-164.

Benoît 1960a = F. Benoît, Nouvelles épaves de Provence II, dans Gallia, 18, 1960, p. 41-56.

Benoît 1960b = F. Benoît, Ambiance et survivances méditerranéennes. Quelques nouveaux exemples de transmission de prototype: d'Orient en Occident, dans Ogam, 12, 1960, p. 176-184 et pl. XXI-XXV.

Benoît 1961 = F. Benoît, L'épave du Grand Congloué à Marseille, Paris, 1961 (Gallia suppl., 14).

Benoît 1971 = F. Benoît, Pièces de gréement et d'armement en plomb, engins et pièces décoratives trouvées en mer, dans Actes du III Congrès international d'archéologie sous-marine (Barcelone 1961), Bordighera 1971, p. 394-411.

Bent 1887 = J. T. Bent, Inscriptions from Thasos, dans JHS, 8, 1887, p. $409-438$.

Bentz 1998 = M. Bentz, Panathenäische Preisamphoren. Eine athenische 
Vasengattung und ihre Funktion vom 6.-4. Jahrundert v. Chr., Bâle, 1998, (AK suppl., 18).

Bérard 1894 = V. Bérard, De l'origine des cultes arcadiens, Paris, 1894.

Bérard 1927-29 = V. Bérard, Les navigations d'Ulysse, Paris, 1927-1929, 4 vol.

Bérard 1957 = J. Bérard, La colonisation grecque de l'Italie méridionale et de la Sicile dans l'Antiquité. L'histoire et la légende, Paris, $1957^{2}$.

Bérard 1985 = C. Bérard, Modes de formation et modes de lecture des

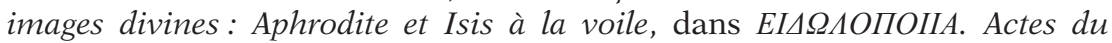
Colloque sur les problèmes de l'image dans le monde méditerranéen classique (Lourmain en Provence, 2-3 sept. 1982), Rome, 1985, p. 163-171 et pl. h.-texte.

Berges Soriano 1969-70 = M. Berges Soriano, Los hallazgos arqueológicos submarinos ingresados en el museo arqueológico de Tarragona, dans Boletín arqueológico, 69-70, 1969-1970, p. 3-17.

Bernand 1970 = A. Bernand, Le delta égyptien d'après les textes grecs. I. Les confins lybiques, Le Caire, 1970, 3 vol.

Bernand 1996 = A. Bernand, Les veilleurs du phare, dans ZPE, 113, 1996, p. 85-90.

Bernard \& Salviat $1962=$ P. Bernard et F. Salviat, Inscriptions de Thasos, dans $B C H, 86,1962$, p. 578-611.

Bernard \& Salviat $1967=$ P. Bernard et F. Salviat, Inscriptions de Thasos, $B C H$, 91, 1967, p. 578-621.

Berranger 1992 = D. Berranger, Recherches sur l'histoire et la prosopographie de Paros à l'époque archaïque, Clermont-Ferrand, 1992.

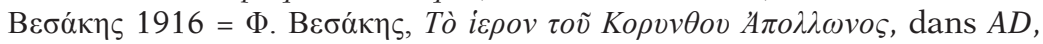
2, 1916, p. 65-118 et pl. A.

Berti 1990 = F. Berti (éd.), Fortuna maris. La nave romana di Comacchio, Bologna, 1990.

Berti 1992 = F. Berti, La nave di Valle Ponti (Comacchio), dans Atti della $V$ Rassegna di archeologia subacquea (Giardini Naxos, 19-21 ottobre 1990), Messine, 1992, p. 219-226.

Beschaouch 1985 = A. Beschaouch, Poséidon en "Barbarie», dans Homme médit. 1985, p. 419-424.

Beschi 1978 = L. Beschi, Gli astragalizontes di un Policleto, dans Prospettiva, 15, 1978, 3, p. 4-12.

Beschi 1990 = L. Beschi, s. v. Demeter, dans LIMC, IV, Berne, 1990, 1 p. 844-892 et 2 p. $563-599$.

Bianchi 1957 = U. Bianchi, La dea di Lindos, dans Epigraphica, 19, 1957, p. 10-24.

Blackmann 1973 = D. J. Blackman (éd.), Marine Archaeology. Proceedings of the twentythird Symposium of the Colston Research Society held in the University of Bristol (April $4^{\text {th }}$ to $8^{\text {th }}$, 1971), Londres, 1973.

Blackmann $1982=$ D. J. Blackmann, Ancient harbours in the Mediterranean. Part 1, et Id. Part 2, dans IJNA, 11, 1982, p. 79-104 et 185-211.

Blatter $1984=$ R. Blatter, s. v. Argonautai et s. v. Argos III, dans LIMC, II, Berne, 1984, respectivement 1, p. 593 n² et 2, p. 430 ; ibid., 1, p. 600-602 et 2, p. 433-444.

Blázquez Martinez 1962 = J. M. Blázquez Martinez, Religiones primitivas de Hispania, I, Madrid, 1962 (Bibl. de la Escuela española de hist. y arqu. en Roma, 14). 
Blinkenberg 1912 = C. Blinkenberg, La Chronique du temple lindien, Copenhague, 1912.

Blinkenberg 1938 = C. Blinkenberg, Triemiolia. Études sur un navire rhodien, Copenhague, 1938 (Lindiaka, 7; Det Kgl. Danske Videnskabernes Selskab, 2, 3).

Blinkenberg 1941 = C. Blinkenberg, Lindos, fouilles de l'Acropole 19021914. II. Inscriptions, Berlin-Copenhague, 1941.

Bloch 1984 = R. Bloch, Du Poséidon, ébranleur du sol, au Poséidon maître de la mer, dans M. G. Marzi Costagli et L. Tamagno Perna (éd.), Studi di Antichità in onore di Guiglielmo Maetzke, Rome, 1984 (Archeologica, 49), p. 115-117.

Bloch 1985a = R. Bloch, Les dieux de la mer dans l'Antiquité classique, dans Homme médit., 1985, p. 437-442.

Bloch $1985 \mathrm{~b}=\mathrm{R}$. Bloch, Quelques remarques sur Poséidon, Neptune et Nethuns, dans D'Héraclès à Poséidon, mythologie et protohistoire, Genève, 1985 (Centre de recherches d'histoire et de philologie de la IVe section de l'EPHE), p. 125-139.

Blue \& alii 2006 = L. Blue, F. Hocker et A. Englert (éd.), Connected by the sea. Proceedings of the tenth International symposium on boat and ship archaeology (Roskilde 2003), Oxford, 2006.

Boardman 1954 = J. Boardman, Painted votive plaques and an early inscription from Aegina, dans ABSA, 49, 1954, p. 183-201 et pl. hors-texte.

Boardman 1958 = J. Boardman, A Greek vase from Egypt, dans JHS, 1958, p. $4-12$ et pl. I. 1970.

Boardman $1970=\mathrm{J}$. Boardman, Greek gems and finger rings, Londres,

Boardman 1980 = J. Boardman, The Greek overseas. Their early colonies and trade, Londres, $1980^{2}$.

Boardman 1989 = J. Boardman, Herakles at sea, dans Beiträge zur Ikonographie und Hermeneutik. Festschrift für N. Himmelmann, Mayence, 1989, p. 191-195 et pl. XXXIII.

Boardman \& alii $1990=$ J. Boardman, A. F. Laurens et S. Woodford, Herakles with Olympian gods, dans LIMC, V, Berne, 1990, 1, p. 132-172 et 2 p. 124-156.

Böckh 1840 = A. Böckh, Urkunden über das Seewesen des attischen Staates, Berlin, 1840.

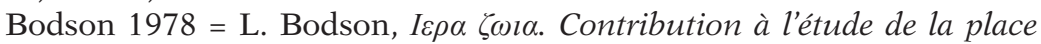
de l'animal dans la religion grecque, Bruxelles, 1978.

Boetto 1997 = G. Boetto, Ceppi litici sacri e culti aniconici a Metaponto e a Locri, dans Arch. sub. Studi 1997, p. 51-64.

Bömer 1963 = F. Bömer, Gedanken über die Gestalt des Apollon und die Geschichte der griechischen Frömmigkeit, dans Athenaeum, 41, 1963, p. 275-303.

Bon \& Bon 1957 = A.-M. et A. Bon, Les timbres amphoriques de Thasos, Athènes, 1957 (Études thasiennes, 4).

Bon \& Seyrig 1929 = A. Bon et H. Seyrig, Le sanctuaire de Poséidon à Thasos, dans $B C H, 53,1929$, p. 317-350 et pl. XVI-XXI.

Bonnechère 1994 = P. Bonnechère, Le sacrifice humain en Grèce ancienne, Athènes-Liège, 1994 (Kernos suppl., 3). 
Bonnet 1986 = C. Bonnet, Le culte de Leucothéa et de Mélicerte en Grèce, au Proche-Orient et en Italie, dans SMSR, 10, 1986, p. 53-71.

Bonnet 1988 = C. Bonnet, Melqart. Cultes et mythes de l'Héraclès tyrien en Méditerranée, Namur, 1988 (Studia phoenicia, 8).

Bonnet 1996 = C. Bonnet, Astarté. Dossier documentaire et perspectives historiques, Rome, 1996 (Contributi alla storia della religione fenicio-punica, 2).

Bonnet \& Motte $1999=$ C. Bonnet et A. Motte (éd.), Les syncrétismes religieux dans le monde méditerranéen antique. Actes du Colloque international en l'honneur de Frantz Cumont, à l'occasion du 50 anniversaire de sa mort (Rome, Academia Belgica, 25-27 septembre 1997), Bruxelles-Rome, 1999.

Bonnet \& Pirenne-Delforge 1999 = C. Bonnet et V. Pirenne-Delforge, Deux déesses en interaction: Astarté et Aphrodite dans le monde égéen, dans Bonnet \& Motte 1999, p. 249-274.

Boon 1977a = G. C. Boon, A Greco-Roman anchor-stock from north Wales, dans AntJ, 57, 1977, p. 10-30.

Boon 1977b = G. C. Boon, The Porth Felen anchor-stock, dans IJNA, 6, 1977, p. 239-242.

Bordenache 1967 = G. Bordenache, Nuovi documenti sui culti di Istros in epoca elenistica, dans StudClas, 9, 1967, p. 143-147.

Borgeaud 1979 = P. Borgeaud, Recherches sur le dieu Pan, Genève, 1979 (Bibliotheca helvetica romana, 17).

Borzsák 1951 = I. Borzsák, Aquis submersus, dans Acta antiqua Academiae scientiarum hungaricae, 1, 1951, p. 200-224.

Bottini \& Fresci 1993 = P. Bottini et A. Fresci (éd.), Sulla rotta della Venus. Storie di navi, commerci e ancore perdute, Tarente, 1993.

Bottini \& Freschi 1994 = P. Bottini et A. Freschi, Una rotta commerciale antica nel basso tirreno attraverso le ricerche subacquee di Maratea, dans Rassegna arch. sub., 1994, p. 31-34.

Bouché-Leclercq 1882 = A. Bouché-Leclercq, Histoire de la divination dans l'Antiquité, Paris, 1882.

Bouché-Leclercq 1913 = A. Bouché-Leclercq, Histoire des Séleucides, Paris, 1913.

Bougot 1881 = A. Bougot, Philostrate l'Ancien, une galerie antique de 64 tableaux, Paris, 1881.

Bourboulis 1949 = P. P. Bourboulis, Apollon Delphinios, Thessalonique,

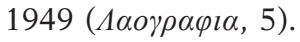

Bravo 1964 = J. Bravo, Un cepo de ancla decorado en aguas de Ceuta, dans RStudLig (Forma maris Antiqui), 30, 1964, p. 309-311.

Bravo 1970 = J. Bravo Perez, Anclas romanas de Ceuta, dans XI Congreso nacional de arqueología (Merida 1968), Saragosse, 1970, p. 821-826.

Bravo \& Muñoz 1966-68 = J. Bravo et R. Muñoz, Hallazgos arqueológicos submarinos en Ceuta, dans Noticiario arqueológico hispanico, 10-12, 1966-1968, p. 159-171.

Bravo Perez 1966 = J. Bravo Perez, Cepos de anclas romanos con relieves, dans CRIS. Revista del mar, mars 1966, p. 2-4.

Breglia 2009 = L. Breglia, I culti di Cuma opicia, dans Cuma. Atti del XLVIII Convegno di studi sulla Magna Grecia (Taranto 27 sett.-1 ott. 2008), Tarente, 2009, p. 231-270. 
Brelich 1960 = A. Brelich, Der Polytheismus, dans Numen, 7, 1960, p. 123-136.

Bricault 2006 = L. Bricault, Isis, Dame des flots, Liège, 2006 (Aegyptiaca Leodiensia, 7).

Briquel 1985 = D. Briquel, Vieux de la mer grecs et Descendant des eaux indo-européen, dans D'Héraclès à Poséidon, mythologie et protohistoire, Genève, 1985 (Centre de recherches d'histoire et de philologie de la IVe section de l'EPHE), p. 141-158.

Brize 1997 = P. Brize, Offrandes de l'époque géométrique et archä̈que à l'Héraion de Samos, dans Colloque Héra 1997, p. 123-137.

Brody 1998 = A. J. Brody, "Each man cried out to his god». The specialized religion of Canaanite and Phoenician seafarers, Atlanta, 1998 (Harvard Semitic Museum monographs, 58).

Brody 2005 = A. J. Brody, Further evidences of the specialized religion of Phoenician seafarers, dans J. Pollini (éd.), Terra marique. Studies in art history and marine archaeology in honor of A. M. McCann, Oxford, 2005, p. 177-182.

Broneer 1935 = O. Broneer, Excavations on the north slope of the Acropolis, dans Hesperia, 4, 1935, p. 109-188.

Broneer $1958=$ O. Broneer, The Corinthian isthmus and the Isthmian sanctuary, dans Antiquity, 32, 1958, p. 80-88.

Broneer 1959 = O. Broneer, Excavations at Isthmia, fourth campain 1957-1958, dans Hesperia, 28, 1959, p. 298-343 et pl. LIX-LXXIII.

Broneer 1971-73 = O. Broneer (dir.), Isthmia, temple of Poseidon, New Jersey, 1971 et Isthmia, topography and architecture, New Jersey, 1973.

Broneer $1976=$ O. Broneer, The Isthmian sanctuary of Poseidon, dans Neue Forschungen in griechischen Heiligtümern (Internationales Symposion in Olympia, 10-12 Okt. 1974), Tübingen, 1976, p. 39-62.

Brugman 1893 = K. Brugmann, Eine archaische Weihinschrift aus Kerkyra, dans Indogermanische Forschungen, 3, 1893, p. 87-90 et pl. I.

Brulé 1987 = P. Brulé, La fille d'Athènes, Paris, 1987.

Brulé $1993=\mathrm{P}$. Brulé, Artémis Amarysia. Des ports préférés d'Artémis: l'Euripe (Callimaque, Hymne à Artémis v. 188), dans Kernos, 6, 1993, p. 57-65.

Bruneau 1961-78 = P. Bruneau, Isis Pelagia à Délos; Isis Pelagia à Délos (compléments); Existe-t-il des statues d'Isis Pélagia?; Deliaca II : $n^{\circ} 25$ (Isis

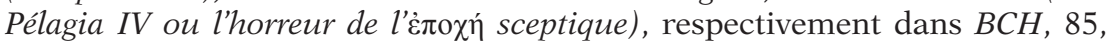
1961, p. 435-446; ibid., 87, 1963, p. 301-308; ibid., 98, 1974, p. 334-381; ibid., 102, 1978, p. 152-161.

Bruneau 1970 = P. Bruneau, Recherches sur les cultes de Délos à l'époque hellénistique et à l'époque impériale, Paris, 1970 (BEFAR, 217).

Bruneau 1970b = P. Bruneau, Tombes d'Argos, dans BCH, 94, 1970, p. 437-531.

Bruneau 1979 = P. Bruneau, Deliaca III. Les jardins urbains de Délos, dans $B C H, 103,1979$, p. 89-99.

Bruneau \& Ducat 2005 = P. Bruneau et J. Ducat, Guide de Délos, Athènes, $2005^{4}$ (éd. refondue et mise à jour avec le concours de M. Brunet, A. Farnoux et J.-C. Moretti).

Bulard 1926 = M. Bulard, La religion domestique dans la colonie italienne de Délos, Paris, 1926 (BEFAR, 131). 
Burkert $2011=\mathrm{W}$. Burkert, La religion grecque à l'époque archaïque et classique, éd. fr. Paris, 2011.

Burzachechi 1962 = M. Burzachechi, Oggetti parlanti nelle epigrafi greche, dans Epigraphica XXIV, 1962, p. 3-54.

Burzachechi 1971 = M. Burzachechi, Gli studi di epigrafia greca relativi alla Magna Grecia dal 1952 al 1967, dans Acta of the V International congress of Greek and Latin epigraphy (Cambridge, 1967), Oxford, 1971, p. $125-134$.

Burzachechi 1979 = M. Burzachechi, Cippi iscritti dall'area sacra di Metaponto, dans PP, 34, 1979, p. 279-295.

Cabanes 1988 = P. Cabanes, Le culte de Pan à Bouthrotos, dans REA, 90, 1988 , p. $385-388$.

Cabanes 1995 = P. Cabanes, Le monde hellénistique de la mort d'Alexandre à la paix d'Apamée, Paris, 1995.

Cabanes $1997=\mathrm{P}$. Cabanes, Corpus des inscriptions grecques d'Illyrie méridionale et d'Épire. I, 2. Inscriptions grecques d'Épidamne-Dyrrhachion et d'Apollonia, Athènes, 1997 (Études épigraphiques, 2).

Cabanes \& Drini 2007 = P. Cabanes et F. Drini, Corpus des inscriptions grecques d'Illyrie méridionale et d'Épire. II, 2. Inscriptions grecques de Bouthrôtos, Athènes, 2007.

Cabantous 1990 = A. Cabantous, Le ciel dans la mer. Christianisme et civilisation maritime XVI-XIX ${ }^{e}$ s., Paris, 1990.

Cadoux 1938 = C. J. Cadoux, Ancient Smyrna. A history of the city from the earliest times to 324 a.D., Oxford, 1938.

Calame 1990 = C. Calame, Thésée et l'imaginaire athénien, Lausanne, 1990, p. 319-322.

Calgano 2006 = C. Calgano, Aeneas' sail: the iconography of seafaring in the central Mediterranean region, dans Blue \& alii 2006, p. 226-233.

Canciani 1984 = F. Canciani, s. v. Athena /Minerva, dans LIMC, II, Berne, 1984, 1, p. 1074-1109 et 2, p. 769-815.

Carlson 2009 = D. N. Carlson, Ships' eyes in classical Greece, dans Hesperia, 78, 2009, p. 347-365.

Caro \& Greco 1993 = S. de Caro et A. Greco, Campania, Bari, 1993.

Carrazé 1973 = F. Carrazé, L'ancre de miséricorde dans la marine antique, dans Archéologia. Trésors des âges, 61, 1973, p. 13-19.

Carrazé $1974=$ F. Carrazé, Note on two decorated lead anchor stocks, dans IJNA, 3, 1974, p. 153-157.

Cartault 1881 = A. Cartault, La trière athénienne, Paris, 1881; rééd., Paris, 2000.

Carter 1977 = J. M. Carter, A new fragment of Octavian's inscription at Nicopolis, dans ZPE, 24, 1977, p. 227-230.

Casson 1971 = L. Casson, Ships and seamanship in the ancient world, Princeton, 1971.

Casson 1989 = L. Casson, The Periplus maris Erythraei. Text with introduction, translation and commentary, Princeton, 1989.

Casson 1991 = L. Casson, The ancient mariners. Seafarers and sea fighters of the Mediterranean in ancient times, Princeton, $1991^{2}$.

Casson $1994=\mathrm{L}$. Casson, Ships and seafaring in ancient times, Londres, 1994. 
Casson \& Steffy 1991 = L. Casson et J. R. Steffy, The Athlit Ram, Texas, 1991.

Castellan 1808 = A. L. Castellan, Lettres sur la Morée, Paris, 1808.

Cavalier 1985a = M. Cavalier, Relitto della secca del Bagno, dans Arch. sub. Eolie 1985, p. 65.

Cavalier 1985b = M. Cavalier, Il relitto A (Roghi) del capo Graziano di Filicudi, dans Arch. sub. Eolie 1985, p. 100-127.

Cavalier 1990 = O. Cavalier, Funérailles d'une navigation tragique. À propos d'une stèle funéraire grecque du Musée Calvet, dans CGITA, 6, 1990, p. 129-141.

Cavalier 1997 = O. Cavalier, Silence et fureur, Avignon, 1997.

Cavvadias 1891 = P. Cavvadias, Fouilles d'Épidaure, Athènes, 1891.

Cazanove 1993 = O. de Cazanove, Suspension d'ex-voto dans les bois sacrés, dans Les bois sacrés. Actes du Colloque international organisé par le centre J. Bérard et l'EPHE (Ve section), Naples, 23-25 nov. 1989, Naples, 1993, p. 111-126.

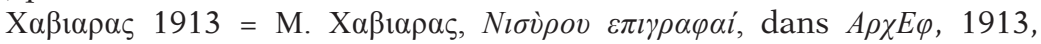
p. 6-16.

Chamoux 1975 = F. Chamoux, L'épigramme de Poseidippos sur le phare d'Alexandrie, dans J. Bingen, G. Cambier et G. Nachtergael (éd.), Le monde grec: pensée, littérature, histoire, documents. Hommages à Claire Préaux, Bruxelles, 1975, p. 215-222 et pl. III 1.

Chankowski 2008 = V. Chankowski, Athènes et Délos à l'époque classique. Recherches sur l'administration du sanctuaire d'Apollon Délien, Athènes, 2008 (BEFAR, 331).

Chapouthier 1935a = F. Chapouthier, Les Dioscures au service d'une déesse, Paris, 1935.

Chapouthier $1935 \mathrm{~b}=\mathrm{F}$. Chapouthier, Inscriptions antiques gravées sur le roc dans le golfe de Mirabello, dans $B C H, 59,1935$, p. 376-381 et pl. XXV.

Chavane 1975 = M.-J. Chavane, Salamine de Chypre. VI. Les petits objets, Paris, 1975.

Chevallier $1968=\mathrm{R}$. Chevallier, Navigation et ports antiques, esquisses d'une problématique, dans Atti del Convegno internazionale di studi sulle antichita di classe (Ravenna 1967), Ravenne, 1968, p. 219-247.

Chirassi 1964 = I. Chirassi, Miti e culti arcaici di Artemis nel Peloponneso e Grecia centrale, Trieste, 1964 (Università degli studi di Trieste. Istituto di storia antica, 3).

Christopoulos $1995=\mathrm{M}$. Christopoulos, Le mât du navire: réalité et imaginaire en Grèce ancienne, dans Tzalas 1995, p. 123-134.

Chronique 1924 = Chronique des fouilles. Égine, dans BCH, 48, 1924, p. $460-462$.

Chronique Kinaion 1924-26 = Chronique des fouilles. Eubée. Cap Kinaion, dans $B C H, 48,1924$, p. 480 et 50, 1926, p. 554-555

Chuvin $1981=$ P. Chuvin, Apollon au trident et les dieux de Tarse, dans JS, 1981, p. 305-326.

Chuvin 1992 = P. Chuvin, La mythologie grecque. Du premier homme à l'apothéose d'Héraclès, Paris, 1992.

Chuvin \& Yoyotte $1986=$ P. Chuvin et J. Yoyotte, Documents relatifs au culte pélusien de Zeus Casios, dans RA, 1986, 1, p. 41-63. 
Ciabatti 1984 = Ciabatti, L'archeologo subacqueo. Manuale di ricerca e di scavo, Pise, 1984 (Il Tagliamare, 41).

Clédat 1914 = J. Clédat, Le temple de Zeus Cassios à Péluse, dans Annales du Service des antiquités de l'Égypte. Kairo, 13, 1914.

Coarelli \& Torelli 1997 = F. Coarelli et M. Torelli, Sicilia, Bari, $1997^{4}$.

Cohen 1978 = G. M. Cohen, The Seleucid colonies. Studies in founding, administration and organization, Wiesbaden, 1978 (Historia Einzelschriften, 30).

Cole 1999-2000 = S. G. Cole, Landscapes of Artemis, dans CW, 93, 19992000, p. 471-481.

Colivicchi 2004 = F. Colivicchi (avec des contributions de G. Gorini et C. Sorrentino), Gravisca: scavi nel santuario greco. XVI. I materiali minori, Bari, 2004. [1883].

Collignon 1883 = M. Collignon, Mythologie figurée de la Grèce, Paris,

Collignon $1886=$ M. Collignon, Torses archä̈ques en marbre provenant d'Actium, dans Gazette archéologique, 11, 1886, p. 235-243 et fig. XXIX.

Collignon $1897=\mathrm{M}$. Collignon, Tablettes votives de terre cuite peinte trouvées à Corinthe (Musée du Louvre), dans Monuments grecs, II, Paris, 1897, p. 23-32.

Colloque Héra 1997 = Héra. Images, espaces, cultes. Actes du Colloque international (Lille, 29-30 nov. 1993), Naples, 1997.

Coldstream \& Huxley 1972 = J. N. Coldstream et G. L. Huxley, Kythera. Excavations and studies conducted by the Univ. of Pennsylvania Museum and the British School at Athens, Londres, 1972.

Conze 1891 = A. Conze, Hermes-Kadmilos, dans $\operatorname{MDAI}(A), 16,1891$, p. 191-193.

Cook 1914-40 = A. B. Cook, Zeus, Cambridge, 1914-1940, 3 t. en 5 vol.

Cook 1957 = J. M. Cook, The Carian coast III, dans BSA, 52, 1957, p. $85-87$.

Corbin 1988 = Corbin, Le territoire du vide. L'Occident et le désir du rivage 1750-1840, Paris, 1988.

Corbin \& Richard 2004 = A. Corbin et H. Richard (dir.), La mer. Terreur et fascination, BNF, 2004.

Corsi-Sciallano \& Liou $1985=$ M. Corsi-Sciallano et B. Liou, Les épaves de Tarraconaise à chargement d'amphores Dressel 2-4, 1985 (Archaeonautica, 5).

Corte 1946 = M. della Corte, Pompei. Scoperte epigrafiche (Reg. I, ins. VII-VIII e varie), dans NSA, 7, 1946, p. 84-129.

Costa \& Fernández 2000 = B. Costa et J. H. Fernández (éd.), Sanctuarios fenicio-púnicos en Iberia y su influencia en los cultos indígenas. XIV Jornadas de arqueología fenicio-púnica (Eivissa, 1999), Ibiza, 2000.

Couchoud \& Svoronos 1921, Le monument dit "des taureaux» à Délos et le culte du navire sacré, dans BCH, 45, 1921, p. 270-294.

Couilloud-Le Dinahet $1978=\mathrm{T}$. Couilloud-Le Dinahet, Recherches à Rhénée, dans $B C H, 102,1978$, p. 874-877.

Counillon 2004 = P. Counillon, Pseudo-Skylax, le Périple du Pont Euxin. Texte, traduction, commentaire philologique et historique, Bordeaux, 2004 (Scripta antiqua, 8).

Coupry 1973 = J. Coupry, Autour d'une trière, dans Études déliennes, Athènes, 1973 (BCH suppl., 1), p. 147-156. 
Crusius 1889 = O. Crusius, Der homerische Dionysoshymnus und die Legende von der Verwandlung der Tyrsener, dans Philologus XLVIII, 1889, p. 193-228.

Cuisenier 2003 = J. Cuisenier, Le périple d'Ulysse, Paris, 2003.

Cummer 1978 = W. Cummer, The sanctuary of Poseidon at Tainaron, Lakonia, dans MDAI(A), 93, 1978, p. 35-43.

Cumont 1927 = F. Cumont, Les Syriens en Espagne et les Adonies à Séville, dans Syria, 8, 1927, p. 330-341.

Cumont 1929 = F. Cumont, Les religions orientales dans le paganisme romain, Paris, 1929.

D'Agostino \& Buchner 1994-95 = B. D'Agostino et G. Buchner, La «stipe dei cavalli» di Pitecusa, dans Atti e memorie della società Magna Grecia, 3, 1994-1995, p. 9-91 et pl. I-XLI.

Dallegio d'Alessio 1946 = E. Dallegio d'Alessio, Galata et ses environs dans l'Antiquité, dans Revue des études byzantines, 4, 1946, p. 218-238.

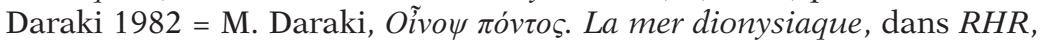
199, 1982, p. 3-22.

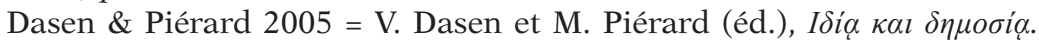
Les cadres "privés» et "publics» de la religion grecque antique. Actes du IX Colloque du CIERGA (Fribourg, 8-10 sept. 2003), Liège, 2005 (Kernos suppl., 15).

Daszewski 1986 = W. A. Daszewski, La personnification et la Tychè d'Alexandrie: réinterprétation de certains monuments, dans Iconographie classique et identités régionales (Paris, 26-27 mai 1983), Paris, 1986 (BCH suppl., 14), p. 299-309.

Daux 1936 = G. Daux, Pausanias à Delphes, Paris, 1936.

Daux 1956-61 = G. Daux, Chronique des fouilles, dans BCH, 80, 1956, p. 586-588; ibid., 82, 1958, p. 682-687; ibid., 83, 1959, p. 759-763; ibid., 84, 1960, p. 751-753; ibid., 85, 1961, p. 776-779.

Davaras 1979 = C. Davaras, Sounion, Athènes, 1979.

Davaras 1980 = C. Davaras, Une ancre minoenne sacrée?, dans $B C H$, 104, 1980, p. 47-71.

Davies 1978 = M. I. Davies, Sailing, rowing and sporting in one's cups on the wine-dark sea, dans Athens comes of age from Solon to Salamis, Princeton, 1978, p. 72-95.

Dawkins 1929 = R. M. Dawkins, The sanctuary of Artemis Orthia at Sparta, Londres, 1929 (Society for the promotion of Hellenic studies suppl., 5).

Defradas 1954 = J. Defradas, Les thèmes de la propagande delphique, Paris, 1954.

De Juliis 2001 = E. M. De Juliis, Metaponto, Bari, 2001.

Delage 1930 = É. Delage, La géographie dans les Argonautiques d'Apollonios de Rhodes, Paris, 1930.

Delatte 1947 = A. Delatte, Les portulans grecs, Liège-Paris, 1947.

Delivorrias 1984 = A. Delivorrias, s. v. Aphrodite, dans LIMC, II, Berne, 1984,1 , p. $2-151$ et 2 , p. 6-153.

Delivorrias 1987 = A. Delivorrias (éd.), Greece and the sea. Catalogue of the exhibition (Amsterdam 29 Oct-10 Dec. 1987), Athènes-Amsterdam, 1987.

Demargne 1984 = P. Demargne, s. v. Athéna, dans LIMC, II, Berne, 1984,1 , p. $955-1044$ et 2 , p. 702-765. 
Demetriou 2010 = D. Demetriou, Aphrodite and the sea, dans Kernos, 23, 2010, p. 67-89.

De Miro 1982 = E. De Miro, Lastra di piombo con scena dionisiaca dal territorio di Piazza Armerina, dans Gualandi \& alii 1982, I, p. 179-183 et III, pl. XLV-XLVIII.

Deonna 1938 = W. Deonna, EAD. XVIII. Le mobilier délien, Paris, 1938.

Deonna $1950=\mathrm{W}$. Deonna, Phalères celtiques et gallo-romaines décorées de têtes humaines, dans $R A, 35,1950$, p. 35-57 et 147-181.

De' Spagnolis 2004 = M. De' Spagnolis, Il mito omerico di Dionysos ed $i$ pirati tirreni in un documento da Nuceria Alfaterna, Rome, 2004 (Studia archaeologica, 128).

Detienne 1967 = M. Detienne, Les maîtres de vérité dans la Grèce archaïque, Paris, 1967.

Detienne 1970 = M. Detienne, Le navire d'Athéna, dans RHR, 178, 1970, p. 133-177.

Detienne 1985 = M. Detienne, Puissance du jaillissement. Entre mythes et paysages, dans Il destino de la Sibilla. Atti del Convegno internazionale di studi sui Campi flegrei (Napoli, 27-28 sett. 1985), Naples, 1985, p. 143-150.

Detienne 1998 = M. Detienne, Apollon le couteau à la main. Une expérience expérimentale du polythéisme grec, [Paris], 1998.

Detienne \& Vernant 1974 = M. Detienne et J-P. Vernant, Ruses de l'intelligence. La mètis des Grecs, Paris, 1974.

Deubner 1927 = L. Deubner, Dionysos und die Anthesterien, dans JDAI, 42, 1927, p. 172-192.

Deubner 1932 = L. Deubner, Attische Feste, Hildesheim, 1932.

Diels $1915=$ H. Diels, Das Aphlaston des antiken Schiffe, dans Zeitschrift der Vereins für Volkskunde, 25, 1915, p. 61-80.

Dinsmoor 1971 = W. B. Dinsmoor, Sounion, Athènes, 1971.

Dionysos 1991 = Dionysos. Mito e mistero (Comacchio 3-5 nov. 1989), Comacchio, 1991.

Di Stefano 2003 = G. Di Stefano, Il Mercurio di Camarina, dans Atti del II Convegno di studi di archeologia subacquea (Castiglioncello 7-9 sett. 2001), Bari, 2003, p. 17-22.

Di Stefano Manzella 1997 = I. Di Stefano Manzella, Avidum mare nautis : antiche epigrafi sul naufragio, dans Arch. sub. Studi 1997, p. 215-230.

Duchêne 1992 = H. Duchêne, Initiation et élément marin en Grèce ancienne, dans L'initiation. Actes du Colloque international de Montpellier (11-14 avril 1991), II, Montpellier, 1992, p. 119-133.

Duchêne \& Fraisse $2001=\mathrm{H}$. Duchêne et P. Fraisse, EAD. XXXIX. Le paysage portuaire de la Délos antique. Recherches sur les installations maritimes, commerciales et urbaines du littoral délien, Athènes, 2001.

Dugand 1974 = J.-E. Dugand, Aphrodite-Astarté (de l'étymologie du nom d'Aphrodite), dans Annales de la Faculté des lettres et sciences humaines de l'université de Nice, 21, 1974.

Duhn 1888 = F. von Duhn, Abschiedsdarstellung auf einer campanischen Hydria in Karlsruhe, dans JDAI, 3, 1888, p. 229-233.

Dümmler 1896 = F. Dümmler, s. v. Athena, dans RE, II, Stuttgart, 1896, col. 1941-2020. 
Dumont 1975 = J. Dumont, Les dauphins d'Apollon, dans QS, 1, 1975, p. 57-85.

Dunand 1977 = F. Dunand, Le syncrétisme isiaque à la fin de l'époque hellénistique, dans Les syncrétismes dans les religions grecque et romaine (Colloque de Strasbourg, 9-10 juin 1971), Paris, 1973, p. 79-93.

Dunbabin 1948 = T. J. Dunbabin, The western Greeks, Oxford, 1948.

Dunbabin 1951 = T. J. Dunbabin, The oracle of Hera Akraia at Perachora, dans $A B S A, 46,1951$, p. 61-71.

Dunbabin 1962 = T. J. Dunbabin, Perachora, II, Oxford, 1962.

Durrbach 1905 = F. Durrbach, Fouilles de Délos exécutées aux frais de M. le duc de Loubat (1903). Inscriptions (suite), dans BCH, 29, 1905, p. 417684 et pl. XVIII-XXII.

Duval 1949 = P.-M. Duval, Du navire grec au navire romain, dans Mélanges d'archéologie et d'histoire offerts à Charles Picard à l'occasion de son $65^{\circ}$ anniversaire, I, 1949, Paris, p. 338-351.

Dyggve 1960 = E. Dyggve, Lindos. Fouilles de l'Acropole 1902-1914 et 1952. III. Le sanctuaire d'Athana Lindia et l'architecture lindienne, BerlinCopenhague, 1960.

Dyggve \& Poulsen 1948 = E. Dyggve et F. Poulsen, Das Laphrion, der Tempelbezirk von Kalydon, mit einem religionsgeschichtlichen Beiträg von F. Poulsen, Copenhague, 1948.

Eitrem 1935 = S. Eitrem, Heroen der Seefahrer, dans SO, 14, 1935, p. 53-67.

Ellinger 1984 = P. Ellinger, Les ruses de guerre d'Artémis, dans Recherches sur les cultes grecs et l'Occident II, Naples, 1984 (Cahiers du Centre J. Bérard, 9), p. 51-67.

Espérandieu \& Lantier 1907-1966 = É. Espérandieu et R. Lantier, Recueil général des bas-reliefs, statues et bustes de la Gaule romaine, Paris, 15 vol.

Étienne \& Braun 1986 = R. Étienne et J.-P. Braun, avec un appendice de F. Queyrel, Tenos. I. Le sanctuaire de Poséidon et d'Amphitrite, Paris, 1986.

Falsone 1988 = G. Falsone, La scoperta, lo scavo e il contesto archeologico, dans La statua marmorea di Mozia e la scultura di stile severo in Sicilia. Atti della giornata di studio (Marsala 1986), Rome, 1988 (Studi e materiali, 8), p. 9-28.

Falsone \& Bound 1986 = G. Falsone et M. M. Bound, Archeologia subacquea a Marsala, dans Archeologia subacquea III, Rome, 1986 (BA suppl., 37-38), p. 161-176.

Fantar 1977 = Mh. Fantar, Le dieu de la mer chez les Phéniciens et les Puniques, Rome, 1977.

Farnell 1896-1909 = L. R. Farnell, Cults of Greek States, Oxford, 18961909, 5 vol.

Farnell 1916 = L. R. Farnell, Ino Leukothea, dans JHS XXXVI, 1916, p. 36-44.

Fenet 1998 = A. Fenet, Caractères et cultes marins des divinités olympiennes dans le monde grec d'Homère à la fin de l'époque hellénistique. Contribution à l'étude de la religion des marins grecs, Thèse de doctorat, Paris X-Nanterre, 1998, 2 vol. 
Fenet 2002 = A. Fenet, Les dieux olympiens et la mer: le cas de la Messénie et de la Laconie, dans Tzalas 2002, I, p. 335-344.

Fenet 2005 = A. Fenet, Sanctuaires marins du canal d'Otrante, dans É. Deniaux (dir.), Le canal d'Otrante et les échanges dans la Méditerranée antique et médiévale. Colloque de Nanterre (20-21 novembre 2000), Bari, 2005, p. 39-49.

Fenet 2011 = A. Fenet, Voyages en mer dans le monde grec et romain, dans ThesCRA. VI. Stages and circumstances of life: work, hunting, travel, Los Angeles, 2011, p. 405-414 et pl. 118-120.

Fernandez Izquierdo 1980 = A. Fernandez Izquierdo, Estudio de los restos arqueológicos submarinos en las costas de Castellón, dans Cuadernos de prehistoria y arqueología castellonenses, 7, 1980, p. 135-190 et pl. I-V.

Ferri 1962 = S. Ferri, L'ex-voto metapontino di Theages, dans RAL, 17, 1962, p. 3-10 et pl. VI.

Ferri 1972 = S. Ferri, Problemi e documenti archeologici III. "Argoi lithoi" : un problema metodologico, dans RAL, 27, 1972, p. 360-364 et pl. V-IX.

Février 1985 = P. A. Février, La maison et la mer, réalité et imaginaire, dans Homme médit. 1985, p. 334-351.

Fiori 1974 = P. Fiori, Le mouillage antique du cap Gros, dans Cahiers d'archéologie subacquatique, 3, 1974, p. 81-102.

Fiorini 2005 = L. Fiorini, Gravisca: scavi nel santuario greco. I. Topografia generale e storia del santuario. Analisi dei contesti e delle stratigrafie, Bari, 2005.

Fíta 1906 = F. Fíta, Inscripciones griegas, latinas y hebreas, dans Boletín de la Real Academia de la Historia, 48, 1906, p. 155-163.

Follieri 1961 = M. Follieri, I pozzi dell'area sacra di Vesta, dans Monumenti antichi, 45, 1961, col. 2-143.

Forsén 2004 = B. Forsén, Greek votive objects, dans ThesCRA. I. Processions, sacrifices, libations, fumigations, dedications, Los Angeles, 2004, p. 287-313 et pl. 72-81.

Foti 1965 = G. Foti, La documentazione archeologica in Calabria, dans Taranto 1965, p. 145-161.

Franco 1996 = A. Franco, Afrodite Euploia a Cipro?, Kokalos, 42, 1996, p. 341-364.

Freyer-Schauenburg $1974=$ B. Freyer-Schauenburg, Samos. XI. Bildwerke der archaischen Zeit und des strengen Stils, Bonn, 1974.

Frickenhaus 1912a = A. Frickenhaus, Der Schiffskarren des Dionysos in Athen, dans JDAI, 27, 1912, p. 61-79.

Frickenhaus 1912b = A. Frickenhaus, Tyrins I, Athènes, 1912.

Froehner 1897 = W. Froehner, Musée de Marseille. Catalogue des antiquités grecques et romaines, Paris, 1897.

Frost $1969=$ H. Frost, The stone-anchors of Byblos, dans Mélanges offerts à M. Dunand, I, Mélanges de l'université Saint-Joseph, 45, 1969, p. 425-442.

Frost $1970 \mathrm{a}=\mathrm{H}$. Frost, Bronze-age stone-anchors from the eastern Mediterranean, dans $M M, 56,4,1970$, p. 377-394.

Frost $1970 \mathrm{~b}=\mathrm{H}$. Frost, Some Cypriot stone-anchors from land sites and from the sea, dans RDAC 1970, p. 14-24.

Frost $1970 \mathrm{c}=\mathrm{H}$. Frost, Stone anchors as indications of early trade routes, dans M. Mollat (éd.), Sociétés et compagnies de commerce en Orient et 
dans l'Océan indien. Actes du VIII Colloque international d'histoire maritime (Beyrouth, 5-10 septembre1966), Paris-Lausanne, 1970, p. 55-61.

Frost $1973=\mathrm{H}$. Frost, Anchors, the potsherds of marine archaeology: on the recording of pierced stones from the Mediterranean, dans Blackmann 1973, p. 397-409.

Frost $1982 \mathrm{a}=\mathrm{H}$. Frost, The Athlit ram; a round table conference at the Centre for Maritime Studies, Haifa University, 2-5 December 1981, dans IJNA, 11, 1982, p. 59-60.

Frost $1982 \mathrm{~b}=\mathrm{H}$. Frost, On a sacred cypriot anchor, dans Archéologie au Levant. Recueil à la mémoire de R. Saidah, Lyon, 1982 (Coll. de la Maison de l'Orient méditerranéen, 12, série archéologique, 9), p. 161-166.

Frost $1984=\mathrm{H}$. Frost, Note on three fragmentary anchors from the Palaepaphos-Skales tombs, dans V. Karageorghis (éd.), Kouklia V, 1984, p. 433-434.

Frost $1985=\mathrm{H}$. Frost, Appendix I. The Kition anchors, dans V. Karageorghis et M. Demas, Excavations at Kition. V. The Pre-Phoenician levels (Areas I and II), Part I, Nicosie, 1985, p. 281-321 et pl. A-J.

Frost 1986 = H. Frost, Stone Anchors; criteria for a corpus, dans Thracia 1986, p. 354-369 et pl. p. 520 .

Frost $1989=\mathrm{H}$. Frost, Pyramidal stone anchors : an inquiry, dans Tzalas 1989, p. 97-114.

Frost $1991=\mathrm{H}$. Frost, Anchors sacred and profane. Ugarit-Ras Shamra, 1986; the stone anchors revised and compared, dans M. Yon (dir.), Ras Shamra-Ougarit. VI. Arts et industries de la pierre, Lyon, 1991, p. 355-394 et pl. I-XIV.

Foucher 1964 = L. Foucher, Hadrumetum, Paris, 1964.

Fuchs 1963 = W. Fuchs, Der Schiffsfund von Mahdia, Tübingen, 1963.

Furtwängler 1885 = A. Furtwängler, Beschreibung der Vasensammlung im Antiquarium, Berlin, 1885.

Furtwängler 1906 = A. Furtwängler, Aegina, das Heiligtum der Aphaia I, Munich, 1906.

Furtwängler 1980 = A. E. Furtwängler, Heraion von Samos : Grabungen im Südtemenos 1977. I. Schicht-und Baubefund, Keramik, dans MDAI(A), 95, 1980, p. 149-159, pl. XLI-XLIII et plans II-VII.

Furtwängler 1997 = A. Furtwängler, L'Héraion de Samos: quelques aspects de l'évolution du sanctuaire du $V^{e}$ s. à l'époque hellénistique. Essai d'interprétation, dans Colloque Héra 1997, p. 141-150.

Gabrici 1927 = E. Gabrici, Il santuario della Malophoros a Selinunte, Milan, 1927 (Monumenti antichi, 32).

Gagé 1936 = J. Gagé, Actiaca, dans Mélanges d'archéologie et d'histoire, 53, 1936, p. 37-100.

Gagé 1955 = J. Gagé, Apollon romain, Paris, 1955.

Gallet de Santerre $1958=\mathrm{H}$. Gallet de Santerre, Délos primitive et archaïque, Paris, 1958 (BEFAR, 192).

Gallet de Santerre $1982=\mathrm{H}$. Gallet de Santerre, Kératon, Pythion et Néorion à Délos, dans Rayonnement grec. Hommages à Charles Delvoye, Bruxelles, 1982, p. 201-226.

Galli 1997 = G. Galli, Nuovi recuperi sottomarini a Ponza, dans Arch. sub. Studi, 1997, p. 157-165. 
García \& Lopez 1979-80 = C. García Rivera et M. D. López de la Orden, Elementos de anclas antiguas del museo de Cádiz, dans Boletín del Museo de Cádiz, 2, 1979-1980, p. 67-72.

García Cardiel 2013 = J. García Cardiel, El catálogo de las naves de Occidente. Embarcaciones de la península Ibérica, Marruecos y archipiélagos aledaños hasta el principado de Augusto, Oxford, 2013 (BAR intern. series, 2462).

García y Bellido 1944 = A. García y Bellido, La navegación iberica en la Antigüedad según los textos clásicos y la arqueología, dans Estudios geográficos, 11, août 1944, p. 51-56.

García y Bellido 1948 = A. García y Bellido, Hispania graeca, Barcelone, 1948, 3 vol.

García y Bellido 1963 = A. García y Bellido, Hercules Gaditanus, dans AEA, 36, 1963, no 107-108, p. 70-153.

García y Bellido 1967 = A. García y Bellido, Les religions orientales dans l'Espagne romaine, Leyde, 1967 (Études préliminaires aux religions orientales dans l'empire romain, 5).

Gardner 1881 = P. Gardner, Boat-races among the Greeks, dans JHS, 2, 1881, p. $90-97$.

Gardner 1883 = P. Gardner, Catalogue of Greek coins in the British Museum. Thessaly to Aetolia, Londres, 1883.

Gardner 1888 = A. E. Gardner, Naukratis II, Londres, 1888.

Gargallo 1961 = P. N. Gargallo, Anchors of Antiquity, dans Archaeology, 14, 1961, p. 31-35.

Gargallo $1970=$ P. Gargallo di Castel Lentini, The ports of ancient Syracuse, dans Archaeology, 23, 1970, p. 312-317.

Gargiullo \& Okely 1993 = S. Gargiullo et E. Okely, Atlante archeologico dei mari d'Italia, Rome, 1993, 3 vol.

Garland $1987=$ R. Garland, The Piraeus from the fifth to the first century b.C., Worcester, 1987.

Gasparri 1986 = C. Gasparri, s. v. Dionysos, dans LIMC, III, Berne, 1986, 1, p. $420-514$ et 2, p. 296-406.

Gauer 1968 = W. Gauer, Weihgeschenke aus den Perserkriegen, Tubingen, 1968 (Istanbuler Mitteilungen, $2^{\mathrm{e}}$ série).

Gebhard 1993 = E. R. Gebhard, The evolution of a pan-Hellenic sanctuary: from archaeology towards history at Isthmia, dans Marinatos \& Haägg 1993, p. 154-177.

Georgoudi 1988 = S. Georgoudi, La mer, la mort et le discours des épigrammes funéraires, dans Atti del Colloquio internazionale di Capri. La parola, l'immagine, la tomba, Naples, 1988 (AION, 10), p. 54-61.

Georgoudi 1998 = S. Georgoudi, Les Douze Dieux et les autres dans l'espace culturel grec, dans Kernos, 11, 1998, p. 73-83.

Geyer 1903 = F. Geyer, Topographie und Geschichte der Insel Euboia, Berlin, 1903.

Giacometti 2003 = D. Giacometti, Theon agorai, dans QS, 58, 2003, p. $141-162$.

Giacometti 2005 = D. Giacometti, Metaponto. Gli dei e gli eroi nella storia di una polis di Magna Grecia, Cosenza, 2005.

Gianfrotta 1974 = P. A. Gianfrotta, Un ceppe di C. Aquillio Proculo 
tra $i$ rinvenimenti archeologici sottomarini a Punta Licosa nel Cilento, dans RStudLig, 40, 1974, p. 75-107.

Gianfrotta 1975 = P. A. Gianfrotta, Le ancore votive di Sostrato di Egina e di Faillo di Crotone, dans PP, 30, 1975, p. 311-318.

Gianfrotta $1977=$ P. A. Gianfrotta, First elements for the dating of anchor stocks, dans IJNA, 6, 1977, p. 285-292.

Gianfrotta 1980 = P. A. Gianfrotta, Ancore romane. Nuovi materiali per lo studio dei traffici marittimi, dans J. H. D’Arms et E. C. Kopff (éd.), The seaborne commerce of ancient Rome. Studies in archaeology and history, 1980 (MAAR, 36), p. 103-116 et pl. hors-texte.

Gianfrotta $1982 \mathrm{a}=$ P. A. Gianfrotta, L'àncora di Kutikluna (ovvero, considerazioni sulla tomba n. 245 di Valle Trebba), dans Musei Ferraresi Bolletino annuale, 12, 1982, p. 59-62.

Gianfrotta $1982 \mathrm{~b}=$ P. A. Gianfrotta, Archeologia sott'acqua. Rinvenimenti sottomarini in Etruria meridionale, dans Arch. sub. 1982, p. 13-36.

Gianfrotta 1986 = P. A. Gianfrotta, Rinvenimenti archeologici sottomarini, dans Le isole Pontine attraverso $i$ tempi, Rome, 1986, p. 217-218.

Gianfrotta 1989 = P. A. Gianfrotta, Testimonianze sottomarine al Circeo, dans Incontro con l'archeologia. Atti del Convegno P. N. Circeo (Sabaudia 1984), 1989, p. 43-53.

Gianfrotta 1991 = P. A. Gianfrotta, Navi mitologiche a Roma, dans Rassegna arch. sub. 1991, p. 85-91.

Gianfrotta $1994=$ P. A. Gianfrotta, Note di epigrafia marittima. Aggiornamenti su tappi d'anfora, ceppi d'ancora e altro, dans Epigrafia della produzione e della distribuzione. Actes de la VII e Rencontre franco-italienne sur l'épigraphie du monde romain (Rome, 5-6 juin 1992), Rome, 1994, p. 591-608.

Gianfrotta 2005 = P. A. Gianfrotta, Note di topografia marina e marittima, dans Rivista di topografia antica XV, 2005. Atti del V Congresso di topographia antiqua. I porti del Mediterraneo in età classica (Roma, 5-6 ottobre 2004). Parte I, Rome, p. 7-36

Gianfrotta \& alii $1997=$ P. A. Gianfrotta, X. Nieto, P. Pomey et A. Tchernia, La navigation dans l'Antiquité, Aix-en-Provence, 1997.

Gianfrotta \& Pomey $1980=$ P. A. Gianfrotta et P. Pomey, Archeologia subacquea, Milan, 1980 (éd. fr., Paris, 1981).

Giangiulio 1988 = M. Giangiulio, Appunti di storia dei culti, dans Neapolis. Atti del XXV Convegno di studi sulla Magna Grecia (Taranto, 3-7 ottobre 1985), Tarente, 1988, p. 101-154.

Giannelli 1924 = G. Giannelli, Cultie miti della Magna Grecia, Florence, 1924.

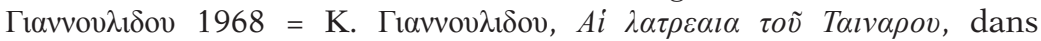
$\Pi \lambda \alpha \tau \omega v, 1968$, p. 223-239.

Ginouvès 1962 = R. Ginouvès, Balaneutikè. Recherches sur le bain dans l'Antiquité grecque, Paris, 1962.

Glotz 1904 = G. Glotz, L'ordalie dans la Grèce primitive, Paris, 1904.

Glueck $1965=$ N. Glueck, Deities and dolphins. The story of the Nabataeans, New-York, 1965.

Gómez Bellard \& Vidal González 2000 = C. Gómez Bellard et P. Vidal González, Las cuevas-santuario fenicio-púnicas y la navegación en el Mediterráneo, dans Costa \& Fernández 2000, p. 103-145. 
Göttlicher 1978 = A. Göttlicher, Materialen für ein Corpus der Schiffsmodelle im Altertum, Mayence, 1978.

Göttlicher 1981 = A. Göttlicher, Nautische Attribute römischer Gottheiten, Brême, 1981.

Göttlicher 1992 = A. Göttlicher, Kultschiffe und Schiffskulte im Altertum, Berlin, 1992.

Göttlicher 2006 = A. Göttlicher, Seefahrt in der Antike. Das Schiffs- und Seewesen bei Herodot, Darmstadt, 2006.

Goyens-Slezakowa 1990-91 = C. Goyens-Slezakowa, La mer et les îles, un lieu du mal et du malheur. Théâtre et realia, dans Realia. Mélanges sur les réalités du théâtre antique (archéologie, épigraphie, anthropologie, littérature), 1990-1991 (CGita, 6), p. 81-128.

Grach 1984 = N. L. Grach, Discovery of a new historical source in Nymphaeum, dans Vestnik Drevnej Istorii 1984, fasc. 1, p. 81-88 et pl. horstexte [en russe, rés. en anglais].

Grač 1987 = N. Grač, Ein neu entdecktes Fresko aus hellenistischer Zeit in Nymphaion bei Kertsch, dans L. Galanina et alii (éd.), Skythica. Vorträge zur Entstehung des skytho-iranischen Tierstils und zu Denkmälern des Bosporanischen Reichs anlässlich einer Ausstellung der Leningrader Ermitage in München 1984, Munich, 1987 (Bayerische Akademie der Wissenchaften, Abhandlungen, 98), p. 87-95 et pl. XXVI-XXXIX.

Graf 1979 = F. Graf, Apollon Delphinios, dans $M H$, 36, 1979, p. 2-22.

Graf 1985 = F. Graf, Nordionische Kulte, Rome, 1985.

Graf 2009 = F. Graf, Apollo, Londres, 2009.

Graffiti Délos 1992 = Récit d'une aventure. Les graffiti marins de Délos (Musée d'histoire de Marseille 18 déc. 1992 - 22 mars 1993), Marseille, 1992.

Grandjean \& Salviat $2000=$ Y. Grandjean et F. Salviat, Guide de Thasos, Athènes, $2000^{2}$ (éd. refondue et mise à jour avec la collaboration de F. Blondé et alii).

Greco 1995 = E. Greco, Magna Grecia, Bari, 1995.

Grimal 1951 = P. Grimal, s. v. Athéna, dans Dictionnaire de la mythologie grecque et romaine, Paris, 1951.

Grotanelli 1981 = C. Grotanelli, Santuari e divinità delle colonie d'Occidente, dans La religione fenicia : matrici orientali e sui luppi occidentali. Atti del Colloquio in Roma, 6 marzo 1979, Rome, 1981, p. 109-133.

Grotta 2010 = C. Grotta, Zeus Meilichios a Selinunte, Rome, 2010.

Gruben 1966 = G. Gruben, Die Tempel der Griechen, Munich, 1966.

Gualandi \& alii 1982 = M. L. Gualandi, L. Massei et S. Settis (éd.), AПAPXAI. Nuove ricerche e studi sulla Magna Grecia e la Sicilia antica in onore di Paolo Enrico Arias, Pise, 1982, 3 vol.

Guarducci 1935 = M. Guarducci, Dictynna, dans SMSR 1935, p. 187-203.

Guarducci $1966 \mathrm{a}=$ M. Guarducci, Divinità fauste nell'antica Velia, dans $P P, 21,1966$, p. 279-294.

Guarducci 1966b = M. Guarducci, Note di epigrafia selinuntina arcaica, dans Kokalos XII, 1966, p. 190-199 et pl. LV, 2. 4 vol.

Guarducci 1967-78 = M. Guarducci, Epigrafia greca, Rome, 1967-1978,

Guarducci $1970=$ M. Guarducci, Nuovi cippi sacri a Velia, dans PP, 25, 1970, p. 252-261. 
Guarducci 1980 = M. Guarducci, Dioniso primaverile ad Atene : reflessioni sul vaso di Lydos nel museo di Villa Giula, dans Numismatica e antichità classiche IX, 1980, p. 37-62.

Guarducci 1983 = M. Guarducci, Dioniso sul carro navale. Ulteriori (e ultime) riflessioni sul vaso ateniese di Lydos nel Museo di Villa Giulia, dans NAC XII, 1983, p. 107-118.

Guenther $1988=\mathrm{K}$. Guenther, Der Poseidontempel auf Tainaron, dans $A W, 19,2,1988$, p. 58-60.

Guglielmotti 1866 = P. A. Guglielmotti, Delle due navi scolpite sul bassorilievo portuense del Principe Torlonia, Rome, 1866.

Guide Delphes 1991a = Guide de Delphes. Le site, Athènes, 1991.

Guide Delphes 1991b = Guide de Delphes. Le musée, Athènes, 1991.

Guzzo \& alii 1992 = P. G. Guzzo et alii, Il santuario di Punta della Campanella. Atti della giornata di studio, dans Annali. Sezione di archeologia e storia antica, XIV, 1992, p. 149-241 et pl. XXI-XXX.

Haack 2007 = M. L. Haack, Phocéens et Samiens à Gravisca, dans BABesch, 82, 2007, p. 29-40.

Hajdari \& alii 2007 = A. Hajdari, J. Reboton, S. Shpuza et P. Cabanes, Les inscriptions de Grammata (Albanie), dans REG, 120, 2007, p. 353-394.

Hammond 1967 = N. G. Hammond, Epirus. The geography, the ancient remains, the history and the topography of Epirus and adjacent areas, Oxford, 1967.

Hammond 1981 = N. G. L. Hammond, Atlas of the Greek and Roman world in Antiquity, Park Ridge, 1981.

Harland 1925 = J. P. Harland, Prehistoric Aegina, Paris, 1925.

Harrison 1888 = J. E. Harrison, Archaeology in Greece, dans JHS, 9, 1888, p. $118-133$.

Harrison 1890 = J. Harrison, Mythology and monuments of ancient Athens, Londres, 1890.

Harvey 1976 = F. D. Harvey, Sostratos of Aegina, dans PP, 31, 1976, p. 206-214.

Hauvette-Besnault \& Dubois $1881=$ A-M. Hauvette-Besnault et M. Dubois, Antiquités de Mylasa, dans BCH, 5, 1881, p. 95-119.

Hawthorne 1958 = J. G. Hawthorne, The Myth of Palaemon, dans Transactions and proceedings of the American philological association, 89, 1958, p. 92-98.

Head 1892 = B. V. Head, British Museum. Catalogue of the Greek coins of Ionia, Londres, 1892.

Head 1897 = B.V. Head, British Museum. Catalogue of the Greek coins of Caria, Cos, Rhodes, etc., Londres, 1897.

Head 1906 = B. V. Head, British Museum. Catalogue of the Greek coins of Phrygia, Londres, 1906.

Head 1911 = B. V. Head, Historia Numorum. A manual of Greek numismatics, Amsterdam, $1911^{2}$.

Head 1977 = B. V. Head, British Museum. Catalogue of the Greek coins. Attica, Megaris, Aegina, Bologne, 1977 (rééd.).

Helbig 1868 = W. Helbig, Wandgemälde der vom Vesuv verschütteten Städte Campaniens, Leipzig, 1868.

Hellmann \& Fraisse 1979 = M.-C. Hellmann et P. Fraisse, EAD. XXXII. Le monument aux hexagones et le portique des Naxiens, Paris, 1979. 
Hemberg 1950 = B. Hemberg, Die Kabiren, Uppsala, 1950.

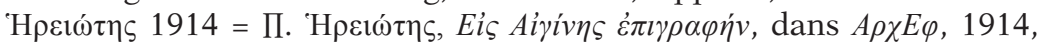
p. $92-94$.

Hermann 1965 = W. Hermann, Santuari di Magna Grecia e della madre patria, dans Taranto 1965, p. 47-57.

Hermary 2000 = A. Hermary, De la mère des dieux à Cybèle et Artémis, dans A A $\alpha \theta \dot{\theta} \varsigma \delta \alpha i \mu \omega v$. Mythes et cultes. Études d'iconographie en l'honneur de Lilly Kahil, Athènes, 2000 (BCH suppl., 38), p. 193-203.

Hermary $2000 \mathrm{~b}=\mathrm{A}$. Hermary, Amathonte. V. Les figurines en terre cuite archaïques et classiques. Les sculptures en pierre, Athènes, 2000.

Hesnard \& Gianfrotta 1989 = A. Hesnard et P. A. Gianfrotta, Les bouchons d'amphore en pouzzolane, dans Amphores romaines et histoire économique: dix ans de recherche. Actes du Colloque de Sienne (22-24 mai 1986), Rome, 1989 (CEFR, 114), p. 393-441.

Hicks 1887 = E. L. Hicks, Inscriptions from Thasos, dans JHS, 8, 1887, p. 409-433.

Higbie 2001 = C. Higbie, Homeric Athena in the Chronicle of Lindos, dans S. Deacy et A. Villing (éd.), Athena in the classical world, Leiden, p. 105-125.

Higbie $2003=\mathrm{C}$. Higbie, The Lindian Chronicle and the Greek creation of their past, Oxford, 2003.

Hildebrandt $1888=\mathrm{R}$. Hildebrandt, A $\theta \dot{v} v \eta \Gamma \lambda \alpha v \kappa \omega ́ \pi \iota s$, dans Philologus, 46, 2, 1888, p. 201-209.

Hill 1897 = G. F. Hill, British Museum. Catalogue of the Greek coins. Lycia, Pamphylia and Pisidia, Londres, 1897.

Hill 1900 = G. F. Hill, British Museum. Catalogue of the Greek coins of Lycaonia, Isauria and Cilicia, Londres, 1900.

Hill 1904 = G. F. Hill, British Museum. Catalogue of the Greek coins of Cyprus, Londres, 1904.

Hill 1910 = G. F. Hill, British Museum. Catalogue of the Greek coins of Phoenicia, Londres, 1910.

Höckmann 1985 = O. Höckmann, Antike Seefahrt, Munich, 1985.

Höckmann 1998 = O. Höckmann, Naval and other graffiti from Nymphaion, dans Ancient civilizations from Scythia to Siberia, 5, 1999, 4, p. 303-356.

Hogarth 1908 = G. Hogarth, Excavations at Ephesus. The archaic Artemisia, Londres, 1908.

Hollinshead $1980=$ M. B. Hollinshead, Legend, cult, and architecture at three sanctuaries of Artemis, Thèse Lett. (Bryn Maur College), 1980.

Holtzmann 2003 = B. Holtzmann, L'Acropole d'Athènes. Monuments, cultes et histoire du sanctuaire d'Athéna Polias, Paris, 2003.

Homme médit. 1985 = L'Homme méditerranéen et la mer. Actes du III Congrès international d'études des cultures de la Méditerranée Occidentale (Jerba, avril 1981), Tunis-Paris, 1985.

Homolle 1882 = T. Homolle, Compte des hiéropes du temple d'Apollon Délien, dans $B C H, 6,1882$, p. 1-167.

Homolle $1886=\mathrm{T}$. Homolle, Inventaires des temples déliens, dans $B C H$, 10, 1886, p. 461-475. 
Homolle $1890=\mathrm{T}$. Homolle, Comptes \& inventaires des temples déliens en l'année 279, dans $B C H, 14,1890$, p. 389-511 et pl. XV-XVI.

Hondius \& Woodward 1919-21 = J. J. E. Hondiuset A. M. Woodward, Laconia. Inscriptions, dans ABSA, 24, 1919-1921, p. 88-143.

Horn 1994 = H. G. Horn, Dionysos und Ariadne. Zwei Zierbeschläge aus dem Schiffsfund von Mahdia, dans Das Wrack. Der antike Schiffsfund von Mahdia, Cologne, 1994, I, p. 451-467.

Huet $2011=\mathrm{V}$. Huet, Calendriers en image, dans ThesCRA. VII. Festivals and contests, Los Angeles, 2011, p. 233-239 et pl. 31-34.

Hülsen 1909 = C. Hülsen, s. v. Euploia 2, dans RE, VI, Stuttgart, 1909, col. 1226.

Iacopi 1952 = G. Iacopi, Capo Cimmiti (Crotone). Iscrizione greca, dans NSA VI, 1952, p. 167-176.

Icard-Gianolio 1997 = N. Icard-Gianolio, s. v. Triton, dans LIMC, VIII, Berne, 1 p. 68-73 et 2 p. 42-46.

Icard \& alii 2011 = N. Icard (avec la coll. de A.-V. Szabados) et P. Linant de Bellefonds, La pêche dans le monde grec et romain, dans ThesCRA. VI. Stages and circumstances of life: work, hunting, travel, Los Angeles, 2011, p. 379-387 et pl. 114-116.

Imhoof-Blumer 1883 = F. Imhoof-Blumer, Monnaies grecques, Amsterdam, 1883.

Imhoof-Blumer 1910 = F. Imhoof-Blumer, Beiträge zur Erklärung griechischer Münztypen. I. Seefahrende Heroen, dans Nomisma, 5, 1910, p. 25-39 et pl. II-III.

Imhoof-Blumer 1924 = F. Imhoof-Blumer, Fluss- und Meergötte auf griechischen und römischen Münzen, Genève, 1924 (= SNR XXIII, 1923).

Imhoof-Blumer \& Gardner 1964 = F. Imhoof-Blumer et P. Gardner, Ancient coins illustrating lost masterpieces of Greek art (a numismatic commentary on Pausanias), ed. \& enlarged by A. L. Oikonomides, Chicago, 1964.

Jacob 1990 = La description de la terre habitée de Denys d'Alexandrie ou la leçon de géographie, Paris, 1990.

Jacob 1991 = C. Jacob, Géographie et ethnographie en Grèce ancienne, Paris, 1991.

Jacquemin 1999 = A. Jacquemin, Offrandes monumentales à Delphes, Athènes, 1999 (BEFAR, 304).

Jacquemin 2002 = A. Jacquemin, Une nouvelle épiclèse de Poséidon à Delphes, dans BCH, 126, 2002, p. 55-58.

Jacquemin \& alii 2012 = A. Jacquemin, D. Mulliez et G. Rougemont, Études épigraphiques. V. Choix d'inscriptions de Delphes, traduites et commentées, Athènes, 2012.

Jal 1848 = A. Jal, Glossaire nautique, Paris, 1848.

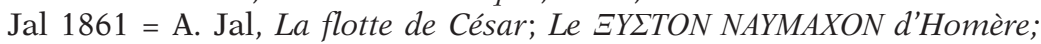
Virgilius nauticus: Études sur la marine antique, Paris, 1861.

Jameson 1960 = M. H. Jameson, A decree of Themistokles from Troizen, dans Hesperia, 29, 1960, 198-223.

Jameson \& alii 1993 = M. H. Jameson, D. R. Jordan et R. D. Kotansky, A lex sacra from Selinous, Durham, 1993 (Greek, Roman and Byzantine monographs, 11). 
Janni 1996 = P. Janni, Il mare degli Antichi, Bari, 1996.

Jáuregui \& Beltrán Martínez 1947 = J. J. Jáuregui Gil Delgado et A. Beltrán Martínez, Acerca de unas anclas romanas del Museo de Cartagena, dans Crónica del II Congreso arqueológico del Sudeste español (Albacete 1946), Boletín arqueológico del Sudeste Español, 4-7, 1947, p. 334-345.

Jeanmaire 1951 = H. Jeanmaire, Dionysos. Histoire du culte de Bacchus, Paris, 1951. $1990^{2}$.

Jeffery 1990 = L.H. Jeffery, The local scripts of archaic Greece, Oxford,

Jehasse \& Boucher 1959 = J. Jehasse et J. P. Boucher, Chronique d'archéologie sous-marine, dans Études corses, 21, 1959, p. 73-74 et pl. h.-texte.

Jeppesen $1960=\mathrm{K}$. Jeppesen, A royal message to Ikaros. The Hellenistic temple of Failaka, dans Kuml 1960, p. 153-198.

Jeppesen $1965=\mathrm{K}$. Jeppesen, A hellenistic fortress on the island of Ikaros (Failaka) in the Persian Gulf, dans Le rayonnement des civilisations grecque et romaine sur les cultures périphériques. VIII Congrès international d'archéologie classique (Paris, 1963), Paris, 1965, p. 541-544 et pl. CXXXVI.

Jessen 1905 = O. Jessen, s. v. Ekbasios, $-a$, dans RE, V, Stuttgart, 1905, col. 2155.

Jessen 1909 = O. Jessen, s. v. Euploia 1, dans RE, VI, Stuttgart, 1909, col. 1225-1226.

Johansen 1945 = K. Friis Johansen, Thésée et la danse à Délos. Étude herméneutique, dans Det Kgl. Danske Videnskabernes Selskab, 3, 1945, 3, p. 3-61.

Johnston 1985 = P. F. Johnston, Ship and boat models in ancient Greece, Maryland, 1985.

Johnston \& Pandolfini 2000 = A. Johnston et M. Pandolfini, Gravisca : scavi nel santuario greco. XV. Le iscrizioni, Bari, 2000.

Jordan 1971 = B. Jordan, The sacred ships of Athens, dans AJA, 75, 1971, p. 205.

Jost 1985 = M. Jost, Sanctuaires et cultes d'Arcadie, Paris, 1985 (Études péloponnésiennes, 9).

Jost 1992 = M. Jost, Aspects de la vie religieuse en Grèce (début du $V^{e}$ siècle à la fin du III ${ }^{e}$ av. J.-C.), Paris, 1992.

Jucker 1982 = H. Jucker, Apollo Palatinus und Apollo Actius auf augusteischen Münzen, dans $M H, 39,1982$, p. 82-100 et pl. hors-texte.

Jurišič $2000=$ M. Jurišič, Ancient shipwrecks of the Adriatic. Maritime transport during the first and second centuries a.D., Oxford, 2000 (BAR intern. series, 828).

Kahil 1984 = L. Kahil, s.v. Artémis, dans LIMC II, Bern, 1984, 1 p. 618753 et 2 p. $442-563$.

Kahil 1994 = L. Kahil, Bains de statues et de divinités, dans L'eau, la santé et la maladie dans le monde grec, Paris, 1994 (BCH suppl., 28), p. 217-223.

Kaibel 1876 = G. Kaibel, Ein Würfenorakel, dans Hermes, 10, 1876, p. 193-202.

Kapitän 1967-68 = G. Kapitän, Sul Lakkios, porto piccolo di Siracusa del periodo greco. Ricerche di topografia sottomarina, dans Archivo storico siracusano, 13-14, 1967-68, p. 167-180. 
Kapitän 1973 = G. Kapitän, Greco-Roman anchors and the evidence for the one-armed wooden anchor in Antiquity, dans Blackmann 1973, p. 383-395.

Kapitän 1979 = G. Kapitän, "Louteria" from the sea, dans IJNA, 8, 1979, p. 97-120.

Kapitän 1980 = G. Kapitän, Meeresarchäologie in Bulgarien. Ankerfunde im Schwarzen Meer, dans Das Logbuch, 16, 1980, 2, p. 45-48.

Kapitän 1985 = G. Kapitän, Capo Graziano, relitto $H$ con anfore tipo Lamboglia 2, dans Arch. sub. Eolie 1985, p. 93-95.

Kapitän 1986 = G. Kapitän, Klutikuna's anchor and the question : was a stone anchor stock in the tomb or a complete stone-stocked wooden anchor?, dans IJNA, 15, 1986, p. 133-136.

Kapitän 1989 = G. Kapitän, Archaeological evidence for rituals and customs on ancient ships, dans Tzalas 1989, p. 147-162.

Karageorghis 1977 = J. Karageorghis, La grande Déesse de Chypre et son culte, Paris, 1977 (Collection de la Maison de l'Orient méditerranéen ancien, 5, série archéologique, 4).

Karageorghis \& Gagniers 1974 = V. Karageorghis et J. des Gagniers, La céramique chypriote de style figuré, âge du fer (1050-500 av. J-C.), Rome, 1974 (Biblioteca di antichità cipriote, 2).

Kennedy 1976 = D. H. Kennedy, Cable reinforcement of the Athenian trireme, dans $M M, 62,1976$, p. 159-168.

Kilian 1978 = I. Kilian, Weihungen an Eileithuia und Artemis Orthia, dans ZPE, 31, 1978, p. 219-222.

Kiock $1915=$ A. Kiock, Athene Aithyia, dans Archiv für Religionswissenschaft, 18, 1915, p. 127-133.

Kirsch 1907 = J.-P. Kirsch, s. v. Ancre, dans F. Cabrol et H. Leclercq (dir.), Dictionnaire d'archéologie chrétienne et de liturgie, I, 2, Paris, 1907, col. 1999-2000.

Kleiner 1959-60 = G. Kleiner, Die Ausbgrabung beim Athena-Tempel in Milet 1957. VI. Die Grabung im norden des Athena-Tempels, dans MDAI(I), 9-10, 1959-1960, p. 86-96 et pl. LXXVIII-LXXXVI.

Knell $1973=$ H. Knell, Artemistempel von Kalydon und Poseidontempel in Molykreion, dans AA, 88, 1973, p. 448-461.

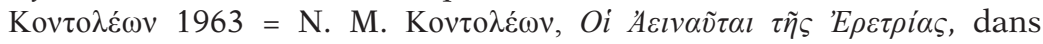

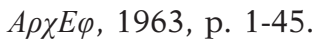

Kopcke 1967 = G. Kopcke, Neue Holzfunde aus dem Heraion von Samos. 46-52 Votivschiffe, dans $\operatorname{MDAI}(A), 82,1967$, p. 145-148 et pl. 83-83.

Kossatz \& Kossatz-Deissmann $1992=$ T. Kossatz et A. KossatzDeissmann, Martin von Wagner, Dionysos und die Seeräuber, dans Kotinos, Festschrift für E. Simon, Mayence, 1992, p. 469-478 et pl. 106-108.

Köster 1923 = A. Köster, Das antike Seewesen, Berlin, 1923.

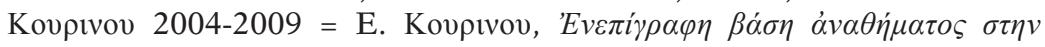

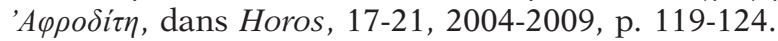

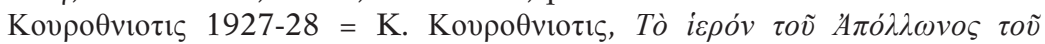
Z $\omega \sigma \tau \tilde{\eta} \rho \circ \varsigma$, dans $A D, 11,1927-1928$, p. 9-53.

Kowalski 2012 = J.-M. Kowalski, Navigation et géographie dans l'Antiquité gréco-romaine. La terre vue de la mer, Paris, 2012 (Antiquité / Synthèses, 14).

Kowalzig 2013 = B. Kowalzig, Transcultural chorality. Iphigenia in Tauris 
and Athenian imperial economics in a polytheistic world, dans R. Gagné et M.G. Hopman (éd.), Choral mediations in Greek tragedy, Cambridge, 2013, p. $178-210$.

Krauskopf 1981 = I. Krauskopf, Leucothea nach den antiken Quellen, dans Die Göttin von Pyrgi (Kolloquium Tübingen 16-17 Jan. 1979), Florence, 1981 (Biblioteca di studi etruschi, 12), p. 137-151.

Krauskopf 2011 = I. Krauskopf, Bilder griechischer Feste, dans ThesCRA. VII. Festivals and contests, Los Angeles, 2011, p. 78-123 et pl. 1-20.

Krauss 1944 = F. Krauss, Die Prora an der Tiberinsel im Rom, dans $M D A I(R), 59,1944$, p. 159-172.

Kritzas 1989 = C. B. Kritzas, Remarks of an inscribed anchor stock from Aegina (IG IV, 176), dans Tzalas 1989, p. 203-207.

Kron 1992 = U. Kron, Heilige Steine, dans Kotinos. Festschrift für E. Simon, Mayence, 1992, p. 56-70 et pl. XVI-XVIII.

Kruse 1953 = G. Kruse, s. v. Pontios 1, dans RE, XXII, Stuttgart, 1953, col. 28-29.

Kruse \& Schwabl 1942-1972 = G. Kruse, s. v. Olympios 55, dans RE, XVIII, 1, Stuttgart, 1942, col. 251-257, complété par Schwabl 1972, col. 342-344.

Kyrieleis $1980=$ H. Kyrieleis, Archaische Holzfunde aus Samos. 1-10 Schiff, dans $\operatorname{MDAI}(A), 95,1980$, p. 87-94 et pl. XVIII-XX.

Kyrieleis $1981=\mathrm{H}$. Kyrieleis, Führer durch das Heraion von Samos, Athènes, 1981.

Labaree 1957 = B.W. Labaree, How the Greeks sailed into the Black Sea, dans AJA, 61, 1957, p. 29-33.

La Coste-Messelière 1936 = P. de La Coste-Messelière, Au musée de Delphes, Paris, 1936.

Lacroix 1949 = L. Lacroix, Les reproductions de statues sur les monnaies grecques. La statuaire archaïque et classique, Liège, 1949 (Bibliothèque de la Faculté de philosophie et lettres de l'université de Liège).

Lacroix 1955-56 = L. Lacroix, Les "blasons» des villes grecques, dans Études d'archéologie classique, 1, 1955-56, p. 91-114.

Lacroix 1974 = L. Lacroix, Héraclès, héros voyageur et civilisateur, dans $B A B, 60,1974$, p. 34-60.

Lacroix 1988 = L. Lacroix, Pausanias, le coffre de Kypsélos et le problème de l'exégèse mythologique, dans $R A, 1988$, p. 251-255.

La Genière 1983 = J. de La Genière, À propos des métopes du monoptère de Sicyone à Delphes, dans CRAI 1983, p. 158-171.

Lamboley 1996 = J.-L. Lamboley, Recherches sur les Messapiens, $I V^{e}-I I^{e}$ s. avant J.-C., Rome, 1996 (BEFAR, 292).

Lambrechts 1952 = P. Lambrechts, De Demeterverering in Sicilie, dans HZnMTL, 6, 1952, p. 3-25.

Lambrechts \& Noyen = P. Lambrechts et P. Noyen, Recherches sur le culte d'Atargatis dans le monde grec, dans La nouvelle Clio, 6, 1954, p. 258-277.

Lambrinudakis \& alii $1984=$ W. Lambrinudakis et alii, s. v. Apollon, dans LIMC, II, Berne, 1984, 1 p. 183-335 et 2 p. 182-284.

La Rocca \& alii 1995 = L. La Rocca, C. Rescigno et G. Soricelli, Cuma: l'edificio sacro di Fondo Valentino, dans Studi sulla Campania preromana, Rome, 1995, p. 51-79 et pl. XVI-XXXI. 
Lattanzi 1987 = E. Lattanzi, Il museo nazionale di Reggio di Calabria, Rome, 1987.

Latyschev $1890=\mathrm{B}$. Latyschev, Inscriptiones antiquae orae septentrionalis Ponti Euxini graecae et latinae, Saint-Pétersbourg, 1890.

Laumonier 1958 = A. Laumonier, Les cultes indigènes en Carie, Paris, 1958.

La Vitali 1932 = A. La Vitali, Fonti per la storia della religione cyrenaica, Milan, 1932.

Lazzarini 1996 = M. L. Lazzarini, Le iscrizioni del Lacinio, dans E. Lattanzi et alii (éd.), I Greci in Occidente. Santuari della Magna Grecia in Calabria, Salerne, 1996, p. 242-246.

Laymond \& Jiménez 1906 = R. Laymond et D. Jiménez de Cisneros y Hervás, Anclas de plomo halladas en el puerto de Palos, dans Boletín de la Real Academia de la Historia, 48, 1906, p. 153-155.

Leaf 1923 =W. Leaf, Strabo on the Troad, book XIII, cap. 1, Cambridge, 1923.

Leake $1830=\mathrm{W}$. Leake, Travels in the Morea, I, Londres, $1830^{3}$.

Le Dinahet 1984 = M.-T. Le Dinahet, Sanctuaires chthoniens de Sicile de l'époque archaïque à l'époque classique, dans Temples et sanctuaires. Séminaire de recherches 1981-1983, Paris, 1984, p. 137-152.

Legrand 1897-1905 = P. E. Legrand, Fouilles de Trézène 1; et Antiquités de Trézène 1, dans BCH, 21, 1897, p. 543-551 et ibid., 29, 1905, p. 269-315.

Lehmann \& Lehmann 1973 = P. W. Lehmann et K. Lehmann, Samothracian reflections. Aspects of the revival of the Antique, Princeton, 1973.

Lemaître $1883=\mathrm{R}$. Lemaître, De la disposition des rameurs sur la trière antique, dans $R A, 1883,1$, p. 89-99 et pl. VI-VIII.

Lenormant \& Witte 1894 = C. Lenormant et J. de Witte, Élite des monuments céramographiques, I, Paris, 1894.

Lequement \& Liou $1976=\mathrm{R}$. Lequement et B. Liou, Céramique étrusco-campanienne et céramique arétine, à propos d'une nouvelle épave de Marseille, dans Mélanges offerts à J. Heurgon, Rome, 1976 (Collection de l'École française de Rome, 27), p. 587-603.

Lerat 1952 = L. Lerat, Les Locriens de l'Ouest. Histoire, institutions, prosopographie, Paris, 1952.

Lesky 1947 = A. Lesky, Thalatta. Der Weg der Griechen zum Meer, Vienne, 1947 (rééd. New-York, 1973).

Letronne 1829 = M. Letronne, Geographi graeci minores, edente J-F. Gail, dans JHS, 1829, p. 114-115.

Levy 1982-83 = B. E. Levy, Kaisar Epibaterios: a seafarer's cult at Alexandria, dans Israel numismatic journal VI-VII (Proceedings of the International numismatic convention on Greek imperials, Jerusalem 2-5 Jan. 1983), Jérusalem, 1982-83, p. 102-117.

Lhôte 2006 = É. Lhôte, Les lamelles oraculaires de Dodone, Genève, 2006 (EPHE. Hautes études du monde gréco-romain, 36).

L'Hour 1984 = M. Lhour, Les statuettes de bois de l'épave Planier 1 à Marseille, dans Archaeonautica, 4, 1984, p. 53-73.

Lilliu 1971 = G. Lilliu, Navicella di bronzo protosarda da Gravisca, dans NSA, 25, 1971, p. 289-298. 
Lilliu 2000 = G. Lilliu, D'una navicella protosarda nell'Heraion di capo Colonna a Crotone, dans RAL, 11, 2000, p. 181-233.

Liou 1973 = B. Liou, Informations archéologiques. Recherches sousmarines, dans Gallia, 31, 1973, p. 592.

Liou 1975 = B. Liou, Informations archéologiques. Recherches sousmarines, dans Gallia, 33, 1975, p. 605.

Lipinski 1995 = E. Lipinski, Dieux et déesses de l'univers phénicien et punique, Louvain, 1995 (Studia phoenicia, 24).

Lissarrague 1987 = F. Lissarrague, Un flot d'images, une esthétique du banquet grec, Paris, 1987.

Lobel \& alii 1957 = E. Lobel, C. H. Roberts, E. G. Turner et J. W. B. Barns, The Oxyrhynchus papyri XXIV, Londres, 1957.

Loicq-Berger \& Renard $1982=$ M.-P. Loicq-Berger et M. Renard, Sur les traces d'Héra-Junon en Occident, dans Gualandi \& alii 1982, I, p. 97-103.

Lolling 1883 = H. G. Lolling, Das Artemision auf Nordeuböa, et Ausgrabung am Artemision auf Nordeuböa, dans $\operatorname{MDAI}(A), 8,1883$, p. 7-23 et ibid. p. 200-210.

Long 1987 = C. R. Long, The Twelve gods of Greece and Rome, Leyde, 1987 (Études préliminaires aux religions orientales dans l'Empire romain, 107).

López Monteagudo 1998 = G. López Monteagudo, El simbolismo de la travesía marina en algunos mitos clásicos, dans Latomus, 57, 1998, p. 38-51 et pl. I-III.

Love 1972-73 = I. C. Love, Excavations at Knidos 1971, et Excavations at Knidos 1972, dans AJA, 76, 1972, p. 402-405 et AJA, 77, 1973, p. 419-424.

Lubtchansky 1998 = N. Lubtchansky, Le pêcheur et la mètis. Pêche et statut social en Italie centrale à l'époque archaïque, dans MEFRA, 90, 1, 1998, p. 111-146.

Luebeck 1894 = E. Luebeck, s. v. Anker, dans RE, I, 2, Stuttgart, col. 2219-2220.

Luzón Nogué \& Coín Cuenca $1986=$ J. M. Luzón Nogué et L. M. Coín Cuenca, La navegacíon pre-astronómica en la Antigüedad: utilización de pájaros en la orientación náutica, dans Lucentum, 5, 1986, p. 65-85.

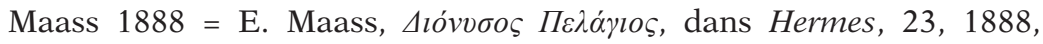
p. $70-80$.

Mac Caslin 1980 = D. E. Mac Caslin, Stone anchors in Antiquity: coastal settlements and maritime trade-routes in the Eastern Mediterranean ca. 16001050 b.C., Göteborg, 1980 (Studies in Mediterranean archaeology, 61).

Maddoli \& Saladino $1995=$ G. Maddoli et V. Saladino, Pausania. Guida della Grecia V. L'Elide e Olimpia, Milan, 1995.

Maetzke 1965 = G. Maetzke, Nuovi documenti della presenza del tabernacolo a bordo delle navi romane, dans Centro studi Ciociaria (éd.), Gli archeologi italiani in onore di Amedeo Maiuri, Cava dei Tirreni, 1965, p. 245-251.

Magon 1894 = L. Magon, Essai de reconstitution de l'ancre du musée d'archéologie de Marseille, dans RA, 25, 1894, p. 220-230.

Maiuri 1958 = A. Maiuri, Navalia pompeiana, dans RAAN, 33, 1958, p. 7-34. 
Malkin 1987 = I. Malkin, Religion and colonization in ancient Greece, Leyde, 1987.

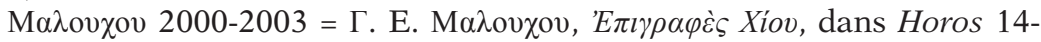
16, 2000-2003, p. 289-295 et pl. LXXI-LXXII.

Manganaro 1968-69 = G. Manganaro, Segnalazioni di epigrafia greca, dans Kokalos, 14-15, 1968-1969, p. 195-196.

Manganaro 1972 = G. Manganaro, Per una storia della Sicilia romana, dans H. Temporini (dir.), Aufstieg und Niedergang der römischen Welt. Geschichte und Kultur Roms in Spiegel der neueren Forschung, I, Berlin-New York, 1972, p. 442-461.

Manganaro 1977 = G. Manganaro, Per la storia dei culti nella Sicilia greca, dans Il tempio greco in Sicilia; architettura e culti. Atti della $I^{a}$ Riunione scientifica della Scuola di perfezionamento in archeologia classica dell'Università di Catania (Siracusa, 24-27 nov. 1976), Catane, 1977 (Cronache di archeologia, 16), p. 148-164 et pl. XLIII-XLVIII.

Manni 1963 = E. Manni, Sicilia pagana, Palerme, 1963.

Manni Piraino 1968 = M. T. Manni Piraino, Iscrizioni greche di Lucania, dans $P P, 23,1968$, p. 419-457.

Manni Piraino 1972 = M. T. Manni Piraino, Iscrizioni greche lapidarie del museo di Palermo, Palerme, 1972.

Marangou 1995 = C. Marangou, A rock engraving in Lemnos (preliminary study), dans Tzalas 1995, p. 309-319.

Marangou $2006=\mathrm{C}$. Marangou, Land and sea connections: the Kastro rock-cut site (Lemnos island, Aegean sea, Greece), dans L. Blue, F. Hocker et A. Englert, Connected by the sea. Proceedings of the tenth International symposium on boat and ship archaeology (Roskilde 2003), Oxford, 2006, p. 130-136.

Marcadé 1946 = J. Marcadé, Sur une base lindienne en forme de proue, dans $R A, 26,1946$, p. 147-152.

Marcadé 1951 = J. Marcadé, Sculptures décoratives du Monument des Taureaux de Délos, dans BCH, 75, 1951, p. 55-89.

Marinatos \& Haägg 1993 = N. Marinatos et R. Haägg (éd.), Greek sanctuaries. New approaches, Londres-New York, 1993.

Martin 1944-45 = R. Martin, Fouilles de Thasos. Campagne de 1939. C. Édifice consacré à Soteira, et Inscriptions, dans BCH, 68-69, 1944-45, p. 147-150 et ibid.154-162.

Martin \& Saludes 1966 = G. Martin et J. Saludes, Hallazgos arqueológicos submarinos en la zona de El Saler (Valencia), dans Archivos de prehistoria levantina, 11, 1966, p. 155-170.

Martínez de Hidalgo 1943 = J. Martínez de Hidalgo, dans Revista general de Marina, 124, 1943, p. 771.

Mas García 1979 = J. Mas García, El puerto de Cartagena. Rasgos geográficos e históricos. Sul tráfico marítimo en la Antiguedad, Carthagène 1979.

Massa 1982 = M. Massa, Rosignano marittimo, dans Arch. sub. 1982, p. 57-62.

Massa 1982-83 = M. Massa, I ceppi d'ancora del museo civico di Robignano marittimo (Livorno), dans Rassegna di archeologia, 3, 1982-1983, p. 167-181.

Mathiesen 1982 = H. E. Mathiesen, Ikaros, the Hellenistic settlements. I. The terracotta figurines, Copenhague, 1982. 
Mattingly 1950 = H. Mattingly, Zephyritis, dans AJA, 54, 1950, p. 126-128. Matz 1951 = F. Matz, Forschungen auf Kreta 1942, Berlin, 1951.

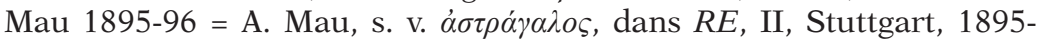
1896, col. 1793-1795.

Mazaubert 1937 = O. Mazaubert, Les dieux marins dans le Livre VI de l'Anthologie Palatine, dans REA, 39, 1937, p. 313-324.

Mc Cartney 1921 = E. S. Mc Cartney, An animal weather bureau, dans The classical weekly, 14, 1921, p. 89-93 et 97-100.

Mc Cartney 1922 = E. S. Mc Cartney, The folk calendar of times and seasons, dans The classical weekly XVI, 1922, p. 3-7.

Mc Cartney 1925 = E. S. Mc Cartney, Magic and the weather in classical Antiquity, dans The classical weekly, 28, 1925, p. 154-157 et 163-166.

Mc Cartney 1926 = E. S. Mc Cartney, The classical astral weather chart for rustics and for seamen, dans The classical weekly, 20, 1926, p. 43-49 et 51-54.

Mc Cartney 1928 = E. S. Mc Cartney, Greek and Roman weather lore of the sun and the moon, dans The classical weekly, 22, 1928, p. 25-31 et 33-37.

Mc Cartney 1929 = E. S. Mc Cartney, Clouds, rainbows, weather galls, comets, and earthquakes as weather prophets in Greek and Latin writers, dans The classical weekly, 23, 1929, p. 2-8 et 11-15.

Mc Cartney 1930 = E. S. Mc Cartney, Greek and Roman weather lore of winds, dans The classical weekly, 24, 1930, p. 11-16, 18-24 et 25-29.

Mc Cartney 1932 = E. S. Mc Cartney, Classical weather lore of thunder and lightning, dans The classical weekly, 25, 1932, p. 183-192, 200-208 et 212-216.

Mc Cartney 1933 = E. S. Mc Cartney, Greek and Roman weather lore of the sea, dans The Classical weekly, 27, 1933, p. 1-6, 9-13, 17-22 et 25-29.

Medas $2000=\mathrm{S}$. Medas, La marineria cartaginese. Le navi, gli uomini, la navigazione, Sassari, 2000 (Sardegna archeologica. Scavi e ricerche, 2).

Medas 2008 = S. Medas, Lo Stadiasmo o Periplo del Mare Grande e la navigazione antica. Commento nautico al più antico testo portolanico attualmente noto, Madrid, 2008 (Gerión, Anejo, 12).

Medas 2010 = S. Medas, Gli occhi e l'anima propria delle barche: religiosità e credenze popolari tra antichità e tradizione, dans Acquaro \& alii 2010, p. 12-23.

Meis 1978 = A. M. de Meis, Ceppi e parti di ancore rinvenuti lungo il litorale di Anzio, dans Bolletino dell'Istituto di storia e di arte del Lazio meridionale, 10, 1978, p. 41-49.

Mercanti 1979 = M. P. Mercanti, Ancorae antiquae. Per una cronologia preliminare delle ancore del Mediterraneo, Rome, 1979 (Studia Archaeologica, 20).

Mercanti 2006 = D. Mercanti, La stoa degli Ateniesi a Delfi, dans Ostraka, 2006, p. 331-340.

Merker 1960 = I. L. Merker, The silver coinage of Antigonos Gonatas and Antigonos Doson, dans The American numismatic Society. Museum notes, 9, 1960, p. 39-52.

Merlin 1912 = A. Merlin, Lingots et ancres trouvés en mer près de Mahdia (Tunisie), dans Mélanges Cagnat. Recueil de mémoires concernant l'épigraphie et les antiquités romaines dédiés par ses anciens élèves du Collège de France à M. René Cagnat (...), Paris, 1912, p. 383-397. 
Mezzetti 2009 = C. Mezzetti (éd.), Il santuario di Hera al capo Lacinio. L'analisi della forma, il restauro, la ricerca archeologica, Rome, 2009.

Miltner 1931 = F. Miltner, s. v. Seewesen, dans RE Supplementband, V, Stuttgart, 1931, col. 906-962.

Mingazzini 1938 = P. Mingazzini, Il santuario della dea Marica alle Foci del Garigliano, dans Monumenti antichi, 37, 1938, col. 693-984 et pl. I-XLV.

Miranda 1989 = E. Miranda, Osservazioni sul culto di Euploia, dans $M G R, 14,1989$, p. 123-144.

Moggi \& Ossana $2000=$ M. Moggi et M. Ossana, Pausania. Guida della Grecia. VII. L'Acaia, Milan, 2000.

Moggi \& Ossana $2010=$ M. Moggi et M. Ossana, Pausania. Guida della Grecia. IX. La Beozia, Milan, 2010.

Moll 1929a = F. Moll, Das Schiff in der bildenden Kunst vom Altertum bis zum Ausgang des Mittelalters, Bonn, 1929.

Moll 1929b = F. Moll, Ein Bleianker, dans AA, 44, 1929, col. 266-271.

Morel 1982 = J.-P. Morel, Marina di Ieranto, Punta della Campanella: observations archéologiques dans la presqu'île de Sorrente, dans Gualandi \& alii 1982, I, p. 147-153 et III, pl. XXIX-XXXIII.

Morelli 1959 = D. Morelli, I culti in Rodi, Pise, 1959 (SCO, 8).

Moreno 1976 = P. Moreno, Una cretula di Cirene e il Posidone del Laterano, dans $Q A L, 8,1976$, p. 81-98.

Morgan 1935 = C. H. Morgan II, The terracotta figurines from the north slope of the Acropolis, dans Hesperia, 4, 1935, p. 189-213.

Morin 1960 = P. J. Morin, The cult of Dea Syria in the Greek world, Ohio, 1960.

Morrison 1941 = J. S. Morrison, The Greek trireme, dans MM, 27, 1941, p. 14-44 et pl. I-VI.

Morrison \& Coates = J. S. Morrison et F. Coates, Die athenische Triere, Mayence, 1990.

Morrison \& Williams 1968 = J. S. Morrison et R. T. Williams, Greek oared ships. 900-322 b.C., Cambridge, 1968.

Morton $2001=\mathrm{J}$. Morton, The role of the physical environment in ancient Greek seafaring, Leyde-Boston-Cologne, 2001 (Mnemosyne suppl., 213).

Motte \& alii 1992 = A. Motte, V. Pirenne-Delforge et P. Wathelet (dir.), Mentor. Guide bibliographique de la religion grecque, Liège, 1992 (Kernos suppl., 2).

Mouchot $1970=$ D. Mouchot, Pièces d'ancres, organeaux et ornements de plomb antiques découverts entre Antibes et Monaco, dans RStudLig, 36, 1970, p. 307-318.

Müller 1855-1861 = C. Müller, Geographi graeci minores, Paris, 2 vol., $1855-1861$.

Murray 1993 = W. M. Murray, Le trophée naval de la victoire d'Actium, dans Marine antique. Dossiers de l'archéologie, 183, juin 1993, p. 66-73.

Murray 1995 = W. M. Murray, La Grèce à l'époque archä̈que, Toulouse.

Murray 2001 = W. M. Murray, A trireme named Isis: the sgraffito from Nymphaion, dans IJNA, 30, 2001, p. 250-256.

Murray 2002 = W. M. Murray, Observations on the "Isis scraffito" at Nymphaion, dans Tzalas 2002, p. 539-562.

Musée docks 1987 = Musée des docks romains, Marseille, 1987. 
Musti \& Beschi 1982 = D. Musti et L. Beschi, Pausania. Guida della Grecia. I. L'Attica, Milan, 1982.

Musti \& Torelli 1986-91 = D. Musti et M. Torelli, Pausania. Guida della Grecia. II. Corinzia e Argolide. III. Laconia. IV. Messenia, Milan, 1986-1991, 3 vol.

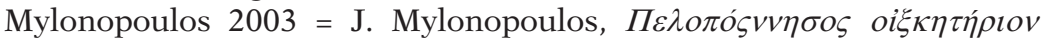

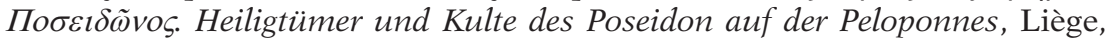
2003 (Kernos suppl., 13).

Nadal 2007 = É. Nadal, De la cavalerie à la flotte athéniennes : l'iconographie attique de Poséidon et l'histoire d'Athènes, dans Chronique d'iconographie antique, Pallas, 75, 2007, p. 151-171.

Nagy 1991 = B. Nagy, The procession to Phaleron, dans Historia, 40, 1991, p. 288-306.

Neilson $2002=\mathrm{H}$. R. Neilson III, A terracota phallus from Pisa ship E: more evidence for the Priapus deity as a protector of Greek and Roman navigators, dans IJNA, 31, 2002, p. 248-253.

Neutsch 1965a = B. Neutsch, [intervention sans titre], dans Taranto 1965, p. 222-223.

Neutsch 1965b = B. Neutsch, Schiffsvotive und Schiffsprozessionen am Cap Palinuro als Nachleben der Antike, dans Klearchos, 7, 1965, p. 93-103.

Newell 1921 = E. T. Newell, The octobols of Histiaea, New York, 1921 (Numismatic notes and monographs, 2).

Nibbi 1984 = A. Nibbi, Ancient Egyptian Anchors. A focus on the facts, dans $M M, 70,1984,3$, p. 247-266.

Nibbi 1991 = A. Nibbi, Five stone anchors from Alexandria, dans IJNA, 20, 1991, p. 185-194.

Nicolás 1974 = J. de Nicolás Mascaró, Arqueología submarina en Menorca. Cepos de ancla romanos, dans Prehistoria y arqueología de las Islas Baleares. VI. Symposium de Prehistoria peninsular (Palma de Mallorca 1972), Barcelone, 1974, p. 447-456.

Nicolet 1988 = C. Nicolet, L'inventaire du monde. Géographie et politique aux origines de l'Empire romain, Paris, 1988.

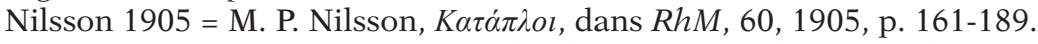

Nilsson 1906 = M. P. Nilsson, Griechische Feste von religiöser Bedeutung, Leipzig, 1906.

Nilsson 1927 = M. P. Nilsson, The Minoan-Mycenaean religion, Lund, 1927.

Nilsson 1954 = M. P. Nilsson, La religion populaire dans la Grèce antique, Paris, 1954.

Nilsson 1955 = M. P. Nilsson, Geschichte der griechischen Religion I, Munich, $1955^{2}$.

Nilsson 1968 = M. P. Nilsson, Dionysos im Schiff, dans Archiv für Religionswissenschaft, II, 1968, p. 399-402.

Ninck 1921 = M. Ninck, Die Bedeutung des Wassers im Kult und Leben der Alten, Leipzig, 1921 (Philologus suppl., 14, 2).

Ninou 1977 = K. Ninou (éd.), Treasures of ancient Macedonia, Thessalonique, 1977.

Nogara 1907 = B. Nogara, Le nozze aldobrandine. I paesaggi con scene dell'Odissea e le altre pitture murali antiche conservate nelle Biblioteca vaticana e nei Musei pontifici, Milan, 1907. 
Nowak $2001=$ T. J. Nowak, A preliminary report on ophtalmoi from the Tektaş Burnu shipwreck, dans IJNA, 30, 2001, p. 86-94.

Nowicka 1999 = M. Nowicka, Quelques remarques sur l'«Isis» de Nymphaion, dans Archeologia, 50, 1999, p. 67-72 et pl. XVII.

Oberhummer 1887 = E. Oberhummer, Akarnanien, Ambrakia, Amphilochien, Leukas im Altertüm, Munich, 1887.

Ohly 1953 = D. Ohly, Holz. VI Votivschiffchen, dans MDAI(A), 68, 1953, p. 111-118.

Oliver 1969 = J. H. Oliver, Octavian's inscription at Nicopolis, dans AJPh, 90, 1969, p. 178-192.

Olmos \& Moreno-Conde $2011=\mathrm{R}$. Olmos et M. Moreno-Conde, Animaux et plantes dans la religion grecque, dans ThesCRA. VIII. Private space and public space. Polarities in religious life. Religious interrelations between the classical world and neighbouring civilizations. Addendum to vol. VI: Death and burial. Supplementum: Animals and plants, Los Angeles, 2012, p. 385-426 et pl. 41-56.

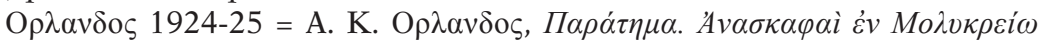

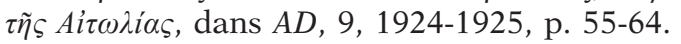

Osanna 1996 = M. Osanna, Santuari e culti dell'Acaia antica, Pérouse, 1996 (Aucnus. Collana di studi di antichistica dell'Istituto di studi comparati sulle società antiche, 5).

Otto 1969 = F. W. Otto, Dionysos. Le mythe et le culte, Paris, 1969.

Overbeck \& Mau 1884 = J. Overbeck et A. Mau, Pompeji. In seinem Gebäuden, Alterhümern und Kunstwerken, Leipzig, 1884.

Pagliara 1971-73 = C. Pagliara, La grotta Porcinara al capo di S. Maria di Leuca I. Le iscrizioni, dans Annali dell'università di Lecce, 6, 1971-1973, p. 5-67.

Pagliara 1991 = C. Pagliara, Santuari costieri, dans I Messapi. Atti del XXX Convegno di studi sulla Magna Grecia (Tarento-Lecce, 4-9 ott. 1990), Tarente, 1991, p. 503-526 et pl. XXIII-XXXII.

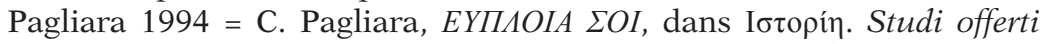
dagli allievi a Giuseppe Nenci in occasione del suo $70^{\circ}$ compleano, Martina Franca, 1994, p. 345-358.

Pailler 1995 = J.-M. Pailler, Bacchus. Figures et pouvoirs, Paris, 1995.

Palladino 2013 = A. Palladino, I "thalamegoi» ellenistici: l'origine e la loro interpretazione come propaganda da parte di Caligola, dans Caligola. La trasgressione al potere, Rome, 2013, p. 135-142.

Pallarés Salvador 1971 = F. Pallarés Salvador, Tipologia y cronologia preliminar de las anclas antiguas, dans Atti Barcellona 1971, p. 384-393.

Panvini 2001 = R. Panvini, La nave greca arcaica di Gela, Palerme, 2001.

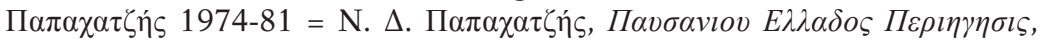
Athènes, 1974-1981, 5 vol.

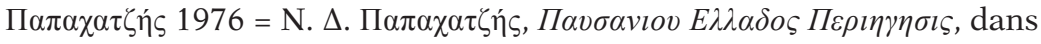
A $\chi E \varphi, 1976$, p. 102-125.

Paris 1906 = P. Paris, Archäologische Funde im Jahre 1905. Spanien, dans $A A, 1906$, col. 168-181.

Parisi Presicce 1985 = C. Parisi Presicce, L'importanza di Hera nelle spedizioni coloniali e nell'insediamiento primitivo delle colonie greche, alla luce della scoperta di un nuovo santuario periferico di Selinunte, dans ArchClass, 37, 1985, p. 44-83. 
Parke $1967=$ H. W. Parke, The oracles of Zeus. Dodona, Olympia, Ammon, Oxford, 1967.

Parke $1977=$ H. W. Parke, Festivals of the Athenians, Londres, 1977.

Parker 1992 = A. J. Parker, Ancient shipwrecks of the Mediterranean \& the Roman provinces, Oxford, 1992 (BAR intern. series, 580).

Parker 1996 = R. Parker, Athenian religion. A history, Oxford, 1996.

Parker $2000=\mathrm{R}$. Parker, Theophoric names and the history of Greek religion, dans S. Hornblower et E. Matthews (éd.), Greek personal names. Their value as evidence, Oxford, 2000, p. 53-80.

Parker 2002 = R. Parker, The cult of Aphrodite Pandamos and Pontia on Cos, dans H. F. J. Horstmanshoff et alii (éd.), Kykeon. Studies in honour of H. S. Versnel, Leyde-Boston-Cologne, 2002 (Religions in the Graeco-Roman world, 142).

Parker 2005 = R. Parker, Polytheism and society at Athens, Oxford, 2005.

Parker 2011 = P. Parker, On Greek religion, Cornell, 2011.

Pascual Guasch 1959 = R. Pascual Guasch, Cepos de ancla romanos recuperados fronte a Blanes (Barcelona), dans Zephyrus, 10, 1959, p. 176-180.

Pasqualini $2000=$ M. Pasqualini, Cumes : cadre géographique et historique, avant-propos à l'étude des ports (note), dans Méditerrannée, 94, 2000, p. 69-70.

Paton 1927 = J. M. Paton, The Erechtheum, Cambridge, 1927.

Patsch 1904 = C. Patsch, Das Sandschak Berat in Albanien, Vienne, 1904 (Schriften der Balkankommission. Antiquarische Ableitung, 3).

Paul 2013 = S. Paul, Cultes et sanctuaires de l'île de Cos, Liège, 2013 (Kernos suppl., 28).

Payne $1940=\mathrm{H}$. Payne, Perachora. The sanctuaries of Hera Akraia and Limenia I, Oxford, 1940.

Peek 1934 = W. Peek, Grieschiche Inschriften, dans MDAI(A), 59, 1934, p. 35-80 et pl. Beitrage IV-V.

Pekáry 1983 = I. Pekáry, Akrostolia auf den hellenistisch-römischen Schiffsdarstellungen, dans Boreas, 6, 1983, p. 119-127 et pl. XVII.

Perea Yébenes 2004 = S. Perea Yébenes, Zeus Kásios Sózon et Afrodita Sózousa, divinidades protectoras de la navegación. A propósito de dos cepos de anclas romanas precedentes de Cabo de Palos, dans Mastia, 3, 2004, p. 95-112.

Perez Casas 1978 = A. Perez Casas, Apuntes para el estudio económico de Almeria en epoca romana: algunos cepos y monedas aparecidos en la costa, dans Cuadernos de prehistoria de la Universidad de Granada, 3, 1978, p. 303-326.

Perret 1942 = J. Perret, Les origines de la légende troyenne de Rome (281-31), Paris, 1942.

Petrakos 1963 = C. Petrakos, Dédicace des Asıvañ $\alpha$ l d'Étrétrie, dans $B C H, 87,1963$, p. 545-547.

Pfuhl 1900 = E. Pfuhl, De Atheniensium pompis sacris, Berlin, 1900.

Phocée 1995 = Phocée et la fondation de Marseille, Marseille, 1995.

Picard 1921 = C. Picard, EAD. VI. L'établissement des Poseidoniastes de Bérytos, Paris, 1921.

Picard $1922=$ Ch. Picard, Éphèse et Claros. Recherches sur les sanctuaires et les cultes d'Ionie du Nord, Paris, 1922 (BEFAR, 123). 
Picard 1940 = C. Picard, L'hérôon de Phrontis au Sounion, dans RA, 16,1940 , p. $5-28$.

Picard 1952 = C. Picard, Sur quelques représentations nouvelles du phare d'Alexandrie et sur l'origine alexandrine des paysages portuaires, $\mathrm{BCH}, 76$, 1952, p. 61-95.

Picard 1959 = C. Picard, Pouzzoles et le paysage portuaire, dans Latomus 18, 1959, p. 23-51.

Picard 1961 = C. Picard, Les marins de Néarque et le relais de l'expédition d'Alexandre dans le golfe Persique, dans RA, 1961, p. 60-65.

Picard $1962=$ Ch. Picard, Lampes d'Isis Pelagia et Euploia : à Délos et ailleurs, dans $R A, 1962,2$, p. 228-230.

Piccirilli 1981 = L. Piccirilli, Le sopracciglia di Artemide, dans CCC, 2, 1981, p. 223-252.

Pickard-Cambridge 1988 = A. W. Pickard-Cambridge, The dramatic festivals in Athens, Oxford, 1988.

Piejko 1988 = F. Piejko, The inscriptions of Icarus-Failaka, dans Classica et mediaevalia, 39, 1988, p. 189-116.

Pippidi 1975 = D. M. Pippidi, Pour une histoire des cultes d'Istros. Documents d'époque hellénistique, dans Scythica Minora. Recherches sur les colonies grecques du littoral roumain de la mer Noire, Amsterdam, 1975, p. 81-95.

Pirenne-Delforge 1994 = V. Pirenne-Delforge, L'Aphrodite grecque, Athènes-Liège, 1994 (Kernos suppl., 4).

Pironti 2007 = G. Pironti, Entre ciel et guerre. Figures d'Aphrodite en Grèce ancienne, Liège, 2007 (Kernos suppl., 18).

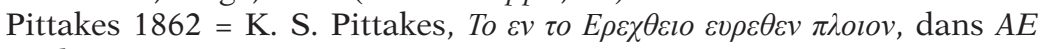
1862, col. 91-94.

Plassart 1928 = A. Plassart, EAD. XI. Les sanctuaires et les cultes du mont Cynthe, Athènes, 1928.

Polignac 1997 = F. de Polignac, Héra, le navire et la demeure: offrandes, divinité et société en Grèce archaïque, dans Colloque Héra 1997, p. 113-122.

Polignac 1998 = F. de Polignac, Navigations et fondations: Héra et les Eubéens de l'Égée à l'Occident, dans Euboica : l'Eubea e la presenza euboica in Calcidica e in Occidente. Atti del Convegno internazionale di Napoli (Napoli, 13-16 novembre 1996), Rome, 1998, p. 23-29.

Polignac 2002, Cultes de sommet en Argolide et Corinthie. Éléments d'interprétation, dans R. Hägg (éd.), Peloponnesian sanctuaries and cults. Proceedings of the $9^{\text {th }}$ Intern. symposium at the Swedish Institute at Athens (11-13 June 1994), Stockholm, 2002, p. 119-122.

Pomey \& alii 1987-88 = P. Pomey et alii, Recherches sous-marines. Antibes, dans Gallia informations, 1987-1988, 1, p. 48.

Poole $1873=$ R. S. Poole, A catalogue of the Greek coins in the British Museum. Italy, Londres, 1873.

Pottier \& Reinach 1887 = E. Pottier et S. Reinach, La nécropole de Myrina, 1887. 1992.

Poursat 1992 = J.-Cl. Poursat, Guide de Malia. Le quartier Mu, Paris,

Powell 1904 = B. Powell, Eniadae III. The small temple, dans AJA, 8, 1904, p. 203-206. 
Prat 1961 = O. Prat, Estado actual de la arquologiá submarina en la Costa Brava (Gerona, España). Ultimas prospecciones y hallazgos. Avance para un estudio de conjunto, dans Atti del II Congresso internazionale di archeologia sottomarina (Albenga 1958), Bordighera, 1961, p. 221-245.

Prestianni Giallombardo 2002 = A. M. Prestianni Giallombardo, L'oracolo di Dodona e le navigazioni adriatiche nei secoli VI-IV a.C., dans L. Braccesi et M. Luni (dir.), I Greci in Adriatico 1. Hesperia 15, Rome, 2002, p. 123-136.

Prêtre 2002 = C. Prêtre (dir.), Études épigraphiques 4. Nouveau choix d'inscriptions de Délos. Lois, comptes et inventaires, Athènes, 2002.

Prontera 1996 = F. Prontera (éd.), La Magna Grecia e il mare. Studi di storia marittima, Tarente, 1996.

Properzio 1989 = P. Properzio, New light on the cults of Artemis and Apollo in Marseilles, dans R. F. Sutton Jr. (éd.), Daidalikon. Studies in memory of Raymond V. Schoder, S.J., Wauconda, 1989, p. 295-299.

Pucci 1976 = G. Pucci, Iside Pelagia : a proposito di una controversia iconografica, dans ASNP, 6, 1976, p. 1177-1191 et pl. LXXIII-LXXVII.

Pugliese Carratelli 1965 = G. Pugliese Carratelli, Theoi apobaterioi, dans Studi in onore di Luisa Banti, Rome, 1965, p. 281-284; réédité dans G. Pugliese Carratelli, Scritti sul mondo antico Europa e Asia. Espansione coloniale, ideologie e istituzioni politiche e religiose, Naples, 1976, p. 513-518.

Pugliese Carratelli 1979 = G. Pugliese Carratelli, Per la storia dei culti delle colonie euboiche d'Italie, dans Gli Eubei in Occidente. Atti del XVIII Convegno di studi sulla Magna Grecia (8-12 ott. 1978), Tarente, 1979, p. 221-230.

Pugliese Carratelli 1992 = G. Pugliese Carratelli, Sul culto di Afrodite Euploia in Napoli, dans PP, 47, 1992, p. 58-61.

Pugliese Carratelli 1996 = G. Pugliese Carratelli (éd.), I Greci in Occidente (mostra del palazzo Grassi, Venezia, marzo-dicembre 1996), Milan, 1996.

Purpura 1986 = G. Purpura, Rinvenimenti sottomarini nella Sicilia occidentale, dans Archeologia subacquea III, Rome, 1986 (BA suppl., 37-38), p. 139-160.

Purpura 1993 = G. Purpura, Rinvenimenti sottomarini nella Sicilia occidentale (1986-89), dans Archeologia subacquea. Studi, ricerche e documenti, I, Rome, 1993, p. 163-184.

Quantin 1999 = Aspects épirotes de la vie religieuse antique, dans REG, 112, 1999, p. 61-98.

Quantin 2004 = F. Quantin, Poséidon en Chaonie et en Illyrie méridionale, dans G. Labarre (éd.), Les cultes locaux dans les mondes grec et romain. Actes du Colloque de Lyon (7-8 juin 2011), Lyon, 2004, p. 153-178.

Quantin 2008 = F. Quantin, Recherches sur l'histoire et l'archéologie du sanctuaire de Dodone, dans Kernos, 2008, p. 9-48.

Quantin \& Quantin 2007 = S. et F. Quantin, Le déplacement du temple d'Athéna Polias en Chaonie. Remarques sur les cosiddetti "temples voyageurs", dans D. Berranger-Auserve (éd.), Épire, Illyrie, Macédoine... Mélanges offerts au Professeur Pierre Cabanes, Clermont-Ferrand, 2007, p. 175-196.

Queyrel $1987=\mathrm{F}$. Queyrel, Le motif des quatre osselets figuré sur des jas d'ancre, dans Archaeonautica, 7, 1987, p. 207-212. 
Queyrel 1990 = F. Queyrel, Aphrodite et les marins, dans H. Tzalas (éd.), TROPIS II. $2^{\text {nd }}$ International symposium on ship construction in Antiquity (Delphi, 27-29 Aug. 1987) proceedings, Athènes, 1990, p. 283-286.

Queyrel 1997 = F. Queyrel, Le motif des quatre osselets sur un jas d'ancre du Musée d'Apollonia de Cyrénaïque, dans Lybia antica, 3, 1997, p. 113-117 et pl. LI.

Radermacher 1949 = L. Radermacher, Das Meer und die Toten, dans Anzeiger der Osterr. Akademie der Wissenschaften in Wien, 86, 1949, p. 307-315.

Radič \& Jurišič 1993 = I. Radič, M. Jurišič, Das antike Schiffswrack von Mljet, Kroatien, dans Germania, 71, 1993, 1, p. 113-138.

Raepsaet \& Tolley 1993 = G. Raepsaet, Le diolkos de l'Isthme à Corinthe : son tracé, son fonctionnement, dans $B C H, 117,1993$, p. 233-256, avec une annexe de M. Tolley, Considérations techniques et mécaniques, dans ibid., p. 257-261.

Ramos \& alii 1984 = J. E. Ramoz, J. Wagner et A. Fernandez, El yacimiento arqueológico submarino de Ben-Afelí. Estudio de los materiales (Almazora, Castellón), dans Cuadernos de prehistoria y arqueología castellonenses, 10, 1984, p. 121-158.

Rassegna arch. sub. 1991 = Atti della IV Rassegna di archeologia subacquea (Giardini Naxos, 13-15 ott. 1989), Messine, 1991.

Rassegna arch. sub. 1994 = Atti della VI Rassegna di archeologia subacquea (Giardini Naxos, 25-27 ott. 1991), Messine, 1994.

Reddé 1986 = M. Reddé, La figure de proue des galères romaines, dans La mythologie, clef de lecture du monde classique. Hommage à $R$. Chevallier, Tours, 1986, (Caesarodonum, 21 bis), I, p. 121-130.

Reinach 1915 = A. Reinach, Notes critiques aux chapitres de Pline relatifs à l'histoire de l'art, dans Revue de philologie, 39, 1915, p. 50-78.

Reinach 1985 = A. Reinach, Recueil Milliet. Textes grecs et latins relatifs à l'histoire de la peinture ancienne, I, Paris, 1985² (éd. complétée par A. Rouveret).

Rendini 1982 = P. Rendini, Isola di Giannutri, dans Arch. sub., 1982, p. 52-53.

Richard 1981 = F. Richard, Les dieux des phares, dans Sefunim, 6, 1981, p. 37-45.

Richter 1936 = G. M. A. Richter, Red-figured Athenian vases in the Metropolitan Museum of art, Oxford, 1936.

Ridder 1896 = A. de Ridder, Catalogue des bronzes trouvés sur l'Acropole d'Athènes, Paris, 1896 (BEFAR, 74).

Ridgway $1970=$ B. S. Ridgway, Dolphins and Dolphin-riders, dans Archaeology, 23, 1970, p. 86-95.

Ringel $1984=$ J. Ringel, Marine motifs on ancient coins at the National Maritime Museum Haifa, Haïfa, 1984.

Ripoll Perelló 1962 = E. Ripoll Perelló, Notas de arqueologia de Cataluña y Baleares. Blanes (Gerona), dans Ampurias, 24, 1962, p. 311-313 et pl. VII, 2.

Robert 1936 = L. Robert, Collection Froehner, I, Paris, 1936.

Robert 1937 = L. Robert, Inscriptions de Téos, dans L. Robert, Études anatoliennes. Recherches sur les inscriptions grecques de l'Asie Mineure, Paris, 1937, p. 9-20. 
Robert 1939 = F. Robert, Thymélé. Recherches sur la signification et la destination des monuments circulaires dans l'architecture religieuse de la Grèce, Paris, 1939 (BEFAR, 147).

Robert 1948 = L. Robert, Le port de Sidè, dans L. Robert, Hellenica. Recueil d'épigraphie, de numismatique et d'antiquités grecques, V, Paris, 1948, p. 69-76 et pl. II, III 1-5.

Robert 1950 = L. Robert, Inscription de Gallipoli et dédicace de Cyzique, dans L. Robert, Hellenica. Recueil d'épigraphie, de numismatique et d'antiquités grecques, IX, Paris, 1950, p. 80-97 et pl. V 5.

Robert 1955 = L. Robert, Apollon Bathylimenitès, dans L. Robert, Hellenica. Recueil d'épigraphie, de numismatique et d'antiquités grecques, X, Paris, 1955, p. 125-133 et pl. XIX 2-3, XXI 1, XXII 3, XXXVIII 2.

Robert $1966=\mathrm{L}$. Robert, Sur un décret d'Ilion et sur un papyrus concernant des cultes royaux, dans Essays in honor of $C$. Bradford Welles, New Haven, 1966 (American studies in papyrology, 1), p. 175-211.

Robert 1968 = L. Robert, Les épigrammes satiriques de Lucillius sur les athlètes : parodie et réalités, dans L'épigramme grecque, Vandœuvres-Genève, 1968 (Entretiens de la Fondation Hardt, 14), p. 181-295.

Robert 1969 = L. Robert, Nouvelles inscriptions d'Iasos. $N^{o}$ 16, dans Opera minora selecta. Épigraphie et antiquités grecques, III, Amsterdam, 1969, p. 1509-1511.

Robert 1989 = L. Robert, Une dédicace de marins, dans L. Robert, Opera minora selecta. Épigraphie et antiquités grecques, VI, Amsterdam, 1989, p. 302-307.

Robert \& Robert 1954 = Louis et Jeanne Robert, La Carie: histoire et géographie historique, avec le recueil des inscriptions antiques. II. Le plateau de Tabai et ses environs, Paris, 1954.

Robertson 1984 = N. Robertson, Poseidon's festival at the winter solstice, dans $C Q, 34,1984$, p. 1-16.

Robertson 1996 = N. Robertson, Athena and early Greek societies: Palladium shrines and promontory shrines, dans M. Dillon (éd.), Religion in the ancient world. New themes and approaches, Amsterdam, 1996, p. 383-475.

Rochier 1975 = R. Rochier, Note sur un des plus gros jas d'ancre antique connu, dans Cahier d'archéologie subaquatique, 6, 1975, p. 149-150.

Rocco 2009 = G. Rocco, Note sul santuario di Afrodite Pandamos e Pontia a Kos, dans ASAA, 87, 2009, p. 599-612.

Roghi 1971 = G. Roghi, La nave romana di capo Graziano, dans Atti Barcellona1971, p. 253-260.

Röhl $1882=\mathrm{H}$. Röhl, Inscriptiones graecae antiquissimae praeter atticas, dans Attica repertas, Berlin, 1882.

Röhl 1907 = H. Röhl, Imagines inscriptionum Graecarum antiquissimarum, Berlin, $1907^{3}$.

Romero Recio 1999 = M. Romero Recio, Inscripción a Zeus Casio y Afrodita sobre ancla de plomo hallada en 1905, dans Ostraka, 8, p. 541-549.

Romero Recio 2000 = M. Romero Recio, Cultos marítimos y religiosidad de navegantes en el mundo griego antiguo, Oxford, 2000 (BAR intern. series, 897).

Romero Recio 2010 = M. Romero Recio, Extrañas ausencias : las fiestas maritimas en el calendario litúrgico griego, dans DHA, 36, 2010, 1, p. 51-117. 
Rougé 1966 = J. Rougé, Le droit de naufrage et ses limitations en Méditerranée avant l'établissement de la domination de Rome, dans R. Chevallier (éd.), Mélanges d'archéologie et d'histoire offerts à André Piganiol, III, Paris, 1966, p. 1467-1479.

Rougé $1974 \mathrm{a}=\mathrm{J}$. Rougé, Conceptions antiques sur la mer, dans Littérature gréco-romaine et géographie historique. Mélanges offerts à Roger Dion, Paris, 1974 (Caesorodonum, 9 bis), p. 275-283.

Rougé $1974 \mathrm{~b}=\mathrm{J}$. Rougé, La marine dans l'Antiquité, Paris, 1974.

Rougé 1987 = J. Rougé, Routes et ports de la Méditerranée antique, dans RStudLig, 53, 1987, p. 151-170.

Rouse 1902 = W. H. D. Rouse, Greek votive offerings, Cambridge, 1902.

Roussel 1915-16 = P. Roussel, Les cultes égyptiens à Délos du III au I Ir s. av., 1915-1916, Nancy (Annales de l'Est).

Roussel 1987 = P. Roussel, Délos, colonie athénienne, Paris, rééd. augm. 1987 (BEFAR, 111).

Roussel \& Hatzfeld 1909 = P. Roussel et J. Hatzfeld, Fouilles de Délos, dans $B C H, 33,1909$, p. 508-510.

Roux 1949 = R. Roux, Le problème des Argonautes. Recherches sur les aspects religieux de la légende, Paris, 1949.

Roux 1957 = G. Roux, Pausanias en Corinthie, Lyon, 1957.

Roux 1963 = G. Roux, Énigmes à Delphes, Paris, 1963.

Roux 1981 = G. Roux, Problèmes déliens : le Néôrion et le "vaisseau de Délos » (Pausanias I, xxix, 1), dans BCH, 105, 1981, p. 61-71.

Roux 1989 = G. Roux, L'inventaire ID 1403 du Néôrion délien, dans $B C H, 113,1989$, p. 262-275.

Rudhardt 1971 = J. Rudhardt, Le thème de l'eau primordiale dans la mythologie grecque, Berne, 1971.

Rudhardt 1992 = J. Rudhardt, Notions fondamentales de la pensée religieuse et actes constitutifs du culte dans la Grèce classique, Paris, 1992².

Ruegg 1893 = B. S. D. Ruegg, The Roman port and bridge at Minturnae, Italy, dans IJNA, 12, 1983, p. 203-218.

Ruiz de Arbulo 2000 = J. Ruiz de Arbulo, El papel de los santuarios en la colonización fenicia e griega en la península iberica, dans Costa \& Fernández 2000, p. 9-56.

Russi 1989 = A. Russi, La grotta con iscrizioni sull'isolotto del Faro di Vieste (Foggia). Note preliminari, dans Miscellanea greca e romana XIV, Rome, 1989 (Studi pubblicati dall'Istituto italiano per la storia antica, 45), p. 289-309.

Russo \& alii $=$ Russo \& alii, Punta della Campanella. Epigrafie rupestre e reperti cari dall'Athenaion, Rome, 1990 (MonAnt, 3, 5).

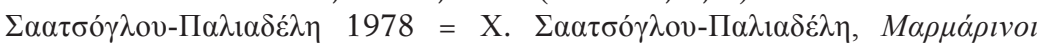

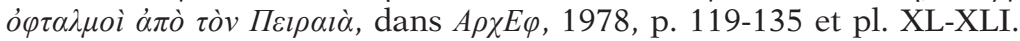

Sahin 2005 = M. Sahin, Terrakotten aus Knidos : erste Ergebnisse. Die Kulte auf der Rundtempelterrasse, dans MDAI(I), 55, 2005, p. 65-97.

Saint-Denis 1935 = E. de Saint-Denis, Le rôle de la mer dans la poésie latine, Lyon, 1935.

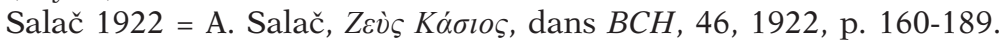

Salles 1984 = J.-F. Salles (dir.), Failaka. Fouilles françaises 1983, Lyon, 1984 (Travaux de la Maison de l'Orient, 9). 
Salles 1986 = J.-F. Salles (dir.), Failaka. Fouilles françaises 1984-1985, Lyon, 1986 (Travaux de la Maison de l'Orient, 12).

Salvi 1991 = D. Salvi, Prime considerazioni sullo scavo di un relitto romano presso l'isola di Mal di Ventre, dans Rassegna arch. sub. 1991, p. 147-153.

Salviat 1984 = F. Salviat, Le navire Argô sur les métopes sicyoniennes à Delphes, dans Archaeonautica, 4, 1984, p. 213-222.

Salviat 1989 = F. Salviat, Le bateau de Thésée, le vase François et les "triacontoroi», dans Tzalas 1989, p. 229-240.

Salviat 1992 = F. Salviat, Sur la religion de Marseille grecque, dans Marseille grecque et la Gaule. Actes du Colloque international d'histoire et d'archéologie et du $V^{e}$ Congrès archéologique de la Gaule méridionale (Marseille, 18-23 novembre 1990), Lattes-Aix-en-Provence, 1992 (Études massaliètes, 3), p. 141-150.

Salviat 1993 = F. Salviat, Timodamos et son gaulos. Oracles et marchands à Dodone, dans L'Illyrie méridionale et l'Épire dans l'Antiquité II. Actes du II Colloque international de Clermont-Ferrand (25-27 oct. 1990), Paris, 1993, p. 61-64.

Sandberg 1954 = N. Sandberg, Euploia. Études épigraphiques, dans Göteborgs Högskolas Arsskrift, 55, 8, 1954; compte-rendu par J. et L. Robert, Bulletin épigraphique, 1956, n 3.

Santuari Calabria 1996 = Santuari della Magna Grecia in Calabria (mostre di Calabria, giugno 1996), Salerne, 1996.

Saporiti 2005 = M. Saporiti, Poseidon-Neptunus a bordo delle navi romane. Note sulla statuetta bronzea dal relitto di Grado, dans Workshop di archeologia classica. Paesaggi, costruzioni, reperti, II, 2005, p. 21-38.

Schachermeyr 1950 = F. Schachermeyr, Poseidon und die Enstehung des griechischen Götterglauben, Salzbourg, 1950.

Schachter 1981-86 = A. Schachter, Cults of Boiotia, I, Londres, 1981 (Institute of classical studies suppl., 38, 1); id. II, Londres, 1986.

Schefold 1981 = K. Schefold, Die Göttersage in der klassische und hellenistische Kunst, Munich, 1981.

Schipporeit $2011=$ S. T. Schipporeit, Kultinstrumente. Wagen, Traggestelle und Schiffe, dans ThesCRA. V. Personnel of cult. Cult instruments, Los Angeles, 2005, p. 286-302 et pl. LIII-LV.

Schlosser 2014 = P. Schlosser, Cyzique et la mer, dans Sève \& Schlosser 2014, p. 253-276.

Schlumberger $1880=\mathrm{M}$. Schlumberger, Ancre antique en plomb, trouvée sur la côte de Carie, dans Bulletin de la Société nationale des antiquaires de France, 1880, p. 85-86

Schmidt 1931 = K. Schmidt, Die Namen der attischen Kriegsschiffe, Engelsdorf-Leipzig, 1931.

Schmiedt \& Chevallier $1959=$ G. Schmiedt et R. Chevallier, Caulonia e Metaponto. Applicazioni della fotografia aerea in ricerche di topografia antica nella Magna Grecia, Firenze, 1959.

Schumacher $1993=\mathrm{R}$. W. Schumacher, Three related sanctuaries of Poseidon: Geraistos, Kalaureia and Tainarion, dans Marinatos \& Haägg 1993, p. 62-87.

Schwabl 1972-78 = H. Schwabl, s. v. Zeus, dans $R E^{2}, \mathrm{X}, 1$, München, 
1972, col. 253-376, complété dans RE Supplementband, XV, Munich, 1978, col. 993-1481.

Schweitzer 1922 = B. Schweitzer, Archäologische Funden in den Jahren 1916-1922. Messenien, dans Archäologischer Anzeiger 1922, p. 310-315

Schwyzer 1923 = E. Schwyzer, Dialectorum graecarum exempla epigraphica potiora, Leipzig, 1923.

Sciarra 1966 = B. Sciarra, Ricuperi sottomarini nel Brindisino, dans Forma maris antiquis, 7, 1966, p. 341-352.

Sciarra 1976 = Sciarra 1976 = B. Sciarra, Brindisi, Museo archeologico provinciale, Bologne, 1976, p. 10-12.

Sciarra 1985 = B. Sciarra, Archeologia subacquea : risultati dell'attività svolta lungo il litorale brindisino, dans VI Congreso internacional de arqueología submarina (Cartagena, 1982), Madrid, 1985, p. 143-145.

Scranton \& Ramage 1964 = R. Scranton et E. Ramage, Investigations at Kenchreai 1963, dans Hesperia, 33, 1964, p. 134-145 et pl. XXIII-XXIV.

Scranton \& alii $1978=$ R. Scranton, J.W. Shaw et L. Ibrahim, Kenchreai I, Leyde, 1978.

Sébillot 1901 = P. Sébillot, Le Folk-lore des pêcheurs, Paris, 1901.

Séchan 1955 = L. Séchan, Légendes grecques de la mer, dans BAGB, 4, Paris, 1955, p. 3-47.

Séchan \& Lévêque 1966 = L. Séchan et P. Lévêque, Les grandes divinités de la Grèce, Paris, 1966.

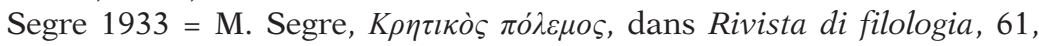
1933, p. 365- 392.

Segre 1993 = M. Segre, Iscrizioni di Cos, Rome, 1993, 2 vol.

Semple $1927=$ E. C. Semple, The templed promontories of the ancient Mediterranean, dans Geographical review, 17, 1927, 3, p. 352-386.

Semple 1932 = E. C. Semple, The geography of the Mediterranean region. Its relation to ancient history, Londres, 1932.

Sève \& Schlosser 2014 = M. Sève et P. Schlosser, Cyzique, cité majeure et méconnue de la Propontide antique, Metz 2014 (Centre de recherche univ. lorrain d'histoire, 51).

Seyrig 1951 = H. Seyrig, Antiquités de Beth Maré, dans Syria, 28, 1951, p. 101-123 et pl. IX-XII.

Shear $1978=$ T. L. Shear, Kallias of Sphettos and the revolt of Athens in 286 b.c., Princeton, 1978 (Hesperia suppl., 17).

Simon 1959 = E. Simon, Die Geburt der Aphrodite, Berlin, 1959.

Simon 1994 = E. Simon, s. v. Poseidon, dans LIMC, VII, Berne, 1994, 1 p. $446-479$ et 2 p. $352-378$.

Simon 1997 = E. Simon, s. v. Kybele, dans LIMC, VIII, Berne, 1997, 1 p. $744-766$ et 2 p. $506-519$.

Simon 1998 = E. Simon, Die Götter der Griechen, Munich, 19984.

Simpson 1966 = R. H. Simpson, Routes from Laconia to Messenia, dans ABSA, 51, 1966, p. 125-131.

Sinn 1988 = U. Sinn, Der Kult der Aphaia auf Aegina, dans Early Greek cult practice. Proceedings of the $V^{\text {th }}$ Intern. symposium at the Swedish institute at Athens (26-29 june 1986), Stockholm, 1988 (Acta Instituti Atheniensis regni sueciae, $\left.4^{\circ}, 38\right)$, p. 149-159.

Sinn 1992 = U. Sinn, Sunion. Das befestigte Heiligtum der Athena 
und des Poseidon an der "Heiliger Landspitze Attikas», dans AW, 23, 1992, p. 175-190.

Sirinelli 1993 = J. Sirinelli, Les enfants d'Alexandre. La littérature et la pensée grecques (334 av. J-C.-519 ap. J-C.), Paris, 1993.

Six 1885 = J. Six, De Gorgone, Amsterdam, 1885.

Six 1894 = J. Six, Der Agyieus des Mys, dans MDAI(A), 19, 1894, p. 340-345. 1955. 1969.

Sokolowski 1955 = F. Sokolowski, Lois sacrées de l'Asie Mineure, Paris,

Sokolowski 1969 = F. Sokolowski, Lois sacrées des cités grecques, Paris,

Somville 1984 = P. Somville, Le dauphin dans la religion grecque, dans RHR, 201, 1984, p. 3-24.

Sonno 1997 = M. Sonno, Rinvenimenti sottomarini lungo il litorale di Civitavecchia, dans Arch. sub. Studi, 1997, p. 75-87.

Sordi 1985 = M. Sordi, L'Apollo del promontorio Pachino e i ludi apollinari, dans Klearchos, 27, 1985, p. 75-81.

Spadea 1994 = R. Spadea, Il tesoro di Hera, dans BA, 88, 1994, p. 1-34.

Spadea 1996 = R. Spadea (éd.), Il tesoro di Hera. Scoperte nel santuario di Hera Lacinia a Capo Colonna di Crotone, Milan, 1996.

Spadea 1997 = R. Spadea, Santuari di Hera a Crotone, dans Colloque Héra 1997, p. 235-259.

Speich 1982 = R. Speich, Korfu, Stuttgart, 1982.

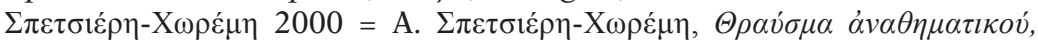

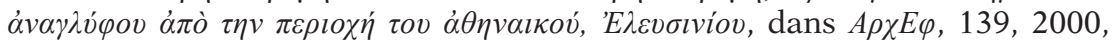
p. $1-18$.

Spigo 1991 = U. Spigo, Due rappresentazioni fittili di navi greche, dans Rassegna arch. sub. 1991, p. 71-83.

Stadler $1901=$ H. Stadler, s. v. Delphinios, dans RE, IV, Stuttgart, 1901, col. 2513-2515.

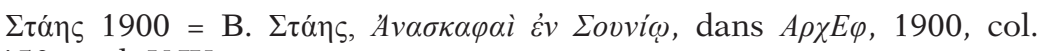
113-150 et pl. V-IX. 1910.

Stais 1910 = V. Stais, Marbres et bronzes du Musée National, Athènes,

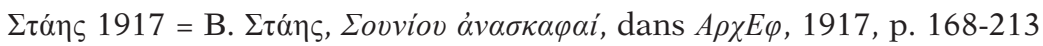
et pl. IV-IX.

Starck 1937 = M. Starck, Baghdad sketches, Londres, 1937.

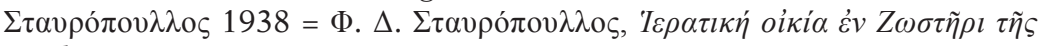

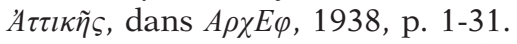

Stazio 1965 = A. Stazio, La documentazione archeologica in Puglia, dans Taranto 1965, 1965, p. 153-178.

Stebbins 1929 = E. B. Stebbins, The Dolphin in the litterature and art of Greece and Rome, Manasha, 1929.

Stefani 1951 = E. Stefani, Una serie di lastre fittili dipinte del santuario etrusco di Veio, dans ArchClass, 3, 1951, p. 138-146 et pl. XXX.

Stefani 1953 = E. Stefani, Veio. Tempio detto dell'Apollo. Esplorazione e sistematizione del santuario, dans NSA, 7, 1953, p. 29-112

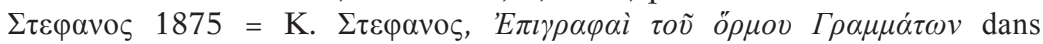
Atqvalov, 4, 1875, p. 3-32. 
Steffy $1983=$ R. Steffy (avec compléments d'autres auteurs), The Athlit Ram, a preliminary investigation of its structure, dans $M M, 69,1983,3$, p. 229-250. 1910.

Stengel 1910 = P. Stengel, Opferbräuche der Griechen, Leipzig-Berlin,

Stillwell 1952 = A. N. Stillwell, Corinth. XV. The Potter's quarter. 2. The terracotas, Princeton, 1952.

Strijd 1904 = J. H. W. Strijd, Epigraphica. De inscriptionibus in insula Prote nuper inventis, dans Mnemosyne, 32, 1904, p. 361-369. 1960.

Susini 1960 = G. Susini, Il lapidario greco e romano di Bologna, Bologne,

Susini 1962 = G. Susini, Fonti per la storia greca e romana del Salento, Bologne, 1962.

Susini 1971 = G. Susini, Iuppiter Serenus e altri dei, dans Epigraphica, 33, 1971, p. 175-177.

Susini 1975 = G. Susini, Culti salutari e delle acque. Materiali antichi nella Cispadana, dans StudRomagn, 26, 1975, p. 321-338.

Svoronos 1894 = J. N. Svoronos, Sur la signification des types monétaires des Anciens, dans BCH, 18, 1894, p. 100-127.

Svoronos 1899 = J. Svoronos, Der athenische Volkskalender, dans Journal international d'archéologie numismatique, 2, 1899, Athènes, p. 21-78 et pl. B-E.

Svoronos 1914 = J. N. Svoronos, Stylides, ancres hierae, aphlasta, stoloi, ackrostolia, embola, proembola et totems marins, dans Journal international d'archéologie numismatique, 16, 1914, Athènes, p. 81-152.

Svoronos 1923-26 = J. Svoronos, Les monnaies d'Athènes, Munich, 1923-1926.

Szeliga 1986 = G. N. Szeliga, The Argo metopes from the monopteros at Delphi, dans AJA, 90, 1986, p. 297-305 et pl. XVIII.

Taranto 1965 = Atti del IV Convegno di studi sulla Magna Grecia (Taranto-Reggio di Calabria, 11-16 ott. 64), Naples.

Tarn 1909 = W. W. Tarn, The battles of Andros and Cos, dans JHS, 29, 1909, p. 264-285.

Tarn 1910 = W. W. Tarn, The dedicated ship of Antigonus Gonatas, dans JHS, 30, 1910, p. 209-222.

Tassignon 2005 = I. Tassignon, Naturalia et curiosa dans les sanctuaires grecs, dans Dasen \& Piérart 2005, p. 289-300.

Teixidor 1979 = J. Teixidor, The pantheon of Palmyra, Leyde, 1979 (Études préliminaires aux religions orientales dans l'empire romain, 79).

Tenne 1915 = A. Tenne, Kriegschiffe zu den Zeiten der alten Griechen und Römer, Oldenburg.

Texier 1839-49 = C. Texier, Description de l'Asie Mineure, Paris, 18391849,3 vol.

Texier 1934 = R. Texier, Aphrodite Aineias à Leucade, dans RPh LX, 1934, p. 159-164.

Thély 2014 = L. Thély, Le culte de Poséidon Asphaleios à Cyzique, dans Sève \& Schlosser 2014, p. 253-276.

Thémélis 1974 = P. G. Thémélis, Sounion-Thorikos, Athènes, 1974.

Thracia 1986 = Thracia Pontica III. III Symposion international. Thème 
général: Les Thraces et les colonies grecques, VII-Ve s. av. n.è. Table Ronde sur les ancres anciennes (Sozopol, 6-12 oct. 1985), Sophia, 1986.

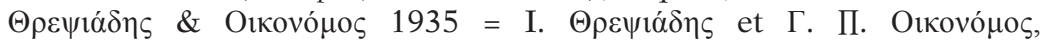

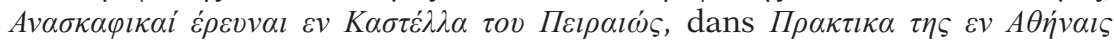

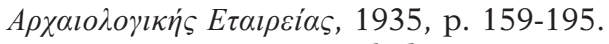

Tiverios 1996 = Michalis Tiverios, Shield devices and column-mounted statues on Panathenaic amphoras, dans J. Neils (éd.), Worshipping Athena. Panathenaia \& Parthenon, Madison, 1996, p. 163-174.

Tod 1943 = M. N. Tod, A Greek inscription from the Persian Gulf, dans JHS, 63, 1943, p. 112-113.

Tod $1946=$ M. N. Tod, Selection of Greek historical inscriptions, Oxford, 1946.

Tomlinson 1992 = R. A. Tomlinson, Perachora, dans Le sanctuaire grec, Genève, 1992 (Entretiens de la fondation Hardt, 37), p. 321-346 et pl. h-texte; discussion p. 347-351.

Tondriau 1948 = J. L. Tondriau, Notes ptolémä̈ques. III. Les cultes maritimes royaux, dans Aegyptus, 28, 1948, p. 172-175.

Torelli 1970 = M. Torelli, Gravisca, santuario greco, dans Nuovi tesori dell'antica Tuscia. Catalogo della Mostra (Viterbo 1970), Viterbe, 1970, p. 55-59 et pl. XVIII-XIX.

Torelli 1971 = M. Torelli, Il santuario di Hera a Gravisca, dans PP, 26, 1971, p. 44-67.

Torelli 1977 = M. Torelli, Il santuario greco di Gravisca, dans PP, 32, 1977, p. 398-458.

Torelli 1982 = M. Torelli, Per la definizione del commercio grecoorientale: il caso di Gravisca, dans PP, 37, 1982, p. 304-326.

Torelli 1986 = M. Torelli, Tarquinia and its emporion at Gravisca. A case in maritime trade in the VIt century b.C., dans Thracia 1986, p. 46-53.

Torelli \& alii 1971 = M. Torelli et alii, Gravisca (Tarquinia). Scavi sulla città etrusca e romana. Campagne 1969 e 1970, dans NSA, 1971, 1, p. 195-299. 1964).

Torr 1894 = C. Torr, Ancient ships, Cambridge, 1894 ( $2^{\mathrm{e}}$ éd., Chicago,

Travlos 1971 = J. Travlos, Pictorial dictionnary of ancient Athens, Londres, 1971.

Travlos 1988 = J. Travlos, Bildlexikon zur Topographie des antiken Attika, Tübingen, 1988.

Tréheux 1976 = J. Tréheux, Retour sur l'Artémision de l'île, dans Recueil Plassart, Paris, 1976, p. 175-204.

Tréheux 1986 = J. Tréheux, Un document nouveau sur le Néôrion et le Thesmophorion à Délos, dans REG, 99, 1986, p. 301-309.

Tréheux 1987 = J. Tréheux, Sur le Néorion à Délos, dans CRAI, 1987, p. 168-184.

Trippé 2008 = N. Trippé, Sur une inscription de Cyzique, dans REA CX, 2008, p. 383-401.

Tronchet Bonaventura $1994=$ E. Tronchet Bonaventura, Scoperte nelle acque di Taormina, dans Rassegna arch. sub. 1994, p. 149-157.

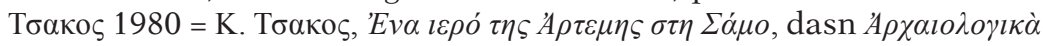
$\dot{\alpha} v \dot{\alpha} \lambda \varepsilon \kappa \tau \alpha \dot{\varepsilon} \xi \dot{A} A \theta \eta v \tilde{\omega} v, 13,1980$, p. 305-318.

Turcan $1992=\mathrm{R}$. Turcan, Les cultes orientaux dans le monde romain, Paris, $1992^{2}$. 
Tusa 1959 = V. Tusa, Rinvenimenti sottomarini nella Sicilia Occidentale, dans Fasti archaeologici, 14, 1959, p. 282 n 4282.

Tusa 1971 = V. Tusa, I rinvenimenti archeologici sottomarini nella Sicilia nord-occidentale tra il II e III Congresso internazionale, dans Atti Barcellona 1971, p. 263-295.

Tusa 1973 = V. Tusa, Ancore antiche nel museo di Palermo, dans Blackmann 1973, p. 411-437.

Tusa $2010=\mathrm{S}$. Tusa, Ritualità e religiosità nelle antiche navigazioni mediterranee nella prospettiva archeologica, dans Acquaro \& alii 2010, p. 1-9.

Tzalas $1989=\mathrm{H}$. Tzalas (éd.), TROPIS I. $1^{\text {st }}$ International symposium on ship construction in Antiquity (Piraeus, 30 Aug.-1 Sept. 1985) proceedings, Athènes, 1989.

Tzalas $1990=\mathrm{H}$. Tzalas (éd.), TROPIS II. $2^{\text {nd }}$ International symposium on ship construction in Antiquity (Delphi, 27-29 Aug. 1987) proceedings, Athènes, 1990.

Tzalas 1995 = H. Tzalas (éd.), TROPIS III. $3^{\text {rd }}$ International symposium on ship construction in Antiquity (Athens, 24-27 Aug. 1989) proceedings, Athènes, 1995.

Tzalas $2002=\mathrm{H}$. Tzalas (éd.), TROPIS VII. $7^{\text {th }}$ International symposium on ship construction in Antiquity (Pylos, 26-29 Aug. 1999) proceedings, Athènes, 2002.

Ucelli 1950 = G. Ucelli, Le navi di Nemi, Rome, 2e éd. 1950.

Valenza Mele 1977 = N. Valenza Mele, Hera ed Apollo nella colonizzazione euboica d'Occidente, dans MEFRA, 89, 1977, p. 493-524.

Valenza Mele 1991-92 = N. Valenza Mele, Hera ed Apollo a Cuma e la mantica sibillina, dans RIA, 14-15, 1991-1992, p. 5-72.

Vallois 1929 = R. Vallois, Le temple délien d'Arsinoé Philadelphe ou d'Agathé Tyché, dans CRAI, 1929, p. 32-40.

Vallois 1944 = R. Vallois, L'architecture hellénique et hellénistique à Délos. I. Les monuments, Paris, 1944.

Van Compernolle \& alii $1978=\mathrm{R}$. Van Compernolle et alii, Leuca, Galatina, 1978 (Collana dell'Istituto di archeologia e storia antica, 1).

Van Nouhys 1951 = J. Van Nouhys, The anchor, dans MM, 37, 1951, 1, p. 17-47.

Van Straten 1981 = F. T. Van Straten, Gifts for the Gods, dans Faith, hope and worship. Aspects of religious mentality in the ancient world, Leyde, 1981 (Studies in Greek and Roman religion, 2), p. 65-151.

Vélissaropoulos $1980=\mathrm{J}$. Vélissaropoulos, Les nauclères grecs. Recherches sur les institutions maritimes en Grèce et dans l'Orient hellénisé, Genève-Paris, 1980 (IVe section de l'EPHE, Hautes études du monde gréco-romain, 9).

Vernant 1970 = J-P. Vernant, Thétis et le poème cosmogonique d'Alcman, dans Hommages à Marie Delcourt, Bruxelles, 1970 (Latomus, 114), p. $38-69$.

Veyne 1965 = P. Veyne, Apulée à Cenchrées, dans Revue de philologie, 39, 1965, p. 241-251.

Vian 1952 = F. Vian, Génies des passes et des défilés, dans RA, 39, 1952, 1, p. $129-155$.

Vian 1968 = F. Vian, La fonction guerrière dans la mythologie grecque, 
dans Problèmes de la guerre en Grèce ancienne, Paris-La Haye, 1968 (Civilisations et sociétés, 11), p. 53-68.

Vian 1974 = F. Vian, Légendes et stations argonautiques du Bosphore, dans Littérature gréco-romaine et géographie historique. Mélanges offerts à René Dion, Paris, 1974 (Caesorodonum, 9 bis), p. 91-104.

Vian 1983 = F. Vian, Le passage des roches Kyanées dans les Argonautiques orphiques, dans Mélanges Édouard Delebecque, université de Provence, 1983, p. 451-463.

Virlouvet 1998 = C. Virlouvet, La culture maritime dans l'Antiquité. Introduction, dans MEFRA, 110, 1998, p. 7-9.

Vlachou 2010 = M. Vlachou, Le Monument des taureaux : une consécration d'Antigone le Borgne et de Démétrios Poliorcète?, dans Mare internum, 2, 2010, p. 71-80.

Volkommer 1997 = R. Volkommer, s. v. Zeus (in peripheria orientali). Anatolien, dans LIMC, VIII, Berne, 1997, 1 p. 374-384 et 2 p. 242-250.

Wace \& Hasluck 1907-08 = A. J. B. Wace et F. W. Hasluck, Laconia II. Topography. South-eastern Laconia, dans ABSA, 14, 1907-1908, p. 160-182.

Wachsmann 1986 = S. Wachsmann, Shfifons-early bronze age anchor shaped cult stones from the Sea of Galilee Region, dans Thracia 1986, p. 395403 et pl. p. 542-554.

Wachsmuth $1967=\mathrm{D}$. Wachsmuth, POMPIMOS O DAIMWN (Untersuchung zu den Antiken Sakhralhandlungen bei Seereisen), Berlin, 1967.

Wade-Gery 1933 = H. T. Wade-Gery, Notes on "akroteria", dans JHS, 53, 1933, p. 99-101.

Waele 1963 = J. A. K. de Waele, Intorno ad un'iscrizione della Malophoros, dans Kokalos, 11, 1963, p. 195-204 et pl. LXI-LXII.

Wagner 1901 = R. Wagner, s. v. Delphin, dans RE, IV, Stuttgart, 1901, col. 2504-2510.

Walsh 1986 = J. Walsh, The date of the Athenian stoa at Delphi, dans AJA 90, 1986, p. 319-336.

Walter 1952 = O. Walter, Zum Lenormantschen Schiffsrelief, dans Festschrift A. Rumpf. Zum 60 Geburtstag dargebracht von Freuden und Schülern, Cologne, 1952, p. 131-140.

Walter 1976 = H. Walter, Das Heraion von Samos, Munich, 1976.

Walter 1990 = H. Walter, Das griechische Heiligtum dargestellt am Heraion von Samos, Stuttgart, 1990.

Walter 1993 = H. Walter, Aigina, Munich, 1993.

Walters $1926=$ H. B. Walters, Catalogue of the engraved gems and cameos Greek, Etruscan and Roman in the British Museum, Londres, 1926.

Weitemeyer \& Döhler 2009 = C. Weitemeyer, H. Döhler, Traces of Roman offshore navigation on Sherki Bank (strait of Sicily), dans IJNA, 38, 2009 , 2, p. 254-280.

Welter 1938 = G. Welter, Aeginetica XV. Anker, dans AA, 1938, col. 489491 et pl. col. 499-500.

Welter 1941 = G. Welter, Troizen und Kalaureia, Berlin, 1941.

Welter 1962 = G. Welter, Aigina, Athènes, 1962.

Werner 1993 = W. Werner, Der Kanal von Korinth und sein Vorläufer, dans Das Logbuch, 1993, p. 1-71. 
Wernicke 1895-96a = K. Wernicke, s. v. Apollon, dans RE, II, Stuttgart, 1895-1896, col. 1-111, avec un complément succinct par W.A. Oldfather, dans RE Supplementband, III, Stuttgart, 1918, col. 133.

Wernicke 1895-96b = K. Wernicke, s. v. Artemis, dans RE, II, Stuttgart, 1895-1896, col. 1335-1440.

Wide 1893 = S. Wide, Lakonische Kulte, Leipzig, 1893.

Wilamowitz-Moellendorff 1919 = U. von Wilamowitz-Moellendorff, Lesefruchte, dans Hermes, 54, 1919, p. 46-74.

Wilamowitz 1931-32 = U. von Wilamowitz, Der Glaube der Hellenen, Berlin, 1931-1932, 2 vol.

Will 1953 = É. Will, Sur la nature de la mantique pratiquée à l'Héraion de Pérachora, dans RHR, 143, 1953, p. 145-169.

Will 1955 = É. Will, Korinthiaka. Recherches sur l'histoire et la civilisation de Corinthe des origines aux guerres médiques, Paris, 1955.

Will 1972 = É. Will, Le monde grec et l'Orient I. Le Ve siècle, Paris, 1972 (ou $2^{\mathrm{e}}$ éd. 1889).

Will 1979-82 = É. Will, Histoire politique du monde hellénistique, Paris, 1979-1982².

Will \& alii 1975 = É. Will, C. Mossé et P. Goukowsky, Le monde grec et l'Orient. II. Le IV siècle et l'époque hellénistique, Paris, 1975 (ou 2 2éd. 1985).

Willetts 1962 = R. F. Willetts, Cretan cults and festivals, Londres, 1962.

Williams 1986 = C. K. Williams II, Corinth and the cult of Aphrodite, dans M. A. Del Chiaro et W. R. Biers (éd.), Corinthiaca. Studies in honor of Darell A. Amyx, Columbia, 1986, p. 12-24.

Williams $1989=$ H. Williams, Figureheads on Greek and Roman ships, dans Tzalas 1989, p. 293-297.

Witte 1879 = J. de Witte, Mélicerte, dans Gazette archéologique, 5, 1879, p. 217-221.

Wolters 1925a = P. Wolters, Ausgrabungen am Aphroditetempel in Aegina 1924, dans Gnomon, 1, 1925, p. 46-49.

Wolters $1925 \mathrm{~b}=\mathrm{P}$. Wolters, Forschungen auf Aegina, dans AA, 40, 1925, col.1-12.

Woodward 1906-07 = A. M. Woodward, Laconia: topography and inscriptions of Taenarum and S. Maina, dans ABSA, 13, 1906-1907, p. 245-246.

Wroth 1892 = W. Wroth, British Museum. A catalogue of the Greek coins of Mysia, Londres, 1892.

Wroth 1894 = W. Wroth, British Museum. A catalogue of the Greek coins of Troas, Aeolis and Lesbos, Londres, 1894.

Wuilleumier $1939=\mathrm{P}$. Wuilleumier, Tarente des origines à la conquête romaine, Paris, 1939 (BEFAR, 148).

Wurster 1974 = W. W. Wurster, Alt-Aegina I, 1, Munich, 1974.

Wüst 1953 = E. Wüst, s. v. Poseidon, dans RE, XXII, Stuttgart, 1953, col. 446-557.

Yon 1982 = M. Yon, Le maître de l'eau à Kition, dans Archéologie au Levant. Recueil à la mémoire de R. Saidah, Lyon, 1982 (Coll. de la Maison de l'Orient méditerranéen, 12, série archéologique, 9), p. 251-263.

Zancani Montuoro $1965=\mathrm{P}$. Zancani Montuoro, (intervention sans titre), dans Taranto 1965, p. 202-213. 
Zancani Montuoro \& Zanotti-Bianco 1951-54 = P. Zancani Montuoro et U. Zanotti-Bianco, Heraion alla foce del Sele, Rome, 1951-1954, 4 vol.

Zapheiropoulou 1997 = P. Zapheiropoulou, La relation entre l'Héraion et la ville de Samos, dans Colloque Héra 1997, p. 151-162.

Zemer 1981 = A. Zemer, Anchor stocks decorated with dolphins and astragals from the sea near Haifa, dans Sefunim, 6, 1981, p. 58-67.

Zucca $1985=$ R. Zucca, Rinvenimenti archeologici sottomarini presso il

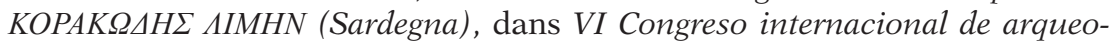
logía submarina (Cartagena, 1982), Madrid, 1985, p. 149-151. 

BIBLIOGRAPHIE DES SOURCES LITTÉRAIRES ET DES CORPUS D'INSCRIPTIONS 

Pour les sources littéraires les plus courantes, nous renvoyons aux éditions bilingues françaises Belles Lettres (signalées dans les notes sous la forme "éd. Budé») et anglaises Loeb, ainsi qu'aux éditions Teubner $(=\mathrm{TB})$ et Oxford Classical Texts $(=\mathrm{OCT})$.

Autres titres utilisés dans ce volume:

\section{Anthologie Palatine}

Pour les épigrammes hellénistiques et de la première moitié du $\mathrm{I}^{\mathrm{er}}$ s. p.C., sont également indiquées les références à l'édition suivante :

The Greek Anthology (I. Hellenistic Epigrams : abrégée en H.E; II. The Garland of Philip : abrégée en G.P.), éd. A. S. F. Gow \& D. L. Page, Cambridge, 1965-68.

Aelius Aristide

Aristides, éd. G. Dindorf, Leipzig, 1829, 3 vol.

Antimaque

Epicorum graecorum Fragmenta, éd. G. Kinkel, TB, 1877.

Aristophane (scholies à -)

Scholia in Aristophanem, éd. W. J. W. Koster, Groningen, 19601996 [pour les Guèpes, les Acharniens].

Scholia graeca in Aristophanem, éd. F. Dübner, Paris, 1842 [pour la Paix].

Callimaque

Pour les Épigrammes : voir supra (Anth. Pal., éd. Gow \& Page).

Callimachus, éd. R. Pfeiffer, Oxford, 1949 [pour les Fragments].

Denys de Byzance

Dionysii Byzantii Anaplus Bospori, cum scholiis X saeculi, éd. R. Güngerich, Berlin, réed. 1958.

Eschyle

Works vol. II, éd. H. Weir Smyth, OCT, 1926 [pour les Fragments].

Etymologicum Magnum

Etymologicum Magnum, éd. T. Gaisford, Oxford, 1848, réed. Amsterdam, 1962. 
Euripide (scholies à -)

Scholia graeca in Euripidis tragoedias I, éd. G. Dindorf, Oxford, 1863.

Eusèbe de Césarée

La préparation évangélique, éd. J. Sirinelli \& E. des Places, Paris, 1974 (Sources chrétiennes, 206).

Eustathe

Eustathii Commentarii ad Homeri Iliadem (...), ad Homeri Odysseam, éd. J.A.G. Weigel, Leipzig, 1825-1830.

Fragments divers

The Fragments of Attic Comedy, éd. J. M. Edmonds, Leiden, 1959.

$F G H=$ Die Fragmente der griechischen Historiker, éd. F. Jacoby, Berlin-Leiden, 1923-1958.

Géographes divers

$G G M=$ C. Müller, Geographi graeci minores, Paris, 1855-1861.

Harpocration

Harpocrationis Lexicon, Leizig, 1824.

Hermogène (scholies à -)

Rhetores graeci ex codicibus (...), éd. Walz, vol. V, StuttgartTübingen, 1833.

Hésychius

Lexicon (vol. I. a-d; vol. II. e-o), éd. K. Latte, Copenhague,1953-1966.

Himerius

Declamationes et orationes cum deperditarum fragmentis, éd. A. Colonna, Rome, 1951.

Homère (scholies à -)

Scholia graeca in Homeri Odysseam ex codicibus aucta et emendata, éd. G. Dindorf, Oxford, 1855.

Lexeis rhetorikai

Anecdota graeca I, éd. E. Bekker, Berlin, 1814, p. 195 ss.

Lycophron

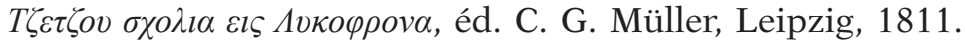

I. Tzetzae, Historiarum variarum Chiliades, éd. G. Kiessling, Leipzig, 1826.

Maxime de Tyr

Maximus Tyrius, Dissertationes, éd. M. B. Trapp, Leipzig, 1994. 
Mythographi vaticani

Mythographi Vaticani I et II, éd. P. Kulcsár, Turnholt, 1987 (Corpus Christianorum - series latina, XCI-c).

\section{Nicetas}

Nicetas Eugenianus. De Drosillae et Chariclis amoribus, éd. F. Conca, Amsterdam, 1990 (London studies in classical philology, 24).

Philochoros

Filochoro di Atene I, éd. V. Costa, Roma, 2007 (I Frammenti degli storici grechi, 3)

Philostrate

Flavii Philostrati Opera, éd. C. L. Kayser, Leipzig, 1870-1871.

Phlégon de Tralles

Opuscula de rebus mirabilibus et de longaevis, éd. A. Stramaglia, Berlin \& New-York, 2011.

Photius 1808.

Photii Lexicon e duobis apographis, éd. G. Hermann, Leipzig,

Polemon

Polemonis Periegetae fragmenta, éd. L. Preller, Amsterdam, 1964. Pollux

Pollucis Onomasticon, éd. E. Bethe, Leipzig, 1931.

Poseidippios

Posidippi Pellaei quae supersunt omnia, éd. C. Austin,

G. Bastianini, Milan, 2002 [pour les Fragments]

Pour les Épigrammes, voir supra: Anthologie Palatine.

Ptolémée

Tetrabiblos, éd. F. E. Robbins, LCL n 435, 1940.

Sappho

Lyrica Graeca Selecta, éd. D. L. Page, Oxford, 1968, p. 97-129.

Servius

Servii Grammatici qui feruntur in Virgilii carmina commentarii III, 1, éd. G. Thilo, Leipzig, 1887.

Souda

Suidae lexicon, éd. A. Adler, Leipzig, 1935.

Stadiasmus Mari Magni

Anonymi Stadiasmus Mari Magni, in G.G.M., éd. C. Müller, vol. I, p. 427-514. 
Stéphane de Byzance

Stephani Byzantii Ethnicorum quae supersunt, éd. A. Meinek, Berlin, 1849.

Strattis

Fragments of Attic comedy, éd. J. M. Edmonds, Leiden, 1957, vol. I, p. 813-837.

Tzetzès : voir à Lycophron.

Pseudo-Virgile

La Ciris, éd. A. Haury, Bordeaux, 1957.

\section{INSCRIPTIONS}

Les références des inscriptions citées dans ce volume figurent dans les notes de bas de page. Elles renvoient soit à des articles ou monographies recensées dans la bibliographie générale (par ex. Segre 1993 pour les inscriptions de Kos), soit aux grands corpus ou revues d'épigraphie suivants :

Bulletin épigraphique

CIG = Corpus inscriptionum graecarum

CIL = Corpus inscriptionum latinarum

FD III = Fouilles de Delphes. III. Épigraphie (depuis 1909)

IC $=$ M. Guarducci, Inscriptiones creticae, Rome, 1935-1950 (4 volumes).

ID 1926-72 = Inscriptions de Délos, Paris, 1926-1972 (7 volumes).

IG $=$ Inscriptiones graecae

$I G \mathrm{II} / \mathrm{III}^{2}=e d$. minor

SEG = Supplementum epigraphicum graecum

Syll. ${ }^{3}=$ Dittenberger $1960=$ G. Dittenberger, Sylloge inscriptionum graecarum, Hildesheim, $1960^{3}$.

Pour la «Chronique lindienne»: voir Bibliographie générale, Blinkenberg 1912.

Pour le pseudo-décret de Thémistocle : voir Jameson 1960. 


\section{INDEX}

La transcription en alphabet latin s'efforce de suivre au plus près l'écriture grecque, sauf pour certains noms de divinités, de lieux ou de personnages historiques bien attestés dans la langue française.

\section{ÉPICLÈSES}

Aeneias [d’Énée] (Aphrodite) : 119, 131.

Agreus [Chasseur/Pêcheur]

(Poséidon -) : 185 n. 193.

Agyieus [des Rues] (Apollon -) : 169 n. 110, 471, 486, 497.

Aigaios [de l’Égée] (Poséidon -): 185.

Aiginaia [d'Égine] (Artémis -) : 199. Aiginètès / Aiginatas [d'Égine] (Apollon -): 153-154, 166-167, 467, 470-477, 499, 596-597 (cat. V3 et fig. 72).

Aiglètès [Éblouissant] (Apollon -) : 145, 164, 167.

Akraia [des Cîmes ou des Promontoires] (Aphrodite -) : 111, 123, 131;

(Héra -) : 69-73, 78, 505.

Akraios [des Cîmes ou des Promontoires] (Poséidon -) : 185. Akreitas [des Promontoires] (Apollon -) : 162, 167.

Akritas [des Promontoires]

(Apollon -) : 155, 505.

Aktios [du Rivage] (Apollon -) : 144-

145, 159-160, 167, 171;

(Pan -) : 171.

Alexikakos [Qui écarte les maux] (Apollon -) : 168.

Amyklaios [d'Amyclée] (Poséidon -) : 183.
Anémôtis [Qui apaise les vents] (Athéna -) : 40-41, 59.

Anthroporrhaistès [Fléau des hommes] (Dionysos -) : 232.

Apobatèria [du Débarquement] (Aphrodite -) : xii, 122, 131, 512;

(Apollonis Eusébès -) : 122;

(Artémis -) : xii, 210, 215-216, 512.

Apobatèrios [du Débarquement]

(Apollon -): xii, 122, 165, 167168, 512;

(Asclépios -) : 513, 512;

(Zeus -) : xii, 96, 98-99, 512, 524 (carte 3).

Asphaleios [Qui donne la sécurité] (Poséidon -) : 34 n. 36, 125, 178179,181 n. 166,184 n. 184,185 n. $189,533$.

Baithmarès [de Beth-Maré] (Zeus -) : 185.

Bathylimeneitès [du Port profond] (Apollon -) : 161-162, 167-168.

Batios [sens ?] (Zeus -) : 90, 98, 488. Bolosia [au Filet] (Artémis -) : 192, 391.

Chitônè [au chiton] (Artémis -) : 211, 215.

Daphnèphoros [Qui porte du laurier] (Apollon -) : 151, 417.

Délien (Apollon -) : 141, 147, 148 fig. $7,152,154,166-167,170,221$, 380, 382, 432, 503. 
Delphinia [au Dauphin] (Artémis -) : 151, 336, 608.

Delphinios [au Dauphin] (Apollon -) : 139-142, 146, 150-151, 157-158, 166-167, 169, 171 n. 117, 207, 315, 415, 608 .

Einalios [Marin] (Poséidon -) : 185.

Ekbasia [du Débarquement] (Athéna -) : xii, 47, 512.

Ekbasios [du Débarquement] (Apollon -) : 145, 162, 167-168, 512.

Embasios [de l'Embarquement] (Apollon -) : 144, 167-168.

Épaktios [du Bord de mer] (Apollon -) : 144-145, 167.

Épèkoos [Qui écoute] (Zeus -) : 90.

Éphésia [d’Éphèse] (Artémis -) : 207, 215.

Épibatèrios [de l'Embarquement] (Apollon -) : 153, 167-168;

(Zeus -) : 96.

Épiliménia [Sur le port ou Littorale] (Aphrodite -) : 117, 131, 401, 596 (cat. V2 et fig. 71);

(Héra -) : 71-72, 78.

Épilimnios [Sur l'eau (mer ou marais)] (Poséidon -) : 185.

Épipontia [Sur la mer] (Aphrodite -) : 131.

Épitragia [au Bouc] (Aphrodite -) : 109.

Ériounios [Bienfaisant] (Hermès -) : 237.

Érykinè [du mont Éryx] (Aphrodite -) : 4 n. 15, 113 n. 110, 528 (carte 12).

Euploia [de la Bonne navigation] (Aphrodite -) : xii, 114-115, 120126, 131-134, 207 n. 81, 265, 287, 289, 609;

(Isis -) : 135 n. 216.

Halieus [Marin] (Dionysos -) : 229.

Hékatos [qui Frappe au loin] (Apollon -) : 163, 167.

Hypatos [Suprême] (Zeus -) : 97-98, 298 n. 284, 302-304, 308 n. 336, $313,321-323,565$ (cat I1 et fig. 51).

Hypsistos [Suprême] (Zeus -) : 90, 98-99.
Iasonia [Jasonienne] (Athéna -) : 46, 460.

Iasonios [Jasonien] (Apollon -) : 162.

Ikmaios [Pluvieux] (Zeus -): 94 n. 41.

Issôria [du mont Issôrion] (Artémis -) : 199-200, 215.

Isthmios [de l'Isthme] (Poséidon -) : 185.

$\mathrm{Ka}(\mathrm{s})$ sios [du mont Kasios] (Zeus -) : 89, 94, 97, 98, 100-104, 134, 297 n. $279,310-312,319$ n. 393,321 , $323,383,390-391,429,566-568$ (cat. I4-I7 et fig. 53-54), 612.

Kènaios [du cap Kènaion] (Zeus -) : 28, 86-87, 98, 518, 524 (carte 3).

Kôlias [du cap Kôlias] (Aphrodite -) Korynthos [sens ?] (Apollon -) : 156, 167, 525 (carte 5).

Koryphasia [du cap Koryphasion] (Athéna -) : 41, 59.

Kynthia [du mont Cynthe] (Athéna -) : 42, 59, 502.

Kynthios [du mont Cynthe] (Zeus -) : 92, 502.

Kythèreia [de Cythère] (Aphrodite -) : voir "Cythère".

Kyzikènos [de Cyzique] (Apollon -): 162.

Lacinia [du cap Lacinion] (Héra -) : 74-76, 323 p. 407, 376, 464, 466.

Laphria [sens ?] (Artémis -) : 203, 215.

Leukôlenos [aux Bras blancs]: (Héra -) 71.

Libystinos [de Libye] (Apollon -): 160-161.

Liménia [du Port] (Aphrodite -): 117-118, 131, 135, 512;

(Héra -) : 70-72, 78, 505, 512.

Liménitis [du Port] (Artémis -) : 218.

Liménoscopos [qui Surveille le port] (Zeus -) : 95, 98-99.

Limnaia [de l'Eau (mer ou marais?)] (Artémis -) : 199-200, 215-216.

Limnatis[de l'Eau (mer ou marais?)] (Artémis -) : 200, 215-216.

Lindia [Lindienne] (Athéna -) : 4344, 59, 279, 386-387, 504-505. 
Lithèsios [de Pierre / Rocheux] (Apollon -) : 155, 167.

Lykeios [Destructeur de loups ? ou de Lycie ? ou Lumineux ?] (Apollon -) : 161, 167, 477-486, 499, 512, 597 (cat. V4 et fig. 53).

Maléatès [du cap Malée] (Apollon -) : 155.

Malophoros [Qui porte des fruits] (Déméter -) : 95, 98, 466 n. 498, 489-491 et fig. 48, 603 (cat. V2425).

Marmarios [de Marmarion] (Apollon -) : 157, 525 (carte 5).

Meilichios [Qui apaise] (Zeus -): 76, 86, 95, 98, 100, 102, 104-105, 464-466, 481 n. 574, 485, 489-491, 496, 499, 512, 595 (cat. V1 et fig. 70), 603 (cat. V24-25).

Mélanaigis [à la Toison de chèvre noire] (Dionysos -) : 229.

Minôis [Minoenne] (Athéna -) : 27-28. Mounichia/Mounychia [de Mounichie] (Artémis -) : 195-196, 211, 215.

Naios [Résidant, Habitant] (Zeus -) : 88-89, 98, 423-425, 540, 614.

Nasiotas [Insulaire] (Apollon -) : 157, 167-168, 525 (carte 5).

Nauklarios [des Armateurs] (Poséidon -) : 181.

Navarchis [Navale] (Aphrodite -): 126, 131.

Nèossoos [Sauveur des navires] (Apollon -) : 145, 167-168;

(Artémis -) : 145 n. 18, 216.

Nikaios [Qui donne la victoire] (Apollon -) : 484.

Olympios [Olympien] (Zeus -) : 94, 98-100, 185 n. 196, 413.

Opsophagos [Gourmet ou Friand de poisson] (Apollon -) : 97, 167.

Optimus Magnus / Maximus (Jupiter-) : 90, 97.

Ornéos [d'Ornoi] (Zeus -) : 97.

Orthia [la Droite] (Artémis -) : 192 n. $10,199,215,392-393$ et fig. 31 , 505, 613 .

Ourania [Ouranienne ou Céleste] (Aphrodite -) : 91, 92 n. 32
Ourios [Qui procure un vent favorable] (Zeus -) : xii, 91-94, 97 n. 48, 98, 100-101,

Pallènis [de Pallènè] (Athéna -) : 278 n. 136, 607.

Pandamos [Populaire] (Aphrodite -) : 124-125.

Paphiè [de Paphos] (Aphrodite -): 110-111, 127-128, 130, 497.

Parthénos [Vierge] (Athéna -) : 278279, 289, 538, 607;

- (Artémis -) : 209, 526-527 (cartes 8-9).

Patrôos [des Ancêtres] (Apollon -): 472 n. 532.

Pélagaios [de Pleine mer] (Poséidon -) : 185.

Pélagios [de Pleine mer] (Dionysios -) : 231;

(Poséidon -) : 185.

Phallène [du Phallus] (Dionysos -): 150, 232-233.

Phôsphoros [Porte-lumière] (Artémis -) : 126, 208-209, 215, 287, 289, 609.

Phykios [du Varech] (Poséidon -): 180.

Phyxos [de la Fuite] (Zeus -) : 104 n. 78 .

Polias [de la Cité] (Athéna -)

Pompaios [Qui conduit] (Zeus -): 100 n. 62.

Pontia [Maritime] (Aphrodite -): $115,117-118,121-122,124-126$, 131.

Pontios [Maritime] (Poséidon -): 179, 185.

Pontomedôn [Roi de la mer] (Poséidon -) : 185.

Porthmios [du Détroit] (Poséidon -) : 185.

Potbatèrios [Qui s'avance par degrés] (Poséidon -) : 186.

Praeia [Douce] (Aphrodite -) : 126, 131, 209.

Prosbèterios [Qui s'avance par degrés] (Poséidon -) : 186.

Prosèoa [Située vers l'orient] (Artémis -) : 215. 
Pyrénaia [Pyrénéenne] (Aphrodite -) : 121, 130.

Pythios [Pythien] (Apollon -): 149, 151 n. 33, 164, 169, 205, 362 n. $60,365,439,518,536$.

Salvia [Salvatrice] : 570 (cat. I16)

Samônia [du cap Samônion] (Athéna -) : 45-46, 59.

Serenus [Paisible] (Jupiter -) : 97.

Smintheus [Destructeur de rats] (Apollon -) : 162-163, 167, 169170, 608.

Sôsandra [Qui sauve les hommes] (Aphrodite/Vénus -) : 121.

Sôteira [Salvatrice] (Artémis -) : 96, 199-200, 206, 212-213, 215-216, $312,315,512$;

(Athéna -) : 33-34, 43, 59, 86, 203, 512;

(Hécate) 204;

(Isis) 114.

Sôter [Sauveur] (Poséidon -) : 186; (Zeus -) : 33-34, 43, 86-88, 92, 9596, 98, 100, 102 n. 74, 103-104, 152 n. $41,168,185,212,269-270$ et fig. 19, 323, 363 n. 66, 512 .

Sôter / Sôteira (indéterminé ou divers): xii, 95, 235, 289, 304 n. 312,308 n. $336,311-314,318$,
$320-321, \quad 324-325, \quad 338, \quad 568-570$ (cat. I10-I15 et fig. 55-56), 609.

Sounias [de Sounion] (Athéna -): 36-38 et fig. 1, 59, 274, 607.

Sôzon [Qui sauve] (Zeus -) : 97, 102$104,134,304-310,321,566-568$ (cat. I3, I7 et fig. 52, 54).

Sôzontes [Qui sauvent] (theoi -) : 276 n. 120.

Sôzousa [Qui sauve] (Aphrodite -) : 97, 103, 134-135, 298 n. 284, 304$310,312,312,567-568$ (cat. I7 et fig. 54), 609.

Tauropolos [Tauropole] (Artémis -) : 190 n. 5, 210-213, 215-216, 283, 608.

thalassioi theoi [dieux marins] : 95.

Thalassios [Marin] (Poséidon -): 185;

(Zeus -) : 92, 98-99;

Triklaria (Artémis -) : 191 n. 8, 230.

Tyrrhena [Tyrrhénienne] (Minerva) : 49-50.

Xénios [Hospitalier] (Zeus -) : 97.

Zéphyritis [du Zéphyr] (Arsinoè - I Aphrodite -) : 127, 131.

Zôstèr (Apollon -) / (cap -) : 152, 167, 408, 525 (carte 5), 613.

INDEX GÉNÉRAL

A

Abydos : 260 n. 61.

accès par mer : 38, 74 n. 196, 152, 179 n. 155,275 n. $113,276,325$ n. $417,487,515,538$.

Acarnanie : 29 n. 17, 159, 203, 363 n. $66,367$.

Achaïe : 39-40, 118-119, 153, 230, $327,358,500,523$ (carte 1: "Teichos d'Athéna »).

Achille : 42, 85, 144, 182, 191, 266, 513.

Actium : 119-120, 153 n. 46, 159-160, 167, 170, 241, 259 et fig. 14, 279, 367-368, 422-423, 425 fig. 36-37,
427-428, 506, 524-524 (cartes 4-5), 610, 614.

Admète : 157.

Afrique : 52-53, 78, 114 n. 112, 165166, 236-237, 288.

Agamemnon : 41, 60, 66-67, 74, 84 n. 4, 191-192, 201, 210-211, 217, 411, 425-426, 428, 459 n. 461, 614.

Agésilas : 199 n. 37, 201, 217, 391 n. 194.

Aigion : $118-119, \quad 129, \quad 524-525$ (cartes 4-5).

Aigos Potamoi : 377-378, 415.

Ainos : 126-127, 236.

aithyia [cormoran] / Aithyia : 39, 47 n. $103,61-65,539$. 
Ajax : 60 n. 145, 63 n. 152, 67, 283 n. $184,356,610$.

akrostolion : 132, 249-250 et fig. 12, $260,418,405$ fig. 15, 418, 420421, 425, 429, 442, 445, 558-559, 614.

akrôtèrion: 149, 195, 251 n. 23, 414, 416-417, 425-426, 614.

Alcibiade: 32 n. 26, 225, 260 n. 59.

Alexandre le Grand : 11, 53, 95-96, $99,182,359$ n. $41,360,381,404$ n. $254,436$.

Alexandrie : 50, 95, 96 n. 47, 102 n. $69,127,153$ n. $46,255,285-286$, 494-496, 605-606 (cat. V34-V37).

Amathonte: 111, 350 n. 4, 375, 611. Amazones : 145, 217, 447.

Ambracie: 119, 159-160, 166, 368, 422, 524 (carte 4).

amer: 51, 77, 79, 92, 113, 121, 158, 161, 176, 211, 275 n. 112, 517-518.

Ammon : 403-404, 433-436, 613.

Ammonios : 115, 540.

Ampelius : 153, 394, 419-420.

Amphitrite: viii, 5 n. 24, 28, 168, $172-174,180,182,183$ n. 177,185 n. 187,273 n. $102,289,335,399$ n. 232, 427, 441 n. $388,513$.

amphore : 53-56 et fig. 2, 143 n. 16 , 149 n. 30, 224, 257, 294-295, 305, $333,335,343$ n. 539, 357, 575, 579.

Ampurias : 208, 528 (carte 11).

Anaphè : 145, 164, 167.

Anaxandrias de Delphes : 377.

ancre: xi, 3, 8, 54 n. $124,60,81$, $83,94,98-99,105,140,169,205$, $246,248-250,262,290-293,381$ n. $153,456-464,512,515,533$, 538, 541, 560-561.

- en bois / partie en bois de l'ancre: 299 n. 292, 463, 479 n. 518,561 ;

- en marbre: 335, 456 n. 448, 473, 476, 482, 484-486, 596-597 (cat. V3-V4), 599 (cat. V7), 602 (cat. V18-V22).

- en pierre (ou jas de pierre autre que le marbre) : xiii, 13, 46,
90, 95, 104, 117, 153, 293, 297, 340, 456-501, 531 carte 15, 560, 595-605 (cat. V1-V37);

- en métal (ou jas de métal) : xiii, 13, 54, 97, 102-104, 13-134, 137, $203,216,238,242,290-347,456-$ 457, 462-464, 560-561 , 563-594 (cat. I1-I25 et D1-D98).

- ancre sacrée: xiii, 295-300 et fig. 20, 304, 307, 331, 536, 539.

Ancyre: 94, 98, 461-462, 500, 527 (carte 10), 538.

Androgée : 264 n. 73.

Andros : 360, 366 n. 82, 463 n. 480. animal : 28, 46 n. 98, 71, 87, 109, $144,128,131,136,212,218$, $226,229,236-237,239,249,256$ n. 50, 232 n. 402, 446, 453; voir aussi "coquillage ", "dauphin", "lion", " oiseau ", " panthère ", " poisson », " taureau ».

Anthestéries : 219 n. 130, 228, 437, 445, 448 n. 420, 449-454, 456 n. 446.

Anthologie Palatine: voir «épigramme ».

Antibes : 315, 336 n. 487, 338, 571 (cat. I18), 582 (cat. D48), 583 (cat. D53), 590 (cat. D75).

Antigone le Borgne: 442 n. 391.

Antigone Doson : 366 n. 82.

Antigone Gonatas : 169, 169 n. 109, 264, 285, 339 n. 510, 359-366, 421, 438 n. 379, 610.

Antikyra : 203, 526 (carte 8).

Antiochos II / Antiochos III : 384.

Antipater de Thessalonique: 334 n. $471,129,157$.

Antiphilos : 25, 168.

Antiquité tardive / fin de l'Antiquité : 11 n. $40,12,156$ n. 60,195 n. 23, 237.

Anubis : 92, 407.

Anytè : 130.

Aphaia : 29 n. 17, 197-199 et fig. 9, 214215, 373, 388, 413, 428, 611, 614.

aphlaston / aplustre : 26, 55-57, 65, 119, 178, 195 n. 22, 216, 250-251 et fig. 12,267 n. $89,269,318,372$, 417, 449, 512. 
Aphrodisias : 607, 116, 128 n. 194, 199.

Aphrodite : xi-xiii, 4 n. 15, 10, 1819, 48, 77, 78 n. 204, 83, 91, 97, 99, 103, 106-136, 163 n. 89, 166, $173,182-183,185,199$ n. 38,207 n. $81,209,216$ n. 122, 236-237, 239, 242, 249, 265-267, 270, 272, 280-281, 287, 289, 298 n. 284, $304-312,317-318,320-321,323-$ $325,330,335-336,339-340,346$, $348,374-376,388,390,401-402$, $404,406,425,427,429,464,466-$ $469,473,475-476,482-483,495$, 497, 499, 501, 504, 506 n. 716, 508, 512-516, 524 (carte 4), 540, 542-543, 567-568 (cat. I7-I9 et fig. 54), 596 (cat. V2), 607, 609, 611, 613-614.

aplustre : voir aphlaston.

Apollodore (pseudo-) : 24-25, 43, 68, 104 n. 78, 109, 144-145, 172 n. 121,184 n. $185,220,222,223$ n. 141,230 n. 167,243 n. 4, 252 n. 34,264 n. $72,353$.

Apollon : xi-xii, 6 n. 25-26, 8, 10, 18 $19,24,43,46,77,84,92,95,109$, 114 n. 117, 118, 122, 125-127, 139-171, 183, 185-186, 197 n. 31, 204 n. 63, 210, 213, 205, 207, 216, 221 n. 137, 236, 242, 256 n. 52, 266, 272, 276 n. 118, 281, 289, $315-316,318,327,336,339,346$, 348, 357 n. 32, 359-368, 374, 378, $380-382,386,388-390,393,395$, $401-402,404,406,408-410,414-$ $420,422-423,425,427-428,430-$ 432, 436, 438 n. 378,441 n. 388 , $460,463,467,470-486,497$, 499-503, 506-507, 512-513, 518, 525 (carte 5), 543-545, 557-562, 596-597 (cat. V2-V4; fig. 71-73), 602 (cat. V17), 608, 610-614.

Apollonia : 88 n. 88, 140, 165, 315 n. $379,337,486$ n. $614,497,577$ (cat. D20).

Apollonidès : 218.

Apollonios d'Aphrodisias : 462 n. 475,538 .
Apollonios de Rhodes: 10, 24-28, $45-46,62-64,67-68,93-94,144-$ $145,162,164-165,174$ n. 130, 192-193, 264 n. 72, 398 n. 230, 412 n. 284, 458, 460.

Apollonis de Pergame : 122.

Apulée : 66, 108, 110, 135, 194, 446. Arabie : 127-128, 504, 529 (carte 13). Arados : 254.

arbres \& plantes : 146, 199, 202, 217 n. $124,222-223,226,264,361$, 451-452, 534, 537-538; voir aussi " myrte».

Arcadie: 113 n. 110, 175 n. 132, 200-201, 210, 214, 498,

archaïque : 10 n. $39,30-31,34$ n. 37, 37-38, 42 n. 78, 45, 47-48, 50, 59, 64 n. 161, 66, 71-74, 76-77, 7982,83 n. 1, 94, 98, 106, 116-118, $130,132,150-154,156,157$ n. 64 , 159-162, 164 n. 96, 169-170, 176, $180,183,186,198,210-211,214$, 216, 234, 254, 271, 274, 293, 304 n. 314,339 n. $506,347,350$ n. 4, $353-356,368-377,379,388-395$, 398-403, 407, 410, 412-414, 425, $427-429,441,454,455$ n. 445,464 n. $484,471,473,479-480,486$, 488-490, 494, 504, 507, 513-514, $517,603,611,613-614$.

archéologie sous-marine: xiii, 2-3, 13, 75 n. 197, 245, 248, 257, 300, 307 n. 329, 579.

architecture navale: 1 n. 2, 246, $248,250,255,262,267,366$ n. 81 , $379,384-385,406,408-409,417$, 426-427.

Arès / Mars : 10, 194, 241, 284, 289, 423, 427, 545, 608, 614.

Argentarius : 542.

Argô : 24-27, 59-60, 62, 64 n. 159, 67$68,80,86,99,144-145,150,153$, $180,183,264$ n. 12,274 n. 107, 353-354, 357, 393-395 et fig. 32, 398,420 n. 323,421 n. 328,427 , $461,610,614$.

argoi lithoi : xiii, 477, 481-482, 484, 491, 496-500, 545.

Argonautes / Jason: xii, 10, 11 
n. $40,21,24-29,45-47,60,63$ n. 155,64 n. $158,67-68,74,76$, $80,82,92-93,99,109,144-145$, $150,153,156,159-160,164,165$ n. $98,168,174$ n. $130,182,184$ n. $185,192-193,241,264$ n. 72 , 266, 353-354, 394-395, 398, 420, 426, 458 n. 459, 460-451, 500, 513 n. 3, 610, 614 .

Argos / Argolide: 32 n. 30, 40, 67 n. $170,71,74$ n. 194,80 n. 214 , 96 n. 47, 117-118, 153, 196-198, 228-229, 233, 323 n. 407, 507, 526 (carte 7).

Ariane : xii, 109 n. 98, 228, 257-259 et fig. 13 .

Arion : 31 n. 21, 149 n. 30, 155-156, 179.

Aristophane: 34 n. 42, 35 n. 45, $60,65,175$ n. $135,176,178,186$, 227 n. 156, 228 n. 159, 242 n. 5, 253-254, 256 n. 50, 267 n. 85, 278 n. 132,432 n. $359,440,465$ n. $490,533-534$.

Aristote: 53 n. 120, 63, 75, 431 n. 351, 433-436, 441.

Aristide (Aelius) : 233, 441, 445-448, 453, 534-536.

Arrien : 11, 53 n. 119, 92-93, 95-96, $103,125,128,182,212-214,236$, 359 n. 41, 461, 506 n. 713.

Arsinoè (Aphrodite-) : 127, 406, 504. Arsinoé Philadelphe :127.

Artémidore: 49 n. 105, 157 n. 65, 205 n. 69, 332.

Artémis / Diane : viii, xi-xii, 6 n. 25, $10,18,29,32$ n. 28,37 n. 50, 47 n. 103,78 n. $204,96,119$ n. 144 , 123 n. 166, 126, 128,145 n. 18 , 151,152 n. $37,166,185,187,189$ $218,230,242,248,283,287,289$, $312,315,318,320-321,324,336$, 340,356 n. 27, 368, 383-384, 389, 391-393 et fig. 31,407 n. 265 , 411,417 n. $311,419,422,425$, 427-428, 431 n. 353, 483, 503-506, $508,512,514,526$ (carte 8), 545$546,608-609,612-614$.

Ascalon : 91-92, 182.
Asclépiade de Myrleia : 52, 419.

Asclépios : 6 n. 25, 116, 124 n. 172, 253, 330 n. 444, 386, 513, 612.

Asie Mineure: 98, 122-125, 129, 161-164, 166, 210-214, 232-234, 238, 242, 453 n. 439, 516.

Astarté 77-78, 91, 92 n. 32, 106, $113-114,124,135,182,325,392$ n. $201,504,513,516$ n. 8 .

astragale : xiii, 133,290 n. 253, 291 n. 255, 295, 298, 300-302, $310,325-335$ et fig. 21, 337-341, $343-345,457,469,512,564,570$ (cat. I16), 573-581 (cat. D1-D43 et fig. 60-61), 588-591 (cat. D68-D81, D84-D93; fig. 67-68).

Atargatis : 108-109, 114 n. 118, 135, 213 n. $112,218,501$ n. 683,505 n. $710,547$.

Athéna / Minerve : xi-xiii, 6 n. 25, 10, $18,31-66,68,82-83,85-86,92,98-$ $99,109,115,119,121$ n. 150,150 , 152 n. 37,165 n. $97,174,176-178$ et fig. 8, 183, 198, 202-203, 242, 253-255, 259-261 et fig. 14-15, 264-266, 268-269 et fig. 18, 272, 277-281, 289, 296, 334, 337, 346, $348,357,363,365$ n. $77,378-380$ et fig. 27, 387, 389-390, 401-404, 411-413, 418 n. 314, 419-420, 425, $427-429,436-446,460,463-464$ n. $484,482,502,505,508,512$, 514,523 carte $1,533-534,538$ 539, 547-548, 607, 610-614.

Athénée: 51, 71, 73, 95, 108 n. 91, 109 n. 96, 113, 127, 130, 161 n. 84,167 n. 105,170 n. 114,171 n. $115,183,204,218$ n. 125 , $227-$ 228, 235, 238 n. 194, 248 n. 13, 266, 270, 299, 359, 361 n. 52-53, $366,381,382$ n. 159,416 n. 302 , 417 n. 312, 505 n. 710, 506, 534.

Athènes / Athéniens : 1 n. 2, 30-33, 34 n. 43, 38, 54 n. 127, 56, 65-66, 104 n. $81,109,115,120,136-138$, 146-147, 149, 151, 158, 163, 167, 176, 178, 181 n. 166,185 n. 196, 205, 211, 224-226, 228, 234, 241 n. $2,255,260$ n. 59,266 n. 84,293 
n. $263,313,357$ n. $33,364-366$, $368,377,413,415-418,430-432-$ 455, 486, 523-526 (cartes 1, 5, 7), 533, 536-537, 559, 568-569, 614; Acropole: 30-33, 38, 55 n. 129, $65,116,156$ n. 59, 176, 337, 356 n. $26,375,378-379$ et fig. 27,381 n. $154,395-397$ et fig. 33,399 , 403-404, 416, 429, 433, 436, 438 n. $378,444,449-450$ et fig. 41,502 , 535-536, 538, 558-560, 611, 613;

Agora: 10, 38, 176 n. 140, 455 n. 446;

Éleusion : 439, 444 n. 399, 536;

flotte - / bateau : 34-35, 75, 94, 97, $116,137,157,178,216,228,242$, 252, 272-274, 277-278, 280-285, $287,289,358,364,396-397,432-$ 435, 487 n. 617, 610.

Athlit: 237, 256 n. 47, 262-263 et fig. 16, 344 .

Atlantique : 7, 78, 122, 208, 517.

Attique : 17, 29-38, 82, 86, 115-116, $129,138,150-152,156-157,175-$ 178,185 n. 188, 189, 195-196, 202 n. 52, 207 n. 82, 225, 228, 257, 266, 357, 432 n. 354, 439, 443, 446, 453 n. 439, 507, 518 n. 17, 519 n. 17, 538, 540; voir aussi "Athènes ", "Sounion » et épiclèse "Zôstèr».

attique (céramique -) : 54-57, 64, 175 n. 137, 224, 240 n. 195, 401, 449, 454-455, 483.

Auguste / augustéen : 23, 25, 38, 48, 153 n. 46, 159-160, 194, 197, 203 n. 59, 218, 231 n. $171,241,260$, $310,315,353$ n. 20, 368, 422-423, 425, 439, 460, 497 n. 668, 505, 568, 591.

Aulis : 85, 191-192, 201, 211, 214, 217, 411, 526 (carte 8).

autel : vii, 10, 37, 43, 47, 53, 59, 69, $71,75,78,87,89$ n. $22,90-93,96$, $98,115,122,123$ n. 165,139 n. 1 , 140 n. $6,142,144-146,149$ n. 29 , 152 n. 37, 160, 164, 179 n. 152, 181 n. $167,182,195$ n. 22,200 n. $44,212-213,239,271,314$ n. $375,341,355,356$ n. $27,362-$ 363,367 n. $83,413-414,422-424$ et fig. 36-37, 427, 484, 489, 503504, 413 n. 3, 515, 540 .

Aviénus : 11, 78 n. 205, 102, 121-122.

\section{B}

Baal : n. 6, 99 n. 55, 100 n. 58, 103 n. $77,458,513$.

Bacchylide: 28, 87, 168, 174, 441 n. 388 .

bain: 31-33, 71 n. 192, 136, 217 n. 124,231 n. 170.

Baléares : 573-593 (cat. D1, D86).

Barcelone (ville ou région): 208 n. 91,300 n. 298,305 n. 318, 342, 581-582 (cat. D47), 585-586 (cat. D62-D63), 591-592 (cat. D82).

base : 37, 44, 71, 73-74, 93, 107 n. 89,115 n. $121,126,149$ n. 29 , $354-356,360,363$ n. 64-65, 385388 et fig. 30, 389-390, 413-414, 465n. 489, 473, 489, 491, 496, 612, 614 .

Basilicate: 310 ; voir aussi "Métaponte».

bataille navale / victoire navale : xiii, 31 n. 23, 43, 65-66, 78, 99, 115, $149,171,178,196$ n. 24, 202, 220 n. $136,358-362,366,385-387$, 396, 401, 413-414, 416-419, 421, $426,447,432,514,535,538$, 610, 614; voir aussi "Actium ", "Aigos Potamoi », "Salamine » et "Salamine de Chypre».

Bentis : 483.

Béotie : 135, 155, 231, 266 n. 84, 382 n. 159.

Bérénice II : 134.

Bérytos : 147, 182, 504.

bétyle: 169 n. 110, 471-472, 486 n. $614,497$.

Bithynie : 161-164, 505.

Boiae : 40, 154-155, 199-200, 214, 217, 242, 523-526 (cartes 1, 8).

bord (à -) : xii-xiii, 2 n. 5, 3 n. 13, 4 n. 18,10 n. $33,13-14,49,51-52$, $60,64,130,133,142,165$ n. 98, 
$169,178,182,186,221,245-348$, $350,440,448,456,458,460$ n. $470,501,506,512,515-516$, 519, 534, 555

Bosphore : 10, 17 n. 1, 47, 92-94, 98, $100,125-126,129,145$ n. 19, 182, 185, 209, 214, 316, 402, 406-407, 516, 524-527 (cartes 3, 9-10).

bouclier : $51-56$ et fig. 2, 254, 259 , 358 n. $38,392,394,414,416,419$, 534.

Boura : 327, 329.

Bouthrotos / Butrint: 48, 94, 97, $101,119,383,389,513,524$ (cartes 3-4), 612.

Brasiae : 40, 230, 523-526 (cartes 1, 7).

Brauron : 189, 195 n. 22, 199 n. 36, 205, 211 n. 102, 215.

Brindisi : 577 (cat. D19), 593 (cat. D93).

British Museum : 26 n. 10, 54 n. $124-125,56$ n. 132,63 n. 152 , 238 et fig. 11, 259 et fig. 14, 297 n. $277,302-303,314,449$ n. $423-$ 424, 450-451 et fig. 40, 565 (cat. I1 et fig. 51).

Britomartis : 190, 193-195, 198, 204207, 214, 550.

Brizô: 204, 382 n. 159, 507, 515, 550.

bronze (âge du -) : 43 n. 84, 112, 153 n. 48, 175, 196 n. 28, 204 n. 63,217 n. 124,293 n. 264,327 n. $428,341,351,352$ n. 15,369 , 371 n. 94,379 n. 140,407 n. 265 , 458-459, 488 n. 627, 492, 506 n. 714, 604 (cat. V27-V31).

bronzes (objets, sauf monnaies) : $31,40,43,73,94,149-150,156$, $183,203,248,251,252$ n. 35,254 , $257,259,268,271,301,327,339$ n. 506, 362, 414, 557; voir aussi : " ancres de métal», "éperon ", "parasèmon» et "vases naviformes ».

Brygéides (îles -) : 193.

Bulgarie: 577 (cat. D22), 581 (cat. D47).
Byblos : 457-458, 494.

Byzance : 47 n. 103, 57 n. 141, 92, 126, 225, 524-527 (cartes 4, 6, 9). byzantins (sources / époque -): 12,32 n. 28,87 n. 12,242 n. 2, 296, 411, 435, 439, 494; voir aussi "Nicetas Eugenianos », "Photius », "Souda », "Stéphane de Byzance », " Maxime Planude », « Tzetzès ".

\section{C}

Cabires / Grands Dieux: 40, 119, 366 n. $81,368,385$ n. 173, 463, 513.

cabotage : 71, 79, 119, 215 n. 115 , 517.

Cadmos : 131-133, 181, 219, 266 n. $84,420,429$.

caducée: 237, 262, 310, 343-344, 584-585 (cat. D55-56 et fig. 63), 588 (cat. D68), cat. 594 (cat. D94 et D97).

Cagliari : 314, 316-317, 570-573 (cat. I12 et I23).

cale / loge : 38, 125, 177, 363, 367 .

Callimaque: 25,32 n. 30, 84, 95, $109,113,127,143$ n. 15, 144, 146-147, 180, 190, 192-195, 197 n. $30,206,210-211,214,217$, 236, 411, 430-431, 459 n. 461, 460, 504.

Callixène : 130, 270,

Camarina: 44 n. 88, 113-114, 240 n. 197,248 n. 16,528 (carte 12).

Campanie : 48, 50, 269, 529 (carte 14).

Carie : 73 n. 190, 123-125, 163, 211212, 214, 262, 313, 538, 568-569 (cat. I10).

Carmanie : 96, 128, 168, 236.

Carnè : 254.

Carry-le-Rouet : 574 (cat. D7).

Carthage : 161, 165, 191 n. 8, 236.

Carthagène: 97, 101-102, 305-307, 309, 566 (cat. I3 et fig. 52), 567 (cat. I8 et fig. 54).

Cartilius Poplicola (tombe de 
C. -) : 256 n. $48,260-261$ et fig. 15, 339 .

Cassandre : 60 n. 145, 63.

Caunos : 124, 211 n. 103, 524 (carte 4).

Celtes : 68, 337.

Cenchrées / Kenchreai : 116, 180, 198, 260.

César : 288, 423, 609 .

Ceuta : 581 (cat. D44), 589-590 (cat. D74 et fig. 68)

Chalcédoine : 10 n. 37, 93 n. 37, 94 n. 42, 185, 525-527 (cartes 6, 9).

Chalcia : 164, 525 (carte 5).

char : xiii, 108 n. 89,174 n. 130,180 n. $160,228,266,372,375-456$; char-bateau: xiii, 31,170 n. 112 , 352,360 n. $43,437-456$ et fig. 38$42,534-538$.

Chariton d'Aphrodise : 114, 131.

Cherronèsos : 205-206, 214.

Chersonèse : 126, 209-210, 214215, 524-527 (cartes 4 et 9: Panticapée).

Chios : 122, 222, 233, 447, 524 (carte 4), 534-535.

Chousor : 105.

Chrysa : 144, 162-163, 166-167, 170, 525 (carte 5).

chtonien: 10 n. 35, 72, 103 n. 76, 104,105 n. 83,134 n. 213,175 , 179,180 n. $157,380,465,489$ n. $632,512$.

Chypre: 43 n. 82, 56-57, 107, $110-$ $111,113,124$ n. 168, 130, 164, 166-167, 212, 328 n. 428, 333, $362,365,375,458,492-494,513$, 604 (cat. V27-V33)

Cicéron : 52 n. 115, 77, 93, 140 n. 5, 147, 403, 414-415, 431 n. 352, 516.

Cilicie : 44 n. 88, 125, 163, 334, 529 (carte 13).

Cimon : 65 .

Circé : 68

Circeo: 121, 140, 528 (carte 12).

Clément d'Alexandrie : 215 n. 116, 264.

Cléopatre VII : 131-132, 160 n. 80, 353 n. $20,367$.
Cnide: 115, 123-124, 129, 132 n. 209,135 n. $215,163,166,330$, 524-525 (cartes 4-5).

colonisation: xii, 4, 6-7, 14, 44 n. $88,47-48,76,79-80,82,88$ n. $19,89,139,140$ n. $7,162,165$, 169 n. $108,170,181,197$ n. 30 , 199 n. 38, 205-208, 211 n. 101, 214-215, 217, 389 n. 189, 427, 453 n. 439,475 n. $542,481,484,492$ n. 642,513 .

Colonnes d'Hercule / Gibraltar: 72, $78,101-102,122,129,517,528$ (carte 11).

Comacchio (épave de -) : 266 n. 82, 271 n. 96.

concours / jeux : 95-96, 119, 159, $153,168,181$ n. 168,199 n. 37 , 206, 229, 284-285, 448, 465, 536; - nautique / aquatique : 31 n. 23, 34,46 n. 101,159 n. 78,165 n. 97, 178,180 n. 159,181 n. 168,196 , 229, 234, 279, 354, 396, 435.

Conon : 115.

coquillage : 44, 114, 123-124, 127, $180,204,300,334,338-341,504-$ 505, 506 n. 714, 512, 575 (cat. D14), 584-585 (cat. D60), 590-592 (cat. D75-D76, D78-D80, D83).

corail : 44, 70, 72,73 n. 191, 77 n. $204,180,504-505$.

Corcyre / Corfou : 56 n. 134, 89, 97$98,101-102,123,133,145,183$, 278-280, 288 n. 232, 288-289, 311, 356 n. 27, 383, 390-391, 429, 459 n. $465,485,499,513,524$ (cartes 3-4), 598 (cat. V5 et fig. 74), 607, $609,612$.

Corinthe: 71, 89, 90 n. 29, 110 , 116-117, 123 n. 166, 130, 136, $138,152-153,155-156,179-180$, 198, 242, 279, 282, 285 n. 218, $353-354,372,374-375,386,398-$ 399,440 n. 387, 446, 524-526 (cartes 4-5, 8), 611, 613; voir aussi «Isthme »;

(golfe de -) : 40, 58, 69, 110 n. 99, $118,129,142,157,166,340$ n. $518,358,516,518$ n. 17. 
Corse : 248, 257, 571 (cat. I14), 575 (cat. D9), 579 (cat. D33).

couronne: $128,151,159$ n. 79,193 , $222-224,226,269,285,344,361$ n. 51,378 n. $132,431,436,440$, 451, 537-538, 584 (cat. D57-D59), 589-590 (D74 et fig. 68).

Crète : 10, 27-28, 41, 44-46, 84, 109, $114,142,145-146,151,162,164$, 168, 173-174, 194-195, 197-198, 205-207, 214, 215 n. 116, 217, 276 n. 119,293 n. 264,369 n. 93, 413, 430-432, 459, 526 (carte 8); voir aussi "Gortyne », "Itanos ».

Croatie: 294 n. 267, 316, 572 (cat. I21 et fig. 59), 577 (cat. D21).

Crotone 74-76, 78-79, 81, 95, 98, 104-105, 376-377 et fig. 26, 428, 464-466, 481, 485, 491, 499-500, 513-514, 528-530 (cartes 12, 15), 582 (cat. D50 et fig. 62), 611.

culte marin (notion de -) : 8-9, 11, 18-19, 512.

Cumes : 76-78, 140, 528-529 (cartes $12,14)$.

Cybèle : 85, 125, 238, 324-325, 339, 346, 407 n. 265.

Cyclades: 41, 123, 129, 147, 174, 418.

Cyrène / Cyrénaïque : 165-167, 296 n. $272,302-303,313$ n. 368,385 n. 173,528 (carte 12), 565 (cat. I1 et fig. 51), 577 (cat. D20).

Cyrus : 378.

Cythère : 111-113 et fig. 6, 129, 199 n. $38,200,280,506,524$ (carte 4), 607.

Cyzique : 46-47, 58-59, 125, 145, 150 , $162,166-167,183,184$ n. 184, 209-210, 238, 412, 460-461, 523526 (cartes 1, 4-7), 614.

\section{D}

Danaos : 44, 59.

dauphin : 107, 113, 118, 123 n. 165 , $137,140,142-143,149-151,155-$ $156,168,171,173-174,179,181$, 185 n. 196, 221-222-226, 257,
276 n. $119,310,316,325-326$, 334-336, 342, 344-345, 457, 506, 512, 571 (cat. I16), 581-594 (cat. D44-D52, D60, D68-73, D82, D96; fig. 62 et 69 )

débarquement / arrivée: xii, 6 n. 26, 42, 46-47, 50, 95-96, 99, $119,122,128,130,140$ n. $6,142-$ 143,161 n. 82, 168, 181, 199, $217,225,230,349,394-395,447$ n. 418,535 .

décor naval : xii, 186, 246-272, 300, 555.

décret / juridique : 1,10 n. 39, 33, 34 n. 36 et 41,35 n. $43,71,87$ n. 13 , 151, 202-203, 206, 253, 442, 536.

Dédale : 206, 482.

Délos : 10 n. 38, 43, 54 n. 124, 72, 78, 91-92, 97, 99-100, 109, 114-115, $135,139,141,146-148$ et fig. 7 , 154, 166, 169 n. 109, 181-182, 204-205, 214, 222, 242, 256 n. 49, 274, 279, 283 n. 186, 289, 315, $350,380-382,396,409-410,418$, 420-422, 425, 428-431, 434, 436, 438, 445, 448, 453, 463, 502-504, 506 n. 714, 507, 523-526 (cartes 1-6, 8), 557-561, 612, 614;

Cynthe : 42, 92, 98, 144;

Édifice des Andriens: 421, 463, 502, 559-561;

Monument des Taureaux: 43, 359-366 et fig. $23,381,421,437$ n. 375,610 ;

Oikos des Naxiens : 365, 558.

Delphes : 10, 47, 84, 139, 142-146, $149-151,153,157,165$ n. 98, 166-167, 170, 171 n. 117, 162, 169 n. $108,183,186,233,274,289$, 330,339 n. 506, 350,357 n. 32, 358 n. $38,364,377-378,393-395$ et fig. 32, 414-417, 420 n. 323, $425,428-429,465,513,516,525$ (carte 5), 611, 613-614; voir aussi épiclèse "Delphinios (Apollon -) ».

Déméter 10, 18, 136-138, 181 n. $168,282,287,289,316,320-$ $321,325,348,380,389,397,410$, 420,436 n. 374,466 n. 498,473 , 
502 n. 689, 507, 572 (cat. I21 et fig. 59), 608, 611, 613.

Démétriade : 144.

Démétrios de Phalère: 431, 433 n. 363, 441 n. 390.

Démétrios Poliorcète : 43 n. 82, 362, 365, 437, 442 n. 391.

Denys : 492, 604.

Denys d'Halicarnasse : 47, 79, 112 , 119, 125, 133.

Denys de Byzance : 11, 46, 47 n. 103, 126, 209-210, 461.

Denys le Périégète : 465 n. 490.

détroit : 89-90, 93, 97, 102, 119, 122, 156 n. $62,157,202,275,359,383,517$.

Didyme: 140, 250 n. 23, 327.

dière : 279 n. 140.

Diktynna: 190, 193-200, 203, 206210, 214-215, 217-218, 551-552.

dîme: 44, 72, 124, 149, 164, 368 n. $84,423,447,518$.

Diodore de Sicile : 75, 113 n. 111, 137, 173, 181, 183, 194-195, 207 n. 80,222 n. 139,225 n. 150, 252 n. $34,253,282,353,358,397$, 487, 492 n. 644.

diolkos : 440 n. 387.

Diomède : 23, 41, 63, 153, 513.

Dion Cassius : 160, 367, 422-423.

Dion Chrysostome : 353.

Dionysos : xi-xii, $8,10,18,33$ n. 33,109 n. 97,128 n. 191,142 , $189,200,219-235$ et fig. 10,252 , 253 n. 36, 257-259 et fig. 13, $283,289,324,336,437,445$, 447-456 et fig. 39-42, 483, 507, 512, 514, 526 (carte 7), 534-536, 551, 608; voir aussi index des épiclèses.

Dioscures : 27 n. 15, 40, 68, 80, 101, 255-256, 262, 272, 276, 290, 323, 346,376 n. 129, 378 n. 132, 394, 407, 414, 483, 513.

Diphile : 95.

Dodone : 24, 86, 88-89, 97-98, 150 n. 32,195 n. $22,423-425,516,524$ (carte 3), 540, 614.

Douze Dieux: 10, 93-94, 101, 182, 185, 513 n. 3, 551.
$\mathbf{E}$

eau potable / puits : 177,317 n. 388 , 399, 456 n. 448, 458-459, 468-469, 492.

économie / commerce : 4 n. 14, 7, 9, 37 n. 53, 88, 102, 112, 118, $130,134,180,215$ n. 115, 228, 234, 257, 272-274, 292 n. 260, 294 n. 269, 301, 308 n. 340, $311,326,343,345,375,385$, 427, 470-471, 476, 515, 518; voir aussi «taxes".

Égée (mer) : 1, 7, 41-46, 60, 97, 164, 166, 178, 180-182, 217, 360, 364, 517, 523-526 (cartes 1-8).

Égine: 117, 130, 149, 166-167, 178 n. 146, 199, 203, 229, 401, 414, 415 n. 296, 416, 459 n. 462, 466-470, 499-500, 524-526 (cartes 4-5, 8), 596-599 (cat. V2, V6; fig. 71, 75), 613-614; voir aussi "Aphaia ", "Sostratos » et épiclèses "Aiginaia ", "Aiginètès ".

Égypte / égyptien : 38, 44, 72, 92, 127 $130,133,185,227,256,261$ n. 60 , 271 n. 95, 273, 293 n. 264, 308, 316-317, 350 n. 4, 351, 372 n. 107, 406, 451 n. 431, 457-458, 462, 499, 504, 538; voir aussi "Isis", "Alexandrie », " Naukratis ".

Eileithyia : 192, 218.

Élaphonisos : 40 n. 65, 200.

éléments(s) : xi-xii, 2, 6 n. 25, 24, 6061,63 n. 153, 80, 83, 90, 99, 105, 136-137, 171-172, 173 n. 128, 184, 220, 229, 234, 241, 251, 299, 335, 439; voir aussi «feu ».

Éleusis : 136-138, 186, 274, 283, 397, 436 n. 374, 507, 613.

Élien: 63, 113 n. 112, 170 n. 114, 180 n. 153, 213 n. 109, 232, 506 n. 717,508 n. $719-720$

embarquement / départ : 6 n. 26, 23, $25,29,33-35,52,60,68,83,95-$ $96,99,100$ n. $62,109,111,131$, 134,140 n. $6,144,146-147,153$, 157, 167 n. $98,168,182,191,201$, 207, 245, 253-254, 264-265, 269, 
275, 282, 344, 391, 394-395, 406, 431, 448, 536.

embolon / embolos : voir "éperon ». emporium : 77, 88 n. 19, 471, 473 n. $536,476,515$.

Énalos : 181.

Enfers / au-delà / eschatologie : 10 n. $35,179,226,234,241,380$.

Énée: 48, 79, 85-86, 112, 119, 125 , 130, 133, 253 n. 36, 324, 430.

Éole : 68, 80, 220 n. 136, 389 n. 189. Éolie / éolien : 506, 577-591 (cat. D24, D60, D79-80).

épave: 51 n. $114,115,202,233$ n. 177,246 n. $3,248,257,264$ n. 76,271 n. $96,292,293$ n. 262 , 298, 307, 332, 518, 573-591 (cat. D2, D21, D24, D28, D36-37, D40, D60, D65, D70, D79-D80); voir aussi "Camarina", "Comacchio », "Grand Ribeau ", "Jeaune-Garbe » et "Mahdia ».

éperon (embolon ou embolos) : 52, $94,147,160,237-238,250-251$ et fig. 12, 256 n. 47, 262-263 et fig. $16,339,344,347,353,367$ n. $83,372,379,382$ n. 160,389 n. $189,413,417-420,422-423,424$ fig. $36-37,425,427,429,443,447$ n. 416, 451, 463 n. 479, 558, 614; voir aussi " rostres".

éphèbes : 32 n. 27, 86, 196.

Épidèlion : 154, 525 (carte 5).

Épidaure : 386, 428, 612.

Épidaure Liméra: 87-88, 98, 200, 214, 524-526 (cartes 3, 8).

épigramme: 1 n. 3, 25, 30, 47, 93, $95,100,104,119-120,127-129$, 133 n. 210, 134, 150, 157-160, $162,168,183,218,237,288$ n. 247,334 n. $471,353-354,368$, 383, 412, 462, 501-506, 508.

Épire: 89, 185, 276, 423.

épisèmon: 53-54, 251, 253-254, 257 n. 54.

équipage: 23, 31 n. 23, 34, 38, 51, 68,87 n. 13, 90, 131, 163, 191, 221, 222, 249, 256 n. 49, 265-266, 275, 279, 289, 291 n. 256, 371,
387, 389, 392, 394 n. 208, 401, 427, 440, 448, 537-538, 612.

Érétrie : 87 n. 13, 157, 235-236, 518.

Éros : 108, 116, 120 n. 147, 375,

Érythrées (Ionie) : 99 n. 56, 122-123, $210,236,242,524-526$ (carte 4, 8).

Escalet : 569-575 (cat. I11, D5-D6 et fig. 56), 590.

Eschyle : 25, 87, 90, 100, 185 n. 198, 191.

Ésope : 30, 63, 514.

Étis : 199.

étoile: viii, 26, 137, 149, 222, 262, 294, 323-324, 378, 412, 414-415, 571 (cat. I19 et fig. 57).

Étrurie / Tyrrhénien : 54 n. 126, $74,76,79,120,128$ n. 191,135 n. $215,142,149,170$ n. 114 , 221-223, 226, 228, 318 n. 391, 324,389 n. 189,469 n. 518,470 n. $522,471,473$ n. $535,476,517$, 578-594 (cat. D11, D28, D38, D77, D94).

Etymologicum Magnum: 151, 171 n. $116,204,462$ n. 475.

Eubée : 28, 60, 76, 86-87, 156-157, 166-167, 182 n. 171, 192, 201-203, 214, 216-217, 228, 235-236, 268, 333, 391, 428, 524-526 (cartes 3, $7,8), 612$.

Euphrate : 212-213.

euploia: 5, 22 n. 3, 46 n. 99, 83, 90, 93, 104, 120 n. 147, 133, 274-277, $280-283,285,287,289,330,407$ n. $266,410,426,607-609$; voir aussi lexique des épiclèses.

Euripide : 29, 35, 60, 85, 131, 132, $137,145-146,170,172$ n. 121,173 n. $123,174,182,185$ n. 188,191 , 194 n. 18, 196, 220 n. 133, 266, 278 n. 130 et 136,283 n. 184,296 , 533, 539.

Europe : 402 n. 248.

Eurynomé : 200, 210, 214, 512.

Eurypyle : 230, 233.

Eusèbe de Césarée: 101-102, 105, 233.

Eustathe : 204, 251 n. 23, 252 n. 29, 328 n. 434, 507. 
$\mathbf{F}$

Failaka : voir «Ikaros ».

falaise : 89, 158, 207, 274-275, 410.

fécondité / fertilité : 8, 70-71, 74 n. $195,80,175$ n. 133,181 n. 168 , 227, 233, 352, 455.

Femine (île delle -) : 310, 342 n. 532, 343 n. 538 et 541,568 (cat. I8), 584-594 (cat. D56, D64, D87-90, D97-98; fig. 63 et D65).

femme : viii, 9 n. 33,32 n. $28,49,55$, $64,86,111,132,152$ n. 37,164 , 194, 198, 200, 203-204, 207, 217, 219, 224, 231-232, 264 n. 75,265 , 267-269, 328 n. 433, 332 n. 454, $392,453,504,515$.

fêtes : 3, 4 n. 19, 34, 73, 114 n. 117, 117 n. 134, 151, 153 n. 47, 157, $159,176-178,181,195,204$ n. $67,228,230-231,356$ n. 28 , $358,375,431$ n. 353,436 n. 374 , 437 n. 376, 443; voir aussi "Anthestéries », «Panathénées » et "Plyntéries".

feu : 68, 95, 120, 179 n. 155, 208 n. 92,223 n. 141,236 n. 187.

filet: 193-194, 218, 233, 501, 503.

folie : $219-220,222-223,230,245$, $535,539$.

fondation : 34, 48-49, 74, 76-77, 92, $94,112,115,128,139,151,153$, 159,160 n. $80,165,169-170,199$ 200, 205, 207-208, 216-217, 246, 276 n. $118,373,419,453$ n. 439, 471, 491 n. 637, 513, 538.

\section{G}

Gadès : 78, 122, 208, 215, 318 n. 391, 528 (carte 11).

Gaudos : 164, 166, 518, 525 (carte 5).

Gaule: 121, 207-208, 336 n. 488, 338 n. 502.

géographie: 1, 4, 7-8, 9, 11-13, 17-18, 44 n. 89, 47, 52 n. 117, 58-59, 78-80, 92, 97-98, 102, 106, $110,112,120,129-130,165-167$, 171-172, 202-203, 208, 213-215,
233-234, 242, 272-274, 500, 511, 515-519, 523-530 (cartes).

géométrique : 72 n. 184, 156, 195, 369, 370 n. 93, 392, 399, 613.

Géraistos : 182 n. 171, 192, 203, 218, $391,612$.

Glaucos : 131 n. 203, 173 n. 122, 220 n. 136.

Glaucos (golfe) : 211, 526 (carte 8).

Gorgone(s) / Gorgoneion / Méduse : 60, 334, 336-339, 346, 457, 469, 583 (cat. D53).

Gortyne : 164, 193, 518.

gouvernail : 44, 142, 153, 183, 192, $204,210,265,269,336,379$, $411-412,420,422,425-427,459$ n. 461,614 .

graffiti : 45-46, 73, 90, 91 n. 30, 152, 275-277, 291 n. 256, 301 n. 299, 361 n. 52, 376, 390, 406-410, 428, 471, 475 n. 542, 476, 483, 613.

Grand Ribaud (épaves): 302, 574 (cat. D4), 575, 585-589.

Grande Grèce : 4, 6, 47-50, 58-59, 74, 77, 79, 82, 120-121, 137 n. 228, 160-161, 214, 226, 299, 326, 333, $341,388,394$ n. 208, 428, 465 n. 493,486 n. $610,497-498,500$, 517, 518 n. 18, 530 (carte 15); voir aussi aux toponymes.

Gravisca : xiii, 77-78, 121, 130 n. $199,153,376,428,465,470$ 477 et fig. 43-44, 486 n. 609, 499-500, 502 n. 689, 514, 596602 (cat. V3, V7-V16; fig. 72 et 76-77), 611.

gréement \& voile : xiii, 26,56 n. 134 , $85,100,115$ n. $119,133,144,146$, $170,192,221-225,249$ n. 17, 265, $364,393,430,439-446,451,456$, 534-538, 557.

grotte : VII, 50, 89-91, 98, 120, 172, $179,229-230,237,239,275,327$ n. 427,369 n. 93,438 n. 378,488 n. 627,515 ; voir aussi «Santa Maria di Leuca ". guerre de Troie : voir Troie guerre du Péloponnèse: 34, 149, $157,177,183,186,253,358-359$, 
396, 415 n. 300, 426, 487 n. 617, 610; voir aussi «Aigos Potamoi ». guerres Médiques : 32 n. 27, 34-35, 37-38, 57, 65, 94, 115, 177-178, $184,186,195$ n. 21, 202-203, 216, 255, 401-402, 414-417, 426429, 437 n. 376, 613; voir aussi "Salamine».

\section{H}

Hadès : 10, 173, 186 n. 194, 241.

Hadrien : 57 n. 137, 96 n. 47, 101 n. $66,255,260$ n. $61,536$.

Haïfa : 578-583 (cat. D27, D51-D52).

Halai : 183, 506, 525 (carte 6).

Halicarnasse : 124, 524 (carte 4).

hameçon : 30, 76, 152, 156, 170, 180 n. $162,408,501-503$.

Harmonie : 131-133, 420, 425, 614.

Harpocrate : 92.

Harpocration : 432 n. 354, 454 n. 435.

Hécate : 204, 208, 287, 491.

Hécube: 161 n. 82, 191 n. 8, 296, $533,539$.

Hékatonnèses : 163, 166.

Hélène: 132-133, 182, 267 n. 86, $392,415$.

Héliodore : 295.

hellénistique : $24,29,32,50,53$, 56-57, 59, 81, 91-96, 101-101, $103,113,119,122,124,128-135$, $143,145,160,169-170,172,186$, 212-214, 216, 218, 237, 256-257, 259-260, 262-263, 271, 273-274, $289,292,318,322,339,346-347$, 359-370, 380-387, 389, 391, 398, 402-407, 410, 418-425, 427-429, $435,455,460,494-496,507,514$, 516, 570-604 (cat. I12, I20, D20, D50, D53, V34), 607-609, 612-614.

Hellespont : 182.

Hémèroskopeion : 208, 528 (carte 11).

Héphaistos : 10, 68, 105, 230, 241242, 285, 289, 608.

Héra : xi-xii, 4 n. 15, 6 n. 25, 10, 18, $21,24-25,27,32$ n. $28,62,66-83$,
$109,198,219,242,286,289,301$ n. $299,315,318,321,323-324$, 333 n. 458, 346, 348, 354-356 et fig. $22,368,370-373$ et fig. 24, 376-377 et fig. 26, 389-390, 402, 408 , 413-414, 425, 427-428, 454455, 464-467, 471, 473-477, 479, 481 n. 573, 483-484, 500, 503, 505-507, 512, 514, 523 (carte 2), 552, 571-572 (cat. I19 et fig. 57), $598,609-611,613-614$.

Héraclès : 10 n. 38, 22, 28, 86-87, $95,145,168,179,290$ n. $252,317-$ $318,321,324,326-327,359$ n. 41 , 360 n. $48,368,513$.

Héraclite : 227.

Hermès : xi-xii, 10, 18, 30, 124 n. $169,128,136,189,235-239$ et fig. $11,257,262,266$ n. 82,286 , 289, 340, 343, 346, 462, 481, 498, 500-503, 507, 552-553, 609.

Hermione : 117-118, 129-130, 229, 233, 524-526 (cartes 4, 7).

Hermippos : 228, 234.

Hermogène : 65 n. 167, 115, 539.

Hérode Atticus : xiii, 438-439, 444.

Hérodote : 29 n. 17, 57, 72-73, 64 n. 42,112 n. 106,115 n. 127, 123-124, 143 n. 15, 149, 152, 156, 161 n. 84,165 n. $98,178,184-186$, 195, 198, 202-203, 206, 209-210, 232, 254-255, 278 n. 136, 356-357, 402, 412-417, 464, 470-471, 477, 459 n. 557.

hérôon: 36 n. 49, 39-40, 53, 401.

Hésiode: 8 n. 31, 71 n. 190, 107108, 110-111, 151, 172 n. 121, 245 n. 2.

Hestia / Vesta : 10, 241-242, 286, 288, 317-317, 320-321, 456 n. 449, 573 (cat. I24), 609.

Hésychius : 32 n. 28, 39, 92, 131, 170 n. 114, 185, 194, 196, 199 n. $37,204,489$ n. 631.

Hiéron de Syracuse (- I) : 380; (- II) : 130, 248 n. 13, 270, 285 n. 218,299 n. $292,361$.

Himérius : 31, 170 n. 112, 439-441, 444-445, 448, 537. 
Hippolyte : 131, 153, 184 n. 185, 194 n. 18, 196.

Histiée : 203, 268.

Horace : 111, 123, 403.

Hvar : 294 n. 267, 316, 572 (cat. I21 et fig. 59).

Hyades : 220.

Hygin : 25, 109, 144, 155, 173-174, 181, 220, 222.

Hymnes homériques : 9 n. 31, 221;

- à Apollon D. : 10, 84, 141-142, 144, 167, 170, 221;

- à Aphrodite: 107, 110;

- à Artémis : 190, 213, 216;

- à Athéna: 24, 66;

- à Dionysos : 128 n. 191, 220-226;

- à Poséidon : 175.

\section{I}

Iapygie : 47-48, 119, 528 (carte 12); voir aussi "Santa Maria di Leuca ».

Ibérique (péninsule -) : 7, 52, 78-79, $81,102,121-122,129,161,166,207-$ 209, 214, 337 n. 491, 419, 471, 528 (carte 11), 581 (cat. D46), 614; voir aussi "Carthagène », "Colonnes d'Hercule ", " cap Palos ».

Icarie : 211, 214, 526 (carte 8).

Ikaros : 92, 96, 185, 212-214, 242, 383-384 et fig. 28, 504-505, 529 (carte 13), 612.

île: xii, 7,40 n. $65,42-46,52-53,62$, $78,85,110-115,122,129$ n. 195 , $145,163-164,166-168,180-183$, 193, 208, 211-214, 233, 239, 242, 275, 515, 517 ; voir aussi aux toponymes ("Ikaros », "Kataiè », "Crète », "Sicile », " Délos », etc.). Iliade: 23, 61 n. 146 et 148, 71, 84 n. 4,100 n. 60,107 n. 87,110 n. 101,137 n. $218,143-144,163$, 170,172 n. $121,173-174,191$ n. 7 , 200, 205 n. 70, 220, 230 n. 167, 231, 237 n. 191,242 n. 4, 250 n. 23, 251 n. 29,281 n. 169.

Illyrie : 88 n. $19,185,261,315,330$, 477 n. 552, 485-486, 497, 499.
Imperia : 315, 572 (cat. I20).

Ino / Leucothée :

initiation : 8, 24 n. 6, 70, 71 n. 180, 136, 138, 191 n. 8, 513.

Ionie : 46-47, 57 n. 136, 99 n. 56, $122-123,140,175,212,236,453$ n. $439,460,476$.

Ionienne (mer -) : 97, 105, 113, $119-120,129-130,158-159,215$ n. $115,418,516$.

Iphigénie : 29, 85, 145, 191, 201, 209, 216-217, 512.

Isis / Isis : 66, 92, 111, 114-116, 127, $135,194,238,255$ n. 46, 256, 260, 265, 290 n. 252, 316-317, 318, $320-321,342,346,403-408,446$, 457 n. 453, 494-496, 513, 572-573 (cat. I23).

Issos : 125.

Isthme (sanctuaire de l'-) : 107 n. 89,116 n. $130,179-180,185$, 276 n. $118,285,353-354,356-$ 357, 361 n. 51, 374, 402, 427-429, 504, 524-526 (cartes 3, 6), 610611; voir aussi "Cenchrées » et "Léchaion».

Isthmia (bateau) : 285 n. 218, 361363, 365, 608, 610 .

Istros : 126, 193, 524-527 (cartes 4, 9).

Itanos : 27, 45, 523 (carte 1).

itinéraires nautiques: 11,12 n. 43, 44, 46-47, 92, 126, 128 n. 192, 241, 461, 515, 517.

Ityque : 165.

\section{$\mathbf{J}$}

jas : voir " ancre ».

Jeaune-Garde (épaves de -) : 298 n. 287, 336-337, 342 n. 532, 581, 583 (cat. D54), 586, 588 (cat. D69 et fig. 67).

Justin : 448 n. 420,481 n. 570.

$\mathbf{K}$

Kalydon: 203, 456 n. 449, 526 (carte 8). 
Kanopos : 44, 60, 411-412, 425-426, 614.

Karpathos : 44 n. 88, 45, 185 n. 199.

Kassiopè : voir "Corcyre ».

Kataiè : 128, 236, 529 (carte 13).

Kéos : 94 n. 41, 441, 538.

Képhallénie : 157, 169 n. 108.

Kinados : 40-41.

Kirrha : 143, 230.

Kition : 407 n. 265, 458.

Klutikuna : 469 n. 518.

Kôlias (cap -) : 115, 129, 280, 524 (carte 4), 607.

Koré : 12, 18, 136-138, 282, 289 , 380, 507, 608, 611.

Kos : 103, 108 n. 91, 124, 132 n. 208, $135,253,359-360,366,421,524$ (carte 4).

Kourion : 164.

Krisa : 84, 142, 149.

Kronos : 107, 173.

Kyanées (roches -) : 26-27, 68, 93 n. 39, 527 (carte 10).

Kydonia : 195, 197 n. 30, 206, 207 n. 81, 526 (carte 8).

Kypris: 110, 127, 133 n. 210, 289, 607.

$\mathbf{L}$

Laconie : 40, 87-88, 118, 154-156, 166, 198-200, 215, 217, 230, 242, 516.

lampe: 30, 291 n. 256, 310, 342, $372,376,378-380$ et fig. 27,382 , 385, 429, 476, 506, 586-594 (cat. D64, D79, D98; fig. 65), 611-612.

Lébédos : 57 n. 136, 211-212,

Lecce : 90, 576 (cat. D18 fig. 60).

Léchaion : 69, 116, 129, 180.

lembos : 288 n. 247.

Lemnos : 205, 407 n. 265.

Lenormant (relief -) : 30, 395-397 et fig. 33,436 n. 374, 613 .

Léonidas de Tarente: 183, 237, 333 n. 456.

Lesbos : 133, 150, 163, 181, 232-234, 525-526 (cartes 5-7).

Léto : 141, 152 n. 37.
Leucade : 119, 129, 158-160, 164, 166-167, 170, 216, 368 n. 86, 418, 506, 512, 524-525 (cartes 4-5), 558-559.

Lexeis rhetorikai : 88, 423, 540.

Libanius : 296.

libation: 10,41 n. 71 et $76,48-49$, 51-52, 99, 144-146, 238, 242 n. 5, 252, 264, 506, 555.

Liberalis (Antoninus -) : 194, 196 n. 29, 198.

liburne: 90, 279, 285-286.

Libye: 161, 165 n. 98, 329 n. 441.

Ligures : 68, 337.

lion : 185 n. 196, 221, 223, 314, 324326, 334, 338-339, 569 (cat. I11 et fig. 56), 590 (cat. D76).

Lipari : 149, 389 n. 189, 575-591 (cat. D14, D24, D60, D79-D80).

Locri Epizephiri / Locride (Grande Grèce) : 127 n. 188, 394 n. 208, 463 n. 484.

Locride (Grèce centrale) : 110 n. 99, 151, 157.

louterion: 264 n. 76.

Lucien : 30, 120 n. 148, 185 n. 193, 220 n. 133,248 n. 13,255 n. 46, 295, 316, 329, 502, 508 n. 721.

lumière: viii, $145,160,168,208$, 342, 363 n. 65.

Lycie: 56, 143 note 15, 170 n. 114, 523 (carte 1).

Lycophron: 59, 60, 63, 74, 161 n. 82,232 n. 175.

Lycurgue : 33,86 .

Lysandre: 377-378, 381, 415, 611.

Lysias : 178, 195 n. 22,

Lysimaque: 57 n. 141, 339, 442, 444, 446.

Lyttos / Lyktos : 205-206, 215, 217.

\section{M}

Macédoine: 136, 360, 362 n. 58, 364, 366, 403, 433, 534.

Magna Mater : 288, 324.

Magnésie : 25, 144.

Mahdia (épave de -) : xii, 257-259 et fig. 13. 
Malée (cap -) : 67, 88 n. 16, 113, 143, 154-155, 165 n. 98, 167, 200, 525 (carte 5).

Malte: 407 n. 265, 77-79, 81, 528 (carte 12).

Maratea : 310, 568 (cat. I9).

Marcien d'Héraclée: 92.

Marica : 121.

Marie (Vierge -) : 10 n. 39, 71 n. 192, 454-455.

Marseille (et région) : 51 n. 114, 121, 166 n. 100, 167, 207 n. 86, 246 n. $3,248,252$ n. $35,302,315,325$, 329, 428, 448 n. 420, 574-589 (cat. D4, D7, D15, D32, D54, D65), 614. Martial : 353.

Massinissa : 77.

mât : 65, 85, 149, 221-222, 224, 246, 296-297, 361 n. 52 et 54, 376, 414, 416, 439, 442-443, 445-446, 448, 451, 455, 534, 538, 614.

Mater Matuta : 220 n. 133.

Maxime de Tyr: 426.

Médée: 27, 71 n. 181, 192, 220 n. $133,266$.

Mégare: 39, 47 n. 103, 61, 63, 71, $94,99,413,429,497,523-524$ (cartes 1, 3), 614.

Mela, Pomponius : 11, 78, 92, 110, 121, 124, 165, 237.

Mélicerte / Palaimon : 31 n. 21, 108, 174, 180, 219-220, 232, 336.

Melqart : 105, 492, 513.

Ménélas: 36 n. 49, 40, 44, 60, 67, $133,412$.

Ménodotos : 71, 74 n. 194.

Messapie : 89-91, 98, 102, 215 n. 115,477 n. $552,485-486,488$, 498-499, 603 (cat. V23).

Messénie : 40-41, 156, 166, 516-517, 525 (carte 5 : Koronè).

Messine : 88 n. 19, 114, 312, 528 (carte 12), 567 (cat. I6).

métamorphose : 39, 61, 85, 109, 142, 221-223.

Métaponte : xiii, 161, 166-167, 477486 et fig. 45-46, 490, 497-499, 528-530 (cartes 12, 15), 597-602 (cat. V4, V17-V22; fig. 73, 78). météorologie : 63-64, 459 n. 461, 83 n. 2, 98, 101.

Milet: 66, 95, 211, 256 n. 49, 289, 463 n. 484, 526 (carte 8), 607.

Milos : 205.

mines: 35, 102, 208, 309.

Minturne : 121, 129, 528 (carte 12).

Misène : 48, 274 n. 105, 279-281, 283287, 314 n. 375, 529 (carte 14).

Mithridate: 154, 184 n. 183, 279, 409, 462, 538.

Mnasalces : 129.

monnaies: 12, 26 n. 10, 41, 54 n. $124,56-58$ et fig. $3,60,89,94$, 99 n. 57, 102 n. 71,113 n. 111, 116-117, 117 n. 137, 118, 140 n. 7,150 n. 30,153 n. 45 et 48 , $159,163,169,171,198$ n. 34,199 n. $37,200,203,206,208$ n. 87, $216,229,231,233,242$ n. 5, 245246, 251 n. 27, 254-256, 260 n. 61, 262, 268-269 et fig. 18, 278-280, 287 n. 232, 288-289, 315 n. 378, $318,324-326,333-337,339,341-$ 346,366 n. 82,381 n. 153,415 n. 296,447 n. $416,462,497$.

mort / noyade: 1,3 n. 13,13 n. 50, 31 n. $23,54,62-63,67$ n. 170,71 n. $180,87,102,105,109,144-145$, $150-151,174,177,179$ n. 152,184 , 186, 199, 219-220, 226, 231, 241, $265,327,332,335,337,340,350$, 352,370 n. $94,373,375,380,389$, $454,459,469,498$ n. 671, 503505, 512; voir aussi "hérôon » et "stèle ».

Moschion : 130, 270, 359 n. 42, 361 n. 53.

Mothone / Méthone : 40-41, 64, 523 (carte 1).

Motyé / Mozia : 492-493 et fig. 49, 528-530 (cartes 12, 15), 603-604 (cat. V26-V26bis).

Moyen Âge: 90, 120, 407 n. 266, 455; voir aussi "byzantin ».

musique : $145-146,155-156,170$, 192, 198, 221-225, 229, 440-441, 444, 451, 448, 535, 538.

Mykonos : 180, 525 (carte 6). 
Mylasa : 124, 524 (carte 4).

Myrina : 435.

myrte : 127-128, 193-194, 199.

Mysie: 88 n. 55, 140 n. 7, 145, 337.

Mythographi vaticani: 160 n. 80, 194.

\section{$\mathbf{N}$}

Nanai : 213 n. 112

Naples (Poseidonia) : 26 n. 11, 49, 76, 79, 328 n. 433, 437 n. 376, 454, 503.

natation: 142-143, 211, 223 n. 144, 229, 231, 234.

nauclère : 3 n. $10,97,102,114,124$ 125, 134, 152 n. 41, 515, 518.

Naucratis : 127-128, 130, 134-135, 470 n. 522, 475 n. 542, 513, 515.

naufrage: 1 n. $3,25,30,60$ n. 145 , 63, 74 n. $193,85,88,143$ n. 13 , $147,164,174,229,234-235,246$ n. 3, 252 n. $31,257,266$ n. 82 , 293, 306, 335, 349, 401, 423, 540.

Naupacte: 39, 157, 166, 358, 525 (carte 5).

navarque : 127,287 n. 184.

Naxos (Cyclades) : 222, 416 n. 306, 418, 559, 597.

Naxos (Sicile) : 76 n. 203, 140.

Néarque : 95-96, 103, 128, 168, 182, 212 n. 104, 236, 515.

Nélée : 211.

Nemi (galères de -) : 257 n. 55, 291 n. 258, 293 n. 266, 337, 462 n. 474.

Nérée : 5 n. 24, 172, 173 n. 122, 180 , 220, 335, 513.

Néréides : 5, 62, 68, 80, 123 n. 165, $131,133,135,137,172$ n. 121, 173,178 n. 149, 180-182, 185, 232, 249, 266, 272, 273 n. 102, 288, 290, 336, 513.

Néron : 89 n. 22, 165.

Nestor : 41

Nice (région de -) : 315, 336 n. 487, 338, 571-579 (cat. I18, D8, D30, D53).

Nicétas Euganianos : 296.
Nikè / Victoire : 21 n. 1, 33, 34 n. 36, 43, 56, 56 n. 130, 57 n. 141, 77-78, 86,99 n. 57, 150, 257, 362, 363 n. 64,365 n. 77,381 n. 153,385 n. $173,386,387$ n. 186 .

noms de bateaux : xiii, $13,17,60,65$, $81,90,97,116,151,169,216,228$, 242, 246, 256, 269, 270, 272-290, 303-304, 312, 314 n. 375, 315, 316 n. $383,318-323,325,336,339$, 346-347, 432-437, 467; voir aussi "Isthmia » et «Syracusia».

Nonnos: 107, 131, 133, 181 n. 168, 220.

Nuceria Altaferna : 226.

Nymphaion : 126-127, 165-167, 256, 260, 265-266, 316, 346-347, 404407 et fig. 35, 428, 524-527 (cartes 4-5, 9), 613.

nymphe: 121,143 n. 13,149 n. 30 , 173 n. 122, 193, 207 n. 81, 220 n. $135,222,269,273$ n. 102.

\section{$\mathbf{O}$}

Odyssée: 11, 12 n. 44, 22-23, 29, 35,36 n. 49, 39 n. 61, 49, 52, $60-62,67,85,99,100$ n. 60,111 n. 105,173 n. $122,174,182,204$, 220 n. 133,223 n. $142,265,283$ n. $186,419,426,429,507$.

Eniadae: 29 n. 17, 203, 204 n. 62, 363 n. 66, 526 (carte 8).

œuf : 334-335, 340 n. 517, 592 (cat. D83).

oikouménè : 7 n. 27, 66, 135, 143.

oiseau: 26-27, 57, 61-65, 68, 113, 115,140 n. 5, 158, 185 n. 196,191 n. 7, 255 n. 44, 266 n. 66, 376, 392, 406, 452, 519, 539-540; voir aussi «aithyia ».

Okéanos : 26, 200.

Olbia: 126, 524-527 (cartes 4, 9), 575.

Olonthe : 206.

Olympie / Olympias: 94, 108, 161 n. 83,185 n. 187,396 n. 219,432 , 435, 524 (carte 3), 536, 608; voir aussi «Olympios (Zeus -)». 
olympiens (dieux) : 9-10.

onéraire (navire -) : 343 n. 542.

oracle / Pythie : 25, 46, 71-72, 88-89, $109,122,149-151,161-162,169$, 172 n. 121, 181, 194-195, 199, 204-205, 210, 230, 233, 330, 364, 415 n. $295,425,439$ n. 384,460 , 479 n. 557, 498 n. 674, 513.

ordalie : 2,158 .

Oreste : 28-29.

Orikos: 121 n. 147, 129, 132, 524 (carte 4).

Oropos : 157, 525 (carte 5).

Orphée : 27, 192, 354, 394 n. 210.

orphiques (Hymnes -): 107-108, 111, 170, 194, 236, 220 n. 133.

osque : 49.

osselet : voir " astragale ».

Ostie : 304, 339 n. 508, 440 n. 387, 565 (cat. I2); voir aussi « Cartilius Poplicola ».

Otrante (canal d'-) : 48, 89-90, 97-98, $276,513,517,528$ (carte 12).

Ovide: 23,25 n. $8,60,63,86$ n. 5 , $107-108,133,159,174,192,222-$ $223,260,261$ n. $62,279,288$ n. 246, 333 n. 455, 347, 607.

Oxyrhynchos (papyrus d' -) : 256 n. 49, 277 n. 124,323 n. 406.

\section{$\mathbf{P}$}

Paestum (Poseidonia): 49, 76, 79, 301 n. 299, 332 n. 450, 437 n. 376, 454-455, 503, 528-529 (cartes 12, 14), 578-584 (cat. D26, D58).

Pagasae : 231-233, 526 (carte 7).

Palerme (musée de -): x, 301 n. 299, 310-311, 317, 319, 342 n. 531, 567-594 (cat. I5, I8, I25, D25, D41, D56, D59, D61, D64, D67, D72-D73, D87-D88, D90, D97-D98 : fig. 61, 63, 65).

palladion: 253-254, 267 n. 85, 533.

Pallène (Pallènè) : 125, 129, 184, 524 (carte 4).

Palos (cap) : 97, 102, 134, 297, 304309, 310 n. 346, 311, 566-567 (cat. I3, I7; fig. 52, 54).
Pan : 30, 146, 170-171, 237 n. 192, 501 n. 683, 502, 505 n. 709.

Panathénées : xiii, $10,31,53-56$ et fig. 2, 170 n. $112,437-448,455$, 534-537.

Pandion : 39, 61, 64.

panthère : 221, 223, 252, 324.

parasèmon: xii, 151, 228, 238, 251, 254 n. 4, 255-259 et fig. 13-14, 261, 263, 271, 277 n. 124, 321 n. $401,323,347,403,405$ fig. 35 , 407, 426, 614.

Patras: 39, 118, 129-130, 191 n. 8, 203 n. 59, 230, 233-234, 315, 524526 (cartes 4-5, 7).

patrôoi théoi : 514.

Paul (apôtre / saint) : 88, 255, 296 n. 274, 298 n. 288.

Pausanias : 11, 110, 365, 512;

$\mathrm{I}: 31,33,35,38-39,86,94,115$, 116,120 n. $148,123,136$ n. 222 , 137, 152 n. 37,169 n. 108,174 n. 131,176 n. $138,177,195-$ 196, 209, 264 n. 73, 278, 280, 337 n. 498, 359, 360 n. 43, 375 n. $126,413,438-439,441$ n. 390 , 461, 507;

II : 90 n. 29, 107 n. 89, 116-117, 153,171 n. $117,179,196$ n. 27, 197 n. 31, 198, 228-229, 330 n. 444,465 n. $493,466-467$ n 489 n. $632,496-498$;

III : 40, 87, 111, 118, 154-155, 179, 185 n. 187, 199-200, 219, 230;

IV : 41, 156;

V: 108,161 n. 83,185 n. 187 ;

VII : 39, 74, 118, 185, 191 n. 8, 203 n. 59, 230, 327 n. 427, 329, $331,477,481-482,496,498$ n. 674,500 ;

VIII : 184 n. $183,200,498$ n. 672 ; IX : 109 n. $98,132,152$ n. 38,179 n. $152,206,231,420$; $\mathrm{X}: 94,110$ n. 99, 149-150, 183, 203, 232, 358, 394, 414-416, 465. paysage : xii, $9,130,517$; voir aussi " rivage " et " port".

pêche: $7,30,42,88,97,105,118$, 124-126, 137, 150, 154, 156, 162, 
$165,170,172$ n. 120, 180, 183, 185 n. 193, 187, 189, 193-194, 197, 209-210, 215, 218, 231-232, 236-237, 239, 340, 368, 462, 501$507,515,610$.

peinture antique: 26, 72-73, 108 n. $91,134,170$ n. 114,221 , 253-254, 265, 267, 271, 316, 328 n. $433,390,402-404,407,433$, 440 n. 387, 536, 613; voir aussi "pinax» et "vases peints».

Pélion : 202, 231.

Péloponnèse : 39-41, 110, 117-119, $129,135,142,152-154,166,179$, 185, 199 n. 39, 200-201, 214, 217, 228-230, 275; voir aussi "guerre du Péloponnèse » et aux toponymes.

Péluse : 101-102.

pentécontore : 394.

péplos : voir "vêtement ».

Pérachora: 69-71 et fig. 4, 72 n. 186,76 n. $203,78-79,375,455$ n. $445,505,518$ n. 17,523 (carte 2), 611 .

Persique (golfe -) : 7, 96-97, 128-129, 185, 213, 215, 242, 529 (carte 13).

Pétrone : 264 n. 75.

Phalantos : 149.

Phalasserne : 206-207.

phallus : 45, 262 n. 68 .

Phanias : 128, 237.

phare : voir «feu ».

Phasèlis : 56-57, 96 n. 47.

Phénicie / phénicien

Phigalie : 200, 526 (carte 8).

Philippe de Thessalonique

Philochoros : 32 n. 27, 229, 433

Philodémos : 183.

Philon de Byblos : 102 n. 68, 105.

Philostrate : 221-224, 252

Philostrate (L. Flavius -) : xiii, 31, 233, 438-440, 446, 448, 453, 536.

Phlyées: 151, 167, 417, 614.

Phocée: 207-208, 325, 471, 473 n. 536.

Phocide : 203, 378.

Phôsphoros (bateau) : 287, 609 .

Photius : 31 n. 25, 32, 195 n. 22, 196 n. 24,339 n. 510,432 n. 359,433 , 435-436, 445, 538.

Phrontis : 36 n. 49, 60, 401

pilote / capitaine : $26,95,155,221$, 223, 363 n. 65, 398, 536; voir aussi "Kanopos », "Kinados » et "Phrontis».

pinax: 72 n. 185, 154, 180, 183, 267 n. $86,398-401$ et fig. $34,403,407$, 427-428, 613.

Pindare: 24 n. 6, 25, 90 n. 29, 99, 143 n. $15,145,153$ n. 47, 172 n. $121,180,182,185,198,223$ n. $141,227,264,292$ n. 260.

piraterie: 31 n. 23,73 n. 192, 74, 77,88 n. $19,92,153$ n. 46, 158 n. 69,159 n. $76,208,220-226$ et fig. $10,228,324,387$ n. 185,409 n. 274,516 .

Pirée: 30-31, 33-35, 39, 43, 86, 97-99, 103 n. 77, 104 n. 79, 115, $130-131,135-136,151-152,176$ n. $140,195-196,203-204,214-216$, 253,293 n. 263,313 n. 367,357 n. $33,399,434$ n. $368,446,523-$ 526 (cartes 1, 3-4, 8), 540, 569.

Pisistratides : 10, 54 n. 127, 444.

Pithécusses: $77-78, \quad 372-373$ et fig. 25.

Planctes (roches -) : 62, 67-68.

Platon : 8 n. 31,107 n. $87,147,184$, 431, 436, 505 n. 710.

Pline l'Ancien : 33 n. 33, 49, 75, 76 n. $199,89,112$ n. $106,123,128$ n. 194,165 n. $99,403-404,411$, 433, 460-461.

Plutarque : 32 n. 26, 53-54, 65, 107, 109,113 n. 109, 115-116, 116 n. 131,117 n. 134,123 n. 166,131 , 134,136 n. $225,137,140$ n. 5, 142$143,146,150-151,154$ n. 52, 155 , 158 n. 69,159 n. 76,161 n. 84, $169,173,180-181,184$ n. 183 , 195 n. 22, 196 n. 25, 199 n. 37, 201-202, 205, 218, 220 n. 133, 225 n. $150,227,254$ n. 41,255 n. 45 , 256 n. 52, 260 n. 59, 264, 282, 285, 287-288, 295, 357-358, 361, $377-378,397,408$ n. 268, 415, 
$417,422,423$ n. $338,431,441$ n. 390,442 n. 391,446 n. 412,479 n. 557, 506, 512, 516, 609.

Plyntéries : 31-33.

poisson : 54 n. 126, 102 n. 71, 108$109,113,137,170,173,180,183$, 190, 192, 199-201, 204, 210, 218, 223 n. 144, 236, 238, 340, 345, 349 n. 2, 382 n. 159, 399, 402, 505-507.

Polémon le Périégète: 51-52, 167 n. 105, 534.

Pollux (grammaticus) : 151, 174, 251 n. 23 et $25,295,361$ n. 52, 536.

Polycharme de Naucratis : 127.

Polyen, Julius : 104, 199 n. 37, 387 n. 184.

Polyrrhénia : 206-207.

Pompéi : 133-134, 253 n. 37, 257, 265, 346, 404.

Pont-Euxin : 7, 91 n. 31, 92-93, 125127, 242, 404, 461, 513, 524-527 (cartes 4, 5, 8, 9).

Ponza : 317, 570-575 (cat. I17, D13). Porphyre: 232 n. 175, 508 n. 719.

port: 3 n. $13,8,11$ n. 39,29 n. 17 , 38-39, 48-51, 58, 69, 71-72, 74, 76, 78, 87-88, 95, 97-98, 103 n. 77, $111,116-119,121-122,124-125$, $128,130-131,135,147,153-154$, $157,160,162-165,167,180,190$, 197 n. 31, 198, 203, 206 n. 77, 207-209, 211, 215-216, 225, 229, 231,241 n. 2,285 n. 218,306 n. $325,310,313$ n. $364,325,373$, 381 n. 153, 384, 391 n. 194, 398, 447 n. 416, 467, 492 n. 642, 494, 500, 506, 512, 515-518, 537, 612; voir aussi "Léchaion », "Pirée » et index des épiclèses.

Port-Aphrodite: 119 n. 146, 130, 528 (carte 12).

Port-Vendres : 121, 129, 528 (carte 11).

Porth Felen : 577 (cat. D23).

Poseidippos de Pella: 95, 127.

Poséidon : xi-xii, 5, 6 n. 25, 10 , $18,28,31$ n. $21,33,35-38,43-$ $44,60,62,67,71,87$ n. 11,93 , $95-96,100$ n. 58,107 n. 89,117 n. $134,118,125,131$ n. 203, $136,139,142$ n. 11,149 n. 30, $164,168,169$ n. $109,171-187$ et fig. 8,191 n. 8, 212, 220 n. 136, 221 n. 137, 227, 237 n. 191, 241,254 n. 42, 262, 272, 285, $289,322,335-336,340,343$, $346-347, \quad 353-354, \quad 356-359$, $363,368,372,374,378$ n. 132, 379,384 n. 168, 388-389, 399, 401-402, 412, 425, 427-428, 434 n. 368, 462, 502-504, 506, 511-512, 525 (carte 6), 553-555, $608,610-611,613-614$; voir aussi index des épiclèses.

Potidée : 184.

poupe: xii, $26,88,99,104,160$, $169,192,224,250-251$ et fig. 12, 253, 264-271 et fig. 17-19, 296, $299,300,324,361,363,372,379$, $383-384,390$ n. 192, 392, 395 n. $213,399,417,423,426,430$ n. $349,431,436,449,452,538$, 540,555 ; voir aussi «aphlaston» et "stylis».

pourpre: 112, 118, 222, 225.

Pouzzoles : 50, 529 (carte 14).

présage: 26, 32 n. 26, 120, 132, 140 n. $5,144,201,330,332,415$ n. $295,422$.

prêtre / prêtresse : 30, 33 n. 33, 109 n. $97,122,124,137,143,147$, 208, 217, 282, 397, 431, 436, 440, 448, 507, 536-538.

Priape: 248 n. 16, 262 n. 68, 502, 505 n. 709.

Priène : 99 n. 56.

procession : 31,32 n. 27, 73-74, 76, 86 n. 7, 96, 159 n. 78, 196, 217 n. $124,218,234,271$ n. 95,354 , ; voir aussi «char-bateau".

Proclus : 107 n. 87.

Procope : 89, 192, 390-391, 430.

proembolon : 250-251 et fig. 12, 455.

Properce : 159-160.

Propontide : 93, 125, 161-162, 523525 (cartes 1, 3, 6).

Prôtè (île) : 274-277, 279-280, 282283, 286, 407 n. 266, 607-609. 
Protée: 6 n. 25, 67, 95 n. 43, 173 n. 122, 223.

proue: xii, 24 n. $7,44,56-58$ et fig. $3,73,149,157,169$ n. 110 , 198, 203, 206, 216, 221-222, 233, 238 et fig. 11, 242 n. 5, 250-263 et fig. 12-16, 274 n. 72,265 n. 81, 266 n. 84, 267, 278-279, 324, 342, $352,362,363$ n. 64,365 n. 77, $367,379,382,385-387$ et fig. 29 , $391-392,394,399,403-404,414-$ $415,417,421,423,426,451-452$, 497 n. 668, 512, 533, 555, 612, 614; voir aussi "akrostolion», "éperon », "épisèmon», "parasèmon » et "stolos ».

Ptolémée (Claude -) : 52, 77, 87, 103

Ptolémée I Sôter : 95 n. 43, 143, 169, 406.

Ptolémée II Philadelphe : 360, 406407, 462, 538.

Ptolémée III : 134.

Ptolémée IV Philopator: 130, 270

Ptolémée V : 262 n. 66.

Ptolémée VI : 262 n. 66.

Ptolémée Kéraunos : 256 n. 49, 339. purification: 2, 32, 73 n. 192, 104 n. $79,136,147,158,231-232,234$.

Pygela : 211, 215, 217, 526 (carte 8).

Pylos: x-xi, 41, 142, 182, 266 n. 84, 523 (carte 1).

Pyrrha (cap de -) : 125, 524 (carte 4).

Pythécusses : 76-77, 528-529 (cartes 12, 14).

\section{$\mathbf{Q}$}

quadrirème : 279, 280, 285-286, 288, 557.

Quintus : 505

Quintus de Smyrne : 23.

\section{$\mathbf{R}$}

rame / rameur: 30, 74, 146, 153, 222, 224, 247 n. 11, 256-257, 296297, 339, 366, 379, 380, 396-397, 401,431 n. 351, 439-440, 451, 455, 469, 503, 536, 614 .
Ravenne : 274 n. 105, 280-282, 284286.

régate : voir " concours".

Reggio di Calabria : 301 n. 299, 315, 571-595 (cat. I19, V1; fig. 57, 70). reliefs figurés (hors ancres) : 1 n. 3 , $26,31,38,86,97,125,126$ n. 182, 133, 137, 162, 199, 200 n. 44, 206, 238 et fig. 11,253 n. 37, 265, 267268 et fig. 17, 332 n. 452, 367-368, 390-398 et fig. 31-33, 429, 443444, 454 et fig. 38, 613; voir aussi "Athlit», "Cartilius Poplicola », «Lenormant», "parasèmon» et «Torlonia ».

stèle (anépigraphe ou inscrite) : 105, 176 n. 140, 202, 211-212, 468, 481-482, 489-491 et fig. 48, 496.

rêve : viii, 10 n. 39, 22 n. 3, 155, 201, 204 n. 69, 207, 231, 332.

Rhéa : 325, 461 n. 472.

Rhin : 262 n. 68.

Rhion : 358, 610.

Rhodes : 31 n. 23, 43-44, 58, 60, 66, 82,103 n. $77,164,167,180-181$, $183,208,211$ n. 103, 212, 256 n. $49,267-268$ et fig. $17,279,386-$ 388 et fig. 29-30, 411-412, 427, 429, 435 n. 372, 459, 504, 523-526 (cartes 1, 6), 607, 612, 614.

rivage : xii, 10,11 n. $40,42,53,74$, $78,86,101,115,118,129,130$, $136,142,144-145,149,151,153-$ $154,157,164,166-167,169,182$, 190, 201, 206, 213, 214, 217, 226, 233, 236, 242, 367, 390-391, 409, 511, 518 n. 15.

rivière / fleuve / embouchure : 7,74 , $76,79,121$ n. $151,126,149$ n. 30 , $167,193,200,210,212,216,236$, 262 n. 68, 266 n. 84, 371, 411, 440, 454, 461, 538.

roche $(r): 45,49,63,69,87,90,120$, 122,152 n. $38,155,158,162,176$, 181, 193, 207 n. 81, 209, 226, 237, 239, 267, 275, 367, 407, 410, 487, 504, 512; voir aussi « Kyanées » et «Planctes ». 
romain (monde -) : 3, 253, 255, 260, 271, 284, 288, 301, 430;

(Empire -) 12, 19, 44 n. 89, 45 n. $95,90,94,96-97,107,110,111$ n. $102,116,133,153,163,169$ n. $110,229,239,260,276$ n. 118 , $277,280,306,308,312$ n. 359, $314,317-318,335,346,385,402$, 446, 447 n. 416, 428, 462, 488, 495, 502, 567-590 (cat. I7, I14, I16-I17, D20, D33, D78);

(flotte impériale -) 239, 273 n. 102, 274, 277, 279, 281, 285-286, 288;

(République -) : 44 n. 89, 90, 113, 304, 307, 317 n. $388,402,565-590$ (cat. I2, I16, D78).

Rome (ville) et Latium : 50 n. 110, 161 n. 83, 226, 288, 294 n. 267, $316-317,324,335,340$ n. 517,353 n. 20,391 n. $198,423,430,456$ n. 449, 592-594 (cat. D83, D96).

Rouge (mer -) : 128, 130, 242, 529 (carte 13).

route maritime: $23,27,60,68,72$, $75,80,102,128,143,155$ n. 53, 161 n. $83,166,168-169,190,222$, 235, 237, 239, 264, 275, 288, 427. 487 n. 617, 492 n. 642, 515, 517.

rostres: 50, 353, 423; voir aussi " éperon".

$\mathbf{S}$

sacrifice: $8,28,34,42$ n. 77, 50, 53, 71, 75, 84 n. 4, 86-87, 95-96, $103,119,126-128,142,143-145$, 147 n. $23,164,168,183-184,201$, $212,230,232,237,242,246,264$ n. 76,349 n. 2, 358, 394-395, 453, 515,555 ; voir aussi «Iphigénie » et « taureau ».

saison navigable : $125,133,135,151$ n. 36,181 n. 168,437 n. $376-377$, 454 n. 440.

Salamine : 55-56, 65,86 n. 8, 94, 115, 147 n. 23, 149, 151, 178, 184, 195-196, 202 n. 52, 214, 216, 255, 356-357, 413, 417 n. 311, 464 n. 488, 465, 526 (carte 8), 610 .
Salamine de Chypre: 43 n. 82, 362, 365, 492, 494, 604 (cat. V27-V33). samnite : 50 n. 110.

Samos: 72-74, 78-82, 123 n. 166, $134,192,198,206,210-211,214$, 236, 323 n. 407, 354-356 et fig. 22, $370-372$ et fig. $24,388,402,408$, $411,413-414,427-429,471,473$ n. $356,477,514,523-526$ (cartes 2, 8), 610-611, 613-614.

Samothrace: 172 n. 121, 257, 363 n. $64,366,368,385$ n. 173,368 n. 175,387 n. $186,403,446$ n. $414,463,506,513,561-562$.

Santa Maria di Leuca : 48, 90-91 et fig. 5, 97-98, 105, 274-276, 280, 407 n. 266, 487-489 et fig. 47, 499, 513, 528-530 (cartes 12, 15), 603 (cat. V23 et fig. 79), 607.

Santo Janni : 568-580 (cat. I9, D12, D39).

Sappho : 110.

Sardaigne: 76-77, 81, 248 n. 16, 314,338 n. 505, 374, 376-377 et fig. 26, 388, 476, 570-594 (cat I13, D10, D34-D37, D66, D70, D76, D95), 611

Séleucos $\mathrm{I}^{\mathrm{er}}$ : 381, 425 n. 343, 557, 612.

Sélinonte : 95, 98, 102, 104-105, 466 n. $498,481,489-491$ et fig. 48 , 497-499, 528-530 (cartes 12, 15), (cat. V24-25).

Sémos de Délos : 204.

Sénèque : 50, 267 n. 85.

Sèpias (cap -) 202.

Sérapis : 92, 143 n. 14, 238, 407.

serpent : 56, 86, 87 n. 9, 169 n. 108, 191 n. $7,222,336$ n. 487, 338, 496 n. 660 .

Servius: 121, 143 n. 13,147 n. 23, 155, 159.

Sicile :75,77, 88n. $19,98,102,113-114$, $130,137,140,160-161,166-167,282$, $311,317,326,369$ n. $92,380,397,449$, 451-452 et fig. $42,454,486$ n. 610 , 487, 517, 528 (carte 12), 580-589 (cat. D40, D42, D71); voir aussi « île delle Femine », « Messine », « Palerme », 
"Sélinonte», "Syracuse » et «Taormine».

Sicyone: 69, 150, 153, 215 n. 116, 393-394, 420, 428, 465 n. 493, 496, 525 (carte 5), 613-614.

Sidè : 46 n. 101, 165 n. 97, 199.

Sidon : 92, 124, 254, 385.

Silius Italicus : 25 n. 8, 249 n. 18 .

Simonide : 441, 444, 538.

Sinope : 143.

Sirènes : 49, 54 n. 125, 63 n. 152, 64, $109,358$.

Skylax: 76, 241, 11, 12 n. 43, 78 n. 205.

Skyros: 42, 58, 71 n. 180, 144, 523 (carte 1).

Skytobrachion (Denys -) : 353 n. 19.

Smyrne: 66, 233, 256 n. 49, 279, $289,313,437,440,447-448,449$ n. $422,453,456,504,526$ (carte 7), 534-536, 607 .

Solon : 132 n. 209.

Sophocle : 87, 90, 175, 185, 242 n. 5, 283 n. 184 et 186,432 n. $354,539$.

Sorrente: $48-50,52,120,129,528-$ 529 (cartes 12, 14).

Sostratos: xiii, 77,95 n. 43, 130 n. $199,153,467,470-477$ et fig. 43, 596-597 (cat. V3 et fig. 72).

Souda: 184 n. 183, 195 n. 22, 296, 431 n. 353,433 n. 359,453 n. 435 , 465 n. 490, 539.

Sounion : $35-38$ et fig. $1,60,86,115$, $152,166,171$ n. $117,176-178$ et fig. 8,186 n. 201, 356-357, 399, 401, 428, 518 n. 17, 523-525 (carte 1, 3-4, 6), 610, 613.

Soura: 170 n. 114.

Sparte : 99 n. 56, 183, 192 n. 10, 199-200, 205, 207, 214, 216$217,384,392-393$ et fig. 31, 428-429, 505, 514, 526 (carte 8), 612-613.

Sporade : 41, 145; voir aussi Skyros.

Stace : 42, 49-50, 85, 120, 132, 135 n. $218,144,146,181$ n. 168,182 , 201, 264.

Stadiasmus: 12 n. 43, 44, 111 n. 104 statue: viii, 21-239 passim, 248, 253, 266-268, 271, 296, 330, 333 n. 458, 341, 352, 357 n. 33, $362-363,365,371,378$ n. 132 et $134,414,417,420,448,453,455$ n. $445,473,482-483,491-492$, 495, 497-498, 515-516, 533; voir aussi "base » et "xoanon ".

Stéphane de Byzance : 78 n. 208, 81, 101 n. 66, 112 n. 106, 155 n. 54, 159 n. 78,199 n. 37, 210, 252 n. $34,462,538$.

Sthénélos : 145.

stolos: 56-57, 249-251 et fig. 12, 255, 260-261 et fig. 15, 263, 271, 347, 405 fig. 15, 407, 451.

Strabon : 11,12 n. 43,44 n. 89,121 n. $154,214,411,418$;

II : 330 n. 444;

III : 52, 78, 208, 309 n. 341, 419;

IV : $121,166,419$;

$\mathrm{V}: 48-49$;

VI : 48, 75-76, 113 n. 111 ;

VII : 159-160, 207, 209, 367, 422 n. 334 ;

VIII : 69, 118 n. 138, 155, 171

n. 117,179 n. 152,184 n. 183 ;

IX : 33 n. 33-34, 86, 116, 157;

X : 87, 157-158, 164, 193, 205-207;

XIII : 125, 144, 162-163;

XIV : 111, 125, 164, 211-212;

XVI : 128, 213, 216, 236-237;

XVII : 95 n. 43, 127, 165;

XIX : 211.

stratège: 33 n. $36,86,115,132$, 455 n. 446, 515, 614; voir aussi «Conon», "Thémistocle», «Timoléon».

Strattis : 439, 445-446, 534.

stylis : xii, 24 n. 7, 47, 56 n. 131, 60, $104,233,250-251$ et fig. $12,268-$ 271 et fig. 18-19, 290, 347, 372, 381 n. 153, 412, 426, 614.

Suétone: 89 n. 22, 330, 422 n. 335. Symè : 313, 568-569 (cat. I10).

Symplégades : voir « Kyanées ». syncrétisme: 4, 108, 114, 132, 135, 163, 193, 325, 516.

Synésios de Cyrène : 296 n. 272. 
Syracuse : 51-52, 88 n. 19, 101, 137 n. 228,267 n. 86,292 n. $260,310-$ 311,335 n. 480,339 n. 511, 380, 528 (carte 12), 534, 566-593 (cat. I4, D15, D17, D49, D81, D91-D92; fig. 53), 611.

Syracusia : voir « Hiéron de Syracuse II ».

Syrie (antique) : 99 n. 55, 102, 109 , 308, 385, 458 n. 458, 612; voir aussi « Atargatis ».

Syros : 275-277, 407 n. 266.

\section{$\mathbf{T}$}

Tabae : 262 .

Table de Peutinger: 92 n. 36.

Tanagra: 231, 233, 526 (carte 7).

Taormine : 576 (cat. D16).

Taras : 31 n. 21, 149, 335.

Tarente: $75,149-150,215$ n. 115 , 335 n. 480 ,

Tarquinia: 153, 449 n. 425, 471, 596-597 (cat. V3).

Tarragone : 333 n. 457, 343 n. 541, 344, 574-588 (cat. D3, D29, D57, D68).

Tarse : 131, 163, 166.

Tartessos : 80, 102, 122, 470 n. 521, 471, 477, 528 (carte 11).

Tatios, Achille : 107 n. 89, 135, 184 n. 185,252 n. 31,402 n. 248.

taureau : 27, 181-183, 192 n. 8, 226, 252, 266 n. 84;

bovinés (vache, bœuf, etc.) : 28,44 , 46 n. 98, 144, 232, 451, 453, 232 ; voir aussi « Délos (Monument des Taureaux)».

Tauride: 145-145, 191; voir aussi «Tauropolos (Artémis -)».

taxe : 34, 74 n. $194,124,151$ n. 41, $177,180,518$.

technique navale : $2,4,10$ n. 39,13 , $25,59,241,247,249-251,292-$ 293, 300-302, 322, 339 n. 508, 361, 396 n. 223, 421, 427.

Teiristasis : 126, 524 (carte 4).

Télémaque : 22-23, 54, 60-61, 174, 182, 265. tempête : 26, 64, 85, 97, 127, 145 , $147,153,172$ n. $120,184,186$, $228,234,261,266,295,296$ n. 274, 297 n. 299, 299, 349, 519.

temple (absence de -) : 40, 87 n. 12 , 98, 275, 422.

Ténare (cap) : 118, 129, 142, 155-156, 167,171 n. 117, 178-179, 200, 205, 512, 524-526 (cartes 4, 6).

Ténédos: 163, 166, 232-233, 525526 (cartes 5, 7).

Téos : 122, 236, 524 (carte 4).

Teuthrone: 200, 526 (carte 8).

Thalassa : 107 n. 89.

thalassocratie : 10 n. 39 .

Thasos: 71,72 n. 186, 78, 180, 274, 276, 277 n. 123, 281-283, 285, 295

n. 270,313 n. 364,333 n. 431,385 n. 173,523 (carte 2).

Théaitètos le scholastique : 502 .

Thèbes: 132, 420, 429, 614.

Thémistocle: 33-35, 115, 202-203, 255, 357, 540.

Théocrite: 75, 95, 133, 171 n. 116, 183 n. 177.

Théophraste : 228.

Théopompe de Chios: 161 n. 84, 231.

théorie: 178, 344 n. 547, 431-437, 441 n. 390, 535.

Théra: 164, 169, 339 n. 506.

Thésée: 24 n. 6, 28, 109, 114, $146-147,151,168,174,181,220$ n. $133,358,365-366,430-432$, 436, 441 n. $388,445$.

Thessalie : 25, 216, 230-233.

Thétis : 68, 85, 131 n. 203, 135 n. $218,136,172$ n. $121,200,220$, 223, 230 n. 167, 232, 242 n. 4, 273 n. 102, 328 n. 435; voir aussi "Néréides ».

thiase marin : 108, 513.

Thrace: 125-126, 129, 202, 236.

Trézène : 153, 166-167, 196, 525 (carte 5).

Tibère : 218, 330 .

Timachidas de Rhodes: 44, 411412. 
Timée de Tauromenium : 235.

Timoléon: 137-138, 150, 282, 288, 397, 608 .

Tinos : 180, 525 (carte 6).

Tite-Live: 33 n. 33, 50, 69, 75, 76 n. 202,161 n. 83,288 n. 246,423 n. 339 .

Torlonia (relief -) : 264 n. 76, 271.

Trente (les -) : 195.

Trézène : 153, 166-166, 196.

triacontore: 365,431 n. 351, 432 n. $354,436,437$ n. 375

Triarius : 279, 409

trident / harpon : 42, 57 n. 141, 70, $163,173,178,180,183,187,237$ n. $192,251,262,294,310,328$ n. $435,335-336,343-344,347$, 406, 502, 561, 594 (cat. D95, D97).

trièmiola: 279, 387.

triéraque: 151, 253 n. 40, 387 n. $184,417$.

trière / trirème : 30,33 n. 36, 65, 94, 97, 115-116, 137,147 n. 23, 151, 157,169 n. $108,202,216,222,228$, 235, 242, 247 n. 11, 250 fig. 12, 253, 254 n. 41, 273-274, 278-289, 293 n. 263,314 n. 375, 356-357, $359,361-366,378,381-382,396-$ $397,404,414,418,432-437,439$ n. 384,441 n. $390,444,447-448$, $533,535-538,540,557-559,610-$ 611.

Triton : 27, 165 n. 98, 173, 174 n. 130 , 180, 223 n. 144, 231, 398, 513.

Troade : 67 n. $170,125,144,162-$ 164, 232.

Troie / Troyen : 22, 40-42, 48, 60, $63,67,74,75,80,84$ n. $4,85,117$ n. $134,119,144,153,162,191-$ 192, 201, 209, 211, 228, 230, 233, 266, 296, 391, 411, 428.

Troizène : 185 n. 195.

Turan : 130 n. 199.

Tychè : 135, 253 n. 37, 265, 317, 321, 564, 570 (cat. I17), 607.

Tyr: 182, 359 n. 41, 360 n. 48, 368.

Tzetzès : 63, 75, 220 n. 133, 232 n. 175,461 n. $473,539$.

\section{$\mathbf{U}$}

Ugarit : 458-459, 494.

Ulysse: 11 n. 40, 22-23, 29, 35, 42, $48-49,52,54,62,65,85,89,144$, 161 n. $82,162,170,174,390,420$ 421, 425-426, 614.

Uria : 120, 528 (carte 12).

\section{V}

Valérius Flaccus : 24, 26, 60, 68, 184 n. 185, 266.

Varron : 119 n. 143.

vases

- naviformes (céramique et bronze) : 147, 234 n. 182, 378-382 et fig. $27,385,389,559-560,611-612$;

- peints : 27 n. 15, 29 n. 16, 31 n. $23,54-56$ et fig. 2,63 n. $152,64-$ $65,104,143,174,175$ n. 137,178 , 223-225, 234 n. 184, 256, 269-270 et fig. 19, 296-297 et fig. 20, 357, $372,375,398,417$ n. 310, 432 n. $354,449-455$ et fig. $39-41$;

autres - (matériaux divers): 51, 70 n. 176, 130 n. 199, 234, 333, $374,398,408,470$ n. 522, 475476, 483, 504, 534.

Vélia : 99-100.

Ventotene : 314, 340 n. 517, 570-590 (cat. I16, D78).

vent(s) : xii, 10, 23, 25, 28-29, 41, 61, $63-64,68,72,80,83$ n. 2, 84-85, 93-95, 99-100, 107, 126, 141-144, 146, 162, 165 n. 98, 170, 190-192, 209-211, 216, 220 n. 136, 221 n. 137, 230, 275-276, 298, 411, 438-439, 441, 442 n. 391, 446, 459, 512, 517, 519, 538.

Vénus : 11 n. 39, 97, 133-134, 265, 266 n. 82, 280, 298, 310, 320-321, 329-335, 335, 568 (cat. I9), 573, 577, 607.

Verrès : 52 n. 115, 77, 93, 147, 516. vêtement : xiii, 31, 193, 206, 220, 267, 403 n. 249, 438-446, 534-536, 538.

Vieillards de la mer: 5, 67, 173; voir aussi « Nérée », "Protée » et «Triton». 
Virgile : 48, 85, 111, 121, 141, 143 n. $15,158,169,181$ n. 168,252 n. 33,253 n. $36,266,403$ n. 249 , 423 n. 340.

Virgile (pseudo-) : 194, 197, 439, 446. Vitruve : 37, 124 n. 169.

voie sacrée: 74 n. 196, 354 n. 24, 356, 378 n. 134, 395.

voile : voir "gréement».

\section{$\mathbf{X}$}

Xénophon : 32 n. 26, 104 n. 81, 191, $195,201,391$ n. 194, 418, 431 n. 352.

Xénophon d'Éphèse : 72.

xoanon : 31, 76, 132, 150, 154, 169 , $198,205,209,215,229,233,236$, 420, 512 .

\section{$\mathbf{Y}$}

yeux (de bateau): 251, 345, 389 n. $189,451,455$.
$\mathbf{Z}$

Zakynthos: 119, 524 (carte 4).

Zarax : 154, 167, 170, 525 (carte 5). Zeus : xi-xii, 10, 18, 22 n. 3, 24-26, 28, 33-35, 42-43, 60, 67, 76, 83-105, 107 n. $87,108,126,130,134,136$, 142,150 n. $32,168,172$ n. 121 , 173, 185-186, 194, 198, 203, 212, 220 n. 35, 221 n. 137, 235, 242, 248, 269-270 et fig. 19, 272, 276, 284, 297 n. 279, 302-304, 307$313,318-323,347,363$ n. 66,376 n. $129,383,385,389-391,413$, $423,425,427,429,461-462,464-$ 466, 485, 488-491, 496, 498-502, 507, 511-513, 518, 524 (carte 3), 540, 555-556, 565-568 (cat. I1-I8; fig. 51-54), 595-603 (cat. V1, V2425; fig. 70), 608, 612, 614 . 


\section{LISTE DES ILLUSTRATIONS}

1 - Temple Athéna à Sounion (d'après Davaras 1979, fig. 23). . . .

2 - Amphore panathénaïque (musée de Boulogne/Mer, inv. 441; Photo F. Lissarrague) ............................

3 - Athéna assise à la proue d'un navire de guerre. Monnaie chypriote de la fin du Ve s. a.C. (d'après Basch 1987, fig. 582) ..

4 - L'Héraion de Pérachora, partie ouest (Photo de l'auteur) ....

5 - Vue depuis l'intérieur de la grotte Porcinara ( ${ }^{\text {ta }}$ Maria di Leu-

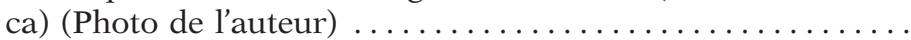

6 - Vue depuis le sanctuaire d'Aphrodite à Cythère (Photo de l'au-

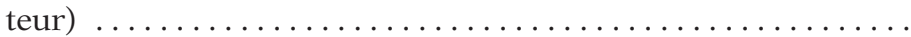

7 - Plan du sanctuaire d'Apollon Délien (d'après Bruneau \& Ducat 2005, pl. I) . . . . . . . . . . . . . . . . . . . . . . . . . .

8 - Sanctuaires d'Athéna (au $1^{\text {er }}$ plan) et de Poséidon à Sounion

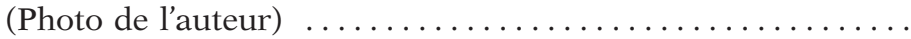

9 - Le temple d'Aphaia à Égine depuis la mer (Photo de l'auteur)

10 - Frise du monument chorégique de Lysicrate (d'après De' Spa-

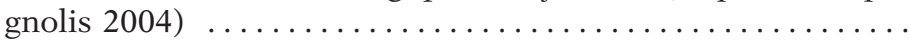

11 - Relief de marbre figurant Hermès dans un contexte naval (British Museum, inv. 80. 5-4. 1; d'après Conze 1891) ......

12 - Poupe et proue de navire type trière (d'après Basch 1987) . .

13 - Parasèmes de Dionysos et d'Ariane, Mahdia (d'après Horn 1994, p. 459) ................................

14 - Parasèmon d'Athéna trouvé dans les eaux d'Actium (d'après

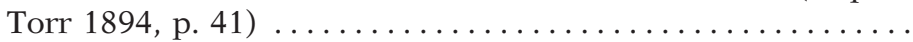

15 - Le bateau du monument funéraire de C. Cartilius Poplicola

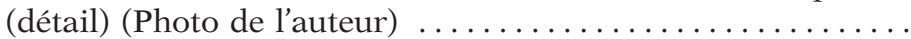

16 - Éperon d'Athlit (d'après Casson \& Steffy 1991, p. 13) ......

17 - Relief de Lindos (d'après Blinkenberg 1941, p. 431) .......

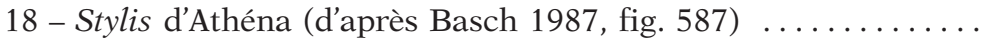

19 - Stylis de Zeus Sôter (d'après Duhn 1888, p. 229) ..........

20 - Vase chypriote avec représentation de l'«ancre sacrée»(?)

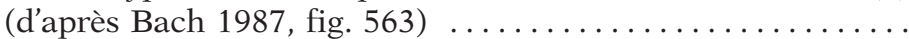

21 - Différentes faces d'un osselet/astragale (d'après Queyrel 1987) 328

22 - L'Héraion de Samos, vers 650 a.C. (d'après Walter 1990) .... 355

23 - Le Monument des Taureaux (ou Néôrion) délien reconstitué (d'après Bruneau \& Ducat 2005, fig. 49) ................ 
24 - Barque en bois provenant de l'Héraion de Samos, vers

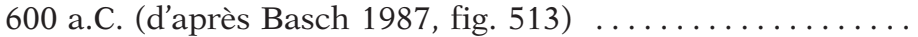

25 - Pithécusses : modèle de bateau $\mathrm{n}^{\circ} 14$ (d'après D'Agostino \& Buchner 1994-95, pl. XXII) .......................

26 - Bateau en bonze sarde; sanctuaire d'Héra à Crotone, bâtiment B (d'après Spadea 1997, p. 249) . . . . . . . . . . . . . . .

27 - Lampe d'Athéna de l'Érechtheion : inscription votive (d'après

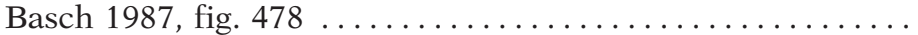

28 - Modèle(s) de bateau(x) de Failaka (d'après Salles 1984,

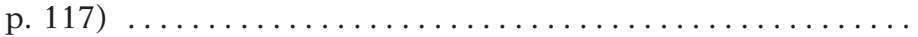

29 - Base naviforme de Lindos : vue et coupe (d'après Blinkenberg

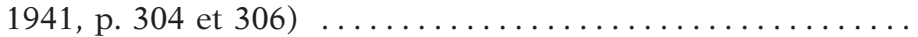

30 - Inscription de la base naviforme de Lindos (d'après Blinken-

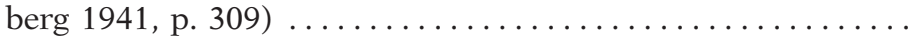

31 - Plaque d'ivoire du sanctuaire d'Artémis Orthia à Sparte (Athènes, Musée national inv. 15362; d'après Bass 1972, p. 42)

32 - Argô à Delphes : reconstitutions (d'après Salviat 1984) ...

33 - Le relief Lenormant (d'après Lemaître 1883) ............

34 - Pinakes navals de Penteskouphia (d'après Werner 1993) ..

35 - Le grand navire de Nymphaion (d'après Murray 2001 p. 251)

36 - Plan du grand autel d'Actium (d'après Murray 1993, p. 68)

37 - Grand autel d'Actium : restitution (détail) (d'après Murray

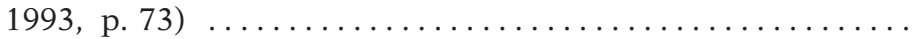

38 - Relief de la Petite Métropole, à Athènes : détail du calendrier

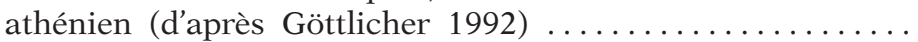

39 - Dionysos et le char-bateau : vase de Bologne, inv. DL 109

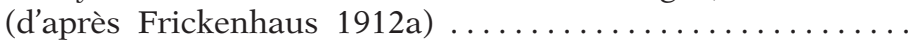

40 - Dionysos et le char-bateau : vase du British Museum, inv. B79

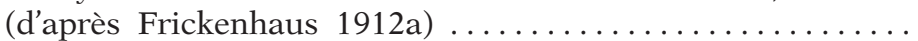

41 - Dionysos et le char-bateau : vase du Musée national d'Athènes, inv. Acropole 1281 (d'après Frickenhaus 1912a) ...

42 - Dionysos et le char-bateau : feuille de plomb (musée d'Agrigente, inv. AG 21065; d'après De Miro 1982, vol. III pl. XLV)

43 - Gravisca, édifice Alpha, cour A : emplacement de l'ancre de Sostratos (cat. V3) et d'un autre jas (cat. V8) (d'après Fiorini

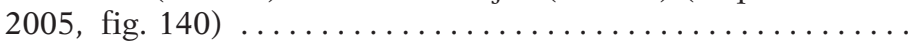

44 - Sanctuaire de Gravisca : édifices Alpha-Epsilon (d'après Coli-

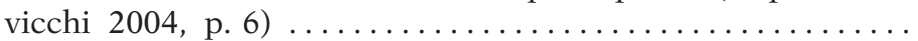

45 - Métaponte, plan des temples A-D, avec indications de leurs diverses phases de construction (d'après De Juliis 2001, fig. 28)

46 - Métaponte : «champ de pierres» à l'est du temple $\mathrm{B}$ (Photo de

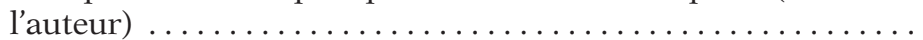

47 - Grotte Porcinara : inscriptions n 6 et n $\mathrm{n}^{\circ}$ 16-17 (Photo de l'au-

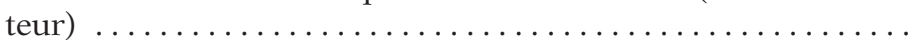

48 - «Champ de stèles» à Sélinonte (d'après Gabrici 1927, pl. 17) 490

49 - Fouilles de Mozia, zone K (d'après Falsone 1988, p. 11) . 493

50 - Jas de plomb............................... 563 
Page

51 - Deux demi-bras de jas : inscription «Zeus Hypatos» (British Museum, inv. GR 1893-11-13-1; (C) British Museum) ......

52 - Jas : inscription "Sozô» (?) de Carthagène (d'après Gianfrotta 1994, fig. 4) ...................................

53 - Reconstitution : ancre de Zeus Kasios de Syracuse (d'après

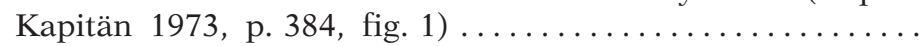

54 - Jas du cap de Palos avec les noms de Zeus et Aphrodite (seul dessin connu : Laymond \& Jiménez 1906) .............

55 - Jas d'Athènes : inscription «Sôteira » (d'après Gianfrotta 1980,

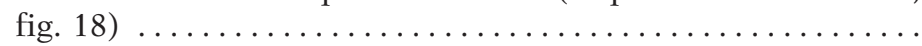

56 - Jas de l'Escalet : inscription «Sôteira » et motif de lion (d'après

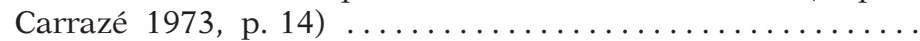

57 - Jas : inscription «Artemidos» (d'après Gianfrotta 1994, fig. 7)

58 - Jas avec inscription «Héra» (Reggio di C. inv. 50456; Photo de

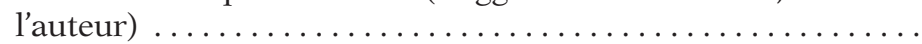

59 - Jas : inscription «Déméter» (?) (musée de Hvar, Croatie; Pho-

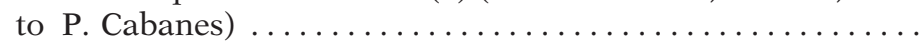

60 - Jas D18: motif de 4 astragales (détail) (musée de Lecce,

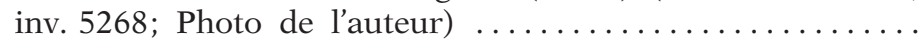

61 - Jas D25 : motif de 6 astragales (musée de Palerme; Photo de

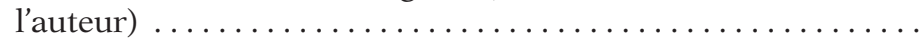

62 - Jas D50 : dauphin (Surint. Crotone inv. 18603; Photo de l'au-

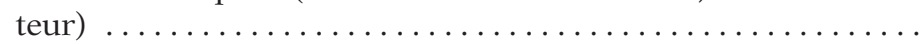

63 - Jas D56 : motif de caducée; musée de Palerme (Photo de l'au-

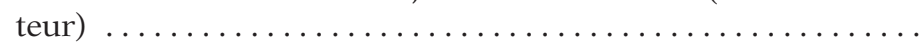

64 - Jas D62 : colonne (Museu d'arquelogia de Catalunya-Gerona;

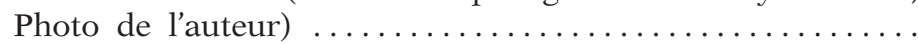

65 - Jas D64 : motif de lampe (musée de Palerme; Photo de l'au-

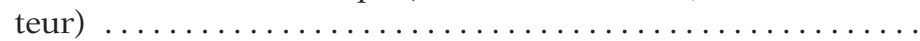

66 - Jas D65, de l'épave la Capte : motif indéterminé (d'après Car-

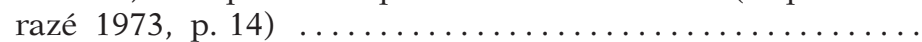

67 - Jas D69, de l'épave Jeaune-Garde B : astragales et dauphins

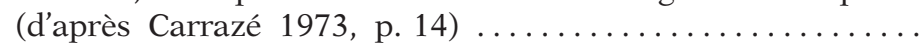

68 - Jas D74, de Ceuta, avec cercles et osselets (d'après Ciabatti

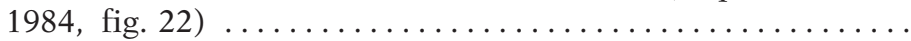

69 - Jas D82 : dauphins et marteau (d'après Benoît 1960b) ...

70 - Jas de Zeus Meilichios (musée de Reggio, inv. 10917; (Photo

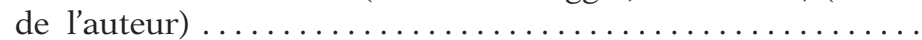

71 - Jas d'Égine à Aphrodite (d'après Welter 1938 fig. 11) ...

72 - Gravisca : jas avec inscription de Sostratos (d'après Colivicchi

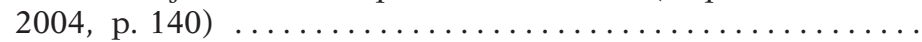

73 - Jas de Métaponte: Apollon Lykeios (d'après Boetto 1997,

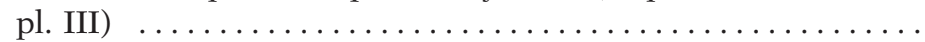

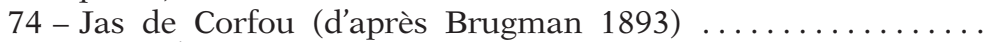

75 - Jas d'Égine : «me kine tode» (d'après Welter 1938 fig. 15)

76 - Gravisca : jas inv. 459 (d'après Colivicchi 2004, p. 142) ...

77 - Gravisca : jas inv. 460 (d'après Colivicchi 2004, p. 142) ...

565

566

566

567

568

569

571

571

572

576

578

582

584

585

586

587

588

589

591

595

596

596

597

598

598

599

600 
78 - Jas de Métaponte, inv. 20536-74 (Photo de l'auteur) ...... 79 - Jas de Porcinara (d'après Van Compernolle \& alii 1978,

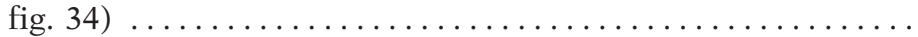

\section{LISTE DES CARTES}

\section{sauf mention contraire : (C) F. Ory (UMR 8546, CNRS-ENS)}

1 - Attestations du culte marin d'Athéna dans le monde égéen et

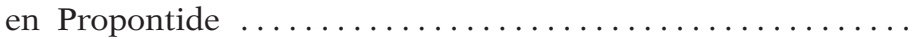

2 - Attestations du culte marin d'Héra dans le monde égéen

3 - Attestations du culte marin de Zeus dans le monde égéen et en

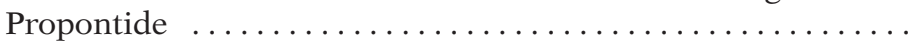

4 - Attestations du culte marin d'Aphrodite dans le monde égéen

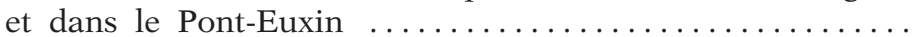

5 - Attestations du culte marin d'Apollon dans le monde égéen et

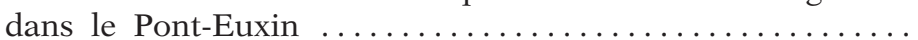

6 - Attestations du culte marin de Poséidon dans le monde égéen

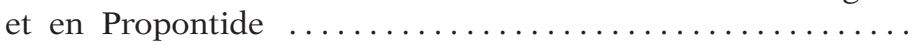

7 - Attestations du culte marin de Dionysos dans le monde égéen

8 - Attestations du culte marin d'Artémis dans le monde égéen et

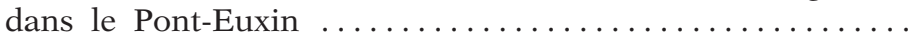

9 - Attestations des cultes marins dans le Pont-Euxin (d'après

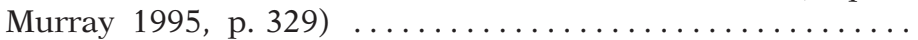

10 - Géographie religieuse du Bosphore (d'après Vian 1974, p. 92)

11 - Attestations des cultes marins dans la péninsule Ibérique

12 - Attestations des cultes marins en Méditerranée centrale

13 - Attestations des cultes marins en Méditerranée orientale, mer

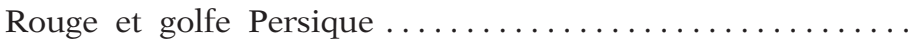

14 - La Campanie et Lucanie occidentale (d'après Greco 1996,

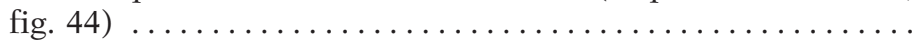

\section{LISTE DES TABLEAUX}

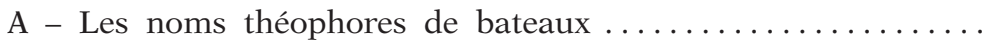

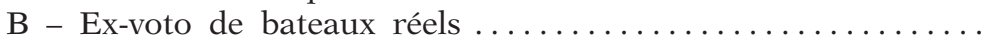

C - Ex-voto de bateaux modèles réduits $\ldots \ldots \ldots \ldots \ldots \ldots \ldots$

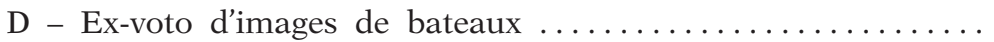

E - Ex-voto de parties de bateaux $\ldots \ldots \ldots \ldots \ldots \ldots \ldots \ldots \ldots$ 


\section{TABLE DES MATIÈRES}

Page

Remerciements $\ldots \ldots \ldots \ldots \ldots \ldots \ldots \ldots \ldots \ldots \ldots \ldots \ldots \ldots \ldots \ldots \ldots$ IX

Préface de Madeleine Jost .................. XI

Introduction $\ldots \ldots \ldots \ldots \ldots \ldots \ldots \ldots \ldots \ldots \ldots \ldots \ldots \ldots$

Première PARTIE

LES DIVINITÉS OLYMPIENNES ET LA MER

Chapitre I - À LA CONQUÊTE DE LA MER $\ldots \ldots \ldots \ldots \ldots \ldots .21$

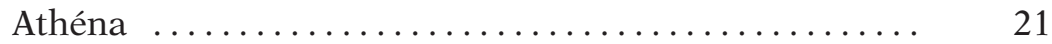

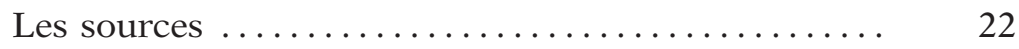

Mythologie et épopée $\ldots \ldots \ldots \ldots \ldots \ldots \ldots \ldots . . \ldots 22$

L'épopée homérique p. 22; L'épopée argonautique p. 24 Autres héros p. 28

Témoignages cultuels $\ldots \ldots \ldots \ldots \ldots \ldots \ldots \ldots$

Attique p. 30; Mégaride p. 39; Péloponnèse p. 39; Îles de la Mer Égée p. 42; Crète p. 44; Ionie p. 46; Grande Grèce et Sicile p. 47; Aux confins du monde grec p. 52

Iconographie isolée : Athéna et l'univers maritime

Le bouclier d'Athéna p. 53; Athéna à l'aphlaston p. 55;

Athéna sur un bateau p. 56

Analyse

Géographie du culte ..................... 58

Personnalité marine d'Athéna ............... $\quad 59$

Athéna et l'art nautique p. 59; Athéna-oiseau et le sauvetage de l'homme en péril p. 61; Athéna et la victoire sur mer : la déesse athénienne p. 65

Héra

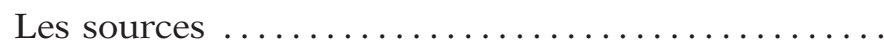

66

Mythologie et épopée $\ldots \ldots \ldots \ldots \ldots \ldots \ldots \ldots . \ldots 6$

L'épopée homérique p. 67; L'épopée argonautique p. 67 
Témoignages cultuels

Pérachora p. 69; Îles de la mer Égée p. 71; Grande Grèce p. 74; Confins occidentaux p. 77

Analyse ...

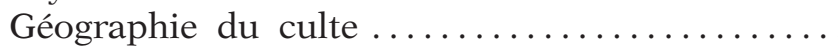

Personnalité marine d'Héra

Chapitre II - LA MAîtRise Des ÉlÉMENTS $\ldots \ldots \ldots \ldots \ldots$

Zeus

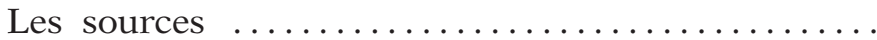

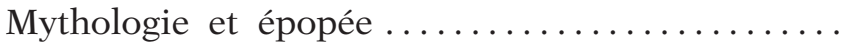

Nature du dieu p. 84; L'épopée homérique p. 84; L'Énéide p. 85

Témoignages cultuels

Attique p. 86; Eubée p. 86; Laconie p. 87; Dodone p. 88; Kassiopè p. 89; Messapie p. 89; Délos p. 91; Bosphore p. 92; Ancyre p. 94

Ex-voto et invocations maritimes

Ex-voto p. 94; Invocations p. 95

Analyse

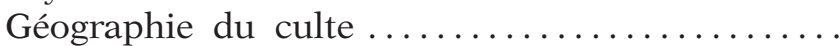

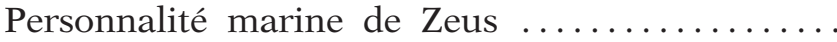

Zeus Ourios p. 100; Zeus Kasios p. 101; Zeus Sôter p. 103; Zeus Meilichios p. 104

Aphrodite .................................

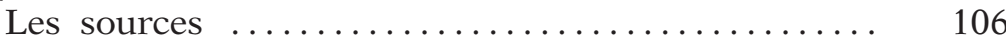

Mythologie et épopée $\ldots \ldots \ldots \ldots \ldots \ldots \ldots \ldots . \ldots \ldots$

La naissance d'Aphrodite p. 107; Descendance marine d'Aphrodite p. 108; Récits héroïques p. 109

Témoignages cultuels .....................

Les îles. Aux origines du culte marin d'Aphrodite p. 110; Attique p. 115; Corinthe p. 116; Péloponnèse p. 117; Mer ionienne p. 119; Grande Grèce p. 120; Gaule et Ibérie p. 121; Asie Mineure p. 122; Autour du Pont-Euxin p. 125; Égypte et Arabie p. 127

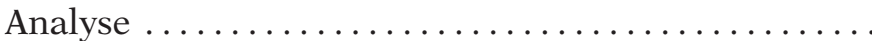

Géographie du culte .................... 129

Personnalité marine d'Aphrodite ............ 130

Euploia p. 132; Sôzousa p. 134; Aphrodite et les autres dieux p. 135 


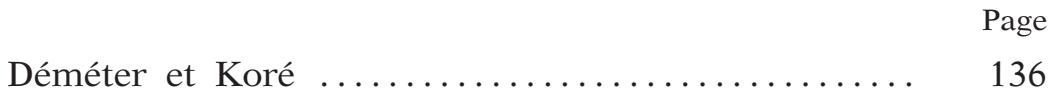

Chapitre III - LA DOMination DE LA MER .......... 139

Apollon ................................... 139

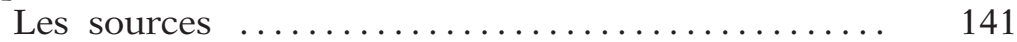

Mythologie et épopée .................... 141

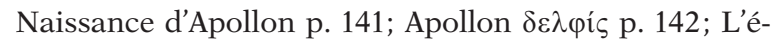

popée homérique p. 143; L'épopée argonautique p. 144; La tragédie p. 145

Témoignages cultuels

Délos p. 146; Delphes p. 149; Attique p. 150; Nord du Péloponnèse p. 152; Laconie et Messénie p. 154; Golfe de l'Eubée p. 156; Golfe de Corinthe p. 157; Leucade et Actium p. 158; Sicile et Grande Grèce p. 160; Asie Mineure p. 161; Îles du sud de la mer Égée p. 164; Confins p. 165

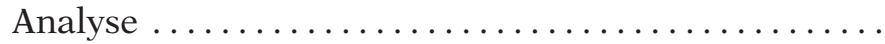

Géographie du culte ...................... 166

Personnalité marine d'Apollon ............... 167

Poséidon .................................. 171

Mythologie et épopée ....................... 172

Théogonie ............................ 172

Interventions marines ..................... 174

Complexité du dieu ...................... 175

Quelques sanctuaires marins $\ldots \ldots \ldots \ldots \ldots \ldots . . . \ldots 176$

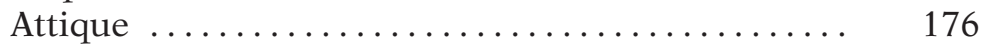

Ténare .............................. 178

Corinthe ............................... 179

Îles de la mer Égée ..................... 180

Sacrifices et offrandes marines ................. 182

Sacrifices de taureaux ..................... 182

Offrandes marines ....................... 183

Analyse ................................. 183

La violence de la mer .................... 183

Évolution du culte ...................... 186

Chapitre IV - LES FRONTIÈRES DE LA MER, OU LA MER DOMESTIQUÉE .................................. 189

Artémis .................................... 189

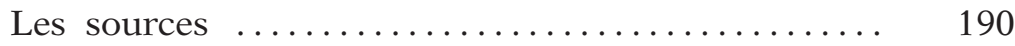


Mythologie et épopée

L'espace d'Artémis p. 190; Artémis à Aulis p. 191; L'épopée argonautique p. 192; Artémis-BritomartisDiktynna p. 193

Témoignages cultuels

Attique p. 195; Argolide p. 196; Corinthe et Laconie p. 198; Arcadie p. 200; Aulis et Eubée p. 201; Grèce centrale p. 203; Délos p. 204; Crète p. 205; Gaule et Ibérie p. 207; Chersonèse et Pont p. 209; Asie Mineure p. 210; Confins orientaux p. 212

Analyse

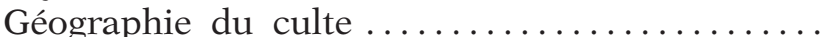
213

Personnalité marine d'Artémis ............. 215

Artémis et la navigation p. 216; Artémis et la colonisation p. 217; Artémis et la pêche p. 218
Dionysos

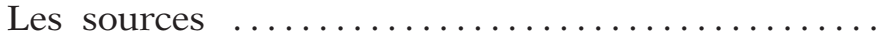
Mythologie
L'enfance de Dionysos p. 219; Dionysos et les pirates p. 220; Exégèses antiques p. 227

Témoignages cultuels .................

Attique p. 228; Péloponnèse p. 228; Béotie p. 231;

Thessalie p. 231; Asie Mineure p. 232

Analyse

Géographie du culte p. 233; Personnalité marine de Dionysos p. 234

Hermès ............................. 235

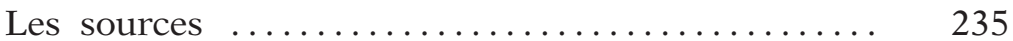

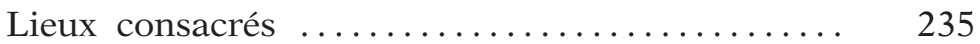

Eubée p. 235; Thrace p. 236; Ionie p. 236; Carmanie p. 236; Afrique p. 236

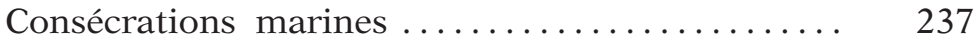

Analyse ............................. 239

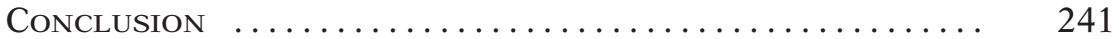


DeUXIÈme PARTIE

PRATIQUES CULTUELLES MARINES

$\begin{aligned} & \text { Page } \\ & \end{aligned}$

Chapitre V - Présence des divinités sur LE BAteau .. 245

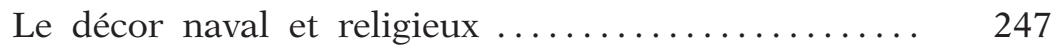

Introduction. Vocabulaire $\ldots \ldots \ldots \ldots \ldots \ldots \ldots . \ldots \ldots$

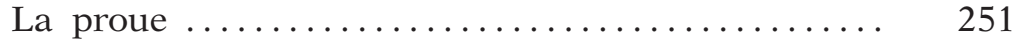

La «figure de proue» p. 252; Le parasèmon p. 255; Le stolos p. 260; L'éperon p. 262

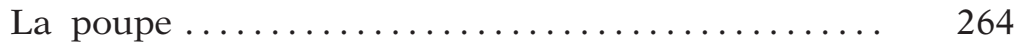

Lieu du sacré p. 264; La stylis p. 268

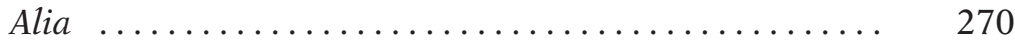

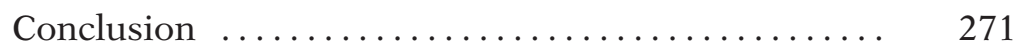

Les noms théophores de bateaux ............. 272

Introduction ........................... 272

Problématique p. 272; Limite des sources; les inscriptions d'euploia p. 274

Inventaire

Athéna p. 277; Aphrodite p. 280; Apollon p. 281;

Déméter et Koré p. 282; Artémis p. 283; Dionysos p. 283; Zeus p. 284; Arès p. 284; Héphaistos p. 285; Poséidon p. 285; Hermès p. 286; Hestia p. 286; Héra p. 286; Épithètes féminines p. 286

Conclusion $\ldots \ldots \ldots \ldots \ldots \ldots \ldots \ldots \ldots \ldots \ldots \ldots \ldots$

Les ancres à bord $\ldots \ldots \ldots \ldots \ldots \ldots \ldots \ldots \ldots \ldots$

Introduction . . . . . . . . . . . . . . . . . . . . . . 290

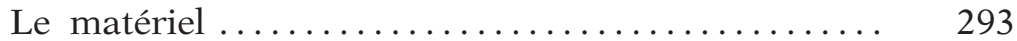

Les ancres ......................... 293

L'ancre sacrée et l'ancre de miséricorde ....... 295

Technique sur jas de plomb ............. 300

Les inscriptions sur ancres de plomb ......... 302

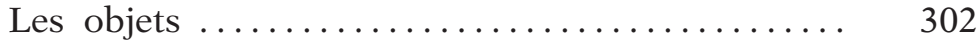


Page

Ancre de Zeus Hypatos p. 302; Autour de l'ancre du cap de Palos (Zeus et Aphrodite) p. 304; Autres ancres de Zeus Kasios p. 310; Ancres de Sôteira et assimilées p. 312; Ancre d'Artémis p. 315; Ancre d'Héra p. 315; Ancre d'Apollon p. 315; Ancres de Déméter-Cérès et Isis p. 316; Ancre de Vesta p. 317; Ancre d'Héraclès p. 317

Nom du bateau ou nom de la divinité tutélaire?

État de la question p. 318; Analyse p. 320

L'association nom + décor $\ldots \ldots \ldots \ldots \ldots \ldots \ldots$

Étoile p. 323; L'avant-train de lion p. 324

Interprétation des décors $\ldots \ldots \ldots \ldots \ldots \ldots \ldots$

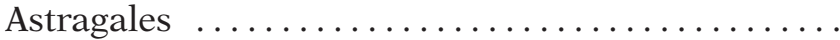

Fréquence et identification du motif p. 326; «Le coup de Vénus» p. 329; Discussion p. 331

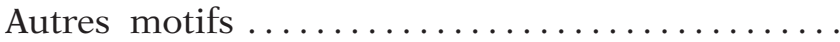

Dauphin p. 335; Tête de Méduse et "tête coupée» p. 336; Lion p. 338; Seiche p. 339; Coquillage p. 340; Colonne p. 341; Clé p. 342; Lampe p. 342; Marteau p. 342; Trident p. 343; Caducée p. 343; Cercle p. 344; Alia p. 344

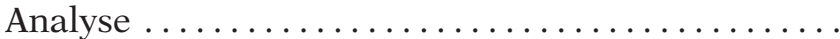

Conclusion : les divinités et le bateau ...........

Chapitre VI - Les EX-Voto À TERRE .............. 349

Dons de bateaux ....................... 350

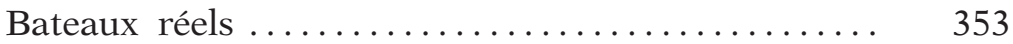

Époque archaïque ................ 353

Tradition littéraire : Corinthe et la nef Argô p. 353; Témoignage archéologique: Samos p. 354

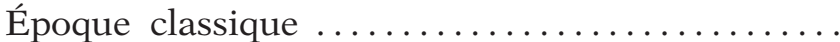

Seconde Guerre médique p. 355; Guerre du Péloponnèse p. 358

Époque hellénistique $\ldots \ldots \ldots \ldots \ldots \ldots \ldots$

Délos p. 359; Actium p. 367; Témoignage littéraire tardif p. 368

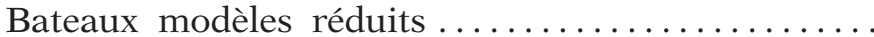

Époque archaïque $\ldots \ldots \ldots \ldots \ldots \ldots \ldots \ldots \ldots$ 
Samos p. 370; Ischia p. 372; Égine p. 373; Corinthe p. 374; Amathonte p. 375; Athènes p. 375; Gravisca p. 376; Crotone p. 376

Époque classique

Delphes p. 377; Athènes p. 378; Syracuse p. 380

Époque hellénistique

Objets de bronze ou céramiques p. 380; Bases naviformes en pierre p. 385

Conclusion $\ldots \ldots \ldots \ldots \ldots \ldots \ldots \ldots \ldots \ldots \ldots \ldots$

Images de bateaux ........................ 390

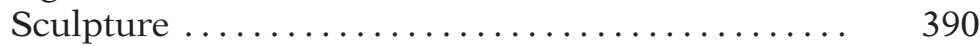

«Bateaux de pierre» p. 390; Époque archaïque p. 392; Époque classique p. 395

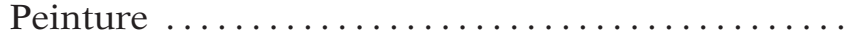

Époque archaïque p. 398; Époque classique p. 402;

Époque hellénistique : Nymphaion p. 404

Le cas des graffiti $\ldots \ldots \ldots \ldots \ldots \ldots \ldots \ldots \ldots \ldots \ldots \ldots \ldots \ldots$

Samos p. 408; Vouliagmeni p. 408; Délos p. 409

Parties de bateaux ..................... 410

Exemples mythiques .................. 411

Samos p. 411; Lindos p. 411; Cyzique p. 412

Époque archaïque $\ldots \ldots \ldots \ldots \ldots \ldots \ldots \ldots \ldots$

Égine p. 412; Mégare p. 413; Samos p. 413

Époque classique $\ldots \ldots \ldots \ldots \ldots \ldots \ldots \ldots$

Delphes p. 414; Phlyées p. 417; Délos p. 418

«Antiquités» de l'époque hellénistique ........

Marseille p. 419; Odysseia p. 419; Sicyone p. 420; Thèbes p. 420

Époque hellénistique

Délos p. 420; Actium p. 422; Dodone p. 423

Conclusion

Conclusion générale ...................... 426

Bateaux sacrés ......................... 430 
Bateaux mythiques

Bateau de Thésée à Athènes p. 430; Théories athéniennes p. 432

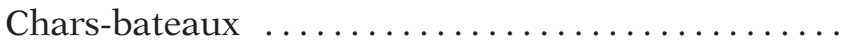

Procession des Panathénées p. 437; Smyrne p. 447; Procession des Anthestéries athéniennes p. 449; Poseidonia p. 454

L'offrande à terre : le cas des ancres .............

Une pratique ancienne $\ldots \ldots \ldots \ldots \ldots \ldots \ldots$

Attestations littéraires et épigraphiques .........

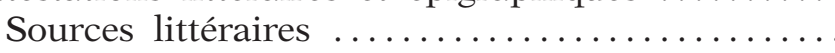

Sources épigraphiques $\ldots \ldots \ldots \ldots \ldots \ldots \ldots \ldots$

Les documents archéologiques ................ 464

Ancre de Zeus Meilichios ................... 464

Ancre d'Aphrodite à Égine .............. 466

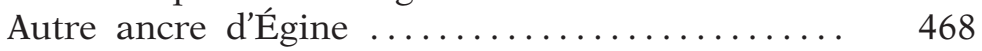

Ancre de Gravisca .................... 470

L'objet p. 470; Le contexte p. 471

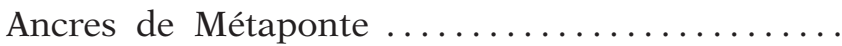

Historique des trouvailles p. 477; Attribution des pierres p. 483

Ancre de Corfou $\ldots \ldots \ldots \ldots \ldots \ldots \ldots \ldots \ldots \ldots$

Ancre de S. Maria di Leuca ................. 487

Ancres de Sélinonte .................... 489

Ancres moins assurées ................ 492

Mozia p. 492; Salamine (Chypre) p. 492; Alexandrie p. 494

Don d'ancre et culte de pierres ............. 496

Problème de vocabulaire ................ 496

Analyse .......................... 498

Autres offrandes marines .................... 501

Attirail du pêcheur ..................... 501

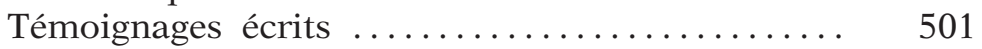

Matériel archéologique ................... 502

Rames ................................. 503

Coquillages ............................... 504

Poissons et fruits de mer ................. 505

Offrandes p. 505; Consécrations p. 506; Interdictions p. 506; Conclusion p. 509 
Cone

CONCLUSION .............................. 509

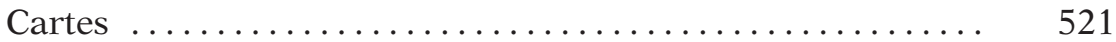

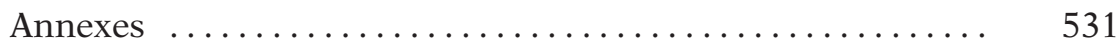

Corpus de sources littéraires choisies ........... 533

Index thématique des sources littéraires .......... 541

Textes épigraphiques : ex-voto navals des inventaires déliens ................................ 557

Catalogue des ancres ...................... 563

Ancres de plomb ....................... 565

Ancres de pierre votives (?) ............... 595

Tableaux: Les noms théophores de bateaux ....... 607

Tableaux : Ex-voto de bateaux réels ............. 610

Tableaux : Ex-voto de bateaux modèles réduits ..... 611

Tableaux : Ex-voto d'images de bateaux .......... 613

Tableaux : Ex-voto de parties de bateaux ......... 614

Bibliographie générale ........................ 615

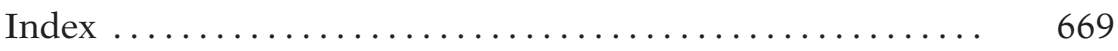

Table des illustrations ....................... 697

Table des cartes ........................... $\quad 700$

Table des tableaux $\ldots \ldots \ldots \ldots \ldots \ldots \ldots \ldots \ldots \ldots \ldots . \ldots \ldots$

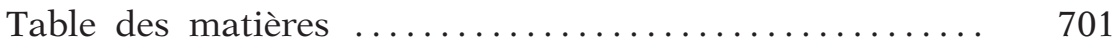



Achevé d'imprimer

en juin 2016

sur les presses de la

Scuola Tipografica S. Pio X

Via degli Etruschi, 7

00185 Roma 
